\title{
SNTDIPAIS
}

\section{MUSCORUII FRONDOSORUII}

OMNIUM HUCUSQUE COGNITORUM.

AUCTORE

\section{Dr. CAR0LO Múluer.}

PARS PRIMA.

MUsC1 VEektatoNis ACnocanpicak.

BER OI.INI

SUMPTI BUS ALB. FOER T NER.

1849 . 


\section{VIRTS CHATESSIMUS}

DE STUDIS BRYOLOGICIS NOSTRIS MERITISSIMIS

\section{G. K U NZE}

ET

\section{F. L. DE SCHLECHTEN D A L}

HANC SYNOPSIN MUSCORUM FRONDOSORUM

D. D. D.

GRATUS AUCTOR. 


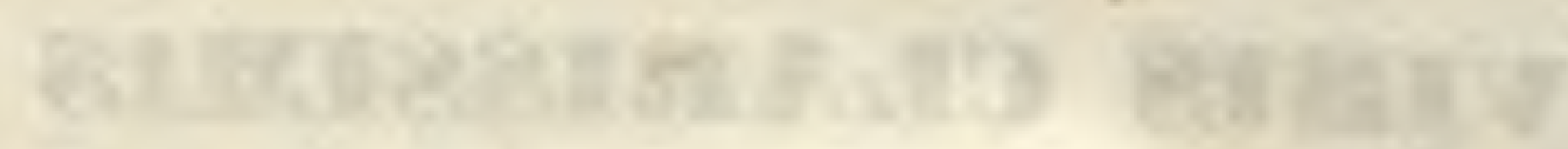

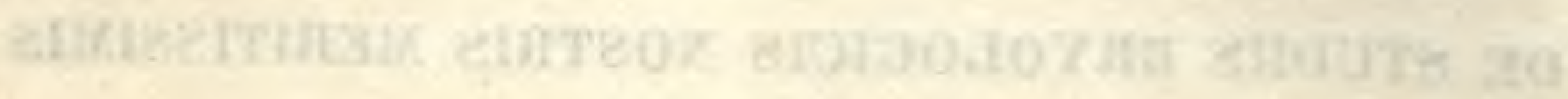

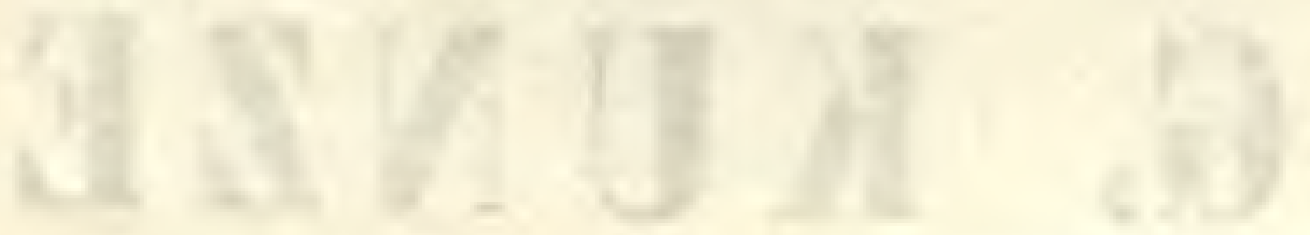

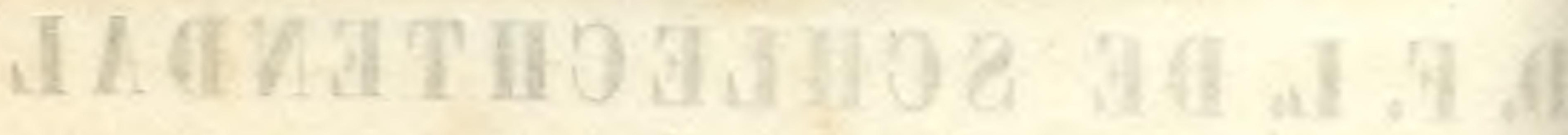

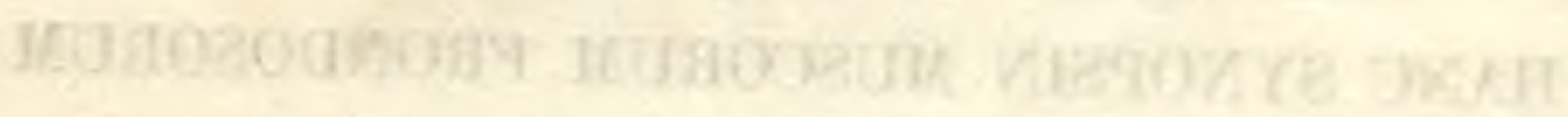

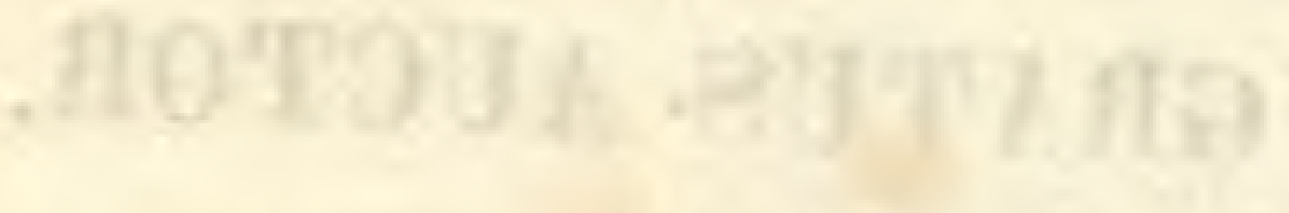




\section{PRAEFATIO.}

Post editionem bryologiae universae Bridelii anni viginti praeteriti sunt. Ex illo tempore omnino mutata est scientia amabilis, nam anatomia et physiologia in systematis principia radices profunde egerunt. Bryologia quoque progressibus hisce gaudet et hoc quidem primum argumentum est, quod bryologiae concordiam cum fructibus temporis vehementer postulabat.

Nunc temporis magis quam prius permulta itinera in terras longinquas facta sunt, unde scientia eximie locupletata est; bryologia quoque progressibus hisce gaudet, nam ex Bridelii temporibus speciebus mille et ultra augebatur et hoe secundum est argumentum optandi, omnes muscos hucusque detectos in synopsin colligendos.

Dubitari non potest, quin hi progressus insignes nominandi sint, quo factum est, ut hodie bryologiae literae amplissimae reperiantur; species novas auctores in libris saepe pretiosissimis, rarissimis vel minus cognitis descripserunt, quos scrutator solitarius vix accipit. Quod est argumentum scribendi operis de muscis universalis tertium.

Opus igitur finis duplicis partes implere oportebat, nempe species omnes ad huc descriptas colligere et ad artem redigere. Praecipue propter phytogeographiam, muscorum frondosorum scientiae tantopere egentem, bryologia prorsus immutanda erat, qua re auctor in diario botanico Botanische Zeitung dicto 1849. No. 13-15 accuratius scripsit. Ad hunc finem necesse fuit, species et patriam optima fide examinare, quam ob rem loca multa ab aliis saepissimime false indicata auctor neglexit.

Quantum e materia bryologiae hodierna duci poterat, tantum egisse auctor sibi conscius est, quum in fundamento bene intellecto systema totum constanter condide- 
rit. Sin vero sibi consentiens non erat, posteri corrigant et ad finem adducant, sed in dijudicando libro difficultatum, in scribendo principia nova bryologiam universam reformanda continente opere auctori obviarum, memores sint. Principia autem nova haec:

"Axis duplex est, primaria et secundaria; itaque musei vegetationis acrocarpicae et pleurocarpicae distingui possunt, dum Bridelius muscos acrocarpicos, pleurocarpicos, cladocarpicos, rhizocarpicos, entophyllocarpicos et hypophyllocarpicos : nominavit. Musci acrocarpici illi appellandi sunt, in quibus axis primariae vita fructu definitur, etsi nonnunquam innovatione nova lateraliter ponitur (Cladocarpi), ut Leucobryaceae, Rhizogonia, Orthotrichaceae Mielichhoferiae ostendunt. Species sunt pleurocarpicae, quarum fructus e gemma laterali semper oritur. Saepe accidit, e. g. in Hedwigia ciliata, Fontinali, Cinclidodonte, Cryphaea et aliis muscis, ut axis haecce lateralis maxime elongetur et plantae habitus acrocarpicus videtur (Cladocarpi). Exemplum optimum praebet Hedwigia ciliata, in cujus cauli gemma lateralis apici proxima oriunda videtur. De Conomitries observationes recentiores optandae sunt.

Musci acrocarpici et pleurocarpici secundum thecae dehiscentiam, a Bridelio et posteris jam rationem habitam, in tres partes: Schistocarpos, Cleistocarpos et Stegocarpos dividuntur, dum Bridelius Schistocarpos tantum et Olocarpos distinxit.

E foliorum dispositione notae tres gravissimae, caulis habitum prominentem efficientes, duci possunt: folia disticha, polysticha et tristicha; sed series haec ulterior sectiones proprias format, si folia seriei hujusce tertiac stipuliformia inveniuntur, ut Hypopterygii folia, Selagimellas in memoriam referentia, ostendunt.

a)lu Nota gravissima tribum sistens folii areolatio est, ubiquึe typice constans et in subtribu tantum singula mutata, sed etiam hic typum pristinum saepe prae se ferens, ut areolatio Orthotrichi Sprucei, Zygodontis conoidei et al. ad Pottias ipsissimas rediit. Areolatio duplex est, paren- 
chymatica et prosenchymatica. Cellulae parenchymaticae illae sunt, quarum plana horizontalia supraposita sunt, dum/cellularum prosenchymaticarum plana in apices plus minus perpendiculares producuntur. Puncta vegetationis retis folii propria tribus discrimina sequentia constituunt, ut Dicranaceae a Leptotrichaceis cellulis alaribus distinguuntur. Pari modo ductus intercellulares Sphagnorum et Leucobryorum notae novae excellentes sunt.

Calyptrae facies autem et peristomium tribum non immutant, sed genera constituunt. Calyptra est dimidiata, si totum thecae apicem circumcirca obtegit (calyptra conica, mitraeformis, campanulata). Calyptra glabra vel plicata notae quoque generibus distinguendis idoneae observantur; nam in congeneribus proximis constantes sunt. Sed ciliae basis calyptrae vel papillae s. verrucae superficiei nullius momenti sunt; in Polytricho tantum calyptra dimidiata indumento villoso campanulata formatur, quam ob rem auctor notam distinguendi habuit. Calyptrae facie procul dubio habitus eximie prominet; nam vidimus in generibus Encalyptae, Calymperis, Schlotheimiae, Orthotrichi, Polytrichi, Funariacearum et aliis, quare hujus auctores semper rationem habere oportet etiam illic, quo minus perspicue prominet, ut in generibus: Acaulon, Schistidium, Gümbelia, Grimmia et aliis. Gümbelia calyptrata igitur et Grimmia laevigata, habitu simillimae, semper separandae sunt. Similitudo illa, species hasce ambas ad genus unicum revocandas esse, non ostendit, sed legem combinationum in genere saepe species analogas alius generis in memoriam referre.

Peristomium eximie varium et nota admodum separans, si deest, aboritum tantum putari potest, quum in speciebus gymnostomis plurimis peristomium minute evolutum observetur, ut in Cinclidodonte, Physcomitrio, Pottia et aliis. Quae species gymnostomae ad illas igitur revocandae sunt, ${ }^{\circ}$ quibus habitu externo et fabrica interna proximae. Sin e gr. accidit, ut posteri Sphagnum novum peristomatum invenirent, genus proprium peristomium non constitueret." 
Fundamentis hisce novis explicatis facillimum est, auctorem ubique acute persequi. Minoris momenti est, sin auctor, in describendis foliorum angulis scala Wahlenbergiana usum esse, indicat. Quoad scalam hancce ab axi divergunt folia erecta $10^{\circ}$, erecto-patentia 30 , patentia 50, patenti-divergentia 70 , divergentia 90 (igitur horizontalia). Infra lineam verticalem divergunt folia divergenti - divaricata $20^{\circ}$, divaricata 40 , divaricato-reflexa 60 , reflexa $80^{\circ}$. - Porro signum + post diagnosin speciei, nobis speciem non visam esse, indicat.

Hoc nunc tantum superest, ut clarissimis viris, qui auctorem tam libris quam muscis adjuverunt, gratias maximas agamus. Quibus praesidet omnibus clarissimus de Schlechtendal, laudis nostrae haud indigens. Post eum nominamus clarissimos viros G. Kunze Lipsiae, Ha mpe Blankenburgensem Hercynicum, Mon tagne Parisiis, operis nostri adjutorem indefessum, W.P.S chimper Argentorati, W. M e is sner Halae Saxonum, Send t ner Monachii, Sullivant Ohioensem Americae sept, Spruce Britannicum, Schwägrichen Lipsiae - primum adjuvantem, nunc avarum - de Notaris Genuae,

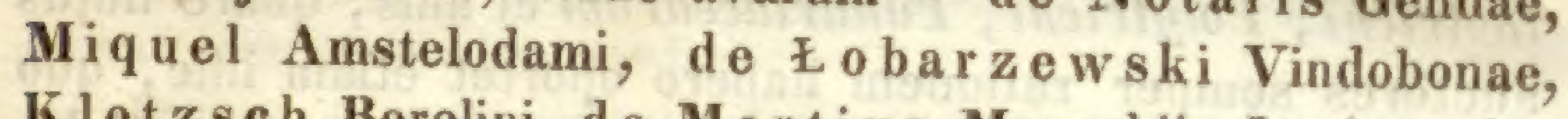
Klotzsch Berolini, de Martius Monachii, Itzigsohn Neodami Neomarchici Borussiae, $\mathbf{R}$ a benhorst Dresdae, B ly t t Christianiae, Ben ek en Naumburgi ad Salam sit., Haro Bargen Emdae, Kegel, peregrinatorem Surinamensem, Wagner, hortulanum Halensem, nunc Columbiam peregrinantem, P abst, hortul. Halens., nunc insulam St. Catharinae Brasiliae scrutantem, Crüger, pharmacopolam insulae Antillarum Trinidad. Gratiis nostris cl. Bruch maturius mortuus est.

Auctor volumen primum finiens, laborem haud exiguum non frustra fuisse, Synopsin ad commoditatem atque gaudium bryologorum scriptam et scientiae muscorum amabili amicos novos et scrutatores indefessos adducere, optans, judicium severum, sed justum, scientiae causa, expectat.

Scribebam Halae Saxonum

Idibus Septembris anni 1849.

Carolus Minller. 


\section{ATIOPAIS}

\section{MUSCORU II FRONDOSORUM.}




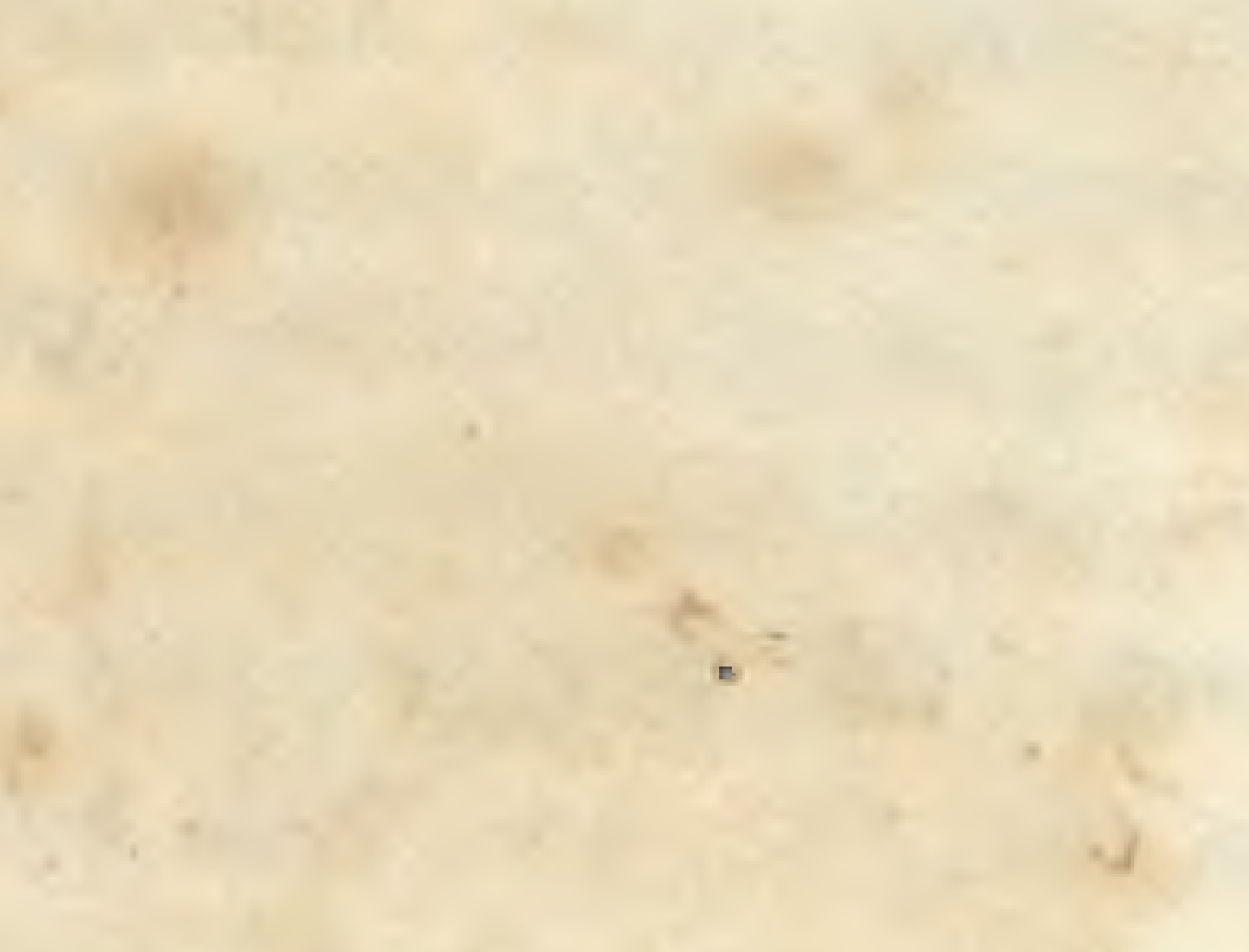

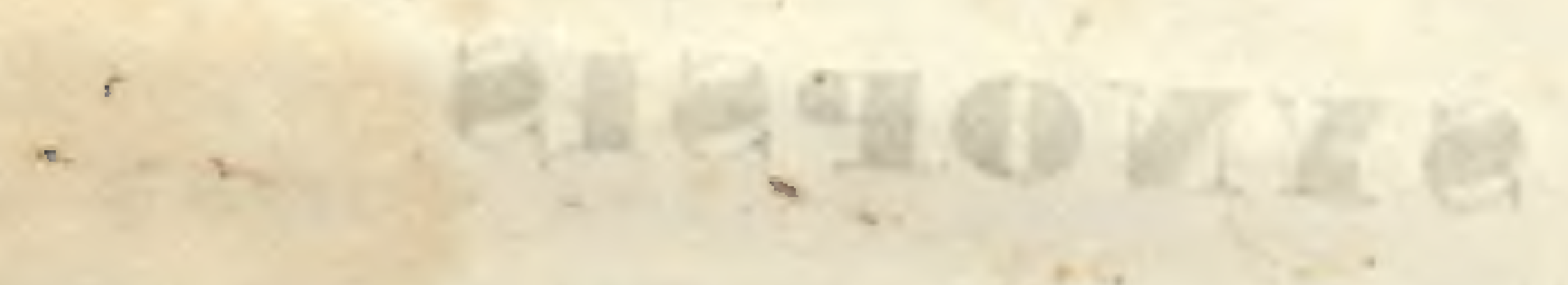

is

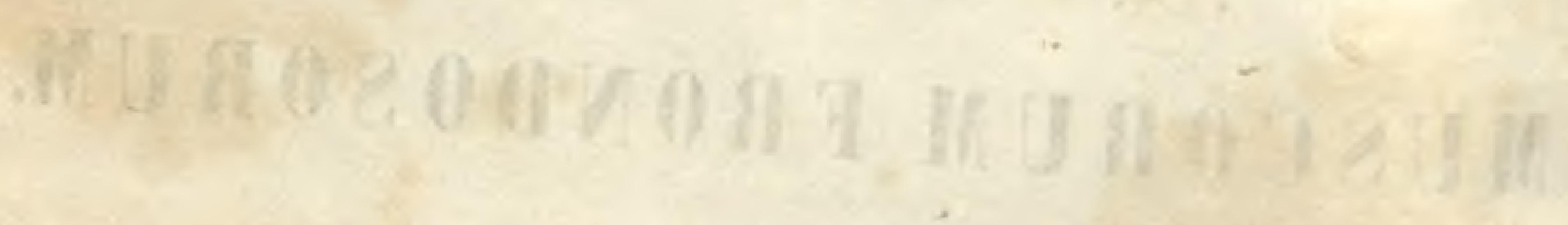

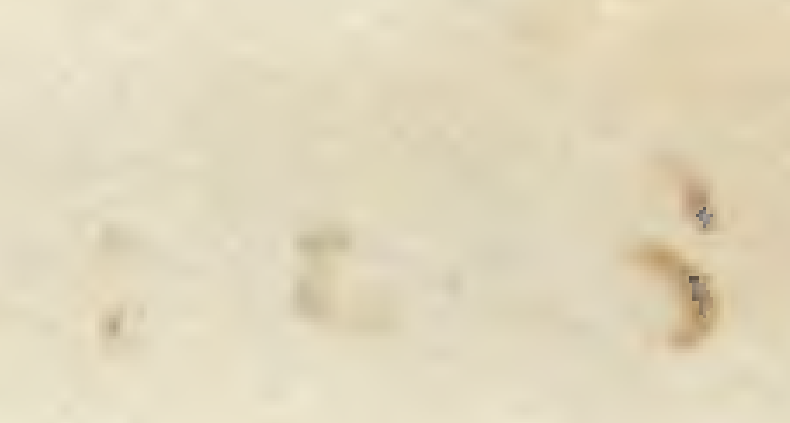

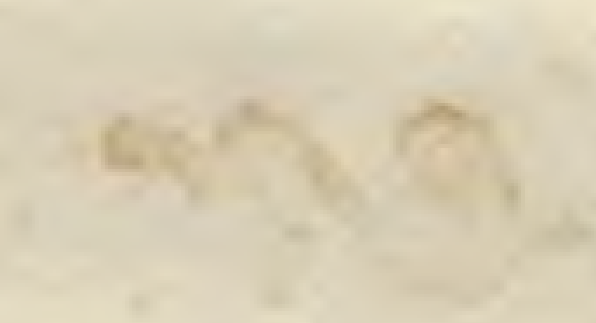

$-1$

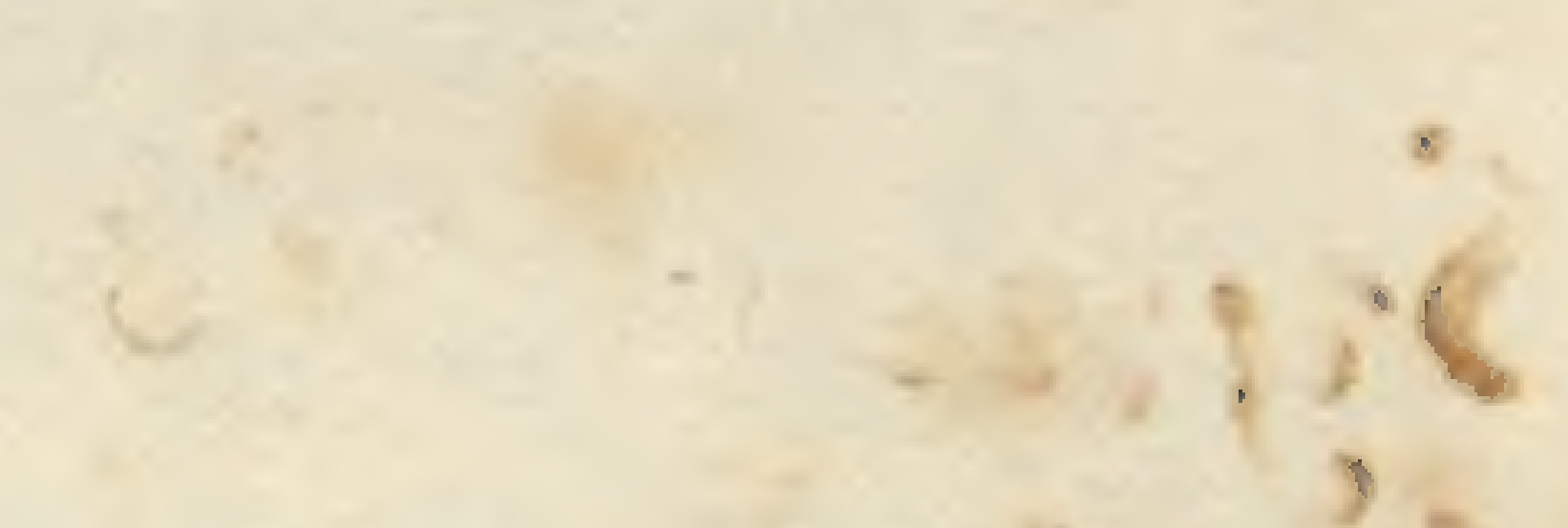

$$
\begin{aligned}
& \begin{array}{l}
-2 \\
\text { a }
\end{array}
\end{aligned}
$$




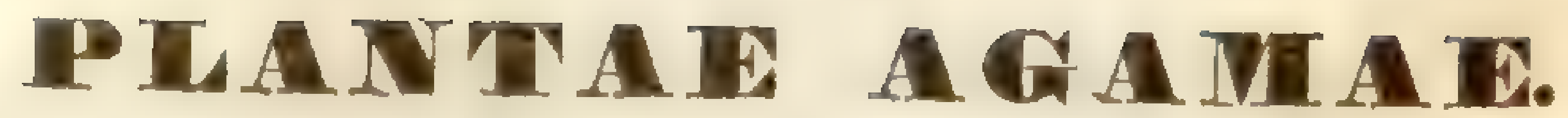

OH D : :

\section{MUSCI FHONIDOSI.}

Plantae cellulares. Folia sessilia. Frnctus: theca unilocularis (Sperangimm) calyptra tecta. Sporangium e partibus tribus essentialibus compositum: Pars I centralis s. columella (plus minusve perfecta); pars II s. sporangidium, in quo semina nascuntur; pars III so epidermis. - Inflorescentia ex antheridiis archegoniis et paraphysibus formata. Pedunculus basi vagina cinctus. 


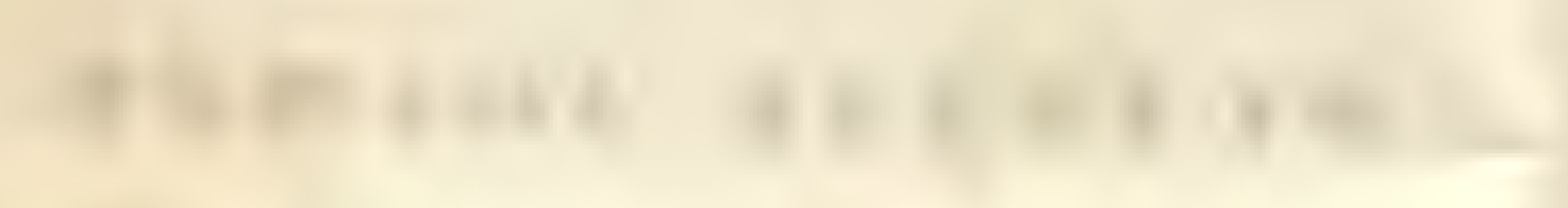




\section{Cuassis I. \\ SCHIS T OCA R PI.}

Theca longitudinaliter in valvulis dehiscens inoperculata.

\section{Trib. I. ANDREAEACEAE.}

Pulvinato cespitosac colore intense viridi v. brunneo-fusco. Folia e cellulis parenchymaticis cum incrassatis parietibus subpapillosis composita (Areolatio densa plerumque rotundata). Theca in valvnlis 4-8 deliscens brunnea decidaa, tela cellulosa interna carens, basi collo pallido apophysiformi instructa, recta viv apiculata, valvulis apice cohaerentibus. Antherilia clavaeformia tenera albida. Paraphyses confervoidoae opacae gelatinosac haud nodose articulatae sed ex cellulis internis moniliformibus constructae.

E thecac forma habitum Jungermanniacearum referentes et nulla tribu alia comparabiles.

Patria. E planitiebus Europaeis (rarissime tamen) usque ad nives acternas utriusque hemisphaerae ascendentes, zonas frigidas autem praeferentes ct rupium incolae.

\section{Gen. I. A ndreace Ehrh.}

Ehrhart in hann. Magaz. 1778. - Brid. bryol. univ. II. p. 725 -32. - Hooher et Wilson in Lond. journ. of bot, 1844. p. 537-8., quos huc sequimur. 
Nomen ab Ehrharto hujusce generis conditore illi in memoriam Andreae inclyti pharmacopoli Hannoverani naturaeque perito scrutatori impositum.

Calyptra thecam tolam primum legens, dehinc horizontaliter rumpens, mitraeformis s. campanulata tenerrime-memloranacea flavida fugacissima. Inflorescentia dioica vel monoica. Flos masculus in ramo proprio terminalis. - Perichactiom plevunque exsertnm turgidum clausum. Pedunculus mollis plerumque pallidior brevis.

Sect. I. Andreaen. Theca in valvulis 4 dehiscens.

\section{A. Folia enervia.}

a. Folin ocato-oblonga obtusa margine reflexo.

1. A. nitida Hook. et Wils. (1. c. p. 535.); caulis suberectus laxe cespitosus parce ramosus; folia erectopatentia ovato-oblonga obtuse-apiculata concava vididu; perichactialia puulo longionu erecta. Auct. 1. c. $\frac{\dagger}{\dagger}$.

Potria. Insula Auchlandi: J. II o o ker.

b. Folia e basi erectu amplexicaulia patenti-incurva.

- 2. A. rupestris Iledw. (opp. posth. p. \$7. tab. \%.), dioica; folia e basi oblonga lanceolalu aculinscula submucronata ralde papillosa integerrima fulcuto-secunda; perichactialia oblonga lata obtusiuscula erecta lacvia; theca $2 / 3$ fissa, seta pallida instructa.

A. petrophila Ehrh. Dec. No. fr. prope Lusaliam lecta e speciminibus autlenticis huc, neque ad serguentem, pertinet. - Brid. II. p. 726. - Jungermannia poupestris Limu, sp. PI. P. 1601. - Lichenastrum alpinum, nigricuns, folies culpilluceis reflesis. Dill. Musc p. 307. tab. 73. fig. 40, A.

I'atria. In montibus altioribus totius Europac et in Brasiliae tractu montis: Serra dos Orgais: Garduer No. 1. Vere - Auct. 4 . 
3. A. alpina Hedw. (1. c. p. 49.); dioica; folia panduraeformia, e busi lata oblonga latere excavatu denticulata longinsculo-acreminata acuta lacria bigibba substrictu, busi 4 ato, apice rotunduto-ureolutu; perichaetialia majora latissima oblonga, apicem rersus albo-marginute acutiuscula erecta laevissima; omnia fusca; seta crassa purpurea; theca $2 / 8$ fissa.

Brid. 11. p. 728. - Hook, et Tay.l. M. Brit. p. 1. tal. VIII. (folia male delineata). Jungermmnia ulpinu, surulis teretibus, foliis onatis putentibus, ralycibus imbricatis Linn. Spec. Pl. p. 1601. Lichenastrum alpinum atro-rubens, teres, calycibus squamosis. Dill. Musc. p. 506. tab. 73. fig. 39. C. D. Vera species!

Patria. Ab anctoribus in totius Europae montibus altioribus praccipue alpinis et in America arctica indicitur. Nobis hucusque tamen e Scotiae tantum alpibus visa. Vere. 4.

Praecedentes duae species, sub nomine unien A.petrophilue Ehrh. saepe connexae, notis datis distinctissimae. An Hedwigius ipse auctor hasce species duas recte cognoverit, nescimus. Dubitamus. In Bructero, quo indicit, non vidimus.

4. A. marginata Ilook. et WVils. (1. c. p. 535.); Caulis laxe cespitosus subramosus; folia erecto-patentia incurva ouda longe-ucuminata infira medium contracta, marginibus inferne pallidis, caulina majora laxa, superiora conferta; perichaetialia longiora late lanceolata couvoluta; theca exserta. Auct. I. c. $f$.

P'utriu. Insula Eremitac at Cap. IIorn Americae antarcticae: J. II ooker.

5. A. acutifolia llook o! Wils. (1. c. p. 535.); canlis fustigiettim ramosus, rami apice ramulosi; folia erecto-patentia incurva rigide lencepheio-subuletu ucuta $\because$ oralia Innge asuminata consentinscula busi gibbosu, siccitate crecta; perichactialia longiora lanceolata' convoluta; theca subexserta. Auct. 1. c.

F'ulviu. Insula Eremitae, Falklandi. Aucklandi et Camplelli: J. H o o k er. E Groenlandia habemus sterilem. 
c. Folia suberecta, subsecunda basi non amplexicaulia.

6. A. mutabilis Hook. et Wils. (1. c. p. 536.); caules cespitosi ramosi elongati gracillimi; folia conferta laxiora erecto-patentia rarius falcato-secunda lanceolata v. ovali - lanceolata concaviuscula siccitate appressa; theca - 8 Auct. I. c. $t$. simis.

a. microphylla, foliis ovali-lanceolatis minutis-

B. subsecunda, foliis laxioribus, inferioribus secundis, superioribus ut in var. $\alpha$.

$\gamma$. uncinata, foliis dissitis falcato - secundis.

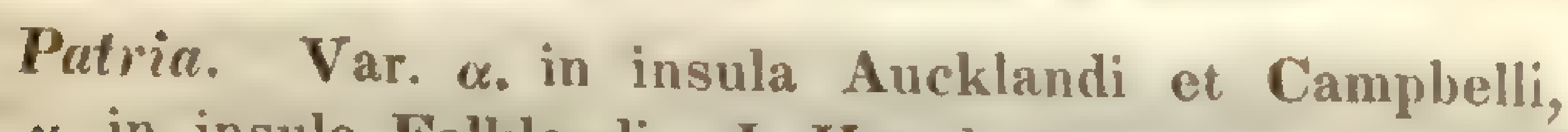
$\beta$. et $\gamma$. in insula Falklandi: J. H o o k e r.

7. A. Iaxifolia Hook. et Wils. (1. c. p. 536.); caules laxe cespitosi parce ramosi; folia lanceolato-subulata obtusiuscula concara, ramulina falcato-secunda, caulina erecta subsecunda laxe imbricata; perichaetialia elongat o orali-lanceolata convoluta; theca exserta ovato-oblonga. Auct. 1. c. $t$

B. minor, theca subexserta.

Patria. Insula Eremitae: J. H ooker.

\section{B. Fulia nervosa.}

8. A. subenervis Hook. et Wils. (Lond. journ. of bot. 1847. p. 289. tab. 10.); caulis elongatus parce ramosus; folia laxe patentia oblongo-elliplicu obtusinsculo-acutu subenervia, neve rulde obscuro lato vix al medium producto; perichaetialia majora erecta; theca cxserta. Auct. 1.'c. +

Putriu. Granada nova Americae meridionalis: Paramo of Ruiz in societate Polytrichi trichodontis corum: Purdie ad nives aeternas in cincre rulcanico legit.

Praecedenti A. laxifolicue affinis, sed foliis'latioribus ellipticis non subulatis differt. E forma thecae Acmschismati U'ilsoni proxima. 
- 9. A. nivalis Hook. (in Transact. of Linn. Soc. $\mathbf{X}$. p. 395. tab. 31.); laxe cespitosa; caulis elongatus gracilis ramis brevibus laxe foliosus upice incurvus; folia caulina lanceolata angusta concava mucronata, ialde papillosu, erosa, apice papillis scaberrima, falcuto-secunda, nervo continuo angusto; perichaetialia conformill; theca exserta $2 / 3$ fissa.

Hook. et Tayl. Musc. Brit. p. 2. tals. 8. - Engl. Bot. tals, 2507. Brid. II. p. 732.

Patria. In rupibus verticis Ben Nevis Scotiae ad extremitatem orientalem $\mathbf{H}$ o o k er et Borrer primi detexerunt. In alpibus Helvetiae (Grimsel et al.) et in Norvegiac prov. Tellemarken: Ângström. Raro fructifera! Acstate. 4.

Foliis perichaetialibus conformibus ab omnibus ceteris speciebus jam recedit.

10. A. Tothii Web. et Mohr (bot. Taschb. p. 386. tab. XI. fig. 7.8.); monoica, densiusculo-cespitosa ; caulis erectus parce ramosus apice subincurvus; folia laxe imbricata e basi latinscula concura ovuli subulata acuta falcata securda subintrgra, nervo basi latiusculo rontinuo; perichaetialia latissima convoluta subito acuminata acutinscule nerro latissimo continuo; ommia sublacria; pedunculus pallidus, theca exserta $\% / 3$ fissa.

ק. papillosu, folia apice cellulis magis papillosis eroso-denticulatis, perichaetialibus (junioribus) longius acuminatis apice inflexo, nervo folii apicem totum occupante. Ludr. fulcuta Schimp. in Hb. Irampeano.

$\gamma$. grimsulanu, foliis lancenlatis acutis confertioribus magis falcatis, perichactialibus elongatis convolutis (Hook. et Wils. 1. c. p. 537.). Andr. grimsulance Bruch mst.

Britl. 11. p. 730. - schwïgr. suppl. 11. p. 19. tal). 106. - A. rupestris Wahleub. F'. Lapp. p. 306. et al. anct. - Lichenustrum "lpinum nigricuns folies capilluribus refleris. Dill. Musc. 1. 507. tal. 73. fig. 40. B.

Putriu. In Furopac totius montibus altioribus alpibusque. In planities denceudit e. gr. Germaniac septen- 
trionalis, ubi in ducatu Bremensi $\mathbf{C}$. $\mathbf{R}$ ot h primus legit. In montibus Carolinae superioris: Sullivant. - Var. ß. in unica rupe ad, Bemina Gletscher im Hugadin": W. P. Schimper. Aug. 1846. Dom. Lesquereux (e litt. Hampeanis) in herevnia superiore observavit. - Var. $\gamma_{0}$ in Helvetiae alpe Grimsel. Vere. 4.

Flos masculus in ramulo proprio (in ramo proprio lateraliter posito) terminalis.

11. A. erassinervia Bruch (in litt.); dinice, dense cespitosa; caulis elatus simplex v. subfistigiatim ramosus apice incurvus; folia e basi vaginante orali-lanceolata falcato - secunda obtusiuscula, mero crusso lulo subexcurrente; perichactialia lato-ovalia obtusa v. acuminata, onnia integerrima; theca exserta oblonga subapophysata.

ß. Heinemanni, humillima simplicissima inferne subnuda, superne foliosa, saepe reclinata; foliis perichactialibus sacpe oblique acuminatis, nervo temiori occulto instructis, theca elliptica apophysata. A. Heinemomi IImp. et C. Müll. in bot. Zeit. 1846. p. 324. tah. 2. -- Varietas exeellentissima, partibus omnibus tenerrima et nervo constantor tenuissimo obserato, species distinctissima!

Patria. In Ifelvetiae alpe Grimsel. - In Norvegia (Renoë Finmark): Ingström. - Var. B. in summis rupibus alpis Grimsel, ubi ad nives aeternas legit anicus He inemann, phamacopola ac mitseorum scruator indefessus 1844. 8. Sept.

12. A. subulata Harv. (Hook. in pl. rar. III. lab. 201.); caulis pusillus subsimplex, apice uncinato-falea-

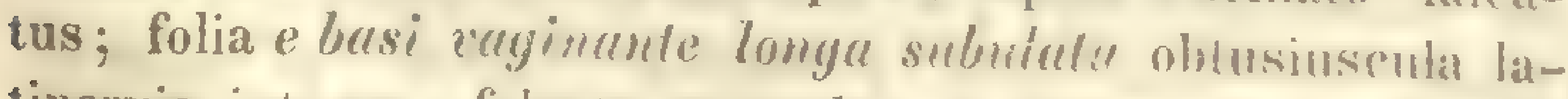
tinervia integra, falcata sermula; pericladialia comboluta late ellipticu apromlalu, theca exserta.

schwiagr. suppt. IV. tah. 301, a. - Hook. et VVils, monour. I. c. p. 536. c. variet. sequentibus:

P. rigida, folis mimus falcatis reassioribus luridis.

$\gamma$ perichuelialis, theca foliis perichactialibus mino-

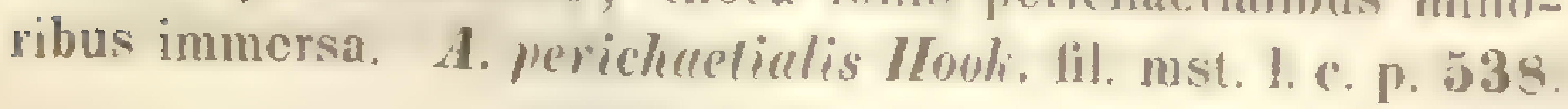


P'atria. In rupibus ad extremitatem faucium ad montem Tabularem ducentium, dictarum, the Port" ad promont. bon. spei. Mensi Martio fruclifera: II a rvey. Var. $\beta$. in insula Eremitae et var. $\gamma$. ibidem et in insula Falklandi: J. H o o ker.

Sectio II. Aerosehisma Hook. et Wils, Theca in valvulis 4-8 dehiscens.

13. A. Wilsoni J. Hook. (1, c. p. 536 et 538.); theca cylindrica e basi ad medium et ultra indehiscens, apicem tantum versus in valvulis $t-8$ fissa. Auct. I. c.

Patria:, In Insulis Aucklandi et Campbelli: J. Ho oker。 


\section{Classis II. \\ C L E IS T O C A R P I.}

Theca inoperculata disrumpendo dehiscens.

\section{Trib. I. B R U CHIA CEAE.}

Pusillaè gregariac vel cespitosac terrestres, acrocarpicae, plenrocarpicae vel cladocarpicae. Caulis humilis simplex rel innovationibus ramosus. Folia e basi plus minusve ovali lanceolata v. subulata, e cellulis parenchymaticis, basi folii majoribus interdum laxis, apicem versus minoribus quudrato-arcolatis composita et nervo lato applanato instrucla, setaceostricta, perichaetialia basi latiora vaginantia; omnia firno-membranacea nitida glabra. Theca ovalis vel globosa plerumque recto-rostellata. Antheridia clavaeformia parva. Archegonia angusta. Paraphyses tenuissimae filiformes brevi-articulatae.

Ex habitu Leptotrichaceis (praesertim Garclieae generi) proximae sed operculo deficiente distinctissimae.

Patria. Per totam Eiuropam et in America ac Africa praesertim, solum argillosum praccipue, interdum stercus animale amantes; e planitiebus in regiones nivales ascendentes.

Phascaceae Bryol. Europ. 


\section{Gen. I. Archidium Brid.}

Brid. br. univ. 1. p. 747. - Phascum nounull. - Evaginulati s. Cladocarpi Brid. I. p. 747. - Diarrhayomitria Hmp. Linu. 1847. p. 66. - Archidiacene C. Müll. bot. Zeit. 1847. p. 97.

Nomen a graeca voce $\alpha_{\varrho} \chi \iota \delta \iota 0 \nu$ primordium huic generi totius muscorum gentis primordio (ex auctoris ratione!) impositum.

Calyptra thecam totam (globosam) includens, dehinc disrumpens. Inflorescentia monoica gemmiformis.

Plantac procumbentes cespitosae innorantes Astomis affinissimac sed calyptra basi thecae persistente distinctissimae nunc cladocarpicae nunc pleurocarpicae. - Ob notas hasce excellentes congeneres tribum propriam (Archicliuce(s) formare 1.c. putavimus. Nunc hanc sententiam errorem habemus, quum ex observationibus ulterioribus eluceat, nec calyptram nec fructus situm tribus formare posse.

1. A. phascoides Brid. (I. p. 7\%.); folia caulina lanceolata remota, perichactialia majora e basi ovali subulata, superne unduluto-denticulatu conferta; theca globosa immersa in rumulo terminalis.

Phascum alternifolium Hook. et Tayl. Musc. Brit. tab. 5. Grev, et W. Arnott new arrang. of the genera of Mosses. - Phascum globiferum Bruch in diario bot. Flora 1823. p. 281. tab. I. Wh. Bruchii Spr. syst. veget. IV. p. 142. - Archid. phascoides Br. Europ. fasc. I. c. tab.

Putria. Germania australis prope Bipontem: B ruch. Sardinia, Gallia occidentalis in ericetis regionis, Perigord"; Anglia et in America septentrionali ubi in pascuis siccis prope Harper's Ferry V'irginiae legit Sullivant. Musc. Allegh. pag. 51. - Per totum annum thecis maturis et immaturis occurrit.

2. A. capense Isch. (Linnaca 1841. p. 135.); caulis brevissimus erectus, interdum innorationibus brerissimis elongatus; folia integerrimu, caulina remota lanceolata acuminata, perichactialia majora c basi latiore ovali concava lanceolata longe-acuminata, minute subquadrato- 
areolata, nervo lato laxo pereurente; theca globosa in ramulo terminatis.

Prtria. Prom. b. spei inter fruticeta in terra loci Löwenrücken dicti. Mensi Octob. 1827: Ecklon.21.

A praecedente tam surculis et imnovationibus multo brevioribus quam foliis integerrimis distinctissimum.

3. A. Iaterale Bruch (in diario bot. Flora 1846. No. 9. p. 132.); subrumosum, ramis conformibus; folia patentia lanceolato-subulata carinata integervima teminerrosu laxe-areolata; theca globosa laterulis.

Patria. Africa in faucibus sylvarum primitiv. prope flumen Umslutic terrae Natal: Krauss. Inter muscos Capenses Ecklonianos invenit Cl. II a mpe. 21.

Ab A. phascoide proximo differt ramificatione conformi, foliis longioribus et fructu laterali.

\section{Gen. II. A stom nm IImp.}

Hmp. in I Limaea 1832. - Pleuridium Brid. II. p. 160. - Phascum al.

Calyptra dimidiata. Theca aequalis. Inflorescentia monoica gemmiformis axillaris vel hermaphrodita.

1. A. subulatum IImp. (1. c.); caulis erectus innovans; folia caulina putula lanceolata, perichactialia $P$ basi oblongu subulata nervo sub upice evunescente; theca orulis pullide-fuscu; calyptra basi subintegra; antheridia foliis perichactialibus libera.

Phascum subulatum Linn. sp. pl. p. 1570. - Brid. 1. p. 37.Bryol. Furop. fasc. 1. Pliaseun p. 15. tab. 7. - Bryum ericetorum Neck. Meth. Muscor. p. 231. - syhagnum acaulon trichodes Dill. Musc. p. 251. tab. 32, fig. 10 ,

Patriu. Per totam Europam et in America septentrionali in solo argilloso areuario. Martio - A m. 2\%.

2. A. alternifolium IImp. (1. c. et mst.); caulis declinatus innouns, innovationes procumbentes fructiferae v. steriles; folia caulina lanceolata patula, perichaetialia e basi ovali subulata, nervo longe-excurrente: theca ova- 
lis; calyptra obliqua wo latere usque fere ad apicem fissa; flos masc. gimmucens parvus axillaris.

Phascum allernifolium Inicka, crypt. fase, 1. p. 2. tah. I. fig. 2. Bryol. Earop. 1. c. p. 15. tah. 7. - Pleuridium alternifolium Brid. 1I. p. 161 et 749 .

Putriu. Britamia. Gallia occidentalis: Normandia. Asatia. Tirolis. Hercynia. Majo. Junio. 2.

Ab antecedente notis illustratis distinctissimum sed rarius occurrens.

3. A. nervosum C. Müll. (bot. '/heit. 18 $\$$ 7. p. 98.); caulis erectus innorans; folia caulina infra julacco-dencissime - imbriculu lancenlato - subulata breviora ; perichaclialia obusi oblongyo - lumceoletu subulute sricte longiora cava angusta, nervo trmi excurpute instructa; theca immersa oeculis pureu breve et acuto rostellutu fusco-nitoms; calyptra angusta tenuissime membranacea basi subfissa in apicem Iongissimum producta fugacissima; flos imasculus al canlis basin gemmacens exsertus perigonio dense clauso orato Tonge-acuminato.

Phuscum nerresum Hooh. Musc, exut. Vol, It. tab. 105. Bitil. 1. p. 36. - Ph. caprense sprenget in schedulis. - Ph, Robinsoni, Mont. in ann, d. sc, nat. tom. IV. sec. ser, p. 96. foliis brevioribus.

Inkrik. Prom. bon. spei: Menzies primus legit. Écklon, Hundl, Paple serius copiose miserunt. Chile respublica prope Quillotam: Bertero. Aug. 4.

A. Pappeuno quam maxime simile, sed ef. adnotationes in speciem hanc sequentem. Inuovationes saepe fructiferae.

4. A. Pappennum C. Mïll. (mst.); caulis erectus subsimplicissimus; folia caulina putulu, e basi ovali latissima longe et lineari-subulata integerrima nervo lato excurrente instructa laxissime imbricala; theca globosa brevi-upiculutu brevi-pedunculata fusco-nitens; calyptra dimidiata basi integra membranacea subcompressa; flos masculus gemmacens in folis inferioribus sessilis parens foliis perignnialibus putulis parris. 
Patriu. Prom. b. spei prope 'Lwellendam inter $A$. nervosum legit Pappe. In terra sylvarum prope eundem locum legit Ecklon. Llb. Kunzeanum 2.

A. nerroso quam maxime símile sed folis caulinis patulis laxissime non julaceo-imbricatis et flore masculo illustrato facillime distinguitur. Ab A. subulato, e foliis patulis affini flore masculo et theca globosa valde refugit.

5. A. Krausennum IImp. (in litt.); folia subsecundu e basi ovali-lanceolata subulato-sctacea solidinervia integerrima; theca latere subexserta muturs subglobosu apiculata; calyptra theca brevior integra $r$. latere fissa rufo-brunnea.

Phascum exiguumb Hook. et Wils. in Hook, ic, pl. rar, tah. 737. B. - Bruchia exigua C. Müll. in bot. Zcit. 1847. p. 99.

Putriu. Nova Hollandia ad flumen Swan River dictum: J. Drummond. - In ericetis prope Kowimanila Novae Hollandiae australis in vicinia loci Port Adelaide dicti: Dr. Behr.

Ex adnotationibus ulterioribus in Iond. journ. of bot. 1846. p. 450. el. auctores putavere, hane specien forte ad eorum genus Eccremidii pertinere, quum cujus theca matura nondum nota sit. E speciminibus, a Dr. Behr e Nova IIollandia relatis et ab amicissimo II a mpe benevole mecum communicatis Astomum verum calyptra dimidiata longe apiculata. A. nerroso valde affine, sed notis illustratis distinctissima. Flores masculi saepe creberrimi ad basin caulis gemmacei exserti ut in $A$. nerroso.

6. A. globiferum C. Müll. (bot. Zeit. 184\% p. 98.); caulis repens filiformis rumosus; folia approximuta, superiora conferta oculi-lanceolata acuminula; theca globosu subsessilis. t.

Pleuridium globiferum Brid. 11. p. 162.

Putria. In insulae Franciae uliginosis in terra nuda, lichenibus crustaceis athaerens caulibus valde implexis non facile extricandum habitat. 4. 
A. alternifolio proximum ut foliis nec alternis nec subulatis sed approximatis ovali-Ianceolatis saepius ita confertis, ut caulis inconspicuus sit, ut et perichaetialibus latissimis conniventibus, theca perfecte globosa longioribus distinctum. - Saepe foliis perichaetialibus humiditate corruptis, theca sese totam fere conspiciendam praebet, lutescens, Sinapeos albae semini similis, decies minor. Brid. ibid.

7. A. nitidum Hmp. (Linnaea 1832.); hermaphroditum, elatior simplex vel innovando ramosum; folı crecto-patula lineari-lanceolata, subsubulata acuta evanidinervia, pellucida vel amoene vividia velutino-nitida, laxe areolata subconcava; theca elliptica brevi-pedunculata (innovationum causa) plerumque lateralis, longiusculo et oblique apiculata pallide-fusca, sporis ferrugineis et calyptra firma breviori.

Phascum nitidum Hdw. Stipp. 1. tab. 34. et ejusd. Musc. Frond. I. p. 92. tab. 34. - Brid. I. p. 35 et 755. - Bryol. Europ. 1. c. p. 12. tah. 6. - Phascum axillare Dicks. crypt. fasc. 1. p. 2. tab. I. - Brid. I. p. 35. - Ph. strictum Dicks. I. c. fasc. IV. p. 1. tab. 10. fig. 1. - Brid. I. p. 34. Foliis angustioribus strictis, statura humiliori. - Ph. stagninum Wallr. Linn. 1840. p. 680. e speciminibus herbarii Schwägricheniani certe huc pertiuet. Folia non sunt enervia, nt auctor dixit. Eandem formam cespitose crescenten prope Allstadiam Thuringiae in piscina exsiccata observavimus.

Patria. In locis argillosis humidis cespitose et in arenosis humidis gregarie per totam Europam crescens. Autumno. $\odot$.

\section{Gen. III. B ruchia Schwägr.}

Schwägr. suppl. II. p. 91. tab. 127. - Bryol. Europ. Fasc. I. Bruchia c. tab. - Saproma Brid. I. p. 52. - Voitia Hsch. in Moug. et Nestl, stirp. cr. vogeso-rh. fasc. VIII. No. 706. - Sporledera Hmp. Linn. XI. p. 279. - Phascum al.

Nomen a Cl. Schwägrichen in honorem bryologi maturius mortui meritissimi Bruch, pharmacopolae Bipontini impositum.

Calyptra campanulata. Inflorescentia dioica vel monoica.

C. Miller: Synops. mus, frond. 
Sectio I. Sporledern Hmp. l.c. Subacaules; theca subaequalis s. pyriformis.

Sporlederce genus amicissimus $\mathbf{H}$ a m pe in litteris contumax defendit. Nescimus, quibus notis a Bruchic certe distingui possit. Theca quidem Bruchiae longe apophysata invenitur, e theca autem Bruchice elegantis pyriformi proximitas dubitari nequit. Calyptra Sporlederue plerumque major quam illa Bruchiue; in Bruchia Lckloniana autem ut in Bruchiis veris parvam vidimus.

1. Mr. Reyrichiana C. Müll. (bot. 'Leit. $184 \%$. p. 99.); folia e basi elongato - lata longissime subulata cupice obscure denticulatu brevi-acuminata solidinervia; theca oblonga; calyptra magna in lacinias latus nonnullas fissa laevis.

Sporledera Beyrichiana Hmp. I. c. - Plascum Beyrichianum Schw. suppl. IV. tab. 301.

Patriu. America septentrionali prope Baltimore: Beyrich primus legit. 24?

2. Br. Mampeana C. Müll. mst.; monoica; folia e basi latiuscula attenuato-subulata obscure denticulatu brevi-acuminata solidinervia; theca oboralis; calyptra onedia in lacinias pluries subaequales fissa papillis maynis verrucosa.

Phascum brevipes schwägr. suppl. IV. tab. 303. l, sed calyptra false epapillosa delineata! - Sporleder se schwïgrichenii Hom. in litt.

Patria. E regno Chilensi CI. Schwägrichen nobiscum prius benevole communicavit. 21 ? sito.

Flos masculus in ramo proprio ad caulis basin po-

3. Br. brevipes IIook. (ic. pl. rar. Vol. III. tab. 231.); monoicu; folia e basi lata longissime subulata apice obscuve denticuluta brevi-acuminata solidinervia; theca globoso-oralis pyriformis apiculata subexserta; calyptra media basi in lacinias plures profunde crenatas fissa laevis. 
Phascum eleynns Hsch, in Linn. (1841) XV. p. 114. - Sporledera brevipes $\mathbf{H m p}$. in litt.

Putria. Prom. bon. spei in solo argilloso lateris borealis montis diaboli ad summos hortos: Heklon. Road side prope Newlands Aug. 24?

Flos masculus in ramo proprio basilari. Folia perigonialia e basi latissima irregulariter crenata subito subuIata nervosa.

Astomo nerroso simillima, sed notis multis diversa.

4. Mr. Eekloniama C. Müll. mst.; dioica; folia e basi latiuscula lanceolato - subulata minutius areolata infegerima nervo cxcurrente lato acutiuscula; theca elTiptica (apice et basi attemuata) longiusculo-et acute-apiculata recta vix emersa; calyptra parra $1 / 3$ thecae apiculatce tegens basi in lacinias fissa glabra lurida.

Phascum nerrosum sprengel in hb. proprio, Hampeano et Meissneriano. - Norledera Echloniana Hmp. in litt.

Patria. Prom. bon. spei: Ecklon. 21.

Flos masculus in planta propria terminalis gemmaceus. In eadem planta interdum flores plures: flores laterales auten in ramulis propriis semper terminales.

Br. elegunti ex habitu proxima, sed inflorescentia dioica thecae et calyptrae forma ac foliis integerrimis distinctissima.

5. Br. palustris C. Miill. mst.; monoica; caulis electus innorans; innovationes fructiferae; folia caulina lanceolata patula, perichactialia e basi lato-ovali subulata, nervo in cuspidem longam excurrente; theca magna ovalipyriformis; calyptra mitraeformis parua basi pluries mofunde fissa.

Phascum palustre Br. Europ. 1. c. p. 15. tab. 7., sed calyptra false dimidiata delineata. - Sporledera palustris Hmp. in litt.

Palria. In locis uliginosis et turfosis ad fossarum margines Thuringiae; in Vogesis prope Bipontem, ubi Bruch detexit et Caesaream Lutram nec non prope Baerenthal Alsatiae et prope Zell am See dition. Salisburgensis. Majo. Junio. 2 . 
Flores masculi gemmascentia in longitudinem totius caulis positi.

Astomo subuluto et alternifolio simillima, notis autem illustratis certe distincta.

Sectio II. Eubruchia. Caulescentes; theca exserta longeapophysata pyriformis longe-apiculata ; calyptra $2 / 3$ thecae tegens.

6. Rr. Vogesiaca Schw. (suppl. II. p. 91. Lab. 126.); divica; caulis e basi decumbente erectus subsimplex; folia e busi orculi subulata, summo apice denticulata; perichactialia e basi latissima longissime subulata, omnia nerro ante apicem exanescente, patula sublaxe areolata; theca ovali-pyriformis.

Saproma Vogesiacum Brid. 1. p. 5ั3. Voitia Voyesiaca Hsch. 1. supra cit.

Patria. In praeruptis frigidis nivosis montis IIoheneck et Kastelberg tract. Vogesorum ad terram in stercore vaccino: Mouge ot hanc primam Bruchiam detexit 1822 d. 24. Septbr. 4. E rarissimis!

Flos masculus in planta propria terminalis magnogemmaceus foliis perigonialibus latissime raginantibus.

7. Br. Mexuosa C. Müll. (bot. Zeit. 1847. p. 99.); dioica; caulis flexuso-erectus simplex; folia e basi oblonga lata longe subulata acuta; summo apice denticulata, perichaetialia latiora; omnia nervo excurrente, patula densiusculo-areoluta; theca ovali-pyriformis. edit.

E spec. Drumm, musc. sub. nom. Bruchiae Vogesiacae var.

ק. minor; in partibus omnibus minor, foliis brevioribus strictioribus angustioribus acutioribus apice hyalino.

Phascun flexuosum schw. suppl. II. tab. 101. - Brid. I. p. 38. - Bruchic Vogesiaca var. Drumm. ex hb. Hampeano. - Sporledera Alexusa Ump. in litt. et sporledera Drummondi ej. il.

Patria. America septentrionalis in terra nuda Pensylvaniae, ubi primus legit Mühlenberg. - Louisiana: Drummond. - $\beta$. Florida: Schimp. subnom. Bruchice brecipedis Hook. in hb. Hampeano. $2 \%$ 
Br. Vogesiacu quidem proxima, sed foliis apice multo latioribus multo laxius areolatis evanidinerviis a $\boldsymbol{B r}$. flexuosa differt.

Ifaec species in omnibus partibus, theca praesertim ac calyptra, cum Bruchia Vogesiuca adeo convenit, ut ab eadem proxima nunquam removeri possit.

\section{Trib. II. PH A S C A CEA E.}

Pusillac interdum elatac, mregariae vel cespitosae acrocarpicae. Caulis simplex vel ramosus. Folia oblonga, ovalia, lanceolata s. spathulata cava, nervo tereli crasso instructi. Areolatio parenchymatica basi laxior, apicem versus sensim densior. Cellulae plerumque papillosae. Theen plerumque oblique-apiculata. Antheridia, Archegonia et paraphyses ut in tribu praecedente.

Ex habitu Pottiuceis proximae, sed operculo deficiente distinctissimae.

Patria. In solo argilloso arenario per totam orbem terrarum e planitiebus in regiones alpinas ascendentes.

phascaceate auct. ex parte.

\section{Gen. I. A c a u 1 o n C. Müll.}

(in bot. Zeit. 1847. p. 99.); Phascum al。

Nomen ob humilitatem congenerum magnam impositum.

Plantac humillimae gregariae. Theea perichaetio clauso inmersa. Calyptra mitraeformis tenera. Inflorescentia monoica (flos masculus in ramo proprio ad basin caulis), vel dioica (flos masculus gemmiformis in planta propria terminalis).

1. A. Nörkeanum C. Mïll. (1. c.) divicum; folia conferta apice patula ovalia brunnea, nervo excedente crassiusculo bruneo cuspidata, maryine revoluta subcre- 
mulata; theca sphaerico - ovalis brevi - apiculata recta. fusco - brunnea.

Phascum Flürkeanum Web. et Mohr hot. Taschb. p. 70 et p. 451. - Brid. I. P. 26. - Br. Europ. fasc. I. Phascum. p. 8. tab. 3. - Ph. minutun Röh. Ann, d. Wett. Ges. 1. p. 185.

$\beta$. foliis longioribus angustioribus c cellulis majoribus pallidioribus compositis: $\boldsymbol{P} h$, badium Bryol. germ. I. p. 53. tab. 5.

Patriu. In terra argillosa prope Jenam F lö lk e primus legit. In iistem locis prope Naumburgum ad Salam sit.: Beneken. Prope Argentoratum, Bipontem et in Normandia prope Falaise. Var. $\beta$. in isdem locis per annos humidiores. Sero autumno et primo vere.

Nervus in foliis interioribus perichaetialibus laxius reticulatis saepe obsoletus. Plantula mascula minuta gemmiformis. Paraphyses nullae.

Colore brumneo jam ex habitu a sequentibus primo momento distinguitur.

2. A. muticum C. Müll. (1. c.); dioicum; folia confertissima late orulia concura commixentia, inferiora minora subintegra excurrentinervia, superiora (perichactialia) latissima apice dentuta $v$. multoties repunda undulate $"$ crencta lurida; theca globosa brevissime apiculata rufo-fusca; calyptra campanulata basi in lacinias tres latas fissa.

Phascum muticum Schreb. de Pliasco pas. 8. tah. 1. - Brid. I. p. 22. - Br. Furop. 1. c. p. 8. tab. 2. - Ph. globosum schleich. ex adn. Br. Lurop. - sphagnum acaule bulbiforme minus Dill.
Musc. p. 252. tab. 32. fig. 12. A. B. C.

Patria. In solo argilloso totius Europae. E promontorio bonae spei societate Astomi Pappeani habemus. Intumno et vere.

Flos masculus eparaphysatus.

3. A. triquetrum C. Müil. (1. c. p. 100.); monoicum; folia exacte trifarie disposita conniventia lato-ovalia carinato-concava, margine reflexa, nervo excurrente cuspidata, plerumque fere e basi usque ad apicem denti- 
culata, apice recurvo, pellucida; theca magna sphacrica vix apiculuta; calyptra parra tubulose-campanulata a medio ad basin subdimidiuta integra tenerrima.

Phascum triquetrum Spruce in Lond, journ. of bot. Vol. IV. (1815) p. 189. - Ph. muticum 1)rumm. musc. Americ. No. 8. Ph. muticum Bruch in musc. Sardois Mïllerianis un. itil. - $\boldsymbol{P} h$. muticum Moug. et Nestl. stirp. Vogeso-Rhen. 1820. No. 802. Ph. carinatum Wils.?

Patrie. Germania: Naumburgum ad Salam sit.: Beneken. In Vogesis: Moug. et Nestler. Sardoa: Fr. Müller. Britannia in locis nudis inter gramina humilia ad summitates rupium inter Brighton et Newhaven: Am. 184t. Borrer legit. America septertrionalis: Drummond. $\odot$.

A. mutico simillimum, sed notis illustratis distinctissimum.

Planta mascula eparaphysata.

4. A. carniolicum C. Müll. (1. c. p. 100.); monoicum, subcunlescens; folia oblongo-lanceolata subreflexa patula integra, nervo excurrente crasso brunneo acuta, amoene viridia, basi laxiusculo, apicem versus dense minute areolata, concava; theca subglobosa brevissime apiculata et pedunculata.

Pluscum carniolicum Web. et Mohr hot. Taschb. p. 69. et 450. - Brid. I. p. 26. - Bryol. Europ. 1. c. p. 12. tah. 5.

Putria. In terra limosa nuda Carnioliae prope Nussdorf: Dr. Wagner primus legit. In tractu Rhenano circa Neowidam: Breutel. In alpib. Salisburg. prope Zell am See: S a uter. Sardinia: Fr. Nüller. V'ere. (-)

Flos masculus paraphysibus instructus.

\section{Gen. II. Phascum Hmp.}

Linnaca 1832. - C. Mïil. Jot. Zeit. 1847. p. 100. - Phascum auct. ex parte.

Nomen Linnacanum at graecac originis, C'sueum barbutum Theophrasti designans. Hedwigius retinuil et sancivit pro muscis inoperculatis omnibus. Hampe pro parte eorum imposuit. 
Plantae elatiores cespitosae. Perichaetium apertum. Theca longius pedunculata et plerumque oblique apiculata. Calyptra dimidiata. Inflorescentia monoica (flos masculus in ramo proprio laterali terminalis gemmiformis vel in ramo fructifero axillaris nudus) v. dioica.

\section{a. Folia lanceotata.}

1. Ph. erispum Hdw. (Muse. frond. I. p. 25. tab. 9.); monoicum; caulescens, apice fastigiato-rumosus, ramis aequalibus; folia caulina lanceolata, perichaetialia Ianceolato-subulata carinato concarca siccitate crispa acutissima, madefacta subflexa integra, basi e cellulis angustis quadratis pellucidis longioribus apicem versus multo minoribus densius areolatis papillosis viridibus composita; theca subsphaerica immersa; calyptra tenera basi integra pellucida.

Brid. 1. p. 46. - Bryol, Europ. I. c. p. 13. talo. 6. - Phascum multicapsulare Sin. F1. Brit. 111. p. 1152. Brid. I. p. 48, - Astomum crispum Hmp. I. c. C. Müll, bot. Zeit. 1847. p. 98.

Patria. In locis campestribus argillosis siccioribus per totam Europam temperatiorem et in America septentrionali. Martio. Aprili. 21.

Flos masculus axillaris triphyllus in ramo fructifero. Rami saepe thecis pluribus praediti.

2. Ph. polyenrpum Br. et Sch. (Bryol. Europ. Phascum p. 14. tab. 6.); caulescens; caulis ramosus; folia mujora ligulato-lanceolata siccitute non tortilia; theca magna
subsphaerica lateraliter emergens. + .

Astomum polycarpum Hmp. C. Mäll. in bot. Zeit. 1847, p. 98.

Patria. In terra lutoso-arenaria prope Wertheimium ad Moenum sit.: Wibel. Vere. 21?

A praecedente foliis majoribus non crispis et theca longius pedunculata differt. Inflorescentia?

3. Ph. rostellatum Brid. (Mant. musc. p. 11. et br. 
superiora anguste lanceolutu longissimu, perichaetialia interiora basi vaginante latiora interdum repanda, omnia nerro excedente acuta, carinato-concava, siccitute crispa, papillis valde asperula, integra; theca longipedunculate ovalis longe et oblique apiculata; calyptra longe apiculata angusta basi integra lurida.

Bryol. Europ. 1. c. p. 13. tah. 6.

Patria. In terra argillosa humida in Britannia primum detectum. Prope Herbipolin et Bipontem Germaniae. Sero autumno. $\odot$.

Flos masculus in ramo laterali terminali gemmiformis paraphysibus nonnullis instructus. Foliorum structura ut in $P$. crispo.

Folia Ph. crispi et rostellati (Ph. polycurpum ex adnot. Br. Europ. proximum nobis hucusque haud visum) Weisiae generis congeneribus ex habitu, forma et structura adeo similia, ut putemus, praecedentes species ad tribum propriam revocandas esse. Folia nervo carinato carinato-concava linearia acuta excellentia! Nos vero nondum separare ausi sumus.

\section{b. Folia ovalia.}

a. Theca immersa.

4. Ph. cuspidatum Schreb. (de Phasco p. 8. tab. 1.); monoicum; caulis subsimplex; folia ovali-lanceolata nevo excedente cuspidata $u$ pilifera concava integerrima margine plerumque reflcxa, e cellulis majoribus a basi usque ad apicem pellucido-reticulata; theca sphaerico-ovalis brevi-pedunculata $\mathrm{v}$. in pedunculo elongato arcuato latere emersa.

Brid. 1. p. 41. - Bryol. Europ. 1. c. p. 10. tal. 4. - Ph. acaulon, acaule, anthera sessili, folis ovatis acutis conniventibus Liun. Sp. P1. p. 1570. - Nihagnum acaulon bulbiforme majus Dill. Musc. p. 252. tab. 32. fig. 11.

B. Elatius subdichotomum, foliis inferioribus remotis: Ph. Schreberianum Dicks. Fasc. Cr. IV. tah."10. - Brid. I. 1. 42.Bryol. Europ. 1. c. tab. 4. fig. $\gamma$ 1. et $\gamma 2$. Ph. macropliyllum Wib. Fl. Werth. p. 282. 
$\gamma$. Foliis lineari-lanceolatis erecto-patulis subrecurvis, inferioribus latioribus nervo excurrente aristatis, theca immersa conspicua: Ph. affine Fr, Nees ab Es, bryol. germ. I. p. 74. tals. 7. fig. 19. - Brid. 1. 1. 43. - Bryol. Europ. 1. c.

J. Caulescens, foliis oblongis piliferis: Ph. piliferum Schreb. de Phasco p. 8. tab. 1. fig. 7. - Brid. 1. p. 38, - Br. Europ. 1. c. fig. $\delta$.

E. Pedunculo incurvo: Ph. curvisetum Dicks. Fasc. IV. p. 3. talo. 1V. fig. 4. - Brid. I. p. 42, - Br. Europ. 1. c. fig. . $_{0}-$

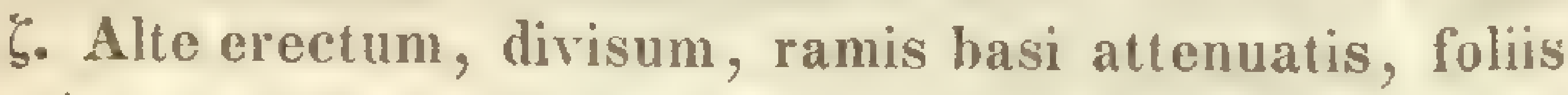
oblongis, perichactialibus conniventibus maximis, theca subnutante conspicua: Ph. elutum Brid. I. p. 45. - Bryol. germ. I. tals. VII. fig. 20. - Br. Europ. I. c. tals. IV. fig. ఢ. - Ph. grandiusculum Brid. Sp. Musc. 1. p. 9.

$\eta$. Caulibus gregariis simplicissimis brevissimis oligophyllis, foliis imis obsoletis, reliquis ovatis latescentibus concavis hyalinis nervo exarato abrupte in acumen praelongum tenuissimum hyalinum obsolete denticulatum excurrens inscriptis, theca globosa sessili apice mamillata tenui coronala (rubra), seminibus sphacricis asperulis mediocriter magnis: Ph. trichophyllum Wallr. Limnaea 1840. p. 679.

Putriu. In locis argillosis totius orbis terrarum per regiones temperatiores. Vere. $\odot$.

Flores masculi foliis caulinis axillares, folio unico perigoniali enervo obtecti, paraphysibus antheridis longioribus, apice incrassatis.

Species e locis natalibus valde polymorpha.

\section{B. Theca emersa.}

5. Ph. subexsertum Hook. (in Musc. Americ. Drummond. No.9.); dioicum, pusillum, folia e basi oblonga lato-ovalia nervo crasso excedente longe cuspidata, carinato-coucava pellucida patula, cellulis cremulatis denticulcta; theca globosu longiusculo of oblique apriculate brevi-exserta; calyptra angusta.

Schwägr. Suppl, IV. tab. 302. 
Putria. America septentrionalis prope Carlon House Saskatchawan: Drummond. $\odot$.

Forsan $P /$. cuspidati (proximae specici) varietas memorabilis? Cl. Wilson in Lond. journ. of bot. 1841. p. 443. quaesivit. Non credimus; nam foliis valde pellucidis crenulatis inflorescentia et thecae forma sat differt.

6. Ph. curvicollum IIdw. (Musc. frond. I. p. 32. tab. XI.); monoicum, brevicaule; folia e basi oblonga lanceolata nerro excedente crusso cuspidutu acutu concava integerrima brunnea; theca ovalis breve et oblique apiculata, pedunculo arcuato mutuns fusco-brumnea; calyptra tenera basi semel fissa flavescens tandem candida.

Brid. I. p. 24 et 754. - Bryol. Europ. 1. c. p. 11. tab. 4. Pyxidium pendulum Ehrh. Beitl. IV. p. 4t. - Phascum cernuum Gmel. syst. Nat. II. p. 1323.

Patria. In locis argillosis subsiccis per totam Europam et in alpes ascendens. Autumno et primo vere. $\odot$.

Flos masculus axillaris in ramo fructifero nudus, paraphysibus nullis $v$, paucis instructus.

7. Ph. reetum Sm. (Flor. Brit. III. p. 115̌3.); monoicum, brevicuule; folia conferta evecto-patula oblongo-lanceoluta nervo excurrente brevi-ucuta luridu valde papillosa, margine reffexa; theca sphaerico-ovalis brevi-et oblique apiculata fusco-brunnea, calyptra basi subinflexa apice asperula et seta rectu instructa.

Brid. I. 1. 25 et $75+$ - Br. Europ. I. c. p. 11. tab. 5.

Putria. In locis calcareo-argillosis in societate Pottiae minutulae et Desmatodontis Starcheani in Alsatia prope Mutzig, ubi in campis montis Dreispitz rarius occurrit; copiose in Gallia occidentali, in Gallia septentrionali, Anglia et Irlandia, in Sardinia et Tyroli. Autumno et primo vere. $\odot$.

Flos masculus in ramo fructifero axillaris nudus.

8. Ph. splachnoides Hsch. (Hor. phys. Berol. p. $5 \%$ (ab. 12.); dioicum, cespitosum humile subsimplex; folia oialia lata nervo crasso excedente brevissime cuspidata 
subobtusa conferta valde concava integerrima glauca, c cellulis magnis superioribus subquadratis, inferioribus ex hexagono parallelogrammis composita; theca ovalis aequalis erectu fusca breve apiculuta obtusa; calyptra latere fissa straminea apice fuscescens.

Schwägr. suppl. Ill. tab. 203. - Physedium splachnoides Brid. I. p. 51. C. Müll. in hot. Zeit. 1847. p. 102. Bridelium errantem sequens, nam folia e speciminihus Ecklonianis haud splachnoidea-, sed pottiaceo - areolata pellucida.

Patria. Prom. b. spei prope "De Kankerbay": Bergius primus legit. Ecklon in locis non indicatis. Julio. $\odot$.

A Ph. recto caule subramoso, foliis oralibus latis dense imbricatis, theca oblongo-cylindrica subapophysata, a Ph. bryoide, cujus praesertim formis minoribus foliis ovalibus latis glaucis magno-areolatis et theca differt.

9. Ph. bryoides Dicks. (Fasc. crypt. IV. p.2. tab. 10.); monoicum, caulescens saepe elatus subsimplex; folia sensim majora superiora ouculi-oblongu lutu nervo crasso excedente cuspidata, in omnibus partibus amoene viridia integra, e cellulis basi majoribus laxioribus pellucidis, apicem versus regulariter parenchymaticis magnis composita concara margine reflexa; theca longi-pedunculatu ellipticu crassa longe et oblipue apiculata nigrescens; calyptra dimidiata robusta.

Brid. 1. p. 754. - Br. Europ. 1. c. p. 11. tal). 5. - Plascum elongutum schultz in Fl. Stargard. p. 273. - Brid. 1. p. 49. Ph. gymnostomoides Brid. 1. p. 48. - Ph. pusillum schleicll.

Patria. In locis argillosis, calcareis et arenariis incultis siccis vel humidioribus per totam Europan. Vere et ultra. $\odot$.

Species ut Ph. cuspidatum e locis natalibus diversis polymorpha, nunc liumilis, nunc elata, foliis cuspidatis $\mathbf{v}$. piliferis, dense imbricatis $v$. patulis, theca autem (interdum subimmersa) nigrescenti-nitida magna valde obliquo-apiculata et foliis magnis erectis confertioribus facile distincta, ex habitu Desmatodontis lanceolati. Flos masculus gemmiformis axillaris. 
10. Ph. tetragonum Ilarv. (in Hook. bot. Misc. I. p. 124. tab. 31.); dioicum, caulescens ramosum, rami apice stelligero-foliosi; folia ovali-lanceolatu nervo excedente crasso brunneo acuta crussissiona basi laxius areolata membranacea, apicem versus e cellulis minimis ralde papillosis densissime reticulata carnosa intense viridia (adeo ut vix areolas videas) integra brevia siccitate subinflexa; theca brevi-pedunculata exserta oblongo-elliptica brevi-et crasso apiculata currinscula quadrangulata fusco-coloreta; calyptra subulata basi in lacinias plures fissa.

schwägr. suppl. 1V. tab. 303.

B. cylindricum; caule breviori foliis siccitate magis tortilibus obtusis apiculatis thecaque haud angulata: $P /$. cylindricum Tayl. in Lond. journ. of bot. 1846. p. 42. Ex adnotationibus Cl. Wilsoni (l. c. p. 447.) huc pertinet, quum formae intermediae inveniantur.

Patvia. Prom. b. spei: 'liger-Bay ubi primus legit II arvey. 'Tigersberg: Pappe. Prope Zuwellendam: EckIon. Var. $\beta$. in Nova IIollandia ad flumen Swan River dictum: J. Drummond. 4 .

Ob folia densissime areolata carnosa intense viridia basi pellucidiora siccitate subconvoluta Cl. Hampe (in litteris!) genus Tetrupterum imposuit, quod Hyophilas referat. Ab hac sententia aversi non sumus, credimus vero, nunc temporis muscos cleistocarpos satis divisos esse. Speramus, fore, ut congeneres mox inveniantur.

$$
\text { Species dubiae. }
$$

1. Ph. stellatum Bridel (br. univ. I. p. 24.); subacaule macrorhizon, foliis ovato-lanceolatis acuminatis undique patentibus subaequalibus, theca ovata subsessili immersa. $\%$

Patria. In Anglia circa Salapiam gregarie habitat. Vere. $\odot$.

Pusillum tenerrimum. Radices longinsculae, simplices. Caulis vix ullus. Folia omnia fere longitudine aequalia, humiditate undique expansa, stelliformia, ovato- 
lanceolata, acuminata, nervo valido. 'Theca orata, subsessilis, intra folia latitans.

A. Ph. cusprilluto non tantum habitu diverso, sed etiam foliis omnibus expansis nee superioribus comniventibus differt, dubitante tamen Sprengelio. N. Entd. II. p. 203.

2. Ph. dubium La Pyl. (Journ. Bot. 1813. p. 274. 1. 19. et Brid. I. p. 43.) ; caulescens; basi ramosum; foliis imbricatis erecto-patulis lucidis, pedicelli ragina conica et calyptra ore contracto campanulato-clongata. t.

Putria. Circa Parisios Persoon legit.

Forsan Ph. cuspidati varietas!

3. Ph. Nepalense Brid. (I. p. 75̃.); subacaule divisum, foliis congestis paucis lanceolato-subulatis canaliculatis incurvis. $t$.

Prtiol. In Irpal Indica regione habitat. Inter muscos inde in Furopam a $\mathbf{W a l l i c h i o ~ m i s s o s ~ n e g l e c t u m ~}$ auctor vidit. 24.

Plantula fructu carens obscura, e toto habitu Phasco adscribenda, cuspudutum proxime referens, foliis speciosis pro stirpis exiguitate, latioribus quam in Ph. subulato praedila. Areolatio vix satis conspicua.

\section{Trib. II. EPIIEMEREAE.}

Pusillac vel elatae, gregariae vel cespitosac acrocarpicae. Caulis subsimplex. Folia plus minusue ovalia s. lanceolata paullum cava pellucida nervosa vel enervia. Areolatio parenchymatica ubique laxa. Cellnlac clongatae epapillosue. Theca, antheridia et paraphyses ut in praccedente tribu. Archegonia laxe cellulosa crassiuscula.

Elatiores congeneres ex habitu Funariaceurum; humiliores Acaulon genus referentes. 
Patria. In solo argilloso per regiones temperatas totius Europae et Americae septentrionalis et in Australia.

Phascaceae auct.

\section{Gen. I. Ephémerum.}

Homp. in Limnaea 1832. C. Miiller hot. Zeit. 1817. p. 101.

Nomen ob vitam congenerum tenerorum brevem impositum, ab i̇s juegos diurmus ductum.

Calyptra campanulala. Inflorescentia dioica rel monoica (flos masculus in ramo proprio ad caulis basin sito humillimo).

Sectio I. Enervia. Plantae humillimae foliis ovali-lanceolatis plerunque profunde dentatis.

1. E. serratum IImp. (1. c.); dioicum; basi filis protothalli instructum; folia lanceolutu profunde dentatu acuta primum viridia, tandem pellucida; theca subsessilis oraliglobosa subapiculata recta, puniceo-fusca; calyptra tenerrima latere fissa.

Phascum serrutum schireb. de Pliasco p. 9. Lab. 2. - Brid. 1. p. 28. 75.4. - Bryol. Europ. l. c. p. 6. tal. 1. - Ph. stoloniferum Dicks. crypt. fasc. 3. tal, 7. fig. 2. Brid. I. p. 50.

Putriu. Per totam fere Europam in terra argillosa humida ad margines viarum et fossarum etc. In alpes ascendens. Sero autumno et primo rere. $\odot$.

Planta mascula ad pedem rel in vicinia femineae. Columella thecae obsoleta.

2. E. tenerum Hmp. (1. c.); dioicum, basi filis protothalli instructum; folia oreli-lanceolute vix dentuta tenerrima pellucida; theca subsessilis subsphaevica vix apiculuta pallide ochracea; calyptra thecam arcte adhaerens vix fissa.

Phascum tenerum Br. Eur. 1. c. p. 6. tab. 1. - schwägr. supplo IV. tab. 302.

Putria. In terra uliginosa stagni exsiccati prope Niestiy Lusutiue: Breutel. C.

Columella thecae obsoleta. 
Sectio II. Nervosn. Plantae humillimae vel elatiores folits ovalibus latioribus nervosis.

a. Ac aulia.

3. E. eristatum C. Müll. (bot. Zeit. 1847. p. 101.); monoicum, exiguum, basi filis protothalli instructum; folia sputhelato-lanceoluta acuminata inciso-dentute, laciniis dentato-ciliutis, dorso ciliuto-cristutu; theca immersa subsessilis ovali-globosa acutiuscula; calyptra campanulata rufo-fusca. t.

Phascum cristatum Hook. et Wils. in icon. plantar, rar. Hookeri tab. 737. a.

Putria. Nova Hollandia ad flumen Sucun River dictum: James Drummond. $\odot$.

E. cohucrenti simile, sed ab eo ceterisque congeneribus foliis supra descriptis jam distinctissimum. - Species pulcherrima foliis erectis subsecundis concaviusculis supra medium dilatatis (quorum nervus basi pallidus evanescens), superne validioribus dorsoque ciliato-cristatis laete viridibus laxe areolatis. Planta mascula ad pedem femineae gemmiformis.

4. E. cohaerens Hmp. (1. c.); dioicum; basi filis protothalli instructum, subacaule; folia orali-lanceoluta servatu, nervo evcusescente (raro excurrente), acuminata; theca globoso-ocalis recto-apiculata obtusa immersa superne brunneo-purpurea; calyptra tenerrima basi lacerata longi-apiculata.

Phascum cohaerens Hedw. Spec, musc, p. 25. tab. I. fig., 1-6. Brid. I. p. 29. - Bryol. Europ. 1. c. p. 6. tab. 1. - Ph. Flotouianum Fk. in litt. foliis angustioribus, nervo breviori. Brid. 1. p.754. - Ph. Lucasianum Bryol. germ. I. p. 44. tab. V. foliis majoribns latioribus, nervo sub apice evanescente. Brid. I. p. 32. - Ph. heterophyllum de Not. Spicil. p. 23. et Syllab. muscor. p. 313!

Patria. In Pensylenia Mühlenberg primus legit. In terra argillaceo - arenosa ad Rheni ripas prope Confluentes, Argentoratum et Landsbergam ad fl. Wartham sitam. In agro Pedemontano legit de Notaris. Primo vere. $\odot$.

$\boldsymbol{E}$. serrato assimile, sed foliis nervosis magis ovalibus differt. Interdum nervi obsoleti. 
5. N. sessile C. Müll.; dioicum, subacaule basi filis protothalli instructum; folia lanceolatu angusta nervo crasso lato excedente crasso cuspidata, apice flexuso suepe longo, densius (quam praecedent.) ureoluta denticulatu viridia; theca parve subsphaerica recta brevissime apiculata; calyptra majuscula.

Ph. crassinerrium 131. Europ. 1. c. p. 7. ta). 2. cum forma Ph. stenophylli Voit in sturm Deutschl. Fl. crypt. fasc. 14.; foliis brevioribus, lineari-lanceolatis, vix serrulatis. Br. Europ I. c. fig. $\beta$. Ephem. crassinervium Hup. C. Müll. in bot. Zeit. 1847. p. 101. Ph. sessile Br. et sch in adnotationibus in "Zweiter Jaliresbericht der Pollichia" p. 49. et in diario hot. Flora 1845.

Patria. E locis argillosis humidis prope Bipontem a Cl. Brucle lectum, et e Surdinia a Cl. Fr. Nüller communicatum habemus. Furopae species tantum hacce esse videtur, nam Ph. crossinerium Schw. cum ca hucusque semper commutatum revera longe distare videtur. Autumno.

Plantula mascula in ricinia femineae gemmiformis.

6. E. crassinervium C. Müll.; divicum? basi filis protothalli instructum, subacaule; folia e lanceolata subulata vage dentata crussa rigida, apice subflexa areolis reticuli magnis parcisque, albido-viridiu ". lutescentia, nervo ad apicem perlingente crasso latissimo, basin versus minus conspicuo viridi; theca globosa brunnea; calyptra ut in congeneribus ceteris, parva.

Phascum crassinervium Schwägr. Suppl. I. p. 4. tab. 2.

Patria. In terra argillosa Pensylvanicue: Mühlenberg. Novbr.

E speciminibus authenticis a praecedente simillimo foliis laxius reticulatis repando-denticulatis longius subulatis valde flexuosis nervoque crassiore differt.

\section{b. Caulescentia.}

7. W. patens IImp. (1.c.); monoicum; folia spathulata obtuse-acuminatu serrata e cellulis crassis magnis laxissime areolata, nervo ante apicem evanescente instructa, pellucida; theca immersa brevi-pedunculata subsphaerica,

C. औl t1 1 r: Synopy. munc. frond. 
brevissime et obtuso-apiculata recta; calyptra angusta campanulata basi subintegra.

Phascum putens Hedw. Stirp. 1. t. 10. Ejusd. Minsc. Frond. I. p. 28. tal. 10. - Ph. Megapolitanum schultz Suppl. Fl. Stargard. p. 2. tah. 1.; folias angustioribus tenerioribus thecisque exsertis.

Petria. In locis argillosis humidis praesertim ad fluminum ripas per totam Furopam temperatiorem rarius. Autumno et primo vere. $\odot$.

Planta mascula minutula ad pedem femineae. - Planta pulchella in omnibus partibus laxissime reticulata ex habitu Funaraccis simillima et nulla alia hujus generis specic confundenda, sed quoque areolatione laxissima foliorum subheterogenea et cum Voitiis maxime congruens.

\section{Gen. II. Ephemerelia C. Müll.}

Phascum al. - Physedium Brid. Müll. bot. Zeit. 1847. p. 101.

Calyptra dimidiata. Inflorescentia dioica vel hermaphrodita.

1. N. pachyearpa C. Müll.; dioica; subacaulis basi filis protothalli instructu; folia lanceolata subconcava flex" recureuta apice denticulatu nervo excedente brevi-subulata densius areolatu intense viridia; theca ovalis subsessilis; calyptra firma magna.

Phascum puchycarpum Schw. Suppl. I. p. 6. tab.II. Bryol. Eur. 1. c. p. 8. tal. II. - Ph. recurvifolium Brid, I. p. 31. - Ephemerum recurvifoliun In bil. cellular.Germ. sept. etc. No. 12. ad Ephemerum patens pertinentibus.

Patria. In campestribus et pratis Thuringiae, $\mathbf{P a}-$ latinati Rhenani, Alsatiae et Galliae. Autumno

Plantula mascula ad pedem vel in vicinia femineae.

\section{Gen. III. Voitia Hornsch.}

Hornsch. Comment. de Voitia et systylio p. 5. tab. 1. - Brid. r. p. B4-66. - Bryol. Enrop. Fasc. I.

Nomen in memoriam Doctoris Suevofurtensis Voit, viri de muscis neriti, impositum. 
Calyptra dimidiato-cucullata, thecam longe et oblique apiculatam multo superans membranacea lurido-alba. Inflorescentia monoica discoidea in ramulo proprio terminalis.

Ex habitu modoque crescendi i. e. in stercore vaccino Splachnaceis similis.

Voitiaceae C. Müll. bot. Zeit. 184\%. p. 102. Hoc loco tribum hancce optime distinctam putavimus. Congeneribus autem ex novo examinatis, nonnullis notis contemtis, ad Ephemereas ducendi videntur. Ex his notis quidem Splachnaceis simillimi inveniuntur, areolatio tamen foliorum, nota pro tribu imponenda essentialis, tota est illa Ephemerearum e. gr. Eph. putentis parenchymatica, e cellulis amplissimis laxe areolatis formata. Quod autem ad Ephemereas ipsissimas pertinet, fatendum est, huc pluribus congeneribus detectis mutationes novas faciendas esse.

1. V. nivalis IIsch. (1. c.); elat $\iota$ dense cespitosa robusta; folia laxe imbricata erecto-patentia lato-ovalia v. oblonga longe cuspidata membranacea magis minusve plicato-concava, nervo apice crasso excurvente, integerrima; perichaetialia longissima cuspidata subflexuosa nervo excurrente; vaginula longa membranacea; pedunculus elongatus; theca oblongo-ovata uequalis apice curvirostri crasso; calyptra basi granuloso-membranacea; semina parva laevia.

Patria. In summis alpibus Carinthiue: Glockner, Pasterze; nec non in Lapponia, ni fallimur, detecta. Cl. Ang ström tamen in sua synopsi muscorum (in El. Fries: Summa Vegetab. Scandinaviae 1846) non memoriam fecit. Versus finem Augusti thecas maturat. 4

2. V. hyperborea Grev. et Arnott. (new arrangem. of the genera of mosses in Act. soc. Wernerian. IV. p. 109. tab. 7.); humilior gracilior; folia dense imbricata erecto-appressu, lato-ovalia subrotundata brevius acuminata firma aequabiliter valde concava, nervo apice evanido, integerrima; perichaetialia longe cuspidata nerva 
excurrente; vaginula longa membranacea; pedunculus humilior; theca ovali-globosa basi subangulata apice curviusculo temiori; calyptra basi granuloso-membranacea; semina minima laevia.

Schwăgr. Supp1. II. tab. 126.

Patria. Insula Melville: Sabine navarchus. Ad fretum Sinjawin Asiae septentrionalis (Hb. Acad. Scient. Petrop.) sec. W einmann syllab. musc. p. 433. 4

Nonnulli auctores hanc speciem formam prioris minorem putavere. Speciei utriusque diagnoses negant. Cetera ut in praecedente specie. 


\section{Cuassis III. \\ S T E G O C C A R P I.}

Theca operculo dehiscens.

SUBCLASISI.

\section{A c $\mathbf{P}$ c a $\mathbf{p}$ i $*$}

Fructus terminal's, tantum innoratione lateralis. Axis vita fructificatione finita.

\section{Distichophylia.}

Folia in series duas rectas disposita.

a. Rxacte verticalis.

Trib. V. SCHIST OSTEGEAE.

Plantae gregariae acrocarpicae. - Caulis inferne nudus, superne foliosus dimorphus: nunc frondiformis filicoideus foliis verticaliter insertis basi connexis, e cellulis prosenchymaticis rhomboidalibus dense areolatis jellucidis $\mathrm{r}$. viridibus compositis, nunc muscis ceteris similis foliis horizontalibus minutis comalibus, quincuncialiter insertis. Omnia folia enervia

*) Nonnullae familiae c. congeneribus cladocarpicis inter Acrocarpos enumerantur, quum plurimi earum congeneres plantae acrocarpicae sint. C. praefationem. 
plana. Theca exannulata minutissima globoso-ovalis operculo minimo convexo. Archegonia crassiuscula eparaphysata; antheridia parva eparaphysata.

Habitus proprius memorabilis ita, ut tribus haecce nulla alia confundi possit, polypodii vulgaris instar ob folia verticalia basi confluentia.

Patria. In cavernis et locis occultis aliis limoso arenariis vel arenariis per fere totam Europam rarius. $\odot$.

\section{Gen. I. Schistostéga Mohr.}

Mohr obs. p. 26. Web. et Mohr botan. Taschb. p. 92. tab. VI. Brid. I. p. 109. - Bryol. Europ. Fasc. XVII. c. tab. - Mnium (osmundaceum) Dicks. Pl. Cr. p. 3. tab. I. - Gymnostomum (pennatum) Hedw. Musc. frond. I. p. 77. tab. 29. Gymn. (osmundaceum) Hoffm. Deutschl. Fl. II. p. 28. - Dicksonia (pusilla) Ehrh. Crypt. Dec. No.65. - Bryum (pennatum) With.

Nomen graecae compositionis a $\sigma \chi \iota \sigma x o ́ s$ fissus et $\sigma \tau \xi \gamma \eta$ operculum, ex errore auctoris, qui, operculum in lacinias lacerari, observasse monuit, impositum. Ii, quorum interest, ut nomina ubique apta sint, cogitent, nomua plurima mutanda esse.

Calyptra cylindrico-campanulata subintegra. Inflorescentia dioica. Planta mascula femineae similis. Flos masculus laxe gemmiformis terminalis.

1. Sch. osmundacea Web. et Mohr (botan. Taschenb. p. 92.); caulis simplex interdum, raro tamen, ex axillis foliorum innovans; folia quincuncialiter inserta lanceolata; disticha orali-rhomboidalia acuminata; omnia integerrima.

Patria. Hercynia. Mons piniferus. Lusatia superior. Ducatus Badensis. Tractus Sudetorum. Ager Halensis. Norvegia. Anglia et Scotia. Junio et Julio.

Protothallus plantae germinantis (Catoptridium smaragdinum Brid. I. Tab. suppl. I.) memorabiliter lucens. 


\section{b. Folia subverticalia.}

\section{Trib. VI. DREPANOPHYLLEAE.}

Iaxissime cespitosae acrocarpicae; caulis frondiformis ramosus; folia verticalia basi paulum amplexicaulia inaequalia falcata, nervo non in medio folii sed latere percurrente instructa, basi e cellulis longioribus angustioribus apicem versus prosenchymatico-rhomboidalibus parris areolata, lacvissima nilida. Theca ovalis erecta obtuso-operculata. Antheridia - ? Archegonia breves crassiusculae intense fuscac paraplyysibus paucis filiformibus aureis.

Habitus proprius memorabilis hic Fissidentibus, illic Phyllogoniaceis similis, sed ab his duabus foliorum forma distinctissima tribus.

Patria. In arboribus regionum tropicarum et hucusque Indiae occidentalis. 4.

\section{Gen. I. Drepanophyllum Rich.}

Rich. in Hook. Musc. exotic. II. tab. 145. - Schwägr. Suppl. Ir. p. 85. tab. 125. - Brid. II. p. 668-670. - Dicranum (falcifolium) Hook. Musc. exot, I. tab. 82. - Fissidens (fulcifolius) Schwägr. Suppl. I. 2. p. 9.

Nomen graecae compositionis a verbis $\delta \varrho \varepsilon \pi \dot{\nu} \nu \eta$ falx et gíllov (ob folia falciformia) deductum.

Calyptra ignotio Inflorescentia dioica.

1. Dr. fulvum Rich. (1. c.); folia caulina apice denticulata lato-falcata nervo excurrente acuta, perichaetialia longiora angustiora; theca operculo conico-obtuso.

Patria. In insulis Bourbonis: Richard; Irispaniola: Thuillers, et ex Surinamo: Weigelt.

Frons fertilis apicem versus crescens, frons sterilis decrescens; caulis in fila articulata stricta longiora brunnea productus. 
c. Folia horizontalia

\section{Trib. VII. DISTICIIIACEA E.}

Dense cespitosae, acrocarpicae v. pleurocarpicae; caulis apicem versus crescens simplex v. ramosus rigidus; folia nervo dorso carinato erquilanti-concava dense imbricata se invicem tegentia; parenchymatico-areolata. Areolatio e cellulis minulis (crassis parictibus) subpapillosis composita densissima subquadrata. Theca ovalis aequalis. Antheridia longa angusta. Archegonia longissime apiculata et paraphyses tenerrimae.

Habitus fissidentoideus, sed foliis elamellosis ab hac tribu valde recedit.

Putriu. E montibus in regiones alpinas utriusque hemisphaerae ascendentes, rupes ac terram amantes. 4

\section{Gen. I. Distichinm Br. et Sch.}

Bryol. Furop. Fasc. XXX. Trichostomacene. - Cynontodium Hedw. sp. Muse. p. 57. - Suartzia Hedw. Stip. crypt. p. 76. Cynodontimn schw. sippl. I. Tom. I. p. 110. - Didymodon anct. Cynodon Brid. I. p. 500.

Nomen ob folia disticha ab anctoribus Br. Europaeae impositum.

Calyptra dimidiata. Theca annulata. Peristomium simplex dentibus $\mathbf{1 6}$ aequilistantibus basi liberis semel $v$. pluries, regulariter vel irregulariter a basi usque ad apicem fissis trabeculatis intense purpureis homogeneis laevibus $\mathrm{v}$. asperis. - Inflorescentia monoica.

1. D. capillaceum Br. Europ. (I. (. p. 4.); late et dense cespitosum; folia e basi oblonga raginante subito longe subulata patentia laete viridia tandem flavescentia nitentia integerrima; perichaetialia tenuinervia; theca erecta oxali-cylindrica; operculo conico brevi; 
peristomii dentes breves irreguluriter et pluries fissi angusti.

Didymodon capillaceus $\mathbf{W}^{r} \mathrm{ch}$, et Mohr bot. Taschh. p. 155. Brid. I. p. ̋̈(1). - Cynodontium capillacenn sihw. Suppl. I. I. p.114. Cynontodium cap. Iledw. Sp. Messe. p. 57. - Trichostomum cap. Sm. Fl. Brit. III. p.1236. - Swavtzia cap. Hedw. Musc. Frond. II. p. 72. tab. 26. - Dillym. distichus Brid. I. 1.50\%. - Did. subulatus Schk. Deutsch. Moos, p.63. tab.28.

Putria. E montilus usque ad alpes ascendens per totam Europam, Asiam, Africam (in Abyssiniae monte Silke: Schimper) et Americam septentrion.

Autheridia in foliorum superiorum axillis nuda.

2. D. inclinatum Br. Europ. ( 1. c. p. 5. tab. 2.); laxe cespitosum; folia ut in praecedente; theca inclinata ovalis operculo conico brevi; peristomii dentes latiusculi regulariter fissi longi.

Cynodontium inclinatum Hedw. Sp. Musc. I. p. 155. - Cynontodium incl. ej. ibid. p. 58. - suartria inclinata ej. Musc. Frond. II. p. 74. tah). 27. - Didymodon inclinatus Sw. Musc. Sulec. p. 28. - Cynodon inclinatus Brid. I. p. 501. - Grimmia inclinata Sm. Fl. Brit. 1II. p. 1193. - Afrelia inclinata Elurl. ('rypt. 193. Bryum inclinatum Dicks. Fase. II. 1). 9.

Patria. Ad rupes madidas, rarius ad terram humosam regionum alpinarum totius Europae, rarius tamen quam praeced. Fi 'Terre Veure inter Wid. fragile Hook. a Cl. Ia Pylaic lectum habemus. Aestute.

Antheridia foliis 1 - 3 perigonialibus cincta.

\section{Giel. II. Eustichia Brid.}

Brid. II. P. 674. - Diplostichum Montagne in ann. des sc. nat. 184.5. Vol. IV. p. 116. - Plerigynandrum Brid. - Didlymodon Schw. - Phyllogoniurn Eustichia Brid. 1. c.

Nomen e verbis graecis e $v^{\tilde{j}}$ et $\sigma t i x o s$ ob folia disticha deductum.

Calyptra dimidiata cucullata. Theca basilaris laleralis aequalis striata examulata. Peristomium simplex: dontibus $\mathbf{1 6}$ aequidistantibus planis lanceolatis trabeculatis longitrorsum (grammice) lineolatis 
apice interdum perforatis aureis. - Inflorescentia dioica.

Genus c. antecedente nunquam conjungi potest, quum forma ac structura dentium peristomii illis generis Distichii dissimillimae.

1. E. Iongirostris Brid. (1. c.); dense cespitosa subulata superne ramosissima, rami tenues simpliciusculi rigidi; folia ovalia nervo excedente brevi-acuta denticulata, perichaetialia longiora subserrata, laxius areolata, theca ovalis ore angusta subrecta, pedunculo longo tenero flavo et operculo e basi conica oblique subulato instructa.

Pterigynandrum longirostrum Brid. II. p. 195. - Dillymodon distichus Schtw. Suppl. 11. tah. 183. nbi D. compressus appellatur. Diplostichun longirostre Mont. I. c.

Patria. Insula Madagascar: Cl. I ubert du Petit Thouars in arboribus putrescentibus primus legit. Chile ad Antuco: Pöppig 1829 collect. Chil. N. 29. 4.

Flores feminei c. 3. unico cauli basilares, sed unicus fertilis, archegoniis perpaucis (c. 3.) elongatis et paraphysibus perpaucis longis tenerrimis hyalinis instructus. Flores masculi (quos deciduos inter plantas pulvinatas invenimus) forsan basilares antheridio ut videtur unico globoso-ovali membranaceo tenero hyalino et paraphysibus perpaucis brevibus filiformibus flavescentibus.

Species non satis nota.

2. W. Norvegiea Brid. (1. c. p.674.); dense cespitosa erecta simplicissima; folia confertissima, inferiora breviora, superiora oblonga rotundato-obtusa subcomplicata, nervo crasso excurrente mucronata, laxius vel pellucidius proecedentibus aroolutu.

Fissidens imbricutus Desv. in Brid. II. p. Gr4.

Patria. Norvegia in solo limoso. - Ex Islandia habemus. - In America septentrionali: in collibus rupestribus umbrosis circa Lancaster Ohionis a Sullivant (an vera?) indicitur. 24 
Planta elegantissima tenella habitu Fissidentis, obscura, e foliorum distichorum areolatione ac forma huc pertinens, juvenilis smaragdina, senilis nigrescens. Vehementer optandum est, fructum mox inveniri.

\section{Trib. VIII. FISSIDENTEAE.}

Gregariae v. cespitosae, homillimae vo elatae, simplicissimae $\mathbf{v}$. ramosissimac, acrocarpicae $v$. cladocarpicae. Folia amplexicaulia e cellulis parenchymaticis minutis dense areolatis saepe valde papillosis composita, dorso et apice in laminam ultra folii apicem producta, quare in folio tres partes distinguntur: 1. folii lamina vera horizontalis; 2. lamina dorsalis, e nervi dorso nata verticalis; $\mathbf{3}$. lamina apicalis, lamina pracedens ultra folii laminam veram horizontalem in utroque nervi latere anceps producta. Antheridia et archegonia parva eparaphysata. Theca aequalis raro annulata.

Habitus proprius lamina folii triplici speciosissimus distinctissimus.

P'atria. In terra, arboribus et aquis, saepe amphibie, viventes per orbem terrarum totum in locis humidis vix nivalibus. In promontorio bonae spei Africae plurimae species inveniuntur. C et 21.

E forma calyptrae genera nova imponenda sunt. Nos autem dividere haud ausi sumus; quum congenerum plurimorum calyptra ignota reperiatur. Formae autem calyptrae tres observantur: conica s. campanulata; mitrueformis basi lobatu et dimidiata. E prima genus Conomitrium, e secunda Fissidens, tertia tandem Schistophyllum formari possit.

\section{Gen. I. Fissidens Hedw.}

Hedw. Fund. Musc. 1I. p. 91. - Brid. Br. Un. II. p. 679-708. Bryol. Eur. Fasc. XVII. - Dicranum auct. mult, - Skitophylum 
La Pylaie. - Fuscina Schrank. - Luida Adans. - Octodiceras Brid. et Br. Europ. - Conomitrium Mont.

Nomen ob dentes fissos ab Hedwigio impositum.

Character ac idem tribus. - Inflorescentia monoica v. dioica gemmiformis, in caule primario v. in ramis brevibus secundariis terminalis.

Sectio I. Hydrofissidens. Plantae aquaticae fuitantes elongatae ramosissimae cladocarpicae. 'Theca in ramo proprio axillari terminalis minuta brevi-pedunculata.

Octodiceras Brid. II. p. 675. et Bryol. Europ. 1. c. - Conomitrium Mont. in ann. des se. nat. Tom. VIII. (1837) p.20\%0. et in Voyage dans l'Amérique mérid. par d'orbigny Tom. VIl. Crypt. p. 99 - 107. - Fontinalis Savi.

t. Fructus in ramo longiugculo.

1. Julianus Schimp. (in Regensb. Fl. olim); monoicus; folia lanceolata obtusiuscula nervo evanido; theca minutissima obconica dentibus proemorsis irregularibus, bi-, rel tri-fidis; operculum conicum rectum thecam aequans v. subsuperans; calyptra conica integra, operculo brevior.

Fontinalis Juliana Savi. Poll. Fl. Veron. III. p. 385. - Skitophyllum fontanum La Pyl. Journ. Bot. Desv. 1813. 11. V. p. 52. tab. 34. - Octolliceras Julianum Brill. II. p. 678. Br. Furop. 1. c. tab. 1. - Conomitrium Julianum Mont. 1. c. Schwägr. Suppl. IV. tab. 313. - Fissidens debilis Schwatur. Suppl. I. P. II. p. 11. Brid. II. p. 706. e speciminibus Bridelianis huc pertinet.

Patria. In fontibus et rivulorum parietibus lapideis per Europam calidiorem et temporatam: In Etruria ubi ad radicem montis $\mathbf{S}$. Juliani Savi detexit; prope Mediolanum ubi fontis parietem domus campestris cujusdam obducit; in insulae Armoricae Ouessant fonte quadam Lanegrach dicta a clar. de La Pylaie et per totum littus Galliae occidentalis a multis botanicis observatus; in alseis aquariis Pirnae Saxoniae et in fonte frigida prope Pforzheim Due. Bad.; in Americae septentrionalis rivulis saxis immersis adlhaerens haud rarus: Beyrich, Sullivant. Vere et aestate. 4.

Flos masculus in ramulo brevissimo axillari terminalis, rarius subsessilis. Conomitrium verum. 
2. F. Medwigil C. Müll.; monoicus; folia lanceolata acuta, nerro fere ad apicem excurente; theca obovata, operculo conico acuminato curiusculo multo minori, dentibus profunde bifulis; calyptra fissu et ideo subdimidiata.

Octodiceras fissidentoides Brid. II. p. 676. - Skitophyllum semicompletum La Pyl. 1. c. p.51. tab. 39. - Cecalyphum? semicompletum P. B. Prodr. p. 57. - Fissidens semicompletus Hdw. Stirp. Cr. 3. p. 34. tal). 13. ex parte. - Conomitrium Heduigii Mont. I. c.

Patriu. Chile prope Valparaiso: Bertero. 4.

Ex habitu Conomitrium quidem, calyptra lamen ad illam Fissidentis accedens.

\section{Fructus in ramo brevissino.}

3. F. Dillenii C. Müll.; caulis frondiformis erectiusculus subsimplex; folia alterna oblongo-lanceolata uniformia pedunculis axillaribus cauligenis (ex ic. Dillen. in ramo brevi); thecae ovalis operculum cuspidutum incurvum. t.

Octodiceras Dillenii Brid. II. p. 6r7. - Iissidens semicompletus Iledw. 1. c. ex parte. - Conomitrium Dillenii Mont. 1. c. Skitophyllum Dillenii La PyI. - Fontinalis yared, foliis lanceolatis Dill. Musc. p. 259. tab. 33. fig. 4.

Patria. F Patagoniae el insulae Providentiae aquis ex Dill. adnot. p. 260. a Guil. Sherardo Dillenio communicatus. 4 .

4. Herterii C. Müll.; caulis filiformis ramis superioribus subfasciculatis, folia angustissima linearia patentia, suprema longissimu, pedunculi $\mathbf{1 - 3}$, thecae erectue operculum acuminutum.

Conomitrium Berterii Mont. ann. d. sc. nat. 1837. 1. 250. et in Voyage du M. d'orbigny. p. 104.

Patria. Ad saxa in scaturiginibus collium editorum Chilensium: Bertero. - Ad prom. b. sp. peregrinator meritus Drige copiose legit et sub No. 9379 a. et b. edidit. 4 .

\section{A praecedente satis differt?}

Scctio II. Pachyfissidens. Plantae elatae terrestres inno"ando ramosae. Folia c. lamina verticali rigida, nervo latissimo dilatato e stratis cellularum pluribus constructa. 
5. F. grandifrons Brid. (II. p. 701.); cespitosus elatus; caulis erectus subincurvus valde ramosus; folia approximata, lamina dorsali folio breviore linealilanceolate, submuticu, margine integerrima.

Skitophyllum congestumb La Pyl. 1. c. p. 57. tab. 39. - Fissidens grandifrons Br. Europ. I. c. p. 11. tab. 6.

Putria. In Nova Anglia, ubi detectus est et unde Cl. Swartz habuit et ad Niagarae cataractam in rupibus irroratis: Sullivant; practerea in insula Bourbonis et in Gallia australi, ubi circa Avenionem Requien legit; serius etiam in Gallia occidentali: Guépin. 24.

Flores feminei laterales; archegoniis $30-60$. Frurtus desiderantur. Planta memorabilis haud enervis ut Bride 1 1. c. dicit sed nervo in laminam folii veram ac verticalem dilatato.

6. F. Iinealis Br. Europ. (I. c. p. 12. tab. 6.); monoicus; folia conferta se invicem tegentia lanceolata, lamina dorsali in medio folio desinente, lamina apicali angusta lineali-lanceoluta nervosa integerrima folio ipso longiore; folia perigonialia subobcordata latissima, lamina apicali vix in folii dorsum producta angustissima longa; perichactialia caulinis angustiora, caeterum similia.

Patria. In prom. b. sp.: Z e y her et Fcklon. 4.

Flores monoici terminales eparaphysati.

Praecedenti paulo humilior, foliis confertioribus et angustioribus, lamina verticali folio longiore et perangusta diversus.

Sectio III. Areofissidens. Folia valde pellucido reticulata.

7. F. splachnifolius Hsch. (Linn. 1841, p. 145.); subacaulis $2-4$ jugis, folia erecto-putentia late-ovalia; lamina folii vera ultra medium producta; lamina apicalis "acutiuscula nerro supra medium dissoluto laxo concolore instructa; omnes laminae immarginatae integerrimae lurido-virides pellucidae; pedunculus erectus brevis, theca erecta minuta oblonga operculo comexo breviter oblique rostellato; calyptra conica minuta basi incisa. $f$. 
Patria. In rertice septentrionali montis Tufelberg dicti prom. bon. sp., ubi in edito secundo mensi Aug. 1827 legit Cl. Ecklon.

Caulis sterilis clatior $2-4 \mathrm{lin}$. longus, apicem versus attenuatus, folis apice recurvis lamina apicali vix nata. Folia perichaetialia duplo longiora quam caulina, lamina apicali exacte lanceolata acutiuscula. Calyptra minuta basi incisa glabra ferrugineo-straminea apice fusca. Inflorescentia?

8. F. pellueidus Isch. (1. c. p. 146.); caulis brevissimus simplicissimus 4 jugus ascendens; folia erectopatentia, lamina apicalis lanceolata obliyuu subcrsiformis, omnes laminae immarginatae integerrimae nervo crasso ferrugineo infra apicem laminac apicalis dissoluto; pedunculus basi geniculatus inde adscendens, theca erecta oblonga operculo convero-subulato recto; calyptra conico-subulata minuta basi irregulariter lacera angusta. $\div$.

Petria. Surinam: Weigelt? $\doteq$

Caulis sterilis brevior foliig apicem versus leviter denticulatis pallide ferrugineis e cellulis circularibus minimis densis composita. Folia perichaetialia maxina. $\mathrm{Ca}-$ lyptra minuta operculum tegens basi irregulariter lacera glabra feruginen-straminea angusta. Inflorescentia?

9. F. Zollingeri Mont. (in ann. des sc. nat. 1845. 4. p. 114.); hermaphroditus; cespitosus; caulis decumbens minimus subsimplex basi polyrhizus; folia flabellatim expansa, folii lamina ultra medium producta, lamina dorsalis lanceolato-acuminata marginata nervo crasso cuspidato, omnes laminae integerrimae; pedunculus basi geniculatus ascendens flexuosus, theca erectu pyriformiclavatu fere aequalis operculo conico oblique rostellato. $t$.

Patria. In terra turfosa insulae Javae: Zollinger collect. No. 1604.

Wolia perichaetialia majora, lamina folii ventricosa.

10. F. hyalinus Hook. et Wils. (Lond. journ. of bot. Vol. III. p. 89. tab. I1.); pumilus subgregarius ere- 
ctus simplex; folia pro plantulae altitudine latissimu; lämina folii vix medium folii aequans; lamina dorsalis rerticalis lato-oblongu acutu; omnes laminae hyalinae eneres integrae; pedunculus crassiusculus albidus semipellucidus; theca erectu orala operculo conico-acuminato; calyptra mitraeformis-conica. $t$.

Patria. America sept.: Cincinnati in terra humida sylvarum umbrosarum humidarum, ubi collegit F. G. Is a. (-)

An species revera enervis? Memorabilis esset, quum putent, laminam verticalem e nervo oriri.

11. F. palmatus IIedw. (Musc. Frond. III. p. 69. tab. 30 A.); dioicus; humillimus simplicissimus decumbens; folia subsexjuga lato-lanceolata subimbricata; folii lamina 1/a producta angusta, complicata tenuissime emarginata; 1. dorsalis basi angusta apicem versus lata crassius marginata; 1. apicalis latu nerro excurrente cuspidatu fere ustue ad aprem crassius marginata; omnes 1. integerrimue; pedunculus a basi geniculatus adseendens longus, theca oblongu horisontulis; operculo conico subulato subincure; calyptra subulata minutissima.

Dicranum palmatum sw. Fil. Ind. Occ. III. p. 178t. - Hypnum palnatum ej. Prods. p. 141. - STilophyllum palmatum La Pyl. 1. c. p. 36. tab. 35. fig. 6. - Brid. II. p. 680.

Putria. In umbrosis argillaceis ad radices palmarum Jamaicae. Lectus quoque in caudice alto Arecue oleruceue latere excavato, humo quisquiliisque foliorum putrefactorum repleto. Swartz detexit.

Speciem saepissime commutatam e spec. Swartz. descripsimus. Folia e cellulis inde a nervo in seriebus obliquis areolatis laxis pellucidis composita. - Fl. mase. in planta propria terminalis.

\section{b. Sullaxe reticulati。}

12. F. cuspidatus C. Müll. (Linn. 1843. p. 588.]; dioicus; caulis subcespitosus simplicissimus humilis erectus; folia lanceolata angusta; folii lamina e busi latiuscula ventricosa flexuosa $2 / 3$ et ultra producta aequalis; lamina verticalis basi obsoleta apicem versus latior; la- 
mina apicalis lanceolata nervo crasso fermyineo excedente longe cuspiduta; omnes laminae flaro-marginutue integerrimue; ped. elongutus rectus subfexuosus; theca oralis horisontalis operculo conico-subrecto.

Patria. l'rom. bon. spei, ad sylvas primaeras Kroluticumme (Distr. Citenhage), ubi in terra argillosohumosa legit Ecklon. Var. foliis angustissimis longe cuspidatis in locis non indicatis legit Mundt.

Flos masculus mininus in ramulo proprio plantulae masculae elatioris brevissimo terminalis. Antheridia minima obovata crassa. Folia perichactialia: lamina folii latissima oralis ad medium producta, lamina rerticalis et apicalis angustissima longissima nervo excurrente.

13. F. Kegelianus C. Müll. (ILinn. 1848. Fasc. II.); dioicus, caulis subcespitosus simplicissimus humilis decumbens; folia latiuscula c. 6-juga, folii Iamina infira medium exunescens rentricosa subuerualis crasso-marginuta busi e cellulis magnis laxe-, apice cellulis minoribus densius areoluta; l. dorsalis ad nervi basin enata, basi angusta apicem versus latior c. 1. apicali lanceolata, nervo crasso viridi flexuoso excurrente brevi-cuspidatu, temissime marginata densiusculo-areolata; omnes 1. integerrimae; ped. e busi geniculata rectus tenuis, theca erecta obovalis mimuta, operculo e basi conica longe subulato recto thecam superante.

Patria. Surinam prope Paramaribo in locis humidis umbrosis cespitose-gregarius. Junio, Julio 1844: Kegel Hb. No. 1226. In insulis Antillis rulgaris. -

F. cuspiduto proximus sed ped. geniculato, theca erecta et operculo longissimo jam sat distinctus. A. $\boldsymbol{F}$. pulmato foliis multo densius areolatis, theca recta, operculo recto longissimo certissime differt. A. F. Zollingeri inflorescentia jam distinguitur. A. $\boldsymbol{F}$. pellucido denique ac $F$. splachnifolio foliis marginatis valde recedit.

Folia perichaetialia lamina folii vera flexuosa instructa.

var. $\beta$. foliis longioribus magis cuspidatis, folii lamina vera stricta ultra medium producta aequalis acutissima, tenuius marginata; setae saepe geminatae.

C. Miller: Synops, musc, frond. 
Sectio IV. Eufissidens. Folia dense et ideo rotumdatoareolata.

\section{A. Fructus lateralis.}

14. F. taxifolius Hedw. (Spec. Muscor. p. 155. tab. 39.); monoicus; humilis basi fusciculuto-rumosus uscendens rel declimutus; folia approximata; lamina folii ultra medium producta, lamina dorsalis e basi latiori folio longiori undulate cum lamina apicali lato-lunceolala ner20 diaphuno crasso excedente mucromata vel cuspidata; omnes laminac dense et minute obscure areolutue p busi nstue ad upicem cellulis pellucidioribus dense-servulutae; theca ruliculis, ped. elongato flexwoso instructa ordlis inclinatu operculo longirostri oblipuo; calyptra dimidiata.

Bril. II. p. 692. Bryol. Fur. 1. c. p. 9. t. 4. - Skitophyllum taxifolium La Pyl. I. c. p. 60. tah. 35. - Dicranum taxifoliumsw. Muse. Suec, p. 31. - Fuscina taxifolia Schrank, Baiers, Fi. II. p. 451. - Hupnum taxifolium Linn. Sp. Pl, p. 15ั4\%. H. laxif. minus basi capsuliferce Dill. p. 263. tal). 34. fig. 2.

Putriu. In solo argilloso in nemorosis graminosis humidiusculis per totam Europam, in America septentrionali et insulis Mascarenis. Autumno et hyeme. 2\%.

Flos masculus ad caulis basin in vicinia feminei et quasi plantulam propriam efficiens vel in foliorum axillis gemmiformis.

15. F. subbasilaris IIdw. (Spec. Muscor, p. 155. tab. 39.); divicus? subsimplex humilis; folia confertissima; lamina folii ad medium producta temissime denticulutu complicata; lamina dorsalis e basi angusta tenuissime denticulata latior; lamina apicalis apice erosodenticulatu acutu nervo basi crassu apicem rersus attemuto ante upicem eranido, ommes partes minutissime et obscure viridi-areolatac; theca in ramulo brevi basilari terminalis, ped. adscendente brevi inslructa cylimbicas. cylimbico-oralis ore constricta, operculo longirostro oblique.

Skitophyllum subbusilare La Pyl. 1, c. 1.62. tah) 35, - Brid. II. p. 694 . 
Patria. In America septentrionali in umbrosis ad terram et truncos arborum haud raro. Mühlenberg in Pensylvania circa Lancaster primus legit. 21. ctissimus.

F. taxifolio proximus sed notis illustratis distin-

16. F. adiantoides Hedw. (Musc. frond. III. p. 62. tab. 26.); monoicus; ramosus elatus; folia ut in $\boldsymbol{F}$. $t(u-$ rifolio sed multo latiora majora apice eroso-, basi mimutiusculo-serratu, nervo crasso plerumque colorato flexuoso unte upicem + - ucutiusculum eranido, immarginata sed cellulis nommellis farioribus quasi marginata mujus areolutu; theca in caulis medio in ramulo brevi axillaris oblonga cermu crassa, ped. elongato flexuoso crasso et operculo longe rostelluto oblirpo; calyptra dimidiata.

Brid. II. p. 702. Br. Kurop. I. c. p. 10. tal). 5. - Fissidens taxifolius $\beta$. Wahlenb. Fl. Lapp. p. 332. - Skitophyllum udiantoides La Pyl. 1. c. 1. 55. tals. 36. - Dicramum adiantoides sw. Musc. snec. 1. 31. - Hypnum adiantoides fronde pinnata ramosa erecta medio redunculifera L. Sp. PI. p. 1588. - Hypmum taxiforme paIustre majus at erectum Dill. 1). 264. tab. 34. f. 3. - Fissidens polyphyllus Wilson ex herl). Sehwägricheniano nobis communicatus ab adiantoide distingui nequit. Folia apice minus dentata margine non byalino.

Putria. In terra lapidosa, ad muros antiquos muscosos, ad arborum radices, in sylvis siccioribus et uliginosis umbrosis per Europam et Americam septentrionalem. Hicme et primo vere. 4

Flores utriusque sexus in axillis foliorum nidulantes; flos masculus gemmiformis. - Saepe elatissimus setisque aggregatis statura polymorpha.

Species e locis natalibus valde polymorpha foliis margine nunc hyalinis nunc homomorphis; nunc toto ambitu nune apice tantum serratis; nunc nervo genuflexo nunc stricto ferrugineo vel viridi, lamina dorsali nunc supra basin nunc ad basin nerwi lato undulata erecta.

17. Hlaucescens Hsch. (Linn. 1841. p. 154.); dioicus? caulis adscendens innorationibus ramosus; folia 
subconferta 15-25-juga erecto patentia apice homomalla glauca; lamina folii ultra medium producta tenera, lamina dorsalis e basi usque ad apicen angusta et c. I. apicali lanceolata oblipue mucromulatu perangusta apice erosu, nerro flexuso diophano mucromulum attingente, omnes laminae subintegrue $v$. cellulis paullo promimulis vix denticulatae, subpellucidar; ped. planta panlo longior infra medium silus, theca oblongo-cylindrica inclinata, operculo conica rostellato thecam subaepuente incurro.

Patria. Prom. bon. sp., in editis diversis montium Tafelberg et Teufelsberg dictorum: Feklon. In locis non indicatis legit geyler: collect. No. 41. c. ex parte. Septbr. 21.

Folia perichactialia multo longiona.

18. F. polypodioiden Hedw. (Musc, frond. III. p. 63. tab. 27.); dioicus, dinse gregarius simplicissimus elatus; caulis filicoidens unicem rersus crescens busi subuudus; folia caulina sublaxe imbricata latissima; lamina folii lata ad medium producta apice inaequalis; lamina dorsalis basi rotundata angustior; lamina apicalis lato-lanceolata apice subdenticulata nervo crussissimo ante upicem evanido; omies laminae rotumdato-areolutue firmue integrae; ped. supru medium positus brevis adscendens, theca obouta submyriformis, operculo conico longe rostrato subobliquo; calyptra conico-dimidiata.

Hypnum polypodioidles sw. prodr. p. 140. - Dicranum polypollioifles sw. fl. Int. Occ. 111. 1. 17j2. - Giilophyllum polyjodioides La Pyl. 1. c. p. t5. tal). 3.5. - Brid. II. p. 69.5.

Putria. In montibus excelsis Jamaicae terram locis umbrosis muscosis declivibus incolentem primus Swartz legit. E Dominica Bridel habuit. In Columbiac colonia Torar germanica in altitud. $5500^{\prime}$ Moritz sterilem legit. 21.

Planta rigida basi polyr rhiza ab omnibus congeneribus caule pro plantac altitudine memorabiliter simplicissimo filicoideo gregario et notis ceteris illustratis excellentissima. Folia perichactialia lamina idorsali vix ulla, apicali angustissima lanceolata. Foliun ipsissimum e basi lata 
attenuata. - Archegonia numerosa eparaphysata. Flores feminei ad caulis apicem plures.

Fissid. filicinus Dz. et Molkib. toto habitu proximus. Planta in pueris rigidissima stoloniformis foliis basi brevissimis densissime imbricatis cauli appressis latissimis amplexicaulibus lamiua dorsali subcarentibus laxe areolatis fuscopurpureis, apicen versus foliis perichaetialibus magis similibus viridescentibus rotundato - areolatis lougioribus apice caulis valde incurvatis.

19. F. anomalus Mont. (in annales des sc. nat. 1841. p. 267.); grandis caulis adscendens? simplex basi nudus; folia alterna subremolu homomulla c. ら̃o-juga, siccitate apice crispula, lamina folii ultra medium producta, lamina apicalis suber(nidinervia acuta, omnes laminae margine non incrassatae albillae tenuissime - denticulatac; ped. seriati brecissimi; theca (ut in Grimmin) oxuli-subrotunda. + .

Patria. In montibus Nilgheriensibus Indiae orientalis: Perrottet. Inter sureulos IIymi serrato. 24.

Folia perichactialia caulina parum superantia. Peristomii dentes 16 fusci profunde bifidi, suepe ad basin lacunosi, cruribus filiformibus articulatis rarioque modo simul concretis.

Nulli congenerum affinis et eximia species.

20. F. maschalanthus Mont. (ann. d. sc. nat. 1845. p. 115.); dioicus, cespitosus; caulis erectus innovationibus ramosus subdicholomms; folia sub 30 -juga dense imbricata erecta lineuru, lamina apicali obtusu acuminulatu, ubique integervimce nerro subcontimo albo instructa stricta, siccitate crispato-inflexa; theca inclinata oblongocylindrice operenlo comere rectirostro. †.

Patria. Ad teram in Chile australiori: Gay. 24.

Flores terminales et laterules in axilla foliorum v. in dichotomia. Calyptra brunnea coriacea cuculliformis. Dentium crures articulati punctato-asperi non trabeculati. 


\section{B. Fructus terminalis. \\ 1. Folia marginata.}

a. Folia crispa.

21. F. rufescens Hsch. (Linn. 1841. p. 15ั3.); monoicus? assurgens superne simplex interdum basi ramosus, 6-10-jugus et ultra, apice subfalcatus; folia remota lanceolata brevia; folii lamina basi latiuscula apice inaequalis marginata, margo flares crassus integerrimus ad basin folii in ejusdem laminam exunescons; lamina dorsalis basi angusta flavo-marginata, lamina apicalis folio subbrevior nervo faro crasso excurrente brevi-cuspidata reflexiusculu flavo - et crasso - marginata integerrima; omnes partes minutissime areolatae flavescenti - rirides; theca ovalis inclinatu collo brevi instructa parva, ped. oblique-erecto substricto rufescente operculoque conico subuluto recto; calyptra junior conica, tandem dimidiata?

C. Müll. Bot. Zeit. 1847, p. 39.

Pulvice. In promont. b. spei locis multis vulgaris sed saepe sterilis: Ecklon, Pappe. - Port Natal: Gueinzius. IIb. Kunzeanum. Septbr. - Debr. 2\%.

22. F. Mornsehuchii Mont. (in ann. d. sce nat. Tom. XIV. et in Lond. journ. of bot. 1845. p. 196. memorat.); monoicus humilis simplicissimus 8-10-jugus apice subfalcatus; folia lanceolata brevia; folii lamina basi latiuscula, upice et busi cellulis promimulis semulutu medio tenu-marginata, margo flarus xix et remote serrulutus ad basin in folii lominam crunescens, marginibus flexuosis; lamina dorsalis basi angusta cellulis prominulis serrulata; lamina apicalis foliis brevior, nervo fluro crussinsculo excurrente brevi-cuspidata refiexiuscula sermlata; omnes partes minutissime areolatae flurescenti-rivides; theca ovalis recta collo brevi subverrucoso instructa, minuta tenera, seta curviuscula adscendente opercuJoque conico recto brevi; calyptra cucullata. 
Fissidens serrulatus Hsch, in flora Brasiliensi fasc. I. p. 91. \{ab. II. non Brid. - H. serrulatus Bruch in litt. ad Hampe. - F. Marlianus Hmp. in litt.

Putriu. Brasilia: in Sicrra d'Estrella et in prov. Mimarum legit Martius. 4 .

Areliegonium ut videtur unicum. Planta mascula ad basin femineae. Antheridia pauca paraphysibus carentia. Folia perigonialia truncato-repanda laxe areolata, lamina dorsalis supra medium folii enata c. apicali acuta cuspidata, omnibus partibus immarginatis serrulatis nervo sub apicem evanescente crasso.

F. semimarginato, rufescenti et submarginato affinis sed notís editis diversus.

23. F. semimarginatus C. Mïll. (bot. Zeit. 181\%. p. 38.); herm(p)herdilus, humilis simplicissimus, 8-10jugus apice subfalcatus; folia lanceolata brevia; folii lamina basi latiuscula uspue ul apicem et ultru crasse-ulbido-marginutu, marginibus flexuosis, intrgerrima; lamina dorsalis basi angusta, cellulis promimulis serrulutu; lamina apicalis folio brevior, nerro excurrente tenui albescente brevi-cuspidata reflexiuscula sermata; omnes partes albescenti-riviles minutissime areolatae; theca ovalis recta collo brevi subverrucoso instructa, minuta tenera, ped. curviusculo adscendente operculoque conico rostrato oblipuo.

Putria. Columbia: Cocollar inter Leucobrya ad radices arborum. Cl. Moritz legit. $\odot$ ?

Basi (foliis minutis) subnudus, apicem versus crescens, apice interdum innovans. Archegonia angustissima brevia c. 6-8, paraphysibus carentia. Antheridia pauca majora ellipsoidea. Folia floralia intima laminis carentia convoluta laxius areolata profunde repanda cuspidata integra.

F. Iornschuchii proximus sed notis illustratis distinclissimus. A. rissid. submaryinalo Bruch caule apice subfalcato, foliis madefactis apice rellexiusculis, lamina dorsali et apicali serrulata sat recedit. 
24. intermedius C. Müll. (Linnaea 1848. 'fasc. II.); monoicus, hunillimus gregarius simplicissinus; folia caulina angusta lanceolata patentia falcata; lamina folii veru flexuosu fluro-marginutu integra; lamina dorsalis cellulis prominulis denticulata immarginatu; lamina apicalis folio brevior cellulis momimelis denticulatu immarginutu nervo flavo excurrente; theca ovalis erecta aperta urceolata operculo subulato recto.

Patriu. Surinam prope Paramaribo in locis umbrosis humidis: Kegel. Januar. 1844. No. 501.

F'los masculus in feminei vicinia gemmaceus. Antheridia parva panca eparaphysata. Folia perigonialia parva pellucida lato-ovalia convoluta, apice subulata integerrima $v$. erenata.

Inter $\boldsymbol{F}$. semimarginatum et submarginatum medium tenens. A primo differt: infloresc. monoica, foliis flavomarginatis grandius areolatis vix papillosis. A secundo distinguitur: foliis angustis apice caulis falcato crispis et inflorescentia androgyna (i. e. flore masculo in vicinia feminei.

25. F. submarginatus Bruch (in Flora 1846. p. 133.); monoicus, pusillus, plantulae $2-3$ lineas longae, innovaudo subramosae declinatae; folia 6-10-juga patentia siccitate deflexa late-lanceolatu acuminata $r$ costa excurrente mucronata; folii lamina $2 / 3$ producta marginata; cet. laminae immarginatae; theca oucli-ellipsoidec recta, operculo rostellato, calyptra conica murgine crenulato. t.

Patril. In faucibus sylvarum Natalensium prope litus: Kraus.

Peristomium Fissid. bryoidei. Flos masculus sessilis. E diagnosi folia integra et hac nota a $E$. semimurgincto nobis jam diversus.

26. F. minutuius Sulliv. (Musc. Allegh. p. 44.); dioicus; perpusillus subsimplicissimus folia $5-12$ juga remotiuscula superiora lanceolata latiuscula; folii lamina ventricosa basi crasso-marginutu aequalis (raro inae- 
qualis); lamina dorsalis longe supra busin folii enuta vix vel temissime marginata; 1. apicalis (foliorum superiorum) lanceolato - acuta vix rel temissime marginata, nervo ante apicem evanido; omues laminae subintegrae saepe repando-flexuosae; seta tenuissima erecta longa, theca (aperta) cylindrica erecta aequalis ore suburnigera tenera parva; calyptra cuculliformis (ex obs. Sulliv.).

Patria. Amerira septentrionalis: Pocky Mountains, et prope Carlton IIlouse: Drummond. Musc. Amer. sub nom. Iissid. bryoidei Indw. $C$.

Planta mascula minuta. Flos mase. terminalis. Folia perigonialia intima caulinis dissimilia: folii lamina aequalis raginante-latissima apice rotundato sinuata subintegra; I. dorsalis ut in caulinis; 1. apicalis e basi sinuata lanceolato acuta, nervo flexuoso ante apicem evanido. PI. masc. juvenilis stolonif. diaph.

F. mimutulus Sulliv. annuus dioicus; floribus terminalibus; caule simplici; foliis $\mathbf{5}-\mathbf{1 2}$-jugis superioribus lineari-lanceolatis margine limbo subrepando haud incrassato plus minus circumductis, costa sub apice evanida; capsula erecta ovali; operculo elongato-conico; calyptra cuculliformi. - In sylvis ad rivulorum cxsiccatorum lapides prope Columbus Ohionis Americae septentrionalis rarius.

Descripta species in partibus tam multis cum planta Sullivantiana convenit, ut persuasissimos habeamus, utramque plantulam, spreta diagnosi auctoris pauperrima, synonymam esse. In planta nostra folia certe crispabilia.

27. F. androgynus Bruch (l. c. p. 13t.); androgyno-monoicus; caulis decumbens $v$. superne declinatus uncialis simplex $v$. innovatione una alterave subramosus; folia multijuga remotiuscula patenti-deflexa, siccitate apice tortilia; folii lamina $1 / 2$ producta, lamina apicalis nerro excurrente mucronata; omnes laminae marginatue; theca orulis truncatu. $\dot{\tau}$.

Putria. Prom. bon. spei ad latera montis Duyvelsberg: Kraus. 
Interdum 2-3 thecae ex unico flore. - Diagnosis auctoris pauperrima.

b. Folia stricta.

28. F. bryoides IIdw. (stip. cr. 1II. p.6\%. (ab. 29.); monoicus; humilis basi fasciculato-ramosus, rami subsimplicissimi; folia remota luto ox'uliu, toto ambilu morginutu integerrima nervo excurente instructa; folii lamina vix $1 / 2$ producta apice saepe inaequalis; 1. dorsalis basi angusta apicem versus latior c. apicali lanceolutu-aculu; omues 1. amoene rirides; theca longisetacea oralis rectu operculo conico obliquo; calyptra conica latere fissa.

Brid. II. p. 686. - Br. Europ. 1. c. p. 8. tab. II. - F. exilis Hilw. Spec. Musc. p. 152. tah. 38. planta annua ex parte. - Brid.II. p. 683. - F. viridulus Wahlber. Fl. Carp. p. 342. et Fl. Lapp. p. 334. - skitophyllum bryoiles La Pyl. I. c. p. 42. (at). 35. Dicranum bryoides Hoth. Fl. Gerin. III. p. 181. - D. vividulum Sw. Musc. Suec. 1. 32. (sub nom. D, hryoidei) et p. 81. tah. Il. fig. 3. - Fuscina bryoinles Schrank Baiers. Flora II. p. 451. Hypmum bryoides L. Sp. P1. p. 15k8. - Hymmm taxiforme exiynum versus extremitaten capsuligerum. Dill. p. 262. tab. 34. fig. 1. -

Patria. In locis humidis umbrosis praccipue argillosis per totam kuropam utramque Americam. Ilieme et Vere, 4.

Folia perigonialia minima lato-vaginantia repanda lamina dorsali infra carentia, lamina apicali angustissima nervo evanescente, tenera. Antheridia pauca parva. Folia perichaetialia multo majora, folii lamina minima oralis ventricosa; 1 . dorsalis e medio folii nascens c. apicali apicem versus lato-lanceolata nervo excurrente.

Flores masculi $F$. exilis (plantae juvenilis) parci vel nulli, in innovationibus plantae annuae creberrini.

29. F. incurvus Schwägr. (suppl. I. P. II. p. כ. et P. 1. tab. 49.); monoicus humilis subsimplex vel basi fasciculato-ramosus, rami subsimplicissimi; folia remota lato-orcelier; folii lamina $1 / 2$ producta apice aequalis marginata; I. dorsalis vasi angustissima apicem versus latior marginata; 1. apicalis lunceolato-acuta nevo, ante upicem 
evonescente marginata, murgo ante apicem exanidus integer, partes ceterae integerrimac amocne virides; theca longisetacea ovalis inclinata operculo conico recto subuluto; calyptra conica latere fissa.

Br. Furop, 1: c. p. 6. tals. I. - Dicranum incurvum Web. et Mohr bot. Taschl). p. 162. - Dicranum bryoides B. Hook. et Tayl. Musc. Brit. p. 49. - D. tamarindifolium T'uru, Musc. Hib. p. 5̌5?Fissidens tamarindifolines Brid. 1I. p. 684.

ק. fontums, major, foliis latius marninatis, obtuse dentatis; theca minori, brevius pedunculata; dentibus peristomii saepe trifurcatis.

Putria. In umbrosis, ad latera viarum humidarum in solo argilloso per totam Europam utramque Americam. Var. $\beta$. prope Durlach Ducat. Badensis: A. B raun.

Folia floralia a caulinis haud diversa. Ex habitu antecedenti simillimus sed notis descriptis distinctissimus.

30. F. eurvatus IIsch. (Linn. 1811. p. 148.); dioicus? pygmuens simplex rel basi innorando-assurgens rufus; folia indistincte distichu; folii lamina ultra medium producta rentricosa; 1. apicalis oblipue lunceolato-acumimuluta, nerro infra upicem dissoluto; ommes l. marginatue integerrimae, minute-areolatae; ped. Irerissimo curreto, thera uborulis erectu operculo conico brevissime rostellato, thecae dimidiam partem longitudine subaequante, subrecto; calyptra cucullata.

Patria. Prom. bon. spei ad muros: Ecklon legit

\section{October 1827.}

Folia perichactialia duplo majora acuminata; folii lamina $1 / 3$ producta nero subexcurente lurido - viridia. Dentes peristomii cruribus inaequalibus subulatis tenerrimis pallide luteis.

31. F. Ceylomensis Dz. et Molkb. (ann, des se. nat. 1844. p. 304.); dioicus? basi ramosus flexuosus; folia in ramis fertilibus subdecenjuga, erecto-patentia; erectocurvata, folii lamina $2 / 3$ producta margine albescenle submarginuto; lamina dorsalis e basi angustissima subcrescens c. apicali lanceoluta acula immarginata nervo diaphuno 
excurrente instructa, omnes 1. minutissime et obscureareolatae virides subintegrae, subundulatae; theca rectisetacea oblongo-cylindrica operculo conico-rostellato curvulo.

Patria. Ceylon.

F. submarginato Bruch affinis sed foliis siccitate non deflexis sed patentibus angustioribus et inforescentia dioica differt.

32. F. remotifolius C. Miill. (mst.); dense gregarius, caulis foliis 10 - 20 -jugis laxe dispositis gracilis tener; folia plantae senilis stricta patula, innovationum juniorum crispa; folii lamina $1 / 2$ producta integerrima flavomarginata, apice incerpulis, alae hand comnutue sed alu unica rotundata oblusu patens ad nervum connata; lamina dorsalis e basi angusta longe decurrente latior marginata integerrima; 1. apicalis ante apicem immarginutu denticulata nervo crasso excurrente moronata; omnes laminae undulatae, minute sed pellucidius areolatac; seta $c$ basi geniculata erecta, theca horisontulis oblongo-rylindrica.

Putria. Prom. bon. spei: '/a ey her collect. Cap. No. 41. C. ex parte in societate Fissid. glancescentis.

Inflorescentia, operculum et calyptra ignotac.

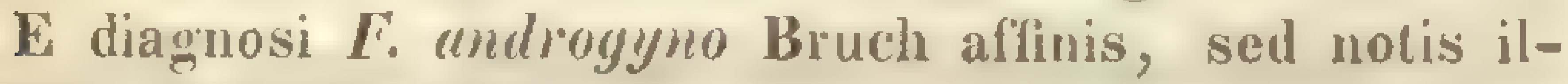
lustratis distinctissimus.

\section{Folia immarginata.}

\section{- Folia crispa.}

33. F. osmundioides Hdw. (Sp. Musc. p. 153. tab. 40.); dioicus; dense cespitosus; caulis erectus innovationibus vage dichotome ramosus; folia sublaxe-imbricata latiuscula; folii lamina $2 / 3$ producta incerpulis, ala unica in medio laminae apiculis commatu obtusa; 1. dorsalis e basi attenuata lata; 1. apicalis lato-lanceolutu acuminutoacuta nervo evenido genuflex'); omnes 1. cellulis prominulis serrulatte minute dense et pellucide areolatae; theca obovalis suboblique parva operculo longe rostruto rectiusculo; calyptra e busi lobuta (submitraeformis) recte rostratu. 
Brid. 11. 689. - Br. Ellrop. 1. c. p. 8. tab. 3. - Skitophyllum osmundioides La pyl. I. c. p. 38, tal). 25. fie. 5. - Dicranum osmundioides swats. Act. Holm. 1795. p. 210. - Fissidens dicarpos Brid. 11. p.698. e spec, authenticis, thecis geminatis, foliis crassinerviis luc certe pertinet.

Pulviu. In pratis uliginosis et turfosis hic illic per Germaniam, Angliam, Sueciam, Lapponiam et Helvetiam, raro. Vere. $2 \%$.

Planta mascula feminea gracilior. Flos masculus terminalis. Folia perigonialia interna raginantia, in laminam rerticalem angustissimam desinentia. Antheridia paraphysibus nom!ullis mista oblonga. Folia perichaetialia aut perigonialia caulinis angustiora et longius alata.

34. F. crispus Mont. (in d'Orbigny Voyage 'I'nm. VII. Crypt. 1. 97.); caulis subsimplex evectus filiformis longinsculus flexnosus, innovationibus divisus; folia 15-20juga siccitule muloreque crispatissima secunda; folii lamina ultra nediun producta; lamina apicalis oblongolancenlata; omnes partes integerrimae margine incrussuto hyalimo nerroque excurente instructae viridi-lutescentes tenuissime areolatac; ped. flexuoso-erecto, theca orali-oblonga inaryulis horisontalis operculo conicoacuminato recto. $t$.

Mont, in ann, des sc. nat. 1837. p. 57.

Pulria. In America meridionali, Prov. Corrientes, ad terram arenosam in collibus sylvaticis, secus flumen Sanctae Iduciae societate Physcomitrii Orbigniani Mont.: d'Orbigny. Jimio mense. 4.

Folia perichactialia intima subscalpelliformia undulata, magis acuta elamellosa. 'Theca olivacea tandem brunnea, ore purpureo.

35. F. eapitatus Ilook. et Wils. (Lond. journ. of bot. 1844. p. 547.); monoicus; caulis subsimplex apice subdivisus; folia 15-juga conferta; lamina apicalis linearilanceolata siccitate incurva nervo subcontinuo diaphano; omnes laminac rotundato subpunctiformi-areolatae; theca ovalis cernua. t. 
P'atria. In sinu insularum (Insel-Bay) Novac Seclandiae.

Caulis apice plerumpue setis 2, seta in rumulo mromio. Antheridia 8-10 eparaphysata. Flos musculus ad basin perichaetii (inflorescentia androgyma?.

E diagnosi paupervima nec affinitas nec substantia speciei intelligi potest.

36. F. oblongifolius Ilook. et Wils. (1. c. p. 547.); monoicus; caulis subramosus; folia 2t-juga linceria obtusu siccitate incurva, nervo subcontinuo pellueido, guttulato-areolata; theca ovalis cernua. $\div$.

Patria. Ibidem ac praecedens.

Flos masculus axillaris.

Ab antecedente differt foliis linearibus obtusis firmioribus, colore flavido-viridi et floris masculi situ. - Diagnosis ut praecedens vaga.

37. F. Mangarevensis Mont. (royage an pùle Sud. Crypt. p. 34t.); cespitosus; caulis procumbens simplex vel innovationibus fasciculato - ramosus, rami subflabellato-ramulosi; folia dense imbricata erecto-patentia sicca in plano involuto-cincinnata; folii lamina ad medium producta; 1. apicalis lineari-lanceolutu, omnes 1. integriusculae nervo ante apicem evanido. $†$.

Ann. d. sc. nat, 1845, 4, p. 113.

Putriu. In insula Manga Reva (Archipel Gambier), ad rupes humidas nec non ad ramos dijectos locis irriguis, imprimis ad radices montis eodem nomine ac insula ipsa nuncupata, hancee speciem, cujus cespites caulibus primariis vel rhizomatibus Neckerce undulatue procumbunt, invenit Cl. II o mbron ad altitud. 220 metra supra mare.

38. F. Anbellatus IIsch. (f1. Bras. fase. I. p. 91. tab. II. lig. II.); dioicus; decumbens brevissimus subfusciculution rumosus, rumi adscendentes innovationibus brevissimis ramulosi flexuosi basi nudi superne magis magisve dense foliosi; folia 8-juga versus apicem magis patentia et longiora linearia; folii lamina sub $2 / 3$ producta; 1. dorsalis longe supra busin enutu angustissima; 1. apicalis 
lineari-lanceolata obtusa summo apice subcremulata, nervo crasso pallidlo, evenescente, omnes l. intense lurido-virides subtilissime areolatac; ped. e busi geniculutu adscendens; theca suberecta parva cylindrico-oblonga parum curvata inaequalis operculo convexo-rostrato recto luteo, theca breviore; calyptra cucullata. †.

Putria. In humidis nmbrosis supra Serro dos Orgaôs terrestris: Beyrich. Jumucerio. $2 \%$

Planta mascula brevissima, flore terminali. Folia perigonialia basi vaginantia lata lamina dorsali ultra folii laminam enata c. apicali lanceolata. Antheridia eparaphysata. Peristomii dentes normales cruribus ferrugineis. CaIyptra cucullata straminca apice fusca.

\section{b. Folia stricta (plantae femineae).}

r. integra.

39. F. pygmaeus IIsch. (Limn. 1811. p. 117.); diaicus? subucunlis ; folia obsolele disticha 3-juga; folii lamina ultra mediun producta rentricose; 1. apicalis oevelis obli-

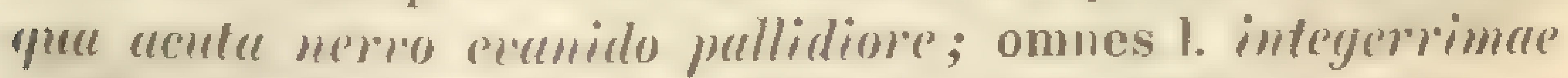
lurido-virides laxe et irregulariter rotundato-areolatae; seta crassa erecta; theca oblongu erectu aequalis pallida ore purpurea, operrulo hemisphuerico brevissime rostellato; calyptra cucullata. $†$.

Putria. Prom. b. spei, ad monumenta lapidea hortorum summorum in vertice boreali montis abularis et in terra loci Lijuenschuans dicti: Ecklon. Junio. ¿.

Folia perichaetialia 2 maxima teneriora pallidiora, nervo excurente. Peristomium normale cruribus subulatis inaequalibus.

40. F. Iaxifolius IIsch. (1. c. p. 149.); divicus? caulis brevissimus simplicissimus rufus; folia obsolete disticha upice, recurve lato-ouculiu; folii lamina uspue ad upicem moductu oblirgu: I. apiealis acumimulatu nervo diaphano supre medium folii dissoluto; omnes 1. circulariter areolatae integerrimae, intense virides; ped. crecto.; theca oblonge obligure cernue parum curvata operculo convexo 
breviler rostellato, dimidiac thecae longitudine, reclo; calyptra conico-subulata. f.

ß. Ureviseta, setis brevissimis.

Palria. Prom. b. spei, ad montem tabularem et diaboli haud raro inter rupes, in sylvis quercinis. Var. $\beta$. in terra loc. umbrosorum montis tabularis: Ecklon. Jun.Aug. $\odot$.

Folia perichactialia duplo majora lanceolata longe acuminata; obliqua lamina folii ultra medium producta rentricosa murginata nervo excurrente; omnes partes intensevirides. Peristomii dentes normales usque ad basin fissi cruribus filiformibus. Calyptra minuta rostellum vix tegens, conico - subulata, basi fissa glabra straminea apice fusca.

41. F. exiguns Sulliv. (Nusc. Alleght. p. 44.); dioicus; caulis simplex foliis 5-9,-jugis oblongo-lanceolatis integerrimis nervo sub apice, dissoluto; theca subobliqua v. erecta, operculo conico-rostelluto; calyptra cuculliformis.

Patrin. In sylvis ad rivulorum exsiccatorum lapides, prope Columbus Ohionis copiosissimus. $\odot$.

Calyptra cuculliformis. Flos masculus terminalis. Diagn. pauperrima!

42. F. obtusifolins Wilson (Lond, journ. of bot. IV. 1845. p. 196. tab. IX. B.); divicus; caulis simplicissimus humillimus; folia 6-10 (in caule sterili 20) parva; subovalia brevissima; lamina folii ultra medium producta; 1. dorsalis angustissima; 1. apicalis latior rotunduto-obtusu exunidinervis; ped. sublincaris; theca erecta subelliptica basi obconica sicea sub ore constricta, operculo conico brevi rubello; calyptra dimidiata.

Putria. Ad dumeta rupis humidae prope Cincinnati: J G. Lea 1843.

Folia perichactialia longiora oblonga siccitate subincurva laete viridia, minutissime rotundo-areolata. Flos masc. terminalis. 
43. N. Taylori C. Müll.; monoicus, humillimns, simplex laxe aggregatus; caulis sterilis flexuosus folis $7-8$ jugis infra laxis, superne confertis erecto-patentibus oblongis obtusissimis nervo apiculatis; lamina dorsalis supra basin desinens; planta fertilis foliis $\mathbf{2}-\mathbf{3}$-jugis erectis adpressis amplexuntibus ucuminatis; seta subflexuosa, theca ovalis inclinata operculo rostrato breviori. $\dagger$.

F. pygmaeus Tayl. n, sp. non Hornsch. in Lond. journ. of hot. 1846. p. 66. - Wilson I. c. p. 45t. - Nomen mutaudum erat, quum $\boldsymbol{F}$. pygmaeo Hsch. supra descripto jam impositum fuerit. mond.

Putriı. Swan River Novae Hollandiae: J. Drum-

Folia plantue sterilis sicca crispa. Peristomii dentes inaequaliter divisi.

F. mygmueo Irsch. affinis, sed firmior et theca inclinata, foliis indistincte obtusis et inflorescentia diversus.

44. F. Iongifolius Brid. (II. p. 682.); cespitosus msillus simplicissimus decumbens filiformis, foliis 5-6-jugis dissitis patentibus superioribus (pro plantulae exiguitate) longissimis, 1. folii ad medium producta; 1. apicalis linervi-lanceolatu nervo contimuo pellucido ucuta; omnes I. amoene virites arctissime areolatae; seta filiformis, theca inclinata ex outi subrotunda, ore contracta exigua.

Whitophyllum longifolium La PyI. I. c. p. 40. tah. 35. fig. 3.

I'utria. In Iispaniola, unde Poitea u retulit. $\odot$. Perichaetialia ut caulina.

\section{ß. denticulata.}

45. F. aerratug C. Müll. (bot. Zeit. 1847. p. 804.); monoicus; humilis simplicissimus (c. 8-jugus); folia stricta cuspriluto-lanceolutu minuta areolata; folii lamina ungusta brevis grosse servatu; lamina dorsalis basi angusta, apicem versus latior et servulatu; nerrus excurrens crassus flavus flexuosus; theca ovalis rectu aequalis minuta longisetucell et (e spec. capensib.) operculo conico obliquo subulato instructa; calyptra conica.

Putria. Javae insula: Zollinger No. 2100. c. Barbulae specie incompleta mixtus. Ad ligna putrida sylvar. pri-

c. M iller: Synops, musc, frond. 
mitiv. prope Krakakammam prom. b. spei collectum communicavit am. Ha mpe.

Archegonia c. 3. Flores masculi axillares gemniformes mumerosi. Folia perigonialia subciliato-serratu.

Fissid. Hornschuchii Mont. affinis sed folis patentibus ubique et grosse-, sacpe cristato-serratis immarginatis distinctissimus. Flores masculi ac feninei in eodem caule creberrimi.

46. F. smoenus C. Müll. (bot, Zeit. 1847. p. 38.); divicus? brevissimus simplicissimus foliis $3-5$-jugis latiusculis plunissimis lunceolutis longis; folii lamina vera brevis; lamina dorsalis basi angusta; 1 apicalis longissimu obtusiuscula; omnes partes amoene virides, cellulis saepe pellucidis, tererue minute hexagono-areolatae, cellulis ubique prominulis servulatue; nervus crassus flarus subexcurrens; theca cylindrico-ovalis subinclinata minutissima tenera, dentibus brevibus setaque curviusculo - adscendente; operculo - ?

Patria. Columbia, prope Caripe inter Mnium rostratum: Moritz. $\odot$ ?

47. F. compylopus Mont. (ann. d. sc. nat. 1845. 4. p. 116.); munoicus; caulis decumbente-simplex, foliis c. 15-jugis dense imbriculis linearibus; lamina apicalis lanceolutu incurva; omnes (?) partes subcrenato-denticulatae; theca resupinata oralis inaequalis cermu, setu basi geniculatu upice curve operculoque convexo recte rostrato. t.

Patric. Chile australis in terra: C. Gay. ¿?

Flores masculi axillares.

48. F. Bloxami Wils. (Lond. journ. of bot. IV. 1845. p. 195. tab. 9. A.); monoices; perpusillus tenerrimus subcespitoso-gregarius simplicissimus declinatus, foliis remotis squarrosis patentibus; folii lamina ad medium usque producta; 1. dorsalis longe supra basin enutu c. upicali Iuto-ovalis acuta, nervo valido viridique sub apicem dissoluto; omnes 1. praecipue folii 1. vera valde denticulatae; pedunculus e basi geniculata adscendens subflexuosus; 
theca anmulata erecta oblongo-elliptica busi attenuata minima, operculo e basi conica oblique-subulato rostrato thecum subaequante; calyptra subulato-conica. t.

Patria. Anglia: Orton Wood, prope Twycross (Leicestershire) solo argilloso societate $\boldsymbol{F}$. taxifolii. April. 1844. A. Bloxam invenit. - Januar. ○.

Lamina dorsalis quasi undulata; omnes partes amoene virides laxe hexagono-, subinde pentagono - areolatae. Flos masculus ad basin caulis gemmiformis tetraphyllus. Theca ore vix contracta, sicca sub ore constricta olivacea. Operculum e cellularum seriebus erectis 32 conflatum, dentibus translucentibus rubrum, margine annulo majusculo albido mox revolubili fimbriatum. Peristomii dentes rubri normales cruribus inaequalibus dense articulatis superne papilloso-scabris. Calyptra conico-subulata, uno latere fissa, operculi longitudinem aequans fuscidula. Sporae minutae olivaceae.

F. Hornschuchii Mont. affinis, sed notis laudatis distinctus. Annulo ab omnibus congeneribus differt.

49. F. prionodes Mont. (ann. des sc. nat. II. ser. Tom. III. p. 200. tab. 3. fig. 1.); caulis simplicissimus ascendens, foliis sub 12-jugis erecto-patentibus linearibus; supremis falcuto-secundis; lamina apicalis lanceoluta, neveo crusso excurrente mucronata; omnes 1 . temissime servulutue; theca oblongu operculo conico-subulato. $f$.

Patria. Guiana Gallica: Leprieur. ¿?

\section{c. Folia homomalla haud crispa.}

50. F. fasciculatus Hsch. (Linn. 1841. p. 155.); dioicus; caulis procumbens prolifero-imnorans fusciculatoramosissimus elongatus polyphyllus vigidus glaneus siccitate varie flexnosus, humificatus substrictus; folia longissima subulata densissime imbricata rigida; folii lamina vera $1 / 3$ producta; 1 . dorsalis basi angustissima; I. apicalis lineari-acuminata nervo crasso apice evanido; omnes partes integerrimae minutissimae et densissime areolatae; theca ovalis parra oblongo-cylindrica curvuta ore majore, 
operculo e basi conica rostrato theca parum breviori, pedunculo rigido purpureo.

Patria. Prom. bon. spei: Dutoitskloof prope Schönfeld altitud. 1800 ped. mensi Martii 1828 Dr ège legit. In locis non designatis leg. Za e y er. 4.

Flos masculus terminalis globulosus in acumen attenuatus. Folia perigonialia basi ventricoso - vaginata in acumen longum lineari-lanceolatum planum folio caulino simile producta, viridia, nervo hyalino in basi ventricosa laxo, in acumine conferto, infra apicem evanido; retis arcolae in basi ventricosa lineares laxissimae, in acumine ut in foliis caulinis. Antheridia 30 maxima oblongo-cylindrica eparaphysata. Folia perichactialia longissima caulinis similia. Dentes peristonii lato-lanceolati usque ad medium fissi, cruribus inaequalibus saepe perforatis.

51. 1. plumosus IIsch. (I Linn. 1811. p. 151.); dioicus; decumbens subsimplicissimus glaucescens rigidissimus arctissime eleganter flabellatus, apicem rersus crescens foliis strictissimis planissimis longissimis angustissimis siccitate homomallis 15 - 18-jugis; folii lamina ultra medium producta inaequalis, ala unica in medio laminac connata acutissima integra; I. dorsalis suma busin unguste enutu integra; I. apicalis obtuse-lanceolutu summo apice serrulalu, nervo crasso ante apicem evanido flexuoso striuto; omnes 1. minute areolatae firmae glaucae; pedunculus basi valde geniculatus adscendens brevis; theca inclinatu oboralis subcermu pallida substrumosa, operculo conico-rostrato longo obliquo purpureo; calyptra longa cucullata operculum totum tegens.

Pulvil. Prom. bon. spei: Mund et Maire. 2\%.

Foliorum perichactii internorum lamina latissima undulata complicata; I. dorsalis supra eam cuata c. apicali quam maxime angusta.

Descriptio nostra ab Hornschuchiance paulum diversa, non dubitamus tamen, quin nobis species vera sit. Fiss. Habellato Hsch. affinis, sed caule subsimplicissimo (basi interdum innovante), foliis oblique-acuminatis lon- 
gioribus subexcurrentinervibus, pedunculo longiore geniculato-adscendente, theca substrumosa (i. e. collo incrassato praedita) et operculo e basi conica longiore distinguitur.

52. F. serrulatus Brid. (II. p. 704.); divicus; frondiformis subsimplicissimus cressus elatus, foliis sub 20 -jugis latissimis luxe imbricutis strictis homomallis superioribus longioribus; folii lamina ultra medium producta, e basi oblonga latior, apice inaequalis: ala unica in medio laminae connata obtusiuscula, cellulis prominulis serrulatu; 1. dorsalis ad basin folii enata, c. 1. apicali latolanceolata obtusiuscula, cellulis prominulis serrulutu, "pice servata, nervo crassissimo flexuoso ante apicem evanido; omnes 1. grandius arcolatae firmae; pedunculus flexuosus; theca orali-oblonga subrentricosu obliqua vel subinclimata, operculo e basi convexu longirostro.

Montagne in Hist. nat. d. I. Canaries par Barker, Webl et Berthelot p. 22. tab. 2. c. icone. Fructus inde noti et optime illustrati.

Putriu. In Teneriffac insula Bory S1. Vincent primus legit.

F. polypodividi lldw. proximus, sed fruetu terminali notisque ceteris illustratis dirersissmus. Sequenti haud dissimilis sed partibus ommibus multo robustior.

53. F. asplenioides Ledw. (Musc. Fr. III. p. 65. tab. 25.); divicus; fromliformis subsimplicissimus angustus subelatus, foliis sub 20 -jugis angustis arcte imbricutis strictis homomallis (falcatis haud crispis), superioribus longioribus; folii lamina ad medium producta inaequalis: ala unica in medio laminae connata rotundato-obtusa; l. dorsalis supra basin folii enata c. l. apicali angusto-lanceolata, nervo eranescente crasso; ommes 1. subintegervimae minute corelatae firmae; pedunculus bre$\checkmark$ is rectus; theca obovata recta aequalis operculo comico "cuminato recto; calyptra cuculliformis.

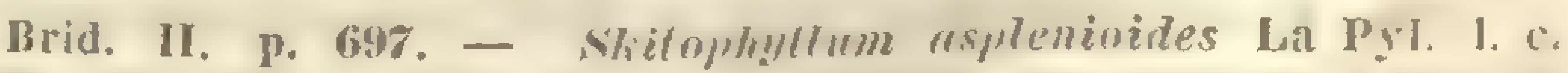
p. 47. tath. 36. fig. $x$ et 9. - Iicromam aspllenioides sw. FI. Ind. Occ. 111. 1. 1780. - Holpmumb aspleniwides ej. Prodr. 1. 110. 
Patria. Ad latera muscosa rupium in montibus altis Jamaicae australis: Swartz.

\section{Species steriles notae.}

54. F. filicinus Dz. et Molkb. (in ann. d. sc. nat. 1844. 2. p. 304.); dioicus; erectus flexuosus subsimplex foliis 20-2̆-jugis, erecto-patentibus lato-lanceolatis; folii lamina ad medium producta, maryine incrussuto subserruluto apice subaequalis; 1. dorsalis ad folii basin enata basi lata undulata, margine incrassuto subservulato; 1. apicalis acuminata margine incrassuto serrato, nervo crassissimo ante apicem evanido.

Putric. Java, 4.

Folia perichaetialia brevia elamellata, margine incrassata integra, intima membranacea acuminata. Archegonia pauca eparaphysata. Flores feminei in planta creberrimi. Fissid. polypodioidi ex habitu similis, sed notis demonstratis ab omnibus congeneribus lucusque cognitis distinclissimus.

55. F. genunervis C. Müll. (mst.); subcespitosus subsimplex gracilis elatiusculus, foliis siccitate valde crispulis densiusculo imbricatis; folii lamina ad $1 / 2$ producta, e basi oblonga, medio latior, apice attenuata integerrima aequalis, alu unica rotunduto-obtusa ad flexuram nervi cum co connatu; 1. dorsalis ad basiu nervi enata, apicem versus crescens integerrima; 1. apicalis lanceolato-obtusa, apice crenulato-denticulata; nervus crassus semel genuflexus, ante apicem evanidus diaphanus; ommes laminae cellulis minutis, granulis obscure viridibus impletis, areolatae.

Prtria. Columbia in granitaceis: Moritz sub collect. Thoreyanae No. 54. 4 .

F. osmundioidi ex habitu simillimus, sed foliis apice laminae apicalis obtuso crenulato-dentato distinctissimus.

56. N. ovatus Brid. (II. p. 696.); tenellus simplicissimus frondiformis ambiln cleganter longe onatus, siccitate introrsum convolutus, humiditate applanatus; folia 
20-30-juga dense disticha patula, linearia lanceolata, media longiora, a basi ad medium usque parallela, inde ad apicem rersus paulum divergentia, nervo tenui albo viridi continuo exarata. $t$.

Putrie. In rupibus et speluncis madidis insularum Franciac et Bourbonis: Bory St. Vincent. ?

Plerumque folia media quac ceteris longiora sunt, humiditate corrupta, solo nervo superstite, multo breviora apparent, hinc incautius observanti caulis non ovatus sed linearis videtur. - Forma caulis ovata huic soli inter congeneres propria, teneritate ac elegantia a $F$. asplenioide, qui omnino linearis est, distinctus. Folia etiam forma ac directione aliquantulum recedunt. Ilinc fructu ignoto et patria diversissima conjungere noluimus. An mera $I$. asplenioidis varietas sit, fructus inspectio nos quondam edocebit. Brid. 1. c. p. 697.

57. F. Linenris Brid. (II. p. 691.); simplicissimus planissimus erectus sublineuris; folia sub 10 -juga approximata subaequalia oblonga sublimereria minima.

Petriel. Nova Hollandia: Hb. Desfont.

Ilabitus Fissid. osmmelioidis, statura cxilis. Folia sicea nec corrugantur nec crispescunt.

\section{Species incertac sedis.}

F. neacioides Brid. (II. p. 705.); simplex vel ramosus erectus infra et supra decrescens, folis ultra $10-$ jugis ovalibus acutis, seta terminali brevissima, theca erecta urceolata sub ore constricta.

Shitophyllum acacioilles La Pyl. I. c. p. 45. tah. 35. fig. 7. Humum acucioides, fronde pinnata ramosa apice pedunculifera Linn. Sp. PI. p. 1588.

„Ilypunm pimmulis Acuciue, setis brevissimis. Surculis tenues, alii simplices, alii ramosi, pinnulis opacis crebris Acaciae similibus, paulo brevioribus, alati, colore ex obscure viridi nigricante. Inter extremas pinnulas setae omnium (praeter quasdam species, quas ex America nuper nactus in Appendicem hujus libri con- 
tuli ${ }^{*}$, quae vidi, Hypnorum, brevissimae fuscae egrediuntur, in quibus capsulae exiguae subrotundae fuscae, urnae per microscopium urceolatae, ora laevi, exiguo anuulo cincta, ciliis inconspicuis, forte quoniam introversae sunt. $\mathrm{Ob}$ exiguitatem perichaetium non comparet. Opercula abierant et calyptrae.

Inter Muscos e Patagonia delatos inveni. Videbatur arboribus adnasci, cum quibusdam exemplaribus ad basin subduri quid, velut e cortice avulsum, adhaereret." Dill. p. 265 et 266. tab. 34. fig. 4 .

„E sola analogia et caulis frondiformis indole hucce retulimus, cum genus non satis luculentum sit; nam, utrum folia fissura feminea genitalia fovente gaudeant dentesque peristomii bifidi sint, jure ambigitur.

In Herbario Dilleniano muscus iste nunc desideratur, in cujus locum, testa occulatissimo Turnero autopta, Fissid. osmendivides, nescio quo casu, subiit, a quo toto coelo diversum esse monuimus, idem sentiente Pylaesio nostro." Brid. II. p. 796.

Omnes auctores speciem hucusque Fissidentem habuere. Dillenianis autem iconibus accuratissime examinalis et ejus descriptione comparatis nobis persuasum est, muscum dubium non ad Fissidentes referri posse. Folia a Dillenio (in figura citala a. et b.) enervia delineata inveniuntur, dun folia Fissidentium verorum constanter nervosa depinxit. Hanc notam, monemus, contra affinitatem Fissidentis generis testimonium nobis perhibere. Ad quod genus autem muscus iste adducendus sit, nobis incertum est. Drepanophyllo maxime similis appellandus est. Speramus fore, ut in Patagonia ex novo mox reperiatur.

$$
\text { Species delenda. }
$$

T. Thunbergii Brid. (II. p. 699.); caule subramoso ereto lineari, apice pedunculifero, thecis incurvis.

*) Auctor. e. gr. Cryphaeam nervosam, Lasiam Trichomitriam etc. delineavit.

C. N. 
Hypnum asplenioides Thunb. Prodr. Fl. Cap. II. p. 175.

Ad Cap. b. spei: Thunberg.

Ex adnotationibus Horuschuchii (Linnaea 1841. p. 15\%.) in hance speciem elucet, eam in hb. Thunbergiano non inveniri. Clarissimus ille bryologus ideo putat, speciem Thunbergianam $\boldsymbol{F}$. asplenividem verum, in prom. b. spei inventum, forsan fuisse.

Species nobis nomine tantum notac.

1. F. Innceolatus Bruch, in prom. b. spei ad latera montis diaboli, in solo granitaceo a Cl. Krauss lectus. Regensb. bot. Zeit. 1816. p. 134.

2. F. Ieptophyllus Mont. In ann. d. sc. nat. 184 . 4. p. 113. memoratus.

\section{PoIyøtichophyIIa.}

Folia in series tres et phures, pro primo adspectu plermunuc spiraliter disposita.

1. Folia (in sectione transversali) ductibus intercellularibus instructa.

lrib. IX. LELCOBRYACEA.

Late cespitosae clatiusculae acrocarpicae, cladocarpicae vel pleurocarpicae. Folia albescentia fragilissima, e cellulis dimorphis constructa: 1. cellulis parenchymalicis columnaribus crassis inanibus, in strata plura connexis, jerforatis; 2. ductibus intercellularibus, inter illas cellulas in serie unica curvata interpositis, $3-4$-angularibus, granulis chlorophyllaceis impletis. Ductus $\mathbf{1}-\mathbf{2}$, in medio folii siti, c serie curvata educti. Pedunculus rigidus valie hygrometricus purpureus. Theca olivacea, brunnea vel tandem purpurea. Peristomium itidem coloratum fir- 


\section{It STEGOCARPI. ACROCARPI. WUCOBRYC.}

mum. Archegonia longissima fusca angustissima vix paraphysata. Antheridia magna clavata tandem brunnea paraphysibus brevibus mixta.

IIabitus proprius e foliis albescenti-glaucis et, si in angulo acuto vides, iricoloribus, Sphngnuceis proximus distinctissimus speciosissimus.

Putria. In terra plerumque ericetorum et in arboribus per totum orbem terrarum praccipue in insulis Archipelagi Indici, cespites maximas saepe densissimas formantes.

Lencophaneae Hmp. in Linnaea X1II. p. 42. Nomen in Lencobryaceas a nobis (Limnaea XV11. p. 315.) mutatum est, qunum Lencobryí generis congeneres plures et per zonas omues terarmm inveniantur. Leucophanis genus autem intra fones angustissinos dispositum et in Europa nulla specie gaudens.

Tribus certe distincta et nulla alia confundi potest.

\section{Gen. I. Teucóbry nin IImp.}

Linn. XIII, p. 42. - C. Müll. Linn. XVII. p. 314-322. et il Linn. XVIII. p. 687-90. - Dicrana glauca auct. - Oncophorus Bryol, Europ. Fasc. XLI.

Nomen graecae compositionis a verbis $\lambda \varepsilon v$ xọ albus, et B@v́av muscus ob folia albescentia impositum.

Calyptra dimidiala cuculliformis thecam superans straminea. Theca inaequalis sacpe strumosa, siccitate plicata, innovatione saepe lateralis, terminalis vel distincte lateralis. Peristomii dentes $\mathbf{1 6} \mathbf{~ d i}$ cranoideo bifidi dense trabeculati purpurei. Ductus intercellulares quadrangulares; unicus in medio folii situs plerumque triangularis. Folia enervia. Infloresceutia monoica $v$. dioica.

Congeneres terram liabitantes.

1. L. vulgare IImp. (Limnaea XIII. p. 42.); dioicum; densissime compactum; caulis elongutus brevi-ramosus, densissime foliosus; folia longiuscula lata erecto-putentiu 
glauce oblongo-lanceolata stricta, apice obtuso-cuspidata integerrima, ultra medium latiusculo-marginata; perichaetialia convoluta longius cuspidata vitra medium marginata; theca innoratione lateralis, mediocriter pedunculata, ovali-cernua vix strumosa, operculo longe subulato oblique rostrato.

C. Müll. Linn. XVIII. p. 687. - Dicranum glaucum Hedw. Sp. Musc. p. 135. - schwägr. Suppl, I. P. 1. p. 187. tab. 48. (exclusis locis natalibus Jamaica et Teneriffa?). - Fuscina glauca schrank Baiers. Flora 11. p. 45\%. - Bryum glaucum Linn. Sp. Pl. p. 1582. Bryum albidum et glaucum, fragile majus, foliis erectis, setis brevioribus. Dill. Musc. p. 362. tah. 46. fig. 20. - Hypnum glaucum Weis Crypt. Goett. p. 208. - Oncophorus glaucus Br. Europ. 1. c. p. 5. t. 1.

ß. minus, gracilius foliis brevioribus densissimis. Lencobr. minus Hmp. Linn. XVIII. p. 42. - Dicranum albillum Web. et Mohr e Brid. br. univ. I. p. 409. - Bry/um albidum et glaucum, frayile, minus, folits erectis, setis oblongis. Dill. Musc. p. 546. tab. 83. fig. 8 .

Putriu. Per totam Europam in terra ericetorum et in pinetis raro fructiferum. In America sept. ad arborum radices in humidiusculis a Marylandia usque ad Georgiam: Sullivant. Var. $\beta$. in Pensylvania, Virginia, Massachussett, Georgia, Alabama, et Ludovicia Americac septentrionalis.

Colore intense glauco jam a sequentibus differt. Folia perichactialia plerumque non exserta, in aliis speciminibus; si fructus exacte terminalis observatur, distincte exserta convolutacea inveniuntur.

2. H. sediforme C. Müll. (mst.); dioicum; humile parce ramosum; folia brexissima latissima densissime imbricuta sediformi-spuarrosa exacte octosticha oblongolanceolata acuta, apice valde concara reflexiuscula, integerrima ultra medium latiusculo-marginata stricta; perichactialia multo longiora acutiora anyustiora vulde exserta convolutu; theca (pro plantulae exiunitate) longipedunculata ovalis cernua inclinata brevis vix strumosa exacte terminalis.

Dicranum glaucum $\beta$. albidum Brid. Hb. Reg. Berol. 


\section{Patria. Insula St. Dominici.}

Praecedenti proximum, sed foliis lurido albis non glancis exacte octostichis Sedi acris instar dispositis squarrosis brevissimis et pro brevitate latissimis fructuque exacte terminali distinctissimum. Operculum et calyptra deerant.

3. L. brachyphyllum Hmp. (1. c.); laxiusculo cespitosum; caulis breviusculus ramosus; folia brevia stricta oblongo-lanceolata vix falcata apice (cellulis dorso mide prominulis) valde servata basi vix marginata; perichaetialia subbreviora caulinis similia stricta rel subundulata maxime servata, intima lacrissima longiora cuspidata e busi usque fere ad apicem lato-marginuta longiora subexserta integerrima; theca lateralis lougipedunculata obconica cernu exacte strumosu ore dilatata operculo longirostrato obliquo purpureo instructa brevis olivacea.

C. Mïll. Linn. XVIII. p. 688. - Dicramum candirlum Brid, I. p. 409. - Schwägr. (suppl. II. 2. p. 119. tah. 187 (๕.) An ק. luc certe pertineat? - Dicr. brachyphyllum Hsch, in Musc. Sieberianis e Nova Hollandia relatis. - Hryum condidum frugile foliis recurvis Dill. Musc. p. 364, tab. 46. fig. 22. sed gracilius elatius densins imbricatum.

Putria. Nova Hollandia: Dampier primus collegit et Dillenio communicavit; R. Brownet Sieber tandem retulerunt.

Var. $\beta$. e Schü̈gricheni observationibus monoicum, sed forsan species propria? - Holia inferiora apice radiculosa.

4. L. Martianum Imp. (l. c.); laxiusculo cespitosum; caulis breviusculus ramosus; folia laxiusculo imbricata brevia perfecte fulcuta stricla (i. e. non flexuosa) oblongo-lanceolata secunda ucuminatu inlegervima busi vix marginata; perichactialia vix breviora e basi latissima ocali angustione linerriu acuta a basi usyne and medium lato-marginata integerrima immersa; theca longipedunculata ovalis cernua perfecte stmomose, purpurea, operculo longirostrato subulato. 
C. Müll. Linn. XVIII. p. 689. - Dicranum Martiannm Hsch. F1. Bras. p. 11.

Putriu. Brasilia in prov. Minarum Gener. ad Ouro preto, prope Sebastianopolin in montosis el ad ripas fluminis Amazonum in cortice arborum: Martius. Surinam: Miquel hb. Guiana anglica: Rich. Schomburgk pulcherrime fructiferum legit.

A sequentibus folis perfecte falcatis distinctissimum. Dioicum.

5. I. Iongifolium IImp. (l. c.); laxiusculo cespitosum; caulis breviusculus brevi-ramosus; folia longissima acule-cuspiduta lineari lancealutu apice (cellulis prominentibus) scabra, busi tenui-marginata subfernosu; perichactialia subbreviora upice linearia acula e basi usyue ad medium lato-marginata integerrima immerse; theca imnoratione lateralis longipedunculata ovalis cernua perfecte strumosce magna operculo longo subulato.

C. Mäll, Limn. XVIII. p. 6×7. - Dicranum albicans Schwägr. Suppl. H. 2. p. 122, tah. 146. - Dicr. megalophyllum Haddi critt. Bras. p. 3. - ? Sylutgunm macrophyllum Brid. I. p. 753. non p. 10. quod sphagum verum distintissimum! - syhagn. iridens Brid. Sp. Musc, p. 20. Nant. Muse, p. Gr. Bryol. mir. p. 19.

Putria. Brasilia ubi in locis permultis at radices arbormm inventum est. Prope 'lijuca in vicinia Sebastianopoleos et in sylvis primaeris ad flumen Paquaquer, in Serra dos Orgàs, Jumurii mensi fructiferum legit primus omnium: Beyrich. In prov. Geraës: Martius.

Forsan dioicum. Arehegonia multa. Dentes peristomii longissimi latissimi ad medium fissi valde trabeculati nodosi. - Foliis longissimis laxissimis ab affinibus praecedente et sequente distinctissimum.

6. I. sanctum IImp. (l. c.); laxiusculo cespitosum; canlis breviusculus ramosus; folia breviora oblongo-lanceolata linearia basi temuissime marginata valde flexuosu apice (cellulis prominulis) scabra valde radiculosa; perichactialia multo breviora e busi lutissima orali subito linearia longe cuspidatu; in medio folii tuntum lato-marginata integerrima, immerse; theca longipedunculata in- 
novatione lateralis ovalis cernua brevis purve perfecte strumosa, operculo rostrato subobliquo.

C. Müll, Linn. XVIII. p. 688. - Dicranum sanctum Nees in Schwãgr. Suppl. II. 2. p. 121. tab. 186.

Putriu. Ad sepulcra sancta Javae insulae. E Singapore relatum $\mathbf{C l}$. K unze benerole communicavit.

A praecedente foliis brevioribus magis flexuosis valde radiculosis, et perichaetialibus, theca minori et habitu multo humiliori diversum.

7. H. Cladopodanthus C. Müll.; dioicum; caulis prostratus elongatus vage et subpinnation ramosus; rami breves conferti adscendentes turgidi; folia densissime imbricata erecta oblonga cuminuto-cuspiduta, flexuosopilifert integerrima concara; theca lateralis breve pedunculata cylindrica angusta aerpulis; dentes congenerum. †.

Cladopodanthus pilifer Dz. et Molkb. Musc. Archipel. Ind. p. 80. tab. 28.

Patria. Java ad arborum corticem in monte Gédé: Zippelius.

Calyptra, operculum et flores masculi desunt. Sectiones transversae ab auctoribus neglectae. E ramificatione Lencobryis dissimile quidem, sed notis caeteris ab iisdem non recedens.

\section{Species steriles notae.}

8. I. Juniperoideum C. Müll. (Linn. XVIII. p.689.); dense cespitosum erectum ranis aequalibus erectis; folia glauca dense imbricata erecto-patentia ovali-lanceoluta juniperoider acuta integerrimu e basi usrue ad modium latiusculo marginatu canaliculata.

Dicranum juniperoideum Brid. 1. p. 409.

Putria. Insula Teneriffa et Bourbonis.

E speciminibus Bridelianis a $\boldsymbol{L}$. glanco proximo habitu juniperoideo foliis angustioribus subulatis diversum.

9. R. erispum C. Müll. (mst.); laxiusculo cespitosum humile; folia laxe imbricatu (pro plantulae exigui- 
tate) longissima valde thexusu et iden crispu e busi oblongu linearia longe cuspidata immarginata integerrima.

Lencobryum Martianum Hmp. Linn. 1847. XX. p. 67.

P'utria. Columbia: Cocollar ubi legit Moritz. Fx Hb. Reg. Berol. communicatum. Moritz collect. No. 131.

Notis illustratis habitu proprio c. L. longifolio et suncto comparandum sed certe distinctum foliis angustissimis longe cuspidatis integerrimis immarginatis.

10. L. faleatum C. Müll. (nst.); laxiusculo cespitosum valde elatum robustum; folia dense imbricuta sed valde matula recurvo-flexuosu mollissima valde robusta fulcato-secunde lutissima valde ivicoloria longissime oblonga faro-mucronata, basi cellulis longissimis angustissimis tenero-marginata, apicem versus dorso cellulis mominentibus serrata.

sylhagnum Jarense schwägr. Suppl. II. 1. p. 4. tah. 102. Brid. I. p. 19.

Patriu. In sylvis alpinis Javae insulae ad montem coeruleum et Sasere anno 1768 mense Octobri Commersous detexit. H prov. Buitenzorg ejusdem insulae ( Miquel benevole communicavit.

Species speciosissima ac distinctissima sed hucusque saepissime commutata, cum sequente proxima congenerum gigantes. Hx habitu e. gr. Dicrum. majus optime foliis falcatis referens, sed foliorum structura e familia distinctissimum.

11. L. giganteum C. Müll. (mst.); laxe cespitosum maxime elutum et robustum, folia busi densissime imbricata vaginantia apice valde patula maxima latissima oblongo-lanceolatu canaliculata apice obtusiuscula integerrima, a basi usque ad medium tenero-marginata, margo e cellulis angustissimis longissimis purietibus interruptis constructus; perichaetialia brevissima caulinis dissimillima.

Leucobr, longifolium Hmp. in Linn. 1847. XX. p. 68. non Dicranum albiccons schwägr. quocum e Cl. Hampe ratione synonymum esse dicitur. Ab hacce specie ultima toto coelo differt et quidem adeo, ut genus proprium in futuro formet. 
80 STEGOCARPI. ACROCARPI. SCHSTOMITRUM.

Patria. Columbia: in montibus nivosis provinciae Meridac, ubi Cl. Moriız cum aliis muscis quam maxime memorabilibus collegit et Hb. Reg. Berol. sub No. 134. a. communicavit.

Folia caulina subglaucescentia undique disposita non falcata s. secunda ut praecedentis. Caulis elongatus ramis basi itidem elongatis simplicibus instructus. Rami juniores graciliores attenuati foliis brevioribus magis albidis $\mathbf{s}$. candidis angustioribus linearibus. - Perichaetia in longitudine cunlis numerosu distincte lateralin et pro pluntue speciosue altitudine brevissima tripuetra bulboso-yemmascentia. Folia perichaetialia e basi latissima vaginali alata ultra medium subito lanceolata flavo-acuta brevissima, basi latissime et tenerrime membranacea et marginata, ultra medium valde subtruncato-crenata vel usque ad apicem integra $\mathrm{v}$. integerrima; margo alaris e cellulis excavatis irregularibus parenchymaticis constructus. - Archegonia eparaphysata longissima fusco-brunnea s. ferruginea.

Species modo descripta inter Lencobrya locum excellentissimum tenet. E floris situ distincte laterali putamus, muscum in futuro forsan genus proprium constructurum esse.

\section{Gen. II. Schistomitrium Dz. et M.}

In Mnsc. Arclip. Ind. p. 67. - Syrrhopodon cor. olim.

Nomen graecae compositionis a verbis oxítos fissus, et píreıo ob calyptram basi fimbriatam deductum.

Calyptra campanulata cylindrica lasi fimbriata. Theca aequalis. Peristomii dentes $\mathbf{1 6}$ simplices trabeculati integri. Ductus intercellulares ut antea. Folia e stratis cellularum duobus composita encria. Inflorescentia dioica terminalis. Vita arborea.

Genus e calyptrae forma Enculyptus Pottiacearum referens speciosum Leucobryaceus congeneribus revera locupletans. 
1. Seh. apieulatum Dz, et Molkb. (1. c. p. 68. tab. 24 et 25.); laxe cespitosum lumile ramosiusculum; folia dense imbricata subsecunda brevia oblongo-lanceolata longe et fusco-mucronata vix marginata integerrima, apice involuta; perichaetialia angustiora basi ad medium latiusculo - marginata; theca brevipedunculata cylindrica parva angusta erecta aequalis et (ex obs. Dz. et M.) spiraliter striata, operculo conico subulato recto; calyptra firma nitens straminea apice fusca.

Syrrhopodon apiculatus Dz, et Molkb. in ann. d. sc. nat. 1844. II. 1. 315.

Patria. Jara in agro Bogoriensi ad trunc. Arengae sacchariferae mense Febr. fructif. legit Zippelius. In monte Pangerang et Fjikoerai: Kühl et ran Has selt. Inmonte Papandajang: Korthals. - Sumatra in sylva montis summi Nerapie ad cortic. Thiebaudiac lucidae: Korthals.

Archegonia eparaphysata pauca fusca. Calyptrae fimbriae breves flexuosac. Theca e nostris observationibus stricte striata. Folia costata esse auctores 1. c. Hescripserunt; nos vero etiam in sectione transversali enervia invenimus. - Theca innovatione lateralis $v$. terminalis.

\section{Gen. III. I, encóphanes Brid.}

Br. univ. I. p. 763. - Nyrrhopodon Nees et Schwägr. - Mielichhoferia et Spirula Dz, et Molkb. - Did!lmodon W. Arn.

Nomen graecae compositionis a $\lambda \varepsilon v x o ́ s$ albus, et qaivw ob colorem albicantem impositum.

Calyptra dimidiata cucullata. Theca aequalis. Peristomii dentes $\mathbf{1 6}$ aequidistantes breves lineares lanceolati vix trabeculati. Inflorescentia dioica vel monoica? Folia e stratis cellularum duobus composita. Dnctus intercellulares ut antea.

Congeneres tam terram quam arborum corticem incolentes.

C. Müller: Synops. musc, frond, 


\section{a. Folia nervosa.}

1. I. octoblepharoides Brid. (I. p. 763.); dioicum; caulis erectus ramosus laxissime foliosus gracilis; folia caulina raginali - conferta lanceoluta angusta cavinatoconcur' e basi usque ad apicem tenue marginata apicem versus denticulata nervo excurrente acuta; perichaetialia caulinis similia; theca brevissime pedunculata ovalis angustu erecta, operculo conico subulato recto.

syrrhopodon octoblepharis Nees in schwägr. Suppl. IV. tah. 311. a.

L. Korthalsii Dz, et Molkb. (in Musc, Archipel. ind. p. 65. tah. 23.) ; dioicum; caulis humilis erectus compressiusculus simpliciusculus; folia subbifaria e basi subvasinante squarrosula glauca linearia acutiuscula apice denticulata marginata, nervo ante apicem evanido, carinato-concava; theca brevipedunculata oblonga erecta sulapophysata, operculo oblique-rostrato. †.

Patria. Java in monte Géde: Zippelius. Borneo prope pagum Martapacra: Korthals. Amboina: Zippelius.

Flos masculus terminalis. Calyptra lacvis apice cellulis protnherantihus rumulosa. Dentes peristomii linea longitudinali media destituti obscure trabeculati, granulosi.

Species huc inclusa notis fere omnilus ad praecedentem accedens adeo, ut al eodem distinguere nequeanus.

Patril. Jarae insula, ubi haud rarum sed sterile colligitur, et in regione Nepal Indiae.

Folia apice interdum radiculos efficientia e cellulis parvis composita candida.

2. T. Reinwardtianun C. Müll. (mst.); dioicum; laxiusculo-cespitosum erectum fastigiato-ramosum densissime foliosum; folia erecto-patentia subrecurertu ovalilanceolata carinata obtusiuscula nerro excedente temui breri-cuspiduta, e basi usque ad apicem tenue-marginata apicem versus serrata mollia; perichaetialia caulinis similia; theca mediocriter pedunculata terminalis vel innovatione lateralis oblonga, ferruginea ore purpurea, operculo convexo-rostrato obliquo thecam aequante. $\div$.

Syrrhopollon candidus Hsch. in Nov. Act. Acad. Leopold. XIV. 2. Suppl. p. 701. tah. 39. fig. 1). -- Schwägr. Suppl, II, 2. p. 105. tab. 183. 
Patria. In Archipelagi Indici insula Saparuria (e Schwägr. 1. c. Japoma) legit Cl. Reinwardt.

Archegonia 6-10 solito crassiora. Peristomii dentes thecae diametro paullo longiores erecti lineari-lanceolati transversim striati et linea media e basi ascendente, superius obliterata. Calyptra cucullata laevis straminea basi integra apice subulata nigra.

A praecedente tam ex habitu multo robustiori et foliis densissime imbricatis quam notis ceteris illustratis valde diversum.

3. I. euspidatum C. Müll. (mst.); dioicum; late et compacte cespitosum humile densissime foliosum subramosum, rami breves; folia caulina e basi ovali oblonga lanceolata flexuosa carinata, a basi usque ad apicem teneromarginata apicem versus denticulata, nervo viridi excedente apice Iyalino serrato pilifero-cuspidata; perichaetialia multo minora ovali-lanceolata integerrima nervo vix conspicuo; theca innoratione saepe lateralis cylindrico-ovalis fusca, operculo e convexo rostrato recto theca breviori concolori.

Syrrhopodon glancus schwägr. Suppi, UI. 2. p 103. talı. 181. Didymodon sphaynifolius? W. Arnott. - Arthrocormus Hookeri Hmp. in bot. Zeit. 1847. p. 922.

Patric. Insula liauwack Moluccarum et cum Octoblephoro albido in insulis Marianis: Gaudichaud.

Sterilem vidimus. - Peristomii dentes lineari-lanceolati e simplici cellularum serie compositi rigidi, thecae diametro dimidio breviores, ferruginei. Calyptra junior subulato-campanulata latere late fissa, theca paullum longior pellucida laevis straminea. - Paraphyses nullae.

A praecedente specie foliis pilifero-cuspidatis rigidis jam distinetissimum.

4. L. Fragile Brid. (Bryol. univ. I. p. 765.); caulis erectus ramosus fragilissimus, rumulis subteretibus superne incrassatis apice ucutis; folia densissime imbricata erectu subappressu stricta (nec madore mutata) lineurilanceoluta carinato - concava, nervo crasso subcontinuo 
acuminata integerrima glauco-albida, cellulis magnis laxissime reticulata; perichaetialia caulinis similia; theca oblonga terminalis $v$. innoratione axillaris longiusculo-pedunculata. + .

Patria. In insula Australiac Lalan ad terram cespitosum: Dumont d'Urville.

Calyptra elongato-subulata angustissima integra bicolor, inferne albicans, apicem versus brunnea et scubriuscula. - An revera nervosum?

\section{b. Folia enervia.}

5. I. speciosum C. Müll.; monoicum? dense cespitosum; caulis erectus crasso-julaceus teres dichotome ramosus; rami fastigiati apice subfasciculatim innorantes; folia densissime imbricata erecta clecetu toto upice margine cochleariformi-concaren imoluta, margo imrolutus hippocrepico-e.xcaralus, oblusissima upice subito longissime acuminatu flexuso-pilifera recurea, integerrima immarginata glauca basi brunnea; perichactialia longiora exserta lanceolata pilifera apice subplana; theca distincte laterulis cylindrica angusta longiuscula, operculo conicosubulato subobliquo, calyptra conico-subulata basi incisula.

Schistomitrium speciosum Hmp. bot. Zeit. 1847. p. 922. Genus e calyptra 11011 verum labemus. - Syrrhopodon speciosus D\%. et Molki. in ann. d. sc. nat. 1844. 2. p. 315. - Spirula speciosa eor. in Musc. Frond. Archip. Ind. p. 72. tab. 26.

Patria. Java insula in monte Gédé: Zippelius.

Species quam maxime memorabilis. Folia e cellulis majoribus crassioribus quam in praecedentibus formata. Folia innorationum juniorum subsccunda. Peristomii dentes 16 lanceolati breves conniventes. Inflorescentia forsan monoica. Gemmulam minimam e foliis duobus latoovalibus brevi acuminatis minimis brunneis compositam sed antheridiis carentem invenimus, quam florem masculum antheridiis abortivis esse putamus. - Nulla alia specie confundendum. 
Species sterilis nota dubia.

1. E. Gardnerianum C. Müll. (Bot. Zeit. 1814 p.741. et 15:5. p. 103.); dense cespitosum pusillum gracile simpliciusculum; folia e basi latiori oblonga cara anguste lanceolata mucronata integerrima stricta canaliculata glauca enervia basi submarginala subrigida.

Putria. Brasilia: Gardner collect. No. 94. c. Leskea cespitosa mixtum.

\section{Gen. IV. Arthrocórung Dr. et M.}

Musc. Al'hipel. Ind. 1, 75. - Mielichhoferin eor. olim. - Leucophunes Brid.

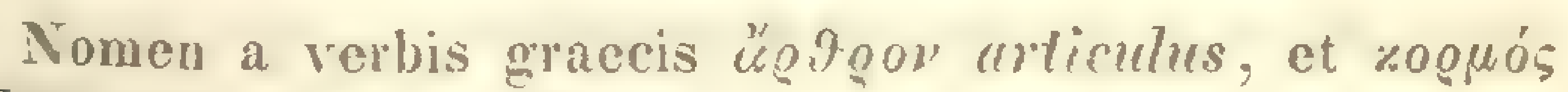
caulis, ob caulem protifero-ramosum derivatum.

Calyptra conico-subutala integra dein latere fissa. l'eristomii dentes 16 brevissimi lanceolali obtusi margini thecae intas adnati geminali tenuiter traberulati hyalini crecti. Folia e stratis multis ut in Ocloblepharo romposita, duclibus intercellularibus autem quadrangularibus ut in generibus pratecolentibus igitur inter eadem et Octoblepharum intermedium. Fulia pulcherrme trifaria. Inflorescentia dioica terminalis. Flos maseulus in ramulo proprio brevissimo.

1. A. Schimperi Dz. et Molkb. (I. c. p. 76. tab. 27.); caulis adscendenti-innorando-ramosus; rami fragilissimi flexuoso-erecti fastigiati; folia e basi vaginante latomembranacea densissime imbricata ererto-patentia integerrima enervia apice subplana cuspidato-acuminata s. mucronata; perichaetialia erecta lanceolata $r$. linearia subulato-acuminata, theca crecta subcylindrica annulata subapophysata, operculo conico subulato subobliquo.

Mielichoferia Schimperi Dz. et Molkh, in ann. d. sc. nat. 1844. 2. 13. 312. - M. trifuria eor. in Hh. Lugd. Batav. - Lencophanes trifarium Hmp. mst. - L. squarrosum Brid. 1. p. 761. nobis 
olim in Hb. Brideliano visum, sed 1. c. nervosum false descriptum. Cl. Dozy et Molkenboer in eundem errorem inducti sunt. In sectione transversali error facile intelligitur. Folia Cl. B ridel etiam disticha false dixit.

Patria. In insula Amboina, unde Clar. Dumont d'Urville primus retulit, cespitose ad terram habitat. Ex insulis Philippinis Cl. Mon tagne accepit (cf. Lond. journ. of. bot. 1845. p. 8.). - Ex insula Borneo, ubi in Arengu succhurifera inventus est, Cl. Dozy et Molkenb o er c. Cl. Hampe communicavere.

Muscus quam maxime memorabilis e cauli perfecte et late triquetro vix alio similis candidissimus. - Ductus intercellularis unicus medius e serie curvata a ceteris ductibus formata eductus quadrangularis.

\section{Gen. V. Octoblépharim Hdw.}

Musc. Frond. 111. p. 15. tab. 6. - Octobleyharis schueh. Gen. P1. n. 1640. - Bryum P. B. Prodr. p. 26. Dill. Linn. Gmel. Luida Adans.

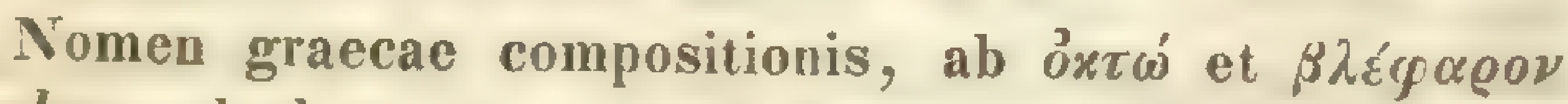
palpebra, ob dentes peristomii dentes octo huicce generi ab Iledwigio conditore impositum.

Calyptra dimidiata cucullata. Peristomii dentes 8 erecti breves lato-lanceolati flavo-diaphani e cellularum seriebus duabus constructi remoti acquidistantes. Folia e stratis cellularum compluribus formata. Ductus intercellulares triangulares; duo medii e serie curvata, a ceteris ductibus efformata, educti. Inllorescentia monoica gemmacea.

Congeneres in arboribus viventes.

1. D. albidum Hdw. (1. c.); erectum ramosum densissime cespitosum; folia caulina e basi latiore erecta lato-marginata membranacea saepe valde emarginata oblonga obtusiuscula apiculata canaliculata apice denticulata recurva; basi alis inaequalibus instructa; perichaetialia caulinis similia; theca brevipedunculata oralis parra operculo e planiusculo longe rostrato subobliquo. 
Bryum Octoblepharis Gmel. Syst. Nat. II. p. 1331. - Bryum albidum antheris erectis, foliis lingulatis obtusis patulis. Linn. sp. Pl. p. 1583. - Bryun nanum lariginis foliis albis Dill. Musc. p. 364. tab. 46. fig. 21.

Patria. Per regiones omnes tropicas Asiae, Africae et Americae vulgare, cespites maximas efficiens.

Peristomii dentes polymorphi nunc ut supra illustrati, nunc 16 e seric cellularum unica formati nodosiusculi, nunc compositi et simplices, lati vel angusti. Planta humilis vel elata. - Flos masculus in feminci vicinia minimus e foliis c. 3 formatus antheridis ferugineis eparaphysatis. Folia perigonialia minima oblongo-lanceolata acuta submembranacea. Flos femineus paraphysibus flavis instructus. Folia saepe e candidissimo v. subglauco violascentia.

2. 0. eylindrieum Schimp. (in hb. Mampeano); caulis fluccilus, foliis ut in praecedente specie formatis acutis subintegris longioribus magis recurvis, theca longe pedurculate longe cylindrica angusta erecta operculo e planiusculo longe subulato subobliquo; dentes peristomii linea media flare incressata instructi; calyntra longior et angustior.

Putria. In Guiana anglica primus legit Rob. Schomburgk. In Surinamo prope Paramáribo legit Kegel pulcherrime fructiferum in societate praecedentis. In Columbia prope Caripe legit Moritz.

Praecedenti quam maxime simile, sed, notis illustratis distinguentibus inventis, species distinctissima. Folia saepe violascentia radiculosa. Inflorescentia, folia et habitus praecedentis.

Trib. X. SPHAGNACEAE.

Late cespitosac elatiusculae saepe quam maxime elatae cladocarpicac. Folia albescentia (seniora rufescentia) e strato unico cellularum crassarum prosenchymaticarum modo vario excavatarum diapha- 
narum chlorophyllo carentium perforatarum saepe fibris annularibus impletarum composita enervia. Inter cellulas ductus intercellulares granulis chlorophyllaceis impleti modo vario compositi. PeduncuIus: ramus elevatus nudus, Hepaticarum pedunculum referens viridis. Theca globosa in apice pedunculi veri subcupulari vel disciformi sessilis operculo hemisphacrico fugacissino parvo et columella brevissima instructa. Archegonium unicum epraraphsatum. Antheridia globosa longistipitata. simus.

Habitus quam maxime proprius speciosus distinctis-

Putria. Loci aquosi praecipue turfosi planitierum atque editorum alpinorum orbis totius terrarum.

Ex hisce notis excellentissimis et calyptra infra describenda scrutatores permulti, hanc tribum distinctissimam e muscorum classi educendam esse, putarunt. Fibrac annulares autem foliorum non essentiales sunt, quum in nonnullis speciebus nullae inveniantur. Calyptra basi persistens dehinc disrumpens in Archidie genere etiam observatur et Archidia ceteris partibus omnibus cum Bruchiis atque Astomis adeo conveniunt, ut genera haecce tria dividi nequeant, qua nota denique dispositio inter muscos frondosos elucet. Pedunculus quidem Sphagni ramulus intelligitur, sel haecce nota unica scparatione non satis idonea appellanda est. Notae autem sejunctionis aliae desiderantur.

Diarrhugomitria Hmp. Linn. 1847. p. 66.

\section{Gen. I. Sphagnum Dill.}

Musc. p. 240. - Hedw. Fund. Musc, 11. p. 85. - Bryol, Germ. I. p. 1. - Brid. Br. univ. I. p. 1. - Fü ru robr in Flora 1833. 1.
p. 1.

Nomen antiquum, a Plinio lichenibus muscisque nonnullis arboreis datum, a Dillenio huicce generi impositum, a Linn a e o et Hedwig i o sancitum. Cr. Dill. Musc. p. 240. 
Calyptra thecam juniorem totam includens dehinc dismmpens. Theca eperistomata. Infloreseentia dioica.

Species permultae hucusque ab auctoribus impositae sunt, sed bene distinctae paucae lantum inveniuntur. Notas hactenus eas optimas habuerunt, quae ex habitu deduci possunt. Vagas intelleximus et aliis melioribus, e structura foliorum caulinorum, rameorum et peduncularium ductis, usi sumus. Sequentes sunt:

1. Folia caulina. In cauli primario plerumque squamaeformia scariosa lingulata membranacea et structura peduncularium simili inveniuntur. Basi omnes cellulis parvis plus minus rotundatis instructa.

2. Folia ranea semper fere structura propria, basi cellulis elongatis semper instructa.

3. Foliu pedunculuria. Perichaetialia nominari nequeunt, quum in longitudine rami totius fructiferi axillaris, saepe creberrima, posita sint. Structura plerumque valde propria basi cellulis elongatis constanter instructa.

4. Cellulue rumorum in longitudine rami, tegmenti instar, positae, constanter elongatae, hyalinae, laxe cohaerentes.

5. Omues hae partes fibris annularibus instructae vel iis carentes, quo factum est, ut termini plures, brevitatis causa, imponeudi sint:

a. cellulue incues: fibris annularibus carentes.

b. cellulae vepletae: fibris annularibus instructae.

6. Ductus intercellutares; inter foliorum cellulas omnium reperiuntur.

a. ductus homomorphi: angusti simplices (i. e. haud iterum reticulati) ideo parictibus cellularum tecti.

b. ductus heteromorphi: parietibus cellularum latiores et ideo ab iis non obtecti. Sunt:

u. simplices, i. e. haud it erum reticulati.

ß. cellulosi, i. e. cellulis pluribus reticulati articulati.

Ductus heteromorphi simplices ac cellulares vel chlorophyllo instructi (repleti) vel eo carentes (inanes). 
7. Cellularum forma. Diversissima, brevis vel elongata, angusta vel ampla, exacte prosenchymatica (hypnoidea vel angulata) parietibus strictis composita vel pluries flexuosa (serpentina). Formae intermediae facile derivari possunt.

Speramus fore, ut hisce notis ac terminis necessurie imponendis species Sphagnorum facile atque feliciter distinguantur.

Fructificationis tempus omnium congenerum Europaeorum, reg. temperatae, arcticae et calidioris: aestate, mensib. Julii et Augusti. 2\%.

I. Holia fibris anularibus nullis.

1. Sph. sericeum C. Müll. (in bot. 'Zeit. 1847. p. 481.); laxe cespitosum; caulis erectus longus apicem versus sensim crescens; rami tenues flexuosi protensi longi attenuati plerumque bini, comales breves erecti $v$. horizontales juluceo-cuspiduti; folia caulina cuspidutu planissima subundulata tenuissime membranacea; ramea flavescentia sericea lanceoluta ucuminatu immarginata integerrima, carinato-concava, basi laxe, apicem versus sensim densissime areoluta e cellulis brevinsculis semel perforatis, ductibus heteromorphis cellulosis instructis composita.

Patria. Sumatra insula septentrionalis in terrae Batta dictae monte altissimo Lubu Radja, ubi in altitudine c. 4000' cespitibus immaniter dilatatis luxuriat: Ju $\mathrm{g}$ h $\mathrm{uhn}$ legit.

Cellulae ramorum inanes.

Planta speciosissima atque ex toto fibris annularibus carens a fere omnibus congeneribus distinctissima. Si quis autem, nota hacce excellentissima rationem confirmari, speciem e Sphagnis excludendam esse, diceret: folia peduncularia nunc fibris, nunc nullis instructa esse significamus. - Foramina in angulis cellularum posita.

Ex habitu Sph. cuspidato simile sed ramis julaceis et cellulis, ductibus apicem versus valde cellulosis incras- 
satis, minimis et densissime areolatis fere homogeneis amoene sericeis facile distinguitur.

2. Sph. macrophyllum Bernhardi (in Brid. Bryol. univ. I. p. 10.); caulis erectus firmus subsimplex; ramulis binis ternisve fasciculatis, fasciculis alternis remotis; folia caulina appressa parva lato-ovalia rotundata, quarum cellulae breves inanes ductibus subheteromorphis interpositis, immarginata integerrima; ramea longa canaliculata subulutu truncatula e cellulis longissimis ungustissimis hypnoideis foraminibus c. 9. seriatis, ductibus subheteromorphis interpositis composita, basi vaginato-imbricata apice patula. Caetera desunt.

Sphagnum macrophyllum Brid. 1. p. 753. excludendum et ad Leucobryum longifolium revocandum.

Patria. America septentrionalis prope Philadelphiam. - Wx adnotationibus Sullivan ti i (p. 50.) juxta Wilmington in Carolinae superioris paludosis arenosis. An verum?

Ab omnibus congeneribus notis editis distinctissimum ex habitu Lencobrya subreferens.

\section{Folia fibris annularibus instructa.}

\section{a. Tolia apice rotundata.}

3. Sph. cymbifolium Ehrh. (in IIannov. Mag. 1780. p. 235.); compracte cespitosum perrobustum, ramis $1-4$ remotiusculis patentibus strictis $v$. rarius curviusculis crassis brevi-cuspidatis, comalibus brevissimis obtusis densissime positis; folia caulina latissime-ovalia apice rotundata basi e cellulis longiusculis angustis apice oblique-quadratis valde serpentinis amplis inanibus composita; ramea ovalia brevia apice involuta obtusa immarginata integra crecto-patentia, e cellulis breviusculis angulato-serpentinis subamplis composita; peduncularia latissime ovalia trunceto-obtuse integerrima immarginata, quarum cellulae bcrsilares longiusculac angustae ductibus homomorphis, mediae ductibus heteromorphis, apicales valde serpentinae ampliores ductibus homomorphis utrinque cellulurum mediurum inanium et apice repletae; pedunculus foliis multis laxe imbricatis concoloribus. 
Brid. Bryol, univ. 1. p. 2. - Bryol. Germ. I. p. 6. tals. I. fig. 1. - Syll. cymbifolium $\beta$. Magellanicum Brid. 1. p. 4. Sph. Magellanicum cj. I. c. - syle. cymbifolium 2. patens Brid. I. p. 4. in hb. Brid. cx insula Boulbonis relatum! - Sph, ohlom!lum P. B. Plodl. p. 15. Brid. 1. p. 6. e spec. anth. herly. Brid. Sph. cymbifolii typus! - Sph. rymbifolium $\beta$. Bourbonense P. B. Prodr. P. K8. ct Brid. I. P. 4. sub nom. Syll. cymbifol. Э. patens ex insula Bourbonis ex habitu spec. anthent. huc pertinet. In hb. Bridelii sterile vidimus et ideo carte nescimus, an huc pertineat. - Syh. serloides Brid. I. P. 750. forma juvenilis e sporis forsan enata foliis rufescentibus quorum cellula parictibus crassis coloratis instructa, caulis principalis foliis cauliuis nondun formatus. Ex insula Terre Neuve primum retulit C. La Pylaie, serius legit CJ. Sullivant in montib. Alleghaniensibus. Syh. Pylaesii Brid. I. p. 749. forma juvenilis mayis quam praecedens evoluta cauli principali jam sacpe instructa sed tenclla gracilis foliis miumis rufescentibus vel nigrescentibus, e reliquis a sph. cymbifolio minime recedens. Ex incula Terre Neuve pariter a CI. La Pyla ie relatum. - Sph. cymbifolioides Brent. Bot. Zeit. 1824. P. 435. - Hypnum cubile Neck. Musc. p. 188. - Sph. palustre, molle, defexum, squamis cymbiformibus Dill. Munc. p. 210, tab. 32 . fig. 1.

a. mycnocladum ramis remotis clongatis cuspidatis attenuatis laxe foliosis flaccidis gracilibus. Sylho obusifolium $\beta$. pycnocladum Mart. Fl. Erl. p. 17.

$\beta$. condensutum ramis brevissimis turgidis cuspidatis densissime foliosis et compacte approximatis humile vel elatius. Sph. imbricatum IIsch. in Hh, Meg. Berol.

$\gamma$. syuarrosulum foliis acutioribus patentioribus nonnullis subsquarrosis. Bryoi. Gern. I. p. 8.

Patria. Per totan Europam rulgatissimum.

Cellulae ramorum repletac.

Species e statura polymorpha sed formis supra illustratis tribus facile distinguenda.

4. Sph. erythrocalyx Imp. (in litt.); compactum, ramis confertis crassis erectis; comales ceteris similes; folia ramea brevia ovalia lata valde concara apice toto involuto-obtusa immarginata integerrima; peduncularia rotundato-ovalia valde convoluta pauca rancis nulto majora membranacea rufescentia, basi e cellulis longiusculis fuscis ductibus subheteromorphis instructis inanibus et solitarie sed grande perforatis, utrinque supra basin folii et apice toto e cellulis temuioribus repletis brevioribus 
cmplioribus parvo-perforatis composita obtusissima immarginata cellularum parietibus productis subdenticulata.

sphe cymbifolium Hsch, in FI. Bras. Fasc. 1. p. 3.?

Patria. Brasilia: Beyrich.

Cellulae ramorum inanes.

Sph. cymbifolio et compacto ex habitu simillimum sed a primo dilfert foliis peduncularibus maximis rufescentibus fere julaceo-convolutis calyciformibus, eorum textura cellulis nediis Syh. cymbifolii aliter constructis deficientibus, foliis rameis dorso apicis sublaevissimis et cellulis ramorum inanibus. A secundo differt foliis rameis non trunratis ct fol. peduncularibus obtusis aliter constructis.

5. Sph. perichatiale $1 \mathrm{mmp}$. (in litt.); humile; caulis robustus ramis $1-3$ approximatis brevibus patentibus, comalibus brevioribus erectis dense imbricatis; folia caulina rotunda integerrima immarginata quorum cellulae subinunes basi longiusculae, apice dense areolatae parrae, ductibus subheteromorphis instructac; ramea squarrulosa, e basi ovali oblonga obtusa integerrima immarginata apice involuta strictuscula e cellulis brevibus angulato-serpentinis, ductibus lomomorphis interpositis, composita; peduncularia oblonge curviusculo-acuminate obtusiuscula inmarginata integerrima, e cellulis ommibus angustis, ductibus hoteromorphis angustis immibus hyalinis interpositis, tonerrimis apice minimis, ante apicem tuntum amplioribus repletis composita, plicuto-umluluta.

Ny.h. compactum Hach. in F\%. Bras. Fasc. 1. p. 3.?

Putria. Brasilia prope Rio Janeiro: Beyrich.

Cellulae ramorum repletue.

Fx habitu Sph. compacto maxime simile sed notis illustratis distinctissimum. I Sph. cymbifolio folis peduncularibus e cellulis fere ex toto inanibus tenerrimis ductibus heteromopphis inanibus interpositis compositis plicato - undulatis acuminatis distinctissimum.

\section{b. Folia truncata.}

4. Folia peduncularia fibris annularibus nullis.

6. Sph. molluscum Bruch (in bot. Leit. 1825. p. 613.); laxe cespitosum elatum gracillimum molluscum 
amoene flavidum, ramis remotis tenuibus parce geminatis laxe foliosis subdeflexis flaccidis curviusculis; folia caulina magna ovalia apice subimvolutu acutiuscula e cellulis parvis rhomboidalibus brevibus, ductibus heteromorphis latis repletis cellulosis interpositis, senioribus inanibus, junioribus apice subrepletis composita; ramea ovalia acuminata truncatula subinvoluta e cellulis brevibus serpentinis subamplis formata; peduncularia lata longe-acuminat acuta, e cellulis brevibus inanibus, ductibus heteromorphis repletis valde cellulosis interpositis, composita tenerrime membranaceo-marginata integra; theca omnium minimu obconica rufo-purpurea sporis sulphureis instructa.

Brid. Br. un. 1. p. 753. Sph. squarrosum Fk, in Sched, - Sph. squurrosum $\beta$. tenellum IIib. Muscol. Germ. p. 23. Sph. tenellum Bryol. Germ. I. p. 8, tab. I, fig. 2.

Cellulae ramorum incenes, foliorum omnium inanes elegantissime areolatae, ut in Sph. sericeo tantum observantur.

Putria. In locis paucis ericetorum Europac hucusque detectum: in paludibus Vogesorum et prope Bipontem legit primus Bruch; pr. Lausigk Saxoniae: Fr. Müller; pr. Jeveram Duc. Oldenburgensis: C. Müller; in Sudetorum paludosis loci Koppenplan: Funk et pr. Krageroe Alp. Norvegiae: B oek in Hb. Reg. Berol. E rarissimis!

Planta speciosissima elegantissima caulibus molluscis amoene flavescentibus et theca rufo-purpurea sporis sulphureis primo intuitu distinctissima! Variat paulisper ramis densius $\mathbf{v}$. laxius foliosis.

7. Sph. squarrosum Pers. (in litt. ad. P. B.; cf. ej. Prodr. p. 88.); compactum robustum elatum, ramis subapproximatis elongatis deflexis julaceis squurroso-foliosis curviusculis, comalibus densissimis stellato-sfpurrosis; folia caulina magna luto-ovalia rotundutu, e cellutis rhomboidalibus amplis inanibus, ductibus subhomomorphis interpositis, constructa immarginata integerrima; ramea $\mathfrak{e}$ basi lato-ovali acuminatu truncutula tenue marginata, e cellulis brevibus amplis angulato-serpentinis formata; 
peduncularia latissime ovalia maxime truncata, basi e cellulis elongatis, ductibus subheteromorphis instructis, apicem versus brevioribus amplissimis vhomboidulibus valde flexusis, summo upice minimis tenuissimis marginantibus, omnibus inanibus composita immarginata integerrima.

Brid. I. p. 5. - Bryol. Germ. I. p. 9. tah. 1. fig. 3.

Putria. Per totam Europam et Americam septentrionalem et arcticam vulgare, sed rarius quam ceteri congeneres Europaei fructiferum.

Cellulae ramorum inanes.

Ab omnibus congeneribus ramis robustis teretibus valde squarrossis primo intuitu distinctissimum.

8. Sph. Meridense C. Müll. (mst.); compacte cespitosum elatum subrobustum, ramis remotis mollibus subgracilibus attenuatis deflexis, comalibus densissimis brevissinis obtusis dense imbricato-foliosis; folia caulina oblonga apice rotunduta vix involutu, e cellulis basi utrinque densissime areolutis, ductibus heteromorphis anyustissimis imanibus interpositis, medio basis laxioribus duct:bus subhumomorphis, omnibus longis, apicem versus brevioribus umplioribus rulde serpentinis inanibus rel raro ex parte subrepletis, utriculo mimordiuli plicuto multiplicutis composita immarginata integerrima; ramea ovalia acuminata apice trucutule subinvoluta immarginata integerrima stricta erecto-patentia laxiusculo-imbricata, e cellulis serpentinis subamplis composita; peduncularia latissima, inferiora truncatula, superiora acuminata, e cellulis laxis majoribus, basi longioribus, ductibus subheteromorphis interpositis, apice illis fol. caul. similibus, ductibus subhomomorphis interpositis, omnibus inanibus composita.

Syha!mum subsecundum C. Mïll. in Linnaea XIX. p. 209. Sph. acutifolium "ar. Merillense Imp. in Linn. XX. p. 66. - Nyp. cymbifolium it. patens Brid. Br. univ. 1. p. 4. in hb. Bridelii ex Hispaniola relatum excl. synon. Syh. cymbifolium Bourbonense P. B. Prodr. p. 88.

Patriu. Hispaniola: Desvaux in Brid. hb. - In montibus nivosis Meridae Columbiae: Moritz No. 179. 
Cellulae ramorum inanes.

Inter Sph. subsecundum et acutifolium. A primo differt jam foliis peduncularibus e cellulis inanibus compositis; a sccundo ramis non capillaceis sed crassiusculis patenti-foliosis, comalibus brevibus obtusis non capillaceis acutis et structura foliorum. - Notis hisce et colore viridescenti-rufescente cum albescente mixto facillime distinguitur. Specimina ex insula Hispaniola relata cum Meridensibus maxime conveniunt.

9. Sph. cuspidatum Ehrh. (Crypt. No. 251.); laxe cespitosum elatum; caulis gracilis ramis $\mathbf{1}-\mathbf{5}$ remotis divaricatis curvalis attenuatis, comalibus superioribus in coma densa positis brevissimis dense et squarroso-foliosis obtusis; folia caulina lato-ovalia obtusissima, e cellulis basis utringue angustissimis densissimis, medio busis et apicem versus laxioribus brevioribus, ductibus heteromorphis cellulosis interpositis, composita; ramea luxe imbricata erecta oblonga cuspidata truncutula cymbiformia tenuissime marginata stricta integerrima anguste et serpentino-areolata; peduncularia latissimo-ovalice oblonga concava obtuso-acuminata vix marginata, e cellulis multo laxioribus, ductibus lato-heteromorphis hyalinis inanibus interpositis, constructa.

Bryol. Germ. I. tab. 4. fig. 9. - Brid. I. p. 14. - Sph. pentastichum Brid. I. p. 13. e speciminihus IIerb. Bridelii huc, non ad sph. recureum, quod ad syll. acutifolium pertinet, revocandum est. - sph. cuspidutiforme Breut. Bot. Zeit. 1824. p. 407. - sph. paInstre, molle, deflexum squanis capillaceis Dill. Musc. p. 243. tab. 32. fig. 2 A.

Putria. In profundis turfosis per fere totam Europam septentrionalem et in America septentrionali.

Cellulae ramorum incues. - Rami comales, saepe quoque laterales fructiferi.

Primo intuitu caule longissimo gracillimo, ramis comalibus brevibus densis squarroso-foliosis et lateralibus longis deflexis laxe foliosis facile distinguitur.

10. Sph. acutifolium Ehrh. (Dec. crypt. No. 72.); densiusculo cespitosum elatum gracile; caulis flaccidus 
ramis $1-4$ remotiusculis elongato-flexuosis deflexis capillaceo-attenuatis appresso-foliosis, comalibus superioribus paucis in coma parva laxiusculo positis brevissimis tenuibus subcuspidatis; folia caulina parva lato-oralia appressa, c reliquis peduncularibus similia; ramea oblonga acuminata apice truncatula, angulato-flexuoso-areolata; peduncularia latissimo-ovalia truncuto-obtusa apice repundo-marginata, upicem versus e cellulis rhomboidalibus amplis, utriculi primordialis plicuturis multiplicatis, constructa.

Sph. acutifulium $\beta$. capillifolium Bryol. Germ. I. tab. 3. fig. 8*. - Sph. capillifolium Ehrh. Hamnov. Magaz. 1780. p. 35. Brid. I. p. 11. - Sph. intermedium Hofm. D. F'. II. p. 22. - Sph. capillifolioides Breut. Bot. Zeit. 1824. p. 438. et Brid. I. p. 751. - Sph. Ascherbachianum Breut. 1. c. 1. 459. et Brid. 1. p. 751. - Sph. recurvum Brid. 1. p. 13. excl. syll. s. pentastichum. - Sph. subulatum Brid. I. p. 18. - Sph. gracile Rich. Fl. Am. Bor. Mich. II. p. 285. - Sph. alpinum Ruehl. - S. palustre 3. capillaceum Weis. Crypt. Gütt. p. 265. - Syl. nemoreun scop. Fl. Carn. p. 161. Hypnum cubile $\beta$. Neck. Mcth. Musc. p. 189.

B. robustum, ramis confertissimis brevibus plurimis patentibus, foliis rubicundis. Bryol. Germ. I. p. 21. tab. III. fig. $8 * *$.

$\gamma$. tenue, ramis recurvis reflexis, summis longioribus attenuatis, foliis viridibus apice subulato-reflexis. Bryol. Germ. I. p. 22. tab. 11I. fig. $8 * * * *$. Sph. intermellium Hoffm.

Patria. Per tolam Europan et Americam septentrionalem atque arcticam vulgatissimum.

Cellulae ramorum inanes.

Ramis capillaceis folis appressis vix patentibus facillime distinguendum.

B. Folia peduncularia fibris anmularibus instructa.

11. Iph. Iaxifolium C. Müll. (mst.); laxe cespitosum elatum; caulis gracilis flaccidus ramis $\mathbf{1}-\mathbf{4}$ remotis divergenti-divaricatis attenuatis, comalibus luxis pancis; folia caulina lato-ovalia obtusissima marginata reflexa, e reliquis peduncularibus similia; ramea laxissime plumosoimbricata patula e basi oblongn angusta attenuatu subfalcata truncatula involuta marginate, margine infra api-

c. Muller: synops. musc, frond. 
cem breviter plamum evcuido basi latiore, anguste et serpentino-areolata; peduncularia latissimo-ovalia apice valde involuto breviter acuminuto-obtusa multo laxius areolata, ad apicem lato-marginutu, apice tantum cellulis vepletis.

Sph. cuspidatum $\beta$. plumosum Nees et Hsch. Bryol. Germ. I. P. 24. tal. 4. fig. 9*. - sph. cuspidutum Fusk Crypt. No. 347. fertile et Crome. Crypt. No. 5 sterile. - Syh. palustre, molle, deflexum, squamis capillaceis. Dill. Musc. p. 24t. tab. 32. fig. 2. B.

ß. hypnoides; humile simpliciusculum, ramis praesertim comalibus fere, et foliis caulinis ex toto carens, foliis uncinatis mollibus margine undulato-excavatis. sy.h. hypnoides A. Braun in bot. Zeit. 1825. No. 40. et in Brid. 1. p. 752. Forma juvenifis e sporis enata. - Primo idspectu fiypn. uncinatum imo et molluscum referens sterile, intedum tamen priesertim in umbrosis virunteis alisque locis ejus perfectiori evolutioni magis faventibus ad formam normalem redux et fructificans.

Patria. In profundis turfosis Germaniae praesertim septentrionalis haud raro, sed sterile plerumque invenitur. - Tar. $\beta$. ad ripas lacus Hornsec in Ifrcynia Suevica inferiore quas saepe ingentibus stratis obducit, habitat, ubi C1. Braun detexit.

Cellulae ramorum inceses.

Species hucusque ab auctoribus c. Sph. cuspidato semper commutata. Ab eodem folis rameis valde plumosis Inngioribus laxissime imbricatis falcatis latiusculo-marginatis, et perluncularibus apice fibris annularibus instructis distinctissima!

E locis diversis valde varians, siccioribus humilius compactius rigidius, ramis rigide cuspidatis, foliis apice plerumque valde subulatis fere piliferis; humidioribus gracilius, saepe quam maxime elongatum filiforme laxissime foliosum valde plumosum ramis valde remotis. E foliis autem laxe imbricatis primo adspectu facile distinguitur.

12. Sph. compactum Brid. (Sp. Musc. I. p. 18 et Br. univ. I. p. 16.); compacte cespitosum elatum; caulis robustus ramis dense approximatis putentibus strictis crassis, comalibus brevioribus conformibus densis; folia caulina minima, e cellulis rhomboidalibus, ductibus homomorphis interpositis, fibris annularibus quum maxime obsoletis in- 
structis, composita integerrima immarginata; ramea e basi ovali suboblique oblonga apice valde truncuta, e cellulis angulato serpentinis, ductibus homomorphis interpositis, amplis formata; peduncularia latissima longe-acuminuta apice falcata undulate tenuiter marginata integerrima, e cellulis summi apicis inanibus angustissimis densissime areolatis tenerrimis hyalinis, ceteris e reliquis caulinis similibus, constructa.

Bryol. Germ. I. p. 13. tab. II. fig. 5. - Sph. humile Br. et Sch. in Hb. Hamp. foliis maxime truncatis peduncularibus apice truncatiusculis, e reliquis autem a sph. compacto non recedens. - Sph. praemorsum Zenk. et Dietr. Musc. Thuring. Fasc. 1. No. 15. et Brid. b. 17. var. compacti. - sph. tristichum sichultz in Bot. Zeit. 1826. - Syl. immersum Nees et Hsch. Bryol. Germ. I. p. II. tab. II. fig. 4. et Brid. 1. p. 9. - Sph. ambiguum Hüb. Muscol. Germ.p. 25. - Sph. Helveticum Schk. Deut. Moos. p. 12. tah. 3. e spec. Hb. Schkuhriani! - Sph. condensatum Schlcich. Cent. I. n. 3. - Sph. obtusifolium $\beta$. condensatum Web. et Mohr. Bot. Taschb. p. 73.

B. robustum ramis densissimis brevibus, statura humiliore, foliis confertis.

$\gamma$. vigidum ramis remotiusculis patentibus longioribus, statura elatiore, foliis patulis. Br, Germ. I. p. 14. tah.11. fig. 5 *.

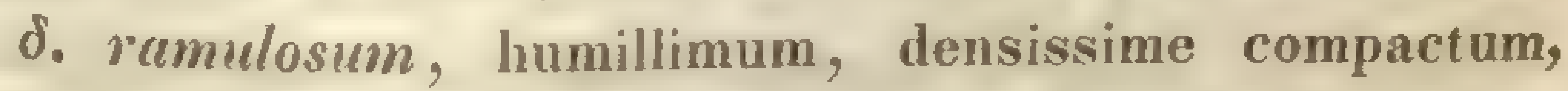
innoratione ramulis elongatis, foliis peduncularibus apice acutis vix cuspidatis haud falcatis.

Putria. In ericetis humidis per totam Europam et Americam septentrionalem. Tar. $\beta$. in locis siccioribus, var. $\gamma$. in locis humidiusculis; $\delta$. in ericetis compactis gelatinoso-humidiusculis Jeverae Duc. Oldenburg. - Sph. humile in Carolina et Florida.

Cellulae ramorum inunes.

Foliis peduncularibus, apice tantum e cellulis inanibus angustissimis tenerrimis densissime areolatis e reliquis autem caulinis similibus compositis ab omnibus congeneribus facile distinguendum.

13. Sph. molluscoides C. Müll. (mst.); compacte cespitosum elatiusculum robustum; caulis mollis ramis brevibus crassis dense approximatis rigidis valde patulofoliosis saepe capillaceo-cuspidatis, comalibus brevissimis 


\section{STEGOCARPI. ACROCARPI. SPHGNU.}

densissimis conformibus; folia caulina magna e basi latissima lanceolato-ovalia truncute rix marginata, basi infima e cellulis longis laxis inanibus, ductibus subhomomorphis interpositis, upicem rersus rameis ex toto similibus vulde repletis, composita; ramea ovali-oblonga acuminata truncatula subinvoluta immarginata, e cellulis valde serpentinis subamplis constructa; peduncularia lata longe acuminatu subtruncata recte undulatu, e cellulis laxis tennibus, ductibus heteromorphis inanibus hyalimis angustis interpositis, apice laxioribus inamibus $\nu$. ante apicem interdum repletis formata; thecae in coma caulis creberrimae.

Sph. compactum $\beta$. rigidum nonnulfor.?

Patria. In ericetis humidis prope Jeveram Duc. Oldenburgensis copiose fructiferum legimus 1810.

Cellulae ramorum inanes.

Sph. compacto simillimum sed foliis caulinis magnis truncatis acuminatis, e cellulis valde repletis compositis et peduncularium structura, e cellalis fere ex toto inanibus tenerrimis ninimis constructa, distinctissimum! Primo intuitu caulibus rigidiusculis molluscoideis, valde patulofoliosis et ramis comalibus ralde fructiferis, pedunculis exsertis, facillime intelligitur.

14. Sph. subsecundum Nees ab Es. (in Bryol. Germ. I. p. 17. tab. III. fig. 7.); compacte cespitosum clatum robustum, caulis rigidus ramis subapproximatis brevibus crassis attenuatis cuspidatis recurvatis, comalibus erectis brevioribus densis; folia caulina e basi latissima ovalia apice rotundata subtruncata, e cellulis longis angustis basi laxioribus e.x toto repletis composita, tenue narginata membranacea; ramea oralia apice involuta subfulcutu in ramis curvatis sacpe secunda subtruncata tenue marginata, e cellulis teneris angustis serpentinis constructa; peduncularia latissima ovalia, apice truncutu murginutu, basi infima e cellulis longis laxis inumibus, apicem versus repletis normalibus formata; theca comalis et lateralis.

ß. contortum, ramis circinatis, foliis longioribus falcatis. Sph. contortum schultz Fl. Stare. p. 64. 
$\gamma$. turgidum, ramis turgidis cuspidatis, foliis apice valde truncatis emarginato-5-dentatis latissimis. - Planta si haecce aquas fluitans habitat, folia latissima remotiuscula, e cellulis longiusculis submarcidis hypnoideis formata, observantur. syl. denticulatum Brid. 1. p. 10. e spec. Hb. Brideliani pessimis!

d. gracile, omnibus partibus tenerioribus ramis lateralibus remotis curviusculis, comalibus densissimis. Sph. tenellum Pers, e spec. anthentico Hb. Bridelii.

Patria. Per totam Germaniam (et forsan quoque Europam ) haud raro. - Var. $\beta$. pr. Neobrandenburgum Duc. Mecklenburgensis: Schultz; pr. Bipontem: Bruch ; pr. Adersbach tract. Hhen. et in Togesis. - Var. $\gamma$. in Hb. Keg. Berol. a Cl. Funk in locis non indicatis collecta. - Var. $\delta$. prope Berolinum: Thiele in Hb. Reg. Berol., et in Duc. Mecklenburgensi: Blandow. In Hercynia legit Persoon.

Cellulae ramorum inanes.

Habitus inter Sph. cymbifolium et compactum. A primo jam differt foliis omnibus truncatis marginatis falcatis. A secundo foliis peduncularibus truncatis, eorum structura et toto habitu facillime distinguitur.

15. Sph. Pappennum C. Müll. (mst.); elatum robustum, ramis dense approximatis patentibus strictis crassis, comalibus densissimis brevibus; folia caulina ovalia suboblonga, e cellulis ex parte repletis, ductibus homomorphis interpositis, angulato-serpentinis amplis formata; ramea e basi ovali erectâ suboblique oblonga subinvoluta, laxe imbricata squarroso-patula, apice valde truncata 5-7 dentata, e cellulis angulato-serpentinis amplis brevibus composita; peduncularia maxima latissime-ovalia apice valde truncata c. 7 dentata, latere et basi e cellulis inunibus elongatis, ductibus subhomomorphis interpositis, upicem versus callinis similibus repletis constructa; theca comalis.

Patria. Prom. bon. spei prope Zwellendam ubi legit Pappe 1838. II b. Kunzeanum.

Cellulae ramorum inanes. 


\section{STEGOCARPI. ACROCARPI. SPHAGNUM.}

Sph. compacto ex habitu maxime simile sed foliis laxius imbricatis et peduncularibus truncatis notisque ceteris valde refugiens.

\section{Species incertae sedis.}

16. Sph. Trinitense C. Müll. (in litt. ad Cl. Crüger, detectorem 'Trinitensem); compactum humile; caulis gracilis tenuissimus ramis subulatis capillaceis; folia caulina longe oblonga erecta apice rotundato-truncata marginata concar'a, temuissime membranacea, e cellulis longissimis angustis, ductibus heteromorphis "latiusculis interpositis, textura rameorum, serpentinis formata, non scariosa; ramea longissima strictissima tenuissima e reliquis caulinis simillima, suprema valde truncata planissima laxe imbricata. Caetera desunt.

Patriu. Insula Trinitatis: Crüger No. 14. 1847 misit. Cellulae ramorum inanes.

Sph. laxifolio proximum, foliorum autem caulinorum structura et foliis rameis valde truncatis longissimis aliter reticulatis distinctissimum.

17. Sph. pulchricoma C. Müll. (in Hb. Brideliano inter Sph. squarrosum); elatum gracile; ramis remotis attenuatis elongatis curvatis deflexis laxe foliosis, comalibus squarroso-foliosis obtusis; folia caulina oblonga latissima apice rotundato-obtusa, utrinque basis e cellulis angustissimis dense, medio basis et apicem versus cellulis amplioribus brevioribus rhomboidalibus, omnibus inanibus, atriculo primordiali plicuto multiplicatis, ductibus heteromorphis interpositis, reticulata; ramea e basi ovali subcava attenuato-acuminata truncatula valde plana tenuissime marginata integerrima, e cellulis angulato-serpentinis vermiformibus angustioribus tenuibus formata. Caetera desunt.

Syh. squarrosum Brid. Hb. et Hsch. in Fl. Bras, Fasc. 1. p. 4. Spec. a Cl. Desvaux lecta.

Patria. Brasilia: Desvaux.

Cellulae ramorum inanes. 
Sph. chspidato quam maxime simile sed foliis caulinis utriculo primordiali multiplicatis et foliis rameis longioribus non usque ad apicem concavis sed e medio planis excavato-acuminatis distinctissimum.

18. Sph. ericetorum Brid. (1.p. 1\%.); caulis erectus simplex, ramulis uniformibus undique confertis deflexis tereti-attenuatis; folis rameis ovatis concavis acutiusculotruncatulis apice involutis integerrimis immarginatis patulis.

syluynum condensatum Brid. 1. p. 18. forsan huc pertinet. In Hb. Bridel. deficit.

Putriu. Insula Bourbonis in ericetis et humidiusculis planitiei des Chicots. In Hb. Bridel. a Cl. Bory de St. Vincent communicat.

Cellulae ramorum inches.

Species ex habitu inter Sph cymbifolium, ob ramos crassos robustos et $S p h$. molluscum, ob ramos molluscos flavescentes, ponendum. A primo differt folis truncatis, a secundo partibus robustis compactis. Species certe distincta sed valde incomplete nota.

Species noljis hand risae, incomplete descriptae.

1. Sph. Cupense IIsch. ( in Linn. XV. p. 113.); caulis erectus inferne nudus sublignosus rigidus superne ramulosus, ramulis subulatis fasciculatis quinis inaequalibus attenuatis, duobus longioribus recurvis, reliquis deflexis, foliis laxe imbricatis lato-ovatis apice subtruncatis tri-, rarius quinquedentatis concavis submarginatis, retis areolis oblongis.

Patria. Prom. bou. spei monte tabulari ad fontem: Ecklon; Dutoitskloof ad cataractam 1600' alt.: Drege.

2. Sph. truncatum Hsch. (1. c. p. 114.); caulis crectus laxissimus, ramulis $4-5$ inaequalibus, 2 crassioribus erecto-patentibus julaceis, reliquis deflexis, foliis arcte imbricatis lato-ovatis truncatis apice 8-12 duplicato-dentatis profunde concavis submarginatis, retis 
areolis serpentinis angustis basi latioribus apice brevioribus.

Patria. Prom. b. spei: in humidiusculis loci Dutoitskloofberg, alt. $3000^{\prime}$ : D r èg e.

Sph. cymbifolio ex habitu simile, caulibus autem flaccidis, foliis truncatis denticulatis et cellulis longis serpentinis valde diversum.

3. Aph. strictum Sulliv. (Nusc. Allegh. p. 49.); caulis erectus subsimplex rigidiusculus, ramulis $\mathbf{4 - 5}-$ natim fasciculatis, 2-aequalibus strictis obtusis horizontaliter patentibus, reliquis deflexis, fasciculis confertis; folia oblongo-acuminata recurva apice croso-6-9-dentata.

Patria. In Carolina superiore ad summum scopulum mirabilem Devil's Court-House dictum.

Sph. compuctum var. humile (Sph. humile Br. et Sch.)?

4. Sph. tabulare Sulliv. (1. c. p. 49.); pusillum; caulis erectus, ramulis substrictis acqualibus $3-4$-natim fasciculatis; fasciculis approximatis; folia orato-lanceolata reflexiuscula apice truncato $-3-5$-denticulata.

Patria. In locis irriguis ad latera scopuli 'Table Mountain dicti, Carolinae superioris, altitudine c. 2500 ped.

5. Sph. molle Sulliv. (1. c. p. 50.); tenellum, dense cespitosum; caulis erectus subindivisus, ramulis erectopatentibus confertissimis indistincte fasciculatis, foliis oblongo-ovatis apice eroso-3-5-dentatis.

Patria. In eodem loco ac praecedens.

6. Sph. Chinense Brid. ( I. p. 750.); caulis erectus simplex, ramulis fasciculatis $\mathbf{3}$ aequalibus attenuatis deflexis recurvis, foliis imbricatis ovato-lanceolatis acutis patentiusculis subrecurvis.

\$yhagnum. Herb. Candoll.

Patria. In Chinae aquis: Staunton.

Flegans, subpendulum, 8-10 unc. longum. Ramuli breviores, fasciculati, terni, fasciculis distantibus. Foliorum reticulatio Sph. capillifolii. 
Syh. squerroso proximum, forte illius forma peculiaris. - In Hb. Brideliano deficit.

Praecedentes species e promontorio bonac spei ac regno Sinensi descriptae forsan, Americanae vix novae. Nulla species acute distingui potest nisi e foliorum structura descripta.

B. Folia ductibus intercellularibus uullis.

I. Folia epapillosa.

1. Laxe areolata.

'Trib. XI. FUNARIOIDEAE.

Folia lato-ovalia spathulata, nervo laxo tereti praedita, e cellulis omnibus parenchymaticis magnis basi laxissimis parallelogrammis, apicem versus hexagonis v.polygonis laxis, granulis chlorophyllaceis suepe valde repletis, plus minus pellucidis composita. Theca pyriformis apophysata, cujus collum stomatiis plerumpe praeditum. Plantite acrocarpicae.

\section{Subtrib. I. FUNARIACEAE。}

Laxe cespitosac $\mathbf{v}$. gregariac terrestres, caulis laxifolius simpliciusculus. Inflorescentia monoica. Flos masculus disciformis plerumpue in ramo proprio radicali terminalis. Antheridia parva ovalia. Archegonia parva anguste apiculata. Paraplyses basi filiformes apice clavato-articulatae. Peristomium sin adsit, cartilagineum rubrum striatum, dentibus obliquis trabcculatis solitariis.

Inabitus proprius, hic et illic Pottiacerum, e thecae coloratae forma pyriformi folisque plerumque amoene viridibus mollibus speciosus.

Patriu. Per orbem terrarum totum, e planitiebus ad Alpes, sed raro, ascendentes, solum argillosum, arena- 
rium vel carbone vegetabilium mixtum vel turfosa praeferentes.

Funariacene auctor, et Bryol. Europ. fasc. XI.

\section{Gen. I. Fundia Schreb.}

Schreb. Gen. Pl. n. 1650 - Hedw. spec. Musc, et anct. rec. Koelreutera Hedw. Fund. Musc. II. p. 95. tab. 10. fig. 54-6il. Strephedia P. B Prodr. p. 89. - Mnium Limn. - Brynm Dill.

Nomen Schreberianum a fune desumptum, quod pedunculus in $\boldsymbol{F}$. hygrometrica lumiditate funis instar contorquetur.

Theca asymmetrica arcuata, orificio obliquo minimo; seta valde arcuata elongata maxime torlilis hygroscopica. Calyptra ventricoso-dimidiata (basi rotundato obtusa theca brevior vel major basi trulcata. - Peristomium duplex erectum; dentes externi 16 obliqui, lato-lanceolati subulati, trabcculati, apicem versus appendicibus instructi, apice disco reticulari frenati; interni totidem externis oppositi et basi adnati lanceolati granulati, linca longritudinali exarati. Opereuli cellulac apice circinalo-reticulatae.

\section{Peristomium internum imperfectum.}

1. F. mierostoma Br. et Sch. (Br. Gurop. Funariaceac. Funaria. Fasc. XI. p. 9. tab. 4.); glegarie cespitosa; folia ovalia acuminata, superiora conniventia majora longe acuminuta, integerrima valde concava evanidinervia; theca substriuta rufa subnitens microstoma, pedunculo valde incurvo crassiusculo operculoque minimo subconico instructa annulata; peristomium internum vix conspicuum dentibus externis adglutinatum nonnunquam in processus productum.

Patria. Locis arenosis humidis: ad viam Splügenstrasse prope Andeer Rhactiae: A 1. B r a un primus detexit. Ad rivulum Tamina retro Vätis Rhactiae: Br. et Sch. - Normandia prope Falaise: de Brébisson. Versus finem uestatis. 
Habitus formae minoris $\boldsymbol{F}$. hygrometricue sed notis illustratis constanter differt.

\section{Peristomium exacte duplex.}

a. Theca striata.

2. F. Hygrometriea Hedw. (Sp. Musc. p. 172.); subsimplex, densiusculo cespitosa; folia caulina inferiora sparsa recurva, perichaetialia connirentia imbricata lato-oculiTanceolata conca'a integerrima, nervo excurrente, perigonialia apice denticulata; theca magna valde incurra pyriformis striata, sicca plicata in pedunculo valde tortili, annulata, operculo conico-hemisphaerico.

Brid. II. p. 51. - Bryol, Europ. I. c. p. 8. tals. 3. - Strephedium hyyrometricum P. B. - Koetreutera hyyrometrica Hedw. Fund. Musc, I. tab. V. fig. 21. 26. II. p. 95. tab. 3. fig. 11. tah. 5. fig. 25. 26. tab. 6. fig. 27. tab. 10. fig. 58-61. - Mnium hygrometricum acaule anthera nutante, calyptra reflexa tetragona Limn. Sp. P1. p. 1575. - Bryum hyyrometricum Neck. Method. p. 221. Bryumb bulbiforme aureum, calyptra quadrangulari, capsulis pyriformilus nutantibus. Dill, Muse, p. 407. tal. 52. fig. 73. - Funaria audrogyna Brid. 1I. p. 58. Vix varietas nominari potest, quum inforescentia monoica sit generis vera. - Fun. campylopus Brid. 1. c. p. 739. - Fun, ramificens Brid. 1. c. P. 738. - F'un. angustifolia Brid. .1. c. p. 58. -

ß. putulu; caule gracilescente ramoso ; foliis comalibus patentibus, margine flexuoso-undulatis, siccitate contortis.

Patriu. Per totum orbem terrarum praeprimis locis exustis, in muris, ad rupes et saxa unbrosa. Var. $\beta$. in locis humidis. Aestute. $\subseteq$ -

3. F. calveseens Schwägr. (Suppl. I. P. II. p. 77. tab. 65.); laxe cespitosa; folia inferiora remota, perichaetialia patulu longe spathulata aculiusculu, marginibus Aexuosis, integra nervo ante apicem evanido instructa; perigonialia obtusa brevissime acuta apice subdenticulata; theca in pedunculo longo stricto e collo angustissimo oblique myriformis erectu parru, opeveulo (pro theca parva) magno hemisphaerico instructa annulata.

Brid. Br. univ. 11. p. 53 et 739. - Fun. hygrometrica \% calvescens Bryol. Furop. 1. c. p. 9. tab. 3. fig. $\gamma$. et auct. mult, recent. - r. Aavicans Hb. permult. 
B. crispu; gracilis foliis siccis ac madidis crispatissimis acutis evanidinervibus.

Patria. Per terras tropicas vulgare. Var. $\beta$. in Chiles republica: Pöppig. Hb. Kunzeanum. (- et $\odot$ ?

Praecedenti maxime similis sed theca constanter erecta angusta pedunculo stricto pracdita parva ab eadem recedit. Bene scientes, auctores plurimos hancce speciem praecedentis formam tropicam putasse, ex novis observationibus tamen nobis persuasum est, comprobandam esse, quum notae illustratae constantes et in regionibus tropicis Funaria hygrometrica ipsissima quoque observentur.

4. F. flavieans Michaux (Richard flor. boreal. Amer. II. p. 303 ); laxe cespitosa gracilis; folia caulina inferiora remota, superiora perichaetialia spathulato-ovalia lata subconniventia integerrima nervo excedente longissime cuspidata, e cellulis densiusculis minus amplis basi longissimis angustissimis apice multo minoribus formatu; perigonialia apice subdenticulata; theca pedunculo longissimo flavido substricto et collo brevissimo praedita subglobosa matars flarida ore purpurea, operculo conico hemisphacrico flavido parvo.

schwägr. Suppl. I. P. II. p. 75. tah. 65. - Brid. II. p. 54.

ß. humilis; folis valde conniventibus, pedunculo brevi ct theca minori. Schwägr. 1. c. fig. 1. specimina duo ad dextram depicta.

Patrie. Carolina: Fraser, Michaux et Bosc primi legerunt. In Florida. In herbariis vera raro occurrit!

$F$. hygrometricue similis quidem, sed tamen characteribus illustratis optima species. Theca non, ut illa pedunculo arcuato, pendula sed in pedunculo stricto nutante primo adspectu facillime distinguitur.

\section{Species nobis haud visa.}

1. F: obtuaifolia Weinm. (Syllab. Muscor. p. 438.); caule erecto ramoso: ramis confertis; folis omuibus imbricatis, inferioribus lanceolatis acutiusculis, superioribus - latiuscula basi lineari-lingulatis obtusis integerrimis; 
nervo crasso subcontinuo; theca pyriformi incurva laevi; operculo convexo brevi-mammillato.

Weinmann in Syllal. Muscor. frondosorum lucusque in imperio Rossico collectorum in Bulletin de la soc. impér. des naturalistes de Moscou 1845.

Patria. In turfosis humids ad fretum Sinjawin (Asiac septentrionalis) et in iisdem locis, sed parum major, in Gubernio Olonetziano. Hb. Ac. Sc. Petrop.

Caulis 3-6" Iongus s. parum altior. Rami simplices, dense foliosi. Holia sacpe convoluta plus minus obtusata, lineari-creolata. Nervus nunc excurrens, nunc subito infra apicem evanescens, satis crassus obscurius coloratus. Perichactialia interdum paulo longiora, ceterum caulinis similia. Seta ex apice ramulorum solitaria $1-11 / 2^{\prime \prime}$ longa stricta, sicca parum tortilis brunnea aut versus apicem aurantiaca. 'Theca obliqua pyriformis, parum arcuata laevis, senior tuntum irreguluriter corruguta flavescens, maturitate nitida. Peristomium duplex; externum: dentes 16 anguste lanceolati horizontaliter trabeculati brunnei incurvi; interius: totidem paulo breviores, fere lineares obtusiusculi, dilute colorati. Operculum convexum breve mammillatum.

H. theca seniore irregulariter corrugata al Funurius thecis striatis pertinere videtur, nobis tamen dubia.

\section{b. Theca lneris.}

5. T. Mühlenbergii Schwägr. (Suppl. I. P. II. p. 78. tab. 66.); densiusculo cespitosa humilis; folia inferiora remota, perichaetialia rosulata lato-ovalia subito longissime acuminata pilifera nerro infru apicem e'unillo apicem versus obsolete denticulata; theca clavato-pyriformis erecta collo et pelunculo brevi stricto sicco dedroursum torto proditu pallida ore purpurea, exannulata, operculo conico pallido.

Brid. H. p. 55. - Bryol. Finrop. 1. c. p. 6. tab. 1. - Funaria calcaren Wahlenb. in Nov, Act. Holm, 1406. tab. 4. fix. 2. - Bryum funerioides Brid. Matnt. Musc. 1. 120. et Bryol. univ. 11. 17. $55 .-$

ß. patula, foliis brevi-acuminatis patulis subintegerrimis. $I$. neglecta De Notaris mst. F. Fontanesii Bruch olim in Musc. Sard. Müllerianis. 


\section{$\gamma$. flaccida, foliis longioribus flexuoso-tortilibus.}

Patria. In America septentrionali: Pensylvania; M üh lenberg primus detexit. In muris calcareis argillosis vinearum prope Durlach mag. Ducat. Badensis: A. Braun; locis similibus prope Zillisheim Alsatiae sup.: Mühlenbeck. In Tiroli prope Klausen: Send tner. - In Scandinariae Gottlandia ex obs. Cl. Angström in El. Fries Summa Veget. Var. $\beta$. et $\gamma$. in Sardinia: Fr. Müller; in Gallia meridionali: Salzmann; prope Vaucluse: C. Schimper; in Mauritania prope Tanger: Salzmann; in Asia minori prope Smyrnam: Fle ischer. Vere. $\odot$.

Dentes peristomii minus obliqui quam in praecedentibus. Sequentibus proxima sed notis editis facile cognoscitur.

6. F. Hibernica IIook. (in Fl. Lond. ed. 2. c. ic.); cespitulosa humilis; folia inferiora remota, perichaetialia lato - ovalia sensim longissime acuminata exanidinevina argute serrata; theca exannulata clatuto-pyriformis erecta collo brevi, pedunculo sicco sinistrorsum torto, brevi stricto operculoque conico praedita pallida.

Hook. et Tayl. Muscolog. Britannic. Lond. 1818. p. 70. tab. 20. - Brid. 11. p. 5̈6. - Bryol. Europ. l. c. p. \%. tab. 2. - Funuria Mühlenbergii Wels. et Mohr. Bot. Taschls. p. 380. - Fun. dentata Crome 3. 12.

Patriu. In editis Zippendorfensibus prope Schwerinum, ubi in locis umbrosis arenariis primi legerunt W eber et Mohr. - In rupibus arenariis Franconiae: Funk; in iisdem,locis prope Gressweiler Alsatiae: Kneiff; in olivetis prope Varennam ad lacum Comensem vulgatissima: W. P. Schimper; in monte "au vieux chàteau" prope Martigny Valesiae: Idem; in monte Salève, loco praerupto „pas de l'échelle" dicto prope Genevam: M ühlenbeck. In tuguriorum tectis Hiberniae loci Blarney prope Cork: Drummond. In Ilercynia inter Rübeland et Königshütte: II a mpe. Incunte aestate. $\odot$.

F. Mühlenbergii proxima, differt autem magnitudine proceriore foliis sensim acuminatis longioribus, argute serratis, serraturae dentibus acutis, pedunculo siccitate om- 
nino sinistrorsum torto sinistrorsumque convoluto, theca longiore minus inflata. An characteres constantes?

7. Ferratn Pal. Beauv. (in Brid. Bryol. univ. II. p. 57. et in Mant. Musc. p. 124.); folia inferiora oblongoacuminata, superiora spathulato-acuminata, acute serrata subtortilia; theca cxannulata subarcuctu, sporangio globoso, collo longione, operculo plano-comere, pedunculo sicco dextrorsum torto, peristomio sublepresso. $\div$.

Bryol. Europ. I. c. p. 8, tab. 3.

Patril. Ad fossarum margines Sardiniac: Fr. Müller. In Pensylrania Palisot de Beauvois detexit. Ineunte cestute. $\odot$

Pracedenti simillima, sed thecae forma, sporangio, operculo plano non conico acuto et peristomio subdepresso distincta.

8. Fhyscomitrioides Mont. (in ann. d. sc. nat. I'om. XVI. 1811. p. 253.); dioica; caulis erectus simplex; folia crecta oblonga acuminata, acumine filiformi tertam folii partem acquante breviorique, nervo ad apicem percurso, integerrima tenerrima flaccida, grosse reticulata, siccitate crispula; pedunculus flexuose erectus apice dextrorsum tortus; theca exannulata crecta pyriformis basi plicata cacterum laevis, operculo planissimo; peristomii exterioris dentes apice non cohuerentes imegulaves conslricto-articulati, interioris punctulati. $\uparrow$.

Funaria submeda Tayl. in Lond. journ. of bot. 1846. p. 57. ex ohservationih. Cl. Wilson (I. c, p. 451.) huc pertinet varietas foliis minus acuminatis.

Petria. Ad terram circa lioitie in montium Nilaghiriensium stris siccis: Perrottet. - E Nora Hollandia ad flum. Swan River lectum habuit Taylor.

Folia fere $F$. flavicuntis, sed theca erecta exannulata aliaeque notac ab ca hance speciem removere suadent. A $F$. Fonturesii differt imprimis ut Physcomitrium Bonplandii a Ph. fasciculari, operculo scilicet planissimo.

An inflorescentia revera dioica? 
9. F. Fontanesii Schwägr. (Suppl. I. P. II. p. 80. tab. 66.); folia inferiora remota, superiora rosulata oblonga acuta serratu margine flexuosa tenerrima, nervo infra apicem evanido, laxissime areolata; theca erectiuscula elonguto-pyriformis laeviuscula forsan exannulata.

Brid. II. p. 56 et p. 739. - schwägr. Sp. Musc. 1830. p. 46.

Patria. In Barbaria lectam Schwägrichenio communicaverunt Desfontaines, ex Acgypto allatam Persoon, Lusitanicam Sprengel. E regno Chilensi Bruch et Schimper habere dicunt Bryol. Europ. l. c. p. 5. Specimina Brasiliensia a Cl. Persoon communicata in Ib. B ridelii vidimus. Differunt autem operculo valde conico, dum auctor parum convexum (Suppl. I. P. II. P. 80.) descripsit.

F. Mïhlenbergii proxima sed foliis acutis, non longe acuminatis, serratis; theca longiore et peristomio breviore differt. An hi characteres sat distinguentes sint, dubitamus. Forsan forma $F$. Miihlenbergii? Auctor tamen (Spec. Muscor. p. 46.) thecam maturam et siccam sulcatam descripsit. Theca immatura per siccitatem ita contrahitur, ut omnino erecta et potius Splachno similis videatur.

10. F. glabra Tayl. (Lond. journ. of bot. 1816. p. 5\%.); folia superiora in rosulam congesta erecta oblonso-obovata apiculata serrulata evanidinervia; theca brevi-pedunculata glabra ovata, hinc gibba illine declinata clongate apophysata, operculo plano mammillato praedita exannulata. $\leftarrow$.

Patria. Nova IIollandia ad flumen Swan River: J. Drummond.

Peristomium interius brevissimum e laciniis valde irregularibus 16 formatum. $\boldsymbol{F}$. Fontunesii proxima, foliis autem latioribus longius acuminatis praecipue peristomio interno brevissimo distinctum.

Species nobis nomine tantum nota.

1. F. mueronata IIartm. in Summa Vegetabil. Scandinaviae auctore El. Fries a Cl. A ngström in Norvegia lecta memorata (p. 88.). 


\section{Gen. II. Pyramidinm Brid.}

Bryol. univ. I. p. 107. - Pyramidula Brid. Mant. Musc. p.20. Bryol. Germ, I. p. 85. - Physcomitrium Fiururohr. Ilampe. Bryol. Europ. Funariaceae. Fasc. XI. - Physcomitrium Puramidula C. Müll. in Liın. XVIII. p. 694. - Gymnostomum Schwägr. et mult. al, anct. prior.

Nomen Bridelianum, e forma calyptrae pyramidali desumptum.

Calyptra tetragona pyramidata apiculata, basi integra, thecam longe superans totam obtegens inflata persistens, medio latere rumpens magna. Theca symmetrica erecta pyriformis pperistomata. Operculum regulariter areolatum.

Ex omnibus partibus Funariacearum habitum referens, e calyptrae forma autem inflato-persistente medio latere rumpente Colymperium congeneres in memoriam redigens et nota hacce excellentissima a Physcomitriis atque Entosthodontibus distinctissimum.

1. P. tetragonum Brid. (I. c. p. 108.); gregarium humillimum subacaule; folia densissime imbricata e basi latissima concava lato - cuspidata, nervo crasso longe subexcurrente praedita, integra arctius areolata; theca brevissime pedunculata, operculo conoideo obtuso.

Pyramidula tetragona Brid. Mant. Mnsc. p. 20. - Bryol. Germ. 1. c. p. 86. tab. 8. fig. 1. - Gymnostomum tetrayonum Schwägr. Suppl. I. P. I. p. 22. tal. 8. - Gymn. pyriforme juvenile Voit. Musc. Herbipol. p. 17. - Physcomitrium tetragonum Fürnr. Hmp. Bryol. Europ. I. c. Physcomitrium p. 9。 tab. 1.

Patria. In 'Thuringiae agris suburbicis circa Gotham et Erofurtum: Bridel primus detexit. Ad pedem Montis Piniferi Franconiae prope Berneck: Funk. Pr. Ratisbonam: Limmerich; pr. Neovidam tract. Khen.: Bre utel. Prope Blankenburgum Ifercyniac ad ped. loci Regenstein: II a mpe. - In Smolandia (Gothiae) et propo Upsalam Sueciae: Âng ström. - In agro Taurinensi: De Notaris. - Species in iisdem locis per plures (sicriores) annos interdum non occurrens. - Primo vere. $\odot$.

C. Mi iller: Synopw. musc, frond. 


\section{STEGOCARPI. ACROCARPI. PHYSCOMITUUY.}

Planta mascula ad pedem femineae parva gemmacea foliis patentibus imbricatis. - Calyptra decidua planta ex habitu Physcomitrico sphuevico ". acuminato valde similis sed quoque calyptra deficiente foliis multo densius areolatis, e cellulis granulis chlorophyllaceis valde repletis compositis longe cuspidatis excurrentinervibus primo intuitu cognoscenda.

\section{Gen. III. Physcomítrium Brid. emend.}

Br. un. I. p. 97. - Hmp. Bot. Zeit. 1837. - Bryol. Europ. Funariaceae. Fasc. XI. - Gymnostomum anct. permult. prior.

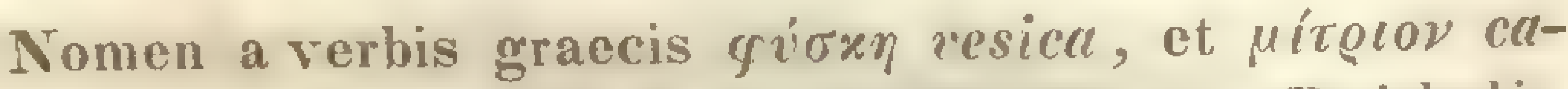
lyptra ob calyptram primam resiculiformem; a B ridelio congeneribus tam hujus generis quam Entosthodontibus eperistomatis impositum, a nobis speciebus sequentibus servatum.

Calyptra mitraeformis busi in pluries lacinias latas inferne integras fissa, theca multo brevior, longe apiculata. Theca symmetrica recta pyriformis eperistomata. Operculum regulariler areolatum.

Congeneres omnes luc in gentus proprium redacti ab omnibus auctoribus prius cum specicbus, calyptra dimidiata instructis eperistomatis, generis sequentis conjuncti sunt. Genus igitur hucusque confusum fuit. Qua de causa nomen Physcomitrii Brideliumum praeferimus, quum nec Bridel, nec auctores ceteri genus clare intellexerint, primus autem, Physcomitria a ceteris Gymnostomis distinctissima esse, jam optime observarerit et (Bryol. unir. I. p. 103.) hanc sententiam acute extulerit, indice tandem (p. 815.) nomen Physcomitrii proprium dederit.

1. Ph. acuminstum Br. et Sch. (in Bryol. Europ. Funariac. Physe. 1841. p. 11. tab. 3.); parce ramosum humile; folia ovato luneoluta nerro crusso longe excurrente acuminutu strictu integerrima vel subdenticulata; theca brevis subgloboso-myriformis orificio lato, operculo convexo recte apiculato. 
Gymnostomum acuminalum schleicher Catal. Plant. Helvet. p. 40. - Gilmm. Iatifolium Hook. in Urumm. Musc. Amer. No. 16. et schwägr. suppl. IV. tah. 304. - Physcomitr. Hookeri Hup. in excus. in Physc. Thieleanum in Ic. Musc. Froud. nov, v. min. cognitor. - Gymnostomum eurystoma N. ab Fis. mst. - Physcomitr. eurystoma sendtn. in Denlischriften der Königl. Baierisclien bot. Gesellsch, zu Regensburg. 3. Bd. 1841. p. 142, variet. foliis distincte sed obtuse denticulatis.

Patria. In limosis Helvetiae (ubi?) Schleicher primus detexit. - In fossis ad piscinas Giersdorfenses in valle Cervimontana Silesiae: Nees ab E. legit Sept. 1834. plantam finclificantem. - Prope Tratislaviam: Wimmer. - Prope Cervimontium Silesiae: v. Flotow. - Prope Niederleipe in ricinitate Javorii in piscina exsiccata: Sendtner. - In America septentrionali: Low points of the Kiver Saskatchawan pr. Carlton House: Drummond No. 16. - Auctumno.

Ph. mriformi proximum, folis autem longius cuspidatis plermmque integerrimis angustioribus excurentinervibus, theca sicca ore amplissima sporisque duplo majoribus differt. E rarissimis!

2. Ph. sphnerieum Brid. (I. p. 97.); humile; folia ovali - oblonga subspathulata obtuse-ucuminatu margine crenulata patentia; theca obsolete pyriformis hemisphuevicu paru stomate amplissimo, operalo magno convexiusculo brevi acuminato et pedunculo temissimo siccitate sinistrorsum torto praedita.

Gymnostomum sphaericum schwägr. in schraders Journal IV. p. 15. c. ic. et in silppl. I. P. I. p. 21. tab. \&. Bryol. Germ. I. p. 124. tal). 9. fig. 3. - Gymenost. Physe. sphaericum Brid. I. p. 97. Physcomilrium sylhaericum Hmp. Regensl). bot. Zeit. 1837.

B. cullescens; foliis patulis remotis latioribus, caule graciliore.

Patria. In solo argilloso prope Dresdam primus legit Ludwig. Per totam Europam temperatam sed nusquam vulgare! Auctumno. $\odot$.

Ex habitu Pottiue truncutue maxime simile sed notis illustratis facillime cognoscendum. E locis diversis magniludine partium omnium valde varians. 


\section{STEGOCARPI. ACROCARPI. PHYSCOMITHIY.}

3. Ph. Thieleanum IImp. (in Ic. Muscor. Fr. nor. r. min. cognit. tab. 30.); subsimplex; folia complissime cellulose oblonge-ovata lanccolata acula dentata, nervo crasso ante summum apicen evanido; theca brevi-pyriformis, deoperculata amplissime cupularis maxime truncatu et urficuluto-apophysatu operculo conico apiculato; calyptra junior mitraeformis.

Fetrill. Brasilia: Monte Video uhi legit Sellow.

E thera maxime truncata hemisphacrica ad Ph. spliclericum accedens sed folis acutis jam distinctum. I Ph. ferminalo statura robustiore folisque evanidinervibus acutis, non longe acuminatis, valde dentatis cellulis amplissimis laxissimis instructis valde refugit. Ex habitu Ph. pyriformi simile sed foliis acutioribus et cellulis, tanlem thecae forma distinctissimum. Inter Ih. sphuericum et Ph. pyriforme intermedium.

4. Ph. pyriforme Brid. (Br. univ. I. p. 98.); late cespitosum robustum; folia caulina inferiora remota ovatolanceolata, superiora sputhulato-rel shonguto-lunceolata pridenter servalu concava, nevero ante apiesm erenido; theca ampla pyriformis, operculo e basi subplana obtuse upiculato.

Bryol, Fump. 1. c. p. 11, tah. 2. et Ilmp. Regensh. but. Zeit. 1837. - Gymnostomum Physcomitrium mifinme Brid. 1. c. p.98. - Gymnostomum pyriforme Hew. Fund. Missc. II. p. \&7. et Brgol. Germ. I. p. 14. tal). 10. fig. 11. - Gymnostom, splachnoirleumb P. B. Prodr. p. 59. - Gymn. Physc. splachnoideum Brid. I. p. 99. Gymn. dilututum P. B. Prodr. p. ป9. - Gymm. turhinatum Rich, in Mich. Fl. Amer. sept. II. p. 2Rf, - Gt/mn. Ph!/sc. turlinatumb Brid, I. p. 100. - Gymn. Physc. tortiples Brid. 1. p. 100. - Pottia my/ri-

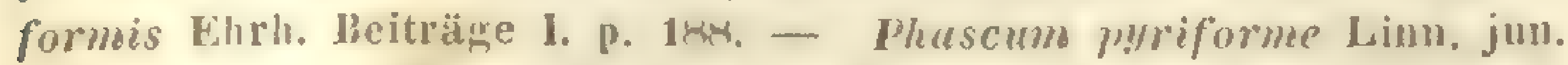
Meth. Musc. P. 361. - Bryum myriforme, antheris erectis ohovatis, calyptra subulata, surculis acaulilus, folis ovatis muticis. Linn. \$p. Pl. p. 1580. - Bryum serpyllifolium, pellucidum, capsulis pyviformibus. Jill. Musc. p. 345. tals. 44. fig. 6. L.

Putria. In limosis, agris et pratis humidis totius fere Furopae et Americac septentrionalis. Vere. $\odot$ 
Species calyptra ignota igitur inceri

$$
\text { generis. }
$$

1. Ph. Eerrottetii Nont. (in ann. d. sc. nat. Yom. XVI. 1811. p. 256.) ; parvulum suburaule; folia orata uenminala in bubum oxtum combentia, exteriora broviona seminervia, intima longiora nereo excurvente cusplulutu; theca concinne pyriformis erecta lacris ore angusto opercuJoque plano. $\leftarrow$.

Putrile. Juxta vias et semitas ad terram humidam circa Koitie in montibus Nilaghriensibus: P'erot tet.

Folia radicalia apice quandoque grosse dentata, ac si crosa fuissent, exteriora minora, nervo dimidiato insignia, interiora s. perichactialia grandiora nervo cuasso virili excurrente cuspidato. Retis areolac clongato-quadratac, limitibus crassis. Pedunculus brevis dextrorsum tortilis. Calyptra generis, straminea. (An dimidiata? An mitracformis?). Folia perigonialia caulinis simillima.

Th. Bomplandii quam proximum, sed caulc subnullo, foliis excurentinervibus cuspidatis nec non alis notis certe diversissimum.

2. Ph. Drbignianum Mont. (Voyage daus l'Amérique mér. par d'Orb. 'T'om. VII. Cryplog. p. в7. c. ic.); caulis erectus longissimus cespitosus simplex r. ramosus; folia e basi amplexicauli slonguto - lanceoluta ucumimata dentuto-spinosu rarinutu undulutu erecta v. reflexa, siccitate crisputo-imroluta, nervo ultra medium subcontinuo; thecae turbinato-obconicae operculo plano $v$. convexiusculo-mammillato. $t$.

Gymnostomum Orbigniunum Mont, in anu. d.! sc. natur. 1837. Vo1. VIII. p. 51.

Patria. America meridionalis in provincia Corrientes ad terram arenosam in collibus sylraticis secus flumen Sanctae-Luciac: d'Orbigny. 4 ? Junio.

Ph. Iyriformis formas elongatur Ph. turbinato simile ab eodem autem et onnibus congeneribus altitudine foliis ferc ut in Mnio spinoso dentato-spinosis, siccis crispato- 


\section{S'TEGOCARPI. ACROCARPI. PHYSCOMITRIT.}

inflexis operculoque plano mammillato nec convexo-umbonato diversum.

3. Ph. Eonplandii Brid. (I. p. 101.); caulis humilis subsimplex gregarius; folia inferiora remota, superiora et perichaetialia rosulato - patentia flarescentia oblongo ovalia apice carinato - concava acute acuminata, nervo evanido crasso fermgineo ante apicem abrupto praedita, e cellulis-laxis sed minoribus reticulata, apice dentata reflexiuscula s. inflexiuscula; theca anguste-pyriformis stomate purvo praedita, longe-pedunculala omnino rufa; operculum (ex observ. Bridelii) planiusculum.

Gymnostomum Physcomitrium Bonjlandi Brid. l. C.

Patria. America meridionalis ubi in locis non designatis legerunt II umboldt et Bonpland. F regno Chilensi in terra arenosa crescens misit philippi: Hb. Reg. Berol. $\odot$.

Species optima ex habitu Entosthod. ericetorum simillima sed foliis immarginatis distinctissima. Ab omnibus congeneribus theca subcylindrico - pyriformi ore angusta et arcte apophysata igitur obovata $E$. ericetorum perfecte simili facillime distinguenda. - Folia interdum subintegra seu obsolete denticulata. Calyptra verisimiliter dimidiata quum planta cum Eut. ericetorum valde conveniat; Eutosthodon igitur erit.

4. Ph. spathulatum C. Müll. (Linn. XV'III. p. 695.); caulis subramosus erectus; folia inferiora remota superiora laxissime imbricata haud rosulata longe-sputhuluto-outulia acuminata evanidinervia e cellulurum serie unicu valde elongutarum flarescentium submarginatu apicem versus denticulata; theca inaperta globoso-pyriformis operculo hemisphuerico-brevi pedunculoque brevi praedita, aperta cyuthiformis ore amplissimo instructa sublongicolla.

ß. brevicollum; foliis latissimis valde dentatis laxissime areolatis theca brevicolla amplissima. (Iymustomum spathulatum verum II or in sch u chii in Linn. 1841. p. 115. descriptum. 
Patria. Prom. bon. spei: Philippstown: Pappe, Ecklon. Var. $\beta$. in iisdem locis. Inter Key et Bosche in locis humidis umbrosis in rivulo exsiccato legit primus omnium Drège Junio 1832. C. IIb. Kunz.

Ph. myriformi simillimum foliis autem submarginatis thecaque minori maxime truncala amplissima cyathiformi operculo obtuso-conico instructa distinctissimum.

5. Ph. Jamesoni Tayl. (Lond. journ. of bot. $184 \%$ p. 329.); caulis brevissimus erectus subsimplex; folia erecta ovato-Janceolata acuminata concula morgine incurec integerima evanidinervia; theca erecta obovata subapophysata operculo minuto plano, ore membrana opace rufobrunnea, e cellulis irregularibus formata, praedita. $\uparrow$.

Patriu. In Pichincha prope Quito Andium: W. Jameson Novbr. 1846.

Entosth. "ipophysuto proximum sed foliis magis erectis brevioribus latius acuminatis differt.

\section{Species nobis incerta.}

1. Aymnostomum Jamesoni Walk. Arnott. (in Wern. Transact. V. p. 200.); folia late lineari-lanceolata margine convoluta integerrima, siccitate incurvo-tortuosa; nervo excurrente; theca turbinata ore amplo, operculo rostrato urna longiore praedita examnulata. $\div$.

Walk. Arm. Mém. de la Soc. d'llist. nat, de Paris I. p. $\mathbf{3 4 7}$ Disporit, method, des Esprèces de Mousses p. 10. - Hormich. in F'. Bras. Hasc, 1. p. 4.

Putria. Brasilia in collibus prope Sebastionopolin: James on.

Cl. M o n t g gue (Aun. d. sc. nat. Tom. VIII. $183 \%$. p.51.); Physcomitrii Orbigniemi affine nominavit, ex qua ratione, hane speciem ad Funariaceas adducendam esse, elucere videtur. Cl. II or ins chu ch (1. c.) Gymnosfomi tortilis varietatilous majoribus sat similem at foliorum thecae el operculi figura distinctam descripsit. An huc pertincat? Judicium non habemus. 
Gen. IV. Entósthodon Schwägr. emend.

Suppl. 1I. P. I. p. 44. - Brid. Br. univ. I. p. 378 et $779 .-$ Bryol. Europ. Funariaceae. Fasc. X1. Entosthodon. - Gymostomum auct. - Physcomitrium al. - W'eisia Hooker et Tayl. Hornsch. - Bergia Fiurnrohr. - Desmostomum Hsch. - Funaria Engl. Bot. Smith.

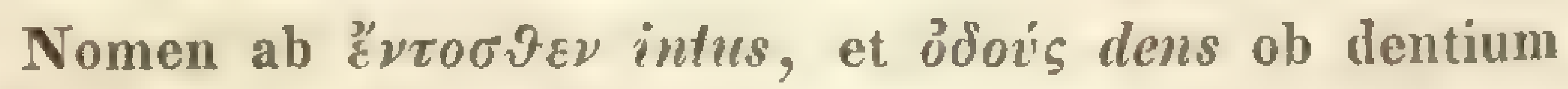
peristomii insertionem deductum.

Calyptra vesiculari-dimidiata longe apiculata, integra rotundata seu truncata fissilis. Theca symmetrica pyriformis recta vel pedunculo arcuato declinata peristomata vel peristomio nullo. Peristomium, sin adsit, horizontale siccum erectum, simplex, internum nullum vel vix conspicnum e laciniis brevissimis constructum. Dentes lanceolati exappendiculati, simplices vel gemelli, extus plani, inter trabecnlati apice plerumque obliqui conniventes sed non connati. - Operculum regulariter areolatum.

Congeneres eperistomati prius Physcomitria nominati sunt; e calyptrae forma autem ab Entosthodontibus nunquam discerni nequeunt.

\section{Eperistomati.}

1. E. Paseiculare C. Müll. (mst.); gregarius; folia inferiora remota, superiora subrosulata ocato-oblonga acuminata vel late lanceolata margine serrata nervo ante apicem evanido; theca perfecte pyriformis ampla erecta operculo convexo; calyptra inflato-cucullata basi rotundata.

Physcomitrium fasciculare Bryol. Europ. 1. c. p. 13. tab. 4. Hampe in Regensh. bot. Zeit. 1837. - Gymnostomum Physcomitrium fasciculare Brid. I. p. 101. - Gymm. fasciculare Hedw. sp. Musc. p. 38. tab. 4. fig. 5-8. - Bryum fusciculure Dicks. Fasc. 111. PI. Crypt. p. 3. talı. 7. - Br. Aegypti Hasselq. It. p. 502. e Smithii auctoritate, Mohro nerante. - Hyssopus sulomonis Hassel@. It. p. 614. Her\%. Limn. - Bryum serpyllifoliun pellucidum, capsulis pyriformilus, Dill, Muse, p. 345. tal), 44, fig, 6. A-K. 
Patria. In campis et aggeribus argillosis per totam Europam. Vere. $\odot$.

Locis siccioribus pedicello incurvo vel arcuato occurrit. Bryol. Europ. p. 10.

2. E. curvisetus C. Müll. (mst.); cespitosus; folia inferiora remota, superiora subrosulata sputhuluto-acumimutu serrata, nervo ante apicem evanido; theca pyriformis longicolla in pedunculo arcuato pendula, operculo convexo-plano, et calyptra longiore busi truncutu inflata.

Physcomitrium curvisetum Bryol. Europ. 1. c. p. 10. tab. 4. Hampe in Regensi. bot. 7seit. 1837. - Gymnostomum Physcomitrium curvisetum Brid. I. p. 103. - Gymostomum curvisetum scliwägr. Suppl. 11. P. P. 17. tah. 105.

Patric. In terra argillosa praeprimis novalium Sardiniae, Siciliae, agri Neapolitani et Romani, Normandiae, Franconiac prope Kulmbach: Funk. In Algiria ad terram collium occidentalium mense Februarii legit $W$. Schimper. Primo vere. $\odot$.

Species optima, ab omnibus congeneribus ceteris theca pedunculo arcuato declinata distinctissima.

3. E. Iottleri C. Müll. (mst.); cespitosus; folia inferiora remota, perpauca, superiora subrosulata patula erecta spathulata nerro fermginen excedente longe-cuspidute denticulata; perigonialia longissime cuspidata subintegra angustiora undulata; theca pedunculo suburcueto breli clacuto-myriformis longicolla, operculo planiusculo parvo calyptra basi truncata.

Physcomitrium Rottleri IImp. C. Müll. in Linnaea X'HIt. D. 696. - Rotlleria g!mmostomoiles Brid. 1. p. 105. - Gymnostomum Rotlleri schwïgr. Suppl. I. P. 1. p. 24. tal). 3.

Patria. In muris lutosis 'Tranquebariac primus legit Rottler. In promontorio bonae spei non raro: Ecklon, Mundt, Pappe.

E. curriseto proximus, folis autem longe cusyridatis excurrentinervibus thecaque subarcuata longiore longicolla ab codem ceterisque Lntosthodontibus sat diversus. 
4. W. ericetorum C. Müll. (mst.); greggrius; folia inferiora remota, superiora patula ocali-lanceolata acute interdum longe acuminata marginata dentata flarescentia evanidinervia; theca purve ovelis vix pyriformis ore angusto operculoque convexo interdum mammillato praedita; calyptra basi rotundata.

Physcomitrium ericetorum Bryol. Europ. 1. c. p. 13. tals 3. physcom. Bonplandi De Notaris Syllab. Musc. p 2x3. - Gymnostomum Ahufeltii F'ries Novit, et in Hartm. skand F', ed. IIL. p.263. - Gymnost. fasciculare Hook. et Tayl. Muscol. Brit. p. 23. tab. 7.

- Gymnost. obtusum savi Bot. etr. 3. p. 32 *. - Gymnost. ericetorum Bals, et De Not. Pugill. n. 27.

Putria. In ericetis humidis. Germania: prope Jeveram Ducat. Oldenburg., Bonnam, tract. Khen., in Ilassia superiore. Alsatia prope Gebweiler. Atalia: prope Mediolanum, in agro Taurinensi, in Etruria. Corsica. Sardinia. Ilibernia. Skandinavia. Gothia (Smålaudia): A hnfelt. Junio. @.

Ab onnibus congeneribus ceteris foliis perfecte marginatis valde differt. Species foliis flavescentibus thecaque parva pulchre rufa perbella.

5. E. Taylori C. Müll. (mst.); caulis abbreviatus subsimplex; folia oblonga tenera concara apiculata subserrulata, nervo ante apicem evanescente; theca ovata longius obconica apoplyssata, operculo plano calyptranue tumida apice subulata. + .

Gymnostomum apophysutum Tayl. (in Iond. journ, of bot. 1846. p. 43. - physcomitrium apoph!satum Wils. I. c. p. 448.: foliis ovatis acuminatis subintegris evanidinervibus theca clavata.

Patria. Nova Hollandia ad flumen Swan River: J. Drummond.

Ex habitu Funurue; folia perichactialia rosulata tumido-congesta; setae c. unc. un. longae. E. Rotlleri proximus sed apophysi longiore et uervis evanescentibus differt.

\section{Peristomati.}

6. E. radians C. Müll. (nnst.); canlis simplex; folia terminalia octonia spathulato - ovalia apice denticulate nervo 
rubente ante apicem evanido praedita; theca subcermu urceolata apophysi obconica. -

Eremodon radians Brid. I. p. 236. - Meisia radians Hedw. Op. posth. p. 73. tah. 13. - Bryum radians Pal. Beauv. Prodr. 1.49. Patria. In insulis Australiac.

A sequente, quocum commutatus, notis illustratis certe distinctus. Ex iconibus Cl. Schwägricheni supra laudatis Entoshliodon verus esse videtur. Dentes lanceolati acuti, tenuissime trabeculati rubentes. Pedunculus erectus tortilis splendens basi ater superne laete rubicundus. Ex analogia specierum peristomatarum huc referimus.

7. E. eurvipes C. Müll. (mst.); caulis simplex laxe cespitosus; folia inferiora perpauca, superiora in coma imbricata posita lato-oblonga acule acuminata ralde concara integra laxissime areolata, nervo crasso evanido concolore; pedunculo sicco dextrorsum torto valde arcuto; theca pyriformis ample operculo conico-hemisphaerico; dentes externi 16 Innceolati trabeculati et linea media instructi purpurei apice pallidiores nodosiusculi; intus sporangidii membrana in lacinias obtusas dentibus alternas producta. p. 697.

Physcomitrium Entosthodon curvipes C. Müll. in Limnaea XVIII.

B. robustior, caule inferne subnudiusculus apicem versus foliis latioribus magis patulis planiusculis obtusioribus, dentibus latioribus robustioribus longioribus intensius coloratis. Funaria radians Bruch et Sich. in Muscis Alyssiuic. Schimperian. In. itiner. An notis species propria?

Putria. Abyssinia: in regione boreali montis Silke ad fines arborum et fruticum 11,000 pedes supra mare inter Solorincum Simensem Hochst. No. 1393. L'n. itin. 22. Febr. 1810 logit $\mathbf{W}$. Sch imper. Var. $\beta$. in locis nobis ignotis Abyssiniae ejusdem collectionis.

Entosth. curriseto proximus sed pedunculo funarioideo-arcuato, foliis integris vix obsolete denticulatis thecaque peristomata valde recedit. Calyptra quidem ignota, sed tamen ex analogia specierum peristomatarum, huc pertinere videtur. 


\section{STEGOCARPI. ACROCARPI. ENTOSTODOS.}

8. W. Mathewsii J. Hook. (ic. pl. rar. Jook. Vol. IV. 1811. tab. 245. B.); cespitosus simplex; folia superiora erecta late oblongo-lanceolata acuminata serrata, evanidinervia; theca anguste-pyriformis operculo convexisculo subconico praedita erecta, pedunculo stricto, dentibusque peristomii linea media exaratis articulatis.

p. Tulifolius; folis obovatis acmminatis serratis, theca lato-pyriform, operculo planiusculo, dentibus peristomii latioribus. Entosth. latifolius J. Hook. 1. c. tab. 24J. C.

$\gamma$. integer; dense cespitosus foliis superioribus rosulato-imbricatis obsolete denticulatis $v$. integriusculis; theca anguste pyriformi brunea, dentbus peristonii angustis brevibus subrugulosis minus articulatis linea media vix exaratis; intus membrana sporangidii in lacinias obtusas brevissimas producta pracdita, calyptra basi trullcata inflata.

Plyscomitvium (Entosth.) Matheusii C. Müll. in Linnaea XVII. p. 697. pro $\alpha$. et $\beta$.

Putria. In locis humidis ,Lomas of Amancoes" dictis prope Limam regn. Peruviani: Mathews. Valp. prope Limam. Var. $\gamma$. Chile: Pöppig. 1829. 11b. Ií unzean um.

Entosthodon Templetomi proximus sed foliis serratis magis attenuato-acuminatis et dentibus linea media pracelitis ab $u_{\text {. et }}^{\beta}$. differt. Var. $\gamma$. jam calyptra basi truncata distincta. - si variet. $u$. el $\beta$. calyptra basi rotundata inveniatur, var. $\gamma$. species propria erit.

9. W. Templetoni Schwägr. (Suppl. II. l’. I. p. 44. tab. 113.); simplex; folia superiora rosulata patula late oborato-acuminata nervo sub apice evanido, marginc crenuta; theca anguste pyriformis anerantiace fongicolla dentibus subulato-lanceolutis in articulationibus nodosis linea longitudinali mulla rel obsoletissima, operculo plane convexo calyptraque busi rotundutu.

Brid. Bryol. univ. 1. p. 379. - Bryol, Furop. Funariac. Entusthodon. I. c. p. 3. tab. 1. - Weisia Templetoni Hook. et Tayl. Musc. Brit. p. 42. tab. 14. - Funaria Templetoni Sm. Engl. Bot. tab 2524. - Physcomitrium latifolium Brid. Br. univ. I. p. 760. lue forsan pertineat? Caule erecto simplici, foliis apice confertis late ovatis apiculatis, thecae erectae subpyriformis pelunculo triplo longiore, 
operculo planissimo. In insula Corsica cum Funaria Mühlenbergii promiscum legit Thomas. Hb. C'and. Entosth. curriseto theca pyriformi et operculo planissimo simillimum distinctum tamen, ut videtur, foliis duplo latioribus brevins acuminatis po'ygono-nec parellogrummi-arcolatis et pedunculo theca erecta triplo longiore cauleque inferme folioso nec nudo.

Putrice. Ad terram humidam Hiberniae, Scotiae, Italiae et insularum mediterranearum. Sardinia. Sicilia. Corsica. In agro Tingitano. Arabia monte Sinai ubi ad fontes riget: IV. Schimper. In Aegypto et in insula 'leneriffa. - Primo vere. $\odot$.

10. E. marginatus C. Müll. (mst.); laxe cespitosus simplex, folia superiora rosulato-patula e basi oblonga quam maxime laxe-ureoluta lato-ovalia obtusoacuminata late et incrassalo-marginata cremelata crispato undulata apicem versus archius areolata nervo ante. summum apicem evanido; theca brevi-prriformis ampla aurantiaca ore parvo et operculo convexiusculo; calyptra basi truncata; dentes peristomii aurantiaci irregulariter trabeculati, linea media longritudinali nulla, subulati.

Putrie. Promont, bon. spei prope Kavellendam: Ecklon. Hb. Kunzeanum.

Antheridia parva paraplysibus maxime clavatis cincta. Folia perigonialia amoene rosulacea horizontalia. Lut. Templetoni ex habitu similis sed ab eodem ceterisque congencribus foliis obtusiswimo-acuminatis incrassato-latomarginatis valde refugit.

11. E. obtusifolius J. Ilook. (in Hook. ic. pl. rar. tab. 245. 1.); dense cespitosus simplex; folia e basi cunlis uspue and apicem crescenti-imbricata elliptico-lanceolatu obtusa integervima; theca anguste pyriformis operculo convexiusculo, calyptra basi rotumdata. $\leftarrow$.

Physcomitrium Eitostholon obtusifolium C. Mïl, in „Linnaea XVIII. p. 697.

Putria. In locis humidis, Lomas of Amancoes" dictis prope Limam regni Peruviani: Mat thews.

Foliis obtusis elliptico-oblongis ab ommibus congeneribus recedit. - Dentes peristomii linea media longitudinali praediti articulato-trabeculati latiusculi. 
12. D. Bergianus Br. et Sch. (Bryol. Europ. 1. c. p. 4. tab. 1.); humilis subacaulis vel elatior dense cespitosus; folia superiora rosulata conferta oblongo-ovalia longe acuminatu evanidinervia, inferiora outia verro excurrente mucronutu onnia integerrima; theca pyriformis brevicolla parva operculo subconvexo; peristomii dentes lineali lanceolati obtusi breves lineu longitudinali pullidiore exurati fissiles trabeculato-nodulosi; calyptra (ex ic. Hornsch.) basi truncata.

Physcomitrium Eutosthodon Beryianum C. Müll. Limu. XVll. p. 696. - Desmostomum Hornseh. Linn. 1811. p. 116. - Bergia Fürnrohr in Regensh. bot. Theit. 1829. Ergälnzungshlatt p. 26. Weisia Bergiana Hsch, in Hor, phys. Berolinens, p. 59. tah. 12.

Patria. Prom. bonae spei ubi ad montem leonis $c$. fructibus maturis primus legit B erg pharmacopola 15. Sept. 1816. - In terra argillosa ochracea locis humidis montis diaboli, nec non in muris hortorum circa urben Capitis bonae spei: Écklon. Drege.

Ex lumilitate partium onnium ac foliis longe acuminatis late ovalibus arctius areolatis ab Entosthodontibus ceteris peristomatis facile distinguitur. Dentium forma variare videtul. In nostris speciminibus (e prom. b. sp. in terra prope van Campsbai lectis) subirregulares linea longitudinali carentes invenimus.

\section{Gèn. V. A mblýodon Pal. Beaur. emend.}

Amblyodum P. B. Prodr.p.41. ex parte. - Bryol Europ. Fase. X. Me esiaceae. Amblyodon. - Meesia anct. al. - Bryun auct, antiq.

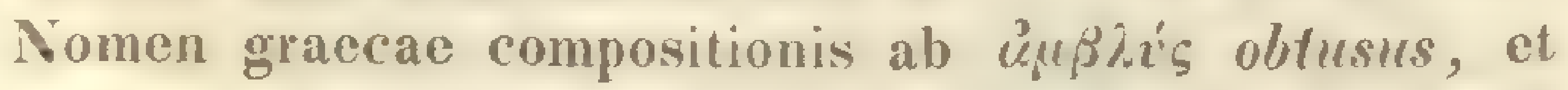
ódor's dens ob dentes externos breves obtusos impositum.

Calyptra cucullala angusia fugacissima longiuscula tenerrima apice e collulis incrassatis minimis qualratis composita. Theca asymmelrica pyriformis recta peristomata annulata. Peristomium duplex; externum: dentes $\mathbf{1 6}$ breves lanceolati oblusi erecti trabeculati linea longitudinali tenera praediti 
rnfi; internwm: dentes tolidem lanceolati subulati medio longiludinaliter fissiles laeves externos longitudine multo superantes flavescentes in membrana brevi sulcala positi. Operculum regulariter areolatnm. - Inflorescentia monoica polygama. Flos masculus discoideus, femineus et hermaphroditus gemmacei. Antherilia, archegonia et paraphrses ut in caeteris.

E structura foliorum Funceriaceis simillimus, e forma thecae Meeseis proximus, e peristomio Bryaceis (Pohliis) affinis. Genus memorabile certe huc, minime ad Meeseaceas pertinens hucusque vi tantum peristomii ad eas relatum. Ab iis foliorum structura toto coelo differt et nunquam cum is conjungi potest.

1. A. dealbatus P. B. (Prodr. p. 41.); humilis dense cespitosus simpliciusculus; folia oblongo-ovata subangusta acuminata obsolete denticulata evanidinervia, e basi et ultra medium e cellulis longis parellogrammis laxis valde viridibus, apice polygonis composita; theca e collo erecto pyriformis subobliqua vel curvata, pedunculo longo et operculo conico obtuso praedita rufa.

Bryolog. Kurop. I. c. p. 5. tah. 1. - Neesia deulhata Hedw. Sp. Musc. p. 17t. tall. 41. - Brid. II. p. 63. - Bryum dealbatum Dicks. Fasc. 11. PI. Crypt. p. 8. tab. 5. fig. 3.

Putriu. L planitichus ad alpes adscendens; in paludosis et turfosis per alpes Europae fere totius, omnis Scandinaviae atque Daniae, Scotiae et Iriae, IIspaniae, Helvetiae et Germaniae. In Germaniac planitie septentrionali prope Neodamum legit It zi gs ohn. - Julio. 21.

Subtrib. II. SPLACHNACEA D.

I.ate-dense-cespitosac, stercus animale plerumque habitantes; caulis lixifolius valde ramosus. Inflorescentia hermaphrodita, dioica, rarius monoica. Flos masculus gemmaceo-capituliformis terminalis. Antheridia magna clavacformia curviuscula. Archegonia angusta longiusculo-apiculata. Paraphyses 
basi filiformes apice subclavatae. Peristomimm, sin adsit, dentibus regulariter lanceolatis nec obliquis nec trabeculatis geminatis rufescenlibus carnosulis. Columella pro more exserta. Thecae apophisis stomatiis plerumque praedita.

Habitus Funuriaceis similis, e ranificatione autem plantarum crebra atque thecae symmetricae apophysi plerumque ventricosa saepe pulcherrime colorata proprius speciosissimus.

Patria. Per orbem terrarum totum ex alpibus in plunities, sed rarius, descendentes, locos humidos nivales v. turfosos amantes. $2 \%$.

Sylachnacene auctor. et Bryol. Furop. Fasc. XXIII et XXIV. Monographia eximia quau partim libenter sequimur.

\section{Gen. VI. Oedipơdiónm Schwägr.}

Suppl. II. P. I. p. 15. tah. 105. - Gymnostomum Smith. - Syluchnum Pal. Beauv. - Bryum Dicks.

Nomen graecae compositionis ab oúdos inlumescentin et roĩs pes, ob pedunculum apicem versus incrassatum.

Calyptra mollis longiusculo-angusta usque ad apicem fere fissa oblusa basi sublacera. Theca subglobosa laxissime reticulata mollis collo longissimo, e pedunculo sensim incrassato, orto, praedita, stomate nudo. Colunella apice dilalata. Omnes partes mollissimae. Inflorescentia monoica: Flores fertiles hermaphroditi patuli, antheridiis majusculis oblongis haud curviusculis, paraphysibus suldaratis mixtis; archegoniis brevioribus paraplysibus filiformibus mixtis. Flores steriles tantum masculi.

Hix habitu Mniculdpheurum congeneribus simillimum, e partibus omnibus mollissimis calyptracque forma bonum.

1. Ded. Grifthianum Schwägr. (1. c.); dense gregarium v. cespitulosum innorationibus annotinis ramosum pulcherrime viridulum; caulis crassus mollis filis longis 
teneris articulatis hyalinis obtectus; folia e basi angustissima, cellulis longissimis laxissimis pellucidis tenerrimis composita, spathulato - lingulata rotundato - obtusissima integerrima, apicem versus e cellulis multo densioribus minoribus, granulis chlorophyllaceis repletis, subpolygonis, parietibus tenuibus instructis, formata, interdum filis, caulinis similibus, basi praedita subconcava, nervo laxissimo molli lato ante apicem obtuso-evanido; pedunculus brevis flavescens, theca ovali-globosa aurantiaca, operculo parvo conico.

Brid. 11. p. 83. - Bryol. Europ. I. c. Oedipodium. p. 4. tab.1.Gymnostomum Griffithianum smith. Fl. Brit. HI. p. 1162. - Hook. 'Tayl. Musc. Brit. p. 11. tals. 7. - Sylachuum Froelichianum Brid. Mant. Musc. p. 105. - Splachnum Griffthiunum With. et Hull, e Musc. Brit. modo laudata p. 11. - Bryum Griffithianum Dicks. Crypt. Fase. 4. p. 8, tab. 10. fig. 10.

Putriu. In Angliae, Cambriae et Scotiae montibus editioribus alpinis, ulsi rupium fissuras et loca humida petrosa tenet: ad latus orientale cacuminis montis Snowdon, ubi Griffith detexit; in rupibus pracruptis montis Ben Nevis; prope Ingleborough in Yorkshire: Dalton et Hooker, et prope Forfar in Angushire: Don. - Novis temporibus in districtu Bergensi Norvegiae detectum. Aestule. Junio ad Augustum.

Planta notis permultis memorabilis, e claracteribus essentialibus generi sequenti proximum quidem, ex illis tamen singularis.

\section{Gen. VII. Tetráplodiom Br. et Sch.}

Bryol. Europ. 1. c. Tetráplodun. - splachnum auct. - Pycnamophyscium Rchb. prioratum quidem tenet, sed genus ab auctore diagnosi non praeditum.

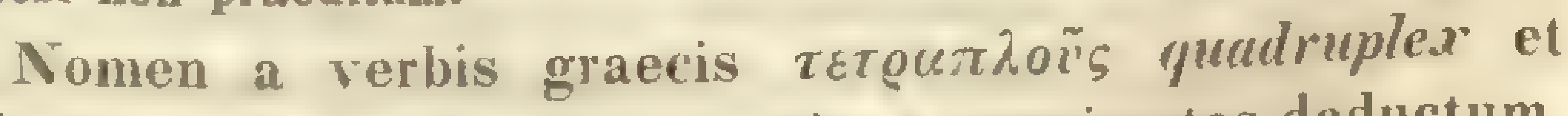
ajoi's dens ob dentes quaternatim approximatos deductum.

Calyptra parvula cucullata usque ad medium fissu apiculata tenera. Theca apophysata ovali-cylindrica. Apophysis obconica, obovalis v. subovalis. Columella apice haud dilatata. Inflorescentia monoica. 
Flos masenlus gemmaceo-capituliformis in foliorum axillis sessilis $v$. in ramulo proprio terminalis. Flos femineus eparaphysatus. Peristomii dentes 16 duplices quaternatim approximati, Ianceolati c cellularum serichus duabus formati, basi per paria connati, siccitate reflexi, humiditate crecto-incurvi theca multo breviores.

IIabitus inter Tayloriam et Splachmum intermedius.

1. r. angustatus Br. et sich. (1. c. p. 4. tab. 1.); cespitulosus elatus; folia remotu erecto-patentia late lanceolata longissime acuminata siccitate subtorta obsolete vel distincte dentatu; theca in pedunculo brevi vix exserto ovalis, apophysi multo majore oblongo-obconica; peristomii dentes quaternatim conferti.

Pyciulophyscium angustatum Ribb. Ic. Crypt. - Splachnum anyustutum Lim. fit. Jescr. Meth. Musc. p. 33. - Hedw. Musc. Frosut. 11. p. 37. tal), 12. - Brid. Br. univ. I. 13. 218. - Splachnugns setuceum Mich. Fl. Amer. Sept. 1I. p. 788. - Brid. 1. c. p. 250. Drumm. Musc. Amer. I. No. 27?

Putria. Per totum alpium tractum Europae centralis, Scotiae et Scandinariac, nusquam tamen copiose, et praecipue in stercore animali. Julio et Augusto.

sequenti e caulibus foliisque similis, sed ab omnibus congeneribus theca vix exserta jam primo adspectu distinctissimus. - Flores masculi nunc ad basin innovationum, nunc in ramulis propriis terminales. Folia perigonialia, e basi lata concava intense lutescente, anguste acuminata obsolete nervosa subintegra. Folia perichaetialia fructu maturo comalibus similia subintegra.

2. T. mnioides Br. et Sch. (1. c. p. 5. tab. 2.); dense cespitosus; folia subimbricuta vel crecto-patentia, oblonga et oblongo-orata, subito tenuissime acuminutu valde concara integerrima sicea subtorta, nervo in apiculum plus mimes moluctum excurrente; theca ovali-cylindrica apophysi crassiuscula suffulta longe exserta, operculo obtuse conico; peristomii dentes octo-yemini.

splachnum mnivides Hdw. Musc. Frond. II. p. 35. tab. 11. Brid. 1. p. 240. - spl. urceolatum Dicks, Wasc. II. Pl. Crypt. p. 2. 
et Hedw. Musc. Frond. p. 39. taly. 13. et Dav. Crantz Hist. Groenl. III. p. 284? Spl. bryoides Zoega FI. Isl, p. 239. adnexa Olafsen's Reise durch Island. 2 Th. Copenh. 1785, 4.? - Spl. urceolatum $\beta$. minus Wahlenb. F'l. Lapp. p. 309. - Spl. arcticum Rob. Br. Fl. Ins. Melville (Capit. Parrys Voyage) 301. - Spl. propinquum Rob. Br. ibid. - Syl. exsertum Rob. Br. ibid. - Spl. paradoxum Rob. Br. ibid. - Phascum mnioides Linn. Meth. Musc. p. 6. - Phascum pedunculatum acaule anthera pedunculata Linn. syst. Veget. p.944.

ß. Breuerianus; ramis gracilescentibus laxius foliosis, foliis angustioribus late lanceolatis patentibus. Spl. Breuerianum Hdw. MIusc. Frond. II. p. 105, tab.38. - Brid. I. p. 251. - Npl. fastigiatum, foliis lanceolatis acuminatis, receptaculo oblongo Dicks. Fasc. III. Pl. Crypt. p. 2. - \$ $\$ l$. mnioides $\beta$ majus Hook, et Tayl. Musc. Brit. p. 20. - Spl. canescens Pal. Beauv. Prodr. p. 88? - Bryumb canescens Vill. Pl. Dallph. 1ll. p. 883? Bryum ampullaceum Dill. Musc. p. 345. t. 44. fig, 5. Herb. Dill. e Brid.

$\gamma$. Adumsiames; theca pyriformis pallida flara ampla collo angusto breviori instructa. Syl. Adamsiınum Hsch. in 11or. phys, Berol. p. 58. tab. 12. - schwägr. Suppl. II. P. 1I. tab. 178.

Patria. Locis subhumidis in stercore animali corporibusque animalium putridis per partem sylratican et subsylvaticam totius alpium tractus et Germaniae septentrionalis torfaceis, raro tamen et valde sporadice; in Scandinavia et Lapponia multo frequentior. In Groenlandia et Labradore copiosissimus et pulcherrimus. - Var. $\beta$. In iisdem locis. - Var. $\gamma$. e Caucaso ab Adams relata.

E theca senectute nigrescenti-purpurea parra apophysi longa theca multo majore et pedunculo purpurascente jurenili flavescente a ceteris speciebus facillime distinguitur. - Fructus numerosissimi. Flores masculi nunc in perichaetii vicinia sessiles, nune in ramulis propriis elati gemmaceo-capitati et gemmaceo-discoidei. Folia perigonialia e basi concara anguste lanceolata atque patula.

3. T. urceolatus Br. et Sch. (1. c. p. 7. tab. 3.); compacte pulvinatus; folia late obovato-oblonga ex apice obtuso apiculata influto-imbricata maxime concala, nervo sub apice evanescente; theca pedunculo crassiore basi valde attenuato :praedita, subcylindrica, apophysi bre- 
viore obovata vel ovali-globosa; peristomii dentes breviores angustiores.

Splachnum urceolatum Brid. Bryol. univ. I. p. 242, ex parte.

Patria. In fimo bovino summarum alpium IIelvetiae, Carinthiae et Salisburgiae, locis perpaucis. In alpe Salmshöhe ad pedem montis Grossglockner Carinthiae: I ornschuch, Hoppe, Fr. Müller; in monte Albula Rhaetiae: Mühlenbeck, Mougeot; in summo Faulhorn Helvetiae: W. P. S ch i m per; in summa alpe Speiereck Lungaviae: Sa uter, W. P. Schimper; in monte Radhausberg Salisburgiac: Nö̈. Loca cetera ab auctoribus designata dubia. - Julio.

Inflorescentia praecedentis. - Dentes peristomii secundum originem atque directionem omnino ut in $T$. mnioide sed angustiores et breviores aurantiaci. Ab omnibus plantis compacte pulvinatis, ramis densissime foliosis, pedunculo brevi flavescente atque thecae forma primo intuitu distinguitur.

\section{Gen. VIII. Taylória Hook. emend.}

in Journ. of Science and the Arts, No. 3. p. 144. T. spiachnoidi imposita. - Bryol. Europ. l. c. Tayloria. - Hookeriu schwägr. Schleich. - Raineria De Notaris.

Nomen ab Hookero in honorem botanici et bryologi Taylor meriti impositum.

\section{Calyptra inflato-conica erecta uno latere fissa}

basi constricta, margine toto ambitu lacera vel erosa. Peristomium infra thecae orificium ortum, 16- et 32-dentatum, lentes singuli per paria approximati vel coadunati, saepe longissimi, humiditate incurvi et involuli, siccitate (in theca supra matura) reflexi thecae adpressi vel tortuoso-defuentes summopere hygroscopici. Inflorescentia monoica. Flores masculi nunc ad basin innovationum, nunc in ramulis propriis capituliformes. Flores feminei paraplysibus brevibus 
vel nullis. Columella thecae maturae plerumque longe exserta planiusculo-apiculata.

Ifabitus e plantis elatis gracilibus laxe cespitosis ac theca magno-cylindracea longicolla colorata, peristomio saepe longissimo hygroscopico proprius speciosus.

\section{A. Peristomii dentes 16 per paria 8 conferti.}

1. T. serrata Br. et Sch. (1. c. p. 6. tab. 1.); laxe cespitosa; folia elongato-obovata acuminata superne grosse dentala, nervo sub apice evanido; theca collo oblongo brevior ovalis, operculo convexo-conico obtuso; peristomii dentes e duplici cellularum serie compositi lutescentes siccitate infra thecue orificium incurvi; sporae minutae sulphureae.

Sylachnum serratum Hedw. sp. Musc. p. อ̈3. tab. 8. - Brid. t. p. 246.

ß. Alagellaris; ramis gracilescentibus fructum superantibus; theca subcernua. Spl. flugellare Brid. I. p. 247. Syl. tenue $\gamma$. flagellure Roehl. Deutschl. M. III. p. 43. - spl. Helveticum Schleich. Cent. II. n. 9. - syl. serratum schwägr. Suppl。 I. P. I. p. 49. - Bryol. Europ. 1. c. tab. 2.

$\gamma$ temeis; foliis brevioribus latioribus, theca minori in pedunculo tenuiori, siccitate valde retracta columella exserta. Sylachn. tenue Dicks. Fasc. II. p. 2. - Brid. I. p. 247.Spl. longicollum Dicks. Fasc, IV. Fl. Crypt. p. 4. tal,. 10, fig. 9. ex Hookeri sententia. - Spl. attenuatum Brid. Maut. Musc. p. 106. et Bryol. univ. I. p. 218. - Spl. lingulatum Hoffm. Fl. Germ. p. 23. n.4. - Syl. serratum schwägr. Suppl. I. p. 49. - Bryol, Europ. 1. c. tab. 2.

Putria. Per alpina et subalpina totius Europac in sylvis abietinis, plantis putredine decompositis vel stercore vaccino insidens vetusto, socio Spluchno grucili, haud raro occurrit. Var. $\beta$. locis valde umbrosis et humidis. Var. $\gamma$. una cum forma vulgari vel locis siccioribus inque ipsa terra arenosa praeprimis Hereyniac atque Sudetorum. - Junio, Julio, in editioribus Augusto.

Flores in eadem planta monoici: masculi nune in ramulo proprio per plures annos innovando terminales, dis- 


\section{STEGOCARPI. ACROCARPI. TAYLORA.}

coideo-capituliformes. Folia perigonialia late ovato-lanceolata e medio patula, margine integra. Folia perichaetialia comalibus minora sed tamen similia. Theca flavescens demum brunnea.

2. T. Moritziana C. Müll. (Linn. XIX. p. 201.); laxissime cespitosa, caulis erectus simplex $\mathrm{v}$. basi ramo instructus; folia remota e basi angustissima lato-rotundato-spathulata lobuto-ciliuta, ciliis longis incuequalibus articulatis, nervo flexuoso sub apice evanido praedita sicca undulato-crispula; theca breviusculo-pedunculata erecta cylindrico-oblonga, collo brevissimo instructu, aperta urnigera, operculo conico brevi- et obtuso-apiculato; dentes crassi rigidi longi intense purpurei lato-lanceolati 16 per paria (igitur 8) positi apice acuto-conexi, madefacti erectiusculi apice subreflexi, siccitate inflexi, seniores forsan valde reflexi.

Patrice. Columbia in montibus nivosis provinciae Meridac inter Hypopterygium tamariscinum, ubi legit Mor itz. No. $\%$.

Taylorice species rera e foliorum forma distinctissima elegantissima. - Folia perigonialia et perichaetialia perpauca minus dentata. Folia caulina laxissime areolata valde remota. Pedunculus purpurascens. Theca pallida, aperta ore planiusculo undulato-reflexo constricta. Columella exserta apiculata. Inflorescentia monoica. Flos masculus in ramo proprio ad radicem plantae femineac terminalis antheridiis brevibus crassiusculis et paraphysibus ejusdem formae numerosis praeditus. Archegonia longiora perpauca intense brunnea. Calyptra ignota. Annulus nullus.

3. T. spathulata C. Müll. (mst.); humilis subsimplex; folia argute serrata evanidinervia siccitate undulato-crispata, pedunculus breviusculus, theca cylindrica exapophysata, operculo conico-apiculato brevi, calyptra mitraeformi hirtu basi appendiculata; dentes peristomii 16 per paria approximati horizontales pallidi siccitate non reflexi. Annulus nullus. Inflorescentia monoica: flos masculus capituliformis. $f \cdot 1$ 
Eremodon spathulatus Hook. et Wils, in Lond. Journ. of bot. 1846. p. 448. Tab. XV. B.

Putria. America meridionalis: I $₫$ ob b. No. 10J.

Species nobis haud visa e descriptione atque icone Wil soni ad praecedentem adeo accedens, ut, synonymam esse, putemus. Folia tamen argute serrata non lobato-ciliata appellantur et operculum conicum, dentes lato-lanceolati e basi usque ad apicem coaliti delincantur, in contextu diagnosis pallidi tandem nominantur.

4. T. Jamesoni C. Nlïll. (mst.); laxe cespitosa elongata erecta subsimplex; folia remota vix imbricata spathulato-ovata obtusa excurrentinerie margine incrassata (the margins thickened) apice denticulata; perichaetialia caulinis similia; perlunculus erectus apice crassus; theca subaequalis oblonga erecta, operculo conico apiculato recto; dentes 16 aequidistantes lanceolati erectiuseuli persistentes; calyptra elongato-conica basi fissa scabra (ex ic. Wils.) basi inflata inflexa vix constricta. $\div$.

Brachymitrium Jamesoni Tayl. Lond. Journ. of bot. 1816. p. 44. - Wilson ibidem p. 448, tab. XV. A, ad Eremodonten vel Taytoriam pertinere monens.

Putria. In sylvis montis nivosi Pichinchae prope Quito Andium tract.

Ex observationibus Cl. Wilsoni (1. c.) Tuylorice Rudolphience affinis, calyptra seabra autem ab ommibus notis congeneribus distinctissima. Forsan ad sectionem secundam pertinens?

\section{B. Peristomii dentes per paria conjuncti demum omnes fere liberi.}

5. T. splachnoides Hook. (Journ. of Science and the Arts No. 3. p. 141.); laxa cespitosa, elata; folia inferiora oblonga, superiora oborato-acuminata et elongatolanceoluta, ad medium ustue grosse dentrata, nerro sub apice eranido; theca in pedunculo elongato temis erectu $\varkappa$. subobligua oblonga $x$ subeylindrica, collo longissimo angustiore, operculo longe conico instructa; peristomii dentes longissimi humiditate involuti, siccitate reflexi, cir- 
rhati; columella longe exserta; calyptra basi integra latere fissa.

Hook. Musc. Hxot, 11. tab. 173. - Bryol, Eur. 1. c. p. 8. tab. 2. Brid, I. p. 266. - Hookeria splachnoides Schleich. in litt. et Brid. 1. c. et schwägr. Suppl. I. P. II. p. 3Ł0. tal. 100. - Hookeria acuminata schleich. in litt. - Tayl. acuminata Horusch. in Regensh. bot. Zeit. 1826. I. p. 78. - Tuyl. obliqua Nees ab Es. Seudtu. in litt., theca longissima obliqua.

$\beta$. obtust; humilior; theca breviore, operculo convexo-conico obtuso, peristomii dentibus brevioribus siccitate reflexis, thecae subalpressis nec cirrhatis. Raineria splachnoides De Notaris Syllah. Musc. p. 275.

$\gamma$. cuspidata; foliis longius cuspidatis et thecae partibus omnibus brevioribus. Tayl. cuspidata Hartm. FI. Skandin.

Putria. Locis umbrosis subhumidis, corporibus animalium putridis insidens, per alpes et subalpinos Germaniae, Helvetiae et Scandinaviae, sylvas acerinas prae caeteris amans; valde sporadica, nusquan copiose occurrens. In Americae septentrionalis Rocky Mountains: Drummond Muse. Am. No. 47. - Var. $\beta$. in locis editioribus ad fines regionis sylvaticac. - Ad aestatis finem.

Flores monoici raro hermaphroditi; masculi subdiscoideo-capituliformes. Folia perigonialia orato-lanceolata basi valde concara erecta dehinc patentia.

6. T. Rudolphiana Br. et Sch. (1.c. p. 10. tab. 4.); dense cespitosa elata robusta; folia crecto-patentia oblongo-acuminata nervo excedente longe cuspidata apice anguste serratu margine reflexu; theca in pedunculo brevinsculo crasso oblongo-ellipticu brevicolla robusta sicca sub ore constricta, operculo conico obtusiusculo; calyptra busi profunde laciniutu latere fissa.

Eremodon Rudolphianus Nees et Hornsch. in Bryol. Germ. II. p. 176. tab. 40.

Patria. In truncis retustis atque ramis muscis, praeprimis Lencorlonte scimoide, obtectis Aceris Psendoplatuni secus viann in faucibus prope pagum L'ntertaucrn ad Jugum Kadstadter-Taueru Np. Nalisburgiae; Rudolphi primus legit; in trunco putrido dejecto ad locum superiorem mont. Dürrenstein Austriae superioris: IV.P. 
Schimper. Ex alpibus Carinthiae (Pasterze?) a Cll. Hoppe et Funk lectam habemus. E rarissimis. - Julio. Augusto.

Flos masculus in ramulo proprio triphyllus. Folia perigonialia comalibus similia. - Species e partibus omnibus robustissimis speciosissima ac nulla alia confundenda.

\section{Gen. IX. Dissodon Grev, et Arnott.}

in Ann. Soc. Linn. 1826. p. 229. Tent. Metl. Musc, et Walk.-Arnott Dispos. méthodique des espèces des Mousses 1825. p. 13. - Eremodon Brid. ex parte. - Systylium Hsch. - splachnum auct. Weisia anct. ex parte.

Nomen graecae compositionis a verbis dís duo et ödor' dens ob dentes geminatos.

Calyptra inflato-conica erecta uno latere fissa basi constricta licera vel crosa. Peristomium ad thecae orificium ortum. Dentes 32 in dentes 8 bigeminatos, vel 16 geminatos connati lanceolati plani transverse articulati, humidi in conum depressum conniventes sicci subincurvi. Inflorescentia hermaphrodita vel monoica. Flores masculi discoileogemmacei; feminei gemmacei paraphysibus filiformibus. Columella immersa v. exserta, planiuscula.

Iabitus foliis viridescentibus, thecis pyriformibus gilvis dentibusque erectis rigidis proprius Tayloriis similis.

sectio I. Systylium. Operculum in columella siccitate exserta persistens; peristomii dentes yeminuti truncati et irregulares.

1. D. Horngehuehii Grev. et Arn. (Tent. Meth. Muse. fasc. III.); monoicus; humilis dense cespitosus, fastigiatoramosus; folia inferiora valde remota minuta, superiora congesta sublaxe imbricata ovalia concava nitida obtusa integerrima nervo sub apice evanido; theca in pedunculo brevi crasso pyriformis longiculla, operculo subconico.

Walker-Arnott Dispos. méthod. p. 13. - Bryol. Europ. I. c. p. 7. tab. 1. - Nystylium splachnoides Hormach. Comment, de Voitia et Systy-lio p. 19. tab. 2. - Regensl, bot. Zeit. 1820. p. 176. c. ic.

- Brid. I. p. 264. 


\section{STEGOCARPI. ACROCARPI. DIS $\$ 0 D O N$.}

Patria. In summis alpibus Carinthiac et Salisburgiae. Locis schistaceis alpis Pasterze prope Heiligenblut, ubi Cl. Hornschueh anno 1817 detexit; similibus locis in alpe Ochsenalpe dicta in der Gössnitz: Hoppe, Funk; in summo Radhausberg Gastuniae: Mielichh ofer; ad latus septentrionale summi cacuminis alpis Speiereck prope St. Michael Lungoviae (Salisburgiae orientalis), ubi una cum Tetraplod. urceoluto, Bryo demisso et Desmatod. Laureri ad terram humosam degit: W. l'. Schimper. - In summis Rocky Mounts non raro ex observ. Cl. Drummond in turfosis reperitur: Spl. Fröhlichiamem Drumm. Nusc. Amer. No. 44 et 46 . ex parte. Sub No.44. Dissod. Fröhlichianum tantum vidimus. - Ad aestatis finem.

D. Fröhlichiano proximus sed dentibus irregularibus fissis, columella operculo apice insidente longe exserta, inflorescentia monoica pedunculisque brevibus facillime cognoscitur. - Flores masculi terminales laxe gemmacei. Folia perigonialia comalibus similia. Flores feminei paraphysibus nullis.

Sectio II. Cyrtodon. Operculum decidunm, columella siccitate retructa; peristomii dentes 16 gemelli, per paria conferti vel aequidistantes.

\section{a. Folia obtusa.}

2. D. Fröhlichianus Grev. et Arn. (1. c. p. 122.); floribus hermaphroditis vel polygamis; humilis densiusculocespitosus; folia inferiora remotiuscula linguaeformia; superiora laxe imbricata oblonga vel ovato-oblonga obtusa vel subacuminata, integerrima; theca in pedunculo longiusculo pyriformis subbrevicolla, operculo obtuse conico; peristomii dentes gemelli regulares per paria conferti.

Walker-Arn. Dispos. p. 13. - Bryol. Europ. 1. c. p. 9. tal).2. - Splachnum Fröhlichianum Hedw. Musc. Frond. 111. p. 99. talb. 40. - Brid. 1. p. 24. - . Sill. reticulatum Swartz. Musc. Suec. p. 24. Bryum reticulatum Dicks. Fasc. 2. Pl. Crypt. p. 4. tab. 4. fig. 6.

Patria. In toto alpium tractu usque in Austriam orientalem, nec non in alpinis Norvegiae et Sueciae, raro Scotiae. Loca petrosa, humosa amat. In Americae septen- 
trionalis Rocky Mounts Drummond legit: Musc. Amer. No. 44. ex parte? - Julio. Augusto.

Praecedenti proximus. De affinitate ac differentiis observationes in D. Hornschuchii comparentur. - Flores cujusque sexus in imnovationibus diversis vel hermaphroditi. Flos masculus gemmaceo-discoideus paraphysibus clavatis numerosis. - Flores feminei atque hermaphroditi paraphysibus paucis filiformibus.

3. D. splachnoides Grev. et Arn. (T'ent. III. p. 121. tab. 13. No. 39-44.); elatus valde ramosus densiusculocespitosus; folia erecto-patentia siccitute torta linguaeformic obtusa integerrima inferiora nigricantia, superiora laete-viridia; theca in pedunculo elongato tenui erecto pyriformis brevicolla parea, operculo obtuse conico; dentes peristomii aequidistantes lanceolati acuti subsubulati.

Walker Arnott. Disp. Métl. p. 13. - Bryol. Europ. 1. c. p. 10. tab. 3. - Eremollon splachnoides Brid. I. p. 234. - Bryol. Germ. II. p. 173. tab. 39. - Cyrtodon splachnoides R. Brown in Parry. Voyage. Verm. bot. Schriften 1. p. 442. - Weisia splachnoides Schwïgl. suppl. I. P. I. p. 63. tab. 17. - Weisia turbinuta Drumm. Musc. Amer. Fasc. I. No. 61. - Silachnum lingulutum Dicks. PI. Crypt. Fasc.IV. p. 4. tab. 10. fig. 6. - Grimmiu splachnoides Engl. Bot. tab. 2164.

Putria. In alpium uliginosis frigidis, Iypno revolvente et Caricibus diversis vulgo intermixtus per totam Europam et in America septentrionali. - Augusto.

Inflorescentia praecedentis. $\mathbf{A b}$ omnibus congeneribus caulibus elongatis dentibusque aequidistantibus longe acuminatis distinctissimus.

4. D. Jacquemonti Br. et Sch. (in Bryol. Europ. I. c. p. 6. memoratus.).

Patria. In sylvis piniferis humidis montium Himalayae altitud. 9000 ped. prope Deorah, ubi Jacquemont plantulam tenellam in terra laxe cespitusam detexit. Octobr.

D. Fühlichiano ex inflorescentia, foliorum, calyptrae ac dentium forma proximus, tamen gracilior et foliis viridescentibus mollibus siccis tortis, theca parva cylindrica 
brevicolla alutacea, operculo convexo parvo pedunculoque tenui stramineo basi rubescente praedita distinctus. Tomentum pulchre rubiginosum. Caetera non descripta.

5. D. Ecabrisetus Grev. et Arn. ('lent. Métll. Musc.); monoicus; laxe cespitosus adscendens inferne tomentosus; folia sputhulato-linguceformice rotundato - obtusa subintegerrima evanidinervia sicca torta; theca cylindrico-oblonga brevicolla operculo convexo parvo, pedunculo breviusculo rerrucis magnis hyalinis scabro et calyptra basi inflatu inflexa haud constrictu proedita.

Walk. Arnott. Dispos. méth. des esp. d. Mousses. p. 13. - Splachnum scabrisetum Hook. Musc. Exot. I. tab. 32. ubi calyptra false delineata. - schwägr. suppl. III. P. II. tal) 263. - Brid. I. p. 245.

Patria. In umbrosis temperatis Americae acquinoctialis in provincia Jaen de Bracomoros inter Gonzanamam et Luzarque; ubi Humboldt et Bonpland in altitud. 1060 hexapodum legerunt.

Ab omnibus Dissodontibus seta scaberrima differt. Flores masculi discoidei in ramulo proprio brevi plantulae femineae terminales. Paraphyses numerosissimae claratae. Folia perigonialia comalibus similia. Peristomii dentes bigeminati flavescentes plani tenues fugaces.

26. D. rotundifolius C. Müll. (mst.); dioicus; gregarius humilis simplicissimus; caulis gracillimus tenerrimus subflexuosus; folia a basi usque ad apicem valde remota tenera subrotunda obtusa tchero-membranacea integerrima arctius areolata; theca in setu brevi innovatione laterali anguste cylindrica parva basi subaedpalis, operculo convexo-conico parvo.

Amblyophyllum splachnifolium C. Müll. mat. - Wetsia obtusa Brid. I. p. 358. - W. obtusifolia Rich, in schwägr. Suppl. II. P. 2. p. 106. - Syrrhopodon obtusus schwägr. 1. C. tal. 182. - Didymodon? splachnifolius Hook. Musc. Kxot. I. tah). 76.

Patrie. In Iispaniola, Dominica aliisque Antillis in terra nuda habitat. 24.?

Flores masculi in planta propria axillares vel terminales pancifolii. Antheridia eparaphysata oblonga majuscula. Folia perigonialia elliptica e reliquis caulinis similia. 
Flores feminei eparaphysati. Peristomii dentes ex iconibus Schürigrichenianis geminati lanceolati longe acuminati e decem cellulis compositi, infra orificium thecae interno lateri adnati ferruginei, madore intus regentes, siccitate semi-erecti, thecae diametro dimidio paullum breviores. Calyptra perfecta ignota, junior ex obs. Schüigricheni subulata (?).

E foliorum forma huc pertinet sed toto habitu ceteris congeneribus alienus et dum calyptra dentesque ignoti sint, dubius.

\section{b. Folia cuspidata.}

7. D. serratus C. Müll. (mst.); dioicus; laxe cespitosus erectus elatiusculus simpliciusculus inferne radiculis amoene purpureis tomentosus; folia erecto-patentia oblongo-outu nerro excedente longissime cuspidata e medio uspre al apicem sublobuto-arguto-servalu sicca torta; theca ovalis erecta brevicolla ochracea in pedunculo brevi rufescente, operculo conico apiculato dentibusque 16 latis geminatis planis obtuso-acutis obscure flavidis ralde erectis; calyptra magna inflata basi constricta lacerata apice papillis majusculis erectis scuberrima.

Orthodon servatus Bory st. Vincent in litt. ad Richard et in Schwïgr. suppl. II. p. 23. tab. 106. - Brill. I. p. 232. - Octoblephurum servatum Brid. Sp. Musc. I. p. 86. et Mant. Musc. p. 27. Bryum orthodontum P. B. Prode. p. 48. - Octoblephurum serratum Ilook. Musc. Exot. II. tab. 136. s. sillachnum syuarrosum ej. in Transact. of Linn. Soc. Lond. 1X. p. 30s. tah. 26. fig. 2.?? CI. Hooker calyptram hasi quadrifidam non constrictam, pilis longis dexuosis albidis articulatis hirtam non scabram, et folia fere e basi serrata descripsit et delineavit. All recte? An propria species?

Patria. E regno Nepalensi Indiae orientalis benevole dederunt Cl. Got s che, a Wallich lectum, et Schwägrichen. In insula Bourbonis: Bory St. Vincent.

Flores masculi in ramulis propriis brevibus axillares subsessiles discoidei, antheridiis magnis, paraphysibus valde clavatis vel acuminatis numerosis foliisque perigonialibus integerrimis evanidinervibus. Planta mascula feminea gracili robustior densius foliosa Folia caulina, 
praesertim plantac masculae, madefacta quoque valde undulata crispa plus minus argute seu lobato-serrata. Species memorabilis, Dissodon verus, e foliorum forma argute serrata Tayloriae Moritzianae nostrae similis, nulla alia specie Dissodontium confundendus. - Cl. Schwägrichen plantam false monoicam descripsit.

7. D. cuspidatus C. Müll. (mst.); dioicus sublaxe cespitosus subramosus inferne tomentosus; folia oblongoovata nervo excurrente longe cuspidutu integerrima patula; theca cylindracea apophysi subsimili; peristomii dentes bigeminati; columella exserta. $\leftarrow$.

Sylachnum octoblepharon Hook. Musc. Exot. tal). 167. - Schwaggr. Suppl. 1I. P. 2. p. 105. tab. 129.

Patria. In truncis arborum emortuarum insulac Van Diemen dictae: $\mathbf{R}$ ob. Brown.

Flos masculus terminalis sed ob innovationes non raro lateralis discoideus (Hook.). Calyptra (junior) campanulata basi inflexa (Schwägr.). Peristomium paulo intra marginem thecac insertum, e dentibus 16 geminatis (8) siccitate subincurvis, madore erectis rel etiam reflexis (?) flavo-fuscis integris, transversim striatis atque lineis tribus longitudinalibus obscure notatis compositum. - Folia perigonialia lanceolata acuminata reflexa (IIook.) Ex his notis secundum observationes Hookeri ad D. servatum accedens. E calyptrac autem forma dentibusque erectis huc forsan certe pertineat.

\section{Dissodontes?}

1. Splnchnum purpuraseens Hook. et Wils. (in Lond. journ. of bot. 1814. p. 529.); caulis elongatus; folia patentia obovato-acuminata apice recurva integerrima ulldulata evanidinervia; theca ovali-oblonga superne angustata, apophysi obconica theca angustiore, operculo conico. $t$.

Iatria. Insula Aucklandi et Campbelli: J. II o oke r.

D. cuspidato affine sed majus et foliis remotioribus apice brevius acuminatis siccitate minus crispatis, theca et apophysi magis angustata differt. 
2. Sp1. plagiopus Mont. (in Ann. d. sc. nat. 1845. 4. p. 121.); caulis cespitosus erectus apice innovationibus fasciculato-ramosus; folia lanceolata vel obovata acuminata nervo conspicuo longe cuspidata integerrima; pedunculus brevissimus basi geniculatus; theca oblongo-cylindracea una cum apophysi obconica clavata, operculo convexo-conico. $\frac{1}{\dagger}$

Patria. Insula Aucklandi: Hombron.

J). cuspiluto et $\mathbf{S} p l$. pupurascenti certe proximum. A primo auctor columella immersa distinguit. An a secundo distet, ut cl. II oo ke r fil. putat, dubium est.

Praccedentes species duas hue retulimus, quum $\boldsymbol{D}$. cuspidati proximae nominentur.

\section{Gen. X. S D İe hum Linn. emend.}

Hedw. Fund. Musc. II. p. 8R. tal, VII. fig. 33. - Schwägr. suppl. I. P. 1. p. 46. - Bryol. Europ. Splachnacede. Nplachnum. - Nyluchnum et Fremodon Brid. - Splachnum et Aplodon Rob. Brown.

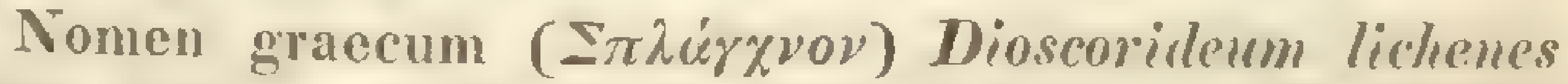
mulmonarius nunc Stictas designans, a Linnueo Splachnacris omnibus impositum et ab Heduigio sancitum.

Calyptra conica parvula integra vel basi hic illic lacera. Peristomii dentes 16 e duplici cellularum serie compositi lanceolati majusculi lutescentes per paria approximati et partion conglutinati, siccitate reflexi thecne adpressi, humiditate erecti apice incurvi. Inflorescentia dioica rarius monoica. Flores masculi capituliformes. Flores feminei plerumque eparaphysati. Columella pro more emergens capitata.

Habitus pedunculis longissimis, apophysi magna saepe pulcherrime umbraculiformi et theca parva cylindracea proprius speciosus, Tetraplodontibus proximus. Ab his genus Syluchmum calyptra conica valde recedit.

sect. I. Ampullaria. Apophysis ampullacea.

1. S. Wormskioldii Hornem. (Fl. Danic. tab. 1659.); monoicum; cespitosum clatum gracillimum valde ramosum inferne tomentosum; folia remota ovalia obtuse acuminata 


\section{STEGOCARPI. ACROCARPI. SPIACINEM.}

concara integerima evanidinervia; theca ovalis apophysi simili paulo majore et subconcolore praedita in pedunculo longo temissimo flavo brunnea, operculo comero parto; peristomii dentes 16 breves liberi subaerpidistuntes; columella immersa.

Bryol. Europ. I. c. p.7. tals.4. - Schwägr. Suppl. II. P.I. p.27. tals. 108. - Aplodon Wormslizoldii Roh. Brown. Vermischte schr. I. p. 442. - Eremodon W'ormskioldii Brid. 1. 1. 237.

Patria. In turfosis Norvegiae, Lapponiae et Americae arcticae Groenlandia et Labradore, ubi rulgatissimum lectum est. In fissuris rupium prope Gothal Groenlandiae primus legit Worm skiold. - Aestate.

Splachno sphacrico e thecae forma proximum sed inflorescentia, habitu multo graciliore, dentibus brevioribus aliter conformatis et columella immersa jam sat distinctum. - Flores masculi creberrimi in ramis propriis clongatis tenerrimis subnudis terminales. Folia perigonialia e basi vaginante fusco-colorata orali longe et olstuse acuminata reflexa. Paraphyses subclavatae. Flores feminei eparaphysati. - Plantae quoad magnitudinem variantes, dense rel compacte-cespitosae.

2. S. sphaericum Linn. fil. (Method. Muscor. p. 33. tab. 1. fig. 1.); divicum; laxe cespitosum molle robustius amoene viride; caulis laxe foliosus tener subelatus inferne subtomentosus; folia e basi angusta latissimo-ozulia longe acuminatu acuta intera vel obsolete denticulata, nervo in acumine evanescente; theca subcylindrica apophysi rutilante nitida globoso-obovali, operculo concexo mammillari praedita; dentes peristomii thecue longitudinem dimidiam ef ultra aequantes submarginati aurantiaci; pedunculus elongatus crassiusculus flexuosus rubellus; columella exserta.

Bryolog. Furop. 1. c. p. 8. tab. 5. - Hedw. Musc. Frond. li. p. 46. tah. 16. - Brid. I. p. 256. - splachn. intermedium Urumm. Musc. Amer. I. No. 39. peristomio breviori. - Spl. viride Vill. Fl. Dauph. p. 861. tal). 44. - Syl. ovatum Hedw. sp. Musc. p. 43, tal.8. - Brid. I. p. 253. - Phascum gredunculalum Hids. Fl. Angl. ed. II. siore. Dill. Musc. p. 34t. tah. 44. fig. 4. - Spl. gracile schwitgr. Suppl. I. P.I. p. 52. tab. 15. - Brid. I. p. 254. et spl. refractumej. 
Sp. Musc. I. p. 145. Spl. longisetum Schrank Baiers. Fl. II. p. 441. Spl. bavaricum Schrank e Brid. ohs. luc pertinet. - \$ \$ l. pusillum P. B. Prodr. p. 89. et Brid. I. p. 257.?

Patria. Locis umbrosis humidis in stercore bovino per regiones subalpinas et alpinas totius Europae haud rarum. Aestate.

Inflorescentia in junioribus plantis monoica, in fructiferis dioica. Planta mascula feminea gracilior. Flos masculus capituliformis terminalis, foliis perigonialibus e basi lata concara fuscescente vaginante longe apiculatis obsolete denticulatis $v$. integris reflexiusculis et paraphysibus longis apiculatis haud claratis. - De affinitate praecelentis observationes in antecedentem speciem conferantur.

3. ऽ. vasculosum Linn. (Spec. Pl. ed. II. p. 1572.); dioicum; humile subsimplex laxe foliosum late cespitosun; folia e basi angusta late orato-acuminata obtusissima integerrima evanidinervia; theca cylindrica, apophysi amplissima ventricosa pulcherrime pupurea, operculo hemisphaerico, columella exserta; dentes peristomii immarginati.

Bryol. Europ. 1. c. p. 11. tab. 7. - Brid. 1. p. 257. - Hedw. Musc. Frond. 11. p. 44. tab. 15. - Greville Scottish Crypt. Flora. tah. 179. et 311. - Spl. rugosum smith. Fl. Brit. 3. p.1173. - Spl. heterophylum Drumm. Musc. Amer. No. 37. varietas theca brevipedunculata apophysi parva ovali haud vix sphaerica differt. E reliquis autem notam nullam a spl. vasculoso essentialiter et acute distinguentem invenire potuimus.

Patria. Locis spongiosis et turfosis alpium Scotiae, et Scandinaviae. In turfosis montis Bructeri Hercyniae fructiferum legisse Ehrhart dixit. Nuperius nisi sterile a cl. Hampe inventum est. In America septentrionali in stercore animali crescens legit Drummond.

Planta mascula feminea gracilior; folia perigonialia e hasi lato-ovali vaginante longe acuminata obtusa evanidinervia integerrima. Antheridia magna valde curvata paraphysibus longis acuminatis mixta. Peristomii dentes geminati lato-lanceolati. - Ab omnibus congeneribus apophysi amplissima pulcherrime purpurea jam primo ad- 
spectu distinctum. 'Theca matura siccitate rugulosa. Aestute.

4. S. ampullaceum Linn. (Spec. Pl. p. 157:); monoicum et dioicum; laxe cespitosum subhumile parce ramosum densiusculo foliosum; folia e basi brevi-angusta lato-oralia longissime acuminatu versus apicem remote sed urgute saepe ciliuto-dentata; nervo ante apicem evanido; theca cylindrica majuscula, apophysi longicollu resiculoso-umpla pulchre colorata lutea rel purpurascente et operculo conico-convexo praedita; dentes peristomii praecedentis sed longiores.

Bryol. Europ. I. c. p. 10. tal. 6. - Brid. I. p. 259. - Hedw. Musc. Frond. II. p. 41. tab, 14. - Syl. Turnerianum Dicks. II. PI. Cryut. p. 3. tah. 10. fig. 11. et Brid. I. p. 260. Nyl. sagittaefolium With. p. 791. tah. 18. fig. 2. - Bryum ampullacenm, foliis thymi pellucidis, collo strictiore Dill. Musc. p. 342. tah. 44. fig. 3.

Patria. In turfosis planitierum copiosissime, in editioribus raro; per totam Europam et Americam septentrionalem fimo animali insidens. - Julio.

Inflorescentia monoica rel dioica. Flores masculi in ramulis rel ramis gracillimis terminales. Folia porigonialia e basi lato-ovali longissime linealia subulata denticulata evanidinervia. Paraphyses longae subrlavatae. Peristomii dentes praecedentis. - Ab ommibus Splachmis apophysi longa resiculari ampla distat.

Sect. UI. Lmbracularia. Apophysis unbraculiformis.

5. Spl. rubrum Linn. (Fl. Suec. p. 963.); dioicum; humile laxe cespitosum, subsimplicissimum; folia obovata longissime acuminata, nervo subexcurente praedita, e medio denticulata, apicem versus serrala, magna undulato-complicata; theca in pedunculo longissimo purpurascente oborala minuta sicca rylindrica, operculo convexo, apophysi mulchervime purpurea; peristomii dentes dorso membrana cancellata praediti.

Bryol. Europ. 1. c. p. 11. tab. 8. - Liun. Amoenit. Acad, ed. 2. 11. p. 220. tah. 3. fig. 2. - Hedw. Muse. Froml. II. 1. 51. tah. 18. Brid. 1. p. 262. - Muscus norvegicus umbraculo ruberrime insignitus Dill. Musc. p. 3547, (ab), 83. fig. 9. 
Putria. In turfosis humidis atque sylvaticis, Norvegiae, Lapponiae, Finnoniae, Sibiriae nec non totius Americae arcticae. Anno $\mathbf{1 6 9 5}$ a $\mathrm{R}$ ich. Wheler in Norvegia prope Portsgrund detectum. Prope Gatschinam et Nowogorodium Rossiae indicit cl. Wreinmann. - Aestate.

Apophysis junior vesicularis oblonga pallida dehine umbraculiformis pulcherrime purpurea. De colore cl. Wahlenberg (in Fl. Lappon. p. 307.) verba sequentes fecit: Color umbraculi adeo saturatissimus et elegantissimus, ut nihil in natura pulchrius esse queat; qui color adfuso acido ex gr. nitrico quidem dilutior fit et ab alkali obscurior, sed a neutro prorsus mutatur, ut inter constantiores colores vegetabiles numerandus est. A prima infantia saturatissime purpureum est umbraculum, nec in senectute mutatur. - Planta mascula feminea multo gracilior, foliis remotis. Folia perigonialia e basi latissima concava convoluta longe acuminata angusta valde serrata evanidinervia. Paraphyses longae clavatae. Antheridia majuscula curvata. - Peristomii dentes dorso membrana cancellata obtecti quibus et theca obovata apophysi purpurea praedita, foliis magis serratis sporisque minoribus a sequente refugit.

6. S. Iuteum Linn. (Fl. Suec. n.964.); dioicum; humile laxe cespitosum subsimplicissimum; folia obovata longissime acuminata, nervo subexcurrente praedita integra rel apice denticulata magna undulato-complicata; theca in pedunculo longissimo purpurascente oralis sicca cylindrica minuta, operculo convexo conico, apophysi lutea sicea magis expansa planiusculo-umbraculiformi; peristomii dentes dorso membrana cancellata carentes.

Bryol. Europ. 1. c. p. 12. tals. 9. - Linn. Amoenit. Acad. ed. 2. 11. p. 254. tab. 3. fig. 1. - Hedw. Musc. Frond. 1I. p. 48. tab. 17. Brid. I. p. 260.

ß. melanocunlon; partibus omnibus minor, pedunculo perbrevi crassiusculo intense purpureo, apoplysi pallidiore. sinl. melanocaulon schwiagr. suppl. II. P. I. p. 2x. tab. 109.! Brid. I. p. 261.

Patria. In iisdem locis antecedentis sed saepins occurrens ef in Gothia Sueciae. Ad lacum Ladoga imperii 
Rossici lectum cl. We inmann designavit. - Anno 1840. a P. ab Adlerheim in Westrobothnia, a Montin serius in monte Snirak detectum. Var. $\beta$. in Kamtschatka a cl. 'Tillesio lecta. - Julio. Augusto.

Inflorescentia, folia perigonialia, antheridia et paraphyses antecedentis. - De affinitate observ. in Spl. rubrum conf.

Splachnaceac suspectac.

1. Eremodon Magellanicus Brid. (I. p. 236.); caulis erectus subdivisus folia oblongo-lenceolata acuminata serrata evanidinervia pedunculis aggregatis, thecae oblongae ovatae apophysis obconica, operculum convexum, peristomii dentes octo. $t$.

Splachnum Magellanicum Scliwägr. Supur. I. P. I. p. 47. tab. 14.

Patria. In freto Magellanico: Commerson.

Peristomii dentes solitarii aequidistantes e basi latissima lanceolati subtriquetri, apice acuto incurvi, madore connirentes, minime reflexiles, linea media longitudinali apicem non pertingente exarati trabeculati, pallide e luteolo rubelli. - Calyptra deest. - Forsan Dissodon?

2. Splachnum longicollum Schwägr. (Suppl. II. P.2. p. 87. tab. 178. excl. syn. Dicks.); caulis simplex; folia spathulato-oblonga acuta ruptinervia denticulata; theca subglobosa apophysi attenuata. $†$.

Patria. In Africae promont. bon. spei: A. Menzies.

Peristomii dentes 16 aequidistantes erecti. Forsan Entosthodon?

3. Splachnum Juressi Schwägr. (Suppl. I. P. 1. p. อૅ.5.); ,elegans species, ut videtur Lusitanica, cujus peristomium vero mihi deest." $\uparrow$. Caetera desiderantur *).

*) Praecedentes species tres ex autopsia cognoscere, ad Ih. Schrïgrichenianum iter fecimus. Possessor antem Schwägrichen, professor scicntiarum naturae atque bryologus dictus, hb. Hedwigii, sed minime animi patris bryologorum, heres, inspectionem quam maxime inhumauus nos recusavit. 


\section{Trib. XII. DISCELIA CEAE.}

Gregariae humillimae acaules in protothallo viridi positac terrestres. Folia vaginantia appressa oblonga aruminata enervia, e cellulis basi et apice laxis rhomboidali-prosenchymaticis chlorophyllo carentibus fuscescentibus inanibus composita. Theca subglobosa inclinata collo brevi praedita annulata longe jedunculata. Inflorescentia dioica. Flos masculus et feminens in unico filo protothalli. Antheridia minuta ovalia. Jaraphyses breves, ex articulis brevibus apice subclavatis constructae. Archegonia brevia crassinscula.

Plantae habitu proprio, Ephemerorum vegetatione, Catoscopii theca, Trematodontis peristomio. $\odot$.

Patria. Terra argillosa ad rivulos in turfosis hemisphaerae borealis.

Disceliaceae Bryol. Europ. Fasc. XXIX et XXX. Discelium. Funariaceae C. Müll. Bot. Zeit. 1813. p. 505.

\section{Gen. I. Discélinm Brid.}

Bryolog. univ. I. p. 365. - Bryolog. Europ. 1. c. - W'eisias Schwägr. Hook. Wahlenh. - Coscinodon Brid. Mant. - Grimmia Turn. Brid. Sp. Musc, - Bryum Dicks.

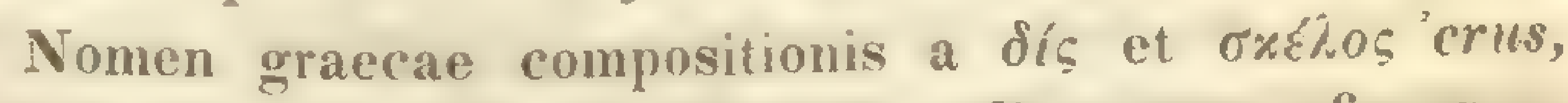
ob dentes in crura duo e basi ad medium usque fissos.

Calyptra longiuscula angustissima fere usque ad apicem fissa medio latior, basi margine utrinque involuta. Peristomium simplex e dentibus 16 lanceolatis medio fissilibus trabeculatis striatis cartilagineis rufescentibus vel a urantiacis formatum.

1. D. nudum Brid. (I. p. 366.); folia dense imbricata integra v. denticulata; theca in pedunculo elongato dextrorsum valde torto subglobosa, operculo conico obtusiusculo instructa; annulus tenerrimus pellucidus e cellulis magnis duplicibus conformatus. 
Bryol. Europ. 1. c. p. 4. tab. 1. - C. Mïll, 1. c. p. 505. tab. 2. Coscinodon nudus Brid. Mant. Musc, 1). 48. -- Weisia nudu Hook. et Tayl. Musc. Brit. p. 43. tab. 14. - W. incarnata sichwägr. suppt. 1. P. 1. p. 66. tab. 18. - W. rosea Wahleub. F. Lapp. p. 325. Grimmia nuda Turn. Musc. Hib. p. 25. - Bryum nudum Dicks. Fasc. IV. P1. Crypt. p. 7. tab. 10. fig. 15.

Patric. Per Galliam septentrionalem, Britanniam et Scandinaviam totam. E rarioribus. - Primo reve.

\section{Trib. XIII. B UXBA U I I C EAE.}

Gregariae quam maxime humiles acaules microscopicae in tomento radiculorum fusco positac. Folia parva plana, e cellulis parenchymaticis minuliusculis hexagonis vel polygonis paucis fuscis chlorvphyllo carentibus inanibus composita. Theca in pedicello elongato crasso carnoso valde scabro omninu muscorum maxima obliqua, uno latere maxime ventricosa, altero latere dorsali oblique erecta, basi cyathiformis et articulate in peduncnlo posita, e toto habitu fungoidea, operculo conico-obtuso recto carnoso pracdita peristomata. Inflorescentia monoica. Archegonia minuta crassiuscula $3-4$ terminalia. Paraphyses nullac.

Nulla alia tribu comparabiles memorabiles valule speciosae, ab auctoribus olim Fungis adnumeratac maxime solitariae. E thecae forma Diphyscio subaffines.

Patria. Ad declives humidos praecipue massa organica gelatinosa obtectos sylvarum umbrosarum vel in ligno putrido utriusque hemisphaerae rarae. $\odot$

Bu.rhaumiaceae Bryolog. Kurop. Fasc. I. Buxbrumia; cxcl, DiWhyscium genere, cujus folia structura maxime aliena praedita sunt.

\section{Gen. I. Tuxbanmia Hall.}

Haller Hist. Stirp. Helvet. 2. p. 83. 11. 27. - Buxhaum, Centu:. Plant. min. cogn. Petroy. 17\%. etc. - Bryolog. Europ. I. c. - Brid. 1. p. 328. - Saccophorum Pal. Beauv, 1'rodr. p. 29. - Hiplopodium Fabric. 
Nomen in honores medici Burbaum, botanici meriti qui ora terrarum orientalium indefessus peregrinavit tandem plantarum imperii Rossici centurias editit, floram Iallensem quoque haud malam scripsit, impositum. Genus in menorian patris Buxbuumium primum nominare ipse voluit, sed, dicit, venit mihi in mentem rulpes, qui deridebatur ab aliis, quod uvas non pro se, sed pro acgrota posceret matre.

Caly jitra cylindrico-campaunlata parva ojerculum tegens fugax coriacea, interdum latere fissa. Peristomium duplex: exterius nunc membrana solida irregulariter inciso-emarginata e strato collularum duplici conformata opaca et obscure rufescens, nunc dentes inaequales moniliformi-articulati vallorum instar angusti solidi; interius membrana albida tenerrima in conmm tubulosum producta valule acute-angulato-plicata, siccitate leviter tortuosa angulosa. Columella in operculum exserta et cum eodem decidua.

1. B. Aphylla Ialler (1. c.); folia inferiora ovala profunde dentata, superiora palmato et longissine ciliata; theca nitida, latere ventrali membranacea, dorsali lirma, peristomio exteriori membrunuceo.

Bryolog. Europ. I. c. tals. 1. - Burb. rulgaris Brid. I. p. 329. - Burb. caule cens. Schmid. Diss. de Buxhammia p. 25. 1. c. ic. Hiphopodium aphyllum Fabric. FI. Butisl). p. 31. - Saccophorus "1phyllus P. B. Prodı. p. 30. et 87. - Muscus capillaceus, aphyllus. Buxl), Cent. 11. p. 18. tah, t. fig. 2. et Dill. Musc. 1). 477. tah, 68. fig. 5.

Putria. Terrestris per regiones temperatiores totius Europae, Asiae finitimae et Americac septentrionalis. Prope Astracanum in vado Volgae primus omnium invenit Buxbaum. - Majo. Junio.

2. B. indusiata Brid. ( I. p. 331. tab. Suppl. II.); folia pracedentis; theca longiore oblonga acutione, latere ventrali membrana tenerima revolubili; peristomio exteruo dentato valliformi pallido. 
Bryol. Europ. 1. c. p. 6. tah. 2. - Buxb. aphylla $\beta$. viridis Moug, et Nestl. Stirp. Crypt. VIII. No. 724.

Putria. In ligno putrido vel terrestris, in iisdem locis praecedentis. In alpibus Sanensibus Ielvetiae anno $1796 \mathrm{Cl}$. B ridel primus legit; in Calabria, in Vogesis, Alsatia, prope Caesaream Lutram, Hanoviam, in agro Manhemiensi et in Hercynia superiore. - Mujo. Junio.

A praecedente peristomio certe distat. et rarior.

3. H. Javaniea C. Müll. (mst.); folia oblonga subacuminata angusta subintegra nunguam dentata vel ciliata; theca minore, latere ventrali ac dorsali solida, peristomio externo dentato valliformi aurantiaco.

Buxb. aphylla $\beta$, minor Hmp. in litt.

Patria. Java insula: J un g hu hn.

A praecedentibus notis illustratis valde differt. Operculum et calyptra desunt. Species sui generis tertia excellentissima.

\section{Folia dense areolatu.}

\section{Trib. XIV. M N I O I DEA A.}

Plantac acrocarpicae vel pleurocarpicae. Folia lato-ovalia spathulata vel ovalia vel lanceolata planiuscula, nervo crasso dorso valde prominente praedita, Areolatio basis: cellulae subparallelogrammae, apicem versus rotundato-hexagonae vel parielibus aequalibus praeditae, chlorophyllo valde repletae, vel utriculo primordiali plerumque valde conspicuo, vel valde incrassatae, firmae, rarissime papillosae.

\section{Subtrib. I. M N I A C A E.}

Late ct laxe cespitosae elatiusculae vel liumillimae stolonibus repentibus foliosis plerumque praeditae acrocarpicae vel plenrocarpicae. Folia e basi plus minus oblonga lato-ovalia vel spathulata vel lingulata vel ovalia. Theca ovalis, pyriformis vel cylindrica annulata. 
Ilabitus bryoideus, sed foliis firmis rigidis saepe amoene undulatis et plantis apicem versus plerumque pulcherrime crescentibus speciosus proprius. - Plantae Bryaceis ex habitu proximae quiden, sed tamen areolatione foliorum propria distinctissimae.

Putria. Loci humidi saepe turfosi profundi tam planitierum quam montium atque alpium utriusque hemisphaerae. Vita terrestris atque arborea. $2 /$.

Bryaceae auct. Bryol, Europ. Fasc. V. Muinm. - Tetraphideae Bryol. Kurop. Fasc. XVII. - Rhizocarpi Brid. II. p. 663. - Aulacomniaceae C. Müll. olim portentae.

\section{Gen. I. Cinclidium Swartz.}

Sw. in Schrad. Bot. Journ. 1801. 1. p. 25. tah. 2. Brid. I. p. 714. - Mnium Br. et Sch. Bryolog. Europ. Fasc. V. - Amblyodon P. B. Prodr. - Meesia Brid. Musc. Hec. 1I. 3. p. 172. ductum.

A xıyxdic cuncelli, ob peristomii interni foramina

Habitus, vegetatio, calyptra et inflorescentia Mnii generis, sed peristomium internum; membrana cupuliformis, foraminibus sedecim dentibus exlernis oppositis, apice aperta, 16 plicala. Dentes exlerni breves truncati.

1. C. stygium Sw. (1. c.); hermaphroditum; dense cespitosum elatum gracile, ramis fructiferis atque sterilibus erectis tomentosis; folia inferiora remota rotundatoovata subobtusa purpurascentia, summa in rosulam congesta, e basi brevissima angusta latissime ovata rotundato-obtusa, nervo excurrente in mueronulum brevem producta, laxe marginuta densius et firme areolutu; theca pendula ovalis brevis busi subapophysiformis crassu, operculo hemisphaerico mumillato; peristomii interni dentes breves lati pallidi; interni membrana aurantiaca, columnis laevibus.

Brid. 1. p. 714. et auct. prior. - Mnium Cinclidium stygium Bryol. Europ. 1. c. p. 17. tab. 1. - Meesia stugia Brid. Musc. Rec. 11. 3. p. 175. - Amblyodum stygium P. B. Prodr. p. 41.

Patria. In turfosis profundis Germaniae septentrionalis sparsim sed raro fructificans. Bavaria prope Moosach 
hucusque tamen sterile: Sendtner. In paludosis turfosis alpium 'Tirolis, Carinthiae et Salisburgiae frequentius fructiferum. In iisdem locis totius Scandinaviae, Daniae, Gothiae, Norvegiae, Sueciae, Lapponiac atque Finlandiae haud raro et, ut videtur, frequenter fertile. Prope U'psaliam a Cl. Swartz primum detectum. E Labradore fructibus creberrimis gaudens inter Iypna adunca legimus. - Julio. In alpibus superioribus Augusto et $S e p-$

\section{- tembri.}

Per longa tempora generis pulcherrimi species unica nota, sequenti proxima quidem, sed tamen distinctissima. Cespites lati maxime tomentosi, inferne nigricantes, superne viridescentes rel purpurascentes. Antheridia maxima, paraphysibus maximis clavatis. Archegonia magna paraphysibus filiformibus sed crassis. Folia perichaetialia lanceolata integra vel apice denticulata immarginata excedentinervia. Fructus raro geminati. Annulus imperfectus, in operculi basi persistens. Dentes externi siccitate reflexi, dein inflexi, humiditate erecti, cupulac foramina claudentes.

2. C. areticum Br. et Sch. (Bryol. Europ. Fasc. XXXI. Mnium. Tab. Suppl. I.); disicum; ex habitu prioris sed foliis oborato-orbicularibus apiculatis, margine tumido nitidis integerrimis, siccitate subundulatis laxe imbricatis; theca exammulata elliptica longicolla, operculo atte convexo papillato; dentibus peristomii externi longioribus angustiovibus, interni membrana columnis appendiculatis ralde pertusis.

Patria. In Norvegiae alpe Dovrefjeld, ubi loca uliginosa retro Kongsvold ad montem Knudshöc, sociis Meeseu uliginose, Pahudella stpurvosu, Hymo nitente et Dissodonte splachnoide, aestate 1814. W. P. Schimper detexit. Ad finem Julii.

Planta mascula femincae intermixta gracilior, caule sul) flore discoideo folis destituto. Pulcherrima species!

Gen. II. VIn IIm Dill. Limn. cmend.

Mnium Dill. Linn. - Mnium, Bryum et Arrhenopterum Brid. Hedw. - Gynnocephalus schw, - Fusiconia P. B. - Orthopyxis 
P. B. - Hypnum Wel, et Molır. - Polla Brid. - Aulucomnion Schwägr. et Bryol, Europ. - Rlizogonium Brid. et al.

Nomen Mnion a botanicis antiquissimis scriptum a uviov muscus ductum. Dillenius in ITist. Musc. p. 229 Mnium scripsit et nomine hoce pro Aulacummiis et aliis muscis usus est. Linnaens primus muscos nonnullos, Mnie nunc temporis appellatos, hocce nomine designarit.

Calyptra conico-dimidiata parva fugacissima. Peristomium duplex. Exterius: dentes 16 lanceolati cuspidati extus trabeculati linea longitudinali praediti, intus lamellosi carnosuli flavescentes. Interius: membrance carinato-plicata, in dentes 16 lanceolatos latos carinatos grandi-pertusns cupuliformiconniventes, dentes externos supcrantes, ciliis filiformibus $2-4$ interjectis producla. Inllorescentia terminalis dioica vel monoica. Flos masculus discoideus paraplusibus clavaeformibus ut in Funarioideis, basi infima pluries brevissime articulatis; femineus et hermaphroditus gemmiformis paraplysibus filiformibus.

Sectio I. Eumnium. Theca myiformis, chraeformis, oralis plerumune pendulu laevis. Folia e ccllulis majoribus composita. Inflorescentia terminalis.

\section{A. Folia marginata.}

a. Folia integra.

1. Mn. punctatum Hedw. (sp. Musc. p. 193.); dioicum; subsimplex erectus; folia orbiculari-sputhulutu e cellulis pellucidis tencris basi majuseulis apicem versus ad latera minoribus arctioribus rhomboidali-hexagonis conformata lato-marginata integerrima obtusissima vel brevissime apiculata vel apice emarginata, nervo crassissimo purpurascente ante apicem evanido pracdita remota patula subhorizontalia; theca ovalis inclinata pallescens, operculo conico rostrato subrecto.

Bryolog. Europ. 1. c. p. 19. tab. 1. - Bryume Polla punctuta Brid. I. p. 706. - Mn. serpyllifolium Hofín. Deutschl. Fl. II. P. 58 ; 
forma humilior, in omnibus partibus minor tenella, theca subglobosa. - Bryum serpyllifulium Swartz. Musc. Suec. P. 51. - Bryum punctatum schreb. Spic. FI. Lips. P. 85. - Hypnum punctatum schrank. Prim. Fl. Salisb. n. 847. - Weh. et Mohr bot. Taschh. p. 296. - Bryum pendulum serpylli folio rotundiore pellucido, thecis ovatis. Dill. Musc. p. 416. tab. 53. fig. 81. A. - 0. - Bryum Polla elliptica Brid. 1. p. 705. Caulis sterilis!

Patria. In locis humidis rupestribus, ad fontes rivulosque sylvestres praesertim, rarius in paludibus; per totam Europam, Americam septentrionalem ac regiones temperatas Asiae atque Africae sat copiose. - Primo vere.

Caulis sterilis plerumque erectus rarius descendens. Planta mascula gracilis paucifolia. Folia perigonialia interiora angusta lanceolata obtusiuscula reflexa tenuiter marginata.

2. Mn. subglobosum Br. et Sch. (Bryol. Europ. Fasc. 31. Suppl. I. Mnium. p. 3. tab. Suppl. III.); helmaphroditum; e reliquis praecedenti perfecte simile foliis autem laxins reticulatis; theca subglobosa minor.

Mn. Mnctatum var. subglobosum Hmp. hl. - Mn. pseudopunctatum Br. et Sich. in Lond. journ. of bot. Vol. 1I. 1843. p. 669. - Bryum mnioides Wils. in Lond, journ. 1813. Fasc. mens. Decemb. et 1844. p. 427. - Mnium punctatumb Drumm. Musc. Amer. No. 253.

Patria. In turfosis montis Bructeri ad Heinrichshöhe: If ampe. Anglia prope Todmorten comit. Lancashire: J. Now ell. In Alpe Dorrefjeld Norvegiac: B lytt, W. P. Schimper. In Canada et Rocliy Mounts: Dru m mond.

Sporac duplo majores quam illae Mrii punctuti.

3. Mn. hymenophylloides Hüb. (Muscol. germ. p. 416.); dioicum; caulis adsendens ramosus humilis tenellus ater; folia remota vix imbricuta erecta rotundo-ovalia parva subplana, nervo crassiusculo purpurascente ante apicem breviter acuminatum evanido praedita, tenuiter marginata amoene viridia v. flavescentia coriucer.

Bryolog. Europ. Fasc. V. p. 37. tab. 15.

Patria. Id rupes abruptos humidos, Anocetangii compucti, Mnii orthorrhynchi, Mn. Hymenophylli et Desmatod. latifolii societate in alpe Dorrefjeld Norvegiae prope 
Kongsvold, ubi aestate anni 1828. legit Hübener. In Lapponia: Ângström. In alpibus Tyrolensibus: Funck. In rupib. calcar. humid, montis Splïgen Rhaetiae: W. P. Schimper.

Planta tenella elegantissima omnium minima filicoidea sequenti proxima. 'I'heca ex observationibus auctoris, tamen dubitabilibus, "pendula oblongo-ovata, operculo hemisphaerico umbonato."

4. Mn. Hymenophyllum Br. et Sch. (Br. Europ. Fasc. 31. Suppl. I. Mnium. p. 5. tab. Suppl. V.); divicum; dense cespitosum robustius minus fragile; folia approximutu decurrentiu erecto-patentia submarginata late ovatoacuminata basi minus angustata, e glaucescente laete viridia inferne rufescentia. $t$.

Patria. In Norvegiae alpe Dorrefjeld prope Kongsvold, ubi in rupium fissuris et ad terram sub rupibus socia Timmia Megapolitana cespitibus pulcherrimis occurril: W. P. Schimper 1844.

A praecedente regetatione dense-cespitosa et foliis angustius marginatis, basi latiori valde decurrentibus primo intuitu monente Schimpero distinguitur. - Flores masculi discoidei.

\section{b. Folia dentata.}

5. Mn. Blyttii Br. et Sch. (Br. Europ. Suppl. cit. p. 6. tab. 5.); divicum; dense cespitosum elatum gracile; folia ovali-oblonga et spathulato-acuminata e cellulurum unica serie marginata, inferiora integra superiora apicem versus molle dentatu madefacta ceruginosa, parva.

Putriu. Ad terram umbrosam locis rupestribus in Norvegiae alpe Dovrefjeld inter Kongsvold et Drivstuen, praeprimis ad Vaarstien: W. P. Schimper 1844.

Mn. stelluri ex habitu proximum, e foliorum forma autem longinquum. - Flos femineus Mnii stelluris. Flos masculus ignotus. E distinctissimis.

6. Mn. Drummondii Br. et Sch. (Lond. journ. of bot. Vol. II. 1843. p. 669.); hermaphroditum; dense ces- 
pitosum subsimplex clatum; folia caulina e hasi angusta oblonga laxe ureolata latissime oralia mucronuto-acuminatu tenuiter marginata e medio usque ad summum apicem incerualiter suepe ciliuto-dentutu, nerro unte apicem eremido; theca ovalis pendula breviuscula, operculo conico brevi acuto.

Mn. spinosum Hook. in Drummond. Musc. Americ. No. 25\%. Mn. affine Sulliv, Musc. Allegh, p. 26.

Patria. America septentrionalis in sylvis prope flumen Smoking dictum: Drum mond.

MU. spinoso ex habitu affine, foliis autem tenuioribus, anguste marginatis, dentibus marginis Jongis inaequalibus ciliato-acutis simplicibus tenuibus haud mucronatis theca tandem valde distans. - A Mnio affini differt foliis e cellulis basi laxiusculis apicem rersus minoribus, parictibus crassis viridescentibus pracditis, pellucidis, composita, et inflorescentia. Folia perichaetialia intima angustiora longe acuminata et longe ciliato-dentata, e reliquis caulinis similia. Paraplyyses filiformes acutac.

7. Mn. rostratum Schwägr. (Suppl. I. P. 2. p. 136. tab. 79.); hermajhroditum; ex innovationibus longe repentibus adscendens laxe cespitosum subhumile, robustum; folia apice rosulato - congesta orali-oblonga latissima basi subangusta fare et lato-marginata brevissime mucronatu - excurrentinervia, remote et breviter denticulata dense areolata; thecae solitariae vel aggregatae nutantes ovales, operculo conico-rostrato ore purpureo-annulato e reliquis flavescente praedita pallida, olivacea, aperta dein ochracea.

Bryolow. Europ. Fusc. 5. p. 27. tal. 7. - Bryum Polla rostrata Brid. I. 1. 700. - Bryum rostratum schrad. Sip. Fl. Germ. p. 72. Br. longirostrum Brid. Mant. Musc. p. 119. - IIymum rostratum Wel. et Mohr. Bot. Taschb. p. 296. - Bryum serpullifolium B. Ifuds. Fl. Angl. p. 492. - Mn. cylindricum Hoffm. 1)eut. Fl. p. 32. e syn. Dill. monente Bridelio. - Mn. ellipticum ej. monentilus Web. et Mohrio Bot. Taschll. p. 296. - Bryum pendulum serpylli folio Iongiore pellucido, thecis oblongis cuspidatis. Dill. Musc. p. 415. tab. 53. fig. 80. A. B. C. - Mn. ramosum Hook ic pl. rar. tah.20. fitr. 2. et Lond. journ. of bot. 1nt0. Vol. 11. d. 11, var. $\beta$. foliis achminatis angustioribus, - Mn. vhynchophorum Hook, ic. pl. rar. 
tal). 20. fiu. 3. et Lond. journ. of bot. 1840. Vol, II, p. 11. var, ${ }^{\prime}$. robustior foliis latissimis suborbicularibus.

Patria. In umbrosis ad terram et saxa per totam Europam vulgare. E regno Nepalensi, ex insula Jara, Chile et Columbia (Jagi prov. Merida, ubi Moritz legit) habemus. I'ar. $\beta$. e Nepal; $\gamma$. e Penang et India boreali: Wallich. - Vere.

Calyptra omnium maxima per longum tenipus persistens. - Sequenti affine, sed foliis obtusis et operculo longirostri jam primo adspectu distinctissimum.

8. Mn. affine Bland. (Musc. exsicc. Fasc. III. No. 153.); dioicum; erectum subsimplex elatiusculum; folia caulina e basi breviter oblonga latissima oralia nervo excurrente longiusculo-cuspiduta lato marginata undulata "ryute serrala; cellulae ad nervum longiusculae in sericbus obliquis reticulatac rhomboidales, latera versus minores, ommes purictibus temibus praeditur flarescentes innnes subcompressce; perichaetialia c. 4 , cxteriora spathulato-angusta undulata marginata serrata, intima integra, omnia nervo excurrente longe-cuspidata, e cellulis longiusculis areolata; theca longe-pedunculata ovalis pendula, operculo hemisphuerico-conico brevi-acuto vel mumillato.

Bryol. Hurop. Fasc. Y. p. 30. tah.9. - Brym Polla affinis Brid. 1. p. 701. - Mnium cuspilatum ק. Hedw. sp. Musc. p. 193. tab. 45. - Muscus squamosus fulis latis subcotumdis. Tourn. Mill. Musc. p. 414. tab. 53. 79 M.

B. ciliure; folia caulina ciliato-serrata; perichactialia c. 5, cxteriora angusta spathulata apice undulato-plicata marginata serrata, intima immarginata dentibus subrecurvis pracdita rel obsolete-denticulata. Bryum ciliare Grev. Annals of the Lyc. Nov. Hvaborac, 1825. p. 275. tab. 23.

$\gamma$. clatum; flores feminei discoidei, paraphysibus clavatis, steriles, foliis involucralibus perichactialibus plantae fertilis similibus. Bryol. Europ. Fasc. V. tal. 10.

d. Rugicum; lumilior compactior; foliis obtuse serratis; folia caulis sterilis subcircularia. Mn. Rnyicum Laurer 
in Regensb. bot. Zeit. 1827. p. 292. - Mn. affine $\%$. Rugicum. Bryolog. Europ. Fasc. V. tab. 11.

Putria. In nemorosis humidis Europae mediae, rarius tamen fructiferum et in Caucaso. Var. $\beta$. in Canada prope Montreal; prope Albany lectum in herbario asservamus. Var. $\gamma$. in locis humidis graminosis Vogesorum. - Var. $\delta$. in liumidis ad "Herdasee" insulae Rugae: La urer. - Aprili. Majo.

Caulis sterilis decumbens reptans. Thecae saepe geminatae. - A Mnio cuspidato inflorescentia dioica, foliis excurrentinervibus e basi usque ad apicem serratis et habitu robustiore differt.

9. Mn. medium Br. et. Sch. (Bryol. Europ. Fasc. V. p. 32. tab. 12.); hermuphroditum; rami fertiles elongati simplices rarius ramos steriles graciles cmittentes; folia inferiora remota majuscula ovato - acuminata, terminalia oblongo-acuminata, basi angustata, omnia angusta marginata, argute serrata; pedunculi solitarii vel geminati; theca ovata oblonga, inclinata pendula, operculo subconico recto.

Putria. In sylvis spongiosis Montis piniferi prope Gefrees: Funk; in iisdem locis Hercyniae in valle flum. Bode dicti: H a mpe; in Vallesia: 'Thomas; in Succiae Sïttna: Angström; in Alpibus Julicis: Sendtuer. Majo. Junio.

lnter Mn. affine et cuspidatum intermedium. A primo differt inflorescentia; a secundo foliis e basi jam argute dentatis majoribus undulatis tenuius marginatis laxius areolatis et operculo conico. E ceteris Mnio uffini simillimum.

10. Mn. cuspidatum Hedw. (Sp. Muscor. p. 192. tab. 45. fig. 5-7.); hermaphroditum; caulis erectus densiusculo cespilosus; folia ramorum fertilium patula decurrentia planiuscula, inferiora late obovato-acuminata, superiora majora angustiora; folia caulium reptantium rotundato-acuminata; ommic dense el minute areolata, granulis chlorophyllaceis valde repleta, marginata e medio us- 
que ad apicem acute-dentata, nervo crasso obscuro viridi praedita, mollia viridissima; theca aperta valde ochracea ovalis crassa, operculo convexo interdum mamillato praedita nutans; peristomii interni membrana aurantiaca valde perforata.

Bryolog. Europ. Fasc. V. p. 29. tah. 8. - Bryum polla cuspidata Brid. I. p. 702. - Bryum cuspidatum Schreb. Spic. Fl. Lips. p. 84. - Br. polymorphum Neck. Metlı. Musc. p. 218, - Br. serpyllifolium $\gamma$. Huds. Fl. Angl. p. 492. - Br. pendulum, folis variis pellucidis, thecis ovatis. Dill. Musc. p. 412. tal). 53 fig. 79. A - L. - Mn. serpyllifolium. $\beta$. cuspidat um Linn. Sp. PI. p. 1577. Hypnum cuspidatum schrank. Baiers. Fl. 11. p. 471. - Hypn. aciphyllum Web. et Mohr. Bot. Taschb. p. 295 excl. Mn. affini Bland. syn.

Patria. In sylvis humidis, ad radices arborum per totum orbem terrarum late cespitosum vulgatissimum. Vere.

Ab omnibus congeneribus peristomii interioris membrana constanter perforata recedit. Nervus excurrens vel ante apicem dissolutus.

11. Mn. undulatum Hedw. (Sp. Muscor. p. 195.); dioicum; latissime et laxissime cespitosum longissime repens, ramis erectis ascendentibus simplicilus vel apice dendroideo-divisis; folia ligulata valde undulata reflexiusculu patula apice obtusiuscula vel nervo excurrente brevissime cuspidata, densissime et minutissime areolata argute serrata; thecae valde aggregatae ovales inclinatae pendulae purpureae, operculis conico-acutis pedunculisque purpureis praeditae.

Bryolog. Europ. Fasc. V. p. 20. tab. 3. - Bryum Polla lignlata Brid. 1. p. 708. - Br. ligulatum schreb. Spic. Fl. Lips. p.84. - Br. undulatum Roth. Fl. Germ. 11. P. 1. p. 249. - Br.dendroides, polycephafum, phyllitidis folio undulato pellucido, thecis ovatis pendulis. Dill. Musc. p. 410. tab. 52. fig. 76. A E. - Нypnum undulatum Schrank. Baiers. F1. II. p. 474. - Hypn. liyulatum Weh. et Mohr. Bot. Taschb, p. 298, - Polytrichum undulatum Schrank. Prim. FI. Salisb, n. 825.

Putria. In umbrosis humidis graminosis etiam cultis totius Europae. In insula Borbonis et ad Prom. bon. spei lectum est. - Primo vere.

C. Miller: Synops. masc. Frond, 
Ab nmmibus congeneribus habitu elegantissimo dendroiden folisque ligulatis utrinque transverse undulatis distinctissima ac pulcherrima species.

\section{c. Folia duplicato-serrata.}

12. Mn. spinosum Schwägr. (Suppl. I. P. 2. p. 130. tab. 78.); dioicum; caulis erectus subsimplex; folia decurrentia, oblongo-lanceolatu, nervo excurrente cuspidata, c busi usque al aprem dense areolata, firma, dentibus fuscescentibus e medio argute serrata, incrassato-marginata; perichactialia intima lanceolata angusta longiusculo-cuspidata, vix marginata, dentibus pellucidis valde serrata; theca breviusculo-pedunculata incliuata v. nutans oralis, operculo conico acuto subobliquo.

Bryolog. Europ. Fasc. V. p. 26. tab. 6. - Brylum spinosum Voit. in sturm. HI. Germ. Crypt. XI. tal). 16. - Br. Polla spinosa Brid. I. p. 701. - Mn. cuspidlutum $\beta$. Hedw. Sp. Musc. p. 193. tal. 45. fig. 7. - Mn. serpyllifoliun $\beta$. cuspidatum Linn. Sp. PI. p. 1578.

Putria. In sylvis praeprimis pinetis humidis montium; in monte pinifero prope Gefrees; in valle alpestri Carinthiae prope Ileiligenblut; in Saxonia et Helvetia. E rarioribus. - Vere, in alpibus m. Augusto et Septembri.

Caulis sterilis simplicissimus erectus. - Ex labitu Mn. orlhorhyncho simile, sed areolatione foliorum dense rotundato-hexagona firma et forma, fructibus tandem plerumque aggregatis facillime distinguitur.

13. Mn. spinulosum Br. et Sch. (Bryol, Europ. Fasc. 31. Suppl. p. 4. tab. 4.); hermaphroditum; e reliquis notis Mnio spinoso simillimum; folia infima basi tenuins ureolutu late obovata basi valde angustata decurrentia, perichactialia oblongo-spathulata, omnia margine tumido purpmereo e medio usque ad apicem argute serrato instructa, Hervo excurrente acute cuspidata teneriort; fructus siepe ageregati, theca evacuata pallidiore peristomio intense rufo, operculo conico-rostrato suboliquo.

Patria. In terra sylvatica prope Iglau Moraviae: Dr. Grüner. Tirolis. - Junio. 
Caulis sterilis e basi fertilis natus erectus v. apice subincurvus. - A praccedente proximo regetatione densius cespitosa, foliis minus viridibus tenuius spinosis tumido-marginatis et inflorescentia hermaphrodita differt.

14. Mn. orthorrhynchum auct.; dioicum; caulis simplex apicem versus crescens; folia outo-lanceoluta subspathulate angusta, nervo excurente brevi-cuspidata, incrassato - malginata supra basin usque ad apicem remote et brevi-dentata, omnium congenerum hujus divisionis mimutissime areolata; cellulae gramulis chlorophyllaceis constanter circum latera interiora densissime positis impletae; theca brevipedunculata horizontulis brevicolla ovalis operculo magno e basi convexa obtuse conico-rostellato.

Bryolog. Europ. Fasc. $\mathbf{V}$ p. 25. tal. 5. - Mnium servatum $\beta_{0}$ Schwägr. suppl. I. P. 11. p. 129; foliis ovatis latioribus, paraphysibus clavatis, flore dioico et tab.? - Bryum marginatum var, tenella thecis oblongis attenuatis. Drumm. Musc. Amer. No, 259.

Patria. In alpibus Carinthiae, Tirolis, Helvetiae et Norvegiae (Dovre) hic illic cum $M n$. servato occurrit. In America sept.: Drummond. E rarioribus. - $\boldsymbol{A} d$ aestatis finem.

Ex habitu Mnii serrati, inflorescentia tamen, areolatione foliorum minore et foliis confertioribus propria species. - Folia perigonialia lato-ovalia, intima parva subcordata, marginato-serrata, basi valde laxe, apicem versus densius areolata, acuminata excurentinervia. Bryum Polla orthorhyncha Brid. non est eaden species hujus nominis auctorum sed Catharinea tenella, ut e speciminibus Megapolitanis hb. Bridel. elucet! An vera species in Ducatu Megapolitano inveniatur, dubii sumus; in Synopsi der Laubmoose Mecklenburg's auct. Fiedler p. 63. iudicatur quidem; an auctor ipse vero collegerit?

15. Mn. serratum Brid. (Sp. Musc. III. p. 44.); hermathroditum; caulis fertilis erectus humilis subsimplicissimus; folia ovato - vel oblongo-acuminata, incrassatoet albido-marginata, nervo excurrente longiusculo-cus- 
pidata, e cellulis parvis firmis parietibus incrussutis praeditis conformata, inferiora integra, superiora brevi-scrrata; perichaetialia intima lanceolata minima caulinis similia; theea brevicolla ovalis subnutans, operculo brevirostro acuto subobliquo.

Bryolog. Europ. Fasc. V. p. 24. tab. 5. - Bryum serratum Schrad. spic. Fl. Germ. p. 71. - Br. Polla serrata Brid. 1. p. 689. - Br. Marginatum Dicks. Fasc. II. PI. Crypt. p. 9. tab. 5. fig. 1.Hook. et Tayl. Musc, Brit, p. 126. tab. 31. - Mn. crudum Lighte. F1. Scot. 11. p. 712. e Smithii fide. - Hypnum maryinatum Web. et Mohr. Bot. Taschb. p. 292.

Patria. In montosis atque regionibus alpinis, inter frutices ad rupes vel ad terram lapidosam humidiusculam per totam Europam, sed rarius. - Majo. Junio.

Praecedenti proximum, primo adspectu tamen statura humiliore, operculo brevi-rostrato, basi purpureo-limbato et peristomio thecae apertae pallidae brunneo-purpureo intelligitur.

16. Mn. heterophyllum Schwägr. (Suppl. II. P. II. p. 22. tab. 159.); dioicum; caulis declinatus radicans demum ascendens breviramosus; folia remota, infima subrotunda evanidinervia, superiora lanccolato-acuminata nervo evanido vel continuo cuspidata, purpurascenti-marginata brevi-serrata; theca brevi-pedunculata badia horizontaliter inclinata ovata parva, operculo comexo mucromulato, e lutescente badio.

Bryum heterophyllum Hook. in Transact. of Linn. Soc. IX. p. 318. tab. 28. fig. 1. et Hook. Ic, PI. tab. 20. fig. 2.

Patria. E regno Nepalensi habuit Hooker a Wallich lectum. Ex adnot. Bryol. Europ. Fasc. V. p. 24. et in Caucaso atque America septentrionali.

Ex habitu Mrio stellato proximum, inflorescentia tamen, thecae forma et operculo recedens. Folia innovationum saepe simpliciter dentata et ut in Mnio stellato subbifaria.

17. Mn. Iycopodiohdes Schwägr. (Suppl. II. 2. p. 24. tab. 160.); dioicum; caulis simplicissimus elatiusculus erectus; folia remota anguste-sputhulata longinscula, nervo 
purpurascente excurrente breviter cuspidata; purpurascenti-marginata supra basin usque ad apicem sensim argute et tenuiter serrata, basi e cellulis longioribus pellucidioribus, apice densioribus valde viridibus formata; theca longipedunculata pro plantulae magnitudine maxima clavato-cylindricu brevicolla obliqua horizontalis pallida, operculo conico oblique rostrato flavido basi purpureo.

Bryolog. Europ. Fasc. XXXI. Mnium Tal). Suppl. 2. - Bryum lycopodioides Hook. in litt. ad Schwägr. - Mnium lycopodioides Hook. in Lond. jouru. of bot. 1840. II. p. 11. An species laeece Nepalensis eadem sit tota ac Bryologiae Europaeae, duhi sumus. Ex iconibus Schwägrichenianis folia jam e basi infma serrata sunt, dum peristomii quoque interni dentes ciliis solitariis deliueantur. E ceteris notis species Europaea Indicae simillima.

Patria. E regno Nepalensi Cl. Hooker primus accepit. In sylva Accris ad pedem montis Gamskaar Gastuniae: W. P. Schimper; in alpibus Julicis prope Slatenig: Sendtner; in monte Gemmi Helvetiae: Mühlenbeck. - Augusto.

Peristomii interni dentes cilis ternis interpositis; dentes externi acuti, apice valde rugulosi. Folia valde decurrentia. Planta mascula gracillima. E reliquis notis Mnio serruto simillimum. Plantae Schwägrichenianae habitus Bryi crudi dicitur.

18. Mn. hornum Hedw. (Sp. Muscor. p. 188.); dioicum; caules basi maxime cespitosi tomentosi mudiusculi vel foliis minimis remotis praediti, apicem versus sensim densius foliosi crescentes; folıa omnia angustu longiuscula spathulato-oblonga amplexicaulia anguste purpurascentimarginata dense serrata mucronato-acuminata, nevo sub apice abrupto dorso spinoso, irregulariter areolata pellucida, sicca subcrispa crecta; theca longe pedunculata maxima oxalis nutans pallida, operculo hemisphacricoconico brevi aurantiaco.

Bryolog. Furop. Fasc. V. p. 22. tab. 4. - Bryum Polla horna Brid. I. p. 695. - Br. hornum Swartz. Musc. Snec. p. 48. - Mn. integrifolium Brid. Musc. Rec. 11. 3. 1. 89. - Bryum stellare hornum sylvarum, capsulis magnis nutantibus. Dill. Musc. p. 402. tab. 51. fig. 71. - Hypnum hornum Wel,. et Molir. Bot. Taschb. p. 293. 
Patria. In paludosis sylvaticis spongiosis planitierum Germaniae septentrionalis, prime in montosis et ad alpes ascendens per totam Europam, rupes madidas vel terram humidam cespitibus maximis habitans. - $A b$ Aprili in Junium thecas maturat.

Planta speciosa distinctissima. Dentes peristomii externi maxime pullidi furescentes. 'Theca prima pallida, demum ochracea in paludosis fusca nitens, ore purpureocolorata. Plantac utriusque sexus numerosissimae intermixtae. Flos masculus eleganter rosulato-discoideus. Folia perigonialia intima parva basi lato-ovalia ventricosa axe areolata pellucida, subito acuminata densius areolata, obsolete marginata acuta simpliciter denticulata subexcurrentinervia. Rami steriles erecti illis Mnii stellaris ex habitu simillimi.

\section{B. Folia immarginata.}

19. Mn. stellare Hedw. (Sp. Musc. p. 191. tab. 40. fig. 1-4.); divicum; caules yruciles humiles, basi dense cespitosi tomentosi foliis parvis apicem versus majoribus remotis instructi; folia subdecurrentia oblongo-ovalia, perichactialia angustissima elongata, omnia e medio simpliciter inaeruale et remote dentatu, acutissime vel cuspidato-acuminatu pellucide areolata abruptinervia; theca solitaria longipedunculata ovalis cerma horisontulis pallida, operculo hemisphaerico pulcherrime aurantiaco; dentes externi brunnei.

Bryolog. Europ. 1. c. p. 33. tab. 12. - Bryum polla stellaris Brid. 1. p. 691. - Bryum stellare Hoth. F\%. Germ. III. p. 240. Br. stellatum La Marck et Dec. Fl. Frallę. 1. p. 507. - Br. stellare roseum pendulum minus, capsulis et setis longioribus. Dill. Musc. 1. 413. tal. 52. fig. 78. - Hypnum stellare Web. et Mohr. Bot. Taschb. p. 294.

Patria. In umbrosis sylvaticis plerumque montanis humidiusculis, declives praeferens per totam Europan usque ad borealem Scandinaviam sparsim et in America septentrionali. - Mujo. Junio. 
Caulis sterilis erectus gracillimus subljifaric foliosus. Planta mascula feminea gracilior, basi valde tomentosa, foliis inferioribus parce dentatis, superioribus perigonialibus e basi lata concava ovato-lanceolata, intima breviora obtusiora, omnia apice denticulaia. - Folia omnia flavido-viridissima, siccitate obscure viridia, madefacla aeruginosa circulari - areolata pellucida parietibus crassis maxime viridibus praclita. Theca sicca nigrescens.

Ilabitus proprius Mnio Blyttii aflinis et ramis sterilibus subbifarie foliosis plumosis facillime cognoscitur.

\section{Dubia.}

1. Bryum Donianum Grev. (Transact. of the Liun. Soc. XV. 2. p. 345. tab. 3. fig. 6.); caulis breviusculus robustus, innovationibus brevilus ramosus; folia dense summitate praceipue aggregata, crecto-patentia, obovala acuta marginata, apice denticulata excurrentinervia; theca longe pedunculata clarata pendula, operculo brovi conico. $\dagger$

\section{Patria. In insulis Ionicis.}

Caulis c. $1 / 2$ unc. alt., robustus, radiculis brunneis tomentosus, ramosus. Folia inferiora laxe disposita, superiora patenti-imbricata lata obovata, innovationum angustiora, apiculata, subconcava, apicem rersus denticulata. margine incrassato, nervo crasso plus minusve excurrente sed nunquam piliformi v. hyalino. Folia inferiora rubescentia, superiora viridescentia, sub microscopio amocne viridia, basi saepe intense rubra. Nervus et margo incrassati sacpe rubri. Reticulatio rotundata parva (smale) basi cellulis longioribus. Pedunc. c. 2. unc. alt., intense ruber. 'llieca pendula brunneo-rubra crassa clavata, operculo brevi obtuso conico. Thecam maturam atuctor non vidit. Perist. int. ext. acquans. Dentes 3-5-costati ( 3 tos ribs) apiculati transverse trabeculati. Cilia illterposita auctor non vidit.

Ex iconib. anctoris Mnium rerum! Forsan Mm. vostratum vel proximum? Ex observationibus auctoris Bryo 
ventricoso ( $\mathrm{Br}$. pseudotriquetro) ex habitu, praecipue thecae proximum, sed differt foliis latioribus crassissime marginatis, nervo excurrente et innovationibus aliis. Cum nulla specie alia confundi potest (auct.)

2. Hypnum Freycineti Schwägr. (Suppl. III. 2. tab. 279.); ,ascendens simplex, foliis patentibus oblongis acuminatis obliquis marginatis ruptinervibus integerrimis. $\uparrow_{\text {. }}$

Mnium giganteum Schwägr. in Freycinet. Itin. per orbem 1. p. 227.; caule simplici praealto ( $4-6$ poll.) foliis patentibus ovatis: terminalibus stellatis.

Irabitus aliquo modo Hypni acicularis. Caulis spithamaeus ascendens simplex, foliis et basin versus etiam radiculis tectus. Folia recto angulo patentia, densa oblonga, in acumen sextuplo brevius quam folium reliquum attenuata, propter basin inaequalem obliqua, margine crasso et lato integerrimo undulato cincta, amoene viridia: nervo crasso ante apicem evanescente concolori: cellulis hexagonis, basilaribus paullum elongatis.

Muscus de cujus genere dubitari potest, foliorum cellulis Mniis, foliorum forma irregulari potius Neckeris similis. Mancat inter Hypna, usque dum fructus innotescant. Si vel maxime genericum nomen mutandum sit, servabilur tamen specificum in memoriam viri de re nautica, geographica et historia naturali meritissimi Freycineti, navarchi."

Sectio 11. Aulacomnion. Schwägr. Suppl. III. I. I. Theca ovalis vel oblonga subcylindracea cernua brevicolla, regularis vel incurva strinta sicca costatr. Folia e cellulis minoribes composita, nitida. Inflorescentia terminalis.

Notas essentiales, Aulacomnia a Mniis veris discernentes invenire nequivimus. Areolatio foliorum eadem est ac Müi, cellulis tantum minoribus. Peristomium typice non distat. Calyptra illa Mniovum. Theca quidem sulcata, sed in Orthotrichaceis nunc sulcata nunc laevis observatur. In Polytrichis tandem thecae forma maxime variabilis reperitur. Ex inflorescentia genera nunquam conformari possunt, quum nota ista maxime variet. Notae aliae autem discernendi non restant. 


\section{Folia secunda.}

20. Mn. heterostichmm Brid. (Bryol. univ. II. p.12.); monoicum; late et laxe cespitosum ascendens humile; folia octosticha nitidissima obovato-ovalia dentato-serrata obtusa, apice acuto, nervo ante apicem dissoluto; perichaetialia intima multo minora laxius areolata subito acuminata denticulata vel integerrima; theca oblongocylindrica incurva angusta, operculo conico oblique rostellato.

Arrhenopterum heterostichum Hedw. Sp. Musc. p. 198. tab. 46. fig. 1-9. - Aulacomnion heterostichum Br. et Sch. Bryol. Europ. Fasc. X. - Orthopyxis heterosticha P. B. Prodr. p. 79. - Bryum heteropterum pellucidum Dill. Musc. p. 362. tab. 45. fig. 11. - Mnium membranaceum Brid. II. p. 13. Bryum membranaceum, foliis membranaceis olutusis. Dill. Musc. p. 551. tab. 85. fig. 19. Varietas humilis.

Patria. In terra humosa Americac totius septentrionalis vulgaris. - Vere.

Flores masculi in caulis fertilis parte superiore solitari vel plures gemmiformes sessiles basi radicantes, foliis inferioribus minimis ovato-acuminatis, superioribus e basi lata concava lanceolatis integerrimis vel apice dentatis, intimis obcordatis acuminatis, omnibus nervosis.

\section{Folia patentia erecta.}

a. $F$. denticulata.

21. Mn. palustre Hedw. (Sp. Musc. p. 188.); dioicum, flore masculo discoideo; late et laxe cespitosum inferne valde tomentosum elatum ramosum; folia elongatolanceolata angusta undulato-flexilia, sicca tortilia subpapillosa vel laevia, apice denticulata, inferne margine revoluta, evanidinervia; perichaetialia intima lanceolata Jonge acuminata, e cellulis angustioribus longioribus teneris composita; theca ovalis cylindrica cernua valde sulcata, longipedunculata, operculo conico brevi obtuso.

Brid. 11. p. 7. - Aulacomnion palustre Schwägr. Suppl. III. 1. 1. tal. 216. et Bryol, Curop. Fasc. X. p. 9. tab. 3. - Gymnocephalus paltustris Schwägr. suppl. 1. 11. p. 87. - Orthopyxis palustris P. B. Prodr. p. 79. - Bryum palustre Sw. Musc. Suec. p. 46. - Hypnum elodes Web. et Mohr. Bot. Taschb. p. 282. - Mnium 
majus, ramis longioribus bifurcatis, Dill. Musc. p. 233. tab. 31. fig. 3. - Mnium inordinatum Brid. 11. p. 7. Mnium, ramis brevibus inordinate progredientibus. Dill. Musc. p. 239. tal). 31. fig. 8.

ß. imbricatum; foliis latioribus imbricatis integerrimis, siccilate haud tortilibus. Bryol, Europ. 1. c.

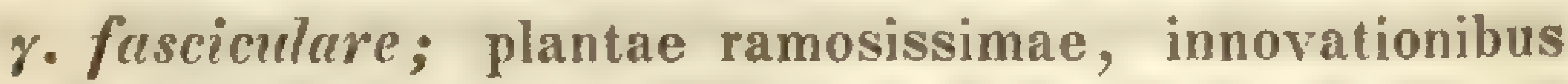
brevibus, fasciculatim foliosis, ramulis sub coma florali egredientibus flagelliformibus. Mnium fasciculare Brid. II. p. 733. Bryol. Europ. 1. c.

ঠ. polycephalum; decumbens ramosum, pseudopodiis elongatis numerosis. Mnium polycephalum Brid. Bryol. nniv.II. p. 10. Bryol. Europ. I. c. - Mn. ramosum Huds. Fl. Angl. p. 403. - Mı. majus, minus ramosum, capitulis pulverulentis crebrioribus. Dill. Musc. p. 235. tal. 31. fig. 4. - Orthopyxis ramosa P. B. Prodr. p. 79. - Bryum androgynum $\beta$, prolixum Roth. Fl. Germ. IlI. p. 229.

Patria. In paludosis turfosis et uliginosis omnium regionum per totam Europam, Americam septentrionalem, usque ad arcticam et in Sibiria australi vulgatissimum. Vere.

Caulis apice pseudopodiis (caule longe producto nudiusculo apice foliis minimis gemmiformibus) saepe praeditus. Flos masculus discoideus, foliis e basi lata concava lineari-lanceolatis, antheridiis copiosissimis brevissime stipitatis paraphysibus clavatis.

22. Mn. androgynum Linn. (Syst. Pl. p. 15\%1.); dioicum, flare musculo terminali gemmiformi; late et laxe cespitosum inferne valde tomentosum humile ramosum; folia elongato-lanceolata, illis proceclentis duplo breviora et angustiora, apice denticulata magis papillosa, inferne margine revoluta evanidinervia magis acuminata; perichactialia intima lanccolato-subulata; theca ovali-oblonga cernua longipedunculata, operculo e basi inflata acute conico.

Brid. II. p. 5. - Aulacomnion androgynum Schwägr. Suppl. III. 1. 1. tab. 215. - Bryol. Hurop. 1. c. p. 11. tah. 4. - Gymnocephalus androgynus schwagr. suppl. I. 11. p. 87. - Fiusiconiu androyyna P. B. Mem. Soc. Linu. Par. I. tal). VH. fig. 5. - Bryum 
androgynum Hedw. Sp. M!!sc. p. 178. - Orthopyxis androgyna P. B. Prodr. p. 78. - Hypnum androgynum Web. et Mohr. Bot. Taschb. p. 280, - Mnium perangustis et brevibus foliis. Dill. Musc. p. 230. tab. 31. fig. 1.

Patria. In nemorosis praeprimis arenaceis montosis Europac mediae et totius fere Scandinaviae ad terram et rupes sed rarissime fructiferum. - Junio.

Planta semper pseudopodie inrenitur. Flos masculus terninalis gemmiformis, foliis externis e basi lata linearilanceolatis, interioribus late lanceolato-subulatis, antheridis haud copiosis, paraphysibus filiformibus.

\section{b. F. integra.}

23. Nn. turgidum Wahlenb. (Flor. Lappon. p. 351. tab. 23.); dioicum, flore masculo discoideo; late et lare cespitosum elatum stramineo-nitidum, interrupte ramosum inferne tomentosum, ramis apice caulis fructiferi dichotomis aequalibus praeditum, turgido-foliosum fragilissimum; folia caulina octosticha dense imbricata, apice in comam patulam congesta, e basi oblonga lingulato-ovalia concava apice cochleariformia plus ninus plicata, margine plana vel reflexa, plerumque laevia raro papillosa, nervo basi crasso superne tenui eranescente concolori pracdita, basi plus minus exacte gibboso-concara, omnino minute areolata integerrima; perichaetialia longiora gngustiora margine valde reflexa plicata, exteriora lingulata, interiora lanceolata plus minus acuta longius areolata; theca in pedunculo brevi stricto oralis brevis cernua basi subgibbosa erecta pallida dein fuscidula, operculo conico brevi mammillato aurantiaco.

Brid. II. p. 11. - Aulacomnion turgidum Schwägr. Suppl. II. I. 1. p. 7, et Suppl. 1. II, p. 123. tab. 27. sub nomino Mnii turgidi Wahlenb. - Bryolog. Europ. 1. c. p. ४. tab. 2. - Arrhenopterum turgidum Wahlenb. sec. Web, et Molr ex Brid. 1. c. - Hypnum illecebrum Linn.

Iatria. In praeruptis irrigatis et in turfosis Norvegiae, Sueciae, Lapponiac, Groenlandiac, Labradoris et in insula Melville, raro tamen fructus proferens. In alpibus 
Helvetiae, ubi e Cl. Funk et Bridel inveniri dicitur, hucusque frustra quaesiverunt. - Aestate.

Planta masculae feminea similis; flores terminales discoidei dodecaphylli; folia perigonialia erecto-patentia caulinis similia basi concara, undulato-plicata; antheridia numerosa brevi-stipitata, paraphysibus filiformibus vel subclavatis lutescentibus mixta. Peristomii dentes e lanceolato subulati lutescentes, siccitate apice incurvi, intus valde trabeculati, interni in membrana altiuscula hyalina valde sulcati et hiantes saepe apice fissi et divergentes, ciliis binis vel quaternis longis tenuibus hyalinis interpositis. - Ex adnotationibus Hübeneri pseudopodiis illis Georgiae pellucidae similibus inveniri dicitur.

Sectio 1I. Thizogonium Brid. II. p. 664. Theca ovalis, obconica, oblonga, cylindracea cernua laevis brevicolla. Folia e celfulis minoribus composita. Inflorescentia plerumque distincte lateralis subbasilaris.

Ab Aulacomniis theca laevi laterali distinctae plantae. Nos forsan vituperabunt, Rhizogonia ad Mnia revocasse, quum inflorescentia distincte laterali gaudeant; Fissidentes et Leucobrya igitur in memoriam redigere volumus. A muscis vegetationis pleurocarpicae Rhizogonia toto coelo distant. E theca Rhizogonii spiniformis congeneres hujus divisionis ad Mnia valde appropinquant, e thecis ceterorum Aulacomnia referentes. Foliis bifariis Rhis. bifarii et Novae Hollandiae caules steriles et fertiles Mnii hymenophylloidis et stellaris iterantur. Nervi tandem plurimarum specierum Rhizogonii ut in Mnio horno dorso spinosi observantur ita, ut ex omnibus his notis, forma atque structura peristomii, foliorum et calyptrae, affinitas intima inter Mria, Aulacomnia et Rhizogonia eluceat. In Polytrichis quoque folia, et codem modo, maxime variabilia inveniuntur.

1. Folia subbifaria

24. Mn. bifarium C. Mill.; dioicum; humile, basi infima tomentosum, erectum apice ramosum, ramis aequa- 
libus; folia indistincte trifaria remota, inferiora elongata angusta longe acuminata vel nervo crasso excedente cuspiduta parce serrata, superiora ovali-lanceolata, nervo crasso dorso parce spinoso excurrente acuta, supra basin usque ad apicem remote et simpliciter serrata; perichaetialia e basi lata amplexicauli, alta nevro excedente sensim longissime cuspidata vel pilifera integra, intima duo brevissima ovalia; theca distincte lateralis longipedunculata ovalis cernua brevis, operculo conico rostrato.

Rhizogonium bifarium Schimp. Bot. Zeit. 1844. p. 125. - Hypnum bifarium Hook. Musc. Exot. tal,. 57. et Schwägr. Suppl. III. 11. 1. tab. 257. - Isothecium bifarium Brid. 11. p. 3556.

Patria. In sinu Dusky-Bay Novae Seelandiae in terra cespitose habitat: Menzies anno 1791 detexit.

Archegonia longissima intense brunnea angustissima paraphysibus longis filiformibus luteis cincta. De affinitate sequentis vide in exc. in $M n$. distichum.

25. Mn. distichum C. Müll.; dioicum; humile, basi infima tomentosum, erectum simplicissimum; folia inferiora ovato-acuminata, superiora oblonga, omnia evanidinevia apice dentata; perichactialia acuminatu exteriora seminervia, interiorachervia; theca in pedunculo perfecte busilari crecto apice deflexo cylindrica aequalis horizontalis. $t$.

Rhizogonium distichum Brid. II. p. 665. - Hypnum distichum Swartz in Schrad. Journ. IV. p. 179. tab. 3. fig. A. excl. Syn. Brid.

Patria. In Novae Seelandiae sinu Dusky-Bay, ubi Menzies detexit cespitosum.

E descriptione modo data a praecedente vix differt. Species ab auctoribus forsan leviter examinata est.

26. Mn. Novae Mollandiae C. Müll.; dioicum; humile, basi infima tomentosum, erectum simplicissimum; folia indistincte trifaria remota, inferiora ovali-lanceolata parva brevi-cuspidata integra, superiora orali-lanceolata latiora, nervo crassissimo dorso laevi excedente brevicuspidata, apice servulata; perichaetialia exteriora ovatoacuminata seminervia, interiora lato-lanceolata longe 
subulata enervia; theca in pedunculo perfecte radicali cylindracea aequalis ascendens.

Rhizogonium Novae Hollandiae Brid. II. p. 664. Suppl. II. Rhizoyonium ad sinistram delineat. fig. 1. 2. 3. - Lesliea Norae Hollandiae Schwägr. Suppl. 1. 11. tab. 83. - Iypmum fissidentoides Brid. sp. Musc. 1I. p. 89. - Fissidens Norue Hollandiue Brid. Musc. Rec. II. I. p. 143. tab. 6. fig. 11. - Slitoplyllum Novae Hollandiae La Pyl. in Journ. Bot. Desv. 1813. n. V. p. 59. tab. 36. fig. 17. - Rhizopelma Novae Hollandiae C. Müll, in bot. Zeit. 1847. p. 803. e peristomio leskeoideo conditum genus. Congeneribus ex novo examinatis, putamus, peristonium ab auctoribus false leskeoideum observatum esse, quum. omnes thecae apertae operculis carentes fuerint.

\section{Putria. Nova Hollandia: La Billardière.}

Species nobis sterilis tantum visa, a penultima certe diversa notis supra datis.

27. Mn. subbasilaxe C. Müll.; monoicum; elatius, basi infima tomentosum erectum subsimplex; folia indistincte trifaria remotiuscula erecta subappressa oblongolanceolata angusta canaliculato-concur'l, grosse et argute serrata, nervo ad summum apicem evanescente fuscoviridi praedita; perichaetialia oblonga longe cuspidata; theca brevipedunculata subbasilaris horizontalis vel pendula oblonga inaequalis sub ore contracta, annulo crasso et operculo thecae dimidiae longitudine conico obtuso mamillato. + .

Rhizogonium subbasilare Schimp. I. c. - Hypmum Sterendon subbasilaris Brid. II. p. 559. - Hypnum subbasilare Hook. Musc. Exot. I. tal). 10, et Schwägr. Suppl. III. II. 1. tab. 216.

\section{Patria. In Terra Statuum prope Promontorium} Horn in terra uliginosa cespitosum: Menzies anno 1787 legit.

Folia perigonialia ovato-acuminata valde concara integerrima, nervo ad apicem fere perdurante. Antheridia truncata pallida paraphysibus filiformibus.

$$
\text { Dubiae species. }
$$

1. Mypnum retieulatum Hook. et Wils. (Lond. journ: of bot. 1844. p. 553.); caule erecto simpliciusculo, foliis 
distichis patentibus orato-lanceolatis acuminatis vix piliferis submarginatis reticulatis, apice serrulatis, nervo tenui subexcurrente. $t$.

Patria. Insula Eremitae ad Cap. Horn ubi sterile legit J. Hooker.

A Mnio subbasilari differt foliis acuminatis distichis, nervo subexcurrente. Habitu Hypno denticulato simile.

\section{Folia imbricata.}

a. Fructus distincte lateralis.

28. Mn. spiniforme C. Müll, hermuphroditum; ela$110 \mathrm{~m}$, basi infima tomentosum, erectum simplex rel ad medium caulis ramosum, ramis aequalibus, apice incurvum, gracile laxissime foliosum; folia caulina fusca clongata angusta lanceolata, margine duplicato-serrata, apice valde et grosse serrata, nervo excedente apicem versus dorso argute serrato-cuspidata; perichaetialia exteriora e basi latissime ovali vaginali cuspidata simpliciter et urgute serratu, interiora sensim minus serrata, excurrentinervia intima brevissima pauca lato-ovalia integra evanidinervia, omnia basi laxius areolata membranacea; theca longissime pedunculata radicalis obconica inclinata ore dilatatu truncata brevis, operculo conico-obliquo.

Rhizogonium spiniforme Bruch in Flora 1846. p. 134. - Hypnum stereodon spiniformis Brid. H. p. 557. - Hymum spiniforme Linn. Sp. PI. p. 1587. et Hedw. Musc. Frond. II. p. 59. tals. 25. Hypnum erectum, non ramosum, spinarum halecum aemulum. Dill. Musc. p. 332. tab. 43, fig. 68.

Patria. Ex insula Jamaica primus retulit Sloane. In insulis Antillis minoribus, et per totam Americam acquinoctialem, in insula Java et in Promontorio bonae spei, ubi in sylva Grootvaterbusch dicta legit Mundt. Tulgatissima species sed minus variabilis.

Partibus omnibus, antheridiis, archegoniis, paraphysibus (claratis), foliis et theca robustum et ab omnibus notis laudatis facillime distinguitur. - Dentes externi peristomii longissimi, basi lati rufi, apice albidi rugulosi. Membranae internae flavidae dentes apice rugulosi albidi, 
ciliis dentibus externis subbrevioribus tenuissimis interpositis.

29. Mn. polyearpum C. Müll.; dioicum; elatum subsimplex erectum inferne valde tomentosum subflexuosum gracile laxissime foliosum; folia caulina viridia subfalcata elongata anguste lanceolata sed praecedente latiora, margine tenuius duplicato-serrata, minute-areolata, nervo ante apicem evanido crasso, dorso argute serrato, acuta; perichaetialia exteriora e basi latissima vaginali subito sinuate longissime acuminata serrata, interiora filiformiacuminata, omnia evanidinervia remote serrulata laxe areolata, intima pauca brevissima ovalia integra obtusiuscula; thecae in longitudine caulis numerosue longe pedunculatae cylindricae lunulato-cernuae basi attenuatae, operculo conico brevi.

Rhizogonium mnioides Sclimp. in hot. Zeit. 1844. p. 125. Aulacomnion Chilense C. Müll, Bot. Zeit. 1843. p. 649. tab. 3. Hypun mnioides Hook. Musc. Exot. tab, 77. et Schwägr. Suppl. III. II. 1. tab. 257. sed male delineatnm! - Hypnum Stereodon mnioides Brid. II. p. 559.

Patria. In terra Statuum prope Promontorium Horn in uliginosis legit Menzies anno 1787. In monte ignivomo Antuco regni Chilensis, in scopulis madidis torrent. legit secundus Pöppig (Coll. Pl. Chil. No. 50.). E locis non designatis regni Chilensis pulcherrime fructiferum $\mathbf{I I b}$. Reg. Rerol. misit Philippi.

Peristomium praecedentis speciei proximae.

\section{b. Fructus terminalis.}

30. Mn. mierophyllum Dz. et Molkb. (Musc. Archip. Ind. p. 26. tab. 12.); dioicum; cespitosum inferne tomentosum; caulis erectus inferne nudiusculus, apice ramulosus, ramis gracilibus densius foliosis, ad perichaetium orientibus; folia caulina remota, infima minima integerrima, reliquis latiora et teneriora evanidinervia, superiora longiora erecto-patentia oblongo-lanceolata, margine recurva serrata; ramulina comalibus duplo fere minora, suprema minima, patentia uti reliqua siccitate contorta; co- 
malia s. perichaetialia lineari-lunceolata elongata grossins serrata, margine recura nervo carinata, interiora breviorl ef angustion: theca inclinata vel horizontalis outa brevicolla rubro-fusca, operculo hemisphacrico mamillato. $t$.

Patria. Japonia: a Siebold.

Planta sterilis gracilior e basi caulis fertilis nascens erecta simplex filiformis. Planta mascula sinplex erecta, apice in comam foliosam inclinatam terminata, folis canlinis illis' plantae fertilis similibus, perigonialibus valde concavis, exterioribus ovato-subrotundis apiculatis, mediis ovato-cuspidatis paullo longioribus, intimis minimis teneris pellucidis lanceolatis evanidinervibus, unica serie cellularum quadratarum majorum marginatis. Antheridia numerosa paraphysibus clavatis.

31. Mn. Menziesii C. Mïll.; dioicum; caulis fertilis erectus strictus elatus inferne simpler, apice demlroideoromosus, basi tomentosus, usque ad apicem foliis remotis appressis syucumaefurmibus scuriosis lancelatis longe "cuminatis, nervo infra apicem eranido, e medio usyne ad upicem cilicuto-dentutis, albidis; folia ramulina ovalilanceolata acuminata acuta, supra basin ad apicem usque simpliciter et breviter serrata, nervo infira apicem abrupto, dorso spinosa subcomplicato-concava; perichactialia latissime ovalia, exteriora late et longissime acuminata, basi Homboideo-, apice rotundato-hexagono-areolata, interiora subpilifera, omnia excurrentinervia, apice ser!̣lata, tenerrima rufescenti-albida, basi laxissime et rhomboideoareolata; pedunculi terminales plures longi erecti; theca cylindrico-ovalis ore dilutata pendula; peristomium perrobustum, magnum.

Rhisogonium acunthoneuron C. Mïll. Bot. Zeit. 1847. p. *03.Iypnum acanthoneuron schwämr. Suppl. 1It. 11. 1. tab. 25x. Mryum Mensiesii Hook. Botanic. Miscell. I. 1830. p. 36. tal. 19.

Putria. In Americac boreatis ora occidentali pr. Noolkam: I enzics. In loco, Observatory Irlet” dicto ejusd. partis terrarum: Scouler. 
Praecedenti ramificatione affine, sed notis laudatis distinctissinum; ambo tamen e ramificatione Mnium undulutum referentia et, contemto fructu terminali, Rhizogoniis proxima et congeneres hujus divisionis $M$ miis veris conjungentia. - Archegonia longissima angustissima. apice laxe cellulosa fusco-purpurea, paraphysibus longissimis rufescentibus, crassiusculis mixta. Speries pulcherrima!

Gen. III. Tyménodon Hook. et Wils.

I.ond. Journ. of hot. 1844. p. 548. - C. Mïllep in hot. Zeit. 1847. p. 802-4. - Mielichhoferia Dz. ct Molkb. - Rhisogfonium Hook. et Wils.

Nomen ab vuriv membrana et ífor's dens, ob membranam peristomii in dentes productam ductum.

Calyptra dimidiata. Peristomiun simplex internum. Dentes 16 in membrana subcarinatoplicala cellulosa positi, lanceolati stricli plani hyalini cellulosi plus minusve perforati. Inflorescentia dioica gemmacea lateralis basalis. Tita arborea.

Rhisogonies ex habitu congeneres affunes, et inter ea atque Georgine species intermedii, caulibus simplicibus apicem versus sensim crescentibus gracillimis teneris.

1. M. sericeus C. Müll. (1. c. p. 803.); caulis basi valde tomentosus dense cespitosus; folia caulina e basi anguste longe ellipsoidea latiuscula tenera lutescentia nitida, margine crenulata, papillis paris, nervo longissime excedente ante apicem folii flexwoso, apice laminae suepe incequelia, inferiora minora, superiora sensim majora; perichaetialia lato - lanceolata longe cuspiduta stricta, nervo subexcurrente, infense brunnea, integerrima; perigonialia latiora convoluta; theca in pedunculo flexuoso purpureo tenero longissimo ovalis brevicolla anuulata, operculo longe rostrato obliquo.

Mielichhoferia sericea Inz. et Molhb, in Musc. Archip. Indic. p. 85. tab. 29. 
Patria. Java in cavis arborum vetustarum regionis paludosae summi montis Gédé, mense Februarii fructificans: Korthals, Zippelius. Borneo supra arbores carie consumtas: Korthals.

Archegonia pauca elongata brunnea, paraphysibus longis luteo-sericeis mixta. Antheridia pauca parva crassa ellipsoidea brunnea, juniora hyalina tenerrime membranacea, paraphysibus brevibus luteo-sericeis intermixtis. Vaginula cylindrica.

2. H. aeruginosus C. Müll. (1. c. p. 804.); caulis basi valde tomentosus dense cespitosus; folia caulina e basi angusta ellipsoidea angustiora valde papillosu, margine crenulata cemginosu, nervo stricto longiusculo-er. cedente; inferiora minora, superiora sensim majora, siccu subfexuosu; perichaetialia lato-lanceolata longiuscula plevumane oblique cuspiduta denticulatu fuscescentia, nervo subexcurrente; perigonialia latiora convoluta; theca in pedunculo flexuoso purpureo tenero longo orulis. Caetera desunt.

Rhizoyonium aernyinosum Hook. et Wits. in Lond. Jonrn. of bot. 1844. Fasc. Marti.

Patriu. Brasilia in Sierra dos Orgaôs ad scap. filicum dendroidium collect. Gardneri. No. 33. ex parte.

Antheridia, archegonia et paraphyses ut in praecedente. Ab hoc statura humiliori graciliori, colore aeruginoso, foliis caulinis multo angustioribus valde papillosis firmioribus, nervo brevius piliferis, nervo stricto, foliis perichaetialibus et perigonialibus denticulatis valde differt.

3. H. piliferus Hook. et Wils. (1. c. p. 548); caules frondiformes, dense fasciculati erecti, foliis subdistichis aeruginosis papillosis, humorum repellentibus; theca alte pedunculata, suberecta subcylindracea.

Rhi Euclad. complanutum memoratum?

Patria. Terra Diemenii et in Nova Seelandia. 
GEORGA.

\section{Species dubiae.}

1. Brachymenium ovatum IIook. et Wils. (1. c. p. 545.); caulis dense cespitosus, inferne valde tomentosus purpureus subsimplex, folia laxe imbricala, inferiora remotissima minuta acuminata planiuscula, superiora confertiora, suprema in comam laxiusculam rotundato-gemmaceam congesta, omnia quinquefaria erecto-patentia, e basi rotundata ovato-oblonga carinato-concava, nervo flavido flexuoso crassiusculo in cuspidem brevem producta mucronata, integerrima, lutescentia, ut in praecedentibus areolata, laevissima nitida.

I'utria. Insulae Falklandi ubi sterile legit J. IIooker.

Ex habitu Georgine Mnemosyno Ehrh. simillimum et a Brachymeniis longissime distans, huc certissime pertinens, sed ob fructum deficientem Hymenodon dubius. A praecedentibus speciebus tribus etsi simillimis foliis apiculatis lamina aequali instructis apice caulis veluti secunde dispositis facillime distinguitur.

\section{Gen. IV. Georgin Ehrh.}

IInn. Magaz. 1780. p. 931, quod nomen, prioratum tenens, retinendum est. Domen Heduigianm, "Tetruphis" in Fund. Musc.II. p. 87. tal). 7. fig. 32. impositum male quoque formatum est, ut C\% Bridel (Bryol. univ. I. p. 130.) docet. - Tetrucis Whrh. olim. Tetracmis Brid. I. p. 129. - Tetrodontium s'chwägr. - Orthotrichum Sm. Brid, - Mnium Linn. - Bryum Web. - Mnion Adans.

Maximo Botanices Promotori, Georgio tertio, magnae Britanniae Regi, cui II edwigi us quoque opus splendidissimum "Descr. et Adumbr. microscopico-cenalytic. Muscorum Frondosorum etc." dedicavit, Ehrhartus consecravit in Beitr. I. p. 176. 188. et III. p. 116. Nomen, ab Ehrharto gratissimo animo impositum, dein ab II edwigio ex arbitrio deletum, e magni bolanici $\mathbf{E}_{\text {h }}$ rharti reverentia retinenlum esse, persuasissimum habemus.

Calyptra mitraeformis plicata. Peristomium simplex e dentibus quatuor pyramidalibus cellularibus 
conformatum. Inflorescentia monoica terminalis gemmiformis.

Sectio 1. Tetrodontium schwagl". Suppl. II. p. 102. Plantac humilimae yreyriae rupiucolae, annotinae, subsimplices, annosiores multicanles. Caulis flore femineo polyphyllo terminatus, ramulos laterales fagelliformes foliis lanceolatis iubricatis vel folia longissima lineari-cuneata integerrina s. incisa proferens. Calyptra majuscula basi pluries fissa, interdum uno latere ad apicem usque dilacerata fusca.

1. G. repanda C. Müll.; rumuli steriles flagelliformes dense foliosi; foliis minutissimis lanceolatis enervibus integerrimis; folia perichaetialia ovato-lanceolata concava enervia vel obsoletinervia; theca ovalis, orificio in dentium interstitiis phus minus repando vel emarginuto et operculo conico erecto acuto.

Tetrodontium repandum Schwägr. 1. c. - Bryol. Europ. Fasc. Xvil. Tetrapleideue. Tetrodontium; p. 4. tab. 2. - Tetruphis repanda Funk in sturm. Fl. Germ. crypt. P. II. Fasc. 17, et Schwïgr. Suppt. II. p. 21. tal, 107. - Brit. I. p. 132.

Patria. In rupibus silicosis Montis Piniferi: Funk; in Hercyniae superioris valle Ilsethal dicta et ad , Hehfelder Graben": Ha mpe; in rupibus schistosis valde umbrosis alpis Gaisstein Pinzgoviae: Sauter et in Sudetis (Heuscheuergebirge in der Grafschaft Glatz auf Sandstein: Sendtner). - Auctumno.

Flos masculus solitarius gemmam brevem crassiusculam referens, foliis late ovato-acuminatis enervibus, internis majoribus; antheridiis crassiusculis paraphysibus brevioribus stipitatis mixtis. - Ramuli interdum quoque foliis cuneiformibus gaudentes.

2. G. Rrowniana C. Müll.; rumi steviles mulli sed ul vicem folia multa cunciformia valde elongata basi teretia, bi-rel trifuda; theca ovalis, orificio vi.x repando, operculo conico abliquo.

Tetrodontium Brounianum Schwiierr. Suppl. II. p. 102. tab. 128. - Bryol. Europ. 1. c. p.4. tab. 2. - Tetraphis Brouniana Brid. I. p. 133. - Orthotrichum Brounianum sm. Fl. Brit. 111. p. 1269.Grimmia Brounianu Engl. Bot, tab. 1122. - Bryum Brownianum Dicks. Fasc. IV. PI. Crypt. p. 7. tab. 10. fig. 16. - Tetraphis ovata 
Funk in Hopp. Deut. Taschb. 1802. p. 41. Forma minor in locis siccioribus nata. - Brid. I. p. 131 et 762. - Tetrodontium oratum Schwägr. Suppl. II. p 102. - Tetraphis rigida Hedw. Fil. Obs. Bot. Fasc. I. p. 7. tab. 2.

Patria. In rupibus arenaceis et graniticis umbrosis, praccipue ad latera versus terram spectantia Angliac, Scotiae et Hiberniae; in Gothia et Suecia Scandinaviae; in Germaniae Monte Pinifero ad radicem m. Ochsenkopf: Fu иk, prope Bipontem: Bruch et im Amsel Grunde Saxoniae: Hübner. - Aestate et anctumno.

Caetera ut in praecedente.

Sectio 1I. Tetraemia Brid. I. p. 134. Plantae cespitosae cretae graciles, caule apicem versus ut in Hymenodontibus scu-im crescente dense folioso. Calyptra minor, ut in praecedentihus albida irregulariter et multoties plicata hasi plus minus lacera.

3. G. Mnemósynum Ehrh. (1. c.); folia caulina tristicha vel pentasticha, inferiora minuta late lanceolata erecta, stfperiora majora ovalo - lanceolata patentia flexuosa integerrima subcomplicato-concava, evanidinervia acuminata; perichactialia multo longiora angustiora longe acuminala subvaginantia basi laxius areolata; theca in pedunculo stricto longiusculo cylindrica angustississima curviuscula, operculo conico alto apice obliquo.

Tetraphis pellucida Hedw. Sp. Musc. p. 43. tab. 7. fig. 1.a-f. - Bryol. Hurop. Fasc. XV1l. Tetrajhideae. Tetraphis. p.6. tab.1.Brid. 1. 1. 134. - T. cylindrica Voit. Musc. Herbip. 1. 17. - T. oblonga Turn. Musc. Hib. p. 12. - Mnium pellucidum Linı. Sp. PI. p. 1574. - Mnium serpylli foliis tenuilus pellucidis. Dill. Musc. p. 232. tab. 31. fig. 2. - Bryum pellucidum Abbot. 237. - Br. diaphanum Web. Sp. F1. Gött. P. 190.

Patria. In udis umbrosis planitiei, pinctis montanis et alpinis ericetisque udiusculis ad truncos dejectos, in lignis morbidis et ad terram cespitosa totum hemisphaerium boreale habitat. - Vere.

Flores masculi in ramulis plurimo tempore binatis et c flore femineo sterili egredientibus terminales, gemmam polyphyllam sistentes. Dentes peristomii longi longe supra orificium oriundi. Columella in theca matura quater lacerata dentibus adglutinata. Caulis apice saepissime 
discoideo-capituliformis, e foliis anorphis gemmiformibus formatus.

Hymenodontibus et Muii androgyni formis minoribus ex habitu simillima.

\section{Gen. V. Ieptotheca Schwägr.}

Suppl. 11. 1I. p. 135. talo, 13\%.

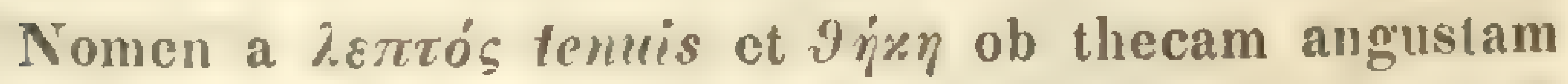
ductum.

Calyptra in Lept. speciosa subulata torta. Peristomium duplex. Externum: dentes sedecim lanceolato-lineares erecti thecae parieti interiori adnati. Internum : membrana tenera in cilia fotidem linearia cum ciliolorum interjectorum rudimentis fissa. Theca aequalis, terminalis. Inflorescentia hermaphrodita vel dioica.

Genus nobis dubium, melius forsan ad Leptostomum, cujus habitum referre dicitur, revocandum.

1. I. Gaudichsudi Schwägr. (1. c.); hermaphrodita; laxe cespitosa basi infima tomentosa; caulis erectus initio simplex post flores innovando aliquoties divisus, interdum dichotomus; rami florigeri speciosiores, steriles cuspidati; folia caulina laxe imbricata, in ramis fructiferis longiora, interdum paullum secunda, patulo-erecta, in sterilibus decussata magis erecta, vel apicibus coarctata, caeterum clongate oblonga, parum carinata, apice grosse dentata, c lutescente viridia, nervo crasso, longam cuspidem formante, apice foveolis quasi exasperato, cellulis quadratooblongis basilaribus, terminalibus qualratis, ammulos simuluntibus; perichaetialia ovato-acuminata integerrima, nervo contimu, in externis paullum emergente; theca in pedunculo erecto badio gracili cylindrica erecta gracilis badia. $t$. p. 212.

Brid. Bryol, univ, 1. p. 838. - Bryum Gaud. Spr. Syst. Veg. IV. 


\section{STEGOCARPI. ACROCARPI. LEPTOSTOMUM.}

Patria. In Nova Walesia meridionali prope portum Jacksonis ad terram arenoso-humosam legit in itinere cum Navarcho Freycinet Cl. Gaudichaud.

Membranam internam auctor imperfectam tantum vidit.

2. I. speciosn Ilook. et Wils. (Ic. Pl. Rả. Ilookerian. tab. 748.); divicu; caulis erectus innovando ramosus; folia dissita patula subsecunda subacuminata ovatolanceolata marginata serrata evanidinervia, inferne margine reflexa, siccitate torta saturate viridia, areolis elonguto-hexagonis mujusculis praedita; theca in pedunculo erecto alto gracili rubro subflexuoso subcylindrica elongata, basi et apice attenuata, pallide brunnea, ore rubro, annulata, operculum theca dimidio brevius crectum rubrum. t.

Patria. Maracaybo in sylvis humidis montium Jamaicae: W. Purdie. Septbr. 184.

Peristomii dentes externi longissimi angustissimi, vix trabeculati rubri. Interni membrana brevis flava, processibus irregularibus brevibus praedita.

An praecedenti revera affinis?

\section{Gen. VI. Leptóstomom $\mathrm{R}$. Br.}

Act. Soc. Linn. X. p. 130. tab. 32. fig. 2. - Gymnostomum Hook. - Bryum Hedw. - Orthopyxis P. B.

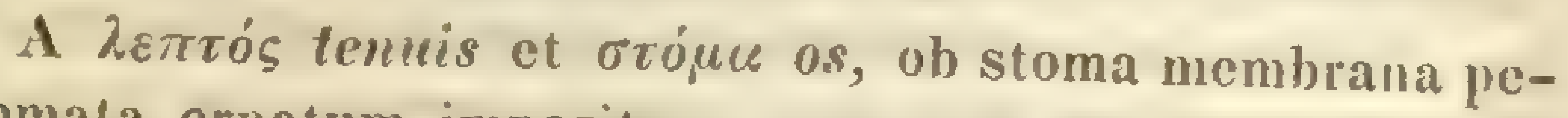
ristomata ornatum impositum.

Calyptra dimidiata fugacissima. Peristomium simplex internum: membrana plus minus alta sedecies plicata albida tenerrima cellularis, apice nec. in dentes nec in cilia producta. Theca ovalis, ellipticar vel cylindriea, ore angustato limbato, plerumque exannulata. Inflorescentia monoica vel dioica terminalis.

Congeneres inter sese affinissimi e foliis atque thecis hic et illic Timmias referentes. 


\section{I. Splachnoides Hook. et Arn. (in Capit. Bee-} chey's Toyage p. 53.); divicum; inferne compacte cespitosum humile; caulis subjulaceo-foliosus apice cuspidatus vel attenuatus; folia caulina ovalia apice subito pilo longissino flexuoso nodoso flavo praedita, planiuscula subintegerrima, nervo ante apicem evanido; perichaetialia sensim acuminata et nervo flavo in pilum quam maxime longum geniculato-flexuosum nodosum excurrente instructa angustiora obsolete denticulata; theca in pedunculo brevi maxima ovalis horisontalis aegualis crassa, operculo hemisphaerico.

Schwïgr. Suppl. IV. tab. 305. - Leptostomum sulcinere K\%e. ill Pöppig. Coll. PI. Chil. III. No. 52. (269.) prioratum tenet, sed diagnosi hucusque ab anctore non descriptum igitur delendum.

Putria. In cortice arborum, rarius ad rupes, tamen haud frequens prope Talcahuano Chiles primus legit Pöp.pig 1528. Septbr. l'rope Conception Chiles leg. Lay et Collie.

Pedunculus dein nigrescens ut in Timmiis, quarum thecae illi Leptostomi splachnoidis simillimae.

2. I, inclinans R. Br. (Act. Soc. I inn. X. p. 302.); dioicum; inferne compacte cespitosum lnumile; caulis subjulaceo-foliosus apice cuspidatus vel attenuatus; folia caulina oblonga obtusa rel immarginate, nevoro crasso in pilum hyolimum flerusum luevem producto, integerima non raro revoluta, flavo-viridia sub lente punctata; perichactialia angustiora marginibus magis reflexis, pilo longiore terminata; theca in pedunculo brevi ondo-oblonga horizontaliter inclinata, operculo conico breri. †.

Schwägr. Suppl. Ill. I. 1. p. 6. tah. 213. - Brid. I. p. 126. Gymnostomum inclinans Hook. Musc. Hxot. 11. tah. 168.

Patria. Rupes et saxa ad latus orientale prope summitatem Mont is ' labularis insulae Van Diemen, Lat. Austr. $43^{\circ}$, elevatione supra mare 3000 ad 3500 ped.: $\mathbf{K}$. Brown.

Praccedenti ex habitu proximum notis autem datis distinctissimum. Peristomium ut in praecelente membrana 
alta plicata. Archegoniis similibus angustissimis Iongissimis, paraphysibus paucissimis praeditis.

3. T. macrocarpum R. Br. (1. c. p. 322.); dioicum; inferne compacte tomentosum humile; caulis dense-foliosus; folia erecto-patentia dense-imbricata lato-oralia crasso-membranucea mollia margine e basi usque ad apicem valde revoluta obtusa, subito nerro crasso flexuso excedente in pilum brevem hyalinum denticulatum rel longum apice ciliato-fissum producta; perichactialiu longissime pilifera, pilo hyalino valde ciliato; theca in pedunculo longo stricto maxima oralis crassa erecta lacrissima badia, operculo obtuse conico dilutius colorato.

Brid. I. p. 125. - Schwägr. Suppl. III. 1. 1. pag. 2. - Bryum macrocurpum Hedw. Musc. Frond. HI. p. 28. tab. 10. - Orthopyxis macrocarpa P. B. Prodr. p. 79.

Patria. In insulis Australibus, praesertim in Otaheiti, ubi primus legit Banks.

Peristomium ut in praecedentibus. Foliorum areolatio ut in Mriis ipsissimis perfecte hexagona pulcherrima, utriculo primordiali eximie conspicuo. Cellulae maguac, parietibus usque ad apicem teneris haud incrassatis, perfecte mnioidecte adeo, ut ex hacce specic affinitas generis Leptostomi et Mnii clare eluceat. Theca ut in Mnio homo formata. Ex imbricatione al sequentem accedens.

4. L. Menziesii R. Br. (1. c. p. 321.); divicum; inferne compacte cespitosum lumile; caulis laxiusculo-foliosus; folia erecto-patentia rigida flavescentia straninea oblonga angusta longiuscula acuminata, nervo flexuoso crasso excedente longissime, flavo- et flexunso-pilifera apice denticulute; perichactialia longius pilifera angustiora crenulata flexuosa; theca in perlunculo brevi elongata rylindrica, ore angustata, evecta vulde incurva; operculo conico brevi obliquo.

Brid. I. 1. 128. - Schwägr. Suppl. II. I. p. 11. tal. 104. schwïgr. Suppl. III. 1. 1. p.6. - Gymnostomum Menziesii Ilvok. Musc. Exot. I. tab. 6. 
Patvia. In terra Statuum prope Promontorium Horn: Menzics 1787. In Eremitac insula vicina: J. Hooker.

Ex imbricatione foliorum Timmiis subsimile, e forma thecae solitarium sed Mielichhoferiam busilurem vel campylothecum subreferens. Species memorabilis.

5. L. gracile R. Br. (1. c. p. 321.); dioicum; inferne compacte cespitosum humillimum; caulis laxinsculofoliosus; folia crecto-patentia rigida flavescentia oblonga acuninata, opice lomince increqualia, margine revoluta, nervo excedente flavo - et flexuoso-pilifera integerrima; perichactialia longius pilifera; omnia flexuosa; theca in pedunculo longissimo flexuoso oblongo-cylindricu longicolla subpendula vel inclinata, operculo hemisphaerico mutico.

Brid. 1. p. 127. - Schwägr. Suppl. 1. I. p. 12. tah. 104. Gymnostomum gracile Hook. Musc. Hxot. I. t. 21.

Patric. In simu Dusky-Bay Novae Seclandiae: Menzies 1791. In insula Campbelli: J. IIooker.

Lx imbricatione foliorum cum praecedente Timmies subsimile.

6. I. erectum R. Br. (1. c. p. 320.); monoicum; inferne compacte cespitosum Inmile; caulis dense-foliosus; folia erecta siccitute in spirulam contorta oblonga obtusa subemaryinuta, nervo crasso excedente mucronala vel longe flexuoso-tenui-pilifera, margine valde reflexu, cel-

- lulis subpellucidis non incrassatis mollia; perichactialia longissime pilifera; omnia integerrima intense viridia; theca in pedunculo longo stricto ellipficu erecta ore angustissimo, operculo hemisphacrico minutissimo.

Brid. 1. p. 125. - schwiagr. Suppl. IIl. I. 1. p. 3. tah. 212. Gymnostomun Leptostomum Hook. Musc. Kixot. II. tab. 169.

Putria. In Novae IIollandiae ora orientali, extra tropicum, in rupibus prope fluriorum ripas in regione montana, ad fluvios llawkesbury et Grose: K. Brown; dein legit Sieber in locis Novae Hollandiae non designatis.

Flores masculi ex observationibus șchwägricheni subglobosi, foliis caulinis dimidio breviores, foliis ovatis acutiusculis piliferis; antheridiis parvis compluribus epa- 
raphysatis. - Membrana peristomii in dentes densissime approximatos veluti connatos producta flava cellulosa.

Ex imbricatione foliorum, siccitate in spirulam contortorum, bryoideum, peristomio omnium maxime evolutum. E thecac forma Georgias minores in memoriam redigens.

?\% L. pusillum Hook. et Wils. (Lond. journ. of bot. 1844. III. p. 154.); caule breviusculo, foliis imbrieatis erectis ovato-lanceolatis acutis, nervo subcontinuo, theca annulata clavato-pyriformi nutante, operculo hemisphacrico-apiculato brevi. $\dagger$.

Putria. Brasilia in Serra dos Orgàos: Gardner No. 30.

Formis angustioribus Bryi polymorphi Br. et Sch. haud dissimile, sed peristomio nullo et sexu distincto. Ex habitu hic Brya illic Mielichhoferius referens.

\section{Gen. VII. Timmia IIedw.}

Musc. Frond. I. P. 83. tah. 31. - Mnium Hoffm. Spreng. Orthopyxis P. B. - Bryum Hall.

Nomen huic generi in memoriam Cl. ' $\mathbf{~ i m m}$, Consulis olim oppidi Malchin Megapolitani, stirpium Megapolitanarum acris investigatoris, impositum.

Calyptra dimidiato-cucullata fugacissima perfecte mnioidea. Peristomium duplex. Fxternum: dentes ut in Mnio genere formati, planissimi tenues membranacei pellucidi, apicem versus valde rugulosi, trabeculati, haud lamellosi, siccitate geniculatoincurvi. Internum: membrana hyalina in cilia numerosa filiformia nodosa valde appendiculata vel rugulosa, inilio inter se anastomosantia, dein libera, producta. Theca perfecte mnioidea ovalis inclinata annulata. Inflorescenia monoica gemmiformis.

Ex habitu caulis Polytrichis plantae simillimae et inter Mniaceas atque Polytrichaceas pulcherrime intermediae, 
illis e gr. Leptostomo spluchnoidi e theca, Lept. Mensirsii c caulis habitu, his e foliis basi vaginatis peraffines.

1. T. Megapolitana IIedw. (1. c.); antheridia longe stipitata; laxe cespitosa; caulis elongatus innovando ramosus; folia e basi subuginante pallida breviore lanceolatu upice denticulutu flexuosa vel undulata, margine inflexa, nervo subexcurrente; comalia longiora; perichaetialia breviora concava lanceolata; theea in pedunculo breriusculo stricto maxime oxulis crassu horizontalis brevis pallida, operculo hemisphuerico depresso vix mamillato raro subconico, aurantiaco; peristomii cilie appendiculis numerosis pruedita.

Brid. II. p. 69. - Bryol. Europ. Fasc. X. Bryaceae. Timmia; p. 6. tah. 1. - Timmia Bararica Hessler Comment. de Timmia p. 19. tig. 3. - T. Megapolituma $\beta$. Bararica Brid. I. p. 71. T. polytrichoides Brid. Mant. Muse. p. 122. - T. cucullula Mich. Ricl,. FI. Am. Bor II. p. 304. - Ortholm.ris Megnuolitana P. B. Prodr. p. 79. - Mninm Timmia Hoffm. Deut. F\%. II. p. 53. Mnimm Meyapolitanum Gmel. syst. Nat. II. p. 1327. - Bryum fuliis lanceolatis falcatis, setis alaribus, capsula ovata inclinata, operculo mammillari. Hall. Hist. St. Helv, u. 1779.

Putriu. In Germania septentrionali prope Malchin Duc. Megapolit. in pratis humidis rarissima. In Franconiae monte Waldstein: Funk; in alpibus 'lirolis, Carinthiae, Salisburgiae ef IIclvetiac haud rara. In Ifalicia, hucusque in agro tantum Leopoliensi Podolico, in rupibus Lisicnicensi- bus, ubi in fissuris umbrosis parcissime habitat, a Cl. Ł. obarzewski lecta. In Scandinariae W. Gothia, Norregia et Suecia boreali. In Scotiae Ducatu Forforshire. In Imerica septentrionali et insula Melville. Crypta amat et loca luci hominibusque impervia. - A mense Jumii ad mensem Septembris.

Flos masculus in axillis foliorum comalium, foliis c basi ovali subito acuminatis evanidinervibus serrulatis minute areolatis, antheridiis longe et crasse stipitatis, paraplysibus filiformibus interpositis.

2. T. Austriaen Iledw. (Sp. Muse. p. 176. tab. 42. fig. 1. \%.); antheridia elongato-cylindrica brevi-stipitata; laxe cespitosa; caulis elongatus innovando ramosus; folia 
e basi longe vaginunte fusca lineuli-lanceoluta grosse dentata, flexuosa vel undulata, margine inflexa, nervo subexcurrente, dorso subspinoso; perichaetialia e basi longiore ceteris similia, omnia minute areolata; theca in pedunculo longo flexuoso myriformi-ocalis horizontalis, operculo hemisplaterico-conico mammillato; peristomii dentes longiores, ciliis granulosis hand appendiculatis.

Brid. I. p. 71. - Bryol. Kurop. I. c. p. \%. tab. 2. - T. Megaypolitanc Flürke, Schleich. et al.

Patria. In Germaniae montibus hucusque tantum in Iercynia inferiore detecta, ubi in valle fluminis Bode dicti a domino Clasen pharmaceuta lecta est. In alpibus Austriac, ubi in monte Schneeberg Cl. Fröhlich detexit; in alpib. Salisburgiae et Carinthiae; in monte Branson prope Nartigny Valesiac et in ascensu septentrionali montis Simplon longe et late cespitosa; in Pyrenaeis et alpib. Scandinavicis, Gothiae borealis, Sueciae atque in Finlandia rarior. - Junio.

A praecedente nolis datis distinctissima. Caetera ut antea.

\section{Genus incertae sedis.}

Cymnostomum (Wucladon) complanatum Ilook. et Wils. (I.ond. journ. of bot. 1814. p. 538.); surculis erectis fasciculatis complanatis, foliis trifariis lateralibus patentibus verticalibus elliptico-lanceolatis acutiusculis integris nervo subcontinuo, dorsalibus erectis apice recurvis subrotundis apiculatis, nervo subcontinuo, perichaetialibus longioribus erectis linearibus, theca erecta elliptico-oblonga, ore angustato annulato, operculo longirostrato, calyptra dimidiata. $t$.

Putviu. Nova Seelandia in truncis filicis dendroidis. societate Rhisogonii piliferi Ilook. et Wils.

Muscus memorabilis, Hypopterygio analogus, forsan novum genus, cui auctores rlarissimi nomen Lucludon dederunt. Theca matura hucusque nondum observata sed annulata; an peristomata? Ex habitu Georgicue atque Schistostegue genus affine, qua de causa luc ex analogia revocavimus. Inflorescentia dioica terminalis. 


\section{Subtribns H. POL Y T ICHACEAE.}

Folia Mniacearum instar forma valde variabili praedita basi plerumque vaginata membranacea, congenerum fere omnium lamina interna lamellosa. Jamellae e cellularum strato unico consiructac in longitudine nervi positae plures. Theea epiphragmate clausa, exannulata, sacpissime angulata, apophysata, inaequalis. Antheridia muscorum fere omnium maxima clavata. Paraphyses floris masculi plerumque apice valde cellulosae subclavatae.

Longe cunctati sumus, Polytrichaceas cum Mnivideis conjungere, quum illis sit habitus maxime proprius. Ex observationibus autem permultis elucet, a Mnivideis nec foliorum areolatione, nec ulla nota acuta separari posse. Polytrichaceis multis folia sunt basi quidem vaginata, quibus habitus polytrichoideus maxime procedit, Cuthurineue tamen hac nota nunc carent, nunc gaudent, et in genere perfecte muioideo, Timmir dicto, species altera folis basi maxime altera vix raginatis observatur. Catharineae caeterum sectionis Arichi ad Mniuceus ex habitu valde accedunt ot Catharinea Callibryon Mnio undulato e foliis, Mnio polycurno e thecis procul dubio persimilis appellanda est. Oligotrichue et Psilopilu, minus similia, ab Atrichis separari non possunt, quum Atrichum ungustutum ad Oligotrichum transeat. Polytrichuceue tandem foliis cirrhatis Rhisogonic iterant, quorum folia, dorso saepe serrata, Polytrichaceis permultis proxima cognoscuntur. I't ut sil, persuasum habemus, Polytrichaceas Mniaceis proximas esse.

Putriu. Loci humidi vel sicci ommium regionum utriusque hemisphaerae, omnium muscorum gigantes et vita longà gaudentes.

\section{Gen. VIII. Catharinea Ehrh.}

Beitr. I. p. 188. - Bíd. 11. p. 97. - Atrichum P. B. et Bryolog. Furop. Fasc. XXI. Polytrichaceae. - Oligotrichum Dec. et 
Bryol. Furop. ibid. - Psilopilum Brid. - Polytrichum Hedw. et al. - Bryum Dill. Linn.

Nomen in lonorem Cathavinae II. Russiac imperatricis ab Ehrharto, forsan grato, datum.

Calyptra anguste-cucullata, apice subscabra, interdnm hirtiuseula. Peristomium simplex polytrichoideum. Dentes 32, e membrana basilari angusta cellulosa ligulati membranacei albidi, filis rufescentibus pluribus inarticulatis percurrentibus, subincurvi haud hygroscopici firmi. Columella apice in epiphragma tympaniforme dilatata, stoma claudens. Theca aequalis. Inflorescentia monoica vel dioica. Flos masculus cyathiformis vel gemmacens.

Sertio I. Atrichum. Folia latiora majora perfecte mnioidea basi haud vaginata theca exacte cylindrica arcuata.

1. C. Callibryon Ehrh. (Beitr. I. p. 189.); monoica, flore masculo in caule annuo terminali, antheridiis parvulis, cyuthiformi; caulis basi repens erectus ramosissimus gracilis laxe foliosus; folia apicem versus sensin majora confertiora longa lingulato-lanceolata, e medio ad apicem undulata, margine unguste limbato dentato, dentibus saepe binis, nervo dorso spinoso subexcurrente; perichaetialia angustiora; perigonialia externa comalibus similia, panto breviora et latiora, interna e basi lata concava brevi-lanceolatu, intima obcordato-acumimulatu, apice cremulata; theca longe-cylindrica arcuata, operculo longissime rostellato curvulo.

Atrichum undulatum P. B. Prodr. p. 42. - Bryolog. Europ. 1. C. P. \&. tah. 1 et 2. - Cullibryum polytrichoides Wieh. F\%. Werth. p. 290. - C. undulutum Zenk, et IDietr. Muse, Thur. Fasc. 11. 11. 41. - Catharinea undulatu Röh. Deutscli. Fi. 111. 1. 61. Brid. Bryol. InIiv, II. p. 102. - Polytrichum undudutum Hedw. Musc. Frond. 1. p. 43. tah. 16 et 17. - Oligotrichum undulutum lamarck et llecand. Fl. Franģ. I. p. 492. - Mnium undululum Linn. jun. Meth. Musc. p. 364. - Bryum undulatum Limn. Sp. P1. p. 1532. - Bryum phyllitidis folio rug0so acuto, capsulis incurvis. Dill. Musc. p. 360. tab. 46. fig, 18. 
ק. attemata; foliis angustioribus tenerioribus, siccitate magis crispatis, nervo angustissime lamellato, theca graciliori. Polytrichum undulatum var. 1. Hook, et Wils. Drumm. Musc. Americ. Fasc. II. No. 66. - Bryol. Europ. 1. c. p. 8.

$\gamma$. abbreviata; pedunculo, theca et peristomii dentibus brevioribus. Bryol. Europ. 1. c. p. 8.

d. brevilamellosa; folia lamellis fere carentia; planta cacterum robusta, thecis aggregatis.

E. subservata; foliis subintegerrimis, apicem versus serratis. Pol. undulatum $\gamma$. subserratum Hook. Lond. journ. of bot. 1840, p. 3.

Putrice. In locis umbrosis graminosis totius Furopac. Var. $\beta$. in America septentrionali. Var. $\gamma$. in terra nuda arenosa. Var. $\delta$. in regno Mexicano: Schiede prope Jalapam, Leiboldt in locis non designatis. Var. E. in Nepal et Ilimalaya Indiae orientalis. - Sero auctumno et hyeme.

Folia perigonialia tenera, haud lamellosa laxins areolata. Antheridia pervula, paraplyysibus pallidis paulo longioribus mixta.

2. C. androgyma C. Müll.; monoica, flore masculo in feminei vicinia, antheridis maximis clazutis praedito gemmiformi; habitus praecedentis, sed folia caulina marginc crussins limbutu, perfecte bispinosa; folia floralia e basi latiore caulinis similia; perigunialia externa lanceolatu spinoso-acuta, simplicitev dentata, interiora basilaliora reflexa integerrima; theca pracedentis. Operculum deest.

Putriu. Promont. bon. spei prope Swellendam in nemoribus ubi m. Octobr. c. thecis deoperculatis legit EckJon. Hb. Kunzeanum.

Cactera ut in praccelente, a qua notis datis facile distinguitur. Archegonia longissima.

3. C. anguatata Brid. (Bryol. univ. II. p. 105.); alioicum; habitus Cath. Callibryi sed gracilior; folia anynstiona firmiora angustissime limbata; breviora, nervo lumellis numerosioribus, minutius areolata, lamellae ple- 
rumpue totum fotii apicem occupantes, ommes partes facile emollientes; theca erecta tenui-cylindrica subarcuata, maturitate sanguinea, operculo brevius rostellato.

Atrichum angustatum Br. et sil., 1. c. 1.9. tab. 3. - Atr. controrersum P. B. Prodr. p. 42. - Polytrichum angustatum Hook. Musc, Exot. tah. 50. - Pol, controversum Brid, M. Musc, 1. p. 78. - P. malulatum f. mimus, theris folisque rectioribus. Hedw. Muse. Frond. I. p. 48. - Bryum juniperi foliis rugosis, capsulis rectiorilsu. Dill. Musc. p. 362. tah, 46. fin. 19.

Patria. In terra arenosa et aruillacea collium subumbrosorum totius fere Europac praccipue Germaniae septentrionalis et in Anerica tota scptentrionali vulgatissima. Sero auctumno.

Folia perigonialia plerumque late lanuellosa. A C. Callibryo notis laudatis distinctissima.

4. C. tenella Röhl. (Imnal. der Wetterauer Gesellsch. III. p. 234.); divicu; caulis lolevis; folia late-lanceolata subundulata, nervo purce lamelloso, margine infra medium dentato; theca brevissimu cylimdrico-ovalis ore amplo fuscescens subarcuata, operculo conico subulato rectiusculo, calyptra apice obsolete lirsuta; peristomio magno.

Atrichum tenellum Br. ct sich. 1. c. p. 9. tah. 4. - Cath. tenella Brid. 11. p. 10t. - Polytrichum undulatum B. minus Funk. Moostaschl, p. 70 . - polytrich. undulatum $\beta$. minus: foliis boevioribus obtusioribus. Wahleub. Fl, Lapp. p. 349. -. Muium orthorrhynchum Brid. Sp. Musc. HI. p. 45. Bryum lolla orthorrhyncha Brid. II. p. 691. e speciminibus herbarii auctoris huc pertinet!

Patria. In solo limoso et turfaceo: in Vogesis prope Bipontem aliisque locis; in Lusatia prope Maffersdorf; prope Francofurtum Neomarchiae; in Austria prope Gmünden; in Norregia prope Drontheim et in Gothia ac Succia. - Augusto. Septembri.

Praccedenti proxima sed primo adspeculu theca brevissima vix cernua discernibilis.

Sertio 1I. Psilopilum. Folia anustiona polytrichoidea, basi haud varinata, sed anplexicaulia; theca complessiuscula, apice subincurva asymmetrica. 
5. C. Elabrata IIook. (Iter Island I. p. 24.); dioicu; humilis simplicissima laxe cespitosa; folia remota laxe imbricata quadrifaria, oblonga valde concava oblusa vel obtuse brevi-acuminatu maryine cremulutu, nervo lamellis undulatis creberrimis praedito dorso laevi; theca basi crassa ventricosa apice attenuata curvula inaequalis, rufa, basi stomatiis instructa, siccitate rugulosa, operculo e basi convexa breve et incurvo-rostellato; calyptra apice obsolete papillosa, cacterum uuda; dentes peristomii pallidi.

Oligutrichum laerigatum Br. et sch. Bryol. Europ. Fasc. 21 22. I'olytrichacene. Oligotrichum; P. 5. tab. 6. - Psilopilum areticum Brid. 11. 1. 46. - Polytrichum laerigutum Wahlent. F'. Lapp. p. 349. tah. 22. - p. glabratum Wahlenh, olim in Weh, et Mulur. 1nd. Musaei. - P. maryinatum schwägr. Suipl. I. 11. p. 329.

Iatriu. In apricis alpinis et borealibus Lapponiae 'Tornensis, Islandiae, Labradoris et in insula Melville. Aestate. lamelloso.

Folia perigonialia obcordato-acuminata, nervo apice

6. C. compressa C. Mïll.; caulis subsimplex; folia erceto-patentia lunceoluto-subulutu concatia carnosa subserrata; theca inclinata orata compressa, microstoma, operculo conico rostrato, calyptra upice subpilose. $i$.

Polutrichum commessum Hook, et Wils. I,ond. journ. of bot. 1844. p. 539.

\section{Pulviu. Insula Eremitae ad Caput IHorn.}

Praccedenti affine, sed theca compressa foliisque angustioribus jam differt.

7. C. trichodon C. Müll, divica; caulis humilis subsimplex; folia crecta ovato-lanceolata valde ucutu cumuliculata integerrima dense imbricuta; apice lamellosa brunnea; thera in pedunculo breviusculo crassiusculo obliqua suberecta oralis seu rotundo-compressa majuscula microstoma, operculo rostrato; dentes peristomii 16 pallidi longi subululi; calyptra glabra apice scabriuscula s. pilosiuscula. $t$.

Polytrichum trichodon Hook. et Wils, in Lond. journ. of lot. 1847. p. 289. tab. 10. 
Patric. Nova Granada prope Paramo of Ruiz in cinerib. vulcanic. ad nives aeternas: Purdie legit Julio 1846.

Praccedenti affinis, differt antem peristomio, e lamina duplici, externa et interna (e sporangidio orta) formato, dentibus subulatis.

Sertio III. Oligotrichum. Folia praecedentis sectionis. Theca cylindrica uninera v, ovalis, baud incurva sed crectiuscula.

8. C. Hereynien Fihrh. (Beitr. I. p. 190.); divira; humilis simplicissima gregaric cespitosa; folia elccto-patentia subarcuato-incurva, siccitate tortuosa, rigidiuscula, e basi amplexicauli lanceolata concara, margine inflexa remote serata, apicem versus lamellis undulatis creberrimis, dorso cristato-dentata; theca erecta ovato-cylindrica symmetrica, operculo conico apiculato; calyptra pilis erectis paucis apice sublirta.

Brid. II. 1.99. - Otigntrichum Hercynicum Dec. Flor. franç. I1. p. 492. - Bryol. Europ. 1. c. p. 4. tal. 5. - Atrichum Hercynicum P. B. Prodr. P. 42. - Polytrichum Hereynicum Hedw. Musc. Frond. I. p. 4h. tah. 15. - Orthotrichum Hercyuicum Hoffm. Deut. Fl. 11. 1. 25. - ruth. Sudetica Presl. (Pogonatum intermedium Opitz.). Brid. 11. p. 106?

Putria. In subalpinis et alpinis Germaniae septentrionalis, centralis (Sudetorum et Montis acriferi), Ilelvetiae, Vogesorum, Sueciae, Norvegriae, Lapponiac et in Islandia fide Steenstrup. Inter Oderbrück ef Indreasberg Hereyniac superioris primus omnium legit Ehrhart. Aestate.

Folia perigonialia e medio patula latissime ovalia minora colorata acula, apice parce lamellosa, dorso laevia, integerrima pellucida.

9. C. Javanien IImp. (Ic. Musc. tab. 22.); divica; pracedenti simillima; sed folia longiora angustiona subulata subacuta, inferiora integra, superiora apice remotissime serruta, nervo dorso apicis cristato-dentata; perichaetialia valde amplexicanlia basi valde pellucida, apice multo angustiora; theca minor obligue erectu, operculo 
convexo conico; calyptra usque fere ad apicem lissa apice pilis erectis paucis subhirta.

Hmp. in Ic. Musc. Frond. tah. 22.; icone al ipso auctore, haul manib. nostris delineata.

Patria. Java, ubi in cacumine montis Sindoro, locis humidis mense Aprilis legit $\mathrm{J} \| \mathrm{ngh} \mathrm{h} \mathrm{h} \mathrm{n}$.

Dentes peristomii 32 filis rufescentibus praediti praecedente.

10. C. Riedeliana Hmp. (Linn. XY. p. 89.); divicu; laxe cespitosa elatiusculc simplicissima; folia remotiuscult, inferiora minora oblonga, superiora oblongo-lanceolata majora latiora; omnia margine unduluto-flenteosa, tenera rividia valde pellucida, nerto apicem versus undulato-lamelloso dorso breviter cristato-dentato pracdita, apice eremulatu concara hund ammlexicumlia; perichaetialia maxima, basi longe raginata laxe et majusculo-reticulata valde pellucida, apice densius areolata magis crenulata, nervo dorso longe cristate et argute serrato, acutiora et ut praccedentia siccitate involuto-cirrhata; theca in pedunculo longiusculo stricto ovalis cresset brevis, ore trincato et operculo e basi conica longe rostrato praculitat erectiuscula; dentes peristomii brevissimi pallidi angusti.

Polytrichum Riedelicnum Nont. Ann. d, st, sat. II. Tom. XVI. 1841. p. 269. - P. nigricuns Hook, et Wils. Lond. journ. of bot. 1844. P. 151 .

Putria. Brasilia: Ricdel primus legit. Ex herbario Lucaeano a Luschnath lectam quoque habemus. Prope Rio Janciro: Gardner No. 10.

Planta mascula mulio gracilior, flore discoideo maximo instructa. Folia perigonialia interiora latissima obcordato-acuminata brevia, integerrima, nervo apice parce lamelloso, exteriora angustiora sublongiora, apice crenulata, basi in nervi tantum vicina concava. Antheridia maxima erelecrima, paraphyshus paucis hyalinis, apice clavatis coloratis mixtis. Calyptra perfecte glabra. Lx habitu plantae cmollitae Africhis persimilis, sed theca distans et C. temurostri magis affinis, caule autem 
elongato, foliis viridibus valde contortis et theca truncata crassa brevi primo intuitu distinguitur.

11. C. tenuirostris Brid. (II. p. 101.); dioice; laxe cespitosa humilis simplicissima; folia confertion palula, e basi subuginante tenerima oblonga obtusiuscula integerrima, apice minutissime areslata nereo lamellis perpaucis brevissimis striclis muedito; theca in pedunculo elongato ovata basi punctata ore angustu, operculo e basi convexiuscula longirostro obliquo; dentes peristomii 32 breves rufescentes; calyptra glabra.

Polytrichum tenuirostre Hook. Musc, Exot. tah. 75. - schwiant. suppl. 11. 11. p. 16. tab. 157.

Patria. In sinu Dusky-Bay Norae Seclandiac: 1. Menzies 1791.

12. C. Molinae C. Mïll; cespitosa simplex clongata; folia ovato-lanceolata obtuse busi quedrulu membranacea hyalina amplexicunlia, margine erecto umblulato, supra medium patenti-incurra, canaliculata integerrima, nervo sensim dilatato percursu, "medio ad upicem mullilampllata, siccitate uncinato-incurva; theca primo orata subinaequalis tandem oblongo-cylindrica subinclinata, operculo e basi conica rostrato, dimidiam thecam vix acquante; peristomii dentes 32 breves; calyptra laevissima fusca fere ad apicem fissa. t.

Polytrichum Molinue Mont. Ann. des sc. nat. 1845. 4. p. 102. et in Hist, de Chile; Bot. Crypt. tab. 4. fig. 3.

Patria. Chile australis, ubi frequenter legit C. Guy.

C. canaliculatue proxima, differt autem statura quater majore, folis obtusis, theca primum ovali dein rylindracea et opereulo thecam dinidiam vix acquante. A r. tomirostri foliis multilamellosis, a C. semilumellate foliis obtusis et multilamellosis, theca erecta et operinlo distinguitur. - Dioica?

13. C. semilamellata IImp. (Linn. XX. 1. 79.); dense cespitosa humilis simpliciuscula; folia lanceolata concava integerrima subcoriacea, laxe imbricutu, siccitate contorta, nerro superne latiore lamellato, lamellis 
undulatis; theca in pedunculo longiusculo inclincele subcylimalracea, opereulo longirostrato reclo. $\leftarrow$.

Polytrichum semilamellutum Hook. fil. in Ic. Plant, rar, tab. 194 A. fig. 1.

Putrie. In montibus Himalaya: Dr. Royle.

Ex affinitate hujus speciei el C. tenurostris atque Molinae forsan huc pertinet. Calyptra ab auctore non observata. Dioica? Folia ex ic. basi haud amplexicaulia.

14. C. canaliculata C. Müll.; dioicu; laxe cespitosa lumilis simplicissima; folia inferiora e basi haud vaginata tenuiore oblongo-lanccolata obtusata integerrima, ubique laevia, apicem versus e cellulis incrassatis minutiusculis composita carnosula, nervo e medio ad apicem usque dense lamelloso crasso totum apicem occupante; perichaetialia basi longe raginantiu multo laxius areolata; theca in pedunculo longiusculo teres mujuscula ore angustior, operculo longe rostrato; calyptra laevissima fusca; dentes peristomii 32 lineares obtusiusculi.

Polytrichum canaliculatum Honk. in Capt. Beechey's Voyage p. 54. - Schwagir. Suppl. IV. tab. 324.

Putria. Conception Chiles: Ia ay et Collie. In iisdem locis, sed non designatis legit Pöppig. Ilb. Kunzeanum.

Ex habitu Cath. temirostris, sed notis laudatis sat discernibilis.

Sectio IV. Dendrolignotrichum. Folia hasi longe vasinala, cirhata. Theca sectionis praecedentis. plantae saepe giganteae,

15. C. dendruiden IImp. (IImn. XX. p. 78.); dinier!; caulis e basi rhisomaloidea radiculoso-tomentosa maxime slongutus trigueter strictus, foliis squamiformibus densissime appressis amplexicuulibus uristutis brunneis prueditus, "ppice dendroideo-romosus; rami plantac femineae dichotomi, masculac fisciculati, simplices elongati; folia octosticha, siccitate patula flexuosa, madefacta patentia stricta, amplectentia, e basi lata membranacea lineariareolata denticulata lanceolato-subulata longissima, grosse 
serrata, apice serrato, nervo crasso excurrente dorso apicis serrato; theca in pedunculo breviusculo flexuoso aequalis ovata brevis maxime truncata, aperta horizontalis; dentes peristomii 64, e membrana alta sulcato-plicati lanceolati latiusculi obtusiusculi involuti; calyptra subglabra, basi pilis longissimis nonnullis nodosiusculis, apice papilloso-scabra.

Polytrichum dendroides Hedw. Sp. Musc, p. 102. et Suppl. 11. 11. p. 1. tab. 151. - Pogonatum dendroides Brid. 1I. p. 112.

Patria. In sylvis, quae Alpibus subsunt Commersomianis, in sinu Baie Française de Bougainville et in Port Galant Freti Magellanici, ubi Commersou Decembri 1767 detexit; praeterea in sinu Dusky-Bay Novae Seelandiae: Menzies. E regno Peruviano, a Cl. Plnilippi lectam et Hb. Reg. Berol. missam benerolentiae Cl. Klotzsch debemus.

Flores masculi in planta unica, sed ramis diversis creberrimi, e centro proliferi, cyathiformes. Antheridia maxima clavata, paraphysibus numerosissinis longissinis filiformibus interdum apice celluloso-incrassatis. Flores feminei creberrimi (in specimine unico 6.30 numeravimus), terminales, dein innovationibus laterules in ramis brevibus. Archegonia quam maxime elongala pallida laxissime cellulosa, apice maxime infundibuliformia tripartita, nucleo parvo, paraphysibus longissimis filiformibus. Omnium muscorum pulcherrima species dendroidea, nulli ali nisi sequenti conparabilis.

? 16. C. squamosa C. Müll.; caulis clongatus squamosus, superne fastigiatim ramosus, rami patentes breres densi curveti; folia dense imbricata suberecta lanceolatosubulata stricta serrata. $t$.

Polytrichum squanosum Hook, et Wils. Lond. jonrn. of bot. 1844. p. 539.

P'utriel. Insula Eiemitac ad promontorium Horn: J. Il o oker.

An forma sterilis alpina praccelentis? altctores 1. (". quacrubt. Habitu autem valde recedens. 
Sectio V. Polytrichadelphus. Folia juniperoidea densissime imbricata. Theca sectionis praecedentis.

17. C. cillata C. Müll.; dioica; maxime data funiformis crassa simplex, e basi uscuc ad apicem foliosa; folia crecta, basi vaginantia ovato-subulata carinata cupice ciliatu, nervo e medio dense et stricte Iamelloso; theca in pedunculo breviusculo senicylindrica acqualis vel ovato-oblonga erecta, dein horizontalis, innovatione plerumque lateralis, operculo conico apiculato; calyptra dimidiata basi valde truncata, upice pilis paucis brevibus, erectis, busi phuibus longis descendentibus hirsutiuscula, flarescenti-brunnea. to

Polytrichum ciliatum Hook, et Wils, Lond. jounn, of bot. 1847. p. 290. tab. 10.

Putriu. Nova Granada prope Paramo de Pamplona raro: Purdie, Septbr. 1845.

Planta speciosissima sequenti affinis, sed solitaria. Planta mascula e centro floris sacpe prolifera. Dentes e nembrana brevi latiusculi breves.

18. C. Magellaniea Brid. (II. p. 106.); divicu; simplex dein apicem versus semel vel bis innovans erecta stricta, basi nudiuscula; folia densa, lumida subpatula, siccitate appressa, e basi batiore amplexicauli longe subulutu canaliculata, cerlilugineo-servulu, pungentia, lincala, crassincria, e viridi spaticea, inferiora decolora; perichactidia interna cordiformia latiora, margine pellucido; theca in pedunculo terminali erecto longiusculo ex ovato rylindrica erecta fusco-pulla, operculo e busi conica in rusirum longum incurrum coluclo; calyptra pilis brevibus (2xasprevalu; dentes peristomii 64 breves erecti albicantes.

Polylvichum Magellanicum Liun. Suppl. p. 419. - Hedw. Sp. Musce. p. 101. tals. 20. fig. 1. 2. - Menzies in Trans. of Limn. Noc. 4. 1. 71. tal., 6. fig. 1. - Collenrinen Pseudopolyl richum Radd. in Memor. di matemat. et fis. llella soc. Ital. Molen. Toun. 1s. p. 113. tith. 18. fig.s. 1. - Pogonatum Dagellumicum P. B. Prodr. P. At. -

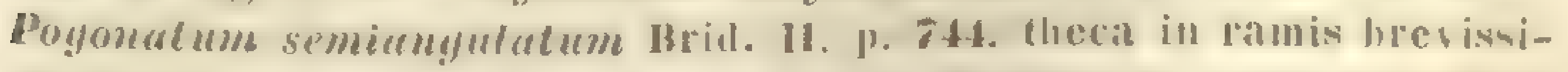
mis quasi lateralis, aperta borizontalis. Pogonatum semiunyulutum Brid. 11. p. 744. 
Patria. Ad fretum Magellanicum primus omnium legit Commerson; in Nora Seclandia: Menzies; in montosis Jozé Dio: Beyrich, Augusto; et in Serra do Frade prope Rio Janeiro Brasiliae: Beyrich, Augusto. In Serra de l'iedados Brasiliae: Gardner No. 14.

\section{Gen. IX. Polýtrichum Dill. emend.}

Hist. Musc. 1. 439, - Mnium Limn. fil, Hall, - Poygnutum Brid. 1I. p. 107. - Catharinea Röh.

Nomen graecac compositionis, apud Apulejum primum occurrens et Polytrichum commune designans, a ro-

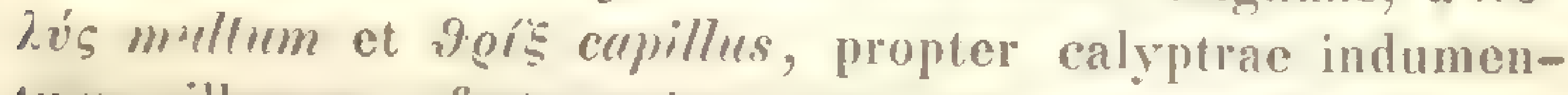
lum villosum, forte etian ob pedunculorum capillorum instar copiam aut radicis crines longos imitantes, ei inditum, toti generi a Dillenio impositum, a Linnceo et Hedwigio sancitum.

Calyptra dimidiata, capillis autem descendenlibus reberrimis indumentum villosum longum formanlibus quasi campanulata. Caetera ut in prarcedente genere.

Sectio I. Aloidella. Plantae humillimae. Folia laxiuscula panca siccilate plus minus involuta aluidea. Theca aequalis parva ore plus minns coarctata.

1. P. nloides Iledw. (Stirp. I. p. 40. tab. 14.); canlis femineus e perichaetio, masculus e perigonii centro innovans, laxe cespitosus; folia e basi laxe raginante late lanceolata obtusuta, supre basin remole denliculate, apicem repsus argute et breviter serratu, nervo e medio multilamelloso folium fere totum occupante, dorso phus mimus serveto; theca in pedunculo stricto longiusculo oralis erectiuscula vel subinclinata ore parum angustiore, operculo convexo-conico brevi praedita, millosa, columella quadrialata.

Po!fonertum aloides Brid. 11. 1. 119. - Bryol. Larop. D. (i. titl.

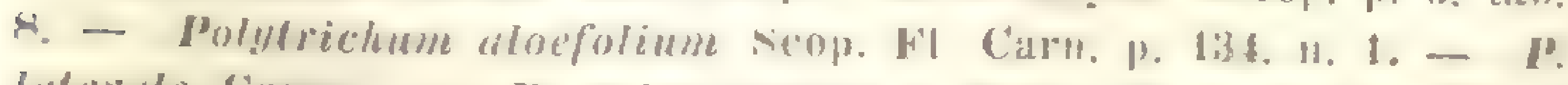

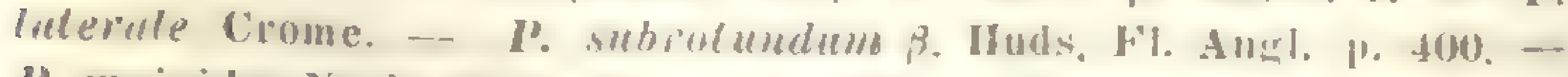
l. mnivides Neck. Meth. Muscor. p. 128, - J. Munun Weis. Cryot. 
Gött. p. 173. - p. partum Aloes folio sorrato capsulis oblongis

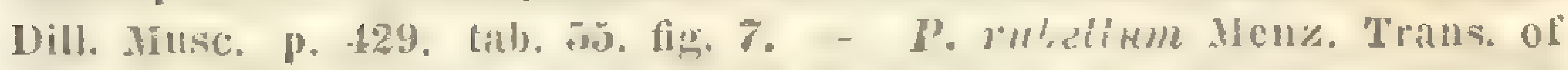
Jinn. soc, 4. p. 79, tal, 7. fig. 3. - 1. Dicksoni Turn. Muscol. Hil. p. 88.

B. defuens, caule et pedicello brevioribus. calyptrac pilis sub theca confluentibus. $p$. defuens Brid. Mant. Musc. p. 200. Br. univ. 11. p, 121. var. aloidis. - Br. kimrop. I. c.

$\gamma$. magnu, partibus omnibus robustior innorationibus clongatis, foliis latioribus rigidioribus, dorso valde serralis siccilate rix tortilibus et theca maxime papillosa majuscula valde truncata.

I'atrie. In ericetis, ad rupes humidas et in rupium fissuris per totan Europam, Americam septentrionalem atque aequinoctialem et Asiac regiones septentrionales. Var. $\beta$. ubique occurrit, praesertim in solo arenario. Var. $\gamma$. ill limos. sylvestr. Oenipont, ubi II ufIer legit. Vere.

Planta mascula gracilior, foliis brevioribus, externis obovata-acuminatis, internis obcordato-apiculatis, intimis e basi angusta dilatatis acuminatis. Paraphyses filiformes vel subclavatac. Dentes peristomii $28,32,36$.

2. Co. Copense IInp. (Ic. Musc. tab. 21.); brevissimum paucifolium simplex; folia e basi diaphana vaginante latioro ovato - lanceolata acutiuspule, siccitate convoluta incurva, in parte superiore nervo lamellato latissimo obducta, margine valde diaphano vemole inciso-dentutu; theca in pedunculo breviusculo orcito-cylindrice lacris crecta operculo brevi conico incurvo; calyptra brevis; dentes peristomii brevissimi lanceolati obtusi sacpe per paria connati.

Patria. Prom, bonac spei: Gueinzius, pharmacopola. Hb. Kunzeanum.

Inter Polytr. aloides et namum intermedium. A priori differt: folis apice remote inciso-dentatis, theca evacuata opaca laevi, operculo breviori conico obtuso, peristomii dentibus ter brevioribus. A secundo proximo loliis brevioribus ad basin magis diaphanis nervoque tentione attenuato, theca ovato-cyliudrica, deoperculata utrinque sub- 


\section{STEGOCARI. ACROCARPI. POLTRICHU.}

attenuata texturae firmioris cellulis duplo majoribus hexagonis dentibusque peristomii latioribus brevioribus et solidioribus saepe binis confluentibus distat.

3. P. nanum Hedw. (Stirp. Crypt. I. p. 37. Lab. 13.); caulis hund e.x upice innoums, subgregurius; folia rigida patentia, e basi laxe vaginante lanceolata, upice mimute et remote denticululu, superiora obtusiuscula; perichaetialia longiora, tenero - membranacea, intima acuminata subnervosa integra clamellosa; theca in pedunculo longiusculo globoso - necoluta subcrivere erectu rel mulans pallide olivacea, ore valde truncato, operculo e basi convexiuscula rostellato recto conico; dentes peristomii magni, amoene purpurei.

Pogonatum.nanum Brid. II. p. 117. - Bryol, Europ. I. c. p. 5. tal. 7. - Polytrichum pumilum sw. Musc. Suec. p. 77. tals. 9. fig. 19. - Poyonatum pumilum Brid. II. P. 116. - Dol. semidiaphaMum Brid. Mant. Musc. p. 200. - Pol. intermedium Brid. Mant. p. 6x. - Pol. ericoides Hotundum Nen\%. Trans. of Limm. soc. 4. B. foliis integerrimis Soffm. Deut. Fl. II. p. 24. - P. aloefolium nana Röhl. Moong. Dent p. 188. Carn. 11. 11. 1290. - Cuthurinea villosa " Limn. Sp. PI. P. 1z6. Mnium polytrichoides, calyptrat rotundis galeritic, aloes folia fig. 6. - Pogonatum pusillum B. Prodp. p. 119. Musc. p. 128. tah. 55.

ק. longisetum IImp., foliis longioribus, lineali-lanceolatis, pedunculo ralde elongato, theca ovali-oblonga. Bryolog. Europ. 1. C. p. 5. tab. 7. $\beta$. 1.

P'utria. In locis argilloso-arenariis sterilibus humidis per totam Europam, Asiam et Americam borealem. Var. $\beta$. prope Halam Saxonum. - Hyeme.

Planta mascula humilior, flore gemmaceo-cyathiforme foliisque perigonialibus externis late ovato - arminatis. nervo crassiusculo apicem versus lamelloso, interiora angustiora obovato - lanceolata tentumervia rubella, intima minima lanceolata, obsolete nervosa tencrima. l'araphyses filiformes tencrimae.

4. P. brachyphylum Rich. (Mich. Fl. Amer. Bor. 11. 1. 295.); dioicum; brevissimm simplicissimmm; foliu penca e basi enginante pellucida latione breciler lingulata 
obtusissima integervima, nevro lamellis numerosissimis crassissimo totum folii apicem occupante, vulde cumosu aloidea, siccu ct malefuctu strictu; perichactialia basi longiore pellucidiore tenuiore; theca in pedunculo elongato ovalis erecta pupillosa, operculo e basi tumida convexa breviter conico; dentes peristomii longiusculi rufi.

P. vaginans Brid. sp. Muscor. 1. p. 68. - Poyountum brachyfhyllum P. B. Prodl. p. 84. - Brid. 11. p. 113. - sillwïgr. silppl. 1I. II. I. tab. 156 .

Patria. In argillosis Carolinae et Pensylvaniac: Richard. Georgia, Alabama, Ludovicia: Sullivant.

5. P. Pengylvanicum Hedw. (Ap. Muse. p. 96. tab. 21. fig. 1-6.); divicum; humile simplicissimun pancifolium; folia erecta strictissima donguta, p basi longe renginante latione sensim acuminata, nevero apice dense lamelligero dorso cristato-dentuto folii apicem fere totum occupante, cremulatu upice dentuta; perichatialia longiora cusprelute crenulata basi loneissima pellucida; theca 111 pedunculo elongato ourelis cylimbicu sub ore courctutu suburcuata, operculo e basi tumida convexa breviter conico; dentes peristomii longiusruli medio rufi; calyptra thecam superans albescens apice subbrunnea.

Scliwägr. suppl. II. II. I. p. 14 tah. 156 - pol. acaulon capillaceun, capsulis cylindricis. Dill. Nusc. p. 434 tah. 5̆. fig. 12. pol. tenue Menz. Traus. of Limn. soc. IV. p. 68. - Pogonutum irevicaule P. 13. Prodr. p. 84. - Brid. 11. p. 114. 7\$3.

B. Torreyumum, caule brevissimo. folis e basi orata longe subulata tenera diaphana integerima, apice valde incurva. Poyonatum Torreyanum Brid. mst. II. p. 115.

Putriu. In terra angillosa secundum viarum latera Americac totius septentrionalis a Marylandia usque ad Georgian, Pensylvania, Carolina, Nova Scotia, Massachusets et in Brasilia unde prope 'lejucam a Cl. Gardner lectum habemus.

Sectio 11. Cephalotrichum. Prantae clatiores sed simplices, hasi nudae, apice comoso-vel rosulato-foliosae. Folia juniperoidea stricta. Theca aequalis. 
6. P. oligodus Kze. (Pl. Chil. Pöpp. Coll. I. No.271.); divicum; folia laxiusculo - imbricata, e basi Jatiusculovaginante pellucidiore subito lato-lanceolata longinscule ot intense brunneo-cuspidata, remote et parce denticululu, dorso lacvia, nervo supra basin diaphanam multilamelloso totum folii apicem occupante, crasso; perichaetialia interiora multo minora, intima subelamellosa, e basi laxe arcolata valde lata subito longe et anguste flexuosocuspidata brunnea integra lacria; thecae saepe geminatae tenuiter flexuose et longiusculo-pedunculatac longinsculocylimbicue rugulosue erectae, operenlo c basi tumido-conica breviter rostellato oblicuo; calypura subaurantiaca tenuiter villosa; dentes peristomii primum 16 latiusculi simplices rufi dein geninati, igitur 32 in membrana basilari brevissima vel vix ulla.

Cephulotrichum oligodus Br. et Sch, Bryol. Europ. Fasc. 21-22. Poponatum; p. 4. - polytrichum aloides $\%$ raule di-, tricarpo, dentibus subinde sedecim. Stehwïr. Sp. Musc. P. 1. p. 13.

Patriu. Chile: Pöppig.

Plama mascula perfecte rosulato-foliosa, perigonio subdiscoideo. Antheridia panca maxima, paraplissibus fere carentia. Species distinctissima gracilis interdum valde elata sed basi longa nudiuscula folis minimis praedita.

7. P. Simense Br. et Sch. (PI. Abyss. Schimper.); hermaphroditum; folia dense et magis rosulato-imbricata valde firma upice subincurve, madefacta crecto-patentia minora quam praccedentis speciei, e basi breviusculovaginante pellucidiore luxiusculo - areoluta lanceolata latiuscula breviter et intense brunneo-cuspidata infegerrima, dorso laevia. nervo supra basin breviter et multilamelloso apicem folii fere totum occupante praedita crassa rigida; perichaetialia c busi longissima venginunte tenerrima longiore, subito et longins cuspridula; omnia carinata; theca in pedunculo breri oblongo-rylindrice longiusculosubrugulosa, erecta rrossinscula, operculo e basi convexa breviter apiculato; dentes peristomii ut in praecedente specie. 
Cephalotrichum Simense Br. et Sch. in Bryolog. Europ. 1. c.

Patria. In alpibus Simensibus Abyssiniae, ubi in monte Silke 10,000 ped. supra mare legit societate Solorince Simensis Hochst. W. Schimper.

Praccedenti proximum, sed notis laudatis distinctissimum.

8. P. perichaetiale Mont. (Ann. d. sc. nat. XVI. 1841. p. 252.); dioicum; folia laxe imbricata valde firma apice sicca atyue madefactu subincurva, erecto-patentia, e basi breviusculo - vaginante laxinscula pellucida superne margine densius et brunneo-aveolate fere subito lanceolata latiuscula breviter et intense brunneo-cuspidata integerrima, dorso laevia, nervo supra basin breviter et multilamelloso apicen folii totum fere occupante praedita, crassa rigida; perichaetialia externa e busi longissima vaginante tenerrima longiora multo angustiora, sensim ef longius cuspidata, interna angustissima basi longissima tenerrima laxe areolata, subito cuspidata plus mims crenata; omnia carinata; theca in pedunculo brevi oblongocylindrica laevis erecta crassiuscula, operculo e basi convexa breviter apiculato; dentes peristomii ut in praecedentibus speciebus.

Patria. Ad terram nudam in montibus Nilgheriensibus: Perrot tet.

Calyptra thecam superans, basi longe descendente pedunculum arcte includens villosissima aurantiaca. Praecedenti proximum, notis autem laudatis distinctissimum. A P. oligodo jam calyptra thecam superanté differt.

9. P. subulatum Menz. ('Trans, of Linn. Soc. IV. p. 303.); dioicum; simplex raro subramosum; folia lanceolata carinata margine et dorso serralu margine albicantia, fragilia tenera siccitate haud stricta fusco-rubella, obtusiuscula, nervo tenui e basi ad apicem usque breviter lamelloso; theca in pedunculo breviusculo cylindrica angusta erecta subaequalis, operculo conico-subulato theca paullo longiore; dentes peristomii 32 ad 40 ; calyptra pilosa parva canescens. t. 
Schwägl". Suppl. 11. 11. I. p. 13. tab. 1555. - Pogonatum subulatum Brid. 11. p. 122.

Patriu. In Nova Seelandia, unde Nels on retulit et cum Menziesio communicavit.

Sectio III. Pogonatum. Elatae plantae ramosae vel simplires liaud rosulato-fuliosae, sed e basi usque fere ad apicfm caulis fonnatum foliis jumiperoideis praeditae. Theca ut antea.

\section{a. Humiliora.}

10. P. dentatum Menz. (Trans. of Linn. Soc. IV. p. S0. tab. \% fig. 4.); dioicum; caulis erectus plerumque divisus in ramos duos vel quatuor, laxe foliosus; folia erectiuscula, inferiora patula rigida, ex ovata amplexicauli basi duplo latiore lanceolata, planiuscula, margine dentibus longis angustis antrorsum curvatis spinarum forma, terminalia lunceolato-cuspidutu, badia, basi latescente, nervo crasso in basi, in angustiore folii parte fere totum folium replente, dorso aliquot denticulis notato, perichaetialia terminalibus similia in cylindrum convoluta; theca in pedunculo longiusculo ovata subaequalis erectiuscula laevis, apicis margine protuberante badia, opereulo planiusculo apiculato; dentes peristomii longi 32 lineari-lanceolati lutei, filis fusco-badiis; calyptra thecae fere longitudine griseo-lutea. $\leftarrow$.

Schwä̈r. Suppl, II. II. I, p. 12. tab, 155. - Pogonulums dentutum Brid. II. 13. 122 et 74. - Pol. urnigerum W. Arı. Nisp. p. 71.

Putriu. In pinetis orae necidentalis Americac septentrionalis: A. Menzies.

Sequenti proximum adeo, ut nobis videatur variotas tantum Pol. migeri.

11. P. urnigerum I. (Sp.PI. 1573.); dioicum; caulis plus minus divisus plerumque fasciculato-ramosus, laxe cespitosus, hasi foliis minutis appressis; superiora dense imbricata stricta patentia e busi breviter vaginunte lanreolate ucutu, margine dense acute et fusco-dentutu, nervo supra basin multilamelloso, apicem folii fere totum occupante, dorso parce serrato; perichaetialia longius vaginantia angustiora nervo supra lamelloso; theca in pedun- 
culo longiusculo gracili ovali-cylindrica erectiuscula medio subconstricta, ore angustiore sed majusculo, operculo e basi tumido-convexa subulato breviusculo erectiusculo; calyptra thecam aequans ferruginea; dentes peristomii longiusculi 32 medio valde ruf.

Hedw. Sp. Musc. p. 100. tals. 22. fig. 5-\% - Pol. pulveruIentum Reymier. Act. Lausanin. 2. p. 11. tab. 2. et Pogonatum pulverulentun P. B. Prodr. p. 84. et Catharinea pulverulenta Röbl. Deut. Moos. p. 216. - P. fasciculatum Mich. Fi. Am. Bor. 2. p. 294. et Poyonatum fasciculatum P. B. Prodr. p. 84. - Pol. axillare Lam. Fl. franç. I. gren. $1264-$ Pogon, urnigerum Brid. II. p. 124. et Bryol. Europ. 1. c. p. 8. tah. 9. - Pog. intertextum Brid. II. p. 742. forma simplicior e spec. antl. - Cathurinea urnigera Roehl. Moosg. Deut. p. 210. - Polytrichun ramosum setis ex alis urnigeris. Dill. Musc. p. 42\%. tab. 55. fig. 5. - Pol. capillare Rich. in Mich. Fl. Am. II. p. 294. statura minore, caule brevi, theca ovata subcernua et folis longioribus apice incurvis a Pol. urnigero differt, igitur forsan varietas. Huc pertinet $\boldsymbol{P}$. capillare Wallenlb. FI. Lapp. p. 347.

Patria. In petrosis, pinetis arenosis et aliis locis sterilibus, sed tamen humidiusculis per totam Europam atque Americam septentrionalem, in alpes ascendens. Hyeme et primo vere.

Planta mascula gracilior, flore cyathiformi, paraphysibus interdum spathulatis. Folia perigonialia latissima ovata brevi-acuminata. - E locis natalibus ramificatione, thecae forma atque statura valde polymorphum, nunc simplicius, nunc valde ramosum, tamen notis laudatis facillime cognoscitur.

12. P. eampylocarpum C. Müll.; dioicum; gregarie cespitosum elatum simplicissimum, labitu $P$. urnigeri; folia erecto-patentia sicea flexuosa subcrispa, e basi vaginante brevi laxiuscule areolata superne dense et firme areolata fusca lalinsculo-lanceolate breviter acuta, apicem versus parce serrata, nervo totum fere apicem occupante multilamelloso praedita, perichaetialia basi longissima membranacea elongate areolata; theca in pedunculo longiusculo laevi cylindrica valde curvata et maxime papillosa pallide olivacea dein fusea, operculo depresso au- 
POLTTRICHEM.

rantiaco apiculato; dentes peristomii 32, simplices rel saepe obsolete geminati, aurantiaci.

Putria. Columbia, prov. Caracas pr. Galipan in terra arenaria, altit. 5000 ped., ubi leg. Funck et Schlim. Coll. Linden. No. 379. - Jamuario.

A P. migero proximo differt: notis cursive impressis prime theca valde papillosa, dum illa $\boldsymbol{P}$. urnigeri minute papillosa observatur.

13. P. patuIum Harv. (Hook. Ic. Pl. tab. 18. fig. 1.); caulis simplex gracilis inferne saepe nudus; folia distantia lanceolata serrata plana laxe imbricata siccitate stricta patentia, nervo crasso; theca brevis subturbinatu mujusculce erecta, operculo rostrato. $\uparrow$.

Patria. Nepal.

Ex icone auctoris praecedenti proximum. An propria species?

14. P. mierostomum R. Br. ('Trans, of Linn. Soc. XII. p. 569.); dioicum; caulis simpliciusculus vel apice innoratione brevi - ramosus, statura Pol. urnigeri, sed folia multo latiora magis obtusa, frrmins areolatu, intense brunnea, nervo multilamelloso, dorso serrato; perichaetialia e basi longiore vaginante angustiora breviora quam caulina; theca innovatione lateralis, in pedunculo breviusculo cylindrico-ovalis majuscula erectiuscula, dentibus 64 et operculo convexo-conico brevi; calyptra ferruginea.

Schwägr. Suppl. II. I. I. p. 10. tab. 154. - Pogonatumb microstomum Brid. 11. p. 745. - Poy. minutum Brid. 1I. p. 127.? talis.

Patria. In regno Nepal et in Himalaya Indiae orien-

Pol. Mnigero quam maxime simile, notis designatis tamen diversum esse videtur.

\section{b. Elata.}

15. P. alpinum L. (Sp, Pl. 1573.); dioicum; dichotome valde ramosum, basi nudiusculum foliis squamaeformibus scariosis dense appressis minutiusculis latis subito plicate plus minus acuminatis serratis, basi longe va- 
ginante anguste et flexuoso-areolatis; caulina linealilanceolata serrate, nervo multilamelloso dorso serrato, basi ut antea areolata, margine hyalina tenerrima; theca in pedunculo ascendente flexuoso crasso ovali-cylindrica erecta vel obliqua, collo brevi tumido instructa, laevis, tenero-membranacea, pallida, stomatiis basi praedita, ore truncata, aperta plerumque arcuata, operculo e basi conica longe subulato temi subobliquo; dentes valde variabiles.

Poyonatum alpinum Brid. II. p. 129. - Bryolog. Ěturop. 1. c. p. 9. tal. 10. - Catharinea alpina Röhl. Moosg. Deut. p. 184. Pol. alpinum ramosum, capsulis e summitate ellipticis. Dill. Musc. p. 427. tab. 55. fig. 4. - Pol. Norregicum Hedw. Ap. Musc, p. 99. tab. 22. fig. 1-5 e Scwägrichen sp. Musc. p. 120. in Indice huc pertinet. Pog. Norvegicum P. B. Prodr. p. 84. excl, syn. Pol. Uederi Brid.

ß. Grevifolium; foliis brevioribus carina laeribus, madore erectis, theca obovata, collo subnullo; dentes peristomii 40 aequali spatio ab invicem remoti, interstitiis angustiores. Pol. brevifolium R. Br. Suppl. Append, It. Parrayan. p. 494. - Brid. 11. p. 131.

$\gamma$. arcticum; theca oblonga subcylindrica, collo nullo. Bryol. Europ. I. e. p. 9. - Polytr. arcticum Sw. Musc. Suec. p. 76 et 109. tab. 8. fig. 17. - Pogonatum arcticum Böhl. Ann. Wett. Ges. 1Il. p. 226. - Pol. sylvaticum Menz. Trans, of Linn. Soc.1V. 1. 83. tab. 7. fig. 6. - Pol. ambiguum Mich. Fl. Am. Bor. Il. p. 297 .

d. campanulatum; humile, fastigiato-ramosum, foliis brevioribus, theca globoso-ovata, calyptrae indumento albido totam thecam obtegente. Bryol. Europ. 1. c. p.9. - Polytrich. campanulatum Hsch. Hor. Phys. Berol. p. 67. tab. 13. Pogonatum campanulatum Brid. 11. p. 133. - Pog. Pylaesii Brid. II. p. 744 .

E. furcutum; collo thecae valde conspicuo, elatius, e basi dichotome valde ramosum. Pol. furcatum Hscl. Hor. Pliys. Berol. p. 67. tab. 13. - Pogonatum furcatum Brid. 1I. p. 133.

Patria. Locis petrosis abruptis graminosis regionum subalpinarum et alpinarum totius Europae, Asiae et Americae septentrionalis. Var. $\beta$. Insula Melville: Sabi lle. Var. $\gamma$. in alpibus editioribus. Var. $\delta$. Unalaschka: 
Chamisso. Var. $\varepsilon$. In Sinu Schismaroff Americae occidentalis frigidissimae: Chamiss o. - Aestute.

Talde polymorpha quidem, theca tamen tenero-membranacea laevi pallida collo pracdila subgibboso-ovali rel cylindrica facillime cognoscitur.

16. P. Eiganteum IIook. (Musc. Exot. tab. 65.); dioicum; maxime elongatum pedule crussum vigidum flexuosum, basin versus indivisum, sursum subfastigiatim ramosum; folia arcte imbricata crecta, intense fusca, lineari-subulata rigida basi raginata, apice solummodo margine narum involuto dorsogue scabra, nervo totum apicem folii occupante multilamelloso; thecac numerosae terminales, sed ob caulis innovationes saepissime laterales, in pedunculis triuncialibus crassiusculis rubris magnue inclinatae ovato-cylindricae fuscae; operculum rostratum curvatum theca duplo brevius; dentes peristomii ut in Pol. communi. t. tab. 325.

Pogonatum giganteum Brid. II. p. 123. - Schw. Suppl. IV.

Patriu. In derexo montis Quindiu, ad radices Ceroxyli andicolae, in temperatis usque ad altitudinem 1450 hexapodum: II u mold et Bonpland. ctissimum.

Pol. alpino ex habitu simillimum, notis tamen distin-

17. P. nexnosum C. Müll. (Linn. XIX. p. 208.); dioicum; caulis e basi repente curvatu ascendens elongutus erectus simplicissimus flexuosus upice recurvus; folia rigida siccitate dispositionibus ruries fulcuta subsecunda, madefacta erecto-patentia falcato-stricta, e basidensinsculo-, "pricem versus purce servatu; perichaetialia ochreato-vaginantia obtuse membranacea dorso scabra; pedunculus brevis minute scuber, theca basi nequalis cylindricooblonga minute scubra; peristomii dentes e menbrana brevissima altitudinis mediae longi obtusiusculi.

Putria. Columbia in Silla de Caracas ad rupes humidiusculas: Moritz Coll. No. 135. 
Praccedenti affne, differt autem caule simplicissimo flexuoso apice reflexo, foliis e basi dense serratis, thecis, pedunculis et perichaetiis scabris.

sectio 1V. Catharinella. Folia latiuscula squarroso-patula Catharineis similia plerumque viritissima siccitate crispatissima cirrhata. Theca praecedentis sectionis, iuterdum subbicarinata. A Catharineis calyptra villosa diversa.

18. Convolutum Linn. fil. (Meth. Musc. p. 374. tab. 4. fig. 3.); thoicum; alte clatum flexuosum simplicissimum, summo apice interdum semel dirisum, basi caulis trigoni nudum vel foliis minutissimis scariosis squnmaeformibus dense appressis obtectum, superne foliis sensim majoribus, supremis maximis, siccitate secundis madefactis valde patentibus, e basi brevi raginante tenera et e cellulis angustis longinsculis pellucidis formutu, longa late et perfecte lanceolata, apice argute et lobato-spinosa, nervo in folii laminan dilatato, dorso apicis fuscospinoso; perichaetialia maxime minuta, interiora lanceolata evanidinervia fusca acuta laxe areolata, intima lingulatc obtusa enervia basi non vaginantia; ommia lamellis carentia, rigida; theca in pedunculo breviusculo eylindrica sub ore dilatato coarctata; calyptra villosissima parva ferruginea; dentes peristomii maximi lati medio latopurpurei margine anguste pallidi.

Schwägr. Suppl. 1. 11. p. 326, tal). 96. - Pogonatum conrolutum Brid. II. p. 110. et P. B. Prodr. p. 84. intermixto tortili. - PoIytrich. pachyneuron Hmp. Lim. XX. p. 80.

$\beta$. cirrhatum; humilius gracilius tenerum, foliis tenerioribus crispatissimis angustioribus haud secundis. polytrichum cirrhatum Sw. in schrad. Bot. Journ. IV. 1. 176. tals. 4.Pogonstum cirrhatum Brid. II. p. 110. - Pol. lencomitrium Hsch. Nov, Act. XIV. 11. suppl. p. 732. ex observationihus schü̈yrichenii (sp. Musc. p. 17.) forma minor huc pertinet. - Specimina nostra Pol. cirrhati, a Cl. Schwägr ichen accepta, partíbus, exceptis foliis hand secundis, omnibus cum P. convoluto conveniunt. Caeterum putamus, Pol. cirlutum sw. a specie Nchüryrichemiuna diversum esse. ,Surculis simplicihus lasi tomentosis, foliis linearihus serrulatis, siccitate incurvis tortisque, capsulis cylindricis erectiusculis. - Differt a $\boldsymbol{P}$. tortili, fere ut $\boldsymbol{P}$. aloides a $\boldsymbol{P}$. mano. Folia tentiora, surculi basi ferrugineo-tomentosi, et fructus diver- 


\section{STEGOCARPI. ACROCARPI. POLYTRICHUM.}

sae figurae et situs, diagnosin praebent." Swartz. Fl. Ind. Occ. 11. p. 1841 .

Patria. In sylvis humidis insulae Bourbonis: Th o uin. In Java insula frequens esse videtur. Var. $\beta$. planta Schwägricheniana in montibus caeruleis insulae Javac, ubi haud raro legitur. E Schwägrichen quoque in insulis Sandwicensibus legit Gaudichaud. Planta Swaraziana in prom. b. spei a Thunbergio lecta.

Planta mascula femineae intermixta. Perigonium perfecte discoideum. Folia perigonialia exteriora e basi latissima subito lanceolata supra basin ad apicem argute serrata, interiora latissime subcordata brevi-acuminata integra, intima omnium minima apice ovato-acuminata acuta, omnia nervosa. Antheridia maxima clavata, paraphysibus elongatis filiformibus apice subclavatis. - Planta speciosissima atque distinctissima Mnicceis ex habitu maxime similis. Lycopodio linifolio quoque haud dissimilis.

19. P. semipellueidum IImp. (Linn. XX. p. 80.); divicum; elatiusculum simplicissimum vel apice innovando semel divisum, basi caulis trigoni nudum vel foliis minutis et ut ceteris mollibus haud scariosis lato lanceolatis brevi-acutis apice argute serratis obtectum, superne foliis sensim majoribus, supremis maximis siccitate tortilibus, madefactis valde patentibus, e busi breviter amplexiculi e cellulis longiusculis angustionibus formuta longiuscula lato-lanceolata, sed medio latiora, apice argute et inaequaliter lobato-serrata, nervo dorso apicis fuscospinoso, parce et breviter lamelloso; perichaetialia maxima, foliis supremis maximis similia basi laxe areolata; theca in pedunculo breviusculo angulato madefucto yeorpe torto ovalis majuscula suboblique posita subbicarinata, operculo e basi conica brevi-apiculato; dentes peristomii ut antea; calyptra villosissima albida.

Polytrichum convolutum Hook. in Kunth. Synops. PI. Aeq. I. p. 48. - P. tortile C. Müll. Limn. XIX. 1) 208.

Putria. In montosis frigidis et opacatis Andium Quinduensium, prope Isa Garita del Paramo de Quindiu, alt. 1760. hexap. (Regno Novo-Granatensi): Hu mboldt 
et Bonpland. Columbia, in montibus nivosis prov. Meridae: Moritz. No. 188.

Planta mascula femineae intermixta et huic similis; flore perfecte discoideo. Folia perigonialia exteriora et interiora quam maxime lato-cordata brevi-acuminata integerrima, sed cellulis margine prominentibus, basi laxe apice minute areolata. Antheridia maxime elongata, paraphysibus filiformibus hyalinis mixta. - Planta Pol. convoluto ex habitu simillima sed notis laudatis distinctissima.

20. P. contortum Menz. (Trans. of Iinn. Soc. IV. p. 78. tab. 7. fig. 2.); dioicum; caulis erectus praelongus innorationibus fertilibus brevissimis pluries ramosus; folia remotiuscula laxe tortilia, ad innovationes densiora, lineari-lanceolata, panllum involuta, toto margine folii et superiori basis vaginantis argute serrata, obscure viridia, seniora fusco-brunnea, nervo obscuriori ad apicem perdurante crassiusculo et (ex ic. Schwägricheni) dorso parce serrato; perichactialia caulinis similia; theca in pedunculo innoratione laterali longiusculo cylindrica subcurvata erectiuscula fusca, operculo conico mucroncto acntissimo curvulo; dentes peristomii $32-40$; calyptra pilosa straminea. $f$.

Scliwägr. Suppl. I. 11. p. 325. tab. 96. - Pogonatumb laterale Brid. 11. p. 112.

Patria. In ora occidentali Americae borealis: Menzies.

Caule ramosiusculo et pedunculis pseudolateralibus a sequente differt. A praecedente foliis linearibus non medio latioribus jam differt.

21. F. tortile Sw. (Fl. Ind. Occ. III. p. 1839.); divicum; caulis erectus basi subnudus; folia e basi tenera subvaginante lanceolata acutu planiuscula, apicem versus temue sermalata, dorso superne spinulosa, suprema longiora confertiora, omnia siccitate fusco-ferruginea, nervo crasso multilamelloso folii fere totum apicem occupante; theca breviusculo-pedunculata, primum ocuta, maturitate subrotunda subcernua fusca, basi papillosa operculo co- 
nico-apiculato obtuso brevi; peristomii dentes $\mathbf{3 2}$ lineares brevissimi obtusi rubri; calyptra ferruginea.

Hedw. Sp. Musc. p. 94. tab. 20. fig. 3-5. - Pol, convolutum Sw. Prodr. Fl. Ind. Occ. p. 139. - Pogonatum tortile P. B. Prodr. p. 85. - Brid. 1I, p. 108. et $\beta$. Domingense ibid. -

Patria. Ad fossas macras argillosas in montibus excelsis Jamaicae australis, in insula Dominici et Franciae: Swartz, Menzies, Bertero, Gaudichaud.

Planta mascula plantae Domingensis feminea altior, densius foliosa. Flos masculus discoideus. Folia perigonialia e basi oblonga valde membranacea latissimo-cordata brevi-acuminata, apice dense lamellosa, usque ad apicem crenulata. Antheridia maxima, paraphysibus filiformibus interpositis. - Sequenti affine, sed notis designatis distinctissimum.

22. P. subtortile C. Müll.; dioicum; humile subsimplicissimum; folia siccitate apice involuta patentia laxe imbricata, basi subvaginantia vel amplexicaulia laxe ureolata, latiusculo-lanceolata, madefacta apice incurva et remote denticulata, dorso parcissime denticulata, acutiuscula, nervo multilamelloso apicem folii fere totum occupante, perichaetialia basi longins vaginate; theca in pedunculo longiusculo cylindrico-ovalis sub ore dilatato subcoarctata, valde papillose, operculo e basi conica longe et oblipre rostrato; calyptra ut antea.

Polytr. aloides Hsch, et Reimw. Nov. Act. XIV. II. Suppl. p.732? - P. aloides Duby. PI. Zolling. No. 853. - P. tortile Mont. in Hib.
Miqueliano.

Putria. In Java insula, ut videtur, haud rarum.

Planta mascula feminea gracilior humilior simplicissima, saepe e flore masculo discoideo prolifera, igitur altior. Folia perigonialia externa latissime cordato-ovalia breviter acuminata cacterum illis praecedentis speciei simillima, sed apice cellulis prominentibus denticulata; interiora minora. Cactera ut antea. - A praccedente proxima specie primo adspectu folis latioribus laxius imbricatis apice tantum involutis et operculo longirostro distinguitur. Planta mascula Cutharineue angustutue valde affinis. 
Sectio V. Aupolytrichum. Theca perfecte $2,4,5,6$ angularis.

\section{a. Thecabiangularis.}

23. P. Iongisetum Hook. (Musc. Exot. tab. 66.); dioicum; caulis erectus rigidus simplex vel divisus; folia arcte imbricata patentia, siccitate erecta, rigida, nigrofusca, lanceolato-subulata margine plana omnino integerrima, nervo stricto totam partem folii occupante; pedunculus palmaris et ultra, flexuosus flavo-ruber ob caulis innovationes saepe lateralis; theca crecta rel demum horizontaliter incliuata, operculo longe rostrato, thecam subaequante curvalo. $t$.

schwägr. Spec. Muscor. p. 5. et Suppl. II. II. p. 4. tah. 152. Pogonatum longisetum Brid. II. p. 128.

Patria. In monte Quindiu, regione temperata, Andium de Cunamara: Humboldt et Bonpland.

Ex observationibus Schwägricheni theca non, ut dici II ooker, tetragona sed, apophysi minuta, tereti; ipsa basi semiteres, inferiore superficic convexa, superiore planiuscula; exoritur ejus e medio dorso linea elevata et ampliatur capsula, ut orificium orbiculare sit Peristomii dentes 64. Capsulae forma Dawsoniam aemulatur." Sp. Musc. p. 6.

\section{b. Theca quadrangularis.}

w. Folia margine integerrimo.

24. P. piliferum Schreb. (Spic. Fl. Lips. p. 71.); dioicum; caulis humilis inferne subnudus apicem versus crescenti - foliosus; folia caulina brevia dense imbricata stricta c basi vaginante colorata margine membranacea hyalina subito lanceolata in pilum longum hyalinum plus minus servatum producte, nervo folii totum apicem occupante dorso laevi; perichaetialia longiona vaginata parce vel obsolete lamelligera; theca oucto-tetruëdra brevis apophysi disciformi purpurea praedita, aperta inclinata, operculo purpureo conico acute apiculato; dentes peristomii 61 in membrana altiore breves; calyptra junior apice purpurascens, dein ferruginea. 
Bryolog. Europ. Fasc. XXI-XXII. Polytrichaceae. Polytrichum ; p. 11. tab. 14. - Brid. II. p. 142. - P. commune $\gamma$. Limn. sp. PI. p. 1573. - P. commune $\beta$. pilosum Ehrh. Hann. Mag. 1780. p. 235. - Polytrichum quadrangulare minus, juniperi foliis pilosis. Dill. Musc. p. 426. tab. 54. fig. 3. - Pol. Hoppii Hsch. Hegenslo. bot. Zeit. II. p. 106 et VI. p. 16. - Brid. II. p. 143 et 747.

ß. hyperboreum; elatum, gracilius, apice ramis fertilibus pluribus divisum. pol, hyperboreum R. Br. Append. It. Parrayan. p. 194. - schwägr. suppl. 11. 11. p. 8. tab. 153. Brid. 1I. p. 144 et 747.

Patria. In locis sterilibus per totam Europam, Asiam et Americam septentrionalem ad alpes ascendens. Var. $\beta$. in insula Melville: Sabinc. - Vere.

Planta mascula laxius foliosa, foliis minus pilosis; perigonialia externa e basi lata breviter lanceolata, superne marginibus inflexis, interiora late obcordata brevissime acuminata, nervo apice lamelloso. Antheridia magna paraphysibus apice cellulosis coloratis interpositis.

25. F. juniperinum IIdw. (Sp. Musc. p. 89. tab. 13.); dioicum; caulis plus minus elatus ramosiusculus basi subnudus, apicem versus dense foliosus; folia caulina elongata, e basi longe vaginante oblonga inferne angustissime et elongato-areolata superne margine lyalino-membranacea lineari-subulata, plus minus et brumeo-aristata, involutu, integerrima; perichaetialia longissime vaginantia convoluta membranacea, nervo crasso brunneo in aristam longissimam et, ut in caulinis, serratam producto elamelloso; theca rhomboideo-quadrangularis majuscula, aperta horizontulis, operculo e basi convexo-plana brevi-rostellato; dentes peristomii 64 in membrana vix conspicua breviusculi pallidi dorso flavido-carinati.

Bryolog. Europ. 1. c. p. 12. tal. 15 et 16. - Brid. 11. p. 136.

B. strictum; caule gracilescente stricto, foliis ercctopatentibus strictis; theca subcubica. Bryol. Europ. 1. c. p. 12. - Pol. strictum Meuz. Trans. of Linu. Soc. VI. p. 77. tab.4. fig. 1. Brid. p. 139.

$\gamma$. alpestre; dense cespitosum, foliis brevioribus, dorso scabriusculis, theca cubica. Bryol. Europ. 1.c. p. 12. Pol. alpestre Hoppe Bot. Taschb. 1801. p. 198. - Brid. Il. p. 140. 
- Pol. affine Fk. Moos Taschb. p. 88. tal). 5t. foliis latirs albomembranaceis, longis setaceis, caule elatiore graciliore. Brid. II. p. 141. - Bryol. Europ. 1. c. p. 13.

d. integrum; foliis longe aristatis, aristis apice summo tantum obsolete denticulatis.

Patria. In locis humidis praecipue spongiosis ericetorum vel sylvarum totius fere terrarum orbis. Var. $\beta$. regiones boreales praefert. Var. $\gamma$. in alpibus. Var. $\delta$. Chile: Pöppig. - Ad veris finem, in alpibus restate.

Planta mascula feminea gracilior, foliis brevioribus.

26. F. Antillarum Rich. (in Brid. II. p. 138 et 147.); dioicum; ex habitu praecedenti simillimum; folia caulina maxime patentia, praecipue superiora dorso upicis dentibus lobatis cellulosis acutis vel rotundato-acutis permultis scaberrima, margine involuto pellucidiore, in aristam longam plus minus scabram fuscam producta; perichaetialia interna longissima et convoluto-vaginantia, omnino membranacea diaphana elamellosa, longissima cuspidata laevissima; theca longiore angustiore, operculo e basi planiuscula oblique mucronato; calyptra ferruginea; dentes peristomii 64.

P. appressum schwägr. Suppl. I. I1. p. 311. et II. II. p. 5. tab. 152. et Linnaea XIV. p. 521. - Pol. scubriusculum Brid. Mant. Musc. p. 195.

Patria. In America meridionali et Antillis vulgare.

27. P. appressum Brid. (II. p. 141 et 74.); caulis erectus strictus semipedalis longior basi subnudus; folia inferiora distantia, tomento obducta, superiora imbricata breviuscula, e basi latiuscula semiamplexicauli linearilanceolata, margine integerrima, membrana plicata nulla, nervo obscuro exarata, apice alba, vix superne carina scabriuscula lineari-areolata, omnia humiditate ad angulum acutissimum stricto-putentiu, siccitute cauli adeo arcte apressa, ut tota stirps inde teres fiat, colore nigricantia; perichaetialia convoluto - vaginantia margine albo-membranacea, in cuspidem setaceam educta; theca in pedunculo longiusculo breviter tetragona crecta dein nutans aureo-purpurea, apophysi distincta, parva, sub- 
globosa; dentes 64; calyptrae indumentum purpurascens. $t$.

Patria. In insulae Bourbonis planitie des Chicots: Bory St. Vincent.

Habitu Pol. elati sed ab co atque P. Antillarum et juniperino notis laudatis differt.

28. P. glabrum Brid. (II. p. 141.); simplex; folia erectiuscula plana integerima apice scabriuscula, nerro totum folium occupante; theca sphaerico-depressa paullum rugosa praedita, apophysi parallelepipeda, operculo e basi planiuscula brevissime mucronato obtuso. $\div$.

schwägr. Suppl. 1. 1I. p. 311. - Sp. IIusc. p. 3. - Pol. Appuleii Commers. mst.

Patria. In insulae Bourbonis montibus altissimis, in ea parte, quae Plaine des Caffres dicitur, et in fossis exsiccatis: Commerson 1771 Augusto legit. In Brasilia auctores nonnulli indicant; an recte, dubii sumus.

Ex obs. Schwägricheni P. juniprerino simillimum, sed diversum foliis toto fere nervo expletis et margine non inflexis, caeterum integerrimis: nervo parum scabro, non serrato.

\section{B. Folia margine serrato.}

29. P. commune L. (Sp. P. II. p. 1573.); dioicum; caulis simplex elatus erectus inferne nudus, superne crescens; folia e basi oblonga erecta longe vaginunte anguste et elongate areolata superne margine dictphano-membranacea subito fere horizontalia vel apice recurva, lanceolata plana, superne et dorso argute serrata dense areolata cuspidata; perichactialia convoluto-vaginantia, membranacea elamellosa, nervo in cuspidem producto fusco; theca in pedunculo longo crasso erecta crusso-tetraidra, dein horizontalis, operculo e basi convexiuscula margine tumida conico brevi-rostellato recto; dentes peristomii 61 breves; calyptra majuscula ferruginea.

Bryolng. Furop. 1. c. p. 13. tab. 17. - Brid. 11. p. 148. quo nomine plerumque forma maxime elongata designatur. - Pol. yuccaefolium Ehrh. PI. Crypt. Exsicc. 214. - Pol, subpilosum P. B. 
Prodr. p. 86, - Pol. Commersnnianum Brid. 11. p. 153. - Pol. propinquum R. Br. Suppl. ad it. Parryan. p. 194. et Brid. 11. p. 150. - Pol. quadrangulare vulgare, Yuccae foliis serratis. Dill. Musc. p. 420, tab. 54, fig. 1.

B. perigoniale; minus, folis perichaetialibus externis longioribus menbranaceis aristatis. Pol, perigoniale Rich. Micll. Fl. Am. Bor. 11. p. 295. - Bryolog, Kurop. 1. c. p. 13. Brid. 11. p. 150.

$\gamma$. minus; caule humiliore, folis perichactialibus externis comalibus similibus, pedunculo breviore, theca minore, calyptrae tomento pallescente.

Patria. Per totan Europam, Asiam temperatam atque Americam septentrionalem per omnes regiones, loca uliginosa praccipue spongiosa praeferens. Var. $\beta$. Locis minus humidis, calidioribus. Yar. $\gamma$. locis siccis hic illic per Europam et in Prom. bon. spei. - Initio aestulis.

Folia perigonialia maxime lata cordato-ovalia plus minus acuminata, superne lamelligera denticulata valde membranacea colorata. Paraphyses apice maxime dilatatae cellulosae coloratae longissimae. Antheridia et cetera generis.

30. P. elntum P. B. (Prodr. p. S5.); divicum; clatum simplex inferne nudum superne praccedenti simillimum; folia cauliua e basi multo brevius voginante, superve margine haud diaphano sed coloruto prodita, Ianceolata breviora plana, nervo totum folium occupante, margine anguste diabhamo et dorso apicis subciliato-et hyalino-dentatu, brevius cuspidata, madefacta vix horizontalia; perichactialia longiora convoluto - vaginantia membranacea cacterun illis Pol. communis $\beta$. perichuetialis similia; theca pro plantac altitudine brevi-pedunculata erecta cubica brevis discoideo-apophysata, dein horizontalis, operculo converinsculo mammillato; dentes peristomii 64 ; calyptra aurea.

Brid. II. p. 152. - Pol. mumuscens ej. Mant. Musc. p. 197.Schwaggr. Suppl. 11. 1I. p. 4. tab, 151.

Patria. Ad crateres montium ignivomorum insularum Mascarenium Franciae et Bourbonis. 
Praecedenti simillimum, sed omnino purpurasens et notis datis distinctissimum.

31. P. remotifolium P. B. (Prodr. p. 86.); caulis praclongus strictus, inferne nudiusculus gracilis simplex; folia inferiora remota, superiora copiosiora, erecta, basi folii trientem efficiente totum fere cuulem vaginantia lanceolato-linearia planiuscula, margine et apice dorsi argute serrata, ferruginea; perichaetialia caulinis paullo latiora et latius membranacea; theca tetraëdra brevis erecta, dein subnutans fusca, apophysi subrotunda concolore, operculo planiusculo breviter et obtuso-mucronato, dentibus 64 albis et calyptra canescente praedita. $\dagger$.

scluwägr. Suppl. I. II. p. 320, et II. 1I. p. 10. tab. 154. et Spec. Masc. p. 7. - Brid. 11. p. 147.

Putria. Insula Bourbonis: Commerson.

De specie nobis haud visa $\mathrm{Cl}$. Schwägrichen in Spec. Musc. p. 7. verba fecit sequentia: ,Licet simile sit communi, separatum tamen servare malui, quoniam non vidi $P$. communis folia, si ab invicem remota sunt, ita brevia, ut spatium intrafoliaceum dupla tantum longitudine superent." Ex ic. caeterum habitu diverso. „Species valde memorabilis folis basis caulis, basi lato-membranaceis caulem vaginantibus, remotis alternis." P. B. I. c.

\section{Species obsenra.}

1. P. elongatum P. B. (Prodr. p. 85.); caulis electus gracilis longus simplex et divisus; folia linearia subserrulata, flores terminales, theca erecta. $\dagger_{\text {. }}$

Brid. II. p. 156. - Schwägr. Sp. Musc. p. 7.

Patria. Ad fretum Magellanicum.

Caule elongato gracili, theca erecta et apophysi speciosa distincta, majore intervallo a sporangio distante a congeneribus e ratione auctoris dignoscitur.

c. Theca quinquangularis.

32. P. Belangeri C. Müll.; dioicum; caulis fertilis humilis, sterilis multo longior gracilis flexuosus; folia caulina siccitate tortilia, madefacta stricta, e basi am- 
plexicauli vix vaginante usque ad apicem densiusculoareolata carinato - lanceolata acutiuscula vel mucronata, apicem versus dentata $\mathrm{s}$. brevissime serrata, nervo multilamelloso dorso carinato parce serrato; theca longipedunculata ovalis longiuscula suberecta, aperta subinclinata, dentibus 32 longiusculis, medio rufis.

Catharinea intermedia Bél. Voy. d. l'Ind. or. Bot. II. Cryptt. p. 101. tab. 11. fig. 3.; ex auctoris ratione inter Cath. tenellam et angustatam quasi medium tenens.

Patriu. In terra inter lapides montis Ponce insulae Mauriti: Bélanger. Ib. Kunzeanum.

Calyptra ignota quidem, sed Catharinea nunquam sit.

d. Theca sexangularis.

33. P. septentrionale Sw. (Musc. Suec, p. 77. tab.9. fig. 18.); dioicum; subhumile ascendens simplex, basi nudum; folia dense imbricata secundu e basi vaginunte laxins areolata carnosula latiuscula, superne margine tennissime membranacea hyalina, subito sed non plicuto-lanceolutu breviter acuta, brevia vigida carmosa concura, margine involuta integerrima, dorso laevia, dense areolata, nervo densissime lamelloso; perichactialia longius vaginata; theca in pelunculo crasso rubello plerumque hexagona, raro tetraëdra vel pentagona, ovata, breris apophysi obsoleta, operculo longe rostrato obliquo, calyptra theca breviore dentibusque brevibus pallidis linea media aurantiaca exaratis.

Fx animadversionihus (l. Schwägrichen in Spec. Musc. p.5.

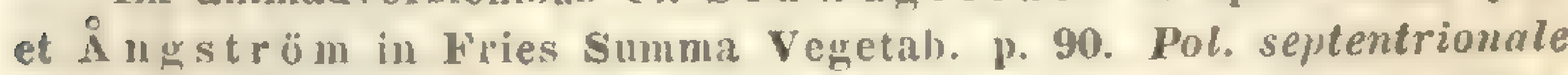
Suartzianum idem atque Pol. sexangulare Hopp. Bot. Taschb. 1800. p. 150. dicitur. - Pol. sexangulare Bryolog. Europ. 1. c. p. 7. tab. 11. - Brid. 1I. p. 145 Auctores ulteriores speciem Suartzianam ad Pol. alpimum revocarunt, an recte, dubitamus, quum ille bryologus suecicus Ångtröm cum $\boldsymbol{P}$. sexangulari synonymam appellaverit. Swartzius auctor speciem suam apice dentatam dicit: an varietatem olsservaverit? - Pul. crassisetum Iam. et Dec. Fl. Franç. II. p. 436. - P. Helêticum Sch!. Cr. Helv. Exs. Cent. 11I. No. 16. - Pol, hyperhoreum Wahlenb. in Web. et Molir. Ind. Musaei : Fl. Lapp. p. 347, - Pol, Oederi Brid. Musc. Rec. II, I. p. 99. 
Patria. In summarum alpium locis depressis humidis, ubi cespites densos, laete virides, longe lateque extensos efformat; praeprimis in nivium regione viget: per alpes Helvetiae, 'Tirolis, Salisburgiae, Carinthiae; in Sudetis (Hb. Schkuhr.), Carpathis, Scotia, Scandinavia tota, Kamtschatka, in sinu Schismaroff (Chumisso) et in insula Melville. - Augusto. Septembri.

Planta mascula humilior, foliis perigonialibus omnibus latissime ovalibus brevissime et subrecurvo-acuminatis integerrimis apice lamellosis coloratis, internis basi laxissime et majusculo - areolatis. Paraphyses paullo cellulosae.

34. P. formosum IIdw. (Sp. Musc. p. 92. tab. 19.); dioicum; elatum, habitu Pol. communis, inferne nudum; folia superiora e basi lata vaginante longe lineali-lanceolata acuta, argute serrata plus minus plana; theca plerumque sexangularis raro tetraëdra vel pentagona tenuimembranacea pallide ochracea erecta, dein horizontalis, apophysi obsoleta, operculo conico ora purpurea praedito, calyptra theca minore; dentes peristomii 64 in membrana vix emersa aurantiaca breves.

Bryol. Europ. 1. c. p. 9. tal. 12. - Brid. 1I. p. 151. - Pol. attenuut um Menz. Trans, of Limn. soc. IV. p. 72. tal). 6. fig. 2. - Pol. commune $\beta$. attenuatum Hook. et Tayl. Musc. Brit. p. 26. - Pol. serratum schrank. Baiers FI. II p. 446. - Pol. stans Thuill. HI, - Pol, superhum scliz. Syllog. in Kiphemerid. bot. Ratish. p. 152. P. marginatum Hedw. Suppl. I. II. p. 329. exclusis synonymis et mentione calyptrae glabrae, quae hand dubie pilosa fuit, sed deficit in speciminibus. Schwäur. Sp. Musc. p. 8, - P. coronatum Brid. II. p. 748, ex eodem auctore huc pertinet: „P. coronatum Brid. sunt in ejus herbario fructus formosi delapsi, mixti cum caulibus P. formosi et juniperini. Descriptio foliorum 1. c. juniperino, descriptio fructus formoso convenit." schw. Sp. Musc. p. 8. - Pol. pallidisetum F'k. Moos Taschl). No. 5ä; caule humiliore, foliis breviorihus, thecae angustioris pedunculo stramineo hreviore. - Polytrichun quadrangulare, Juniperi foliis hrevioribus et rigidiorihess. Dill. Muse. p. 424. tab. 54. fig. 2. comparato Dillenii herbario e Schwägriche n sp. Musc, p. 8, huc pertinet.

Patria. In sylvis montosis nunquam in turfosis usque in regionem subalpinam, per totam Europam et Americam septentrionalem. - Aestate. 
A Pol.communi, quocum sacpe commutatum est, theca ochracea pentagona vel hexagona obsolete apophysata longiore et operculo conico haud planiusculo mucronato differt.

35. P. gracile Menz. (Trans. of Linn. Soc. IV. p. 73. 1ab. 6. fig. 3.); dioicum; ex habitu praccedentis proximi; folia e basi breviter vaginante margine tenuissime et hyalino-membranacea e majuseulis cellulis plus minus laxis pellucidis areolata lanceolata breviter et brunneo-cuspidata, margine lutiore pellucido argute serrata, nervo to1 um fere folii apicem occupante praedita, plana intense viridia ; theca ovata obtuse-cingulutu, ore angustata, operculo basi rubro-marginato longe et oblique rostrato; dentes peristomii in membrana basilari subnulla 32 regulares vel 64 irregulares; calyptra theca brevior aurantiaca.

Bryolog. Furop. 1. c. p. 10. tal) 13. - Brid. 11. p. 15t. - Pol. 7ongisetum Sw. Muss. suec. p. 76. tal). 8. fig. 16. - Pol. "uurunttiucum Hoppe. Bot. Taschb, 1800. p. 131. - Pol, nitjescens Cand. FI. Franç. II. p. 490.

Putria. In paludosis turfosis planitierum usque ad alpes totius Europae atque Americae septentrionalis. Ad veris finem.

A praecedente foliis brevioribus, margine latioribus, theca obtusangulari operculoque Iongius rostellato differt. Varictas forsan tantum pracectentis e locis turfosis nata.

\section{Gen. X. Dawsonia R. Br.}

Transact. of Limn. Soc. Lond. X. p. 316. tal 23. fig. 1. - Triplocoma Rachelot de la Pylaie Journ. Bot. Devaux. 1813. n. 5.

Nomen huic generi in honorem elarissimi et acuratissimi nalurae, praesertim plantarum agamarum investigatoris Danson Thrner impositum.

Calyptra dimidiata, pilis erectis serratis villosissima capillamenti instar conica. Peristomium simplex penicillalum, ciliis numerosissimis capillaribus rectis aequalibus inarticulatis, basi planis apicem versus in cylindrum convolulis, his $e$ the- 
cae parietis interni protuberantia annulari, illis e columella sub apicem. Theca inaegualis, dorso rotondata, supra planiuscula. Inflorescentia dioica. Flos masculns more Polytrichorum discoideus.

F toto habitu polytrichoidea, e forma autem thecae Burbumius vel Jiphyscium in memoriam redigens.

1. D. polytrichoides R. Br. (1. c.); caulis triqueter elatiusculus simplicissimus, inferne quasi nudus, folis minutissimis squamaeformibus scariosis membranaceis, e celIulis elongatis apice minoribus subrhomboidalibus reticulatis, superne dense foliosus; folia caulina e basi longe vaginante tenerima membranacea angustissime et longe areolata lauccolata stricta acuta, latissime lamellosa, margine dentibus acutis fuscis e medio ad apicem usque serrata, nervo dorso parce serrato; theca in pedunculo brevi, operculo conico cylindraceo basi incrassato subrecurvomucronato.

Honk. Musc. Fxnt. tab. 162. iconibus optimis. - Schwägr. suppl. 11. p. 175. táb. 150. - Brid. 11. p. 156. - Triplocoma polytrichoides La Pyl. J. co p. 7.

Patria. Ripae subumbrosae rivulorum ad radices montium, in vicinitate Portus Jackson, Novae Hollandiae: R. Brown primus, dein Sieber in locis non designatis legit. Formam minorem a $\mathbf{C l}$. Chamisso peregrinatore - locis non dictis accepisse Cl. Schwägrichen I. c. scripsit.

Calyptrae pili erecti stricti latiusculi ferrugineo-purpurei longissimi valde serrati, illi basis calyptrae filis longissimis valde tortuosis hyalinis nodosis ramulosi, speciosissimi, apice calyptrae breves.

2. D. superba Grev. (Ann. and Mag. of nat. Hist. 1847. p. 226. tab. 12.); procera; folia uncialia, sublaxe patentia, illis praccedentis ter majora, lincari-subulata rigidiora, spinuloso-dentata, nervo dorso apicis summi dentato, basi latissima membranacea purpurascentia; pedunculus breviusculus; theca et operculum praecedentis.

Polytrichum longifolium Br. et Sch. in Bryol. Europ. Fasc. 21-22. Polytrichum p. 2. memoratum? 


\section{Patriu. Australia, unde misit Augustus Erstine.}

Planta altissima c. 14 unc. longa, foliis 1 unc. longis, Peristomium ignotum. Ex icone auctoris Dansonia vera esse videtur. - Musco auctorum Bruch et Schimper altit. ped. plur. esse, 1. c. dicitur.

\section{Gen. XI. Iyellia R. Br.}

Trans. of Linn, soc. Lond. XI1. 11. p. 561.

Nomen in honorem D. IAyell, botanici Britannioi acutissimi conditum.

Calyptra dimidiata nuda. Peristomium nullum, clausum epiphragmate (crasso depresso) cujus discus circularis a limbo (latiori) persistente secedens, cum columella remanenti inclusa cohaeret. Theca superne plana, inferne convexa, Buxbaumiae, Diphyscii vel Dawsoniae instar conformata. Inflorescentia dioica. Flos masculus discoideus.

Vi tantum stomatis nudi atque thecae figura genus proprium inter Oligotrichum et Dawsonicom intermedium.

1. M. crispa R. Br. (1. c. p. 562.); caulis triqueter elatiusculus simplicissimus, inferne nudiusculus fohis squamaeformibus minutissimis scariosis appressis obtusiusculis apicem versus sensim acuminatis, superne dense foliosus; folia superiora e basi longe vaginante purpureo-fuscescente subito lanceolata, madefacta erecta patentia, sicca valde crispa, apicem versus brevi-serrata, nervo dorso apice lamellato-serrata, totum folii apicem summum occupante, lato-lamellosa; perigonialia e basi latissima subito acuminata, lato-lamellosa nervosa, apice serrata colorata; theca in pedunculo longiusculo erecta, basi stomatiis praedita; calyptra apice scabra.

Brid. 11. p. 94. - Hook. Musc, Exot. tab. 161. optima. Schwaggr. Suppl. II. II. tab. 149.

Putriu. In regione Nepal Indiae orientalis, ubi D. Gardner in vicinia oppidi Kathmandu detexit. 
Antheridia maxima clavata, paraphysibus apice cellulosis hyalinis mixta.

? 2. C. bifureata Bél. (Voy. dans l'Indie orient. Bo1. II. Crypt. p. 99.); caule crecto longissimo bifurcuto; folia subverticillata, e basi lata vaginante anguste lanceolata serrata, siccitate tortilia. $f$.

Patria. In locis attioribus circa locum Gàtes dictum in peninsula Indiac orientalis: Bélanger.

A praccedente ex adnotationibus auctoris differt: caule longiore, foliis latioribus apice densioribus supra ramos verticillate plus minus approximata. - Auctor ut nos quoque, plantam sterilem tantum legisse, vehementer commiscratur. An revera Lyellia?

\section{'Trib. XV. BR Y A CEA E.}

Cespitosac raro gregariac lumiles vel elatae plerumque innovando ramosae acrocarpicac vel pleurncappicae. Folia lanceolata, ovalia, rotunda et spathnlati, inferne ecllulis parallelogrammis superne rhomboideo-prosenchymaticis plus minus densis chlorophyllosis vel utriculo primordiali instructis vel dein inanibus areolata, lacvissima. Theca plus minus pyriformis, clavata, ovalis vel cylindrica, operculo hemisphaerico vel conico pricelita, erecta, untans vel pendula. Peristomiun externum molle lamellosum, internum membranaceum. Archegonia nucleo magno instructa. Antheridia clavata. Paraphyses filiformes.

Iabitus proprius hic illic mnioideus, theca plerumque pyriformi distinctus.

Patria. Per orbem totum terarum, regionum omnium incolac, arbores, paludes, rupes atque terram diversissimam ornantes et distributione latissima gaudentes. XXIV.

Bryaceae omnium auct. et Mielichnoferieae Bryol. Europ. Fasc. 


\section{Gen. I. Mielichhoferia Hsch.}

Br. Germ. 11. p. 179. - Br, Europ. Fasc. XXIV. Weisia Hsch. olim, Hook, et al. - Oreas Brid. - Schiahymenium Hook. et schwägr. Apiocarpa Hiib. Musc, Germ, p. 154.

Nomen in honores Cl. Mielich ofer, a consiliis supcrioribus fodinarum Salisburgiae ditionis, muscorum plerumque alpinorum nonnullorum pulchellorum detectoris nunc mortui conditum.

Calyptra conico-dimidiata latere fissa. Peristomium nullum vel simplex: dentes 16 aequidistantes filiformes subplani articulati pallidi interdum in membrana basilari sulcata reticulata brevi positi. Theca lateralis annulo duplici praedita. Inflorescentia hermaphrodita vel dioica.

Mielichhoferice Bryis proximae adeo, ut ab hisce discerni nunquam possint, quum foliorum structura interna, Bryo elongulo, crudo etc. plerumque affinis, perfecte similis observetur et a Bryis peristomii vi simplicis atque fructificatione laterali, nota non discernente, distinguantur.

\section{Theca eperistomata.}

1. M. hymenostoma Br. et Sch. (in Musc. Ahyss. No. 469.); hermaphrodita; pusilla, densissime cespitosa; caulis fertilis basi tenerrimus nudiusculus, apice densissıme gemmiformi-foliosus, foliis perichaetialibus lanceolatis apice denticulatis, nerro infru apicem dissoluto, basi brunncis supra coloratis viridescentibus; innovationes cauli fertili subsimiles, folis ovali-lanceolatis acute acuminatis obsolete druticulatis, basi laxiuscule, supra dense areolalis, nero ante apicem evenido; theca breviter pedunculata clavato-ovalis parva angusta nutans, ore rubclla, operculo conico acuto parvo; stoma columella cupuliformicxsprta acuta laxe reticulatu clansum.

Patria. In Abyssiniae alpe Deggen, ubi in allit. 12000 ped. supra mare legil $W^{2}$. se chimper d. 3. Mart. 1840. Un. itin. No. 469.

Archegonia 2-3. Antheridia 2. Parapliysis 1. 
2. M. Schiedeana C. Müll.; hermaphrodita; pusilla basi densissime cespitosa; caulis fertilis basi tenerrimus nudiusculus apice densissime gemmiformi-foliosus, foliis perichaetialibus lanceolatis longe acuminatis acutis sibbdenticulatis tenerrimis obsoletinervibus; innovationes cauli fertili subsimiles, foliis lanceolatis, nervo tenui fleruoso excurrente longe et tenuissime cuspidatis tenerrimis subintegris; theca breviter pedunculata clavato-ovalis parva angusta nutans, operculo conico acuto parvo; stoma columella vix exserta acuta vix clausum.

Pohlia minor Hsch. in Musc. Mexicanis a Cl. Dep pe et Schic de collectis No. 1078, ex parte.

Patria. Mexico in monte Orizaba vulcanico.

Praecedenti ex habitu toto simillima sed gracilior et notis laudatis distinctissima.

\section{Theca peristomata.}

a. Theca cylindrica curvata.

3. M. basilnris Br. et Sch. (in Musc. Abyss.); hermaphrodita; innovationes simplicissimae erectae elatae basi nudae apicem versus sensim crescentes, densissime foliosae, foliis lanceolatis angustis longissime cuspidatis evanidinervibus frmis, e medio sensim distincte denticulatis, comalibus brevioribus mollioribus; caulis fertilis subbasilaris brevissimus, foliis perichaetialibus basi laxius areolatis fuscescentibus longiusculo-acuminatis denticulatis, intimis minoribus lanceulatis latioribus subintegris, omnibus obsoletinervibus; theca longe pedunculata angustissime cylindrica clongata longicolla, operculo brevi conico acuto; dentes peristomii teme filiformes e membrana immersa orti, longinsculi, basi latiusculi, linea media distincte procditi tenuiter arliculati subrugulosi.

Putria. In Abyssiniac alpibus legit W. Schimper. c. 3.

Antheridia 5- 10. Archegonia 3-6. Paraphyses

4. M. Eekloni Hsch. (Limn. 1841. p. 118.); hermaphrodita; innovationes simplicissimae crectae clatae basi 
nudae apicom versus sensim crescentes densissime foliosae, folis lanceolatis angustis brevi-acutis evmidinervibus tenero-membranaceis submollibus, fere e basi sensim distincte denticulatis, comalibus brevioribus similibus; caulis fertilis subhasilaris brevissimus, foliis perichaetialibus ommino laxins areolatis fuscescentibus acuminatis obsolete denticulatis, intimis minoribus lanceolatis latioribus subintegris, omnibus obsoletinervibus; theca longe pedunculata angusta cylindrico-clacalu panlisper curvata, operculo brevi conico acuto; dentes peristomii temue filiformes e membrana elate exserta sulcuta orti longinsculi basi latinsculi, linea media praedita 2 - saepe mulla, subplani laeres fissiles saepe subramosi irregulares.

Schiahymenium bryoides Harv, in Hook. Ic. Pl. lar. I1I. tal., 202. et Schwägr. Suppl. IV. tal). 317. - Oreas Capensis Bruch in litt. et collect. Zeyheri.

Patria. In promontorii bon. spei locis multis e. gr. loco Löwenrücken, in cacumine montis Hottentots-IIollands-Berg in terra arenosa ochracea: Ecklon, Zeyher, Harvey. - Lug. Septbr.

Archegonia 3. Antheridia 1-2. Paraphyses 1-2. Planta inter M. basilarem el campylothecam medium tenens et notis laudatis distinctissima.

5. M. campylotheea C. Müll.; hermaphroditu; innovationes simplicissimae crectae clatae basi nudae apicem versus sensim crescentes densissime foliosae, foliis lanceolatis angustis longissime cusprilatis subpiliferis excurventincribus e medio obsolete denticulatis, comalibus brevioribus exacte denticulatis; caulis fertilis subbasilaris brevissimus, foliis perichaetialibus basi luxius areolatis fuscescentibus longe acuminatis, nepro medio dissoluto, denticulatis, tenuioribus; theca longe pedunculata angustissime cylindrica, elongula longicolla éalde curvelu, operculo brevi conico acuto; dentes peristomii temissime filiformes e membrana immersa orti brewes basi aenuales linea media vix praediti sublaeves. 


\section{STEGOCARPI. ACROCARPI. MHELCHOFERM.}

Weisia camplocarpa Hook. et Arn. in 1c. Pl. rar. tab. 136? Pohlia minor Hsch. in Musc. Mexic. a Dep pe et scllica lectis No. 1078. ex parte.

Patria. Mexico in monte Orizabae vulcanico. E regno Peruviano prope Surucucho a cl. prof. W. Ja meson lectam Cl. Ho o ker habuit.

$\boldsymbol{M}$. basiluri ex toto habitu simillima, notis illustratis tamen propria species. - Antheridia 2. Archegonia 2-3. Paraphysis 1. - Praecedentes species hujus divisionis quatuor inter sese affinissimae, ex habitu innovationum apicem versus crescentium comali-foliosarum Weberis nonnullis similes.

\section{b. Theca pyriformis aequalis.}

6. M. elavata Br. et Sch. (in Musc. Abyss.); divica; densissime compacte cespitosa pusilla valde nitida; innovationes breves densissime foliosae, inferne nudiusculac apice crescentes, caule rubello, foliis oralibus lanceolutis curis bryoideis laxiusculo-areolutis, nervo crasso ante apicem evanido, subintegerrimis margine subrevolutis, pellucidis inlerioribus purpurascentibus; caulis fertilis brevissimus basilaris, foliis perichaetialibus illis innovationum similibus; theca pro plantulae exiguitate longe pedunculata clurato-pyriformis horisontulis; dentes peristomii regulures e basi lata alta pallida subtrabeculutu fere subito longe cuspidati suburliculati connizentes, siccitate horizontales, malefucti inflexi.

M. pellucida Hmp. IC. Muscor. Dec, III, tah, 27. var. ramis gracilioribus, foliis nervo flaccidiore praeditis; thera maxime clavatopyriformis, operculo conico ohtuso minimn. Capensis. - Weisia reticulata Hook. Bot. Miscell. 1. 1830. 1. 121. tal.29.

Patrie. Abyssinia: W. Schimper in collect. un. it. Prom. b. spei prope Swellendam: Pappe in hb. Kunzeano. Ibidem ad Cap 'lown: Mundt in hb. Hookeriano.

Planta mascula feminca robustior, flore gemmilormi. Antheridia majuscula clavala brevistipitala, paraphysibus bryoideis pluribus coloratis cincta. Folia perigonialia illis 
innovationum similia, nervo ad medium dissoluto. Archegonia plura paraphysibus c. 10. pracdita.

7. M. pleurogena Mont. (in ann. d. sc. nat. 1815. 4. p. 117.); hermaphroditu; caulis erectus dense radiculosus innovationibus ramosus; foliis imbricat is ovato-lanceolatis integerrimis, nevo sub upicem exundo, inferioribus minutis; caulis fertilis basilaris lateralis brevissimus, foliis perichaetialibus upice dentatis; theca inclinata oblonga, uno latere basin rersus amplior; peristomii dentes lineares apice trabeculatis conjuncti; operculo conrexo-conico brevissimo; annulus simplex.

Petria. Chile australis: C. Gay.

8. M. Jamesoni Tayl. (Lond. jouru. of bot. 1817. 4. p. 331.); caulis brevissimus cespitosus crectiusculus rubellus, innorationibus clavatis; folia arcte imbricata erecta, ovalia acuta subintegerrima; pedunculi caule 4 plo longiores apice incurvi; theca rotumlato-oralis, apophysi obconicu, siccilate rugosa; peristomii brevissimi albidi dentes lanceolati per paria subapproximati sape truncuti. Tayl. 1. c.

Bryum turbinatum ß. minus Kunth. Syn. PI. Aeq. 1. p. 57. Bryum annotinum Brid. 1. p. 818! - Did!monlon me!jalocarpus W. Am. Disp. Meth, Mouss. p. 36, et schwätgr. Sinppl, 111. P. II. tah. 265. - Sylachnum turbinutum Brid. I. p. 780! - E descriptione Taylori huc: pertinet! Especiminibus anthenticis, a Cl Hu Hebold t et Boupland lectis species Mielichhoferin vera, distinctissima, hermaphrodita, hand dioica, ut dicit schwä vationes humiles inferme nudae, apice comoso-foliosae clavatae gracillimate, foliis lanceolatis angustis, nervo excurrente brevi-acutis, olsolete denticulatis; caulis fertilis hasilaris bevis, fulis longioribus angustiorihus remote sed acute denticulatis v. inter riusculis, intimis multo minoribus latioribus ovalibus laxins areolatis integris, omuibus coloratis evanidincrvilus; theca longe et tenuissime apice arcuato-peduculata, longicolla ovalis vix cernua pyriformis parva laevissima nitida; dentes peristomii ex iconibus sichü̈yricheniunis et deser. Cl. W. A nott (1. c.) et Taty lor per paria approximati fatiuscule sensim cuspidati linea longitulinali exarati transwerse trabeculati flavescentes. Antheridial hrevia c. 7 - 8. Archegonia c. 3. Paraphyses c. 2. - Ex halitu toto ad M. busilurem, Fichlonianam, camyylothecam, et longisetam accedens. 
Patria. In monte Pichincha Andium Quitensium: W. Jameson Nov. 1816. - In conrallibus Andium Noro-Granatensium inter Almaguer et Pasto altitud. $1200-1500$ hexapod. cespitosam leg. If umboldt et Bonpland.

Ex habitu $M$. macrocerpue sed innovalionibus magis clavatis, pedunculis longioribus, theca magis rotunda. Ab omnibus congeneribus dentium forma toto coelo distat, sed Mielichhoferia vera!

9. M. brevicaulis IIsch. (in FI. Bras. Nasc. I. p. 8. tab. 1. fig. 2.); hermaphrodita; innovationes breviusculae densiusculo foliosae inferne nudiusculae apice crescentes rufue filiformes v. clavatac, foliis lanceolutis lutioribus acutis ceanidinevibus subdenticulatis; caulis fertilis brevissimus basilaris, foliis perichaetialibus lanceolatis acutis apicem rersus remote sermulatis, nervo ante apicem evanido, parum concava luteo-viridia; folia innovationum angustiora; theca pyriformis erectu longicolla, opereulo conico mammillato; dentes peristomii e membrana brevi reticulata filiformes basi latiores linea media sulcati, apice simplices articuluti rugulosi. $\div$.

Patria. Brasilia in Monte Video: Sellow. Chile: C. Gay sec. Cl. Montagne.

Antheridia plura. Archegonia pauca. Paraphyses paucissimae fitiformes.

10. M. nitida Ilsch. (in Bryol. Germ. II. p. 183. tah. 41.); dioicu; innovationes erectae gracillimae filiformes fere e basi usque ad apicem acqualiter filiosac, foliis erecto-patentibus confertis veali-lanceolutis apice dentutis coutis evanidinervibus; caulis fertilis brevis basalis vel medius, foliis perichactialibus majoribus obtusiusculis laxius areolatis subintegris evanidinervibus; theca brevipedunculata elegunter pyriformis subereclu pure, operculo brevi conico; dentes peristomii busi con/luentes, a busi latiuscula subito anguste lineales subplani arliculis transrersulibus numerosis, momimulis, ex unicu cellulurum serie conformuli, gramulali obscure flacescentes vix hygroscopici. 
Bryolog. Europ. I. c. tal). 1. - Weisia Mielichhoferiana Funk iu Hoppe et Horusch. Crypt. Cent. 1. Dec. IV. et Hengensls. bot. Zeit. 1819. p. 86. - Oreas Mielichhoferi Brid. 1. p. 381.

ß. gracilis; densius cespitosa, foliis brevioribus magis confertis subimbricatis; thecac erecto-pedunculatae. Bryol. Europ. 1: c. p. 6. tab. 2.

$\gamma$. intermedia; dense cespitosa, folis erectis angustioribus; theca in pedunculo arcuato demissa, illa formac typicae minori, matura pallide olivacea. Bryol. Europ. I. c. p. 6. talo. 2.

d. elongata; compacte cespitosa uncialis et semipedaJis, ad innovationes usque fusco-atra, foliis imbricatis, theca in pedunculo brevissimo flexuoso arcuato sacpe inter innovationes demissa, crassiuscula olivacea. Bryol. Europ. 1, c. p. 6. tals. 2 $\delta$ - Mielichhoferin elongutu Nees et Hsch, Bryol. Germ. II. p. 186. tal, 41. fis. 2. - Weisia Mielichhoferi ק. elongatu Schwïgr. Suppl. II, 1. p. 47. tab. 114. - W'eisia elongatı Hook. Musc. Hxot. 11. tab. 102. - Greas elonguta Brid. I. p. 382.

E. microcarpu; folis obtusioribus et innovationibus densius foliosis magis clavatis. Weisia macrocarpu Hook. in Irumm. Musc. Amer. No. 74. - Mielichhoferia macrocarja Br. et sch, in Lond. journ. of bot. II. 1843. p. 665 .

Patria. In rupibus micaceo-schistosis ad fodinam Schwarzwand dictam in valle Salisburgensi Grossarl ubi Cl. Mielich hofer anno 1317 deteril; in der Ideiter prope lleiligenblut Carinthiac: II o ns in ach, II oppe, Funk; an der Messerlingwand prope Windischnathey, in valle Tefereggen Tirolis: Funk, Hornsehuch; in valle de Lio pyrenaeorum oricntalium: 'Thom as; ad rallis Velberthal initium prope Mittersill Pinzgoviac: Sauter, W. P. Schimper. In alpe Dorrefjeld Norvegiae et in Suecia (Areskut): Angström. Var. $\beta$. ad fodinam Scliwarzwand, ubi locis humidis (sub ponte) sensim

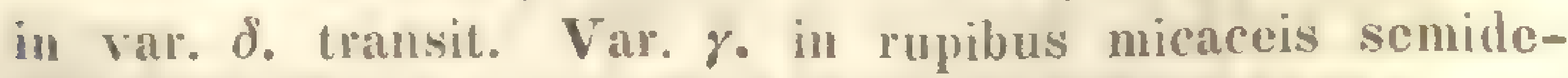
compositis haud irroratis ad fodinam Schwarzwand et in muro ferruginco fodinae secus viam, quac a pabo llittschlag per montem Whroneck in Gastuniam durit, et in valle di Furba rersus mont. Zebru Vallis-'Tellinac: W. P. Schimper. Var. $\delta$. in rupibus decompositis, rivulo 
e fossa Schwarzwand proveniente irrigatis, cespitibus ingentibus, longe lateque extensis. Var. $\eta$. in America septentrionali ubi in Rocky Mountains legit Drummond. - Augusto et Septembri.

Planta mascula feminea paullisper gracilior, ramosior polyantha; flores in ramulis brevibus e caulc primario egredientibus gemmiformes polyphylli, folis intimis mollibus subenervibus. Antheridia $1-2$, paraphysi 1. Archegonia c. 10, paraphysibus filiformibus pluribus. $\mathbf{E}$ pulcherrimis muscis alpinis!

11. M. Iongiseta C. Müll, hermaphrodita; innovationes simplicissimae erectae subhumiles basi nudae apicem versus sensim crescentes dense foliosac, foliis lanceolatis acuminatis nervo tenui excurente breviter cuspidutis angustis purum fulcutis flavescentibus apice ubsolete denticulatis; perichactialia latiora acute acuminutu cuanidinervie subintegerrima, intima multo minora hyalina incerpuliter dentata; theca in pedunculo longissimo gracili fhexuoso pyriformis brevicolla crassiuscula, sicea crecta, madefacta inclinata, operculo conico mammillato brevissimo; dentes peristomii in membrana brevi longi erecti angusti parum sulcati linea longitudinali exarati flavidi, interdum apice subappendiculati.

Bryum nutans 3. minus Kunth synops. Pl. Aeq. I. p. 58.

Patria. In jugis Andiun, regione temperata: If umboldt et Bonpland.

Mielichh. Jumesoni proxima, theca autem Iongissinc pedunculata et peristomio distincta. A. M. Mlenrogence el breviculi notis editis certe differt.

\section{Gen. II. Leptochlacna Mont.}

Alnales des sc. nat. 1845. 4. p. 105.

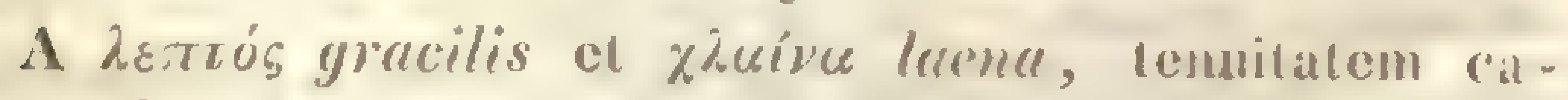
lyptrae denotans.

Calyptra lincari .. subulata longa fugarissima riridis apice fusca, basi lateraliter lissal. P'oristomium diplex. Externum: deutes 16 breves lineari-lan- 
ceolati articulati, madore erecti hyalini. Internum: membrana brevissima, in cilia totidem filiformia cum dentibus alternantia fissa. Theca lateralis. Inflorescentia monoica.

Genus Mielichoferies ex toto habitu proximum et peristomii vi duplicis distinctum, sed futuro forsan melius ad illas revocandum.

T. Chilensis Mont. ( 1 . c. p. 106.); monoicum; cespitosum, basi subnudum, apice interrupte comoso-foliosum erectum, innovationibus plerumque binis infra perichactium enatis fertilibus ramosum; folia ovato-lanceolata, nervo basi crassiore superue tenui flexuoso excurrente acuta, paulum flexuosa, subdenticulata, margine paullisper revoluta, e cellulis basi laxis superne angustissimis densissimis inanibus areolata, lutescentia, superiora majora in comam densiusculam imbricata; theca cylindracea erecta vel inclinata anapophysata, pedunculo gracillimo flexuoso et operculo conico-acuminato brevissimo pracdita.

Mont. in Gay: Ili-t. de Chile, Bot. Crypt. tah. 4. fig. 1.

Putriu. Ad truncos arborum prope St. Jago reipublicae Chilensis. - Murtio, 1829: C. Gay.

Antleridia in axillis foliorum floralium sessilia libera oblonga fusca el cum archegonits floris feminei intermixta. Flos feminens in ramulo apice comoso terminalis gemmiformis. - Fructum non vidimus.

\section{Gen. III. Orthodomtiom Schwägr.}

suppl. 11. P. I1. 2. p. 123. - Bryol. Europ. Fasc. XXIV. Orthodlontiun. Bryum auct. nonnulf.

Ab ógiós rectus et ỏdor's dens, ob dentes erectos ductum.

Calyptra parvula cuculliformis fugax. P(ristominm infra thecae orificium oriens duplex. Fxternum: dentes cxterni 16 lanceolati-subulati, Bryi meneris, siccitate infra thecae orificium deflexi, 
madefacti erecti. Internum: cilia dentibus externis allernantia duplo breviora vel subaequalia, e membrana brevi subcarinata filiformia. Foliis longis lanceolato-subulatis angustissimis subcrispis apice caulis conalibus plantae graciles cespitulosae. Theca annulata vel exannulata, sublongricolla. Inflorescentia monoica vel dioica.

\section{Foliavalde patula.}

1. 0. grneile Schwägr. (in litt. ad IVilson); monoicum; humile, laxius cespitosum; folia longissime subulata angustissima, basi luxe, upicem versus densiusculoareoluta, flexuosa integriuscula, nervo in subulam evanescente subcarinato-concava; perichactialia intima minora coloratu ommino laxius areolatu; theca in pedunculo inaequaliter longo tenuissimo suberectu ouculis longicolla pyriformis angustissimu lapeis, operculo conico rostellato; peristomii dentes externi brevinsculi ungusti dense trabeculati malefacti aurei, interni dimidio breviores filiformes articulati.

Bryolog. Europ. 1. c. p. 4. tal). 1. - Bryum (Pohlia) gracile Wils. in Gardner Muscol. Brit. talo. 34. App.

Putriu. In rupibus arenariis prope Irelsby Comit. Cheshire Angliae, ubi Cl. W. Wils on anno 1833 detexit. In Abyssiniae alpibus Simensibus: W. Schimper. - Martio.

Plantae tenellac fragiles parce ramosae. Antheridia sub flore femineo in foliorum comalium axillis per paria disposita numerosa, paraphysibus filiformibus mixta. Theca examnulata. Orth. lineuri Schwägr. simillimum, species haece tamen differt: inflorescentia, foliis multo laxius areolatis, dentibus. externis latioribus, internis externos aequantibus et theca basi subaequali horizontali. - Planta Abyssinica foliis laxius areolatis, cacterum Europacae simillima.

2. D. Ineare Schwägr. (Suppl. II. P. II. p. 124. 1ab. 188.); monoicum; humile, laxius cespitosum; folia 
longissime subulata angustissima, laxius areolutu, flexmosa integriuscula, nervo in subulam evanescente subcarinatoconcava; theca in pedunculo apice inclinato horisontulis busi subuequalis oxulis, operculo conico suboblipuo acuto breviori; peristomii dentes externi latiores dense trabeculati, interni externos aeguantes filiformes tenuissimi articulati. +

Patriu. In prom. b. spei: Menzics.

Flos masculus gemmiformis, foliis perigonintibus minimis obtusis enpribus. Theca exannulata.

3. D. sulcatum Hook. et Wils. (in Hook. Ic. Pl. tab. 739. B.); monoicum; humile, laxius cespitosum; folia longu subulata, basi ungustioru, upicem versus lutiora, apice subulato-acutu, angustissime areolutu integriuscula subconcara, nervo supra medium evanido; folia perichaetialia intima minora angustiora; theca in pedunculo elongato tenuissimo erecta vel vix inclinata ovalis brericollis, aperta sulcuta, operculo conico rostellato obliquo; dentes peristomii externi oblongi obtusiusculi brees trabeculati ferruginei, interni externos dimidio superuntes concolores articulati tenuissime filiformes.

O. infractum l)z. et Mollil, in ann. d. sc. nat. HI. 2. 1844. p. 313 ; et in Musc, Archip. Ind. Fase. II. Orthodontium p. 31. tal). 14.

Putrie. Nova IIollandia ad flumen Swan River d:ctum: J. Drummond primus legit. In Javae insulae monte Gédé, ubi in cacumine mont. Sedaratoe legit Korthals.

Flos masculus axillaris gemmiformis minutus, foliis perigronialibus lato-ovatis convolutaceis, integerimis acuminatis enervibus brunneis laxe areolatis. Antheridia brevia ellipsoidea, paraphysibus brevibus luteis cincta. Thera examulata. - Pracedentibus ex habitu simillimum, notis tamen laudatis distinctissimum.

4. D. australe Iook. et Wils. (in Lond, journ. of bot. 1844. p. 545.); monoicum; caulis humilis, fastigiatoramosus; folia erecto-putentia erecture subrecurer linearia flexuosa, nervo subcontinuo praedita, angustissime 
elongate et densissime areolata, theca laevis suberecta oblonga brevicolla, operculo brevirostruto.

Putria. Insulac Falklandi atque Eremitac et in terra Van Diemenii.

Orth. gracili proximum, sed differt theca, peristomio minori pallido et nervo distinctiore. Ab Orth. lineuri an$1 \mathrm{em}$ valde diversum.

5. D. pellueens Br. et Sch. (Bryol. Europ. Fasc. XXIV. Orthod. p. 3.); elongutum robustum valule rumosum cespitosum; folia patentia flexuosa linearia acuta integerrima, nervo gracili evanescente carinato-concara, laxe et pellucide reticuluta, siccitate nitidiuscula, flarovirescentia; thecue numerosue in pedunculis brevibus gracillimis fulvis subindinatae pallidae pyriformes apophysalar, dein subsulcatae, operculo e basi conica sublange rostrato pracditae, ore subcontractae; peristomii dentes externi angusti, dense trabeculati, interni externos aequantes e basi latiuscula subulati articulati. $\rightarrow$.

Brynm (Puhliu) pellucens Hook. in Ic. Pl, rar. 1. tab. 34.

Putria. Peruria in monte Survucucho prope Cuença: James on.

Notis designatis ab omnibus congeneribus distinctissimum.

\section{b. Folia appressa erecta.}

6. D. tenne C. Müll.; dioicum; msillum simplex, gregurie cespitosum; folia caulina lanceoluta angusta longinscula ucutu integerrima flexuosa caviuscula, nervo excurrente; perichactialia longiora; theca minima horizontalis inclinata ovalis aperta cylindracea brevicollis, operculo conico brevissimo, ammulo pervon et pedunculo brerissimo flexnoso pracdita; dentes peristomii externi breves, transverse trabeculati angusti pellucidi, interni ciliiformes bifidi, e basi ad medium tantum secedentes.

Bryum (Pohliu) humile Mont. in Aun. des se, nat. 1845. 4. p. 104.

Patria. Chile australis: Pöppig 1828. IJb. Kunzeanum. Ibidem: Gay in hb. Mont. 
Archegonia longissima 5-6, paraphrsibus nonnullis teneris mixta. Flos masculus ignotus. - Ommium congenerum humillimum, pygmaeum, Orthodontium verum et distinctissimum exiguitate, inflorescentia, thera annulata et dentibus peristomii. Speries tenella.

\section{Gen. IV. Mryum Dill. emend.}

Hist. Musc. p. 338. Br. Kurop. Fasc. VI-IX. - Acidudoutium schwïgr. Megalungium Brid. - Peromnion schwägr. - Bruchymenium Hook. - Muinm auct. Houn. - Webera Hdw. Pohlia Hdw. - Hemisynupsium Brid. - Ptychostomum Hsch. Cladodium Brid. - C'ynodontium Hdw. - Hypmum et Leskea Wel, et Molir.

Nomen antiquum in Dioscoride et Plinio occurrens, a Dillenio huice generi affinibusque impositum, ab Itedwigio sancitum.

Calyptra dimidiata parvula cuculliformis. Peristomium duplex. Extermum: dentes 16 lanceolati molles llavescentes acquidistantes, dorso plani transversim trabeculati, linea media Iongitudinali Rexuosa exarati, intus lamellati hygroscopici. Internum membrana tenera sedecies carinata magna in dentes lanceolatos plus minus perfectos producla, cilis srepe interjectis vel mullis. Inflorescentia hermaphrodita, munoica, dioica rol androgy na. Theca plerumque anumlata.

Clavis annalyticus e peristomio ductus.

\section{A. Acidodontium Schwägr.}

Steppl. II. II, p. 152.

Dentes externi longissimi lati, apice subito suhulati incurvi, latere valde hyilino-lamellosi. Membrana interua altissima in dentes 16 lancenlatos carinatos. apicem versus secclentes, sunmo apice comnatos deiu hifidos, ciliis hinis hrevissimis interjectis, e hasi usque al apicem demsissime transverse traberulatos producta.

1. Br. megalocarpum Hook. 30.

2. - seninerve C. Mùll. 31.

3. - Taylori C. Müll. 32.

C. Milller: Synops. muec. frond. 


\title{
B. Brachymenium Hook.
}

\author{
Schwägr. Suppl. II. I. p. 131.
}

Dentes externi ut in Bryis ceterisque sectionihus una cum intemo peristomio e sporangidi membrana oriundi. Membrana interna dentibus rudimentariis, vel nullis et ciliis perfectis seu rudimentariis.

1. Folia julaceo-imbricata.

4. Br. splachnoides C. Müll. 75.

5. - pulchrum C. Mïll, 135.

6. - Koratranum C. Müll, 136.

2. Folia plus minus patula.

a. Folia marginata.

7. Br. Abyssinicum Br. et Sch.34.

8. - flexifolium Br. et Sch. 35.

9. - Peromuion C. Müll. 131.

10. - Hornschuchianum C. Müll. 132.

11. - hrevicaule Hmp. 133.

12. - Hookeri spr. 134.

b. Folia immarginata.

a. Denticulata.

13. Br. Montagneanum C. Mäll, 33.

14. - Eystylinm C. Mïll. 129.

15. - leptostomoides C. Müill. 130.

16. - microstomum C. Müllı. 137.

17. - Weisia C. Müll. 138.

18. Br. Mexicanum C. Müll. 10.

B. Integra.

19. - Meyenianum C, Müll. 86.

20. - Harveyanum C. Mäll. 116.

21. - Sellowianum C. Miill. 127.

22. - Martianum C. Müll. 128.

\section{Ptychostommm Hsch.}

Regensb, bot. Zeit, 1822. Syll. I. P. 62.

Peristom. internum externo adglutinatum, dentibus lanceolatis plus minus perforatis ciliisque inermibus vel uullis praeditum.

23. Br. cernutum Br. et Sch. 36.

24. - Gayanum Mont. 37.

25. - Melvilleanum C. Müll. 38.

\section{Pohlia Hedw.}

\section{Musc, Frond. I. p. 96. t. 36.}

Peristom. internum: dentes lanceolati plus minus perforati, ciliis rudimentariis interpositis vel nullis. 
1. Inflorescentia hermaphrodita.

26. Br. lacustre Bland. 39.

27. - inclinatum Br, et Sch. 40.

28. - arcticum eor, 41.

29. - purpurascens eor. 42.

30. - Archangelicum eor. 43.

31. - Indicum Dz. et M. 117.

2. Inflorescentia monoica.

a. Folia lata.

32. Br. uliginosum Br. et Sch. 44.

33. - Warneum Bland. 45.

34. - leptophyllum Br. et Sch. 46.

35. - Brownii eor. 47.

36. - latifolium Br. et Sch.68.

37. - orthodontioides C. Mill. 81.

b. Folia angusta.

38. Br. acuminatum Br. et Sch, 139.

39. - cucullatum Schw. 143.

40. - polymorphum Br. et Sch, 144.

3. Inflorescentia dioica.

a. Theca irreyularis.

41. Br. Zierii Dicks. 71.

42. - demissum Hook, 72.

b. Theca regularis.

43. Br. compressidens C. Müll. 74.

44. - platyphyllum C. Müll. 77.

45. - clavatum Schimp. 79.

46. - tenuicaule Mont. 80.

47. - papillosum C. Müll, 140.

48. - braclıydontium Hmp. 141.

$\beta$. Folia excurrentinervia.

49. Br. rutilans Brid. 48.

50. - Gilliesii Hook. 78.

51. - microcarpum C. Müll. 82.

52. - imbricatum schw. 100.

4. Inflorescentia ignota.

53. Br. calophyllum A. Br. 70.

๖. - ambigutm Dub. 83.

55. - flexuosum C. Mül. 142.

\section{E. WVebera Hdw.}

Hist. Musc, p. 95.

Peristomium internum ut antea, ciliis perfectis nudis interpositis 
1. Inflorescentia hermaphrodita. 56. Br. pyriforme Hdw. 145.

2. Inflorescentia monoica.

a. Antheridia in gemmis inclust.

57. Br. subrotundum Brid. 49.

58. - paradoxum Schw, 73.

59. - doliolum Dub. 102.

60. - Nepalense Spr. 112.

61. - multiflorum C. Müll, 160.

b. Antheridia in axillis folionm libera.

62. Br, nutans Schreb. 153.

63. - longicollum Sw. 15*.

64. - elongatum Dicks. 155.

65. - leptoblepharon C. Mi̊ll. 156.

66. - integridens C. Miill, 157.

\section{Inflorescentia dioica.}

a. Folia nervo eacurrente rel evanido.

67. Br. cinclidioides Blytt. 8.

68. - carneum L, 84,

69. - albicans Wahlenb. 85.

70. - orthocladon Br. et Sch, 124.

71. - Sphagni Brid. 146.

72. - annotinum Hdw. 147.

73. - pulchellum Hdw. 148.

74. - Lndwigii spr. 149.

75. - crudum Schreb. 150.

76. - Schimperi C. Mill, 151.

b. Folia nervo in cuspidem exeunte.

77. Br. Decaisnei Dz. et. M. 9.

78. - macropelma C. Míll. 50.

79. - dichotomum Hdw. 101.

80. - dicranoides Hsch, 110.

81. - Preissianum Hmp. 111.

82. - exile D\%。 et M. 113.

83. - coarctatum C. Mäll. 114.

84. - megalacrion Schw. 115.

85. - microtheca C. Miill. 119.

86. - leucophyllum Dz. et M. 120.

87. - semiovatum Brid. 122.

88. Br. geniculatum Brid, 51.

89. - nitens Hook. 168. 
90. Br, soboliferam Tayl. 161.

91. - Bridelianum C. Müll. 165.

F. Mryum Dill. emend.

Bryal. Europ. Fasc, VI-IX.

Peristom. intenum ut antea, cilis perfectis appendiculatis interjectis.

1. Inflorescentia hermaphrodita.

92. Br. bimum Schreb. 20.

93. - nivale C. Müll. 28.

94. - torquescens Br, et Sch. 52.

95. - Philippianum C. Müll. 53.

96. - intermedinm Brid. 54.

97. - cirrhatum H. et Hsch. 55.

98. - microstegium Br. et Sch. 56.

2. Inflorescentia monoica.

99. Br. pallescens Schw. 57.

100. - Sauteri Br. et Sch. 58.

101. - Sandii Dr. et M. 92.

3. Inflorescentia dioica.

a. Folia julaceo-imbricata. a. Mollia.

102. Br. Blindii Br. et Sch, 89 .

103. - conicum Hsch. 94.

104. - bulbillosum Mont. 95.

105. - Funkii Schw, 103.

106. - argenteum L. 118.

107. Br. julaceum Sm. 121.

$\beta$. Rigida.

108. - prostratum C. Müll. 123.

1. Folia apice caulis in rosulam congesta latissima spalhulata.

109. Hr. roseum sichreb. 1.

110. - giganteum Hook. 2.

111. - Umbraculum Burch. 3.

112. - grandifolium C. Mäll. 7.

113. - Beyrichianum C. Mïll. 5.

114. - Commersoni Brid. 4.

115. - patens Hook. et Wils. 6.

c. Folia patula in caulis longitudin. sparsa.

c. Folia confertius imbricate.

1. Folia stricta.

116. Br. australe Hmp. 65.

117. - alpinum L. 66. 


\section{STEGOCARPI. ACROCARPI. BRYM.}

118. Br. Mühlenbeckii Br. et Scl. 67.

119. - erythrocarpum Schw. 87.

120. - marginatum Br. et Sch, 88,

121. - Tozzeri Grev. 90.

122. - pachypoma Mont. 91.

123. - Crïgeri Hmp. 93.

124. - atropurpurenn Wahlenb. 104.

125. - pachytheca C. Mïll. 105.

126. - coronatum schw. 106.

127. - apiculatum schw. 107.

128. - versicolor A, Br. 108.

2. Folia plus minus torta.

129. Br. Canariense Schw, 11.

130. - capillare Hdw. 59.

131. - platyloma Schw. 60.

132. - obconicum Hsch. 61.

133. - creberrimum Tayl. 62.

134. - cavum C. Mũll. 63.

135. - cespiticinm L. 64.

P. Folia Jaxe imbricata.

136. Br. truncorum Brid. 15.

137. - Ehrenbergianum C. Müll. 16.

138. - Neelgheriense Mont. 17.

139. - pallens Sw. 19.

140. - pseudotriquetrum Hedw. 21.

141. - Neodamense Itzigs. 22.

142. - turbinatnm Hdw. 23.

143. - Duvalii Voit. 24.

144. - gracilescens C. Miill. 25.

115. - rigidum C. Miill. 29.

146. - cyclophyllum schw. 69.

\section{Brya incertae sedis.}

147. Br. andicola Kth. 18.

\section{A d. F. 3. c, $\beta$. ?}

148. - Auberti Brid. 27.

149. - erythrocaulon Brid. 26.

$$
\text { A d. F. 3, c. } \alpha, 2 \text {.? }
$$

150. Br. Billardieri sichw. 12.

151. - leptothecium Tayl. 14.

152. - campylothecium ej. 13.

A d. H. 3, a, \&.?

153. Br. puugens Tayl. 96.

154. - inaequale ej. 97.

155. - multicaule ej. 98. 
Cujus sectionis?

156. Br. blandum Hook, et Wils. 125.

15\%. - laevigatum eor. 126.

158. - gracilisetum Hsch. 159.

159. - angustifolium Brid. 109.

160. - recurvifolium Tayl. 163.

161. - cellulare Hook. 76 .

162. - tenuifolium H, et W. 152.

163. - teretiusculum Hook. 99.

164. - Zollingeri Dub. 162.

165. - palmifolium Brid. 164.

Spec. sec. affinit. natur. disposilac.

Sectio 1. Platyphyllum. Plantae laxifoliae muioidede clatae rohustae. Folia latissima spathulata, nervo hasi crassiscimo. superne tenuiter evanido praedita, e cellulis maximis utriculo primordiali plerumque valde evoluto praeditis coustrucla, planiuscula, margine basi tantum revoluta; thecae cylindricae plus minns majusculae saepe valde aggregatae.

1. Br. roseum Schreb. (Spic. Fl. Lips. 1) 84.); divicum; caulis apice interdum innovationibus brevibus stellato-foliosis ramosus; folia e basi breviter luto-sputhetlata lato - ovalia acuminata, nervo basi crasso tenuiter evanescente fuscidulo praedita, inferne margine revoluta, a medio uspue ad apicem simpliciter et brevi-servutu, e cellulis utriculo primordiali plerumpue maxime croluto praclitis majusculis viridibus composita; perichactialia multo minora angustiora, longissime acuminata, denticulata nervo excurrente cuspidata; thecae solitariac vel aggregatae longipedunculatae subgibboso-cylimdrice pendulu, ore requali, operculo convexo-conico mammillari, peristomio magno Bryi.

Br. Furop. 1. c. p. 56. t. 25. - Br. Polla rosen Brid. I. p 696. - Mnium roseum Hdw. Sp. Musc. p. 194. - H!/jnum roseum Weh. et Molir. Bot. Taschb. p. 207. - Mn. proliferum Gmel. syst. Nat. 11. p. 1330. - Rryum stellare roseum unajus, capsulis ovatis pendulis. Dill, Musc, p. 411. t. 52. fig. 77.

Patria. Per orbem totum fere terrarum in locis humidis praccipue graminosis sed raro fructiferum. - Anchumm.

Flos masculus gemmiformis, foliis ovato-lanceolatis cvanidinervibus integerrimis. Planta e perigonio saepe prolifera. 
2. Mr. giganteum IIook. (in S'rhwägr. Suppl. II. II. I. p. 20. tab. 158.); dioicum; folia caulina e basi longe ef anguste spathulata latissimo-ovalia acuminata, nervo lenui evanido purpurascente praedita, inferne margine revoluta, medio simpliciter upice vero argute et flace duplicuto-serrata, e cellulis utriculo primordiali plerumque maxime evoluto praeditis majusculis viridibus composita; perichactialia multo minora angustiora, interna plus miuns lanceolata longissime acuminata simpliciter serrola excurrentinervia; thecae solitariac vel aggregatac longipedunculatae elonguto-cyliudricue curviusculue horisontules, ore cumpliores, operculo conico, peristomio nagno.

\section{Bryum Polla rosea $\dot{\gamma}$ yiguntea Brid. I. p. Xə̆t.}

Putria. Nepal: Wallich. Java in monte Patsia: Reinwardt, caeterum quoque in montibus céde, Salak, Megamedong, in sylva Burangrang et in Bornen teste Korthals, vuluare.

stinctum.

Br. roseo proxinum, sed notis illustratis certe di-
ctum.

3. Br. Cmbraculum Burch. (Ilook. Musce exo1. Lab. 133.); divicum; simplex basi purpurascens; folia caulina e basi lato-spathulata lato-ovalia arminala, inferiora evanidinervia, superiora nervo excurente basi crasso purpurascente superne tonui praedita, inferne matrine revoInta, e basi temuiter ol laxims purymoscenti-murgincta, e medio simpliciter sed aryute servata, e collulis cransiusculo-rhomboideis minus elongatis utriculo primordiali plus minus croluto praeditis composita, majora planiuscula, angustione murgims velde undulute; perichactialia interna minora longins acnminata excurentincria; theca solitaria longiusculo-pedunculala cylindrica, ore ampliori,
pendula intense rufo-fusca.

Mnium I mhraculume schwägr. Nuppl. 11. 11. 1. p. 22. t. 159.-

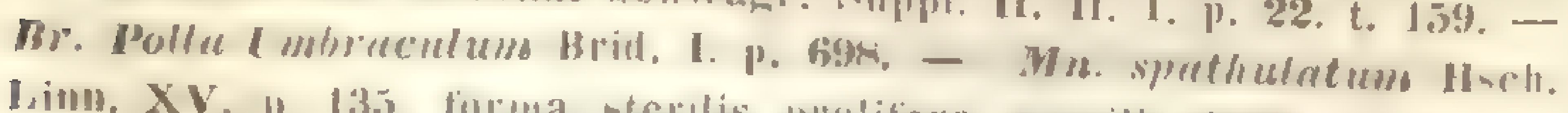
Limn. XV. p. 135. forma nternlis profitera macilis folio minus pti-
catis argute serratis.

I'nlviu. Prom. bon. spei: Ad terran in lmbrosis sylvarum densarum Anlennigualand, ubi Burclicll de- 
texit. Port Natal in sylra prope Omblas in terra: Drè ge sterile legit. Prope Philippstown in sylvis montanis: E cklon sterile.

4. Mr. Commersoni Brid. (Mant. Musc. p. 119.); dioirm; elatum subsimplex proliferum, e basi usque ad apicem laxe, apice stellatin foliosum; folia e basi longe et anguste spathulata lato-ovalia acuminata, nervo crasso purpurascente excurrente, e cellulis crussis aequalibus phus minus pellucidis composita, cellulis angustioribus reluti laxe marginatu, dentibus inaequalibus argutis basi non confluentibus ciliato-serrata; perichactialia lanceolate rel ovato-acuminata acutissima, remote et quasi spinosociliata.

Mnium Cummersoni schwägre. Suppl. I. Il. p. 134. tab, 80. Bryum Polla Commersoni Brid. I. p. 710.

Putria. Insula Bourhonis: Commerson.

A Br. Cmbraculo proximo foliis crassius arcolatis vix marginatis, vix plicatis jam statu sterili differt. Br. Beyrirhirmm simillimum foliis dentibus basi conlluentibus quasi limbatis distat.

5. Hr. Beyrichianmm C. Miill.; divicum; elatum subsimplex proliferum, e basi usque ad apicem laxe, apice stellatim foliosum; folia e basi lato-spathulata lato-ovalia accuminata, nervo crasso purpurascente excurente, e cellulis majusculis longioribus quam latis utriculo primordiali valde conspicuo praeditis composita, cellulis angustioribus reluti laxe muryinutu, dentibus inaequalibus argute vel ciliato-serrata; perichaetiatia multo minora ovatolongo-acuminata immarginata breviter serrata subexcurrentinervia; theca longipedunculata elonguto-cylindrice longirolla currata arcuato-homisomtalis pallida, operculo convexo breviter rostellato subobliquo aurantiaco.

Mnium Ieyrichiumum IIsch. Fl. Bras. Fasc. 1. P. 15. - Brynm roseum Walk. Art. in Act. Soc. Wern. V. p. 201.

Palria. Brasilia, ubi Beyrich legit, in locis pluribus et, ut videtur haud rarum. In Chile: Pöppig. Columbia: Moritz. In Cordilleribus: Il umbold 
Br. Commersoni et Umbraculo proximum; ab ambobus jam differt foliorum dentibus confluentibus, ab ulteriore quoque thecae forma.

6. Br. patens Hook. et IVils. (Lond. Journ. of bot. 1844. p. 155.); caulis ramosus, ramis brevibus inferne subnudis; folia in rosulam congesta patula obovata subplana apiculata, margine plano, superne serrulata, siccitate erecta subcrispata, nervo subexcurrente; theca clavato-abovetu cernua, operculo conico-mammillato. t.

Patria. Brasilia in Serra da Araripe, rupes habitans: Gardner, Oct. 1838. Coll. No. 39.

B). roseo ex auct. proximum sed gracilius, theca angustiore ad insertionem pedunculi attenuata, horizontali haud pendula et pedunculo semper solitario differt.

7. Br. grandifolium C. Müll.; caulis elongatus erectus subsimplex; folia inferiora distantia, superiora in rosulam congesta patentia elongate obovata apiculata subimmarginatu subdenticulula; thecae subbinac inuernales lineari-obocatae cermue subapophysatue, operculo conico acuminulato. $f$.

Mnium grandifolium Tayl. Lond. jour'm. of bot. 1847. p. 336.

Putria. In Andibus Quitensibus, monte Pichincha: W. Jameson. Oct. 9. 1827. et Nov. 1816.

Bryo roseo ex auct. animady. proximum, sed differre dicitur caulibus magis tomentosis et elongatis, foliis magis marginatis subintegris et theca longiore angustiore. Inflorescentia forsan dioica.

8. Br. cinclidioides Blytt. (in schelulis!); dioicum; elongatum parce ramosum; folia caulina inferne remota, apicem versus densiora lato-ovalie vel oblongu rel suborbicularia, retis cellulue inde a nervo in seriebus obliquis positue, longinsculo-rhomboidules tenues, utriculo primordiali maxime eroluto moreditue, cellulue marginales angustiores longiores in seriebus circularibus positue, folia igitur submarginata, remole denticulata, rel integerrima, apice ubtuse vel emarginata vel brevissime acruminata, nervo basi crasso tenuiter evanescente flavo; perichaetia- 
lia spathuluta minora plus minus acuminata; theca plerumque solitaria longipedunculata ocalis crussu brevis pendulu operculo convexo apiculato; peristomium internum Weberae mnivideum exappendiculatum robustum.

Mnium cinclidivines Hüb. (non Blytt, ut dicit Br Europ. Fasc. 31. Stupl. Mnitu, p. 6.) Muscol. Germ, p. 416. et Br. Lurop. Hasc. V. p. 34. to 14 .

Patria. Norvegia, ubi primus omnium detexit Blyt t non $I$ übener mendax, in paludosis Nordlandiae: in Hedemarken, Kommerige et Ringeriget; Suecia in palude umbroso sylvae Sunerstaskag supra Wårdsätra ditionis L'psaliae: Lindgren; Finlandia ex Angström et in monte Meissner Germaniae, ut ex hb. Ifampeano elucet. E rarioribus.

Planta mascula tenerior, flore discoideo foliisque perigonialibus e basi ovata concava ligulato-ovalibus, interioribus quadrato-obovatis brevissime apiculatis minoribus nervosis, paraphysibus mnioideis apice subclavato-articulatis. - Planta ex habitu omnino mnioidea, e. gr. formis majoribus Mnii menctuti haud dissimilis, sed foliorum areolatione Bryum verum et a Mniis toto coelo distans. E distinctissimis.

9. Br. Decaisnei Dz. et M. (Muse. Archip. Ind. p. 19. t. 9.); divicum; caulis e basi ascendente radiculosa erectus subnudus simplex subhumilis, e coma prolificans; folia in comam rosaceam pattulam congesta, inferioribus adpressis majora, spathulato-ovata acuminata, versus apicem plicatum reflexiusculum remote denticulata. margine e cellulis Aluris densissimis elongatis incrussute et luto-marginatu, basi infima margine subreflexa, superne plana, e cellulis minutis densis incuibus firmis basi laxioribus areolata; nervo tenui excurrente breviter cuspidata; theca cylindricu angustu currulu subnutans, ore dilatato, operculo brevi conico obtuso; peristomii dentes interni membrana alla brees valde hiantes, riliis termis inermibus interpositis.

Br. conicum cor, in Ann. d. sc. nat. 1814. p. 300. 
Putrie. Java ad fissuras corticis arborum putrescentium montis summi Gédé.

Pl. mascula gracilior apice amoene rosulata inferne nuda, foliis ovatis cuspidatis haud spathulatis minoribus. Ab omnibus congeneribus theca angusta cylindrica atque habitu pusillo facillime distinguitur.

Sectio 1I. Eubryum. Plantae dense et late cespitosae plerumque tomentosae plus minus clatac saepe muioideae. Folia latoovalia basi vel omnino margine distincte revoluta, e cellulis latis (haud laxis), chlorophyllosis vel utriculo primordiali instructis areolata, nervo basi crassiore praedita, theca forma pyriformi variabili inclinata horizontalis vel pendula.

1. Folia apice caulis densiora in rosulam congesta lata. Plantae elatae.

10. Br. Mexicanum C. Müll.; dioicum; densiusculocespitosum, basi compactum, superne laxe cohaerens, pluries proliferum, rosaceo-foliosum, imnoutionibus crassiusculis oroideo-comosis dense foliosis binis praeditum, rigidum erectum subhumile; folia dense imbricata e basi oblonga saepe constricta ovato-acuminata, nervo crasso viridi cxcedente crasso-cuspidata, margine medio folii retlexa, cellulis densis viridibus plus minus pellucidis areolata, integerrima; perichaetialia interna longius cuspidata e basi latiuscula perfecte lanceolata, intima multo minora lata planiuscula subito acuminato-cuspidata crenulata excurrentinervia; theca in pedunculo stricto breviusculo pallescente gracili subapophysata, operculo convexo-conico minimo; peristomium Brachymenii.

Bruchymenium Mexicanum Mont. Ann. d. sc. nat, 1838. IX. p. 54. - Br. erectum Hook. in Kunth. Nym. PI. Aeq. 1). 58? et in Brid. I. P. 626. theca cylindracea elongati suberecta ut in $\mathbf{B r}$. elongato.

Putria. Ad terram in prov. Oaxaca regni Mexicani: Andrieux. Br. erectum leg. If umboldt el Bonpland in locis excelsis apricis temperatis pr. Arjo r. Mexicani, alt. 1000 hexapod.

Ex habitu caulium prolificantium Campylop. medico haud dissimile. 


\section{Br. Canariense Schwägr. (Suppl. III. I. 1. tab.} 204.); dioicum; laxe cespitosum reluti molifero-vermosum; folia inferiora remota, superioru in rosulam densum siccitate gemmiformem congesta, erecto-patentia hutul tortilia rigille, ovato-acuminata lata, margine revoluta, apice dentata, nerro in mucronem rigidiusculum producto, intense riridia concava, e cellulis densis firmis statu cmolliendi mollioribus composita; theca obconico-pyriformis in pedhuculo superne aveunto pendula fusca, operculo convexo breviter apiculato pulcherrime anvantiaco rel purpureo nitido.

Brid. I. p. 672. - Br. Billardierii Bryol. Europ. I. c. p. 58. t. 26. et De Notaris, syllab. Musc. p. 131.

B. Aluccidum; caulis coma foliosa minus densa sed flaccida, folia e basi longius oblonga parum torta, inferne

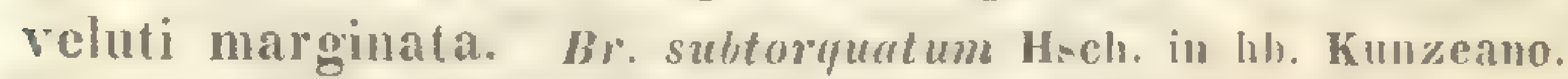

Pulriu. In gramineis arenosis insulae Teneriffae: Rudley detexit. Prope Pirano Istriae et in monte Santo Sardiniae: Fr. Müller; Romac ad Colossaeum: Friedrichsthal. Prom. b. spei: Feklon, Mundt ropiose legerunt. Var. $\beta$. pariter loc. iisdem ad Groodvaterbosch: Ecklon. Septbr. Octbr:

A Bryo copillari proximo notis cursive impressis diversissimum; a Br. Billurdierii foliis stricte mucronatis rigidis et thecae forma distat.

12. Br. Bullardierii Schwägr. (Suppl. I. II. p. 11 5. t. 76.); caulis mediocris bifidus; folia inferiora remota, superiore in rosulum congestu concava carinata patula oblonga oblipue cuspidatu absyue margine notabili (igitur ex auct. immarginata), siccitate undulutu of puulum complicutu, apice dentata, amocne viridia, nervo crasso ferrugineo in mucronem producto; theca in pedunculo fuscobrunneo apice ad horizontem eurvato oblonga incurre of per curcaturam pendula, ore vix contracta fusco-brunnea, operculo plano-comexo mucromulato concoluri. $\div$.

Brid. I. P. 667.

Putria. In Novo Belgio: La Billardiere.

A $\boldsymbol{B}$ : conpilluri proximo notis designatis differt. 
13. Br. campylothecimm Tayl. (Lond. journ. of bot. 1816. p. 52.) ; caulis cespitosus erectus ramosus, basi tomentosus, apice incrassatus, folia in rosulam aggregata erecto-patentia, siccitate adpressa atque paululum torta, oblongo-orata acutiuscula murginata, apice serrulata, nervo in mucronem elongatum excurrente; theca ex apophysi angustiare ovato-cylindracea incurva, operculo conico mammillato. $\leftarrow$.

Patria. Nova Hollandia ad fl. Swan River: J. Drummond.

Differt a Br. Billardievii Schw. foliis magis concavis longius acuminatis et latius areolatis.

14. Nr. leptothecium 'layl. (Plytologist. 1814. No. 41. p. 1091.); laxe cespitosum erectum e basi perichactii innorationibus paucis ramosum, inferne subnudum, superne dense foliosum, humiditate stellatum; folia obovata oblique cuspidala marginata dentata sicca torta, madefacta recurvata et stellato-posita; theca in pedunculo apice curvato lineavi-oblongre currete, operculo conico acuminulato. $\%$

Potria. Norfolk insula: A llán C'unningliam. Nova Seelandia: Menzies 1814.

Br. Billardievii differt: foliis immarginatis atque theca pendula oblonga. A $\boldsymbol{B} r$. cumpylothecio nervo foliorum breviter execlente et theca e basi tenui curvata sensim incrassata distat.

15. Br. truncormm Brid. (Mant. Musc. p. 119.); dioicum; apice innovationibus paucis brevibus stellatofoliosis ramosum; folia caulina e basi breviter oblonga lato-ovalia acuminata, nervo tenui excurrente purpurascente longe et acute cuspidata, e busi usque ad apicem cellulis angustissimis latissime marginatu, apice simpliciter argute sed tenu-servulatu, e cellulis minutiusculis sed angustis utriculo primordiali plus minus plicato et conspicuo praeditis composita; perichactialia perfecte lanceolata, nerro basi crassissimo apicem versus crasso fusco excurrente longissime cuspidatu concara marginata, 
remote denticulatu, longius et angustius ureolatu; theca solitaria longipedunculata clongato - cylindrica inclinata, operculo conico acuto brevi.

Mnium giganteum Schwägr. Sp. Musc. p. 28. ex parte. - Bryum Polla truncorum Brid. 1. p. 699. - Br. roseum $\beta$. Domingense Brid. I. p. 698 !

Patria. Insula Bourbonis in sylvis editioribus ad pedem truncorum muscosorum: Bory St. Vincent.

Species notis distinctissima.

16. Mr. Ehrenbergianum C. Müll.; dioicum; laxe respitosum clatum ascendens, apice imorationibus comphribus romosum robustum; caulis crassus usque ad apicem tomentosus, foliis torymescentibus deuse foliosus; folia caulina e basi breviter oblonga latiusculo-acuminata, apice undulato, nervo flaro decurrente et ultra apicem breviter excurrente cuspidata, inferne margine revoluta, anyuste et flaro-marginata, superne remote et flaro-dentata, e cellulis submagnis, utriculo primordiali parietis instar evoluto praeditis, vivilibus composita; perichaetialia longiora angustiora pellucidiora apice madefacta magis torta; theca longipedunculata humiditate inclinatopendula e collo breviusculo elongalo-cylindriea subincurva fuscidula, operenlo conico acuto brevi atro-merpmero; perist. Bryi.

Patria. Mexico: C. Ehrenberg.

Hx habitu speciminibus majoribus Bryi toryuescentis hand dissimile sed multo robustius et altius.

17. Br. Neelgheriense Mont. (in litt.); dioicum; laxe cespitosum elatum plus minus erectum, apice innovationibus compluribus ramosum robustum; caulis crassus usque ad apicem tomentosus, foliis subtoryuescentibus densiuscule apice subrosulato-foliosus; folia caulina e basi breviter oblonga latiusculo-acuminata, apice re/lexo, nervo inferne purpurascente apice pupureo decurrente et ultra apicem longinsculo-excurrente cuspidata, inferne margine revoluta, latiusculo- ot purpureo-marginata, superne purpureo-et arguto-serrata, e cellulis submagnis, 
utriculo primordiali parietis instar evoluto serpentinoAexuoso praeditis, subuallidis composita; perichactialia angustiora longiora pellucidiora stricta longe cuspidata; theca in pedunculo elongato flexuoso gracili peudula, e collo breviusculo elongato - cylindrica fuscidula; perist. Bryi.

Putria. In montibus Nechgeriensibus: Perrottet. Br. Ehrenbergiano ex habutu simillinum, sed notis cursive impressis distinctissinum.

\section{$0 \mathrm{bscuriora.}$}

18. Br. andicoln Hook. (Kunth, Srnops. Pl. Aeq. p. 58.); caule breriusculo; foliis patentibis obovato-oblongis, marginatis apiculatis, apice serratis, nervo excurrente; theca cylindracea cermua. i.

Brid. I. p. 667.

Putria. In frigidis 'Toluccae et Islahuacac, alt. 1330 hexapod., regni Mexicani.

llabitus Bryi cupilluris, sed caules longiores, folia ad apicem evidentissime serrata, non pilifera. - $\boldsymbol{B r}$. Ehrenbergiano affine?

2. Folia ratula lareimbricata. Plantae longiscentes plus minus mnioideat.

19. Br. pallens Sw. (Musc. Suec. 1. 47 et 98. t. 4. f. 12.); dioicum; laxe cespitosum, inferne valde radiculosum, ramis gracilibus plus minus elongatis electis, foliis remotis pancifariis rufescentibus, erecto patentibus decurrentibus ovato-acuminatis, nervo crasso purpurascente mucronatis, semper anguste marginatis, apice denticulatis, margine basi subrevolutis, e cellulis majusculis utriculo primordiali valde conspicuo praeditis viridibus mollibus compositis; folia perichactialia longius cuspidata longiora anerustiora subflexuosa, interiora minora evanidincrvia; theca in pedunculo elongato purpureo oboneto - rel clucolomyriformis longicolle incurre, mulars rel pendula ore hand rel iror ronstrictu; pallida, operculo conien breviter acuminato laevi nitente, dein fusco-brunnere loevis nitens; perist. Bryi. 
Bryol. Europ. 1. c. p. 68. t. 33. - Brid. 1. p. 642. quod hls. ex parte! - Br. turbinatum Hook. et Tayl. Musc. Brit. p. 122. ex parte. - IIynum pallens Web. et Mohr. Bot. Taschi. p. 286. Br. speciosum Voit. Sturm. Fl. Germ. Crypt. Fasc. 14. theca aequali subclavata ore angustiore. Br. Eur. 1. c. p. 69. et Brid. 1. p. 666. Bo. elegans Grev. Trans. of Linn. Soc. XV. p. 344. t. 3. f. 5.?Br. obscurum Sendtn. in sched., Ptychostomum cernuum Hïb. Muse. Germ. p. 493; e spec. Sendtnerianis peristomio, ut videtur, obsoleto. - Br. attenuatum Brid. 1. p. 638. e sudetis huc pertinet.

Patriu. In locis paludosis saepe una cum Br.turbinuto associatum per totam fere Europam e planitiebus usque ad alpes ascendens. - Aestute.

Bryo turbinato, quocum saepe commutatum, simillimum, sed thecae serius maturae forma distat.

20. Br. bimum Schreb. (Spic. Fl. Lips. p. 83?); hermaphroditum; laxe et late cespitosum humile vel elongatum, innovationibus erectis plus minus dense foliosis ramosum; folia decurrentia patentia ovato-lanceolata majuscula carinata, nervo crasso flavo flexuoso purpureodecurrente excedente mucronato-cuspidata, margine basi usque ad apicem subdenticulatum revolutu submarginctu, e cellulis densis viridi-pellucidis subparvis amoene arcolata; perichaetialia intima angustiora magis revoluta longins acuminute haud cuspidate; theca in pedunculo elongato crassiusculo purpureo apice arcuato pallidiori pendula ovato-pyriformis plus minus elongata, pallida dein fusca, operculo majusculo conico brevissime acuto laevi subnitido; perist. Bryi.

Bryolog. Europ. Fasc. 6-9. p. 50. tab. 21. - Br. pseudotriquetrum Brid. et al. ex parte. - Webera affinis Bruch in Brid. I. p. 848. - Bryum hybridum Bruch in schedulis. - Pohlia paradoxa Hüb. Musc. Germ. p. 479. e spec. hb. Göppertiani luc perlinet.

Patria. In locis humidis prime turfosis ad terram et rupes totius Europae atque Americae septentrionalis. Ad finem veris et aestate.

A $\mathbf{B r}$. pseudotripuetro inflorescentia hermaphrodita, innovationibus gracilioribus et cespitibus laxioribus differt. In locis siccioribus plantac valde humiles et magis cespi-

C. Mulle: Synops. musc, frond, 
tosae et Bryo pullescenti similiores reperiuntur. Flores exacte feminei interdum, sed steriles, occurrunt. Peristomii dentes interni latissimi densissime trabeculati et maxime hiantes subrugulosi cilis $3-4$ longissimis robustis appendiculatis interjectis.

21. Rr. pseudotriquetrum Hdw. (Sp. Nusc. p. 190.); dioicum; densiusculo-cespitosum elongutum, habitu et foliis Bryo bimo perfecte simile; folia perigonialia lato-orulia subito longiusculo-acuminata reroluta, interiora evumidinervire vix revolutu; theca Bryi bimi semper elongato-pyriformis; perist. Bryi.

Br. Europ. 1. c. p. 54. tals. 24. - Brid. I. p. 676. partim luce, partim ad Bryum bimum pertinet. - Mnium psendotriquetrum Hdw. Musc. Fr. IIl. p. 19. tab. 7. ex parte, - Br. ventricosum Dicks. Fasc. I. 4. et mult. al. - Br. cubitule Dicks. Fasc. II. t. 5. et Brid. I. p. 677 ex parte. - Br. subobliquum Lindyr. Bot. Notis. 1842. p. 118. - Cognitionem Bryi limi et pseudotriquetri anctores plurini quam maxime confucam fecerunt adeo, ut synonyma vix recte intellipi possint. In herbario e. gr. Brideliano sub nomine $\mathbf{B r}$. pseudotriguetri, Br. bimum, Schleicheri, uliyinosum, alpinum quin etiam Mnium hormum et alia Brya reperiuntur. - Synonymia autem schüïgricheni in sp. Musc. sul Br. ventricoso p. 54 data maxime dubia est.

Putria. In locis humidis praeprime turfosis cum $\boldsymbol{B}$ r. bimo per totam Europam atque Americam septentrionalem usque ad alpes ascendens. - Tere, aestate.

Br. bimo locis uliginosis enato proximum.

22. Ix. Neodamense Itzigsohn (in Regensb. Fl. 1841. I. p. 360.); divicum; dense cespitosum et tomentosum subclongatum; caulis ruber inferne nudiusculus, apice dense foliosus; folia inferiora minora orbicularia, sen oblonga rotundato-obtusissima, apice involuto, alveato-concula, nervo crasso tenuiter usque ad apicem evanescente intense purpureo, e cellulis minutis quadrato-rhomboideis apice minoribus pellueidis arcolata, margine involutaceo, late et Aluv-maryinata, superiora majora amoene lutescentia, suprema in comam veluti truncutam congesta, e basi haud decurrente sed rentricoso-infata brevissima oblonga breviter acuta margine basi revoluta, e cellulis 
parvis firmis virdescentibus subchlorophyllosis omnino rhomboideis areolata; perichactialia seniora pellucide reliculata, intima immarginata minora lanceolata acuta; omnia integra; theca in pedunculo elongato pendula oblongo-pyriformis angusta fusca; peristomium Bryi.

Patria. Prope Neodamum Neomarchiae Germaniae septentrionalis: Dr. It $\mathrm{z}$ i g s o h n detexit, in turfosis.

Ex habitu $B r$. pseudotriquetro vel bimo affine, notis antem laudatis distinctissimum. Pulcherrima species et observationibus bryologorum dignissima. - Peristomii interni dentes in membrana alta subpallida angusti valde compressi, cilis solitariis basi fissis tenuissimis parce appendiculatis interjectis.

23. Br. turbinatum IId. (Schwägr. Suppl. I. II. p. 110.); dioicum; inferne compactum, superne ramis gracilibus plus minus elongatis cespitem laxiusculum formantibus; folia subdecurentiu remotiuscula ovato-acuminata, concava, basi margine subrevoluta, integerrima vel apicem versus denticulata, nervo crasso flexuoso flavo breviter cuspidata, e cellulis majusculis utriculo primordiali valde conspicuo praeditis viridibus mollibus composita; perichactialia magis acuminata; theca in pedunculo stricto purpureo apice tenuissimo perfecte pendula crasse ventricoso-pyriformis ore valde constrictu pallida, operculo conico mamnilla aurantiaca praedito subconcolori lutescente nitente, dein aperta fusca vel purpurea; perist. Bryi.

Bryol. Europ. 1. c. p. 65. t. 32. - Brid. 1. p. 681. - Bryum palustre complicatum rubens, capsulis turbinatis pendulis. Dill. Muse. p. 406. t. 51. f. 74. - Mnium turbinatum IIdw. sp. Masc. p. 191. - Hypnum turbinatum Wel. et Mohr, Bot. Taschh. p. 282. - Br. ni!picans Dicks. Fasc. IV. P1. Cr. p. 15. tab, 11. f. 10. et Brid. I. p. 6×2. ex Hook, et Tayl. Musc. Brit. p. 122. - Mnium nigricans Brid. Musc. Rec. II. III. p. 90.

ק. proelongum; laxe cespitosum, caule ramisque elongatis basi radicantibus, ramulis innovationibus similibus, e coma nascentibus, foliis remotis teneris pallide viridibus, theca majuscula ventricosa. Br. Eur. 1. c. - Br. schlei- 
cheri 3. tenerius Schwägr. Suppl. I. II. p. 113. - Br. glaciale Schl. ex parte; ibid.

$\gamma$. latifolium; procerum, cespites ingentes nitidos efficiens; caule elongato, fructifero declinato, innovationibus ramulisque erectis basi radicantibus robustis, foliis majoribus late ovato-acuminatis ralde concaris subimbricatis solidioribus nitidis conspicuo-marginatis, nervo in acumen breve producto; pedunculo basi geniculato, theca magna. Br. kur. I. c. p. 66. - Br. schleicheri Schwäщr. Suppl. 1. 11. p. 113. tah. 73. - Brid. I. 1) 683. ex parte. - Mnium Intifolium schleich. mst. - Bryum Polla latifolia Brid. I. p. 710.

Putril. Ad saxa et terram humidam in locis paludosis e planitiebus usque ad nires alpium ascendens per totam Europam haud rulgare occurrit. In monte Sinai: W. Sc himper. In Himalayae monte Kamoun: Jacquemont. Var. $\beta$. in subalpinis et alpinis, ubi ad scaturigines atque nives aeternos cespites longe et late extensos efficit sed rarius fructificat. Var. $\gamma$. ad fontes frigidos et rivulos alpium editiorum 'lirolis, Ilelretiae, Scandinaviac ct Pyrenaeorum.

Planta mascula femineac intermixta rel gregaric crescens gracilior, flore gemmiforni foliisque lato-ovalibus breviter acuminatis evanidinervibus. - Śpecies polymorpha et formis majoribus $\beta$. et $\gamma$. speciosissima, thecae forma primo intuitu discernibilis.

24. Rr. Duvalii Voit. (Sturn Deutschl. Fl. Crypt. Fasc. 12.); dioicum; laxe cespitosum, maxime elongetum, gracillimam remotifolium; folia ovato - acuminata, maxime decurrentia, nervo ante apicem exanido, tenuissime marginata, ut in Bryo turbinuto arcolata, emollita cyanescentia; perichaetialia intima minora lanceolata; theca longipedunculata, forma Bryi turbincti sed minore; perist. Bryi.

Bryolog. Europ. 1. c. p. 64. t. 31. - Brid. I. p. 679. - Mnium Duvalii schwägr. Suppl. 1. 11. p. 126. tab. 179. - Br. ventrieosum var. Sclıwägr. \$p. Musc. p. 54.

Patriu. In locis humidis, pratis uliginosis prope Ratisbonam, ubi primus legit Duval; in Carinthiae alpe 
Pasterze: Funk in hb. Brid. in Silesia, Franconia, Thuringia, Sylva nigra, Vogesis, Norvegia, Finlandia et in Terre Neuve. E rarioribus! - In depressis inemite aestute, in montosis Angusto, Septembri. Raro fructificat.

Planta mascula femineae similis, flore gemmaceo. Bryo turbincto simile quidem, sed caule foliis decurrentibus alato ab codem ceterisque congeneribus maxime differt. Specimina Carinthiaca multo minora densius foliosa, apicem versus crescentia.

25. Br. gracilescens C. Müll.; dioicum; elongutum grucillimum laxe cespitosum apice innovationibus gracillimis ramosum vulde remolifolium, caule purpureo substricto; folia caulina oblongo-lanceolata acuminata longiuscula subangusta medio paullo latiora, nervo infernc purpureo superne flavo et tenui-excurrente brevi-cuspidata, e busi uspre ad apicem flaro-marginutu ot dentibus flaris inaermalibus e medio argute servata carinutosubconcare, e cellulis angustis plus minus pellucidis parvis amoene areolata; perichaetialia interna multo minora angustiora lanceolata immarginata longe cuspidata; theca in pedunculo longissimo purpureo erecto elongato-cylindrica curviuscula horizontalis humida nutans pallide fusca, operculo conico acuto brevi brumeo nitido; perist. Bryi.

Mnium schistoneuron Kze. in Pl. Püppig Cliil. No. 234.

ß. densifolium; humilius igitur densifolium subtomentosum. Bryum Polla densifolia Brid. I. p. 855. e spec. - Br. Auberti schwigr. sp. Musc. p. 54, planta fertilis e spec. et Suppl. II. II. 2. tab. 195.

$\gamma$. decumbens; caule decumbente ascendente gracili; cacterum formae typicac simillimum, Br. Auberti Hsch. Fl. Bras. p. 45, t. 2. f。 1.

Patriu. Peru, Auchero: Pöppig 1829. Var. $\beta$. in Andibus: Il umboldt; in Brasiliae sylvis umbrosis ad Hio de Janeiro et Serra dos Orgâs: Beyrich. Var. $\gamma$. pr. Rio de Janciro: II a ge end orf.

Planta mascula femineae simillima, flore masculo discoideo. Folia perigonialia externa e basi lata subplicata acuminata caulinis similia, interua multo minora lato-ova- 
lia vaginantia teneriora integerrima immarginata nervo excurrente breviter cuspidata. Antheridia magna numerosa, paraphysibus longis cuspidatis cincta. Archegonia magna longe apiculata. - $\mathbf{E}$ distinctissimis et $\boldsymbol{B r}$. erythrocaulo proximum.

26. Br. erythrocaulon Brid. (Mant. Musc. p. 119.); cespitosum subhumile subsimplex subgracile; caulis erectus purpureus strictus remotifolius; folia subspathulatoacuminata medio lationa complicato-concuva, nervo decurrente crassiore excedente cuspidata, e busi usque ad apicem latius sed subindistincte flavo-marginata, margine verolutu et remote denticulata, basi multo laxius areulatu.

Mnium erythrocaulon schwägr. suppl. 1. Il. p. 127. tab. 80. Bryum Polla erythrocaula Brid. 1. p. 711.

Patria. Insula Franciae: Commerson.

Br. gracilescenti proximum, sed notis cursive impressis distinctissimum.

27. Br. Auberti Brid. (Mant. Musc. p. 119.); elatum gracile subsimplex caule flexuoso purpurascente remotifolio; folia e basi oblonga lato-acuminata nedio latiora, nervo tenuiter excurrente, e medio argute incequaliter serratu, immurginatu, inferne revoluta, superne subcomolutu, basi laxe et parallelogrammo-areolata, superne e cellulis perfecte rhomboideis utriculo primordiali valde evoluto elliptico attenuato praeditis composita.

Br. Polla Auberti Brid. 1. p. 711. - Mnium Auberti scliwïgr. suppl. I. 11. p. 132. t. 80.

Putria. Insula Franciae: Aubert Du Pelit. 'T houars.

Br. erythrocaulo prime gravilescenti proximum sed notis designatis facillime distinguitur.

28. Ir. nivale C. Nüll.; hermuphroditum, laxe cespitosum; cespites magni; caulis clongalus ascendens innovans, inferior folis nigrescentibus, superior foliis flatvescentibus, purpureus; folia caulis inferioris senioris la10-lancenlata acula firma, nerro crusso excurrente, margine cellulis nonnullis angustioribus submarginatis, sub- 
convoluta; folia caulis superioris seu innovationis multo latiora plana, inferiora oblusissima firmiora, superiora acutu membranacea, apice caulis convolutacea; omnia laxe areolata, nervo crasso plerumque excurrente basi purpureo apicem versus flavescente; perichaetialia longiusculo-cuspidata; omnia apice interdum subdenticulata.

Patria. Chile australis in rivulis niveis in jugis Andium inter montem ignivomum Antuco et la Sierra vellada. Muscus omnium altissime in Andibus crescens: Pöppig, 16. Febr. 1829. IHb. Kunzeanum.

Br. turbincto var. Schleicheri proximum, sed inflorescentia hermaphrodita et foliorum forma sat differt. Antheridia et Archegonia magna paraphysibus robustis coloratis mixta. Seta elongata tenuis. Cactera desunt. Species pulcherrima.

29. B1. Migidum C. Müll.; dioicum; erectum breve simplex innovans, inferne remote, superne dense foliosun, comam laxam formans; folia erecto-patentia, inferiora minora latiora, superiora oblongo-lanceolata canaliculata marginata serrato-dentata, nigro-viridia in innovationibus jurenilibus amoene viridia, nervo rufo excurrente, e cellulis parvis et angustis areolata; perichaetialia in rosulam parvam congesta patentia oblonga, interiora minora lanceolata argute serrata, intima minuta tenera ovatoacuminata concava obtuse serrulata subdiaphana, omnia nervo valido excurrente, e cellulis subquadratis reticulata; theca in pedunculo solitario erecto apice incurvo purpurascente superne flavescente nitido pendula, oblongocylindrica brunnea laevis, operculo convexo brevissime apiculato purpureo. t.

Hnium rigidum Hsch, in Fl. Bras. Fasc. 1. p. 46.

Vutriu. Monte Video Brasiliae: Sellow.

Peristomii dentes externi apice hyalino bifidi, interni in membrana lutescente pertusi, ciliis brevioribus interpositis. Cui affine? Br.gracilescenti? 
3. Foliadense imbricata. Plantuehumiles innovationibus tantum gracilescentes.

\section{a. Peristomium Acidodontii.}

30. Br. megalocarpum Hook. (in Kunth. Syn. Pl. Aeq. p. 59.); divicum; caulis elongatus inferne tomentosus innovationibus ramosus; folia patenti-erecta ovala integerrima, e nervo excurrente pilifera laxius areolata; theca longe pedunculata orata horisontulis longicolla clavata majuscula, operculo alte convexo apiculato.

Acidodontium Kunthii Schw. II. II. p. 15̃2. t. 196. - Negalangium Kunthii Brid. II. p. 29. in ic. sub Macrothecio; tals. supp. III.

Patria. In crepidinibus Andium, inter Tulcam el Quito, ubi Humboldt et Bonpland densissime cespitosum legerunt.

Icones dentium externorum a Bridelio recte latere lamellosac, a Schüigrichenio false clamellosac, interni peristomii a Bridelio et Schwrigrichenio ex parte rectac delineatae sunt. Primus cilia interposita recte cognovit, sed dentes male depinxit; secundus dentes recte delineavit, sed cilia interposita praetervidit. Peristomium a Bryis ceteris typice non refugit. - Flos masc. terminalis gemmaceus, folis oblongis breve acuminatis evanidinervibus, intimis enervibus.

31. Hr. seminerve C. Müll.; dioicum; longius, densc cespitosum; folia crecta ovato-lanceolata (cuminutu subintegra seminervia; pedunculus clongatus apice decurvus; theca pyriformi-clacetu horizontalis, operculo hemisphuerico, peristomio albido. 't.

Acidodontium seminerve Hook. et Wils, Isond. Journ. of bot. 1846. p. 451. to 16. J.

Patria. In sylvis Andium, ubi in monte Pichincha fructu immaturo legit Prof. W. Jameson.

Folia nitenti-viridia subpilifera siccitate non crispala.

32. Hr. Taylori C. Mïll.; caulis cespitosus crectus subramosus; folia laxe imbricata crecto-patentia, siccitate torta, ovato-oblonga longius apiculatu, upice serru- 
lata marginatu, nervo percurrente; pedunculus elongatus apice decurvus; theca ex ungustu busi subrotunda, opercule conico brevi. t.

Acidodontium subrotundum Hook, et Wils. Lond. Journ. of bot. 1846. p. 451. (al). 16. H. - Brachymen. subrotundum Tayl. I. c. p. 56 .

Putrie. In monte Pichincha Andium pr. Quito: W. James on, 1826. Febr.

Ex ic. Cl. Wilsoni Acidodontium verum, ex habiu praccedenti simillimum, notis autem distinctissimum.

\section{b. Peristomium Brachymenii.}

33. Br. Montagneanum C. Müll.; dioicum; dense cospitosum ascendens robustum, ramis brevibus erectis dense foliosis acutis, folia ramorum e basi oculi perfecte lanceolata majuscula robusta, nerro crassissimo rubro excedente crusso-cuspidutu, margine revoluta, apice inaequalia subdenticulata, lurido-viridia, perichactialia caulinis similia apice aequalia; theca in pedunculo elongato purpurascente ascendente pyriformis crasso-rlavata longicolla ochracea nitida pendula, operculo hemisphaerico mammillato.

Brachymenium pendulum Mont. Ann. d. sc. nat. Tom. XVI. 1841. p. 254.

Putriu. In terra nuda ad imos arborum truncos sylvarum humidarum prope Dodabett Indiae orientalis Neelgheriensis: Perrottet.

Perist. dentes externi ultra medium trabeculati fusci, apice cellulosi, cellulis moniliformi-articulatis pellucidis; membrana interna lutea in cilia obsoleta vel irregularia divisa. - Br. alpino maxime simile, sed e peristomio jam distans.

34. Rr. Abyssinieum Br. et Sch. (Musc. Abyss. Schimp. II. No. 434.); hermaphrulitum; dense cespitosum humile apice comoso-densiusculo-foliosum; folia e basi oblongà ovata latiuscula minutiuscule et densiusculoareolata, nervo tenui excedente brevi-cuspidala, latiusculo-marginata, apice exacte denticulata caviuscula; pe- 
richaetialia angustiora; theca cylindrico-pyriformis, aperta nutans angusta longicolla, operculo umbonato-apiculato.

Br. (Brachymenium) Abyssinicum Br. et Sch. I. c.

Patria. In Abyssiniae monte alpestri Silke, ubi 20. Febr. 1810. legit W. Sehimper.

Dentes peristomii externi longi cuspidati tenues valde trabeculati laeves, humiditate usque ad thecae membranam reflexi; membrana interna alta in dentes breves luteos vel apice hyalino-membranaceos producta.

35. Br. flexifolium Br. et Sch. (Musc. Abyss. Schimp. II.); dioicum; (leusiusculo-cespitosum robustum humile laxe foliosum; folia e basi oblonga lato-oralia concava siccitute torquescentia, margine hic illic revoluta, plus minus lato-marginatu, basi purpurascentia, apice denticulata, nervo excurrente purpurascente breviter cuspidata, apice minute et dense basi laxius areolata, inferiora apice flexuosa angustiora; perichactialia intima multo minora angustiora ovato-lanceolata immarginata nervo excurrente cuspidata tenera integra; theca c collo longiusculo pyriformis ore constricta, aperta nutans, operculo conico acuto brevissimo.

Br. (Brachymenium) flexifolium Br. et sich. 1. c.

Putria. Abyssinia: W. Schimper.

Dentes peristomii exterui humiditate subreflexi et medio subgeniculato - inflexi angusti, dense trabeculati rubri; membrana interna subalta, dentibus obsoletis ciliis solitariis interdum interpositis.

\section{c. Peristomium Ptychostomi.}

36. Br. cernumm Br. et Sch. (Br. Europ. Bryum; p. 14.t. 1.); hermuphroditum; compacte cespitosum humile ramosum, ramis ascendentibus dense foliosis apice incrassatis; folia caulina patula lato-ovalia, nervo crasso plus minus flexnoso excedente longe cuspidata, margine revoluta, carinato-concava, integerrima vel apice denticulata; perichaetialia caulinis similia; theca in pedunculo crasso rigido clcuto-myriformis crussinscula, siccitute ore cocercuta pendula, operculo parvulo convexo acuto; 
peristomii dentes externi lati lanceolati, interni externis adglutinati subulati perforati rugulosi in membrana brevi firma positi, ciliis inermibus interpositis.

Br. Europ. I. c. - Brid I. p.600. - Cyuontodium cernum Hdw. Sp. Muse. p. 58. t. 9. - Cynodontium cernum sichw. Nuppl. 1. I. p. 110. - Cynodon cernus Brid. Mant. Mnsc. p. 99. - Didymodon cernuus sw. Musc. suec. p. $2 \times$ et 83. tab. 1. f, 2. Suartzia cernua Poir. - s'w. raliculosa Hcdw. sen. non fil. e Schwägr. sp. Musc. p. 77. sub) nom. Ptychostomi radiculosi Brid. I. p. 83\%. - Ptych. pendulum Hsch. in Regensh. bot. Zeit. 1822. Syll. I. p. 64. et Brid. 1. p. 837. ex ejus spec. auth. pariter huc revocandum est. - Ptych. compactum Hsch. 1. c. p. 62. et Brid. I. 1. 598.

Patria. Per omnes regiones totius fere Europac, societate Bryi inclinati et cespiticii, quibuscum saepe commutatum. - Aestatis initio.

A Br. inclinuto et cespiticio primo intuitu theca, operculo conico acuto sensim acuminata distinguitur.

37. Ex. Gayanum Mont. (in litt.); hermaphroditum; compacte cespitosum, clongatum gracile, innorationibus gracilibus erectis dense foliosis ramosum, luteo-viride; folia oblongo-acuminata, nervo flexuoso crasso ferruginco basi purpurascente decurrente cuspidata, elongata, c basi usque fere ad apicen margine reflexa, e cellulis submagnis basi laxioribus superne utriculo primordiali tenerrimo flexuoso plus minus praeditis areolata, apice obsolete denticulata; lloralia intima multo minora latiora ovata subito acuminato - cuspidata cxcurentinerva crenulata; theca in pedunculo stricto apice paulum inclinato nutans vel pendula minuta vix myriformis overtis mullida, ore non constricta, operculo depresso apiculato aurantiaco; peristomii dentes externi angustissimi subulati, interni in membrana fugacissima diaphana ciliiformes externis alylulinati fugrecissimi.

Patria. Chile: Gay.

Bryo lacustri of cemmo proximum, sed notis illustratis praceipue peristomio distinctissimmm.

38. Ir. Melvilleanum C. Müll,; folia oralo-lauceolata acuminata integerrima, theca sphaerico-obovata, 
operculo hemisplacrico mutico, dentibus peristomii exterioris apice liberis basi mediante membrana colaerentibus. $f$.

Ptychostomum pulchellum R. Br. App. ad It. Parrayan. p. 197. et in Brid. 1. p, 601.

Patria. Insula Melville.

Cui affinc?

\section{d. Peristomium Pohliue.}

a. Inflorescentia hermaphrodita.

39. Br. Iacustre Bland. (in Brid. Musc. Rec. p. 121.); gregurium vel laxe cespitosum plus minus elongatum, inferne tomentosum, gracile, basi remotifolium superne subcomosum, innorationibus brevibus gracillimis ramosum, umoene lutéscens, caule purpureo; folia inferiora ovatoacuminata, superiora ovato-lanceolata, veulde concura, margine basi valde superne paulum revoluta, integerrima, nere plerumque in apicem brevem excurrente, e collulis subparvis densis incenibus pellucidis areolata; floralia intima multo minora longe cuspidata; theca in pedunculo elongato gracili flexuoso purpureo pendula pyriformi-vicalis pare crassinscula, firme membranacea, ore dilatuta, fuscescens, operculo pareulo concexo apiculato.

Br. Europ. I. c. p. 16. t. 2. - Br. Webera lacustris Brid. I. 1) 637. - Br. cernuum Brid. 1. p. 851. suh nom. Hohline cernume Bruch in hl,. Bridel. - Mnium lacustre Bland. Musc. exs. Fisc. 3. 11. 132. et in Sturm Fl. Germ. Crypt. Fasc. 10. - Myjnum lacustre Web. et Mohr. Bot. Taschl. p. 285. - Pohlia lacustris Hïh. Mus:. Germ. p. 483. non Bruch in Schwiigl. Sp. Musc. p. 73, - Br. cespiticium var. Hook. et Tayl. Musc, Brit. p. 121.

B. alpinum; foliis angustioribus, theca graciliore subhorizontali, peristomii interni processus angustiores, rarius pertusi. Br. Europ. 1. c. p. 16.

Patria. In graminosis humidis arena suffusis prope Waren ad lac. Müritz diet. Sept. 1804. legit Blandow; locis similibus prope Bipontem: Bruch; in Anglia, Gothia atque Finlandia. Var. $\beta$. in alpe Salisburgensi $\mathbb{P}^{2}$ sterze. - Majo, Junio. 
Br. annotino ex habitu simile, notis autem illustratis facile discernibile. Dentes peristomii interni valde hiantes, ciliis vix rudimentariis interpositis.

40. Br. inclinatum Br. et Sch. (Br. Europ. 1. c. p. 17. 1. 3.); humile compacte cespitosum innorando ramosum; folia ovato-lanceolata, longe acuminata nervo crasso viridi cuspidata, toto margine revoluta, immarginutu, integra e cellulis leniter emollientibus submagnis densis chlorophyllosis areolata; floralia intima multo minora; theca in pedunculo erecto elongato rigido brunneo pendula rentricoso-myriformis crusse reguluris brericollu fusca Iacvis, microstomu, operculo minulo conico apiculuto.

Pohlia inclinuta sw. Musc. Suec. p. 45 et 96. t. 5. f. 11. Cladorlium inclinutum Brid. 1. p. 621. - Bryum turlbinatum var. Hook. et Tayl. Musc. Brit. p. 122. - Lesken inclimuta Wel. et Molr. Bot. Taschl,. p. 244 et sul Myjm. intermedio p. $4 \times 2$. - Br. Ionyisetum Bland. in Britl. I. p. 673. et Schwägr. Suppl. I. II. p. 10J. tab. 74.

Patria. In saxis humidis et terra umbrosa per totam Luropam non rarum; e turfosis profundis planitierum in alpes editiores ascendit. - Majo, Junio.

A Br. vliginoso notis cursive impressis facile distinguitur, et habitu Br. cespiticio affinc. - Peristomii dentes interni in membrana altiuscula angusti longiusculi externos acquantes rugulosi pertusi, ciliis plus minus rudimentariis interpositis. - Species e locis uatalibus polymorpha, interdum quoque floribus dioicis.

41. Br. areticum Br. et Sch. (Br. Eur. Fasc. XXXII. Suppl. p. 2. t. 2.) ; laxe cespitulosum subliumile; folia inferiora remota late lanceolata, superiora plus minus conferta acuminato - ovalia vel lineali - lanceolata, limbo e cellulurum sericbus dubus angusturum formato ferrngineo murginutu, integra margine revoluta, nervo crasso ferrugineo plus minus excurrente in cuspidem brexem hyulinum moducta, apice subdenticulata, e cellulis laxis crussiusculis plerumine valde chlorophyllosis reticulata; folia floralia intima multo minora orato-acuminata subcrenulata evanidinervia densius arcolata; theca in pedun- 
culo breviusculo superne arcuato pendula elongato-pyriformis paullo incurve pallidu mollis, operculo parvulo, e basi humidiuscula conico manmillato subaurantiaco, peristomio parvo apice ruguloso, interno dentibus arcte adherente ciliis abbreviatis.

Pohlice areticu 1R. Br. suppl. App. ad iter Parrayan. p. 196. Hemisynupsiug areticum Brid. 1. p. 606, - Br. mutans var. Drumm. Musc. Amer. No. 263 B.

Patria. Locis humidis ad terram et in rupium fissuris regionis alpinae et subalpinae: in summo jugo inter alpes nivosas Faulhorn et Wildgerst Itretiae ef in Norvegiae alpe Dorrefjeld: Mr. P. Schimper; in Gestricia prope Gevaliam ad mare Bothnicum: 'Thedenius; in Jurassim, Chasseron: Lesquereux; Manhard in alpib. Julicis: Sendtner. In America boreali: Drummond. Julio.

Ex habitu speciminibus Bryi uliginosi ninoribus simile sed ab eo atque $B$ r. murmroscente notis illustratis diversissimum.

42. Br. purpuraseens Br. et Sch. (Br. Furop. Fasc. Suppl. XXXII. p. 2. tab. 3.); cespitosum; folia caulina decurrentia ovato-acuminata concava remotiuscula, apicem versus in comam laxinsculam congesta, comalia majora longius ucuminata subcurinutu, margine reflexa, perichaetialia lanceolata, omnia mollia purpurascentia, reticulo tenui rhombeo-hexugono, anguste marginata integerrimu, nervo in mucronem brevem producto; theca longipedunculata nutans vel pendula elongato-pyriformis aequalis brunnescens, operculo majori courexo apiculato siccitate dilatato.

Pohlia purpurascens R. Br. Suppl. App. all iter Parrayan. p. 197. - Pollia arctica B. murnurascens schw. Sp. Musc. p. 74. - Hemisynapsinem arcticum B. mopurascens Brid. 1. p. 606.

Patriu. In Norvegiae alpe Dovrefjeld, ubi praccipue prope Fogstuen in arena secus rivulum sub Sulice Lapnonum copiosissime legit IV. P. S chimper 1844. et sec. Cl. Ángström in Gothia atque Finlandia pr. Uleåborg. In Groenlandia et Labradore. 
Br. uretico proximum sed differt: plantis late cespitosis gracillimis saepe valde ramosis, foliis purpurascentibus mollioribus angustius marginatis et brevius acuminatis, theca symmetrica firmiore operculo atque peristomio majori.

43. Br. Archangelienm Br. et Sch. (Br. Europ. Fase. XXXII. p. 1. t. 1.); hermuphroditum rel dioicum; dense cespitosum; caulis brevis tomentosus frrgilis; folia longe ucuminutu concavo-carinata, margine plane rol hic illic reflexa, solo apice denticulata; nervo in aristam viridem dentatam excurrente, hexagono-rhombeo-areolata; thera Ionginsculo pedunculata obuerte rel oblonga, operculo parvo, annulo lato, peristomio brevi pallido, dentibus 15 -articulatis. $f$.

Putria. Ad mare album prope Kippinä ditionis Archangelicae: Ângström. - Acstute.

Flores hermaphroditi fertiles graciles, masculi incrassato - gemmiformes, foliis perigonialibus internis oratoacuminatis evanidinervibus. - $\mathrm{A} B$ r. purpurescente proximo differt: cespitibus densioribus tomentosis, foliis longins mucronatis haud purpurascentibus, inflorescentia polygama, theca breviore et peristomio multo minore; ex habitu modoque crescendi $\mathbf{B r}$. cemuo haud dissimile.

\section{$\beta$. Inflorescentia monoica.}

44. Br. uliginosum Br. et Sch. (Br. Europ. I. C. p. 18. 1. 4.); dense (espitosum humile, innovationibus brevibus ramosum, robustum dense et comoso-foliosum; folia caulina elongata, ovali-lanceolata longe acuminata, e cellulis angustis elongatis concoloribus latiusculo-marginata, e basi usque fere ad apicem margine revoluta subintegerrima, nervo excurrente crasso sordide viridi longe cuspidata, e cellulis submagnis chlorophyllosis viridibus firmis areolata, perichactialia intima et perigonialia multo minora immarginata tenuinervia; theca in pedunculo elongato stricto rigido purpureo urcueto-inclinatopendulu subclurato-pyriformis irregularis, pallida dein fusca nitida, collo subarcuato, ore dilatato, operculo co- 
nico parro mammillari; dentibus internis valde compressis latiusculis rugulosis externos acquantibus, ciliis rudimentariis interpositis.

Br. Furop. 1. c. p. 18. t. 4. - Pohlia uliginosa Bruch in sched. - Cladodium uliginosum Brid. 1. p. 841. - Br. cespiticium syn. schw. Sp. Musc. p. $60 ! ! !-B r$. turbinatum $v$, pallens Drumm. Musc. Americ, No. 267.

Patria. In turfosis ad Rhenum prope Karlsruhe sociis Br. inclinato, Amblyod. dealbato et Bartram. Marchicu: Cl. Braun detexit. In pratis humidis pr. Argentinam: K ı eiff. Iı Neomarchia pr. Neodamum: Itzigsohn. Gothia et Succia Scandinaviac. In Angliae nonnullis locis observatum. E Terre Neuve retulit La Pylaie. In Rocky Mountains: Drum mond.

Ex habitu $\mathbf{B r}$. intermedii et inclinati; a primo autem theca et peristomio, a secundo thecae forma facile distinguitur.

45. Br. Warnenm Bland. (in Brid. 1. p. 675.); laxe cespitosum crectum innovatione rumulis plemumpe apice flayelliferis, seu clongatis foliosis teretibus divisum, folia caulis fertilis ovato-lanceolata acuminata, nervo crasso purpurascente excedente cuspidata; margine paullum revoluta (reluti marginata), e basi ad apicem e cellulis laxiusculis summo apice obsolete denticulato densis angustis areolata; f. innovationum flagelliformium minora tenuiora evanidinervia; theca in pedunculo rigido longo stricto pendula ventricoso - pyriformis brevis microstoma interdum longicolla, operculo conico mammillari, atque peristomio longo.

Bryol. Europ. I. c. p. 20. t. 5. - Brid. 1. p. 675. - Pohlia V'arenensis sichw. suppl. 11. I. 2. tab. 236. - Bryum cespiticium $\beta$. H'arneum schwïgr. Suppl. I. II. p. 109. - H!/pnum cespiticium Wel, et Molrs. Bot. Taschlb. p. 285. ex parte, - Br. flugellure Brid. Mant. Musc. p. 118. - Pohli cirrhifer De Not. Mant. Musc. No. 9.; forma compacta valde et pulcherrime purpureo-cirrhifera, foliis deusius et minutius areolatis Jongius cuspidatis, caeterum a musco Megapolitano haud recedit.

Patria. In udis limosis fluminumque ripis Megapolitanae ditionis Sept. 1704. detexit Blandow prope Wa- 
len. In arena humida inter gramina prope Neodamum Neomarchiae Borussiac Sept. 1842. logit Itzigsohn. In spongiosis ad nives deliquescentes montis Sempronii Italiam versus: mense Aug. 1834 lg. De Notaris. In Gothia et in Lapponia.

Dentes perist. ext. longi lato - lanceolati subulati fusciduli; interni membrana dentibus adhaerens, in processus angustos parce pertusos producta, cilis plus minus imperfectis instructa. Flos masc. gemmaceus, - Br. lacustri Brid. ex habitu proximum, notis datis autem diversum.

46. Brynm Ieptophyllum Br. et Sch. (in Muse. Abyss. II. No. 451 et 460 ); laxe cespitosum humile et laxe foliosum; folia caulina siccilate torta latiusculo-oblonga, nervo excedente basi crasso apicem versus temi flexuoso longe et flare cuspielatu, majusculo-areolatu, temissime marginatu flexusu integerrima; perichaetialia pellucidiora maxime areolata; theca pro plantulae brevitate longipedunculata clavato-prriformis crassa longicolla, siccitate aperta ocluracea collo inclinante subnutans.

Putria. Abyssinia in prov. Schoata, 15. Juli 1838 c. fruct. mat. ad truncos arbor. Igt. W. Schimper.

Flos masc. in feminei vicinitate gemmaceus, foliis perin. caulinis similibus sed minoribus magis oralibus immarginatis evanidinervibus, antheridis paucis et paraphysibus vix ullis. Peristomii dentes externi latiusculi densissime trabeculati, apice albidi; interni apice secedentes subrugulosi albidi.

47. Br. Brownii Br. et Sch. (Br. Europ. Fasc. XXXII. Suppl.p. 3.tab. 4.); dense cespitosum gracile ramis compluribus elongatis gracilibus ramosum; folia innorationum subdecurrentia ovali-acuminta nervo excedente cuspidata, apice denticulata, margine revoluta, emollita cëruginosa, inferiora obtusiora, e cellulis majusculis utriculo mimordiali eulde conspicuo repletis raro flavidis inanibus composita; perichactialia omnibus partibus robustiora subinania, intima angusta longiora lanceolata longius acuminata; theca in pedunculo longo gracili purpureo anguste pyri-

C. Müller: Synops, mase, frond. 
formis longicolla pendula regularis pallida dein fuscescens, operculo e basi subtumida alte convexo apiculato, peristomio magno, processibus angustis ciliis perfectis dentibus externis athacrentibus binis conglutinatis subrugulosis.

Pohlia bryoides R. Br. App. ad it. Parrayan. p. 196. - Memisynresium bryoides Brid. 1. p. 605 et 840. Planta ex lin. Brideliano vera in Terre Nenve lecta.

Patrit. Insula Melville: Sabine. Terre Neuve: La Pylaie. Norvegia in alpe Dorrefjeld prope Fogstuen et Jerkin sociis $\mathbf{B r}$. purpurascente et Luduigii var. grucili copiose legit W. P. Schimper 1844, Julio. In Labradore prope Okak vulgare.

Flores monoici in ejusdem innovationis apice approximati; flos masculus crassiusculus triphyllus, foliis lave areolatis margine areolatis. - $\boldsymbol{B r}$. mormorascenli proximum, notis autem laudatis diversum. Foliis cyanescentibus facillime cognoscitur.

\section{$\gamma$. Inflorescentia dioica.}

48. Bryum rutilans Brid. (I. p. 684. ex ej. hb.); dense cespitosum; caulis ramosus yuum muxime frugilis; folia rufo-aenea patula rigida oralo-ucuminata concava firma minutiuscule sed dense areolata margine inferne valde revoluta, integerrima, veluti marginata, nervo crassissime purpureo in mucronem pallidiorem excurrente flexuoso; perichaetialia multo minora; theca longiusculopedunculata nutans clarato-pyriformis subincurva fusca mollis, collo angusto sporangium longitudine aequante, operculo parvo convexo-conico; peristomium Bryi arctici.

Br. aeneum Blytt in Br. Europ. Fasc. 32. Suppl. p. 4. tal. 5.

Patria. Ex insula Melville sterile lectum Bridelius descripsit; dein a Cl. Blytt in turfosis alpis Dovrefjeld Norvegiae inter Fogstuen et Jerkin raro legit. In Norregia legit quoque Cl. Lessing ad Torfield (?) pulcherrime fructiferum, - Aestate.

Colore et nervo siccitate flexuoso crassissimo atque fragilita:e caulium maxima primo adspectu facillime co- 
gnoscitur. Species memorabilis. - In axillis foliorum fila articulata oriunda. Flos masc. ignotus.

\section{e. Peristomium Weberae.}

49. Er. subrotundum Brid. (I. p. 687.); monoicum; humile cespitulosum; caulis ramosissimus, innovationibus brevibus gemmiformibus; folia imbricata oborato-acuminata, superiora oblongo-lanceolata et lanceolata, omnia concava, nervo excedente mucronata et breviaristata, margine plana, solo apice obsolete serrulata; perichaetialia minora mollia valde concava, juniora laete viridia dein purpureo-fusca, nervo nigricante; theca pro plantulae exiguitate longipedunculata nutans vel pendula, e globoso pyriformis rarius oblongo-pyriformis, brunnea, operculo parvo e basi tumidiuscula depresso-conico intense aurantiaco.

Br. Furop. Fasc. XXXII. Suppl. p. 9. talı. 9. - Br. pallescens

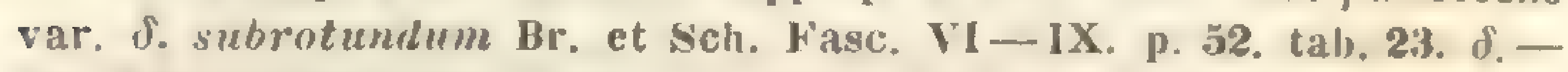
Br. brunnescens sichl. mst. - Br. pohliaeforme Brid. I. p. 687.

Patria. Ad terram humosam et in rupium fissuris alpium Tirolis et Helvetiae vix in arborum regionem descendit. - Aestate.

Flos masculus ut in Bryo pallescente. Peristomii dentes ad mediam longitudinem lineali-lanceolati, e rufo Intescentes, dehinc subulati pallide lutescentes, processus pailide lutescentes in carina valde hiantes, cilia $\boldsymbol{W}^{\top} e_{-}$ bevice.

50. Br. macropelma C. Müll.; dioicum; dense cespitosum tomentosum subhumile erectum densifolium, innovationibus gracilioribus longioribus sed tomentosis; folia crecto-patentia oblonge vel ovato-acuminata non decurrentia elongata nervo crasso flexuoso ferrugineo purpureo-decurrente longe flexuose et acutissimo-cuspidatu, e cellulis angustissimis flavis o basi fere lato-marginata integervima vel obsolete denticulata, basi e cellulis majusculis elongatis parallelogrammis apicem versus multo minoribus rhomboideis pellucidis formata; perichaetialia intima minima angustiora longius cuspidata margine in- 
ferne revoluta; theca in pedunculo quam maxime elongato substricto elongato-pyriformis rpice puello attemula ore subconstrictu pendulu mujuscula pallida, operculo majusculo conico breviter acuto aurantiaco nitido.

Patria. Chile australis in Andibus de Autuco: Poppig. Hb. Reg. Berol.

Flos masculus terminalis subdiscoideo-gemmiformis, folia perigonialia e forma perichatialium intimorum, sed immargiuata. Antherulia maxima numerosa paraphysibus longis cuspidatis flavis numerosis cincta. - $\mathrm{Hx}$ habitu Br. grucilescenti var. densifolio simile sed folis integerrimis lato-marginatis latioribus longioribus et theca maxima pyriformi longissime clongata ab eo ceterisque congeneribus recedit. $\boldsymbol{B r}$. bimi formis robustioribus ex habitu caulium atque thecae forma quorue simile, sed notis datis facile discernibile. Peristomium W'eberue magrnum, ciliis binis interjectis.

\section{O bscuriora.}

51. Br. genienlatum Brid. (I. p. 842.); caulis erectus innovando ramosus, ramis brevibus teretibus acutis, folia laxiuscula ovato-lanceolata concava brevissime mucronata subintegerrima, e lurido squalide viridia, suprema paulo lactius colorata; theca in pedunculo infra medium geniculato - flexuoso badio-purpureo superne pallidiore pendula, oblongo-pyriformis, e rubello badia, operculo convexo-obtuso submammillato; perist. Bryi cespificii. $\dot{+}$

\section{Br. Webera geniculata Brid, 1. c.}

Patria. In Tirolis montibus Schleerngebirg: Funk.

Weberum lacustrem habitu et foliorum forma atque areolatione refert; at theca nullatenus ventricoso-pyriformis elongata ut in Br. cespiticio, a quo seta in medio flexo-geniculata et intense purpurea, operculum lutescens et folia concava integerrima abunde distinguunt. - In Ib. Brideliano non vidimus. 


\section{f. Peristomium Bryi.}

r. Iuflorescentia hermaphrodita.

52. Br. torquescens Br. et Sch. (Br. Furop. Fase. VI-IX. p. 49. t. 20.); dense cespitosum apice ramosum subhumile, inferne tomentosum; folia inferiora ovato-lanceolata cuspidata, superiora ovata cuspidata, integervima vel sublenticulutu, margine reflexa, siccitate dextrorsum spiraliter incumbentia, angustissime marginata, nervo plus minus excedente; theca elongato-cylindrica magna inclinato - pendula fuscidula, operculo conico-apiculato auranticuco nitente.

Patria. In muris antiquis propugnaculi Argentinensis; iisdem locis Monspeliae, in Anglia, Hispania, Sardinia, Istria, Dalmatia, prope Snyrnam, in prom. bon. spei vulgare, in insula Chiloë et Nora Hollandia. - Junio.

E theca $\boldsymbol{B r}$. obconico, ex habitu et foliatione $\mathbf{B r}$. $\mathrm{cl}_{-}$ pillari proximum sed inflorescentia jam differt.

53. Hr. Philippianum C. Müll. (Linn. XVIII. p. 701.); compacte cespitosum; caulis breviusculus, innovationibus ramosus basi radiculosus s. tomentosus; folia oblongu angusta, longiusculo-cuspidata, aprec denticuluta flexusa s. undulata spiraliter incumbentia caviuscula, laxe areolata pellucida nervo crasso excurrente; folia floralia evenidineviar; theca longissime peduncululu oblongo-cylindricu longa pendula, operculo conico atro-purmoreo nitente; dentes externi longissimi lato-lanceolati in apicem filiformem pallidiorem rugulosum linea media exaratum producti, interni e membrana alta valde suleato-plicata compressi latissimi et majusculo-hiantes, filiformes, ciliis 3 tenuissime filiformibus nodoso-appendiculatis interjectis.

\section{Putria. Chile: Philippi.}

Antheridia basi bulboso-celluloso-incrassata stipitata magua clavata creberrima; archegonia magna numerosa, paraphysibus numerosis cincta. - Br. torfuescenti proximum, foliis autem semper denticulatis multo laxius arcolatis minus torquescentibus vix marginatis distat. 
54. Ir. intermedium Brid. (Mant. Musc. p. 120.); liunile cespitosum robustum et habitu Bryi bimi formae humilis sed gracilius; folia caulina ovato-lanceolata, nervo crasso excedente longe cuspidata, immarginata e basi usque ad apicem obsolete denticulatum vel integrum margine reflexa, angustiora; floralia intima perfecte lanceolata multo minora sed longissime cuspidata; theca in pedunculo elongato subrigido inclinato-pendula claratopyriformis inaequalis longicolla, ore aequali non constricto, brunnescens, operculo convexo-conico plus minus apiculato.

Bryol. Europ. 1. c. p. 47. tab. 19. - Br. Webera intersmedia Briu. 1. p. 632. ex herb. ej. partim ad Br. pseudotrifuetrun pertinens. - Webern intermedia schwägr. Suppl. 1. I1. p. 67. t.75. Br. pallescens schwägr. Sp. Musc. 1. 61. - Br. turbinutum val. Hook, et Tayl. Musc. Brit. p. 122. - Hypmum intermedium Wob. et Mohr. Bot. Taschl). p. 283. - Mnium intermedium Ludw. ('ent. Musc. 1. n. 81. - Pohlia intermedia Brid. Musc. Rec. 11. 111. p. 144. t. 2. f. 12. sed false delineatum.

Putria. In rupibus, muris pracprimis arcnariis et in arenosis humidis passim per Europam. - Toto fere anno thecis maturis et immaturis.

Peristomii minuti dentes interni angustissimi valle sulcati, ciliis $\mathbf{2}-\mathbf{3}$ tenuibus strictis minute appendiculatis. - A $\boldsymbol{B r}_{r}$. bimo thecae forma et peristomio longe distat.

55. Rr. cirrhatum Hoppe et Hsch. (Regensb. bot. Zeit. 1819. p. 70.); dense cespitosum plus minus elatum ramosum, ex upice arcte folioso ramulosum; caulis erectus radiculoso-tomentosus; folia erecto-patentia ovatoet oblongo-lanceolata, ramuliua latiora breviora, irregulariter carinata, margine integro c basi usque ad apicem valde revoluta, nervo crasso brunneo excedente cuspidata, minute et pellucide areolute, lamina folii in aristan denticulatam longe producta; theca breviusculo-pedunculata pendula obcunica exacte regularis, parea crassinscula, operculo mugno hemisphaerico breviter conico aurantiaco. 
Bryol. Europ. Hasc, 32. Suppl. p, 8. t. 11. - Blid. 1. p.672.Br. intermedium $\beta$. cirrhatum B1. Hurop. Fasc. 6-9. p. 47. - Br. cespiticium Schwägr. Sp. Musc. p. 59.

Putril. Locis humidis graminosis alpium Ilelvetiae, Germaniae et Scandinaviae: in Rhaetiae valle Engadin prope moles glaciales Bernina dictas una cum $\boldsymbol{B}$ r. Ludwigii et mutunte longe lateque cespitans, in summo Radstadter Tauern: W. P. Schimper; in Norvegiae alpe Dorrefjeld: Kurr, W. P. Schimper; in rupibus faucis Lueg 'Tirolis: IIornschuch et Hoppe detexerunt. Aestute.

Inter $\mathbf{B r}$. intermedium et bimum medium tenens. A primo proximo theca brevi crassa haud clavato-ventricosa primo adspectu distat. Plantarum altitudo valde variat. Peristomii dentes interni angusti valde hiantes, ciliis binis tenuissimis valde appendiculatis.

56. Br. microstegium Br. et Sch. (Br. Eur. Fasc. XXXII. Suppl. p. \%. t. 8.); humile cespitulosum, innovationibus perbrevibus gemmiformibus ramosum; folia subimbricata, inferiora ovalo-acuminata, superiora cuspidala, summa oblongo-acuminata cuspidata, carinato-concava, margine plana limbo angusto; theca in pedunculo superne arcuato nutans oblonge et clavato-pyriformis, operculo minuto concexo conico apiculato, peristomio perro. †.

Putriu. In terra sicciore ad latera viae prope Kongsvold in alpe Dorrefjeld Norvegiae: W. P. Schimper.Julio.

Formis minoribus Bryi pallescentis simile, e theca Br. polymorpho var. brachycarpo seu Br. subrotudo, ex operculo parvo Cladodiis affine.

\section{P. Inflorescentia monoica.}

5\%. Br. pallescens Schwägr. (Suppl. I. II. p. $10 \%$. t. \%.); dense cespitosum plus minus compactum, inferne tomentosum ramosum subhumile; folia e basi rotundata ovato-lanceolata longe acuminata, nervo excedente cuspidata, subintegerrima, margine e basi usque ad apicem reflexa, e cellulis subinanibus subparvis viridibus basi 
purpurascentibus composita; perichaetialia intima multo minora evanidinervia; omnia immarginata tenera; theca in pedunculo flexuoso plus minus elongato crassiusculo horisontalis inclinatu elongato-pyriformis sublongicolla ore vix constricta pallide ochracen dein fusca, operculo acute et longiusculo-acuminato concolori.

Br. Europ. 1. c. p.51. t. 22. - Brid. I. p. 645. - B1\% rupincolum schleich. - Br. boreule schwägr. Suppl. 1. 11. p. 96. t. 69. Hypmum boreale $\mathbf{W}^{\prime}$ eh. et Mohr. Bot. l'aschb. p. 287. forma valde ramosa, foliis comalibus patulis, theca minore nutante vel suberecta Br. Hurop. I. c. p. 52. et Brid. I. p. 643. - Br. contextun Hsch. in Regensl). bot. Zeit. 1819 1. p. 91. forma elongata compacta, theca crassa subventricosa vix nutante longipedunculata. Br. Europ. I. c. p. 52. et Brid. I. p. 646.

Putria. Ad rupes et muros in montanis atque alpinis totius Europae passim copiose. - Majo, Junio, in alpibus Angusto et Septembri.

Peristomii dentes interni in membrana pallida latiusculi valde hiantes remote trabeculati, ciliis subtenuibus appendiculatis binis interpositis. Flos masc. in ramulo proprio terminalis, foliis perigonialibus intimis obcordatoacuminatis. - A $\mathbf{B r}$. cespriticio cespitibus pallescentibus haud sericeis et notis cursive impressis distinguitur.

58. Hr. Sauteri Br. et Sch. (Br. Eur. Fasc. XXXI. Suppl. p. 10. t. 10.); cespitulosum valde ramosum; folia erecto-patentia ovato - acuminata oblongo-et clongatolanceolata valde concava, margine plano integra, nervo crassiusculo in mucronem excedente, alis temubus hyulinis; perichaetialia angustiora tenuinervia; theca in pedunculo eygneo pendula gracilis leviter incurva solida sanguinea, operculo majusculo brevi-conico. $\leftarrow$.

Patria. Ad terram lumidam jugi Bormiensis prope 'Trafoi, ad ripas arenosas fl. Salyach pr. Mittersill et ad viam praceuptan inter Iol- et Bad-Gastein Salisburoviac inferioris: W. P. Schimper anmis 1840 et 1843 legit. Julio.

Planta pulchella, Br. pullescenti ex habitu caulium toliis diversis aflinis, vel erythrocurpo e thecae forma et colore subsimilis. 


\section{$\gamma$. Inflorescentia dioica.}

59. Mr. capillare Hdw. (Sp. Musc. p. 182.); innovando ramosum subhumile dense cespitosum tomentosum; folia caulina plus minus patula, superne in comam laxiusculum phes minus tortum congest clongate oblonga subspathulato-ovalia acuminata, nervo tenui excedente raro exanido longissime cupillaria, e basi usque ad apicem tenuiter marginata, apicem versus denticulata, siccitute torpuescentia; perichactialia multo laxius areolata teneriora; theca in pedunculo longiusculo horizontalis, inclinata vel pendula, plus minus cylindrico-pyriformis vel ovalis, dein brunnea, operculo conico acuto.

Br. Europ. I. c. p. 60. tab. 28, - Brid. I. p. 665. - Bryum foliis latiusculis congestis, capsulis longis nutantibus. Dill. Musc. p. 398. t. 50. f. 67. - Br. squalidum Vill. Fl. Dauph. III. p. 889. t. 54. - Mnium capillure L. syst. Veget. p. 947. - Hypmun capillare Web. et Muhr. Bot. Taschl, p, 286, - Br. insulare De Not. Spic. p. 7. et syllab. p. 128 ?

$\beta$. compuctum; compacte cespitosum caule ramisque gracilescentibus, foliis obsolete marginatis. Hr. cupillare var. Carinthiacum Br. Europ. I. c. p. 61. et Br. Ferchelii Fk. in sched. ex parte.

\%. cochleurifolium; compactum crassum, habitu Bryi Fentici, foliis cochleariformibus grandius areolatis marginatis. Br. Ferchelii Fk, in Brid.1. p.847. et var. cochlearifolium Br. Europ. 1. c. et Brid. I. p. 666. - Br. Funtii var. Ferchelii Schwägr. Sp. Musc. p.69, - Br. elegans Nees ab Es. in Bril. I. p. 819 .

d. Capense; ranis clongatis laxissinis, folis remolissimis flaccidis viridissimis; thecis laevissimis. $\boldsymbol{B} r \cdot C^{\prime} \boldsymbol{u}$ pense Hmp. in litt.

E. Domingense; humile tomentosum, folis breviter cuspidatis marginatis. Br. Domin!lense C. Mïll. Lim. XVII. p. 594. - Br. tomentosum Brid. I. p.618. - Br. Mlaccilum Brid. I. p. 667 .

Pulvia. In locis liumidis praecipue humosis atque lignis putrescentibus vel vetustis per totum fere orbem terrarum. Var. $\beta$. in alpibus Carinthiac. Var. $\gamma_{0}$ in al- 
pibus Salisburgiac. Var. $\delta$. in Promont. b. spei. Var. $\varepsilon$. in Hispaniola.

Flos masculus gemmaceus terminalis, foliis perigonialibus e basi concava late obovatis lanceolatis apiculatis nervosis, e medio paulo reclinata ita, ut flos subapertus sit.

60. Hr. platyloma Schwägr. (Suppl. I. II. p. 116. Ł. 76.); habitus Bryi cupillaris; folia caulina oblongoovata lata acuninata viridissima, margine crasse ef flarolimbatu vemote denticulatu, nevero crasso flavo excedente crasso-mucronate; perichaclialia interna multo angustiora minora margine valde revoluta; theca in pedunculo longiusculo purpurascente apice arcuato elongato-cylindrica ore coarctala fusca, operculo conico acuto concolori nitido.

Br. Europ. I. c. p. 59. tab. 26. - Brid. I. p. 668.

Patria. Insula Madera. Dalmatia: Pappafava. Italia: De Notaris, Rabenhorst. Sardinia: Fr. Müller. Sicilia. Corsica: Soleirol, Thomas. Algiria: W. Schimper. Insulac Canarienses: Webb.

A Bryo copillari foliis crassissime limbatis valde refugit.

61. Mr. obconicum Hsch. (in Bryol. Europ. 1. c. p. 59. t. 27.) ; humile cespitosum innovando ramosum; folia ovata. oblongo-ovata, acuminata, nervo excedente longe cuspidata submarginata, margine non incrassato revoluto-recurva subintegra, apice obsolete denticulata, concava, apicem versus carinata, erectiuscula, sicca vix tortilia, theca pendula longicolla clavata, operculo hemisphaerico papillato.

Patria. In rupibus et muris humidiusculis hic illic in valle rhenano; prope Bipontem ad rupes arenarias sociis Br. inclinato et cespiticio: Bruch. In Anglia prope Barnard Castle: Spruce. E rarioribus. - Junio.

Peristomium magnum, illi Bryi bimi simillimum. Plantarum habitus et magnitudo medium tenet inter $\mathbf{B r}$. capillare et cespiticium, huic praeprimis coma florifera 
gernmiformi modoque innovandi persimile, theca autem longicolla elongata, plurimo tempore perfecte pendula, primo adspectu discernibile. A $\boldsymbol{B}$ r. platylomate foliis marginc haud incrassatis, superne in comam subclausam conlertis, theca longiorc, collo sporangium fere aequante satis superque recedit.

62. Br. creberrimum Tayl. (Isond. jouril, of bot. 1846. p. 54.); aggregato-cespitosum rufescens crectum ramosum; folia pallide olivacea, perichaetialia pauca in rosulam coarctatam congesta ovata, innovatioum elongufarum magis distantia lanceolata acuminata margine subreflexa flexuosa subintegerrima; omnia nervo in cuspidem cxcurrente; thecae in pedunculis elongatis flexuosis creberrimae nutantes ex angusta rugosa apophysi cylindraceue, operculo convexo mammillato. $t$.

Patric. Nova Hollandia ad flum. Swan River: J. Drum mond.

A Br. obconico, cujus varictatem Cl. Wilson (l. c. p. 451.) putet, ex obs. auctoris innovationibus longioribus, foliis angustioribus et theca magis elongata diflert.

Dioicum?

63. Br. cavnm C. Müll. (bot. Zcit. 1815. p. 94.); densiusculo-cespitosum subhumile innovationibus paucis gracilibus erectis ramosum; folia innovationum cymbiformi-currata concave anguste acuminata orato-oblangu, marginibus reflexis flexusis, integerrima, amoene viridia, nervo ferrugineo crasso in cuspidem longam apice acutissimam hyalinam producta, angustissime marginatn, siccitate torquescentia, humectata imbricuto-patentiu, mimutinscula subyuadruto-rhomboideo-areolata; perichaetialia longissime cuspidata; theca in pedunculo gracili plus minus longo flexuoso fusco obconica nutans parva fusca, operculo e basi tumida conico brevissimo concolori.

Bryum capillare? var. cymbifolium Hook, et Wils. Lond, Journ. of bot. 1844. p. 15 .

Pntria. Brasilia in muris antiquis prope Arrayas: Gardner No. 36. b. Martio 1840. 
Inter $\boldsymbol{B} r$. obconicum et cupillare et notis designatis distinctissimum.

64. Dr. cespiticium L. (Sp. P. p. 1286.); dense cespitosum inferne radiculosum tomentosum innovans ramosum, ditissime fructiferum, ramis plus minus gracilibus intense viridibus vel lutescentibus magis minusve sericeis; folia e busi rotundato-ovutu lato-ovalia acuminata, nervo crasso sordide viridi excedente longe ef acute cuspidata, immurginatu obsolete denticulata, e cellulis minutis chlorophyllo repletis vel inanibus viridibus composita, margine revoluta; theca in pedunculo purpureo rigido substricto crassiusculo pendula, e collo brevissimo ovalis crassiuscula, ore tumido pallidiore subcunstricta, coriacea subbrunnea, operculo subdepresso conico purpureo.

Bryol. Europ. J. c. p. 70. tal. 34. - Brid. 1. p. 669. et 850. Br. pendulum ovatum cespiticium et pilosum, seta bicolori. Dill. Musc. p. 396. t. 50. f. 66. - Nnimm cesyitivium Brid. Musc. Hec. 11. III. p. 96. - Hymmm cesprticimm Web. ct Moln. Bot. Taschb. p. 283. - Br. badium Brurll in Brid. 1. p. 85̆0. var. $\%$. Bryi cespiticii. - Br. Kuntzii Hoppe et Hsch, in Resensl, bot. Zeit. 1819. I. p. 90. - Br. teclorum De Not. in schedulis.

Putria. In muris, tectis retustis, arborum truncis putrescentibus in siccis vel humidis per totam Europam vulgatissimum, montes autem cditiores refugiens; in Asia minore, et in partibus diversis Africae occidentalis et meridionalis atque Americae septentrionalis et australis. Majo, Junio.

Valde varians, e cespitibus autem densis sericeis viridibus vel lutescentibus, foliis capillaribus pracditis atque thecis creberrimis rigido-pedunculatis ovali-oblongis coriaceo-coloratis primo adspectu facile discernibile. Peristomium ut in Bryo bimo. Planta mascula multo gracilior, ex annuis innovationibus ramilicationes complures exhibens, cespitulos proprios efficiens vel femincis intermixta, inferne subnuda, apice capituliformis. Folia perigonialia interna late subrotundato-ovalia, e cellularum serie unica elongatarum veluti marginata obsolete denti- 
rulata longe cuspidata, e reliquis caulinis similia. Antheridia numerosa, paraphysibus innumeris acutis cincta.

65. Irr. anstrale Hmp. (Ic. Musc. tab. 26.); dense cespitosum; caulis erectus tomentosus superne parce ramosus; folia caulina inferne remota superne comam formantia suborali-lanceolutu strictu, omnia nervo crasso excurrente cuspidata quesi pungentia, integerrina immarginata; theca in pedunculo elonguto grucili flexwoso anguste ovato-cylindrica ascendens horisontalis, operculo conico mammillato obtuso; dentes magni robusti.

Patria. Nova Ilollandia ad flumen Swan River dictum: Preiss.

Inter Bryum pallescens (var. borenle) et Br. cespiticium. Ab ulteriori proximo differt: folis angustioribus immarginatis integerrimis, nervo duplo erassiore cuspidalis, cellulis minoribus, pedunculo gracili clongato atque theca ascendente horizontali.

66. Br. alpinum Linn. (Mant. Mnsc. II. p. 309.); pulvinato-cespitosum, ramis apree attemutis robustis densissime foliusis; folia innovationum oblongo-acuminutu valde concava crecto - appressa oliearea nitentia, nevo cresso purpureo mucromato-cuspidulu, margine valde revoluta, apice sacpe subinaequalia sublenticululu, e cellulis angustis densis homogeno-olieaceis composila; perichactialia fuscescentia, internora nulto angustiora; theca in pedunculo longiusculo purpureo gracili tenui basi geniculato-ascendente oralis crassiuscula subatro-purpurea, ore purpureo, subrugulosa pendula, operculo e basi paullo tumida convexo-conico breviter acuto aurantiaco lacvissimo-nitente.

Br. Europ. Fasc. VI-IX. p. 76. tal). 39. - Brid. I. p. 663. Br. hypnoides pendulum sericeum, coma insigni atro-rubente. Dill. Musc. p. 394. t. 50. f. 64. - Mniun alpinum L. jun. Meth. Musc. p. 366.

Patria. In montanis, subalpinis et alpinis totius Europae, loca lapidosa humida praeferens. In insulis Canariensibus inventum esse Cl. Montagne indicavit. Aestate. 
Planta mascula femineae simillima perigonio clauso.

67. Br. Muhlembeckii Br, et Sch. (Br. Europ. Fase. XXXII. Suppl. 1. 11. tab. 13.); cx habitu Bryi alpini; folia ramorum inferiora ovalia breviter et obtusiusculoccuminata, evanidinervia, superiora magis acuminata excurrentinervia sed semper oblusiuscula, omnia latiora; perichaetialia interiora magis acuminata laxius areolata; omnia integerrima fusco-olivere houd nitentia; theca oblongo-pyriformis fusce pendula.

Patria. In saxis irroratis jugi montis St. Gotthard versus Airolo: Mühlenbeck 1839. Ex alpe Grimsel a W. P. Schimper lectum misit am. Hampe.-Septbr.

A Br. alpino differt: plantis fusco-olivaceis, foliis latioribus apice subincurvis, e cellulis majoribus formatis atque theca ferruginea.

Sectio 11. AmbIyophyllum. Plantae gregarie vel dense cespitosae folia laxe imbricata, ofbicularia usque ad apicem valde quin imo fere patelliformi-concava, cellulis quadrato-rhomboideis laxis areolata, hasi raro maruine revoluta, superne plerumque illvoluta, ahruptinervia, theca pendula plus minus pyriformis.

68. Rr. Iatifolium Br. et Sch. (I. c. p. 19. 1. 4.); monoicum; gregarium humile, foliis laxis siccitate tortis, parce rumosum et raliculosum; folia inferiora orbicularia, superiora late orata majora, ralde prin imo cochleariformin, e cellulis brevibus crussis obsolete rhomboideis subpellucidis compositu, exunidineria, margine inferne subplano-reflexiuscula superne subinvoluta; perichactialia ovato-lanceolata; theca in pedunculo longo crasso stricto pendula oboralis brevicolla crussiuscula brevis, operculo minutissimo conexiusculo apiculato longe thecue adhaerens; peristomium Pohliae per longum tempus existens.

Pohlia latifolia Bruch in schedulis. - Bs: ohtusifolium Turn. in Musc, Hitb. p. 116. t. 11, f, 1, e Brid. 1. p. 639?

Putvil. In terra arenosa humida prope Bipontem ad Neuhäuseler-Weiher: Bruch. Nusquam alias repertum, igitur rarissimum. - Majo.

Flores masculi solitarii vel per paria ad perichactii basin dispositi, foliis perigonjalibus ovato-oblongis acu- 
minatis ultra medium nervosis concavis; antheridiis minoribus. Peristomii dentes externi lineari-lanceolati ferruginei, apice pallidi siccitate incurvi, interni illos subaequantes, e membrana altiore pallida angusti hiantes, ciliis imperfectis. - Pulcherrima species, ex areolatione foliorum $\boldsymbol{B r}$. cyclophyllo simillima.

6I. Br. eyelophyllum Br. et Sch. (Br. Europ. Fasc. VI-IX. p. 63. tab. 30.); dioicum; laxe cespitosum subhumile, basi et apice ramulosum tenerum remotifolium, pallide viride; folia caulina lato-orcalia suborbicularia obtusissima integervima, e serie cellularum simplici marginatu, Iaxiusculo-areolatu, nevro ante upicem abrusto; perichaetialia multo minora oblonga; theca in pedunculo caulium longitudine solitario ovato - prriformis pendula parva pallida, sicca ore constricta, opereulo parvo convexo mammillato subaurantiaco; perist. Bryi.

Mnium cyclophyllum Schwägr. Suppl. II. IJ. p. 160. tal. 194. Br, obtusifolium Turn. Musc, Hib. p. 116. tah, 11. f. 1. et Brid. I. p. 639? In hb. Brideliano sub hocce nomine occurrit. - $\mathrm{Br}$. tortifolium Brid. I. p. 844.

Putril. In limosis humidis, graminosis: in piscina exsiccata Franconiae prope Gefrees: Fu k detexit; pr. Bipontem: Bruch; in turfosis prope dem Wildbade sylvae nigrae et pr. Reichenbach in valle Murgthal dicto: A l. B raull. H rarissimis et rarissime fructificans. Vere.

Planta mascula e Schüigricheni observationibus feminea gracilior, flore discoideo, foliis perigonialibus quatuor orato-acuminatis. In axillis foliorum fila articulata ramosa saepe observantur.

70. Rr. calophyllum R. Br. (Suppl. App. ad It. Parrayan. p. 196.); dense cespitosum intricatum elongatum erectum subsimplex laxifolium filiforme vel robustius; folia e basi subdecurrente ovalia inferiora valde obtusa, superiora vix vel brevissime acuta, juniora margine rerolute reluti marginate inteyerrima, senione latiora masgine haud revoluta, e cellulis densis angustis flucis elongatis marginatu, apice parce et obsolete denticulata, 
omnia nerro ante apicen abrupto flexuoso fuscescente praedita, e cellulis superne et inferne sublaxis crassiusculis rhomboideis basi parallelogrammis laxioribus fuscis inanibus areolata, murgine unduluto instructu; theca in pedunculo elongato solitario sesquiunciali apice incurvo pendula obovalis basi vix attemuta acutiuscula, operculo concolori hemisphaerico minute pupillato, perist. Pohliae.

Cladodium calophyllum Brid. I. p. 622. - Pohlia calophylla Schwägre. Sp. Musc. p. 75. - Br. intricatum Brid. I. p. 680.

\section{Patria. Insula Melville.}

Fructum non vidimus. - Peristomii dentes externi rufescentes superne pallidiores, interni in membrana alta leviter carinata imperforati, interstitis subdenticulatis. Br. cyclophyllo proximum, notis auten laudatis facile distinguitur.

Nectio IV. Areodictyon. Plantae cespitosae humiles. Folia subdense imbricata ovalia valde concava, margine e cellulis pelluridis teneris plerunque basi purpurascentibus laxis rhomboideis areolata, nervo basi crasso evanescente purpurascente pracdita, theca plus minus pyriformis et inclinata.

\section{a. Theca irregularis.}

71. Br. Wierii Dicks. (P1. Crypt. Fasc. I. t. 4. f. 10.); rivicum; compactum subhumile innorationilns fragilibrs julaceis compluribus ramosum; folia innovationum appressa, e basi oblonga brevi ovalia cochleuriformi-concura, majuscule et pellucide areolata, nervo ante apicem aruminatum subrecurvum evanido; perichaetialia majora minus concava tenuiora; omnia integerrima; theca in pedunculo breviusculo purpurascente e collo longissimo gibboso pyriformis funaroideo - arcuata pallida dein fusca, operculo conico brevi acuto recto aurantiaco; dentes peristomii externi basi pulcherrime aurantiaci apice hyalini, interni subaurei liberi ciliis brevissmis interjectis, omnes fragiles cartilaginei; perist. Pohliae sequentis.

Br. Europ. I. c. p. 29. tah. 9. - Brid. I. p. 641. - Pohlia Zierii schw. sp. Musc. p. 76. - Mnium Zierii P. B. Prodr. p. 77. - Hymum Zierii Wel). et Mohr. Bot. Taschb. p. 275. 
Putvia. In rupium fissuris humidis umbrosis totius Europae in subalpinis et alpinis Sudetorum, Franconiae, Ilelvetiae, Norvegiae, Sueciae, Lapponiae, Carpathorum et totius Britanniae, nusquam vulgare. - Auctumno et ineunte hyeme.

Ex habitu caulium Bryo argenteo, e theca Bryo demisso simile, notis autem discernentibus maxime speciosum. - Flos masc. gemmaceus.

72. Mr. demissum Hook. (Nusc. Exot. tab. 99.); divicum; humillimum densiusculo - cespitosum innovationibus brevissimis gemmiformibus compluribus ramosum; folia innovationum appressa parva velde concure ovalia integerrima, nervo excedente crasso purpureo longiusculo cuspidata; perichaetialia lanceolata; omnia purpurascentia omnino fere e cellulis parallelogrammis crassiusculis laxis pellucidis areolata; theca asymmetrica, in pedunculo brevissimo demissa, subgibboso-pyriformis longicolla pallida dein fusca, ore oblique posito angusto operculoque conico parvo acuto; dentes externi breves basi aurantiaci apice hyalini, interni in membrana subaurantiaca longiores carinati apice irregulariter connati fragiles lacves hyalini, ciliis brevissimis interjectis.

Bryol. Europ. 1. c. p. 31. tah. 9. - Meesen dembissa Hopp. et Hscl. Regensh. hot. Zeit. 1819. p. 106. - Brid. Il. p. 64. - PohLia demissa Hib. Muscol. Germ. p. 466. - Bryum curvulum Schl. inst. et Timmine n. sp. Schmidt ex Hookeri Musc. Exx.

P'tria. In summis alpibus, ubi ad terram et in rupium fissuris inter plantulas alpinas viget. In monte $\mathrm{Ce}-$ nisio supra 7000 ped. elevation. Cl. II o oker 1814 detexit et in monte Faulhorn. In alpibus Carinthiac (Pasterze), Tirolis, Scotiac et Norvegiae. Raro! - Augusto, Septembri.

E theca Br. Zierii similis quidem, e cujus forma autem asymmetrica et notis ceteris laulatis species solitaria. Foliorum areolatio basi funarioidea, sed apice rhomboidea, igitur bryoidea. - Flos masculus gemmaceus.

C. Mhller: Synops, mugc, frond. 


\section{b. Theca regularis.}

73. Br. parndoxum Schwägr. (Suppl. III. I. 1. tab. 221.); manuicum, flores masculi ad basin ramorum ted arl cunlem arillares; cunlis mocumbens, ramis erectis simplicibus; folia superne densiora erectiuscula, oratoacuminata marginala integerrima lurido-viridia, nervo crasso in cuspidem crassiusculam producto, busi e cellulis quedratis multis superne longioribus rhomboideis areolata; perichactialia lanceolato - acuminata; thera in pedunculo breviusculo arcuato-nutans clongate prriformis curvula laevis badia, ore haud constricta, operculo convexo obtuse mucronato; perist. Wreberae.

Putriu. India orientalis, unde primus accepit II o o ker.

Peristomii dentes externi lanceolati transversim sulcati fernginei, interni in membrana lutescente lati valde hiantes, riliis binis capillaribus incrmibus interpositis. Folia perigonialia orata longe acuminata. E florum mase. situ et ramificatione ab omnibus congeneribus differe videtur, ex auctore (Sp. Musc. p. 5y.) Bryo copillari proximum.

74. Br. compressidens C. Müll.; dioicum; dense cespitosum rufo-badium; caulis erectus apice curvatus innovando ramosus teres badius; folia ovato-oblonga, inferiora magis elongata, apice mucrone minimo praedita, integervima limpida in consortio badia, dense imbricata, nervo apicem versus crancscente, e cellulis praegrandibus hexagonis areolata; theca in pedunculo apice currato breviusculo ferrugineo inclinata subparia e collo breviusculo pyriformis, ore amplo, laevis ferrugineo-badia, operculo consexo mammillato concolori vel rufescente; peristomii Pohliar dentes externi superne albidi inferne lutei, interni in membrana brevi ralde sulcata lutescente marime compressi angustissimi. $\doteqdot$.

Pohlia turbinata schwïgr. Suppl. II. II. 2. 1. 150. t. 194.

Potria. An terram argillosam regni Nepal inter Mar chantias. 
Folia perigonialia fore enervia. - $\mathrm{Br}$. Wraneo e structura interna proximum.

75. Br. splnchnoides C. Müll.; caulis elongatus inferne dense cespitosus subramosus obtusus; folia dense imbricuta "ppressu lato-oralia, nereo rubro excurrente subacuta, concara integerrima laxe reticulata pallida; theca erecta ovata apophysutu pyriformis crussu brevipedunculatu; perist. Brachymenii. †.

Brachym. splachnoides Harv, in Hook, Ic. Pl. Rar. tab. 19. f. 2. et in Lond. Journ, of bot. 1840. II. p. 10.

Patria. Nepal: Wallich.

Peristomium hucusque imperfecte ab auctore obserratum.

76. Br. cellulare Ilook. (in Schwägr. Suppl. III. I. 1. 1. 214.); dioicum; laxe cespitosum aliquoties innovaus humile; folia caulina subluxu putula, suprema erecta oblonga acuta planiuscula integerrima pallide badia, solitarie lustrata limpida, nervo crasso ante apicem abrupto praedita, grosse areolata tenerrima; perichaetialia intima lanreolata; thera in pedunculo longinsculo apice parmon eurrato suberectu tereti-piyriformis paveu, operculo convexo mucronato rufo-badio. $\%$

Putria. Nepal Indiae: Royle.

Sicctio V. Apalodictyon. Plantac humiles dense imbricatae waciles. Folia stricta ovato-lanceolata, maruine vix vel paulisper revoluta, cariuato-concava, pelfucide, minute et tenello-, interdum laxiusculo - areolita, nervo crasso plerumpue davo evauido, excurrente vel in aristam crassam flavam producta, theca pendula dolioliformis vel plus minus oblonga vel pyriformis.

\section{Nervo evanidovel excurrente.}

\section{a. Peristomium Polliae.}

7\%. Mr. platyphyllum C. Müll.; divicum; compactum humillimum inlerme nudiusculum, superue densissime foliosum, crasso-romosum, innovationibus terminalibus tenuissimis brevissimis nontullis ramosum; folia appressa, inferiora at imnovationum lato-vedelia concuree obtusa, brerissime acuminata, mero crasso purpurascente ante api- 
cem exunido, margine integerrimo revoluto, dense sed pellucido-areolata amocne viridia, superiora longiora oblonga subacuminata, perichaetialia sublanceolata; theca pro plantulae brevitate longipedunculata clarato-pyriformis crussu collo longiusculo praclita inclinata horizontalis purpureo-fusca, operculo longissime conico; subhemisphaerico.

Pohlia plat.phlylla Schwägr. Suppl. IV. tab. 321.

Patria. Chile in rupibus madidis ad Antuco 1828: Pöppig. Hb. Kunzean.

Dentes peristomii externi lato-lanceolati breves, interni apice albidi medio secedentes albidi laeves.

78. Nr. Gilliesii Hook. (Bot. Misc. I. 1830. p. 3. tab. 2.); dioicum? cespitosum humile apice et infra apicem innorans rubicundum; folia subarcte imbricata erecta exacte ovata concava obtusissimu integerrima mollia grosse reticulata pallide viridia, nervo valido usque ad apicem excurrente; theca breviter pedunculata inclinata vel nutans una cum apophysi subaequali pyriformis viridis dein luteo-fusca, operculo conico-hemisphaerico obtuso; peristomii dentes externi breriusculi aureo-fusci acuminati, membrana interna flava dentibus remotis erectis angustis strictis ciliis interpositis carentibus.

Pohlia Gilliesii Mont. in Voyage daus l'Amérique méridion. par d'Orbiguy, VII. II. p. 93. et VII. p. 18.

Patria. In terra ad radic. mont. in Andibus prope Mendozam: Gillies delexit. Supra saxa in terra inundata prope flum. Rio Negro: d'Orbigny.

Br. platyphyllo proximum, sed foliis obtusissimis multo minoribus et peristomio differt.

79. Br. clavatum Schimp. (Pohlia. Inn. des sc. nat. 2. VI. p. 148. t. 11.); dioicum? dense cespitosum; caulis erectus ramosus; folia erecto-patentia patulave ovatolanceolata obtusiuscula subconcava integerrima, nervo sub apice evanescente; theca in pedunculo elongato recurvato inclinato-horizontalis clacaeformis angustr, operculo convexo papillato. $t$ 
Putria. Chile ad scaturigines collium prov. Quillotae: Bertero.

Species pulchella, thecae forma atque toto habitu Pohliis simillima, peristomio autem interiori, cujus cilia, numerus et forma valde variabilia denticulis carent internis, ad Bridelii C/culodia accedit.

80. Br. tenuieanle Mont. (Amn. des sc. nat. 1815. 4. p. 104.); divicum? caulis tenuis brevissimus innovando ramosus, innovationibus hypogyneis vel e ramis repetitoproliferis gracilibus basi subnudis apice comoso-foliosis; folia caulina ovata acuta concaviuscula margine subrecurva integerrima patentia, innovationum oblusa, nervo evanescente, pellucida, theca in pedunculo erecto horizontalis myriformis, operculo convexo absque apiculo.

Putria. Chile prope Valparaiso: Gaud ichaud.

A praecedente nobis hand viso distinctum?

81. Ar. orthodontioides C. Müll.; monoicum; hut mile compretum suljulaceum, ramis brevibus; folia uppressa oblongo-oralia valde concava obtusinsculu ved brerissime acuminutu, integerrima margine plana non reflexa, e cellulis subparvis utriculo primordiali tenerrimo serpentino-flexuoso praeditis pellucidis areolata, nerro fluro ante apicem abrupto; perichaetialia multo minora; theca in pedunculo brevi erectiuscula obconica parea, ore dilatuta pallida, operculo breviter conico majusculo fusco; peristomii dentes externi lineari-lanceolati integri pallidi tenerrimi linea longitudinali carentes, interni in membrana brevissimu ciliiformes busi lati hund pertusi pullidi, ciliis interjectis nullis.

Orthodontium juluceum Schwägr. Suppl. II. II. 2. p. 123. t. 188.

Patria. Brasilia.

Flos maseulus ovatus, foliis oblongis acutis, nervo infra medium evanido praeditis et paraphysibus tenuissimis diaphanis. Ex habilu Bryo megulucrio affine, foliis autem obtusis evanidinervibus jam distinctissimum; $\boldsymbol{B}$ r. claceto, ut ex ic. elucet, e structura foliorum proximum. 
82. Br. microcarpum C. Müll.; dioicum; humile gracile erectum infra apicem innovationibus aequalibus; folia inferiora dissita erceto-patentia ovata acuta, superiora in comam fastigiatam conferta imbricata lato-lanceolata acuminata canaliculata integerrima pallide viridia, nerro excurrente, ramea appressa lato-ovata obtusa concava nereo cresso vivili in upiculum brevissimem excurrente, laxe areolata; theca in pedunculo longiusculo erecto parum flexuoso curvato purpurascente pendula purre myriformis fusca, operculo conico breviter apiculato. $\dagger$

Pohlia microcarpa Hsch, in Fl. Bras, Fasc. I. p. 38.

Putria. Prope Sebastianopolin Brasiliae ad terram nudam: Merkel. - Alugusto.

Cui affine?

83. Br. ambignum Dub. (Moritzi, Systemat. Verz. p. 132.); cespitosum minutum; caulis brevissimus innovando ramosus, innovationibus simplicissimis tenuibus foliosis brevibus; folia imbricata erecta lineari-lanceolata acuminata integerrima immarginata, nervo apicem attingente; perichaetialia similia sed hasi latiora el nervo magis excurrente; theca in pedunculo elongato tenui flexuoso horizontalis v. cernua pyriformis sicca sub ore constricla, operculo convexo conico absque appiculo. †.

Patriu. Java, ad lapides in 'Tjapus.

Affine Br. temicunli Mont. An revera nova species, auctor ignorat. - Peristomii interni dentes plerumque lacunoso-perforati sine cilis interjectis.

\section{b. Peristomium Welberae.}

81. Rr. carneum I. (Sp. PI. p. 158\%); divicum; laxe cespitosum vel gregarium, erectum vel basi decumbens humile simplex apicem versus innovans; folia inferiora lanceolata, margine parum revoluta, omnia cinguste clongule sed luxiusculo-ureululu pellucidu, apice serrulata evanidinervia; thera in pedunculo longiusculo flexuoso purpurascente vel flavesrente apice arencrto incressselo

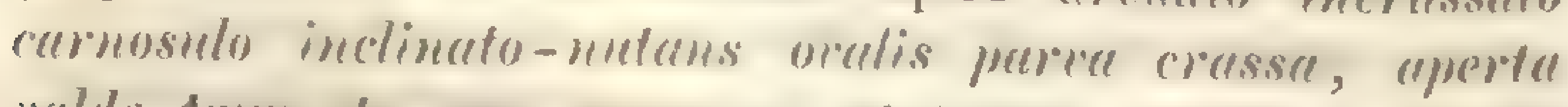
ralde truncula ore suepe coceretuta excumulata subsan- 
guinea, operculo hemisphaerico conico plus minus mammillato; neristomii dentes externi longi angusti lutescenles dein purpurei, interni in membrana alla amocme flara valde hiantes serrati, ciliis binis nodosis interjectis.

Br. Europ. 1. c. p. 43. - Brid. 1. p. 6.52. - Br. delicutulum Hdw. Muse. Frond. 1. 1) 52. t. 20. - Br. Jullidisetum Brid. Mant, Musc, p. 11\%, - Bryum compuctum 1)icks. Fasc. IV. p. 15. t. 11. f. 11. et Brill. I. p. Gis6. - Br. melanodon Brid. I. p. 845. ex lit. Brid.! - Br coupctutum siclultz. Ephem. bot. Hegenslo. Syll. PI. 11. p. 91. e sihwär. huc pertinet. - Bryum lanceolatum pelluci-

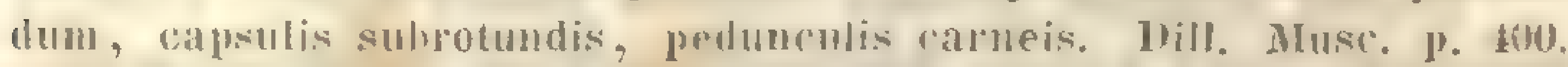

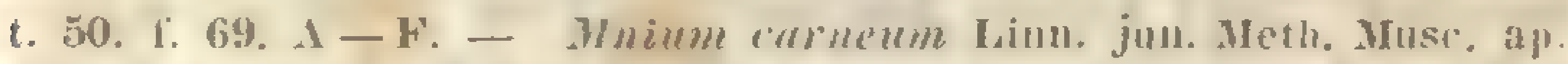
Iandw. 1. 366. - Mn. ruhellum P. B. Prodr. p. 76. et? Br. rum bellum Bril. 1. p. 650. c spec. pessimo hh. Bridel. a P. B. misso. Mypnum carneum Web, et Mohr. But. 'Taschb. 1. 278.

Putria. In terra arenoso-argillacea humida sterili per totam Europant. - Vere uspre in aestutem.

Planta mascula simplex, e ceteris $\boldsymbol{B}$ ). pulchello similis.

85. Hr. albieans Wahlenb. (in Web. et Mohr ind. mus. (f. Fl. Iapp. p. 353. 181\%.); divicum; laxe cespilosum plus minus elongatum erectum vel declinato-crectum simplex rel apiec innovans; folia lanceolata, superiora andustiora, ommia sublecurrentia anguste of densiusculo-areolatu pellucida evanidinervia apice serrata; theca in pedunculo longo flexuoso purpurascente temi pendula breviter pyriformis exammulute subsanguinca, operculo hemisphacrico - conico plus minus mammillato; peristomii dentes externi longi angusti lutescentes dein fusci, interni in membrana alta pallida valde hiantes hued serrati, cilies solitaries ed binis nodosis tenuissimis interjectis.

Brid. 1. p. 6isf. - Mnium albicans Wahlenh. FI. Lapp. p. 353.

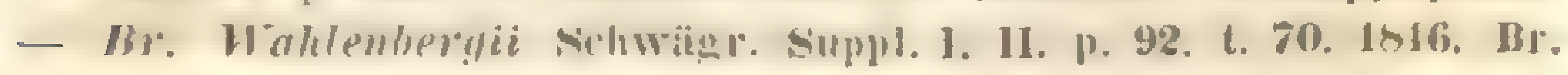

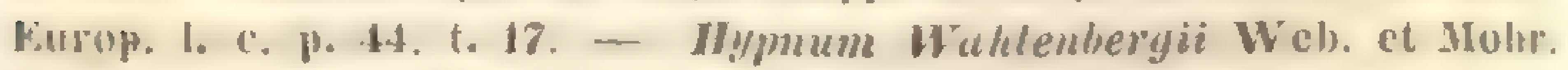
Bot. Taschi. 1. 280.

B. glaciale; clatum gracile robustum ramosissimum, longe pedunculatum, folis laxius el gramdius areolatis subglatucescutibus vel albescentibus majoribus latioribus. 
Br. glaciale schleich. in Brid. 1. p. 852. - Br. Europ. I. c. p. 45. - Mnium glaciale schleich. Cent. 111. 41. - Mr. Schleicheri schw. sp. Musc. p. 55. - Varietas Bryo schleicheri analoga rohusta alpina.

Patrie. In terra arenosa humida plerumque inundata planitierum, montium atque alpium totius fere Europac et Americae septentrionalis. Insula Falklandi et Kerguelen: J. Ilooker. E Nova Hollandia accepisse $B r$. et Sch. dicunt. - In depressis Majo, in alpinis Angusto.

Planta mascula gracilis inferne nuda, apice comosa innovans, flore crasse gemmaceo. Folia perigonialia externa e basi lata ventricoso-vaginante laxe areolata fusca lanceolata recurva serrulata evanidinervia densius areolata, interiora multo minora sed lato-ovalia apice tantum recurva omnino laxe areolata purpurascentia integerrima. Antheridia numerosa paraphysibus clongatis purpurascentibus mixta. - Bryo corneo e formis minoribus, Bryo Schleicheri e formis majoribus simile, primo proximum, a quo foliis decurrentibus arctius areolatis, pracsertim thecae forma differt.

\section{c. Peristomium Brachymenii.}

86. Br. Meyenisnum C. Müll.; dioicum; dense cespitosum humillimum ramosum; folia latiusculo-ovalia concava parva subacuminata, integerrima pellucido-tenera, nervo tenui ante apicem evanido; perichaetialia intima angustiora longiora acuminata, nervo purpureo; theca in pedunculo longiusculo tenui clarata longicolla angustissima perea arcuata erecte, operculo conico brevissimo.

Webera Meyeniana Hmp. Linn. X1. p. 278. - Mielichhoferia Chilensis ej. in Hb. Reg. Berol.

Patria. Chile: Meyen.

Perist. dentes externi e basi angusta remote trabeculata lutea brevi subito longe subulati laeves hyalini articulati; membrana interna tenerrima vix conspicua fugacissima plicata apice valde irrewularis, quibus notis ab omnibus congeneribus differt. Ex habitu Mielichlo/erius in memoriam redigens, peristomio externo Orthodonlies simile, interuo autem ad Brachymenium pertinens. 


\section{d. Peristomium Bryi.?}

87. Mr. erythrocarpon Schwägr. (Suppl. I. II. p. 100. 1. 70.); divicum; subgregarie cespitosum humile ramis plus minus clongatis; folia erecto-patentia vel patula lanceolata, nervo sordide viridi excedente breviter cuspidata integra vel obsolete denticulata, margine paulisper reflexa, minute anguste et dense areolata; theca oblongo-pyriformis brevicolla inclinato-pendula colorata coriacea fusca vel sanguinea, operculo conico acuto magno purpureo nitido.

Br. Furop. 1. c. p. 72. t. 36. - Brid. 1. p. 6ăอ. - Br. sanguineum Brid. 1. p. 671. - Br. raliculosum Brid. 1. p. 655. Br. Morisii Bruch in Musc. Sardois Müllerianis.

Patria. In solo argillaceo vel arenario humidiusculo per totam Europam passim et in Africa, Isia et America meridionali. - Junio, Julio.

P1. mascula femineac exacte similis vel gracilior, perigonio crassiusculo terminata gregaria vel fomineae intermixta, foliis perigonialibus externis e basi lata anguste lanceolatis concavis, internis late obovatis cuspidatis. In axillis foliorum corpuscula gemmiformia rotunda purpurascentia inveniuntur. - Peristomii dentes externi longissimi subulati apice pallidi fissiles, interni valde sulcati et liantes, ciliis dentes aequantibus tenuissimis valde appendiculatis binis rel ternis.

88. Br. marginatum Br. et Sch. (Br. Europ. I. c. P. 74. tab. 38.); diricum; dense pulrinato-cespitosum rufo-viride crmo-nitens; caulis innovando ramosus; folia conferta erecto-patentia ovalia acuminata, comalia interna oblongo-elongata, omnia margine integerrima vel apicem versus obsolete serrulata, limbo angusto rufescente circumducta, nervo solido cum apice evanido; theca in pedunculo collum cygneum sistente pendula, clavato-oblonga longicolla purpurascens; peristomii interni processibus siccitate dentibus depressis.

Patria. In rupibus archariis tam siccis quam irroratis: prope Bipontem late cespitosum sed rarissime fructificans detexit Bruch; pr. Andegaviam Galliae occidenta- 
lis: Guépin et in ditione urbis Gallicac Bar-sur-Seine. E rarissimis ! - Junio.

1'. mascula gracilior, inmovationibus ramosa, cespitulos proprios efficiens. Folia perigonialia late ovalia brev-acuninata, intima encria tencriora; antheridia numerosa, paraphyses superantia. - Br. erylhrocurpo proximum, differt autem cespitibus multo densioribus, foliis magis nitentibus apice rufo-brunneo-coloratis, ommino auro-nitentibus et theca in pedunculo cygneo-arcuato magis pendula.

89. Br. Blindii Br. et Sich. (Br. Europ. Hasc. XXXII. Suppl. 1. 11. t. 12.); divicum; laxe cespitosum rel gregarium, faxe imbricutum julaceum yracile subfustigintorumosum; folia caulina ouculi-oblongu cymbiformi-concueu, pellucide et longiusculo-rhomboideo-areolata tenera, nervo flaco temi ante apicem obtusinsculum ceunido, vix carinata, immarginata integerrima; perichactialia longiora angustiora sed oblusinscule, murgines subimulutu, longius areolata; theca in pelumculo clongato stricto rigido sub thecac collo subito incurvo pendula, globoso-myriformis

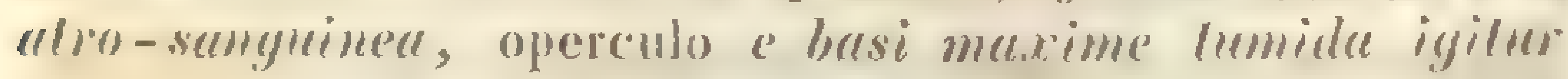
ora prominente instructo conico mammillato concolori nitido.

Br. Funliz var. Br. et sch, in Br. Hurop. Monogr. Bryi p. 77.

Palria. In ascensu septentrionali Rhaetiae M. Bernhardino: Blind 1839. detexit et in valle sit. Nicolad pr. Bormio; ad ripas arenosas flum. Salzach prope Mittersill Pinzgoviac: Sauter, W. P. Schimper. - Mestule.

Br. Funlii e forma caulis proximum, sed notis cursive impressis diversissimum. E thecae forma ad $\mathrm{Br}$. utropurpureum, rersicolor praesertim puchylhecum accedens. - Inllorescentia Bryi Funlii. Planta pulcherima.

90. Br. Tozmeri (Hev. (Acot. Fl. V.); dioicum; gregurium humile simplex crectum; folia inferiora remola obovato-lanceolata, superiora late obovata apiculata, summa comam paucifoliam formantia majora latiora apiculata, omnia integerrima, nervo rubello ultra medium 
evenido praedita, e cellulis elongato-octaëdris luxis composita, pallide viridia dein rubella, murgine limbo latiusculo haud incrassato rubello e cellulis angustis clongatis formuto instructu planiuscula vel hic illic reflexa; theca ocali-pyriformis brevipedunculata nutans unmuluta, aperta ore saepe constricta pallide fusca, operculo rufo convexoconico breviusculo; peristomium $\mathrm{Br}$. curnei, dentibus lutescentibus et processibus margine minus dentatis. $\uparrow$.

Br. Kurop. 1. c. p. 41, tal, 16. - Br. muryinatum Bruch in sched.

Patria. Ad terram argillosam secus rivulos: in Anglia ad flum. Dart, Devonshire: 'To z zer detexit. l'rope Torquay ex animadv. Éphemerid. Phytologist 1843. VIII. No. 22. p. 260. a Niss Cl. Griffith lectum esse dictur, in Sardinia prope Sto. Angelo in solo arenaceo-argilloso: Fr. Müller. E rarissimis. - Vere.

A Br. curneo proximo notis laudatis distinctissimum.

91. Er. pachypoma Mont. (Aun. des sc. uat. $18 t 5$. 4. p. 104.); dioicum; late et densinsculo-cespitosum subhumile, ramis celongutis flernosis apire dense foliuso incurvis flaccidis phumoso-foliosis lutescrutlitus nitidis; folia oblongo-lanceolata angusta clongata integerrima, nervo excurrente enui flexuoso breviter cuspidatat, carimatoconcava, hasi e cellulis quadratis magnis rufescentibus superne elongatis angustis subpellucidis viridibus areolata; theea in pedunculo longiusculo flexuoso purpureo arcuatonutans, primum obconica dein prriformis, tenero-membranacca pallida, operculo majusculo conico-hemisphuerico oblusissimo aurantiaco pracdita, dehinc fusca nitens.

Br. Sereilleanum Iz. et M. Musc. Archip. Ind. p. 16. tal, 8. caule fructifero breviusculo, imnovationilus tenuilus rectis, operculo conico crasso. - Br. Mumosum 11z. et a. I. c. p. 16. tal. 7. fotiis apice olssolete denticulatis, quilus a praecedente format diflert.

Patria. Java in terma et, ut videtur haud rarum.

PI. mase. femincao similis sed gracilior, flore mimule gemmaceo terminali, antheridis et paraphysibus pancis parris, foliis perigonialibus internis quam maxime teneris diaphanis enervibus laxe areolatis ovalibus plus minus 
acuminatis convolutis. Peristomii dentes interni valde hiantes ciliis valde appendiculatis interpositis. - $\boldsymbol{B r}$. erythrocurpo proximum, notis autem laudatis diversissimum.

92. Mr. Sandii Dz. et Molkb. (Musc. Archip. Ind. Ł. 10 ); monoicum; caulis brevis erectus ramosus; velmi erecti superne incrassuti; folia imbricata electo-patula oblonge vel ovato-lanceolata, nervo crassiusculo sordide flavo excurrente brevissime cuspidata, integerrima apice obsolete denticulata, minute dense pellucide basi panlum grandius areolata, margine haud reflexa, paulisper concava; perichaetialia longiora flaccida longius acuminata, laxius areolata tenera; theca pendula oblongo-cylindrica, operculo convexo apiculato.

Patria. Java in monte Megamedong.

Br. cespiticium affine differt: inflorescentia dioica, foliis omnibus ex ovato-lanceolatis, eorundem areolationc et theca subpyriformi. $\mathrm{Br}$. pachypoma proximum inflorescentia et toto habitu primo adspectu et notis cursive impressis distinguitur.

93. Br. Crügeri Hmp. (in litt.); divicum; laxe cespitosum humile rufescens gracile, innovationibus brevibus acutiusculis laxifolis ramosum; folia oblongo lanceolata angusta longiuscula acuta carinato-concava, nervo rufescente excurrente in mucronem brevissimum producta, margine integerimo paulisper reflexa vel plana, e cellulis elongatis pellucidis utriculo primordiali tenuissimo praeditis areolata; theca in pedunculo elongato purpurascente pendula obconica pallida operculo aurantiaco majore conico nitido praedito, dein inclinato-pyriformis subparva; peristomii dentes interni breves ciliis binis tenuissimis appendiculatis interpositis:

Putria. Insula Trinitatis: Crïger. Surinam prope Paramáribo in locis apricis: Kegel, Julio. Coll. No. $\mathbf{2 0 3 .}$

Br. pachypoma proximum, sed $\boldsymbol{B r}$. Crügeri differt habitu multo humiliori graciliori, ramis strictis apice non comoso - secundis rufescentibus, foliis obtuse acutis e operculo conico - acuto. 
94. Ir. conicum Hsch. (Fl. Bras. I. p. 43.); caulis fertilis erectus brevissimus, ramis brevibus julaceis densissime foliosis fastigiato-ramosus; folia caulina rel perichaetialia lato-lanceolata cuspidata laxe areolata, intima tenera subhyalina; f. innovationum oblonga apiculata canaliculata carinata integerrima flavo-viridia, nervo crasso carinato ferrugineo in apiculum exeunte, e cellulis parallelogrammis minus laxis composita; theca in pedunculo semunciali erecto parum flexuoso vel curvato basi purpurascente apicem versus pallide luteo horisontulis parva angusta oblongo-cylindricu luteo-brunnea ore purpurea, operculo brevissimo conico obtuso purpureo. $\leftarrow$.

Br. Funkii Br. Eur, 1. c. p. 77. et Nchwïgr, sp. Muse. p. 69. sub patria memoratum?

Patria. Brasilia al latera rivorum prope NovoFriburgum: Beyrich; Decbr.

A $\mathrm{Br}$. Funkii, cui summopere affine, differt: statura humiliore, caule brevissimo fastigiato-ramoso, foliis appressis flavo-viridibus, perichactialibus lato-lanceolatis, theca horizontali oblongo-cylindrica, operculo roniro obtuso. De Br. bulbilloso affini excurs. in hanc speciem conferatur.'

95. Nr. bulbillosum Mont. ( Inn. des sc. nat. II. XYl. p. 268.); dioicum? caulis fertilis brevissimus purpureus flaccidus deuse tomentosus, immorationibus juluceis rel gracilescentibus subfastigiato-ramosus; nommlli vomuli et cuulis fertilis ex axillis foliorum superiorum bulbillos confertos obovatos dein mupurascentes tenerrimos gerentes; folia caulina remota, sensim conferta oblonga acuminata concuve tenera viridia integervima nervo cuspidata; folia innovationum dense imbricata up)resso minus acuminata evanidinervia; omnia minute, pellucide, tenero- et elongato-areolata; perichaetialia interiora breviora triangularia; theca in pedunculo semunciali rubro flexuoso ovoidea cepuculis nutans vel pendula basi subattenuata, sicca suburceolata rufo-brumea, operculo convexo brevissimo mammillato concolori. 
Putria. Brasilia, ad terram prope Rio Janeiro: Riedel.

Peristomii dentes externi subulati rufi, apice pallidi tenuissime punctulato-scabriusculi; interni ciliolis subbinis uncinatis interpositis. - Bryo Luduigii proximum, sed differt folnis concavis integerrimis, theca regulari, operculo paullum longiore atque cilis peristomii interni appendiculatis. - $\boldsymbol{B r}$. conico Hsch. e descript, auctoris peraffine, sed bulbillis descriptis et theca ovoidea haud cylindrica differre videtur.

Peristomium non sutis notum rel ignotum.

96. IBr. pungens Tayl. (Lond. jourl. of bot. 1846. p. 342.); laxe cespitosum crectum yrucile subfastigiatum apice incrassatum; folia arcte imbricata erecta cordatotriangularia longius et tenuiter acuminata integerrima excurentinervia; perichaetialia brevissima; theca lomginsculo-pedunculatu latu rlongate pyriformis subhorisontalis; peristomii dentes interni ciliis solitariis interjectis. t.

Pulriu. In locis siccis montis Pichinchac prope Quito Andium: W. Jameson.

Ex obs. Cl. IVilsoni (1. (•. p. 450.) sequentibus inter sese affinibus speciebus duabus proximum.

97. Br. inacquale Tayl. (1. c. p. 53.); subcespitosum gracile humillimum crectum subramosum olivaceum; folia madefacta in capitulum imbricata, crecta adpressa orata acuninata subsermlute, basi margine rellexa, excurrentinervia; theca flexuose et breviusculo-pedunculata cylimlracen-myriformis subcerma, opereulo conico mammillato. \%०

Pulrill. Nova Inollandia ad flumen Swan River: J. D rum mond.

A Br. Immhii differt: folis magis acuminatis densius imbricatis, nervo ad apicen tantum exrurente praeditis.

98. Hr. multicaule Tayl. (1. c. p. 53.); respilosum nitidum pallide virescens elongatum basi ramosum sursum 
incrassatum; folia imbricata erecta apice patentia cordata acuminata serulata, basi margine recurva, excurentinervia; theca cylindraceo-pyriformis subnutans, operculo conico. t.

Putriu. Nova Ilollandia ad flumen Swan River: J. D r um mond.

Ex habilu $\mathrm{Br}$. plonguto vel innovationibus gracilibus dense foliosis Iypno simile.

pracredentes species tres huc retulimus, quum auctor Br. incerpunk Bryo Fumlii simile et CI. Wilson omnes species inter sese affines nominarerint.

99. Mr. teretiusculum Ilook. (in Wallich Catal. I. 9597 et Harv. in Lond. Journ. of bot. 1840. II. p. 9; ie. in Ilook. Ic. PI. 1. 20. f. 1.); laxe cespilosum humile rectum ramosum, folia erecto-patentia subconcara ovalolanceolata stricta obtusiusculo-acuta integerrima, margine recurva, excurentinervia; theca in pedunculo erecto substricto mediocri inclinata cressiuscule subrotumdato-verula, operculo minuto apiculato. t.

Putrin. Nepal.

Ex obs. Harreyumis Br. turbinalo proximum, sed thecae forma distinctum.

2. Nervo in aristan producto.

100. Br. imbrientum Br. et $\mathrm{Sth}$. (Br. Furop. I. c. D. 29. t. 5.); divicum; humile compactum ramosum, remis sterilibus suljulucess, floriferis comosis; folia imbricata orato-acuminata concava integerrima, margine remurva, nervo sordide viridi cercedente mucronutu, e cellulis submagnis polyoono-rhomboideis pellucidis areolata sordide viridia; thera in pedunculo erecto superne arcuato horizonlalis rel pendula elongato-pyriformis fusea, collo aepuli rel breviore, operendo a basi convexa ucute conico; peristomium mimutum, dentes externi angusti suloulati, imlerni in membrana dimidio breviore angusti vix hiantes externis breviores parce serrulati, riliis rudimentariis vel nullis interpositis. 
Pohlia imbrienta schwägr. Suppl. 1. 11. p. 71. t. 64. $\rightarrow$ Rr. maryinatum Brid. I. p. 849. e spec. hb. Brid. foliis noll marginatis sed perfecte revolutis,

Putria. In alpinis Holvetiae: Schleicher. Carinthia in IVindischmattreyer 'Tauern et in der Leiter ut in Gastonia: II ppe et Hornschuch? H rarisimis. Aestate.

Ex habitu Br. marginato Bruch simillimum sed folis nervo excurrente mucronatis rel pungentibus atque peristomio Pohliae differt.

\section{a. Peristomium Weberce.}

101. Ir. dichotomum Hdw. (Sp. Muscor. p. 183. 1. 42.); dioicum, erectum subchongatum grucile, dichotome rumosum ramis elongatis gracilibus; folia arcte imbricata subdecurrentia, e basi igitur cordata ovato-acuminata integerrima, nervo subdecurrente flavo excedente flavo - pungentia, inferiora involutaceo-, superiora latius concava, basi utrinque e cellulis multis quadratis crassiusculis latiusculis superne angustis minutis flavo-viridibus areolata; theca in pedunculo longiusculo flexuso apice arcuato subgloboso-ovelis pendula, dein purpurascens, operculo hemisphacrico conico; peristomii dentes externi latiusculi fusci apice subulato pallidi subrugulosi linea tenuissina hyalina exarati, interni integri vix hiantes e basi latiuscula subulati pallidi subrugulosi, ciliis solitariis sed linea longitudinali obsoleta exaratis tenuibus interpositis.

Brid. I. p. 646. - Mnium dichotomum P. B. Prodr. p. 74.

Patria. Nova Seelandia: Banks.

E lheca Bryo curneo, ex areolatione atque forma foliorum Bryo dicranoidi affinibusque ceteris affinc, sed notis illustratis distinctissimum.

102. Br. doliolum Dub. (Moritzi, Syst. Verz.p. 133.); monoicum; dense cespitosum sed laxe cohacrens radiculosum; caulis fertilis brevis innovationibus ascendentibus subhumilibus subramosus; folia densiusculo-imbricata, illa innovationum lanceolata, nervo crasso flavo-viridi in 
aristam clongatam subintegram acutam producta, integerrima; margine paulisper revoluta, e cellulis subporis brevibus utriculo mimordiali serpentimo-flexuoso mueditis subpellucidis rreoluta; perichactialia longiora margine magis et exacte reffexa, intima minora angustiora; theca in pedunculo brumneo fragili stricto ad insertionem thecae inserto horizontalis vel nutans dolioliformi-ublonga brunnea parva basi haud collosa sed aequalis, ore aequali et operculo convexo-mammillato.

Putria. Jara ad terram prope Pandar peté et ad rupes calcareas pr. Kuripan: Zollinger collect. No. 1533 et 1538.

Peristomii dentes interni angusti pertusi, ciliis paucis mudis interjectis. - $\boldsymbol{B}$ r. coronato e forma thecae simile sed notis laudatis distinctissimum.

\section{b. Peristomium Bryi.}

103. Br. Funkii Schwăgl". (Suppl. I. II. p. 89. 1. 69.); dioicum; laxe cespitosum dense imbricatum julaceum crussum breviter rumosum; folia caulina oveliu, cochleariformi-concur', plus minus pellucide et minute rhomboideoareolata, tenera, nervo crussissimo fluro in inweronem crussum producto, reluti pungentice, carinata, immarginata integerrima; perichaetialia multo angustiora longion"l, margine revolutu, longins areolata complicuto-concaure; theca in pedunculo longiusculo gracili purpurascente apice paulo curvato pendula crasse oxulis, dein ore constrictu, pallida ore aurantiaca, operculo conico hemisphaerico brevissime acuto aurantiaco nitido.

Br. Europ. 1. c. p. 77. t. 44. - Brid 1. p. 660. - Br. articulatum sendtn. in sched., forma gracillima comparta e speciminilus prope „Mertenstein bei Kaufung im schönaner Kreise" Silesiae lectis lue pertinere videtur.

Intria. Ad muros vetustos et in terra argillosoarenaria: in arce delapsa Grünstcin dicta prope Gefrees Franconiae: Funk detexit; in rupibus arenariis pr. Bipontem: Bruch; prope Burgdorf Ilelvetiac ad vias et rupes: Märker; ad viam septentrionalem montis Beruhar-

c. Müller: Synops, musc. frond. 
dino Rhaetiae: Schimper, Blind et Mühlenbeck; pr. Mariaeinsidl dit. Monachii: Sendtner; in declivibus prope Schiffersiuh Florac Francofurtanae: Itzigsolin; in Hereynia inferiore: Hampe. - Mujo et Junio, in alpibus Augusto.

Flos masculus dense genmacens foliis orato-actiminatis.

104. Br. atropurpureum Wahlenb. (in Web. et Mohr. Ind. Mus. Vid. Fl. Lapp. p. 360.); divicum; humile compacte cespitosum amoene viride dense imbricatum ramosum, ramis brevibus aequalibus; folia e basi latiuscula ovali-lanceolata valde concava, nervo crasso flavo exccdente mucronata vel longius cuspidata integerima, margine recurva, inferne e cellulis parvis multis subquadratis superne rhomboideis inanibus areolata; theca in pedunculo longiusculo flexuoso purpureo ventricoso-ovalis rel oblonga crassinscula parva atro-purpurea, collo brevissimo ruguloso praedita, operculo magno hemisphaericoconico pallidius murpureo nitido.

Br. Nurop. I. c. p. 73. t. 37. - Br. pulchellum $\beta$. atropurpureum Wahlenb. Fl. Lapp. I. c. - Br. curneum $\beta$. atropupureum Schwägr. sp. Musc, p. 67. - br. erythrocurpum Brid. I. p. 654, Bl: biculor Turt. Muse. Hil, p. 121. t. 11. f. 2. - Br, erylhrocrrpon $\beta$. bicolor Brid, I. p. 655. - Mnium bicolor P. B. Prodl. p. 74 ,

Putriu. In terra arenoso-argillacea sublumida sociis Br. aryenteo, erythrocurpo, Funciu hygrometricu et al. per totam Europam passim, sed alpes refugens; in insulis et ad oras maris mediterranei atque atlantici; in monte Sinaï: Wr. Schimper. - I'ere.

Br. coronuto proximum, notis tamen laudatis distinctissimum. - Flos masc. subglobose gemmaceus, foliis perigonialibus late ovatis acuminatis nervo mucronatis. Dentes peristomii externi longe subulati lutei apice hyalini margine valde lamellosi, interni in membrana alta pallide aurantiaca breviusculi, valde hiantes, ciliis tenuissimis appendiculatis $2-3$ hyalinis interpositis. 
105. Mr. pnchytheea C. Müll.; dioicum; habitus omnino Bryi atropurpurei; folia minor'l sed lato-ovaliacuminata, nervo crasso flavo longe excedente cuspidata, valde concava, inferne e cellulis quadrutis pluribus, $e$ toto majoribus areoluta, margine subplano, non revoluta; thecae forma parva ventricoso-ovalis crassiuscula illi Bryi atropurpurei simillima, sed ut in Bryo coronato pedunculo in collum thecae brevissimum inserto praedita, basi torosa rugulosa atropurpurea, operculo breviusculo hemisphaevico-conico pullidius purpureo nitido.

Bryum coronatum $\beta$. minus Hmp. in PI. Preiss. p. 117.

Patrit. Nova Hollandia prope York: Preiss. India orientalis: Hb. Gottscheanum.

Inter $\boldsymbol{B r}$. coronatum et atropurpureum medium tenens. A primo differt foliorum forma et areolatione atque thecae partis inferioris forma et colore atropurpureo; a secundo foliis minoribus majus areolatis margine non revolutis et thecae parte superiore $\boldsymbol{B r}$. coronato simili valde distat. - Peristomium Bryi atropurpurei.

106. Br. coronatum Schwägr. (Suppl. I. II. p. 103. t. 71.); dioicum; laxe cespitosum inferne tomentosum amoene viride ramosum, ramis gracilibus flaccidis laxifuliis; folia caulina erecto-patentia elonguta oblongo-lancooluta, nervo subtemi excedente mucronata vel longe cuspidata, subplana, e cellulis inferne parallelogrammis longinsculis lutiusculis utviculo primordiali valde instructis igitur valde chlorophyllaceis composita, margine haud revoluta, subintegerrima; perichaetialia $e$ basi lata subito perfecte lanceoluta, longe cuspidata excurrentinervia; pedunculus elongatus gracilis purpureus apice parum incurv'us et in collum thecue brevissimum insertus; theca pendula oblonga ore coarctata busi torosa rugulosa fuscescens, operculo majusculo acuto basi tumido purpureo nitido.

Brid. I. p. 650 .

Putria. Cuba: Pöppig detexit. Brasilia: Gardner No. 35. Chile: Pöpig. Guyana: Richard. Hispaniola: Bertero. 
Areolatio foliorum Bryi carnei, theca propria illi $\boldsymbol{B r}$. atropurpurei similis sed ad insertionem pedunculi torosa veluti coronata. Species pulcherrima. - Peristomium ut in $\boldsymbol{B r}$. atropurpureo.

107. Br. apieulntum Schwägr. (Suppl. I. II. p. 102. 1. 72.); dioicum; compactum subrobustum subhumile erectum sordide viride; folia ovato-lanceolata latiuscula inferne margine subrevoluta, integerrima nervo crasso flavo dein purpureo breviter sed crasse cuspidata; theea in pedunculo breviusculo flexuoso e collo longinsculo elongatepyriformis brunnescens inclinata, operculo brevissimo conico atro-pupureo nitente; peristomium ciliis internis binis appendiculatis.

Brid. 1. 644. - Hornsch. Fl. Bras. p. 44. - P. B. Prodr. p. 73. quod schoug gichen synonymum in spec. Musc. 1p. 63. citavit, alia species esse videtur, ut jam e patria (Insula Franciae) putemus.

Putriu. America meridionalis. E Montevideo Brasiliae a Sellow lectum habemus.

Cellulae basilares subrotundae, aequali-quadratac.

108. Hr. versicolor A. Br. (in Br. Europ. 1. c. p.75. t. 38.); dioicum; laxe cespitosum humile sordide viride rigidum densissime imbricatum ramosum, ramis brevibus subteretibus; folia ovato-lanceolata, nervo crussissimo in cuspidem longam rigidam crassum produclo, margine e basi usque ad apicem revoluta, periclıctialia majora robustiora fuscescentia; theca in pedunculo elonguto stricto budio subito inclinato-pendula, ovalis crassa badia, collo brevi crassiusculo saepe toroso ruguloso, operculo majusculo conico mammillato concolori nitido basi tumido, peristomio magno. notis?

Br. turbinatum var. Schwägr. Sp. Muscor. p. 56 !! quibus ex

Putria. In humidis argillaceo - arenosis pracprimis in fluviorum vicinia, sociis Dicrano vervo et Metageria pingui: ad pagum Istein prope Basileam in Rheni ripis: A. Braun detexit; pr. Salisburgum et Meran: Funk; pr. Taurinum: De Notaris; pr. Argentoratum in Rheni 
ripis: W. P. Schimper; pr. Steyr Austriae superioris in iistem locis: W. P. Schimper. - Junio, in ulpibus Angusto, ineunte Septembri.

A Br. atropurpureo notis cursive impressis differi, habitu proprio. - Pl. mascula flore crassiusculo subdiscoideo; foliis perigonialibus internis e basi maxime lata convoluta amoene aurea laxiuscule areolata subito et breviter acuminata excurrentinervia, paraphysibus elongatis aureis et antheridiis numerosis majusculis. Peristomium Bryi atropurpurei.

Peristomium ignotum.

109. Br. angustifolium Brid. (I. p. 685.); dioicum; laxe cespitosum humile gracile; folia crecto-patentia superne densius conferta, elongata lanceolata longe acuminata subplana, nervo crasso flavo longe cuspidata, angusta integerrima margine plana, inferne e cellulis laxiusculis magnis quadratis pellucidis superne multo densioribus elongutis vivilibus areolata, perichaetialia interna angustiora; pedunculus strictus.

Putriu. Hispanjola: Green in hb. Brideliano.

Sectio V. Diernnobrynm. Plantac gracillimae tencllae. Folia dense imbricata lanceolata, margine haud revoluta, mimute et donse areolata, carinato-concava, nervo aequaliter crasso flivo pungentia, integerrima, theca erecta dicranoidea, ore coarctata, plus minus urceolata.

110. Ar. diernnoideg Hsch. (Limn. XV. p. 134.); dioicum; densiusculo - cespitosum humile; caulis fertilis brevissimus basilaris, innovationibus brevibus erectis grecilibus compluribus viridibus ramosus; folia ovato-lanceolata integerrima vel summa obsolete denticulata immarginata, nervo erasso in perichactialibus ferruginco decurrente crasso-cuspidata, minute et pellucide areolata; theca in pedunculo longo gracillimo flexuoso suburceolata oblongo-cylindrica annulata pallida dein fusca, busi crussu, ore constricla, dein inclinata, operculo e busi lutiore tumide conico-acuto concolori; dentes peristomii externi longissimi angusti tenuissime subulati inferne fusei apice 
BRYUM.

pallidi rugulosi; membrana interna subcarinata breviusculu pallida, in dentes longos rugulosos angustos subulatos nodosiusculo - articulatos vix carinatos externos aequantes pallidos, ciliis solitariis filiformibus brevibus hyalinis interjectis, producta.

Patria. Prom. bonae spei: ad muros et valla lapidosa ad montem tabularem: EckIon. Octobr. - Prope Swellendam in umbrosis: Pappe.

Ex habitu Br. erythrocarpo et e theca Ceratodontibus simile, notis autem laudatis a primo diversissimum. In axillis foliorum corpuscula gemmiformia viridia dein fusca ut in $\mathbf{B r}$. erythrocarpo atque Preissicmo reperiuntur. Perigonia perichaetiis e forma et foliis simillima, antheridis crassis majusculis numerosis, longiusculo stipitata, apice ramosa, plantis femineis parce intermixta.

111. Hx. Preissianum Hmp. (Ic. Musc. tab. 25.); laxe cespitosum humile; caulis fertilis brevissimus basilaris, innovationibus elongatis erectis quam maxime gracilibus compluribus velutino-viridibus ramosus; folia ovato-lanceolata integerrima immarginata, nervo crasso decurrente crasso-cuspidata, minute et pellucide areolata; theca in pedunculo longo gracillimo flexuoso oblongo-cylindrica annulata pallida parum curvata, basi crassiore, ore angustiore, dein inclinata ore vix coarctuta, operculo conico breviter subulato erectiusculo aurantiaco; dentes peristomii externi laeves longissimi anguste tenuissime subulati subpallidi; membrana interna subcarinata brevis hyalina, in dentes longos lueves subulatos angustos subhiantes subcarinatos externis breviores pallidos tenues, cilis solitariis filiformibus brevioribus hyalinis interjectis, producta.

Putria. In rupibus calcareis Novae Hollandiac prope Freemantle legit Preiss.

Br. dicranoidi Hsch. simillimum sed thecae oris et operculi diametro aequali atque peristomio interno differt. An ejus varietas? In axillis foliorum ut in Bryo erythrocarpo et dicranoide corpora gemmiformia viridia dein fusca inveniuntur. Dioicum? 
112. Br. Nepalense Spreng. (Syst. Veget. IV. 1 . p. 211.); monvicum; dense cespitosum hunile frostratum; caulis lertilis brevissimus basilaris, innovationibus brevibus erectis subsimplicibus dense foliosis; folia ovato-lancoolata medio latiora crecta integerrina sordide viridia marginata (?), nervo crasso cuspiden tertiae folii parti asqualem formante lutescente; theea annulata in pedunculo longiusculo vecita crecta basi et apice attemuata, opreculo comico obtusinsculo diametro oris thecue unguali concolori; dentes peristomii exterii lineari-subulati, albido-lutescentes transverse sulcati; membrana interna dimidio brevior in dentes cilifformes nodosinsculo-arliculatos rix hiuntes, cilies brerissimis ivreyularibus interjectis, producta. †.

Brachymenium bryoides Hook, in Schwägr. Suppl. II. 2. p. 131. t. 135. et Brid. I. p. 603. - Brach, herpocaulon Brid. mst. I. c.

Putriu. Ad terram in sylraticis Nepalensibus.

Br. exili proximum, notis autem designatis distinclissimum.

113. Hr. exile Dz. et Molkb. (Musc. Archip. Ind. p. 13. t. 6.); dioicrm; dense cespitosum hunile; caulis fertilis brevissimus basilaris, innovationibus erectis sublerelibus gracilibus compluribus lutescentibus ramosus; folia crecto-patentia siccilale subupmressu, orato-lanceolata integerima immarginata, nervo crasso decurente crasso cuspidata, minute et pellncide areolata; theca in pedunculo longe gracillimo orali-urceoluta ore nerangusta erecta fusca annulata, operculo e basi latiore tumida bre viter conico-acuto concolori; dentes peristomii externi angustissimi lanceolato - subulati linea media exarati et e cellularum serie duplici formati subcarinati pallidi; menbrana interna dimidio brevior in dentes externis adglutimatos tenuissimos, ciliis binis brevissimis interjectis, rugulosos pallidos producta.

Putria. Java in monte Patocha et Simpai et in Sumatra.

Br. dicranoidi, Preissiano et Nepalensi affinissimum. sed folis longius cuspidatis, innovationibus subteretibus. 
theca perfecte urceolata erecta atque peristomio differt. Corpuscula in axillis foliorum parce tantum observantur.

114. Mr. conretatum C. Müll.; dioicum? densiusculo-cespitosum humillimum; caulis fertilis brevissimus basilaris, innovationibus brevibus erectis dense foliosis; folia innovationum e busi breviter oblongu orali-lanceolutu nervo crasso constanter ferrugineo longinsculo-cuspidatu summo apice pili acuta hyulina, integerrima immarginata, perfecte rhomboideo - mosenchymatico - et la.ro-areolata; perichaetialia majora longiora angustiora intima angustissima et e cellularum serie subduplici angusturnm angnstissime maryinata pellucidiora longius cuspiduta upice subdenticulata; theca in pedunculo elongato gracili flexuoso oveli-cylindrica utrinque attemuta ore constricta crecta fusca, operculo e basi tumidiuscula sublatiori breviter conico acuto; peristomii dentes externi breviusculi inferne fusci apice hyalini; membrana interna dimidio brevior in dentes externis alglutinutos, cilis irregularibus interjectis, producta.

Br. exile var? Hmp, in litt.

Putria. Java.

Ex habitu bryi exilis, sed foliorum innovationum et perichaetialium forma et textura ab co ceterisque congeneribus differt.

115. Hr. megalacrion Schwägr. (Suppl. I. II. p. 104. t. 71.); divicum; lumillimum, innovationibus erectis brevibus; folia perichaetialia conferta, imnovationum remota, lanceolata nervo crasso flavo longe et crasse cuspidata, parum concava erecta stricta integerrima cellulis minutis densis areolata, pallida vel luteo-viridia; theca in pedunculo brevi flexuoso erecta obconica ore cmplior pallida, operculo conico brevi aurantiaco; peristomii dentes exterui lanceolati remote trabeculati solidi angusti breves, interni in membrana lntea lancerolati laliusculi imperfarati, ciliis solitariis interjectis. + .

Brid. I. p. 610, quod e spec, unico hb. Bridelii novwn videtur, excludendum. 
Putril. Insula Franciae: A ub. D u Petil Thouars.

Br. dicranoidi proximum, sed notis cursive impressis distat.

116. Br. Marveyanum C. Miill.; caulis brevinsculus, innovationibus longis erectis ramosus; folia orato-lanceolatu acuminatu acutu, integervima excurventinerevia, tenero-membranacea late-cellulosa; theca erecta oblongopyriformis operculo conico; perist. Brachymenii. †.

Brach. acuminatum Harv, in Hook, 1c. PI. Rar. t. 19. f, 3. et in Lond. Journ. of bot. 1840. II. p. 10.

Putria. Penang Indiae orientalis: Wallich.

Ex ic. et speciminibus Montagneanis (an authenticis ipsissimis?) $\boldsymbol{B r}$. exili proximum.

117. Ar. Indieum Dz. et Molkb. (Musc. Archip. Ind. p. 22. t. 11.); hermaphroditum; densiusculo-cespitosum humile; caulis fertilis brevissimus basilaris, innovationibus longiusculis erectis subgracilibus dense foliosis sordide viridibus ramosus; folia erecto-patentia siccitate in spirum obsoletum congestu, ovata, nervo crasso sordide flavo excedente crasso-cuspidata, integerima, siccitate cellulis marginalibus exsiccatis veluti dentata, apjec tantum obsolete denticulata, e cellulis submagnis brevibus utriculo primordiali hic illic praeditis pellucidis composita; theca in pedunculo flexuoso cylindrica ore vix constrictu erecte subcureulu fusea annulata, operculo conico brevissimo concoluri; dentes peristomii externi $\boldsymbol{B} r$. exili similes fusci; membrana interna in dentes solitarios fugacissimos rugulosos ciliis rudimentariis interpositis fissa.

Patriu. Java et Amboina in solo calcareo.

$\boldsymbol{B} r$. exili proximum, sed inflorescentia, arcolatione foliorum laxiore et theca aequali-cylindrica, operculo basi aequali obtecta, distat.

sertio VIl. Argyrobryum. Plantac plus minus cespitosic plenumue julace-folinsae. Folia dense imbriata minute areolata mollia argentca, chlorophyllo superue destituta, theca pendula ovalis. 


\section{S'TEGOCARPI. ACROCARPI. BRYUM.}

118. Rr. argenteum L. (Sp. Pl. p. 1586.); dioicum; cespitosum subhumile erectum ramis julaceis argenteis vel glaucis plus minus elongatis et clavatis; folia caulina latiusculo-ovalia subito acuminata valde concava, inferne viridescentia dense areolata, superne decoloria tenerime membranacea, nervo infra apicem veluti evanido sed obsolete hyaline in cuspidem exeurrente, subtenui flavido; perichactialia sensim et longius acuminata; omnia integerrima; theca longiusculo-pedunculata pendula oblongo-or'elis subentricosu parva ore courctulu colorata, operculo c basi trmidiuscula conico acuto majusculo concolori; peristomium Bryi.?

Br. Europ. 1. c. p. 78. t. 41. - Brid. I. p.667. - Br. pendulum julaceum argenteum et sericeum. Vill, p. 392. t. 50. f. 62.Mnium rorgenteum Hoffu. Deut. Fl. I1. p. 51. - Mymum aryenteum s'clirank. Baier's. Fl. II. p. 469.

8. lanatum; ramis magis clavatis foliis longe crinitis apice reflexiusculis albido-argenteis. Br. Furop. 1. c. - Br. lanatum Brid. 1. 1.659. - Mnium lanalum P. B. Prodi. 1. 75.

$\gamma$. majus; clongatum, foliis brevissime acuminatis submuticis vilescentibus. Br. Furop. 1. c. p. 79. - Br. julaceum Schrad. Spic. Fl. Gelm, p. 70. n. 2. et Brid. I. 1. 659. cx maxima parte.

Patrie. Planta cum var. $\gamma$. per totum orbem lerrarum occurens. Var. $\beta$. imprimis regiones intra zonam tropicam positas praeferens. - Hyeme et rere. Var. $\beta$. Septembri.

Species e colore et magnitudine partium singularum valde polymorpha, sed foliis plus minus argenteis julaceoimbricatis facile distinguitur. - Planta mascula gracilior, foliis perigonialibus e basi late ovali valde concava apiculatis.

119. Br. microtheea C. Müll.; divicum; habitus omnino Bryi argentei; folia caulina pareu cochleariformiconcura ovalia subito longe cuspidata pilifera, nervo inferne flavo, superne hyalino obsoleto veluti evanescente sed tenuiter excurrente pracdita, inferne minule el dense areolata viridia, superne sublaxius reticulata decoloria te- 
nerrime membranacea; perichaetialia sensim et longius acuminata; omnia integerrima; theca in pelunculo longiusculo apice valde descendente arenato pendula minntissima obconico-subglobosa ore dilutato haul constricta flavescens, operculo perfecte hemisphacrico nec busi tumido, nec apice mummillato aurantiaco; peristomium internum Weberae, ciliis brevibus.

Patria. Manila: Me yer.

A $\boldsymbol{B r}$. argenteo simillimo notis cursive impressis alque peristomio parvo distinctissimum.

120. Mr. Ieueophyulum $\mathrm{Dz}$, et Molkb. (Musc. Archip. Ind. p. 15.); dioicum; habitus Bryo argeuto similis sed planta multo humilior amoene sericea nilida; folia imbricata erecta orato-lanceolata acuminato-cuspidata, cuspide serratu, basi infima colorata, superne omniuo decoloria, nervo obsoleto in cuspidem producto; perichaetialia lanceolato-acuminata cuspidata omnia furum concure subpluna; theca longiusculo-pedunculata nutans ovalioblongu fuscidula operculo conico-obtuso aurantiaco; peristomii interni dentes angusti, ciliis fugacissimis irregnlaribus avticulatis fragilibus $1-3$ interpositis.

Putria. Java in terra: a Junghuhn lectum habemus. Oahu: Meyen.

A Bryo argenteo colore pulcherrime nitido sericeo, peristomio et foliis planiusculis atque caulibus humillimis valde differt. A $\boldsymbol{B r}$. microtheca notis isdem et thecae formá longe distat:

Sectio VII. Selerodietyon. Plantae Jaxe cespitosae valde ramosae; Holia valde concava fere cymbiformia, e cellulis firmis (partim vel omuino) inanibus rhomboideis plus minus latis nou angustis areolata, coriacea, nitida rigida, theca pendula plus minus oblongo - pyriformis,

\section{a. Folia julaceo-imbricata.}

121. Br. Julaceum Sm. (F゙. Brit. III. p. 135\%.); dioicum; elongatum cespitosum gracilescens, ramis inarqualibus tereti-julaceis filiformibus rigidis, folia densissime appressa, illa ramorum ocalia acutiuscula, arcte et 
minutiuscule basi tenerius pellucidius superne magis flavescenti-areolata, rigida integra subcarinato-concava, nevo Acuro infra apicem dissoluto, perichaetialia angustiora acutiora basi purpurascentia; theca in pedunculo breviusculo flexuoso subpendula pallida oblonga, operculo conico brevi mammillato aurantiaco; perist. Bryi.

Br. Europ. J. c. p. 79. t. 40. - Brid. I. p. 659. e minima parte huc pertiuet. - Sclwwägr. Suppl. II. II. 2. t. 195, - Br. filiforme Dicks. Fasc. IV, PI. Crypt. p. 16.

Patria. In subalpinis et alpinis locis irriguis Angliae, Scotiae, Hiberniae, Norvegiae, Sueciac, Lapponiac, Tirolis in valle Oetzthal dicta: Sendtner; in Gastunia: Fu $\mathbf{k}$; in alpibus Salisburgensibus ad catarractam Krimmler-Fall dictam alt. 4000: sa u ter, W.P.Schimper, pr. Purtschinsk ditionis Meranensis: F. Braun. E rarioribus et raro fructiferum. - Aestute.

P1. mascula femineae intermixta, et huic simillima, subsimplex, e basi usque ad apicem dense foliosa; flore terminali gemmaceo minuto; foliis perigonialibus externis c basi lata ovata concavis angustatis obtusiusculis, internis angustioribus minoribus acuminatis enervibus; antheridiis minutiusculis numerosis, paraphysibus filiformibus mixtis. Dentes peristomii externi lanceolati basi ferruginei, apice hyalini, interni in membrana alta aurantiaca valde sulcati et hiantes pallidi vix serrulati, ciliis $1-2$ hyalinis laevissimis vix appendiculatis nodosis interpositis. Pulcherrima species.

122. Br. semiovatum Brid. (I. p. 846.); divicum; hrumillimum compactum upice ramis gracilibus brevibus tereti-julaceis rigidis filiformibus compluribus praeditum; folia densissime appressa, illa innovationum lanceolatu, arcte et minute areolata; subpellucida rigida integerrima subcarinato-concava, nevo crasso flun excedente apire sacpe recurviusculo crasse mucronutu, perichaetialia e cellulis longioribus laxioribus sed firmis composita; theca in pedunculo elongato stricto cylindraceo-oblonga subpendula lusea, operculo hemisphaerico-conico obtuso; perist. U'eberae. 
Br. julacent Kuntl., 8ynops. PI. Aeq. p. 56.

Putru. In sylvis opacis humidis prope Pasto, regione frigida, alt. 1350 hexap. et in jugis Andium, regione temperala: Humboldt et Bon pland.

Peristomium magnum; dentes externi fusci apice hyalini, intemi ex obs. Bridelii pulchre hiantes ciliolis singulis brevissimis interpositis. Pl. mascula humilis inferne nuda superne ad florem capituliformem ramis binis brevissimis praedita. Folia perigonialia externa perichactialibus e forma et areolatione similia sed basi latiora, nervo ferrugineo praedita, interna convoluto-vaginanti-ovalia minora obsoletinervia laxius areolata. Antheridia elongata paraphysibus multis mixta. - Ex habitu $\boldsymbol{B}$ r. juluceo simile, sed foliis crassinervibus mucronatis, operculo et floris masculi structura longinquum.

123. Hr. prostratum C. Mïll,; dioicum; labilus Bryi julacei, sed prostratum altins ef ommibus purlibus robustius rigidissimum, foliis rameis similibus minutissime crenulatis, perichaetialibus denticulatis, perigoniolibus untem maxime latis conrolutis plicutis ovalibus breviter acuminatis, e cellulurum serie unicu reluti marginutis, cvanidinervibus laxe areolatis aureo-coloratis, intimis obtusatis minoribus, antheridis maximis cylimdricis instructum; theca in pedunculo quam maxime elongato grocili purpurascente flexuoso apice parum arcuato horizontaliter nutans elongate pyriformis longiculla ore constricta fuscu, operculo conico majusculo acuto concolori; peristomii siccitute valde depressi maximi dentes externi lati longissimi latere valde appendiculati, interni illos reguantes in membrana alta pallida lati et lato-hiantes apice in cilia bina tennissima bifidi, cilies $\mathbf{3}$ longissimis valde appendiculatis hyalinis interpositis.

Putriu. Columbia, prov. de Merida in Serra Nevada altit. 9000 ped., 1846. Sept. in arboribus putridis leg. Funck et Schlim. Collect. Lindenian. No. 1081.

A $B r$ juluceo, primo adspectu proximo notis cursive impressis distinctissimum et pulcherrima species. 
- b. Folia laxe imbricata.

124. Br. orthocladum Br. et Sch. (Musc. Abyss. No. 589.); dioicum; compacte cespitosum elongatum robustum erectum nitidum inferne purpurascens superne flavescens ramosum, ramis crassis follis dense apnressis juluceo-teretibus; folia caulina oblongo-ovalia obtusa vel acutiuscula valde concava integerrima, e cellulis ubique firmis subinumibus vividibus corieceo-firma, nerro subtenui evanido virili, basi crusso mulcherrime purpureo proedita immarginata; perichaetialia externa oblonga, subplana veluti elongato-ligulata s. caviuscula, intima multo minora ovali-acuminata crenulata, omnia basi vel omnino pulcherrime purpurea evanidinervia, e cellulis longis angustis parietibus flexnosis praedilis formata; theca in pedunculo e basi ascendente purpureo apice arcuato tenuiore pendula elegunter pyrifurmis exucte symmetricu purpurascens parra subangusta, operculo conico brevissime acuto basi purpureo nitente; perist. Weberce.

P'atria. Abyssinia ubi legit W. Sch imper.

Planta pulcherrima, $\boldsymbol{B r}$. lueviguto proxima, sed differt jam foliis immarginatis omnino e cellulis firmis parietibus tenuioribus, compositis, partibus omnibus purpurascentibus et notis ceteris illustratis. - Archegonia et paraphyses creberrima purpurea. Peristomium ex obs. anct. Weberae.

125. Br. blandum Ilook. et Wils. (Lond. journ. of bot. 1844. p. 546.); laxe cespitosum erectum subsimplex robustum purpurascenti-nitens ramis reluti truncuto-obfusis; folia laxe appressa lato-elliptica obtusa valde concara, integerrima, inferne e cellulis clongutis angusliusculis pellucidlis, apice multo minoribus firmissimis purietibus incrussutis flacis pracditis compositu, nervo temi fermine subcontinuo instructa.

Putria. Insula Campbellii: J. II ooker.

Bryo celluluri Hook. ex habitu simile sed notis illustratis al) eo ceterisque congeneribus distinctissimum. 
126. Ir. lacvigatum Hook, et Wils. (Lond. journ. of bot. 1844. p. 546.); compacte cespitosum elongatum robustum erectum ramosum; folia dense imbricata erecta laxe appressa oblongo-ovalia obtusa vel acutiuscula valde concava integerrima s. summo apice subcrenulata, basi margine parum revoluta, a cellulis infima basi laxis superne furmis pariptibus incrassatis praeditis subinamibus viridibus areolatu coriuceo-firma, margine e cellulis longioribus reluti incrassuto-marginata, nerro subtemi ante apice merunido fuscescente praedita nitida; theca pendula obovato-oblonga, operculo conico obtuso.

Patria. Insulac Eremitae, Falklandi ad Cap. Horn sterile; in terra Van Diemen fertile, quibus speciminibus ad fructum describendum usi sumus.

Ex habitu Bryo pseudotriquetro haud dissimile, e structura autem foliorum et ex habitu, praescrtim speriminum ralde compactorum, Bryo orthochado $\mathbf{B r}$. et sich. simillimum.

"sectio XX. Orthocarpus. Plantae dense cespitosae vel compactae. Folia acumilata plerumque pilifera elongate angunta et paulisper laxe areolata mollia, margine rato revoluta plerumque plana concava saepe cochleariformia, theca erecta pyriformis. Peristomim omnium congencrum Brachymenii.

1. Folia patula erecto-appressa.

a. Folia immarginata.

127. Hr. Sellowianum C. Nüll.; divicum; erectun apice fastigiato-ramosum; folia crecta subappressa oblonga superne latiora carinato-concava, neve crusso fluro excedente crusse ef breviter mucronuto, margine upicis cellulis minoribus reluti murginuntibus prominentibus repando-denticulata, e cellulis rhomboidalibus pellucidis utriculo primordiali instructis arcolata; theca in pedunculo elongato flavo strictiusculo orali - cylindrica crecta flavida, operculo concolori conico brevi et collo brevissimo praedita.

Didlymodon Klotzschii schwïgr. Suppl, 1V. tab. 310.

Putria. Brasilia: Sellow. 
Peristomium nobis ignotum ex if. Schwăgr. externum tantum observatum, e dentibus pallidis lato-lanceolatis constructum. Internum verosimiliter Brachymenie.

128. Br. Martianum C. Mïll.; densiusculo-cespitosum; caulis erectus apice fusciculution ot breviter rotmosus, inferne nudus; folia erecto-patentia, siccitate appressa, subtorta inferiora remota oblongo-lanceolata acuminata canaliculata, superiora lato-ovalice in acumen producta, nevo crasso rufescente supra folii medium dissoluto, subquadrate et laxissimo-areolata; perichaetialia majora oblonga, margine involuta, intima duplo minora angustiora lanceolata plana amoene viridia; theca erecta crassa ovata, ore angusto.

Brachymenium michellum Hsch. H1. Bras. Fasc. 1. 1. 36.

Patria. Brasilia in Minis generalibus ad cortices arborum: Martius.

Peristomii dentes externi humiditate erecto-patuli, siccitate conniventes lanceolato-lineares solidi arliculati subnodosi, inferne ferruginei, superne albidi; membrana interna albida dentibus exteriorjbus dimidio brevior, apice dilacerata, in processus 16 irregulares producta. $-\mathrm{Br}$. IIornschuchiuno simile, notis tamen laudatis distinctissimum. Dioicum?

129. Br. Systylium C. Müll.; divicum; dense intertextum lato-cespitosum viride crectum gracile; folia erecta subappressa, innovationum inferiora ovalia oblonga integra, nervo excelente cuspidata, concava, superiora longiora basi angustiora pilifera planiuscula subintegra; perichaetialia multo longiora angustiora margine revoluta longe acuminata pilifera, nervo ferrugineo ante pilum obsoleto, summo apice subdenticulata; thera in pedunculo clongato torto cyliudrico-oblongu brevicolla majuscula crecta fusce, operculo conico brevissimo atro nitido, drin columella subexserta elevato.

Acidodontium hunthii Hsch. in Musc. Mexic. a neppe et schiede collectis.

Patria. Mexico prope Xalapam. 
Peristomii dentes externi lanceolati breviusculi crassiusculi fusci, apice rugulosi albescentes; membrana interna dimidio brevior flavescens, apice laciniato-dentata vel interdum in membranam tenerrimam hyalinam, cilis nomnullis filiformibus fugacissimis dentibus externis adglutinatis praeditam, producta. - $\boldsymbol{B r}$. leptostomoidi proximum, differt autem: colore viridi, nervo omnium foliorum apice multo tenuiori, in perichactialibus ante pilum obsolet.o, foliis perichaetialibus margine revolutis, theca brevicolla fusca et operculo atro.

130. Br. Ieptostomoides C. Müll.; dioicum; compactum intense brunne-tomentosum lato-cespitosum lurescens nitidum erectum subcurvum, foliis planiusculis subappressis sciuroideum; folia caulina superiora ovalilanceolata, nervo crasso flavo in pilum longissimum flarem apice tantum summo hyalinum sublacem flexuosum producto, superne subdenticulata; perichaetialia multo longiora angustiora longe acuminata nervo crasso excedente cuspidata e cellulis valde angustis elongatis pellucidis areolata firmiora subintegerrima margine flaviora; theca in pedunculo longiusculo ex ochraceo purpurascente ascendente erecta pyriformis subbrevicolla clacuta auranliacu, operculo conico minuto brevissimo convexo purpureo nitido.

Brachymenium pulchrum Hmp. in litt. - Bruck. ciliare Mont. in litt.

Putria. India orientalis: IIb. 11 a mp. E montibus Neelgheriensibus: IIb. M on tag $n$.

Plantae masculae femineis intermixtae. Flos mase. terminalis femineo similis. Folia perigonialia perichaetialibus simillima sed multo breviora et magis concava. Antheridia pauca eparaphysata. Membrana interna brevis apice dentato-laciniata. Br. Systylio proximum, Br. pulchro et Korctrano e cespitibus maxime compactis et ferrugineo-tomentosis affine, sed haud julaceum.

\section{b. Folia marginata.}

131. Bx. Peromnion C. Müll.; dioicum; laxe cespitosum; raulis erectus prolifero-elongatus, inferne unc. Mi il er: Synops. musc, frond. 
diusculus, superne rosulatus simpliciusculus; folia comalia erecta elongata angusta acuminata, nevo crasso e.xcedente longissime cuspidutu, murgine flexuoso-undulata, e medio ad apicem usque tenuiter et flavo-marginata subdenticulata, bası e cellulis maximis laxis pellucidis vel rubescentibus, apice minoribus angustis viridibus densioribus areolata; theca in pedunculo elongato stricto longe cylindricu ungustu suberectu longicolla, anmulata, operculo conico acuminato brevissimo.

Peromnion radiculosum schwägr. suppl. 111. 1. 2. tal., 250. cum peristomio false delineato.

Patria. In sylvis antiquis Brasiliac prope NovoFriburgum: Beyrich ad truncos arborum legit.

Peristomii dentes externi angusti subulati clongati opaci. Membrana interna exacte sulcata plicata in cilia tenuissima filiformia producta. Planta mascula femineae similis; flore discoideo folisque ovalibus acuminatis nervo ante apicen evanido praeditis immarginatis integerrimis parvis valde pellucidis.

132. Hr. Hornschuchianum C. Müll.; divicum; dense cespitosum gracile; folia caulina oblougo-lanceolata pilifero-ucumincutu undulata laxiusculo-rveolutu et imbricata, tennissime marginata apice subdenticulata, mero ante apicem evanido; perichaetialia perfecte lunceolutu longiora et longius pilifera, e cellulis laxioribus et multo longioribus areolata evanidinervia integerrima immarginata pellucidiora; theca longiusculo - pedunculata erecta crussu ovcuto-pyriformis ore constricta annulata pallida, operculo conico brevissimo recto obtuso.

Brachymenium Iornschuchianum Mart. Ic. Crypt. Bras. 36. tah. 20. f. 4. et in FJ. Hras, Fasc. 1. p. 36.

Prtria. Brasilia in pracruptis viarum, nec non in radice arborum annosarum in prov. Minarum passim: Martius. Gardner No. 32. - Primis anmi mensibus.

Peristomii dentes externi breves rugulosi valde trabeculati. Membrana interna brevis in dentes interdum altiores asperrimos obtuso-articulatos producta, ciliis omnino carens. 
133. Hr. brevicaule IImp. (in IIb. Gottscheano); monoicum; laxiusculo - cespitosum lıumillimum robustum simplicissimum; caulis brevissimus dense et comoso-foliosus; folia caulina oblongo - ovata valde concava lata nervo crasso ferrugineo excedente longiusculo-cuspidata, basi laxe apicem versus minute et dense areolata, margine sacpe revoluto late et flavo-marginata subintegerrima; perichactialia intimn lanceolata longissime cuspiclutu multo minore et angustioru, longe areolata; theca longipedunculata clavaeformi-pyriformis longicolla erecta dein nutans.

133. Nepulense Dz. et Molkb. Muse. Ind. Archip. p. 12.?

Patria. Java insula.

Dentes peristomii externi subreflexi angusti carnosuli dense trabeculati; membrana interna alta in dentes irregulares breves rugulosos ciliis carentes producta. Flos masculus in feminei ricinia terminalis gemmaceus. Folia perigonialia caulinis similia, longius cuspidata, intima minora laxissime areolata enervia immarginata integerrima. Omnes partes rufescentes. Areolatio foliorum ut in $\mathbf{B r}$. Aexifolio et Abyssinico. Forsan sequentis varietas.

134. Br. Wookeri Spr. (Gyst. Veget. IV. p. 212.); monoicum; laxe cespitosum robustum imnorationibus apice rumosum inferne muliusculum; folia ovata lingulata vel obovato-lingulata marguata serruta amoene viridia, nervo excedente rufo cuspidata parum concava; perichaelialia, excepto intimo, caulinis similia; theca pyriformis recta, orificio duplo angustiori, badia, operculo conico brevissimo.

Bruch. Nepalense Hook, in Schwägr. Suppl. II. II. p. 131. tah. 135. - Brid. 1. p. 602.

Patria. In Nepal Indiae in terra humosa.

Peristomii dentes externi reflexinsculi angusti breves linea media exarati subfusci; membrana interna lutea in dentes carinatos utriuque repandos brevissimos, ciliis irregularibus interjectss, producta. Folia perigonialia ovata acuminata, nervo mucrouta, inlima nervo vix conspicuo, rufo-viridia. 
2. Folia julaceo-imbricata.

135. Br. pulchrum C. Müll.; divicum; maxime compactum lato-pulvinatum erectum subhumile; caulis inferne maxime 1omentosus, summo apice tantum liber, densissime et julaceo-foliosus teres; folia caulina oruto lanceoluta, perichaetialia busi lutissima perfecte lanceoluta, omnia longissime hyalino-pilifera, subintegerrima, pilo denticulato, concura, nervo crasso ante pilum evanido praedita, flavescenti-albida nitida, immarginata, dein margine subpellucida, laxe areolata pellucida; theca brevipedunculutu pyriformis votundata crassa brevicolla erecta annulata, operculo conico obtuso.

Brach. pulchrum Hook. Botanic. Miscell. 1830. I. p. 136. t. 3 .

Patviu. In nemoribus prope Swellendam prom. bon. spei: Mund t.

Peristomii dentes externi angustiores; interna membrana dimidio brevior apice dentato-laciniata, hic illic perforata. - Sequenti quam maxime simile, sed foliis angustioribus sublanceolatis longioribus margine minus pellucidis et theca breripedunculata brevicolla sat differt.

136. Lr. Koratranum C. Müll.; dioicum; maxime compactum lato - pulvinatum erectum subhumile; caulis inferne maxime et ferrugineo-tomentosus, summo apice tantun liber, densissime et julacen-foliosus teres; folia caulina maxime oralia rentricoso-rel cochleariformi-concava breviora latissima, nervo crasso in pilum longissimum denticulatum hyalinum excedente, apicem versus leviter serrulata, margine lato-pellucidu lase areolata; perichaetialia interiora lato-lanceolata, longissime pilifera evanidinervia; theca longe pedunculatu, pyriformis clavata longicolla erecta.

Brach. julaceum Hisch. Linn. XV. p. 133.

Patriu. Africa australis, Outniqualand prope Koratra in arboribus sylvarum, ubi in altitud. 800 ped. 24. Sept. 1831. fructibus deoperculatis legit Drège. Ad flum. Kat-Rivier dictum pro. Philippstown legit sterile Ecklon: Hb. Kunzeanum. 
Innovationes juniores graciliores inferne tenues, apice truncato-clavatae breves. Dentes externi ut in $\boldsymbol{B}$ r. pulchro humidi reflexi, siccitate conniventes lanceolati obtusi rufescentes; membrana interna brevis hic illic pertusa lutescens, apice in processus plures irregulares erosos producta. - A $\mathrm{Br}$. pulchro simillimo notis cursive impressis certe distat.

Sectio X. Senodictyon. Plantae plus minus huniles laxe cespitosae. Folia superne in comam plerumque apertam congesta, angusta plus minus lanceolata, e cellulis angustissimis densissinnis firmis plerumque elongatis et inanibus viridibus areolata, medio marmine revoluta, nervo tenui evanido vel excurrente, firma, plerumque nitida et serrulata, carinato-concava, theca inclinata anususta plus minus cylindrica et longicolla, vel ovalis pendula.

\section{Peristomium Brachymeni.}

137. Br. microstomum C. Müll.; caulis gracilis breviusculus subramosus; folia lanceolata acuta supra basiu usque ad apicem subserrata erecta, siccitate stricta, excurrentinervia; theca longissime pedunculata erectu ocate, ore angusto, operculo plano. t.

Br. microstomm Harv. in Hook. Ic. PI, Rar. t. 19, f. 4. et in Lond. Journ. of hot. 1840. 11. p. 10.

Putriu. Nepal Indiae: Wallich.

Ilabitus Bryi cunotini et affinium, differt autem jam peristomio.

138. Br. Weisia C. Mïll.; gracile breviusculum, inferne dense cespitosum; folia lanceolato-subulata stricta e basi usque ad apicem serrata, excurrentinervia; theca brevi-pedunculata erecta ovata crassa brevicolla, operculo conico. t.

Brach. Weisia Hook. Harvey in Lond. Journ. of bot. 1840. II. 10. 10. et in Hook. Ic. Pl. t. 19. f. 1.

Putriu. Nepal Indiae orientalis: Wallich.

Dentes peristomii externi angusti dense trabeculati subulati; membrana interna alla, dentibus et ciliis obsoletis. - E ratione Cl. W ilson (in litt. ad Cl. $\mathbf{M}$ ontagne) species fallax et per se non existens. Quid autem? Ex ic, Br. polymorpho affine videtur. 


\section{Peristomium Pohliae.}

139. Br. acuminatum Br. et Sch. (Br. Liurop. Bryum; p. 21. t.6.); monoicum, flore masculo gemmaceo ad basin feminei; dense cespitosum simplex vel innovationibus ramosum; folia caulina inferiora remota minuta ovato-lanceolata, superiora lanceolato-acuminata, margine valde revolutu, complicato-concava, apice serrata, nervo subcrasso fuscescente excurrente in cuspidem brevem producto praedita, anguste dense et Tongiuscule infima basi laxius ureolutu, viridissima submollia; perichaetialia intima multo minora haud revoluta integra; perigonialia e basi vaginante lato - ovali multo laxius areolata subito acuminata, interiora haud revoluta, omnia denticulata; theca in pedunculo longiusculo apice arcuato cylindricopyriformis longicolla horizontalis pallescens, operculo longiuscule conico-acuminato suboblipno aurantiaco.

Pohlia acuminutu Hpp. et Hsch. in Regensb. bot. Zeit. 1819. 11. p. 94. et in Brid. I. 1. 610. - Webera elongata ß. acuminut sichwäg1. sp. Muse. p. 49 - pohlia elongata $\gamma$. acuminatı Hïl. Muscol. Germ, p, 473 - Pohlia arcuut Hup. et Hsch. Regensh. hot. Zeit. 1819. 11. p. 98. et Brid. 1. 10.614, forma minntissime areolata. Pohlia regeta et putens Hpp. et Hsch. I. c. p. 101. et Brid. I. p. 620. espcc. auth. nostris suspectissimae species, ex obs. Br. Kurop. ex parte huc et ad Br. nutans atque polymorphum pertinent. Varietates omnes ceterae Bryol. Europ. ad Br. polymoryllum revocaudae sunt, ut e speciminibus nostris inflorescentia androgyna gandentibus authenticis elucet.

Putria. In alpinis et subalpinis totius kiuropac. Versus aestutis finem.

Primo adspectu theca elongato-cylindrica acuminatooperculata angusta distinguitur.

140. Br. papiHosum C. Müll.; dioicum; subsimplicissimum humile; folia imbricuta parrum secunda of mudefucta punllisper tortu oblique, lanceolato-acuminata. nervo ante apicem evanido instructa carinata, apice serrulata longiuscule anguste et dense ureolutu rividiu; theca in pedunculo elongato gracillimo flexuoso apice arcuato nutans, ventricoso-pyriformis ore constricta tenuissime membranacea subglauca, dein fusca, calde papillose oper- 
culo breviter conico ora aurantiaca praedito; dentes peristomii externi et interni ut in $\mathbf{B}$ r. brachydontio ciliis nullis interpositis.

Putria. Columbia, prov. de Caracas ad Galipan alt. 5000': F'u uck et S'chlim mense Januar. Collect. Liudenian. No. 346.

Br. brachydontio simillimum, forma caulis et structura foliorum $\boldsymbol{B r}$. nutanti affine, sed notis laudatis facillime distinguitur.

141. Br. brachydontium Hmp. (in litt.); divicum; diviso-ramosum inferne radiculosum laxe cespitosum, ramis gracilibus laxe foliosis; folia lanceolutu longe acuminat $九$ angusta, margine revoluta, nervo ante apicem evanido ferrugineo, apice serrulata, anguste, laxiuscule et pellucido-ureolate; theca in pedunculo elongato gracillimo flexuoso apice arcuato nutans, ventricoso-ovalis suburceolata, basi el ore constricto attenuata fuscescens, operculo breviter conico; peristomium brevissimum: dentes externi basi latissima tenera dense trabeculati et densissime approximati, breves obtusi pullidi, superne valde rugulosi et obsolete articulati, interni in membrana brevissima hyalina tenervima longiores irregulariter subulati vix hiantes valde rugulosi mallidi, ciliis rudimentariis vel nullis interpositis.

Putria. Java in saxis sylvarum montis Merapi meridionalis alt. 3-4000': Junghuhn. - Aprili.

Br. muturti ex habitu fruct. affine, ex areolatione autem foliorum ad $\boldsymbol{B r}$. corneum magis accedens, notis laudatis peristomio praesertim ab omnibus congeneribus distinctissimum. - Planta mascula gracillima sacpe ramosa et floribus 1-3 gemmaceo-capituliformibus praedita. Folia perigonialia e basi latissima ventricoso-vaginante fusca sensim subulata subexcurrentinervia integerrima laxe arcolata. Antheridia multa crassa, paraphysibus paucis brevibus cincta.

142. Br. flexuosum C. Müll.; laxe cespitosun subgregarium humillimum simplex; folia lincari-subulata, 
superne denticulata, nervo tenui excurrente; theca in pedunculo elongato valde et arcuato-flexuoso inclinata vel suberecta cylindracea angusta brevicolla operculo rostratosubulato praedita. t.

Pohlia Rexuosa Hook. in Wallich Cat. H. 7591. et Harvey in Loud, Journ. of bot. 1840. 11. p. 9; ic. in Hook. Ic. Pl. t. 19. f. 5.

\section{Patria. Nepal: Wallich.}

Ex ic. Br. elongato quoad structuram foliorum afline. Inflorescentia androgyna?

143. Br. cucullatum Schwägr. (Suppl. I. II. p. 94. t. 68.); monoicum, antheridia in axillis foliorum superiorum libera majuscula; caulis humilis laxe cespitosus erectus vel basi declinatus radiculosus ramulosus inferne remotifolius, superne dense comosus; folia inferiora lattiusculo-ovuto-lunceolutu obtusiuscula integerrima, superiora lanceolata angustiora longiora, margine revoluta, apice denticulata; omnia parva nervo crassiusculo subferrugineo evanido praedita valde concava, anguste sed laxinsculo-arcoluta viridissima mollissima; perichaetialia intima multo minora acuminata obsolete denticulata; theca in pedunculo breviusculo llexuoso crassiusculo purpurascente pendula ovalis crassinscula brevicolla fuscescens, operculo hemisphaerico-conico obtuso parto.

Br. Lurop. I. c. p. 27. t. 7. - Brid I. p. 649. - Pohlia cucullata Schwägr. Sp. Musc. p. 73. et Bruch Regensh. hot. Zcit. 1826. p. 274. Brid. 1. p. 840. - Pohlia laetevirens De Not. Mant. 11. 7. et syllab. p. 111. forma robusta.

Patriu. In alpinis et subalpinis ad ierran humidam. L Finmarkia prius habuit IIedwig; practerea in monte IIoheneck Vogesorum: Nouge ot, Blind, W.P.Schimper; in alpibus Penninis, 'Tirolis et Carinthiae: Comba, Funk, Hoppe, Helvetiae: 'Thomas, Schleicher, Salisburgiac, Norvegiae, Sueciac, Iapponiac et in Groenlandia ubi primus legit Giseke. E rarissimis! - Aestate.

Ex labitu Br. mutunti simile, sed peristomio, cujus dentes interni angusti tencri cilis rudimentaris fugacissimis interpositi, foliorum arcolatione omnino laxiore, fo- 
liis inferioribus obtusioribus latioribus, theca microstoma atque operculo parvo differt.

144. Br. polymorphum Br. et Sch. (Bryol. Europ. 1. c. p. 25. t. 8.); monoicum, untheridiu in axillis foliorum superiorum libera per paria disposita; habitus Bryi acuminati, sed densius cespitosum humile coma densiore subclausa; folia oblongo-lanceolata, parum revoluta, apice serrulata, evanidinervia, minutissime angustissime et densissime infima basi quadrato-areolata; theca oblongo-pyviformis brevicolla, horizontalis, operculo plus minus conico-acuminato; perist. Bryi acuminati.

Pollia polymorpha Hpp. et Hsch. Hegensb. bot. Zeit. 1819. p. 95. - Brid. I. p. 619. - Pollia minor schleich. Cent. IV. n. 19. et Brid. 1. p. 611. - Pohlia polyseta Hpp. et Hsch. I. c. p. 99. Hrid. I. p. 617. - Br, acuminatum $\gamma$. polysetum Br. Lurop. 1. c. p. 21. Pollia polymoryha ${ }^{\prime}$. polyseta Häl). Musc. Germ. p."470. - Pohlia brachycarpa c. polyseta schw. Sp. Musc. p. 72. - Pohlia pulchella Hpp. et Hsch. I. c. Brid. I. p. 613. - Bryum acuminutum $\gamma \cdot p_{0-}$ lysetum Br. EArop. 1. c. p. 21. - Pohlia gratilis $\gamma$. mulchella Hüb. Musc. Germ. p. 472. - Webera elonguta $\beta$. minor Schwägr. sp. Musc. p. 49. - Pohlia xanthocurpu Hpp. et Hsch. I. c. p. 98. Brid. I. p. 617. - Br. acuminatum $\%$ polysetum Br. Europ., I. c. p. 21. - Pohlia gracilis p. Santhocurpu Hül. I. c. P. 472. - Pohlia brachycarpa scliw. Sip. Mu*c. p. 72. - Pohlia tenella Hyp. et Hsch. 1. c. p. 95. Brid. 1. p. 614. - Br. acuminatum S. tenellum Br. Kurop. 1. c. p. 21. - Pollia polymor/ha f. tenella Hül. I. c. p. 470. - Pohlia brachycurpu schwager. Sp. Muse. P. 72. - Pohlin dimorphat le Not. spic. n. 4. et Syllah. p. 112. - Pohlia affinis Hpp. et Hscl. I. c. p. 97. - Pohlia minor f. affinis Brid. I. p. 612. - Weber elonguta $\beta$. minor schwiär. Sp. Musc. p. 49. Pohlia gr'acilis H. et Hsitho I. c. p. 100. Brid. I. 10618. Hül), Musc. Germ. p. 472. - pohlia brachycarpa schwägr. Sp. Musc, p. 72. Br. polymorphlum $\delta$. gracile Br. Europ. 1. c. p. 25. - Pohlia bruchycarpa H. et II. I. C. p. 96. Brid. I. p. 616. schwägr. f. c. 1. 72. - P. polymorpha \&. brachycarpa Hïb. M. Germ. p. 470. - Br. polymorphum k. hrachycarpum Br. kurop. 1. c. p. 25. - P. curviseta H. et Hiscl. 1. c. 1. 98. Brid. 1. 1. 618. - Meesia curriseta schwägr. suppl. III. 1. tab. 234. - Br. polymorphum s, c'urrisetum Br. Europ. 1. c. p. 25. - P. cluretu sendtn. in schedulis. var. robusta.

Patria. In subalpinis alque alpinis at terram et in rupium lissuris per totam fere Europam. - V'resus uesfutis finem. 
Species maxime polymorpha et nomine digna, habitu Br. acuminato saepe similis, sed infloresecntia atque theca brevicolla plerumque crassiore et operculo hemisphacrico conico praedita certe distincta.

\section{Peristomium Weberae.}

a. Influrescentia hermaphrodita.

145. Br. pyriforme Hdw. (Ilist. Nusc. I. t. 3. f. 12.); laxe cespitosum simplicissimum, raro apice innovans, crectum subelatum velutino-viride gracillimum, inferne foliis minutissimis, apice longissimis e basi latiore setaceis subcrispis nervo latissimo crasso in laminam folii dilatato excurrente cuspidatis, busi sublaxe, superne angustissime areolutis denticulatis comosum; theca in pedunculo elongato gracillimo inclinato-metans e collo longo vesicularipyriformis tenerrime membranacea laevissima nitida primum pallida, dein fusca, operculo concolori vel aurantiaco conico-acuto.

Br. Furop. I. c. p. 45. t. 18. - Br. Webera pyriformis Brid. I. p. 631. - Hebera mriformis Hedw. Musc. Frond. 1. p. 5. t. 3. Br. rureum schreb. Spic. F'. Lips. P. 81. - Br. pendulum Ellth. Crypt. exs. 11. 163. - Br. mnioides Gmel. syst. Not. 11. 1. 1330.Br. trichodes aurenm capitulis pyoiformilus untantilus. Dill. Musc. p. 391. t. 50. f. 60. - Inium jyriforme I. spec. Pl. p. 1576. Hymum pyriforme Wel, et Mohr. Bot. Taschls. p. 274.

Putria. In locis valde humidis in fissuris rupium atque murorum et in terra turfosa per Europam, Asiam el Americam septentrionalem. - Mujo, Junio.

Peristomii interni dentes maxime sulcati el hiantes valde serrati igitur veluti (sed nom) appendiculati hyalini, ciliis solitariis brevibus non appendiculatis liyalinis interpositis. Formam peristomii hance in speciminibus permultis examinatis invenimus, et Bryol. Europ. indolem non vidimus. Planta igitur ad Heberas veras pertinet et vicinitatem Bryi elongati tenet, e reliquis autem solitaria.

b. Inflorescentia dioica.

146. Br. Sphagni Brid. (I. p. 852.); caule Iongissimo gracillimo ramoso remote folioso fragilissimo; folia 
inferiora minuta ovato-acuminata, superiora sensim magis conferta et majora, dein comam polyphyllam formantia, oblongo-elonyato-et lineali-lanceolata, apice serrata nitida, omnia e cellulis pachydermis ansis mimulis flavis areolatu, nerro crasso plus minus flexuso purpurascente ante upicem abrupto praedita; perigonialia intima temuissima subenevia laxe areolata; perichactialia anguste lanceolat $\iota$; theca in pedunculo longissimo gracillimo nutans oblongo-obconica, operculo magno convexo aurantiaco mammillato, peristomio magno pallido.

Br. sphagnicola Br. et Sch. Br. Europ. Fasc. XXXIr. Suppl. p. 6. taly. 7. ex ic. et descript. cum planta Brideliana, nobis in ej. hb. visa, omniuo convenit. Folia horun speciminum magis obtusoacuminata.

Patria. In sphagnosis turfaceis insulae Terre Neuve sterile legit: La Pylaie. In locis iistem ad lacun Lysager prope Christianiam Norvegiac meridionalis: W. P. Schimper 1814. - Julii initio.

Inter $\boldsymbol{B} r$. mutuns et crudum intermedium, sed notis laudatis pulcherrima species, inter Sphaynu gregarie degens. - Flos masculus illi Bryi crudi similis subcapituliformis.

147. Br. annotinum Hdw. (Sp. Musc. p. 18t. t. 43.); dense gregurimm subsimplex rel inferne innovationibus ramosum, in uxillis folionum plenumpue gemmis foliuceis maeditum, erectum bumile gracile; folia caulina patentia, inferiora lato-lanceulatu evandinervia concurillscula stricta, superiora longiora acuminata margine marum revolutu, apice denticulutu, e cellulis angustis densis sed inanibus viridibus composita submollia; perichactialia intima multo minora; theca in pedunculo longiusculo flexuoso nutans oblonyo-pyriformis puren pallida. operculo conico breviter acuto aurantiaco.

Br. Europ. 1. c. p. 40. t. 15. - Brid. 1. 1) 662. - Weberu annotiun schwignt. sp. Musc, p. מ2. - Mnium annotinum L. Sp. P. p. 1576. - H!pmum annotinum Web. et Mohr. But. Taschh. p. 280. - Tremtemhlia ererta Roth in Uateri Annal. hot. X. p. 52. - Bryum annotinum lanceulatum pellucidum capsulis oblongis 
pendulis, Dill. Musc. p. 399. t. 50. f. 68. - Br. decipiens Brid. I. p.687.?

Patria. Per totam Europam in arenosis et argillosis humidis. - Majo, Junio.

Planta mascula elongata gracillima laxifolia, flore crassiusculo - gemmaceo. Folia perigonialia externa, e basi lata vaginante laxiusculo-areolata subito acuminata angusta valde revoluta serrulata evanidinervia, interiora multo minora denticulata. Antheridia numerosa, parapliysibus aureis cincta. Peristomium W'eberee parvum.

148. Br. pulchellum Hdw. (Musc. Frond. III. p.95. t. 35.); laxe cespitosum simplex humile; habitus Bryi curnei; folia inferiora lanceolata, superiora acuminata longiora, omnia angustissime elongate et densissime areolata viridissima, margine revoluta, apice serrulata evanidinervia; theca in pedunculo longiusculo flexuoso purpurascente apice arcuato subito pendula regularis ovali-pyviformis brevicolla exannulata, operculo hemisphaericoconico breviter mammillato; peristomium Bryi curnei.

Br. Europ. 1. c. p. 42. t. 15. - Brid. 1. p. 651. - Mnium pulchellum P. B. Prodr. p. 76.

Patria. Ad terram alpium 'lirolis, IIelvetiac, Salisburgiae, Carinthiae, Gothiae Scandinaviae, Iapponiac et Islandiae e Schwägrichou. - Aestute.

Planta mascula gracilior ramosa, flore gemmaceo et folis perigonialibus ovato - lanceolatis, internis apicem versus recurvis, omuibus apice serrulatis. A $\boldsymbol{B r}$. carneo notis cursive impressis distinctissimum.

149. Br. Ludwigii Spreng. (Schwägr. Suppl. 1. II. p. 95. t. 68.); caulis fertilis decumbens imnoutionibus ascendentibus; folia inferiora lato-ovalia, media late ovalilanccolata ut summa lanceolata apice serrulata, omnia concava margine reflexa plicala evanidinervia, subanguste et subdense areolata plus minus viridia; perichactialia intima lanceolata multo minora; theca in pelunculo geniculato-ascendente tenuissimo pendula oblongo-pyriformis pure pallida, dein fuscescens vel atropurpurea, operculo hemisphaerico-conico obtuso vel mammillari. 
B1. Europ 1. c. 1. 38. t. 14. - Brid. I. p.647. - Br. Iteigelii spreng. Cent. PI. p. 42. - Muium turbinatum $\beta$. Luduigio Roehl. Dent, FI. 11. p. 95.

B. grucile; elongatum gracile subfiliforme foliis appressis parvis minoribus lanceolatis, coma clausa, theca breviore et bulbillis in axillis foliorum numerosis. Br.gracile Schleich. Br. Europ. 1. c. p. 39.

Patriu. In subalpinis et alpinis ad loca aquosa frigida Suletorum ubi Ludwig am Schneegraben et am Weisswasser detexit, Hercyniae, Vogesorum, Helvetiae, Norvegiae, Sueciae atque Iapponiac. - Ang., Sept.

A Br. cuculluto inflorescentia, peristomio atque thecis tenuissime pedunculatis parvis differt. - Planta nascula femineae similis, flore gemmaceo et foliis perigonialibus externis e basi dilatata lanceolatis obsolete denticulatis, interioribus brevioribus dilatatis acuminatis integris nervo ultra medium producto praeditis. Antheridia per paria in axillis fol. intin. disposita. Peristomium Weberue; dentes interni valde hiantes apice serrati hyalini ciliis tenuissimis $\mathbf{2}-\mathbf{3}$ inaequalibus nodosiusculis interjectis.

150. Br. erudum Schreb. (Spic. Fl. Lips. p. 83.); rovius hermalhoditum; cespitosum erectum subulatum flaro-nitens, caule atro fragili, amoene foliosum, apicem versus crescens, gracile; folia caulina latiusculo-ocuta "cuminutu exunilinevia subintegervima, ungustissime et longissime "reolatu; perichaetialia externa multo longior" et ungustioru flexuosu vemotu dentuta, intima minuta lanccolata, omnia nervo purpurascente praedita; theca in pedunculo gracili arcuato-flexuoso eylindrico-pyriformis curviuscula erecta, horizontalis vel inclinato-pendula fuscescens, operculo brevissime conico concolori.

IBr. Lurop. 1. c. p. 37. tal. 13. - Bryum Polla cruda Brid, I. p. 693. - Bryum pendulum hormum molle foliis et lanceolatis et gramincis. Dill. Musc. p. 401. t. 51, f, 70. - Mnium crudum Huw. Muse. Frond. I. p. 99. t. הK. - Hebera cruda schwigr. Sp. Musc. p. 50. - Web. intermedia schleich. Cent. 1V. 1). 18. forma folis omnibus angustioribus longioribus cuspidatis. - Hypmum crudum Web. et Mohr. Bot. Taschb, p. 290. 
Petrie. Per totam Europam praecipue in montosis ad declives umbrosas humidas haud raro. - Vere, in alpibus Julio et Augusto.

Flores hermaphroditi polyphylli, antheridis in axillis foliorum involucralium dispositis. In inflorescentia dioica flos masculus terminalis crasse gemmaceus subcapituliformis, folia perigonialia externa perichatialibus externis similia, interna e medio arcuato-recurva remote denticulata, interna multo minora latiora vaginantia cuspidata apice crenato - dentata, mullo laxius areolata purpurascentia. Antheridia maxima elongata clavata parapliysibus carentia. - Peristomium ut in $\mathbf{B r}$. longicollo.

Br. longicollo ex habitu sinillimum, notis antem illustratis distinctissimum.

15̆1. Br. Schimperi C. Müll.; dense cespitosum; caulis gracilescens e foliorum axillis radicans; folia rufa, inferiore remote mimutu ovato-acuminata, superiora et summa in comam subimbricatam conferta, oblongo-et. elongato-lanceolata, upice subsempluta; theca breviusculo-pedumculata nutans vel pendula, oblongo-pyriformis mollis, operculo convexo manmillari; peristomium pallidum dentibusque multoties articulatis, processibus hyalinis, multoties pertusis, ciliis nodosis.

Br. rutilans Br. et Sch. Br. Furop. Fasc. XXXII. Suppl. p. E. t. 6. - Nounen mutandum erat, quum Bryo reneo Blytt a Bridelio jam prius impositum fuerit.

Patria. In uliginosis prope Jerkin alp. Dovrefjeld Norvegiae: W. P. Schimper. In uliginosis infra finem betulae ad orient. Jättafield Norvegiae primus omnium legit Cl. I cesing, Composit. monogr. - Junio, Julio.

Flos masculus ut in Bryo crudo. - Br. nutarti proximum sed differt foliis rufis densius areolatis, inflorescentia dioica atque peristomio minori. - In speciminibus Lessingiunis thecam minutam rugulosam inveninus. - Species maxime pulchella et primo adspectu partibus tenellis minutis, omuibus caulibus gracillimis tenerrimis foliisque rufescentibus facile distinguitur. Planta mascula simplıcissima gracilima, flore crasso capituliformi terminata. 
Obscuriora.

152. Hr. tenuifolium Hook. et Wits. (Lont. journ. of bot. 1844. p. 346.); divicum; caulis humilis simplex; folia erecto-subsecunda lanceolato-subulata acuta integerrima margine reflexa evanidinervia; perichactiaha longiora attenuata; theca subpendula oblonga curvula basi obconica subapophysata, operculo conico. $†$

Prutril. Ad Insel-Bay Novae Seelandiae: J. II ooker.

Minutum, Bryo polymorpho Br. et Sch. simile, rapsula autem ralde diversa, peristomio interno ciliato.

\section{c. Inflorescentia monoica.}

153. Br. nutans Schich. (Spic. Fl. Lips. p. 81.); hermephrorlifum; rel cmlroyynum, antheridia in axillis foliorum perichaetialium per paria lisposita libera; habitus Bryi elongati, sed dense cespitosum, humile; folia inferiora ovato-lanceolita obsolete denticulata, superiora clongato-acuminata angusia flexuosa, margine parum revoluta, apice serrulata, nerro crassinsculo subexcureute, prachita, ommino elongale ef subunguste busi autem subpellucide ef lariusculo-areolula, viridissima mollia, perichactialia intima multo minora sed angusta lanceolata acute acuminata sublenticulata; theca in pedunculo elongato flecuoso pendulu veuli-myriformis crussinscula plus mimus brevis brumeo-fusce, operculo majusculo conico.

Br. Eur. 1. c. p. 34. t. 12. - Bryum V'ebera mutans Brid. I. p. 634. - Mebera nutans Hedw. Musc. Frond. 1. 1. 10. t. 4. IIypn. nutuns Web. et Molu. Bot. Taschls. p. 289. - Mnium mutans P. B. Prodr. p. 7i. - Bryum trichodes Hdw. Fund. Musc. I. t. 4. f. 16-20. - Wehern trichodes Hdw. Hund. Musc. It. p. 95. - Br. trichodes laete virens capitulis cernuis oblongis. Nill. Musc. p. 391, t. 50. f, 61. - Webera mutabilis Ildw. Fund. Musc. IJ. p. 104. t. 6. f. 28. - Bryum W'ebern fasciculata Brid. I. p. 627. e schwägr. sp. Musc. p. 51. - Mehera cespitosa Hsch. et Hpr. Regrensl). hot. Zeit. 1I. p. 102. - Bryum Webera cespitosa Brid. I. p. 629. et Br. Kurop. I. c. var. ß. - Bryum Irebera sublenticuJuta Brid. I. p. 634. et Br. Hur. I. c. var. $\delta$. - Br. Webera pendula Brid. 1. p. 636. e Schwägr. Sp. Musc. p. 51. - Webera bicolor Hpp. et Hsch. I. c. p. 102. - Br. Webera bicolor Brid. I. 
p. 630. Br. Furop. I. c. var. $\jmath$ - Br. I'ebera longiseta Brid. I. 1. 636. foliis longiacuminatis. - Webera strangulata Necs al) Es. in Hïl. Muscol. Germ. p, 428, e spec. Sendtnerianis forma robustior.

Petrie. Ad saxa, rupes, in terra sicca, humida, ericetorum et furfosorum per totam Europam. In America septentrionali atque arctica et Asia boreali. - Vere, in editioribus alpinis aestate vel rersus anctumni initium.

Species polymorpha, plantis Bryo elonguto similibus sed dense cespitosis atque thecis crasso-ovalibus pyrifornibus pendulis brunneo - fuscis brevicollis primo adspectu facillime cognoscitur. - Peristomii interni dentes longi valde hiantes pallidi tenuissime subulati appendiculato-serrati, ciliis binis apice subconnatis longissimis tenuissimis nodosiusculis interjectis.

154. Rr. longicollum Sw. (Musc. Suec. p. 49. t. 6.); monuicum, antheridia elonguta clarueformia, in axillis foliorum superiorum libera; habitus Bryi elongati, sed pluntue dense cespitosue elatue robustue apice innorantes, dense foliosae; folia nilentia majora latiora luxins et longius ureolutu molliora magis concura; theca robustu collo breriori crassiori perfecte subgibboso-inclinata; dentes peristomii externi robusti valde et furcuto-trabeculati flari apice rugulosi, interni robustiones exacte serrati hiuntes perfecte sulcati ciliis binis longissimis temnissimis nodosis lucviusculis interpositis.

Br. Eur. Fasc. XXXII. Suppl. p. 7. icon. in Fasc. VI-1X. t. 11. var. $\beta$. - Hebera longicollis Hdw. Sp. Musc. p. 169. t. 41. Bryum Webera Brid. 1. p. 625. vix hb. - Web. alpina Hsch. Regensb. bot. Zeit. 1819. I. p. 104. et Brid. 1. p. 626. - Web. Grimsulanı Brid. I. p. 628. - Br. elongatum $\beta$. alpinum Br. Fur, Fasc. VI-IX. p. 32. - Hypnum longicollum Web. et Mohr. Bot. Taschb. p. 291. - Orthopyxis longicolla P. B. Prodr. p. 79. - Wehera pennina De Not. in sched. s. Bryum Boissieri ej. Syllah. p. 134. e spec. forma minor huc pertinet.

Putria. In alpibus Carinthiae, Tirolis atque Helvetrae. - Auctumno.

155. Br. elongatum Dicks. (F'asc. II. Pl. Crypt.p.8.); monoicum vel androgynum, untheridia copiosu majuscula 
per prove in axillis foliorum libera; gregarie cespitosum; caulis humilis simplex rarissime apice innovans, inferne subnudus superne crescens, apice foliis erectis patentibus comam apertam efficiens; folia caulina e basi subrotundata lanceolato-acuminata, nervo crassiusculo fuscescente excurrente breviter cuspidala, margine revoluta, plemempue sub/alcata, apicem versus serrata subnitida frma, angustissime areolata plus minus pellucida; perichactialia intima minora e basi latiuscula lanceolato-cuspillata, inferme integra, apice serrutu, firmu; theca Iongiuscule pedunculata elongato-cylindrica angustissima pallida, suberecta vel horizontalis longicolla, operculn conico brevi aurantiaco; peristomii dentes externi lancelato-subulati subangusti pallidi lueviusculi, interni in membrana hyalina trienli-breviore angusti temissime subulati apice sermulali vix suleati plermmue hiuntes vix rugulosi, ciliis 1-2 breribus imeguluribus rugulosis interpositis.

Br. Eurnp. 1. c. p. 32. - Welerk elongata schwäigr. sp. Muse. 1. 19. - Pohlia elongata IIdw. Muse Frond. 1. p. 96 tab. 36. et Brid. 1. p. 60x. - Lesliea elongula Weh. et Mohr. Mot. Taschb. p. 243. - Puhlia cylindrice Hsch. et Ilopp. Hegensh. hot. Yeit.

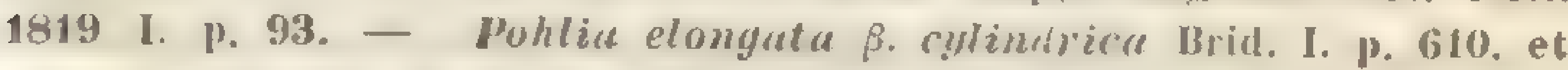
Bryun cylindricum Dicks. Crypt. Fasc, IV. p. 12, t. 11. f. 4.

B. macrocurpum; theca breviore pro magnitudine crassiore, sicca deoperculata sub orificio. constricta, peristomii interni processibus longioribus, saepe apice cohaerentibus, ciliis plurimo tempore regularibus. Br. Furop. I. r. var. $\gamma$ - Webera macrocarma Hsch in Regensh, lrot. Zeit. 1819. 1. p. 104. - Br. Webera macrocarpa Brid. 1. p. 628.

Putria. Per totam Europam in montosis ad terram Jumidam umbrosam. - Auyusto, Septembri.

156. Br. Ieptoblepharon C. Müll.; monoicum, anIheridia of archegonia crassiora quam longa numerosa, paraphysibus carentia, foliis floralibus intimis multo minoribus acuminalis enuidinervibus tenerioribus cremulalis interpositis; gregarie cespitosum, habitus et theca Bryi elongati; folia caulina confertiora latiora magis falcata serrulata vix nitida; peristomii dentes externi apice

C. Mitller: Synops, muse, frond, 
ralde rugulosi, interni in menbrana trienti-breviore angusti temissime subulati apice serrulati exacte sulcati lationes rugulosi, ciliis binis longissimis dentes uerpantibus tenuissimis rugulosis nodosinsculis interpositis.

Putria. Prom. bon. spei prope 'Lwellendam et ad Grootvadersbosch: Ecklon. Octobr. 1826. IIb. Kunzeanum.

A $\mathbf{B r}$. elonguto notis laudatis differt et primo adspectu canlihus densius foliosis partibusque omnibus robustioribus distinguitur.

15\%. Br. integridens C. Müll,; monoicum, v'pl undrogynum, antheridia pancissima minula solitaria in axillis foliorum superiorum libera paraphysibus pancis praedita; gregarium; habitus Bryi clongati; folia caulina e basi utrinque rotundata lanceolato-acuminata, nervo crassiusculo fuscescente excurrente breviter cuspidata, margine revoluta, upicem versus denticulatu, vel serrulata, hand nitida mollia, angustissime areolata, viridissima; perichactialia intima multo minora lato-lanceolata acuminata excurentinervia teneriora, apice denticulata, inferne cremulatu; theca longiusculo-pedunculata, elongatocylindrica angustissima pallida suberecta vel horizontalis longicolla, operculo conico brevi aurantiaco; peristomii dentes externi lanceolato-subulati angusti pallidi cprice rugulosi, interni in membrana hyalina dimidio breviore angusti subulati omnino rugulosi vix sulcati, haud hiantes, ciliis $2-3$ brevibus irregularibus valde rugulosis fugacissimis interpositis.

Patria. Mexico: C. Ehren berg.

A Br. clongato notis cursive impressis differt.

$$
\text { Inflorescentia ignota. }
$$

158. Br. nitens Hook. (in Wall. Cat. 11. 7592. et Harv. in Lond. Journ. of bot. 1840. II. p. 9.; ic. in Hook. Ic. PI. t. 20. f. 6.); gracile crectum subhumile laxe cespitosum; folia ovatu acutu ruadrate et majusculo-areolatu, e basi uspue ad apicem serrulatu, nerro crusso excur- 
rente proditu, excellentissime rividia splendentia; theca brevi-pedunculata oblonga cernua subhntizontalis, operculo conico-acuminato. †.

Patria. Nepal: Wallich.

Dentes peristomii externi angusti, interni valde hiantes angusti illos aequantes, ciliis binis brevioribus interpositis.

Obscuriol"a.

159. Br. gracilisetum Hsch. (Fl. Bras. Fase. I. p. 41.); caulis brevissimus innorationibus brevibus apice incrassatis; folia caulina erceto-patentia, inferiora remota lanceolata, superiora conferta lanceolata cuspidata canaliculata integerrima amoene viridia, nervo valido ferrugineo in cuspidem brevem excurrente, retis areolis parallelogrammis angustissimis, perichaetialia exteriora caulinis similia, interiora longiora angustiora longius cuspidata; theca in pedunculo erecto gracili purpurascente parum flexuoso pendula oblongo-cylindrica flavo-brunnea dein atropurpurea, operculo brevissimo conico - apiculato purpureo apiculo fusco. +

Putria. In solo argilloso humido inter Trematodonles prope Novo-Friburgum: B e y r i cl.

$\boldsymbol{B r}$. longiseto Schwägr. proxime accedit, differt antem: statura duplo minore, foliis breviter cuspidatis, pedunculo duplo breviore, theca oblongo-cylindrica, operculo conieo-apiculato.

160. Mr. multiflorwm C. Müll.; monoicum; /lores masculi gemmiformes axillares mumerosi, antheridies attue archegoniis sterilibus nomullis intermixtis; dense cespitulosum humile, basi fastigiato-ramosum; folia imbricata erecto-patentia oblongo-ovata acuminata carinata integerrima lurido - viridia, nervo crasso carinato fusco excurrente; perichactialia et perigonialia interiora longiora angustiora lonius acuminata; theca in pedunculo parum flexuoso apice reflexo purpurascente pendula, cylindrica laevis viridi-brumnea, sicca et deoperculata angustata, ore amplo purpureo, operculo conico apiculato rufescente; 
peristomii dentes interni in membrana lutescente, ciliis binis tenerrimis interpositis. t.

Webera pulchella IIsch. Fl. Braa. H'asc. 1. p. 43.

Patria. In muris pr. Sebastianopolin: Merkel, pr. Tijuca: Olfers. - Julio et Mugnsto.

Cui affine?

161. Br. soboliferum Tayl. (I ond. Journ. of bot. 1846. p. 51.); dioicum; laxe cespitosum brunneo-viride; caulis fertilis brevissimus foliis congestis, innovationibus elongatis filiformibus crectis, foliis distantibus erecto-patentibus margine planis subserrulatis; theca elongate pyriformis nutans, operculo conico; peristomium internum ciliis solitariis. $\%$

Patria. In Pichincha prope Quito: W. Jameson, 1842.

162. 1Br. Zollingeri Dub. (Moritzi, Systemat. Terz. p. 133.); dioicum? cespitosum erectum subdichotomum, caulis basi foliis antiquioribus marcescentibus onustis; folia erecto-patula laxe sed ad apicem rami densius imbricata, siccitate crispa, serrata, lanceolata vel ovatolanceolata acuminata, juniora angustiora vix marginata; theca in pedunculo terminali sed innorationibus laterali stricto erecto elongato horizontalis $v$. subcernua pyriformis, operculo conico brevi. $t_{\text {. }}$

Patrill. Java ad rivulos montis Pangerango alt. $5000-6000^{\prime}$ : Zo llinger collect. No. 1914. Non accepimus.

163. Br. recurvifolium Tayl. (Edinb. Trans. of the Bot. Soc. 1845. II. I.); caulis erectus subsimplex subflexuosus; folia oblongo-orata acuta laxa ex amplexante basi recurvantia margine flexuosa minutissine serrulata. $t$.

Patriu. Hibernia apud montem Knocka vohila prope Dunkerron in Comit. Kerriensi.

Ex habitu Dicrani squarrosi et e structura Br. cuspidato simile. 
164. Br. palmifolium Brid. (I. p. 68\%); caulis tenuis apice ramosus, folia linearia oblonga acuta remota alterna solidinervia, nervo viridi. $\leftarrow$.

Mnium palmifolium P. B. Prodr. p. 76.

Patriu. In insula Bourbonis sterile lectum, suspectissimum. Forte Fissidens e Bridelio.

165. Br. Bridelianum C. Müll.; caulis erectus, innovationibus ramosus; folia ovato-lanceolata, e nervo crasso colorato excurrente longe acuminata, acumine subpiliformi, margine integerrima sicca subcrispula, obscure viridia, lineari-areolata, patenti-erecta; theca in pedunculo flexuoso-erecto gracili dilute castaneo nutans, oblonga, cum apophysi nigricante basilari anguste obconica subrugosa pyriformis badia; operculo convexo-apiculato; peristomii Ireberue dentes externi profunde rubri, interni albidi pulchre perforati, ciliis 2 duplo brevioribus interjectis. t.

Br. Webera flexuosa Brid. I. p. 843.

Patria. Insula 'l'erre Neuve in uliginosis: La PyIaie.

Ex observ. auctoris Br. longicollo e theca affine, forte hermaphroditum. In hb. auct. non vidimus.

\section{Trib. XVI. DICRANACEAE.}

Cespitosae rarissime gregariae acrocarpicae innovando ramosae vel ramis fertilibus apice pluries divisae. Folia lanceolata vel subulata, canaliculatoconcava, nervo plerumque dilatato applanato rarius tenui, vix terete pracelita. Retis cellulae prosenchymaticae parenchymaticis saepe mixlae, raro papillosac, plerumque inanes, sarpe superne incrassatae, igitur rotundatae vel ellipticae; basilares ad margines folii aggregatim dispositae, distincte diversae: parenchymaticae laxae crassue magnae 
planae vel ventrum plus minus crassum et palelliformem efficientes, tenerae vel robustae, hyalinne, fuscae, brunneae vel purpureae, dein marcescentes, plerumque maxime conspicuae (collulae alares). Theca ovalis vel cylindrica, nunc arcuata nuuc stricta, basi apophysata vel strumosa, operculo subulato. Peristomia purpurea, dentibus trabeculatis. Archegonia longissime apiculata, nucleo parvo praedita. Antheridia clavata. Paraphyses filiformes.

Leptotrichaceis ex habitu proximac, sed cellulis alaribus ab his ceterisque muscis acrocuprecis distinctissimae et facillime discernibiles.

Patria. Per orbem totum terrarum, regiones omnes atque loca diversissima habitantes. 21.

Weisiacene Hmp. ex parte. - Dicranacene Br. Hurop. ex parte.

\section{Gen.I. Mlindia Br. et Sch.}

Br. Furop. Fasc. 33-36. - Weisia anct. - Grimmia Turn. - Nchistidium Brid. - Anoectungium Schwägr. - Gymnostonum Web. et M. - Stylostegium Br. et Sch.

In honores pastoris Blind Monasterii Vogesorum bryologi indefessi nomen impositum.

Calyptra dimidiato - cucullata. Peristomium nullum vel simplex: dentes 16 aequidistantes lanceolati remote articulati laeves tenues intus leviter trabeculati purpurei cartilaginei. Theca exanmulata. Antheridia oblonga paraplysibus filiformibus mixta.

1. B1. acuta Br. et Sich. (1. c. Blindiu, c. tab.); divicu; laxe et late cespitosa erecta elata gracilis ramosissima lutescens rigidiuscula; folia caulina conferta erecto-patentia interdum secunda oblongo-lanceolata limenrisubulate acuta teminervia subintegerrima convolutaceoconcava; perichactialia e basi lato-vaginante sublonga subito et plirato-subulata; theca brevi-pedunculata py- 
riformi-ovalis peristomata pallida erecta, operculo depresso longe subulato obliquo aurantiaco.

Weisia acuta Hdw. Mnsc, Frond. III. p. 85. t. 35. - W. rupestris $\mathbf{H d w}$. Sp. Musc, p. 72. t. 14. - W. fastigiata Bryol. Germ. 1I. II. p. 120. t. 35. f. 31. forma lumilior brevius pedunculata. Grimmia ucuta sm. Fl. Brit, 11. 1. 1192. - Bryum acutum Dicks. Herb. sicc. Fasc. XVII. 20. Br. pilosum sphagni subulati facie. Dill. Musc, p. 374, t. 47. f 34 .

Putria. Ad rupes madidas per regionem alpinam et subalpinam totius Europae, in America septentrionali et in insula Eremitae prope Cap. Ilorn: J. II ooker. Aestate.

Flos masc. terminalis gemmaceus ovalis fuscus, foliis perigonialibus lato-convolutis breviter acuminatis obsoletinervibus.

2. F1. stricta C. Miull.; dioicu; laxe et late cespitosa parce ramosu erecta flexnosu flaccida hand rigidu, apice convolutuceo-foliosa incurva gracilis lutescens; folia caulina conferta secunda latiora oblongo-lanceolata subulata integerrima falcata obtusinscula crussinervia; perichaetialia longe vaginantia; theca breviter pedunculata peristomata subrotunda longius operculate, calyptra muxime lata dimidiata.

Weisia stricta Hook. et Wils. in Lond. Journ. of bot. 1844. p. 540 .

Patria. Insula Kerguelen antarctica: J. H ooker.

A pracedente simillima notis cursive impressis differt.

3. Bl. tortifolia C. Müll.; divicu; laxe cespitosa sublumilis densifolia inferne nigrescens superne lutescens parce et breviter ramosa; folia caulina ubique patentia, siccitute torta, madefacta stricta, apice purum falcuta, lanceolata angusta integerrima obtusiuscula, minutissime quadrato-arcolata, cellulis alaribus parvis quadratis robustioribus fuscis, nervo latiusculo fuscidulo vel concolore; perichaetialia e basi lato-ovata firma inferne tenera convolutacea subito fere el breviter acuminata, c reliquis caulinis similia; theca paullo exserta imnoutione laterulis rotunda longe et oblique operculata glaberrima fusca ni- 
BLINDIA.

tida; perist. dentes breves lanceolati aurantiaci; calyptra maxime lata dimidiata.

Weisia tortifolia Hook, et Wils. Lond. Journ, of bot. 1844. p. 540.

Patria. Insula Kerguelen: J. H o oker.

A Bl. strictu affine notis cursive impressis primo adspectu distinguitur. E folis crispatis $\boldsymbol{B}$. anturcticue similior.

4. B1. antaretien C. Müll.; monoich; laxe cespitosa elatiuscula atro-virens ramosa densifolia erecta; folia caulina crispula ubique patentia lanceolato-subulata angusta integerrima acuta canaliculato-concara, e cellulis angustissimis incrassatis inferue elongatis superue minutissime quadratis areolata, amoene flavida vel fuscescentia angustinervia, cellulis alaribus ventricosis permultis parvis brunneis firmis; perichaetialia cylindraceo-convolutacea subito acuminata, intima subobtusa, angustinervia; theca longiuscule pedunculutu oudis purra, longe et oblique operculata, fusca nitida.

Weisia crispula Wils. in schedulis.

Putria. Insula Campbelli et Eremitac ad Cap. IIorn: J. Ho ok er.

Bl. tortifoliue ex habitu caulium similis sed thecac forma jam primo intuitu diversa. Heisiue crispulue simillima, sed e foliorum structura aliena. - Flos masculus ad basin perichactii parvus, foliis lato-convolutis coloratis brevi-acuminatis integerrimis tenuinervibus angustissime et elongate areolatis; antheridiis elongatis angustis, paraphysibus parum longioribus fuscis.

5. W1. contectn C. Mïll.; divica? laxe cespitosa erecta elata parce ramosa stricta rigida inferne fusca, superne lutescens nitida; folia caulina erecto-patenlia subappressa rigida elongata, convolutaceo-subulata latinervia, inferiorl in pilum hyelimm producta, ommia apices summo dentirulata; theca peristomete brevissime perlunculate immerse turbinate, operculo mostrato praedita. p. 540.

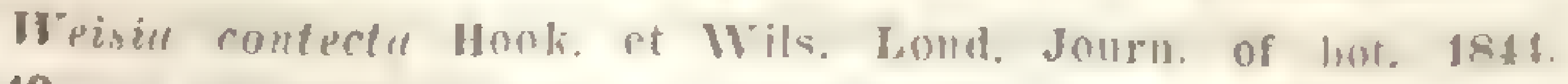




\section{Putriu. In insula Campbelli antarctica.}

Fructum non vidimus.

6. Bl. Stylostegium C. Müll.; monoicu; habitus Bl. ccutue sed humilior et dense cespitosa erecta flexuosa fastigiato-ramosa rigida lutescens; folia caulina erectopatentia couferta ex oblongo subulata in acumen brevissimum hyalinum producta integerrima tenuinervia; perichaetialia vaginautia multo latiora et majora; theca immersu obouto-globosu truncutu gymnostoma pallescens, operculo aurantiaco e depresso oblique subulato, colimelleve adnato.

Stylostegium cespiticium Br. et sch. Br. Europ. Fasc, 33-36. Stylostegium, cum icone. - Shistidiun cespiticium Brid. Mant. Musi. p. 21. - Anoectungium cespliticium schwigl. schrad. Nen hot. Journ. IV. p. 13. t. 2. A. - Gymnostomum (espiticium Web. et Mohr. Bot. Taschb. p. 77 et 452.

Palvile. In summis alpilus Ilelvetiac, Germaniae et Scandinaviac rupes humidas habitans. - Aug.

Flos masc. terminalis gemmiformis minutus, folis perigonialibus parvis lato-ovalibus hreviter acuminatis obsoletinervibus.

\section{Gen. II. Wucámuptodon Mont.}

Aln. des sc. nat. 18t5. 4. p. 120. t. 14. f. 3. Weisiu (Eucamptodon) prichutialis ej. inid. p. 119. - Comptes rendus 1845 . septbr.

Ab $\varepsilon^{3}$ perfecte, xuptutós incurvus et ófoŕs lens, ob dentes peristomii madefactos perfecte incurros nomen ductum.

Calyptra dimidiata. I'eristomium simplex: dentes 16 aequidistantes lati carnosi linea hyalina longitudinati et lineis transversalibus nonmullis exarati purpurci, madefacti horisontaliler incurvi, integri.

Ad Dicnemon ex habitu accedens calyptra et peristomio autem diversus. 
1. E. perichaetialis Nont.; monoicus; cespitosus subhumilis robustus ramosus; folia caulina erecto-patula conferta stricta oblongo-lanceolata acuminata acuta paulisper convolutaceo-concava integerrima, e cellulis elongatis pachydermis prosenchymaticis flavidis, alaribus vix ventricosis, areolata, nervo vel nullo, vel partim obsoleto; perichactialia e basi longe vaginante convoluta superne sinuato-rotundatu subito longe flexuse et loriformi-ucuminutu; theca brevipedunculata ouclis crecta longe rostrata.

Patriu. Ad teram nudam Chiles australioris: C. Gay.

Flos masc. infra perichactium dispositus parvus gemmaceus oblongus, foliis convoluto-ovatis breviter acuminatis enervibus, antheridis elongatis stipitatis paraphysibus filiformilus mixtis. Gemmulae thecae, quas Cl. Mo ntagne in Compt. rend. descripsit, cellulac sunt primordiales seminum juniorum.

2. macrocalyx C. Müll.; cespitosus valde robustus elatiusculus dichotome ramosus lutescens; folia caulina erecto-patula stricta conferta late convolutaceoacuminata integerrima, marginibus volde involutis, obtusinscula, perfecte enervia, e cellulis elongatis in mombranam subhomogeneam firmam lutecum veluti conflutis areolata, cellulae alares haud ventricosae pachydermac fuscae multae; perichaetialia in cylindrum longissime exsertum convoluta vaginantia lineuri-lancestutu in acumen phus minus loriforme longissimum sensim utlemulu; theca erecta cylindricu, operculo subulato recto.

Ho'omitrium enerve Dz. et Molkh. Musc. Archip. Ind. t. 3. Dicrunum enerve Hmp, hl. - Dicr. macrocaly.x A. Br. hb.

Patria. In locis paludosis montis Gédé insulae Javac.

E foliorum enervium structura simillima, labitu plantae et perichactio huc retulimus. Peristomium ignotum. Dioicus ut videlur. Calyptra dimidiata.

\section{Gen. III. Dicnémon Schwägr.}

suppl. 11. 11. 1. p. 72... Leucodon Hook. -. Fincuemis Brid.

- Jyellia Hook. 
Nomen a dis bis et хvंnu crus, ob peristomii dentes bicrures ductum.

Calyptra campanulata. Peristomium simplex: dentes 16 basi connati, ultra medium bipartiti.

E foliis striclis involutaceo-concavis latis, caulibus turgidis et perichactiis longissimis Eucumptodontibus affine, e reliquis notis Dicranis nonnullis simile et caulibus repentibus excellens.

1. D. calycinum Schwägr. (1. c. p. 74.); decumbens ramis simplicibus erectis rel ascendentibus dense foliosis; folia conferta ovato-lanceolata integerrima rigida firma nitida e luteo viridia badia vel fusca, nervo crasso apicem versus evanescente, e cellulis linearibus seriatis ad nervum rectis versus marginem divergentibus areolala; perichaetialia in cylindrum longum convoluta raginantia, externa ovato-lanceolata, interna oblonga basi et apice attenuata, nerro brevi vel obsoleto praedita; theca oblonga cernua basi stromosu sub ore contracta ferrugineo-fusca, operculo e busi conica obliqua gibbosa in rostrum longum lenissime curvatum educto, dentes peristomii rubri profunde bifidi, cruribus linearibus acuminatis inflexis sulcatis rigidis trabeculato-nodulosis; calyptra basi subsexfida apice scabra pallide fusca. $\div$.

Brid. 11. 1. 215. - Leucodon caly/cinus Hook. Musc. kixot. tal. 17. Schwägr. suppl. II 1. p. 82. t. 121. - Eucnemis calycinu Brid. olim.

Putria. In Sinu Dusky - Bay Novae Seelandiac: Menzies 1791.

Inflorescentia? Species genus bonum constituens. An et sequens huc certe pertineat?

2. D. rngosum Schwägr. (Suppl. II. II. 1. t. 174.); monoicum; procumbens ramis simplicibus teretibus obtusis fuscis; folia caulina densa erectiuscula ovato-lanceolata, margine involuta igitur veluti ovato-lanceolata, transtersim rugosa, integerima fuscescentia, nervo angusto excurvente apiculutu; perichaetialia insignia, exteriora minora, late ovata anguste attenuata, interiora lon- 


\section{STEGOCARPI. ACROCARPI. PILOPOGON.}

gissima longe acuminata, omnia cranidineria; theca cylindracea subcerpulis subinclinata rufo-fusca; peristomii dentes dicranoideo-bifidi. $t$.

Brid. 11. p. 216. - Leucodon rugosus Hook. Musc. Exot. tab. 20. - Eucnemis rugosa Brid. olim.

Petriu. Nova Ilollandia, unde Dickson babuit.

Calyptra? Flores masculi in brevissimo ramulo, folii caulini ne quintam partem aequantes, gemmiformes, fere terminales in ramulo suo florigero, innorando fiunt axillares. Holia perigonialia ex ovato acuminata, apicis margine involuto, ut orata subulata esse videantur, enervia lutescentia. Antheridia valle lurgida, paraphysibus filiformibus hyalinis mixta.

\section{Gen. IV. Pilopogon Brid.}

Mryol. univ. 1. 1. 519. - Didymadon Hook. Musc. Exut.

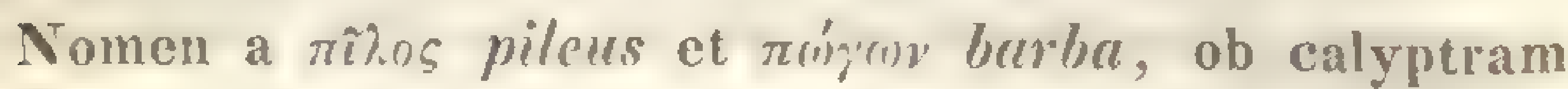
margine basilari barbatam ductum.

Calyptra dimidiata. Peristomimm simplex: dentes 16 aequidistantes erecti longi in conum dispositi filiformes rugulosi integri interdum linea media hic illic exarati humomorphi haud trabeculati.

1. P. Eraeilis Brid. (1. c.); dioicus; dense cespitosus elatus rigidus subgracilis, inferne nigricans superne flavescens, subsimplex, ad perichaetium ramo geniculatopatente longe attenuato bilidus; folia caulina erecta appressa rigida stricta elongata angusta convolutaceo-concava, in subulam producta, apice summo in denticulos nonnullos dissoluto, nervo lato et excurente plano; perichaetialia longissina cylindrum tenuissimum pedunculi diametrum aequans formantia, nervosa, longe et perfecte cylindrico-convolutacea, superne subito vel sensim longe subulata, apice denticulato, exteriora parva ovalia; theca in pedunculo gracili superue scabro parum flexuoso cylindrica curvata erecta angusta, operculo longirostrato crecto; calyptra basi longe ciliata. 
Dialymodon gracilis Hook. in Kunth Syn. PI. Aeq.p.51. et Musc. Exot. t. 5. Schwatgr. suppl. III. 11, 1. t. 265.

Putria. In monte Quindiu regionis temperatae Anlium de Cundinamara: II umboldt et Bonpland.

Habitus Campylopodibus nommulis rigidis simillimus. Hlores masculi jageregati gemmacei crassiusculi. Folia perigonialia externa e basi latiscula acuminata subulata apice denticulata latinervia, interiora lato-ovalia convolutacéa breviter et obtuso - acuminata obsoletincrvia integerrima. Antheridia longissima, paraphysibus lutescentibus illa aequantibus mixta.

\section{Gen. V. Molomitrium Brid.}

I. p. 226. suls nomine fialoe scripto olnmitrii. - Trielustomum Hook. Musc. Exot. - Treisia Schwägr".

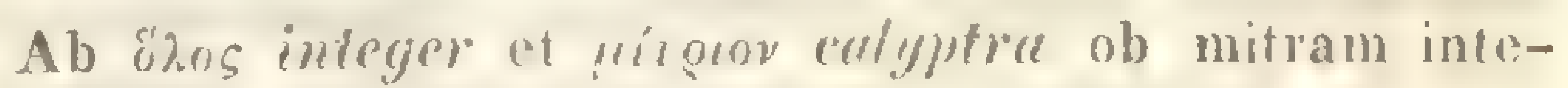
gerriman, notan sentiente Briblio discernendi necessariam, nomen ductum.

Caigltra dimidiala. Peristominm simplex : dentes 16 acquiristantes madefacii recurti lanceolati subulati, inferne trabcoulati linea media in crura duo cohacromia raro secedcntia filiformia rugulosu fissi, longe infra orificium oriundi. - Archegonia longissime apicunta. Folia basi e cellulis elongatis superne parris incrassatis subqualratis occultis reticulata. Inllorescentia monoica.

Holomitriaceae Hmp. Liun. XX. p. 70.

1. I. DHfersianmm ISch. (in Fl. Bras. p. 18.); dense cespilosum humile, inferne simplex tomentosum, superne fastigiato-ramosun rigidum volde fortile; folia caulina - basi amplexante oblonga superne latiore lanceolata acula canaliculato-concava brevia, nervo subtenui et subapplanato in apiculum vix recurvatum excurrente, apice grosse serrata, dorso parce denticulata; perichaetialia cylindrum crassiusculum longun flavidum nitidum formantia, cxteriora e basi superne renulata convoluta subito longe acu- 
minata grosse serrata excurrentinervia, interiora sensim attenuata; theca in pedunculo paullo exserto erecta e basi crossinscula conicu ore attenuata laevis; operculo longirostrato obliquo; dentes perist. Iongiusculi.

Pretria. Brasilia: Martius primus legit. - Primis anni mensibus fructificat.

Flos masculus ex ic. Fl. Bras. in ramo (axillari?) breviusculo terminalis, foliis parvis gemmacco-vaginantibus latis acuminatis.

2. H. crispulum Mart. (Ic. Pl. Crypt. Bras. p. 35. t. 18. f. 2.); densiusculo-cespitosum erectum flaccidum elatum dichotome ramosum inferne radiculosum; folia caulina e basi longiusculo-vaginante plus minus crenulata superne subundulata subuluto-acuminatu acuta elongata valde crisputu angustu canaliculata, superne dorso parce dentata, margine remote et grosse serrata, tenuinervia; perichaetialia longissime vaginantia; theca in pedunculo paullo exserto crecta cylindrica aequalis ore angustato, operculo longirostrato erecto; dentes perist. longiusculi.

Holomitr. Moritrianum Hmp. Limn, XX. p. 70. - Weisia Sellowii Schwägr. suppl. IV. t. 309. - Dicranum calycinum sw. Fl. Ind. Occ. 111. p. 1768. Bryun calycinum ej. Prodr. H1. Ind. p. 139. Weisia calycina Hdw. Sp. Musc. p. 70. t. 14.

Putria. Brasilia et Columbia hic ex altitud. c. 6000 ped. prope Tovar coloniam Germanican: Moritz. No. 181. et pr. Caracas: Coll. Linden. No. $37 \%$.

3. H. vaginatum Brid. (I. p. 227.); dense cespitosum rigidum suberectum brevi-ramosum; folia caulina dense imbricata erecta paullo patentia e basi amplexante convolutuceo-lanceoluta firma brevia integérrima arctissime areolata; nervo in apiculum reflexum excurrente subapplanato; perichaetialia cylindrum brevitor exsertum formantia pauca, e basi longe vaginante subito vel sensim attenuata breviter subulata integerrima tenuinervia; theca in pedunculo longiusculo-exserto erecta cylindricoovalis ore attenuata, operculo longirostrato recto; dentes perist: breviusculi. 
Trichostomum raginatum Hook. Musc, Exot. t. 64, et schwägr. suppl. IV. t. 309. - Dicranum calycinum Brid. I. p. 452. excl. syu. Hedwig., siswägrichenian. et swart»ianis. - Dicr. cylindrareum Brid. 1. p. 458. Cecalyy)hum P. B. Prodr. p.51. Weisia vaginans Brid. 1. p. 807.

Pritria. In insula Otaheite maris pacifici: Menzies 1792 detexit. Fx insula Bourbonis olim comunicavit Achwägrichen. In prom. bonae spei inter Omsamwubo et Ontata inter rupes fructibus maturis 15. Maj. 1532 et prope Outniqualand circa Koratram in sylvis altitud. 800 ped. 15. Oct. 1831. fruetib. vetustis: Drige.

Specimina hacc Capensia a Bourbonensibus statura robustiore et praesertim ramis gracilibus filiformibus ex apice caulis oriundis subjulaceis remotifolis et folis apice plerumque valde recurvato et marginibus minus convolutaceis praeditis paullo recedunt. An propria species?

4. I. perichnetinle Brid. (I. p. 227.); dense cespitosum erectum robustum subhumile breviter et parce ranosum, infima basi tomentosum; folia caulina e basi oblonga lanceolato-acuminatu subsubulatu acutu longinscula crisputu, madefacta erecto-patentia, integerrimaflexuosa subfalcata, nervo subtenui applanato instructa, canaliculata; perichaetialia in cylindrum brevem exsertum convoluta, longe raginantia longe subulata integerrima; theca in pedunculo longe exserto erecta conico-ovalis, operculo longirostrato obliquo; dentes peristomii breviusculi saepe irregulariter fissi.

Sprucea perichaetialis Hook. et Wils. in sched, musc. antarct. - Trichostomum perichaetiale Hook. sen. Musc. Exot. t. 73.

Putria. In Sinu Dusky-Bay Norae Seelandiae legit Menzies 1781. In insula Campbelli antarctica novissimis temporibus legit J. Hooker.

Gen. VI. Dícranum Hdw. emend.

Fund. Musc. 11. p. 91. - Dicranodontium Br. et sch. Campyloms Brid. et al. - Didymodon nonu. - Arcton Br. et sich. Cecalyphum P. B. - Fuscinu schrank. - Luida et Polla Adans. - Bryum et Hypnem L. et al. 
Nomen a graeca voce díncuroy fuscima, ob dentes peristomii fuscinae instar bifurcos.

Calyptra dimidiata. P'eristomium simplex: dentes basi connati in membrana plus mimus emersa vel aequidistanles infra orificium oriundi, in crura duo raro plura libera plus minus profunde saepe interdum usque ad basin fissi purpurei inferne trabeculati superne nodosi. - Cellulae foliorum raro papillosae, nunc molles inanes vel chloropliyllosi rhounbideo-prosenchymatici vel parenchymatici, nunc incrassati quadrati inanes obscuri; cellulae alares nunc planae nune ventricosic; cellularum parietes regulares vel interupti veloti moniliformes.

sectio 1. Leucolóma. Bid. II. 218. Plantac suluhumiles tamen rohustae, blus minus framiles, molles et cespitosae. Cellulae foliorum alares plantae vel ventricosate laxae; maryo folii "lbescens e cellulis longlissimis tenuissimis halalinis compositits: cellulae superiores subpapillosic minutae quadratie, infimae longiusculate omues iucrassatae. Nervus temuis flavidus. Inffuescentia omminm dioica?

1. D. Sieberianum Hsch. (Musc. Sieber. Nov. Holl. No. 16.); dense cespitosum erectum, in axillis foliorum tomentosum, ramosum terelinsculo-gracile, dense sed paullisper remote foliosum, flavidum; folia caulina siccr crerto-incumbentia subappressa, madefacta patentia, e basi latiuscula convolutacco-concava plus minus flexuosa acuminata, superiore in ucumen hyalinum froductu, pupillis truncatis ralde scabra, temuissime marginata, evanidinervia cellulis alaribus valde fuscis praedita, integerrima vel apice obsolete denticulata; pericliaetialia in cylindrum brevinsculo-exserfum muxime comrolulu superne margine flexuosu plus minus sensim longe acuminata subulata pallida facile mareescentia; theca longipedunculata oecelis cer)nua parra, operculo longirostrato obliquo; calyptra glabra; dentes perist. summo apice et irregulariter fissi intense purpurei. 
Schwăgr. Suppl. II. I1. 1. t. 252. Sprenk. syst. Veuct. 1V. Z. p. 322. Dicr. hypnoides R. Br. in litt. ad schwäw1".

Patria. Nova Hollandia.

2. D. Sprengelinnum C. Mïll.; dense cespitosum sed laxe cohaerens inferne tomentosum, humile ascendens flexuosum ramosum upice comoso incurvum firminsculum; folia caulina e basi convolutaceo-concava perfecte convoluto-subulata acutiuscula, falcata, integerrima vix rugulosa, tenuissime marginatu evanidinervia, cellulis alaribus subventricosis robustis praedita secunda; perichaetialia pauca longius raginantia et subito subulata parum longiora tenuinervia; theca in pedunculo brevinsculo innovatione laterali erecta cylindrico-oualis parva aequalis, dentibus perist. angustis.

Dicranum fasciatum sprellg. Syst. Veget. IV. II. P. 322.

Patria. Prom. bonae spei. Hb. Sprengel.

Ex habitu J. congesti formis ninoribus simillimum.

3. D. Zeyheri C. Müll.; dense cespitosum sed laxe cohaerens inferne parce radiculosum flexuosum robustum submolle densifolium subcrispatum upice $v \%$ incurvum; folia caulina subsecunda e basi convolutaceo-concava convoluto-subulata falcata subintegerrima laevin temnissime marginata evadinervia, cellulis alaribus subrentricosis robustis praedita; perichactialia e basi breviter vaginante subito subulata parum longiora, nervo excurrente tenu; calyptra brevis firma basi pluries et breviter laciniata inflexa apice scabriuscula.

Weisia n. sp. Zeyher: Coll. Pl. Cap. No. 496.

Patria. Prom. bon. spei.

A D. Sprengeliano proximo primo adspectu differt: caulibus multo mollioribus tenerioribus, apice non vel vix incurvis, foliis magis crispatis; an et fructus adhue ignotus distet, latet.

4. D. Commersonianum C. Müll.; procumbens dichotome ramosum ramis ascendentibus elungulum pared foliosum flaccidum; folia caulina laxu palentiu, upice incurriusculo subsecunda, e basi lanceolata longe linearia 


\section{STEGOCARPI. ACROCARPI. DIRAYY.}

nervo excurente subulata acuta integerrima cunuliculutoconcana haul rel parum comoluluced, laliusculo-marginutu, cellulis alaribus planis; perichactialia oblongo-lanceolutu, canlinis parum minora; theca in pedunculo innovatione laterali perum exserto erecta ovalis parra fusca, operculo conico subulato incurvo; perist. dentes profunde fissi.

Lencolum bifidum Brid. 11. p. 218. - Hymum bifidum Brid. Musc. Ree. 11. I1. 1. 51. t. 1. f. 4. - Dirranum breriset um Brid. 1. p. 467. - Trichostomum liffihm Bitd. Mant. Mlusc, p. 5t. Trich. lencolona schwätrr. Sulpl. II. 1. 1. 76. tab. 122. - Leucoboma angustifolium Brid. 1.,p. 752?

Petrill. Insula Bourbonis: Commersou. In Madagascaria: Du l'et it 'houas.

5. D. Bridelianum C. Nïll.; lare cespitosum mollissimum ascendens humile parce ramosum pallidum densifolium, apice longinscule attemuto suberecto capillari; folia caulina enecto-patentia made/acta calde patula elongata, e basi latisstime canaliculato-concaea sensim subulata acuta, cixcurentineria, apjece minute serrulatu, latissima-maginalu, cellulis alambns planis teneris.

Lencoloma serrulatum Brid. II. p. Tü2.

Pulriu. Hispaniola: Desvaux. Brasilia.

6. D. molle C. Mïll. : laxe et late respitosum mollissimum ascendens humile parce ramosum pallidum pare foliosum greceilius, aprice valde incurro comoso; folia caulina secumde e basi canaliculato-concava longissime subuluta, nerso excurrente acuta, apice minute serrulata, latiuscule marginata, cellulis alarbus planis toneris praedita.

Putriu. Java inter muscos alios a Cl. Junghuhn leetos.

7. D. sinuosum Brid. (1. p. 427. excl. syn.); caulis ascendens ramosus robustus, densifolius; folia caulina maxime fulruto - secumla longinscula; e basi latiuscula margine undulatu lanceolato - subulata, nervo angusto excurrente cumaliculato, involutaceo-concava fragilissima, margins tenuiter albo, summo apice denticulatu, dorso 
superne aspera vel laeviuscula, e cellulis ellipticis rel apicem versus rotundis valde incrassatis areolala, pallida, cellulis alaribus muxime vemricosis of robustis intense brunneis maguis praedita; perichaetialia vaginantia basi laxe areolata tenuinervia e reliquis caulinis similia; thecae binae vel solitariae in pelunculis olongutis striclis tenuibus cylindricae erectae, operculis longirostratis.

Trichostomum longifolium Brid. 1. p. 496. et var. $\beta$. Lumile, Tr. pallido hand dissimile. Folia laeviora.

Putriu. Insula Madagascar et rar. $\beta$. in insula Franciae: A ubert du Petit Thouars. Insula Bourbonis: Bory St. Vincent.

sertio 11. Oneophorus. Brid. I. p. 389. Plantae humiles vel elatae robustae cespitosae. Cellulae foliorum alares planae vel ventricosae; cellulae superae omnes elongatae, rarins minutae incrassatice subuadratae prosenchymaticae, parietius sitepe interruptis veluti moniliformibus praeditae, raro rhorophyllosae et papillosae. Nervus temuis interdun obsoletus vel latus deplanatus. Folia immarginata. Theca inaequalis cernua, hasi plus minus strumosa vel strumoso-apophysata, ammlata vel examulati. butlorescentia monoira vel dioica. Calyptra hasi integra.

\section{Nervo serrato.}

a. Folia undulatu.

8. D. undulatum 'Iurn. (Musc. Hib. p. 59.); lense cespitosum clatum ascendens valde tomentosum, ramis dichotomis elongatis paucis; folia caulina plus minus secunda patula e basi lata lanceolata falcata, plus mimus pliculu, inferne margine revoluto, superne et dorso grosse serrata, phus minus complicuto-concura, nervo applanato pro foliorum latitudine angusto priedita, valde undulata; perichaetialia latissima in cylindrum laxum convoluta, in subulam loriformem flexuosam superne grosse serratam producta, tenuiter vel obsolete nerrosa; omnia elongute "reolata; thecae agyregatae obconico-arcuatae cylindricae basi ventricosae, operculo conico longirostrato; denfẹs perist. maximi bifidi.

D. Jujosum lirid. 1. p. 414. - D. polyselum Sw. Musc. suec. p. 34 et 8 \%. tals. 3. f. 5. et 13rid. I. p. 413. ex parte. -- Bryum rugosum Hofm. Dent, Di. H. P. 39. 
Putriu. In sylraticis glareosis et in ericetis tam siccis quam turfosis per totam Europam et Americam septentrionalem. - Julio, Aug.

Pl. mascula ignota. Florem masc. invenerunt Br. et Sch. in tomento minutum gemmaceum, foliis ovato-lanceolatis apice dentatis, internis ovato-acuminatis enervibus.

9. D. Trummondi C. Müll.; dense cespitosum elatum ascendens valde tomentosum, innorationibus electis; folia caulina undigue patentia recurva et sursum curvata vel secundu, siccitute apice tortiliu, e basi lata robusta in subulam latiusculam producta falcata conrolutaceoconcava, omnino fere e cellulis minutis incrussutis plus minus rotundatis reoluta, nervo applanato pro foliorum latitudine angusto excurrente, parce undulata, upicem rersus denticulate dorso scuberrime; perichaetialia in cylindrum brevem densum convoluta plus minus subito longe et anguste subulata inferne elongate areolata; thecae rygregatce breviter pedunculatae obconico-arcuatae cylindricae basi ventricosae, operculo conico longirostrato; dentes perist. subirregulariter bifidi.

D. robustum Blytt in Br. Europ. Fasc. $37-40$. p. 43. tals. 36. (1847.). - D. undulatum, val. foliis angustioribus subtortuosis Drumm, Musc. Aner. No, 86. Forma minor.

Putria. In sylvaticis montosis loco Bogstadaas prope Christianiam Norvegiae: Blytt. In sylvis umbrosis Canadae superioris vulgare: D r u m mond.

Flos masc. ut in praecedente.

10. I. spurium IIdw. (Musc. Frond. II. p. 32. t. 30.); laxe cespitosum tomentosum sed laxe cohaerens erectum vel ascendens dichotome ramosum plerumque interrupte foliosum; folia caulina conferta patentia, inferiora mimuta, superiora multo robustiora comam polyphyllam sistentia, late lanceolata et clongate lanceolata acuta, valde undulata, margine eroso-denticulata dorso ubifue valde et mimute scubra, ut in praccedente areolata, convoluto-conrolle, suprerue madefacta tortilie, nervo pro latitudine fo- 
lii tenui applanato sub apice cranido praedita; perichaetialia patule superne rotundata rel simuto-truncatu subito breviter acuminutu omnino fere elongate arcolata evanidinervia; theca solituria in pedunculo flavo flexuoso longo obconico - arcuala cylindrica basi ventricosa subparva, operculo conico longirostrato obliquo; dentes peristomii ut antea.

Bryol. Europ. Fasc. 37 - 40. p. 41. t. 33. - Brid. I. p. 416. Oncophorus conglomeratus Brid. 1. 1. 405. - Oncoph. fragilis Brid. I. p. 403. - Dicranum fragile ej. Mant. Musc. 1. 55. D. condensatum Hdw. Sp. Musc. p. 139. tah. 34. et Brid. I. p. 421; forma humilis, foliis vix undulatis et D. longirostratum Brid. Mant. Musc. p. 55. - Oncophorus longirostris ej. I. p. 403. - Cecalyphum longirostratum P. B. Prodr. p. st ; forma foliis laeviorilus.

Patria. In ericetis arenosis, ad sylvarum margines et in sylvarum glareosis, et in turfosis per totam Luropam prime borealem et in America septentrionali. Aprili et Julio.

Planta mascula ignota, ejus loco gemmulae e tomento caulino enascentes.

11. D. Hergeri Bland. (Musc. Fr. Exs. III. n. 114; nomen antiquissimum); dense cespitosum elongatum erectum valde tomentosum, ramis clongatis; folia caulina dense imbricata erecto-patentia superiora subsecunda, lato-lanceolata obtusiuscula complicato-sen cunaliculatoconcara parce undulata, superne eroso-denliculata ef e cellulis robusto-incrussatis plus mims roturdatis inferne elongatis, omnibus in membranam dorso lacrissiman firmam nitidam flavidam confluentibus areolata, nerro apice parce denticulato applanato tenui evanido praedita; perichaetialia patula minora ut in praecedente formata, sed e cellulis robustioribus minus clongatis areolata et longius acuminata atque saepe undulato-flexuosa; theca pracedentis solitaria longe et flavide pedunculata. peristomio minori.

Dirr. Schraderi Weh, et Mohr. Hot. Tasthh. P. 187.; nnmen sentiente ipso Mohrio posterius (iu litt. ad B! a ndow!). Br. Furop. 1. c. p. 40. tah. 32. - Dicr. undulatum selirad, spicil. Fil. Germ, 
p. 59. et Brid. 1. p. 415. - b. fulculum Schrad. 01. Inst. et schleich. Crypt. Helv. 11. 15. - 0 , intermedium Crome, samml. Crypt. Gew. 11. 66. p. 21. - D. affue Funk. Fasc. Crypt. V1. 11. 136. D. fastigiatum schult\%. Fl. starm. p. 300. - Cecalyphumb undulatum P. B. Prodr. p. 52. - Nomen Blandouii in memoriam centurionis de Ber er Megapolitani senkowiensis, scrutatoris olim indefessi et hujus musci in turfosis siitzenianis detectoris impositum.

Putriu. In turfosis tan planitierum quam regionis montanae et alpinae per totam Europam et Imericam septentrionalem. - Acstule et anctumm.

A D. spmio proximo notis cursive impressis distinctitissimum. - Planta mascula ignota, gemmulac masculae in tomento nascentes plus minus copioside.

\section{b. Folia aequaliu, i, e. non undulata.}

12. D. convolutum IInp. (in litt.); compactum usque ad apicem fere maxime tomentosum apice ramis fertilibus brevibus divisum alongatum erectum sordide lutescens; folia caulina erecto-pulentia substriclu, sicer opice incumbentia, brevia, lanceolato-acuminata. nervo subapplanato angusto, apiris margine denticulata, dorso breviter serrulata, cellulis alaribus planis teneris repletis fuscidulis, inferne e cellulis angustis sublongis, parietibus temuibus praeditis superno parvis subquadratis mollibus areolata; perichaetialia immersa cylindracen-convoluta raginantia, e (ellulis longioribus laxioribus areolata; theca annulata in pedunculo substricto rubescente rylindracea parum arcuata busi vir. inaequalis lae?issima fuscescens, operculo conico - subulato subobliquo rubente; calyptra longa tenerrime membranacea pallida magna supra fusca; perist. dentes fragiles amoene pupurei ad medium usque fissi.

Pulviel. In sibiria regione transbalcalensi, loca ut videtur uliginosa habilans.

b. spurio praestrlim var, condemseto proximum, differt autem folis laeribus dorso tantum seabris, nervo latiore, cellulis laxioribus mollioribus et thera basi hand ventricosa. 
13. ID. seoparlum Hdw. (Fund. Musc. II. p. 92. t. 8. f. 41.42.); diulcum; dense cesputosum valde tomentosum ascendens elatum, ramis gracilescentibus dichotomis elongatis apice comoso curvatis; folia caulina secunda e basi plus minus ventricosà lanceolata subulata acuta latiuscula, e cellulis elongutis pariclibus valde incermptis proeditis robustis ureolutu, canaliculato-concava, nervo excurrente applanato pro latitudine folii angusto dorsi apice serrato, apice serrata dorso lacvia; perichaetialia interiora majora in cylindrum vix exsertum patulum convoluta, superne subito longe et reflexo-acuminata loriformia serrata; theca solitariu exammulata cylinaricu busi subinaequalis coriacea arcuatu crassa, operculo longirostrato obliquo; lentes perist. maximi robusti bilidi.

Br. Europ. I. c. p. 3t. t 26 et 2\%. - Bril. I. p. 410. - D. vecureatum sichnltz, Fl. stare. p. 295. - D. reflectens Brid, ol. I. p. 412. - D. condensutum sipr. in sched. - D. Dillenii T. Tayl. Ann. and Mag. of nat. Hist. 1843. p. 113. et hot. Keit. 1,43. 1.695. - Cecalyphum scoparium P. B. Prodr. p. 51. - Fuscina sroparia Schrank. Baiers, HI. II. p. 452. - Brymus scoparium L. Ep. PJ. p. 15\%2. - Bryum reclinatum, foliis falcatis, scoparum efligie. Dill. Musc. p. 357, t. 46, f. 16. A. B. C.

Patria. Ad terram, rupes, arborum radices ot in tectis stramineis per Lotam Europam, Americam et Asiam. - Julio, Augusto.

Planta mascula in cespite feminco vel proprio, gracilior folisque brevinribus, flore termiuali. Folia perigonialia ex ovata basi anguste lincaria, apice denticulata interua breviora integra. - Planta e Incis natidibus polymorpha.

14. D. pallidum Br. et Sch. (in Br. Europ. Fase. 37 - 40. p. 39 memoratum); monoicum; hahitus J. scoparii, sed mallidins; folia caulina e cellulis elongatis et angustis, paricthms hand rel rix interruptis temuissimis pracelitis areolata; perichactialia superne marime rolumdato - simmalu cormululu itidem sed laxius rediculata; theca solitaria cylimbira valde arcuata basi subaetualis pellescenti-ochrecere examulata. opcreulo fongisubulato concolori basi rubente:. 


\section{StegocaRPI. ACROCARPI. DICRANum.}

D. scoparium Sulliv. Musc. Allegh. No. 155.

Putria. America septentrionalis: Beyrich, Sullivant in sylvaticis ad terram.

Flos masculus in ramo axillari brevi gracillimo, foliis externis patulis basi ovalibus brevibus acuminatis apice obtusiusculo parce dentata obsoletinervia, internis lato-ovalibus convolutis brevissime acuminatis enervibus, antheridiis paucis brevibus ovatis. - A D. scopario simillimo inflorescentia notisque ceteris cursive impressis distinctissimum.

15. D. congestum Brid. (Mant. Muse, p. 57 el I. p. 418.); divicum; laxe et dense cespitosum, tomentosum plerumque molle et saepe crispum ramosum, apice curvato-secundum; folia caulina secunda lanceolato-subulata subfalcata basi tenera, e cellulis rotundutis purvis parietibus teneris areolate, superne margine serrulata canaliculato-concava, nervo excurrente angusto applanato, superne dorso scabriusculo; perichaetialia basi vaginantia convolutacea subito longe acuminata subulata acul a margine et dorso serrulata excurentinervia immersa; theca breviter pedunculata pareu obovalu curvelu commluta subgibbose el parce ventricosa, operculo longirostrato, obliquo fiexuoso; dentes perist. ut antea.

Br. kurop. I. c. p. 36. t. 29. - D. vupestre Brid. 1. P.419. D. longirostrum schwägr. Suppl. 1. 1. p. 170. tab, 44. - D. fuscescens smith, Fl. Brit. III. B. 1204. - D. scoparium B. fuscescens Hook. et Tayl. Musc, Brit. p. 58. - D. flexicaule Brid. I. p.421. D. fuscescens Hsch, in litt. ad Brid. ibid.

Putria. Per montes usque ad alpes totius Luropae et in America septentrionali. - Aestate.

A I). scoperio proximo notis cursive impressis dislinetissimum.

16. D. majus Sm. (Fl. Brit. III. p. 1202.); laxe cespitosum molle elatum ascendens flexuosum dichotome et vage ramosum suhgracilescens apice incurvum; folia caulina elongata secunda, e basi lata robusta lanceolatosubulata falcata convolutaceo-concava, nervo angusto applanato excurrente superne dorso serrato praedita, acuta, 
margine superne serrata, e cellutis omnino elongatis purietibus vix intervuptis pracditis angustis in membranam plus minus homogeneam nitidam conflatis non pellucidis areolatu; perichaetialia in cylindrum robustum exsertum dense clausum convoluta latissima, subito et brevius acuminato-subulata apice serrulata excurentinervia, textura caulinorum; thecae aggregatue obovales subparue crassiusculae curvatue celunmulatue, operculo longissime rostrato subobliquo; perist. dentes robusti intense purpurei.

Br. Europ. I. c. p. 43. t. 37. - Schwägr. Suppl. I. I. p. 163. t. 40. - Dicr. polysetum Brid. 1. p. 413. ex parte. - D. scoperium var. a. Hook. et Tayl. Musc. Brit. p. 58. t. 18. fig. dextera? D. scoparium T. Tayl. Ann. and Mag. of nat. Hist. 1843. 1. 113, et bot. Zeit. 1843. p. 695 . - Bryum reclinatum, folits falcatis, scoparum effigie. Dill. Musc. p. 357, tał. 46. fig. 16. D.

Patria. In montosis sylvaticis subhumidis Furopae mediae in planitie sylvatica septentrionalis. - Aestate.

Flores masculi: gemmulae in tomento caulino nidulantes. - A D. scopario proximo fructibus aggregatis et foliorum areolatione facillime jam distinguitur.

17. D. robustum Hook, et Wils. (Lond. Journ. of bot.' 1814. p. 242.); habitus praccedentis; folia caulina elongata secunda, e basi lata robusta flexuosa lanceolatosubulata falcata convolutaceo-concara, nervo angusto applanato hand cumaliculato concolore excurrente superne dorso denticulato praedita, acuta, marginis apice argute et tenuiter serrata, e celluhs omnino elongatis parietibus magis conspicuis vix interruptis pracditis angustis non pellucidis arcolata; perichaetialia in cylindrum dense clausum emersum angustum convoluta lata, externa multo minora, interna longe raginantia superne valde obtusa et subito setacea, nervo tenuiore excurrente instructa et e cellulis laxioribus robustioribus parietibus valde interruptis areoluta, apice serrulata; theca solituria perfecte cylindrica currata basi magis strumulosa anyusta, operculo longirostrato.

Pritria. Insula biemitae al Cap. Horn: J. Hooker. 
A D. majori Sm. simillimo notis cursive impressis distinctissimum.

18. D. dichotomum Brid. (Mant. Muse. p. 55.); dioicun; elatum fleruosum dichotome et breviter ramosum furescens apice incurvum; folia caulina lata perfecte secunda mimus fulcuta, e basi lata cellulis alaribus robustis brunneis praedità lanceulatu brevia valde concava, uervo tenuissimo comspicuo excurrente, e cellulis angustissimis parietibus maxime incrassatis areolata, superne margine aryute et temiter dorso nervi purce denticulatu; perichaetialia in cylindrum breviter exsertum convoluta, exteriora breviter aristata, interiora longiora mutica encrvia; theca breviter pedunculata subcylindracea cernua basi substrumulosa coriacea glabra, operculo curvirostro mediocri.

Oncophorus dichotomis Brid. I. p. 401. - Nicr. Borymum sichwägr. suppl. 11. 1. p. 71. t. 121. - Cecal!yphum dichotomum P. B. Prodr. P. 51.

Putria. Insula Bourbonis, in planitic des Chicots, terram uliginosam habitans: Bory st. Vincent.

A $\boldsymbol{D}$. Feryuplensi notis cursive impressis certe diflert.

19. D. assimile IImp. (Ic. Musc. tab. 24.); habilus penultimi; folia caulina elongata secunda, e basi lata robusta flexuosa lanceolato - subulata falcata convolutaceoconcava, nervo applanato angusto rix concliculato flaviore excurrente superne dorso serrato praedita acuta, maruine apice argute et grosse serrata, ut in 1 . m(lumi areolata; perichactialia in cylindrum dense clausum exsertum robustum convoluta latissina, longe vaginantia fiere subito selacea excurrentinervia subintegervima rel summo apice parce denticulata, e cellulis elongatis parictibus strictis haud interuptis praeditis areolata; therac agoregatac longiusculo-pedunculatae ereetere elungutue cylimblicue an-

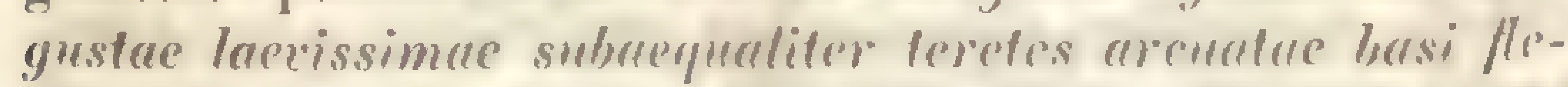
xuoso-apophysutue ammulatue, operulis londrostratis pallidioribus subobliquis: dentes perist. Imgissimi forfmosocepillares, cruribus inacqualiter latis sulcato-disposilis maxime trabeculatis fuscis. 
Putria. : Java : J unghu hn.

I). mujori simillimum, sed thecae forma primo adspectu discernibile, speciosum.

20. D. dienrpum Ifsch. (Nusc. Nieber. Nov. Holl. No. 10.); monoicum; densinscule respitosum humile densifolium breviramosum ascendens inferte fomentosum, apice subfalcatum; folia caulina secunda, e basi lata reflexa anriculat $\ell$ cellulis alaribus magnis brunneis praedità lanceolata subulata falcata, nervo superne profunde canuliculcto angusto dorso valde serrato excurrente acuta, inferne e cellulis elongatis angustissimis usque arl medium folii margine moductis superne rotundutis ud nerrum descendentibus parvis areolata, apicem versus dentibus pallidis grosse et argute servatu; perichaetialia in cylindrum exsertum dense clausum convoluta vaginantia, medio margine obtusato crenata, subito longe subulata excurreutinervia; thecae binae brerissime pedunculatue oboratae subcurvatue, snperne crussiores, basi courctuto-upophysutue ammulutue, operculis longirostratis erectis; perist. dentes breviusculi normales.

sprengel, syst. Veget, IV. II. 1. 322. - sihwïn. Suppl. H. 11. 1. t. 251. - Dicr. subraygregalum H. Br Im-t. ihid.

Putriu. Nova llollandia: sicber. Terra Diemenii: R. Brown.

Flores masculi (e schw itgrichen) minuti terminales aetate laterales ovali ferruginei, foliis ovato-acuminatis, exterioribus obscure uninervibus, interioribus enervibus, concavis integerrimis et antheridiis turgidis. Formis minutissimis Ificr. scoprerii haud dissimile, sed nulla specie alia confundi potest.

2. Nervo laevi.

a. Folin integra.

21. D. Falcatum IIdw. (Sp. Musce. p. 1500. (ab. 32.); monoicum flore masculo in vicinia feminei posito; respitosum sed laxe cohaerens humile ascendens gracile, inferne denudatum superne dichotome et fustigialo-ramo- 


\section{STEGOCARPI. ACROCARPI. DICRAYU.}

sum, apice falcatum; folia caulina secunda falcata lanceolato-subulata convolutace-concava subintegerrima minutissime areolata, nervo angusto maxime applanato haud canaliculato excurrente et cellulis aluribus purcissime quin imo fere obsolete evolutis praedita; perichactialia e basi latiore subvaginante superne fere subito setacea; omnia viridissima crispata; theca breviuscule pedunculata obovata cernua parra lacvis, collo tumido-strumoso pracdita unicolor fusca, operculo e basi lata oblique rostellato purpureo, annulo angustissimo; peristomii dentes angusti intense purpurei.

Br. Europ. I. c. p. 27. t. 18. - Oncophorus falcatus Brid. I. p. 393. - Cecalyphum scrophulosum P. B. Prodr. p. 51. - D. Sendtneri Flotow in schedulis.

Patria. In alpinis, raro subalpinis ad rupes madidas atque terram humidam per Europam totam, D. Starchii saepe associatum. - Augusto, Seplembri.

Folia perigonialia externa caulinis sinilia, sed basi convolutaceo-vaginante latiora, interna brevissime acuminata fusca. - Notis cursive impressis a sequente proximo facile distinguitur.

22. D. Starekii Web. et Moln. (Bot. 'Taschb. p. 189.); monoicum, flore masculo in vicinia feminei posito; labitus prioris, sed folia caulina magis falcata hand crispata latiora, cellulis uluribus perfecte erolutis subrobustis pruedita, perichactialia sensim subulata, ommia magis clongate areolata, theca stricta oblonga vel oblongo-cylindrica gibbosa et arcuata, perfecte strumosa, anmulo duplici revolubili atque peristomio mbello pruedila, operculo conico longirostrato obliquo; foliis perigonialibus internis longe acuminatis.

Br. Europ. 1. c. p. 27. t. 17. - Oncophorus starckii Brid. 1. p. 394. - Dicr. curvifolium schleich.

Patria. Ad rupes et teram in regione subalpina et alpina praesertim loca granitacea habitans per totam Europam. - Aestate.

23. D. Blyttil Br. et Sch. (Br. Europ. I. c. p. 26. 1. 16.); monoicum, flove masculo longe infia perichactium 
posito; dense cespitosum, habitus prioris, sed fragilius, folia caulina undique magis flexuoso-patentia minus secunda, elongate areolata sed amoene pellucidu teneru, cellulis alaribus amoene fuscis laxis diaphanis mrueditu, perichaetialia multo luxius areoluta et cellulis busilavibus pariter amoene fuscis laxis instructa; theca oruta laevis subcernua plus minus incurva sicca strumosa, operculo conico longirostrato obliquo, ummelo simplici; folia perigonialia interna breviter acuminutu.

Putrif. In summo monte Sempione Helvetiae cespitibus ingentibus ad rupes Rhododendro umbratis: W. P. Schimper 1840.; in alpe Nassfelder Tauern Gastuniae et in summo m. Gemmi Helvetiae: W. P. Schimper 1842 et 1843. In Norvegiae alpibus legit Blytt et prope Ilolmiam Thedenius.

A praecedente notis cursive impressis certe distat.

24. D. tenuifolinm Hook, et Wils. (Lond. Journ. of bot. 1844. p. 542.); dense cespitosum sed laxe cohaerens humile valde ramosum tenue apice incurvum nigrescens nitidum; folia angustissima lanceolata longissime subulatu integerrima, nervo lato perfecte concolori igitur vix conspicuo excurvente, c cellulis maxime anyustis elonyutis ureolutu et cellulis alaribus mimutis diaphanis praedita; theca suberecta turbinata, operculo longirostrato.

Patrice. Insula Eremitae ad Cap. Horn: J. Ilooker.

Praecedentibus proximum, notis autem cursive inpressis distinctissimum. Fructum non villimus.

25. D. elongatum Schleich. (Cent. III. n. 2\%.); dioicum; dense cespitosum compuctum elongutum gracile erectum pluries dichotomum; folia caulina parer erectopatentia vel secunda lanceolata et breviter subulata acuta, convolutaceo-concava subintegerrima, nervo lato applanato, inferne elongate superne minute et plus minus rotundato-areolata; perichaetialia pauca cylindraceo-raginantia immersa subito subulata tenuinervia; theca brevipedunculata obovalis obliqua subcernua et subgibbosa basi 
collo instructa hand strumosa, lenissime striata, operculo longirostrato angusto praedita aunulata.

schwär. suppl. 1. 1. p. 181. tab. 43. - Bryol. Europ. J. o. p. 35. t. 28. - Brill. I. p. 429.

B. orthorenpum, foliis brevioribus, thera suberlindruca

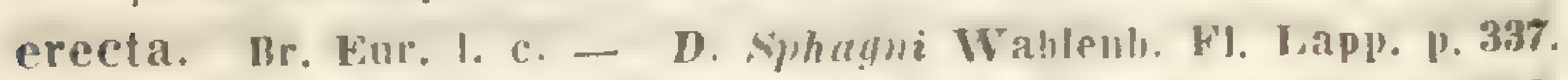
et Brid. I. P. 461. exel. syn. Dillen. - D. Groenlandicum Brid. I. p. 460. e speciminimus lah. Bridelicuni sterilibus.

Putria. In alpinis supra rupes humidas et ad terram umbrosam, praeprimis in regione Pini Punilionis. Var. $\beta$. in turfosis regionis septentrionalis et arcticae. - Ad aestatis finem.

Pl. mascula femineae intermixta vel in cespite proprio, gracillima. Flores in eodem ramo secundi, capituliformes, foliis externis e basi ovata lineari-subulata, internis apiculatis lutescentibus.

26. D. Habradoricum C. Mïll.; dioicum; pulvinatum subhumile parce dichotome ramosum; folia caulina erecto-patentia substricta multo latiora breviora perfecte lanceolatu, inferiona acuta, superiora ralde obtusa, ommia supra basin lationa, apice valde combolutucea, nerro tenui evunescente, e cellulis robustioribus areolata, integerrima; perichactialia longius vaginantia ef subito brevius acuminata, nervo tenui excurrente; theca breviter pedunculata marra cylimdracea curvata basi aequalis stricta, operculo longirostrato subulato obliquo.

D. Groenlandicum C. Müll. in sched.

Putriu. Labrador: Kurr in hb. Kunzeano.

A praccedente proximo notis cursive impressis valde distans.

\section{Incertae.sedis.}

27. D. imponens Mont. (Ann. des se. IIat. Tom. XVI. 1841. p. 241.); erectum dichotome ramosum fastigiatum, ramis cuspidatis, flavescens nitidum apice paulisper incurvun rigidum; folia (aulina undique imbricata erecto-patentia, e basi amplexicauli lata robusta cellulis alaribus valde brunneis multis robustis praedita lanceolata stricta 
superne convolutacea obtusa, mervo tenui applanato haud canaliculato ante apicem evanido, omniso e cellulis clongatis parietibus subinterruptis areolata.

Putrir. In freto Magellanico, loco Baie de Saint Nicolas dicto: Jacquin o t.

\section{Obscuriora.}

1. D. Mörkianum IIsch. (Regensb. Flora 1825. I. p. 78.); folia subfalcata lanceolato-linearia; perichactialia erecta lanceolato-subulata; pedunculus brevis apice strumosus, theca subimmersa rotundato-ovata, operculo conico oblique rostellato subulato. †.

Patria. Inter Wrisiam crispulam insulae Island: Mör k.

2. Oncophorus strigosus Brid. (I. p. 405.); erectum subramosum; folia laxiuscula patentissima subreflexa et quasi in globum expansa, colore infra obscure viridi, superne pulcherrime viridi flavicante, lincari-lanceolata acutissima siccitate undequoque contorta crispata carinata, margine incrassato integerrima. Hervo crasso continno in

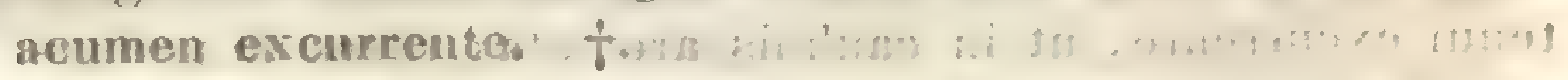

Putriu. Ilispaniola: Bertero?

E colore (monente auctore) facile discernibilis; sed generis suspectissimi.

\section{b. Folia denticulata.}

28. D. pungens Ilook. et Wils. (Lond. Journ. of hot. 1844. p. 541.); dense cespitosum sed laxe cohcuerens robushum elongate dichotomum erectum flarescens, apice fulcutum; folia caulina robusta secunda brecia pungentia subrigielu, lanceolato-subulata, convolutareo-concava, basi reflexiuscula fragili, cellulis alaribus planis uequaliter hexagonis paris permultis partem totam infimam occupantibus teneris hydlinis rel fluridis, superne ubique e cellulis angustis elongatis parietibus interrupte obsoletis praeditis reticulata, nervo tennissimo subobsoleto, superne margine parce denticulata; perichaetialia pedunculum bre- 
vem rufum arcte cylindrico-amplexantia longissime exserta, interna subito capillacea, e reliquis caulinis simillima; theca cylindrico-oblonga obsolete strumulosa curvula longirostrata laevissima fuscescens.

Patria. Insulae antarcticae Aucklandi, unde solo fertile vidimus, Kerguelen, Eremitae et Falklandi: J. Ho oker.

D. setoso proximum.

29. D. setosum Ilook. et Wils. (Itond. Journ. of bot. 1814. p. 541.); dense cespilosum sed lare cohuerens robustum elongate dichotomum erechum stramineum, apice dense et stricte foliosum; folia caulina robusta stricta longiora latiora fregilia lanceolato - subulata mimus convolutaceo-concava, basi vix reflexiuscula cellulis alaribus inaequalibus ad marginem infimum elongatis laxis magnis fuscis robustis praclita, e reliquis foliis $\boldsymbol{D}$. pungentis simillima; perichaetialia in cylindrum arctum immersum convoluta, e basi lato-vaginante superne rotundata subito tenuissime subulata, externa breviora et subintegra, interna longius capillacea et denticulata, omnia nervo obsoleto tenui excurrente, ut in caulinis areolata; theca in pedunculo brevi busi geniculuto cylindrico-oblonga obsolete sed magis strumulosa curvula longirostrata laevissima fuscescens.

J. H o oker.

Putrie. Insulae antarcticae Camplolli et Aucklandi:

A $\boldsymbol{D}$. pungente notis cursive impressis distinctissimum. Ex habitu 1). Billardierii quoque simile. - In axillis foliorum gemmulae folis minutis couvoluto-orbicularibus densius areolatis coloratis inveniuntur. An flores masculi steriles?

30. D. Millardieril Schwägr. (Suppl. II. p. 70. tab. 121.); dense cespitosum laxe cohacrens robustum densifolium struminem upice temuiore fulcuto; folia caulina erecto-patentia brevia secunda, e basi latu plund acnminata ucuta "pice semel torta concrua parcissime denlimulata, nervo muxime temi veluti filiformi excurrente, 
omnino e cellulis elongatis parietibus stramineis areolata, cellulis alaribus, parum ventricosis robustissimis permultis intense brunneis dein marcescentibus hyalinis totam basin folii occupantibus; perichactialia in cylindrum breviter exsertum convoluta, latissime vaginantia margine membranacea e reliquis caulinis similia, externa breviora superne rotundata subito et breviter acuminata acuta integerrima, intima sensim longius acumiuata obsolete denticulata; theca in pedunculo rubro crasso solitario cylindrico-ovalis perfecte strumosu arcuata, operculo Iongirostrato; perist. dentes robusti intense purpurei perfecte irifidi.

Brid. I. p. 401.

Putria. Nova Ilollandia: I a Billardiere; prom. b. spei: Zeyher; insulae Aucklandi et Falklandi: J. Ho oker.

31. D. Ronjeani De Not. (Syllab. Musc. 1838. p. 213.); dense cespitosum fragile erectum vel ascendens fastigiatim breviter-ramosum robustum dense foliosum, apice substricto vel subcuspidato; folia caulina paulisper secunda vel erecto-putentia, e busi latu pland lanceolata latiusculo-acuminata dentibus acuta, apice subplano loriformi, superne argute serrata et leviter transversim undulutu, nervo angustissimo evanido, omnino e cellulis longis robustis purietibus crassis valde interruptis flavidis praeditis areolata, cellulis alaribus planiusculis paucis robustis brumeis dein marcescentibus; perichaetialia in cylindrum convoluta late raginantia superne sinuato - rotundata subito acuminata integra obsoletinervia; theca oblongo - cylindracea erecto - curvala subapophysata laevis exannulata fuscescens, operculo longisubulato; perist. dentes angusti pallide purpurei bifidi.

D. palustre Br. Europ. (liand La Pyl.) Fasc. 37-40. p. 39. t. 31. - D. juniperifolium Sendtn. in Flora 1840. 1. p. 59, et in Denckselariften der k. bot. Gesellsch. zu Regensh, III. p. 144.

6. polycladum, innovationibus valde ramulosis, ramulis gracilibus minute et imbricato-foliosis. Br. Europ. 1. c. p. 39.

C. M i lles: Synops, musc, frond. 
Patria. In turfosis montis Cenisii: Bonjean; in sylvis prope 'Taurinum: De Notaris; in Sudetis: in monte Altvater im mährischen Gesenke: Diaconus Kramer 1839., im Kessel auf der Janowitzer IIaide ad fontes declivos: Sendtner; pr. Christianiam: Blytt. Var. $\beta$. in valle Rhenana sterilis. - Aestute.

Pl. mascula ignota. - D. Schruderi et spurio primo praesertim proximum, notis illustratis autem facillime discernibile.

32. D. Kerguelense C. Nüill.; laxe cespitosum elatum erectum substrictum fragile apice valde incurvum dichotome et elongate ramosum fuscescens; folia caulina lata perfecte secunda valde falcata, e basi lata cellulis alaribus multis mollibus pallescentibus praedità in subuTam longam planam summo apice parce denticulatam producta, nerro tenuissimo obsoleto, e cellulis quam maxime angustis parietibus maxime incrassatis areolata, valde concava.

Dicr. Boryunum Hook, et Wils, in sehed, musc, antaretic.

Putria. Insula Kerguelen: J. II ooker.

A D. dichotomo simillimo foliis longe subulatis obsoletinerribus aliter reticulatis et dorso laevibus, denique statura robustiore strictiore atque colore fuscescente certe distat.

33. D. Mählenbeckii Br. et Sch. (Br. Furop. Fasc. 37-40. p. 38. 1. 30.); compacte cespitosum erectum valde ferrugineo-tomentosum dichotome et elongato-ramosum - fulvello lutescenti-viride; folia caulina undique patentia flexuosu apice torta sicce crisputu, lanceolato-subulata concava murginibus conniventibus, apice remote denticulata, nervo solido laevi deplanato-convexo, ut in $\mathbf{D}$. congesto areolata; perichaetialia in cylindrum convoluta, interna subito acuminata, excurrentinervia; theca in pedunculo longo tenui pulchre stramineo stricto cylindracea erecta arcuata subaequalis pallide castanea annulata obsolete striata pachyderma, operculo e basi convexa rubella longirostrato; perist. I). congesti. $\uparrow$. 
Patria. In arborum truncis emortuis faucium inter Tusis Rhaetiae et Tiefenkastel retro der Sägemïhle: M ühlenbeck, 1844.

Species ex animadr. auct. pulcherrima, ex habitu $\mathbf{D}$. pallido affinis. - Pl. mascula ignota.

\section{Incertae sedis.}

34. D. fasciatum IIdw. (Sp. Musc. p. 127. t. 28.); depressum assurgens subdivisum, divisionibus simplicibus, radiculosum, obscure coloratum; folia caulina confertissima longa canaliculata heteromalla absque nervo evidente, basi modice lata fusca reticulata (cellulae alares), pallide viridia; perichactialia cylindraceo-convoluta; pedunculi gemelli raro solitarii brevissimi; theca pyriformis cernua, dentibus bifidis. to

Brid. 1. p. 432. non hb. excl. syn. Palis.

Patric. Insulae maris pacifici.

Sectio 1I. Drthodieranum. Cespites et folia ut in Oncophoris. Theca erecta cylindrica aequalis annulata. Inflorescentia dioica vel monoica.

\section{a. Folia falcata.}

\section{c. Inflorescentia monoira}

35. D. fulvellum Sm. (Fl. Brit. III. p. 1209.); dense cespitosum mulchre fulvellum, humile erectum rel e busi decumbente ascendens; folia caulina densa subsecunda et falcato-secunda longe subuluta, basi latiore viridia nitida, subula fusca apice denticulata, elongate areolata, cellulis alaribus laxis planis paucis; perichaetialia externa e basi oblonga raginante longe subulata, intima angustiora setacea, erecta vel ad unum latus dejecta; theca in pedunculo paulo exserto erecta aequalis rel subcerma et dorso conex'll, fermginea estriata, operculo rubello oblique conico-subulato; perist. dentes unguste lanceolati, longe ef pallide subulati bifuli, cruribus apice conglutinutis, siccitute patulis, in theca exucuata e basi patula incurvis. †.

Brid. 1. p. 813, - Arctoa fulrella Br. Europ. Fast. $33-36$. Arrtoa, p. 4. t. 1. - Weisia fleruosa Nees et Hsch. Bryol. Gerit. 11. 1. 121. t. 35. - Dicr. Seligeri Brid. 1. p. 429? 
Putria. In rupium fissuris et ad terram humidam alpium summarum et regionis arcticac. In Scotiae monte Ben More: Dickson, Ben Nevis: Borrer, Snowdon: Wilson; in Norregiae Dovrefjeld ad pedem m. Sneelıättai ad nives aeternas: Kurr, W. P. Schimper, in alpe Fillefjeld: Blytt; ad mare album: Angströ m; in Carinthiae alpibus Malnitzer Tauern: F. M üller et Pasterze: A. Braun. - Julio.

Flores masculi in ramulis propriis rel in innovatione, e qua feminei egrediuntur, terminales; folia perigonialia extema e basi ovata concavâ longe subulata, interna breviora orata acuminata subenervia. Paraphyses et antheridia pauca. - D. hyperboreo proxinum.

36. D. hyperboreum Sm. (Fl. Brit. III. p. 1227.); cespitulosum, e rufo viride, fragile, $\boldsymbol{D}$. fulvello simile, sed robustius; folia caulina patentia et subsecunda siccitate incurva subflexuosu lanceoluta et e basi lanceolatà lanceolato-subulata, subula vix aspera, densius areolata; perichaetialia e basi longe vaginante aristata tenuinervia; theca in pedunculo paulo exserto erecta vel subcernua ovata, collo tumidulo, substriata, sicca evacuata cyathiformis plicata; perist. dentes latiores brevius subulati distinctius strigillosi, apice 2-3-fuli ot ad medium pertusi, siccitate e patenti basi erecti, apice comniventes. $\uparrow$.

Brid. 1. P. 458. - Arctoa hyperborea Br. Nur. Fasc. 33-36. Arctoa, p. 5. t. 2. - Bryum hyperboreum Gunnerus Fl. Norveg. No. 1060. et Oeder Fl. Dan. tab. 538. No. 3. - Dicran. fulvellum Grev. Scott. Fl. Vol. IV. t. 188. ex parte.

Patria. In Norvegiae alpe Dovrefjeld prope Kongsvold versus Drivstuen in rupium siccarum fissuris: $\mathbf{O e -}$ der, Kurr 1825., W. P. Sch imper 1844. - Julio.

Flores masculi crassiores, ad pedem perichaetii fertilis; folia perigonialia ovato-acuminata nec subuligera, subenervia et enervia. Paraphyses et antheridia longiora.

\section{ק. Inflorescentia dioica.}

37. D. longisetum Hook. (Musc. Exot. tab. 139.); Tate et dense cespitosum pulvinatum subhumile depressum 
nitidulo-flavescens basi innovando ramosum, ramis aequalibus; folia caulina secunda in comam subfalcatam longisetaceam congesta parum crispata, e basi latiuscula ad nervum e cellulis laxis diaphanis ad marginem angustioribus temioribus flavis areolatâ lanceolato-subulata, apice summo margine serrulata, nervo lato laxo totam partem supremam occupante, cellulis alaribus planis paucis fuscis submarginalibus; perichaetialia basi latiora laxius reticulata; theca in pedunculo elongato plus minus torto erecta anguste ovalis sulcata operculo longirostrato obliquo; perist. dentes ad medium fissi, cruribus binis purpureis superne rugulosis.

Brid. I. p. 428. - Dicranodontium? Br. et Sch. Br. Curop. Fasc. 41, p. 2.

Patria. In sylvis regni Novae Granadae prope Fusagasaga et in apricis frigidis montis Chimborazo, alt. 1430 hexapodum: Humboldt et Bonpland. Brasilia in cacumine tractus montis Serra dos Orgaôs dicto: Gar dner Coll. No. 21. Columbia: Sierra nevada de Merida: Moritz, ex altitud. 8000 ped., Funck et Schlim in Coll. Linden. No. 996. Septbr. 1816.

38. D. reflexum C. Müll.; laxe cespitosum radicnlosum elatum ramosum ascendens vel reduncum apice fulcalum sordide viride; folia caulina secunda e basi latu reflexiuscula lanceolato-falcata maxime plicato-concara brevia margine et dorso argute et dense serrata, cellulis alaribus permultis fuscis planis magnis laxis, omnino $e$ cellulis angustis elongutis veluti in membranam conflatis tenerrimis areolata, nerro angusto in plica percurrente; perichaetialia in cylindrum exsertum dense clausum convoluta longe vaginantia tenerrime membranacea subhyalinc rotundato-sinuata subito subulata, nervo flavo tenui excurrente, e reliquis caulinis similia, haud plicata; thecae in unico perichartio geminatue longe cylindrico-orales robustce longiusculo-pedunculatae pallidac acquales, operculis longe et oblique subulatis; perist. dentes breves lanceolati subintegri, apice in conum congesti cohaerentes hyalini irregulariter fissi basi valde conflati. 


\section{STEGOCARPI. ACROCARPI. DICRANU⿴囗}

D. reduncum Duby in Zollinger Coll. PI. Jav. No. 2101.

Patria. Java.

Ex habitu D. scopurii s. pallidi, sed theca erecta cylindrica jam primo adspectu diversum. - Calyptra longa, $2 / 8$ thecae aequans.

39. D. maeropts Kze. (Pöpp. P). Chil. Coll. III. No. 271.); dense cespitosum flaridum ascendens dichotome ramosum subgracile, apice longe frulcuto-comosum robustius, flexuosum; folia caulina secunda lanceolatosubulata acuta canaliculato-concava falcata, summo upice solummodo margine denticulatu, sed dorso e basi fere ubique temiter scuberima latinervia, cellulis alaribus laxis fuscidulis planiusculis, inferne e cellulis angustis elongatis parietibus parum interruptis superne minutissimis areolata; perichaetialia cylindrico-convoluta immersa longe vaginantia, e cellulis valde angustis et elongatis, parietibus flexuosis perdurantibus areolata, sensim subulata laeviora; theca in pedunculo elongato fluvo flexwoso longe cylindrico-elliptica pallida laevis, operculo crecto longirostrato pallidiore pracdita.

Patria. Chile austraits, in truncis et rupibus ad Antuco: Pöp pig. Noobr.

Pl mascula multo gracilior falcata, flore crassiusculo terminali et infra perigonium innovationibus masculis novis. Folia perigonialia lato-convoluta subito plus minus subulata obsoletinervia, dorso subulae scaberrima apice margine denticulata, basi laxe areolata colorata. Antheridia naxima clavata arcuata, paraphysibus parum majoribus flavidis. - $\boldsymbol{D}$. longifolio ex habitu proximum sed aureo-flavidum et notis laudatis praesertim foliis dorso ubique scaberimis distinctissimum.

40. D. Iongifolium Ehrh. (Dec. Crypt. No. 114.); laxe et late cespitosum molle sericenm pallide rel glancoviride ascendens phuries dichotomum, apice falcatum; folia caulina secunda falcata lanceolata canaliculate el loriformi-subulate, superne dorso ubigne of margine culde servulutu, nervo latissimo totum folium superum occu- 
punte, basi e cellulis parvis parallelis tenuibus angustis parietibus parum interupte obsoletis inanibus areolata, cellulis alaribus parum ventricosis laxis fuscidulis; perichactialia longissima e basi convolutacea lato-vaginuntia tenera laxius areolata superne simute perum erencto flexuose et canaliculato-subulata et caulinis simillima, tenuinervia; theca in pedunculo breviusculo suberecto elliptico-cylindrica erecta, operculo longe subulato obliquo pallido; perist. dentes parvi, cruribus profunde bifidis irregularibus superne flavescentibus laevibus.

Br. Lur. Fases $37-40$. p. 32. tal. 25. - Brid. 1. p. 430 . Hedwig Musc. Frond. 11I. p. 24. to 9.

Patria. Prope Tpsaliam primus legit Ehrliart; praeterea e planitiebus editioribus Germaniae septentrionalis Megapolitanae ubi ad lapides viget, per regiones montanas usque ad alpes ascendens totius Europae et in America septentrionali. - Auctumno.

Pl. mascula gracilior, floribus in cadem innovatione compluribus. Folia perigonialia maxime falcata, externa subito subulata, intima breviter acuminata obsolete nervosa.

41. D. Sauteri 13r. et Sch. (Br. Europ. Fasc. 3741. p. 33. t. 24.); late cespitosum molle luete rivide nifidum; habitus D. Iongifolii, sed folia caulina nerro multo angustiore alis igitur latioribus pracdita, apice summo margine denticulata rel integra, dorso ad carinam tantum apice denticuluta; perichactialia angustins raginantia sensim fere subulata parcissime denticulata; caetera ut in $\boldsymbol{D}$. Tongifolio.

Patria. In regione infraalpina et subalpina, ubi ad fagorum truncos cespitibus latissimis viget: in sylva densa ad montem Dürenberg prope Gaming Austriac superioris: Sauter; in monte Feldberg et Bölchen Sylvae nigrae: A. Braun; Helvetia: Schleicher; Moresh in alpibus Julicis: Sendtuer. - Luy., Septbr.

42. 10. brevisetum Dz. et Molkb. (Ann. d. sc. nat. 1811. I1. p. 302.); late et laxe cespitosum elongatum fle- 
xuosum dichotomum robustum dense foliosum, apice falcato plerumque reflexo, stramineo-fuscescens; folia caulina falcato - secunda longa, e basi reflexiuscula amplexicauli cellulis alaribus robustissimis planis intense brunneis dein marcescentibus byalinis infima parte rulde incrussutis longioribus praeditâ lato-lanceolata subulata convolutacco-concava, margine et dorso argute serrata, nervo angusto excurrente, e cellulis elongutis angustis paristibus in membranam veluti conflutis ulbescentibus areolata; perichaetialia dense imbricata basi multo latiora vaginantia sensim capillacea, e reliquis caulinis simillima immersa; theca innovando lateralis brevissime pedunculutu plerumque solitaria brunnescens nitida ovalis laevissima, operculo conico-subulata obliquo; perist. dentes longissimi inaeguatiter profunde $2-3$-fidi cruribus valde nodosotrabeculatis purpureis.

Didymodon brachymes Hmp. in schedulis.

Patria. Java in monte Pangerango: Reinwardt, in locis aliis nobis ignotis $\mathbf{J}$ ung huhn et alii legerunt.

Habitus D. scoparii, sed notis laudatis planta distinctissima. E theca brevissime pedunculata et foliorum areolatione $\boldsymbol{D}$. Blumii affue.

\section{b. Folia patentia.}

43. D. strictum Schleich. (Cent. III. No. 26.); dense cespitosum laete vel e lutescente viride subnitidum subhumile radiculoso-tomentosum, erectum breviter ramosum; folia caulina erecto-putentiu, junioru subsecunda, siccitate stricta fragilissima, lanceolato-subulata, apice obsolete denticulata, superne marginibus subconniventibus convolutaceo - concava semel torta, nervo angusto excurrente, dorso laevia, cellulis alaribus teneris pancis planiusculis fuscis, basi e cellulis elongatis angustis superne ellipticis areolata; perichactialia convolutaceo-vaginantia sensim subulata subintegerrima, e reliquis caulinis similia; theca in pedunculo stricto stramineo ovatoclongata subcylindrica, operculo oblique subulato; perist. 
dentes angusti cruribus tenuissimis pallidis liberis vel conglutinatis conferte articulatis.

Br. Europ. Fasc. $37-41$. p. 28. t. 19. - Brid. I. p. 459.

Patria. Ad terram, radices arborum et truncos putridos per regionem alpinam Helvetiae, ubi in sylvis supra Moriles Vallesiac detexit Schleicher, in iistem locis ascensus septentrionalis montis Sempione: W. P. Schimper et in monte Pindus Thessaliae. E rarioribus. - Aestate.

P1. mascula feminea gracilior minus tomentosa. Folia perigonialia externa e basi ovata concavà lineari-subulata, interiora latiora tenuiora acuminata. Antheridia parva, paraphysibus longioribus teneris superne breviter articulatis mixta.

44. D. Fragile Hook. (Musc. Exot. t. 134.); dense cespitosum fragile elatum erectum aliquoties ramosum dichotomum radiculoso-tomentosum; folia caulina erecta, terminalia paullum secunda, e brevi lincari vel lanceolata basi sensim longissime acuminata concava, subtiliter sed argute serrata, pallide viridia, nervo valido concolore excurrente, e cellulis basi oblongis, superne elongatis areolata, cellulis alaribus quadratis fermgineis; perichactialia e basi breviter vaginante fere subito longius subulata; theca in pedunculo breviusculo futescente stricto erecta cylimdracen tores flavo-fusca; perist. dentes breves rubri ultra medium fissi interdum inferne pertusi, cruribus subinaequalibus. +

Brid. I. 1. 419. - schwïgr. Suppl. 11. Il. 1. tał. 254.

Patria. Nepal: Wallich 1791.

45. D. maerodon Hook. (Ic. Pl. Rar. t. 349.); hllmile cespitosum erectum subramosum; folia caulina undique inserta erceto-patentia subulata paululum falcata integerrima, nervo mediocri infra apicem evanido; theca in pedunculo elongato evecta angusto-pyriformis, operculo e lata basi subulato-obliquo; peristomii dentes plonyati profunde biparliti in conum approximati. $\dagger$. 
Putria subdubia, forsan Pillzhum in provincia Cuença dicta, ubi W. James on collegit.

Ex ic. D. longiseto haud dissimile.

46. D. aciphyllum Hook, et Wils. (Lond. Journ. of bot. 1814. p. 511.); compucte cespitosum tomentosum erectum ramosum subulatum densifolium subrobustum flavescens; folia caulina erecto-patentia stricta rigida parum flexuosa perfecte et longe lanceolata subulata canaliculato-concava integerrima, nervo lato maxime conculore, igitur veluti enerviu, basi e cellulis parallelis perietibus flavidis valde intermptis praeditis laxioribus superne minutis valde incrassatis areolata, cellulis alaribus tenerrimis hyalinis fugacissimis planis, dorso laevia; perichaetialia intima pauca vaginantia, ut basis caulinorum areolata, subito loriformi-subulata; theca in pedunculo crasso rigido stricto purpurascente erecta oralis crassinscula dein fusco-nitida, operculo subulato obliquo; perist. dentes angustissimi subintegri parum bifidi, cruribus arcte coharentibus rugulosis subhyalinis.

Putrie. Cap. IIorn, insulae Eremitae et Falklandi: J. Ho oker.

J. stricto subaffine, notis autem facile discernibile.

47. D. speciosum llook. et Wils. (Lond. Journ. of bot. 1847. p. 291. t. 11.); caulis longissimus robustissimus subsimplicissimus dense foliosus erectus; folia erectopatentia longissima upice canlis rix secunda robusta latu e basi ovato-lanceolatà lineari-attenuata apice subserrulata siccitute spiruliter comroluta, nervo latiusculo basi folii distinctiore flavido, dorso laevia, parum concava; perichaetialia convoluta latiora; theca solitaria in pedunculo flavescente brevi ovato-subcylindracea erecta, operculo thecam aequante subulato; perist. dentes angusti intense purpurei ad medium usfue fissi, sed cruribus apice connatis. $t$.

Putriu. Novo-Giranada: Purdic.

Omnium congenorum gigas, statura robustissima, quibus notis ab omnibus facillime distinguitur. J. speiro- 
phyllo Mont. (ubi descripto?) secundum auctores affine, sed foliis remotis sparsis divaricatis lanceolatis apice serrulatis et nervo angustissimo differre dicitur.

48. D. Blumii Nees ab Es. (Nov. Act. Leop. XI. I. p. 131. t. 15.); caulis tenello-gracillimus erectus longissimus dichotome divisus ater luxe et remote foliosus fragilis flexuosus; folia caulina ungustissima longissima putentissima straminea, apice caulis in comam elongatum tenuissimam substrictam conyesta, e busi refiexa valde amplexicauli lanceolato-subulata acuta maxime intortoet cylindrico-conroluta, apice cunaliculato-concava et margine denticulata, dorso laevia, nervo tenuissimo filiformi excurrente, omnino e cellulis angustis clongatis parietibus maxime incrassatis et interupte obsoletis flavidis praeditis stramineis arcolata, cellulis alaribus robustissimis intense brunneis permultis; perichactialia dense imbricata, e basi lata superne rotundata subito et patulocapillacea; theca innovando lateralis brevissime pedunculata oralis solitaria lacvis ore constricta, operculo conicosubulato subobliquo; perist. dentes longi cruribus binis tenuissimis apice hyalinis.

Brid. 1. p. 453. - schwïgr. suppt. 11. 11. 2. p. 116. t. 185.

Petria. Java in montibus excelsis partim ignivonis Salak et Gédé: Blum e.

Planta speciosissima rafiflora, quacum nulla alia confundi potest. Fructum non vidimus.

\section{c. Folia crispa.}

41. D. montanum Hdw. (Sp. Muse. 1. 145. 1. 35.); puleinuto-cespritosum amoene subgramineo-rivide molle humile, dichotome ramosum radiculosum, vix falculum; folia caulina lanceolato - subulata undique potentice vix secunda siccitute crisputissima canaliculato-concava, nervo angusto superue tenuiore cariuato excurrente, dorso ubique levissime scabra, busi " cellulis elongutis angustis superne minutissime quadratis areolata. cellufis alaribus paucis teneris parvis fuscidulis planiusculis, supernc nargine crenulato-denticulata; perichactialia cylindrico-con- 
voluta longe vaginantia superne truncato-sinuato-rotundata crenulata subito longius subulata, inferne $e$ cellulis angustissimis tenerrimis plus minus elongatis vermiformibus massa gramulosa grisea repletis ad subulam quadratis areolata; theca in pedunculo stricto longiusculo flavo dein fusco cylindrico-ovalis olivacea dein fusca obsolete striata sicca late sulcata, operculo longirostrato obliquo pallidiore; perist. dentes bifidi cruribus angustissimis cartilagineis tenuissimis laevibus.

Br. Europ. Fasc. 37-41. p. 29. t. 20. - Brid. I. p. 454. Dicran. Scottiunum var, montanum Hook. et Tayl, Musc. Brit, p. 56.

Patria. Ad arborum praesertim Pinuum et Betularum truncos per totam Europam satis vulgare, rarissime tamen fructiferum. - Aestate.

P1. mascula femineae intermixta, floribus $D$. stricti. - Colore amoene viridi atque foliis crispatissimis ubique patentibus primo adspectu facile distinguitur.

50. D. interruptum Brid. (I. p. 438.); laxe cespitosum obscure et olivace-viride duriusculum erectum vel ascendens rufo-tomentosum interrupte foliosum breviter ramosum, apice parum fulcutum; folia caulina lanceolatosubulata falcato-secunda siccitate crisputa canaliculatoconcava, nervo lato superne temuiore carinato dorso scabro excurrente, omnino e cellulis minutissimis viridibus quadrutis areolata, cellulis alaribus teneris quadratis flavidis dein albescentibus parvis, parum ventricosis pracdita, summo apice obsolete denticulata; perichaetialia cylindrico-convoluta longe vaginantia nitide superne truncuto-sinuato-rotundutu crenata longius subulata elongate et angustissime areolata; theca in pedunculo stricto breviusculo rigido stramineo dein fusco cylindrica fusca longiuscula striata, operculo oblique subulato fusco; peristomii dentes irregulariter fissi pertusi, cruribus apice pallidis.

Br. Furop. Fasc. $37-41$. p. 30. 1.22. - Dier. fulrum Hook et Wils. in Drumm. Musc. Auter. No. 19. et Sullivant Musc. Allegh cxsicc. IL. No, 139. 
Patria. In rupibus arenaceis et graniticis umbrosis Vogesi, Sylvae nigrae, 'Tirolis, Pyrenaeorum et in America septentrionali. - Septembri.

Pl. mascula cespites proprios efficiens vel femineis intermixta. Flores $\boldsymbol{D}$. flagellaris. - $\mathbf{E x}$ habilu ad $\boldsymbol{D}$. longifolium, magis autem ad $I$. flagellare accedens.

51. D. Angellare Hdw. (Muse. Frond. III. p. 1. tab. 1.) ; dense cespitosum lacte viride rufo-tomentosum erectum vel ascendens breviter ramosum, flagellis axillaribus rigidis filiformibus, apice parum falcatum; folia canlina lanceolato-subulata falcato-secunda siccitate crispata marginibus comniventibus comrolutaceo-concave parmm torta, nervo subangusto superme tenuiore carinato dorso serrulato excurrente, omnino e cellulis mimutissimis busi parum majoribus pallescenti-viridibus qualrutis areolata, cellulis alaribus $\boldsymbol{D}$. intervpti sed pluribus, summo apice serrulata; perichaetialia cylindrico-convoluta longe raginantia sensim fere subulata, elongate angustissime et flexuose areolata, summo apice dorso et apice serrulala; theca in pedunculo elongato strictiusculo gracili pallescente longe cylindrica olivacea striata, operculo longirostrato obliquo fusco; perist. dentes angusti dense trabeculati bifidi.

Br. Lurop. Fase. $37-41$. p. 30. t. 21. - Brid. 1. p. 422 . Bryum flagellare Dicks. Crypt. 1II. p. 6.

Putria. E planiliebus turfaceis usque ad montes altiores, ad arborum radices et in truncis putridis vigens, per totam Europam, Asiam et utramque Americam. Junio, Julio.

Pl. mascula feminea gracilior, flore crassiusculo. Folia perigonialia e basi lato-convoluta ventricosa laxius areolata coloratà subito et breviter et latiusculo-acuminata obsoletinervia summo apice parum denticulata dorso laevia. Antheridia magna clavata curvata, paraphysibus parum longioribus flavidis. - Ex habitu $\boldsymbol{D}$. interupto proximum.

52. D. Seottianum Turn. (Musc. Hibern. p. 75. t. 6. f. 1.); dense et subpulvinato-cespilosum pluries dicho- 
tomum basi intertextum, e fulvello pallide viride rel omnino fulcellum, erectum vel ascendens robustum densissime foliosum; folia caulina putentia et subsecunda, siccitate incurel rel apice subtortilie longa lanceolatosubulata concava margine integerrima angustinervia, basi latiore clongate superne minute quadrato-areolata, cellulis alaribus laxis quadrat is ferrugineis; perichactialia latiora raginantia subito subulata; theca in pedunculo longiusculo elongato-elliptica recta vel subarcuata flavida vel pallide feruginea estriata, sicca cylindrica subplicata, operculo conico-subulato obliquo pallido; perist. dentes breves infra thecue orificium oriundi lineari-lanceolati integri vel apice 2-3-fuli, rubelli apice mallidi, frogiles.

Br. Europ. Fasc. 37-40. p. 31. t. 23. - D. Hostianum Schwăgr. Suppl. I. I. p. 177. t. 41. e spec. auth. Hb. Brid. foliis breviorilus denticulatis magis crispatis.

Putria. In rupibus umbrosis Scotiae, Normandiae, Helvetiac prope Interlacken, Austriae inferioris in monte S(hnecberg et in alpibus Julicis (Mogenza). - Auctummo.

Pl. mascula in cespite proprio gracilior et magis ramosa. Perigonia numerosa. Folia perigonialia exterua lanceolato-subulata, interna e basi lata acuminata. - A D. intermpto et flugelluri differt: cespitibus densioribus pulvinatis leviter nitentibus, foliis densioribus subrigidis vix crispatis, nervo angustiore et crassiore, theca pallida saepe subarcuata et peristomii forma.

\section{d. Folia reflexa.}

53. D. reflexifolium C. Müll, late et laxe cespitosum elatum ramosum ascendens vel reduncum, viride vel flavo-nitens, inter foliorum axilla maxime albidotomentosum, folia caulina igitur madefacta perfecte horizontalia, sicea reflexa ubique patentia, apice caulis comosa et parum secunda, e basi lata reflexiuscula cellulis alaribus permultis magnis fuscis laxis praedita lanceolata apice subfalcata, e cellulis parvis angustis inaequalibus parietibus saepe interruptis pellucidis areolata, margine 
et dorso dense et argute serrata, plicata, nervo angusto in plica percurente; perichaetialia in cylindrum dense clausum exsertum terminale convoluta, late et longe vaginantia anguste et elongate basi laxe areolata, superne rotundato - sinuata crenata subito subulata obsoletinervia, ad subulam margine et dorso argute serrata; therae in unico perichaetio plures breviter pedunculatae cylindricae brevicollae, caetera ut in D. reflero?

Patria. Java: Hb. Miquelianum.

D. undulato ex habitu simile, e sectione tamen et notis laudatis ceteris diversissimum. E structura interna foliorum $\boldsymbol{D}$. reflexo affine.

Sectio IV. Campylopus. Plantae cespitosae raro gregariae. Folia latinervia, infernc laxius superne minntius plermmque incrassato-areolata. Nervus applanatus, ad paginam superiorem s. interiorem e cellulis laxis plus minus latis, ad pawinam extcriorem s. inferiorem e cellularum stratis complurilus incrassatarum compositus vel omnino incrassatus, dorso plerumque ad paginam interiorem raro lamellatus. Pedunculus thecae junioris ad avilla foliorum plernmque decurvatus et ibidem calyptra radices efficiente fixus, rarius erectus. Calyptra basi fimbriata ve' intenra. Inforescentia dioica.

Sectio pulcherrime naturalis, sed nunquam gemus proprinm, quum a Dicromis pedunculo, non autem semper arcuato et calyptra non autem semper ciliata, nolis igitur nec essentialibus nec constantibus distet.

\section{Folia epilifera.}

\section{A. Nana.}

54. D. nanum C. Müll.; gregurium, pusillum simplex sen subramosnm; folia caulina e basi oblonga subulata parum secunda firna; perichactialia e basi convoluta membranacea lata subulata; perigoniala e basi latissima convoluta ventricosa brunnea tencro-membranacea subulata; omnia nervo lato cxcurrente, integerrima brevia; theca solituria in pedunculo brevi et pro plantulue exignitate crasso, primum valde curvato tandem substricto fiavo laevi oblonga mimutu aequalis rufescens annulata, oper- 
culo conico subulato obliquo; calyptra dimidiata basi infegra; dentes perist. breves angusti bifidi, cruribus hyalinis dense approximatis vix conspicue secedentibus.

Campylopus namus C. Ml̈̈ll. Bot. Zeit. 1847. p. 804. - Dicran. flexuosum var. calyptra cucullata basi integra Hsch. Linn. XV. p. 124.

Patria. Prom. bon. spei: Gnadenthal in monte 3800' alt. in rupibus, Novbr. 28 legit D rege. Java in monte Salak inter Catharineam Jaranicam Hmp.: Junghuhn, Aprili; et in collectione Zollingeriuna Javanica inter muscos alios.

Pl. mascula feminea humilior; antheridia magna clavata, paraphysibus teneris flavis paucis intermixtis. Annulus multiplex. - A $D$. fexwoso notis illustratis distinclissimum.

55. D. humile C. Müll.; caulis vix ullus basi decumbens; folia dense imbricata fulva lanceolato-subulata falcato-secunda, nervo tenui, apice denticulata; theca oborata inacqualis, madida brevis, sicca tenuissime striatula, calyptra basi albo-fimbriatu. †.

Crompylop. humilis Mont. Ann. d. sc. nat. 1845. 4. p. 110.

Putria. Ad ligna putrida in Brasilia: B lanchet.

A D. ncuo calyptra fimbriata differt.

56. ? D. Nepalense C. Müll.; gregurium tenuissimum humillimum simplicissimum rbido-vivens; folia caulina homomalla cunustissime lanceolato-subulata falcata latinervia apice denticulata omuino minutissime areolata, cellulis alaribus maxime teneris hyalinis laxis fugacissimis ventricosis praedita.

Didymodon Nepalensis Brid. 1. p. 821.

Patria. Nepal inter muscos $\boldsymbol{W}^{\prime \prime l l l}$ chianos exemplaria pauca invenit Bridel.

E tenuissimis. Cumpylopns videtur.

B. Elata.

1. Caulis inferus folits appressis teres.

57. D. exasperatum C. Müll.; basi cespitosum purpureo-tomentosum, caulibus plongatis soliturie ascenden- 
libus flexusis simplicibus partim filiformibus julaceis partion laxe foliosis, farescentibus nitidis, apice fertili rosulatis, masculis interruptis infra perigonium cyathiforme julaceo-innorantibus; folia caulina lato-oblonga, cellulis alaribus robustis brunneis praedita, superne convolutacea flavida, inferiora obtusissima temissime cremulatu, superiorc acuta vel ucuminutu summo upice margine et dorso denticulata, omnia nervo latissimo concolore linea media exarato instructa; perichaetialia multo angustiora subito setacea erecto-patentia raginantia, inferne laxe areolata, apice dorso et margine denticulata, tenuinervia; theca in pedunculo brevi arcuato superne maxime verrucoso exasperuto ovalis vix sulcata, annulo magno multiplici praedita, operculo conico brevi erecto; perist. dentes angustissimi longissimi rugulosi intense purpurei cruribus 2 temissimis; calyptra hand fimbriata sed cellulis brevissimis basi limbata.

Campylopus exasperatus Brid. I. p. 473. - Thysanomitrium e.tusperitum Nees al) Ks. in Act. Acal. Nat. Lenp. XI. II. p. 134. t. 15. f. 2. a - c. - Trichostomum exasperatum sichwägr. Suppl. I1. 11. 2. p. 112 t t. 184 .

Putriu. Java in montibus Salak et Gédé: Blume 1820. Zollinger, Collect. No. 1806.

Flos masculus e gemmis minutis fuscis r. 20 compositus. Folia perigonialia parva subconvolutacea oblonga vel ovalia breviter acuminata tenera integerrima, nervo inferne angustato superue dilatato praedita vel obsoletinervia fuscescentia. Antheridia magna clavata curvata fusca, paraphysibus fuscis filiformibus mixta. - Thecae aggregatae.

58. D. Dozyanum C. Müll.; caulis erectus subsimplex gracilis teres, apice attenutus rel in capitulum fructiferum proliferume incrassatus; folia dense imbricata erecto-patula stricta lineari-lanceolata subulatoacuminala subintegerrima apice involuta, nervo lato excurrente, dentata; thecae plures in capitulum folis numerosis rosaceo-congestis lutioribus plunioribus cinctum congestae, pedunculi brevis apice scabri curvatura ad

C. Muiller: Synops. musc, frond, , 
fructus maturitatem usque intra folia perichaetialia reconditae, ovules busi asperulae siccitate plicatae, operculis conico-acuminatis subincurvis; calyptra lacero-fimbriata. †.

Trichostomum Blımii Dz, et Molkb. Ann, d. sc, nat. 1844. 2. p. 316.

Putria. Java, Borneo.

Dentes peristomii forsan profunde fissi rugulosi?

59. D. Surinamense C. Müll.; inferne dense cespitosum, caulibus ascendentibus sublumilibus solitaviis substrictis tenuissime filiformibus subjulaceis apice stellatocomosis infima basi laxe foliosis; folia caulina infra perigonium disposita lanceolata brevia latiuscula valde plicata et igitur varie concura, apicem versus eroso-denticulata, nevo ante apicem evanido pro latitudine folii temi, partim medio brevissime lamelloso, partim superne dorso scubro; folia inferiora lanceolata valde canaliculata angusta igitur latinervia haud plicata, e reliquis superioribus similia; omnia e cellulis parvis inanibus rhomboideis pellucidis areolata, alaribus teneris hyalinis praedita.

Compylop. surinamensis C. Mïll. Liun. XXI. p. 186.

Patria. Surinam prope Paramáribo inter fruticeta, terram arenariam humidam cespitose habitans: Kegel. Aug. 1844.

Pl. feminea ignota. Flores masculi e gemmis 1-12 compositi. Folia perigonialia exteriora e basi lato-convoluta breviter acuminala plicata apice denticulata excurrentinervia, intima brevissima acuminata tenuissime nervosa colorata. Antheridia crassa clavala, paraphysibus flavis mixta. - D. exasperato ex habitu et structura interna proximum, notis autem illustratis facile discernibile. Planta tenella pulchella.

60. D. Gundalnpense Brid. (I. p. 463.); cespitosum sed laxe cohaerens simplicissimum strictum rigidum subhumile parce tomentosum Rarescens, inferne gracile filiforme, superne patulo-comosum; folia caulina erectoappressa stricta brevia perfecte lanceolata dorso vix la- 
mellosa concava latinervia summo upice denticulata, cellulis alaribus subventricosis perfecte conspicuis teneris fuscidulis, inferne e cellulis subquadratis superne minutissimis areolata; flos masculus compositus; folia perigonialia externa lato-convoluta sublonge acuminata integerrima tenuinervia, intima obtusiuscula haud acuminata obsoletinervia, omnia colorata.

Putria. Insula Guadaloupe: Badier, serius Bertero.

De $D$. Grateloupii affinilate cf. exc. in hanc speciem. - Pl. feminea ignota. Antheridia elongata, paraphysibus filiformibus flavidis mixta.

61. D. Gràteloupii C. Müll.; maxime elatum simplicissimum filiforme flexuosum, tomentosum apice perichaetiis compluribus rosulatum flavescens nitidum; folia caulina erecto-appressa stricta brevia perfecte lanceolata dorso vix lamellosa concava latinervia summo apice denticulata, cellulis alaribus mullis, inferne e cellulis pellucidis viridescentibus angustis elongatis pavallelis superne minutissimis areolata; perichactialia paulisper vaginantia subito fere et longius subulata, cellulis alaribus pancissimis tenerrimis hyalinis praedita.

Campylop, elongatus Brid. 1. p. 815.

Putria. Circa Dax Aquitaniac: D. Grat eloup. Ilb. Bridel. et Candoll.

A D. Guadulupensi proximo notis cursive impressis certe distat. Planta speciosa et observationibus bryologorum Gallicorum dignissima.

62. D. leucogaster C. Müll.; laxe cespitosum erectum elatiusculum simplicissimum veluti candatum flexuosum molle flaccidum flarescens gracile subfiliforme sed luxifolium; folia caulina subappressa apice in comam longiusculam erectam patulam parram congesta, erectopatentia, e basi latiuscula lanceolato-subulata parum curvata summo apice dorso et margine serrulata, caeterum laevissima tenera, cellulis alaribus velde Taxis mugnis of marime rentricosis albis tenervimis, basi e cellulis laxis 
teneris superne minutissimis arcolata, nervo lalissimo, folii partem tolam fere superam occupante praedita.

D. fliforme Hsch. in Musc. Mexicanis a Deppe et Schiede lectis.

Patria. Mexico prope Xalapam: Deppe et Schiede.

Caulibus caudatis D. porphyreodictyi simile, notis autem illustratis ab omnibus congeneribus differt. Forsan caulibus dimorphis?

2. Caulis foliis ubique patulis heteromorplus.

a. Folia heteromalla.

a. Remota.

63. D. arenntum Brid. (I. p. 463.); elongatum erectum vel flexuosum simplex robustum rigidiusculum upicem versus perichaetiis compluribus incrassatum ramis infra perichatium oriundis strictis longe cuspidatis plerumque binis, laxifolium, in axillis foliorum uspue ad apicem radiculosum pallescens interdum proliferum; folia caulina erecta apice patula latiuscula lanceolato-subulata, concava, nervo latissimo laxo dorso laeri cxcurente, omnino minute areolatu, cellulis alaribus permultis robustis purpureo-brunneis maxime quin imo patelliformiventricosis praedita, apice obsolete denticulata; perichaetialia multo angustiora breviora inferne laxe superne minutissime areolata, sensim subulata, basi purpureo-brunneo-colorata.

- Cecalyphum fasciatum P. B. Prodr. p. 51. - Dicran. fasciatum Brid. hb.

Patria. Insulae maris pacifici: Ho. Palis. de Beau v. Insula Bourbonis, in monte excelso Piton des Neiges et in planitie des Chicots, altit. 1000 hexapodum: B ory $\mathbf{S t}$. Vincent.

Perichaetia compluria in coma caulis subrosulata.

61. D. eygneum Hedw. (Sp. Musc. p. 148. t. 37.); caulis cespitosus simplex erectus subtenuis valde conspicuns igitur remolifolius purpurens subvillosus; folia caulina ceruabiliter patentia vel distantia plura unum latus 
spectantia, ex amplexiuscula basi sensim in acumen subulatum longum canaliculatum producta, rigida integerrima subfalcata, cellulis alaribus permultis praedita; thecae binae in pedunculis solitariis siccitate exporrectis madore perfecte cygneis ovatae subgibbosae aequales, operculis conico-subulatis basi amoene rubentibus; perist. dentes haud profunde fissi. $t$.

Campylop, cygneus Brid. I. p. 475.

Patrie. In insulac Hispaniolae montibus des Grandes Anses dictis: Swartz.

Caule simplici remotifolio facile discernibile. - Flos masc. e gemmis 10 compositus, foliis perigonialibus e basi lato-covolutacea subito acuminatis acutis. - Commentator Schwägrichen folia enervia forsan false et speciem male descripsit.

\section{$\beta$. Imbricata.}

+ Patula.

65. D. holomitrium C. Mull.; caulis elongatus subramosus gracilis; folia caulina dissita patula e busi dilatata vaginante longicapillacea flexuosa integerrima solidinervia; perichaetialia longiora erecta, theca in pedunculo arcuato elliptica striata strumosu, operculo rostrato, calyptra basi integra. t.

Camp. capillaceus Hook. et Wils. Lond, Journ. of bot. 184t. p. 543.

Patria. Ad Insel-Bay Norae Seelandiae: J. Hooker.

D. filifolio IIsch. ex auct. animadversionibus affine.

66. D. trachyblepharon C. Müll.; erectum strictum interrupte comosum rigilum valde tomentosum subsimplex vel breviter ramosum; folia caulina erecto-patentia, sicca subappressa breviuscula paulisper recurva anguste lanceolata acuta, e cellulis ubipue minutis rotundatis busi pecedratis areolata, cellulis alaribus ventricosis fuscidulis mollibus ef nervo lato canaliculato lamelloso praedita, apice margine et dorso valde serrata; perichactialia vaginantia longe flexuse et firmo-setace, inferne elongate 
laxiuscule areolata, nervo basi tenui elamelloso apicem versus latiore lamelloso praedita, haud cylindraceo-congesta, superne margine et dorso serrata; theca in pedunculo cygneo ovalis gibbosa basi strumulosa olivacea subsulcata, operculo conico subulato recto fusco; perist. I. lamellinervis; calyptra cilis permultis albis nodosis flexuosis longiusculis fimbriata.

\section{Patria. Brasilia.}

Ex habitu D. clavato proximum, D. lamellinervi e nervo lamelloso magis, quoad staturam minus affine. A primo simillimo differt folis nunquam piliferis lamellinervibus apice valde serratis et perichaetialibus longe setaceis. - Thecae aggregatae.

67. D. lamellinerve C. Müll.; laxe cespitosum ereclum strictum albescenti-tomentosum submolle magis rigidum robustum, ubique foliis reflexis dense foliosum viridescens vix nitidum; folia caulina inferiora maxime reflexa, superiora sensim erecta, suprema substricta, latolanceolata subulata falcata, cellulis alaribus teneris rentricosis haud constrictis pracdita, basi e cellulis rlongatis parietibus internuptis superne minutissimis rotundatis mollibus areolata, nervo latissimo maxime lamelloso superne dorso scuberrimo, dense et argute servatu; perichaetialia cylindraceo-convoluta sensim fere subulata, basi e cellulis laxis parietibus normalibus areolata; theca in pedunculo tenello-cygreo subascendens obconica subarcuata subgibbosa basi strumulosu ralde sulcata olivacea, operculo conico acuto subulato fusco; perist. dentes angusti longissimi cruribus tenuibus inferme fusco-striatulis superne hyalinis subrugulosis; calyptra longe et albofimbriata.

Dicr. concolor C. Miill. Bot. Zeit. 1844, p. 709. et IIsch. Wl. Bras. p. 11.?

Petriu. Brasilia, ut videtur haud rarum. Ga liner No. 7 et 25. in Corcovado lectum.

Thecac aggregatae. Pl. mascula gracilior, infra perigonium innorans. Flos mase. e gemmis compluribus 
ovatis compositus. Folia perigonialia e basi latissima concava convolutacea colorata plus minus acuminata, intima minuta, exteriora canaliculata, nervo superne breviter lamelloso, intima obsoletinervia laxe areolata. Antheridia elongata clavata, paraphysibus filiformibus flavis mixta. A $\boldsymbol{D}$. concolori simili notis cursive impressis facillime distinguitur.

68. D. concolor Hook. (Musc. Exot t. 138.); laxe et late cespitosum mollissimum fuscidulo-tomentosum robustum, inferne remotifolium, superne dense et crasse comosum et pulisper incurvum, strumineo-nitidum concolor, flaccidum flexusum; folia caulina erecto-patentia mugis mimusie appressu sed laxe imbricatu apice falcata lanceolato-subulata, superne margine et dorso serrulala, nervo latissimo laxe reticulato et cellulis alaribus robustis ventricosis praedita, minute basi margine albescenti-areolata; perichaetialia basi magis vaginantia et laxius reticulata; omnia viridescentia tenera; theca in pedunculo brevi arcuato torto ovalis superme gibbosa basi perfecte strumosa sulcata olivacea, operculo conico subulato obliquo fusco; perist. dentes bifidi cruribus hyalinis rugulosis; calyptra fimbriatu dein ciliis brevibus destituta.

Campylopus concolor Brid. I. p. 476.

Putria. In locis frigidis regni Novi Granatensis, in Alto de Aranda prope Pasto, alt. 1560 hexap., ubi leg. Humbold t et Bonpland. Columbia, prov. de Caracas in Colonia 'Tovar Germanica alt. 5600 ped.: Funck et Schlim in Coll. Linden. No. 469. Jamurio, in trunc. arbor. vetust.

'Thecae aggregatae. Planta notis illustratis speciosissima.

69. D. Jamesoni Ilook. (Ic. Pl. Rar. t. 179.); digitale cespitosum superne ramosum robustum dense foliosum; folia erecto-patentia secunda nitida plus minus flexuosa, e basi lata planiuscula lanceolato-subulata, apice ad marginem et carinam serrulata nervo latissimo laxo; pedunculi aggregati flexuosi ob innovationes caule bre- 
viores; theca oblonga inclinata sulcata basi strumosa, operculo conico-subulato; perist. dentes longiusculi rubri ultra medium fissi. $t$.

Patria. Columbia, monte Surrucucho: W. Jam es 0 n.

Quibus notis a D. concolori ex icone simillimo distinctum?

\section{to stricta.}

70. D. bieolor Hsch. (in Musc. Sieber. No. 9.); dense cespitosum humile robustum rigidissimum subtruncetum inferne nigrescens superne flavidum, nitidum; folia caulina erecta subappressa dense imbricata brevice strictu, oblonga perfecte cymbiformia, superne usque ad apicem obtusum dorso scubrum murgine convolutucea, latissime nervosa, basi utrinque laxe anguste et tenero-membranacea, hyalina, omnino integerrima, inferiora apice canescentia, cellulis alaribus perpaucis vix conspicuis praedita; perichaetialia omnino fere tencra vaginantia superne subsubito acuminata acutiuscula apice dorso scabra tenuinervia immersa; theca in pedunculo brevi valde arcuato paulisper emerso superne verrucoso rigido ovalis, operculo curvirostro, calyptra brevis basi ciliis brevibus flavidis crassis flexuosis acutis fimbriata.

Putria. Nora Hollandia: Sieber.

Pulcherrima species et folis obtusis brevibus summo apice involutaceo crasso scabris veluti erosis et caulibus subtruncatis bicoloribus facile discernibilis. - Thecae ag,regatae.

71. D. Funkii C. Müll.; pulvinato-cespitosum humile pullide viride fragile subsimptex strictum, inferne fuscidulo-tomentosum temins, superne crussius foliosum, perce fructificuns; folia caulina erecto-patentia strictu $e$ busi longu teneru laxissime et pellucide ureoluta lanceolato-acuminata latinervia, dorso scabra, apice denticulata, collulis alaribus raro conspicuis, pancissimis tuntum marginalibus hycelinis; folia ramorum sterilium apicis angustissime lancoulata linearia laxe quadrate et amoene pel- 
lucide areolata valde conaliculata strictissima laxinervia crussa; perichaetialia vaginantia basi laxius sed superne ut in caulinis minute et incrassato-areolata; thecae poncae soliturice in pedunculis valde cygneis ovales subpyriformes leviter sulcatae olivaceae, operculis conico-subulatis rubentibus obliquis; calyptra parce fimbriata; peristomium D. turfucei.

Camp. penicillatus Brid. I. p. 478. - Camp. frugilis Br. Europ. Fasc, 41. 1. 4. t. 2. - Dicran. flexuosum P. fougile Turn. Musc. Hib. p. 74 - D. densum Flk. Cent. No. 634.

Putria. In locis humidis rupestribus per Europam temperatam raro. In turfosis circa Bex in pago Lemanensi IIelvetiae $\mathbf{R}$ oger primus legit et Bridelio communicavit. - Sero auctumno et mimo reve.

A D. turfaceo proximo ceterisque congeneribus Europacis notis laudatis distinctissimum. - Pl. mascula $\boldsymbol{D}$. turfacei.

72. D. Schleicheri C. Müll.; dense cespitosum, lutescenti-rivide serice-nitens phus mims slatum pluries dichotomum rumulis temuibus persistentibus basi et in ramorum axillis rufo-tomentosum; folia caulina conferta crecto-patentia, sicea erecta stricta, inferiora anguste lanceolata, superiora comantia, e basi lanceolata anguste lanceolato-subuhata, latinervia, apice dentata, dorso scaberula, basi laxe areolata. $t_{0}$

Cummylop. densus Br. Lurop. Fasc. 41. p. 6. tab. 5.

Putria. In petrosis Ilelvetiae: Schleicher, in Palatinatu: Gü mbel.

Ex animadversionibus auct. quoad formas majores $\boldsymbol{D}$. flexuso, minores $\mathbf{D}$. turfaceo simile dicitur.

73. D. nivale C. Müll.; dense cespitosum sed laxe cohaerens subhumile substrictum rigidinsculum pallescens; folia caulina erecto-patentia stricte in comam rengustam densiusculum sublongam congestu brevia, e basi lanceolata valde concas à subito fere marginibus involutis convolutace - setacea inteyervimu acuta, nervo maxime lato partem folii superiorem ex toto occupante dorso scabro, 
inferne clongate laxiusculo-areolata, cellulis alaribus teneris paucis; perichaetialia subvaginantia, patula non cylindraceo-convoluta, intima inferue tenuinervia tenerrime laxe et elongate areolata, e reliquis caulinis similia; theca solitaria in pedunculo pseudolaterali dein substricto breviuscu!o fuscescente ovalis parva ore coarctata glabra sulcata fuscescens, operculo longe subulato obliquo purpureo; perist. parvum, ad basin usque fere fissum, cruribus teneris hyalinis sublaevibus; calyptra -

Campylop. Perrottetii Mont. in litt. et C. Mexuosus ej. pro parte olim. - Camp. nivalis Brid. I. P. 477! - Weisic nivalis Brid. Mant. Musc. p. 48.

Patria. India orientalis, in montibus Neelgheriensibus, loca humida prope Neddoubetta habitans: Perottet. - Insula Bourbonis, monte Piton des Neiges, in altit. 1200 hexapolum: Bory St. Vincent primus omnium legit.

A D. areodictyo simili notis laudatis distinctum; $\boldsymbol{D}$. Turneri pariter affine.

94. D. areodictyon C. Müll.; compactum pulvinatum subhumile substrictum rigidiusculum sordide viride; folia caulina erecto-patentia strictissima in comem patulam scopariam congest brevia, e basi lanceolata valde concavà subito fere marginibus involutis convolutaceosetacea, summo apicc viridi obtusiusculo deuticulato, nervo maxime lato partem folii superiorem ex toto occupante dorso incrassato scubro laxissimo, inferne elongate laxiusculo-areolata, cellulis alaribus teneris paucis; perichactialia raginantia patula non cylindraceo-coneoluta, inferne temineria tenerrima et laxissime areolata, superne longius setacea subflexuosa, e reliquis caulinis similia; theca solitaria in pedunculo valde arcuato dein strictiusculo longiusculo fuscescente ovalis crassiuscula ore coarctata busi scubriusculu sulcata fuscescens, operculo longe subulato obliquo purpureo, calyptra basi integra inflexa sublaciniata; perist. dentes angusti cruribus tenuissimis hyalinis rugulosis. 
Patria. Columbia, prov. Merida, e Sierra Nevada alt. 9000 ped.: Funck et Schlim in Coll. Linden. No. 1082., in arborib. putrescentibus mense Septbr. 1846.

D. flexuosi formis compactis vel $D$. nivali simile, notis autem laudatis propria species. - In apice caulis ramuli saepe reperiuntur firmi brevissimi subjulacei, foliis oblongis subobtusis integris.

75. D. chlorophyllosum C. Müll.; dense cespitosum elongatum pluries et elongute rumosum gracile flaccidum subcompressum sordide vivide nitens apice subcuspidato; folia caulina erecto-parentia perfecte lanceolata obtusiusculo-acuta substricta canaliculata, summo apice obsolete denticulata, nervo lato excurrente dorso valde lumelloso, cellulis alaribus maxime teneris hyalinis rentricosis et inferne margine e cellulis tenerrimis hyalinis, ceteris quadratis, laxiusculis, superne rhomboideo-ellipticis chlorophyllosis vividissimis minutis reticulata.

Patria. Prom. b. spei: Gueinzius 1842., Hb. Kunzean.

A I). atro-virente proximo notis illustratis distinctum. Foliis praecipue superioribus chlorophyllosis cum praccedente inter Campylopodes solitarium.

\section{b. Folia homomalla.}

a. Ralcata.

76. D. porphyreodietyon C. Müll.; inferne cespitosum caulibus ascendentibus plus minus solitariis flavescentibus parce tomentosis, dimorphum, fertile humile moliferum, prolificationibus brevibus oblique positis inferne mudiusculis apice sparse vel fulcuto-comosis, sterile simplex elongatum candatum curvatum arctissime foliosum subteres; folia caulina plantae fertilis e basi brevissima latiusculà lanceolato-subulata, nervo latiusculo valde canaliculato, inferne e cellulis elongate superne minute ellipticis densis viridibus areolata, cellulis alaribus umoeme purpureis, apicem versus margine et dorso denticulata; perichaetialia vaginantia subpatula subito fere subulata 
laxe areolata, basi cellulis purpureis multis saepe solitariis praedita, nervo inferne purpurascente; folia plantae sterilis latiora breviora acutiora cellulis alaribus ventricosis purpureis; theca in pedunculo breviusculo torto tenui obovalis subcernua basi strumulosa sulcata olivacea operculo conico subulato obliquo rubro; calyptra ciliis angustis flexuosis flavidis paucis fimbriata; perist. dentes ad medium fissi, cruribus hyalinis rugulosis.

Dicr. arctocarpum C. Mäll. Linn. XIX. p. 205. - Thysanomitr. arctocarpum $\beta$. Moritzianum Hmp. Linn. XX. p. 75.

Patrice. Columbia in Silla de Caracas: Noritz. No. 144 a.

Thecae rarius aggregatae. - Pl. mascula gracilis flore e gemmis compluribus composito. Folia perigonialia externa subito acuminata basi lato-convoluta purpurascentia, interna breviora, omnia obsoletinervia, subintegerrima sublaxe areolata. Antheridia clarata, paraphysibus fuscidulis mixta. - A D. arctocarpo proximo notis cursive impressis planta cellulis splendidissime purpureis speciosa certe refugit.

77. D. capillaceum Brid. (I. p. 400.); dense cespitosum humile erectum rigidiusculum omnino densifolium apice paulisper falcatum, rumo fertili stricto innocuns; folia caulina lanceolato - acuminata falcata subbrevia latinervia apice obsolete denticulata, dorso sublaevia, inferne e cellulis angustis pellucidis elongatis superne minutissimis areolata, cellulis alaribus paucis laxis fuscidulis planiusculis; perichaetialia stricta paulo raginata; theca solitaria in pedunculo superne cygneo oblonga cermu sulcala basi paulo strumulosa, operculo e basi conica rostellato; perist. dentes ad medium usque fissi, cruribus hyalinis rugulosis.

Patria. Insula Madagascar.

Ex habitu D. cluceto afline sed gracilius.

78. D. reduneum IIsch. et Reinw. (Nor. Act. Leop. XIV. II. Suppl. p. 703.); ascendens semipollicare sub apice inuovans dense foliosum; innovationes basi laxe fo- 
liosae vel nudiusculae apice patulo-comosae; folia caulina patentia homomalla, sicca parum flexuosa; e latiore basi longe capillaria acuta, dorso convexa et laevia superne canaliculata, apicem versus sparsim serrata, pallide viridi-lutescentia, nervo medio crasso, s. potius plaga lata e cellulis angustis elongatis exstructa, praedita, areolis baseos lateralibus laxis saepe rubro-tinetis, maryinalibus mimutis rotundatis seriatis; perichaetialia basi mugis dilatata oblonga laxius reticulata vaginantia, intima e basi lata fornicala purpureo-fusca subulatà stricta erecta; thecae plerumque plures in pedunculis longiusculis tenuibus pallide stramincis madefactis undatis siccitate tortilibus erectae subgibboso-obconicae striatac pallidae parvae; perist. sequentis. $f$.

D. concolor Nees et Blume in Nov. Act. Leopold. XI. I. p. 133. 1. 16. - D. sinuosum Hrid. 1. P. 427, ex parte. - D. Auberti Bél. Voy. d. l'Ind. p. 10 ł.

Putrie. Java: Blume; ibidem in terra humida sỵlvarum distr. Buitenzorg altitud. hexapod. legit Bélanger.

Ex ic. et descr. inter praecedens et sequens intermedium.

79. D. comosum Schwägr. (Suppl. II. II. 2. p. 114. t. 181.); gracile vigidum erectum fusco-tomentosum, innovationibus temibus yracillimis filiformibus foliis densissime uppressis rigidis fere juluceis cuspidutis strictis infra perichuetium comosum oriundis ramosum; folia caulina $e$ basi oveli angusta minute areolata lanceolato-subulata rigida ad comum parum fulcata breviora latinervia, apicem versus serrulata lurido - viridia ; perichaetialia longiora $e$ basi lanceolata subito in acumen subulatum longissimum subfalcatum producta, apice serrata; theca in pedunculo longiusculo dein stricto torto oblonga incurva basi alipuantulum exusperata sicca sulcata brunnea, operculo obliquo subuluto; peristomium $\boldsymbol{D}$. caudati; calyptra basi laciniata. + .

Thysanomitr. comosum R. et Hsch. Nov. Act. Leop. XIV. II. suppl. p. 706. t. 39. f, c. 
Patrie. Java: Reinwardt.

Thecae aggregatae. Flos masc. e gemmis $6-8$ compositus; folia perigonialia universalia in discum congesta, e basi latiore concava subulata, ceterum caulinis similia; propria exteriora dimidio minora, basi ad medium latiora, apice breviter subulata, subintegerrima, angustinervia et laxius areolata; interiora minuta ovato-acuminata integerrima evanidinervia laxissime areolata. Antheridia oblonga truncata ferruginea, paraphysibus filif. flavescentibus mixta. - A D. cundato notis cursive impressis differt.

80. D. chionophilum C. Müll.; caulis erectus ramosus fusco-tomentosus, apice dense foliosus parum falcatus stramineus; folia caulina erecto-putentia lanceolatocapillaria, siccitate parum torta, madefacta parum falcata, nervo lato laxo ubique omnino elumelloso summo apice solo denticuluto, cellulis alaribus planiusculis fuscidulis laxis, e cellulis ubigue minutis areolata, superne margine obsolete denticulata, canaliculato-concava; perichactialia convolutacea elongate et laxius areolata, longius capillaria et acutius serrata; thecae apice caulis plerumque plures in pedunculis valde cygneis gibboso-ovales olivaceae perfecte strumosce sulcatac, operculis purpureis subulatis; calyptra ciliis longiusculis acutis plus minus flexuosis albidis fimbriata; perist. dentes cruribus binis rugulosis hyalinis.

Patria. Columbia in Sierra nevada de Merida altit. 8000 ped., ubi inter Dicr. longisetum nives habitat: Funck et Schlim in Coll. Linden. No. 996. intermixt. Septbr. 1846.

A D. lamellinervi ex habitu proximo notis cursive impressis facile distinguitur. Statura D. Rexnoso haud dissimilis.

81. T. aretocarpum: IIsch. (Fl. Bras. p. 12.); monomorphum, humile proliferum, prolificationibus brevibus inferne nudiusculis apice sparse vel falcato-comosis; folia caulina lanceolato-subulata latinervia valde concava 
apicem versus margine et dorso denticulata, inferne e cellulis elongatis larinsculis diaphanis et alaribus brunneis, superne minutis subrpudratis rhomboideis rividibus areolata; perichaetialia similia subvaginantia patula subito fere subulata, inferne laxius areolata tenera margine angustissime albescentia basi brunnescentia; theca in pedunculo longiusculo torto tenui obovalis apice incrassata basi strumulosa olivacea, sicca arcte cylindrica sulcata, operculo conico subulato subrecto rubro; calyptra ciliis longis tortis angustis albis eleganter fimbriata; perist. I. porphyreodictyi.

Patria. Brasilia in campis Montevidensibus: Sellow. - Coll. Blanchetiance No. 355̆.

A D. porphyreodictyo proximo notis cursive impressis differt. - Theca plerumque solitaria.

82. D. flexifolium IIsch. (Schwïgr. Suppl. II. II. 2. p. 115. t. 185.); humile fulcutum subsimplex val perichaetiis pluribus apice divisum rel innovationibus infru perichuelum oriundis comosis falcatis moliferum; folia caulina secunda, e basi lanceolatà lineari-subulata falcala integerrima viridi-lutea latinervia, inferne elongato-quadrate superne minutissime areolata; perichaetialia longiora caulinis similia; theca in pedunculo tenui pallido tortuoso-arcuato oblonga laeris, calyptra lutere fissu. $t$.

D. flexuosum Hsch. in Nov. Act. Leop. XIV. II Suppl, p. 703?

Putria. Java insula.

D. flexuoso proximum, differt autem planta mascula, folis integerrimis, calyptra et thecis laevibus. - Planta mascula robustior, floribus aggregatis compluribus in capitulum congestis parvis gemmaceis coloratis. Folia perigonialia lato-convoluta breviter acuminata tenuinervia. Antheridia numerosa tereti-ovata, paraphysibus tenuissimis albidis mixta.

83. D. turfaceum C. Müll.; dense cespitosum humile inferme interdum dirisum erectum hand tomentosum viride substrictum, inferme muliusculum, superne longe comosum, houd falcatum; folia caulina erecto-patentia apice 
paulisper falcata, lanceolato-subulata longius cupilluceu canaliculata latinervia, dorso scabra, summo apice denticulata, cellulis alaribus minus conspicuis parvis laxis teneris puncis planis praedita, e cellulis inferne quadratis pellucidis provis superne minutissimis areolata; perichaetialia intima cylindraceo-convoluta, e basi longe raginante magis sensim subulata, inferne laxe pellucide superne minute areolata, longiora, apice denticulata; theca plerunque solitaria in pedunculo valde arcuato ovalis basi vix apophysata glabra sulcata pallida, operculo conicosubulato obliquo longiori rubente; perist. dentes ad medium fissi, cruribus tenuissimis hyalinis rugulosis hand nodusis; calyptra cilis albis inaequalibus flaceidis fimbriata.

C'ump. torfucers Br. et sich. Br. Europ. Fasc. 41. Campylopus. p. 4. t. 3. - C. Mexuosus Bril. 1. p. 469. ex parte. - C. pyriformis schult\%. Fl. stare. suppl. p. 73. et Brid. 1. p. 471. Dicran. Mexuosum var. schultz. N. starg. p. 298.

Irutril. In turfosis regionum tam planitierum, quam montanarum, totius Europac. - Vere.

A D. Rexnoso notis cursive impressis certe distat. Pl. mascula nana, floribus pusillis solitariis. Folia perigonialia intima e basi lata breviter acuminata tenuinervia.

84. D. flexnosum Hedw. (Sp. Muscor. p. 146. t. 38.); dense cespitosum subhumile, infra perichuetium ramis tenuissimis interdum divisum; erectum inferne tenue superne crussius foliosum rufo-tomentosum flavidum, upice subfulcuto; folia caulina erecto-patentia apice paulisper falcata, lanceolato-subulata canaliculata latinervia, dorso scabra, summo apice denticulata, cellulis alaribus per/ecte conspienis laris fuscis planis permultis, pracdita, e collulis inferne subruadrutis pellucidis sublax is superne mimutissimis elliptico-incrassutis areolata, perichaetialia intima cylindraceo - convoluta, e basi longe vaginante subito subulata, inferne tenuiter, pellucide et laxe, superne minute reticulata, longiora, apice denticulata; therac aggregatae in pedunculis valde cygueis ovatae basi subapophysatac gla- 
brae sulcatae pallidae, operculis conico-subulatis obliquis concoloribus; perist. dentes ad medium fissi, cruribus tenuibus hyalinis valde nodosis sublaevibus; calvptra ciliis longis griseis flaccidis fimbriata.

Campylop. flexuosus Brid, 1. p. 469 ex parte. - Dr. Furop. Fasc. 41. Campylopus; p. 3. tab. 1. - Dicr. palustre Isa Pyl. in Brid. I. p. 814. e spec, auth. forma elongata uliuinosa, certe ad Campylopodes pertinens. - Bryum pilosum molle, setis intortis. Dill, Musc, p. 373, t. 47, f, 33, F, G.

Patria. In regionibus montanis tolius Europae, rupes habitans. - Vere.

A $D$. turfaceo saepe commutato habitu jam valde refugit. Pl. mascula $D$. turfacei, floribus parvis interdum pluribus.

85. D. smaragdinum C. Müll.; humile interlextum gracile decumbens ramis ascendentibus teneris smarugdinis attemutis reluti caudatis; folia caulina in ramis crassioribus substricta, in teneris falcata, brevia angusta lanceolata vel lanceolato - subulata canaliculata latinervia, dorso sublaevia, apice denticulata, omnino minute areolata, cellulis alaribus paucis hyalinis puntisper ventricosis praedita.

Didymodon smaragdinus Brid. 1. p. 819.

Patria. Insula Ascensionis ad terram: Dumont d'Urville.

D. cauduto ex habitu affine, sed notis cursive impressis distans.

86. D. caudatum C. Miill.; gracile flaccidum flexuosum fusco-tomentosum, innovationibus tenuibus gracillimis cundatis curratis inferne mudis superne longe-foliosis infru perichatium comosum oriundis interrupte ramosum; folia caulina secunda e basi latiuscula plus minus laxe creolata et cellulis alaribus ventricosis fuscis multis instructa lanceolato-subulata haud rigida fulcuta, inferne remota superne comosa, latinervia, apice minute areolato denticulata, viridescentia, angusta; perichaetialia cylindraceo-convoluta superne sinuata crenulata plus minus 


\section{STEGOCARPI. ACROCARPI. DICRANUM.}

subito subulata falcata summo apice denticulata; theca in pedunculo Iongiusculo arcuato tandem rectiusculo flavido ovalis sulcata flavida annulata, glabra, operculo purpureo conico obliquo; peristomii dentes dense conniventes purpurei cruribus hyalinis tenuissimis laevibus; calyptra primum fimbriata dein cilies destituta.

Camp. flexuosus Mont, in Ann. d. sc. nat. 1812. Crypt. Neelgher. No. 52.

Patria. In locis humidis prope Neddoubetta mont. Neelgheriens, ad terram: Perrottet. Hb. Montagn. Java: Blume primus legit.

D. comoso ex habitu quoad icones simillimum, differt autem textura haud rigida sed molli, innovationibus gracillimis nec cuspidatis nec julaceis sed caudatis flexuosis, folis sparse imbricatis basi latioribus valde falcatis longius setaceis et theca glabra. Thecae aggregatae.

87. D. macrophyllum Kze. (in Pöpp. Coll. MII. No. 231.); laxissine cespitosum tencllum gracillimum crispalum nudum sed tomentosum flaccidum apice tantum sparse comosum, innovationibus proliferis similibus supremis caudatis subgeniculato-elongatum igitur interrupte foliosum sordide viride; folia caulina anguste lanceolata longe subulata subfalcata latissime nervosa canaliculata, cellulis alaribus magnis fuscidulis ventricosis diaphanis, basi e cellulis sublongis angustis viridibus teneris superne minutissimis areolata, dorso scabra, margine apicem versus denticulata; perichaetialia similia patula raginantia sensim longe subulata; theca in pedunculo sicco stricto, humido apice arcuato cylindrica valde curvatu basi strumulosa superne incrassata ore dilatata haud sulcata laevissima, operculo conico subulato subrecto; peristomium $\boldsymbol{D}$. filifolii, calyptra breviter parce et inaequaliter ciliata.

D. flifolium C. Müll, Linn, XVIII. p. 691, ex parte.

Patria. Peru ad Cuchero: Pöppig.

A D. filifolio simillimo notis cursive impressis distat. - Thecac rarius aggregatae. 


\section{B. Uncinata,}

88. D. filfolium Hsch. (Fl. Bras. p. 12.); haxissime cespitosum tenellum gracillimum rigidum muxime nulum haud tomentosum apice tantum sparse comosum, innouktionibus proliferis similibus sumemis subcaudatis subgeniculato-elongatum igitur interrupte foliosum farescens; folia caulina anguste lanceolata longe subulatu subfalcatu latissime nervosa canaliculata, cellulis alaribus magnis fuscidulis diaphanis, basi e cellulis elongatis angustis viridibus teneris superne minutissimis areolata, dorso scabra, margine apicem versus denticulata; perichaetialia similia patula raginantia superne subsinuata igitur subito fere longe subulata; theca solitaria in pedunculo sicco stricto, humido apice arcuato erectu oboralis basi strumulosa superne incrassata ore dilutata haud sulcata laerissima, operculo conico subulato obliquo; perist. dentes ad medium usque fissi; calyptra ciliis longis teneris strictis hyalinis fimbriata.

Putria. Brasilia, in truncis demortuis sylvarum primaevarum prope Novam Friburgam, Jumurii mense: Beyrich; ad Sincora et Kios dos Contas, Octubri: Martius; Corcovedo: Gardner.

89. D. denudatum Brid. (Sp. Musc. I. p. 184.); dioicum; laxe et late cespitosum inferne parce tomentosum erectum vel ascendens plus minus clatum viride capillaceum; folia caulina e basi oblonga latiuscula ommino $e$ cellulis parris mollibus viridi-pellucidis tenuibus areolatn longe subulata, superne parce denticulata, nervo lato applanato excurrente, involutaceo-concava, cellulis alaribus subventricosis totam partem baseos infimam occupantibus hyalinis teneris praedita, dorso laevia; perichactialia intina e basi longe vaginante subito subulata, inferne multo laxius areolata; theca in pedunculo primum cygneo-incurvo dein ascendente tenui subcylindracea tenella crecta, operculo longirostrato stricto; calyptra integra.

Dicranodontium longirostrum Be. et Sch. Bryol. Furop. Fasc. 11. p. 2. tab. 1. - Didymodon longirostris Wel. et Mohr. Bot. 


\section{STEGOCARPI. ACHOCARPI. DICRANUM.}

Taschb. p. 155. et Schwägr. Suppl. 1 I. p. 111. tab. 29, - Brid. I. p. 512. - Cynodontium longirostrum Mart. Fl. Erl. Crypt. p. 94. Bryun pilosum nolle, setis intortis. Dill. Musc. p. 373. tab. $47 \mathrm{f}$. A $-\mathbf{E}$.

P'utria. In terra sylvatica umbrosa vel in truncis putridis per regionem montanam totius Europae et in regione temperata Asiae atque Americae septentrionalis.

Planta mascula femineae similis, flore gemmaceo. Folia perigonialia parva e basi convolutacea ovata breviter acuminata sub-vel omnino enervia. - Camp. Rexuoso ex labitu simile.

90. D. Incinatum C. Mïll.; divicum; laxe et late cespitosum clatum flexuosum molle dichotome et elongate ramosum apice maxime falcatum aureo-nitens rubenti-10mentosum; folia caulina maxime secunda falcata, e basi lata ad nerrum e cellulis laxis parietibus flavidis incrassatis praeditis magnis pellucidis quadratis margine antem densissimis favidis elongatis angustis ureolatn longe subulata, nervo lato supra basin totum folium occupante, canaliculato-concava, dorso et margine apicem versus denticulata, e reliquis laevissima, cellulis alaribus totam partem baseos infimam occupantibus planiusculis magnis laxis emarcidis hyalinis; perichaetialia e basi breviter vaginante latiore ubique laxe areolata superne subsinuatà sensim capillacea; theca solitaria innovando lateralis in pedunculo flexuoso erecta oblongo-ovalis aequalis leviter sulcata glabra; perist. dentes subulati longi purpurei ad basin usque fissi leviter trabeculati rugulosi, infra orifcium oriundi.

Thysunomitrium uncinatum Harvey in Hook. Ic. PI. Rar. t. 22. f. 5. et Lond. Journ. of bot. 1840. H. p. 6.

Patria. Nepal: Wallich. Java: Junghuhn. Hb. Gottscheanum.

Operculum sec. Harvey longirostratum. Calyptra ignota. - Planta pulcherrima colore aureo-nitente ceterisque notis laudatis facillime discernibilis.

91. D. stenopus C. Müll.; erectum gracile elongate ramosum geniculato - Hexuosum flaccidum apice genicu- 
lato-reflexum incurum, laxe foliosum, interrupte fructiferum; folia caulina inferiora patentia subsecunda, superiora comoso-falcata lanceolato - linearia canaliculata, apice argute serrulata, nervo latiusculo, inferne minute quadrato-superne elliptico-areolata, cellulis alaribus brunneis ventricosis praedita; perichaetialia basi convolutacea tenuinervia; pedunculus solitarius superne scaber erectus hund arcuutus, theca solitaria subcylindrico-ovalis purva ungusta sulcata, recta vel curvata glabra annulata, operculo conico subulato recto; calyptra fimbriata; perist. dentes angusti bifidi, cruribus filiformibus tenuissimis pallidis laevibus.

Thysanomitrium stenocarmm Hmp, 1r. Musc. t. 23 A. ct Th. scabrisetum ej. ibid. t. 23 B. forma rohustior theca curviuscula.

Patria. Brasilia, in Monte Video: Sellow.

D. concolori ex habitu affine, ab omnibus congeneribus autem pedunculo stricto distinctum.

\section{Folia pilifera.}

a. Pilo reflexo.

91. D. introfiexum IIdw. (Sp. Muse. p. 147. t. 29.); laxe cespitosum humile, inferne teme, upice dense foliosum comosum breviter rumosum flavescens; folia caulina lanceolata, in pilum hyalinum denticulatum plus minus reflexum producta, superne marginibus conniventibus convolutacea et minute areolata, basi elongate pellucide et tenero-reticulata, cellulis alaribus tenerrimis pallidis praedita, nervo lato superne dorso breviter lamelloso; perichaetialia subvaginantia ex apice sinuata vel sensim pilifera inferne multo laxius et tenerius areolata; theca in pedunculo valde arcuato flavo globoso-ozalis basi perfecte strumosa glabra olivacea, operculo conico obliquo fusco; perist. dentes angusti, cruribus tenuissimis hyalinis rugulosis; calyptra ciliis albidlis teneris nodulosis fimbriata

Putriu. Nova Hollandia, unde primus Hedwig labuit; temporibus novissimis peregrinator Preis inde retulit; insulae Falklandi et Campbelli: J. Hooker. 
Planta mascula humillima simplicissima apice flore composito. Flos masculus gemmaceus, foliis externis caulinis similibus angustis integerrimis epiliferis acutiusculis, internis coloratis lato-convolutis brevi-acuminatis obsoletinervibus. Antheridia elongata, paraphysibus filiformibus flavis mixta. - Thecae aggregatae.

92. D. aureo-nitens (. Müll, habitus ef colol I). grisei; folia caulina latiuscula lanceolato-subulata, nervo lato interius incrassato dorso valde lamelloso in pilum elongatum hyalinum reflexum valde et argute serratum producta, apice laminae folii anreac margine canescente integro, basi uspre ad medium tenero-hyalino- et laxiusculo-superne mimute aureo-et incrussuto-ureolata, cellulis alaribus intense brunneis robustis; perichactialia minora, inferne tenuiora pallidiora laxius areolata, superne aurea plus minus vaginantia et incrassato - reticulata, nervo tenui subito fere in pilum longum flexuosum tenue apice hyalinum parce denticulatum producta; theca in pedunculo brevi arcuato tortuoso ovalis basi scabra sulcata, operculo conico subobliquo, calyptra ciliis brevibus substrictis albis laevibus inaequalibus fimbriata.

C'nmpylop. introflexus Brid. ex parte Br. univ. I. P. 472.

Patria. Insula Bourbonis: Bory sit. Villcent. Hb. Bridelian.

A D. griseo sinillimo notis parallelis longe distat. Thecae aggregatae.

93. D. griseum C. Müll.; dense cespitosum sed lare cohaerens, elatum subsimplex vel elongute rumosum densifolium yrucile suberectum, aureo-flurens foliis piliferis griscum, sterile coma elongatu pilifera, fertile perichaetiis compluribus apice rosulatum; folia caulina latiuscula lanceolato-subulata, nervo lato dorso valde lamelloso in pilum elongatum hyalinum reflexum valde et argute serratum producta, apice lamince folit uneae dentibus hyalinis brevibus amoene serrata, omnino fere munute areolata, cellulis alaribus intense brunneis robustis; perichaetialia multo minora et tenuiora pallida laxe areolata te- 
nuinervia longius subulata sed in pilum breve denticulatum producta, cellulis alaribus tenerrimis hyalinis.

Thysanomitr, griseum Hsch, in F'. Bras. p. 16. - Campylop. introflexus hb. nomull.

Patria. Brasilia in campis Montevidensibus: Sellow.

D. aureo-nitenti simillimum. - 'Thecae aggregatae.

94. D. lepidophyllum C. Müll.; humile strictum inferne tenue superne elongate comosum rigidum simplex compactum sed laxe cohaerens polycarpum; folia caulina perfecte ovali-lanceolata latissima squamaeformi-plana et tenerrimu, nervo latissimo superne dorso breviter lamelloso et paulisper canaliculato in pilum hyalinum plis minus reflexum denticulatum producto, cellulis alaribus tenerrimis albescentibus, basi latissima elongate pellucide tenerrime et rhomboideo-, superne elliptico-areolata viridia; perichaetialia multo angustiora longiora vaginantia sensim fere pilifera in cylindrum convoluta tenuinervia; pedunculi apice caulis creberrimi concolores pallidi varie arcuati rigidi; theca obconica arcuata paria olivacea sulcata, operculo conico subrecto fusco praedita busi aequetlis vel paulisper strumulosa, calyptra ciliis acutis albidis substrictis laevibus fimbriata.

Dicr. mudicum Hsch, in Drègre Musc. Capensibus.

Patria. Prom. bon. spei; in cacum. montium ad flum. Paimut-Rivier dictum: Fcklon. In collibus formicosis antiquis editi secundi prope Gnetpagar district. Caledon: Ecklon. Ib. Kunzeanum. - Julio.

A D. introflexo simillimo caulibus non incrassatocomosis sed tenerioribus elongate-comosis, foliis squamaeformibus planis latis atque thecae forma longe distat.

95. D. pudicum Hsch. (Musc. Sieber. Nov. Holl. No. 24.); dense cespitosum sed laxe cohaerens fuscidulotomentosum ascendens rigidiusculum flexuosum inferne nudiusculum superne subcomosum, interupte innovans, innorationibus filiformibus infra perigonium oriundis solitariis subcuspidatis; folia caulina lanceolata in pilum hyalinum plus minus reflexum denticulatum producta cana- 
liculata angusta superne marginibus conniventibus convolutacea, dorso parce scabra; cellulis ulavibus fere carentia, nervo lato elamelloso, basi elongate pellucide tenuiter superne minute elliptico-areolata; flos masc. e gemmis compluribus angustis compositus; folia perigonialia externa caulinis similia, interna plus minus acuminata latiuscula apice parce denticulata tenuinervia intima latoconvoluta brevia colorata laxe areolata obsoletinervia.

Putriu. Nora Irollandia: Si e ber.

Antheridia angusta elongata, paraphysibus filiformibus flavis mixta. - Ex habitu $D$. lamellato simile, sed minus rigidum, tenuius, pallidius, foliis reflexo-piliferis elamellosis facile discernibile. Pl. feminea ignota. - A $\mathbf{l}$. introflexo, quocum commutatum in herbariis vidimus, statura alta gracillima interupte innovante, foliis elamellosis et perigonialibus longe distat.

96. D. erectum C. Müll.; basi densissime cespitosum; caulis strictissimus, inferne foliis brevioribus dense appressis madefactis erecto-patentibus appressis filiformis, apice glomerato-foliosus simplex $\because$ molifer valde rigidus; folia caulina inferiora anguste lancoolate involuto-concuve integerrima, nervo lato longicuspidato s. piligero apice fuscescente s. hyalino denticulato, dorso cellulis ralde prominulis; suprema lato-oblonga apice breviter acuminata acuta margine cremulata vel denticulata nevo latissimo ante upicem evanescente; theca ellipticooblonga stricta annulata, operculo conico recto, calyptra eleganter fimbriata.

C'(cmpylopus strictus C. Mün. Linn. XIX. p. 207. - Thysanomitr, introftexum Hmp. Linı, XX. p. 74.

Putria. Columbia pr. Galipan: In ritz Collect. No. 145.

A I). inlorflen proximo longe distat. - phecre aggregatae.

b. Pilo slricto.

97. D. incrasentum Kze. (in Pöpp. Pl. Chil. No. 22.); dense cespitosum omnino pallescens elongatum ramosum 
strictum rigidum, albido-tomentosum; folia caulina e basi latissima longissima subulata falcata vaginantia, nervo latissimo excurrente, basi luxissime areoluta alba tenerrime membranacea, medium versus laxe areolata margine albido, integerrima, apicem versus minute areolata scabra, apice hyalino subpilifero scabro; perichaetialia latissima convoluta membranacea subulata pilifera; theca ovalis sulcata glabra aequalis perve annulata, pedunculo arcuato tandem recto torto sublongo, operculo conico subulato subrecto, calyptra laevis basi ciliis brevibns flexuosis, thecae magnitudinem subaequante; dentes peristomii longissimi tenuissimi angusti basi fusci cruribus albescentibus longissimis laevibus nodosis binis interdum temis praediti basi connati.

Campylopus incrassatus Kze. C. Müll. in Linn. XVIIl. 1. 686.

Patria. Chile in sylvis ad 'Talcahuano: Pöppig' 1826 et 1829.

D. griseo e descriptione simile. Ex habitu J. introflexo affine. A prima specie differt: folis caulinis laxissime reticulatis, perichaetialibus caulinis longioribus; secunda species foliis retroflexis facile distinguitur.

Thecae aggregatae.

98. I. Iaeve C. Müll.; cespitosum strictum subfasciculatim ramosum, ramis rigidis erectis, stramineum, inferne brunnescens; folia imbricata erecta lincari-lanceolata, late nervosa concava pilifera; theca elongate ovata ore angustata loevis haud sulcata inaequalis minute nigrescenti-apophysata, pedunculo brevi arcuato, operculo elongate conico, calyptra busi piloso-hirsutu. t.

Cumpylopus laevis Tayl. Lond. Journ. of bot. 1846. p. 47.

Palvia. In Andium monte Pichincha prope Quito: W. Jamesoin, 1827. 9. Octbr.

A J). Hexuso, quocum auctor compararit, notis cursive impressis differre dicitur.

99. D. rigidum C. Müll.; malinatum ascendens, fertile subsimplex moliferum, prolificutionibus gracilioribus remote ef parce foliosis ad apicem comosis, sterile ramo- 
sum, dense foliosum; folia caulina erecto-patentia sicco appressa lanceolato-acuminata canaliculata involutaceoconcava integerrima rigida atro - fuscu suprema luteoviridia, nervo latissimo concolore striato, laxe aveolata; perichaetialia in pilum serratum productu; thecae flavobrunneae aggregatae in pedunculis inflexis oblongo-cylindricae basi exusperatue, operculis purpureis breviter subulatis, calyptra elegantissime fimbriata; perist. dentes cruribus filiformibus in spiram fere contortis pallide luteis. $f$.

Thysanomitr. rigidum Hsch. F\%. Bras, p. 15.

Patria. Brasilia in Minis Generalibus ad urbem Ouro preto, Aprili: Martius.

Flos masculus disciformis compositus. Holia perigonialia minuta, externa late ovata ventricosa acuminata integerrima fusco-viridia, nervo lato excurrente, interna brevius acuminata. Antheridia numerosissima maxima curviuscula truncata, paraphysibus filiformibus lutescentibus mixta.

100. D. truncatum C. Müll.; compacte cespitosum; caulis strictus prolifero-elongatus rigidus; folia erectopatentia laxe imbricata stricta rigida, e basi lata angustà superne sinusa vel perfecte truncuta, cymbiformi-concava, marginibus involutis; nervus latissimus obscurus in acumen longissimum hyalinum denticulatum productus, dorso papillosus; perichaetialia lanccolato-piliformia apice denticulata; perigonialia lato-orata complicato-vaginantia apice denticulata s. integra, nervo excurrente, dorso scabro; theca in pedunculo valde arcuato ovalis interdum subcernua sulcata, operculo conico obliquo; calyptra basi fimbriata; perist. dentes longissimi lanceolati basi adnati apice in crura duo interdum adnata filiformia laevia hyalina fissi.

Camp. truncatus C. Miill. Linn. XVIII. p. 697. - Cump. ranthophyllus Mant. Ann. d. sc. nat. 18.5. D. 111. et in Gay Hist. de Chile, Bot. Crypt. tab. 4. fig. 2., forma foliis minus truncatis.

Putriu. Chile australis: Philippi et C. Gay. 
Thecae aggregatae. Flos masc. disciformis terminalis e gemmis $\mathbf{6}$ oblongis rigidis aggregatis constructus. Antheridia perlonga clavato - elliptica curvata, paraphysibus filiformibus mixta. - D. longipilo proximum, sed folis caulinis truncatis nervo excurente piliferis facile distinguitur.

101. D. Inmellatum C. Müll.; dense cespitosum strictum rigidum inferme purpureo-tomentosum et folis appressis remotis filiforme nudiusculum, apice folis in rosulam densum congestis, flores femineos permultos includentibus, infra rosulam innovatione solitaria stricta cuspidata densissime imbricata filiformi; folia caulina inferiora anguste lanceolata valde canaliculata apice marginibus conniventibus involutacea, in pilum hyalinum serratum producta, superiora breviter pilifera, basi elongate pellucide et laxe, superne minutissime rotundato-areolata, cellulis ularibus fere curentia, brevia stricta; folia perichactii universalis breviora lutissima synamaeformia subplana breviter pilifera, cellulis alaribus flavis incrassatis; perichaetialıa caulinis similia in mucronem denticulatum flavum producta, cellulis alaribus paucis ventricosis laxissimis teneris, intima convolutaceo-vaginantia breviora acuminata integerrima tenuinenia el clamellosa, folia omnia cetera nerro latissimo lamelloso praedita.

Camp. lamellutus Mont. Aun. d. sc. nat. 1838. IX. p. 52. et D'Orbigny Voyage p. 90.

Putria. In sylvis densis ad margines viarum prope Chupé regni Peruviani, prov. Yungas late cespitosum: D'Orbigny.

Thecae aggregatae.

102. D. Iongipilam C. Mïll.; dense cespitosum humile robustum densifolium rigidissimum evectum plus minus strictum dichotome ramosum fuscescens polytrichoideum, sterile cuspidatum, fertile rosulatum; folia caulina lanceolata, nervo latissimo dorso valde lamelloso in pilum hyalinum strictum serratum producta, subintegerrima, basi 
planiuscula e cellulis tenerrimis pellucidis quadratis laxis, superne minutissimis incrassatis areolata, cellulis alaribus laxis fuscis paucis planis; perichaetialia lationa basi maxime tenera pellucida squamaeformia teminervia, intima epilifera inteyerrima.

Camp). pilifer Brid. Mant. Musc. p. 72. - Camp. longipilum ej. I. p. 477. ex parte; Bryol. Europ. Fasc. 41. Cumpylopus p. 6. t. 5. - Cump. polytrichoideus De Not. syllah. Nusc. p. 222!

$\beta$. elongatum, ramis elongatis proliferis viridescentibus; foliis dorso maxime lamellosis.

Putria. In sylva prope Fontainebleau: Bridel; prope Falaise Normandiae: de Brebisson; Ilispania: W. P. Schimper; in ericetosis collinis montanisque Italiae superioris vulgare, etiam ad rupes, in Sardiniae australis montanis: De Notaris. Insula Ischia: Bride l. Var. $\beta$. prope Andegavum Galliae occidentalis in collibus schistosis: Guépin.

Flores feminei creberrimi aggregati. P1. masculae et thecae ignotae.

103. D. brevipilum C. Müll.; gracilescens frugile dense et fasciculato-foliosum; folia caulina breviora superne in comam densam imbricata lanceolata vel oblongolanceolata acuminata, mucrone hyulino dentuto terminata, margine reflexa, nervo angustiore dorso laevi, juniora lacte et aureo-viridia, seniora atro-rufa, areolis basilaribus haud ferrugineis. $\leftarrow$.

Camp. brevipitus Br. et Sch. 1. c. p. 7. t, 4.

Putria. Prope Fontainebleau, praecedenti intermixtum: A. Braun.

A praecedente notis landatis differre videtur. Forsan planta mascula futura?

104. D. Clavatum R. Br. (in Schwägr. Auppl. III. II. 1. t. 255.); dense cespitosum erectum strictum intermpte comosum rigidum valde tomentosum breviter ramosum; folia caulina erecto-patentia, sicca subappressa breviuscula paulisper recurva anguste lanceolata acula, e rellulis ubique minutis plus minus quadrotis areolata, nervo 
lato concolore elamelloso praedita, quaedam piliferu apice denticulata fere cylindrico - concava flavo-aurea; perichaetialia oblongo-acuminuta cuspidata; theca in pedunculo valde arcuato ovalis cequalis leniter sulcata, peristomio D. trachyblephari. $f$.

Patria. 'Terra Diemenii: R. Brown et Sieber.

Operculum et calyptra desunt. Pl. mascula flore o gemmis compluribus ovatis composito. Folia perigonialia ovato-acuminata solidinervia colorata; antheridia teretia lutea, paraphysibus tenuissimis hyalinis mixta. A D. truchyblepharo notis laudatis differt. Folia revera elamellosa? Thecae aggregatae?

105. D. Michardi C. Miill.; caulis erectus sub/lexilis inferne foliis dense appressis nigrescentibus, superne viridescentibus comosis, breviramosus submollis; folia caulina inferiora oblongo-lanceolata integerrima, apice brevissimo hyulino denticulato, concava, nervo lato excurrente s. cuspidato dorso collulis prominentibus, superiora magis acuminata subulata, perichaetialia longe subulata; theca in pedunculo brevi flexuoso oblonga basi uepualis verrucosu striata annulata; operculo conico recto; calyptra latissima busi pluries laciniuta truncuto-inflexa eleganter fimbriatu reluti compamulata.

Camp. Richardi Brid. I. p. 474. - Thysanomitr. Richardi Schwägr. Suppl. 1I. I. p. 61. t. 118. - Weisia Richardi schwägr. mst. - Camp. leptodus Mont. Ant. d sc. nat. 1845. 4. p. 111 . et Hist. de Chile auct. Gay, Bot. Crypt. t. 3. f. 3.

Patria. Ad terram saxaque montis sulphuriferi Guadelupae dense cespilosum: Richard. Funck et Schlim in Coll. Linden. No. 229. Columbia ad Caracas: Noritz No. 141. Chile: C. Gay.

Specimina Guadelupensia a Columbianis statura robustiore altiore magis flexuosa et colore splendidiore paulisper distant. - Flos masc. terminalis e gemmulis nonnullis minimis constructus. Antheridia brevia, paraphysibus filiformibus apice breviter articulatis cincta. Folia perigonialia e basi latissima acuminata integra, exteriora subulata apice hyalino denticulato. Dentes longissimi te- 


\section{STEGOCARPI. ACROCARPI. DICANUN.}

nuissimi usque ad basin fere in cilia duo filiformia fissi pallescentes rugulosi. - 'Thecae aggregatae.

106. D. atro-virens C. Müll.; dense cespitosum elongatum pluries et elongute rumosum gracile flaccidum subcompressum atro-virens nitidum apice tenerrime comoso parce falcuto; folia caulina erecto-patentia perfecte lanceolata apice denticulato cuno igitur subpilifera acuta substricta canaliculata, nervo lato excurrente dorso parce et breviter lamelloso, cellulis alaribus maxime teneris fuscidulis vel hyalinis ventricosis, inferne e cellulis mimutis subruadratis, superne elongatis angustissimis rermiformiMexuosis chlorophyllosis riridissimis reticulata.

Campylop. atrovirens De Not. Syllah. Muse. p. 221, et Br. Eur. Fase. 41; Campylopus; p.5. t. 4. cum planta fertili Brasiliensi, quacum Italiana omnino conventice dicitur. Hatio nobis incerta atque dubia est, dum planta Italiane fertilis inventa erit. Planta Brusiliensis in Br. Kurop. descripta est verlbis sequentihus: folia perichaetialia intima vaginantia in subulam teusissimam producta, theca minuta ovata in pedunculo cywneo demissa, sicca erecta; calyptra ciliis brevissimis fimbriata; perist. deutes angusti ad medium fissi cruribus rngulosis.

Putric. Italia, ad rupes montium ad Verbanum: Cesati, De Notaris; ad Larium: Garovaglio.

U. chlorophylloso soli affiue, notis parallelis facile discernibile.

\section{Species non satis notae.}

107. D. cuspidatum IIsch. (Fl. Bras. p. 13.); ascendens $2-3$ unciale robustum fragile fastigiato-ramosum dense foliosum, ramis cuspidatis pungentibus; folia subsecunda dense imbricata, siccitate cauli appressa, rigida oblongo - lanceolata acuminala brevipilosa integerrima concava, apicem versus marginibus involutis, inferiora fusca, superiora straminea nitentia, nervo crasso e cellulis linearibus composito concolore excurrente, retis areolis parallelogrammis confertis. $\leftarrow$.

Putria. Brasilia prope Sincora et ad Kio de Contas: Martius. 
108. 10. peniclllatum Hsch. (Fl. Bras. p. 13.); robustum assurgens $2-3$ unciale fastigiato-ramosum dense foliosum, ramis cuspidatis; folia longa falcata, siccitate torta, rigidiuscula lanceolato-subulata argutissime serrata canaliculata, suprema erecta duplo longiora vaginata con-voluta teneriora quasi penicillum formantia, inferiora fuscescentia, superiora luteo-viridia, omnia nervo latissino obscure colorato plus quam tertiam totius folii latitudinem occupante striato, retis areolis basi laxioribus subquadratis, in reliqua folii parte linearibus. $\leftarrow$.

Patria. Brasilia, in prov. Miuas Geraës et ad ripas fluvii Rio de Contas, prov. Bahiensis: Martius.

109. D. subfalcatum IIsch. (Fl. Bras. p. 13.); ascendens biunciale flexuosum fasciculato-ramosum dense foliosum; folia rigida secunda subfalcata lanceolata acuminata concava integerima, inferiora fusca, superiora luteo-viridia, nervo lato striato concolore excurrente, retis areolis linearibus obscurioribus. $\dagger$.

Patria. Brasilia in montibus sylvestribus prope Sincora prov. Bahiensis: Martius.

\section{Trib, XVII. IAE T O'TR I C II A CEA E.}

Cespitosae plus minus clatae, sappius gregariae pusillae, acrocarpicae, innovando ramosac vel ramis fertilibus apice pluries divisae. Folia lanceolata vel subulata, sacpe canaliculato-concava, nervo plerumque applanato vel tereti praedita. Retis cellulae prosenchymaticae parcnchymaticis saepe mixtae, laxae, laviusculae vel julus minus firmac inanes, apice haud raro incrassatac igitur quadratac. Theca ovalis rel cylindrica, nnnc arcuata, nunc stricta, basi saepe strumulosa, operculo conico vel sululato. Archegonia, antheridia et paraphyses plerumque ut in Dicranaceis. 


\section{STEGOCARPI. ACROCARPI. BRACHYOUS.}

Dicrunaceis ex habitu proximae et saepius simillimae, cellulis tamen alaribus deficientibus longe diversae.

Patria. Per orbem totum terrarum, regiones omnes atque loca diversissima, partim libenter argillosa et alia, partim rupes nudas habitantes. 21.

Angströmiaceae Br. Europ. Fasc, 33-36.

\section{Gen. I. Rrachýodus Fürnrohr nom. emend.}

in Br. Germ. 11. 2. p. 5. - Gymnostomum al. - Weisia Hook. et Tayl. - Anoectangium al.

E vocibus Boayis brevis et ỏdor's dens nomen compositum.

Calyptra mitraeformis. Peristomium simplex: dentes 16 brevissimi lati obtusi irregulariter lacerati tenerrime membranacei pallidi fugacissimi, aequidistantes vel parum confluentes. Theca annulo magno peristomium subsuperante. Inllorescentia monoica.

Statura Seligeriurum pusillarum, e peristomio autem memorabili genus distinctum.

1. Br. trichodes Fürnr. (1. c.); gregarius nanus simplicissimus vel parce divisus; folia caulina flavescentia, e basi oblonga minute subtenero-areolatâ subulata obtusiuscula integerrima, ad subulam e cellulis minutissimis obscure viridibus reticulata, nervo tenui subulam totam fere occupante praedita, parum concava; perichaetialia basi tenuius areolata; theca in pedunculo brevi stricto flavido ovalis minuta erecta, operculo longe subulato recto pallido, basi conica rubella praedito, sicca striata.

Br. Furop. Fasc. 33-36. Compylosteliaceae, c. ic. - Brachyodon et Brashydontium Fürnrohr in Regensl), hot. Zeit. 1827. 2. Beil. 1. p. 37. et 2. p. 112. - Gymnostomum trichodes Web. et Mohr. Bot. Tasclib. p. 85. - G. Davallianum Sm. in Schrad. Journ. i. p. 191. - Anoectang. trichodes Schw. Suppl. I. I. p. 33. t. 10. 
Putria. In rupibus diversis humidis umbrosis regionis montanae totius Europae. - Veris initio ad auctumnum.

Flos masculus in ramo brevi basilari. Cactera ut in Campylostelio.

Gen. II. Campylostelium Br. et Sch.

Br. Europ. Fasc. $29-30$. Dicranaceae dein Campylosteliareae. - Campylopus et Weisia Brid. Mant. - Dryptodon Brid. Br. univ. - Grimmia Schwägr. - Dicranum Web. et M.

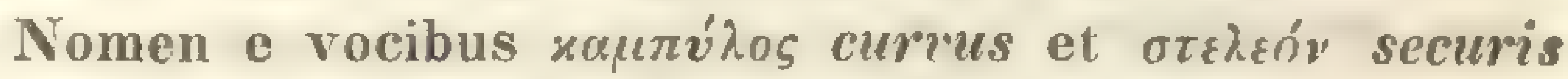
manubrium q. e. pedunculis, ob pedunculum curvum Campylopodi affinem ductum.

Calyptra mitraeformis. Peristomim simplex: dentes 16 in membrana reticulata emersa aequidistantes lanceolati purpurei dicranoideo-bifidi. Inflorescentia monoica. Theca annulata.

Statura Seligeriarum pusillarum, pedunculus Campylopodis sectionis, peristomium Dicrani, calyptra Brachyodontis.

1. C. saxicola Br. et Sch. (1. c. p. 3. t. 1); gregarium nanum simplicissimum vel parce divisum; folia caulina viridissima e basi oblonga pellucide laxius et teneroareolatâ lineari-subulata acuta integerrima, ad subulam e cellulis minutis quadratis viridibus laevibus reticulata, nervo angusto subexcurrente; perichaetialia basi latiora; theca cylindrica minuta olivacea, operculo longe subulato purpureo stricto thecam aequante; calyptra operculum tegens tenera basi pluries laciniata.

Grimmia geniculata Schwägr. Suppl. I. I. p. 82. tah. 22. et Brid. 1. p. 189. - Weisia geniculata Brid. Mant. p. 38. - Dicranum saxicola W. et M. Bot. Taschlb. P. 167. - Campylopus saxicola Brid. Mant. p. 72. - Dryptodon saxicola Brid. I. p. 770.

Patria. Ad lapides et saxa humidiuscula granitica et arenacea umbrosa per regionem montanam Germaniae, Angliae, Hiberniae et in fageto Bucze prope Nawsie Wielopolskie Haliciae: Łobarzewski. In Ducalu Brunsvicensi detexit Schrader. - Primo vere.

c. Muller: Synops. masc. frond. 
Folia perigonialia floris masculi in ramulo brevi basilari positi minuti convolutacea breviter acuminata obtusiuscula. Paraphyses et antheridia parva.

\section{Gen. III. Seligeria Br. et Sch.}

Br. Europ. Fasc. 33-36. seligeriaceae. - Anodus eor, I. c.Weisia al. - Gymnostomum al.

Nomen in memoriam pastoris ecclesiae Seliger Silesiaci, scrutatoris muscorum Silesiae olim acerrimi et indefessi impositum.

Calyptra dimilliata. Peristonium nullum vel simplex: dentes 16 aequidistantes lanceolati planissimi aurantiaci articulati laevissimi interdum pertusi et fissiles vel linea media exarati, medio igitur fissiles. Inflorescentia monoica vel dioica.

Euseligeriue habitu Brachyodontis; Leptotrichellue generi Angströmiae sect. Dicranellae vel Leptotrichis nonnullis affines.

sectio 1. Euseligerin. Plantae exiguae humillimae paucifoliae, foliis parvis milute et dense arcolatis; theca gymnostoma vel dentihus planissimis aurantiacis laevissimis integris raro pertusis vel fissis. - Seligeriaceae Br. Kur. Fasc. 33-36.

1. S. pusilla Br. et Sch. (1. c. p. 4. t. 1.); monoica; gregaria vel cespitulosa brevissima simplex vel dichotoma; folia caulina anguste lanceolata vel e basi latiore longe subulata acuta, nervo angusto subulam totam superam occupante, pellucide et mimete areolata amoene tenera, superne leviter cremuluta; perichaetialia latiora et longiora; theca in pedunculo brevi stricto flavido pyriformi-ovalis, minuta olivacea, evacuata turbinata fusca, operculo conico subulato obliquo tenero-membranaceo; perist. dentes madefacti inflexi, siccitate seniores reflexi, lanceolati planissimi amoene aurantiaci, margine irregulares, raro pertusi, remote articulati.

Weisia pusilln Hdw. Mnsc. Frond. II. p. 68, t. 29. - Brid. I. p. 349. - W. paludosa Brid. Musc. Rec. II. 1. p. 74. - Grimmia 
pusilla Schrad. Samml. fide Web. et Mohr. Bot. Taschb. p. 140. Swartzia pusilla Elırh. Hann. Mag. ex Brid, - Afrelia pusilla Ehrlı. PI. Crypt. Exs. No. 183. - Mnium paludosum L. jun. Meth. Musc. p. 365. - Bryum paludosum L. Sp. P1. p. 1584. - Bryum trichodes acaulon palustre minimun, setis et capsulis lorevissimis. Dill. Musc. p. 387. t. 49. f. 53. - Weisia Seligeri Nees et Hsch. Br. Germ. 11. p. 105. t. 34. f. 26. - Brid. 1. p. 350. - Grimmia Seligeri W. et M. Bot. Taschb. P. 140 et 459. - Weisia calcarea sulliv. Mnsc, Allegh. Exs. No. 142.

Patria. Loea umbrosa humida ad rupes et saxa praeprimis calcarea per regionem montanam et subalpinam totius Europae. - Aestute.

Flos masc. in ramo ad basin perichaetii posito gemmaceus minutissimus, foliis perigonialibus minutis concavis ovatis brevissime acuminatis haud coloratis teneris, antheridiis pariter minutis et paraphysibus tenerrimis brevissimis mixta.

2. s. calcarea Br. et Sch. (1. c. p. 4. tab. 1.); monoica; habitus S. pusillae; folia caulina ov'uta v'el ovetolanceolata, superiora ex ovato anguste lanceolata, obtusiuscula, breviora sordide rividia, e cellalis basi teneris angustioribus superne incrassatis multo frmioribus areolata; theca praecedentis, sed major robustior, dentibus latioribus obtusioribus magis approximate articulatis.

Weisia calcarea Hdw. sp. Musc. p. 66. tab. 11. - Brid. I. p. 351. - Grimmia calcarea sm. Fl. Brit. 11. p. 1187. - Bryum calcareum Dicks. Fasc. 11. PI. Crypt. p. 3. t. 4.

Putria. In rupibus cretaceis Britamniae et insulae Rügen Germaniae, ubi II ornschuch detexit. - Vere.

Folia perigonialia longiora, antheridia majora, paraphysibus saepe nullis. - A S. pusilla notis cursive impressis longe distat.

3. S. recurvata Br. et Sch. (1. c. p. 6. t. 3.); monoicr; habitus $S$. pusillue; folia e basi oblonga lanceolato-subulata elongata flexuosa acuta, iuferne e cellulis clongatis angustis teneris pellucidis ad subulam minutissimis obscuris incrassatis areolata, integerrima, nervo angusto subulam totam superam occupante; perichaetialia majora subvaginantia; theca in pedunculo elatiusculo apice 
recurvato ovalis vel subpyriformi-ovalis, ore angustiore, operculo subulato subrecto; perist. dentes lanceolati vel obtusi, integri vel irregulariter bifidi, densiusculo-articulati.

I'eisia recurvata Brid. 1. p. 352. - W. parasitica Roehl. Deut. Fl. III. p. 51. - Grimmia recurvata HdW. Musc. Fr. I. p. 102. t. 38. - Gr. parasitica Voit in sturm Deut. Fl. Crypt. Hasc. 11. - Bryum recurvatum Hoffm. Dent. Fl. 11. p. 31.

Patria. In rupibus et saxis calcareis, arenaceis et graniticis per regionem montanam totius Europae et in America septentrionali. - Vere.

Inflorescentia $\boldsymbol{S}$, pusillae.

4. \$. tristicha Br. et Sch. (1. c. p. 5. t. 2.); monoica; habitus S. pusillae; folia tristicha stricta lanceolato-subulata obtusiuscula, brevia, e cellulis parvis infima basi pellucidis, superne sordide flavis firmis areolata, nervo angusto subulam integerrimam supremam totam occupante; theca $S$. pusillae.

Weisia tristicha Brid I. p. 355. - Grimmia tristicha Schwägr. Suppl. 1. 1. p. 84. tals. 26. - Gr. trifuria W. et M. Bot. Taschl). p. 141 et 460.

Putria. Ad rupes calcareas madidas per convallia alpina IIelvetiae, 'Tirolis, Salisburgiae, et Lapponiae, nec nou in montosis jurassicis Franconiac, Cebennarum atque Hercyniae. - Majo, in alpibus Julio et Angusto.

Inflorescentia $S$. pusillae.

5. S. Doniana C. Müll.; monoica; brevissima gregaria simplex; folia caulina lanceolato-subulata acutiuscula crenulato-denticulata, perichaetialia breviora obtusiuscula, omnia e cellulis basi tenerrimis pellucidis minutis subquadratis superne valde chlorophyllosis igitur obscure viridibus areolata, nervo angusto subulam supremam totam occupante; theca in pedunculo stricto flavido subpyriformi - ovalis gymnostome minutissima olivacea, ore ampliori, operculo conico brevi subobliquo.

Anodus Donianus Br. Europ. Fasc. 33-36.; Seligeriaceae; cum ic. - Gymnostomum Donianum Eugl. Bot. t. 1582. - Brid. 1. p. 66 . 
Patria. Ad rupes arenaceas et calcareas occultas Britanniae montosae, ubi in spelunca Duppliniana (Pertshire) detexit G. Don; Scotia: Greville. Germania ad rupes marmoreas Hercyniae prope Rübeland: Hampe; Bavaria superiol in monte Peissenberg ad rup. arenac.: Send ther.

Flos masc. in ramo proprio basilari terminalis; folia perigonialia externa oblongo-lanceolata subenervia, interna minora tenuiora enervia; antheridia pauca minuta eparaphysata. - A S. pusilla simillima theca constanter eperistomata specifice sed minime generice distat.

Sectio 1I. Eeptotrichella. Plantae clatiores, foliis partibus omnibus majoribus, perist. dentibus linea media plerumque exaratis igitur saepe medio secedentibus. - An genus proprium?

6. S. Iongirostris C. Müll.; dioica; exigua erecta innovando subramosa; folia caulina subsecunda densa, inferiora lanceolata, superiora lanceolato-linearia integerrima, suprema s. perichactialia rarius pilifera et ad basin pili interdum parce denticulata, luteo-viridia, senio fusco-nigra, nervo crasso ad apicem fere extimum perdurante, e cellulis linearibus seviatis subtilibus areolata; theca in pedunculo recto siccitate parum tortili longiusculo erecta ovalis parva aequalis luteo-brunnea annulata, operculo longe et oblique subulato; perist. dentes lanceolato-subulati trabeculati, inter trabes singulas medias lacuna s. fissura angusta pertusi, apice integri, aetate saepe bifidi, cruribus inaequalibus, ferrugineo-rufi. $\leftarrow$.

Trematodon longirostris schwägr. Suppl. 1. p. 343. - Weisia longirostris ej. suppl. II. I. p. 54. t. 117. - Coscinodon longirostris Brid. 1. p. 376. - Leptotrichum longirostre C. Müll. Bot. Zeit. 1847. p. 806.

Patria. In monte sulphurifero Guadelupae inter $D_{i}$ cranum Richardi: Richard.

7. S. Kunzenna C. Mïll.; dioica; gregaria cespitosa gracillima tenuis erecta adscendens subhumilis, apice innovando ramosa, innovationibus filiformibus; folia caulina e basi subraginante lanceolata, oblonga rel oratn subu- 
lata, linearia, acuta angusta madefacta flexuosa, plicatoconcava canaliculata, nervo crassiusculo subexcurrente, margine parum recurva; perichaetialia angustiora obtusiuscula evanidinervia; omnia undique e cellulis parvis pellucidis quadrato - rhomboideis subangustis reticulata; theca in pedunculo longiusculo tenuissimo erecto pallido erecta urceolato-ovalis annulata parva brunnescens, operculo longe et oblique subulato; perist. dentes breves lanceolato-lineares acuti tenuissime trabeculati rugulosi ferruginei interdum subpertusi.

Leptotrichum Kunzeanum C. Miill. Bot. Zeit. 1847. p. 806. Weisia tenuis Kze. in Pöpp. Coll. Pl. Cluil. IV. No. 230.

Patria. Chile et in Peru ad Cuchero: Pöppig.

Pl. mascula quam maxime tenuis pluries e perigoniis innovans igitur quasi prolifera, floribus $\mathbf{2}-\mathbf{5}$, interdum ramis masculis divisa. Flos masc. pro plantulae exiguitate crasse gemmaceus; folia perigonialia e basi latoovata colorata tenuius areolata valde concavà subito et breviter acuminata obtusa subintegerrima evanidinervia, intima brevissime acuminata convolutacea enervia; antheridia haud copiosa submagna, parapliysibus aequalibus hyalinis tenuibus mixta.

8. S. pallidiseta C. Müll.; dioica; erecta firme subhumilis simplex vel apice divisa; folia caulina superiora densiora erecto-appressa, madefacta erecto-patentia, ovato-lanceolata, nervo crasso lutescente contimu, suprema longiora subulata basi vaginantia marginibus imvoluta, siccitate leniter incurva, e luteolo vel lutescente viridia; ramea brevia laxa appressa; omnia integervima rigida e cellulis subquadratis areolata, theca in pedunculo brevi recto luteo vel luteo-ferrugineo erecta late annulata ovala lacvis badia, operculo conico subulato obliquo rufo-badio; perist. dentes lineari-lanceolati transverse sulcati badii foraninibus quinis pertusi. $T$.

W'eisia pallidiseta schwägr. Suppl. 11. p. 54. t. 117. - Coscinodon pallidisetus Brid. 1. 1. 377.

Putriu. Insula Madagascar: Aubcrt du Petit Thouar. 
9. S. Miqueliana C. Müll.; dioica; cespitose gregaria misilla prostrata innovando ramosa; folia caulina erecto-patentia homomalla lanceolata latiuscula stricta breria acuta carinata vel plicato-concava margine parum revoluta, nervo flaro crassiusculo ante apicem denticulatum cranido, undique e cellulis elongatis ampliusculis pellucidis tenuibus areolata; perichaetialia majora obtuso-acuta; theca in pedunculo elongato purpureo rigido stricto erecta vel parum obliqua anguste cylindrica fusco-purpurea, operculo longe et obliyue subulato; perist. dentes approximali latiusculi lineari-lanceolati obtusi basi crasse trabeculati erecto - conniventes.

Weisia Miqueliana Mont. in Lond. Journ. of bot. 1844. p. 633 et in Anı. d. sc. nat. 1845. 4. p. 118. - W. macrorrhyncha Mont. Ann. d. sc. nat. 1. c. p. 11\% e spec. auth. huc pertinet!

Putria. In terra nuda prov. Buitenzorg Javae insulae: Hb. Miquelian. Kollinger Coll. No. 1532.

Flos masc. in planta propria multo graciliore simplicissima terminalis, habitu Astomi. Folia perigonialia e basi lato-ovata valde concava tenuius areolata colorata breviter et brevissime acuminata. Antheridia haud numerosa submagna, paraphysibus tenuibus brevioribus hyalinis mixta.

10. \$. pallens C. Müll.; cespitosa subramosa $2-3$ linearis; folia suberecta lineari-lanceolata, siccitate vix tortilia, lanceolata integerrima evanidinervia, laxe reticulata; theca in pedunculo humili pallide rubello suberecta pyriformis, sicca subcylindrica, ore parum constricto, badia, operculo conico brevi oblique rostellato; perist. dentes pyramidati angusti rubri. $f$.

Weisia pallens Hook, et Wils, in Hook. Ic. PI. Rar. t. 739 A.

Patria. Nova Hollandia ad flumen Swan River: James Drummond.

A S. Mipueliana ex ic proxima notis cursive impressis distat. 
Gen. IV. Garckea C. Müll.

Bot. Zeit. 1845. 1. 865. - Dicranum Hook. - Grimmia Dz. et Molklo. - Weisia Hmp.

Nomen in honores amicissimi Garcke, florae Halensis praestantissimae nunc ad lucem pertractae auctoris spectatissimi conditum.

Calyptra campanulata. Peristomium fere Trematodontis simplex: dentes 16 lanceolati, basi tantum paucis trabeculis, medio perforati ita, ut membrana tenuissima hyalina reliqua sit. Inflorescentia dioica.

Habitus Bruchiaceis simillinus. Genus memorabile, hucusque Indicum, specie unica tantum gaudens.

1. G. phascoides C. Müll. (1. c.); gregaria, filiformis recta fragilis simplex, inferne foliis minoribus, apice majoribus comosa, floribus femineis masculisque $2-3$ ramosa; folia caulina lanceolata subcava, excurrentinervia integra; perichaetialia parce denticulata apice saepe obliqua crassinervia oblongo-lanceolata; theca immersa cylindraceo-oblonga parva, operculo conico recto basi tumido, annulo tenero duplici haud volubili; 'perist. dentes scaberrimi; calyptra operculum tegens valde papillosa basi non laciniata.

Dicranum phascoides Hook. Miscell, bot. 1830. I. p. 39. t. 21. Weisia phascoides Hmp. in sched. - Girimmia comosa Dz. et Molkb. Ann, do. sc, nat. 1844. 1I. p. 304.

Putria. India orientalis prope Sylhet: Wallich. Java, ubi inter Trematodontes viget, in provincia Buitenzorg: IIb. Miquelianum; in locis aliis non designatis: Zollinger, No. 1579. Ex insula Sumatra acceperunt Dozy et Molkenboer.

Flos masculus gemmiformis in planta simplicissima terminalis perigonio longissimo inclusus. Folia perigonialia e basi latissima valde convoluta superne sinuatoconstricta et apice rotundata subito capillaria flexuosa, inferne laxe arcolata. Antheridia parva clavata vix sti- 
pitata, paraphysibus tenerrimis cincta. - Astomo subulato ex habitu simillima tenella et Angströmiue filiformi pariter affinis.

Gen. V. Eccremidium Hook, et Wils.

Lond. Journ. of bot. 1846, p. 450. - Bryum Tayl. - schistidium Hook, et Wils, in Hook. Ic. PI. Rar.

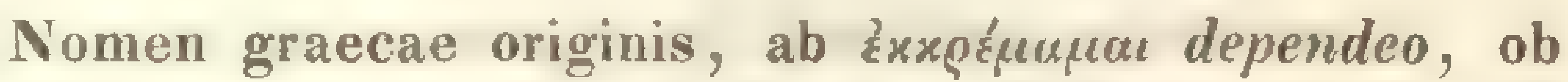
thecam pendulam, ductum.

Calyptra minuta campanulata. Theca gymnostoma medio dehiscens cum operculo arcte connata.

Plantae e thecis, exiguitate et habitu Bruchice exigute similes, sed musci stegocarpici, quoad caules Angströmiis julaceis proximae, nobis tamen hucusque haud visae, ex iconibus et descriptionibus autem huc pertinentes, memorabiles.

1. E. areuatum Hook. et Wils. (1. c.); fertile simplex pusillum lineare et ultra, sterile duplo longius; caulis fertilis basi erectus, apice arcuato-inflexus; folia caulina trifariam imbricata appressa thomboideo-orata oblusiuscula, margine minutissime crenulato-denticulata, carinato-concava, nervo valido subcontinuo; perichaetialia lanceolato-acuminata subfalcata; theca in pedunculo breviter exserto superne incrassato pendula, cum operculo pyriformi-globosa obtusiuscula, medio dehisceus, rufo-brunnea; calyptra conico-mitraeformis membranacea luteola.

Schistidium arcuntum cor. Hook. Ic. PI. Rar. t. 738 A. Bryum tenuissimum Tayl. Lond. Journ. of bot. 1846. p. 52.

Patria. Nova Hollandia ad flumen Swan River: James Drummond.

2. pulchellum Hook. et Wils. (1. c.); duplo longius grucilius nitidum lenissime curvutum, hic illic rumis erectis filiformibus; folia caulina arcte imbricata appressa nec trifaria ouatu apiculato-acuminata integerrima, nervo in foliis caulinis subcontinuo in ramulinis abbre- 
viato; perichaetialia ovato-lanceolata longe acuminata; theca in pedunculo breviter exserto incurvo superne incrassato pendula, pyriformis rufo-brunnea, operculo conico-acuminato subcoriacen lutea.

Schistidium pulchellum Hook, et Wils, in Hook. Ic. PI, Rar. t. $738 \mathrm{~B}$.

Patria praecedentis.

Angströmiae andicolue ex habitu caulium et structura foliorum simile.

\section{Gen. VI. Angströmia Br. et Sch.}

Bryol. Europ. Fasc. 33-36. - Dicranum al. - Weisia al.

Nomen in honores bryologi Suecici $\AA$ ng gström, de muscis Scandinaviae perscrutandis meriti, conditum.

Calyptra cucullata. Perislomium nullum vel simplex: dentes $\mathbf{1 6}$ aequidistantes basi plus minus dense approximati bifidi, dicranoidei inferne trabeculati, cruribus articulatis. Inflorescentia monoica vel dioica.

Habitus partim dicranoideus, partim proprius.

Séctio 1. Euangströmia. Plantae julaceae, folis densissime appressis amplexantilus, dioicae. - Plantae suo generi ut Bryum julaceum allalogum Bryo generi et ab Angströmits ceteris typice minime distantes.

1. A. longipes Br. et Sch. (1. c. p. 3. t. 1.); basi cespitulosa humilis erectu rumulosa viridis; folia caulina densissime erecto-appressa, inferiora minuta, superiora sensim majora, e basi lato-vaginante e cellulis ampliusculis pellucidis teneris superne minoribus magis incrassatis areolatâ breviter acuminata, obtusa, nerro angusto flaviore temissimo evanido, integerrima, convolutaceoconcava; perichaetialia majora latiora laxius reticulata magis acuminata subacuta; theca in pedunculo elongato purpureo globoso-ovalis brevis exannulata, operculo conico brevi recto; perist. dentes ad medium bifidi angusti, cruribus inaequalibus rectiusculis. 
Dicr. julaceum Hook, et Wils, in Drumm. Musc. No. 100. Weisia longipes sommerf. Suppl, ad Wahlenl, Fl. Lapp. p. 54. t. 1.

Patria. In valle Saltdalen Nordlandiae Norvegiae, terram argillosam humidam ad rivulos montanos habitantem detexit Som merfeld $t$, in loco vicino Sandhorn versus meridionalem locum Saltenfjord legit Lessing; in rupibus ad Portage River prope flumen Columbia Canadae superioris legit Drummond.

Pl. mascula gracillima, flore capituliformi crassiusculo denso. Folia perigonialia perichaetialibus similia acutiuscula tenuinervia magis convolutacea colorata. Antheridia magna, paraphysibus longioribus breviter articulatis mixta.

2. A. valeanica C. Müll.; basi cespituloso-cohaerens elata erecta subflexuosa simplicissima filiformis; folia caulina densissime appressa erecta, lanceolati et nerro in subulam cunaliculatam longiusculam acutum mroducto flavo, integerrima, e cellulis angustissimis subfexnosis longiusculis incrassutis subconflatis firmis areolata, canaliculato-concava; perichactialia majora in comam elongatam strictum congesta longissime et flexuose subuluta, intima minora et laxius reticulata; theca in pedunculo immerso cylindrica parua erecta, operculo conico-rostrato brevi subrecto; perist. dentes breves transverse sulcati incurvi, apice tantum bifidi, luteo-rufi.

Dicr. vulcanicum Brid. I. p. 466 . - D. filiforme Schwägr. Suppl. II. p. 72. t. 122. - Veisia vulcanica Brid. Sp. Musc. 1. p. 124.

Patvia. In crateribus incensis montium ignivomorum insulae Bourbonis, 1300 hexapodes supra mare: Bory St. Vincent.

Flos masculus in planta femineae simili terminalis, foliis perigonialibus perichactialibus simillimis longissime cuspidatis, intimo rarius mutico. Antheridia elongata, paraphysibus paucis aequalibus tenuibus flavidis mixta. Schwägrol.c.

3. A. Gayana C. Müll.; cespitulosa clongata simplicissima flexuosa; folia caulina dense appressa apice pu- 


\section{STEGOCARPI. ACROCARPI. ANGSTROEMA.}

rum putula, e basi amplexante oblonga e cellulis inferne pellucidis subteneris longiusculis superne incrassato-ellipticis firmis areolatâ breviter acuminata, nervo in subulam brevem carnosulam fuscam obtusam excurrente flavido crassiusculo, integerrima; perichaetialia latiora magis vaginantia basi tenuiora, intima longius acuminata, summo apice indistincte pluries emarginata; theca in pedunculo brevi purpureo stricto crasso erecta ovalis major fusca, operculo longe subulato oblipeo; perist. dentes robusti carnosi subbreves intense purpurei mofunde bifidi ad basin densissime approximati subconflati, apice incurvi, cruribus crassis teretibus scuberrimis.

Dicr. Gayanum Mont. Ann. des sc. nat. 1845. 4. p. 112. et in Gay Hist, de Chile Bot. Crypt. t. 2. f. 3.

legit C. Gay.

Patria. Chile australis, ubi ad terram frequenter

Pl. mascula apice perigonio breviter comoso crasso et infra idem iterum innovatione mascula graciliore divisa. Folia perigonialia latissima convolutaceo-vaginantia colorata, inferne laxius areolata, ad subulam magis emarginata. Antheridia numerosissima maxime elongata robusta curvula, paraphysibus brevioribus flavidis mixta. - Planta speciosissima. Ab A. vulcanicu proxima jam notis cursive impressis, primo adspectu autem pedunculo multo longius exserto facillime distinguitur.

4. A. andicola C. Müll.; (in bot. Zeit. 1847. p. 189.); basi cespitulosa humilis tenella tenuissime julacea, inferne simplex, superne ramis tenuissimis brevibus curvulis divisa, facescens nitida; folia densissime appressa, inferiora minora, superiora majora amplexantia canaliculato-concava orata acuta, margine tenuissimo cremulata, amoene anrea, nervo obscuriore crassinsculo ante apicem pranido, e cellulis minutis incrassatis in membranam firmam conflatis areolata; perichaetialia e basi convolutaceo-vaginante subito acuminata, excurrentinervia, longius reticulata; theca in pedunculo longiusculo tortuosostricto rigido purpureo elliptica erecta firma fusca, oper- 
culo longe et oblique subulato et annulo maximo revolubili pruedita, sed gymnostoma.

Gymnostomum julaceum Hook. Musc. Exot. t. 42. et Schwägr. Suppl. III. I. 1. t. 206. - Brid. I. p. 92.

Patria. In crepidinibus montis ignivomi Rucu-Pichincha prope Tablahuma regni Quitensis, regione frigida super basaltum, altitudine 2340 hexapodum: $\mathbf{H u m b o l d t}$ et Bonpland.

Pl. mascula ignota. Species memorabilis certe huc pertinens, notis illustratis e distinctissimis.

Sectio II. Campylopodium. Plantae Campylopoditis simillimae pedunculis cygneo-recurvis.

5. A. euphoroclada C. Müll.; humilis gracilis, inferne nuda, superne foliis capillaceis parce foliosa, simplicissima, apice ramis fertilibus pluribus sublongis teneris divisa, tenella flexuosa fuscescens; folia caulina homomalla subfalcata, e basi vaginante latiuscula superne sinuata planiuscula subito flexuoso-capillacea acuta, apice obsolete denticulata, e cellulis angustissimis elongatis parietibus flavidis instructis flexuosis inanibus flavescentibus rel pellucidis areolata, nervo basi tenui superne tolum folium occupante; perichaetialia inferne laxius reticulata; theca annulata in pedunculo brevi valde cygneo semper descendente fusco oralis parra basi apophysata subrugulosa aequalis fusca, operculo conico subulato recto; calyptra basi laciniato-fissa inflexa; perist. dentes profunde fissi, cruribus hyalinis rugulosis tenuissimis fissilibus.

Didymodon medius Duby in Moritzi: Syst. Verz, der Zolling. Pf. P. 134? - D. grimmioides Dub. 1. c.?

Patria. Java: Hb. Gottscheanum. Zollinger Coll. No. 411. zo a. et b.

Campylopodibus ex habitu simillima, sed structura interna i. e. cellulis alaribus deficientibus foliisque caulinis vaginantibus toto coelo distat. 
Sectio III. Mierane IIa. Plantae simplices folis plus minus patulis pedunculisque erectis.

\section{a. Folia homomalla.}

c. Theca strumosa.

6. A. cervieulata C. Müll.; dioica; dense cespitosa vel compacta humilis erecta parce ramosa subvelutine flavide virescens, inferne tenuis, superne crescens; folia caulina inferiora lanceolato-subulata, erecto-patentia appressa, superiora e basi semivaginante temissime membranacea pallescente elongate pellucide angustiuscule et laxe areolatâ canaliculate flexuoso-setacea acuta secunda, apice obsolete denticulata, nervo lato valde applanuto totum subulam occupante concolore; perichaetialia latiora et longius vaginantia; theca in pedunculo longiusculo tenuissimo flaro flexuoso-erecto globoso-ovalis basi depressostrumosa minutissima leviter striata olivacea dein aureonitens, cernua, annulo spurio, operculo conico longe et oblique subulato rubente; perist. dentes angusti breves luteo, ferruginei ad medium bifidi, crurbus tenuissimis asperulis ferrugineis.

Dicr. cerviculatum Hdw. Musc. Frond. 111. p. 89. t. 37 B.Bryum cerviculatum Dicks. Fasc. Crypt. 11. p. 7. - Oncophorus cerviculatus Brid. I. p. 391. - Dicranum flavidum sclıwägr. suppl. I. 1. p. 192. t. 45. - Oncophorus flaridus Brid. I. p. 392. Dier. uncinatum sim. Fl. Brit. p. 1207. - Oncoph. cerviculatus $\beta$. uncinatus Brid. 1. p. 392. - Dicr. pusillum Hdw. Musc. Frond. 1 I. p. 80. t. 29. f. 13. - Oncoph. pusillus Brid. 1. p. 390.; forma liumilis sinplex, foliis minoribus suberectis atque theca minore minus gibbosa.

Patria. In ericetis et turfosis per totam Europam, e planitie usque ad alpes ascendens et in America septentrionali. - Junio uspue ad Augustum.

Pl. mascula minor; flos capituliformis; folia perigonialia ex ovata et valde concava basi lineari-subulata; paraphyses et antheridia parva sat copiosa. - Ab $\boldsymbol{A}$. heteromalla proxima notis cursive impressis longe distat.

7. A. Sauteri C. Müll.; monoica; brevissima simplex cespites pusillos densos ditissime fructificantes effi- 
ciens; folia parva erecta densa obscure fusca lanceolatu carinata obtusa, nervo crasso subexcurvente, superiora rigidiuscula in acumen breve angustata fasciculata pallide viridia; perichaetialia vaginantia ovato-lanceolata; theca in pedunculo solitario erecto flavido obovata cernua dorso gibboso-obliqua, ore angustata flavida, evacuata amplior, striata, basi strumulosa, operculo e basi convexa oblique et flavide rostrato; perist. dentes lanceolati rubri dense trabeculati inflexi dein reflexi, ad medium usque fere fissi. to

Dicranum pumilum Saut. in Regensb. Flora 1839. I. p. 264.

Patriu. Alpes Salisburgiae, in terra glimmeracea, altitudine 6000 ped. montis Feubachhorn dicti versus meridion. ditionis 'Lell am See: Sauter 1835. Sept. 23.

Ab A. cericulatu, ex obs. anctoris proxima, inflorescentia monoica et notis ceteris laudatis distat.

8. A. conretata C. Müll.; divica; habitus $A$. heteromallae; folia caulina inferiora lanceolato-subulata, media e basi lutiusculo-vaginante flavida anguste dense longiuscule areolata superne subsimatu margine crenuluta et minutius reticulatà subito subulata falcata acuta, apice summo denticulata, nervo latiusculo flavo canaliculato subulam superam totam occupante; perichaetialia longius et angustius vaginantia, inferne laxius areolata; theca in pedunculo elongato apice parum inclinata erecta ovalis ore coarctata basi strumosa annulo lato valde verolubili mraedita fuscescens, operculo longe et oblique subulato; perist. dentes dense approximati longi angusti inferne robuste trabeculati et intense purpurei, superne vix ad medium bifidi, cruribus strictis crassiusculis asperis flavescentibus dense cohaerentibns.

Putria. Java: Zollinger Coll. No. 411. z; specimina pauca Leptotr. Boryano intermixta invenimus.

Ab $A$. heteromalla nolis cursive impressis distat.

9. A. aulacocarpa C. Müll.; dioica; cespitulosa humilis simplex amoene flavida, inferne foliis minoribus superne majoribus densius imbricatis, siccitate crispatis 


\section{S'IEGOCARPI. ACROCARPI. ANGSTROEMA.}

subsecundis; caulina e basi elongate oblonga superne latiore sinuta e cellulis elongatis pellucidis ampliusculis teneris flexuosis superne minoribus subincrassutis areoluta subito loriformi-subulata obtusiuscula integerrima, nervo angusto tenui subulam canaliculatam superam totam occupante; perichaetialia superne magis convolutacea; theca in pedunculo brevi stricto flavido erecta subgibbosoovalis parva rubens striata annulata basi strumulosa, operculo longe et oblique subulato pallide rubro; perist. dentes ad medium bifidi angusti, cruribus apice pallidis tenuibus.

Dicranum aulacocarpum Mont. Ann. d. sc. Iat. 1845. 4. p. 113.

Putria. Chile australis ad terram nudam: C. Gay.

Ab A. heteromalla proxima notis cursive impressis distat.

\section{B. Theca exsirumosa.}

10. A. heteromalla C. Müll.; dioica; simplex humilis vel elatiuscula ramosa; folia caulina perfecte homomalla, e busi angustu e cellulis angustissimis densis subparvis arcoluta lineari-setacea falcar a minute denticulata, nervo angusto subulam superam totam occupante; perichaetialia basi latiore vaginante inferne laxius areolata; theca in pedunculo tenuissimo flavido elongato flexuosoerecto subgibboso-ovalis subcernua subaerualis nitida striata rubens angustissime anmulata, operculo longe et oblique subulato intense purpureo; perist. dentes $2-3$ - fidi valde purpurei plus minus robusti lati tenues, cruribus tenuibus ferrugineis rugulosis.

Dicranum heteromallum Hdw. Mnsc. Frond, I. p. 68. t. 26. Bryol. Europ. Fasc. $37-40$. p. 25. t. 15. - Brid. 1. p. 423. Fuscina heteromalla Schrank. Baiersche F1. 11. p. 451. - Bryum heteromallum 1)ill. Musc. p. 375. t. 47. f. 37.

B. stricta; foliis undique erecto-patentibus strictis, pedunculo elongato flexuoso. Br. Europ. I. c.

$\gamma$. interrupta; major, caule altiore ramosiore nunc interrupte folioso, foliis patentibus rel subsecundis. Br. Europ. 1. c. - Dicr. interruptum Hdw. 8p. Musc. p. 129. t. 29. D. caducum Brid. 1. p. 425. 


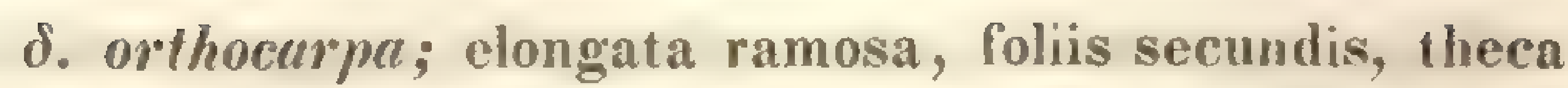
cylindrico-ovalis erecta aequalis. Dicr. orthocurpum Hdw. s. Musc. p. 131. tal. 30. - D, heteromullum val. 2. Sulliv. Misc, Exs, Allegh, No. 166.

Putria. In terra denudata et rupibus praeprimis arenaceis et in turfosis planitierum et regionis montanae totims Europae atque Americac septentrionalis. - Primo reve.

P1. mascula femineae aequalis rel minor. Folia perigonialia e basi ovata concavà subito subulata tenuius nervosa; intimum latissimum brevissime subulatum tenerrimum. Paraphyses et antheridia mediocriter numerosa.

11. A. subulata C. Müll.; dioica; interrupte cespilosa, erecta vel e basi decumbente ascendens, cumoene serice-rividis, humilis gracilescens ramosa, apice innovans; folia caulina falcato-secunda, c basi oblonga e cellulis angustissimis densis subteneris areolatà falcato-setacea, integerima, nervo latiusculo obscuriore subulam canaliculatam angustam superam totam occupante; perirhactialia comoluteceo-vaginutia ut coulinu sol parum larins reliculate; theca in pedunculo purpureo cermua gibboso-oralis coriacer obsolete striata annulata, opereulo recurvirostri longissimo concolore; peristomium A. curvatee.

Dirranum subulatum Hdw. sp. Musc. p. 12\%. t. 34. - Br. Earop. Fasc. 37 -40. p. 23. t. 13. - Brid. I. 1. 426. - D. secundun Sw. Act. Holın. 1795. p. 244. - D. Suleticum silhwithr. Suppl. I. 1. p. 175. tab. 45., forma elatior e spece. Ludwigianis.

Patricl. In terra micacea et arenosa per regionem subalpinan et alpiuam Germaniae, Ilelvetiac, totius Scandinaviae et in America septentrionali. - Augusto.

Pl. mascula gracilior subsimplex, sub flore innovans; flos capituliformis; folia perigonialia ex orata valde concava colorata et tenero-areolata basi subulata; parapliyses et antheridia pauca tenera.

12. A. curvata C. Müll.; divica; gregaric et laxe cespitosa pluries divisa subhumilis gracilis subremotilolia sordide lutescens; folia caulina falcato-secunda, e basi 
oblonga angusta e cellulis elongatis angustissimis densissimis in membrunum veluti conflatis areolatà falcatosetacea, upice obsolete denticulute, nervo latiusculo concolore subulam canaliculatam angustissimam superam totam occupante; perichactialia basi longiuscule vaginantia tenerrime ef pellucide reticulatu diaphana; theca in pedunculo longiusculo substricto brunneo erecta vel parum currata oveto-oblonga uequalis brunneo-fusca annulata striata, ore subtrunceto, operculo conico-subulato obliquo; perist. dentes elongati angustissimi ad medium bifidi plus minus aurantiaci planissimi, cruribus tenuissimis laevibus.

Dicranum curratum Hdw. Sp. Musc, p. 132. tal, 31. -- Br. Europ. Fasc. 37 - 40. p. 24. tab. 14. - Brid. I. p. 425.

Patria. Ad rupes et terram denudatam arenaceoargillosam per regionem montanam sylvaticam Germaniae, Galliae, Britanniae et Scandinaviae Lapponiac prope Kipinä ex Angström. - Sero auctumno et primo vere.

Inflorescentia $A$. subulalue, quacum saepe commutata sed notis cursive impressis facile distinguitur.

13. A. Perrottetii C. Müll.; divicu; laxe cespitosa elatiuscula crecta gracilis, inferne gracilior superne densius foliosa; folia caulina erecto-patentia vel secunda, e basi ovata vel lanceolata elongute unguste dense ampliuscule et vulde flavido-arpolata inferiora sensim superiora fere subito subulata acutiuscula integerrime canaliculata, nervo lato deplanato subulam superam totam minute areolatam occupante concolore; perichaetialia interiora e basi angustiore medio latiore supra attenuata elongate ampliuscule et pellucide reticulata sensim el brevius subulata; theca in pedunculo strictiusculo flavo apice parum inclinato cressiuscule oralis pured coriacea annulata, operculo Ionce et oblique rostrato; perist. dentes vix ad medium bifidi, cruribus conniventibus tenuibus asperimis ferrugineis.

Dicranum Perroltetii Mont. Ann. d. sc. nat. 1843. XIX. p. 241. - D. sclerocarpum Hook, et Wils. Lond. Jonrn. of bot. 1847. p. 291.

1. 11. ex ic huc pertinet. 
Patria. Insula Martinique: Perrottet. Ex insula Guadeloupe a C. S. Parker lectam et e Nova Granada acceperunt Hooker et Wilson.

Pl. mascula cespitulos proprios efficiens gracillima flexuoso-erecta ad perigonium innovans. Folia perigonialia caulinis superioribus e forma et areolatione similia sed convoluta colorata, interiora laxius et tenuius reticulata; antheridia majuscula, paraphysibus tenerrimis aequalibus mixta.

14. A. brachyblepharis C. Müll.; dioica; laxe cohaerens erecta tenuis simplicissima sordide viridis; folia caulina apice densiora subsecunda, e basi oblonga vel ovali sensim et latiusculo-subulatu subfalcata acuta integerrima, e cellulis albido-pellucidis sed parietibus flavis prededis ampliusculis inferne elongatis superne parallelis strictis composita; perichaetialia basi longiore parum vaginante inferne angustiore; omnia nervo crcssiusculo rufescente in subulam supremam eranescente; theea in pedunculo breviusculo stricto pallido erecta elliptice parva annulata aerperlis sulcata rufescens, operculo longe et oblique subulato; perist. dentes brevissimi profunde et irvegulariter bifidi purmer, cruribus brevibus strictis subhyalinis.

Dicr, curvatum Hsch. in Mrusc, Depp. et Schied.

Patria. Mexico prope Xalapam: Deppe et Schiede.

Pl. mascula multo humilior saepe ramo masculo dichotoma, flore terminali; folia perig. e basi lato-ovali valde concava sensim subulata obtusiuscula, interiora tenuius areolata et colorata. - Ab $A$. aulacocarpa proxima notis cursive impressis facile distinguitur.

15. A. varia C. Müll,; dioica; humilis erecta cespitulosa basi divisa; folia caulina densiuscula imbricuta erecto-patentia vel secunda flavescentia, lanceolato-subulata acuta angusta, carinata integerrima vel parce denticulata, nervo in acumen breve excurrente flavo angusto, undique e cellulis angustis firmis densis longiusculis purietibus pallidis areolata, perichaetialia subraginantia; 
theca in pedunculo mediocri purpureo ascendente obovulis oblique brevis subcernua firma coriacea exannulata, operculo conico rostellato obliquo; perist. A. rufescentis.

Dicranum varium Hdw. Musc. Frond. 1I. p. 95. t. 34. - Br. Europ. Fasc. $37-40$. p. 20. t. 10, 11. - Brid. I. p. 435. - Diç. varium "r. viride Hook. et Tayl. Musc, Brit. ed. II. p. 102. t. 17 ex parte, - Dicr. laxifolium Brid. 1. p. 431., folis valde secundis e spec. auth. sterilibus liuc forte pertinet. - Dicr. rigidulum, innovationibus pedunculo longioribus, foliis secundis. Sw. Musc. Suec, p. 89. t. 3! - Dicr. callistomum Brid. sp. Musc. 1. p. 187.; forma minor A. rufescenti similior. - Bryum callistomun Dicks. Fasc. III. PI. Crypt. p. 5. t. 8. f, 10. - Fuscina simplex Schrank. Baiers. H1. II. p. 453. - Bryum simplex L. Np. Pl. p. 1587. - Bryum trichodes capsulis rubris cernuis. Dill, Musc. p. 390. t. 50. f. 59.

ß. tenuifolia; foliis tenuioribus obsolete nervosis. Br. Furop. 1. c. p. 21. - Dicr. tenuifolium Bruch in Fr. Mülleri Musc. sard.

Petric. Ad terram denudatam argillaceo-arenosam humidam per Europam totam. Var. $\beta$. in Europa meridionali, Africa et America septentrionali. - Auctumno et primo vere.

Pl. mascula gracilior; flos tenuis; folia perigonialia cxterna ex ovata et concava basi anguste lanceolato-subulata, interna sensim brevius acuminata, dein late orata breviter apiculata; anthericlia parva et una cum paraphysibus tenuissimis brevibus haul copiosa.

16. A. rufescens C. Müll.; divicu; humilis oblique erecta gregaria vel gregarie cespitosa simplex vel parce ramosa; folia caulina secunda remota rufescentia, lanceolato-subulata acuta angusta, nervo ferrugineo in acumen evanescente, apicem versus denticulata, undique e cellulis elongatis ralde pellucidis angustis laxiusculis parietibus vufescentibus areolata, perichaetialia longius subulata; theca exannulata in pedunculo brevi geniculato-ascendente purpureo flexuoso erecta ovalis aequalis parva ferruginea, operculo conico rostellato obliquo; perist. dentes breves inflexi angusti irregulariter ad medium usque 2-3-fidi, cruribus tenuissimis hyalinis asperulis.

Dicranum rufescens Turn. Musc. Hibern. P. 66. - Br. Europ. Fasc. 37 - 40. p. 22. t. 12. - Brid. 1. p. 437. - Dicr. eurium $\beta$. 
rufescens Brid. Mant. Musc, p. 62. - D. curvatum sichultz. Suppl. Fl. Stary. p. 71. - D. carneum Blandow in sturm Deutschl. Fl. 1I. Fasc. II. - Bryum rufescens Dicks. Fase, III. P1. Crypt. p. 6. t. 8. f. 1 .

Patria. In tera argilloso-arenaria humida umbrosa Germaniae, Galliae atque Britanniac. - Auctumu per hyemem uspue ad rer primum thecis maturis.

Ab A. eqria proxima foliorum areolatione certe distat. Inflorescentia praecedentis.

\section{b. Folia heteromalla.}

r. Squarrobo-retlexa.

$\div$ Elatae.

17. A. IReinwardti C. Nüll.; monoica; adscendens, ramis brevibus compluribus fertilibus divisa, valde robusta elata aureo-nitentia; folia caulina e basi lato-amplerante brevi convolutacea superne amiculato-flexusa e cellulis elongatis angustis partim flaris partim aurantiacostriatis areolata subito reflexa squarroso-tortilia in subulam latiusculam superne angustam acutam canaliculatam emarginate serrulatam e cellulis minoribus robustis ralde incrassatis compositam producta, nervo angusto cxcurrente superne dorso scubro; perichactialia latiora pallidiora breviora sed longius vaginantia et laxius reticulata; theca anguste annulata in pedunculo substricto breviusculo rubente crecta otalis crussa majuscula rubens, operculo oblique rostrato; perist. dentes robusti intense purpurei valde trabeculati profunde $2-3-$ fidi, madefacti reflexi.

Dicr. Reinuardti Dz. ct M. An!, d sc. nat. 1844. II. P. 303.D. tortifolium A. Br. mst. ex Hampe.

Patria. Java. Borneo.

Flos masc. axillaris crassiuscule gemmaceus; folia lato-convolutacea breviter acuminata et apice parum reflexa obsoletinervia vel enervia, obtusinscula flave vel aurantiaco-tincto-arcolata; anthericlia elongata angusta purpurea, paraphysibus aureis longioribus breviter articulatis mixta. - Jicrono Wrummondi e foliis squarrosotortilibus haud dissimilis. 


\section{S'T'EGOCARPI. ACROCARPI. ANGSTROMHA.}

18. A. squarrosa C. Müll.; dioica; robusta eleta erecta dichotome ramosa dense radiculosa squarroso-foliosa e viridi aurea; folia caulina lata e basi latissime vaginante superne sinuatà reflexa brevia lato-canaliculatu upice ligulato - obtusu integerrima vel emarginata, nervo flavo tenui evanido, basi e cellulis laxissimis elongatis amplis utriculo primordiali valde instructis superne minoribus apice subincrassatis areolata, perichaetialia intima superne haud sinuata sed reflexa et sensim oblonga; theca exannulata in pedunculo breviusculo carnosulo crasso purpurco stricto oblonga cernua strumulosa firma coriacea, operculo conico brevirostrato obliquo purpureo; perist. dentes robusti lati longi $\mathbf{2}-\mathbf{3}$ - fidi amoene purpurei, cruribus irregularibus flexuosis apice pallidis.

Diobelon squarrosum Hmp. in litt. Dicranum squarrosum starcke in litt. ad schrader! ut ex ejus schedulis in Hb. Heg. Berol. elucet. Schrad. in Bot. Journ. V. p. 68. - Br. Europ. F'asc. $37-$ 40. p. 17. t. 5. - Oncophorus squarrosus Brid. I. p. 404. - Bryum palustre Dicks. Fasc. IV. PI. Crypt. P. 11. - Br. pellucidum $\beta$. L. Sp. P1. [3. 1583. - Bryum erectis capitulis brevibus, foliis reflexis. Dill. Musc. p. 365, t. 46. f. 24.

Patria. In locis aquosis praeprimis montium altiorum, ubi ad fontes et rivulos frigidos caespitibus latis raro tamen fructifera viget per totam fere Europan et in America septentrionali. - Aestute et sero anctumno.

Pl. mascula femineae similis; flores capituliformes; folia externa e basi lata concavà lanceolata patentia, interna breviora tenuiora. Intheridia maxima, paraphysibus teneris longioribus breviter articulatis.

\section{t+ Humiles.}

19. A. Sehreberi C. Müll.; dioica; densissime gregaria lıumilis parce divisa viridis; folia caulina omnia e basi lato - vaginante anguste dense elongate et firme areolata difficile emolliente superne siuuato-flexuosâ sensim acuminato-subulata reflexa viridia acuta apice denticulata, nervo latiuseulo tenui in subulam canaliculatam minutius reticulatam excurrente; perichaetialia majora; theca in pedunculo strictiusculo purpureo flexuoso oblonga 
cernua basi strumulosı excunulatu firma coriacea, operculo conico longe subulato crasso obliquo purpureo; perist. dentes intense purpurei angusti longi conniventes, ad medium bifidi, cruribus tenuibus apice hyalinis trabeculatis subrugulosis.

Dicranum Schreberi Hdw. Sp. Musc. p. 144. t. 33. - Br. Europ. Fasc, $37-40$. p. 18, t. 6. - Brid. 1. p. 449. - D. recognitum Röhl. Mooser. Deut. p. 377. - Barbula schreberi Brid. Musc. Rec. 11. I. p. 207. - B. mutabilis Bangg. Fl. Lips. 11. 1263. - B. crispa Hdw. Fund. Musc. 11. p. 92. - Bryum crispum schreb. spic. Fl. Lips. p. 79.

Patria. In terra argillosa humida sylvarum praecipue umbrosarum regionis montanae et planitiei per totam Europam, sed rarior. - Auctumno.

Pl. mascula minor subsimplex, flore capituliformi.

20. A. Grevillenna C. Müll.; monoica; habitus $\boldsymbol{A}$. Schreberi; folia caulina omnia e basi longiore ungustius et mollius areolata superne valde sinuato-flexuosa facile emolliente sensim flexuoso-subulata reflexa, integerrima, nervo angusto tenuiore excurrente; theca exannulata, operculum et peristomium A. Schreberi.

Dicranum Grevilliumum Br. Europ. Fase. 37-40. p. 19. เ. \%.D. Schreberi $\beta$. Grerillinnum Brid. I. 1. 450- D. Schreherianum Hook. et Tayl. Musc. Brit. ed. 11. p. 95. t. Supp?. 3. - Grev. scott. Ciypt. Fasc. 24. tab. 116. - Drummond. Musc. Amer. No. 43.

Patria. In terra humida denudata per regionem alpinam Scotiae, IIclveliac, Italiae, Germaniae et Scandinaviac. In locis iisdem alpinis Americae septentrionalis haud raram legit Drummond.

Folia perigonialia floris masculi in ramulo brevi gracillimo terminalis basi convolutaceo-vaginantia laxius tenerius et longitus reticulata colorata superne sensim fere subulata.

21. A. crispa C. Müll.; monoica; laxe cespitosa simplex lumilis flavescens tenuis; folia caulina inferiora ot superiora e basi oblonga ommino e cellulis angustioribus pellucidis elongatis areolatà reflexa et pluries flexuosa subulata acuta, apice denticulata, inferiora busi longiore 
Avgstroemi.

angusta haud plicata, superiora tantum sinuata; perichaetialia longius vaginantia, inferne multo laxius et tenuius reticulata; theca in pedunculo longiusculo purpureo stricto erecta ovclis truncutu fuscescens luevis, sicce strictu angustissime annulata, operculo conico subulato elongato obliquo purpureo; perist. dentes purpurei ad incdium bifidi, cruribus ferrugineis teneris subrugulosis.

Dicranum crismum Hdw. Musc. Frond. I1. p. 91. t. 33. - Br. Europ. Hasc. 37 - 40. p. 20. t. 8. - Brid. 1. p. 451. - Bryum maryinale Dicks. Fasc. 111. PI. Crypt. p. 8.

Putria. In arenosis humidis regionis montanae et : ubalpina per totam fere Luropam sed raro et in America septentrionali. - Aestate.

Flos masculus in ramuio brevi radicali gracillimo tenuiter gemmaceus, foliis convolutaceo-concavis, basi coloratis, e reliquis caulinis inferioribus similibus. Antheridia majuscula pauca, paraplyysibus longioribus fuscis remote articulatis.

22. A. Guillemininna C. Müll.; dioica; laxe cespitosa simplex liumilis flavescens robusta; folia caulina inferiora minora, superiora majora, e basi luto-ruginante superne plicato-sinuata latiore flexuosa anguste elongate et pellucide superme mimulissime incrussate of angustissime areolata sensim acuminato-subulata, sicca valde crispa, madefacta flexuosil, cpice obtusiusculo obsolete denticulata, nervo angusto llavo in subulam canaliculatam excurrente; perichactialia majora longius laxius ef pellucillius reticulata; theca annulata in pedunculo longiusculo stricto flavido erecta elliptice plicate aequalis olivacea operculo longe et oblique subulato purpureo; perist. dentes angusti usque ad medium bifidi, cruribus inaequalibus hyalinis subrugulosis erectis conniventibus.

Dicranm, Guilleminimnum Mont. An!. d. sc. not. 1K11. XVI. D. 267. - D. sulcritun C. Miill. Bot. Zeit. 1844. p. 709 et 1845. p. 93.

Putria. Brasilia ubi ad terran micaceam prope Rio de Janeiro primus legit $\mathbf{R}$ i edel; in rupibus humidis prov. Corcovalo: Gardner Coll. No. 26. 
Ab A. crispe proxima stalura multo robustiore, folis latioribus, aliter areolatis et partim formatis praecipue thecae forma facile distinguitur.

23. A. cylindrien C. Müll.; dioicr; grenaria vel cespitulosa humilis flavescens simplex vel parce divisa; folia caulina undique patentia, e basi vaginante anguste ofongute et firme areulutî reflexo-capillaria flexuosa siccitale crispa acula, nervo latiusculo concolore subulam superam denticulatam totam occupante; perichatialia magis vaginantia subito subulata; theca in pedunculo elongato purpurascente tortuoso-stricto crecta angustissime cylindrica curviuscula, annulata, operculo conico brevi recto; perist. dentes regulariter mofunde bifidi longi purpurei, cruribus remote articulatis.

Ceratodon cylindricus Br. et Sch. Br. Europ. Fasc. 29-30. p. 6. t. 3. - Trichostomum cyllindricum Hdw. sp. Mnce. p. 107. t. 24. - Tr. tenuifolium schrad. Bot. Joum. 11. 1. 58. - Dillymorlon cylimbicus Wahlenb. FI. Suec. p. 754. - Dicranum cylindricum Weh, et Mohr. Bot. Taschb. p. 202.

Patrill. In terra arenosa denudata lumida et subspongiosa per regionem infra alpinam et alpinam, rarissime in planitie; in Alsatia, Silesia, Rhactia, Salisburgiac ditione et Scandinavia tota. E rarioribus. - V're, in alpibus aestate.

Pl. mascula gracilior; folia perigonialia caulinis similia sed convolutaceo-concava subulata; antheridia numerosa paraphysibus tencris parum longioribus. - Ab $\mathbf{A}$. crispu simillima jam thecae forma primo adspectu differt.

\section{B. Crispato-flexuosa.}

24. A. tenuirostris C. Müll.; dioica; cespitulosa humillima gracilis ramis brevibus aequalibus compluribus fustiginto-rumosa glanco-rividis; fola caulina e basi oblongà perfecte lineari-subulatu vel loriformia angusta flexuoso-crispata, apice valde obtusu denticulalu, nervo pro folio andusto latiusculo deplanato flavo ante upicem curmido flexuso, informe elongate anguste ef laxe superne minutius sed laxe et pellucide arcolata. canalicu- 
lato-concava; perichaetialia intima angustissima; theca in pedunculo sublongo tenuissimo flavido erecta ovalis minuta aequalis, annulata, coriacea, laevis, operculo longissime tenuissime et oblique subulato thecam superante rubro; perist. dentes longi angustissimi profunde bifidi ferruginei, cruribus tenuissimis fuscidulis asperulis.

Dicranum tenuirostre Kze. in Pöpp. P?. Chil, Ill. No, 232. et in Schwaggr. Suppl. IV. tab. 308.

Putria. Chile australis: Pöppig 1829. E Cayenna accepisse $\mathrm{Cl}$. Montagne indicavit.

P]. mascula robustior densius foliosa, sed humillima, ramis 2-3 masculis; flos masculus oblongo-gemmaceus in foliis caulinis immersus; folia perigonialia interiora valde convolutacea breviuscule acuminata, intima integerrima acuta breviora, colorata tenerrime reticulata et membranacea; paraphyses et antheridia subparva pauca.

25. A. euchlora C. Müll.; monoicre; pumila cespitosa innovando-ramosa; folia caulina e busi oblongd subulata canaliculata patenti-inflexa siccitate flexuosa margine tenuissime denticulata, nervo mediocri ad apicem continuo; perichaetialia conformia basi ampliore vaginantia; theca nutuns oblonga pancistriata obsolete strumulosa, operculo conico oblique rostrato thecam dimidiam superante. $t$.

Dicranum euchlorum Mont. Anı, d sc. nat. 1845. 4. p. 112. Patria. Chile ad terram et in ranulis dejectis: C. Gay.

Ex animadvers. auctoris $A$. temirostris affinis.

26. A. Milariana C. Müll.; dioica; cespitulosa humillima subsimplex basi innovando divisa; folia caulina undique patentia, sicca et madefacta subcrispata, oblongolingueformia obtusa plicuto-flexuosu, upice suberosn, basi e cellulis laxis elongatis teneris flavide pellucidis superne minutis et minutissimis pellucidis areolata, nervo canaliculato angusto flavo flexuoso crassiusculo ante apicem evanido; perichaetialia distincte obtusa; theca in pedunculo brevi erecta ovalis brunnescens minuta aequalis, 
sicca cylindrica, operculo longe et oblique subulato; perist. dentes inflexi rubri ad medium usque bifidi, cruribus tenuissimis hyalinis longis subrugulosis.

Dicranum Hilarianum Mont. Ann. des sc. nat. 1839. p. 52. t. 1. f. 2. - D. Sellouii Hsch. Fl. Bras. 1810, p. 14. e spec, auth.! D. innonans C. Mïll. Bot. ZLeit. 1844. p. 709. - D. purvulum var. Hook. et Wils, Lond. Journ. of bot. 1844. p. 151.

Patria. Brasilia meridionalis ad terram: Hb. Montagneanum. In campis Mondevideusibus: Sellow, prope Sebastianopolin: Merkel, mense Julio et Augusto; Parahybuna: Gardner Coll. No. 19. C. mense Oct. 1840.

27. A. Tovariensis C. Müll.; dioica; laxe cespitosa elatiuscula erecta apice densius comosa, ad perichaetium innourtione elonguta gracillima remotifolia, viridis; folia caulina undique patentia sicca crispula madefacta stricta, e basi vaginante dense longiuscule anguste incrassate firme difficile emolliente et viridi-areolatâ subito canaliculato-subulata acutiuscula integerrima, nervo latiusculo concolore subulam superam totam occupante; perichactialia latius vaginantia busi laxins pollucidins et tennius superne rhomboideo-, ad subulam inferam minutissime incrassate reficulata; theca in pedunculo longiusculo stricto purpureo erecte orolis parva annulata coriacea, operculo longe et oblique subulato; perist. dentes angusti purpurei ad medium bifili, cruribus comiventibus scaberimis ferrugineis.

Dicranum Perrottetii C. Nüll. in Limaea XIX. P. 206.

Patria. Columbia, ubi in colonia 'lovar Germanica altitud. 5000 ped. inter P'olytricha viget: Moritz.

Pl. mascula femineae intermixta multo gracilior et ad perigonium innovalıone gracillima; folia perigonialia e basi lato-convoluta superue valde sinuata elongate angustissime et tenero-areolata colorata subulata; antheridia numerosa majuscula, paraphysibus teneris brevioribus paucis mixta. - Fx habitu A. Perrotletii simillima, notis autem cursive impressis et planta mascula multo minore aliter formata longe distat. 


\section{$\gamma$. Stricta,}

28. A. exigua C. Müll.; dioica; nuna, ramis brerissimis gemmaceo-minutis divisa, flavescens erecta; apice curvata, folia caulina erecta dense uppressa lanceoluta nereo crassissimo tereti in infimis cunido in supremis cuspidem longiusculam crussam acutam efficiente praedita, undique e cellulis minutis firmiusculis subquadrato-rhomboideis areolata, carinato concava; perichactialia majora; theca in pedunculo brevi ochraceo crecta ovalis parva coriacea minute annulata, operculo subulato obliquo; perist. dentes yuum muxime angusti tenelli profunde bifidi, cruribus brevibus dense articulatis ferrugineis.

Dicranum parvulum Hsch. Fl. Bras. p. 14. - D. debile Hook. et Wils, in Drumm. Must: Amer. No.š. ex eorum ratione, in Lond. Jourн. of bot. 1844. p. 151. data! - Weisia exigua Sclawägr. Suppl. 11. 11. 2. t. 179.

Patria. Brasilia, in solo limoso in Serra d'Estrella, Augusti mense, in umbrosis montium prope Sebastianopolin Octobris et Februarii mense: Beyrich; in Minis generalibus: Martius; in rupibus humidis m. Corcovado: Gardner Coll. No. 19.

P1. mascula minutissima, ad perigonium crassiusculum ramo brevi multo graciliore divisa; folia perigonialia ex ovata valde concara colorata basi sensim subulata, nervo tenuiore cuspidata, laxius et tenerius areolata, intima convolutacea latiora sed brevissima acuminata enervia; antheridia pauca subparva, paraphysibus paucis aequalibus teneris mixta. - Hx habitu Seligeriis minoribus aflinis sed distincta species.

29. A. bicolor C. Müll.; dioica; densissime et late cespitosa sed laxe coharens, inferme lutescens supurme amoene vividis, erecta humilis gracilis, opice rlongutoattemuatu, copillaris, basi divisa, ad perichactium innovatione gracillima tenuissima, mollis; folia caulina erecta appressa, e basi oratu concure e cellulis subpuadratis subparvis densiusculis fluridis ad subulum minoribus plus minus incrussutis reticulatà, canaliculato-subulata acuta, 
nervo flavo crassiusculo subulam superam totam occupante, integerrima; perichaetialia busi longiore subugimante; theca in pedunculo tenui longiusculo flexuosoerecto brumescente erecta suburceoluto-ovelis purm. gibbosa brumea striata annulata, operculo conico-subulato obliquo cum calyptra deciduo; perist. dentes breves ad medium fissi pallide ferruginei, cruribus hyalinis laevibus.

Dicranum densum C. Müll. Linn. XIX. p. 206. - D. densum B. minus Hmp. Linn. XX, p. 73.

Patria. Columbia, ubi in colonia Germanica Tovar altitudine 5500 ped. legit Moritz, Coll. No. 21 b.

Ab A. densa proxima e spec. auth. nobis nume emanata notis cursive impressis facile distinguitur. 1'. mascula ignota.

30. A. densa C. Mïll.; dioicu; dense cespitosa compacta humilis, basi divisa flarescens tenuis; folia caulina inferiora lato-lunceolule subulatu, superiora sensim majora basi latiora, omnia acuta integerrima canaliculata, nervo latiusculo crasso flavo in subulam canaliculatam excurrente supremam totam occupante, basi e cellulis clongutis ampliusculis pellucide viridibus parietibus crussinsculis fluris moreditis, superne minoribus plus mims quodrutis reticulata; perichactialia caulinis superioribus simillima, sed majora et magis raginantia; theca in pedunculo brevi rubente stricto apice vir inclinato erecta urceoluto-ovulis puru firma coriacea lato-annulata, operculo longe et oblique rostellato concolore; perist. dentes breves angustissimi profunde bifidi, cruribus tenuibus aurantiacis nodosis asperulis subinflexis.

Dicranum densum Hook. Muse. Hxot. tal). 140. - Brid. I. p. 464.

Putria. In crepidinibus montis Quindiu regni Mexicani, in regione temperata: II u m bold t et Bonpland.

P1. mascula femineae intermixta et similis; folia perigonialia lato-concava laxius reticulata colorata subito fere subulata tenuinervia, intima convolutacea; antheridia elongata, una cum paraphysibus haud numerosa. 


\section{Obscuriores.}

Ceucophanes Leanmm Sulliv. (Musc. Allegh. Exs. No. 172.); densissime cespitosum humile, inferne intertextum ochraceum, superne viride, sericeo-nitens, apice subcurvatum, fastigiato-ramosum; folia caulina lanceolato-subulata convolutaceo-concava tenuiter sublonge et sublaxe arcolata, pellucida, vel albido-viridia, e compluribus stratis tubulosarum cellularum (nervi obsoleti dorso sublaevis, haud incrassatarum) conformata igitur carnosula.

Patria. America septentrionalis, ubi in sylvaticis depressis inter montes Alleghanies, ad arborum truncos putridos, nec non in Ohione haud infrequens, at semper sterile legit T. G. Lea.

Ad apicem caulis saepissime gemmulae, folia juniora carnosa linearia brevia stricta efficientes, ramis brevissimis similes, reperiuntur. Muscus dubius, dum fructus haud innotescit.

\section{Gen. VII. Leptótrichum IImp.}

in Liunaea 1847. p. 74. et C. Miill. in Bot. /2eit. 1847. p. 806. Aschistodon Mont. - Didymodon noumult. - Trichostomum nonunll. - Weisia al.

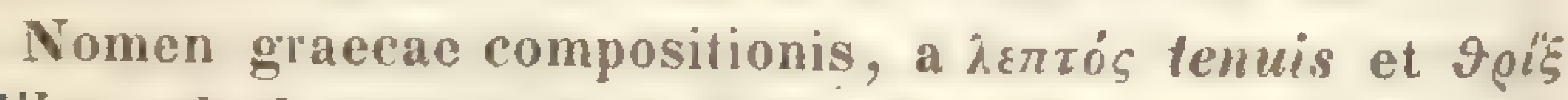
capillus, ob dentes peristomii graciles ductum.

Calyptra dimidiata angusta torta. Peristomium simplex: dentes 16 aequidistantes, subulati ciliiformes linea media exarati vel in cilia fissi igitur 32 per paria appruximali, basi in membranam plus minus elatam confluti rubescentes. Theca annulata. Inflorescentia monoica vel dioica.

Habitus partim dicranoideus, partim proprius.

a. Folia crispata.

1. I. plieatum C. Müll.; manoicum; flores masculi minuti oblongi plures infra perichaetium positi axillares; 
laxe cespitosum gracile flexuoso-erectum inferne mudum, superne crispato-comosum, amoene fluvescens; folia caulina laxe imbricata sicca et madefacta crispata, e basi anguste oblonga dense anguste et elongate areolata vaginante valde flexuoso-capillaria, marginibus ad subulam nervo pro latitudine folii lato omnino occupatam subinvolutis canaliculata, summo apice denticulata; perichaetialia longe vaginantia subito subulata; theca in pedunculo Jongiusculo tenui flavido cylindrica erecta, operculo conico brevi recto.

Didymodon plicatus Mout. in litt. - D. cirrhifolius Mont. in Crypt. Neelgher Aun, d. sc. nat. 1842. No. 36.

Patria. In sylvis Neelgheriensibus humidis post Bangalo tov Avalanchy: Perrottet.

Habitus caulis Bryi pyriformis; theca Leptotrichi. Folia perigonialia parra angusta parce denticulata breviora, interiora obtusiuscula.

\section{b. Folia stricta.}

2. L. tenue $\mathrm{C}$. Müll.; dioicum; gregarie cespitosum humile simplex, vel ramo gracillimo basilari divisum; folia caulina uppressı erecta stricta, e basi ovatà lunceolato-subulata obtusinsculo-acuta, subintegervima, nervo tereliusculo crasso in subulam excurrente, omnino e cellulis flavidis parvis superne minutissimis arcolata; perichactialia longiora subvaginantia, inferne elongute vulde laxe et pellucide superne minutissime reticulata; theca in pedunculo breviusculo rubente erecta ovalis mimuta pallida, operculo conico subulato obliquo; perist. dentes breves maxime tenues rubri geminati in membrana brevi annulo magno obtecta positi.

Trichostomum tenue Hdw. sp. Musc. p. 107. t. 24. - Brid. I. p. 491. - Br. Europ. Fasc. 18-20., p. 13. t. 2?

Patriu. America septentrionalis ad fossarum margines. Specimina Br. Europ. ad Vicentiam Italiae lecta.

Planta mascula valde humilis simplicissima, inferne subnuda, apice densifolia; folia perigonialia e basi ovata e cellulis tenerrimis inferne laxis pellucidis superne amoene 
viridibus areolat à subito fere breviter subulata obtusa, ad acumen minutissime reticulata, excurrentinervia, intima convolutacea. Autheridia magna curvala paraphysibus tenerrimis copiosis.

3. L. subulatum IImp. (I. c.); monoicum; antheridiu ad basin perichuetii libera per parier approximatu, paraphysibus paucis teneris mixta; habitus L. Cupensis; folia caulina lanceolato-subulata breviuscula stricta, superiora flexuosa, omnino e cellulis firmis subpundratis purvis pellucidis ureolutu, integerrima subcanaliculata, nervo latiusculo pullido subulam totam superam occupante; perichaetialia basi longiore raginata longius areolata; theca in pedunculo stricto purpurascente erecta ovalis aurea, operculo conico brevi obliquo; perist. dentes in membrana breviter enersa tenuissimi capillures geminati inaequales haud nodosi subrugulosi.

Trichostomam subulatum Br. et seh. Br. Europ. Fasc. 18-20. 1). 17. t. 13. - Villmmorlon subulatus Bruch in De Notaris syllat. Musc. p. 199. - Did. aureus De Not. 1. c.

Pullil. In pascuis Sardiniae centralis: Comba, Sicilia: Balsamo, Corsica: Léveillé, in campis 'Tingitanis: Salzmann.

4. I. Montngnei C. Miill.; divicum; planta mascula ad perigonia terminalia pluries innovans igitur interrupte elongata; gregaric cespitosum, sterile lumile simplicissimum gracillimum attenuatum flavidum, fertile elongatum ad perichaetia ramis pluribus sacpe fertilibus divisum, obscure flavidum inferne nigrescens; folia caulina erectopatentia firma substricta, e basi ovato-oblongà lanceolato-subulata hyalino-acuta, ad subulam marginibus parum convolutis canaliculata, integerrima, omnino e cellulis minutissimis incrassatis llavidis basi ad marginem tenoro-membranaceis areolata, nervo lato subulam superam totam occupante; perichactialia longe convolutacea panca, subito el breviler acuminata, intima inferne magis elongate areolata; theca in pedunculo stricto breviusculo purpurascente elliptica, operculo conico recto brevi; 
perist. dentes in membrana brevissima longi filiformes rugulosi basi rubri superne pallescentes parec et remote nodosiusculi integri aequales.

Aschistodon conicus Mont. Ann. d. sc. nat. 1845. 4. p. 109.

Putvia. Chile meridionalis: C. Gay.

Folia perigonialia lato-ovalia acuta, intima convoluta latiora tenuiora laxius areolata colorata breviter acuminata, omnia nervo excurrente angusto. Antheridia numerosa elongata curvata, paraphysibus aequalibus flavis.

\section{c. Folia secunda.}

c. Elata.

5. T. flexicaule IImp. (1. c.); divicum; dense cespitosum tomentosum elutum dichotome ramosum /lexicaule, aureo-flavidum, inferne fuscum, ad perichuctium innovationibus gracilibus apice longe comoso subfalcatis; folia caulina secunda superne densiuscula longa lanceolatosubulata acuta falcata, e basi marginibus conniventibus canaliculata subtorta, nervo lato applanato concolore in subulam excurrente, apice summo denticulata, inferne e cellulis oblongis anguslis firmis robustis incrassatis superne minoribus areolata; perichaetialia vaginantia subito llexuose longe loriformi-setacea, basi e cellulis amplioribus elongatis ad nervum parietibus interuptis crassis flavidis, ad marginem e cellulis minoribus tenuioribus ad subulam minutis incrassatis ellipticis areolata, nervo subulam totam superam occupante; theca firma in pedunculo clongato purpurco rigido torto stricto elliptica erecta plus minus curva fuscescens, operculo arete adhaerente conico brevi recto rubro; perist. dentes in membrana breviter emersa subliberi inaequales longi tenerrimi pallidi rugulosi vix articulati fugacissimi.

Trichost. flericaule Br. Kurop. Fasc. 1A-20., p. 15. t. 11. Cynordontinn flericaule schwïar. Suppr. 1. p. 113. t. 29. - Didymodon flexicaulis Brid. I. p. 506.

Patria. In apricis calcareis, pracprimis formationis jurassicae per edita alpina et subalpina totius fere Europae in America septentrionali. - Mujo et Junio.

C. M i ller: Synops. musc, frond. 
Pl. mascula gracilior, interdum cespites proprios efficiens, floribus terminalibus et innovando lateralibus crassiusculis gemmaceis. Folia perigonialia externa e basi ovatâ subulata, interna late ovata acuminata enervia minora. Paraphyses et antheridia parva.

6. I. Mornschuchii C. Müll.; divicum; planta masrula gracillima, flore terminali unico ad perigonium gemmaceum semel innovans; laxe cespitosum clatum gracile flexuosum parce ramosum; folia caulina e busi vaginate oblonga superne simuto-rotundata subintegra subito canaliculate et flexuose subulata acuta integerrima, basi e cellulis elongutis densis firmis irregularibus phurimis prosenchymaticis superne quadratis incrassatis areolata, nervo Tato subulam superam totam occupante; perichaetialia latiora convolutacea longiora inferne laxius reticulata; theca in pedunculo crassiusculo cygneo-flexuoso oralis pallida leviter plicata, operculo subulato recto; perist. dentes breves per paria approximati tenues apice pallidi.

Didymoton moscriptus Hsch. in Hor. Pliys. Berol, p. 60. tah. 12. - Brid. 1. P. 517.

\section{Putria. Insula St. Ifelena: Hb. Willdenowi.}

Folia perigonialia e basi maxime vaginante superne maxime sinuata flexuosa tenuiter sed minute areolatà ut caulinia sed tenuinervia, intima lageniformi - convoluta tenuius reticulata colorata capillaria vel brevi-acuminata, elongata. Antheridia paraphysibus tenerrimis brevioribus. - L. flexicauli ex habitu proximum.

\%. L. Hookeri C. Müll,; monoicum; flos masculus in ramo infra perichaetium oriundo terminalis; deuse cespitosum gracile erectum atrovirens subrigidum, apice subcuspidato virescente parum falcato subcompresso, breviter ramosum, flexuosum; folia caulina siccitate et madefacta erecto-patentia parum secunda rigida firma anguste lanceolata subulata falcata concava laevissima, summo apice parce denticulata, e cellulis superne minutissimis incrassatis ellipticis inferne longioribus tenuissimis areolata, angustinervia perichaetialia e basi vaginante 
firma superne rotundata setacea, nervo subulam summo apice denticulatam totam occupante, inferne elongate et sublaxe areolata pallide fuscescentia; theca in pedunculo elongato stricto purpurascente cylindrico-elliptica stricta, operculo brevi-conico; perist. dentes in membrana exserta subreticulata erecti ad basin usque fissiles nodosi rugulosi pallidi.

Didymodon longifolius Hook, et Wils, in schedulis.

Patria. Insula Eremitae ad Cap. Horn: J. H o oker.

Folia perigonialia e basi brevi lato-convoluta sensim subulata tenuiter et minute areolata colorata, nervo in subula evanescente vel excurrente, summo apice denticulata, intima breviora integerrima. Antheridia elongata paraphysibus flavis parum longioribus. - L. flexicauli ex habitu atque statura simile.

\section{$\beta$. Pusilla}

8. C. pallidum IImp. (1.c.); monoicum; flores masculi tenues ad perichaetii basin plures axillares gemmacei; gregarie cespitosum humile simplex strictum flavescens; folia caulina crecto-patentia vel parum falcatosecunda, e basi orata elongate laxe of temiter areoluta lanceoluto-subulatu acuta canaliculata latiuscula, superne denticulata, ad subulam inferam angustissime elongate reticulata, nervo latissimo totam subulam occupante; perichactialia basi latiora laxius reticulata tenuiora; theca in pedunculo longissimo flavo stricto torto elliptica erecta, pallide nitens dein fusca, operculo conico brevi obliquo rubente; perist. dentes intense rubri longissimi capilliformes geminati scaberrimi nodosinsculi in membrana brevi positi.

Trichostom. pullidum IIdw. Stirp. Crypt. p. 71. t. 27. - Brid. 1. p. 489. - Br. Europ. Fasc. 18-20. Trichostomum, p. 18. tal). 14. - Trich. pallidum $\beta$. strictum schwägr. Suppl. I1. 1. p. 77. t. 123. - Trich. strictum siw. Fl. Ind. Occ. Ill. P. 1781. - Dicran. pallidum W. et M. Bot. Taschb. p. 196. - Didymorlon pallidus P. B. Prodr. p. 56. - Bryum mallidum schreh. Spic. Hl. Lips. p. Ko. - Bryum acaulon heteromallum, setis loncis pallidis. Dill. Musc. p. 389. t, 49. f, 57. 
Patria. In terra argillacea sylrarum totius Europac et Americae septentrionalis. - Mujo.

Folia perigonialia ovato-lanceolata angustissime lanceolata tenuinervia, interna ovata acuminata enervia. Caetera congenerum.

9. L. Dorynnum C. Müll.; monoicum; flores masculi tenues ad perichaetii basin plures axillares gemmacei; habitus perfecte $L$. Mullidi; folia caulina subsecunda, c basi oblonga elongate angustissime firme et subincrassate aveolatí lanceolato-subulata obtusiuscula canaliculata angresta, summo apice denticulata, nervo latissino totam subulam ferc occupante; perichaetialia basi vaginante latiora tenuius membranacea pallidiora sed anguste elongate et incrassate reticulata, e reliquis caulinis simillima; theca in pedunculo longissimo flavo longe cylindrico-elliptica crussiuscula major crecta dein curvata fuscescens, operculo conico brevi obliquo obtuso; perist. dentes L. pallidi.

Trichostomum pallidum Brid. hh. - Trich, difficile Duby in Moritzi Verz. der Zollinger'sch. Pfl. p. 134.

Patria. Insula Bourbonis: Bory St. Vincent. Java: Zollinger Coll. No. 411.z.

Folia perigonialia pauca, cxterna lanceolata, interna e basi convolutacea colorata superne sinuata pro exiguilate folii latiusculo-subulata, nervo in subulam excurrente praedita, obtusa denticulata, tenuius rhomboidco-prosenchymatico-areolata. Antheridia panca parva. - A L. pallido simillimo notis cursive impressis certe refugit. L. "ffine foliis crispatis jam distat.

10. I. affine C. Nüll.; (Bot. Zeit. 1847. p. 825.); monoicm ; flos masculus ad basin perichaetii gemmaceus; habitus L. mallirli; folia canlina sicce crisputa "basi tenerrime membranacea convolutacen e cellulis pavis anguestis ron/luentibus composila angusta lineruvi-subulata bbusinscule, apice denticulata, nervo latiusculo subulam totam superam orcupante; perichactialia basi vaginante latiore temerime mombranacen inferne elongate angustissime superne incrassate et elliptico-reticulata; theca in 
pedunculo elongato flexuoso-stricto pallido erecta cylindrica attenuata curviuscula, angusta dein fusca; perist. dentes in membrana breviter exserta ciliiformes rugulosi longi rubri haud nodosi.

Putria. Chile australis: Pöppig.

Folia perigonialia e basi latiuscula ventricoso-convoluta tenuius reticulata coloratà breviter subulata obtusa integerrima. - A L. pallido simillimo notis cursive impressis certe distat.

11. L. Capense C. Müll.; monoicum; flos masculus infra perichactium axillaris; habitus $L$. offinis; folia caulina crispa lineari-subulata acuta apice obsolete denticulata, malcfucta valde flexusa, omnino minute et incrassate areolata, nervo subangusto concolore supremam subulam occupante; perichactialia latiora tenerrime membranacea vaginantia; elongate angustissime et tenerrime areolata; theca in pedunculo brevi stricto pallido erecta elliptica pallide nitida, dein fusco-nitens cermu parea, operculo conico brevi obliquo; perist. dentes breves temissimi scuberrimi haud nodosi in membrana brevi immersa inaequaliter geminati.

Didymodon longifolius et Trichost. longifolium herb. nonnull., non Brid.

Putria. Prom. b. spei, in locis humidis ad catarractam Hontis 'Tabularis orientalis et in fissura loci "Van Kamps-Bay": Écklon; Port Natal: Gucinzius.

Folia perigonialia e basi convoluta tenera pellucida colorata brevia acuminata obsoletinervia flexuosa vel reflexa integra obtusiusculo-acuta. Autheridıa pauca parva purpurea. - A L. pallido et affini notis cursive impressis longe refugit.

12. L. homomallum IImp. (1. c.); dioicum; laxe cespitosum humile romosum gracillimum vivide, apice subfulcutum; folia caulina homomallu lanceolato-r'upillarie acuta integervima angusta nilida, nervo latiusculo concolore canaliculato excurrente, ommino breviter ungustissime et firme areolatu; perichactialia longe vaginantia 


\section{STEGOCARPI. ACROCARPI. LEPTOTRICHUH.}

subito et falcato-capillaria longius sed firme reticulatu; theca in pedunculo stricto longiusculo purpureo erecta elliptica pallida, dein brumnea, parva, operculo conico brevi obliquo; perist. dentes in membrana brevi immersa geminati saepe conglutinati dein irregulariter fissi vix articulati rugulosi tenuissimi breves ferruginei.

Trichost. homomallum Br. et Sch. Fasc, 18-20. p. 16. t. 12. Didymodon homomallus Hdw. Sp. Musc. p. 105. t. 23. - Brid. I. p. 510. - Grimmia homomalla Sm. FI. Brit 11I. p. 1194. - Did. heteromallus Hook. et Tayl. Musc. Brit. p. 68. t. 20. - Weisin heteromalla Hdw. stirp. Crypt. I. p. 22. t. 8. - Brid. I. p. 361. Grimmia heteromalla W. et M. Bot. Taschb. p. 137. - Afrelia heteromalla Ehrh, P1. Crypt Exs, n. 173.

Patria. In locis argilloso-arenariis, ad viarum latera, muros, in terra sylratica etc. per totam Europam montanam. - Auctumno et primo vere.

Pl. mascula gracilior dichotome ramosa; flores innovationes terminantes; folia perigonialia lanceolato-capillaria tenuinervia.

13. L. tortile Hmp. (1. c.); dioicum; gregarie cespitosum humile gracillimum basi divisum, laete viride; folia caulina erecto-patentia subsecunda lanceolato-subulata apice obsolete denticulata, nervo teretiusculo crasso flavido excurrente subcanaliculato, omnino minute firme areolata, margine peullo reflexa; perichactialia vaginantia inferne laxius et longius reticulata, superne subito fere subulata reflexiuscula; theca in pedunculo stricto mediocri purpurascente erecta cylindrica pallida, operculo conico breviusculo obliquo; perist. dentes subtorti elongati capillares aequales geminali vix nodosi rugulosi purpurei, in membrana emersa positi.

Trichost. tortile schrad. Syst. samml. Crypt. Gew. No. 49. Br. Europ. Fanc. 18-20. p. 14. t. 10. - Brid. 1. p. 488. - Didymodon tortilis W. Arll. Disp. meti. p. 37. - Dicranum tortile W. et M. Bot. Taschb, p. 198. t. 7. f. 12. 13.

B. pusillum; caule simplicissimo vel subramoso, foliis patentibus vel homomallis, brevioribus; theca oblongoovalis, dentes perist. breviores. Br. Europ. I. c. 1. 14. Irichost. pusillum Hdw. Musc. Frond.1. p. 78. t. 28. f. 2. 4.9. 10. - 
Trich. vaginans Sulliv, in Musc. Allegh. No. 176. - Didymod. rusillus Hdw. sp. Musc. p. 104. - B1.d. 1. p. 509. - Barbula curta Hdw. Musc. Frond. 111. p. 75. t. 31. - Tortula curta sw. Misc. Snec. p. 41. - Desmatodon curlus Brid. 1. p. 526.

Patria. In argillosis per Furopam totam fere et Americam septentrionalem. Var. $\beta$. praeprimis in arenosis humidis. - Ab auctumno per hyemem thects maturas ferens.

Pl. mascula tenuior; flores terminales, interdum $2-3$ aggregati; folia perigonialia externa e basi lata anguste lanceolata, interna ovato-acuminata, nervosa. Antheridia parva pauca paraphysibus parce cincta. - A L. homomallo notis cursive impressis distat.

\section{Gew. VIII. Lophrodon Hook. et Wils.}

Lond. Journ, of bot. 1814. p. 513.

Nomen a graeca voce horion parra crista et ódoŕs dens, ob peristomium breve contitum.

Calyptra cucullata. Peristomium simplex: dentes 16 pyamidali, per paria approximati, comniventes siccitate erecti breves apice attenuati. Inflorescentia dioica.

Ilabitus Blindiac; retis cellulac Angströmiarmm, firmae in membranam crassam firmam connatac, angustissimae subparvac.

1. I. strictus cor. (1.c.); compactus prostratus longiusculus gracilis valde ramosus nigrescens, apice lutescens; folı caulina erecto-patentia rigidissima subsecunda stricta, e basi lanceolata concara margine hyalinâ lineari-subulata, nervo lato continuo, apice denticulato obtuso paulo latiore; perichactialia majora vaginantia intima convolutacea firma acuta integra; theca in pedunculo rigido breviusculo purpureo plus minus curvato crecta ovato-cylindracea par va basi rotundata balia lacris nitida, operculo conico-subulato recto paulo longiori; calyptra theca longior fusca.

Patria. Insulae Aucklandi et Campbelli: J. Hooker. 
Pl. mascula longior cacterum femineac simillima, floribus pluribus terminalibus noduloso-gemmaceis. Folia perigonialia externa caulinis similia loriformi-subulata veluti truncato-obtusa denticulata, intima multo minora tenuiora convolutacea ovata integerrima obsoletinervia, c cellulis parvis ampliusculis tenuibus parum flexuosis arcolata aurca. Antheridia elongata hyalina lein fusca clarata inferne angustata substipitata, paraphysibus numerosis tenuibus aureis sacpe tortilibus mixta.

\section{Gen. IX. Tremátodon Rich.}

in Fl. Am. Bor. Mich. 11. p. 289. - Dicranum Hdw. - Cynontodium P. B. - Bryum et Mnium nonnull.

Nomen a $\tau \rho \tilde{r}_{\mu a}$ foramen et ỏjots dens, ob dentes cruribus cohaerentibus parum secedentibus veluti perforatos ductum.

Calyptra cucullata. Peristomium nullum vel simplex: dentes 16 basi connati erecti lanceolati trabeculati strigillosi granulati purpurei fissiles, cruribus plus minus secedentibus, igilur veluti perforati. Inflorescentia monoica. Theca amulata, ad collum stomatiis pracdita.

Habitus e theca collo elongato praedita speciosissimus et maxime naturalis. Plantae gregariae vel cespites parvos efficientes.

\section{a. Peristomium nullum.}

1. Tr. paradoxns Hsch. (Linn. XV. p. 122.); flos masculus in ramo basilari gracillimo inferne subnudo apice autem comoso capituliformi-gemmaceus; subhumilis ramis pluribus basilaribus; folia caulina sicca crispata, e basi oblonga laxissime et maxime pellueide areolalâ angustata apice ligulato-obtusa, integerrima, superne minutius sed laxissime reticulata, canaliculata, nervo tenui flavo evanido; perichaetialia basi latiora; theca in pedunculo subbrevi pallido erecta, e collo brevi ventricosa clavaeformis fuscescens, operculo oblique subulato. 
Patria. Prom. bonae spei, ubi in fissuris humidis umbrosis Montis 'Tabularis legit Ecklon. - Novbr.

Folia perigonialia externa basi convolutacea e reliquis caulinis simillima, intima multo breviora, superne lanceolato - acuta. Paraphyses et antheridia pauca. Nulla alia specie confundi potest. Folia funarioideoareolata.

\section{b. Peristomium indivisum.}

2. Tr. brevicollis IIsch. (IRegensb. bot. 'Zeit. 1819. p. 83.) ; flos masculus in ramo brevi terminalis; humillimus, fragilis, ramis basi subnudis; folia dense imbricata rigida stricta, caulina ovato-lanceolata, superiora majora, concava, nervo depresso angusto cranido, integerrima, subparva sed laxe areolata; perichactialia longiora magis amplexantia majora; theca in pedunculo brevi stricto flavo erecta, e collo brevi haud ventricoso sed aequali clavacformis leniter incurva fuscescens, operculo longe et oblique subulato; perist. dentes breves pallide aurantiaci vel intense purpurei lanceolati integri sed lissura media plus minus distincta exarati.

Br. Europ. Tremutolon. p. 5. t. 1. - Brid. I. p. 385. - Tremat. antriguns $\beta$. brevicollis schwïgr. Suppl. 11. p. 69.

l'atria. In summis alpium cacuminibus: Tirolis in lauschnitzer Alpe: Hornschuch; in alpibus V'alesiacis: Schleicher; in summo Fauthorn altitud. 8800 ': Mühlenbeck, W. l'. Schimper. - Lling., Septbr.

Folia perigonialia minuta, externa ovato-acuninata, interna convolutaceo-acuminata, omnia nervosa. Antheridia parva, paraphysibus tenerrimis mixta. - E' rarissimis.

\section{c. Peristomium fissile.}

3. Tr. nmbiguus IIsch. (Regensb. bot. 'Zeit. 1819. p. 88.); flos musculus in remo busilari longiusculo terminalis, mimum ad basin perichustii; clatinsculus ramosus; folia caulina erecto-patentia vel patula apice incurva vel flexuosa, e basi ovata laxe areolati subito fere setucea acutiuscula subintegerrima, margine haud reflexa, 
parum canaliculata, nervo tenui partem subulac totam superam occupante; perichactialia multo majora, e basi lata plana tenerrima laxissime areolata sensim el breviter subulata stricta, nervo caulinorum; theca in pedunculo elongato substricto flavo crecta, e collo sublongo arcuato crassiusculo ventricoso oblonga crassa fusca, operculo oblique subulato; perist. dentes longi angusti irregulariter $\mathbf{2}-\mathbf{3}$ fissi purpurei tenuiter trabeculati.

Br. Europ. Trematodon; p. 5. t. 2. - Trem. vulyaris Brid. I. p. 386. - Dicranum ambiguum Hdw. Muse. Frond. I11. p. 87. tal). 36. - Mnium setaceum L. S'p. P1. p. 1576?

Patria. In locis humidis vel uliginosis e planitie usque sed raro ad alpes totius Europac ascendens, passim. - Junio, in alpibus Septembri.

Folia perigonialia parva, intima convolutacea breviter acuminata subenervia.

4. Tr. Iongieollis Rich. (in Mich. Fl. Am. Bor. II. p. 289.); flos masculus gemmacens ad basin plantae femineae brevissimus; simplex; folia caulina erecto-patula, sicca et madefacta flexuosa, e basi orali amplexante latiuscula laxe areolath setacea canaliculata, apicem versus denticulata minute areolata, ucutiusculu, nervo angusto subexcurrente; perichaetialia basi tenuiora apice obtusiora; theca in pedunculo elongato erecto subtorto flavo erecta, e collo elongato basi ventricoso angustissimo arcuato oblongo-cylindrica fusca nitida, operculo oblique subulato; perist. dentes erecti conniventes intense purpurei longi usque ad apicem fissi, sed cruribus cohaerentibus nodoso-trabeculatis striatis inaequaliter latis.

Brid. I. p. 388. - Dicranum longlicollum ej. sp. Musc. I. p. 203. - Cynontodium trematodum P. B. Prodr. p. 52.

Patria. America septentrionalis, in arenosis humidiusculis Alabamae, Georgiae et Carolinarum.

Folia perigonialia valde convoluta colorata, e reliquis caulinis similia.

5. Tr. acutus C. Miill.; Ros masculus in remo basilari brevi; habitus $T r$. reflexi; folia caulina crispatis- 
sima, e basi oblongâ dense mimute et quadrato-areolatô limeuri-setaceu aculissima, margine parum reflexa, canaliculata, superne minutissime quadrato et incrassatoareolata, nervo latiusculo excurvente, subintegervima; perichaetialia longiora, apice parum denticulata, basi longiore clongate anguste temiter pellucide et multo laxius "reolata; theca in pedunculo elongato flavo tenuissimo flexuoso crecta, e collo tenuissimo clongato ventricoso arcuato cylindracea valde angusta pallide fusca, operculo oblique subulato; perist. dentes $T r$. longicollis, sed angustissimi.

Tr. longicollis $\beta$. crispatissimus Hsch. Nov. Act. Leop. XIV. II. suppl. p. 702?

Patria. Java: Hb. Miquelianum.

A Tr. longicolli proximo notis cursive impressis distat. - Folia perigonialia externa caulinis similia, intima convolutacea laxe areolata. Antheridia numerosa paraphysibus tenerrimis multo brevioribus mixta.

6. Tr. pancifolius C. Müll.; flos masculus in ramulo basilari brevi terminalis; simplex humillimus gregarius; folia caulina punce sicen et malefucta substricte vel parum fulcata brevia oblongo-acuminuta obtusinscula valde canaliculata ad apirem denticulata rividissima, nervo angusto excurrente, basi dense longiuscule minute quadrate superne minutissime non autem incrassate sed molliter areolata, marwine non reflexa; perichaetialia stricta majora parum laxius areolata; theca in pedunculo longinsculo tenuissimo curvato ventricoso ovalis minuta pallide fusca, operculo oblique subulato; peristomium $\mathbf{T r}$. acuti.

Trematod. longicollis Dub, in Zallinger Coll. No. 1943.

Patria. Java: Zollinger.

Folia perigonialia externa caulinis similia, intima convoluta basi laxius areolata colorata, cactera ut in $T$. acuto. - Tr. ambiguo ex habitu proximum.

7. Tr. reffexus (. Mül.; flos masculus in volumulo basilari brevi terminalis; laxe cespitosus simplex laro basi 
ramosus; folia caulina e basi oblonga anguste elongate et dense ureolatâ valde canaliculuto-angustata sicca ct madefacta valde crispata vel flexuosa, murgine valde reflexu latiora, upice ligulato-obtuso denticulato, nervo tenui evanido pracdita, superne minutissime areolata; perichactialia strictiora, e reliquis caulinis simillima; theca in pedunculo sublongo stricliusculo flavo crecta, e collo clongato basi ventricoso angustissimo arcuato pyriformi-orulis pallide fusca, operculo oblique subulato; perist. dentes $\boldsymbol{T} \boldsymbol{r}$. longicollis, sed pallidiores, magis incurvi et sacpe trifidi.

Tr. affinis Br. et sch. in Bryol. Europ. Fasc. 29-39. Trematodun P. 4 memoratus? - Tr. longicollis hb. nonnull.

Patria. Brasilia: ab Hagend orf.

Folia perigonialia caulinis similia. Antheridia et paraphyses $T r$. longicollis, a quo notis cursive impressis certe distat.

Species nomine tantum notae.

8. Tr. divaricatus Br. et Sch. (in Br. Europ. Trematodon; p. 4. menoratus.); $T$. ambiguo proximus, sed tenuius, foliis angustioribus et dentibus perfecte bitidis, remote articulatis differt.

Patria. Prom. b. spei: Krauss.

9. Tr. brachypus Mont. (1. c. memoratus).

Patria. Brasilia.

\section{Gen. X. Symblépharis Mont.}

Anis. d. BC. nat. 1837. VII. p. 252.

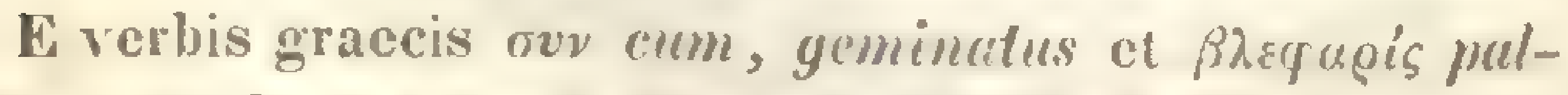
pebrae, ob dentes geminatos nomen comprositum.

Calyptra dimidiata angusta cylimbrico-subulata basi angustissine lissa. Peristomiun simplex: dentes 16 per paria approximati infra orificium oriundi ad basin infimam subcomncxi lanceolati usque ad 
basin trabeculatam bifidi, sed cruribus cohaerenlibus rugulosis nodosis in conum conniventibus. Inflorescentia monoica.

IIabitus Angströmies heteromullis foliis squarrosoreflexis similis. Peristomium Iolomitvii.

1. s. helicophylla Mont. (1. c.); laxe cespitosa parce et breviter ramosa flavescens; folia caulina e basi valde vaginante superne latiore sinuato-flexuosa e cellulis elongatis ampliusculis areolatà reflexa valde crispatoinvoluta, in subulam incrassato-quadrate arcolatam canaliculatam apice denticulatam producta, nervo angusto excurrente apice dorso scabro; perichactialia longius vaginantia; thecae innovando laterales in pedunculis saepe geminatis brevibus flavidis tenuissimis erectac angustissime cylindricae elongatac estriatac fuscescentes exannulatae.

Patria. Mexico in prov. Oaxaca: Andrieux; in cavernis aluminatis ad pedem montis Cerro de los Nebejos: C. Ehrenberg.

Flos masc. tenuis axillaris compressus, e foliis perigonialibus paucis Iato-convolutaceis brevi-acuminatis integris haud coloratis tenuissime nervosis constructus; artheridia pauca elongata, paraphysibus subnullis.

\section{Leptotrichaceac?}

1. Didymodon? Tortuls Harv. (Lond. Journ. of bot. 1840. II. p. 4; c. ic. in Hook. Ic. Pl. Rar. tab. 18.); erectus clatus dichotomus robustus; folia subsecunda ovato-lanceolata serrata, marginibus reflexis, siccitate crispatis contortis, theca oblonga crecta breviter pedunculata; perist. dentes basi subconnati longissimi filiformes subtorquati. $f$.

Patria. Nepal: Wallich.

Barbulue similis, foliatione autem habituque Didymorlonti vel Trichostomo (quo sensu?) magis affinis: Auctor. 
2. Did. vaginatus Hook. (l. c. p. 5. c. ic. I. c.); erectus elatus valde ramosus robustus; folia subulata falcato-secunda, siccitate crispata involuta vaginata, vagina latissima oblonga; theca breviter pedunculata erecta cylindracea, operculo rostrato obliquo; perist. dentes per paria approximati elongati basi connati. $\leftarrow$.

Patria. Nepal: Wallich.

Symblephari ex ic. similis.

3. D. cirrhifolius Harv. (1. c. c. ic. l. c.); erectus elatus ramosus robustus; folia longissima subulata flexuosa patentia, siccitate crispata, basi ovata vaginante; theca breviuscule pedunculata erecta oblonga, operculo conicoacuminato; perist. dentes tenuissimi tortiles. $\dagger$.

Patria. Nepal: Wallich.

Didymod. capillaceo (sensu antiquorum!) proximus, sed differt foliis siccitate magis crispatis: Auctor.

4. Did. calyptratus 'Tayl. (Lond. Journ. of bot. 1818. p. 188.); uncialis, cespitosus erertus subsimplex, partibus junioribus glauco-viridibus; folia laxe imbricata erecto-patentia incurva linearia acuta, siccitate torta integerrima, basi maxgine inflexa; theca tenella ovato-cylindrica basi subplicata, siccitate rugosa, operculo longirostro; perist. dentes filiformes linea media opaca exarati angusti; calyptra linearis thecam duplo superans torta. $\div$.

Patria. In Andium Quitensium monte alpino Pichincha: W. Jameson, Hec. 1846.

Fx habitu W'eisice temirostri Hook. el 'Tayl. quae Didymodon videtur, affinis, sed calyptra memorabiliter longa differt. - E descriptione Leptotrichum videtur.

5. Did. polyeephalng Mont. (Ann. d. sc. mat. 1815. p. 108.); dioicus; cespitosus erectus filiformis innovando ramosus, folia undique imbricata, e basi ovatâ lanceolato-subulata stricla, nervo lato continuo, sumno apice

*) Quo loco descriptae? nolsis ignotae. 
acuto canescentia integerrima, perichaetialia acuminatocuspidata convoluta; theca cylindracca tandem falciformiattenuata. Caetera desiderantur.

Putriu. Chile australis ad terram arenosam: C.Gay.

Pilopogo grucili simile, sed differt foliis brevissime piliferis et perichaetialibus duplo longioribus: Auctor. Species valde obscura.

6. Did. teneHus Hdw. Fil. (in hb. Candoll. et Brid. I. p. 821.); caule simplicissimo, foliis ovato-subulatis appressis inflexiusculis, theca urceolata brevi. $\div$.

Patria ignota. Hb. Candoll.

Species suspectissima.

1I. Folia papillosa.

Trib. XVIII. BARTRAMIOIDEAE.

Cespitosac plus minus elatae, pusillac et clatae, graciles v. robustae, polymorpho-ramosae, acrocarpicac. Folia lanceolata, ovata, subulata, carinatav. planiuscula, stricta v. reflexa, nervis teretibus percursa. Retis cellulae parenchymalicae, in pagina saepe utraque ad parietes transtersales, nomnullis speciebus exclusis, papillis solitariis instructae, plerumque quadratae s. plus minus hexagonae, laxac, laxiusculac et densae raro chlorophyllosae vel utriculo primordiali instructac, raro incrassatac. Theea longicollis funarioidea pyriformis vel splaerica regnlaris et asymmetrica, recta et polymorjho-inclinata, lacvis et sulcata, operculo plerumque hemisphaerico seu conico, rarissime rostellato. Archegonia et antheridia normalia, paraphyses, ut in Funarioideis, clavato-articulatae vel acutae.

Funarioideis partim affines, partim habitum maxime proprium tenentes. 
Putria. Per orbem totum terrarum, plerumque locorum uliginosorum amantes. $2 \%$.

\section{subtrib. I. MEE SEACEA E.}

IIabitus funarioileus Amblyodontis. Areolatio foliorum partim laxa lacvis, utriculi primordialis sacpe expers (Meesea), partim laxa et densa papillosa (Paludella). Thece erecta clongata collo plus minus elongato procdila, igilur plus ninus pyriformis, laevis, collo stomatiis praedita. Antherillia tribus. Paraphyses clavatac. Inflorescentia gemmacea $\mathbf{v}$. discoidea.

Patriu. Paludum incolac, zonam borealem solam fere praeferentes. 4.

Meeseaceas cum Burtramiaceis conjungoites, rationem am. II a me sequimur. Habitus quidem theca longicolla alienus fit, candem formam tamen theca B. longicollis inclinata pariter offert. Areolationem quoque laxam laevem Meeseurum haec species Javanica memorabilis ostendit; Paludella denique, ut Bartrumia peristomii Bryi expers et Meesencel vera, rete folii Bartramiarum totum papillosum possidet, ut, tribum utramque conjungentes, ob causas hasce rationem nostram justificatam habeamus.

\section{Gen. I. Meesea HIw.}

Fund. Musc. 1I. p. 97. t. 9. 1. 56. 57. sul) nomine Meesine. Amblyodon P. B. - Diplocominm Brid. - Bryum et Mnium Linll. et al.

In memoriam hortulani botanici Meese Batavi nomen conditum.

Calyptra dimidiata. Peristomim duplex. Externum: dentes 16 brevissimi lati obtusi linea media exarati vel lissiles. Internnm: membrana brevis, in dentes 16 linea media exaratos vel fissos et pertusos cartilagineos producta; dentes ciliis plus 
minus perfectis plerumque irregulariter cohaerentibus appendiculiformibus interpositis saepe cohaerentes. Inflorescentia hermaphrodita, monoica v. dioica. Arcolatio foliorum laxa monomorpha.

Ilabitus funarioideus et proprius, Amblyodonti simillimus, sed foliis ubique parenchymatico-areolatis distat.

1. M. uliginosa Hedw: (Musc. Frond. I. p. 1. t. 1. 2.); floribus hermaphroditis et monoicis in eudem planta; humilis dense cespitosa innovans; folia caulina unguste liguluta obtusa integerrima, inferne e cellulis elongatis laxissimis angustis superne minutis quadratis areolata, nervo basi latissimo superne sensim angustato sub apice evanido, canaliculato - concava; perichactialia longiora, omnia margine subrevoluta; theca annulo simplici praedita longe pedunculata, e collo brevi recto recurvo-pyriformis, operculo conico obtusiusculo; perist. dentes $M$. hexagonue, sed ciliis internis minus perfectis.

Br. Europ. Fasc. X. p. 5. t. 1. - Brid. II. p. 60. - Amblyodon uliginosus P. B. Prodr. p. 41. - Vebera trichodes Hdw. Fund. Musc. 11. p. 95. - Mnium uliginosum Grmel. Nyst. \at. p. 1329. Bryum trichodes aureum, capsulis incurvis obtusis in setis longis. Dill. Nusc, p. 389. t. 49. f. 58.

B. Alpina; folis strictis undique patentibus vel subhomomallis acutioribus, capsula breviore. Br. Europ. I.c.M. alpina Fk. Bot. Zeit. 1\$25. 1. 274. - M. strictu et anyustifolia Brid. II. p. 61 et 62.

$\gamma$.ninor; humilis, folis erectis brevioribus muticis, capsula perbrevi crassiuscula in pedicello brevi. Br. Europ. I. C. - M. minor Brid. II. p. 62.

Patria. In uliginosis rupibusque irriguis, e planitiebus usque in alpina edita ascendens, per Europam totam et Americam septentrionalem atque arcticam. Var. $\beta$. et $\gamma$. in alpibus. - Junio, in alpibus Julio et Augusto.

Flos mase. gemmaceus, foliis perigonialibus ovatolanceolatis obtusis; paraphyses et antheridia pauca.

2. M. longisetn Hdw. (Musc. Frond. I. p. 36. 1. 21 et 22.); hermaphrodita; late et laxe cespitosa, elongata 
gracilis tomentosa innorans; folia caulina erecto-patentia siccitate tortilia ovato - laticcolata acutinscula carinatoconcava, margine integerrimu reflexiuscula, basi laxe sllperne incrassata et densius reticulata, nervo crasso sub apice evanido; perichactialia longius acuminata, intima minuta lanceolata dense areolata; theca longissime pedunculata e collo erecto arcuato-pyriformis fusca, cmmelo simplice et operculo conico brevi acuto; perist. M. tristichae.

Br. Furop. Fasc. X. p. 6. t. 2. - Diplocomium longisetum Moug. et Vestl. Stirp. Vugeso-Hhell. C'ryut. Fisc. IV. No.327. Brid. II. p. 66. ex pale. - Nymonyma ratera incela, quum planta cum M. tristicha simili persappe rommutata sit.

Patria. Per Europan mediam et borealem e planitie usque in editiora ascendens, loca profunde turfosa habitans. - Julio.

Antheridia pauca longe clavata violacea.

3. M. hexagrona Albertini (in Brid. II. p. 68.); monoica; habitus M. Iongisetur; sed folia caulina mugis lanceoluta, margine valde reflexa; theca exammuluta brevior crassion; perist. dentes externi brevissimi, interni breviores stricti remole arlicululi in crura duo cohacentia ad latera subglabera hand rolumblato-articuluta divisi rufi, ciliis dubus fugarissimis fragilissimis pallide flaridis articulatis interpositis.

Meesia Albertinii Br. Kurop. Fase. X. p. 7. t. 3. - Diplocomium hexastichum Fk. Moostaschh. 1. 43. t. 27. - Brid. 11. 1. 68.

Putriu. Germania, in turfosis prope Teodamum Neomarchiae Borussicac: I 1 \%igsohn; Milesia: Alberlini primus legit; Franconia prope Ratishonam: Fumerich; prope Karlsruhe: A. Braull. H rarissimis! - Julio.

Flos masculus louge infra peribactium in ramulo proprio subdiscoidens, antheridis et paraphysibus numerosis. Folia perigonialia M. tristichere, sed magis acuminata et haud incrassate sed pellucide areolata.

4. M. tristicha Br, et Sch. (Br. Hurop. Fase. X. Meesia, p. 8. 1.4.); divicu; late et laxe cespitosa, elon- 
gata innovans radiculosa; folia caulina tristiche sunerrosopalula, basi lata laxissime areolata decurrente semiamplexicueli reflexu, micato-curinalo-concura lanceolatus. cuspidutu, flexuosa, margine plano argute denticuluta, superne laxe sed minutius reticulata, nervo subexcurrente; perichaetialia longiora angustiora, nervo lato cuspidem longam totam occupante; theca excmmeluta in pedunculo longissimo, e collo basi subventricoso erecto curvata, irregulariter pyriformis fusca, operculo conico acuto brevi; perist. dentes externi breves obtusi medio fissi secentes, interni longissimi medio linea cxarati pertusi, margine grosse crenati veluti articulati, appendicibus articulatis pallidis irregularibus praediti fusci cartilaginei.

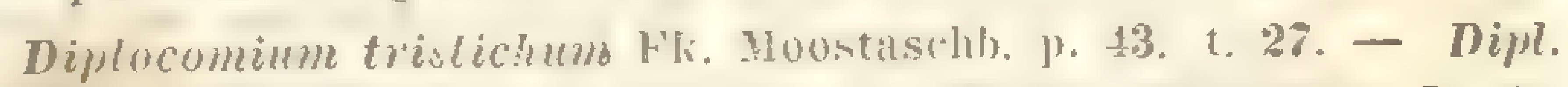
longiselum Brid. II. 1. Cot. ex parte. - Mninm triquetrum L. sp.

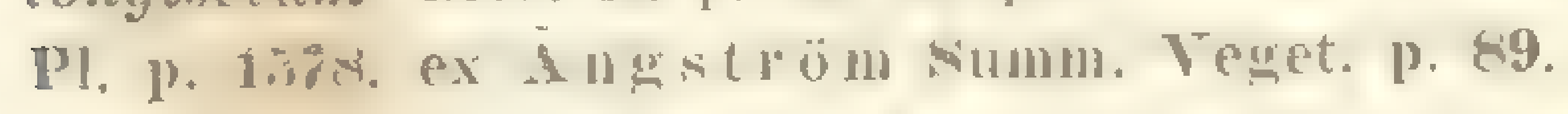

Putria. Per Germaniam, Helvetiam et Scandinaviam in turfosis profundis raro. - Julio.

Flos masc. discoideus terminalis. Folia perigonialia latissime ovata acuminata subexcurrentinervia, margine subcrenulata, superte dense areolata. Paraphyses et antheridia copiosissima.

J. Nor. vatagus C. Müll.; caulis vage ramosus erectus elongalus; folia laxe imbricata, comailia subsecunda, patentia hatiusculo-ovalo-lanceolata, apiculata, nervo tenui aute apicem evanido pracdita, flavescentia, c Gusi usprue fore ul apicem e cellulis longissimis angustissimis marginuta, remote denticuluta, e cellulis elongatis superne paullo minoribus laxissimis pellucidis composita.

Bryun ragans Ifooh. et Wils. Lont. Journ. of bot. 184t. P.516.

Patria. Insula Eremitae ad Cap. IIorn: J. Hooker.

Ex arcolatione foliorum Meesed vera, nunquam Bryntm et species pulcherrima.

\section{Gen. II. Paludella Ehrh.}

Phytophylac. No. 96. - Bryun L. Hedw. - Mnium L. Wahlenh. - Itymum Wel. et M. - Orthopyxis P. B. 
E voce palus nomen conditum, quum species unica hucusque detecta in paludibus profundis habiter.

Calyptra dimidiata. Peristomium duplex Pohliae. Inflorescentia dioica. Areolatio foliorum dimorpha, laxa et densa.

Genus maxime memorabile, Meesenceas cum Burtramiaceis conjungens, quum areolatione et forma reflexa foliorum Burtramiarum, praesertim sectionis Pliculellue, thecam Meesearum teneat.

1. P. squarrosa Brid. (Mant. Musc. p. 11\%. t. 2. f. 13.); dioica; elongata subsimplex tomentosa profunde cespitosa; folia caulina laxe imbricata maxime squarrosa, e basi decurrente carinato - vaginata laxe areolata superne maxime dilatata subito maxime reflexa late carinato-lanceolata, margine recurvo eroso-denticulata, nervo crassiusculo carinato evanido dorsi apice scabro, e cellulis minutis pellucidis quadratis versus apicem sensim densioribus ad paginam folii superiorem minute et creberime papillosis areolata; perichaetialia sensim magis comosa erecta longius acuminata apice recurva; theca annulata in pedunculo elongato recto tenui brevicolla ovali-oblonga parum inclinata laevis, basi stomatiis praedita, operculo conico-obtuso mammillari.

Brid. II. p. 1. - Br. Europ. Fasc. X. p. 3. t. 1. - Bryum squarrosum Linn. sp. PI. II. p. 1585. Hdw. Np. Muse, p. 166. t. 44. f. 6-11. - Mnium squarrosum Linn. fil. Meth. Musc. p. 364. Orthopyxis squarresa P. B. Prodr. P. 79. - Hypunu Paludella Web. et Mohr. Bot. Taschb. p. 274.

Patria. In paludibus profundis Germaniae septentrionalis, Saxoniae, Silesiae, Inclvetiae, Rossiae, totius Scandinaviac et Labradoris. In promontorio bonac spei specimina legit Berg, quae cum Europacis omnino conveniunt. - Aestate.

Pl. mascula femineac similis, paullum gracilior, flore discoideo. Folia perigonialia latissime obovato-lanceolata, laxius areolata, apice obsolete denticulata nervosa. Antheridia parva, paraphysibus clavatis numerosis mixta. 


\section{Subtrib. 1I. BA RTA M A C EAE,}

Habitus proprins. Areolatio foliorum laxa lacvis, laxa pajillosa, densa laevis et densa papillosa. Theca erecta $v$. inclinata, lorizontalis et penduli, regularis v. asymuctrica, laevis v. sulcata, plus minus autem sphaerica, stomatiis carens. Antheridia tribus. Paraphyses clavatac et acutac. Inflorescentia gemmacea $v$. discoidea.

Putril. Per totum orbem terrarum, regionum ommium, e planitiebus usque ad nives acternas, incolae, locis omnibus, uliginosis v. apricis, contentae. $2 \%$.

\section{Gen. III. Cónostomum Sw.}

S'chrad. Neu Bot. Journ. I. III. p. 14. - Bartramia Brid. et Br. Europ. - Grimmia sm. - Weisia Hdw. - Bryum al.

Nomen graecae originis, a xüv'os conus et orúuce, ob peristomii dentes constanter in conum conniventes ductum.

Calyptra dimiliata. Peristomium simplex : dentes 16 lanceolati sicci et madefacti erecti dense et nodoso-trabeculati, linea media exarati, apice per paria coaliti et in conum clausum obliquum connali, basi spatio aequali infra orificium oriundi. Habitus bartramioidens.

1. C. boreale Sw. (Schrad. Neu Bot. Journ. I. 3. p. 24. t.5.); divicum; compactum gracile erectum, ramis filiformibus attenuatis pentagonis subfasciculatis gluncescentibus fragilibus; folia dense conferta pentasticha, lato-lanceoluta mucronata brevia, carinato-concava, margine servuluta, undipue e cellulis mimetis ampliusculis irregulariter hexagonis papillis subcarentibus pellucidis areolata, nervo latiusculo obscuro evanido v. excurrente, dorso scubriusculo; perichactialia multo longiora, elongate laxe areolata tenuiora; theca in pedunculo elongato erecto apice subventricoso subito obovato-globosa gibbosa, dein sulcata, luteo-fusca, operculo conico rostrato oblipeo. 
Brid. I. D. 150. - C.arcticum Nw. in Brid. Sp. Muse. I. 1) 127.Bartrambit conustoma BH. Hulop. Fiss. XII. 1. 16. t. 7. - Grim-

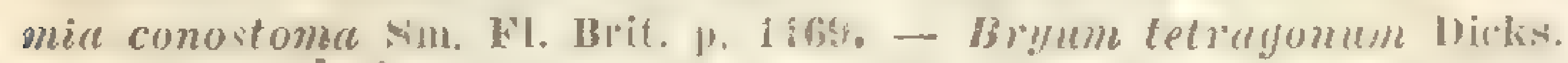
lasc. Crypt, il. p. 8. t. 4. f, 9.

Putrea. In summis jugis alpium IIclvetiac, Tirolis, Carinthiae raro, Scandinaviac, Lapponiac et Scotiac frequenter, in America et Asia septentrionalis v. aretica, loca uliginosa praeferens. - Aestute.

Pl. mascula fertili similis, flore discoiden, foliis perigonialibus externis ovato-aruminatis imbricaltis, internis e hasi late ovata concara erectis patentibus obsolete denticulatis tenuinervibus firmis laevibus. Antheridia magna clavata, paraplyssibus longioribus, longe articulatis obtusis subclavatis pallide luteis.

2. C. australe Sw. (1. c. p. 134. t. 1. f. 3.); dioicum; compactum robustires erectum, ramis crossinsculis attenuatis subeuspidatis pentagonis subfasciculatis glancescentibus dein luteis flaccidioribus; folia donse conferta pentasticha, majore, anguste lemeeolule, nervo lato obscuro in chspidem longem aculissineren serpue apice piliferam moducte, stricta, ubique e celiulis elongatis angustis, basi tenerionibus lavioribus supreme densis fle.rusis areolata, superne margine ereeto et dorso maillis creberrimis scaberrime sermlulu, inferne laevia; perichae-

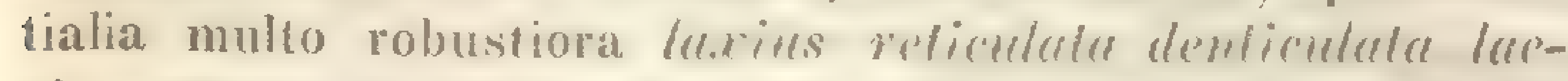
ria; theca in pedunculo clongato erecto subito subryundrate globose amilu cernua brecis, sublaceris, operculo Tongirostrato.

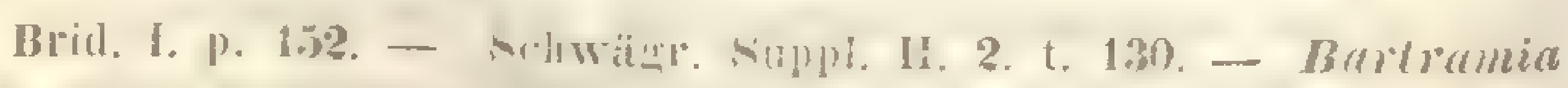

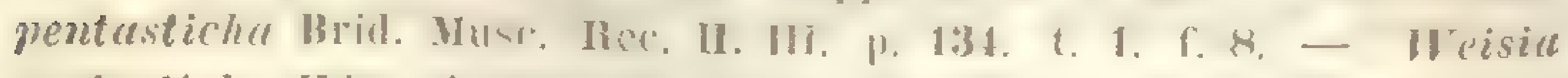
penlasticha Hdw. in Brid. I. P. 1.32. - Brym rm!nlosum Menz. ibidem.

Patria. In freto Magellanico primus legit Commerson; in 'Terra statumm: Menzics; insula Auchlandi et Eremitac ad Cap. Irorn: J. D. II ooker.

P1. mascula fertili similis, flore gemmacen. Folia perigonialia e basi lato - ovata complicato - concava laxe areolata colorata tenera lanceolata, nervo lato pungentia stricta 
laevia. Antheridia et paraplyses ut in specie praecedente simili notis datis distinctissima.

\section{Gen. IV. Bartramia IIdw.}

Vust. Frond. Il, p. 111. t. to. - Burtramialula Br. Furop. -

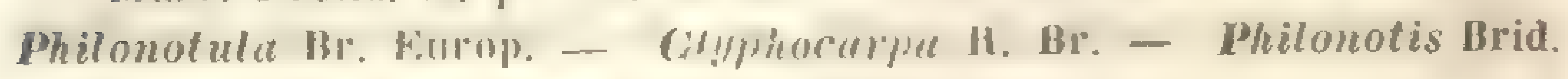
- Bryum, Mrium, Hymum al. antiq.

Nomen in memoriam 13 a r 1 rami coloni Pensylvanici, qui Dillenium muscis pluribus Americanis donavit, impositum.

Calyptra dimidiata. Peristomium nullum, simplex rel duplex. Fxtroum: dentes 16 Innceolati laeves trabeculati linca media exarati v. interdum medio secedentes, madefarli erecti, sicci incurvi, puli. Internum : membrana sedrcies plicata, in denles 16 lanceolatos carinatos lalos, dein in lacinias duas divergentes arliculatas fissas, producta, ciliis 1 -3 interjectis vel mullis.

Habitus theor plerumpue sphacrica asymmetrica amplat proprius. Peristomium duplea Bryi-Acidodontid.

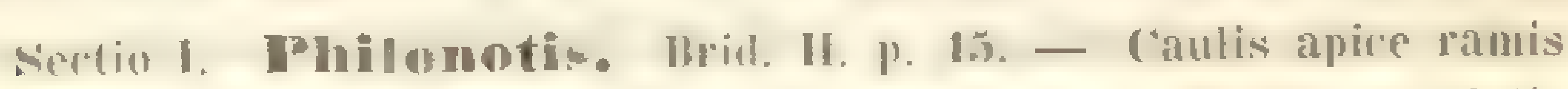

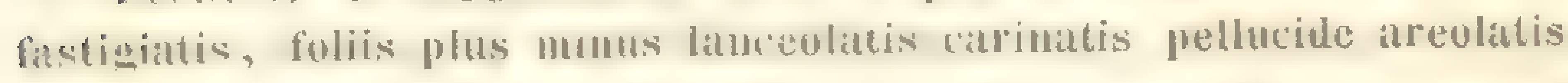
carnosulis erectis.

\section{A. Robustiores.}

Philonotis Br. Europ.

a. Folia heteromalla.

1. B. rigida Bals. ef De Not. (Pugill. 11. 1.); momira; dense cespitosa lumilis robusta erecta $r$. prostrala tomentosa; caulis fortilis informe romis solituriis, appe fustigiatis permultis innerpulibus breribus rigides aprem rensus crescentibus moenlitus; folia caulina erecto-appressa patentia stricta lanceolata, nervo creasso dorso sectbrido in cesplidem morluclu, maryinc simpliciter dentala, dorso papillis obscuris brevissimis asperula, undique e cellulis angustis elongatis viridibus areolata; perichactia- 
lia latiora longius cuspidata; theca in pedunculo elongato crasso rigido subflexuoso subito globosa submicrostoma magna inclinata sulcata, operculo depresso conico; perist. duplex normale $\boldsymbol{B}$. Marchicue.

Br. Europ. Fasc. XII. p. 20. t. 11. - De Notaris syllab. p. 102. Philonotis rigida Brid. II. p. 17. - b. fontana sichw. Sp. Husc. p. 92.

Patria. Calabria in sabulosis humidis: Requien detexit. Sicilia prope Messanam in humentibus collium: Balsamo. Torlano in Friaul: Sendtner. Madeira: Holl 1829.

Flos masc. gemmaceus juxta femineum positus, foliis perichaetialibus similibus robustis. Antheridia elongata, paraphysibus clavatis obtusis mixta. - Ramificatione et inflorescentia facile discernibilis, B. Gardneri et speciminibus B. Marchicae minoribus similis.

2. R. Mühlenbergii Schwägr. (Suppl. I. II. p. 58. t. 61.); dioicu; dense cespitosa; caulis nudus humilis tomentosus erectus, apice ramis permultis subsimplicibus elongutis flexuosis gracilibus, fusciculatis; folia laxius imbricata erecta, lato-lanceolata subacuminata subdenticulctu parum concava rigida amoene viridia, nervo crasso rufescente excurrente, e cellulis parallelogrammis minutis densis areolata; perichaetialia interna quadruplo minora Tanceolata obtusa solidineria tenera et albicuntia; thecae solitariae v. plures in pedunculis erectis subflexuosis horizontales, e collo brevissimo globosue breres sulcatae, operculis e convexo acutissime et brevissime mucronatis; perist. duplex normale. $t$.

Philonotis Mühlenberyii Brid. II. p. 22.

Putric. Pensylvania: Mühlenberg.

B. Gurdneri ex habitu similis et formis minoribus B. fontunue atque Murchicue haud dissimilis, sed notis cursive impressis facile distinguitur.

3. R. Turneriana Schw. (Suppl. III. I. 2. 1. 238.); dioicu; laxe cespitosa subhumilis lare foliosa, erecta, caulis fertilis inferne simplex luxissime foliosus robustus ra- 
diculosus, apice ramis pancis compressis fluccidis incrassutis brevibus, plantis sterilibus compressis apicem versus crescentibus apice attenuatis mixtus; folia caulina perfecte lanceolata longissime cuspidata, nervo excurrente tenui, margine erecto denticulata, angustissime elongate areolata, papillis remotis humilibus scabra; perichaetialia latiora maxime sefucea; theca in pedunculo elongato subito globosa maxima et orificio amplissimo praedita subinclinata sulcata; perist. duplex normale robustum.

Patria. Nepal, in arenosis.

Pl. mascula femineae similis flaccida, apice ramis solitariis vel $2-3$ brevibus oblique positis compressis. Flos discoideus latus. Folia perigonialia basi latissima multo laxius areolata, longissime cuspidata, caeterum perichaetialibus similia. Antheridia normalia, paraphysibus numerosis clavatis obtusis mixta. - Ab omnibus congeneribus ramis compressis flaccidis et notis cacteris illustratis facile distinguitur.

4. I. erythrocaulis C. Müll.; dioica; laxissime cespitosa inferne tomentosa; caulis sterilis et masculus erectus flaccidus longiusculus flexuosus, inferne inter folia radiculosus, rufus rigidus; folia remote disposita e basi ovala vel lato-lanceolata longe et acute cuspidata, carinate vel complicate concara, margine revoluta denticulata, undique e cellulis minutis rectangularibus pellucidis angustis arcolata, papillis scaberrima.

B. affinis Hsch. in Muse. Mexic. a Deppe et schiede Iectis.

Putria. Mexico: Deppe et Schicde.

Flos masculus terminalis, inter ramos binos breves dein elongatos flaccidos apice comosos positus, crasse gemmaceus. Folia perigonialia basi latissime ovata concava laxius et amplius areolata, cactcrum caulinis similia. Antheridia elongata, paraphysibus numerosis clavatis pallidis mixta. Formis flaccidioribus B. fontance? haud dissimilis, amocne viridis, gracilis, primo intuilu $\boldsymbol{B}_{r}$ yo erythrocuuli ex habitu affinis. 


\section{b. Folia homomalla.}

a. 'Thera sphaerica.

5. I3. fontana Schw. (Anppl. I. I1. p. 61.); divira; dense cespitosa clonuata, inferne tomentosa, valde ramosa; caulis crectus, apice ramis fastigiatis robustis permultis ercelis inaequalibus clongatis; lolia raulina erectopatentia heteromalla rel homomalla biformiu, huec ourto-

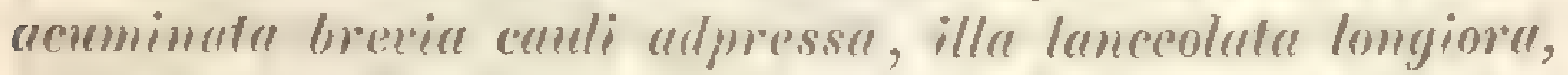
basi plienta et margine sarpe deplanutu revoluto minute denticulata, carinato-complicata, mulique e cellulis parvis plus minus rectangularibus viridibus densiusculis basi laxioribus amplioribus papillis remotis scabridis instructis areolata; perichaetialia multo latiora in subulan latiusculan longius cuspidatam producte tencriora; perigonialia interna e basi lata concara horisontalia oblusa eneria, $e$ cellulis rulde angustis elangatis sub/lexnosis, basi trnerrime membranaceis albidis areoluta, apice eroso-denticulatu; theca in pedunculo elongato crasso rigido erecto inclinata, subito globosa magna sulcata mohyderma, operculo breviter conico acuto; perist. duplex normale robustum magilum.

I31. Furop. Fase, XIJ, p. 18. t, 9. - Ihilonotis fontuna Brid. 11.

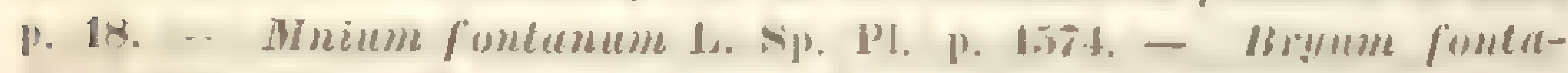

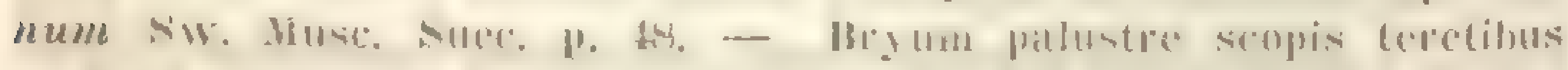

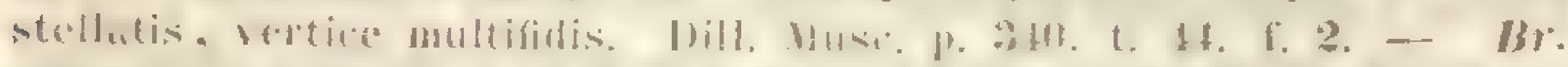

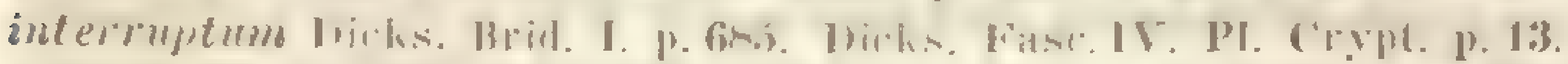

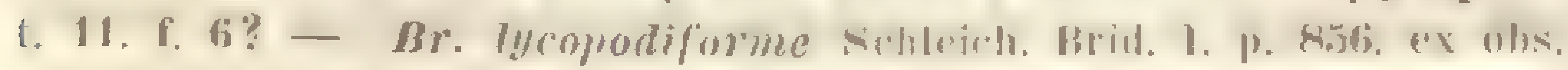

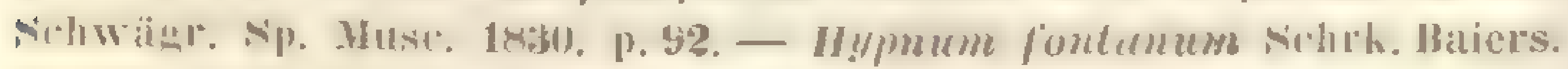
Fil. II. p. 472.

p. alpina; humilis subuncialis robustior, ramis densissime foliosis, foliis ovato-lanceolatis mucromatis; pedunculis brevioribus. Br. Furop. 1. C. Milonotis fontanat $\hat{\imath}$. alpina Brid. H. p. 20.

$\gamma$. falcuta; ramis apice aduncis, foliis omuibus falcatosecundis latescentibus, nervo crassu rufescente. Br. wurnp.

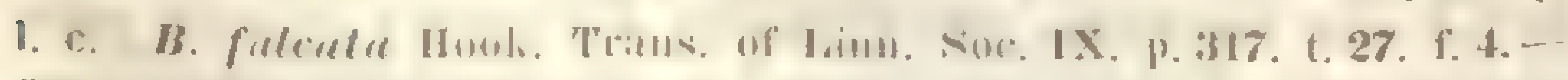
Ph. fontand $\zeta$. fulcata Brid. 11. p. 21.

Pulviu. In locis uliginosis planiliei usque ad alpes cutius Europac et Americac septentrionalis. Var. $\beta$. in 
alpibus summis Tirol. Ilisp. et Nepal. Tar. $\gamma$. ad scaturigines alpium. Fx India accepisse $\mathbf{B r}^{\circ}$. et sch. dicunt. Ad fretum Magellanicum legit Co mmerson.

Pl. mascula fertili similis, imovatione florifera stricla, sub flore ramulis subrerticillatis brevbus ramisque imovationes sistentibus fascorvatae. Fulia perigonialia inferiora imbricata, late ovala tenuissime acuminata nervosa, sequentia e basi lata vaginante patentia, intima majora ut supra descripta. Paraphyses et antheridia $\boldsymbol{B}$. Marchicue simillima.

6. F. calearea Br. el Sch. (Br. Furop. Fasc. XII. p. 19. t. 10.); dioica; habitus B. Pontance; folia uniformile, caulina secunda v. subsecunda conferta ovato-acuminata plicata longiore conssinerria, multo larins e celbulis heregonis mullis fere creventibus toneris amplis reticulate; perigonialia ommin acute acumimala sulidimervia; perist. minus, dentibus remote articulatis.

Putria. In rivulis calcarois. Prope Bipontem el in Ilassia superiore prope Biedenkopf: 3 ruch; pr. Fleurier Jurasi: Lesquereux; in meluga Rharefie: B r. et Schimp.; pr. Brumblepf circa Ammergan alpium Bara-

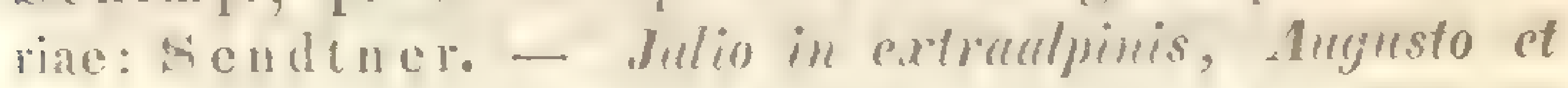
Septembri in alpinis.

I b. Funtune simillima notis datis revera distincta videtur.

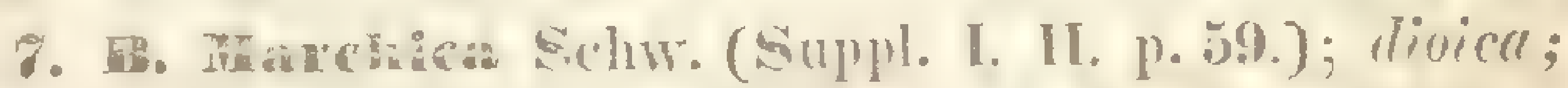
lense cespitusa plus mimus clongatal, inferne tomentosil,

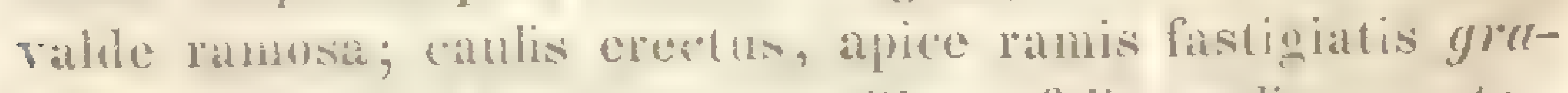
cilibus permultis enectis inacqualibus; folia canlina erecto-

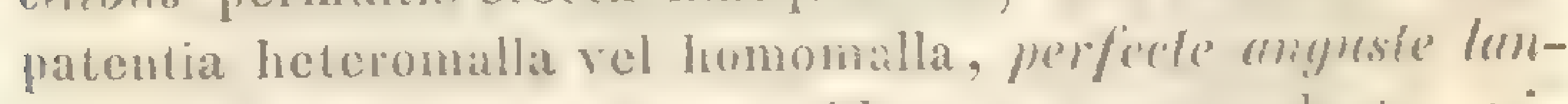
ceolute, nervo crasso in cuspidem aculam producta, mi-

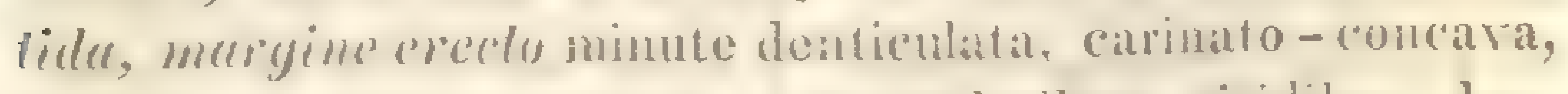
undipue e cellulis paris recetangularbus viriblibus den-

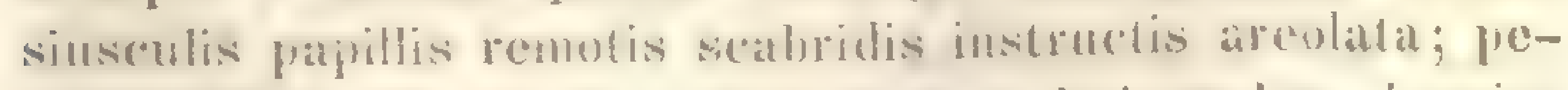

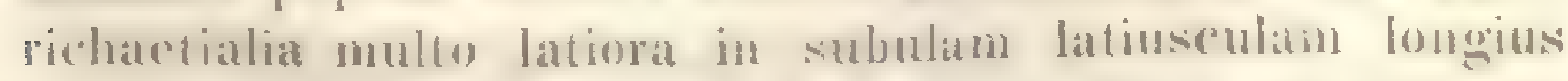
ruspidatam producta tencriorat perigonialia incrua suberecta lanceolata acela mereoser; theea in pedunculo elon- 
gato crasso rigido erecto inclinata, e collo brevissimo subito globosa magna sulcata leptoderma, operculo breviter conico acuto; perist. duplex normale robustum magnum.

Br. Europ. Fasc. XII. p. 17. t. 8. - Brid. Mant. Muse. p. 116. B. fontuna $\beta$. Marchica llook, et Tayl. Musc. Brit. p. 87. - Philonotis Marchica Brid. II. p. 23 et 735. - Mnium Murchicum Hdw. Muse, Frond. II. p. 108. t. 39. - Lesken Marchica Willd, Prodr. Fl. Ber. \o. 944. t. 6. f. 12. - Bryum Marchicum Hoth. Fl. Germ. 11. p. 236.

Patria. In pratis humidis et uliginosis, ad rivulorum margines, praecipue in solo lutoso-arenoso Europae occidentalis et borealis. Prope Spandau detexit Willdenow. Rarior. - Aestute.

Pl. mascula gracilior, sub flore ramulosa; folia perigonialia externa ovato-acuminata, interiora e basi lata concava anguste lanceolata acuminata, nervo tenui subexcurrente. Antheridia numerosa, paraphysibus innumeris robustis breviter articulatis clavatis mixta. - Notis

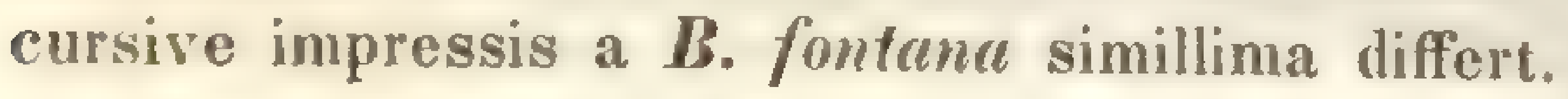

8. B. uncinata Schwägr. (Suppl. I. II. p. 60. t. 57. sub nom. B. scabridue.); dioicu; dense cespitosa elongutu foliosa, inter folia ad apicem fertilem tomentosa, plantis sterilibus simplicibus elongatis mixta, apice $3-4 \mathrm{ramis}$ crassinsculis brevibus secundis sacpe rumulosis Inteis; folia caulina dense conferta secunda, perfecte lanceolata stricta v. subfalcata, nervo crasso in cuspidem longiusculam acutam flavidam producto, carinato-concava, murgine e basi usque ad upicem revoluta et serrulutu, dorso papillis argutis scaberrima, undique c cellulis rectangularibus minutis densis areolata; perichactialia multo latiora, acutissime et elongate subulata, angustissime longins et temiter reticulata, temiora lasvissima vix denticulata plicata tennimervia; theca in pedunculo elongato horizontalis globosa magna sulcata macrostoma puchyderma, operculo conico; perist. duplex normale, interni dentes lati valde striatuli.

Philonotis uncinata Brill. II. P. 22. - Ph. Contana 7. Ianatı Brifl. 11. 1. 21. caules steriles, - Ph. fontana \%. dealbalu Brid. II. p. 21. 
Putvia. In monte sulphurifero Guadelupae: Richard.

Flos masculus in planta distincta minori terminalis gemmiformis ex obs. Schwägricheni l. c. Iconibus Schwägrichenianis male illustrata et colorata. - A $\boldsymbol{B}$. fontana praesertim Marchica notis cursive impressis et flore masculo certe differt.

9. B. Cardneri C. Müll.; dioicu; dense cespitosa humilis tomentosa, apice ramis c. 3 incepulibus tenerioribus viridibus; folia caulina conferta secunda, perfecte lanceolata stricta $v$. subfalcata, breviorl, nervo crasso sub apice exanido, carinato-concava, margine e basi usque ad apicem fere revoluta et serrulata, dorso papillis brevioribus scabra, undique e cellulis reclangularibus minutis densis areolata; perichaetialia multo latiora, acutissime et elongate subulata, angustissime longius et tenuiter reticulata, intima tenuiora laevissima vix denticulata, exteriora canlinis similia, sed latiora ef media longe subulata margine valde serrulata et dorso scuberrima, nerro excurrente tenui; theca ef caetera ut in B. uncinata.

B. uncinata C. Muill. et Wils, in Gardner: Coll. Muscor. Brasil. No. 44.

Patria. Brasilia monte Corcovado: Gardner.

A B. uncinatu proxima notis cursive impressis certe distat.

10. R. tenuis 'Tayl. (Phytologist. 1814. p. 1095.); late cespitosa erecta subsimplex gracilis pallide luteo-viridis uncialis; folia laxa erecto-patentia, ex lata ovata basi lanceolato-subulata serrulata flexuosa subsecunda; theca rotundato-oblonga curvato - cernua striata, basi hine gibba, e cellulis laxis rufo-brunneis reticulata, operculo convexo umbonato; perist. duplex normale. $\div$.

Patria. Insula Norfolk: Allan Cunniugham. Nova Seclandia: Rich. Cunning ham 1826.

A formis tenuioribus $\boldsymbol{B}$. fontance $\mathrm{ex}$ animadv, auctoris foliis longioribus angustioribus minus denticulatis distare dicitur. 
B. Theca longicollis.

11. 1. longicollis IImp. (in litt.); divica; laxe cespilosa tomentosa; caulis ferlilis erectus v. ascendens foliosus et inter folia tomentosus, apice ramis fastigiatis longinsculis flexuosis crinte foliosis; folia caulina laxe imbricata patentia secundat, lato-linceolata cuspielata, valde fulcata, nervo tenui excurente, margine revoluta, denticulata, carinato-roncartal, busi e cellulis hexugunis lapribus amplis laxissimis sumu medium folii angustis densis mimutis subluevibus areolutu; perichactialia exterma latiora caeterum caulinis similia, basi multo laxius reticulata, interiora tencrima plicata colorata larvissinat theca in pedunculo longissimo crecto flexuoso crasso apice parum arenuto subinelinula, e collo longinsonlo subrylindrice, orificio courelatu, rugulosu; perist. duplex nommale robustum magnum horizontale.

J'ulvile. Java: Junghuhn. Ilb. Gottse heanum.

Operculum et flos masculus desunt. - syecies memorabilis, habitu meeseoideo.

\section{B. Graciliores.}

Philonotula Br. E'urop.

a. Theca gymostoma.

12. B. Roylii C. Müll, hermaphroditu; pusilia; caulis brevissimus erectus radiculoso - tomentusus, ramulis $2-4$ tenubus erectis subsecundis rigilis frerinsculis; folia caulina conferta brevia paulisper secumba lanceolata, nervo crasso in acumen semulatum paullo falcalum producto, carinale-concava, ad mareinem exectum superne denticulata, moligne edellulis minulis sublensis busi mayis quedrulis areuhlu; perichacedalia longius subulatat ma-

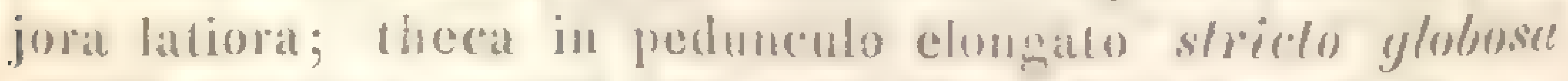
ampla erecte lacvis fiscescens, operculo depuesso mammillato.

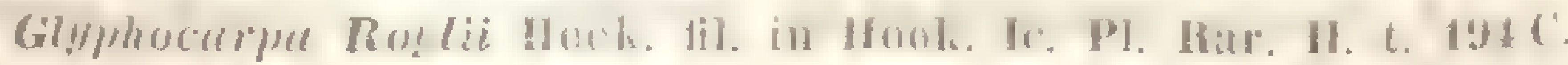

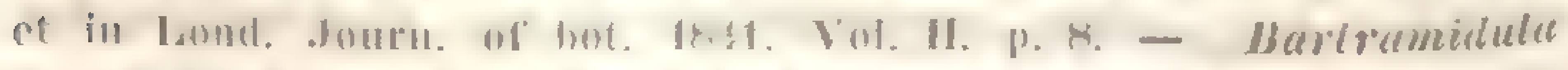
Roylii Br. Furop. Fals: 2:--33. Bartlamidulat, p. 2. 
P'atril. In Himalayae montibus legit Dr. Royle. In montibus Neclgheriensibus legit Perrottet. IIb. Montagneanum.

B. Wilsoni proxima, sed notis illustratis facile distinguitur.

13. 5. Wilsoni C. Müll.; hermaphroditu; pusilla; caulis brevis prostratus radiculosus, ad apicem fertilem ramis plerumque 3 brevibus secundis; folia caulina imbricata brevia secunda lanceolata subfalcata, nervo crasso sulbontimu vel in aristam valde denticulatam producto, carinato-concara ad marginem erectum raro revolutum supra basin regulariter dentata, e cellulis mugnis inforne cmplioribus superne anyustioribus rectangulari-hexagonis interdum chlorophyllosis areolata; perichactialia longiora tenuius nervosa; thecae 1 - ó globosene brevicollue in pedunculis Ingiusculis cygneis horiantules tenniter membranacene laeres dein rugulosue, mallide rubiginoscer demum fusco-brunneac nitidue, exannulatac microstomar operculis mimntissimis convexis. $†$.

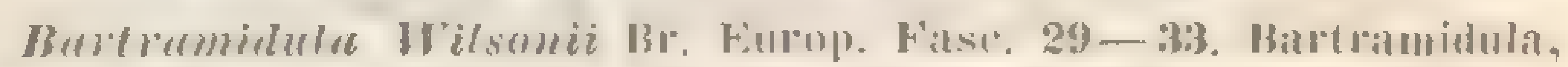
c. ir. - Gl!lhhocarpa? cermua Wils. in Lond. Journ. of hot. $18+1$. p. 8. memorata.

Patritl. In montosis Britanniae et IIberniae ad Cannor Ilill; prope Corn Bychon Valesiae; in alpibus Scotiris ad Glen-Dole in Clova mountains copiose. Wilson anno 1829. detexit.

Paraphyses fl. fertilis tenues acutae. - $\boldsymbol{B}$. cycmeat simillima, sed notis cursive impressis distinctissima.

14. IB. eyenen Mont. (B. Philonotis. Ann. d. sc. nat. 1845. 1. p. 102.; c. ic. in Hist. 1. Chile. Bot. Cr. 1. 2. f. 2.); divice; pusilla; caulis brovissimus erectus radiculoso-tomenlosus, ramulis $2-4$ tenuihus subsecundis verlicillatis erectis hrevinsculis; lolia canlina imbricata brevia secunda, lanceolata filcalla, nervo crasso dorsu superne sermulato in aemen pruduclo, carinato-concara, ad marginem erectum tenuiter el argute dontata, molique e cellulis rectungularibus minutinsculis viridibus areo- 
lata; perichaetialia longiora acutissime subulata; thera solituria in pedunculo elonguto cyyneo-flexnoso sphuericu erecta vel nutans 8 -striatu, operculo convexo.

Putriu. Chile, in locis fuliginosis: C. G ay.

Pl. mascula simplex, flore terminali gemmaceo fusco ob innorationem brevissimam laterali. Folia perigonialia e basi late convolutacea tenuiter reticulata colorata in subulam reflexiusculam denticulatam producta. Antheridia subparva curviuscula paraphysibus flavis obtusis nixta. - B. Wilsoni sinillıma, sed differt ramis Iongionibus, folis excurrentinervibus, pedunculo longiore magis cygneocurvato, theca striata et inflorescentia dioica.

15. D. pusilla C. Müll.; caulis subramosus pusillus; bilinearis; folia erecto-patentia ovata acuta reticulata (1. c. laxe reticulata?), margine plana, nervo subcontinuo; theca cernua globosa, operculo conico. $t$.

Glyphocarpa gusilla Hook. et Wils. Lond. Journ. of hot. 1844. p. 545.

I'utria. 'T'era V'an Diemen: D. Lyall.

H.x animadvers, auctorum, B. Wilsoni similis.

\section{b. Theca peristomata.}

a. Caulis filiformis teres.

16. R. Iaxissimn C. Müll.; dioica; late et laxe cespitosa, laxe cohaerens radiculosa glanco-viridis; caulis elatiusculus, apice rumis longis fliformibus flexuosis tenerrimis apice uncinatis; folia caulina laxe disposita erecto-appressa subsecunda, lato-lanceolata brevia parum fulcata, e cellulis amplis laxis pelluridis hexagonis papillis obscuris et utriculo primordiali tenerrimo instructis reoluta, margine e basi fere usque ad apicem duplicatoserrata, nervo crasso viridi ante apicem dissoluto; perichactialia longe acuminata excurrentineria denticulata; theca in pedunculo elongato flexuoso erecto globosa horizontalis brevis, operculo hemisphaerico mammillato; perist. duplex normale breve, internum rugulosum. 
B. falcata Hb. Miquel. et Gottschean. - Hupmum hasfatum Duby in Moritzi Verz. d. Zolling. Pf. v. Java p. 132. No. 1813!!

Patria. Java.

Cespites lati parce fructiferi. - B. filiformi IIsch. proxima, sed partibus omnibus robustior et notis cursive impressis facile distinguitur.

17. D. sphnericarpa Schw. (Suppl. I. II. p. 59.); dioica; caules aggregati unciales erecti, tomento radicali vestiti, inferne simpliciusculi filiformes, ramis fasciculatis brevibus tenuissimis reflexis, caulibus sterilibus simplicibus mixti; folia undigue sparsa mimula approximata imbricata patentia, lanceolata acuminata cuspidata, nervo continuo, quadrate laxius areolata, margine denticulata, dorso papillis hispidula; theca in pedurculo elongato horizontalis subito globosa ampliuscula brevis, operculo subplano brevissime acuminato; perist. duplex normale angustum. if

Philonotis sphaericarpa Brid. 11. p. 2.5. ex parte. - Mnium sphaericaryum IJdw. Muse. Fr. HI. D. 93. t. 38. A. - Bryum sphaericarpon \$w. Fl. Ind. Occ. HI. p. 1835.

Patria. In umbrosis muscosis montium sumnorum Jamaicac australis: Swartz.

Pl. mascula simplex, flore terminali rel innovando. laterali minutissime gemnaceo. Holia perig. basi latiora concava teneriola. - A $B$. fomella folitis magis acuminatis et thecae forma distat.

18. D. tenella C. Müll.; dioica; pusilla dense cespitosa lutescens; caulis brevis radiculosus $r$. tomentosus, apice ramis $5-10$ inaequalibus secumdo-recuris subprostratis subteretibus temibus breviusculis; folia caulina conferta subsecunda lanceolata brevia obluse acuta curinla carinato-concava, margine obscure duplicato-serrulata dorso papillis remotis scabra, undique e cellulis laxis minutis areolata, nervo viridi subcontinuo; perichactialia lationa tenuiter cuspidata teneriora lacvia; theca in pedunculo elongato classiusculo inclinate iel horisonlalis minute globoso-oblonga, sicea cylindrico-cernua subgib-

C. Mitller: Synops. muse, frond. 


\section{STEGOCARPJ. ACROCARPI. BARTRAMA.}

bosa leviter sulcatu, operculo conico acuto, perist. duplex normale breve.

Philonotis Mühlenbergii $\beta$. tenella Brid. II. p. 23.

ß. humilis; perpusilla, ramis erectioribus tenuioribus, foliis angustioribus pellucidius laxius areolatis, crassius nervosis, confertioribus et erectis haud secundis. Philonotis humilis 13rid. II. 1. 17. - Anoectungium Portoricense spreng. in Brid. ihid. - Bartr. radicalis Hmp. in sched. - Bartr. Contana Schw. p. 92.

$\gamma$. erectu; rami erecti gracillimi apice uncinati. Planta mascula simplex apice flore praedita vel pluries furcata et inter ramos breves flore gemmaceo crassiusculo fusco instructa. B. glaucescens Hsch. Fl. Bras. 1. 40?

ס. gracillima; inferne compacte tomentosa, ramis clongatis gracillimis tenuissimis flexuosis. Pl. mascula simplex tenuissima flore terminali vel innovatione laterali gemmaceo tenui. B. filformis Ilsch. Hi. Bras. p. 40?

Patria. Insula Trinitatis Antillarum: Crüger. Ilispaniola: Bertero. Var. $\beta$. Hispaniola et Portorico ad saxa humida: Bertero; in montibus St. Jan: Brentel. Var. $\gamma$. Serra dos 0rinas: Rie del. Var. J. Brasilia, solum humidum praeferens.

P1. mascula perpusilla tenerrima, caulis clatus tenerrimus curvus, apice ramis 2 brevissimis furcatus, inter eos flore masculo gemmaceo crassiusculo parvo; folia perigonialia e basi lato-ovata concava colorata subito fere in subulam latiusculam acutam subflexuosam producta, laxe areolata tenera, nervo tenui excurrente.

19. R. rufiflora IIsch. (Fl. Bras. p. 40) ) dioicl, dense cespitosa; caulis fertilis chutusculus filiformis, inferne radiculoso-tomentosus, apice ramis fastigiatis pluribus brevibus subsecundis et interdum iterum fertilibus; folia caulina crecto-appressa subsecunda, madefacta paulisper patentia, lalo-lunceolata brevia, nervo crasso subcontinuo arutiuscula, margine duplicato-serrulata, dorso papillis remotis obscuris sublacvia, carinato-concava vix curvula, undique e cellulis ampliusculis laxis hexayono- 
queulrutis pellucidis areolutu; perichactialia e basi latoovata tenerrime reticulata plicata pellucida fusco-colorata in subulam longam subtortan schsim producta, intima laevia vix denticulata; theca in pedunculo elongato fle$\mathbf{x u o s o}$ rigido inclinata globosa brevis ampliuscula rugulosa, operculo hemisphaerico mammillato; perist. duplex normale majusculum.:

B. angulata T'ayl. Lond. Jour's, of hot. 1846. p. 55.: ex obs. CI. W ilson l. (*. p. 451. forma foliis quinutefaris $\boldsymbol{B}$. ruffurae.

Pulriu. Brasilia; Serra d'Estrella supra saxa rivorum et in solo glareoso, Augusto: Beyrich. Serra dos Orgatos: Gardner No. 46. In Andibus Quitensibus: WV. James on. Hb. Taylor.

Pl. mascula gracilior, inferne foliosa, apice floribus solitariis vel binis et ternis plus minus conglomeratis crassis fuscis ternatus et ex iis ramis tenuissimis flexuosis brevibus imovans. Folia perigonialia e basi lato-ovata convolutacea fusco-coloratil tenero-reticulata subito in subulam latiusculam, nervo excurrente percursam, denticulatam scaberulam producta. Antheridia majuscula, paraphysibus numerosis aureis obtusis cincta. - Foliis lato-lanceolatis, altitudine et planta mascula a speciebus liumilioribus sectionis Philonotis praesertim a $\boldsymbol{B}$. tencllu facile distinguitur.

20. H. elegantula 'Tayl. (Lond. Journ. of bot. 1847. p. 335.); laxe cespitosa gracillima crecta triuncialis subfasciculatim ramosa; folia approximata erecta lanceolata subdenticulata, nervo sub summo apice evanescente; perigonia paucifolia arcte imbricata subrotunda; theca in pedunculo caulem superante flexuoso inclinata subglobosa subacqualis striatula, operculo convexo acuminulato; perist. duplex normale. $t$.

Pulvia. Nonte Pichincha Andium Quitensium: W. Jameson. Nov? $18 t 6$.

B. filiformi IIsch. ex animadv, auctoris affinis, sed minus ramosior, basis folii angustior, apice magis acuminato, nervus evanescens, areolatio latior, pedunculus 


\section{S'TFGOCARTI. ACROCARPI. BARTR.MA.}

crassior, theca amplior et folia perigonialia magis appressa.

21. B. minuta Tayl. (Itond. Journ. of bot. 1847. p. 335.); caules aggregati, dein innovando ramosi erecti trilineares, rami minuti stricti rigidi et foliorum apicibus acuminatis setacei; folia arcte imbricata stricta erecta anguste lanceolata acuminata subserrulata, margine basi reflexa; theca in pedunculo elongato apice incrassato subsphacrica erectiuscula subpellucida, operculo convexo-conico subpellucido; perist. duplex normale. $\leftarrow$.

Patria. Prope Quito Andium: W. Jameson. Muremb. 1816.

A B. Marchica e sententia auctoris exiguilate, foliis dense confertis, theca pailida magis sphacrica estriata differt.

\section{B. Caulis plumosus.}

22. I. mollis Dz. et M. (Ann. d. sc. nat. 1844. II. p. 300.); divica; late et laxe cespitosa prostrata, innovationibus elongatis sterilibus gracillimis mixta, caulis elutiusculus, inferne foliosus tomentosus, apice ramis tenuibus brevibus $3-6$ erectis, aurcis vel flavido-viridibus; folia caulina erecto-patentia laxa, lanceolata, nevo subtenui in cuspidem piliferum elongatum producta, basi latiora, margine toto duplicato-serrulata, dorso breviter et renote papillosa, undique e cellulis elongatis angustis laxiusculis viridibus areolata; perichaetialia similia basi latiora; theca in pedunculo elongato globosa oblique gibbosı, orificio magno obliquo, sulcata, senectute basi subyuadratu, operculo convexo; perist. duplex normale, internum striatulo-asperum.

B. sphaerocarpa Mont. in Hl), Miqueliano.

Patria. Java.

PI. mascula multo gracilior prolifera parce ramosa; flore terminali gemmaceo colorato. Folia perigonialia basi convolutace-concava colorata fusca tencrime areolata laevia sensim pilifera, superne margine et dorso nervi 
denticulata. Antheridia subparva, paraphysibus aureis obtusis humilibus cincta. - B. Berteroune proxima.

23. B. Berteroana C. Müll. (Linn. XVII. p. 590.); dioicu; dense cespitosa humilus inferne tomentosa, ad apicem fertilem ramis $5-7$ canle mesillo longioribus gracilibus curvulis ad basin tomentosis pallide viridibus, $v$. luteis; folia caulina tenervimu in caulem rubentem luxe disposita, anguste lanceoluta cunaliculata currula, margine e basi usque ad apicem fere tenuiter revoluta duplicato-serrulata, dorso papillis - pro cellulis laxis pellucidis rectunguluribus teneris minutis - crassis scabra, nervo subtenui subcontinuo; perichaetialia similia, basi latiora longe acuminata, intima lacviora teneriora, ommia excurrentinervia; theca in pedunculo elongato globose macrostoma senectute truncula parea recta regularis vix sulcala; perist. normale inflexum, internum striatulum.

B. Aluccidu; ramis longissimis gracillimis flexuosis luteis, foliis patentibus.

Patria. Insula Trinitatis Antillarum: Cr üger. Var. $\beta$. in insula Guadeloupe: Bertero.

Pl. mascula elatior, apice $2-3$ ramis recurvis tenerrimis brevioribus, inter sese flore crassiuscule gemmaceo. Folia perigonialia e basi lato-ovata concava colorata tenera subito lanceolato-subulata subexcurrentinervia lacvia parce denticulata. Antheridia numerosa, archegoniis majora, paraphysibus aequalibus breviter articulatis obtusis mixta.

24. B. radienlis P. B. (Prodr. p. 44.); dioice; muxime humilis erecta tomentosa, apice ramis tenellis circa 4 simplicibus; folia caulina elonguta putenti-confertu, angustissime lanceolata, nerro crasso luteo in cuspidem crassinsculum et ucufissimum producto, margine erecto simpliciter sermuluto, dorso papillis crassiusculis remotis scabra, ubique e cellulis angustis elongutis luxis pellucidis areoluta; perichaetialia latiora et laeviora; theca in pedunculo maxime elongato subradicali crasso rigido ho- 


\section{STEGOCARPI. ACROCARPT. BARTR.IMA.}

rizontalis globosa magua, macrostoma; perist. duplex normale, internum subasperum.

Schwägr. suppl. I. 11. p. 56. t. 61. - B. longiseta Rich. Fl. Am. Bor. Mich. II. p. 301. - Philonotis radiculis Brid. II. I. 16.

Patria. Virginia: Boscq. Carolina meridionalis, in humidis: P. d. Beauv.

Species notis illustratis e spec. auth. distinctissima saepe commutata, e pedunculo longissimo, exiguitate caulis folisque longissimis cuspidatis angustis futcillime discernibilis. Ex obs. Cl. Bridel et Śchwägrichen in axillis foliorum occurunt frequenter bubi rufescentes decidui, foliis suboctonis, lanceolati obtusiusculi compacti, ut in Bryo annotino reperiuntur. In specimine unico IIb. Bridel. non vidimus.

25. B. Pabstiana C. Nüll.; divica; laxe cespritosa inferne radiculosa humitis erecta gracilis; caulis fertilis brevissimus, ramis c. 10 gracilibus brevibus subuncinatis plumose fotiosis fastigiatis; folia caulina laxe imbricata homomalla, anguste lanceoluta sublonge acuminata, nerro crasso viridi excurrente, curvula carmato-concava, margine duplicato-serrulata, dorso paprillis obscuris remotis

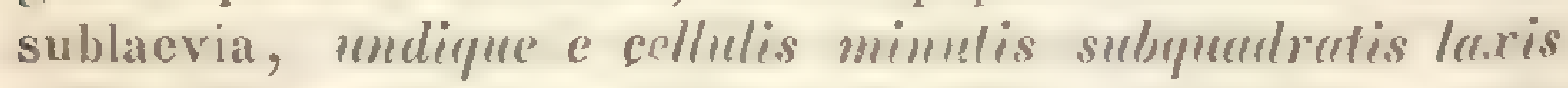
pellucidis areolala; perichactialia latiora tenuiora longe et flexuose cuspidata excurrentinervia, intima laevia denticulata; theca in pedunculo radicali clongato crasso rigido horizontalis subito subghobusa brevis ampla sulcatorugulosa, operculo hemisphaerico mammillato; perist. duplex normale robustum.

B. plumosa; amoene viridis, laxius subgregarie cespitosa clatior gracilescens valde plumoso-foliosa.

Patria. Insula St. Cathatrina Brasiliac, societate Physcomitrii inter fruticeta coloniate Germanicac, all flumen Itajahi conditae, thecis apertis, Iug. Fepr. 1816 leg. Pabst, hortulanus Ifalensis. Var. $\beta$. Ibidem in viis cavis locorum umbrosorum montosorum prope Destero, thecis junioribus, Mart. 1847 leg. P'a bst. 
1P. mascula subsimplex, parce ramosa flore terminali v. ob innovationem laterali gemmaceo tenui. Folia perig. - basi lato-ovata concava colorata tencro-areolata subito in subulam latiusculam acute acuminatam producta, nervo tenui excurrente praedita, denticulata. - B. sphuerocurpac e forma thecae affinis, sed imbricatione foliorum plumosa, ramis subuncinatis et foliis homomallis distat. A B. tenella foliis angustioribus longioribus acutioribus plumose dispositis et thecis collo carentibus subito globosis brevibus siccitate haud cernuis amplioribus certe differt. A B. radiculi foliis brevioribus, non pungentibus, aliter areolatis et thecae forma distinguitur. Proxime autem ad $\boldsymbol{B}$. Berteroctum quoad imbricationem foliorum accedit, sed foliis laxius et amplius areolatis et thecac forma facile cognoscitur.

Nertioll. Plicatella. Caulis vawe - et apire fascirulato-ramosus, foliis e hasi erecta reflexis, anguste clongate, basi ntrinque ad maninem amplius areolatis, longitudinaliter plicatis plus mints fragilibus.

\section{a. Brevipedunculatae.}

26. B. areunta Brid. (Spec. Musc. III. p. 79.); divica; dense cespitosa elongata, inter folia tomentosa, aureoviridis nitens, vage ramosa, ramis inaequalibus, robusta; folia caulina erecto-patentia conferta, e basi lata amplexicauli rectiuscula orato-lanceolata et subreflexa, multoties plicata, margine subrevoluta superie denticulata, nervo tenui in cuspidem acutam excurrente, undique e cellulis angustissimis rectangularibus areolata, papillis tenuissimis scabrida; perichaetialia ovato-lanceolata stricta laevia; theca in pedunculo brerinsculo flexuoso-arcuato inter ramulos nonmullos inaequales posito crasso pendula subito sphaerica microstoma magna, suleata ferruginea, operculo minuto conico-mammillato; perist. duplex normale $B$. Iullerianae.

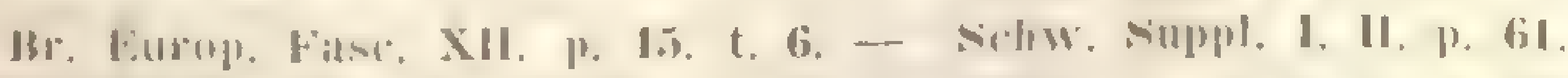

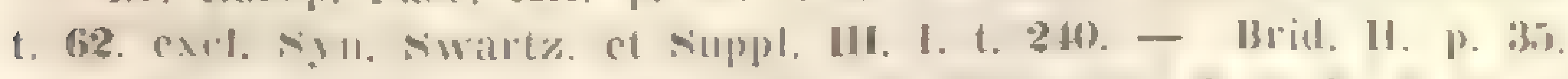

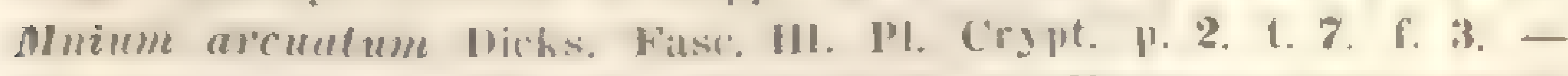

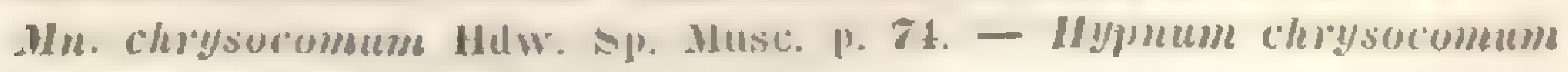


licks. Fast. III. Pl. Cr. p. 12. - Hypnum palustre erectum, coma lutea, basi nigricante. Dill. Musc. p. 302. t. 39. f. 36.

Patria. In rupibus humidis irroratis Angliae, Scotiae et Hiberniae, ubi haud rara reperta est. In monte Rigi Helvetiae sterilem legit He gets chweiler. - Vere.

P1. mascula subsimplex, sub flore innovationem unicam, rarius plures, emittens, unde post generationes complures geniculata et multiflora apparet, ramulis singulis gracilibus. Flos terminalis discoideus polyphyllus; folia perigonialia exteriora e basi lata valde concava lanceolata, interiora e basi erecta recurva, caeterum caulinis similia; antheridia copiosa, brevistipitata; paraphyses numerosae subclavatae lutescentes. Br. Furop. 1. c.

27. B. tomentosa Hook. (Musc. Exot. t. 19.); dioicu; caules tomento ferrugineo densissime obsiti, digitales ad palmares, vage ramosi, ramis hic illic tomentosis, subpinnatim divisis saepe fasciculatis flexuosis gracilibus inaequalibus; folia dense imbricata horizontaliter patentia subrecurva nitida flavescentia, ovato-lanceolata longe acuminata, serrulata plicata, margine inferne revoluta, nervo tenui percursa, undique e cellulis rectangularibus angustis minute papillosis areolata; perichaetialia interna multo latiora, basi laxissime elongate areolata tenera; theca in pedunculo brevi erecto horisontalis magna oratoglobose sulcata; perist. duplex normale.

? Philonotis tomentosa Bril. 1I. p. 26. - Bartr. arcuata sisw. Suppl. 1. II. ए. 62. - Mnium tomentosum sw. Prodr. p. 139. Bryum tomentosum sw. F1. Ind. Occ. 111. 1. 1837.

Patria. Ad latera sylvarum montium altissimorum Jamaicae: Swartz. Columbia, Silla de Caracas: Moritz.

Pl. mascula vage ramosa maxime tomentosa, flore terminali et ob innovationem novam masculam plus minus elongatam tomentosam laterali discoideo. Folia perigonialia omnia e basi recta reflexa, externa e basi latissima laxe areolata tenera lanceolato-acuminata plicata denticulata, interna e basi colorata laxissime reticulata subito reflexa obtuse acuminata subligulato-ovata eroso-denticu- 
lata obsoletinervia. Antheridia elongata angusta, paraphysibus numerosis filiformibus et crasse clavato-articulatis mixta. B. arcuatue proxima.

28. R. gnaphalea C. Müll.; caulis crectus elongatus gracilior, inter folia tomentosus, ramis vagis gracilibus subpimnate dispositis faccidioribus, apice elongatis strictis rubustioribus; folia caulina imbricata squarrosa, e basi oblonga erecta plicata in subulam plus minus reflexam lanceolatam et nervo tenui excedente acutissime cuspidatam producta, margine denticulata et dorso ubique papillis teneris acutis remotis scabra, e cellulis angustissimis sublongis pellucidis areolata.

B. arcuata Brid. II, p. 35. - B. tomentosa schw. sp. Nuse. 1890. P. 97. - Hypnum? ynaphateum P. B. Prodr, p. 64.

Patrie. Insula Bourbon, Plaine des Chicots: Bory St. Vincent altitud. 1000) hexapod. legit.

A B. arcuatu et tomentosa proximis notis datis distat.

\section{b. Longipedunculatae.}

29. B. gigantea Schw. (Suppl. I. II. p. 63. t. 63.); dioica; procera elongata robusta rigida crecta v. geniculato-flexuosa; apice rami pauci robusti breves summo apice foliis nommenlis comrolutis cuspiduti; folia caulina reflexa squarrosa rigida, e basi latissima colorata bre?iter erectu valde plicutt, utrinque ad marginem cellulis albidis laxis praedita, in subulam latissimam lanceolatocuspidatam elongatam producta, subtorta, margine erecto denticulata, e basi ad apicem pluries plicata, nervo tenui excurrente, e cellulis angustis.imis remote papillosis areolata; perichactialia angustiora erecto-apmpressa, maxima parte folii lacria laxissime elongute ef tenervime reticnlata pulcherrime ferrnginea, plicala, nevo in laminam superum dissoluto fermugineo; theca in pedunculo stricto inter ramos binos posito et innovando caulis laterali incurvo fragilissimo horizontalis alonguto-pyriformis striata; perist. normale duplex, ciliis interpositis nullis. 


\section{0

schw. Suppl. 11. II. p. 30. t. 161. - Brill. II. p. 36. - Dicramum giganteum IBrid. Sp. Musc. 1. p.97. - Hypmum arumdinifolium Dub. in Moritzi Verz, d. Zullingerschen Pf. v. Java 1. 131!!

Paria. Insula Bourbon, planitie des Chicots c. 6000 ped. supra mare: Bory $\$$ t. Vincent. Java, ad rupium parietes juxta tlum. 'japus circa 5000 ped.: Lollillger Coll. No. 1811.

Fructum non ridimus. Ápecies maxime memorabilis, muscis pleurocarpicis valde similis et Spridenlis genus haud male referens, omnium congenerum gigantea hyplioidea.

30. B. scopnria Schw. (Suppl. III. I. 2. t. 241.); dioice; caules steriles in cespites latissimos congesti, Jongissimi parce tomentosi, ranis pinnate dispositis inaeyualibus rectiusculis vel horizontalibus llaccidis, approximatis vel remotis; fertiles multo humiliores foliosi et inter folia valde tomentosi, apice ramis fasciculatis brevibus, crectis; folia caulina siccu et mad'/acta erecto-patentia laxiuscula, e basi lato-oveta plicala, ubingue ad marginem infermem e cellulis nommullis multo majoribus laxioribus fuscidulis crevlata, in subulan lanceotatan lonsissime cuspidatam denticulatam plus mintis plicalam prolucta, margine inferne revoluta, nervo tenui excurrente, e rellulis angustissimis subpellucidis reticulata; periclatetialia caulinis similia; theca in pedunculo clongato erecto myiformi-orata erecta regularis mer/fore sulcala.

Patria. Insula Martinique: (X. Si e ber.

Operculum et peristomium desunt. Wheca B. Sicheri, habitus $B$. tomentusae. - Nlores masculi inter Iongissimos caules et inter breviores fertiles, disciformes utrogue caule crassiores, foliis octonis $v$. duodenis patentibus, ex ovato longe acuminatis, nervo apice evancscente, basi crecta concara ferruginea, superiore parte pafonte flavoviridi. Antheridia paraphysibus longioribus numerosis diliformibus limpidis cincta.

31. F. integrifolia 'T'ayl. (Lond. Journ. of' bot. 1816. p. 5.5.) ; dioica; caulis cespilosus clongatus crectus vage 
ramosus, ramis subfasciculatis pallide luteo-viridibus; folia imbricata erecto-patentia ovato-lanceolata longius acuminata integerrima, margine reflexa, apice semel torta, inferne concava; theca pyriformi-oblonge cermuce striata, operculo umbonato; perist. duplex normale. $\div$.

Jutria. In Andibus Quitensibus: W. Jameson 1845.

Hx auctore $B$. fomentosue affinis, sed humilior et loliis integris thecaque pyriformi-apophysata differe dicitur. Fx observationibus Cl. Wilson (l.c. p. 45̆l.) a $B$. pendula vix differt, serraturis foliorum abscntibus exceptis. Folia perigonialia orata squarrosa.

32. B. pendula Ilook. (Nusc. Exot. t. 21.); divira; dense cespitosa tomentosa subhumilis erecta sordide viridis; caulis fertilis inferne maxime tomentosus, apice ramis compluribus rectis, pro plantulac altitudine longiusculis, rigidis; folia cauliua erecto-patentia lave imbricata, sicca crispata, e hasi amplexicauli rectiuscula in subulam lanceolatam reflexam acutissimam producta, nervo subtemui excurente, margine basi paulisper revoluto, apice dentrculata, undique e cellulis angustissimis longinsculis minute et remote papillosis areolata; perichatialia e.rferma multo lationa substricte, caeterm cantinis similia, ressus raginam sensim laxissime areulate, intima sffurmanformia lato-ovala acuminala pulchre pisen integra enervia tenerrima; theca in pedunculo crasso longinsculo apice arenato pendula orelo-rylindricu sulcata, operculo planiusculo; perist. duplex normale robustum.

sichwits. suppl. 111. 1. 2. t. 239. - Philonot is pendula Brill. II. p. 27. - Mnium pendulum sin. Trans. of Limn. Soc. WI. p. 262. Bryum pendulum Brid. Mant. Musc. P. 120.

Putriu. In sinu Dusky Bay Novac Seelandiac: Me nzies 1794. Insula Eremitac pr. Cap. Ilorn: J. D. Il o oker.

Areolatio Philonotis et forma folii Plicatellae, habitus $\boldsymbol{B}$. tomentosie.

33. E. Sieberi Inch. (in sich. Musc. Nov. Inoll. No. 13.); divicu; dense cespitosa, inter folia tomentosa erecta sublonga robusta, aureo-viridis; caulis fertilis strictus 
simplex vel longe infira florem ramis inaequalibus brevibus gracilioribus parce ramosus, apice romis compluribus brevissimis gemmiformibus discoideo-stellatus comosus; folia erecto-patentia, siccitate crispa, caulina patentidivergentia, e basi lata complicalo-concava erecta in subulam reflexam lanceolato-cuspidatam producta, margine ex maxima parte folii revoluto superne denticulato, nervo ferrugineo carinato-excurrente dorso scabro, undique e cellulis angustissimis minute et remote papillosis subflexuosis longiusculis aureis areolata; ramea basi magis ovato-dilatata vix reflexa; perichaetialia his similia, sed multo angustiora longiora lanceolata longe cuspidata acutissima excurrentinervia, basi parce plicata; theca in pedunculo elongato erecta ovato-globusa regularis perfecte sulcata.

B. pendula spreng. Syst. Veget. IV. 11. p. 323. - B. scoparia schw. Sp. Musc. p. 98.

Patria. Nova Hollandia; Sieber.

Operculum, peristomium et florem masculum non vidimus. Perist. forsan nullum? Fructum caeterum deciduum inter cespitem invenimus.

\section{Obscuriores.}

Mypnum consimile Hook. et Wils. (in sched. musc. antarctic.); simplex foliosum radiculosum, apice ramis 2 inaequalibus brevibus vel elongatis cauli commun simillime foliosis, flaccidis; folia caulina laxe imbricata patentia, e basi lata subovata utrinque ad marginem planiusculum e cellulis laxioribus quadratis amplis pellucidis latolanceolata, nervo subtenui in cuspidem brevem excurrente, margine erecto serrulato-denticulata, e cellulis angustis minutis inferne laevibus longioribus superne quadratis papillosis areolata, plicata.

Patria. Insula Aucklandi: J. D. Hooker.

Sectio III. Vaginella. Caulis dichotome ramosus, foliis e hasi vaginata laxe areulata erecta subito reflexis minute reticulatis. 


\section{a. Longipedunculatae.}

34. B. ithyphylla Brid. (Sp. Musc III. p. 85.); hermaphroditu; subpulvinata subhumilis radiculosa ramosa, ramis brevibus strictis dichotomis, laete viridis vel fuscescens; folia caulina erecto-patentia conferta breriorn, - basi breviore ungustiore tenera laxe anguste elongate et pellucide areolata superne dilatata et minus rotundute subito in subulan canaliculatam lanceolutum breviorem margine parce denticulatam et dorso papillis brevibus scaberulam minute areolatam producta, nervo lato viridi subulam superiorem totam fere occupante; perichaetialia sensim magis subulata; theca in pedunculo elongato temi innovatione laterali globosa basi subquadrata profiunde sulcula, e cellulis multo densioribus reticuluta, obliqua, operculo convexo-conico; perist. normale.

Brid. II. p. 43. - Br. Furop. Fase, XII. p. 11. t. 2. - B. romiformis Wahlenh. Fl. Lapp. p. 362.

Patria. Ad terram et rupes in montanis et alpinis per totam Guropam, Asiam et Americam borealem. Majo et Junio, Julio et Augusto in alpinis.

B. matenti proxima et notis cursive impressis distincta.

35. A. subulata Br. Europ. (Fasc. 31. Suppl. c. tab.); androgyna; purvula compucte cespitosa glanco-vividis, inferne valde tomentosa, pluries dichotoma; folia caulina conferta stricta erecta, siccitate appressa, e basi lata vaginante laxe areolata hyalina subito in subulam lanceolatam reflexiusculam minute reticulatam chlorophyllosam margine apicis grosse serrulatam tuberculoso-exasperatam producta, nervo excurrente vel cum apice evanido; perichactialia erecta ex oblongo-lanceolato subulata, basi pluries plicata laxius areolata tenuius nervosa; theca in pedunculo trilineari rigidulo tereti rubello erecta globosoorata paulisper striata microstoma, operculo minuto convexo-conico; perist. mullum, sed membrana capsularis ad orificium e cellulis transverse elongatis hexagono-rotundatis conformibus teneris areolata. $†$. 
Sul Glyphocurpare sectione 1. c. - Weis. virilissima Brid. I. p. 364. e spec, auth. forsan hue pertinet.

Putviu. In summo cacumine montis Gaisstein Pinzgaviae alp. Salisburg, altitudine 8000 ', legit W. l'. Sc h im per 1843. - Augusto et Seplembri.

Flos masc. gemmaceus juxta femineum. - Irabitus $\boldsymbol{B}$. ithyphyllae formac alpinae, notis cursive impressis facile discernibilis.

36. E. patens Brid. (Sp. Musc. III. p. 82.) ; hermuphrodita; laxe cespitosa subhumilis radiculosa ramosa, ramis brevibus strictis dichotomis, fuscescens vel viridis; folia caulina maxime patentia laxe dispositu longa, e basi elongate tenera laxe anguste elongate et pellucide areolata superne dilatata et valde rotundata subito in subulam canaliculatam elongute setucerm margine parce denticulatam et dorso papillis brevibus scaberulam minute areolatam producta, nervo lato viridi subulam superiorem totam fere occupante; perichactialia sensim magis subulata; theca in pedunculo elongato rigido innovatione brevi laterali globosa magna temiter membranacen larevis vix sulcalu, e cellulis maynis laxis mulche reticulatu obliqua, operculo convexo-manmillato; perist. normale, internum exteruo valde adglutinatum.

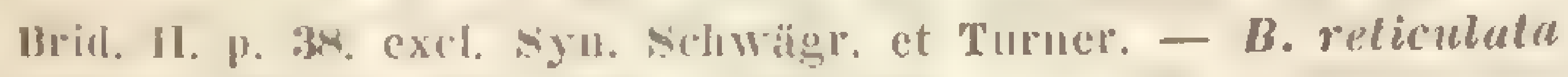
P. R. Prodr. P. 44 !

Putria. In freto Magellanico detexit Commersoll. Ex insulis vicinis Falklandi et Eremitac ad Cap. Horn retulit J. D. H o oker.

Antheridia maxima clavata, archegonia clongata angusta, paraphysibus longis acutis flavis numerosis cincta. - B. ithyphyllae similis.

\section{Non satis notae.}

37. B. Potosica Mont. (Ann. d. sc. nat. 1838. IX. p. 56. et in dorbigny Voyage p. 95.); laxe rohacrens stolonibus tenuissinis humilibus mixta, simplicissima, inferne tennis parce foliosa, apjecm rersus valde erescens, "pice truncuto-comosu; folia dense conferta crecto-ap- 
pressa, sicca et madefacta stricta, e basi elongate vaginata tenerrima anguste elongate et pellucide areolata superne parum dilatata igitur subruadrata subito in subulam sublongam lanceolatam aculam carnosam concuram, nerro lato puasi toto occupatam obscuram, dorso scaberrimum margine tenuissime serrulatum moducta, frugilissima.

Palrill. In jugis Andium prov. Potosi, ad rupes prope glacies aeternas: d'Orbign $\mathbf{y}$.

Species etsi sterilis, tamen memorabilis, ex habitu B. strictue, B. ithylhyllae autem quoad foliorum formam mag's affinis, notis illustratis facillime discernibilis.

38. I. robusta Ilook. et Wils. (in sched. musc. antarctic.); compacte (espitosa inferne tomentosa humilis, rumis brovibus gracilibus fastigiatis densissime ummorimatis vulde robustu frogilis; folia caulina crecto-patentia crispu, mulefuctu stricta frugilissimu, e basi latovaginata clongate laxiuscule tenuiter areolata superne dilatata sensim minntius reticulata in subulam lanceolatam

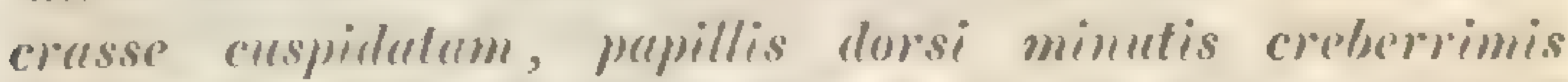

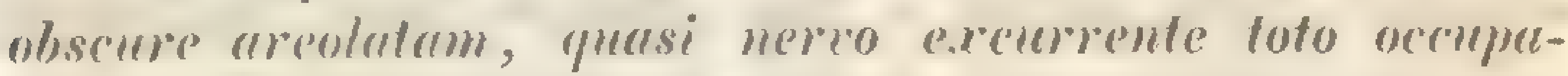
fum, canaliculatam margine papillis denticulatam plus minus flexuosam producta.

I'ulviu. Insula Aucklandi: J. D. II o oker.

Foliorum areolatio $\boldsymbol{B}$. Potosicae, habitus $\boldsymbol{B}$. ithyphyllae.

\section{b. Brevijedunculatae.}

39. F. Halleriana IIdw. (Musc. Frond. II. p. 111. 1. 40.); monoicu; laxe cespitosa mollis inferne tomentosa crecta clongata glancescens v. flavescenti-virilis, ramis lastigiatis $\mathrm{v}$. inaequalibus; folia caulina patentia rel subsecunda llexuosa, e basi subreflexa lato-oblonga lanceolato-subulata, versus apicem margine reflexa et dorso serrulata, basi elongate anguste tenuiter superne minute reticulata, nervo crasso excurrente; perichaetialia similia; thecae breviter pedunculatae subimmersae subglobosae 
parvac pallidae striatae geminatae in ramis lateralibus brevibus terminales, pedunculis subarcuatis operculisque conicis; perist. duplex: dentes externi lanceolati subulati integri trabeculati rubri, interni bartramioidei normales.

Br. Furop. Fase XII, p. 14. t. 5. - Brid. II. p. 33, - Webera Halleriuna Hdw, Fund, Musc, II. p. 95. - Web. clandestina ilbid. p. 104. t. 6. f. 39. - Mnium laterale Hoffm. Deut. Fi. II. p. 54.Bryum laterale F.h.h. Crypt. Wxs. n. 33. - Br. Norvegicum Oed. Fi. Wan. t. 538. f. 3. - Dir. pendulum FI. Dan. V. t. 835. f. 1. Br. recurevm Wulf, in Jacq. Coll. II. p. 224.

Putior. In montosis praecipue subalpinis, fissuras rupium prime quarzosarum cespitibus insignibus habitans per Europam totam. - Mujo, Junio et Julio.

Flos masculus in vicinia feminei vel infra, folis tenuioribus laevioribus, antheridis elongatis et paraphysibus flavis.

40. B. viridissimn C. Müll. (Linn. XIX. p. 202.); hermaphroditu; laxissime cespitosa; caulis crectus longiusculus mollis basi tomentosus laxissime foliosus, simplex r. basi ramosiusculus fertilis apice ramis nomullis comosus; folia caulina e basi oblonga brevi longissime subulata setacea, jam e basi ad apicem duplicato-dentata, dorso serratiformi-papillosa, apice supremo integra, amoene viridia, anguste et clongate reticulata, flexuosa erecto-patentia excurentinervia; perichactialia basi insigniter dilatata; theca sessilis erectu terminulis ellipticoglubosa mugna laevis pallida dein brunnea, operculo planissimo membranaceo hemisphaerico; perist. simplex: dentes lanceolati lacerati medio fissibiles brevi-articulati cartilaginei aurantiaci.

Cryptopodium Hookeri Hmp. Linn, XX. p. 75. - Leucodon bartramioides Hook. Ic. PI. Har. I. t. 71.

Putria. Columbia, Surrucucho prope Cuença: W. Jameson primus legit; prope coloniam Tovar Germanicam prov. Meridae, altitud. 5500 ped. legit Moritz 1845.

Antheridia maxima clavata; archegonia elongata, paraphysibus permultis cincta. 
41. B. brachypus Br. et Sch. (in Musc. Abyss. No. 441.); hermaphrodita; dense cespitosa inferne tomentosa ramosa, ramis densis strictis brevibus; folia caulina erectoappressa, madefacta patentia, breviora, glanco-viridia, e basi longiore multo laxius elongate areolata et superne dilatata subito canaliculato-subulata acuta, margine haud revoluto denticulata, dorso breviter papillosa, nervo viridi subulam minute reticulatam totam fere occupante; perichaetialia interna magis sensim subulata; theca in pedunculo brevi substricto vix exserta globoso-obliqua stricta, stomate minuto; perist. dentes extemi parie angusti lineari-lanceolati trabeculati, interni normales, sed perbreves.

Putriu. Abyssinia in monte alpestri Silke: W. Schimper, 16. Febr. 1940. L'n. it. Abyss.

A B. velcunicu proxima notis illustratis certe distal.

42. B. vuleaniea Brid. (II. p. 3\%); hermaphrodita; ramosa, ramis densis strigosis, radiculoso-tomentosa sublumilis superne lutescens inferne ferruginea; folia conferta strictu patentia longa, e basi oblonga superne latiora subentricosa inferme plaminscula subiaginata elongute laxe areolutu subito subulata acutissima setacea, minute reliculata, nervo lato ferrugineo subulum cumaliculalum totam fere occupante praedita, margine hand revoluto et dorso denticulatu; perichaetialia sensim subulata; theca in pedunculo brevi subarcuato paulisper exserta globosa pseudolateralis striata, operculo convexo mammillato.

B. giguntea Bory st. Vincent. Voy, ell Afriq. III. p. 96. - $\boldsymbol{B}$. putens sichw. suppl. 1. 11. p. 5̆. t. 62. - B. syuarrusa Turn. in Konig et sims Ann. Bot. I. p. 329. t. 2. f. 2?

Patria. Insula Bourbonis, in crateribus montium ignivomorum, ex. gr. in Kamonde crat. ad 800 hexapodum et Piton des Neiges ad 1103 altitudinem cespitose vigens: Bory St. Vincent.

Species pulcherrima, ex habitu B. Hulleriunue haud dissimilis, sed notis cursive impressis distinctissima.

c. Muller: Synops. musc. frond. 
Fructus imperfectus. Antheridia crassa clongata una cum archegoniis paraphysibus numerosis flavis cincta.

43. D. Iongifolia Fook. (Musc. Exot. t. 68.); cespitosa; caulis erectus elatus flexuosus sacpe ramosus; folia sordide viridia arcte imbricata patentia, longissime subulutu setacer flexuosu, busi breviter vugimutu, nervo crasso subulam superam totam occupante obscuro, margirie supra basin tenuissime serrulata; theca in pedunculo brevi ob innovationem saepe laterali inclinata, e collo brevissimo globosa magna sulcata microstoma, operculo conico obtuso. $t$.

Brid. II. p. 39.

Patria. In devexis udis frigidis montis Quindiu (Cordillera de los Andes de Cundinamarca), altitudine 1400 hexapodum, graniti habitans: II u $\mathrm{m}$ boldt et B on pland.

B. pomiformi haud dissimilis, sed foliis raginatis longe distat. $B$. putenti proxima.

44. I. Mülleri Mont. (in litteris!); dioica? dense cospitosa; caulis elatus teretinsculus recurvo-fexusus, apice comoso incurvato, inferne tomentosus, albido-viridis; folia caulina erecto-appressa superne falcuto-secunda, e basi elongato-ruginata albida pellucida laxiuscule elongate anguste et tenuiter reticulata superne dilatata subito latiuscule canaliculate et elongate subulata acuta, margine haud revoluto sensim urgute serrutu, ad subulae minute reticulatae dorsum papillis densis brevibus scaberrima, nervo crasso excurrente viridi subulam totam fere occupante; perichactialia sensim magis subulata; theca in pedunculo brevi pseudolaterali globosa crassa obliqua profunde sulcata, operculo hemisphaerico conico; perist. duplex normale magnum.

B. Potosira ('. Müll. Linn. XIX. p. 204 et Hmp. Linn, XX. p. 76. - B. patens IJock. in Kunth symops. Pl. Aeq. P. 55.

Putrie. Columbia, Sierra Nevada prov. Meridae: Moritz No. 187. b. In sylvis Cinchonarum editioribus Americae meridionalis prope Loxam primus legit II $\mathrm{m}$ bold $\mathrm{t}$. 
Archegonia elongata, paraphysibus longissimis breviarticulatis clavatis flavissimis numerosis mixta.

Sectin IV. Eubartramia. Caulis dichntome ramosus, foliis strictis erectis, nec vitginatis, nec plicatis, minute areolutis.

\section{A. Crisputce.}

\section{a. Longivedunculatue.}

45. B. pomiformis IIdw. (Sp. Musc. p. 164.); undrogyna; late et pulvinato-cespitosa glauco-virilis vel lutescens inferne tomentosa longiscens dichotome ramosa, ramis fastigiatis substrictis; folia caulina erecto-patentia crisputa conferta lanceolato-subulata, margine revoluto sensim argute serrata, canaliculata, dorso serrulato-scabra, nervo excurrente subtenui praedita, minute basi sublongius sed deuse areolata; perichaetialia angustiora; theca in pedunculo elongato pseudolaterali flexuoso globosa obliqua profunde suleata, operculo conico; perist. normale.

Brid. II. p. 39. - Br. Kurop. Fuse. XII. p. 13. t. 4. - B. rulgaris ller. HI. Franç. I. p. 509. - Webera pomiformis Haw. Hund. Musc. 11. 1. 95. - Bryum capillaceum, capsulis sphateris. 1 ill. Musc. p. 339. t. 44, f, 1.

ß. crispa; major, foliis longioribus remotioribus, ramis thecas saepe superantibus gracilibus. Br. Kurop. I. C. 13. (rispa sw. Musc. suer, p. 73. - Brid. 11. p. 41. - B. pomiformis $x$ major Musc. Brit. p. жă. - B. Hercynicu flörke in sihnad. But. Journ. 1799. 11. p. 71. - B. incurca Hoppe in stirm fil. Germ. Crypt. Fasc. 6.

$\gamma$. heteromalla; maxime crispata foliis subsecundis. B. heteromalla Brid. II. p. 42.

Putriu. Ad terram et rupes per Europam totam vulgatissima, in Asia et America septentrionali. Var. $\beta$. in rupium fissuris humidis regionis subalpinae et alpinae; Var. $\gamma_{0}$ in America sept. - V'ere et aestute.

Flores masculi et feminei plures terminales approximati. Folia perigonialia loriformi-angusta linearia paura, superne serrata. Antheridia pauca paraphysibus nonnullis mixta. 


\section{b. Brevipedunculatae.}

46. B. Jamesoni Tayl. (Iondl. Journ. of bot. 1847. p. 334.); laxe cespitosa crecta dichotome ramosa binncialis gramineo-viridis, caulibus upice incressutis; folia arcte imbricata elongata, sicca tortilia, ex subulata amplexante basi linearia acuminata celluloso-subserrulata, nervo in cuspidem distincte excurrente; theca axilluris sessilis erectu rotundato-oborata laevis; perist. simplex internum: dentes in membrana pallida crassa infra orificium enata lanceolati acuminati medio longitudinaliter linea exarati interdum perforati. $t$.

Putria. Monte Pichincha Andium Quitensium: W. Jameson. Nov. 1816.

B. Ilalleriunce affinis, sed brevior, ramis incrassatis, fuliis longioribus, theca sessili et peristomio. longe differre dicitur.

\section{B. Rigidae.}

\section{a. Longipedunculatae.}

47. B. strieta Brid. (Mant. Muse. p. 116. et Bryol. Univ. II. p. 45.); hermuphoditu; compacte cespitosa humilis dichotome ranosa, ramis aequalibus strictis, glancoviridis inferne zonato-coloruta subferruginea vel lutea; folia caulina erecto-appressa, madeficta paulisper patentia, e basi lato-oblonga lanceolato-subulata acuta strictissima, margine e basi folii veroluta integra, superne ad subulae marginem et dorsum serrata, ubique minute areolata, dorso papillis hrevissimis scaberula, nervo crasso viridi excurrente; perichaetialia similia hasi latiora, tenuius et Iongius areolata; theca in pedunculo elonguto terminali vel innovando laterali subglobosa stricta, busi subquadrato-obtusu, operculo convexo mammillato; perist. simplex extermm: dentes lanceolati brees hinc inde pertusi.

Br. Furnp. Fase. XIl. p. 10. t. 1. - Sirlwitgr. Suppl. 1. II. p. 58. t. 60. - B. strictifolia Tayl. Lond. Journ. of bot. 1846. p. 54; ex obs. Cl. Wilson 1.c. p. 451 lue pertinet. 
Patrie. Ad terram et rupes prime viarum cavarum Italiae vulgatissima, Siciliae, Sardiniae, Hispaniae, ubi in Pyrenaeis et Monte Serrato 1803, serius in Apenimnis, primus legit Bridel. Ex Africa septentrionali retulit Desfontaines. Ad firetum Magellanicum: Commerson in Hb. Brideliano. E Nova Hollandia ad Swan River a J. Drummond lect. accepit 'I'aylor.

Antheridia maxime clavata, archegonia angusta, paraphyses numerosissimae.

48. B. compacta IIsch. (Hor. Phys. Berol. p. 63. 1. 53.); hermaphrodita; compactu lemillima ramosa, ramis brevibus strictis dichotomis, apice glauco-viridis inferne ferruginea; folia caulina sicea et madefacta erectoappressa parva stricta, lanceoluto-subulutu basi plus minus ovata, ad marginem superiorem plerumque reflexum serrulata et dorso superiore scaberula, nervo crasso viridi excurrente, ubique minute subquadrate viride areolata; perichaetialia similia; theca in pedunculo terminali vel imnovando laterali brevi subylobosa vegularis minuta precta glabra fuscescens gymnostoma, operculo minute conico.

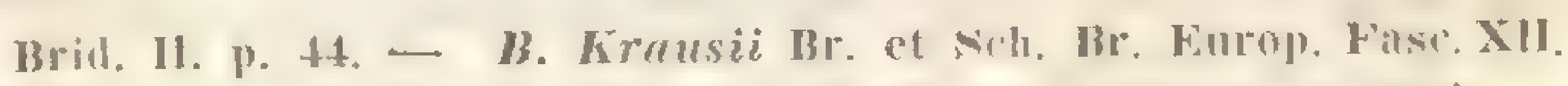

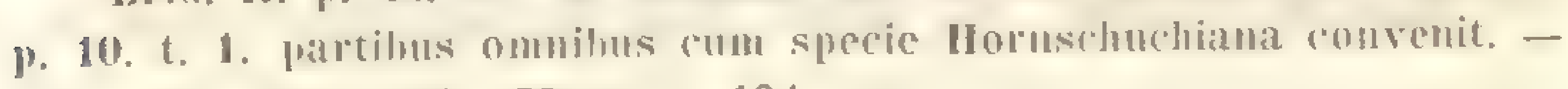
B. stricta schw. \$p. Musc, p. 104.

Patria. Promont. bonac spei, in monte Leonis arborum cortices habitans: Bergius; ad terram humidam in umbrosis serius legit in promontorio Dr. Krauss 18:38. Julio.

Paraphyses et antheridia pauca parva. B. strictue ex habitu aliquantulum affinis, sed notis illustratis species distinctissima et tenella.

49. B. incana 'Tayl. (Lond. Journ. of bot. 1848. p. 189.); divica? uncialis cespitosa dichotome ramosa abbreviata crecta intense olivacea, junior viridis, ramis subdivaricatis; folia arcte imbricata crecta, fam unadore quam siccitute stricta, triangulari-lanceolata acuminata subserrulata, apice diaphano incano; theca in pe- 
dunculo axillari caulem superante erecta oblongo-rotundata striata; perist. duplex: dentes externi truncati. $T$.

Patria. Monte Pichincha Andium Quitensium: IV. J a mes on.

Ex animadr. auctoris $B$. strictue affinis, sed foliis incanis margine haud reflexis et theca majore erecta differre dicitur.

50. I. ambigun Mont. (Ann. d. sc. nat. 4. 18tŏ. p. 103.); dioice; laxe cespitosa subhumilis erecta dichotome ramosa, ramis aequalibus strictis, sordide viridis; folia caulina conferta erecto-appressa apicibus pulisper fulcuto-reflexu, madefuctu patulo-rccurra, e basi ampliate oeutu oblongo-subulatu elongata, margine e basi ultra medium revoluto superne serrulato et apice serrato, dorso scaberima, concava, nervo crasso viridi dorso serrato excurrente, ubique minute areolata; perichactialia basi elongate anguste dense reticulata subplicata; theca in pedunculo elongato inuovando laterali erectu perfecte glubosa regularis profunde sulcata, operculo convexo hemisphaerico; perist. simplex breve: dentes externi lineures angusti irregulares cortilaginei fusci.

Patria. Chile, in terra nuda et ad rupes prope $\mathbf{S}$. Jago et in Chile australiori: C. G a y et Pöppig.

Ilabitus B. ithyphyllue et strictue; ab illa jam differt ex foliorum forma, ab hac notis ceteris cursive impressis.

51. H. sericen IIsch. (Hor. Phys. Berol. p. 63. t. 13.); hermaphodita; denso cespitosa humilis ramosa, ramis strictis dichotomis brevissimis, glauce vel luteo-viridis; folia caulina stricta erecto-appressa madefacta paulisper patentia, e basi latinscule lanceolute, nervo crasso in ccumen breve crossum moducto, ad marginem erectum superne dentata, dorso vix scubra, undique e cellulis quadratis densis minutis areolata; perichactialia similia; theca in pedunculo elongato substricto globosa crecta regularis basi subquadrata sulcata yymonostoma macrostoma, operculo minute conico. 
Glyphocarpa Capensis R. Br. Trans. of Limm. Soc. XII. p. 575. Glyphocarpus Capensis lirid. 1I. p. 91. - Nohwiiglt. siupl. 11. p.98. t. 128. - Gymnostomum Capense Hok. Musc. Fxot. t. 165.

Putria. In prom. b. spei rulgatissima, terram et arborum corticem habitans: Bergies primus legit. - Julio ad Noubr.

Antheridia parva, paraphysibus acutis paucis flavidis mixta. - B. strictae similis, sed notis illustratis longe differt.

52. B. quadrata Ilook. (Musc. Exot. t. 132.); dioica; laxe cespitosa erecta flexuosa elongata superne ramosa, inferne praecipue tomentosa; folia caulina sparsu erecta, e lineari longe acuminata planiuscula subtiliter serrata, basi subintegerrima, amocne viridia basi ferruginea, e cellulis subtilibus linearibus areolata, nervo valido ad apicem tenuiore pertingente ferrugineo; perichaetialia interiora sensim minora basi badia; theca in pedunculo elongato erecta v. inclinata, e conico globosa irregulariter anguluta, interdum fere quadrangula, medio contractu, mudu, sicca valde sulcata, microstoma, operculo planiusculo mammillato, centro impresso. †.

Gl!yhocarpus quadratus Brid. II. p. 92. - Glyphocarpa quadrat "s.chw. Suppl. II. I. p. 94. t. 128. - Gymnostomum quadratum Hook. Musc. Exot. t. 132.

Patria. In saxis humectatis umbrosis, ad scaturigines, in cacumine montis altissimi l'ostberg dicti, prope pagum Georgii in regione Anteniqualand prom. b. spei: Burchell.

Flos masc. terminalis capituliformis, foliis 4-6 ovatoacuminatis brevibus enervibus badiis. Antheridia ovatooblonga, paraphysibus subclavatis mixta. - Species quoad thecae formam ab omnibus congeneribus primo adspectu distinguitur.

\section{b. Brevipedunculatae.}

53. B. intertexta schimp. (B. [Glyphocurpal in IH. Schlechtend.); divica; latissime cespitosa subprostrata, tomento fusco inferne intertexta, cmoche lutescens, ra- 
mosa, ramis perbrevibus teretibus curviusculis attemutis; folia caulina erecto-appressa, madefacta erecto-patentia longa, lanceolato-subulata acutissima stricta, margine toto fere revoluto et minute serrulato, dorso valde serrulato-papillosa, e cellulis ubique aequaliter mimutissimis, densis firmis rotundatis areolata, nervo crasso viridi in acumen serrulatum producto; perichaetialia teneriorcl longius setacen integra laevia; theca in pedunculo inter ramos duos posito perbrevi cygneo globoso-elliptica, siccu ore subcoarctata, magna laevissima marpurascens nitida gymnostoma, ore purpureo-anmulato, teniter membrunacea exserta, operculo hemisphaerico.

Gymnostomum setifolium Hook. Ic. Pl. Rar. II. t. 135.

Patria. Nexico: C. E hrenberg. Peru pr. Huamantantga: Mathews.

Flores masculi in plantis propriis subsimplicibus intertextis cespites proprios efficientibus terminales gemmiformes crassiusculi ob innovationem perbrevem laterales fusci. Folia perigonialia e basi maxime concava latoconvolutacea margine paulisper denticulata tenuius arcolata subito in subulam reflexam flexuosam subcanaliculatam parce denticulatam producta laevia. Antheridia maxima crassa superne attenuata curviuscula, paraphysibus tenubus aureis acutis mixta. Vagina pedunculi lutei altitudinem aequans crassa fusca. - Species pulcherrima et nulla alia confundi potest. $B$. I'ebbii proxima est.

54. B. Webbii C. Müll.; dioica; procumbens subpulvinata sed laxe cohuerens ruliculosa, pluries dichotome ramosa, ramis brevibus una cum caule teretibus attenuatis, lutea inferne feruginea; folia caulina dense conferta erecto-appressa, e basi subovata lanceolato-subulata robusta, margine revoluta serrulata, dorso scaberrima, undique e cellulis minutissimis densis yuudratis arcolata, nervo crasso in acumen robustum excurrente; perichaetialia angustiora longiora laeviora longius reticulata teneriora; theca in pedunculo recto brevissimo inter ramos duos breves posito subexserta pachyderma glubosa 
tandem urceolata aequalis lacvis erecta, gymnostoma, operculo, hemisphacrico depresso mammillato.

Glyphocarpa Webbii Mont. in Ann. des sc. Mat. 183N. IX. p. 56. et in Hist. des Iles Canar, p. 28. t. 2. f. 2.

Patria. Insula Teneriffa, ad summam vallem Orotaviensem in fissuris rupium, quas incolac los Organos dicunt, nec alibi: Webb.

Calyptra ex auctore conica mitraeformis (?) subventricosa, margine repando v. integro, glabra. Flos masc. ignotus. - $\boldsymbol{B}$. intertextcre proxima, sed multo robustior longius radiculosa, haud tomentosa intertexta, theca pachyderma in pedunculo recto posita globosa.

55. M. Menziesii Turn. (in Konig et Sims Ann. Bot. I. p. 225. t. 11. f. 1.); dioica; elonguta erectu Rexuosu flaccida mollis sericea pare et dichotome ramosu, inferne tomento dense obsita; folia arcte imbricata crecta appressat stricta flavo-viridia, e basi lanceolata margine reflexa longe subulata, apicem versus denticulata, nervo crasso continuo, undique e cellulis subquadratis areolata; perichactialia interna longissime subulata; theca in pedunculo innovando laterali brevi erecta globose regularis laceris, operculo convexo lato-mucronato; perist. mullum? †.

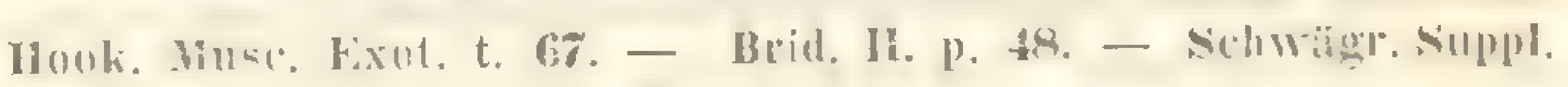
111. 1. 2. t. 260.

Putria. In plaga occidentali Americac borealis: Menzies 1792.

Ex animadr. Hookeri B. gracili ex habitu similis, ex iconibus autem magis ad $\boldsymbol{B}$. intertextam accedens.

56. H. affinis Ilook. (Nusc. Exot. t. 176.); divice; clongata erecta flexuosa dichotome ramosa, inferne tomentosa, fusco-lutea; folia caulina undique imbricata erecto-patentia stricta, ovato-lanceolata, nervo crasso subferrugineo in cuspidem longam crassam producta, margine (tenuiter reflexa?) incrassata denticulata, c cellulis minute quadratis basi utrinque ad marginem amplioribus areolata; perichactialia intima minora et angustiora; theca 
in pedunculo brevi apice arcuato peudula sphaerica ampla brevis macrostoma sulcata; perist. duplex (destructum). $f$.

Brid. Il. p. 49. suh alio nomine B. Brovinei, quum nomen, ex sententia Bridelii vera, vix satis idoneum sit. - schwägr. suppl. III. I. 2. t. 237.

Patriu. Insula Van Diemen: R. Brown.

Ex animadv. II ookeri primo intuitu B. Mensiesii similis, sed foliis brevioribus latioribus patentioribus et notis ceteris datis distat. Schwägrichen $\boldsymbol{B}$. fontunue proximam habet. Planta mascula gracilior, flore terminali discoideo. Folia perigonialia late ovata acuta obsoletinervia, inferne gibbosa i. e. basi erecta inde patentia, aurantiaca. Antheridia longa, paraphysibus numerosis breviter articulatis obtusiusculis pallide flavescentibus.

57. B. Abyssinica C. Müll.; divica? dense cespitosa humilis dichotoma, ramis aequalibus strictis, glauco-viridis; folia caulina erecto-appressa, madefacta crectopatentia, e basi orata concava lanceolato-subulata acuta stricta et puelisper fulcutu, margine ad medium folii paullo revoluta integra, superne ad subulae marginem et dorsum serrata, basi minutiuscule dense superne minute areolata, dorso papillis brevissimis scaberula, nervo crasso viridi excurrente; perichaetialia similia longius areolata; theca in pedunculo brevi stricto ob innovationem laterali exserta globosa, operculo parvo hemisphacrico aurantiaco et stomate nudo.

Glyphocarpa Abyssinica Hmp. hb.

Putria. Abyssinia, inter muscos alios Schimperianos collegit II a m pe.

Florem nasculum in ramis fertilibus frustra quacsivimus. Archegonia copiosa paraphysibus mumerosis llavis mixta. B. strictce simillima, sed notis datis lacile discernibilis.

58. M. Inevisphaera C. Müll.; caulis larp cespitosus semiuncialis brunnco-olivaceus erectus subramosus; folia imbricata valde rigida, madefactu patenti-vecurve 
secunda, lanceolato - subulata longe setacea serrulata, margine reflexa excurrentinervia; theca in pedunculo perbrevi subexsertu erecta sphaerica laevis; peristomium: membrana brevissima ammularis. t.

Glyphocarpa laevisphaera Taylor. Lond. Journ. of bot. 1816. p. 56.

Patria. In monte Pichincha Andium Quitensium: WV. Jameson. Septbr. 23. 1826.

59. B. subsessilis Tayl. (Iond. Journ. of bot. 1817. p. 331.); subcespitosa erecta subsimplex, inferne brunnea superne amoene viridis; folia arcte imbricata subsecunda, ex oecuta basi subulato-setuceu, margine reflexa denticulata, siccitale stricta rectiuscula; theca in pedunculo brevissimo subexserta erectiuscula spharerica estriata, operculo minuto; perist. nullum? t.

Patria. Monte Pichincha Audium Quitensium: W. Jameson. Novbr. 1816.

B. II alleviance affinis, pedunculo breviore, foliis strictioribus angustioribus.

60. E. Cryptopodium C. Müll.; divica; caulis erectus elongatus, inferne demulatus, rersus upicem incrussatus, simplex v. dichotomus robustissimus; folia caulina undique imbricata sparsa erecto-patentia, linceri-subulata setacea parum falcata longissima rigida carinata, firsco-rividia $r$. ru/o-fusca, margine erecto et ad nervi ferruginei crassi excurrentis dorsum serrata, e cellulis undique subrotundis minutis areolata; perichactialia paullo ninora; theca in pedunculo brevissimo parum curro immersa late ouata erecta fusco-flarescens luevis terminalis; perist. duplex praegrande: dentes externi lanceolatoacuminati rubri transversim striati intus denticulati, margine pellucidi flavescentes, interni longe lanceoluti ulbidi, lacinies comnatis hand divergentibus, medio, pro more Bryi, lacunosis, cilis elongatis $1-2$ interpositis. $\div$.

Cryptopolinm bartramioides Brid. 1I. p. 31. - Cryptop. Bartramia silowägr. Ap. Muse. 1830. 1. 90. - Bryum bartramioides Honk. Must. Exot. t. 18. - Bryum Bartramia schw. Suppl. II. 11. p. 25. t. 160 . 


\section{Patria. In sinu Dusky Bay Novae Seelandiae: M e n-} zies 1791. In insulis Sandwicensibus: Gaudich a d.

Pl. mascula dichotome ramosissima, floribus terminalibus creberrimis terminalibus crasso-genmaceis. Folia perigonialia ovata acuta solidinervia. Antheridia numerosa, paraphysibus filiformibus tenuibus mixta. - Species memorabilis, habitu aliquantulo $B$. viridissimae theca terminali immersa et statura robusta similis, sed foliis eraginatis longe distat. Cryptopodii genus delemus; nam peristomium ab illo Bartramiae lacinis semper connatis haud divergentibus differt, utrumque autem est perist. Rryi; aliud (Bartramiae) sectionis Acidodontii, aliud (Cryptopodium) sectionis ITeberae. Peristomia igitur typice non divergunt.

sectio V. Oreadella. Caulis fastigiato-ramosus, foliis lanceolatis ut in Weisiis complicato-carinatis, nervis carinatis percursis, margine maxime revolutis, quadrate weisioideo-areolatis, sublaevibus.

62. H. gracilis Flörke (in Schrad. bot. Journ. 1799. II. p. 171.); hermaphrodita; lata et laxe cespitosa clata gracilis inferne radiculosa viridissima v. sublutesens vage ramosa, ramis inaequalibus fastigiatis; folia caulina laxe disposita erecto-patentia falcato-recurva, lanceolata complicato-carinata, margine e maxima parte folii valde revoluta, apice et dorso nervi carinati excurrentis simpliciter serrata, laevia, e cellulis minutis quadratis densis, utriculo primordiali viridissimis, areolata; perichactialia similia, sed basi e cellulis elongatis angustis plus minus laxis tenuioribus reticulata; theca in pedunculo substricto elongato globosa obliqua parva, sicca profunde sulcala, operculo conico acuto parvo; perist. B. pomiformis.

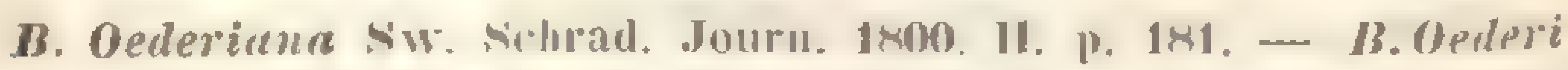
schwigr. suppl. 1. II. p. 49. t. 59. - Brid. II. P. 46. - Br. Nurop. Fasc. XII. p. 12. t. 3. - Bryum Oederi (imm. Nil. Norv, 1. 100.) Bartr. grandifora schwitgr. Suppl. 1. II. p. 4\%. t. 54. - B. pomiformis sulliv. Musc. Allegh. No. 121. - B. longiseta Brid. Mitnt. Musc. p. 116. - B. subintegrifolia P. B. Prodr. 1. 4. 
B. tomentosa; humilior compacte tomentosa gracilior.

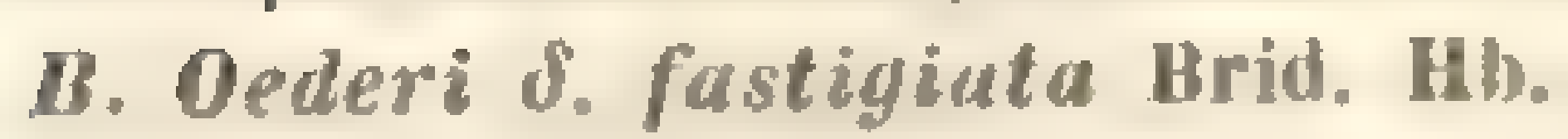

Patria. In rupibus humidis praesertim calcareis per subalpina et alpina totius Europae et Americae septentrionalis. Var. $\beta$. in alpibus. - Majo ad Augustum.

Species distinctissima et foliorum forma habituque animum ad Oreadem Murtianam referens, solitaria.

\section{Gen. V. Oréas Brid.}

Br. univ. I. p. 3๕0. - Catoscopium Hïh. - Weisia Hsch.

Nomen ab auctore a graeca voce ópos (gen. ö́øоs) mons ductum est: melius autem ab Oréus (montis Nympha) derivatur. Nomen ante illud Chamissoanum synonymum prioratum tenet.

Calyptra cucullata. Peristomium simplex: lentes 16 lato-lanceolati, linea media carentes, intus lamellato-articulati, tenues laevissimi plani, interdun hic illic perforati, amoene aurantiaci, Longitudinaliter striati, malefacti horizontales, sicci ererti. - Theca e collo globosa bartramioidea regularis sulcata exannulata. Habitus caulis weisioidens, B. gracilem in memoriam redigens et Catoscopio similis.

1. D. Martiana Brid. (l. c. p. 383.); monoica; late et dense cespitosa, inferne tomentosa et arcte cohaerens, erecta elongata gracilis lutescens dichotome ramosa, innovationibus fastigiatis; folia octosticha sublaxe imbricata erecto-patentia parva, siccitate crispula, lanceolata stricta carinata, nervo excurrente, margine parum revoluta integerrima, ubique e cellulis quadratis leptodermis subpapillosis areolata; perichactialia longius et acutius cuspidata, basi longius et tenuius reticulata; theca in pedunculo brevi cygneo-curvato nutans v. plus minus erecta parra sulcata nitido-rubra, operculo conico-rostellato obliquo.

Br. Furnp. Fase. XII. Oreas, p. 4. c. tah. - Catoscopium Martianum Hül. Muscolog. Germ. p. 153. - IVeisia Martiana IIsch. Flora 1819. 1I. p. 86. 
Patric. In alpibus Tirolis, Salisburgiae et Carinthiae: Windisch-Mattreyer Tauern: Hornschuch detexit, Pasterze: Hornschuch, Funk, in schistosis apricis am Gaisstein im Pinzgau 6000': Sauter. E rarioribus. Aestate.

Flos masc. terminalis, dein innovatione feminea lateralis minutus triphyllus. Folia perig. ovato - lanceolata obtusa. Antheridia pauca parva, paraphysibus paucis tenuissimis mixta.

\section{Gen. VI. Catoscopium Brid.}

Br. univ. I. p. 368. - Weisia Hdw. - Grimmia S'm. - Bryum Dicks. - Melania Brid. olim.

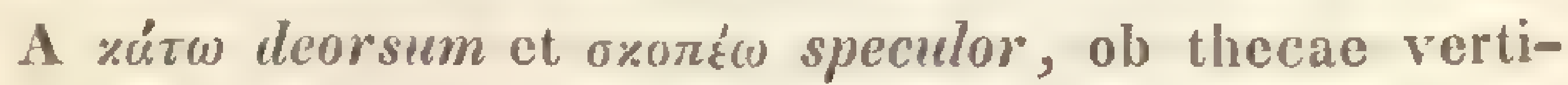
cem deorsum spectantem.

Calyptra cuculliformis parvula. Peristomium simplex: dentes 16 brevissimi truncato-lanceolati difformes inaequales transverse articulati, linea media exarali, albidi mgulusi rigidi suberecli. Theca c collo inclimato globosa parva discelioidea nitida brunnea dein nigrescens pachyderma subcornea exannulata lacvis. Habitus caulis in Oreadem inclinans.

1. C. nigritum Brid. (1. c.); divicum; late et dense cespitosum, inferne tomentosum, sed laxius cohaerens, crectum elongatum gracile lutescens vage et dichotome ramosa; folia caulina octosticha laxe imbricata erectopatentia parva, lanceolata stricta carinata, nervo excurrente, margine parum revoluta, integerrima, ubique e cellulis quadratis pachydermis laevibus areolata; perichaetialia longius et acutius cuspidata, basi longius areolata; theca in pedunculo elongato erecto rigido dextrorsum torto purpureo apice in collum incrassato inclinata exannulata.

Br. Kurnp. Fass. XII. Orendene Catoscopium, p. 4. c. tall, Weisia nigrita IIdw. Musc. Frond. I11. 1. 97. t. 39. - Grimmia nigritu sm. Fl. Hrit. HI. p. 1195. - Bryum nigritum Dichs. Fasc. III. PI. Crypt. p. 9. 
Patria. In rupibus irrigatis et pratis spongiosis ad alpium latera totius Huropae, rarius in planitiei turfosis et in America septentrionali, ubi in Rocky Mountains turfosa loca copiose habitat: Drummond. 'Terra Nova insula: La Pylaic. - Junio et Julio.

Pl. mascula femineae similis, flore terminali gemmaceo fusco. Folia perigonialia lanceolata stricta, basi magis concara tenuius reticulata. Intheridia pauca crassa, paraphysibus paucis tenuibus pallidis obtusiusculis mixta.

Genus incertum.

\section{Plagíopus Brid.}

in Br. univ. I. p. 596. - Burtramia seringe 1. c.

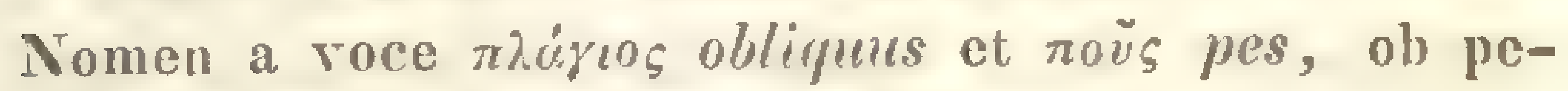
dunculum thecae oblique insertum, ductum.

Calyptra dimidiata? Peristomium duplex. Exterius: dentes 16 lanceolati acutiusculi aequidistantes. Interius: cilia totidem erecta, filiformia, cum dentibus alternantia, iisque subaequalia articulata pallida.

Ex ic. Brideliunis Bartramiae fructum habet, sed specimina ejus herbarii carent, quare de peristomii structura referre non possumus. Ex habitu, forma et areolatione folii ad $\boldsymbol{B}$. gracilem accedunt.

PI. serratus Brid. (I. c.); divicus; gracilis, erectus, dichotome ramosus, inferne valde tomentosus; folia conferta erecto - patentia, oblongo-lanceolata plus minus complicato-concava, carinata, margine reflexa flexuosa, superne denticulata et apice serrata, e cellulis quadratis pachydermis sublacvibus areolata; perichactialia magis comosa longiora; theca in pedunculo ob innorationem saepe laterali erecto stricto semunciali erecta, irregulariter e ventricoso ovata, lacris, e lutescente fuscidula, operculo brevi conoideo obtuso, thecae concolori.

Patria. In uliginosis alpium Helvetiae densissime cespitosa habitat: Seringe 1822 ad Bridelium misit. 
Optandum est, muscum hunc semel tantum lectum mox iterum reperiri.

Trib. XIX.P O'T'II OIDEA E.

Cespitosae raro gregariae, plus minus elatae sacpe humillimae, graciles v. robustae, simplices $v$. ramosissimae, acrocarpicae $\mathrm{v}$. ob innovationes pleurocarpicac. Folia lanceolata, ovata, rotundata, spathulata v. Ioriformia, carinata, complicata v. planiuscula, stricta $v$. reflexa, nervis teretibus instructa. Retis cellulae parenchymalicae perfecte hexagonae $v$. quadrate hexagonae, basi semper laxiores saepe laxissimae, plus minus pellucidae saepe maxime hyalinae amplae fragiles vigidae foraminatae, superne papillis solitariis $v$. pluribus confluentibus, igilur saepe truncatis apice tuberculosis, in medio cellulue positis, plerumque chlorophyllosate, raro utriculo primordiali pracditae, sacpe minuissimae et incrassatae. Theca erecta rarissime inclinata, ovalis, elliptica v. pyriformi-oblonga, laevis v. striata, operculo plerumque conico v, rostrato. Archeenonia et antheridia normalia, paraphyses plerumque filiformes.

Iabitus distinctus nullus quidem, sed e foliorum areolatione inter sese intime cohaerentes plantae.

Putria. Regiones omnes orbis totius terrarum.

Subtrib. I. CAL Y M E R A EA E.

Cellulae folii hasilares rigidae lygalinae sape fragilissimac plus minus amplac inanes, distincte foraminatae.

Putria. I'sque ad nives acternas per orbem totum terrarum, sed Enculyptue hemisphaeram borealem prime amantes, Calymperes et Syrrhopodontes meridionalem solam praeferentes. 
Plantae perfecte pottioideae, hic illic Lencophanis congeneres imitantes, subtribum maxime naturalem formantes, a Polliaceis nec foli areolatione, nec ulla nota alia typice recedentes.

\section{Gen. I. Encaly'pta Schreb.}

Gen. PI. 1. 1613. - Leersia IIdw. - Bryum, Mnium antiq.

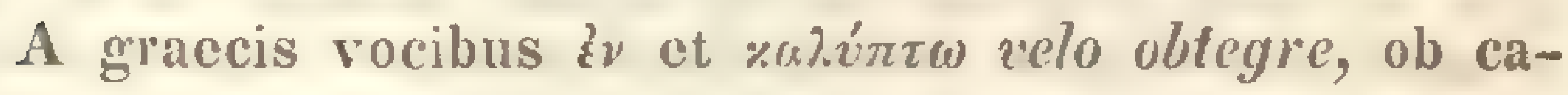
lyptrac totam thecam amicientis indolem.

Calyptra longe cylindrico - campanulata, superne operculi instar clavellate angustata, thecam superans firma, basi integra, lacerata v. ciliata. Perist. nullum, simplex r. duplex; externum: dentes 10 lancerlati v. longe subuliti ciliformes, plerumpue linea longitulinali exarati rubentes rugubsi; internum: membrana tencra dentibus adglutinata in cilia deatibus opposita s. interposita jpoducta.

Habitus calyptra excellentissime efformala proprius, e folis involuto-tortuosis Hyonhilis similis, cellulis autem basilaribus folii perfecte calymeroidcis ab is distans. Folia basi e cellulis maxime pellueidis rectannulari-hexagonis flerumque rigidis fragitibus, pariedibus teneris pallidis, dein rubentibus praeditis, superne groske rotundatis maxime sarpe truncato-papillosis areolata, opaca. Nervis basi purpureus superne flarus crassus.

Sectio I. Pollotheea. Theca whan estriata.

\section{a. Peristominm nullum.}

1. E. comunitata Nees et IIsch. (Br. Germ. II. p. 46. t.15.); monvica; pierumque elongata vahle dichotome ramosa ubique radiculosa; folia caulina erecto-patentia, patula v. squarrulosa, orato-lenceolulu cictminatu, nemo in. chsplidem plus minus elongulam moductu, concara subundulata, basi e cellulis multis laxis erythodermibus reticulata margine cellulis multis angustioribus flavidis limbata, superne minutius ureolatu, maxime opaca, te- 


\section{STEGOCARPI. ACROCARPI. ENCALYPTA.}

nuius papillosa, hand revoluta; perichaetialia similia; theca in ped. longiusculo purpureo erecta, subcylindrica, basi aequalis, laevis v. senectute striis rubentibus, haud sulcata, simpliciter annulata, operculo longe subulato recto; calyptra basi aequalis $v$. lacerata haud ciliata superne glabra.

Br. Europ. IV. p. 8. t. 1. - E. affinis Schw. suppl. I. I. p. 68. t. 16. - Brid. I. p. 143. - E. alpina Wahlenb. in Fl. Lapp. p. 312.

Patria. In summis alpibus totius Europae, ubi ad nives aeternas usque rupium fissuras v. terram nudam habitat, et in America septentrionali. - Julio, Augusto.

Flos masc. lateralis, foliis perig. ovato-lanceolatis apiculatis, superne opacis, nervo evanido v. excurrente; antheridis paucis, paraphysibus flavidis clavate articulatis mixtis. - Notis illustratis ab $E$. vulguri el omnibus congeneribus certe refugit.

2. E. Incera De Not. (Mant. n. 66. et Syllab. p. 268.); monoicu; laxe cespitosa erecta innovando ramis tenuibus fastigiate ramosa; folia caulina crecto-patentia oblongosubovata v. oblonga acuminata canaliculato-subundulata integra, nervo valido crasso sursum attenuato apicem subattingente, juniora cuspidulata cava demum acuta $v$. obtusiuscula, sicca complicate incurva, basi e cellulis permultis laxis erythrodermibus, margine elongatis angustatis limbum flavidum efficientibus, superne minutis valde opacis tenuissime papillosis areolata; perichactialia similia; theca in ped. mediocri rubente erecta cylindracea aequalis annulata laevis, operculo conico subulato breviori; calyptra basi hund courctuta cilies laciniformibus latis inflexis divisa, apice scaberula.

Patria. In alpibus Penninis: Co mba; in monte Cenisio: B onnaz.

Ab $E$. commutata et ciliata calyptrac indole primo intuitu certe differt.

3. F. microstomn Bals, el De Not. (Pugill. n. 18. et Syllab. p. 269.); monoica; laxe cespitosa erecta sub- 
elongata parce breviter ramosa inferne radiculosa; folia caulina patenti-erectu haud reflexa, late ovata obtusiuscula evanidinervia v. nervo excurrente mucronata, basi brevi e cellulis parvis erythrodermibus pancis margine limbum vix efficientibus superne robustis hexagonis viridissimis tenuissime pupillosis areolata, margine haud vel vix revoluta; perichaetialia similia; theca in ped. brevi rubente erecta, cylindracea oblonga utrinque sensim attenuatu, ore angustissima, operculo subaequante, calyptra basi minute et irregulariter fimbriata denticulata lacerave apice summo scaberula.

Enc. ciliata v. gymnostoma Hb. nonn.

Patria. In monte Adula (St. Gottardo) Brambilla detexit, in summo Faulhorn, in jugo Bormiensi pr. Trafoi: W. P. Sch., in m. Geistein 'Tirolis altit. 7000': Sauter.

Notis cursive impressis ab E. cilicta proxima distat.

4. E. euspidata Br. et Sch. (in Muse. Abyss. Schimp. No. 492 b.); monvica; dense cespitosa erecta elongata robusta breviter ramosa, inferne sordida vel mupurascens, superne virescens; folia dense imbricata, late oblonga subcomplicata, nervo valido excedente crasse cuspidata robusta, basi brevi cellulis erythrodermibus multis limbum vix efficientibus superne viridissimis perfecte papillosis opacis areolata, margine revoluta; perichaetialia latiora; theca in ped. brevi rubente erecta cylindracea, operculo breviori; calyptra magna busi courctata, laciniis latis eleganter fimbriata, summo apice scaberula.

Putria. In monte Simensi Bachit Abyssiniae: W. Schimper.

Flos masc. axillaris, foliis perig. latissime ovatis cuspidatis laxe reticulatis rufis, superne subpapillosis subviridibus, antheridiis elongatis numerosis, paraphysibus crassis flaccidis aureo-flavis acutis mixtis. - Ab E. ciliatu simillima theca gymnostoma, a ceteris congeneribus hujus divisionibus calyptra basi coarctata et foliis senectute purpurascentibus differt. 


\section{h. Peristomium simplex.}

5. N. vulgaris Hilw. (Sp. Musc. p. 60.); monoice; humilis dense cespitosa parce dichotoma, radiculosa; folia caulina oblongo-lanceolata obtusa v. plus minus acutiuscula et nervo sacpe excurrente apiculata v. pilifera, basi margine c cellularum angustarum seriebus compluribus limbata, obsolete denticulata, superne haud revoluta; perichactialia similia; theca in ped. breviusculo purpureo plerumque crecta raro obliqua perfecte cylindrica rubens simpliciter annulata, operculo longe subulato recto; perist. nullum vel fugucissimum, e dentibus lanceolatis s. truncatis obsolete articulatis albidis rugnulosis compositum; calyptra pallida basi uequalis 2 . lacerala superne scabra.

Brid. I. p. 139. - Br. Hur. IV. p. 9. t. 2. - E. exstinctoria

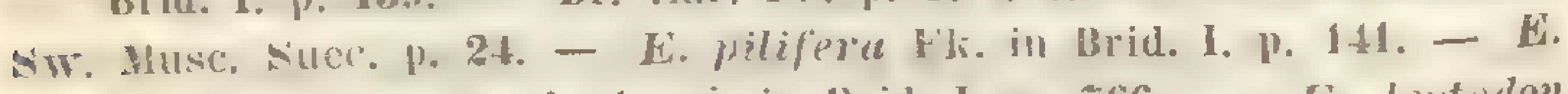

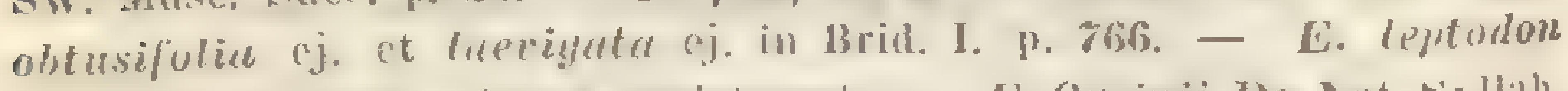
Brwh in schedabis, forma peristomata. - E. Orsinie be sot. syllall. p. 267. - Leersia vulgaris Haw. Nuse. Fr. I. 1. 16. tals. 1\%. -

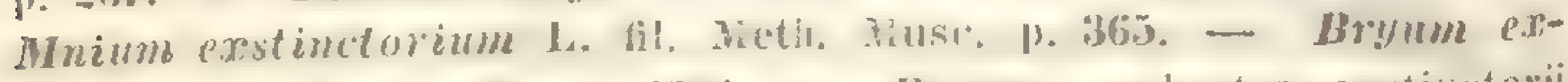

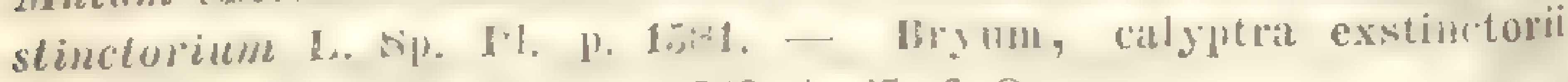
forma, minus. Dill, Musce, p. 249. t. 45. f, 8.

Putrill. Per totam Furopam, muros, saxa, graminosa, terram nulam praccipue argillosim habitans, usque ad alpes ascendens. - Vere.

Flores masc. laterales angusti, folis perig. convolutaceo-oratis acuminatis obsoletiner ibus eroso-denticulatis, ubique laevibus et pellucide reticulatis, antheridis paucis, paraphysibus paucis filiformibus tenuissimis mixtis.

6. F. Mexicana C. Müll.; monoicu; labitus L. vwlgaris, sed robustior; folia caulina nervo excurrente apiculata; perichactialia similia; theca in ped. longiore flavido dein rubente erecta cylimbica angusta simpliciter annulata, opereulo louge suluulato recto; perist. simplex, c dentibus lanceolatis brevibus rubentibus rugulosis superne albidis obsolete arliculatis compositum; calyptra basi perfecte et longe fimbriala superne glabra.

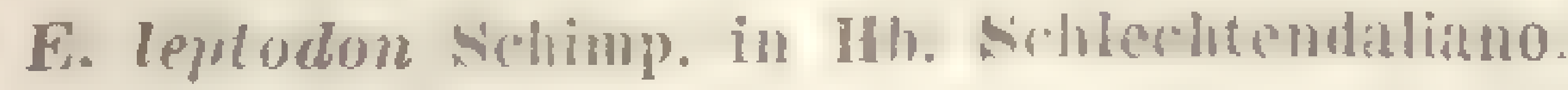

Patria. Nexico: C. Ehrenberg. 
Flores masculi laterales, crussi, foliis perig. late ouvtis acutis, nervo evanido $\%$ excurrente, apice denticulatis et opace areolatis scaberrme papillosis; antheridis paucis, paraphysibus mumerosis claruto-cirliculutis mixtis. -- Ab $E_{\text {. }}$ illyuri notis cursive impressis certe distat.

7. E. microphylla Nees ef Hsch. (Br. Germ. II. p. 44. t. 14.); munuica; dense cespitosa humilis inferne radiculosa pluries dichotoma gracilis, intense olivacea apice amocne rirescens; folia caulina purua subspuarrosa oratoelliptica, nervo crasso excurrente, apice purum recurea; perichactialia majora oblonga undulata, intima minuta lanceoluta obsolesinevire diaphana; omnie longicuspiduta; theca in ped. brevi cylindrica erecta aequalis laevis; perist. simplex, e dentibus 13 simplicibus lanceolato-subulatis purpureis compositum; operculo dimidio breviori, calyptra basi integ pluries laciniala. $\quad+$

Irofia. Wirolis, inter , dem brenner und dem Vitschthal", ubi legit kuk $1325 .-$ Julio.

Flos mase. Iateralis, folis previg. ext. rotundato-obunsis evandinervibus, infernis caulinis similubus minori-

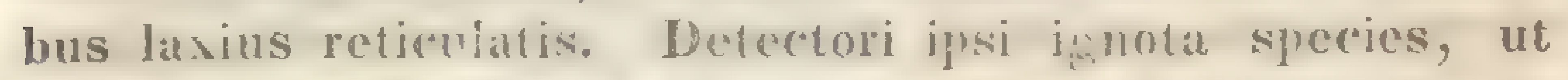
ex animadv. Br. Hurop. elucet, racterum gracilitudine et

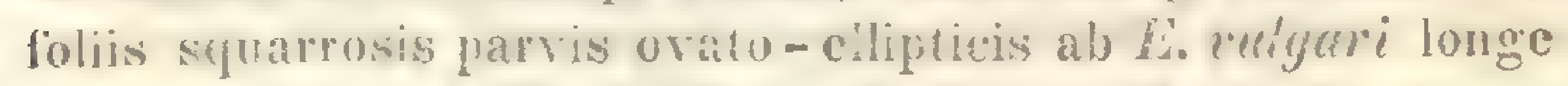
distare videtul.

8. E. cirigta Huw. (Sp. Musc. p.6.); monoica; Jaxe cespitosa breviter dichotone ramona intense virdis; folia

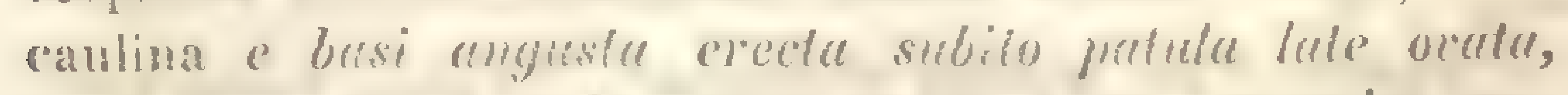

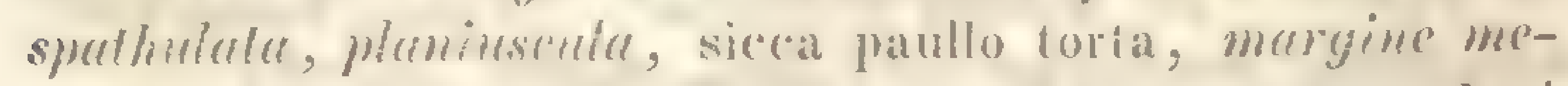
dii revolute, nervo in acumendemiculatum producta, basi

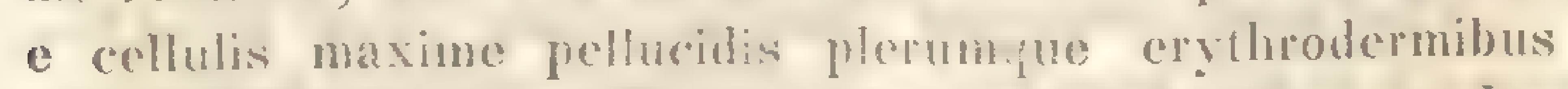
margine vis limbum clicicntibus superne arosse rotundatis el maxme papillosis areolata, perichactialia similia; thera in ped. longinsculo flarido dein purpureo erecta, subcylindracea intense rubens, simplecter annulata, operculo fonge subulato recto; perist. simplex, e dentibus $\mathbf{1 6}$, divisione saepe multiplicatis, longe infore orifienom orinndis, lanceolatis articulatis rugulosis rufis compositum; ca- 


\section{STEGOCARPI. ACROCARPI. ENCALYPTA.}

lyptra basi coarctata, fimbriis inflexis pulchre reticulatis eleganter ciliata, amoene flavida, summo apice scabra.

Br. Eur. IV. p. 10. t. 3. - E. fimbriata Brid. I. p. 145. E. clausa Wallr. Fl. Germ. Crypt. - I.eersia fimbriata Brid. Musc. Rec. II. I. p. 53. - L. ciliata IIdw. Musc, Fr, I. p. 49. t. 19. - L. laciniata Hdw. Fund. Musc. II. p. 103. - Bryum exstinctorium formà majus et ramosum. Dill. Musc. p. 350. t. 45. f. 9.

Patria. In montosis usque ad alpes totius Europae et in America septentrionali, rupes et terram nudam habitaus. - Vere.

Flos masc. minutus lateralis, foliis perig. ovato-lanceolatis acuminatis evanidinervibus, externis apice subopacis, internis ubique pellucide reticulatis, antheridis copiosis, paraphysibus clavato-articulatis flavidis mixtis.

9. E. apophysata Nees et Ilsch. (Br. Germ. II. p. 49. t. 15.); monoica; dense cespitosa tomentosa humilis parce ramosa; folia caulina late lanceolata, nervo excurrente mucronata carinate concava, basi brevi pellucida rubiginosa haud limbata, superne maxime opaca, saepe plicata undulata, valde papillosa, perichaetialia in pilum brevem denticulatum producta; theca in ped. breviusculo rubente erecta, ex ovato cylindrica collo instructa, operculo longe subulato recto et annulo imperfecto persistente; perist. simplex: dentes angusti longiusculi pallicli rugulosi articulati linea longitudinali exarati v. fissi ; calyptra maxime scabra, basi irregulariter laciniata.

Br. Eur. IV. p. 11. t. 4. - E. cylindrica Jees et Hornsch. I3r. Germ. p. 52.

Patria. In alpibus Ilelvetiae, 'Tirolis, Carinthiae, Sudetorum, Norvegiae. - Ang., Sept.

Flos masc. angustus lateralis, foliis perig. $3-4$ latiuscule ovatis mucronato-acuminatis, nervo evanido, superne opacis angustis; antherid. paucis, paraphysibus longis flaccidis superne flavidis longe articulatis tenubus mixtis. E. rhabdocarpae affinis, sed theca estriata longicolla jam primo adspectu differt.

10. E. Iongicolla Br. et Sch. (Br. Eur. IV. p. 12. t. 5.); monoica; dense cespitosa radiculosa, interdum so- 
litaria v. aguregata, humilis parce breviler dichotoma; folia caulina e basi oblonga medio coarctata margine haud limbata late fancelata aculiuscular r. apiculata, concava, nervo apice evando. Hand revoluta. maxime opaca; perichaclialia ovato-fanceolata tembssime apiculatas. pilitera; theea in ped. breviuscule) rubente crocta ryriformioblonge longirolla, denperculatu ore rempliatu, simpliciter

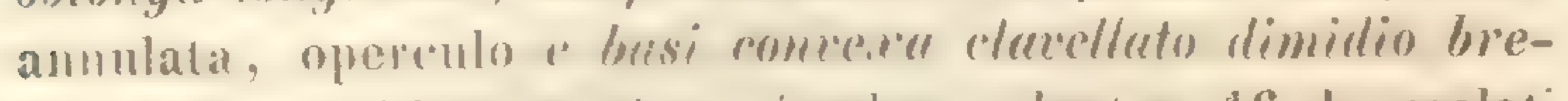
viuri dirromorlen; perist. simplex: dentes it lanceolati longi, linen longinulimali meluti in ciliu cohuerentia saepe rumuloso-rlilurerule fissi. rurius subintegri, intense purpurve; ralyptra hasi remulato-lacinata apice scabra sordide flava.

Patrie. In monte sichwarzenberg regionis Wochein alp. Carniol. legil primus Fr. Mïller saxa habitantem 1826. Id Chasseron mont. Jura legit W. P. Śchimper 1846. In alpib. Bavaricis, schattenberg 5-5600' alt. leg. Sendiner. Hi rarissimis! - destute.

Flos mase. latroalis angustus longus. doliis perig. anguste lanceolatis acoutuscoulis concavis apice opacis evanidinervibus, antheridhis pancis, paraphysibus longis rufescentibus tenuibus mixtis.

11. F. brevicolla Burbl (in seluchulis); monoica; E. Comgirollur simillimal folia latiora, theca cylindrica. collo brevi angustiori; perist. dentes similes breviores albidi, sporae duplo minores. fo

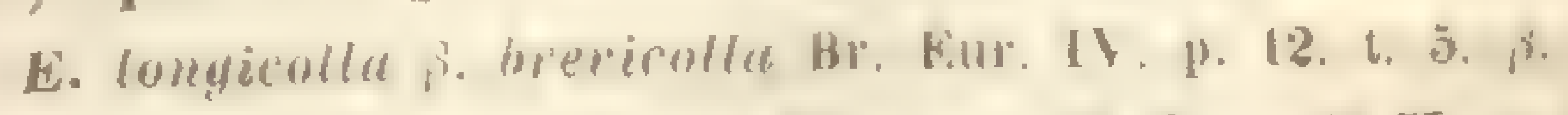

Patriu. Norvegia mr. Kongsvold detexit K urr; praeterea ex Angs/röm in suecia. Lapponia pr. Kandalax, et in Finlandia pr. Kuusamo.

sertio 11. Bhabolotheca. 'Theras - Ulcattit

12. W. spathulater C. Müll.; monoicel humillima gracillima, ramis duobus dixisu, subagyregute cespitosa readienlosu; folia caulina madefacta et sicen manime patula minus tortu, "basi longa " cellulis elongatis angnstis pellucidis favidis raru inferne rufescentibus fragili- 


\section{STEGOCARPI. ACROCARPI. ENCALYPTA.}

bus reticulata nargine vix limbata ungusto sensim ovata,. igitur sputhulatu, undulata planiuscula, apice reflexa, infima obtusa, superiora et perichaetialia in pilum longum flexuosum obsolete denticulutum hyalinum producta, superne maxime opaca et papillosa; theca in ped. longiusculo purpureo crecta, subcylindracen, ore acpuali subangusto, longicolla laeviter ef erecte striala gymmostoma, simpliciter annulata, operculo breviori conico-subulato recto; calyptra flavida, hasi laciniate aequalis, summo apice minutissime scabra.

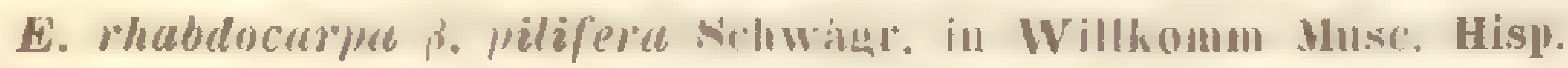

Putrier. Hispania, in fissuris rupium calcar. montis Santa Maria dicti in Sierra de Chiva. 5500' altitud. 2. Juni 1844: Will k om m.

Flos masc. in rumulo proprio terminalis minutus, foliis perig. parvis externis late ovatis pilileris, superne opacis, internis angustis piliferis pellucide reticulatis excurrentinervibus; antheridiis magnis pancis, paraphysibus pancis crensis clucuto-articulatis rellulosis $r$ ramosis raro simplicibus rigidlis llavidis mixtis. -.. Notis cursive im-

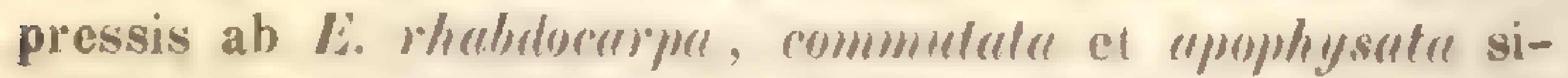
millima distat.

13. W. rhabdecarpa Schw. (Suppl. 1. I. p. 56. 1. 17.); monoica; dense cespitosa radiculoso-tomentosa parce et. breviter dichotoma folia caulina late lanceolata s. oblonga acutiuscula $v$ pilifera acutiuscula, margine basis limbat.ı subdenticulata, haud revoluta, nervo evanido v. excurrente; perichaetialia obusiuscula; theca in ped. breviusculo purpureo erecta ovata dein subcylindracea, stries 8-16 mfis recelis sulcalu, simpticiter innulata, operculn longe subulato recto; perist. simplex, edemlibus 16 late lanceolatis sublvigomis, linese longitudinali curinatu suepe obsoletu excurulis, articulatis plevempue integris rugulosis rufis rel phes minus albilis compositum; calyptra basi sublacerata, superne scabra.

Brid. I. p. 142. - Br. Eur. IV. p. 13. t. 6. - E. affinis Hdw. Fil. in Wel. et Molir. Arch, syst. nat. Gesch. I. p. 121. 
Patria. In subalpinis et alpinis totius Europae et Americac septentrionalis. - Julio, Augusto.

Flores masculi laterales, foliis perig. late oratis breviter acuminatis, superne opacis, basi margine limbata, antheridiis paucis, paraphysibus numerosis saepe tortuosis aureo-viridibus longis crassis mixtis.

14. E. streptocarpa IIdw. (Sp. Musc. p. 62. t. 10) ); divica; dense cespitosa radiculoso-tomentosa elongata robusta parce dicholoma; folia caulina valde involuto-tortuosa, madefacta patula, e basi angustiore fragilissima ad marginem denticulatum cellulis angustioribus longioribus limbatà late et obtuse lanceolata, parum concara, nervo crssso flavido dorso scabro evanido basi purpureo, grosse rotundato-areolata viridissima, in utraque pagina robuste papillosa igitur opaca; perichactialia e lianceolato subito acuminata; theca in ped. longo crasso pupureo stricto erecta, elongate cylindrica, basi ovata aequalis, spiruliter profunde sulectu, pailida, late annulata, operculo longe subulato recto aurantiaco; calyptra longe falcata comea sordide flava basi lacerata, apuce scaberima; perist. duplieis dentes externi lomgi stricti 16 subututo-

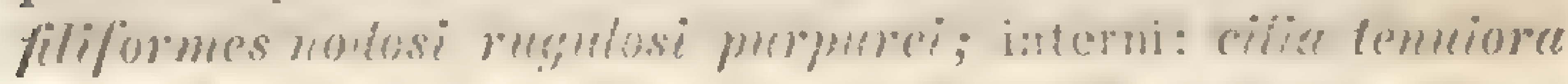

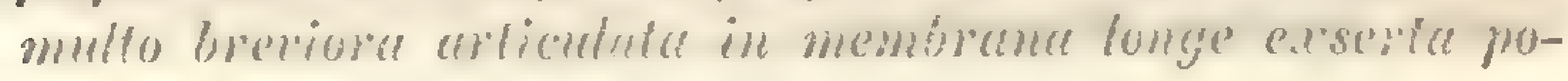
situ rugulosa fescidula.

Brill. I. 1. 1:1. - Jir. Eur. IV. 1. 1\%. t. 7. - E. grmmlis Nw.

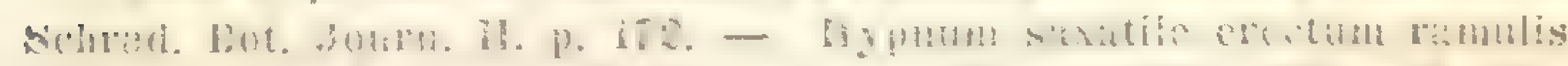

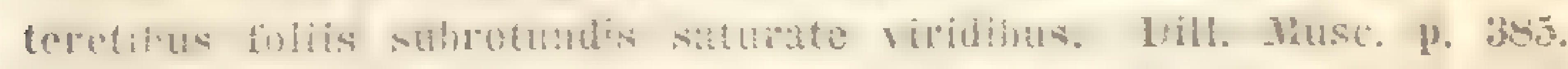
t. 43. f. 11.

Inatrie. In rupiom fissuris et muris prime calcareis per totam Europam, e planitie ad alpes ascendit, sed ratrissime fertilis. - Mujo, Junio, in alpibus dugnesto.

11. mascula paulo gracilior, femineac intermixta. Flos terminalis in ramulo proprio remuntornis, tolis perig. internis late-ovatis subacuminatis; antheridiis numerosis, paraphysibus clavato-articulatis mixtis. - Ex axilhs folior. super. radiculi fasciculate ramosi egrediunt.

15. E. procera Br. et Scin. (Br. Kur. IV. p. 14.t. 6.); monoica; habitus L. streptocorpac; folia e basi margine 
vix vel haud limbata integerrima breviore latiore late et obtuse lanceolata subligulata, margine revoluta, papillis longis creberrimis ubique obtecta; superiora et pericliaetialia in pilum longum flexuosum denticulatum producta; theca multo laevius spiraliter sulcata; perist. duplicis dentes externi 16 inaequales lineari-subulati linea longitudinoli excruti transverse articulati rufi rugosi, interni: cilia 16 dentibus similibus opposita lineari-lanceolata lutescentia punctulata transverse articulata, e membrana obscuriore in dentium interstitiis linea rufa ornata procedentia, dentes externos aequantia, calyptra minus cornea scaberrima flavide nitens.

E. streptocarpa Hook. in Drumm. Musc. Amer. No. 48.

Patria. Norvegia, in alpibus Kongsvoldianis: Dr. Kurr 1827. - America septentrionalis ad saxa et rupes in Hocky-Mountains: Drummond.

Flores masc. laterales plures, foliis perig. patulis e basi angusta laxe reticulata late-ovala breviter acuminata, superne margine papillis eroso-denticulata evanidinervia; antherid. magnis clavatis, paraphysibus numerosis clavato-acutis flavis mixtis. Caetera: theca, operculum, annulus praecedentis.

\section{Incertac sedis.}

E. Caucasica Ruprecht (Bull. de la soc. imp. des nat. d. Mosc. 1816. p. 521.); caulis crectus s. adscendens, dense foliosus, ramis inaequalibus; folia sparsa congesta erecto-patula carinata, lanceolata longissime acuminatocuspidata, subinde apice diaphana, sicca contorta, tenuissime areolata, nervo crasso excurrente; theca in per. mediocri rubente oblongo-cylindracea laevis, basi et apice colore croceo ornata, operculo longe acuminato recto, calyptra basi in lacinias inaequales obtusas fissa, laciniis inaequaliter incisis. $t$.

Patria. In monte Kasbeck Caucasico, ex altitud. 1526', prope nives liquescentes, Aug.: Kolenati. 
Proxime accedit ad $\boldsymbol{E}$. commututum et ciliatam; differt ab antecedente: calyptra basi laciniata, ab insequente foliis lanceolatis acuminato-cuspidatis, haud spathulatis, apiculatis. Perist. thecac imperfectae auctor non vidit.

\section{Gen. II. Calýmperes Sw.}

Jahroücher der Gewächskunde von sprengel, Schrader und Link. 1818. p. 1. t. 1. - Cryphium P. d. B. mat.

A graeca voce $x \dot{u}\rangle_{v \mu \mu}$ tegmen, et $\pi \varepsilon \dot{\rho} \omega$ transudigo nomen compositum.

Calyptra totam thecam involvens latere fissa torta basi angustata persistens plicata. Peristomiun nullum. Caetera Syrrhopodontis.

Calyptrae typus Pyrumidulce, qua nota congeneres Syrrhopodontes certe refugiunt.

sectio I. Hyophilina. Folia late convoluta, marginibus involutis, nervo crasso calli instar folium percurente.

1. C. Moluccense Schw. (Suppl. II. 2. p. 99. t. 127.); dioicum; brevicaule robustum molle dense cespitosum brevissime ramosum; folia densa patentia lanceulato-lineurie oblusu, margine undulata, hic illic inflexa, integerrima, sicca tortilia, basi pellucida, superius virore a margine versus nervum oblique ascendente, mollia, amoene viridia, nervo lato ad apicem saepe latori concolori; perichaetialia sextupto minora; theca brevipedunculata cylindrica gymnostoma laevis badia, operculo triplo minori conico-subulato; calyptra profunde sulcata. $\leftarrow$.

C. Afzelii $\beta$. Moluccense Brid. II. p. 87.

Patria. Insula Rauwack Archipelagi Moluccensis, lignis adnatum: Gaudichaud.

F patria el notis supra datis a C. lafifolio certe distare videtur.

2. C. Afzuelii Sw. (1. c. p. 3. t. 1. ex parte); dioicum; habitus C. Richardi; sed robustius magis ramosum mollius, folia multo angustiora, superne madefacta quoque 


\section{S'IEGOCARPI. ACROCARPI. CATMPERES.}

valde convolutacea angusta, nervo dorso scaberulo in cuspidcm crassissimam terelem oblusutam utringue serrulutu-scubervimum saepe anomalam producto, upice serrulete, supra basin anguste basi late limbata; theca brevipedunculata ovalis gymnostoma, opereulo subulato recto brevi; calyptra plicata.

Brid. 11. p. 86. - C. Pulisoti schw. Supul. I. I. p. 33t. ex parte. - Dicranum ustulatum Brid. I. p. 458 !

Patria. Ad Sierram Leonam Africae; ubi ad arbor. legit Afzelius.

Notis cursive impressis a C. Richardi simillimo facile differt.

3. C. Michardi C. Müll.; divicum; laxe cespitosum gracile subsimplex rigidum viridissimum; folia caulina rigida torta, madefacta patula, e basi erecta superne dilatata laxe areolata longiuscula latiuscule flavile limbata crenulata subito reflexiuscula convolutaceo-oblonga un-

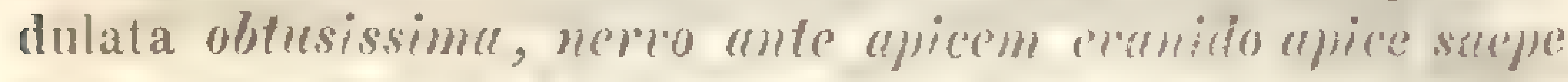

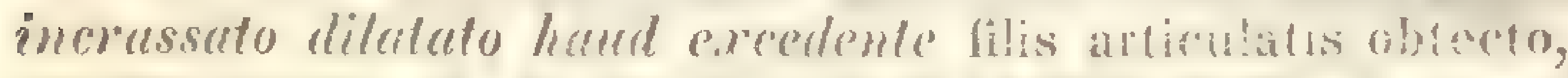
minute areolata opaca, temusime papillosa, infegrprimen, supra basin ultra medium angustissine fero obsolete flavide limbata; theca breviter pedunculats ovalis ?:-ymostoma examulata, operculo conico sumbato recto brevi; calyptra flavida plicata, apice tenuissime scabra.

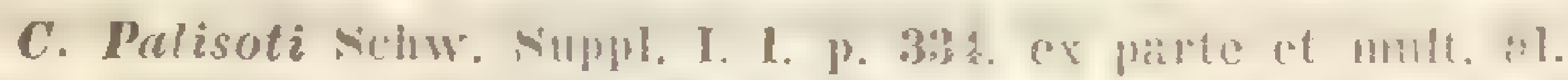

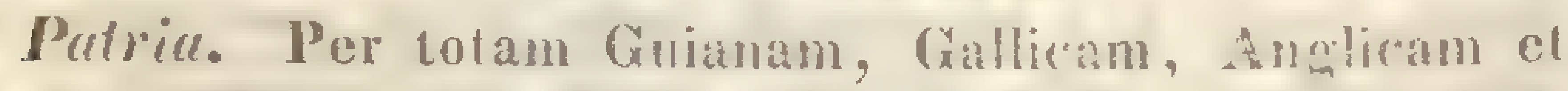

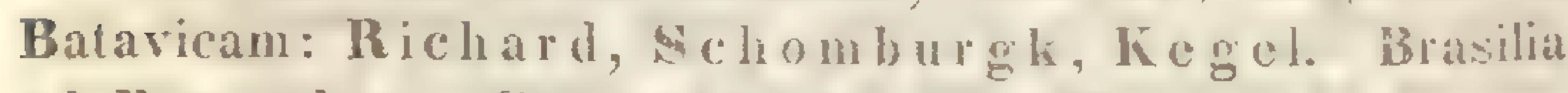
ad Pernambuco: Garduer Coll. No. 17.

A C. Afolii notis illustratis certe distat.

4. C. erosun C. Müll. (Iinn. XXI. 1819. p. 182); divicum; breviusculum erectum, apire breviter et lastigiate ramosum intur comosum, basi simplex fonue, molle, viridissimum, tenellum; folia caulina hresia crispala, madefacta patula, basi crecta vaginante brevi inferne angusta superne lata maxime pelluciela laxa, morginc limbo incrassuto tenervime of anguslissime memhramaceo hyuline serrulato pracdita, supra basin constrictam parum 
reflexa convolutaceo-oblonga obtuse acuminata, nervo crasso ante apicem evanido dorso scubro, minutissime areolata opaca, tenuissime papillosa, toto ambitu undulata eroso-servululu; theca in ped. brevi rubente flexuoso crecta angusta oralis, operculo subulato recto; calyptra longa torta angusta plicata, plicis scrulato-scabris.

Patria. Ad truncos arborum surinami, inter Cladonias legit Kegel, inter Hypna misit Miquel.

Calymperi Richardi proximum, sed foliis illustratis facile discernibile.

5. C. Iatifolium IImp. (P1. Preiss. p. 116.); C. Richurdi simillinum; folia rigida torta viridissima, spuhnlato-oblongu obtusa brevissime acuta, nervo crasso ante apicem evando, ubipue infegerrima, basi cellulis laxis nepue pellucidis fragilibus, sed mollibus flaridis, margine hand limbate, superne minutissime areolata opaca, tenuissime papillosa.

Fatria. Sova Hollandia, inter Fubronium IfLmpeanam prope oppid. Perth: Preiss 1540. No. 2473.

A C. Richardi notis datis facillime distinguitur. Folia anomala non vidimus.

6. C. disciforne C. Müll. (Limn. XXI. 1845. p. 183.); pulvinate cespitosum crectum rigidum crassum subsimplex sordhle viride; folia caulina rigida, parum incurra, madefacta value patula; inferiora majuscula curvata, convolutareo-oblonicat, nervo dorso apicis interdum scabro cxcurrente nucronata, integra, basi $1 / 3$ laxe areolata, celInlis amplis lompidis, maregine fiavide maromata, superne oprace minnte reliculata, tenuissime papillosa; snjertoru cunlis sterilis apree combis discum formuntia latissime orala abute phandesmle, nervo latissimo continuo, medio filis arlindatis fassoulutis mumerossis conglomeratis instructo, basi hatul mareinata, mimus laxe, superne najus arenlata; theca brevipedunculata ovalis, operculo conico obliquo, calyptra plicata, al plicas et summo apice scaberrima. 
Patria. Surinam pr. Paramáribo in ramis tenuibus loc. valde humid. et occultorum: Kegel Aug. 1844. legit. Ex insula 'Trinitatis Antill. mis. Crü ger. Rarissimum.

Caulis e disco saepe quasi polytrichoideo - prolifer, qua nota species e distinctissimis.

7. C. repeng C. Müll.; late et dense cespitosus, repens effusus, pusillus densifolius robustus, fastigiatus brevissime ramosus, aureo-viridis, rigidus; folia densissima tortuosa, madefactu subdivaricala, e basi erecta brevi e cellulis pellucidis angustis reticulata late flavide limbatâ reflexa, late lingulate oblonga, nervo tenui flavido in mucronulum brevissimum excurrente, minutissime rotundate areolata vix opaca viridissima, tenuissime papillosa, margine vulde unduluto involutaceo limbo angusto flavido ante apicem evanido instructo, toto ambitu crenulatu.

Syrrhopodon repens Harv. Jand. Journ. of hot, 1840. II. p. 7. Ic. in Ilook. Ic. Pl. Har. t. 22, f. 4; sed maloune nimis serrulato delineato!

Putria. India orientalis, Penang ad cort. arborum.

E structura foliorum (normalium) ad Culymperis genus magis quam ad Syrrhopodontes pertinet.

Siectio II. Euealymperes. Folia plus minus plana, nervo carinato.

\section{a. Folia loviformia.}

8. C. Monchophyllum Schw. (Suppl. I. II. p. 333. t. 98.); dioicum; late laxe cespitosum molle acaule cerino-viride, in ramos acaules permultos comose dispositos divisum; folia clongata maxime tortuosa, madefacta stricta, parum canaliculata, longe lanceolata, basi ovate dilatata: ad nervum crassum continuum e cellulis permult is amplis pellucidis areolata, utrinque limbo obscuro incrassato marginata, limbo iterum membrana tenerrima hyalina crenulata limitato, superne utrinque margine lamellata, lamellis obsolete et remote denticulatis, minute flavide areolata firma; theca in ped. mediocri exserto recto cylindraceo-ovalis gymnostoma exannulata fusca, oper- 
culo in columella exserta longe persistente subulato recto; calypira profunde plicata, apice plicis denticulatoscabris.

Brid. II. p. 88, excl. Syn, C. Palisoti.

Patria. In arboribus Guianac detexit Richard. Ex insula 'Trinitatis Antillarum misit Crüger, qui in monte Tamanaco pulcherrime fructiferum legit.

Archegonia permulta angusta, paraphysibus numerosis filiformibus elongatis maxime hyalinis breviter articulatis mixtis.

9. C. serratum A. Br. (in Nees Hb.); dioicum; habitus C. lonchophylli; sed folia breviora, basi e cellulis multo minoribus arcolata vix limbata, lamellis folii superioris serratis, nervo in apicem crassum producto.

Patria. Java: Junghuhn.

\section{b. Folia lanceolata.}

10. C. Crügeri C. Müll.; divicum; laxe cespitosum elatiusculum erectum robustum parce divisum sordide viride; folia caulina dense imbricata tortuosa squarrosa, basi erecta vaginante inferne angusta superne sensim late dilatata, cellulis amplis pellucidis, margine late flavide et incrassate limbata, subito reflexa anguste lanceolata, apice nervo crasso percurso rigido crasso obtuso subanomalo, margine incrassate limbata integerrima, canaliculata minutissime flavide areolata; perichaetialia erecta latiora longe vaginantia, cellulis elongatis angustis teneris flexuosis reticulata; thecae saepe geminatae brevipedunculatae erectae ampliuscule ovales laevissimae nitidae gymnostomae exannulatae, operculis conico-subulatis rectis; calyptra nitida laevis dein plicata apice scabra.

Putria. Insula Trinitatis Antillarum, monte Tocuche: Cr üger, 4. Dec. 1847.

Archegonia pauca, paraphysibus longissimis numerosis tenuissimis acutis longe articulatis mixtis. - Species pulcherrima. 
11. C. Guildingii Hook. et Grev. (in Brewster Edinb. Journ. of Sc. III. p. 223.); caulis elongatus; folia lincarisetacea subrigida, sicca subtorta, madefacta stricta, sensim acuminata, omnino integerrima; pedunculus vix exsertus; calyptra fusca. $t$.

Patria. In locis umbrosis, ad trunc. arborum montis St. Andreae insulae St. Vincentii: Rev. L. Guilding.

An a C. Criigeri distet, e diagnosi pauperrima haud elucet.

\section{Species delenda.}

c. Nerterii Spreng. (in Neu. Eutdeck. III. p. 1.), quod e sper. IHb. Spreugel. compositum est c linaria hygrometrice et Bryo quodam sterili.

Gen. III. Syrrinópodon Schw.

Sippl. Il. 2. p. 110. - Cleistostoma Brid. - Orlhothera Brill.

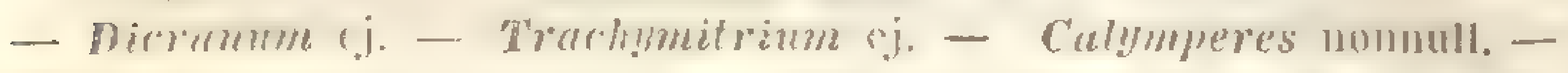
Codonoblemharum 17z. et. M. $\rightarrow$ Weisia al.

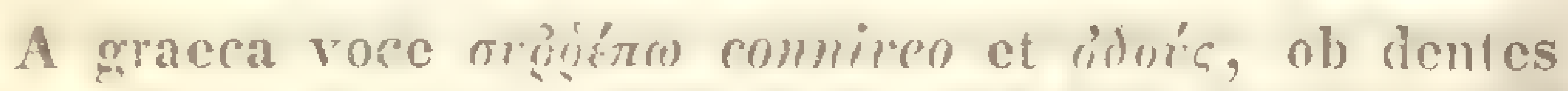
peristomii conniventes fere horizontales, nomen ductum.

Calyutra dimidisa curullata. Peristom. odentibus 19 lanceolatis integris plerumque Jorizmatabus compositum, v. mullum. Thecae orificium interdum epipliragmate clausum.

Calyptra sola a Calymperi differt.

Sertio I. Hyophilidium. Fulia phus mimus reflexa, e basi

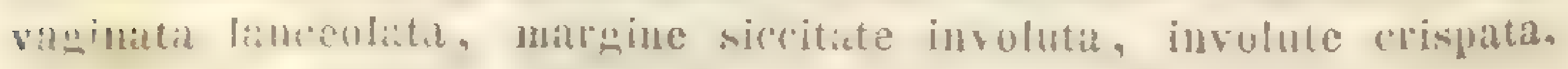
rigida, crassinervia.

1. S. Elornsehuchii Mart. (F1. Has. p. 6.); crectus fasciculato-ramosus, inferne subnudus, ramis dense foliosis; folla rigliuscula, fortilia, madefarctal patentia, inferiora ovato-lanceolata denticuha margine iovoluta inde subulata, superiora longiora e basi membranacea vacinante excarata pallidiore lincaria arutiuscula carinata marginata pellucide serrata margine inflexo, rufescentia, nervo 
crasso ferruginco plerumque ultra apicem excurrente; perich. latiora; thecae subinde geminatae in ped. erectis longiusculis apice incrassatis erectae oblongae laeves fuscae, operculis conico-subulatis obliquis duplo fere Jongioribus; calyptra subcampanulata longa glabra straminea, apice fusca, latere fissa. $t$

Patria. Brasilia, prov. Minarum Generalium et in regionibus flum. Amazonum: Martius.

Calymp. A/selii proximus dicitur. Perist. ignotum.

2. S. fascheulatus Ilook. et Grev. (in Brewster Edinb. Journ. of Sc. III. p. 225.); dioicus; subrepens dense cespiinsus clatus crussus robustus rigidus flavescens densifolius dichotomus, rumis fustigiatis flexuosis ascendentibus; folia caulina densissima erecta crispata subanmesset, madefuctu muxime patula, e basi luta erecta vaginante brevi e cellulis pellucide flavidis ampliusculis laxis moxime conspicue foraminatis reticulata late flavide limbata superne dilatata integrà subito luto-lanceolutu sensim reflexa, maxime undulata, e cellulis ralde incrassatis rotundatis angulatis minutis flavidis tomissime mpillosis areolata, versus apicem descrescenti-limbata valde crosodenticulata, nervo crassiusculo concolore in mucronulum producto, dorso distincte scubro; perichactialia breviora Convoluta ubique latissime limbata, interna lasi longius pellucida rhomboidaliter laxe reticulata; thera in ped. sesquiunciali erecto vix tortili ferrugineo malis robustu laevis badia, operculo rostrato breviori, calyptra longa.

sidiw. suppl. 111. II. 2. t. 299. - s. undulutus A. 13r. 1mst. in Bot. Deit. 1847. p. 9:38. a recensente $\mathbf{H}$ ampe momoratus?

Pulria. Insula Ternate: Dicksou Ifl. Sincapore. Java, ubi haud rarus videtur.

Calyptram, ab auctoribus consociatis II ooker et Greville calymperoideam basi theram anplectentem et lateraliter fissan delineatam, etsi nobis haud risam, Syrrhoprodontis dimidiatam habemus.

3. S. Codonoblepharum C. Müll.; divicus; reprens,

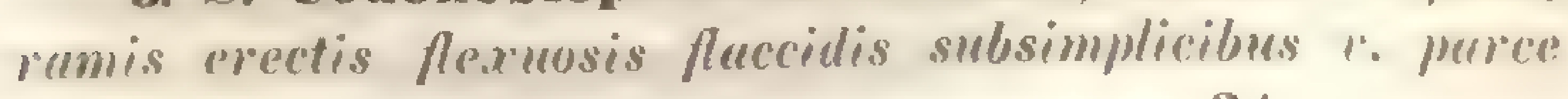

C. Müller: Synops. musc, frond. 


\section{STEGOCARPI. ACROCARPI. STRIIOPODON.}

dichotomis clatiusculis gracilibus remotis, flarescens; folia laxe imbricala fulcuto-erecta parum crispatula, mudefacta erecto-patentia, teneriova, e basi erecta brevi latiuscula e cellulis angustis flavide pellucidis reticulata rngustius flavide limbata superne paullo dilatata integrâ sensim lanceolato-acuminata et reflexa, undulata, e cellulis incrassate hexagonis minutissimis sublaevibus diaphanis areolata, toto ambitu angustissime limbata temuissime eroso - denticulata, nervo crassiusculo continuo, dorso sublaevi; perich. breviora convolutacea, basi e cellulis angustis rectunguluribus pellucidis superne minutissime rotundatis areolata; theca in ped. flexuoso mediocri erecta oblonga parra brevicolla, operc. longe oblique subulato; perist. duplex: ext. dentes breves lanceolati lutei firmi integri tenuiter articulati granulosi geminati in conum conniventes, interni e membranula carinato-plicata vix emersa lineares conniventes; calyptra apice scabra.

Codonoblepharum undulatum Dz. et Molks, in Muse. Archip. Ind. p. 96. t. 32.

Patria. Ad arborum cortices insularum Java, Borneo juxta Martapoera el Sumatra juxta flumen BataugBessie: Korthals.

Notis cursive impressis a $\boldsymbol{S}$. fasciculato affini facillime distinguitur.

4. S. Dregei Hsch. (Linn. XV. p. 116.); dioicus; dense cespitosus elatiusculus rigidus, viridis inferne nigrescens, inter folia tomentosus, dichotome divisus, ramis fastigiatis; folia caulina rigida valde involute crispa appressa, madefacta patula, c basi erecta e cellulis ampliusculis flavidis maxime distincte foraminatis reticulata subito late oblongo-lanceolate curmosula obtusa, evanidinervia, margine valde involuta, maxime opaca, papillis ubique maesertim apice longis densissime obtectu et igitur margine mominula, integerrima immarginata; perich. in cylindrum angustum valde exsertum apice patulum convoluta erecta, intima longe acuminata excurrentinervia basi tenerrima pellucida elongate laxe reticulata, pa- 
rum superne papillosa; theca in ped. breviter exserto ovalis turgida magna sordide flava, ore constricta, epiphragmate camosulo clausa, operculo oblique rostellato, dentibus late lanceolatis flaridis robuste trabeculatis, infra orificium oriundis involutis.

S. perichatialis Bruch in Regensh. Bot. Zeit. 18t6. p. 132.

Patria. Prom. b. spei, inter Schiloh et Wwart-Key, Windroogelbere, in Encephalurto Frid. Guilielmi, altitud. 5000': Drège, 22. Novbr., in cacumine M. 'Tabularis ad saxa: Ecklon. Ad trunc. Zamicue Cu/frue in summitate montium Winterhoek, Citenhage, Aprili, all. $3-4000^{\prime}$ : Krass.

Notis illustratis species distinctissima, $S$. cluruto et pomiformi proxima. - Flos masc. axillaris.

5. S. pomiformis Hmp. (Hb.); divicus; habitus praccedentis, ferrugineo-aureus; folia caulina rigida; densissime imbricuta, valde involute crispa appressa, madefacta erecto-patentia, e basi erecta e cellulis angustis laxis irregulariter hexagonis superne minoribus pellucidis reticulata oblonga concavâ parum reflexa, late lunceolutu ucuta canaliculata carnosula, superne cellulis minutis rotundatis subopacis areolata, toto ambitu ulbide murgimata, margine erecto, dorso praecipue nervicrassi excurrentis longe papillosa, integerrima; perich. in cylindrum angustum valde exsertum apice patulum convoluta erecta, intima longe acuminata, basi longa pellucida elongate anguste reticulata, apice scabra; theca in ped. parum exserto sphuevicu ore coarctata fuscidula, dentibus late lanceolatis involutis trabeculatis, operculo oblique rostellato.

Weisin pomiformis Hook. Muse. Ex, t, 131. - ? Grimmia pomiformis Brid. 1. p. 187.

Patria. Prom. b. sp., in rupibus humidis soli et tempestati expositis, montium altissinorum ad locum Mountain Station dictum, rivulo Krombeks vicinum, et alibi in jurisdictione Zwellendam: 13 ur hell. Z/ ey he r No. 493. F cklon. Rarissime fructificans. 
A S. Dreyei proximo notis cursive impressis facile disceruibilis.

6. S. Clavatus Schw. (Suppl. III. II. 2. t. 299.); S. pomiformi simillimus; folia densissima, e basi ovata lineari-lanceolatu, loteribus inzulutu, margine tenui albicante eroso, sicca contorta, luride viridia, nervo crasso tereti, ex apice tuntillum emergente lutescente, basi e cellulis parallelogrammis pellucidis superne subrotundis opacis areolata. $t$.

Patria. Nora IIollandia: Guil. Sieber.

Notis designatis a praccedente sat distinclus.

sertio II. Orthophyllum. Folia plus mimus erecta sitrictit. haud refluxa, hasi longissima pellurida, haud vaginata, superne e cellulis minutis pancis areolata, lanceolata.

7. S. revolutus $\mathrm{Dz}$. et M. (Musc. Archip. Ind. p. 59. t. 22.); monoicus; late cespitosus dense congestus glancescens humilis pusillus densifolius breviter fasciculate ramosus; folia caulina arcte appressa perfecte erecta stricta breviuscula anguste lanceolata, basi longa pellucida usque fere ad apicem producta et ibiden utrinque cellulis minutis rotundatis flavidis diaphanis asperulis apicis summi circumducta, tolo fore ambitu anguste diaphane limbata integerrima, margine apicis repolula, nervo tenui flavidn in mucrouulum brexem excurente; perichactialia latiora amplius et magis irregulariter retirulata, theca in ped. mediocri rigido rubro erecta ouchlis brexicollis ore constricta fusco-badia, operculo subulato recto tenuissimo, dentibus brevibus muntiucis lanceolatis infra orificium oriundis dense articulatis stepe fissis, calyptra dimidio breviore decidua, conico-campanulata, dein ad medium usque lissa, busi laciniutu pallida, apice rufescente scabra.

Pulvill. Java, in arborum cortice: Korthals. Borneo, prope pagum Enjarmassing: Ko rlla als.

Flos masc. in ramulo proprio graciliori, foliis perig. ext. 3 paullo majoribus latioribus, int. 2 ovato-lanceolatis concavis marginc versus apicem planiusculum revolu- 
tis, intimo ccostato; antherid. stipitatis, paraplysibus nullis. - S. in?oluto et rigescenti proximus, sed ab hoc differt notis cursive impressis, ab illo simillimo foliis strictis firmioribus apice diaphane ninute areolatis, integerrimis, thecac figura et dentium longitudine.

8. S. involutus Schw. (Suppl. II. 2. p. 117. 1. 132.); divicus? dense cespitosus teres humilis pusillus glaucescens densifolius breviter fasciculate ramosus; folia sicca apicis marginibus valde imolutis tortiliu, tenerima perfecte erecta stricla breviuscula angusta lanceolata, basi longa pellucida crassa cellulis apicis mintus viridibus opucis crorioribus superne circumblucta et terninata, margine parum involuta serrulutu, luteo-viridia, nervo crasso concolore continuo, tenuissime papillosa; theca in ped. brevi erecta subglobosa 2 oralis badia minuta, operculo subulato recto, dentibus infra orificium oriunds lanceolato-subulatis longis aurantiacis linca media minus perspicua exaratis interdum pertusis, calyptra parum breviore straminca apice fusca (scabra?). †.

Pulriel. Insula Rauwack Molnccensis: Ga ud ic lı a ud.

Ic. auctoris folia basi limbata ostendit. A S. reroluto simbilimo notis cursive impressis differt.

9. s. rigescens âd. (suppl. II. H. 2. p. 102. t. 181.); divicus? late compacte cespitosus sordide gluncus uncialis tennis fragilis, madore moliescens, parce brevissime ramosus; folia dense imbricata perfecte erecta stricta breviuscula anguste lanceulata, basi longa pellucida usque fere ad apicem producta et ibidem utrinque cellulis minutis subquadratis flaridis diaphanis apicis summi circumducta, margine apreis imeshet, nervo tenui flavido confimo; theca in ped. mediocri fusco mimula brevis subeylimbrice, orificio valde incrassato obscurius colorato, fusca, operculo subulato concolori thecae longitudine, dentibus brevihus lanceolatis mallidis infra orificim orinndis paree articulatis integris, calyptra thecam tegente subulato-campantulata (deiu dimidiata?) pellucida (scabra?). $i$.

Putriu. Insulac Malouinac: Gaudichalld. 
A S. revoluto affini notis cursive impressis discrepat.

10. S. rufescens Ilook, et Grev. (in Brewster Edinb. Journ. of Sc. III. p. 227.); laxe cespitosus humilis grucilis tenellus albidus, rudiculis rufis temibus rufescens, parce ramosus, frugilis, mollis; folia caulina dense imbricata, madefuctu patula, parum subsecumda, erectu 2 . magis minuste falcala, anguste elongate lanceolata acutu, conaliculatu, basi longissima e cellularum amplarum hyalinarum seriebus paucis laxe reticulata, apice ccllulis minutissimis cerino-flavidis rotundatis utraque pagina papillosis areolata, e basi usque fere ad apicem angustissime limbata, nervo tenuissimo continuo; perichactialia intima multo breviora erecta omnino laxa; omnia integerrima; pedunculus temissimus rufescens fragilis longiusculus.

Putria. India orientalis, Sincapore, Penang.

Paraphyses nullas iurcnimus, archegonium unicun.

11. S. spiculosus Ilook. et Grev. (in Brewster Edinb. Journ. of Sc. p. 226.) ; folia anguste linearia, dorso marginibusque incrassata lyaline inaequaliter spiculoso-denticulata. †.

Putvin. Sincapore: Wallich.

E folis S. rufescenti test. auctorib. proximus.

sectio 11. Orthotheca. Brid. I. p. 77r. Folia rigida, plerumque limbo lamellato v. imcrassato, lato nullo prachita. c hasi vaginante superne dilatata reflexa canaliculata. sordide viridia, ditfcile emollientia.

\section{a. Folia limbo lamelloso.}

12. S. Mobsoni Hook. et Grev. (in Brewster Ediub. Journ. of Sic. III. p. 224.) ; dioims; dense cespitosus erectus curratus crassiusculus parce breviler ramosus sordide viridis fuscidulus; folia raulina rigida demsu, e basi angusta superne parum dilatata longiuscule pellncide persistente, inferne limbo angusto diaphumo superne in collulas mimutus elliplicus dirphlhunes dissoluto circumducta supra distincte cremuluti angustato- Janceolata obtusata acuta, 
c cellulis minutissimis hexagonis diephanis areolata, ad margines lamina horizontali utrumque serrata ante summum apicem dentatum evanida; nervo crasso ante apicem abrupto, apice dorsi scabro; theca in ped. brevi elliptica, erecta, fusca, orificio angusto coarctato incrassato brunneo, dentibus brevibus lanceolatis, calyptra glabra.

s. incompletus sichw. Nuppl. II. 2. (1824.) p. 119. sul nom. s. semicompleti sippl. II. II. 2. p. 97. - Cleistostoma incompletum Brid. I. p. 15\%. - Calymperes Hobsoni Girev. ill Ann. of the Lyt. of Nat. Hist. of New - York. V. 1824. p. 271. c. ic.

Putriu. Guiana: IIobson, Cuba: Pöppig et in insulis vicinis haud rarus, ad trunc. arborum.

Notis cursive impressis a $S$. rigido facillime distinguitur.

13. S. Miquelianus C. Müll.; divicus; S. vigido simillimus; folia breviora liguluto-Tanceolatu obluso-ucutu multo latiora, basi inferue angusta supra versus dilatata concava margine denticulata, ad partem inferiorem brevissime pellucida, cellulis flavidis parum angustioribus laxis reluti marginata, ad superiorem cellulis percis flavidis firmis rectangularibus apicem versus sensim minoribus hexagonis $v$. quadratis incrassatis, supra basin parum falcato-reflexa ullice medium usque complicutione constrictu, apice planiuscule lingulata, supra basin margine lamina horizontali utrinque serrata ante summum apicem evanida, nervo crasso ante apicem abrupto; theca in ped. brevi apice incrassuto inclinate ovalis, raro erecta; operculo longe subulato recto; calyptra glabra.

Patria. Surinam: Hb. Miquel.

Flores masc. axillares minuti fusci, foliis perig. 6. Iate ovatis breviter acuminatis evanidinervibus concav is crenulatis, antheridiis turgidis paucis, paraph. flaccidis mixtis. - A S. rigido notis cursive impressis distinctissimus. Perist. nullum?

14. S. longisetnceus C. Müll.; divicus; laxe latissime cespitosus intertextus elatus fusco-viridis, ascendens, veluti simplex, sed ramis breribus appressis divi- 
sus superne crescens, tomentosus, laxifolius; folia longa flexuosa obscure viridia patula, e basi brevi erecta e cellulis ampliusculis flavidis inferne hyalinis reticulata, limbo lato breviter rectangulari-reticulato, ad partem superiorem dilatatam in cellulas permultas minutas rotundatas incrassatas papillosas folii superioris dissoluto, circumducta maxime eroso-denticulatà parum reflexa, longe anguste lanceolutu "cuminutu ucutu, omnino complicate carinata, margine limbo lamellato utrinque remote dentato, tenuiter tuberculose papillosa; theca in ped. longissimo rigido purpureo mugna erecta ellipticu, basi et orificio angusto attenuata, fusco-nitida pachydermis, operculo subulato recto concolori, loco peristomii membrana brevissima albida tenervimu, calyptra glabra.

Calymperes androgynum Mont. Ann. d. sc. Inat. III. P. 195. -

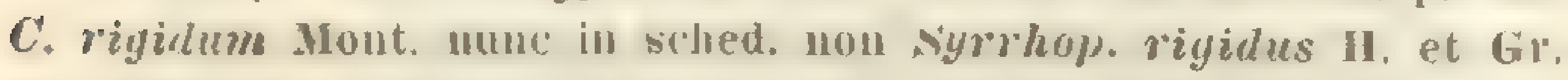

Patria. Guiana Gallica: Leprieur, Insula Trinitatis Autillarum, monte 'locuche: Crüger', 20. Jan. 1817, pulcherrime fructificans.

Sp. Montugneunu folia apice anomalo habet. Fi pedunculo longissinı, theca nitida magna elliptica et folis longis primo adspectu a sequentibus differt. - Flos masc. axillaris minutus fuscus, foliis perig. paucis oblongo-oratis acuminatis serrulatis haud limbatis, antherid. purpureis longiusculis, paraplysibus flavidis acqualibus mixtis.

15. S. rigidus Ilook. et Grer. (in Brewster Edimb. Journ. of Ac. III. p. 226.); dense cespitosus elatiusculus, ramis elongatis dichotomis fustigiutis robustis crussis densifoliis curvatis sordidissime viridibus inf'erne pallide ferrugincis divisus, caulis inferne foliis obesis teres, tomentosus; folia flexuosa, madefacta stricta patentia breviuscula, robustu, e busi late concura superne maxime dilutata longe pellucida laxa, limbo e cellulis angustioribus rectangularibus areolato superne in cellulas quadratas soluto circumducta integerima, superne crenulata immarginatâ parum reflexa, late lanceolutu, apice reluti maemorsu, runaliculatu, minutissime quadrate areolata, nervo 
lutissimo ante apicem serratum abrupto opice dorsi grosse serruto, margine lamina canaliculata utrinque scrrata ante summum apicem evanida.

Patria. Insula Trinitatis Antillarum, Moruja: Cr ïger, 20. Oct. 1847. Ad arbor. trunc. m. divi Andreac ins. St. Vincentii, 1012' alt.: Ilb. If ook.

Notis cursive impressis ab affuibus $S$. Hobsoni et Berterouno facillime distat. Folia apice filis brevibus saepe obtecta. Hace species e speciminib. authent. Hb. Schwägrichenian i vera est auctorum Hook. et Gr.

16. S. sordidus C. Müll. (Bot. Zeit. 1818. p. 766.); prostrutus, cespites latissimos humiles efficieus, paree ramosus grecilior sordide viridis fuscidulus curvalus; folia caulina rigida crispata, laxa, madefacta difficile emollientia, marginibus flexuosis, e basi oblonga brorissime pellucille fugucissima e cellulis parvis laxis albidis reticulata latiuscule anreo-limbulu infogervimu superne rix 2 . permon dilateld angustato - lanceolata uculu, canaliculatoconcava, nervo tereti crasniusculo dorsi apice parce dentato excurrente, e cellulis quadratis firmis apicem versus sensim minoribus areolata, ad margines lamina lrorizontali utrumque sertata longe infia apiecm deutatum folii eranida.

Orthothe'th circinnata Brid. I. p. S89. - Dicromume circinnatum Birid. 1. p. 446.

Putria. Guadeloupe, ad trunc. arbor. arete cohaerens: Hb. Hridel. Columbia, prov. Carabobo, pr. Cumbre de Valencia, altitud. Jo00'. Funck et schlim in L indén Coll. No. 617. Majo.

Fructum non vilimus, Bridelius autem descripsit thecam erectam fuscam ovatam subinaequalem arcu altero valentiore orificioque tantillum obliquo in ped. crecto subflexuoso folis perich. multo longiore apice leviter incrassato fusco. Peristomii destructi vestigia vix ulla. In ejus Hb. tamen deest. - I S. Hobsomi simili notis cursive impressis distat. 
17. S. Gardneri Schw. (Suppl. II. 2. p. 110. t. 131.); divicus; laxe cespitosus humilis flexuosus, interupte foliosus, fermoineus apice fruide virescens, tortuosus, fragilis, rigescens, parce breviter ramosus; folia e basi erecta inferne angusta superne parum dilatata pellucida laxe reticulata utringue latiuscule flavide marginata et rulde eroso-denticulatu vix vel paullo reflexa, lingulatolanceolata, minutissime quadrate rotundato-areolata opaca viridia, convolutaceo-canaliculata, margine limbo lamellato, lamellis utrinque remote serrulatis, nervo continuo carinato flavido dorso scabro; theca in ped. perbrevi erecta ovalis ore contracta lacrissima fusco-badia, operculo subulato recto; dentibus brevibus lanceolatis rubris infia orificium oriundis; calyptra dimidia theca longiore.

Cleistostoma Gavdneri Brid. 1. p. 15̄5. - Culymperes Gurdneri Hook. Musc. Exot. t. 146.

Patria. Nepal.

Folia apice sacpe fila articulata efformantia.

\section{h. Folia limbo incrassato, haud lamelloso.}

18. S. Iycopodioides C. Nüll.; divicus; Iaxe cespitosus longissimus maxime breviter et elongate remote ramosus subcompressus, inferne nigrescens, snperne itridis $v$ plerumque cerino-flucescens, fragilissimus; folia clongata loriformia flexuosa laxe imbricata patula, e basi brevi erecta e cellulis ampliusculis hyalinis reticulata, limbo lato elongate anguste reticulato, ad partem superiorem dilatatum in cellulas permultas magnas rhomboideo-rotumdatas utriculo primordiali instructas papillis tuberculosas dissoluto, circumducta integerrimâ subito reflexa, anguste lanceolata planiuscula, limbo angusto cresso argute et robuste serrato maryinata, e cellulis parvis depresso-hexagonis tenuiter papillosis subopacis areolata. nervo crasso in acumen breve excurrente; theea in ped. breviter exserto erecta obovelis magna fusco-nitida orificio angustiori incrassato brumeo, operculo subulato recto, dentibus brevibus, calyptra turgida apice scabra. 
Orthotheca lycopodioides Brid. I. p. 778. - Dicranum? lycop. sw. Fl. Ind, Oce, HI. p. 1066. - sichw. suppl. 1. 1. p. 185. t. 40.Bryum lycop. Sw. Prodr. Fl, Ind. Occ. p. 139.

Patria. In montibus umbrosis muscosis silvestribus, altissinis insulae Jamaicae: Swarz, Porto-Rico, Guadeloupe: Bertelo, Trintatis Antillarum, monte Tocuche: Crüger et in montibus altissimis prov. Meridac Columbiac: Moritz.

19. S. Herteronnus C. Müll.; divirus; S. Llobsoni simillimus, sed folia e basi longius pellucida laxiore convoluto-latissina superne valde sinuato-dilatata vix crenulata longius lauccolata, nargine limbiformi-incrassato laud lamellato remote denticulato, theca cylindrico-oblonga brevissime peristomata.

Orthotheca Berteriana Brid. 1. p. 798 . ex pate. - Dicranum Berterianum Brid. I. p. 445.

Pulriu, Portorico, ad Irunc. arbor. montium: Bertero, 1319. Apr. Insula Trinitatis Antillaum, Caura, 18. Jul. 1847.: Crüger.

Hlores masc. in planta femineae simili axillares minute gemmiformes, foliis perig. externis c basi late convolulacea pellucida late marginata subito acuminatis, internis latioribus tencrioribus brevius acuminatis, omnibus margine haud incrassatis obsolete dentatis, antheridiis clongatis, paraphysibus longis filifornibus flavidulis.

20. S. Malouimensis C. Müll.; S. Crvillemo sinillimus; sed folia e basi late convoluta longe pellucida laxissime persistente, inferne late flavide marginata angusta, superne valde dilatata rotundate minute areolata valde denticulata sinuatà subito canaliculate anguste lanceolata longiuscula, margine incrusscito haud lamellato grosse serrata, nervo crasso ante apicem obtusiusculum dentatum abrupto.

Wrthothece Berteriuna Brid. I. 1. 774. Cx parte.

Pulviu. Insulate Malouinae: Dumont d'troille. 


\section{c. Folia limbo nullo.}

21. S. Urvilleanus C. Müll.; dioicus; S. Berteroano simillimus; folia caulina e basi longa convolulacea superne maxime simuato-dilatata, inferne brevissime pellucida fugucissimu, superne e cellulis elongutis angustis fluvidis incrussutis intermute urticulatis reticulata haud marginata integra plicata subito sensim longe acuminata, hund limbatu, sed grosse et inuequaliter serrutu minute areolata opaca, sordide viridia, evanidinervia; perich. in cylindrum longe e.rsertum angustissimum congesta longe convolutacer longissime acuminuta, basi elongate anguste flavide areolata; theca in ped. breviusculo erecta veralis majuscula, longinscule peristomitu.

Orthotheca Berteriana Brid. I. p. Fro. ex parte.

Putria. Insula St. Catharina Brasiliae: D 11 mont d'Urville.

Nectio IV. Eusyrehopodon. Folia mollia, limbo plexumque angustissimo diaphano, e basi vaminante superne plus minus dilatati reflexa candiculata, alhida, viriliat farescentia, falcibe emollicutia.

\section{a. Albide virinles.}

22. S. tristichus Nees (in Schw. Suppl. IV'. 1.311.); divicus; laxe cespitosus elutus parce ramosus gracilis fivgilissimus albidus; folia clongete srunerroso-putenlice firtgilia, e basi longa raginante laxe et pellucide reticulata reflexa, e cellulis minutissimis cerino-flavidis tenuisime papillosis areolata, e basi usque ad apicem anguste limbata, "pice temiter dentutu, nervo albido continuo temui; theca in ped. brevi erecta cylindraceo-ovalis, fuscobrunnea, dentibus normalibus 16 articulatis, operculo oblique subulato.

Patria. Java, ubi haud rarus videtur. Sumalra: Korthals.

Flos mase. terminalis gemmaceus, folis perig. externis caulinis similibus, internis brevioribus convolutaceis, haud limbatis vix laxe areolatis denticulatis, nervo tenui evanido. Antheridia pauca, paraphysibus nullis, - Species excellentissima. 
23. S. Leprieurii Mont. (Ann. d. sc. nat. II. p. 197. t. 3.); divicus; laxe cespitosus mollis tortuosus albidoviridis humilis gracilis parce ramosus; folia e basi erecta late vaginante maxime pellucida laxissima anguste diaphana marginata longe ciliutu reflexiuscula brevia, anguste et convolutaceo-oblonga mucronata, angustissime diaphane limbata, flexuosa, minutissime rotundate areolata opaca viridissima, nupillis creberrimis ciliformibus uncinalis apice majoribus hyalinis dorso scaberrima, nervo tenui continuo; theca in ped. mediocri torto rubro oblipua oralis minutu fusca, dentibus longis dense trubeculutis fuscidulis conniventibus.

Patria. Guiana: Leprieur.

Pulcherrima species, foliis basi ut in S. ciliuto margine ciliatis facile discernibilis.

24. S. nlbovaginatus Schw. (Suppl. II. 2. p. 112. t. 131.); divirus; dense cespitosus humilis parce ramosus albide riridis ascendens, mollis; folia laxa secunda parum involuta, e basi vaginante maxine pellucisla submorgindu integervima magis reflexu lingulato-lanceolata, munutissime areolata virdia, margine lamellis croute serratis, nervo contimo carinato flavilo, ntraque pagina papillosa; theca in ped. brevinsenlo erecta minute oralis laevissima fusco-badia, operculo subulato recto, dentibus infra orificium oriundis, longis, per puria, trigas $x$. qualrigas "1pmoximatis, luteo-abidis articulatis, calyptra theren breviore. †.

Cleistostoma alhorayinatum Brid. I. P. 136. - Culymperes albovaginatum W. Arn. Disp. p. 14.

ratriu. Ad ligna putrida insulae Radack Archipelagi Moluccensis: Gaudi chaud.

Folia apice saepe anomala. - Notis cursive impressis a S. Gurdneri refugit.

\section{b. Sordide flavescentes.}

25. S. flavescens C. Müll.; dioicns; habitus S. mupillosi; folia caulina longissima sordide fluescentia, e 
basi multo latiori et breviori subito longiuscule linearia, apice ccuto ciliato-dentatu, toto ambitu anguste limbata, e cellulis minutis arcte aggregatis opacis subinamibus rotundatis dorso papillosis arcolata, nervo continuo tenui diaphano, canaliculata; perichaetialia multo breviora; theca in ped. mediocri stricto rubro fragili anguste ovalis fusca, operculo longe oblique subulato; calyptra dimidiata angusta apice scaberula; dentibus brevibus anguste lanceolatis longe infia orificium coarctatum oriundis.

Patria. Insula 'l'rinitatis Antillarum, monte Tocuche, ubi mensibus Decembr. et Maji fertilem legit Crüger.

\section{c. Glauco-virides v. virescentes.}

26. \$. prolifer Schw. (Suppl. II. II. 2. p. 99. t. 180.); dioicus; laxe cespitosus humilis, parce breviter fastigiate ramosus, mollis crassiusculus albido-viridis; folia caulina longinscula tortuosa madefacta erecta flexuosa, maxime patula mollia, e basi longa angusta superne sensim dilatata raginata e cellulis amplis laxis pellucidis reticulatâ subito anguste flexuose longiuscule lanceolata minulissime arcolata viridia opaca, toto ambitu anguste limbata, apice inacqualiter et remote dentata, nerro tenui subcontinuo dorsi apice plus minus scabro, canaliculata laevia; theca brevipedunculata erecta ovalis fusco-brumnea, operculo conico subulato recto, dentibus 16 brevibus lanceolatis.

ß. acunthoneurus; folia breviora, perfecte acuta, molliora, basi longius laxa, margine et nervi dorso supra medium folii valde dentata. s. acanthoneuros C. Müll. Bot. Zeit, 1845, p, 106.

Putria. Brasilia, Serra dos Orgaos: Beyricl. Columbia: Moritz Coll. I. No. 57. Var. $\beta$. Serra de Natividade: Gardner No. jo. Decbr. 1839.

Folia interdum apice prolifera i. c. plantas juniores efficientia. Archegonia pauca, paraphysibus tenuissimis paucissimis.

27. 5. Crandichaudi Mont. ( Inu. d. sc, nat. II. p.376. 1. 16.); dioicus; laxe cespitosus mollis subulatus parce 
ramosus albide viridis tortuosus densifolius; folia brevia undulata, e basi longa inferne angusta superne parum dilatata latiuscula raginante maxime pellucida anguste diaphane limbata oblongo-lanceolata acutiuscula, canaliculata, minutissime areolata opaca viridia, subcrunosa, angustissime diaphane limbata, apice summo eroso-denti. culata, dorso nervi continui apice acule scabro; theca brevipedunculata erecta oralis, fusco-badia, operculo subulato recto, dentibus brevibus articulatis carnosulis fuscis longe infira orificium ampliusculum oriundis.

S. undulatus C. Müll. Bot. Zeit. 184t. p. 727.

Putria. Insula St. Catharina Brasiliac: Gaudichaud. Serra dos Orghàos, trunc. putrid. habitans: Gardner No. 45. Aprili 1837.

A S. molifero notis cursive impressis refugit.

28. S. obliquirostris C. Müll.; dioicus; S. Gundichaudi simillimus, sed humilior, folia basi plerumque obsolete denticulata, theca minor angustior, operculo tenuissime maxime obliquo stricto.

Patial. Prom. b. spei, Groodvaterbosch: Ecklon. IIb. Kunz.

Species haecce, e patria jam distincta, S. Gumdichaudi licet sit maxime similis, operculum tamen maxime curvirostre proprium apparet adeo, ut plantam utramque operculatam primo adspectu distingui possit. 'Theca omnino matura nobis non est, dentes igitur diversi quoque forsan reperiantur.

29. \$. papillosus C. Müll. (Bot. Zeit. 1818. p.766.); dioicus; acuulis, ramis brevissimis in comum longissimam congestis; folia caulina longissima mollia fragilissima, laxissime imbricata, flexuosa haud tortilia, glanca, e basi longissima angustissima laxe pellucide reticulata longe linearia, apice saepe incrassato obtusuto subanomalo dense ciliato-denticulata, toto ambitu anguste limbata, e cellulis minutis chlorophyllosis solituris rotumlatis dorso papillosis arcolata, nervo continuo tenui diaphano. 


\section{S'IEGOCARPI. ACROCARPI. SYRRHOPODON.}

Putria. Columbia, prov. de Caracas, pr. Galipan 5000 altitud. in arboribus: F unck et schlim in Lind. Coll. No. 358.

A S. prolifero foliis longissimis et caule brevissimo subnullo primo adspectu differt.

30. S. parvulus Schimp. (in litt.); divicus; gregarius r. cespitulosus humilis, parce ramosus dense foliosus pallide glauco-viridis, folia patentia, sicca flexuosa, linearia concava, margine albida, summo apice serrulata et hic illic filamentorum brevium fasciculo instructa, nervo excurrente pallido, basi e cellulis magnis rectangularibus hyalinis superne punctiformibus chlorophyllosis prominulis areolata; theca in ped. lineari v. bilineari erecta, parvula oblongo-cylindrica, castanea vernicosa, calyptra albida ad thecae basin producta, operculo rostellato breviore, dentibus sub orificio oriundis brevibus lineari-lanceolatis stramineis. $f$.

Putria. Ilypmis intermixtus prope Mirador Mexicanorum.

E minoribus gentis, S. moliforo similis, sed minor, foliis atque pedunculo brevioribus primo intuitu distinguendus.

31. A. ciliatus Schw. (Suppl. II. 2. p. 114. t. 130.); dioicus; dense cespitosus lumilis subsimplex v. parce breviter ramosus mollis dense foliosus, viridescens inferne ferrugineus, fragilis; folia laxe patula tortilia, subspullulato - lingulut a acuta basi laxissima pellucida, angulo acuto in laminam folii superiorem viridissimam minutissime areolatam opacam productà, foto combitu ef durso nerei excurrentis longissime uncinute hyuline cilintu; theca in ped. perbrevi erecta ovalis parva laevis badia, operculo conicorostrato obliquo, dentibus longis dense trabeculatis fuscidulis comniventibus; calyptra theca longiore ubique scabra, dein dimidiata. $\leftarrow$.

Trachymitrium ciliatum Brid. I. p. 159.

Heisia riliatu Hook. Musc. Exot, t. 171. 
Putriu. Insula Ternate Oceani Indici ad ligna putrida, unde Dickson jam habuit. Bornen, in cortice Metroxyli: Korthals.

A S. Leprieurii affini notis cursive impressis longe distat.

32. S. Jamesoni Tayl. (Iond. Journ. of bot. 1847. p. 331.); uncialis cespitosus erectus subsimplex viridissimus; folia sicca crispa, laxu, ex exsucca amplexante Ionga erecta basi patenti-recurva, dentata, nervo subpellucido; theca in ped. tenui ovata incerpulis inclinutu, dentibus rongatis sublifidis r. trifidis angustissimis opucis brumeis, siccitute incolutis $r$. tortis. -

Putriu. I. Pichincha Andium Quitensium: IV. Jameson, Nov. 1846.

E ratione auctoris species haece notis cursive impressis ab omnibus congeneribus ceteris differre dicitur.

Syrrhopodontes incerti.

1. S. elatus Mont. (Ann. d. se. nat. III. p. 198.); erectus simplex v. parce ramosus; folia undique imbricata erecto-patentia lineari - lanceolata plana, basi oblonga amplexicaulia solidinervia margine incrassato denticulato. $f$.

Putriu. Guiana Gallica: Lueprieur.

2. S. Taylori Schw. (Suppl. II. 2. p. 115. t. 132.); monoicus; subsimplex lumilis erectus $r$. curvalus parce divisus ferrugineus basi fuscus; folia terminalia erecta, lateralia falcata $r$. secunda sparsa, e basi amplexante cellulis lutescenti-badiis majoribus nonnullis pracdità subito canaliculate subulata brevia, margine involuta, v. plana, sicca valde contorta, integerrima viridia, papillis tenuibus scabra, nervo crasso concolori v. pellucido ante apicem evanido; thera in ped. erecto badio erecta cylindrica laevis badia, operculo concolori subulato recto, dentibus horizontalibus ad marginem adnatis breviusculis lutescentibus dense trabeculatis, calyptra Iongiore albida dimidiata. t.

C. Mirller: Symope, musc. frond. 
Cleistostoma Taylori Brid. I. p. 156.

Patrict. Nepal, in cortice arborum putrido.

Flos masc. axillaris gemmiformis, foliis subbinis ora10-acuminatis, nervo minus perspicuo; autheridiis longiusculis curvulis, paraphysibus longis filiformibus mixtis. - Fx anctoris descriptione et iconibus Blindia videtur!

3. S. recurvifolius Hsch. (Linn. XV. p. 118.); late et laxe cespitosus, caulis primarius repens $v$. prostratus fasciculato-ramosus radiculosus, ramis erectis, plerumque dichotome ramulosis, foliosis, inferne interdum subnudis; folia conferta recurva sicca parum crispabilia rufescentia v. luteo-viridia, e basi latiore oblonga subraginata integerrima subpellucida e cellulis linearibus laxis reticulatà lanceolata canaliculata, irregulariter grosse et argute serrata, nervo crasso concolore infra apicem evanido, superne minutissime rotundate areolata. $\leftarrow$.

Patria. Prom. b. spei: Ecklon.

Ex animadr. auctoris habitu Macromitrii vorthotrichi, nobis igitur dubius.

\section{subtril. II. P OTTIACEA.}

Cellulae folii basilares molles pellucidae longiores, plerumque inanes, raro utriculo primordiali instructae.

Patvire. Per zonas omnes totius orbis terrarum.

\section{Gen. IV. Pottia Ehrh.}

Beitrïge 11. p. 175. - Anacalypta Rühl. et al. - Gymnostomum Hdw. et al. - Dermatodon Hïh.

In memoriam Profess. Botanices Brunsuicensis Joh. Fr. Pott, auctoris Florae Brunsuic., nomen conditum.

Calyptra dimidiata. Peristomium simplex, e dentibus lanceolatis articulatis simplicibus s. linea longitudinali exaratis rugulosis carnosulis compositum $v$, nullum. 
Sectio I Anacalypta Rölıl. Moosg. Deutschl. I. p. 108. Theca distincte peristomata. Folia latiuscula planiuscula v. concava, plus minus spathulata.

a. Caulis tenellus patentifolius.

1. P. Starekeana C. Müll.; monoicu; anmul pusilla gregarie cespitulosa simplex; folia pauca patentia conferta, oblongo-ovali-lanceolata, nervo crasso ferrugineo excedente breviter mucronata, valde subplicate concava margine e basi usque fere ad apicem revoluta, integerrima, basi e cellulis amplis hexagonis pellucidis laevibus, superne multo minoribus opacis tenuissime papillosis areolata; perichaetialia intima perfecte oblonga angustiora; - theca in ped. brevi stricto minute ovalis, erecta fusca, annulo angustissimo et operculo hemisphaerico-conico obtuso; perist. dentes mutabiles breves erecti truncati articulati pallidi rugulosi simplices saepe lacunosi.

Anacalypta starheana Br. Germ. II. p. 138. t. 36. f. 2. - Br. Furop. Fasc. 18-20. p. 2. t. 1. - Dermatodon Starkii Hiil. Musc. Germ. p. 109. - Weisia starkeana Hdw. Musc. Fr. III. p. 83. t. 34. - Brid. I. P. 3as3. - Grimmia Starkeana W. et M. Bot. Taschl. p. 137. - Bryum Starkeanum Hoffm. Deut. Fl. II. p. 32. Br. minutum Dichs. Fasc. 1V. PI. Cr. p. 7. t. 10. f. 17 fide Smith.

ק. brachyodus; perist. dentibus brevissimis praemorsis. Br. Fur. I. c. - Dermatodon affinis Hül. I. c. p. 110. W'eisic uffinis Hook. et Tayl. Mlusc. Brit. p. 44. t. 14. - Brid. I. p. 354.

Patvic. In terra argilloso-calcarea agrorum et camporum sterilium per Europam mediam et calidiorem. Var. $\beta$. passim cum forma normali pr. Bipontem, prime in Gallia meridionali, in Sardiniae insulis et in Britannia haud infrequens. - Primo vere.

Antheridia ad pedem floris feminei plerumque nuda eparaphysata minuta $2-3$. - Ex habitu P. minutulue simillima.

2. P. cespitosa C. Müll.; monoica; annosior pusilla gregarie cespitulosa elatior gracilior ramosa; folia patentia, orato- et oblongo-lanceolata angustiora, nervo temui ferrugineo excurrente brevissime mucronata, cym- 
biformi-concute margine hund renoluta, integerrima e cellulis minutis basi rectangularibus pellucilis, superne opacis tenuissime papillosis areolata; perichactialia longiora, reginuntia; theca in ped. brevi ovata erecta, anguste annulata, fusca nitida, operculo conico longe subulato obliquo; perist. dentes plus minus perfecti erecti breves pallidi linea media longitudinaliter plus minus divisi vel lacunosi obtusati angusti.

Anacalynta cespitosa Bruch in Br. (icrm. II. 2. p. 146. t. 37. Br. Europ. Fasc, 18-20. p. 3. t. 2. - Weisia cespitosu Brtch in Brid. I. p. For. - Wr. tenella Brid. I. p. 809? in Ull, B rideliano nobis haud visal. - Gymnostom. carbunculoides le Dot, in schedulis! -- Dermatodon respitosus Hih. Musc. Germ. p. 111.

Patriu. In collinis calcareis pr. Bipontem: Bruch; pr. Falaise Normandiae: De Brébisson; in pascuis pr. Cagliari Sardiniae: De Notaris. - V'ere.

Flos mase. ad pedem fl. feminei minute gemmaceus angustus, in innovationibus primaris terminalis, dein pseudolateralis, foliis orato-acuminatis, nervo excurrente vel evanido, antheridis minutis paraphysatis. - A P. Starklecenc notis cursive impressis primo adspectu distat.

3. P. faccida C. Müll.; respilosa pusilla innovando ramosa intense viridis flaccida; folia patentia valde: faccide orcetu obtuse, merro expmrente, pellucide reticulata tenera; theca in ped. perbrevi erecta ovata parva. $\leftarrow$.

Weisia fluccidu Harv. It. in Hook. Ic. PI. Har. t. 1\%. f. 3. et Isond. Journ. of hot. 1840. II. p. 6. rum diagnosi.

Petria. Nepal: Wallioh.

Operculum ac peristomium perfectum deerant, in $1-2$ thecis aliquot dentes breves inventi sunt, generi IVeisia similes. Auctor.

\section{b. Caulis robustus patentifolius.}

4. P. Innceolata C. Müll.; monoica; biennis laxe et plus minus extense cespitosa mollis, simplex humilis $r$. magis minusve ramosa elata intense viridis; folia caulina patentia laxe disposita, sicea parum torta, ovali-oblongolanceolata, nervo crasso in aristam flexuosam producto, 
margine usque fere ad apicem obsolete crenulatum revoluta, subcomplicato-carinata, ubique e cellulis firmis sublaevibus parce chlorophyllosis hexagonis basi majoribus areolata; perichaetialia angustiora; theca in ped. breviusculo erecta, ovalis brevicolla brumescens, annulo simplici et operculo conico plus minus subulato obliquo aurantiaco; perisi. dentes in membrana exserta pallida rugulosa erecti longiusculi inaequaliter articulato-subulati obtusati latıusculi pallidi rugulosi medio longitudinaliter fissiles $\mathbf{v}$. lacunosi.

Ancralyptri lanceolata Höhl. Hoosinesch. Deut. I. D. 10२. - Br. Germ. 1. 1. 141. t. 36. 1. 3. - Br. Eurnp. Fasie. 18-20. p. 4. t.3.Dermatodon lanceolatus Hïh. Musc. Germ. P. 112. - Mreisia lanceolata Hook, et Tav1. Huse. Brit. p. 44. t. 14. - Coscinudon lanceolatus Brid. 1. p. 372. - Enralypta lanceolata Hdw. sp. Husc. 1. 63. - Leersia lanceolata Hdw. Musc. Fr. 111. p. 66. t. 23. L. cuspidata schrk. Baiers. Fl. 11. 1. 4.12. - Grimmia lanceolata

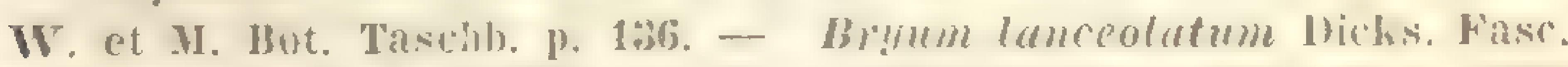
11. P. Cr. p. 4. - Br. cuspirlutum Gimel. Nyst. Dat. IJ. p. 1332. - Coscinodon aciphyllus Brid. 1. 1. B78. - Wreisia aciphylla Wahlenh. in Yov. Art. Holn. 1mak. p. 133. t. 4. f. 1. - Grimmia aciphylla W. et M. I. C. I. 139. at 4.57. - - Coscindelun connatus Brid. I. 1. 374. - Grimmia commata hidull.

B. angustulu; theca garacilior; peristomii dentes in membrana exserta obsoleti. Br. Furn]. 1. (. Fintosthymenium mucronifolium Bruch in Fr. Müller Muse. Sard. et Hegensb. Florit 1829. p. 387. - Pottia brevicaulis De Not.

Patria. Ad terram nudam ubique per totam Europam temperatam et meridionalem vulgatissima. Var. $\beta$. pr. Smyrnam: Fleischer, pr. Genuam in collibus ad margines agrorum: De Notaris. - Primo rere.

Flos masc. minute gemmaceus, foliis minutis late ovatis acuminatis, cum rel absque nervo.

\section{c. Caulis robustus julaceus.}

5. P. Intifolia C. Mül!.; monoica; gregaria vel dense cespitosa humilis robusta gemmaceo-julareo-foliosa, simplex v. innovando ramosa, argenteo-viridis; folia caulina arcte imbricata, cochleariformi-concava latissime obovata rotundata, obtusa vel apiculata, nervo tenui ferruginco 


\section{0 STEGOCARPI. ACROCARPI. POTTA.'}

$\mathrm{v}$ viridi ante apicem evanido, nitidula, margine haud revoluta, e cellulis basi amplis hexagonis laxis pellucidis laevissimis superne minoribus, sed pellucidis plus minus scariosis echlorophyllosis reticulata, integerrima laevia; perichaetialia basi longa laxe reticulata valde angustata; theca in ped. longiusculo stricto aurantiaco erecta, ovalioblonga, anguste annulata, fusca, operculo brevirostro obliquo; perist. dentes latiuscule lanceolati integri rel ad medium bifidi, linea longitudinals destituti, in membrana perangusta positi, pallidi laeves vel rubelli et subrugnlosi.

Anacalypta latifolia Br. Germ. II. p. 135. t. 36. - Br. Filr. Fasc. 18 20. p. 5. t. 4. - Dermatodon latifolius Hïls. Muse. Germ. p. 115. - Didymordon bulbosus et bullatus Hartm. fide §̊ II s tröm. - Weisia latifolia schw. Suppt. I. I. 1. 64. t. 18. - Grimmia laizfolia W. et M. Bot. Taschb. p. 147.

ß. pilifera; folis in pilum longam flexuosam acuminatis. Br. Europ. I. c. Br. Gierm. I. c. p. 237. sub nom. Anucul. latifoliae $\beta$. piliferae. - Coscinodon pilifer Brid. 1. p. 810. W'eisia pilifera Fk. unst. - Dermatodon Funkii Hüb. Musc, Germ. p. 115.

Pulria. Ad terram in summis alpibus Europac et in America septentrionali. Tar. $\beta$. in locis siccioribus. Aestate.

Flos masc. terminalis, dein ad pedem innovationis femineae gemmiformis, foliis 3 ovalibus obsolete nervosis, antheridis elongatis, paraphysibus robustis clavatis mixtis.

sectio II. Eupottia. Thera gymnostoma vel hoco peristomii membrana basilaris laciniata. Folia tata planiuscula vo conteava, plus minus spathulata.

\section{A. Folia lamellosu.}

6. P. cavifolia Ehrh. (Beitr. II. p. 187.); monoica; annua vel biennis, gregaria vel cespitulosa pusilla subsimplex viridis; folia caulina arcte imbricala, e basi oblonga sersim rotundato - ovata cochleariformi - roncat', nervo viridi in pilum plus minus elongatum flexuosum producto, lamellis latis undulatis pluribus superne propdito, integerrima, margine haud rcvoluta, inferne e cel- 
Iulis elongate hexagonis pellucidis superne minoribus irregulariter subrhomboideo-hexagonis laevibus parce chlorophyllosis diaphanis areolata; theca in ped. brevi purpureo rectiusculo ovalis turgescens brunnea erecta exannulata, operculo c convexa basi oblique rostellato.

Br. Europ. 18-20. p. 7. t. 2. - Gymnost. oratum Hdw. Muse. Fr. 1. p. 16. t. 6. - G. pusillum IIdw. Fund. Musc. 11. p. 32 et 87 . Bryum ovatum Dicks. Wasc, 1., PI. Cr. p. 4.

Patria. In cultis murisque totins Europac vulgatissima et in America septentrionali, usque ad alpina edita ascendens. - Vere.

Flos masc. primo terminalis, dein ad pedem rami fertilis subgemmaceus, foliis $\mathbf{2}-\mathbf{3}$ late ovatis apiculatis subseminervibus; antheridiis majoribus, paraphysibus subclavatis mixtis.

\section{B. Folia elamellosı.}

a. Folia dentata $v$ serrata.

7. P. Heimii Fürur., monoica ravins hermuphrodila; pulvinato-cespitosa viridis inferne fuscescens biennis $v$. triemis ramosa flaccida, folia laxe imbricata erecto-patula, sicca subtortilia, late lon a ovato-oblonga acuminata, busi e cellulis elongutis pellucidis teneris laxis laevibus superne multo minoribus perfecte aequaliter hexugonis creberrime munctulato-papillosis igitur subopacis ureolata, marginc cellulis plemumpe spapillosis lacribus usque fere ad apicem risis quasi marginatu, apice inaepuliter serrata, nerco in mucronem brevem producto $r$ ante apicem exanido fuscescente; perichactialia longius acuminata majora; omnia plus minus aequaliter concava saepe complicata flexuosa haud revoluta tenera; theca in ped. purpurascente erecto longiusculo erecta, ovata truncutu fusca, operculo oblique rostrato columella exsertu elevato longe persistente.

Br. Furop. 18-20. p. 12. 1. 7. - Gymnost. Systilium Fk. G. obtusum Turn. Must. Hih. P. 9. T. 1. - G. alfine Br!nt. (ierm. 1. p. 138 et $140 . t .9$. 
ß. intermedia; folia superne e cellulis diaphanis vix papillosis firmioribus echlorophyllosis areolata. - Forma, quae typum cum sequente varietate, per se quasi propria specie, conjungit.

\%. chlorophyllosa; folia superue e cellulis valde chlorophyllosis laxis vix papillosis v. lacvibus areolata. Gymonost. Heimii Hdw. Musc. Fr. I. p. xt. t. 30. e spec. Heduiginuis!

Patril. In locis praccipue salsosis per Huropae partem magnam passim et in Anterica septentrionali: D rummond; pr. Cap. Horn in insula Fremilae: J. D. II o o ker. Prope Spandau Berolini vicinam urbem detexit Cl. Il eim, medicus ille scientiae nostrae intimus, ingenio excelso. Majo, in alpibus aestate.

Flos masc. in ramo brevi terminalis, foliis $2-\mathbf{3}$ caulinis similibus, antheridiis robustioribus, paraphysibus multis robustis acutis $v$. plus minus clavatis brevibus mixtis.

8. P. flavipew Mont. (AnI. J. sc. nat. 1845. 4. p. 122.); monvica; cespitosa, radiculis permultis intertexta, subsimplex, innovando ramosa; folia laxe imbricata crecto-patentia, late oblongo-lancenlata elongulu longe ucuminulu, nervo temi flexnoso fermugneo eranido, apice purcissime dentatu, margine haud revoluta, basi e cellulis laxissimis elongate hexagonis tenerrimis pellucidis superne minoribus rotundato-hexagonis pellucilis lacvibus reticulata; theca in ped. elonguto flavido superne purpurascente recto mimate obconica, deoperculata turbinata bruncata masertstome, operculo convexo-conico oblique rostrato, columellae tandem liberae exsertae adhaerente.

C. Gay. Hist, de Chile, Bot. Cr. t. 3. f. 2.

Puriu. Chile, ad terran: C. Gay.

Flos masc. in ramo brevi infra llorem fent. posito terminalis; foliis perig. canlinis similibus, antheridiis elongatis robustis paraplysibus crasse clavatis mixtis. - A $P$. Heimii proxima notis illustratis facile distinguitur.

9. P. Iongirontris IImp.; monoica; laxe cespitosa humilis robustu simplex; folia laxe imbricata crecta patentia elongata pauca, upice porum falcuta, lute otato- 
lenceolutu concava, nervo crasso ferruginea vubiginosomecronata, margine medio parum revoluta, apicem versus sensim increqualiter grosse servuta, marginata, basi e cellulis laxis amplis hexagonis pellucidis laevibus, superne minutis opucis tenuissime papillosis areolata; perichaetialia majora; theca in ped. elongato flexuoso erecto purpureo cylindrico-oblonga robusta crecta fusca, operculo conico longirostrato obliquo.

Gymnostomum longirostre Br. et sich. in Mrse. Ahyss. Schimp. 11. No. 475 .

Patria. Abyssinia, in alpe Deggen altitud. 12000', 3. Nart. 1840: W. Schimper.

Antheridia in axilla folii late cordato-acuminati brevis multa robusta, paraphysibus multis longe stipitatis et acute clavatis robustis fuscis breviter articulatis mixta. Inabitu Burbulue subulutue, P. Ileimii proxima et pulcherrima species.

\section{b. Folia integra. \\ r. Folia acuminata.}

10. P. eustoma Khrh. (Beitr. II. p. 187.); monoicl; laxe cespitosa $r$. gregaria, simplex $v$. dichotome ramosa, humilis $\mathrm{v}$. elata; folia patentia et patula, e basi oblonga angusta elongate hexagone pellucide parce chlorophyllose reliculata tenera laevi sensim intundato-ovata acuminata, nervo crasso viridi in mucronem plus minus elongatum strictum producto, margine integerrimo va apice obsolete crenulato plus minus revoluta, superne e cellulis minoribus amoene chloromhyllosis diuphanis rehti luerissimis areolata, plus minus complicate concara; perich. majora; theca in ped. brevi purpureo truncato-aboeate macrostoma, operculo e basi convexa oblique rostrato; calyptra glabra.

P. trunctet Bi. kirrop. 18-20. p. 9. t. 4 ct 5. - P. enstoma

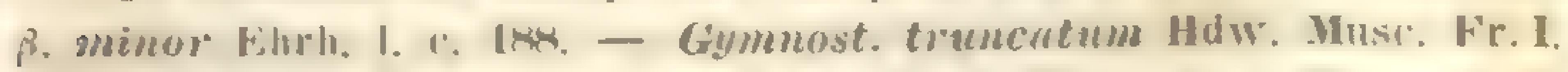
1. 13. 1. 5. - G. Eruncutulum Hew. Fund. Must. H. W. 87. - Brid. I. 1. 67. - G. cuspidutum kophl. Aull. Wett. Grsells. 11. p. 130. e

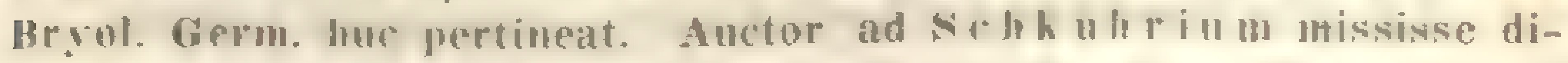
ritur; in cjus herhario autem frustra quaesivimus. - Bryum trun- 


\section{5๊4. STEGOCARPI. ACROCARPI. POTTIA.}

catulum L. Sp. Pl. p. 1584. - Br. exiguum, creberrimis capsulis rubris, Dill. Musc. p. 34, t. 45. f, 7. F-K.

$\beta$. major; robustior, theca ovali-oblonga truncata.

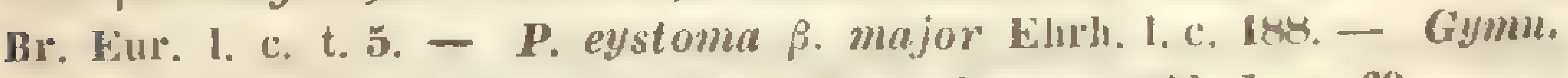
intermedium schw. Suppl. I. I. p. 19. t. 7. - Brid. 1. p. 69.

$\gamma$. subcylindrica; foliis ex ovali late lanceolatis loumgitus mucronatis, theca subcylindrica. Br. Eur. 1. c.

Patria. In agris, graminosis, pratis liumidis, ad fossarum margines, in muris rupibus et arborum truncis terra obtectis per totam Europam, in Africa et Anerica sept. Var. $\beta$. ubique vulgatissima; var. $\gamma$. in agris Sardiniae.

Hlos masc. P. minutulue. Specimina prope Halam in truncis populorum antiq. excarat. terra obtectis legimus, quorum thecae loco peristonii membranam basilarem ralde exsertam laciniatam ostendunt.

11. P. Wilsoni Br. et Sch. (Br. Europ. 18-20. p. 14. 1.6.); monoica; liabitus $P$. eustomae; folia laxe imbricata patula, e basi angusta oblonga elongate hexagone pellucide reticulata tenerrima lacvi sensin rotundato-ovata obtusa, nervo crasso viridi in aristam plus minus flexuosam producto, margine integerimo superne parum revoluta, superne e cellulis minoribus opacis tenuissime pupillosis areolata, subcomplicate concava; perichactialia majora; theca in ped. brevi flavido oblongo-clliptica, ore paulisper contracta, exannulata fusca, operculo oblique rostrato, calyptra superne scubra.

Gymnostomum Wilsoni Hook, Bot. Miscell. I. 1830. 1. 143. t. 41. - G. solivagum Green in Brid. I. p. 69?

Patria. In Anglia ad terram pr. Orer in comitatu Cheshire: Wilson detexit; in arvis pr. 'Torfar Scotiae: Drummond.

Antheridia in axillis folior. super. solitaria v. binata libera, longiuscule stipitata, paraplysibus teneris litiformibus mixta. Spec. tenclla!

12. P. Mexieana Hmp. (IIb.); monoica; habitus P. enstomae $\beta$. majoris; folia caulina subspathulata, e basi 
oblonga laxe reticulata sensim ovata dilatata, nervo crasso in cuspidem producta, e cellulis amplis teneris chlorophyllosis mollibus hexagonis areolata, integerrima, margine parum revoluta, concara, paullo flexuosa, lacvia; theca in ped. Grevi rubro erecta brevis maxime truncata turbinuta ampla physcomitrioidea.

Patria. Mexico.

A P. eystoma $\beta$. majori simillima thecae forma primo adspectu differt, a $P$. flaripede simili pedunculis brevioribus, foliis integerrimis firmioribus et theca ampliore distat.

13. P. minutula IImp.; monoica; ammu subsimpled pusilla greguriu; folia pauca erecto-patentia ovato-et oblongo-lanceolata, nervo crasso ferugineo pungentia, margine integerrimo ubique fere revoluta, subcarinate concava, basi e cellulis laxis pellucidis amplis brevibus paucis superne minoribus parce chlorophyllosis diaphanis parce et tenuissime papillosis firmis areolata; perich. lanceolata; theca in ped. brevi flavido minute ovato-truncata macrostoma fusca examulata, operculo late obtusoconico.

Br. Europ. 18-20. p. 8. t. 3. - Gymnost. minululum schw. suppl 1. I. p. 25. t. 9. - Brid. I. p. 61.

ק. vufescens; foliis angustioribus rufescentibus. $\mathrm{Br}$. Fur. 1. c. - G!/mn. rufescens sichultz. Fl. starg. p. 27\%. - lc. in Br. Gelim. 1. p. 121. t. 9. - Brid. I. p. 62.

$\gamma$. conica; foliis ovato-lanceolatis brevius mucronatis, theca ore angustata. 13r. Eur. 1. c. - Gymnost. conicum schw. suppl. I. 1. p. 26, t. 9. - Brid. I. P. 63. - G. reftexum Brid. 1. p. 63 !

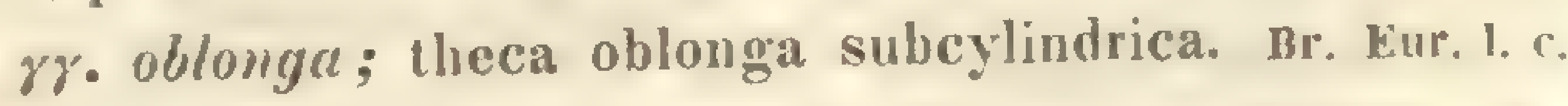

Patria. In locis natalibus $P$. eystomue regionum prime montosarum Europae mediae et occidentalis. Tal. ry. E Sardinia retulit Fr. Müller. - Auctumno et mimo vere.

Flos mase. in axillis folior. super. sessilis gemmiformis minutus, foliis $2-\mathbf{3}$ ovato-acuminatis concavis cner- 
vibus fugacissimis, igitur antheridis plerumque nudis $\mathbf{2}-\mathbf{3}$ minutis stipitatis, paraphysibus tenerrimis $v$. nullis mixtis.

14. P. brevicaulis C. Müll.; subcespitosa brevis simplex; folia late ovata, nervo excurrente apiculata, margine recurva integerrima; theca cylindraced exannulata subaequalis, operculo conico apiculato. $\div$.

Gymnost. brevicaule Tayl. Lond. Journ, of bot. 1846. p. 42.

Patria. Nova Hollandia ad flumen Swan River: J. Drum mond.

Ex obs. Cl. Wilson (1. c. p. 447.) a P. minutula $\gamma$ obtusa vix diversa videtur; sed folis magis ellipticis, nervo vix excurrente et operculo apiculato distat.

15. P. macrocarpa Schimp. (Ann. d. sc. nat. Ser. II. T.VI. p. 115. t. 8.); monoicl; caulis brevis subramosus; folia ovato-lanceolata, terminalia majora, concara integerrima, margine haud revoluta, nervo sub apice evanido, erecto-patentia, sicca incurva, laxe heragono-areolata; theca eiserta magna subsphaericu brevicolla, operculo plane convexo umbonato. t.

Patria. In terra lutoso-arenaria pr. Talparaiso Chiles: Bertero.

\section{B. Tolia obtusata.}

16. P. obtusifolia C. Müll.; monoicu? brevicanlis pusilla annua subsimplex erecta; folia crecta, arcte imbricuta, inferiora e cordato ovata, superiora oblonga, suprema fere spathulata, upice rotundata, intererrima, pallide c viridi badia, nervo crasso ante apicem evenido lurido, e cellulis subquadrate hexagonis pellucidis, inferioribus dimidio longioribus quam latioribus, areolata; theca in ped. erecto brevinsculo orata truncata laevis baclia, operculo e convexo brevirostri obtuso rolumellare exsertar adhaerente. t.

Gymnost, obtusifolium R. Br. Suppl. Appent. II. Parryan. p. 299. - Schwägr. Suppl. 11. II. 2. p. 83. $t .176$.

Patria. Insula Melville: Sabine, navarchus. 
A P. eystome fide Sclıwägricheni simillima notis cursive impressis diversa.

17. P. amblyophylla C. Müll.; cespitosa brevis erecta innovando ramosa pallide viridis; folia patentia v. erecto-patentia oratu obtusissima, basi dilututu, margine recurra, integerrima concava mimute reticuluta, nerro valido subcontimo, ramulina magis exacte orata, margine minus recurva; theca in ped. longiusculo semunciali gracili flavo-rubicundo terminali oruto-oblongu, supra medium leniter contractu, rufo-fusca, operculo conico acuminato thecam subacquante recto. $\div$.

Gymnost. amblyophyllum Hook. Rot. Miscell. I. 1830, p. 352. tab. 75.

Pratria. America meridionalis, ad ripas circa Mendozam: Gillies.

18. P. vernicosa IImp. (IIb.); dioica; gregaric cespitulosa maxime explanata, intense viridis pusilla subramosa; folia caulina ovato-oblonga obluse integervima seminervia, ramulina subrotumduta, luxe pellucide areolata; therae reberrimae in ped. perbrevibus ovatae crectae brumene nitidissimue, opereulis longe rostrutis.

Gymont, vernicosum Hook. ill Wall. ('at. 11. 7549. - IC. PI.

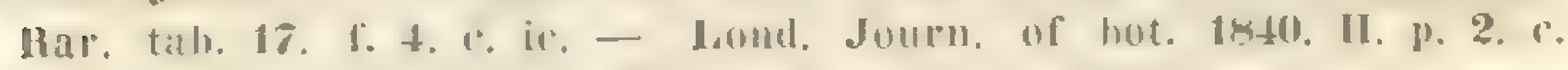
diagnosi.

Futriu. India orientalis, Prome: Wallich. Java, in muris pr. Diocja societate Bryi exilis: Junghulın, Aprili.

Spec. Javanica ramulos tenuissimos erectos remotifolios viridissimos, capitulis patulis instructos, effundunt. Species pulcherrima tenella.

\section{Species non satis notae.}

Gymnostomum Japonicum IIdw. (Sp. Musc. p.34. t. 1.); pusilla crecta tenera simplex; folia remola pauca oblongo-lanceolata integerrima tenera subexcurrentinervia; theca in ped. purpurascente longiusculo ovata brevis marrostoma fuscella, oper(ulo conico-hemisphaerico mammillato. 
Brid. I, p. 67.

Patria. Japonia: 'T hu n ber g.

Ad Poltiacens magis, quam ad Funurioideus pertinere videtur. Ilabitus inter Pottium eystomum et mimutulam.

Sectio III. Tyophila Brid. I. p. 760. - Thera gymmostoma, rarissime peristomata. Folia plus minus lata maruinibus involutis, hasi pellucide superne minute opace areolata, plerumque farile emollientia. Inforescentia dioica. Calyptra plerumune angusta suhtorta. - A Pottia nunquan discerni potest, nam areolatio folii omnino Eupottiae est, ut in Hyophila blanda videmus.

\section{A. Acaules.}

19. P. Barbula C. Müll.; acaulis gregarie cespitosa paucifolia simplicissima; folia conferta vix tortilia, oblongo-lanceolata inferiora acuminata, superiora obtusiuscula, parum involuta, basi parallelogramme superne grosse rotunduta, margine igitur subcrenulatu, nervo subcontinuo; theca in ped. breviusculo purpurascente erecta cylindrica vix curvula angusta brunnea annulata, operculo conico subulato rectiusculo.

Hyophila Burbula Hmp. Bot. Zeit, 1846. p. 267. - Gymnost. Barbula schwiigr. suppl. II. II. 1. p. 77. t. 175.

Putriu. Insula Cuba, ad rupes calcareas: Pöp pig.

P1. mascula robustior, flore terminali minuto tetraphyllo, foliis minutis ovatis acutiusculis enervibus. Antheridia parva turgida, paraphysibus tenuissimis mixta.

20. P. blanda C. Müll.; acaulis, gregarie cespitosa paucifolia simplicissima; folia conferta parum tortilia, e busi breviter oblongu laxiuscule molliter pellucide reticulata late liguluto-sputhuluta, sicca valde convoluta, obtusata, nervo crasso ante apicem evanido, integerrima; theca in ped. brevi flavido erecta cylindrico-elliptica brevicolla fusca minuta, annulo lato columellae arcte appresso, ore angusto, operculo oblique subulato.

Hyophila Gardneri Hmp. Bot. Zeit. 1846, p. 267. - Hymenostom. abtusifolium C. Müll. Bot. Zeit. 1845. p.91. - Gymnostom. blandum Hook. et Wils. Lond. Journ. of l,ot. 184. p. 151. 
Patria. Brasilia, in rupibus arenaceis pr. urbem Oeiras, Majo 1839.: Gardner Coll. No. 6.

Structura foliorum maxime ad Eupottiam accedens.

21. P. obtusifolia C. Müll.; acaulis cespitosa paucifolia simplicissima; folia conferta valde tortilia, e busi longe oblonga pellucide minutius reticulata longiora snperne ligulata vix spathulata, apice obtusata plerumpue cmarginatu, nervo continuo, e cellulis multo minoribus et magis opacis areolata, tenuissime papillosa, integerrima; theca in ped. brevi flavido erecta cylindrica angustissima (annulata?), operculo longe et oblique subulato tenuissimo.

Hyophila Wilsoni Ump. Bot. Zeit. 1846. p. 267. - Weisia obtusifolia (c. Müll. 1. c. 1845. p. 91. - Gymnostom. Barbula Houk. et Wils. Lond. Journ. of bot. 1844, p. 151.

Patria. Brasilia, Serra di Araripe pr. Brejo Grande in prov. Ceará. Febr. 1839.: Gardner Coll. No. 3 et 4.

A $P$. blandu notis cursive impressis facile distinguitur.

22. P. spathulnta C. Müll.; acaulis gregarie cespitosa paucifolia; folia conferta, e busi brevissime oblonga subito late spathulata, obtusiuscula valde comroluta, integerrima, nervo continuo; theca in ped. brevi erecta, cylindracea; operculo subulato. +

Gymmest. spathulutum Harr. in Hook. Ic. PI. Rar. t. 17. et diagnosi in Lond. Journ. of hot. 1840. HI. p. 2.

Patria. Nepal: Wallich.

\section{B. Caulescentes.}

a. Folia integerrima.

23. P. Tortula C. Müll.; dense cespitosa pusilla erecta parce ramosa; folia brevia densa oblonga planiuscula, basi paulum angustuta obtusiuscule acuta, integerrima, parum involuta amoene viridia, nervo crasso fuscescente continuo, basi laxiuscule superne minute areolata; theca in ped. breviusculo purpurascente erecta 
cylindrica angusta rix curvula brunnea, operculo conico oblique subulato.

Hyophila Tortula Hmp. Bot. Zeit. 1846. p. 267. - Gymnost. Tortula Schw. Suppl. II. 1. 1. p. 78, t, 175.

Patria. Insula Cuba: Pöppig. Brasilia pr. Rio Janeiro: B e ske.

A P. Burbula proxima notis cursive impressis certe distat.

24. P. involuta C. Müll.; cespitosa humilis simplex; folia laxe imbricata tortilia, e basi brevissima angusta late orato-oblonga sublonga breviter acuminutu, sicce et madefactre valde involuta, nervo subcontimuo ferrugineo, basi e cellulis parvis firmis quadrate hexagonis pellucidis superne minutissimis opacis areolata; perichactialia intima breviora; theca in ped. elongato flavido inferne purpurascente erecto tenui erecta, uefuchlis, cylindrica parum curvula angusta longiuscula fusca anuulata, operculo subulato obliquo breviusculo.

Hyomhila Hoolieri IImp. Bot. Teit. 1446. P. 267. - G!lmnost. inrolutum Irook. Nuse. Ex. t. 154. - Brid. I. p. 75. - Sidiw. Suppl. 11. 2. p. 81, t. 176.

Patria. Nepal: Gardner.

25. P. involutifolia C. Müll,; habitus P. involutne; folia breviora, madefurta concupa quidem, sed hand involuta obtusiuscula, vel nervo crasso ferruginco distincte in apiculum producto; perichaetialia intima magis acuminuta; theca minus cylindrica, sed brevior cylindrico-elliptica haud curvula.

Iyophila Caripensis Hmp. I.inn. XX. p. 68. - Hymenostom. inrolutifolinm ('. Mïll. Limm. XIX. p. 198.

Patria. Columbia, pr. Caripe: Moritz Coll. No. 127.

26. P. Javanica C. Mïll.; dense cespitosa pusilla simplex basi innovans; folia inferiora appressa suberecta oblongo-lanceolata ferruginea, suprena patentia ovata saturate nitideque viridia; omuia obtusa, nevo valido fusco mucromulutu, superne dense, infima basi pellucide areolata; perichaetialia paullo breviora orata acutiuscula evanidinervia; theea in ped. interdum gemino tenui fla- 
vido inferne purpurascente erecta, cylindrica paullo curvula brevicolle fusca, ore contracta, annulata, operculo subulato obliquo breviori.

Hyophila Javanica Brid. 1. p. 761. - Rottleria Jaranica Brid. I. p. 106. - Gymnost. Jatanicum Nees ah Fis. in Mov. Ait. Plyys. Med. Ac. Caes, XI. I. p. 129. t. 14. f. 2. - Bril. I. p. 757.

Patria. Java: Bl u me.

A P. imvolut simillima notis laudatis differt.

27. F. Zeyheri Hmp. (in litt.); dense cespitosa humilis parce dichotoma rigidissima; folia parum tortilia, latiuscule lunceolata sensim perfecte acnminala, nervo crusso in mucronem elongatum crassiusculum strictum moducte, parum convolutu, perichaetialia longius cuspidata; omnia basi laxe hexagone reticulata pellucida; thecae in ped. brevibus flavidis erectae ovales breves fuscidulae saepe binatae brevicollac, cxannulatae, operculis longe subulatis obliquis.

ITeisin Capensis spreng, in schedulis. - Gymnost. euchurum Teyher. PI. Cap. No. 480.

Patria. Prom. b. spei: Za yher.

28. P. rufescens C. Müll.; pusilla laxe cespitosa erecta innovando ramosa vufescens; folia remotiuscula erecta, rigidu non tortu, rufescentiu, superne luto-lunceolute, margine arcte involuta integerrima, nervo continuo crasso suturute ferrugineo, basi e cellulis ampliusculis pellucidis superne minutissimis opacis tenuissime papillosis areolata; theca in ped. breviusculo ferrugineo crecta tereti-oblonga aequalis fusco-badia maxime late annulata, operculo longe subulato obliquo. $\leftarrow$.

Gymnost. rufescens Hook, in sichw. Suppl. III. 11. 1. t. 206. et Harvey in Hook. Ic. PI. Har, t. 17.

Putria. Nepal: Wallich.

29. F. Mollii C. Müll.; dioica; humilis parce divisa rigida sordide viridis; folia caulina contorta, late oblongolanceolata, basi dilatata, nerro cresso in cuspielem brerem excurente, basi e cellulis Iongioribus laxioribus llavide diaphanis superne minutissimis opacis areolata; pe-

c. Müller: Synops. musc。 frond. 
richactialia subconvolutacea; theca in ped. stricto medio rubente erecta oralis, peristomatu; peristomii dentes infra orifocium oriundi membranacei articulati latiusculi; operculum ronico-subulatum subrectum.

Iymenostomum contortum Kze, in liegensh. Flora 1830. II p. 373.

Patria. Insula Madera, in Pico branco ad lapides: 11 oll 1828. Decbr.

Dentes imperfectos, tenuissime membranaceos, liyalinos, breves vidimus et hac nota species memorabilis, habitu et structura omnino Iyophilue. Perist. ut in Intcalypta?

\section{b. Folia dentuta.}

30. P. cylindrica C. Müll.; habitus P. imolutae; polia multo lutiona, marlefacla minus imeoluta, upice distincte servatu, neren cressissimo subferrugineo ante apicem evanido; perichactialia intima luo obtusissima upice cremulute, nervo temi longe infra apicem evanido.

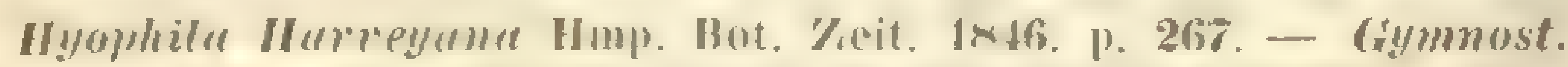
cylimericum Hook. It. Pl. Halr. t. 17. et diagnosi in Land. Jourll. of loot. 1840. II. 1.2. - schw. suppl. IV. t. 305.

Patria. Nepal, Prome: IVallich.

31. P. Pöppigiana (.. Müll.; habitus P'. cylimbrecre, sed mullo robustior, dense cespitosa; lolia arefo imbricata tortilia, e basi breviter pellucida late ovato-oblonga breviu, madefacta magis involuta, apice dentata, undulata, nervo minus crusso in upiculum distincte producto; perichactialia exteriora distincte acuminatu excurrentinervid, intimum nhicum obtusissimum apice cremulatum; theca P. cylindricae.

Putriu. Chile australis: Pöppig.

Sertio IV. Fymenostylum Brid. II. p. 81. - Folia angusta, maleinihus creetis v, revolutis, carinata linuceulata.

32. P. longirostris C. Mïll.; dioicu; sequenti similis, sed yracilion et superme glenen-viridis; folia caulina crispula minus homomalla, madefacta valde patula, 
longiuscula angustissime lineuri-lunceolutu acutu, integerrima, basi infima e cellulis pellucidis teneris parris irregulaviter rectungulari-hexugonis superne minutis subquadratis sordide rividibus, hund chlorophyllosis mollibus, firmis, tenuissime papillosis areolata, parum flexuosa, nervo ante apicen evanido; perichaetialia e basi multo laxius reticulata longe pellucida tenera lato-ovata subvaginante sensim longe lineari-ucuminata; theca in ped. breviusculo fusco erecta obovata, fusca, dein ovalis brunnea exannulata parva, operculo longe et oblique subulato.

Gymnostomum longirostre Kze, in Pöppig ('oll. Pl. C'lil. III. No. 230.

Putria. Chile australis in Andibus: Pöppig.

A P. xanthocarpa simillima notis cursive impressis certe distat.

33. P. xanthocarpa C. Müll.; divicu; dense cespitosa elatiuscula erecta, brevissime et parce ramosa, inferue pallide ferruginea superne intense sordide rividis, inter folia tomentosa; folia caulina crispula rigida, ad innum latus spectantia, madefacta valde patula, longiuscule luto-lanceoluta, integerrima, basi infima e cellulis pelluridis laxis majusculis hexuyonis superne depresse quadule heragonis rhlorophyllosis dein diaphanis tenuissime papillosis areolata, parum flexuosa, nervo subexcurrente; perichactialia similia, hasi laxa pellucida longiore; theca in ped. breviusculo fusco crecta obovalis exannulata parva fusca, operculo, longe et oblique subulato concolori.

Hymenostylium xunthocurpmm Brid. II. p. 2 2. - Gynnostom. xanthocarpum Honk. Musc. Exot. II. t. 153.

Patria. Nepal: Gardner.

34. P. bicolor C. Müll.; divicu; dense cespitosa humilis parce ramosa, intense viridis inferne ferruginea radiculosa, gracilis; folia caulina conferta, e basi erecta ovata v. oblonga plus minus recurva lanceolata carinata acuta evanidinervia, margine interdum revoluta integer- 
rima, inferne cellulis plus minus elongatis subrhomboideo-hexugonis angustis ferrugineo-coloratis firmis superne sensim minutissime quadrate hexagonis tenuissime papillosis opacis arcolata, scabriuscula; perichactialia externa basi latiora breviter vaginantia, intima longe vaginantia breviter acuminata ubique e cellulis rhomboideoclongatis reticulata; theca in ped. breviusculo rigido purpureo crecta, elliptico-oblonga brevicolla purpurea, late ammulata, gymnostoma, operculo conico obliquo brevi et orificio angusto.

Gymnostomum (Gymnoueisia) bicolor Br. Fur, 33-36. p. 4. tab) 1.

Patria. In terra calcarea montis Radstadter 'Tamern alp. Salisburgiae: F unk et in alpibus Julicis: Send tner. In alpib. Bavaricis, Hochrogel 6200' alt. leg. Send ner. Rarissima. - Aestute.

Pl. mascula gracilior, floribus hexaphyllis. Folia perig. ovato-lanceolata nervosa.

35. P. ceratodontea C. Müll.; dioica; late laxe cespitosa radiculosa simplex, upice innovanlo semel divisu, luteo-viridis crispula; folia caulina laxe imbricata crecto-patula, oblongo-lanccolata, complicato-carinata parum undulata, margine inferne valde revoluta, integerrima, superne e cellulis minutis rotundatis diaphane opacis basi parum majoribus quadrate hexagonis firmis areolata, sublacria, nervo crasso evanido flavido; perichactialia robustiora; theca in ped. Iongiusculo purpureo flexuoso erecta, elliptica ochracea exannulata, operculo oblique subulato, ad colunellam longe adnato.

Patria. Prom. b. spei, Philippstown ad flumen KatRivier, Junio: Ecklon.

Habitus Ceratodonti pupureo primo adspectu similis, sed planta pottioidea.

\section{Pottiae obscurae.}

1. Gymnostomum simplieissimum Brid. (I. p.67.); bipollicare simplicissimum erectum pallidum; folia capillaria tenuissima imbricata; theca rotunda nuda. $\div$. 
Sylagnum simplicissimum Loureiro FI. Cochincl. II. p. 839.

Putre. Cochinchina, in muris et truncis arborum, tempore pluvio.

2. Gymnost. Nilotieum Delile (F). Aegpt. p. 45. Illustr. 31.); pusillum simplicissimum; folia $6-8$ amplexicaulia acute lanceolata subcarinata lineam longa, suprema perichaetialia grandiora rosacea fructum obvelantia, theca in ped. recto, thecam aequante, intra folia subimmersa subsphaerica depressa margine crassiuscula laevissima nuda, operculo depresso-convexo acuto brevissime rostellato; calyptra parva pyramidalis, a basi ad medium fissa. $\%$

Brid. 1. p. 736.

Patria. In fossis prope hydraulicas rotas in Cahiro, Gizeh etc. ad canales, et in Aegypto inferiore cespitosum: Delile.

3. G. foliosum Roehl. (Ann. Wett. Ges. II. p. 129.); caulis 3-4 linearis longior erectus ramosiusculus. Folia densissime conferta, caulem prorsus obvelantia, directione varia, angusta, oblongo-subulata, obtusa carinata integerrima, nervo crasso exarata, suprema viridia, caetera squalide brunnea; ped. terminalis erectus, vix foliorum apicem superans tortilis dilute brunneus; theca parvula ovata, orificio mediocri, concolor. $\dagger$.

Brid. I. p. 95.

Patria. In Suecia pr. Amboga cespitibus dense implexis vivit.

Species delenda.

Gymnost. Anceidum Brid. I. p. 96. Specimina sterilia Hb. auctoris ad Bryum quoddam, forsan erythrocerpum pertinent.

\section{Gen. V. Schistidium Brid.}

Mant, Must. p. 21. - Br. univ. I. p. 113. - Fiedleriu Rabenh. in Hegensh. Lot. Zeit. 1848. et Deut. Crypt. - Pottic Br. ct sch. - Gymonostomum al. - Anaectangium Höhl. 
Nomen a graeco $\sigma x i$ ç findo, ob calyptrae fissuras basilares.

Calyptra mitraeformis basi laciniala. Peristomium nullum. Cactera Poltiae.

Habitus Phasci cuspidati et genus ob calyptram distinctissimum.

\section{a. Folia lamellosa.}

1. Seh. subsessile Brid. (1. c.); monoicum; gregarium $\mathrm{v}$. late cespitulosum humillinum annuum $\mathrm{r}$. bienne ramosum, foliis piliferis canescens, intense viride; folia dense imbricata erecto-patentia, e basi angustiore sublaxe pellucide reticulata brevi sensim latiora ovata, nervo crasso viridi in pilum dongum denticulatum producto superne lamellis undulatis lobatis pluribus praedito, margine integerrima subinvoluta, superie e cellulis minoribus amoene chlorophyllosis hexagonis diaphanis papillosis areolata, plus minus valde concava; theca immersa breviter pedunculata subglobosa brunnea, aperta cupuliformis ampliata macrostoma, operculo magno rostellato recto; calyptra glabra tenera profunde laciniata flavida.

Fiedleria subsessilis Habmh. Dent. Crypt. 11. 1. 98. - Poltia subsessilis Br. Hur. 18-20. 1.6. t.1. - Gymnost. subsessile sichw. supul. 1. I. p. 27. - G. acuule Wr. et M. Bot. Tisi(hl), p, 79. t. 6. f. 4-8. - Anoectanyium acaule Rïhl. Ann. Wett. Gies. Il. 1. 200.

Putria. In terra argillosa, prime muros amans, per totam Germaniam passim et in America septentrionali: Drummond. Prope Jenam detexit Flörke. - Vere.

Flos masc. femineo approximalus sessilis, foliis $\mathbf{1} \mathbf{- 3}$, ovato-acuminatis concavis laxe reticulatis enervibus fugacibus, antheridiis parvis et paraphysibus clavatis.

\section{b. Folice elamellosa.}

2. Sch. marginatum Ilook. et Wils. (I tond. Journ. of bot. 1814. p. 539.); monoicum? dense cespitosum lutmile ranosum ferrugineum; folia dense imbricata erectopatentia, e basi angustiore clongate sublaxe pellucide reticulata brevi sensim latiora ovato-lanceolata, nervo crasso 
ferrugineo in acumen breve producto, margine c cellulis densissimis incrassatis e basi usque ad apicem late et ferrugineo-limbata, apice denticulata, superne e cellulis minutis opacis tentissime papillosis areolata; theca immersa breviter pedunculata subrotunda brumnea, operculo rostrato erecto, calyptra magna firma fusca e cellulis incrassatis reticulata, basi laciniis multis irregularibus pracdita, apice scabra.

Putriu. Insula Kerguelen maris antarctici: J. D. II o o k e r.

A Sch. subsessili simillimo longe recedit, pulcherrima species!

Gen. VI. Trichóstomum lldw. em.

Musc. Fr. I. t. 28. - Leptodontium IImp. - Desmatodon Brid. - Dilymorlon mult. allt. - Dicremum Weh. et Molis. Barbula, Grimmia, Weisia, Cynodun nommll. ex parte. - Plaubelia Brid. - Suartaia IIw. - Bryum et Mnium intiq.

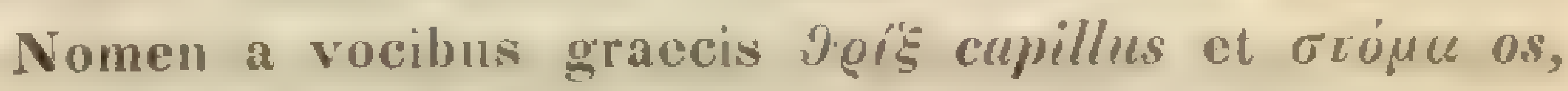
ob dentes perist. capilliformes, ductum.

Calyptra dimidiata. Peristomium simplex: dentes sedecim ad basin in cilia duo, interdum irre„ularia igitur plura, fissi, erecti stricti hrud tortuosi.

Barbulae generi proximum.

sertio I. Pyenophyllum. Folia plus mimus andusta stricta

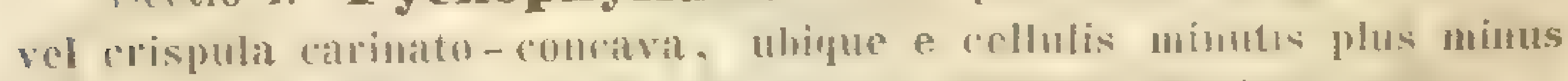
momomorphis et rhopophrllosis sappe quadratis aleolata crecta. Inforescentia dioica rarissime monoica.

\section{A. Tenella.}

1. Tr. brevicaule Ilmp. (IIb.); brerissimm pancifolium subsimplicissimum; folia lingulato-oblongu apiculata subcomolulucee, integerrima, madefacta patentia, sicea incurva contorla, nerro apice evanilo, basi e cellutis pellucidis amplis hexagonis superne grosse rolundutis haud opacis firmis chlorophyllosis arcolata; theca in ped. erecto stricto tenui rubente oblique cylindrica erecta 


\section{S'TEGOCARPI. ACROCARPI. TRCHOSTONUM.}

angusta annulata, operculo conico subulato dimidio breviori, dentibus gracilibus aequalibus rugulosis usque infra medium partitis rubris.

P'utriu. Java, ad parietes calce callitos balnearii ad Djocjo, Aprili: Junghuhn, societate Pott. Jartunicue legit.

Pottine Burbulue ex labitu simile.

2. Tr. Drientale Willd. (IIb.); late cespitulosum; caulis pusillus tenellus gracillimus fragilis, apice in ramos brevissimos duos divisus et reclinutum vel flexuose ascendens; folia mimutu erecto-appressa stricta, sicca tortilia, curinato-oblongu, obtusinscula, angustiora, nervo flavido in cuspidem brevissimam plus minus reflexam producto, dorso scaberrimo, margine parum unduluta integra paullo recoluta, e cellulis basi minutis quadrate hexagonis pellucidis teneris, superne minutissimis obseuris tenuissime papillosis areolata; perichactialia angustiora longiora basi amplexantia teneriora; thera in pedunculo brevi rectiusculo suepe geniculate descendente ochraceo crecta ovalis minuta plus minus tuberculose ochracea, operculo conico obtuso obliquo; perist. dentes tenues, basi membranacei fusciduli haud trabeculati subvemoti, ciliis binis obscuris regulosis.

Trich. Indicum schw. Suppl. I. 1. p. 142. t. 36 , non Willdenow! - Barbula Indica Brid. I. p. 54. - Turtula Indicat Hook. Musc. Exot. t. 135. excl. Syll. Willd, quocum tam sclw quam Hooker et Bridel commutavere.

Putriu. India orientalis, ubi cum plantis multis aliis apostolus ecclesiae Klein in parietibus domorum mensibus Dec. et Jan. primus legit et ad Willdenow misit. Ad terram et in muris Ilorti Botanici Calcuttac leg. RottJer et Wallicls.

3. Tr. Berteroanum C. Müll.; cespitosum, tenellum gracillimum flexuose evertum tenerrime foliosum viridissimum, inferne ferrugineum subsimplex; folia minuta erecto-patentia sicca tortilia, lineari-ablonga obtusinscula, nervo flavido erassiusculo in cuspidem brevissimam pro- 
ducto, margine integra revoluta s. plus minus involuta, basi minute quadrate superne fuam maxime minute hexagono-areolata, tenuissime papillosa; perichaetialia basi e cellulis amplis parvis pellucidis hexugonis reticulata, apice parum crenulata; theca in pedunculo brevi temissimo flavido erecta, cylindrico-elliptica ore paullo coarctata ungustissima mimuta bruunescens, parum incurva, annulata, operculo conico - rostrato obliquo breviusculo; perist. dentes breves fusci rugulosi, inaequaliter binati et irregulares, in membrana valde exserta fusca positi.

Plaubelia tortuosa Brid. I. p. 522. e spec. Hb. Brideliani! Barbula Sprengelii schwägr. Sulpl. II. p. 64, t. 119. - Brid. I. p. 532. - Weisia Berterouna spr. syst. Veget. 1V. p. 156.

Patria. Hispaniola: Bertero.

Species omnium tenerrima, speciminibus $T r$. mut bilis vel crispuli minoribus vel $\boldsymbol{T r}$. Indico affinis.

\section{B. Elatu.}

\section{a. Inflorescentia monoica.}

4. Tr. glaucescens Sw. (in IIdw. Musc. Fr. III. p. 91. t. 37. B.); monoicum; dense cespitosum erectum elatiusculum valde fastigiate ramosum, e viridi lutescens, inferne ferrugineum saepe tomentosum superne moductione leprosa farinosa glaucescens, gracillimum; folia caulina inferne minuta remota, apice comosa subtortilia, e basi lanceolata lineari-subulata acuta carinata, margine erecto, apice dentata, nervo evanido, laevia, ubique e cellulis quadratis rectangularibus firmis chlorophyllosis areolata; perichaetialia basi laxiora pellucidiora longius reticulata; theca in ped. breviusculo purpurascente elliptica olivacea dein fusca leptodermis, annulata, operculo anguste conico subobliquo; perist. dentes valde variabiles longi erecti intense purpurei subrugulosi cruribus binatis v. subsolitarii v. partim obsoletis articulatis.

Bryol. Europ. 18-20. p. 18. t. 15. - Didymod. glaucescens W. et Y. B. T. P. 158. - Brid. 1. p. 513. - Leptotrichum glaucescens Hmp. Limn. XX. p. 71. - Bryun glaucescens Dicks. Hasc. 1V. PI. C'r. p. 10. - Br. caesium Vill. PI. Dauph. III. p. 879. 
ß. brevipedunculatus; theca in ped. paullo exserto. Did. aeruginosus Hook. in Brid. I. p. 516.

Patria. In rupium fissuris et praeprimis pascuis subalpinis et alpinis totius Furopac et in America septentrionali. Var. $\beta$. in istem locis rarius occurrit. -- Per totum acstutem thecis reperitur.

Flos masc. in ramo proprio plus minus clato ad pedem feminei posito, gemmaceus tenuis, folis perig. e basi late ovala concava colorata tenuiore subito patulis subulatis, antheridiis angustis longiusculis cparaphysatis.

\section{b. Infloresc. dioica. a. Folia tortilis.}

5. Tr. rigidulum Sm. (Fl. Brit. III. p. 1235.); laxe cespitosum vel subpulvinatum, e viridi ferrngineum, parce dichotome ramosum, subgracile plus minus humile; folia caulina crecto-appressa subtorfiliu, anguste oblongo-lanceolutu, carinato-concava, nervo crasso ferrugineo contimuo, obtusiuscule acutata, nurum recurer, rigidu, margine integerrimo revoluto, e cellulis ubique parvis, busi yuudrute hexuyonis pellucidis, superno incrussule rolun datis areolata, sublacvia; perichactialia busi amplexicunli longius amplius pellucidius of tenerius reticulatu, longiora; theca in pedunculo breviusculo purpurascente rigido substricto crecta, elliplico-cylindrice subangusta, annulata, coriacea dein fusca, operculo conico-subuluto oblipuo, thecte arcte adhaerente; perist. dentes in mentbrana brevi fuscidula erecti stricti regulariter binati, e basi articulatu fiescidula tenues nodosi fusci.

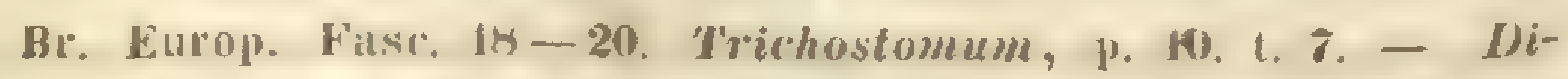
dymodon rigidulus Hdw. Musc. Frond. III. p. \&. 1. 4. - Bryum

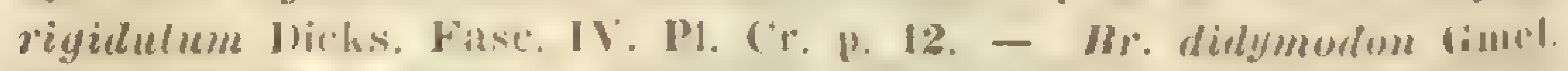
Nyst. Mat. II. p. 1333. - Desmutodon viupestri.s Fih. in Brid. I. P. 822. ex parte.

Parra. In muris rupibusque humidis rel siceis per totan fere Europan rarius, et in America septentrionali. - Auctumno et hyeme, in alpibus aestate. 
Pl. mascula fenincac similis, llorc gemmaceo. Folia perig. externa caulinis inferioribus similia, sed paullo lationa, interna breviora e basi lata concava longe acuminata ncrvosa. A Tr. conico notis cursive impressis distat.

6. Tr. mutabile Bruch (Br. Europ. Fasc. 18-20. Trichost., p. 8. t. 5.); dense cespitosum humile rigidum, infra comam fertilem innovans, sordide viride; folia erecto-patentia laxa, sicca tortilia firma, fatiusculo-lanceolata, nervo crasso depressiusculo flavido in cuspidem rectam planum crussiuscule acutam producto, margine parum undulata, integerrima, basi e cellulis tenuioribus plus minus flavidis et firmis, superne minutissime hexagonis et papillosis areolata; perichactialia angustiora et longius acuminata, linearia; theca in pedunculo longiusculo purpurascente erecta, plus minus ovuta breviuscula subumple sordide brumnea, exannulata, operculo conico longirostrato obliquo; perist. dentes valde mutabiles incermales brevissimi, per puria cohuerentes in membrana brevi positi, obsolete articulati sublacves pallide lutei vel rufescentes rugulosi.

Tr. brachyluntium Bruh et Nïll. in Hegensh, bot. Zeit. 1829. 1. 393. t. 3. - Didlynod. Brachylontius Wils. in Fingl. Flora V. 1. 30. - D. crispulus IVils, et D. Benthami Am. - plauhelia tortuosa Bruch in Mïll. Musc. Sardois.

Putriu. Sardinia, in fruticetis prope Cagliari et in angere limoso pr. Golfo di Spezzia: Fr. Müller 1827 detexit. Dalmatia in insula Passmann ad Porto St. Anconio et insula Lussin in Guarnero: Sendtner. Gallia sept. pr. Falaise: de Brébisson; in Pyrenacis: W. P. sch. Algeria: W. Schimper. Anglesca, in rupibus calcareis maritimis pr. Carneg Omen et 'Tros-y-Marian: Wilson. - Murtio, Amili, in reg. sept. Junio.

Flos masc. Tr. crispuli simillimi.

7. Tr. erispulum Bruch (Miill. in Regensb. bot. Leit. 1829. p. 395. t. 4.); habitus T). mutubilis; lolia caulina lanceolata et lincari-lanceolata, murgine incurvo obsolete unduluta; perichactialia basi ad 'modium engi- 
nunte elongate anguste flexuose firme areolata praedita; omnia, infimis exceptis, apice subincurva et fere cucullata, nervo excedente mucrohata; theca praecedentis; perist. dentibus gemellis inaequalibus vel in unum coalitis tenerrimis pallide flavicantibus vel rubellis fugacissimis.

Br. Europ. Fasc. 18-20. Trichostomum, p. 7. t. 4.

ß. brevifolium; dense cespitosum gracilius, foliis brevioribus lanceolato-acuminatis mucronulatis, theca minori. Br. Europ. I. c.

$\gamma$. angustifolium; dense cespitosum, humilius densius foliosum; foliis anguste lineari-lanceolatis acuminatomucronatis; perist. dentibus perfectioribus, cruribus subaequalibus. Br. Europ. 1. c. Trichost. viridulum Bruch. Mïll. ilt Regensb. bot, Zeit, 1829. p. 301, t. 5 .

Patria. In collibus dumetosis et rupibus prope $\mathrm{Ca}-$ gliari Sardiniae: Fr. Müller; Italia orientalis, in muris pr. Taranto: Habenhorst; Algeria: W. Schimper; Dalmatia, Torrette prope Spalato et in Littorale, Cersotsha pr. Flitsch. Sendtner. Var. $\beta$. formae typicae intermixta. Var. $\beta$. in arenosis humidis insulae Rhenanae Argentinensis: Kneiff; in Helvetia an obern Grindelwald-Gletscher: W. P. Sch imper.

Planta masc. nunc fertili similis, nunc gracilior et subsimplex. Folia perig. ovato-acuminata, tria interna externis minora obsolete nervosa. A $\boldsymbol{T r}$. mutabili notis cursive impressis distat.

8. Tr. brevifolium Sendtner (in litt.); dense cespitosum pulvinatum gracillimum erectum elatiusculum, apice solo viridissimum, inferne ferrugineum; folia caulina erecto-patentia, sicca tortilia, lineari-lanceolata obtusiuscula, nervo in cuspidem brevissimam subrectam producto, apice margine incurvo, integerrimo, basi e cellulis minutis flavide pellucidis quadratis firmis superne minoribus opacis hexagonis areolata; perichaetialia sensim longe vaginantia et longe acuminala, intima nervo excedente longe cuspidatu, teneriora pellucidiora laevia anguste elongate superne minute pellucide reticulata; theca in peduaculo 
elongato tenui stramineo dein purpurascente tortili crecta, mimute ellipticu fusca, exannulata, operculo longirostrato tenuissimo obliquo thecam superante purpureo; perist. dentes erecti longiusculi tenuissimi geminati aeguales rugulosi nodosinsculi fusci, in membrana brevi positi.

Patria. Bosnia, Sutynska: Sendt ner 1847. Jumio.

A Tr. crispulo simillimo foliis caulinis apice haud cucullatis, perichaetialibus longe acuminatis et cuspidatis atque theca minute elliptica, a $T r$. mutabili foliis perichaetialibus, theca et peristomio regulari distinguitur.

9. Tr. tophaceum Brid. (Mant. Muse. p. 84.); late dense cespitosum erectum plus minus elatum gracile fasciculato-ramosum, e viridi ferrugineum; folia erecto-patentia, sicca subtortilia, inferiora remota, superiora sensim confertiora majora, ovato-lanceolata obtusuta, nervo viridi ante apicem evanido dorso scubro, margine integerrima et e basi usque fere ad apicem ralde revoluta, carinato-concava, undipue e cellulis firmis subrotundatis subincrussutis parvis sordide viridibus areolata; perichaetialia longius laxius pellucide et perfecte hexagono-reticulata; theca in ped. longiusculo rigido purpureo erecto elliptica fusca excumulata; operculo longiuscule conico oblique rostellato; perist. dentes rariabiles, e membrana angusta aequales, v. cruribus solitariis obsoletis, v. sacpe integri per totam longitudinem perforato-cribrosi, rubri.

Brid. I. p. 495 . - Br. Furop. Fasc. 18-20. p. 9. tall. 6. Ancealypta tophacea Bruch in Br. Germ. 11. p. 148. t. 37. - Trichost. lineare \$m. FI. Brit. 1II. p. 1247?

Putria. Ad rupes toplaceas perpetuo irriguas nuscus crescens, cujus surculi innovati aquam terra calcarea impraegnatam filtrando singulis annis in tophum abeunt, hic illic per Germaniam; pr. Comburg Suevorum detexit Februario 1808 Fröhlich. In Gothia et Norvegia australi ex $\mathbf{A}$ gström. In Gallia sept. in abruptis maritimis calcareis et in maritimis Algeriae: W. Sehimper. Aestate. 
P. mase. gracilior, valde ramosa, floribus terminalibus gemmiformibus, folis perig. externis e basi concava lineari-lanceolatis obtusis, internis ovato-acuminatis, nervosis, paraphysibus et antheridiis numerosis. - I'eisicue verticillutue persimile, et folis interdum e cellulis longioribus quadratis areolatis pracditum.

10. Tr. Iaetum Kze. (in Pöpp. Coll. Pl, Chil.); gregarie cespitosum simplex, basi innovatione feminea longiore flexusa gracillima subremotifolia divisum, subhumile laete viride; folia omnia paru erecta, sicca tortilia, e basi amplexante concura ovata breviter acuminuta, inferiora obtusiora, superiora magis acuta, ubique quadrate, sed inferne magis rectangulari-arcolata, leptoderma, nervo subtenui ante apicem concarum subreflexum cranido flavido, dorso sublaevia; perichaetialia longiora; omnia margine flexuosa subinvoluta; theca in pedunculo elongato gracillimo flexuoso purpureo erecta cylindrica subaequalis angusta exannulata fusca, operculo conico longirostrato obliquo; perist. dentes in conum congesti brevinsculi tenerrime subulati angusti intense mupurei, rugulosi, basi in membranu breviter exsertu positi, in cruru duo laxins cohuerentia fissi.

Patria. Chile austr. in terra limnsa: Pöppigg.

\section{B. Folia stricta.}

11. Tr. trifarium Sm. (FI. Brit. III. p. 1235.); subpulvinatum sed laxe cohaerens teres rigidum erectum humile parce et breviter dichotomum, fuscescens; folia caulina erecto-appressa stricta rigida, madefacta patentia, ovato - lanceolata obtusiuscula, carinata, nervo crasso continuo, margine integerrimo busi recurro, undigne e cellnlis rolumlatis incrussulis areolata, sublaevia; perichaetialia mullo latiora obtusa, e ceteris cunlinis simillima; theca in pedunculo breviusculo rigido tortili purpureo erecta, oblongo-cylindrica, brunnescens, annulo simplici et operculo conico obtuso obliquo praedita; perist. dentes, mo more imperfecti, breves irregulares, usyue ad basin 
bifili, rel hic illic conglutinati pallide Alaridi remote et obsolete articulati lacevs.

Trich. limoides Fnal. Bot. t. 2295 non llirks. ex II o oker, Didymodon luridus Hornsill. in sipr. syst. Venet. IV. p. 173. - Hr. Furop. Fass. 29-30. bidymodon, 1. 4. t. 2. - Cynorlon luridus Brid. I. 1) 11\%. - Did. trifurius Nw. Musc. suer. p. 28. - Brid. I.

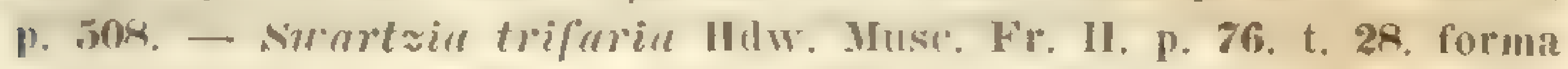
wratrilior, foliis lonuins acuminatis videtur! - Barbulu deusta Brid. I. p. 553 !

Putrill. In terra humida rel in saxis arenosis semidecompositis hic illic per Scandinaviam, Germaniam, Galliam, Britaniam et in America sept. ad catarractan Niagarae: Dr um ond Musc. No. 120. - Martio, Aprili.

P1. mascula gracilior, foliis minus confertis, flore terminali, foliis perig. cxternis erecto - patentibus ovato lanceolatis, internis in gemmam clausan conjunctis, brevioribus evanidinervibus.

12. Tr. conicum Нmp. (in litt.); laxe cespitosum, e viridissimo ferrugincum, parce dichotome ramosum, subgracile, lumile; folia caulina erecto-appressa parva,

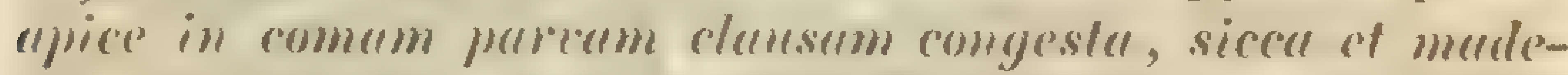

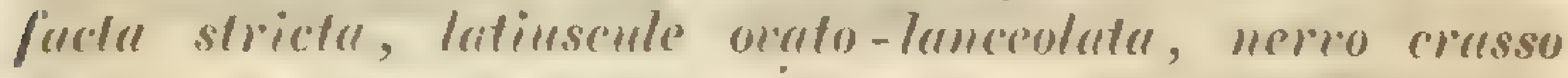
viridi dein ferrugineo in cuspidem arentam froducta, vipidissimu, margine integerrimo revoluta, undipne e cellu-

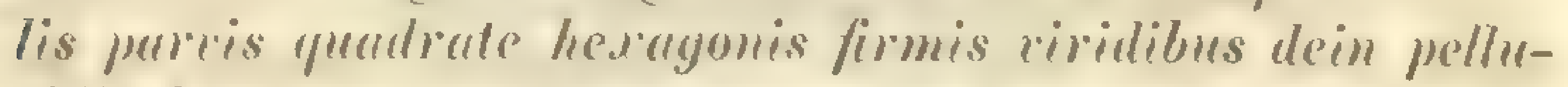
cidis hum incrussulis areolata, laevia; perichaetialia inlima convolutaceo-vaginatia obtusatu, excurrentinevia, multo laxius complius et pellucidius reticulata; theca in pedunculo longiusculo purpureo tortili, erecta parra, ellipticu complinscula, fusca annulata, operculo conico obtuso recto brevi facillime decilluo; perist. dentes in membrana brevi pallescente erecti stricti regulariter binati, $e$ basi trabeculata morpurea sensim tenuissimi nodosi purpurei.

Pulria. Germania septentrionalis, Flegesen virca Нameln prope Hohnsen in muris: Schlotheuber. - Mujo.

A $T r$ r rigidulo proximo theca ampliuscule elliptica breviter conico-operculata primo intuitu jam distat, folis 
autem pungentibus laevibus ab omnibus affinibus congeneribus differt.

13. Tr. strietum Bruch (in De Not. Syllab. Musc. p. 190.); late et laxe cespitosum, laxissime cohaerens, sordide viride, caulis erectus, ad florem femineum ramis plerumque binis divisus, sterilis simplex, substrictus dense foliosus subteres parce radiculosus; folia caulina erectopatentia strictu, e basi lato-ovata amplexante, e cellulis subquadratis subfirmis pellucide flavidis amplioribus reticulata, subito in subulam lanceolatam firme minute quadrate areolatam opacam concavam crassam rigidam integerrimam nervo lato deplanato in cuspidem longam acutam producta, dorso papillosa; perichactialia longe invoTute vaginantia, e basi elongate anguste irregulariter hexagono-reticulata, superne interdum sinuatâ subito subulata; theca in pedunculo strictissimo purpurascente v. stramineo longiusculo erecta elliptico-oblonga subincurva, anmulo robusto duplici praedita, nitide purpurea dein atrobrumner, operculo conico brevirostrato recto; perist. dentes tenuissimi longissimi in conum congesti, dense approximati, fusci, subrugulosi, basi in membranam brevissimam conflati.

Ceratodon chloropus Brid. 1. p. 486. e spec, Hl, Brideliant! forma tenuior basi compacte cespitosa subtomentosa. - Dicr. chloэ.opus Brid. Mant. Musc. p. 70. - Didymodon ictericus De Not. spicil. p. 13.

Putria. Circa Romam in herbidis humentibus primus legit Bridel. 1818. Aprili. Sardinia, in pascuis siccis: Fr. Müller 1828. Italia orientalis, Caserano in terra di Otranto; Rabenhorst 1847.

Pl. mascula gracilior, flore terminali, foliis e basi lata concara subito acuminatis evanidiuervibus. Cevatodonti purpureo haud dissimile.

14. Tr. Chilense Mont. (in Ann. d. sc. nat. 184. 4. p. 109.); simplex, basi innovatione feminca divisum, humile erectum, sordide viride; folia inferiora minuta, apicem versus sensim mujora, evecto-putula subsecunda, e basi amplexante oblonga erecta, e cellulis rectangula- 
ribus flavidis firmis laevibus areolata subito in subulam flexusum minutissime quadrate arcolatam opacam concavam, dorso scaberrimum, crassiusculam lanccolatam, nervo lato excurrente percursam, producta; perichaetialia longius et tenuius amplexuntia longiora; theca in pedunculo longo erecto purpureo erecta cylindrica subaequalis examulata brumea, operculo conico-subulato longo erecto; perist. dentes longissimi angusti in conum congesti, dense approximati, e basi brevi rubra trabeculata in crura duo aequalia arcte cohacrentia pallida rugulosa et valde appendiculiformi-nodosu fissi.

Patria. In terra arenosa Chiles australioris: C. Gay.

Leptotricho tortili hand dissimile, sed foliis papillosis jam distat. E forma folii $\boldsymbol{T} r$. stricto proximum.

Sectio II. Leptodontium Hmp. Linn. XX. 1. 70. - Folia squarroso-reflexa complicato-concura fleruosa, basi e cellulis inanihus Iongioribus superne subchlorophyllosis areolata. - Theca omnium cellulis neificii terminalibus annulo similibus veluti anmulata. Inflorescentia dioica.

\section{A. Pusilla.}

15. Tr. Aexifolium Sm. (Fl. Brit. III. P. 1216.); gregurie cespitosum pusillum subsimplex fragile lutescens; folia caulina erecto-tortilia, madefacta reflexa, parva, oblongo-ligulata breviter acuminata, parum complicata, reflexa, e basi usque ad medium et ultra margine revoluta, apicem versus inaequaliter serrata, basi e cellulis quadrate hexagonis parvis ampliusculis pellucidis laevibus paucis, superne minutis hexagonis tenuissime papillosis areolata; perichaetialia e basi longe convolutaceo-vaginante e cellulis inferne pellucide laxe elongate hexagonis lacvibus superne angustioribus punctulatis reticulatà erecta; omnia subexcurrentinervia; theca in pedunculo longiusculo flavido strictiusculo v. tortili tenui crecta, cnguste cylindrica parea pallida deiv fusea, operculo conico-obtuso brevi; perist. dentes breves pullidi, plus minus regulares, plerumpue dense cohaerentes binati laeves.

c. Muller: Synops. musc, frond. 
Brid. I. 1. 499. - Didymodon flexifolius Hook, et Tayl. Musc. Brit. cd. 11. 1. 45. t. 20, - Br. Fill, Fase. 29-30, 1) 6. t. 4. I eptolontium flexifolium Hmp. Linn. XX. p. 70. - Desmatodon flexifolius Hmp. Veget. Cellul. Coll. No. 112. - Bryum Rerifolium vicks. Fasc, III. PI. Cr. p. 5. t. 7. r. 9

Putria. In locis sterilibus petrosis prope Croydon: Dickson et in multis locis aliis Britamiae; in iistem locis Germaniac prope Blankenburg llercyniae: II a mpe; Oberstein Borussiae Rhenanae et Ludwigshütte Ilassiae superioris: Bruch, sed hic sterile. E Lusitania a Schrader acceptum in Hb. Bridelii vidimus. - Vere.

Pl. mascula gracilior, flore terminali minuto, foliis perig. externis orato-lanceolatis, e basi concara erecta patentibus, internis duplo fere minoribus, ovato-acuminatis integris. - Omnium congenerum Leptodontii sectionis humillima species.

\section{B. Elata.}

16. Tr. squnrrosum Schwägr. (Stıppl. II. I. p. 78. 1. 123.); elongatum flexuosum, ramis elongatis flexuosis parce dichotome ramosum, subrobustum, e luteo viride inferne nigrescens; folia erecto-patentia tortilia, madefacta valde squarrosa, late complicato-lanceolata; undulato-flexuosa, apicem versus subaequaliter serrata, margine supra basin elongate subanguste pellucide laxe areolatam laerem superne solo punctulalum ultra medium revoluta, superne minute rotundata tenuissime papillosa; perichaetialia e basi longe vaginante laxissime elongate anguste reticulatu laevi concolutuceo-erectu; omnia subexcurrentinervia; theca in pedunculo brevi erecto rigido flavido erecta cimpliuscule cylindrico-oblonga robusta fuscescens, operculo longirostrato obliquo; dentes perist. breminsculi ciliis binatis plus mimus coalitis plerumque arcte cohuerentibus lacvibus fuscidulis.

Bricl. 1. p. 498. ex parte. - Didymodon squarrosus Hook. Musc. Exot. t. 1 范。

Patria. Nepal Indiac: Gardner.

17. Tr. ulocalyx C. Müll.; tomentosum; habitus Tr. stpurrosi; folia caulina longiora angustiora, basi e cellu- 
lis ungustis firmis restangularibus inferne laevibus superne punctulatis, supra basin angulato-rotundatis minutissime papillosis areolata, supra basin hrevissinam margine ultra medium revoluta, apicem versus inaequaliter serrata, excurrentinervia; perichaetialia e basi longe vaginante, cujus cellulae angustae elongutue ubigue parietibus interruptis instructue firmae hand laxue tenerae, longe anguste acuminata valde undulata; theca in pedunculo brevi tortili rigido erecta cylindrico-oblonga; perist. dentes (thecae deoperculatae supramaturae) rudimentarii brevissimi.

Trichost. squarrosum Hsch. in Minsc. Vexic. Ilepp. et sichied. Didymodon luteus Tayt. in Lond. Journ. of hot. 18!6. p. 48. operculo breviter rostrato?

Patria. Mexico: Deppe et Schiede. Monte Pichincha Andium Quitensium: Wr. Jameson.

A Tr. squarroso simillimo notis cursive impressis distat.

18. Tr. epunctatum C. Müll.; habitus Tr. squarrosi, sed gracilius flavius humilius; folia caulina angreste lunceulctu tortilia, madefacta flexuosa, valde falcata, apicem versus inaequaliter serrata, margine parum revoluta, basi e cellulis mimute hexayonis teneris pellucidis laevibus hand punctulatis brevissima praedita, supra basin minutissime incrassate rotundato-areolata, minutissime papillosa, nervo subexcurrente; periclactialia convolutaceo-vaginantia, longiora, basi longa elongate anguste flavide areolata laevia; theca in pedunculo brevi erecta cylindrica.

Trich. squarrosum Brid. I. p. 498. excl. Sym. Hook. - Neckera viticulosoides P. B. Prodr. p. 78. e spec, auth. - Eincalypta squarrosa Brid. Sp. Musc. 1. p. 93.

Palria. Insula Bourbonis, ubi in planitie des Chicots latissime cespitosum legit Bory St. Vincent.

19. Tr. stellatum C. Müll.; caulis erectus elongatus valde squarrosus robustus dichotome ramosus, apice stellate comosus, ramis elongatis; folia lute complicuto- 
lanceolutu, valde reflexa, apicem versus grosse inaequaliter serrata, margine e basi usque fere aul apicem muxime revoluta, basi c cellulis minutis fengustis rectangularibus firmis haud pellucidis valde menctulatis, superne minute rotundatis areolata, papillis creberimis ud marginem revolutum valde conspicuis praedita, nervo subexcurrente.

Dicranum stellatum Brid. I. p. 443.

Patria. Insula Bourbonis, in humidis: Bory $\mathbf{S t}$. Vincent.

A $T r$. cpunctuto notis cursive impressis facile distinguitur, a $T r$ aggreguto maxime simili, sed graciliori papillis foliorum valde rqbustis distat.

20. Tr. aggregatum C. Müll.; late et laxe cespitosum elongatum gracile flexuosum, innovationibus infra apicem breviorem caulis elongatis flexuosis gracilibus parce dichotome ramosum, luteum inferne brunneum $v$. nigrescens; folia erecto-patentia tortilia, madefacta valde squarrosa, late complicato-lanceolata, nervo subexcurrente, undulato-flexuosa, apicem versus valde grosse illaequaliter serrata, margine e basi usque fere ad apicem valde revoluta, valde reflexa, basi e cellulis minutis angustis rectangularibus punctulatis firmis flavidis haud pellueidis, superne minutissime rotundatis areolata, minutissime papillosa; perichaetialia e basi elongate anguste flavide rel fusce reticulata subaginante reflexa hand convolutacea; thecae plerumque plures $1-4$, in pedunculis brevibus flaris tenuissimis arcuatis angustissime cylindricae erectiusculae arcuatae, collo subeentricoso brunmescente praeditae, pallide ochraceae pachydermes, operculis longirostratis tenuissimis concoloribus; perist. dentes longissimi erecti stricti laeves rubelli, regulariter binati v. plus minus coaliti.

Leptodontium agyreyatum C. Miill. Lot. Zeit. 1847. p. 829.

Patria. Java: Zolling er Coll. No. 2130.

Pulcherrima species, Tr. stellato proxima. Calyptra glabra nitida. 
Incerta.

1. Didymodon? Pichinchensis Tayl. (Lond. Journ. of bot. 1848. p. 280.); caulis laxe cespitosus erectus, apice prolifero, simplex apice incrassatus, inferne ferrugineus superne pallide viridis; folia arcte imbricata squarrosorecurva, ovata acuta flexuosa, margine tumenti-recurva, nervo pellucido excurrente, serrulata immarginata; perichaetialia minora; theca erecta inaequalis operculo tenuiter longirostro. +

Patria. Monte Pichincha Andium Quitensium: W. J a me s o n, 5. Jul. 1847.

Habitus $T r$. squarrosi.

2. Rarbula Jamesoni 'Tayl. (Lond. Journ. of bot. 1846. p. 48.); caulis laxe cespitosus erectus subramosus, 2-3 uncíalis, flexuosus, pallide olivaceus, ramis clongatis paucis; folia laxa patenti-recurra, sicca torta atque incurva, ex lata amplexante basi lineari-lanceolata obtusiuscula, margine infero reflexa, supero serrulata, nervo valido percurrente, dense et minute areolata; theca in ped. unciali terminali cylindracea crecta parum curvula, perist. brevi pallido. t.

Patria. Pichincha Andium Quitensium: W. Jameson. Oct. $182 \%$.

Ex animadr. auctoris Barb. cylindricac Hiberniae (Zygotrichice Fl. Hib.) ${ }^{*}$ ) proxima. Ex obs. Wilsoni (1. c. p. 449.) Trich. luteo affinis et peristomio Trichostomi instructa, $\boldsymbol{B a r b u l i s}$ valde dissimilis.

Nectio 11I. Eutrichostomum. Folia carinato-concava erecta inflexo-tortilia, basi pellucide laxe calymperoideo-reticulata, superne papillis maxime opara, longa angusta.

\section{A. Infloresc. hermaphrodita.}

21. Tr. rubellum Rabenh. (Deutschl. Crypt. Bd. II. p. 115.); laxe cespitosum, innorationibus sacpe valde ra- 
mosum, intense viride dein maxime rubellum; folia caulina patenti-recurva, sicca tortilia parum inflexa, e basi erecta laxe pellucide sublonge hexagone et tenerrime reticulata oblongà recurva carinato - lineari - acuminata, nervo excurrente acuta, margine reflexa, superne e cellulis parvis tenuissime papillosis chlorophyllosis dein rubellis areolata, integra, inferiora intense igneo-rubella; perichaetialia basi latiore laxius areolata; theca in pedunculo stricto purpureo tortili longo erecta cylindrica, raro elliptica, annulata, pallida dein rubella, operculo conicosubulato obliquo; perist. dentes cruribus arcte cohaerentibus rarius solitariis appendiculariter nodosis subrugulosis, igitur veluti sedecim lineari-subulati, fusci subrugulosi.

Didymodon rubellus Br. Europ. F'usc, 29-30. p. 3. tab. 1. Weisia recurvirostra Brid. 1. p. 347. - W. recurvirostris Hdw. Musc. Fr. I, p. 19. tals. 7. - W. revoluta schl. fide Bridel. Grimmia recurvirostris sm. Fl. Brit. HII. p. 190. - Gr. currirostra Web. et M. Bot. Tas(h). p. 135. - Gr. rubella Moth. 'Tent. Fl. Germ. 111. I. p. 147. - Anacalynta recurvirostris Br. Germ. II. 2. p. 151. t, 37. - Anacal. rubella Hiil, Niss' Germ. p. 119. Tortula lecustris P. B. Prodr. 1. 92. fide B10 idel; itidem Bryumb palustre Brid. Mrusc. Rer. 11. III. p. 35, B. setaceum $\beta$. Huds. Fl. Angl. 1. 4\$2, et Bryum stellare, lacustre, foliis rulris capillaceis. Dill. Musc. p, 3k2, t. 48, f. 45. - Br. recurvirostrum Dicks. Fasc. II. P1. Cr. p. 7. - Br. rubellum Hoffm. Deut. Fl. H. p. 33. Barbula Turneri Brid. Mant, Musc, p. 93. - Barb. fallax S. Turneri ej. I. p. $\mathbf{5 5 9}$.

Patria. In rupibus et muris umbrosis, rarius ad terram per totam Europam et Americam septentrionalem. Ex Abyssinia misit $\mathbf{W}$. Schimper. E planitie usque ad alpes summas ascendit. - Auctumno.

\section{B. Infloresc, monoica.}

22. Tr. distans IInp. (in litt.); cespitulosum litlmillimum, ramis aequalibus brevissimis fastigiatis in comam congestis igitur quasi simplex, amoene virescens; folia laxe imbricata, erecto-patula, lineari-lanceolata angusta elongata parum flexuosa, sicca involute tortilia, apice acutissime cuspictuto vix reflexo, integerrima, nervo 
crassiusculo excurrente flavido praedita, basi tencrime pellucide elongate superne minute quadrate hexagonoareolata, sublaevia; perichaetialia longiora basi tenuiora; theca in pedunculo erecto longiusculo flavido erecta oc'alis pallida exannulata leptodermis, operculo longirostrato obliquo; perist. dentes brevissimi oblipue erecti rubri cartilaginei laeres parum nodosiuscule articulati lineares, infra orificium oriundi, cruribus hand juxta sed pone positis igitur primo intuitu veluti simplices weisioidci.

Didymodon leptocarpus Br. et sch. ill Coll. Schimp. Alyss. 11. No. 462.

Patria. Abyssinia, ad ripas rivulorum, in paludibus uliginosis montis Silke prope Cosso Berri 11000 pedes supra mare, d. 25. Febr. 1840 leg. W. Schimper.

Antheridia in axillis foliorum rami fertilis superiorum ad pedem floris feminei nuda.

23. Tr. Barbula Schwägr. (Suppl. I. I. p. 144. ᄂ.36.); laxe cespitosum loumile, innovationibus ad comam fertilem oriundis dichotonum, amocne virens rigidum; folia laxe imbricata erecto-patentia tortilia, madefacta stricta, comalia e basi temiter pellucide areolata brevi lato-lanceolata parum concura, nervo latissimo depresso ante apicem evanido obscuro laevi, margine parm undulata apice plerumque dentutu, e cellulis minutis hexagonis tenuissime papillosis obseure areolata; theca in pedunculo elongato purpurascente crasso erecta ublongo-cylindrica longa robuste llavida dein coriacea pachydermis parum curvata, exannulata, operculo conico rostrato rectiusculo crasso; perist. dentes longiores robustiores nodosi purpurei.

Br. Europ. Fasce. 18-20. Trichostomum; p. 5. t. 1. - Tr. barbuloides Brid. 1. p. 4!3. - Tortula Lasitanica Brid. Sp. Musc. 1. p. 249.

Putria. Terrac maris mediterranci.

A Tr. Aaro-virente proximo notis cursive impressis facillime dislinguitur. - Antheridia in axillis foliorum ad pedem floris feminei nuda. 


\section{Infloresc, dioica.}

a. Robusta.

24. Tr. corniculatum Schwägr. (Suppl. II. p. 75. t. 118.); habitus Tr. Barbulae; folia jum supra medium dentata; theca ammuluta; perist. dentes laeves pullide fusci nodosiusculi.

Brid. I. p. 494. - Encalypta corniculata Wahlenl, in. Berl. Mag. V. p. 295. t. 7. f, 2.

Patria. Kamtschatka in humo arenosa cum Ceratod. purpureo: Tillesius.

E spec. authenticis species notis illustratis a $\boldsymbol{T}$. Barbula simillimo distinctissima.

25. Tr. Alexipes Br. et Sch. (in Br. Europ. Fasc. 1820. Trichostomum, p. 6. t. 2.); habitus Tr. Burbulae, sed humilius et infra comam innovans: folia caulina in comam patulam congesta erecto-patula, sicca tortilia, linearilanceolata, basi tenuiter pellucide elongate hexagonoareolata brevi praedita, superne minute hexagone areolata minutissime papillosa, apice dentata, latinervia; theca in pedunculo siccitate cygneo-arcuato breviusculo crecta elliptico-cylindrica brevior umulatu coriacea pachydermis, operculo conico rectiusculo crassiusculo; perist. dentes elongati stricti rugulosi haud nodosi fusci.

Patria. Sardinia prope Iglesias rivulo exsiccato: Fr. Müller. - Vere.

Pl. mascula gracilior, ex apice innovans, foliis externis ovato-lanceolatis, internis ovato-acuminatis nervosis. Species distinctissima.

26. Tr. cirrhatum Hmp. (Ic. Musc. tab. 24.); laxe cespitosum humile, innovationibus infra comam fertilem oriundis, flaro-virens rigidum; folia laxe imbricata erecto-patentia tortilia, madefacta stricta, illa comac fertilis lineari-lanceolata elongate cuspidatu, basi e cellulis elongate hexagonis pellucidis superne minutis tenuiter papillosis subobscure areolata, integra, nervo flavido excurrente; perichaetialia longiora; illa comae sterilis multo 
robustiora et maxime obscure areolata, basi breviuscula elongate pellucide reticulata, supra basin ad marginem cellulis basilaribus submargmata, nervo crasso carinato in cuspidem brevem acutam producto, margine subundulato et involuto; theca in pedunculo elongato purpureo erecta ovato-cylindrica pallide fusea longiuscula exannulata, operculo conico rostrato obliquo; perist. dentes stricti longissimi amoene fusci laevissimi, sed creberrime minute nodosi.

Patria. Nova Hollandia ad flumen Swan River dictum, Barbulae calycincte intermixtum: Preiss No.2458.

A Tr. flavo-virente proximo notis cursive impressis, prime foliis comae fertilis longicuspidatis primo intuitu distinguitur.

27. Tr. flavo-virens Bruch (Fr. Niiller in Regensb. bot. Zeit. 1829. p. 304. t. 7.); laxe cespitosum humile, innovationibus ad coman fertilem oriundis dichotomum, flavo-virens molle; folia laxe imbricata erecto-patentia tortilia, madefacta stricta, comalia e basi oblonga tenervime elongate et pellucide reticulata longû lineavi-lanceolutu, margine vulde undulata, nervo dorso laevi crasso flavido ad apicem planiusculum erectum in cuspidem brerem acutum producto, supra busin e cellulis minutis hexagonis tenuissime papillosis obscure areolata et ad murginem supra basin cellulis basiluribus tenerrimis pellucide marginata, superne immarginata integra; theca in pedunculo longo purpureo erecta ovato - cylindrica pallida, dein fusca, leptodermis exannulata, operculo conico rostrato obliquo; perist. dentes stricti intense purpurei rugulosi, cruribus regularibus binis.

Br. Europ. Hasc. 18-20. Trichostomeae; p. 6. t. 3.

Putria. In fruticetis maritimis Sardiniae detexit Fr. Müller; Otranto, in terra di Otranto: Rabenlorst; in pinetis sabulosis pr. Massiliam: Jordan; ad mare Algeriae: W. Schimper; in ericetis 'Tingitanis: Salzmann; pr. Pola Istriae et in insula Pasmann Dalmatiae: Sendiner. - Martio. 


\section{STEGOCARPI. ACROCARPI. TRICHOSTOMU.}

Pl. mascula gracilior subsimplex, foliis late ovatolanceolatis, internis brevioribus obsoletinervibus. - $\mathrm{Tr}$. Burbulae proximum.

28. Tr. fragile C. Müll.; dense cespitosum crectum strictum, aequaliter e basi usque ad apicem foliosum, tomentosum frugile; folia caulina erecto-appressu, flexuosa rigida fragilia, madefacta erecto-patentia, lineari-lanceolata acuminata erecta, nervo carinato lacri subcontinuo tenui flavido, integerrima, basi longa clongate pellucide areolata et margine subundulata, supra basin cellulis basilaribus pellucidis marginata, minutissime hexagonoareolata et papillosa; perichaetialia basi longissima tenerrime elongate reliculata; theca in pedunculo elongato rigido fragili purpureo erecta cylindrica robusta, columella filiformi exserta.

Didymudon fragilis Hook. in Drumm. Musc, Americ. No. 127.

Patria. America septentrionalis ad margin. lacuum alpin. legit Drummond, sed rarissime, fertile. Terre Neuve: La Pylaie primus legit, sed sterile.

Species primo intuitu distinetissima et notis cursive ${ }^{-}$ impressis, prime fragilitate maxima, facile distinguitur.

29. Tr. cylindricum C. Müll.; late et laxe cespitosum amoene luteo-viride valde crispulum parum inflexum, plus minus humile, depressum fastigiate ramosum, molle; folia caulina erecto-patentia subflexuoso-recurva, anguste lineari-acuminata, nervo excurrente acutiuscula, margine papillis subcrenulata flexuosa haud revoluta, e cellulis basi laxis pellucidis elongatis superne minutis tenuissime papillosis opacis areolata, carinata; perichaetialia basi magis vaginante longius pellucida praedita, valde acuminata; theca in pedunculo longiusculo flavido substricto erecta anguste cylindrica longiuscula, pallida dein fuscescens, annulata, operculo conico-subulato obliquo; perist. dentes $\boldsymbol{T} r$. rubelli, sen saepins bifidi 2 cribrosi.

Didymodon cylindricus Br. Kurop. Fass. 29-30. p. 5. t. 3. D. tenuirostris Wils. in Lond. Journ. of hot. 1841. B. 376. - Weisia cylindrica Bruch in Br. Germ. II. 2. p. 38. t. 29. - Brid. I. 
p. 806. - II. tenuirostris*) Hook. et 'Tayl. Musc. Brit, ed. II. p. 83. Suppl. 3.

Putria. In rupibus arenaceis umbrosis per Vogesum, ubi pr. Bipontum detexit B ruch, Sylvam Nigram, 'Thuringiam, Barariam superiorem pr. Kothenbach (Sendtner) et in Britannia atque Hibernia. In India orientali Br. Europ. pariter indicavit. - Sero anctumno.

1P. mascula gracilior, sed magis ramosa, floribus terminalibus. Folia perig. e basi ovata concara anguste lineari-lanceolata. - Speciminibus Bubbulue tortnosue minoribus haud dissimile, et peristomio, a Trichostomis typice minime refugiente, a ceteris congeneribus hujus sectionis, $\boldsymbol{T r}$. rubcllo excepto, facile distinguitur.

\section{b. Pusilla.}

30. Tr. inftexum Bruch (Fr. Müller in Regensb. bot. Zeit. 1829. p. 402. t. 6.); pusillum tenellum simplex cespitulosum virens; folia panca erecto-patentia, sicca tortilia, cingustissime lineari-lanceolata, apice breviter acuto semper plus minus arcuuto-inflexu, basi tenera pellucide areolata et nervo tenui excurrente praedita, integerrima, superne minutissime hexagono - reticulata et papillosa; theca in pedunculo erecto stricto flarido temei erecta elliptica angustu pare amoenc fuscu, examnulata, operculo conico-rostrato recto purpureo; perist. dentes erecti temissimi fusci sublueres.

Br. Europ. lasc. 18-20. Trichostomum, p. 12. t. 9.

Patria. Sardinia prope Laconi in rupibus: Frr. Müller; Istria prope Rovigno: Sendtner; Otranto, in terra di Otranto Italiae: $\mathbf{R}$ abenhorst.

Pl. mascula gracilior, foliis ovato-lanceolatis, externis apice inflexis, internis tenuioribus evanidinervibus.

31. Tr. calcicola Hmp. (Ic. Nusc. t. 29.); cespitulosum pusillum subsimplex e virente flavescens rigidum erectum; folia in comam patulam congesta, erecto-paten-

*) Adnotat. in pag. 462 deleatur. 


\section{STEGOCARPI. ACROCARPI. TRICHOSTONUM.}

tia tortilia, madefacta stricta, lanceoluta obtusato-acutu, nervo crasso flavido ante apicem evanido, margine integerrimo erecto, basi quadrate hexagone pellucide reticulata brevi, superne e cellulis submagnis rolundato-hexagonis incrassatis opacis areolata, subcanaliculata; theca in pedunculo erecto tortili longiusculo purpureo erecta, ovato-cylindrica subaequalis, brnnea pachydermis, exannulata, operculo conico subulato obtuso rectiusculo; perist. dentes longissimi albidi lueves hund nodosi.

Patria. Nova Hollandia, in rupibus calcareis prope Freemantle: Preiss, 14. Aug. 1839.

Sectio IV. Desmatodon Brid. Mant. Musc. p. 86. et Br. miv. 1. 1). 523. - Dermatodon Hüh. - Trichostomum al. - Fulia lata plus minus plana et ovata, ubique e cellulis hexanonis ampliuseulis chlorophyllosis basi plus minus pellucidis areolata, cynbiformi-concava $v$. plus minus carinata.

\section{A. Theca erecta.}

a. Inflorescentia monoica.

32. Tr. Intifolimm Schwägr. (Suppl. I. I. p. 145.); monoicum; laxe cespitosum humile parce ramosum; folia laxe imbricata patentia, sicca fere in spiram contorta, late oblongo-lanceolata, nervo crasso in aristum plus minus longum flexuosum aculam producto, margine inferne parum revoluta, distincte papillosa, apice subcrenulata, basi longa e cellulis elongatis laxissimis pellucidis laevibus reticulata pracdita, superne e cellulis multo minoribus opacis viridibus areolata; theca in pedunculo elongato flexuso haud tortili lutescenti-purpureo erecta, oblongo-cylindricu, pallide lutea leptodermis nitida, dein fusce, annulo simplici et operculo obligue et obtuse rostellato basi amoene aurantiaco; perist. dentes purpurei, in membrana brevi positi, e basi latiuscula subregulariter bifidi articulati rugulosi, siccilute incurvi.

Desmatodon latifolius Brid. I. p. 524. - Br. Europ. p. 3. talı. 1. 一 D. brevicaulis Brid. I. p. 52.5. - D. Systylius IBlytt in litt., in insula Tronsóe Norvegiae lectus, $-D$. Güntheri Nendtu. in sichedulis. - Trichostomum piliferum sm. Fl. Brit. IH. 11. 1245. - Di- 
cranum latifolium Hdw. Musc. Fr. I. p. 89. t. 33. - Swartzia pilifera Brid. in schrad. Journ. 1800. p. 289. - Mnium latifolium Gmel. Nyst. Nat. II. p. 1328. - Bryum piliferum Dicks. Fasc. IV. Pl. Cr.t. 11. f. 1.

ק. muticum; altius valde ramosum, foliis evanidinervibus. Br. Europ. I. c. Desmatodon latifolius $\beta$. muticus Brid. I. p. ั125. - D. glacialis Fk. in Hrul. 1. p. 822. - D. spathulatus Hartm. fide A naström in Fries summ. Veget. p. 94. - Dicran. latifolium Hook. in Iblumm. Musc. Amer. No. 109. - Trichost. Hoppeanum sichultz in syllog. Katish. 1828. p. 140?

Patria. Ad terram in subalpinis et alpinis per totam Europam, in alpibus rulgatissimum. Var. $\beta$. in summis alpibus et in Rocky Mountains Amcricae septentrionalis. - Aestate.

Flos masc. in axillis comac foliorum superiorum subterminalis sessilis 1 - 2 pliyllus, foliis perig. orato-acuminatis solidinervibus. Antheridia brerissime stipitata, paraphysibus claratis flavidis mixta.

33. Tr. Systylium C. Mïl,; monoicum; cespitulosum humile parce ramosum; folia densissime imbricata patentia, sicca tortilia, inferiora oblongo-lanceolata, superiora latissime oblonga et spathulato-oborata, margine plana, apice crenulata, vix papillosa, nervo temi flexnoso in aristam longam valule flexusam acutam viliferam nroducto, superne e cellulis majoribus diaphanis subrhomboideo-hexayonis tenmioribus parce chlorophyllosis vel perfecte pellucidis reticulata; theca in pedunculo longiusculo recto cylindrica crecta fusca pachydermis, annulo simplici et operculo columella exserta elevato plus minus persistente; perist. dentes abbreviati pallide ferruginei inaepualiter 2-3-fidi eel lacunosi, basi integri, in membrana sat exserta concolore conjuncti, siccitate incurvi.

Desmatodon Systylius Br. Europ. Fasc. 31. Suppl. c. tal.

Patvia. Norvegia, in alpe Dovrefjeld et in valle Gulbrandsdalen ad latera viac cavae prope Ringbóe: W. P. Sch. detexit 1814. Fillefjeld et Gustafjeld: B lytt. In 
alpibus Bavaricis pr. Linkerskopf, in locis imperviis, altitud. 6856' legit 'Send tner.

Flos masc. I). glacialis, a quo notis cursive impressis facile differt.

34. Tr. Guepini C. Müll.; momoicum; cespitulosum subramosum; folia patentia, inferiora ovato-lanceolata, superiora orali-oblonga, nervo excedente subaristata, margine revoluta; theca in pedunculo breviusculo erecta oblongu subcylindrace badia, annulo simplici et operculo majuscule conico oblique apiculato concolori; perist. dentes subaequales longinsculi perfecte regulariter ad basin fissi et per paria approximati, humiditate et in theca recenter deoperculata in conum obliquum conniventes, sicci strictiusculi rubello-rufescentes valde granulati. $\leftarrow$.

Desmatodon Guepini Br. Europ. Fasc 1s-20. p. 4. t. 4.

Putria. In terra argillosa prope Angers Galliae occidentalis: Guépin.

Flores masc. axillares gemmiformes $\mathbf{2}-\mathbf{3}$-phylli apice patuli; folia perig. ovata acuminata, obsolete et nullo modo nervosa; antheridia $2-\mathbf{3}$; paraphyses nullac. Ab Anacalypta lanceolata simillima notis cursive impressis distat.

35. Tr. convolutum Brid. (I. p. 492.); monoicum; humile subpulvinato-cespitosum dichotomo ramosum; folia dense imbricata, sicce in spiram conrolutu, madefacta erecta stricta, orali-oblonga, nervo crasso flavido in mucronem brevem acutum producto, margine integerrimo revoluta et parum flexuosa, basi e cellulis pellucidis tenerrimis parvis laevibus superne minutis opacis tenuissine papillosis areolata, carnosula; perichactiale intimum brevius, margine haud revolutum; theca in pedunculo breviusculo purpurascente erecta ovalis, plerumpue exammlata, pallide lutea dein fuscescens, operculo conico breviter oblique rostellato; perist. dentes longiusculi volde incequales, in membrana altiuscula pallida positi, fusciduli rugulosi.

Trich. nerrosum Bruch in Musc. Nlïler. Sard. et Hiil. Musc. Germ. D. 295. - Desmatodon nervosus Br. Fur. Fase. 18-20. p. 6. 
t. 3. - Didymodon nervosus Hook. et Tayl. Musc. Brit. p. 66. tal. 20. - Brid. I. p. 516. - Did. Capensis Nur. syst. Veqet. IV. II. p. 323. - Grimmia atrovirens sim. Emml. Bot. t. 2015. fide Ho0ker. - Weisia nerrosa Hook. in 13rid. 1. p. 808. e spec. imperfertis patcis authent. huc pertinere videtur. - Barbula circinalis C. Müll. Linn. XVII. p. 703, sed annulo simplici. - Tortula rarvula Hook. Brid. I. p. 825.

ß. edentulum; operculo conico breviusculo, peristomio solam membranam basilarem sistente. Bi. Europ. I. c.

Petria. In muris argillaceis et rupibus semidecompositis hic illic in valle Khenana pr. Gebweiler Nisatiae, pr. Bonam et Kreuznach, in Gallia occidentali pr. Angers, in Italia, Britannia, Sardmia, 'Tiroli pr. Botzen et in prom. b. spei rulgare. - Vere, in Africa Jumio ad Sept.

Flos masc. ad pedem feminei minute gemmaceus, foliis perig. externis ovato-lanceolatis solidinervibus, internis minoribus tenuioribus tenuinervibus. Antheridia paraphysibus temuibus subclaratis mixta.

36. Tr. favienns C. Müll.; monoicum; hunile cespitosum parce dichotome ramosmm; folia conferta parvula, sicca incuno-subtortilia, late oblonga obtusa vel broviter acuminatu, maroine parum revoluta integerrima, basi e cellulis pellucidis tenerimis parvis laevibus superne ninutis valde op acis tenuissime papillosis areolata, carnosula, nervo crasso evanido; perichaetialia basi longius pellucida; theca in pedunculo breviusculo stramineo dein purpurascente erecta orali-oblonga, late ammiluta lutea dein fuscescens, operculo conico breviter oblique rostrato; perist. dentes longiusculi subaequales fusciduli sublaeves.

Desmatodon flaricans Br. Furop. Fasc. 18-20. 1) 7. t. 4. Didymorlon flaricans Fk. in schedulis. - Dir. oblongifolius Hook. in IJrumm. Muse. Amer. No. 114. - Tortula humilis Hook. ihidem No. 137. Hoแ Hdw. - Barbula obtusifolia schwäir. Suppl. I. I. p. 129. t. 31! - Brid. I. p. 532. excl. syll. sichultz.

I'atria. Ad rupes umbrosas pr. Heiligenblut Carinthiae, pr. Waldstein Montis piniferi: Funk; Faulhorn loco Bachalpe: W. P. Sch., ad Sentis Helvetiae: Mühlenbeck, Valesia: Schleicher. America sept. in ru- 


\section{STEGOCARPI. ACROCARPI. TRICIOSTONUY.}

pib. calcareis ad lacum Winipeg et in Rocky Mountains: Drummond. - Aestute.

Flos masc. Tr. convoluti proximi, a quo notis cursire impressis facile distinguitur.

\section{b. Infloresc, dioica.}

37. Tr. amblyophyllam C. Müll.; dioicum; cespitulosum brevicaule, innovando ramosum; folia laxe imbricata, e basi plevumque subinvoluta cellulis elongatis laxis pellucidis laevibus areolata longâ elongate oblonga obtusiuscula, inferiora upice emarginata, nervo autem in aristam brevem acutissimam flavidam producta, margine plus minus revoluta et valde flexuos pillis tenuissimis aspera, supra basin minutissime opace areolata; perichaetialia intima e basi angustissima longe subspathulata breviter mucronata, omnia basi laxissima tenerrima; theca in pedunculo longo purpureo recto $c y$ lindrace erecta, fusca annulata, operculo subuluto obliquo; perist. dentes in membrana brevi positi, breves sinistrorsum subtorti, rugulosi intense purpurei, binati tenues.

Desmatodon amblyophyllus Mont. in Amln. d. sc. nat. 1845. 4. p. 108.

Putviu. Chile, ad terram prope Valparaiso et S. Jago: C. Gay. - Aprili 1830.

Tr. obliquo simile, notis autem sat distinctum. Pl. mascula multo ramosior, innovationibus masculis pluribus brevibus dense comosis. Folia perigonialia externa e basi late ovata concava tenera brevi lanceolata concava obtuse acuta evanidinervia, pellucidius, sed minute areolata, margine vix revoluta; interna late cordato-acuminata undique tenerrime reticulata colorata, nervo tenui evanido. Antheridia magna, paraphysibus flavidis subacutis cincta.

38. Tr. Schimperi Mont. (in $\Lambda$ nn. d. sc. nat. 1815. 4. p. 103.); divicum; cespitulosum brevissimum subsimplex; folia erecto-patula in comam crassiusculam congesta, lato-oblonga carinato-liguluta obtusissima, norvo 
tenui ante apicem evanido, margine integerrimo parum flexuosa, e cellulis basi ampliuscule hexayonis subfirmis pellucidis laevibus superne minoribus minutissime papillosis areolata; theca in pedunculo breviusculo purpureo erecto orulis paria brunnea, operculo conico recto obtuso thecam superante; perist. dentes in membrana brevi pallide fusci geminati subrugulosi.

Mont, in Gay, Hist. de C'hile. Bot. ('rypt. t. 2. f. 1.

Putria. Chile, in terra muda pr. loc. Racangua: Bertero.

\section{B. Theca oblipua vel nutans.}

39. Tr. inclinatum C. Nüll.; monoicum; lımmile gregarium vel cespitulosum parce diclotome ramosum; folia caulina laxe imbricata, late oblongo-lanceolata, nervo crasso in cuspidem brevem acutam producto, margine inferne revoluta, tenhissime subobsolete pupillosu, apice subcrenulata, basi longa e cellulis elongatis laxissimis pellucidis laevibus reticulata praedita, superne e cellulis submujusculis valde et comoene chlorophyllosis areolata, superiora submarginata; theca in pedunculo elongato purpureo sinistrorsum tortili erecto minnte globoso-orulis, collo angusto inclinuto oblinue, pallide lutea leptodermis nitida dein fusca et nigrescens, annulo simplici et operculo conico recto breviter ucuto aurantiaco; perist. dentes amoene aurantiaci, in membrana brevi positi, e basi latiuscula irregulariter bifidi articulati rugulosi, siccitute recti.

Desmatodon inclinatus sendtu. in Hegensh. Denrhschrift. 1841. 1. 144. - Anucalypta inclinuta Nees Mst. - Desmatodon cernus Br. Furop. Fase. 18-20. 1. 8. t. 5. 1843. - Dilymodon latifolius Wahlenb. Fl. Lajp. p. 313. t. 20. - Inok. in Wrumm. Musc. Amer. No. 115. et al. auct. - Cynodontium latifolium sidw. suppl. I. I. 1. 110. t. 24. - Cynodon Lalifolius Brid. 1. p. 502. - Desmatodon cernu Hëil), M. Germ. p. 117. 1833.

Putrill. Norvegia, Lapponia, Suecia, Tirolis, Carinthia, IIelvetia, Salisburgia, in Sudetis Bohemiac et in Rocky Mountains Americae septentrionalis, muros calcareos pracerens, passim. - Irrsus nestatis finem.

C. Muller: Synops. musc. frond. 
F'los masc. ad pedem feminei, antheridis, foliis duobus brevioribus tectis, longiuscule stipitatis, paraphysibus valde clavatis mixtis. - Partibus multis cum Jiscelio mudo convenit et unlla alia specie confundi potest.

40. Tr. obliquum C. Müll.; androgymum; cespitosum brevicaule subramosum; folia dense imbricata late orato-lanceolatu, basi e cellulis laxis amplis hexagonis longis brevibus e medio usque ad apicem multo minoribus opacis areolata, nervo constunter in aristum flexuoscun productu, margine, apice crenulato excepto, ubique revoluta, tenuissime papillosa; theca in pedunculo longiusculo erecto purpureo parum inclinata cylindraceo-cermuce fuscescens annulata, operculo conico acuto; perist. praecedentis.

Desmatodon obliquus Br. Europ. Fass. 18-20. p. 10. t. 7.Desmatodon Tortula Bruch in schedulis. - Tortula suberecta Hook. in Drumm. Musc. Amer, No. 145.

Patria. In rupestribus alpis Pasterze pr. Heiligenblut Carinthiae et in alpe Radstadter- Tauern dicta: Funk. In alpib. Bavaricis, Linkerskopf, 6856' altitud. leg. Se nd tner. In locis umbrosis alpinis ad marginem rivuli in Rocky Mountains Americae septentrionalis: D r u m mond. - A estate.

Caetera ut in praccedente specie, quacum notis illustratis nunquam confundi potest.

41. Tr. Manderi Schultz (in Regensb. hot.Zeit. 1827. p. 163.); androgynum; dense cespitulosum humile parce dichotomum; folia dense imbricata, e basi oblonga e cellulis magnis hexagonis amoene pellucidis superue valde punctulatis veticulata late ovata obtusinscula upiculata, nerto evanido vel in cuspidem producto, margine, apice denticulato excepto, ubique revoluta, superne e cellulis valde chlorophyllosis majusculis tenuissime papillosis arcolata, carinata; perichaetialia longiora magis acuminata; theca in pedunculo breviusculo apice arcuato miturs, oralis purrula fuscescens annulata, operculo minute rostrato obliquo parvulo; perist. dentes sinistrorsum semel torti, e membrana brevissima longiusculi ad basin bifidi, cruribus 
obtuse tetragonis subaequalibus nodosiusculis amocne anrantiacis.

Desmatodon Laureri Br. Furop. Fasc. 18-20. p. 9. t. 6. D. Blyttii Hartm. ex $\AA$ ngström summ, Veget, auct. F. Fries. p. 94. - Tortula bryoides Hook. in Drumm. Musc. Amer. No. 135!

Putria. Locis rupestribus in der Leiter prope Heiligenblut Carinthiae: La urer detexit. Norvegia pr. Kongsvold: Kurr. Helvetia in summo Faulhorn prope casam: Mühlenbeck et W. P. Sch. - In alpib. Bavaricis, Linkerskopf, 6850' altitudine: Send tner. Manhard inter Carinthiam et Littorale: Sendtner. America sept. in terra mont. Rocky Mountains: Drummond. Augusto.

Antheridia ad basin floris feminei in axillis foliorum comalium subnuda. Paraphyses subclavatae breviter articulatae. - A Tr. obliquo notis cursive impressis jam facillime distinguitur.

\section{Gen. VII. Barbula IIdw.}

Fund. Musc. II. p. 92. - Tortula ej. ibid. - Zyyotrichin Brid. - Mollia Nibank. - Streblotrichum P. B. - Syntrichin W. et I. - Mnium Linn. Jun. - Bryum Dill. Jinu. et al. Hypmum Hall, - Luida Adans.

Nomen ob cilia instar barbac os thecae cingentia conditum.

Calyptra dimidiato - cucullata. Perist. simplex ciliforme; cilia 32 solitaria $v$. per paria approvimata, in membrana basilari plus minus exserta, in ciliola duo postica fissa, longissima, articulata rucrulosa, in spiram unicam v. complures sinistrorsum rarissime dextrorsum contorta, hygroseopica. CelIulac operculi et calyptrae itidem contortae.

vomen ,Tortuln" prioratum tenet quidem, sed oh synonymum „enus phancrogamicum (malum nunc olssoletum) prius deletum, bryologos, qui momine, ,Brorbula" dein usi sunt, alienavit, quare hoc nomen posterius anteponimus, dum alii Tortulan rectius praeferunt. Prinbatus eran anctori illi erit, qui specicm primus novam descripsit, ctiansi Tortulam nominaverit; nam nomen pro nomine immutare furile et iøitur ridiculosum est, prioratum simul mutare. 
Sectio I. Aloina. Foliorum nervus laxus latus deplanatus stperne fila artinulata efficicus; folia e hasi tenera vaginatà reflexa, carnosula, margine involuto, involute tortilia, viridissima, integerrima. Perist. sinistrorsum contortum.

1. R. rigida Schultz (Rec. Barb. t. 32.); dioicu; brevissima, simplex $\mathrm{v}$. semel basi innovans; folia oblonga obtusa, brevissime mucronata v. superiora pilifera concava, margine membranacea; theca elliptico-oblonga recta, annulo revolubili, operculo oblique et longe rostrato busi crenuluto, calyptra thecam dimidium obtegente, perist. longiusculo, spiras complures efficiente.

Br. Hurop. 13-13. p. 13. t. 1. - Weh. et Mohr. Bot. Taschb, p. 212. ex parte. - Tortula enervis IIook. et Tayl. Muse. Brit. ed. 11. p. 52. t. Nppl. 2. - Tortula bifrons Ve Not. Spec. de Tort. Ital. No. 17. forma pilifera.

Patria. In muris, rupibus schistosis, calcareis atque siliceis et ad terram argillosam per totam Europam temperatam et calidiorem, forma pilifera in Italia et prom. b. spei, ubi legit Drège. - Auctumno et liyeme.

Pl. mascula fem. intermixta minutissima triphylla, flore gemmif., foliis perig. late ovatis concavis tenuibus obsolete nervosis nudis, antherid. oblongis, paraphys. subclavatis.

2. B. ambigua Br. et Sch. (Br. I. c. p. 14. t. 2.); dioica; habitus praecedentis, brevicaulis; folia patula ligulato-lanceolata obtusa, apice subincurva; theca cylindricu erecta, annulo subpersistente, operculo breviori elongato-conico margine integro, calyptra breii operculum solum obtegente, perist. brevi semel contorto.

B. rigida Hdw. Musc. Fr. I. p. 65. t. 25. f. 3 et $\mathbf{5}$. Fjusd. sp. Musc. p. 116. - Brid. I. p. 528 et P. 824.

Putriu. In locis iisdem praecedentis prime argillosis forsan per totam Luropam temperatam et calidiorem. Alctumno, hyeme et primo vere thecis maturis atque juvenilibus.

E.x obs. auctorum species praecedenti intime proxima notis illis leviter distinguentibus constantibus inveniri fertur.

3. B. aloides Br. et Sch. (Br. Europ. 13-15. p. 15. t. 2.); dioica; humilis cespitosa simplex; folia patula lan- 
ceolata obtusiuscule acuta, supra basin longiusculam reflexa, superiora erecta, nervo mediocriter lato; theca in ped. longiusculo flavo-rubente flexuoso inclinata, gibboso-cylindrica, flavida dein fusca nitida, operculo longo temirostri obliquo, annulo lato longe persistente, dentibus humidis in spiram unicam contortis, longis, per paria approximatis, siccis divaricatis.

Tortula rigida Hook. et Tayl, Musc. Brit. ed. 2. p. 53. t. 12..Trichostomum aloides Koch in Brid. I. p. 816.

Patrie. In rupibus arenariis, muris calcareis et locis argillosis per Europam mediam sparsim, et in Terra Nova, ubi legit La Pylaie. In Germania prope Bipontum: Bruch, pr. Esslingan: II ochstet ter, pr. Detmold: C. Müller; pr. Naumburg: Beneken. In Anglia pr. Yarmouth et Henfield. In Gallia australi: Decandolle. Hyeme.

4. B. brevirostris IIook. et Tayl. (Tortula in Muse. Brit. ed. 2. p. 53. Suppl. t. 2.); hermaphrodita; cespitulosa humillima simplicissima; folia orato-rolumutu late oblonga, valde concava, in gemmum clausum puncifoliam congesta, vix rel pullo reflexu, latissime nervosa, margine hyalino toto ambitu inflexa, ad folii partem superiorem filis obtecta; theca oblonga erecta, operculo triplo breviore, annulo latiusculo revolubili; perist. dentes in spiras complures contorti.

Br. Furop. 13 - 15. p. 16. t. 2 bis. - B. rigida nomnull.

Putria. In argilloso-arenaceis Scotiae, ubi detexit Stewart, Sueciae pr. Ipsaliam: Wahlenberg et al. America sept., Rocky Mountains et ad York factorey: Drummond No. 136.

Ex inflorescentia hermaphrodita facile cognoscitur.

sertio 11. Argyrobarbula. Foliorum nervis teres. superme massia filamentosa quasi byssoidea obtectus; folia erecta lato-ovata, basi haud vayinata, superne chloroplyllo destituta, marme erecto v. revoluto, pilis lats maxime cauescentia. Perist. siuistrorsum contortum.

5. H. membranifolia Hook. ('Tortula in Musc. Exot. 1. 26.); munoicu; innovando ramosa pulvinato-cespilosa; 


\section{STEGOCARPI. ACROCARPI. BARBLA.}

folia erecto-patentia late ovata et late elliptica, apice membranacea hyalina, nervo tereti in pilum longum denficulatum producto; theca erecta elliptico-oblonga, latiuscule annulata, operculo brevirostri; perist. membrana basilaris annulo triplo longior; calyptra in dimidium fere thecam descendente.

Br. Europ. 13-15. p. 17. t. 3. - Barbula chloronotos Brid. 1. p. 539. ex parte.

Patvia. In muris, rupibus et collibus lapidosis apricis Italiae, Sardiniac, Galliae meridionalis, Algeriae, 'lirolis, Duc. Badensis super. et IIassiae superioris. Ex insula Teneriffa primus retulit Schmidt. - Inemte restute.

Flos masc. ad basin feminei vel innovationis fertilis sessilis gemmiformis diphyllus; folia perig. caulinis breviora, nervo obsoleto v. nullo; antherid. pauca, paraphysibus subclavatis.

6. B. chloronotos Brid. (Mant. Musc. p.90.); dioica; pracedenti simillima, folia imbricata late ovata concava omnino viridia, dein chlorophyllosa, integerrima, superne mayis rotundata, nervo in pilum sublaevem excurrente; theca elliptico-oblonga annulata parvula.

Bric. I. p. อ399. excl. syn. Hook. - Br. K'urop. I. c. p. 18. t. 4. - Tortula crassinervia lle Not. Spec. de Tort. Ital. No. 15.

Patria. In Pyrenaeis ad terram ochraceam: Bridel detexit; in lapidosis calcareis et ad moenia Monspessulani: Salzmann, WV. P. Sch.; pr. Cagliari Sardiniac: Fr. Müller. - Vere.

Flos masc. in pl. graciliore terminalis polyphyllus; fol. perig. ext. nervo in pilum excunte, interiora obsolete nervosa subnutica, intima omnino enervia, antheridia sat copiosa, paraphysib. apicem versus scirsim incrassatis mixtis.

7. B. papillosa Wils. (Tortula in Lond. Journ. of bot. 1845. p. 192.); cespitulosa brevis basi ramosa; folia patentia, haud recurva, valde concava obovata, nervo in mucronem r. pilum producto, superne filis brevibus articulatis obtecto, magis hyalina fragilia luxius areolata 
dorso distincte papillosa, sicca marginibus involutis et rpicibus conniventibus. †.

Patria. Ad truncos vetust, ulmorum Angliae, pr. Huntington pr. York, Majo 1843; Castle-Howard park; pr. Llansaintffraid (N. Wales) Jun. 184t: Wils on.

Ex habitu et charactere essentiali B. Iuevipilae formis minoribus similis, caeterum B. membranifoliae proxima dicitur.

sectio 111. Tortella. Folia cirruata rigida opace et minute areolata, hasi vayinante plus minus alhida tenera, maryine crecto v. plus minus involuto, rarissime revoluto, carinata. Perist. sinistrorsum in una specie dextrorsum contortum.

Generi Burbulue, quod sectio Eutrichostomi affinis generi Trichostomo.

a. Perichaelio exserto cylindraceo.

8. B. calycina Schw. (Suppl. II. I. p. 63. t. 119.); dioica; laxe cespitosa innovando dichotoma rigida lutescens cirrhato-tortilis; folia caulina madefacta patentia, e basi breviter vaginante laxe et elongate reticulata utrinque pellucida ad nerrum flarida subito lanceolata reflexa, nervo crasso flavo canaliculato - concavo in mucronem brevissimum producto, minute areolata opaca viridissima, tenuissime papillosa, margine parum involuta; perichactialia in cylindrum longe exsertum convoluta erecta, elongate laxe reticulata subtorta; theca in ped. elongato $r$ gido erecta cylindraceo-oblonga parum arcuata fuscobadia, operculo longe subulato recto; perist. elongatum pluries contortum.

Brid. 1. p. 541.

Putria. Nova Ifollandia: La Billardiere primus legit. Ad fl. Swan River legit Preiss.

A B. inclinata et affuibus ceteris notis illustratis fatcillime differt.

9. E. Iamprocalyx C. Müll.; dioicu; dense cespitosa subdeclinata fastigiate breviter ramosa, densifolia crassiuscula viridis, teretiuscula; folia caulina appressa subtorta, madefacta erecto-patentia, dense conferta, e basi 
rectiusculâ oblonga, obtusa v. plus minus acuminata, nervo viridi in aristam brevem viridem laevem producto, integerrima, margine ubique revoluta, inferne e cellulis ubique laxis hexagonis teneris flavidulo-pellucidis longiusculis, superne sensim minutissimis maxime opacis viridissimis tenuissime papillosis arcolata; perich. in cylindrum exsertum flavidum nitidum subclausum congestu, erecta, latiora, elongate acuminatu et aristata, basi longiore pellucida, medio plicato-concava; theca in ped. longiusculo flexuoso tenui rubro erecta anguste cylindrica curvula leptodermis fusca, operc. longe conico, annulo nullo, perist. elongato laxe contorto, in membrana brevi posito.

Patria. Chile: Pöppig. Ilb. Kunz.

B. Northiance affinis, sed inter Torlellas fere solitaria.

\section{b. Perichnetio immerso patulo.}

10. E. inclinata Schwägr. (Suppl. I. I. p. 131.t 33.); divica; late et laxe cespitosa breviter dichotoma erecta, plus minus elata plevmpue humilis flavide rarius lacte viridis, frogilis densissime imbricata; folia caulina cirrhato-tortilia, madeficta erecto-patentia, e basi breviter vaginante pellucida laxe et elongate reticulata partem superiorem minute areolatam opacam tenuissime papillosam margine igitur subcrenulatam inferne pellucide cingente erectà parum reflexa, perfecte lanceolute, nervo in mucronem brevem producto carinato, margine crecto v. parum incurvo vix nudulato, latiora breviora, integerrima; perichactialia longiora erecta longius cuspidata longe vaginantia et laxe reticulata; theca in ped. mediocri oratooblonga subgibbosa curvula obligua, dentibus lare contortis apice divergentibus tubum vix basi efficientibus.

Brid. 1. p. 585. - Br. Fiur. 13-15. p. 25. t. 12. - B. nercosa Brid. Mant. Muse. p. 95. - Tortule curvutu Nehleich. in sched. : - Barb. angustifolia Brill. 1. p. 568.

Patria. In glareosis secus fluviorum ripas, in collibus calcareis et in alpinis totius Europae. - Irimo vere, in alpibus aestate. 
Pl. masc. fertili nunc similis, nunc gracilior et ramosior; flores terminales gemmiformes; fol. perig. externa et media orato-lanceolata, interna ovato-acuminata, omnia nervosa. - A $\boldsymbol{B}$. tortuosa affini notis cursive impressis facile distinguitur.

11. W. tortuosn Web. et Mohr (Bot. Taschb. p. 205.); dioica; late et pulvinate cespitosa elata dichotome ramosa dense imbricata viridis v. lutescens; folia erecto-tortilia, madefucte erecto-putula flaccida flexuosa, e basi longe vaginante pellucida laxe et elongate hexagono-reticulata, partem superiorem minutissime areolatam viridem opacam margine parum cingente anguste lanceolata acuta elongata flexuosa, margine undulata, integerrima, popillis temissimis margine subcremulata, perichactialia longiora longe vaginantia, laxius articulata, caeteris caulinis similia, omnia nerro in cuspidem acutam parce deuticulatum mroducto; theca in ped. elongato stricto suberecta, plus minus arcuata cylindrica, operculo subulato longo aurantiaco; perist. e membrana brevissima compluries contortum.

Isricl. 1. p. 574. - Br. Fur. 13-15. p. 26. t. 13. ex parte. Mollic tortuosa sidnek. Prodr. Fl. Sialish). 11. 8333. - Mnium tortuosum L. jun. Netl. Must. 1. 364. - Bryum tortuosum L. Np. P1. p. 15\$3. - Br. cirhatum setis et capsulis longionihus. Dill.

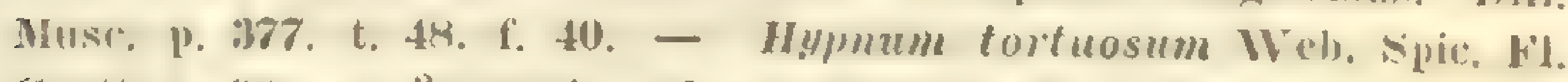
Goett. p. 50. - ? syrrhopodon dubius sendtn. in sched.

futria. Ad rupes, humo obtectas, praesertim calcareas per lotam Europam in subalpinis et alpinis et in America sept. - Vere, in alpibus rersus aestutis fincm.

Pl. mascula similis, floribus terminalibus solitariis $\mathbf{v}$. angregatis gemmiformibus. Folia perig. interna caulinis lationa breviona longius acuminata.

12. B. squarrosa Brid. (I. p. 833 !); dioica; late et lure cespitosa clata dichotoma dense imbricata lutescens; folia erecto-tortilia, malefuctu refexo-squerrosa flaccida subflexuosa breviora, e hasi breviler vaginante mimule rectangulari-areolata Aavida, margine solo ecellulis pelTucidis purvis laxioribus cinctà distincte roflexu, flexuosa, lanceolata evanidinervia, margine distincte denticulata, 
et tenuissime papillosa; perichactialia breviora, breviter vagimantia valde reflexa, inferne laxius reticulata; theca erecta elongate cylindrica subarcuata, operculo conicosubulato, annulo simplici, perist. dentibus teneris valde papillosis.

Br. Eur. 31. Suppl. t. 1. - Tortula? squarrosa De Not. Spec. de Tort. Ital. n. 29. - Barbula tortuosa Br. Lur. 13-15. p. 26. ex parte.

Patrin. Ad terram in pascuis aridis, humilioribus totius fere Italiae c. Sicilia et Sardinia: De Notaris, Fr. Müller. Gallia, pr. Monspessulanum in collibus calcareis apricis: W. P.Sch. Anglia, ad littora prope Ilastings et in Beeding Chalkpit (Sussex): Spruce. In insulis quoque Canariensibus vigere dicitur.

A B. tortuos habitu simillima areolatione folii jam toto coelo et notis ceteris cursive impressis differt.

13. IB. Northiana Grev. (Tortula in 'T'rans. of the Linn. Soc. XV. II. p. 342. t. 3.f.4.); monoica; innovando parce dichotoma subsimplex cespitulosa, amoene viridis nitida inferne albida, humilis; folia caulina cirrhato-tortilia, madefacta erecto-patentia, e basi breviter vaginante pellucida laxe et elongate reticulata partem superiorem minutissime areolatam viridissinam opacam tenuissime papillosam margine parum cingente paullo reflexa, lanceolata mucronata excurrentinervia; integerrima parum undulata, margine erecto; perichaetialia basi laxiore longiore patula; theca in ped. longiusculo flavo-rubente flexuoso evecta cylindraceo-oblonga plus minus arcuata, operculo subulato recto; perist. pluries contortum tubulosum.

B. cirrhata Br. et Ach. Br. Fur. 13-15. p. 24. t. 11. - Tortula cirrhata W. Arn. Bruch. - T. intermedin lle Not. Myllat. p. 181. - Barb. cespitosa sillw. sinpl. I. 1. p. 120. 1. 31. - B. cespitosa sulliv. Muse, Mllegh. No. 150. - Brid. 1. p. 53. - $B$. humilis Hdw. sp. Musc. p. 116. t. 25 et Brid. 1. p. 537. e sper. 14 \%. Bridel, huc pertinet.

Putria. Italia tota et ager Mediterrancus, Africa septentrionalis atque meridionalis et utraque America, 
arborum truncos emortuos vel humum mollem libenter habitans. - Aestate.

Flores masc. plures axillares breviter stipitati in caule fenineo positi tenuiter gemmiformes paucifolii; fol. perig. late ovata acuminata apice recurva laevia tenera pellucida cnervia; antheridia pauca, paraphysibus filif. paucis mixtis. - A B. inclinatu haud dissimili notis laudatis longe distat, Eutrichostomis e. gr. Tr. Burbulae simillima et e distributione geographica lata polymorpha.

14. F. anomala Br. et Sch. (Br. Europ. 13-15. p. 45. t. 29.); monoica; laxe cespitosa erecta elatiuscula comose foliosa inferne nudiuscula, innorando pluries divisa; folia longiuscula tortilia, madefacta crecto-patentia laxe imbricala, viridissima nitida, inferiora minora, ligulate lanceolata, margine subinvolutaceo plus minus flexuoso, supra basin elongate anguste pellucide et laxe reticulatam usrpue al apicem dentato, dense minute areolata, sed lacvia haud opaca mollia, nervo crassiusculo subexcurrente; theca in ped. Iongo flexuoso rubro tenui erecta longiuscule cylindrica subobliqua fuscescens nitida, operc. conico recto breviusculo, annulo duplici revolubili, perist. dextrorstum contorto longo ralde scabro ad basin usque fere fisso, ciliis binatis.

Putrier. In olivelis pr. Taremam ad lac. Comensem et in ipsius lacus ripis fruticibus umbratis, praeprimis versus Bellano: W. P. Schimper et Mühlenbeck, ineunte Julio 1810.

Flores mase. in ramulis propriis terminales solitarii v. aggregati gemmacei; fol. perig. ovato-acuminata nervosa parva diaphana; antheridia pauca minuta, paraphysibus filiformibus paucis mixta. - Trichostomo Burbulae maxime similis, sed peristomio barbuloideo dextrorsum contorto ab eodem ceterisque congeneribus longe distincta.

15. I. angustifolia Hook. el Grev. (Brewster Fdinb. Journ. I. p. 299. t. 12.); clongata subramosa; folia linearia carinata acuta subapiculata rigidiuscula, siccitate tortilia; theca cylindracea, operculo longirostrato. †. 


\section{B. tenuirostris Brid. I. p. 826.}

\section{Putria. Nepal: Wallich.}

B. lineari affinissima, distincta tantum caule elongato et foliis carinatis vix mucronulatis. $\boldsymbol{B}$. tortuosam etiam referre dicitur, sed longe brevior et folis nullatenus undulatis.

sectio IV. Hyophiladelphus. Plantae graciles, foliis involutis plus minus spathulatis, hasi e cellulis majorihus limpidis superne minutis plus minus opacis minus papillosis areolata. Perist. sinistr, c.

16. B. agragria Sw. ('Tortula in Fl. Ind. Occ. III. p. 1763.); monoica; flos masculus in ramo proprio basilari breei minutus paucifolius, foliis perig. convolutuceis acuminatis erectis, nevro ante apicem cranido flavido; caulis pusillus simplex dense cespitosus paucifolius; folia caulina erecto-conferta apice parum curvata, marginilus involutis, madefacta laxe conferta, spathulato-lanceolulu, nervo valido flavido excurrente, integerrima, basi e cellulis majusculis utriculo primordiali tenuissimo instructis superne minoribus densioribus hexagonis hand opacis arcoluta, paullo concava; perichactialia intima duo convolulacen breviora laxius reticulatu, apice obtusiuscule roturdata, nerero ex'unido in intimo obsoleto; theca in ped. longiusculo cylindracea subcurvula annulata, operculo conico obliquiusculo; perist. pluries contortum, e membrana brevissime exserta ortum.

Brid. 1. p. 532. - Hdw. Muse. Fr. III. p. 17. t. 6. - B. stelluta Brid. Mant. Musc. p. 88. - B. conira Brid. Muse. Rec. II. I. p. 193. - Bryum agrarium sw. Prods. p. 1399. - Barbula acuminata Brid. Musc. Hec. II. I. p. 208. - Tortula deripiens Brid. Sp. Musc. 1. p. 247. - Bryum acuminatum sw. Prodr. p. 139. e sper, auth.! - Barb. domestica Brid. Mant. Muse, p. 49. Br. unis. 1. 1. 536 ! - Barb. latifolia Brid. 1. p. 536 ! - B. pallens Brid. I. p. 331 !

Patria. In Antillis insulis omnibus et terra continente vicina, in muris, agris saccharinis rupibusque.

17. B. spathulata Dz. et Molkb. (Musc. Archip Ind. p. 49. t. 19.); dioicu? praecedenti simillima; folia inferiora magis dissita, superiora in comam congesta recurvo-pa- 
tentia, e basi caulem amplectente sputhulutu, versus upicem denticulata, margine undulata, nervo crasso una cum apice desinente, late obovata obtusata saepe apice emarginata, basi e cellulis subquadratis majusculis elongatis limpidis superne minimis rotundato-hexagonis chlorophyllosis areolata; perich. minora ped. mediocrem amplectentia oblonga evanidinervia; theca erecta cylindrica purra, annulo simplici revolubili, operculo conico-acuminato curvulo.

Putria. Java, in horto Bogoriensi: Korthals. Amboina, in solo calcareo: 'Zi ippelius.

A B. Juvanica laeviter differt.

18. H. Javaniea Dz. et Molkb. (Musc. Archip. Ind. p. 47. t. 18.); divice; laxe cespitosa erecta humilis, innovationibus teneris divisa, basi foliis remotis apicem versus densioribus incrassata, gracilis; folia caulina sicca inflexo-tortilia, e basi caulem amplectente lata laxe et pellucide reticulata involutaceo-oblonga obtusa, nervo crasso ante apicem cranido s, excurrente, integerrima, minutissime areolata viridia haud opaca; perichactialia oblongiora vaginantia convoluta; theca in ped. longiusculo flexuoso rubente recta anguste cylindracea, operculo conico rectiusculo, annulo angusto, perist. parce contorto in membrana brevissima posilo.

B. calynuperifolia C. Müll. Limn. XVIII, p. 703.

Putrie. In terra nuda summi montis Gédé: Zippelius. E prov. Buitenzorg inter Bryum pachypoma Mont. misit M i que l.

Pl. mase similis, flore terminali gemmaceo; fol perig. latissime ovalis acuminatıs obtusiusculıs, intimo enervi subrotundato; antherid. numerosis, paraph. filiformibus mixtis.

19. H. inflexa Dub. ('Tortula in Moritzi Verz. d. 'Zoll. Pfl. p. 133.); divicu; ex habitu $B$. Jurcunicue simillima, folia caulina convolutaceo-concava oblongo-lanceolata abvupte uculu integerrima, nervo excurrente v. ante apicem summum evanido crassiusculo, basi e cellulis hexagonis 
longiusculis firmiusculis superne minute hexagonis hand opacis sublaevibus areolata; perich. Iongiora; omnia sordide viridia, sicca inflexo-tortilia; theca in ped. mediocri rubro erecta cylindraceo - oblonga, operc. oblifue longe rostrato; perist. dense contortum in membrana perangusta positum.

Patria. Java, ad terram humidam rivulorum Pantar Petè: Zollinger No. 1603.

A $B$. Javenica proxima notis cursive impressis certe distat.

sectio V. Senophyllum. Plantae suraciles. Folia plus minus torta, angusta, plerumque lanceolata, carinata superne minute et rotundate areolata saepe opaca, margine plus minus revoluto s. erecto. Perist. sinistr. cont.

\section{A. Fotiu margine erecto.}

a. Nervus excurrens vel evanidus.

20. B. erythrodonta Tayl. (Iond. Journ. of bot. 1846. p. 50.); laxe cespitosa crecta subuncialis pallide lutescentiolivacea, ramis crebrioribus fertilibus erectis fastigiatis; folia imbricata erecto-patentia subrecurva subfasciculata, elongate lanceolato-acuminata carinata longe setuceo-apiculata, margine infero recurea, haud revoluta, supero serrulata, marginata, nemo percurente; perich. conformill; theca in ped. perbrevi stramineo torto erecta oblongo-cylindracea ampla aerpualis, opere. obluse conico brevi, perist. intense purpureo brevi dense contorto anguste tubuloso. f.

Icon Wilsoni 1. c. p. 450, t. XV. F.

Putrill. Monte Pichincha pr. Quito: WV. Jamesoll.

Ex animadr. Wilsoni stirps memorabilis, habitu Leptothecue specioste Hook. et Wils.

21. B. Pöppigiana C. Müll. (Linn. XVII. p. 585.); divicu; dense cespitosa pusilla, sordide viridis, innovationibus aequilongis stellatim superne dispositis nommllis ruasi truncula 2 . siccitute deuste, inferne paucifolia, superne comosa; folia caulina sicca subspiraliter torta, madefacta recurvo-patentia, parva, e basi brevi tenerime 
hexagone reticulata muxime pellucida recurvo-lanceolata, e cellulis minutis opacis hexagonis suepe diuphunis areolata, margine integerrimo erecto; perich. erecta basi latiora et multo tenerior laxius reticulata amplexicaulia; omnia vix viridia, sed grisen, nervo excurrente rufescente; theca in ped. mediocri erecta elliptica, badia, simpliciter annulata, operculo conico obliquo brevi, perist. in membrana brevisissima parum contorto sublaevi fuscidulo.

Putriu. Chile australis: Pöppig Coll. Pl. Chil. No.4.

E ramificatione et foliorum structura singularis species.

22. B. paludosa Schw. (Suppl. I. I. p. 124. t. 30.); dioicu; Jate et dense cespitosa elata erecta, fastigiate ramosa, amoene virescens inferne fuscescens; folia caulina parum tortilia, madefacta erecto-patentia, lanceolata, canaliculato-concava, basi erecta unguste elongute firme reticulata, subpellucide flavida, superne plus minus reflexa e cellulis minutis quadratis firmis incrassatis tenuissime papillosis opacis areolata, margine erecto apice plus mimus remote denticuluto, superiora et perichaetialia basi laxius reticulata, haec subraginantia longius acuminata; omnia nervo excurrente; theca in ped. mediocri parvula elliptica plevempre irreguluris curvelu, igitur subgibbosu, badia, excummlutu, operc. subulato recto, perist. pluries contorto, in membrana basilari angustissima.

Br. Fir. 133-15. p. 21. t. 7. - Brid. I. P. 562. - B. crocea Brid. Mant. Musc. p. 90.

B. Funtiuna; humilior tenerior, foliis angustioribus,

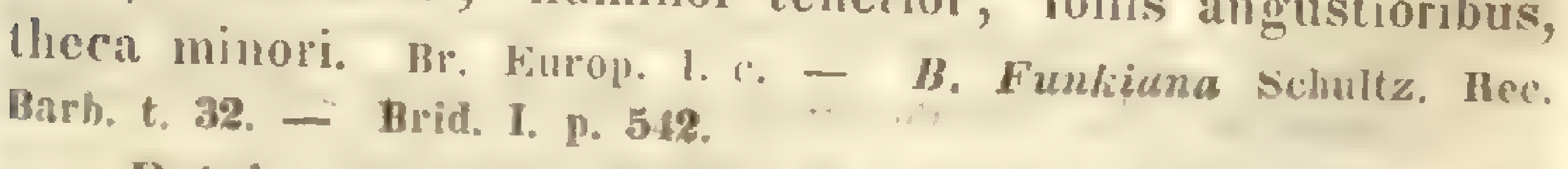

Putriu. In udis et irrigatis alpinis et subalpinis Germaniae, IJelvetiae, Sabaudiae, Rhactiae, Nalisburgiac, ditionis Mediolanensis ad lac. Comensem et majorem, et in Bavaria. - Aestate.

Flos mase. in pl. propria terminalis gemmiformis, foliis perig. ext. ovato-lanceolatis, intimis minoribus, nervo brevi tenui. - In axillis foliorum super. auct. Br. Eur. corpuscula cellulosa invenerunt. - E distinctissimis. 
23. D. Inrida Hsch. (F). Bras. p. 18.); erecta uncialis simplex, inferne radiculosa, superne foliosa, gracilis; folia erecto-putentiu, siccu torpuescentiu, lanceolatu obtusa planiusculu, integerrimu, lurido - viridia, nervo crasso carinato rufescente infra apicem evanido, retis areolis subquadratis minutis; perich. ext. erecta basi vaginata, interiora minuta lanceolato-acuminata; theca in ped. terminali v. innovationibus brevibus laterali purpureo flexuoso erecta, cylindrico-oblonga parum curvata, laevis brunnea, operc, conico brevissimo concolori. $\div$.

Putriu. Brasilia in Minis Generalibus: Ma rt ius.

Cui affinis?

\section{b. Nerrus excedens.}

24. M. Morngehuchiana Śchultz. (Nov. Act. 1823. XI. I. p. 217.); divicu; laxe et late cespitosa flavescens fragilis gracillima erecta parce breviter dichotoma; folia caulina siccu incumbentiu, madefacta patentia, perfecte late lanceolata acutissima, nervo crasso excurrente $r$. in superiuribus cexcelente, integerrima, inferiora minute sed dense areolata subluevia margine mims rovoluto, superiora verichactialia jurum majus areolata, margine erecto; theca oblongo-cylindrica, badia parva subcurvula, anguste annulata, operculo oblique subulato; perist. praccedentis.

Br. Europ. 13-15. p. 28. t. 10. - B. veroluta $\beta$. Hornschnchiana Brid. I. p. 572. - B. revoluta Wel,. et Mohr. Bot. Tuschol. p. 210.

Putria. In apricis per totam Europam temperatam ct calidiorem. In Africa septentrionali a W. Schimper lectam Br. Eur. indicat. - Vere.

Fl. masculus B. revolutue simillimac, a qua notis cursive impressis certe refugit.

25. B. Linenris Siw. (Tortula in Fl. Ind. Occ. III. p. 1765.); divica? Inumillima simplex; folia elongate lineuri-lanceolutu, patula, sicea incurva, busi brevissime laxe reticulata, superne e cellulis minutissime rotundatis opacis tenuissime papillosis areolata, planiuscula, margine 
erecto, nervo crasso flavido excurrente mucronata; theca in ped. mediocri rubente cylindracea parva, operculo oblique subulato, annulo duplici revolubili, perist. pluries contorto, in membrana basilari vix exserta.

Brid. I. p. 533. - Schwägr. Suppl. 1. I. p. 119. t. 30.

Patria. In siccis calcareis Hispaniolae: Swartz.

A $\boldsymbol{B}$. agraviu longe distat.

26. I. flexuosa Hook. (Musc. Exot. t. 125.); rix uncialis crecta crassiuscula apicem versus praecipue ramosa, fusco-viridis; folia caulina arcte imbricata crectopatentia rigidiuscula lanceolata subcurvula carinata, margine erecto subundulata integerrima, nervo valido intense fusco, paulo ultra apicem excurrente; perich. elongata, pedunculi elongati flexnosi flavo-rubentis basin insigniter vaginantia atyue circumioluta flavo-fusca longe acuminata obsoletineviva; theca cylindracea badia, operc. elongate rostrato acutissimo rectiusculo, perist. longo flaro-rufescente compluries contorto ad basin usque fisso. $\div$

Brid. 1. p. 573.

Prutril. Ad prom. b. spei: Menzies 1791.

B. Folia margine revoluto.

a. Folia stricta.

a. Perichaetium patulum.

+ Nerous excurrens.

27. 1. Eracilis Schwägr. (Suppl. I. I. p. 125. t. 34.); dioica; laxe cespitosa parum cohacrens, fuscescens, rarius viridis, humilis, simplex v.innovationibus fastigiatis; folia caulina madefacta et sicca erecto-patentia stricta densinscule imbricata e basi late oruta concara marginibus convexo-recurvis instructa lanceolato-acuminata, nervo rufescente excurrente, integerrima, haud plicata, ubique cellulis frmis parvis infima basi pellucidis quadratis paucis superne plus minus rotundatis incrassatis robustis vix papillosis areolata; perich. longe et flexwose ccuminata, intima basi amplexante laxius et pellucidius reticulata; theca in ped. mediocri rigidulo erecta, ovalis

c. Müller: synops, musc, frond. 
v. oblonga regularis v. curvula, exammulata, operc. subulato obliquiusculo, perist. vix contorto, in membrana latiuscula.

Br. Eur. $13-15$. p. 22. t. 8. - Brid. 1. p. 536. - B. acuta Bricl. I. p. 5.̆t! - B. rectifolia Tayl. Lond. Journ. of bot. 1846. p. 49. ex animadv. Wils on $i$ (l. c. p. 450.) huc var. seta longiori pertinet.

B. vividis; clatior; folia angustiora elongato-lanceolata laete viridia, sicca laxe imbricata et subtortilia. Br. Fur. I. c. - Tortula fallax stricta De Not. spec. de Tort. Ital. No. 26.

Patria. In glareosis calcareis v. arenaceo-argillosis per totam Europam et in Andibus, m. Pichincha 12,000' alt. Tar. $\beta$. in umbrosis Sardiniac, ubi legit Fr. Müller. - Vere.

Pl. masc. similis, flore gemmiformi; fol. perig. ext. caulinis paulo latiora, interna e late ovato acuminata, nervo ante apicem evanido.

28. B. fusea C. Müll.; dioicu; B. gracili simillima, sed folia perichuetialia canlinis simillima, intima basi laxius arcolata, omnia e cellulis multo densioribus firmioribus inanibus diaphanis areolata, latiora unnulo simplici praedita, cactera praccelentis.

Patria. Chile, ad Talcalıuano: Pöppig.

29. B. comosa Dz. et Molkb. (Musc. Archip. Ind. p. 46. t. 17.); dioica; ascendens simplex v. apice innovationibus binis brevibus ramulosa luteo-viridis subgregaria pusilla; folia caulina sicca adpressa subtortilia, madefacta erecto-patentia, inferiora minuta remota subtriangularia, superiora sensim majora et conferta, anyuste lanceolata subacuta, summo apice obsolete denticulata, margine angustissime longe ultra medium folii reflexa, ubique e cellulis submollibus parvis subhexagonis diaphanis arcolata, nervo tenui excurrente carinato; perich. longiora basi amplexicaulia; theca in ped. longiusculo rubente erecta $c y$ lindrice mimute, operculo conico-subulato subaequilongo recto, perist. in membrana cmnulum haud superante compluries contorto. 
Putrifl. Amboina, in solo calcareo: Z ippelius.

A B. gracili proxima notis cursive impressis facile distinguitur.

30. B. graminicolor C. Müll.; divica ; laxe cespitosa erecta subhumilis gracilis, e perichaetio saepe semel vel bis prolifera, e ceteris simplex, umoene viridis; folia erecto-tortilia, madefacta erecto-patentia stricta, inferiora minora remota, superiora confertiora subcomantia, - basi erecta tenerrime reticulatu pellucida recurva, anguste lanceoluta acuta, margine integerrima supra basin parum revoluta, minute areolata opaca, tenuiter papillosa, nervo tenui excurrente viridi, perich. basi teneviora laxiora; theca in ped. longo rubro stricto tenui erecta oblongo-cylindrica subcurvula, pallida, dein fuscescens, operc. conico-subulato obliquo, annulo simplici angustissimo persistente, perist. longo pluries contorto ad basin resyee fisso pallide fusco laeviusculo.

B. Atlantica schimp. in schedulis.

Putric Chile, ad terram loc. umbr. pr. Racangua: Bertero legit 1828. Junio.

Pl. masc. gracilior, flore terminali, innovando dein laterali gemmaceo; fol. perig. ext. basi late ovata, interna multo breviora ovato-acuminata acuta fusca diaphana, omnia nervo evanido rufescente; antheridia pauca turgida, paraph. paucis filif. mixta. - A $\boldsymbol{B}$. elate Mont. affini notis cursive impressis facile distinguitur.

31. F. torquata Tayl. (Lond. Journ. of bot. 1846. p. 50.); cespitosa brevis erecta subramosa, superne flavescenti-viridis inferne brunneo-flavescens; folia sicca spiraliter atque arcte convoluta, conferta erecto-patentia lanceolata acumiuata integerrima margine reflexa, nervo percurrente; perich. conformia; theca in ped. subflexuoso pallide rubro tenui erecta subaequalis oblongo-ovata, operc. elongate conico, perist. pluries contorto ad basin usque fisso, t.

Putria. Nora Hollandia ad flumen Swan River: J. Drummond. 
Ex auctore siccitate foliorum torsione habitum Rhacopili tomentosi referens, ex animadr. Wilsoni (1. c. p. 450.) $B$. unguiculatue affinis, sed foliis acutioribus distare dicitur et siccitate $\boldsymbol{B}$. veplicutae simulans.

\section{tt Nervus excedens,}

32. F. unguiculata Hdw. (Musc. Fr. I. p. 59. t.23.); dioicı; lave et late cespitosa, plus minus elata, et dichotome ramosa, sordide viridis inferne fuscescens parce radiculosa; folia erecto-patentia $v$ patentia siccitate subtorta adpressa, ovate et lineari-lanceolata plus minus obfusiuscula, nervo crasso carinato flavido excedente mucronata, margine integerrima vapillis tenuissimis asperula, inferne revoluta, basi e cellulis parvis rectungularibus pellucidis superne quadratis multo minoribus opacis areolata; perich. putule longiora basi longiore laxius reticulata; theca in ped. mediocri purpureo substricto crecta oblongo-cylindrica saepe curvula fusca leptodermis subnitida, operc. Ionge subulato rectiusculo, annulo nullo, perist. in membrana angustissima pluries contorto intense purpureo papillosa.

Br. Lurop. 13-15. p. 19. t. 5 et 6. - Brid. 1. p. 563. - Mollia unguiculatu schrank. Baic's. Fl. II. p. 457. - Dicranum Iaxum Brid, Musc. Rec. II. I. p. 175. expl. Synon. - Bryum unguiculatum et harbatum surculis in summitate crassioribus. Dill. Musc, p. 3\$3. t. 48. f. 47 .

Barb. amoena schumar'h. F1. Saelaudiae II. p. 48. et Brid. I. p. 538, testil. WV eber et Mohr luc revocanda.

Barliula aristata Brid. Mant. Musc. p. 92. - Tortula aristata sm. Fl. Brit. 11I. P. 1261. - Orthopyxis aristata P. B. Prodr. p. 79. - Bryum aristatum Dicks. Fasc. IV. PI. Cr. p. 12. t. 11. f. 7 .

Barbula dubia Brid. Mant. Nusc. p. 93. - Tortula dubia P. B. Prod. p. 92. - Tort. barluta sm. Fl. Brit. HI. p. 1260. Bryum barbatum Curt. Fl. Lond. Fase. 1V. t. 65. - Bryum ungruiculatum et barbatum, tenuius et stellatum. Dill. Musc. p. 384. t. 48. f. 48.

Tortula mucronulata sm. FI. Brit. III. p. 1250. - Bryum mucronulatum Dicks. Fasc. III. Pl. Cr. P. 3.

Barb. apiculata Hdw. Sp. Musc, p. 117. t. 26. - Brid. I. p. 560 ct 831. - Trichostomum Pensylvanicum \$pr. syst. Veget. IV. I. p. 170, non Hmp. Linn. XIII. p. 41. 
Barb. microcarpa sichultz, Rec, Barb, t. 33. - Brid. 1. p. 561.

Barb. lanceolata Hdw. Sp. Musc. p. 119, t, 26! - Brid. I. p. 368. - Barb. obtusifolia scliultz Hec. Barb. t. 32. - Brid. I. p. 552. excl, Syn. Schwägr.

Barb. stricta Hdw, 1. c. t. 26 ! - Brid. I. p. 540.

Barh. fastigiata schultz. Hec, Barl, t. 33, - Brid. I. p. 554.

B. cuspiduta; humilior, foliis angustioribus longius et sensim mucronatis, perichactialibus nervo longius excedente fere cuspidatis. Br. Europ. 1. c. - Brid. I. p. 5̆6. Barh. cuspidata schultz. Rec. Barb. t. 32. - Tortula mucronulata Sw, Musc. Suec, p. 40.

$\gamma$. Patagonica; fastigiato-ramosa, foliis plerumque obtuse rotundatis, nervo excedente mucronatis. C. Müll. Linn. 1843.' p. 583. - Syntrichia ericetorum Brid. 1. 1. 588. Tortula ericetorum sm. Fl. Brit. III. p. 1258? - Bryum ericetorum Dicks. Fasc. II. Pl. Cr. p. 5? - Bryum ruralis facie, foliis minoribus et noll pilosis Dill. Musc. p. 354. t. 45. f. 13. e spec. Hh. Dillen.!

ס. brachypus; humilis simplex subgregaria, folia robusta torla, pedunculus perichaetium parum superans, theca parva ovalis. B. brachypus Brid. I. p. 551. - Tortula acuminata ej. sp. Musc. I. p. 252. Varietas memorahilis, a B ridelio in Monte serrato Cataloniae et cirra Gotham Thuringiae lecta, typice autem a $B$. unguiculata non recedens.

Patria. Per orbem Europam totam et Americam septentrionalem, terram nudam habitans, vulgatissima polymorpha. - Auctumno.

Pl. mascula femineae similis v. gracilior, flore terminali gemmaceo; fol. perig. ext. ovato-lanceolata, media similia et breviora, intima e basi lata acuminata breviora; anth. crassiuscula, paraphysibus filiformibus cincta.

33. I. Havesceng Hook. et Grev. (Brewster Edinb. Journ. I. p. 297. t. 12.); flavescens elongata ramosa; folia erecta, sicca tortilia, e basi ovata apice acuminata obtusiuscula e nervo subexcedente apiculata, inferne margine recurvo; theca cylindracea, operculo longe rostrato thecam aequante. $f$.

Brid. I. p. 831. - B. fuscescens Wallicl. Catal. No. 7567.

Patria. Nepal, in solo argilloso: Wallich. 
Habitus et caulis $\boldsymbol{B}$. fallacis, sed folia longius acuminata, humida erecta, sicca tortilia. A B. unguiculatu simili operculo multo longiore differt.

34. M. iemadophila Schimp. (Br. Europ. Suppl。ined.); divica; dense cespitosa, sed laxe cohaerens, proceru grucillima flexuosa, innovationibus brevibus subcuspidatis parce divisa, subjulacea rigida, sordide viridis $\mathrm{v}$. fuscescens; folia caulina erecto-conferta, madefuctu parum patentia strictissima, perfecte ovato-lanceolata, superiora nervo excedente in subulum angustam longam substrictam producto crasso fuscescente, margine vix revoluto v. convexo integerrimo, laevia, ubique e cellulis minutis firmis quadratis diaphanis areolata; perich. longius subulata, basi tenuiore, magis amplexante latiore; theca in ped. breviusculo rubro torto erecta oblonga minuta ore angustate, operculo oblique rostrato acuto rubro, annulo simplici, perist. longiusculo pluries contorto ad basin usque fisso.

Patria. Ad catarractam „Krimmlfall" Pinzgoviae societate Bryi julucei, ubi legit W. P. Schimper.

Notis editis ab affinibus $\boldsymbol{B}$. vineali et gracili longe refugit et species distinctissima. Parce fructificat.

35. E. teretiusena Schimp. (in litt.); dioica; dichotome ramosa, ramis siccitate teretibus; folia conferta erecta, sicca imbricata, ovato-lanceolata, nervo excurrente mucronata, margine basin versus reflexa; perich. late lanceolata subvaginantia, nervo apice evanido; theca ovali-oblonga erecta, annulo simplici angusto, operc. rostrato theca breviori, perist. semel torto. t.

Patria. Mexico, ad montem Orizaba: L i i b mann.

A B. yrucili proxima tam magnitudine quam habitu ct colore, thecae forma et peristomii torsione, foliis tamen brevius acuminatis, nec in subulam abeuntibus, siccitate arete imbricatis, annulo latiore constanter distincta.

$\beta$. Perichaetium convolutum.

36. N. convoluta IIdw. (Nuse. Fr. I. p. 86. 1. 32); divicu; dense cespitosu pulvinatu, erecta gracillima par- 
vula dichotome ramosa lacte $\mathrm{v}$. flavo-viridis, inferne radiculosa $\mathrm{v}$. tomentosa; folia caulina erecto-putentia purea carinato-lanceolata, ubique e cellulis minutis superne subopacis viridibus quedrate lexugonis basi rectangularibus pellucidis areolata, integerrima, inferne margine paullo reflexa; perich. nonnulla exserta convolutacea ubigue elongate et distincte laxe reticulata flavide pellucida, acuminata intima obtusa obsoletinervia; theca in ped. elongato flavido stricto tenui inter ramos 2 posito erecta $v$. subobliqua anguste oblonga, badia, operculo oblique longirostrato, perist. compluries contorto in membrana basilari annulum revolubilem duplicem superante.

Br. Fur. $13-15$. p. 29. t. 16. - Brid. I. p. 569. - B. setacea Hdw. Fund. Musc. II. p. 92. - B. jurpurea Agardl ex' animadv. Hornschuchii in Brid. I. c. - Streblotrichum convolutum P. B. Prodr. p. 89. - Mnium setaceum Ehrh. Hann. Mag. 1780. p. 235. - Bryum setaceum Vill. PI. Dauph. 1II. 1. $\$ 80 .-B$ convolutun Dicks. Fase. II. PI. Cr. p. 6. - Bryum stellare, nitidum, pallidum, capsulis tenuissimis Dill. Musc. p. 381. t. 48. f. 44. Hypnum setaceum Weis. Crypt. Goett. p. 206.

p. Sardoa; foliis magis opacis, perich. internis acuminatis. Br. Eur. 1. c.

Patrice. In apricis per totam Europam et Americam septentrionalem. Var. $\beta$. in Sardinia: Fr. M üller. Aestate ineunte.

Pl. masc. gracilior ramosior, flore gemmiformi, fol. perig. ext. caulinis brevioribus, mediis ovato-lanceolatis, intimis ovato-acuminatis tenuinervibus.

37. B. leucoealyx Mont. (Ann. d. sc. nat. IX. 1838. p. 53.); divica; erecta, innovationibus iteratis apice stellate foliosis brevibus veluti prolifera, inferne subnuda; folia caulina ima spuamueformice appressa minutu, suprema rosaceo-congesta late ovato-lanceolata, upice incurvo obticsiusculo, margine revoluta, canaliculata, integra v. papillis distinctis densissimis crenulata, e cellulis hexagonis basi infima laxis parvulis flavidis superne minutis apice opacis areolata, nervo crasso excurrente, perich. in cylindrum exsertum convoluta, synumaeformi-ligulata, 


\section{STEGOCARPI. ACROCARPI. BARULA.}

interiora maxime obtusata, basi laxissime superne minutius sed pellucide reticulata obsoletinervia, albida; theca in ped. ob innovat. laterali mediocri stricto rubro cylindracea subincurva, operc. subulato.

Patria. Chile, ad terram: Bertero.

Planta memorabilis singularis.

38. F. inaequalifolia 'layl. (Lond. Journ. of bot. 1816. p. 49.); brevis gracilis simplex; folia evecto-patentia subimbricata, inferiora minora ovata, superiora lanceolata, omnia obtuse acula, margine integerrima revoluta, nervo valido percurente, perich. majora erecta clongata, basin pedunculi mediocris v"ryinantin, cylindmu fere efficientia, theca erecta cylindracea leviter curvula, pro gracilitudine caulis late, operc. conico brevi, perist. bis contorto pallide rubente ad basin usque fisso. $\uparrow$.

Ic. Wilsoni 1. c. p. 450, t. XV. D.

Patria. Mons Pichincha Andium Quitensium: W. Jameson.

Notis datis a $\boldsymbol{B}$. revoluta et affinibus distare videtur.

$$
\begin{aligned}
& \text { b. Folia recurva. } \\
& \text { a. Nervus excurrens. } \\
& + \text { Perichaetium patulum. }
\end{aligned}
$$

39. 7. Tallax Hdw. (Musc. Fr. I. p.62. t. 24.); dioica; longe laxe lateque cespitosa plerumque rufescens erecta plus minus elata subsimplex v. pluries dichotona; folia caulina madefacta celeriter syuarroso-veflexu, sicca erecto-patentia subtortilia, inferiora minuta, superiora majora subcomantia, e basi lata subito angustato-lanceolata acuminata, reflexa, nervo excurente rufescente, inferne valde revoluta, integerrima, e cellulis basi parvis firmis quadratis, superne minoribus angulato-rotundatis incrassatis igitur obscuris non papillis opacis, in urapue ala plica longitudinali pracdita; perich. longiora, e basi tenera pellucida vaginante erecta curvula; theca in ped. mediocri atro-rubente tenuiore erecta, plus minus cylindracea angusta : cxannulata badia nitida leptodermis, operculo rostrato rectiusculo thecam aequante, perist. fugct- 
cissimo tenuissime ciliato laxe et pluries conitorto, in membrana brevissima posito.

Br. Eur. 13-15. p. 23. t. 9. - Brid. 1. p. 556. - Tortula imberbis Sm. Fl. Brit. HI. 1. 1261. - Mollia fullux schranck. Baiers. FI. II. p. 458. - Bryum fallax Dicks. Fasc. III. PI. Cr. 1. 5. - Br. imberbe Limn. Mant. PI. I1. p. 309. - Br. tenue, imberbe et pallidum, foliis crebrioribus. Dill. Muse, p. 3×2. t. 48. f. 46.

B. flarescens Brid. Nant. Nusc. p. 92. - B. fallax $\beta . \mathrm{Br}$. univ. 1. p. 558. p. $55 \%$.

B. reflexa Brid. Mant. Musc. p. 93. - B. fullax $\gamma$. Br. univ. I.

ß. brevicuulis; caulis brevis subsimplex; folia conferta patentia margine subundulata, operculo brevirostro. Br. Eur. I. c. - B. brevicaulis schw. Suppl. 1. 1. 1. 126. t. 32. Brid. I. p. 551 .

$\gamma$ brevifolia; dense cespitosa gracilescens fastigiate ramosa; folia ovato-lanceolata breviora, perichactio breviori. Br. Kur. I. c. - B. (Tortula) brevifulia Sill. Fl. Brit. HI. p. 1259. - Brid. I. p. 555.

Putria. In collibus lapidosis calcareis et argillososiliceis, ad aggeres, muros retustos, rupes tam siccas quam humidas, per totam Europam rulgatissima. - Sero auctumno et hyeme.

Pl. masc. ramosior, floribus terminalibus, fol. perig. ext. caulinis similibus, medis brevioribus, intimis e basi lata concava anguste lanceolatis, nervo tenuissimo v. nullo, ommibus basi biplicatis. - Notis cursive impressis a $\boldsymbol{B}$. myniculatu sacpe commutala facile distinguitur.

40. B. vinealis Brid. (I. p. 830.); divica; B. fulluci simillima, folia caulina recurvo-patentia, e basi late orata sensim angustate lanceolata acuminata parum curvata, nervo subexcurrente rufescente, inferne revoluta, integerrima, e cellulis ubique firmis parvis basi infima quadratis pellucidis superne minutissimis incrassato-rotundatis ob papillas tenuissimas punctulato-opacis areolata; perich. longiora, e basi tenera pellucida r. flavida raginante erecta curvula; theca in ped. mediocri rubente ereeta, ovato-oblonga v. oblongo-cylindracea ammlata brerivostris, perist. in membrana latiore semel contorto. 
Br. Enrop. 13-15. p. 24. t. 10. - Tortula fullax vinealis De Not. spec. de Tort. No. 27. - Tort. insulana De Not. I. c. No. 28. - Weisia monoclados Brid. I. 1. 360.

Patria. In vincarum muris soloque calcarco circa Durlach Duc. Badensis: A. B r a u detexit, practerea hic illic in rupib. arenaceis, rarius fertilis. - Mujo, Junio.

Infloresc. $\boldsymbol{B}$. fallacis simillimac, a qua notis cursive impressis certe refugit.

41. B. Crïgeri Sonder (in litt. ad Crüger); dioica; late et laxissime cespitulosa subaggregata, crecta gracilis simplex, apice semel innovans, sordide v. lutescenti-viridis; folia caulina in caule rubro remotu subtorta, madefacta valde patula parum recurva, apice incurva, oblongolanceolata obtusa, acumine quam maxime brevi acutata, margine inferne revoluta, integerrima, nervo crasso subexcurrente viridi, e cellulis basi minute quadratis viridibus firmis superne minutissimis maxime opucis papillosis areolata, carinata; perich. majora, basi latiora laxius reliculata; theca in ped. mediocri rubro erecta, anguste cylindrica pallida, operc. oblique rostrato acuto rubro, annulo nullo, perist. ad basin usque fisso longo tenuissime ciliato longo.

Patria. Insula Trinitatis Antillarum: Cr üger legit in terra argillosa ad La Ventille, die Aug. 2. 1846, fructibus supramaturis in muris ct rupibus calcareis forman confertiorem Nov. 28.

Pl. mascula cespites propr. efficit, gracilior, floribus in codem cauli pluribus remotis lateralibus gemmaceis sessilibus; fol. perig. interiora e basi lato-ovata valde concava laxe reticulata fuscescente breviler et profunde canaliculate lanceolata brevissime acutata, nervo tenuiore; antherid. majuscula multa, paraphys. longioribus subclavatis flavidis mixta. - A $\boldsymbol{B}$. unguiculate proxima notis laudatis facile distinguitur.

42. B. Australasiae Iook. et Grev. (Brewster Edinb. Journ. I. p. 301. t. 12.); breviuscula semuncialis rutilans, vix ramosa; folia inferiora dissita, superiora densiora, 
lineari-lanceolata carinata acutissima patentia, marginc reflexa integerrima, sicca tortilia, pallide olivacea; theca ovato-cylindracea erecta, operculo brevirostrato; peristomii cilia basi membrana angustissima unita; parum torta. $t^{\circ}$

Erid. I. p. 828. - B. rufiseta Tayl. Lond. Journ. of bot. 1846. p. 51. teste Wilsoul. c. p. 450.

Patria. In Novac Hollandiae King Georg's Sound Labitat: Menzies 1791.

Habitum ferc Ceratodontis purpurei habere fertur. Ex animadv. Wilsoni ad $B$. vinealem forsan pertineat, sed peristomio pracdita, cujus cilia binata Trichostomis affinia dicuntur.

43. B. campylocarpa Tayl. (Lond. Journ. of bot. 1848. p. 187.); dioica; laxe cespitosa subramosa breviuscula, inferne brunnea, apice flavide viridis; folia laxe imbricata patenti-recurva, ex lata ovata basi lincarisubulata, integerrima, margine recurva, summa siccitate convoluta; perich. majora erecta dense appressa; theca in ped. rubro-brunneo clongato-cylindrica, hine curvatoinclinata, operc. longirostro. $\dagger$.

Patvia. Monte Pichincha Andium Quitensium: W. Jameson. Febr. 1847.

A B. fullaci theca curvata, foliis magis subulatis, a B. vineali perichactio majori et foliis basi latioribus refugere legitur.

44. R. Xanthocarpa C. Nüll. (Linn. XVII. p. 581.); divice; dense cespitosa, sed laxe cohaerens, rigidissima longiuscula flexuosa gracilis, apicem versus crassior lutescens, inferne sordide fusca, innovatione brevi solituriu terminali dein canle iterate longiscente laterali parce ramosa; folia caulina inferiora minuta remota, apice comantia, recurvo-patula flcxuosa, sicca subincumbentiu, robustu vigidu, c basi oblongur lanceolutu, obluse acutu, margine integerrimo valde revoluta, nervo crussissimo rufescente excurrente, profunde canaliculata, basi e cellulis cingustis longinsculis rectangularibus flaridis supernc 
maxime minutis incrassato-rotundatis obscuris haud opacis areolata; perich. interiora vaginantia breviora, apice rotundata breviter acuminata obsoletinervia, ubigue tenervime pellucide reticulutu; theca in ped. mediocri rubente flexuoso erecta elliptico-cylindracea lutescens, breviter annulata, operc. conico-acuminato recto, perist. pluries contorto in membr. brevi posito.

Patria. Prom. b. spei, inter fruticeta camporum juxta flum. Zwartkoppsrivier dictum: Ecklon. Ad montem Leonis.

A $\boldsymbol{B}$. vineali affini et omnibus congeneribus caeteris notis laudatis distinctissima.

45. R. elata Durieu et Mont. (Fl. Alger, mox ed.); dioica; elatiuscula gracilis flexuosa superne innovationibus c. 3 longiusculis divisa, remotifolia, sordide viridis; folia sicca erecta vix torta laxe imbricata remota, mudefacta valde recurio-putula, caulina e busi decurrente oblonga margine revoluta sensim et valde recurvo-lanceolata, integerrima, nervo rufescente excurrente, ubique c cellulis parvis parum pachydermibus mollibus inferne subpellucidis superne opacis minoribus areolata, pericl. longiora basi latiora tenerius et pellucidius reticulata; theca in ped. longiusculo stricto rubro erecta majuscule oblonga, leptodermis, operc. conico recto acutiusculo, anmulo arcte adhaerente simplici, perist. in membrana laliuscula compluries contorto lutescente.

Patria. Algeria: Durieu.

A $\boldsymbol{B}$. fallaci jam theca annulata, a $\boldsymbol{B}$. vinculi notis caeteris cursive impressis differt.

46. R. Eeniculata Mont. (Ann. d. sc. nat. 1815. p. 107.); dioice; humilis pallide ferruginea, ramis brevibus paucis dichotome divisa, apice densius foliosa; folia caulina sicca et madefacta stricta, haud tortilia; brevia, late lanceolata vix recurva, obtusiuscule acuta, e cellulis basi laxis teneris pellucidis medio folii minoribus depressohexagonis diaphanis apice magis incrassalis rotundatis fuscidulis areolata, integerrima; margine erecto v. parum 
reflexo, nervo excurrente rufescente, canaliculata; perich. similiu intima basi teneriora; theca in ped. mediocri rubro erecta ovata minutu simpliciter annulata badia, operc. conico duplo breviori, perist. in membr. brevi parce contorto ruguloso.

Patria. Chile pr. Valparaiso: C. Gay.

A B. Pöppigiance proxima notis cursive impressis refugit. Nomen truviale vix idoneum.

If Perichaetium contolutum.

47. R. flavipes Br. et Sch. (Br. Eur. 13-15. p. 30. t.15.); divica; late cespitosa, sed laxe cohaerens, humilis, basi innovando parce divisa, tenella; folia caulina sfuarroso-patula, elongate lanceoluta carinata, margine revoluta flexuosa, dense rotundate areolata opaca tenuissime papillosa, basi pellucidiora magis rectangulari-areolata; perich. nonnulla longe convoluta, externa apice subito lanceolata, excurrentinervia, interna breviter acuminata evanidinervia, onuia basi peliucidiora laxius, sed anguste reliculata; theca in ped. elongato stricto flavido subobliqua ablongo-cylindracea fuscescens, operc. oblique rostrato rubro, annulo duplici, perist. compluries contorto in membrana breviter exserta posito. dictos.

b. lutescens Laurer in schedulis longe ante auctores supra

Patria. In alpinis Salisburgiae, Bavariae alpestris et pr. Monachun (Bayerbrunn: Sendtner), Carinthiae pr. Ileiligenblut, Austriae sup. pr. Steyr et ditionis Mediolanae, pineta alpina calcarea et loca denudata habitans. - Junio ad Augustum.

Pl. mascula gracilior longior, fol. brevioribus angustioribus; flore terminali gemmiformi; fol. perig. ext. ovatolanceolatis, mediis ovato-acuminatis, internis ovatis temuissime nervosis. A $\boldsymbol{B}$. comoluta notis laudatis certe distat.

48. I. revoluta Schw. (Suppl. I. I. p. 127. t. 32.); dioica; compacta et subpulvinata humilis erecta gracillima pluries dichotoma, laete viridis, inferne fuscescens; folia 
caulina spiraliter ad sinistram contorta, madefacta crectopatentia, e medio parum recurva, ablongo-lanceoluta tenuissime mucronuta, margine muxime revoluta igitur unguste, superne opaca minutissime rotundate areolata tenuissime papillosa, inferne laeviora parum majus et quadrate areolata; perich. longiora acuminata basi laxe areolatu vaginante tenera superne tuntum revolutu laevi; omnia excurrentinervia carinata; theca in ped. longo stricto rubente erecta elliptica, ore angustato, badia, simpliciter annulata, operculo subulato recto; perist. compluries contortum, in membrana sat exserta positum.

Br. Eur. 13-15. p. 27. t. 14. - Brid. I. p. 571. - Tortula revoluta Hook. et Tayl. Musc. Brit. ed. 2. p. 54. t. 12.

Patria. Ad muros et saxa Germaniac, Galliac, Britanniac, Italiae, Sardiniae et Africae septentrionalis rarior. - Vere.

P1. masc. gracilior magis ramosa. Flores gemmiformes terminales, foliis perig. ext. ovato-lanceolatis, mediis latioribus, brevioribus, intimis orato-acuminatis teneris, margine erectis obsoletinervibus. Antherid. parva, paraphys. filiformibus mixta. - A B. Hornschuchiunu haud dissimili notis cursive impressis longe differt. A B. convoluta, e cespitibus affini, perichaetio magis patulo jam distat.

B. Nervus excedens.

49. I. spiralis Schimp. (in litt.); dioica; dense foliosa fastigiatim ramosa; folia patentia et recurva, sicca spiraliter incumbentia, lanceolata obtusa canaliculata, marginibus valde revolutis, nervo valido in mucronem exeunte; perich. late lanceolata, haud vaginantia, nervo solido; theca elliptica annulata, operc. conico brevirostro. + .

Patria. Mexico, Yarrea (?) pr. Mirador: Lucbmann.

A B. revoluta simillima, cujus folia, peristomium, annulum et sporas habet, statura majore et fortiore, foliorum imbricatione spirali et perichactialibus haud raginantibus differre dicitur. 
50. R. replicata Tayl. (Lond. Journ. of bot. 1846. p. 49.); simplex pusilla erecta subcespitosa pallide virilis; folia contorta, madefacta laxe imbricata erecto-patentia subrecurva subovate lanceolata obtusa, nervo crasso excedente apiculata, margine toto revoluta, integerrima; theca in ped. mediocri erecta longiuscule ovata, operculo subulato rectiusculo. $f$.

Ic. Wilsoni I. c. p. 450, t. XV. C.

Patria. Ad muros prope Quito: W. Jameson.

B. unguiculatue ex ic. subaffinis videtur, sed statura et notis cursive impressis distincta.

sicctio VI. Eubarbula. Plantac humiles mimus ramosae, Eupottis mavis similes, foliis plus minus spathulatis oblongis, mitraine erecto v. revoluto, tenuiter papillosa $v$. lacviora, basi e cellulis magis faccidis mollibus reticulata. Perist, sinistrors. cont.

\section{A. Margine revoluto. \\ a. Peristom, tubulosum.}

51. B. subnlata Hdw. (Fund. Musc. II. p. 92.); monoict; late cespitosa humilis crassa robusta latifolia breviter ramosa, viridissima, rosacco-foliosa; folia conferta plus minus spathulato-oblonga, nervo crasso excedente mucronata, margine integerrimo v. subserrulato erecto vel parum revoluto paulisper flexuoso, basi e cellulis laxis elongatis pellucidis superne multo minoribus valde chlorophyllosis tenuiter papillosis opacis areolata, limbo plus minus conspicuo circumductu; theca in ped. crasso rubente longiusculo erecta longissime cylindrica curvula badia, operc. conico brevi, annulo duplici, perist. membrana basilari in tubum pallidum longum quadratim et oblique tessellatum producta, dentibus rubellis.

Br. Eur. 13-15. p. 36. t. 21. excl. B. inermi. - Syntrichia subulate Weh, et Mohr. Bot. Taschb. P. 214. - S. alpina Brid. Mant. Musc. p. 97. - Tortula Hercynice sichrad. spic. Fl. Germ. p. 65. - Mollire subulata Nidrek. Prim. Fl. Salislo. No. 830. - Mnium subulutum Iinn. Jun. Meth, Muse. 1). 36.J. - Bryum subulatum L. spec. Pl. p. 1581. - Bryum capsulis longis subulatis. Dill. Musc. p. 350. t. 15. f. 10. - Syntrichia subulata d. macrocarpa Brid. I. p. 582. sen 
Barbula macrocarpa ej. sp. Musc. 1. p. 267. secundum specimen unicum Hh. Bridel. ex Hispaniola relatum species diversa videtur, foliis longrorihus angustiorilus complicate concavis, vix limbatis, mangine revolutis, e cellulis magis diaphanis minus vel vix opa(is sublaevibus areolatis, mucronatis.

Putriu. Ad aggeres, arborum radices, muros terra obtectos totius Europae. - Aestute.

Flos masc. axillaris gemmiformis, subsessilis $r$. in ramulo brevi; fol. perig. parvula ovato-lanceolata evanidinervia; paraphyses filiformes et subclavatae.

52. B. inermis Mont. (Archiv de Bot. I. p. 136. 1.4.); monoicu; B. subulatue simillima, sed folia densa perfecte oblonga obtusa et muticu, margine integerrimo e busi usque ad apicem valde revoluto haud limbato, ubique mimetius reticulata magis carnosula upaciora firmiora; theca brevior.

B. subulata $\gamma$. inermis Br. Lur. $13-15$. p. 37. t. 22. - Syntrichia subulata $\gamma$. inermis Brid. I. p. 581.

Patria. In fissuris rupium pr. De Senna Pyrenaeorum: Montagne; in Galliate australioris provincia de la Lozere, in montanis et circa $\Lambda$ venionem, ubi Requien primus legit; pr. Rüdesheim ad Rhenum: Bruch.

E notis cursive impressis constantibus speciem distinctam putamus.

53. B. mueronifolia Schwägr. (Suppl. I. I. p. 136. t. 34.); monoica; B. subulatae simillima, sed folia oblongo-acuminata mucronata margine integerrimo vix vel parum revoluta e cellulis teneris mollibus ubique lacvissimis diephunis reticulata; theca brevior, peristomii tubulo breviore laxius tessellato, interdum cribroso-perforato.

Br. Lur. 13-15. p. 3r. t. 23. - syutrichia mucronifolin Bıil. Mant. Musc. p. 97. et Br. univ. 1. p. 5*2. - Tortula subulata ß. mucronifolia Röh. Neut. N1. 11. 1. 78. - T. subulata Drumm. Musc, Am. No. 144.

Patria. Ad rupes terra obtectas et ad viarum latera alpium Germaniae, Helvetiae, Norvegiae, Pyrenaeorum et Americae sept. - Julio.

Fol. perig. laevissima, caetera B. subulutue distinctae. 
54. D. canescens Bruch (in Br. Eur. 13-15. p. 34. 1. 19.); monoicu; gregarie cespitosa humilis subsimplex, B. murali simillima, sed folia margine vix vel purum revoluta, longe pilifera, theca erecta minor, operculo conico obliquo, peristomii membrana basilaris in tubum oblique tessellutum longiusculum exserta.

Patriu. In pascuis, ad rivulorum margines, ad lupes et arborum truncos totius sardiniac vulgaris: Fr. Miiller detexit; in Gallia occidentali, septentrionali et meridionali pr. Collioure. - Vere.

Infloresc. Barb. muralis distinctae.

\section{b. Peristom. profunde fissum.}

55. B. muralis Hdw. (Sp. Musc. p. 123.); monoica; plus minus compacte et late cespitosa humilis parce ramosa, viridis subtorta firma; folia plus minus spathulatooblonga obtusa, nervo in pilum hyalinum producto, margine supra busin usque ad upicem requaliter et valde reroluto, ecllulis minutis valde chlorophyllosis opacis tenuiter papillosis basi laxioribus longioribus pellucidis areolata; theca in ped. longo flavo vel rubro erecta oblongorylindrica leniter curvula, operculo oblique conico-rostellato, annulo angustissimo simplici sulpersistente, perist. in membrana basilari angustissima longo compluries et arcte contorto.

Br. Hurop. 13-15. p. 35. t. 20. - Brill. I. p. 5+6. - Mollin muralis sidrank. Prim. Fil. Nalish. 11. 832. - Mninm murale Lim. Jun. Metl. Husc. p. 364. - Bryum murale L. Np. P1. p. 15̈81. Bryum tegulare, humile pilosum et incanum. Dill. Muse. p. 365. t. 45 . f. 15.

Tortula Goettingensis Brid. Musc. Her. 11. I. P. 185. - T. pi-

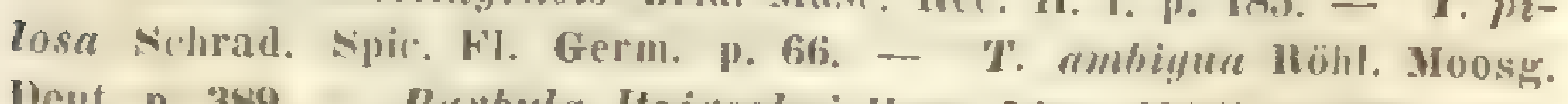
Dent. p. 3\$9. - Burbula Itzigsohni Hmp. Linn. XVII. P. 673.

ß. incena; brevicaulis microcarpa, foliis ovali-lanceolatis brevioribus longipilis. Br. Europ. I. c. - Grimmia crasse spr. syst. Veg. IV. II. p. 321.

$\gamma$. cestivu; longe lateque cespitosa gracilescens, foliis longioribus angustioribus lineari-Janceolatis, nervo in mucronem $\checkmark$. pilum brevem producto. Br. kir. I. c. - B.

c. Müller: Synops, musc. frond. 
aestive schultz. Nor. Act. Leop. XI. I. p. 223. t. 31. - Brid. I. p. 518. - B. cuneifolia Weh. et Mohr. Bot. Tasehl, 1. 207. -

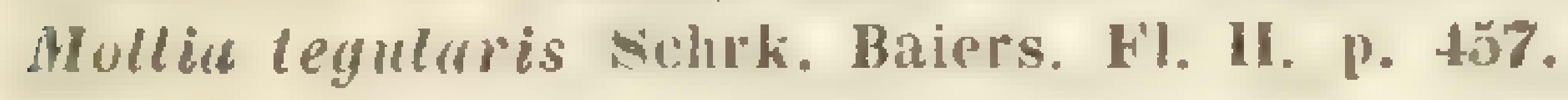

Putvic. In muris, parietibus, saxis etc. per totum fere orbem terrarum vulgatissima. Var. $\beta$. in muris calcareis gypsaceis siccis et in Monte Leonis prom. b. spei; var. $\gamma$. in rupibus praeprimis arenaceis humidiuseulis $s$. umbrosis, inque murorum fissuris. - Aprili, in edilioribus Majo et Junio.

Flos masc. in ramulo gracili terminalis gemmiformis, fol. perig. ovato-oblongis et ovatis obtusis breviter pilosis, antherid. majusculis, paraph. filif. et subclaratis.

56. B. emarginata Dz. et Molkb. (Musc. Archip. Ind. p. 50. t. 20.); monoica; B. murali simillima, sed folia angustiora longe lineari-oblonga valde obtusa et profunde emarginata, margine supra basin longan pellucidam ad apicem usque revoluto, longe pilifera; perigonialia similia brevia longe pilifera; theca anguste cylindrica, operc. conico obliquo obtuso; perist. dentes membrana basilari angusta vix annulum superante.

Patria. Japonia: a Siebold.

A B. murcali parum sed distincte recedit.

57. E. Vahliana Schultz. (Nor. Act. Leop. XI. I. p. 222. t. 34.) ; monoica; gregaria v. cespitulosa, brevis viridis, B. muruli similis; folia oblongo-cuneata, nervo III aristam viridem acutam producto, murgine vix vel supra basin tantum parum revoluto, ubique laxins reticulata diaphana rix rel parum opaca et integerrima; theca elongate oblonga cylindrica saepe leniter curvula, operc. brevi subobliquo, perist. membrance basilaris annulo latiusculo quadruplo longiore laxe tesselluta.

Br. Eur. 13-15. p. 33. t. 18. - Brid. I. p. 545. - B. extenuata De Not. spec, lle Tort. It. No. 12. forma minor.

Putria. In terra argillosa humidiuscula ad viarum et fossarum margines Sardiniae, pr. Cagliari: Fr. Müller, De Notaris. 
Flos masc. in ramulis gracilioribus microphyllis terminalis gemmiformis; fol. perig. ext. ovali-oblonga, interna paullo breviora et latiora, nervo in mucronem $\mathrm{r}$. aristam brevem excedente; paraphyses subclavatae, antheridiis majusculis longiores. - A B. murali notis laudatis certe differt.

58. I. recurvata Hook. (Musc. Exot. t. 130.); monoica; humilis breviter et parce ramosa crassa; folia rigida, madefacta erecta stricta, lato-lanceolata acuminata concava, marginibus recureatis haud perfecte revolutis integerrimis, nervo crasso excurrente obtuse acutata, e cellulis basi pareis quadratis subpellucidis superne minoribus firmioribus carnosulis chlorophyllosis magis rotundatis vel pachydermibus areolata; theca in ped. mediocri oblonga erecta brunnescens, annulo simplici, operc. conico obliquo obtusiusculo pallidiori; peristomium in membrana latiuscula breve.

B. parrula Hook. Spreng. Syst. Veg. IV. I. p. 179. - Entosthymbenium "lpiculatum et rubellum Hsch. in H). Kumzeano.

Patril. l'rom. b. spei, terram habitans, haud rara.

Flos masc. gemmaceus, in ramo proprio radicali; antheridia pauca magna, paraphys. filiformibus longiusculis rincta; fol. perig. basi laxiuscule apicem versus densiuscule hexagono-areolata. - Trichost. nerroso simillima, sed peristomii ciliis in duo ciliola postiea fissis barbuloideis e genere differt.

59. 1. Quitoensis Tayl. (Lond. Journ. of bot. 1817. p. 332.) ; (caulibus brevibus aggregatis, innovando ramosis; folia erecto-patentia, ex angusta amplexante basi elongate obovata apiculata, integerrima, madefacta fragilissima, grosse cellulosa, tenella, hrunnea; theca erecta cylindrica subcurvula, operculo conico-rostrato, annulo persistente, perist. ad basin usque fisso. $\frac{1}{6}$ 1816.

Palvill. Prope Quito Andium: W. Jameson. Nor.

A B. subuluta peristomio, operculo theca breviori, foliis superne latioribus et aliter reticulatis ex animadv. anct. differt. 
60. P. Pichinchensis Tayl. (Lond. Journ. of bot. 1817. p. 333.); laxe cespitosa erecta breviuscula subsimplex, inferne ferruginea, superne pallide viridis; folia imbricata patenti-recurva lingulata obtusissima subrepandodenticulata, nervo excurrente, dorso subdenticulato, flexuosa, margine reflexa; theca ovato-cylindrica inaequalis subcurvata, operculo rostrato inclinato, perist. brevi ad basin usque fisso, $t$.

Patria. Monte Pichincha Andium Quitensium: W. Jameson. Nov, 1846.

B. Qnitoensi e foliis lingulatis et thecae forma affinis, sed foliis siccis subquarrosis dense et apice magis rotundate arcolatis et pedunculis brevioribus differre fertur.

\section{B. Margine erecto. \\ a. Folia immarginata.}

61. B. cuneifolia Hook. et Tayl. (Musc. Brit. p. 31. t. 12.); monoice; laxe cespitosa sacpe gregaria humilis subsimplex amocne viridis; folia inferiora remota late ovata acuminata, putredine suepe echlorophyllosa albida, superiora in rosulam patulam congesta plus minus elongate spathulata acuminulata, laevissima, nervo flaccido tenui ante apicem exunido $\mathrm{v}$. in mucronem rarius in pilum laevem producto, integerrima, margine erecto plus minus flexuoso, tenera, mollia, saepe complicate concava, basi e cellulis elonyatis laxissimis maxime pellucidis superne minoribus mollibus granulose chlorophyllosis amoene diaphanis reticulata; theca in ped. longo purpureo stricto erecta oblonga atro-fusca, operc. oblique conico brevi, annulo simplici persistente; perist. in membr. latiuscula breve dense contortum rubellum.

Br. Wur. 13-15. p. 31. t. 17. - Brid. I. p. 549 et 829 . excl. syn. Web. et Molır., Nichrk, et Funk. - B. Dicksoniana sichult\%. Nov. Act. XI. I. p. 224. t. 34. - Tortula spathulaefolia le Not. spec. de Tort. Ital. No. 10. - T. acuminatu Brid. Musc. Hec. II. I. p. 188. - T. mutica ej. sp. Musc. 1. p. 251. - Bryum cuneifolium Dicks. Fasc. 1II, PI. Cr. p. 7. - Bryum humile, pilis carens, viride et pellucidum. Vilı. Musc. p. 356. t. 45. f, 15. 
Patrie. In terra argillosa ad fossarum margines et in limosis humidiusculis per totam Galliam occid. et merid., per Britanniam, ubi Dillenius detexit, per Italiam et insulas mediterraneas haud rara. - Majo.

Flos masc. primum terminalis, innovatione fertili lateralis $1-3$ phyllus, fol. perig. tenerrimis parvulis late ovatis obtusis $v$. acuminulatis, nervo tenui $v$. obsoletissimo, antherid. parvulis, paraphysibus filif. paucis. - A B. murali toto coelo distat.

62. I. contorta Hmp. (Hb.); gregaria erecta simplex subgracilis; folia sicce et madefacta laxe imbricate solitaria spiraliter incumbentia, maxime complicata, plicutu, e basi lata acuminata, ubique e cellulis diaphanis laxis majusculis, sed inferme majoribus perfecte pellucidis laevibus, superne papillis tenuissimis punctulatis reliculata; theca in ped. longo stramineo-rubente erecta oblongo-cylindracea subcurvula, operc. acuto subulato, annulo composito adhaerente, perist. breviter tubuloso compluries contorto longo albido.

Patria. Chile: Bertero.

Notis cursive impressis constantibus stirps distinctissima, B. Kun:eanue haud dissimilis.

\section{b. Folia marginata.}

63. 13. marginata Br. et Sch. (Br. Eur. 13-15. p. 33. t. 19.); dioica; humilis simplex gregaria r. cespitulosa; folia spathulate et obtuse lanceolata longiuscula superne latiora, nervo in mucronem v. aristam excedente, ad basin subventricose concavam laxe et late reticulata pellucida, versus apicem sensim minulius arcolata carnosula, papillis tenuissimis maxime punctulato-opaca viridissima, concava, margine limbato evecto, superne e cetlulis densis incrussutis basi angustis plongatis reticulato; theca in ped. longiusculo erecta cylindraceo-elliptica sordide badia, operculo brevi obliquo, annulo duplici, perist. pluries contorto in membrana annulum superante. 
Barb. cespitosn Bruch. in sched. Musc. Müll. Sardiniae. $-\boldsymbol{B}$. subpilosa Brid. I. p. 534. e spec. unico Hb. Brideliani forma foliis margine plerumque revolutis.

Patria. In terra argillosa et ad saxa humo obtecta: in Gallia merid. pr. Corbières, loco, Hermitage de St. Antoine de Galamus": M on tagne, in Sardinia pr. Iglesias serius legit Fr. Müller, in Italia merid., in, terra di Otranto" ad muros legit $\mathbf{R}$ abenhors t, pr. Steyr et Salisburgum in muris Sa uter legisse dicitur, in Lusitania Holl, ex Algeria misit W. Schimper. - Vere.

Fl. masc. in pl. simili terminalis gemmaceus; fol. perig. caulinis minora.

64. Is. Kunzeana C. Müll. (Linn. XVII. p. 586.); dioica; humilis simplex aggregata; folia $\boldsymbol{B}$. marginutae, sed laxissime imbricuta valde patula et apice servatu, nervo excurrente; theca in ped. elongato erecta elongute cylindrica pallide fusca, operculo longe conico-subulato suboblipuo, annulo longe persistente, perist. in membrana longissime tubulosa grosse areolutu pluries contorto mimum albido dein purpureo.

Tortula murginata Kze. ill PI. Chil. Püppig. No. 19: sed diagnosi carens, qua de causa nomen illi speciei praccelentis postponendum erat. pig 1828.

Putrice. Chile australis, Antuco in argillosis: Pöp-

Pulcherrima species, a B. marginuta proxima 1010 coelo distincta.

65. B. longipeduneulata C. Müll.; divica; simplex cespitulosa humilis, rigidu; folia sicca tortilia, madefacta erecto-subappressa, c basi oblonga laxe et flavide reticulata concava haud ventricosa breviter et obtuse lanceolata, marginibus flexuosis plus minus involutaceis, e cellulis fuscis diaphanis puchydermibus minutis limbatis, minute opace hexagone areolata viridia, integerrima, nervo crasso rubente in mucronulum plerumque excurrente, tenuiter papillosa; perich. latiora: theca in ped. longissimo flexuoso rubente erecta plongute cylindracea cum operculo 
conico acuto arcuta, annulo simplici, perist. in membr. brevi compluries contorto.

Patria. Prom. b. spei, prope Zwellendan: Pappe 1838.

A B. marginata subaffini notis datis toto coelo differt.

66. A. densifolia Hook, et Wils. (Lond. Journ. of bot. 1814. p. 543.); dioica; cespitulosa humilis, breviter ramosa, densifolia; folia siccu et mudefacta erectu haud "ppressu, e basi erecta laxe elongate ampliuscule plerumque flavide reticulata vix vel parum reflexa longe angustiuscule lanceoluto-ucuminatu ucula canaliculata, superne minute areolata opaca viridia maxime tenuiter papillosa, margine erecto ubique cellulis, praesertim apice folii servulato, incrassatis elongatis angustis flaridis limbata, nervo crassiusculo rubente excurrente; perich. conformia; theca in ped. stricto stramineo longiusculo oblonga, operc. subulato, perist. in membrana breviuscula compluries contorto.

Putriu. Insulae Falklandi: J. D. Hooker.

A B. longinedunculatu aftini notis landatis, margine limbato excepto, longe recedit.

Obscurac.

B. lencostomn R. Br. (Suppl. Append. ad iter Parlayan. p. 298.); erecta brevis semiuncialis subsimplex; folia dense conferta ovato-lanceolata, nervo valido in mucronulum cxcurrente, margine integerrimo anguste revoluta, sicca appressa parum lorta; theca in ped. terminali erecto solitario laevi fusco oblonga aequalis laevis, operculo conico aculo subobliquo breviori, perist. albo tubuloso. t.

Tortula leucostoma Hook. et Gr. Brewst. Edinb, Journ. 1. 1. 294, quo loco auctores perist. tuhulosum indirant, quod Brownius e dentibus 32 dilif. per paria approximatis dimidionue inferiore traheculis connexis suprat dintimctis apieimos parum tortis compositum de scripsit. - Zygotrichia leucostoma Brid. 1. 1. 521 et 821.

Patria. Insula Melville: Sabine. 


\section{S'TEGOCARPI. ACROCARPI. B.ABULA.}

sectio VII. Gyntrichin. Plantae elatiores saepe procerac ct valde ramosie, Enculyptis magis similes, foliis plus minus spathulatis ohlongis, margiue erecto v. revoluto, plerumpuc yrosse papillosa, basi e cellulis magis hyalinis dein saepe frayilibus calymperoideis reticulata. Perist, sinistrors. cont.

A. Nervus in apiculum productus $v$. excurrens.

a. Nolia marginala.

67. n. mnioides Schw. (Suppl. IV. t. 310.); divica; dense cespitosa humilis parce dichotoma erecta fusco-viridis radiculosa; folia caulina dense conferta recurvo-patula, lanceolato-cuspidata, interdum apice obtusiuscula, margine revoluta, apice juniorum plus mius argute hyaline et tenuiter dentata, dentibus senectute fugacibus, nervo in cuspidem excedente dentato, cellulac basis inferioris laxae amplae hexagonae fragiles calymperoideac, superioris parietibus crassis fascidulis plus minus interruptis instructae, superne sensim maxime incrassatae vix diaphanae fuscae, apice subvirides minutae opacac, marginis multo densiores intensius fuscae igitur limbum toto ambitu efficientes; perich. basi vaginante longius laxione, longiora erecta; theca in ped. breviter exserto cylindricoelliptica curvula pachydermis badia, operc. conico acuto crasso recto, ammulo arcte adhacrente latiusculo, perist. in membr. tubiformi magna.

B. prostrutu; radicans prostrata robustior; cellulac foliorum supra basin laxam parietibus interruptis praeditae, superne vix opacae, sed maxime incrassatac subdiaphanae fuscae. Barb. prostrata Nont. in Ann. des sc. nat. 18t5. p. $10 \%$.

P'atria. Chile, ad trunc. arborum : Pöppig, C. Gay.

B. Folia immarginata.

+ Integra.

68. B. Intifolia Br. et Sch. (Br. Eur. 13-15. p. 41. 1. 25.); divica; late et laxe cespitosa viridissima humilis gracilis parce et breviter ramosa, laxe foliosa; folia caulina e sputhuluto orutu oblusatu, medio apicis pherumpue emarginutu, margine vix vel parum revoluta, concava, 
flexuosa, sicca subtorta, basi longiuscula pellucida laxissime hexagone reticulata tenera molli, superne minute arcolata, papillis tenuissimis opaca, nervo crasso cum apice abrupto dorso apicis scabro; perich. interna magis complicate et oblonga; theca in ped. mediocri rubro erecta, cylindracco-oblonga curvula, pallide badia, annulo simplici, operculo suboblique subulato, perist. Iongiuscule tubuloso, pluries contorto.

Nantrichia latifulia Bruch in Bril. I. p. 836. - S. Iaevipila B. mutica sichultz. Hec. Batrb. in Nov. Act. Leop. XI. I. 1\$23. p. 230. t. 34. f. 4. B.

Pulriu. Ad arbores campestres, praesertim populos, c. B. laceipila sacpe consociata per Europam passim, sed rarissime fiuctificans et facile aboriens. - I'ere.

Pl. masc. ignola. - species, ex infloresc. jam diversa, saepe falso credita, scrutatori naturac vivae primo intuitu a $B$. lacripila distinctissima.

69. M. subspathulata C. Müll.; dioice; dense cespitosa subuncialis breviter dichotome ramosa radiculosa, sordide viridis parum rufescens; folia erecto-appressa vid torte; madefacta erecto-patula, haud recurva, e basi angusta breviuscula c cellulis porvulis hexagonis teneris pellucidis mollibus reticulata late subspulhulato-oblongoorcila, planiuscula, erecta, nervo viridi in mucronulum excurrente, mimute areolata, opaca, carnosula, tenuiter papillosa, margine integerrimo plus minus flexuoso hand revoluto; perich. conformia; theca in ped. brevi rubente cylindraceo-oblonga vix curvula, opere. acule subuluto obliquinsculo, anmulo simplici, perist. longo semel contorto in membrana breviter exsertu posito. Kze,

B. glucialis Br, et sich, in Musc. Alyss. Schimp. No. 491. hatud

Patria. Abyssinia, ad rupes madidas montis Bachit, societate B. mollis, 19. Aug. 1838: IV. Schimper.

Magis ad $B$. subulutum versus quam glucialem verlit; a prima peristomio hand tubuloso, magnitudine, foliorum textura et aliis notis jam longe differt, a secunda habitu et notis laudatis toto coelo refugit. 
70. 1. Fragilis Tayl. (Lond. Journ. of bot. $184 \%$. p. 333.); laxe cespitosa erecta subdichotoma breviuscula ferruginea superne olivacea; folia imbricata erecta, suprema patentia, sicca uppresse torta, lata, lineari-lanceolata obtusa, nervo excurrente apiculatu, integerrima, margine flexuosa, fragilissima, inferne laxe reticulata hyalina, superne lense areolata; theca in ped. demum axillari subflexuoso tenui innorationes superante, ex ovata basi cylindrica hinc incurva, operc. longirostro obliquo, perist. brevi pallide rubro ad basin usque fisso. †.

Patria. Mons Pichincha Andium Quitensium: W. Jameson. Nov. 1846.

A B. rurali notis cursive impressis ex auctore recedere dicitur.

71. E. EIncialis Kze. (in Pöppig Coll. P1. Chil. III. No. 272. [54.]); divica; dense cespitosa clata robusta innovando breviter fastigiate ramosa, rubiginoso-viridis radiculosa; folia inferiora appressa latiora ferruginea, planiuscula, superiora flexuose subtorta viridia firma, late oblonga lanceolata, nervo crasso rubente cxredente rufomucronata, inferne margine revoluta, integerrima, e basi e cellulis elongatis laxis pellucidis mollibus reticulata longiusculà parum recurva, superne mimulissime areolata opaca temissime papillosa; perich. interna angustiora; theca in ped. perbrevi rubro crasso flexuoso erecta majuscule oblongu rubens, operc. abtuse conico brevi recto, annulo latiusculo composito, perist. brme tubuloso permun contorto; calyptra robusta nitida sordida lacvis.

Patria. Chile australis, in summis rupibus inter glacies perpetuas montis ignir. Antuco, 11,300'. F'bruar. Pöp pig.

Ex habitu $B$. condicolue similis, sed notis laudatis longe differt.

72. M. scabrinervis C. Mïll.; dioice; humilis parce ramosa v. simplex densifolia viridis v. rufescens; folia dense conferta et appressa, vix tortilia, brevia erectopatentia, late oblongo-lanceolata, basi brevi ubique laxe 
pellucide el tenuiter reticulata, superne minute areolata opaca, integerrima, margine medio folii reflexa, nervo crasso purpureo excedente dorso papillis hycelinis plerumpue ciliformibus interdum obsoletis scabro breviter "piculata; theca in ped. breviusculo rubro flexuoso erecta angustius cylindraceo-oblonga, operc. conico recto acuto, annulo simplici lato; peristomii rugulosi membrana basilaris longiuscule tubulosa tessellata.

Patria. Chile australis, in truncis arborum prov. Quillotae, in convall. "los Chorillos" dicto, ubi legit soc. Leskene seminervis Kze. Pöppig, Septbr. 1827. mibilis.

B. laceipilae affinis, sed notis illustratis facile discert+ Folia dentata $v$. serrata.

73. B. robusta Hook. et Gr. (Brewstel Edinb. Journ. I. p. 209. t. 12.); dioicu; elongata parce dichotome ramosa laxe cespitosa pallide viridis dein rufescens; folia caulina parum torta, madefacta recurvo-patula, e basi erecta ubique elongate laxe pellucide reticulata reflexa lanceolutu "cuminatu, nervo excurrente, margine erecto apicem revsus incerualiter servata, e cellulis majuscule hexagonis chlorophyllosis subpellucidis temissime pupillosis areolata, opaca; perich. erecta latiora longiora diaphana sublacvia flavida, longitudimalitev plicutu planimsculu, nervo rubro ill acumen hreve hyalinum producto, superne dentibus hyulinis argutis teneris fugucissimis serratu; theca in ped. mediocri cylindrica curvula, operculo subulato, perist. longe tubuloso.

Mnium punctulatum Brid. II. p. 734. - Barbula speciosu

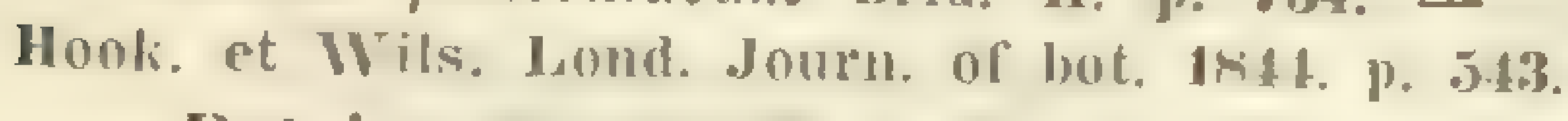

Putriu. Insula Fremitae ad Cap. Horn: J. D. IIooker. In insulis Falklandi primus legit Dumont dir ville.

Pl. masc. ramis binis; flos in ramo terminali brevi inter illos ramos posito crasse gemmaceus subdiscoideus; lolia perig. ext. rellexa, interiora sensim breviora latiora, late ovata acuminata subintegra, nervo tenui excurente, e cellulis laxis flavide pellucidis laevibus amplis parieti- 
bus plus minus interruptis praeditis reticulata; antherid. longa clavata numerosa, paraphysib. creberimis robustis clavatis mixtis. - Notis cursive impressis ab omnibus Syntrichiis facile distinguitur.

74. I. Ehrenbergiana C. Müll; dioica; laxe cespitosa stepe recure gracilior elatiuscula parce ramosa sordide viridis $v$. rufescens; folia caulina dense conferta subtorta, appressa, madefacta patula vix reflexa, e basi erecta longiuscula laxe elongate anguste flavide reticulata sensim recurva anguste canaliculate lanceolata acuminatu, nervo rubro in mucronem producta, margine infero anguste revolutu, supero remote et obscure denticulata, mimutissime areolata, opaca tenuissime papillosa; perich. basi latiore longius pellucida laxiore amplexante, intima brevissima laxissima hyalina obtusiuscula, theca in ped. breviusculo rubro angustiuscule cylindrica curvula longiuscula.

Patria. Mexico: C. Ehrenber $\mathbf{g}$.

Formis minoribus $\boldsymbol{B}$. ruratis subafinis.

75. 13. serrulata Ilook. et Grev. (Brewster Ediub. Journ. I. p. 298. t. 12.); aurantiaco-brunnea, elongata subramosa; folia crecto-patentia ovato-lanceolata carinata, margine erecto superne serrulata, nervo valiclo; theca cylindrica inclinata; perist. valde contorti membrana basilaris latiuscula. $\%$

Brid. 1. p. 833.

Patria. Terre de Feu, unde primus habuit Dicksol. B. centarcticae proxima videtur.

\section{B. Nervus in aristam productus.}

\section{a. Infloresc, hermaphrodita.}

76. 1. princeps De Not. (Ápec. de 'Tort. Ital. No. 1.); hermaphrodita; compacte cespitosa elongata crussu crecta, sub apice innovationibus brevibus crassis repetitis divisa, in axillis foliorum tomentoso-radiculosa, dense foliosu, pulchre ferruginea; folia siccu urcte apressu, summa subtorta viridia, madefacta imbricato-patentia, late ob- 
longo - oveta rotumlata, nervo crasso rubro in aristam longiusculam crassum hyalinam denticulatam producto, margine revoluta basi e cellulis amplis laxis pelluridis inanibus dein fragilibus utrinque marginis mhs mims massa grisea repletis dein firmioribus inamibus qeluti limbutu, superne grossiuscule areolata haud opaca mollia grosse papillosa; theca in ped. longo crasso rubro flexuoso crecta cylindrica curvula elongata, operculo conico - subulato acuto, annulo duplici, perist. longe tubuloso pluries contorto dein dissoluto.

Barbula Mülleri Br, et sch. Br. Fur. 13-16. p. 44. t. 28. Syntrichia Mülleri Bruch in Musc. Müller. Sardois.

Patria. Ad truncos arborum et ad rupes Sardiniac, Siciliae, Italiae merid. ad Promontorio del Gargano, ubi $18 \pm 7$ legit $\mathbf{R}$ abenhorst et Ilispaniac, ubi in Sierra Nevada Pyrenaeorum ad Guéjar de la Sierra legit W. P. Sch. 5. Jul. 1847.

Paraphyses longae clavatac. - A B. rurali subaffini notis cursive impressis facile discemibilis.

77. D. mollis Br. et Sch. (in Musc. Abys. Schimp. No. 467.); hermaphrodita; dense cespitosa breviuscula subuncialis subgracilis fuscescens, ramis brevibus appressis dichotoma; folia caulina erecto-appressa vix torta, madefacta erecto-patentia arcte imbricata, oblongo-ovala obtusiuscula $\imath$ oblongo-acuminutu, nervo crasso rubro in pilum hyalinum longum sublaevem producto, margine distincte revoluto integerrimo, basi e cellulis laxis longiuscule hexagonis fere crythrodermibus pellucidis teneris superne parvulis opacis tenuissime papillosis areolata, perich. externu basi latissima laxissime veticulata longe acuminatu pilifera, intimum multo brevius ubigne tenerrimum pellucidem; theca in ped. longo straminco erecta, cylindraceo-oblonga curvula fuscidula, operc. conico-subulato subobliquo, annulo composito, perist. longo in membr. longe tubulosa parum contorto.

Putria. Abyssinia, ad rupes madidas montis Bachit: V. Schimper, 14. Aug. 1838. 
Antheridia numerosa magna, paraphysibus creberimis clavatis flavidis cincta, archegonia multo pauciora. A B. lacripila proxima notis cursive impr. longe distat.

78. Is. antaretica IImp. (in litt.); hevmaphrodita; cespilosa, sed laxissime cohuerens radiculosu, rigida, sed facile emolliens, seminncialis, pulchre rufescenti-flavida, parce dichotome ramosa, teretiuscula, hund compressu, grucilior; folia caulina erecta appressa ubique subtortu, malefacta erecto-patula parum vel vix recurva, lute oblonga obtuse acuminata, superne diverse complicuta, nervo crasso rubente in aristam hyalinam longam seratam producto, margine valde revoluta, integerima, basi e cellulis laxis amplis mollibus ubique valde pellucidis, utrinque marginis interdum flavidis, inanibus, superne minoribus compresse hexagonis firmis chlorophyllosis dein inanibus diaplianis haud opacis, tenuissime papillosis areolata; perich. teneriora planiuscula; theca in pel. stricto rubentistramineo erecta, operc. conico subulato recto.

Tortula Mielleri Hook, et Wils, in sched. Musc. Antarert.

Putrie. Insulae Falklandi: J. D. H ooker.

Antheridia majuscula numerosa, interdum pauca, paraphysib. robustis clavatis flavidis cincta. -- A B. Mïllevi longe differt et magis $\boldsymbol{B}$. laevipilue aflinis. Fructum immatur. tantum vidimus.

\section{b. Infloresc, monoica.}

79. B. Inevipila Schw. (Suppl. II. I. p.66. t. 120.); monoice; late et laxe cespitosa robustior elatior, breviter dichotome ramosa confertius foliosa; folia caulina appressa parum torta, madefacta patula, oblonga $v$. plus minus spathulato-oblonga, apice obtuso, nervo rubro in aristam longam hyalinam veflexam pare denticulatum r. luevem moducto crasso, margine vix vel parum revoluta, basi laxe hexagone tenuiter utrinque minutius reticulata sublonga pellucida, superne multo minutius areolata, papillis plus minus tenuibus dorso plerumque obsoletis opaca; perich. magis acuminata; theca in ped. mediocri rubro erecta cylindracea curvula badia, operculo suboblique 
subulato, annulo duplici, perist. Ionge tubuloso pluries contorto.

Br. Furop. 13-15. p. 40. t. 25. - Syntrichia laeripila Brid. I. p. 5k6. - s. montana Nees in Hegensto. Bot. Zeit. 1819. 2. p. 301. - Tortula vuralis $\beta$. Iaevipila Hook. et Tayl. Musc. Brit. ed. 2. p. 56.

Patria. Per totam fere Europam temperatam et calidiorem, nec non in Africa septentrionali, ad arbores campestres. - Junio.

Flores masc. in axillis foliorum nunc sessiles, nunc ramulis brevibus gracilibusque insidentes parvuli gemmiformes 3-6 plyylli; folia perig. ext. ovato - acuminata brevipila, apice recurva, interna longiora, acuminata fusca sublacvia tenerius areolata; antheridia majuscula pauca, paraphys. clavatis mixlis. - A $\boldsymbol{b}$. latifolia notis cursive impressis distat, a $\boldsymbol{B}$. rurali inflorescentia, pilo breviore minus dentato, perist. breviori et cespitibus densioribus distinguitur.

80. 1. Alpima Br. et Sch. (Br. Eur. 13-15. p. 39. 1. 24.); monoicu; B. lactipilue simillima, sed folia molliora temiora magis diaphana, arista breviore semper rubra, $s$. mutica, plerumque pallide rarius purpureofusca; thera in ped. longiore rubente temiove cylindrica curvula badia leptudermis, operculo oblique rostrato, annulo duplici, perist. breviter tubuloso semel laxe contorto.

Patria. In alpibus Tirolis: Funk, Gastoniae Salisburgensis ad muros: A. B rann, Pinzgoviae prope Mittersill, ubi in umbrosis arcis antiquae ad rupes calcareas detexit Sauter. - Aug., Septbr.

Inflorese. B. Taevipilae.

\section{c. Infloresc, dioica. \\ c. Folia obtusa.}

81. R. ruralis Hdw. (Sp. Musc. p. 121.); divica; laxe late cespitosa elata dichotome ramosa rufescenti-viridis; folia caulina subcontorta, madefacta squarroso-recurva, laxe imbricata, e basi longe erecta amplexante longa pellucida tenera hexagone laxe elongate angustius- 
cule reticulata dein fragili, margine utrinque collulis intense faviaribus veluti limbata reflexa, plus minus complicate oblonga oblusu, nervo in aristam elongatam valde dentatam lyaalinam producto dorso scaberrimo, margine ubique revoluta, superne e cellulis mollibus parvulis heragonis valde chlorophyllosis areolata, grosse papillosa; perich. longiora crectiora; theca in ped. plus misus longo crasso basi vix tortili purpureo erecta, oblongo-cylindrica curvula, pachydermis badia, annulo duplici, operc. subulato rubro subobliquo, perist. longe tubuloso longe ciliato.

Br. Hur. 13-15. p. 42. t. 27. - syntrichia ruralis Wels. et Mohr. Bot. Taschn. p. 215. - Brid. I. p. 584. - Mollia ruralis schranli. Prim. Fl. Nalish. No. 831. - Mnium rurale Linn. Jun. Meth. Musc. p. 364. - Brinum rurale 1. \$p. PI. p. 1541. - Bryum rurile unguiculatum, hirsutum elatius et ramosius. Dill. Muse, p. 352. t. 45. f. 12. - Hypnum rurale Weis. Crypt. Gütt. p. 210.

$\beta$. rupestris; humilior densius cespitosa, foliis magis erectis, ovalibus obtusissimis, pilo magis erecto, theca breviore. S!ntrichia intermerlin Brid. 1. P. J\$6. - Tortula ru-

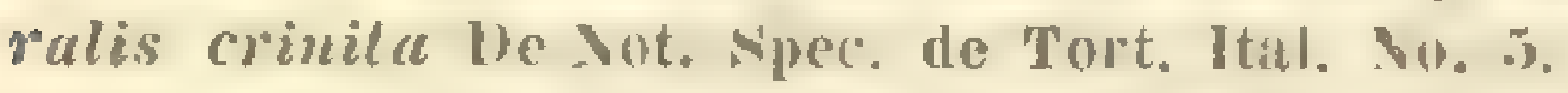

Patrill. Per totam Europam et Americam septentrionalem vulgatissima in rupibus, tectis, arboribus et terra. Var. $\beta$. in Duc. Badensi pr. Durlach, in Alsatia, Gallia merid. et sept., pr. Fiume, in Sardinia, rupes, praesertim calcareas, et nuros in ditione Smyrnensi et prom. b. spei, habitans. - Vere et ineunte acstate.

Flos mase. in planta terminalis crasse gemmaceus, foliis perig. ext. rameis similibus, sed minoribus, e medio patulis, secundis brevioribus, omnino erectis et pilo breviore instructis, intimis orato-oblongis submuticis; antherid. et paraph. subclavatis numerosis.

82. B. obtusissina C. Mïll.; divica; B. rurnli simillima, sed folia spuurvoso-putula, latissime complicate ovata obtusissimu cmarginutu, robustiora, basi vix erectu, rix r. parum pullide limbata e cellulis laxissimis amplissimis pellucidis maxime foraminatis ubiyne conformibus reliculata, superuc majus arcolata, papillis grossis mujo- 
vibus verrucosa, nervo in aristam muxime elongutum flavide hyalinam serratam producto; theca in ped. longiusculo erecta cylindrica curvula, perist. longe tubuloso, annulo duplici.

B. ruralis Schimp, in $\mathrm{Hb}$. Schlechtendal.

Patria. Mexico: C. Eh r e nberg.

Notis cursive impressis sp. distinctissima.

83. B. leucostega C. Müll.; divica; B. rurali simillima, sed folia erecto-patentia, e basi cellulis ubigue mollibus laxis pellucidis reticulatn hand limbatn breviter oblongu parum currata, apice obtusissimo plerumane inaeanuliter emurgincuto, toto ambitu margine revoluta, grossius papillosa, longius pilifera; theca angustius cylindrica fusca, operc. conico - subulato pallide rubente; perist. albido; caetera $B$. rurulis.

I'atria. Prom. b. spei, pr. Swellendam in tectis: Ecklon, 1828. Octobr.

84. R. pilifera Hook. (Musc. Exot. t. 12.); dioicu; densiuscule cespitosa erecta subuncialis, robusta flexuosa, multoties dichotoma, lutescenti-viridis, firma; folia caulina appressa, parum apice autem spiraliter torta, madefacta erecto-patula paullo recurva, e basi latiuscule amplexante e cellulis ubique parrulis flavidis subrectanguluri-hexugonis laxis reticulata erectâ recurvo-oblonga obtusa, nervo viridi crassiusculo in aristam apice hyalinam subluevem longam obliquam producto, margine revoluto, ynadrate firme areolata, papillis tenuissimis opaca; perich. in cylindrum parum exsertum congesta, longe acuminata pilifera, ubique fere tenuiter et laxe reticulata; omnia integerrima; theca in ped. longiusculo rubente substricto robusta erecta cylindraceo-oblonga, curvata coriaceo-brunnea, operc. oblique conico-subulato, annulo persistente duplici, perist. ad basin diviso pluries dense contorto rubente.

Brid. I. p. 572. - B. crinita Schultz. Nov. Act. Leop. XII. I. p. $226 . t .34$.

c. Miller: synops, manc. frond. 
B. gracilis; gracilior humilior, folis siccitate appressis, caulem igitur teretiusculum efficientibus, angustioribus tenuinervibus, perichactio vix exserto et theca anguste cylindraceo-oblonga minore.

Putriu. Java, unde Dickson primus habuit. Prom. bonac spei, ubi vulgatissima videtur. Chile: Pöppig et al. Var. $\beta$. in prom. b. spei et in Manila, ubi Meyen legit.

A $\boldsymbol{B}$. lacvipila subaffui notis illustratis longe distat.

85. R. Alagellaris Schimp. (Ann. des se. nat. II. Ser. 'Tom. VI. p. 146. 1. 10.); dioicl, elata ramosa, ramis brevioribus rectis $v$. elongatis flagellıformibus basi declinalis radicantibus, foliis denudatis, apice erectis foliosis; folia patentia tortilia siccitate incurva, oblongo-carinata, obtusa, margine reflexa, nervo in aristam producto $v$ sub apice evanido; perich. caulinis similia erecta; theca elongata subcylindrica longius suboblique rostellata, perist. tubuloso-barbato. $f$.

Putril. Chile, ad arbor. truncos: Bertero.

Magnitudine et habitu B. ruveli haud dissimilis, foliorum arista hreviore laevique cum $B$. laphipila congruit; ab utrisque autem ramificatione propria discrepat. $\Lambda$ prima foliis angustioribus haud reflexis acuminatioribus, theca diversa atque irregulari pedunculoque inferne dextrorsum superne sinistrorsum contorto, ab altera infloresc. dioica differt.

86. 1. Preissiana C. Müll.; dioica; Iaxe cespitosa humilis, innovationibus brevibus apice crassioribus parce dichotoma; folia caulina erecto-subtortilia, madefacta e basi longu erectu subito recure, complicate oblonga obtusiuscula, nervo rubente in aristam denaculatam reflexiusculam hyalinam producto; perich. conformia; theca in ped. breviusculo erecta anguste cylindrica curvula, annulo composito revolubili, perist. in membr. longe tubulosa parum contorta albido.

B. laevipila Hmp. in PI. Preis. II. p. 114. Coll. No. 2467. 
Patria. Nova Ilollandia, in ramis putrescentibus insulae Roseness: L. Preiss. Aug. 19. 1839. Ab originibus "Worup" dicta.

A B. laevipila simillima notis cursive impressis certe distat.

\section{B. Folia lanceolato-acuminata.}

87. B. aciphylla Br. et Sch. (Br. Eur. 13-15. p. 42. 1. 26.); dioica; B. rurali simillima, sed folia squarrosopatula, basi minus erecta utrinque margine haud flavide limbata sed conformia v. chlorophyllosa, ovato-lanceoluta acuminata, nervo viridi in aristam rubellam snbspinulosam producto, tenuius papillosa; theca oecuta vel ovatooblonga, in ped. a basi ad medium dextrorsum tortili.

Torlula ruralis alyina De Not. spec. de Tort. Ital. No. 4. Syntrichia Norreyica Brid. 1. p. 5st; an et Wuhlenberyii? B. Enderesii Garov. in Bryol. Austr. p. 37?

Patria. In alpibus Germanicis, Helveticis et Pyrenaicis, ubi in casarum vicinitate ad muros et saxa umbrosa cespitose habitat. - Julio et Augusto.

88. M. andicola Mont. (Ann. d. sc. nat. IX. 1838. p. 53.); dioica; dense cespitosa compuctu tomentosa elonyata, innovationibus terminalibus elongatis binis divisa, inferne maxime ferruginea, apice pullide vivescens; folia caulina inferiora sicca laxe appressa, superiora flexuososubtorla, e basi laxe hexagone maxime pellucida encalyptacea amplexicauli late oblongo-lanceolata obtusiuscula v. acuminata concava, nervo crasso intense purpureo in pilum hyalinum rufescentem dentatum producto, margine ubique revoluto apice dentato, grosse hexagone areolata, papillis grossis in utraque pagina creberrimis opaca scaberrima; perich. minora longe pilifera; theca in ped. brevi inter innovationes posito atro-rubente subarcuato erecta elongate cylindricu angusta fulcuto-arcuata brevicolla pallida, dein fuscescens, operculo longe subuluto recto, annulo simplici persistente; perist. dentes busi liberi albidi, dein vix rufescentes, semel torti rugulosi; columella longe exserta; calyptra longissima purpurea. 


\section{STEGOCARPI. ACROCARPI. BARBUI.}

Putria. Ad terram inter rupes in declivibus orientalibus Andium de la Paz prope nives aeternas, longe supra oppidum 'Tajesi: D'Orbigny. Columbia, Sierra nevada de Merida: Noritz No. 18\%. a.

Notis cursive impressis ab omnibus congeneribus jam facile distinguenda pulcherrima solitaria species, foliis perfecte encalyptoideis.

89. 11. subaristata Br. et Sch. (Musc. Abyss. No. 418.); dioica; dense cespitosa, sed laxe cohaerens, subhumilis rufescens, innovando parce ramosa; folia caulina erecto-subappressa, madefacta erecto-patula parum recurva, late oblongo-lanceolata, concava, nervo crasso rubente in aristam brevem recuram superne hyalinam dentatam producto, margine revoluta, basi laxe pellucide hexagone reticulata molli, superne multo minutius areolata subopaca, integerrima, temuter papillosa; perich. similia; theca in ped. brevi innoutionem brevem haud superante rubro elliptica, vix curvula, badia, operc. conico rectiusculo rubro, annulo simplici persistente, peristomio longe tubuloso albido.

Patria. Abyssinia, in jugis ad arbores 12000' W. Schimper, 1840. 18. Febr.

P1. masc. parum gracilior, florib. terminalibus ob innovat. lateralibus crasse gemmaceis; folia perig. late ovata breviter acuta excurentinervia, interna obtusata evanidinervia, omuia tenuiter et pellucide flavide reticulata maxime concava; antherid. magna clavata, paraphys. numerosis flaccidis longis clavatis mixtis. - A B. latifolia habitu affini notis cursive impressis, et foliis perigonialibus longe differt.

\section{Incertae sedis.}

90. E. breviseta Mont. (Ann. d. sc. nat. 1845. p. 107.); dioica; humilis subramosa; folia sicca haud tortilia, oblonga obtusa non acuminata canaliculata, margine incurvo recurvove, basi pellucila parallelogramme reticulata, a medio ad apicem patenti-recurva, obscure punctiformiareolata, nervo crasso in pilum apice canum abeunte per- 
cursa; theca lineari-cylindrica longiuscula c. operculo conico brevi pedunculum aequante; perist. sat longioris et torti membrana basilaris angustissima, annulo nullo. t.

Patria. Chile, in terra circa S. Jago: C. Gay, 1829. April.

Syntrichia forsan erit.

Barbulae obscuriores v. delendae.

1.? Dicranum stygium Brid. (I. p. 444.); caulis elongatus divisus, ramulis subnullis, basi radiculoso-tomentosus; folia trifariam cauli arcte circumposita, e basi amplexicauli lanceolato-acuminata, undulato - flexuosa, reflexa, integerrima, supra basin subplicatam margine planiusculo reflexo praeditam complicate concava, nervo crasso continuo ferruginco dorso scabro, e cellulis parvis basi quadratis superne incrassatis angulato-rotundatis inanibus tenuissime papillosis areolata, sicca apicibus valde contorta et crispata, fuscescentia.

Patria. In Delphinatu prope Magnam Carthusiam in uliginosis: Dejean.

\section{An Barbula?}

2. Harbula linoides Brid. I. p. 5.13 e spec. a Cl. Green Bridelio missis Pottiucea quidem, sed ob perist. carens incertae sedis, suspectissima igitur e genere ejicienda.

3. Barb. diaphann Brid. (I. p. 57\%) e spec. Hb. auctoris Grimmia videtur.

4. Barb. flexifolia Brid. (I. p. 560.) ex Hb. auctoris Macromitrium quoddam sterile.

5. Barb. tenera Brid. (I. p. 577 et 835.) e verbis auct. ipsis delenda.

\section{Gen. VIII. Ceratodon Brid.}

1. p. 480. - Aegiceras Green in Brid. Mant. Musc. p. 69. sed nomen jandiu generi phanerogamico impositum. - Dicranum Hdw. et al. - Didymorlon Ilonk. et Tayl. - Fuscina Schrank. Mnium Linn. - Bryum Dill. et al. - Luida Adans. 


\section{STEGOCARPI. ACROCARPI. CERATOdOS.}

A xégas cornu et ódov́s dens, inde quod peristomii dentes inflexione sua et trabeculis nodulosis caprae cornua referunt.

Calyptra dimidiata. Peristomium simplex: dentes 16 basi membrana cellulosa connati, in crura duo longa nodoso-articulata fusca utrinque pallidiora fissi, parte inferiore dense trabeculali. Habitus theca pachyderma nitida cernua, collo subno doso instructa, (annulata) proprius.

1. C. purpureus Brid. (I. p. 480.); dioicus; dense cespitosus, sed laxe cohaerens, inferne radiculosus, dichotome ramosus, sordide viridis, erectus plus minus elatus; folia caulina erecto-patentia laxius imbricata sicca subtortilia, oblongo - lanceolata, subcomplicate concara, toto margine revoluta integerrima $v$. apice parce denticulata, excurrentinervia, undique e cellulis rotundato-quadratis sublaevibus chlorophyllosis areolata; perichactialia longiora, intima longe vaginantia superne sinuata et subito saepe plus minus acuminata et apice crenulato-denticulata, tenerrime longius reticulata, tenuinervia; theca in pedunculo longo mupureo magis minusve inclinata obTonga turgescens cernua purpurea, collo brevissimo et operculo conico nitido; perist. dentes longissimis cruribus latis valde bicoloribus purpureis.

Br. Europ. Fast. 29-30. Ceratodon, p.5. t. 1 et 2. $-D_{i-}$ cranum purpureuon Hdw. Sp. Musc. p. 136. t. 36. - Didymodon furpureus Hook, et Tayl. Iusc, Brit. p. 65. t. 20. - Fuscinn puspurea sclirank. Baiers. Fl. 11. p. 453. - Mnium purpureum L. N1. PI. p. 1575. - Bryum purpureum Neck. Meth. Musc. p. 211. Br. tenue vicks. Fasc, HI. PI. Crypt. D. \&. - Br. tenue, stellatum, setis purpureis. Dill. Musc. p. 3k6. t. 49. f. 51. - - Dieranum Celsi Ildw. sp. Musc. p. 149. t. 33. f. 1-4. Dryum Celsii L. Sp. Pl. p. 1.jes. Br. triolodes acaulon minimum setis et capsulis oblongis. Vill. Muse. p. 388. t. 49. f. 54. - - Diermum purpurascens Hdw. Husc. P. 137. t. 35. f. 1-7. - - Dicr. intermedinem Hdw. sp. Muse. 1. 13\%. t. 31. f. 1-6. - - Dicr. bipartitum Nm. Fl. Brit. III. p. 1218. Bryum bipartitum Dicks. Fase. 11. Pl. Crypt. p. 7. Bryum parvum surculis et setis geninatis. Dill. Musc. 1. 385. t. 49. f. 50. Trichostomum tortum schrank. Baiers. 
FI. II. 1. 449. - - Dicr. palustre Brid. Musc. Rec. II. I. 1. 174. Dicr. longisetum Brid. Mant. Muse, p. 66. Dirs. strictum sm. Fl. Brit. 11. p. 1218. Trichostomum basiflormm sibli. Baicrs. H1. II. 1. 44. Bryum basiflorum Gmel. Syst, Nit. 11. p. 1332. Bryum strictum Jirhs. Fise. IV. Pl. ('r. p. 13. Mrytm polytrichoides paJustre, setis Jomginribus rubris scriceis. Dill. Muse: p. 377. t. 49. f. 52. - - Trichostomum fupillosum sim. Fl. Brit. Ill. p. 123\%, Bryum gapillosum Wiks. Fasc. IV. Pl. Cr. p. 12. t. 11. . 5. - Barbula Sanssuriuna Britl. Mint. Musc. p. 94. Tortula saussuriana Brid. Musc. Rec. II. I. p. 203.

I'utriu. Cosmopolites omnium muscorum maximus, orbis totius terrarum inhabitans, bryologis tanquam taediun creatus. - Vere.

Pl. mascula gracilior, flore terminali gemmaceo. Folia perigonialia cxterna e basi lato - ovata acuminata margine valde reflexa crassincrvia, e cellulis quadratis pachydermis areolata, interna lato-convolutacea obtusa vel acuminata tenerrime et rhomboideo-reticulata fusca integerrima obsoletinervia. Antheridia brevistipitata magna crassa, paraphysibus flavidis obtusis filiformibus mixta. Valde polymorpha specics, quoad thecas purpureas sulcatas pachydermas nitidas inter formas diversissimas facile discernibilis, discipulo autem terribilis.

2. C. stenocarpus Bi. et Sch. (in Monogr. Ceratod. p. 4. memoratus.); dioicus; habitus (C. purpurei; theca in perlunculo Aarido plus mimus cylindrica, cernua; perist. dentibus brevioribus angustioribus fuscis submicoloribus rugulosis, ad busin uspue fore fissis.

C. purpureus var. malustris Mont, in Musc. Vecluheriensib. $n o$. 57. - Barbula conica spr. syst. Veget. IV. II. p. 323.

Patria. Zonam calidam solam habitans: in promont. b. spei sat copiose legit E cklon, e. gr. in locis humidis rupestribus cacuminis montis 'labularis. In montibus Veclgheriensibus prope Neddoubetta: Perrottet. Nexico: I i ebmanll. Columbia, prov. Caracas, prope coloniam Germanicam 'Tovar in apricis altitud. 2600 ped. 1845. Jan. Funck et Schlim.in Coll. Lind. No. 173.

Specimina multa labemus et thecam valde polymorpham, nunc elongatam, nunc brevem et plus minus cy- 
648 S'TEGOCARPI. ACROCARPI. TRIDONTIUM. WEISIA.

lindricam videmus. Pedunculo flavido primo adspectu distinguitur.

Gen. IX. Tridontium Hook. fil.

Hook, Ic. PI. Har. HI, t. 148.

Nomen ob dentes trifidos ab auctore huic generi impositum.

Calyptra conica latere fissa. Peristomium simplex: dentes 16 elongati, siccitate reflexi, e ciliis tribus articulatis magis minusve connexis formati.

Habitu Angströmiue pellucidue haud dissimile. Auctor Scouleriae et Wardiae comparavit.

1. Tr. Tasmannicum Hook. fil.; dioicum? elongatum innovando ramosum rigidum flexuosum fuscum laxe cespitosum; folia laxe undique disposita patentia, oblongolanceolata obtusa, nervo valido fusco subcontinuo, supra canaliculata, integerrima, e cellulis basi angustis subrhomboideis superne minutis rolundatis incrassatis laeviusculis areolata, ad marginem interdum cellulis magis incrassatis quasi limbata; perichaetialia angustiora subacuminata; theca in pedunculo breviusculo rigido fusco turbinata brevis ampla macrostoma, operculo conico longe rostrato, calyptra fusca.

Patria. In locis aquosis irroratis m. Ben Nevis Terrae Diemenii: Ronald Gunn.

\section{Gen. X. Weisia HIdw.}

Fund. Musc. H. p. 90. - Rhabdoweisia Br. Fur. - Eucladium Br. Eur. - Grimmia non!. - Gymnostomum mult. - Dicranum Brid. partim et Hdw. - Hymenostomnm R. Br. et al. Afzelia Elrh. - Coscinodon Brid. - Trimatium Frohl. - Bryum antiq.

Nomen Hedwigianum, memoriam Weisii, stirpium cryptogamicarum Goettingensium sagacis ac modesti illdagatoris, professoris botanices, illustrans.

Calyptra dimidiata. Peristomium simplex, e dentibus 16 lanceolatis $v$. subulatis integris $v$. cribrosis aequidistantibus compositum, saepe nullum. 
Sectio 1. Rhabdoweigia Br. Europ. Fasc. 30-36. - Theca sulcato-striata; perist. dentes subulati; folia crispata.

1. W. fugax Hdw. (Sp. Musc. p. 64. t. 13. f. 5-I0.); monoica; dense cespitosa pulvinata valde crispula amoene viridis erecta gracillima tenella fastigiate ramosa; folia caulina conferta, madefacta reflexo-patula, e basi recta perfecte rectangulari-quadrate pellucide firme leviter reticulata angusta brevi reflexiuscula flexuosa lineari-lanceolata acula, evanidinervia, apice subintegra v. denticulata, margine vix revoluta, superne e cellulis depressoquadratis plus minus incrassatis papilla mica vesiculiformi praeditis areolata, carinata; theca in ped. tortili brevi tenuissimo flavido erecto globoso-ovalis minuta aurantiaca, dein fusca, exannulata perfecte sulcata, operculo longirostri obliquo; perist. dentes longi tenuissime subulati fugaces articulati plus minus regulares.

Brid. 1. p. 340, - Rhabdoweisia fugax Br. Eur. $33-36$. p. 4. t. 1. - W. striata Kaulf in sturm. Fl. Germ. II. Fasc, 16. t, 24. W. pumila Brid. I. p. 33s. - W. leptodon Plauh. in Brid. 1. p.341.Grimmia striata W. et M. Bot. Taschh. p. 325.

Patvia. Ad rupes praecipue arenaceas et graniticas, nec non ad terram praeruptam graminosam per regionem subalpinam et alpinam totius Europae. - Junio, in alpinis Julio et Augusto.

Flores masculi gemmacei minuti in vicisia feminei, foliis perig. caulinis similibus, internis minoribus, antheridiis 3 eparaphysatis.

2. W. vuleaniea C. Müll.; monoica; habitus $\mathrm{I}^{r}$. fugucis, sed laxe cespitosa humilior tenella, amoene viridis inferne radiculosa haud tomentosa, parce fastigiate ramosa; folia caulina ubique laxe imbricata crispula, madefacta flexuose patentia, e basi mimute firme hul pellucille areolata vix erecta reflexiuscula, lineari-lanceolata acutissima subintegerrima, ubique e cellulis minutissimis, papillis tenuissimis praeditis, opacis areolata scaberrima, nervo evanido dorso minutissime scabro, carinata; theca et perist. regulure ut in praecedente. 
Patria. Mexico, in cavernis trachytaceis crateris m. Cerro de los Nebejos, Mart. 1839: C. E. hrenberg legit societate Bartr. intertextae.

W. fuguei simillima, sed notis illustratis distinctissima, pulchclla species.

3. W. denticulata Brid. (Mant. Musc. p. 4(0.); monoica; habitus $\boldsymbol{W}^{\text {T}}$. fugacis, sed folia basi a cellulis multis amplis laxis pellucidis elongate quadratis laevibus reticulata, superne remote et grosse dentata nitida latiora, minus crispata, theca collo distinctiore, sicca turbinatu minuta et perist. dentibus majoribus, e basi latiore subito longe subulatis robustioribus.

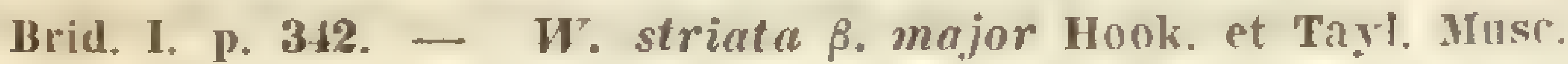
Brit. ed. II. p. 81, t. 15. - W. crispata Brid. olim Muse. Hec. II. I. P. 73. - Bryum crispatum Dicks, lasc. IlI. Pl. ('r. p. 3. t. 7. f. 4. fide Bridel. - Rhabdoweisia denticulata Br. Eur. Fasc. 33-36. p. 5. t. 2.

Patria. In subalpinis et alpinis locis praeruptis ad moles graminosas, rarius in rupium fissuris per totam fere Europam temperatiorem. - Aestate.

4. W. Sehisti Brid. (Mant. Musc. p 39.); monoice; habitus $\boldsymbol{W}$. fugucis; folia caulina lincari-lanceolata, e basi erecta subito valde reflexa, margine revoluta, ubique e cellulis minutis flavidis quadratis inferne magis rectangularibus superne pagina superiore valde papillosis areolata, igitur margine valde cremulata; perichactialia basi multo tenerius reticulata longe vaginantia, omnia nervo dorso apicis scabra; theca ovalis, collo conspicuo, operculo brevirostro crassiusculo obliquo; perist. dentes longissimi subulati trabeculato - articulati fusciduli paulisper latiores.

Brid. I. p. 339. - Rhabdoneisia Schisti Br. Fur. 1. c. p. 5.

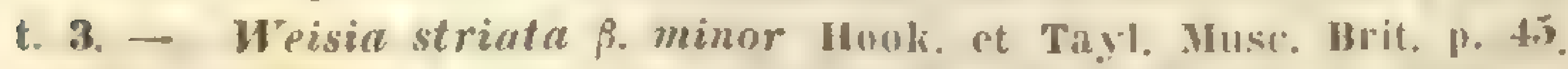
t. 15. ex parte. - Grimmia schisti Sim. H1. Hrit. III. p. 118.5. Dicranum splachnoides Brid. olim Musc. Hec. II. I. p. 81. - Bryum schisti Oeder F1. Dan. t. 53\%.

Patria. In rupium fissuris humidis et ad terram humosam per Lapponiam (sec. Hb. Bridel.), Gothiam et Norvegiam Scandinaviac, ubi pr. Christianiam primus legit 
Oeder, et in alpibus Germaniae et Angliae. Raro. Julio, Aug.

Dentes perist. in speciminibus pec Bridelian is, nee Swartzian is tam latos et robustos invenimus, ut Br. Lurop. delineatos indicat. E structura folii $\mathrm{W}$. sermlatue haud dissimilis.

sectio II. Huweisin. Thera laevis peristomata $v$. mula : dentes lancolati, saepe pertusi. Folia crispula, interdum rigida.

\section{A. Peristomatue. \\ a. Folia crispula.}

5. W. viridula Brid. (I. p. 334.); monoica; laxe plus minus late saepe subpulvinate cespitosa, laete viridis, ramosa, plus minus humilis; folia caulina involute crispata, madefacta erecto-patentia, inferiora minuta lanceolata, superiora in comam patulam congesta longiora, e basi rectiuscula lineari-lanceolata subreflexa, integerrima, murgine superne incoluto, nervo crasso flavido in mucronem acutum brevem producto, basi e cellulis parvis rectangularibus pellucidis teneris superne minutissime quedratis et pupillis tenuissimis opacis intense viridibus; perichaetialia comalibus similie; theca in ped. breviusculo pallido erecta raro subobliqua, plus minus ovalis, orificio et anmulo angusto praedita, sordide fusca, operculo longe subulato obliquo; perist. dentes variabiles breves, linearilanceolati obtusi, integri $v$ apice fissi $v$. pertusi ferruginei subrugulosi.

Br. Furw. $33-86$. p. 5. t. 2 et $3 .-W$ controversa Ildw. Musc. Fr. III. p. 12. t. 5. - W. mutubilis Brid. Sp. Must. 1. p. 103, W. virens e.j. Muse, Hec. H. I. 1. 69. - W. crispa Timm. Prodl. Fl. Megap. II. 736. - Wr. Dicksoni Gmel. syst. Natt. II. p. 1334. -

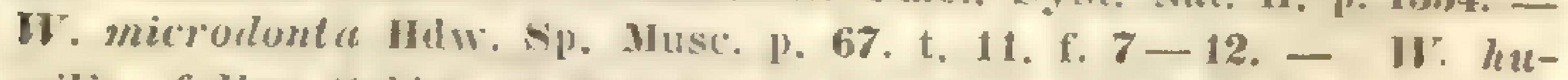
milis, fullax selhm. et Bruchiana Br. Germ. II. 2. p. $36 \mathrm{ct} 3 \times$. tah. 26 et 24 - W. Cyrmaea Brid. 1. p. K03. - W. tortilis spr. syst. Veget. IV. 2. P. 321. - W. curricaulis Brid. I. p. 336. - W. obscura Hïhl. Amm. Wett. Ges. III. p. 99. et Brid. 1. p. 337 ? - Dicranum santhodon $\mathrm{Hdw}$. sp. M. p. 14.5. t. 30. - D. flexifolium Hook. Musc. Kant. t. 14t? - Hymenostom. subglobosum Br. Gierı. 1. p. 103. t. 12. et Brid. II. p. 79. - Grimmiu controversa W. et M. Bot. Taschl. P. 133. - Afselia crispa Ehrh. Cr. Exs. n. 222. - 
Bryum vividulum L. Sp. PI. p. 1584. - Br. virens Dicks. Fasc. II. Cr.p.4.-Br. paludosum $\beta$. viridulum Web. sp. Fl, Goett. 1. 11. Br. controversum Hoffin. Deut. Fl. II. p. 34. - Bryum capillaceum breve pallide et laete vireus, capsulis ovatis. Dill. Musc. p. 380. t. 48. f. 43.

$\beta$. stenocurpa; pusilla, theca attenuata subcylindrica. W. controversa $\beta$. stenocarpa Br. Germ. p. 45. t. 17.

$\gamma$. densifolia; elatior compacte cespitosa ramosissima, dense et fasciculate foliosa, folis angustioribus, perist. dentibus minus perfectis. Br. Hur. 1. c. - $\boldsymbol{W}$. densifolia Wils. Ms.

d. amblyodon; foliis nunc lineari-lanceolatis, nunc oblongo-lanceolatis, perist. dentibus maxime polymorphis brevissimis, truncatis, acutis $v$. apice fissis, pallidis $v$. lutescentibus. Br. Eur. 1. c. - W. amblyodon Brid. I. p. 805. И. gymnostomoides et microstoma Br. Germ. 1I. 2. p. 34 et 52. t. 25 et $\mathbf{3 7}$.

E. gymnostomoides; perist. dentibus valde imperfectis pallidis. Br. Eur. I. c. - W. gymnostomoides Brid. I. p. 3+2. W. Rudolphiana Br. Germ. II. p. 33. t. 25.

S. mucronata; folia margine plerumque erecto rarius involuto, distinctius mucronata, peristomium fugacissimum. W. mucronata Bruch in Br. Europ. $33-36$. p. 7. t. 4. sub nom. $W$. mucronulatae. - Hymenostomum rutilans Br. Germ. 1. p. 201. t. 12.

Patria. In terra nuda liumosa rupium, murorum, sylvarum, pratorum etc. per totam Europam vulgatissima una cum variet. illustratis et in Americae septentrionalis, Africae et Asiae regionibus temperatis. _ Vere, in Africa merid. Septembri.

Flores masculi in innovationibus terminales sacpe plures aggregati, minute gemmacei, colorati; foliis perig. parvis e basi late ovata concara tenerime et pellucide areolata acuminata subconvolutacea evanidinervia; antleridis crassiusculis, paraplyysibus paucis mixtis. - Ápecies foliis superne valde involutis facile discernibilis.

6. W. cryptodon Mont. (Ann. d. sc. nat. 1845.4. p. 120.); monoica; cespitosa, procumbenti-erecta basi et apice innorando divisa humilis; folia crispata, madefacta 
erecto-patentia conferta, inferiora minora angustiora lanceolato-acuminata, carinata, apice vix inflexa, superiora sensim latiora, apice inflexu, plicate concain, margine valde revolutu integerrima, fusco-viridia, e cellulis basi rectangularibus superne multo minoribus perfecte quadratis echlorophyllosis pellucidis flavide pachydermis areolatis, nervo subevanido; perich. intimum obtusiusculum breve; theca propter pedunculum arculum breve flavidum quasi horizontalis, erecta oblongo-cylindrica turgida sordide fusca, operculo conico rostrato recto dimidio breviori; perist. dentes breves lanceolati obtusi integri laeves amoene purpurei trabeculati.

Putria. Chile australis: C. Gay.

Flos masc. in axilla folii inferioris crassiuscule gemmaceus sessilis, foliis perig. paucis lato-ovatis acuminulatis convolutaceis laxiuscule reticulatis. - A W. viridula proxima notis cursive impressis facile distinguitur.

7. w. Wimmeriana Br. et Sch. (Br. Eur. 33-36. p.4. t. 1.); undrogyna; pusilla dense cespitosa innovando ramosa; folia caulina stricte patula, siccitate crispata, e Iuteo viridia dein rufescentia, inferiora breviora lanceolata, superiora anguste lanceolata acutissima, apice subcucullata, supra basin involutacea, integerrima, evanidinervia carinata, e cellulis basi rectangularibus pellucidis tenerrimis minulis versus apicem sensim minutissimis opacis maxime tenuiter papillosis areolata; perichaetialia basi longe vaginante tenera, omnia plus minus flexuosa; theca in ped. longiusculo flavido stricto erecta interdum obliqua, ovali-cylindrica r. ovalis minuta, annulata fuscescens, operculo oblique subulato; perist. dentes brevissime rudimenturii truncati pallidi.

Gynnost. Wimmerianum Sendtner in Alegensh. Bot. Zeit. 1840. I. p. 50. et in hegensl). Denchischriften 1841. p. 141. - Gymn. Trafoiense Schimp. in sched.

Patria. In rupium fissuris humo repletis in montibus depressis Sudetorum prope fontes Morae, in sic dicto Kessel auf der Janowitzer Haide detexit Sendtner; 


\section{STEGOCARPI. ACROCARPI. WEISI.}

practerea in jugo Bormiensi pr. Trafoi, in summa Albula Rhatiae retro Weissenstein aliisque locis Ilelvetiae et Tirolis: IV. P. S ch.; in monte Chasseron Jurassi: I esquereux; in Norvegiae alpibus: Angström. - Julio.

8. W. reflexa Brid. (I. p. 35̆.); dioica; pusilla cespitulosa, innovando ramulosa; folia panca reflexa, anguste lanceolutu ligulato-obtusu, margine erecto integra flexuosa parum carinata magis plana, basi e cellulis rectunguluribus luxis parvis pellucidis superne minutis echlorophyllosis granuloso-papillosis pallide viridibus areolata, nervo evanido flavido; theca in ped. erecto longiusculo tenui flavido oblongo-elliptica, late annulata fuscescens parva, operculo conico obliquo obtuso; perist. dentes breves lineares obtusiusculi articulati ferruginei subgranulosi.

Br. Hurop. Fasc. 33 - 36. p. 7. t. 4. - Gymnost. irretitum Brid. 1. p. 758 !

Putria. In terra calcarea prope Arenionem Galliae australis: Kequien detexit; pr. Pessulanum (Montpellier): salzmann et pr. Mende: Prost.

1. mascula minor, parce ramosa, flore terminali minuta gemmaceo, folis perig. exteruis ex ovato lanceolatis medio recurvis, internis ovatis, antheridis et paraphysibus paucis parvis. - $\boldsymbol{J}^{\top}$. temi sinillima.

9. W. compacta Brid. (Mant. Musc. p. 42.); monoica; compacte cespitosa plus minus meleinatu, atro-viridis, fastigiate ramosa, dense foliosa humilis tenella, crispulu; folia caulina plus minus patentia, e basi latiore oblongu sensim lanceolato - subuluta obtusiuscula, valde concura subinrolutucea, margine integerrimo, nervo tenui sub apice evanido ferruginco, basi infima e cellulis rectangularibus temuioribus pellucidis, superne perfecte quadratis parvis pachydermis obscure coloratis haud opacis tenuissime papillosis arcolata; perichatialia longe venginuntia, breviter acuminata, intimum ligulato-obtusum tenerum pellucidum; theca in ped. brevi flexuoso purpurascente oxulis subrecta, sordide brumnea, cxamunlata, pachyderma, sicca rugosa, operculo oblique rostrato ob- 
tusiusculo; perist. dentes lineari-lanceolati apice subbifidi dense trabeculati rufo-purpurei, siccitate reflexi.

Brid. I. 1) 345. - Br. Europ. $33-36$. p. 8. t. 5. - W. atrovirens Br. Germ. II. 2. p. 56. t. 29. - W. condensata Brid. Mant. Musc. p. 41. - Grimmia compacta Nchleich. P1. Helv. Exs,

Patria. In summis alpibus Helvetiae, ubi in glareosis alp. Sanensium 1801 legit Bridel, Tirolis, altitud. $8-9000^{\prime}$ ad rupes humidiusculas semidecompositas et Salisburgiae. - Aestate.

Flos masc. minutus, foliis internis latiuscule ovatis acuminulatis obtusis. - Primo intuitu Grimmiae conferfue cespitibus gracillimis compactis haud dissimilis.

10. W. serrulate Funk (in Brid. I. p. 804.); monoica; dense cespitosa ubique in axillis foliorum radiculosa, interrupte ramosa, ramulis saepe brevissimis, fragilis; folia dense conferta erecto-patentia torquescentia, late lanceolata et lineari-lanceolata obtusa vel acuminulata, plus minus complicate concava evanidinervia, basi e cellulis tencrioribus pellucidis rectangularibus laxiusculis superne minutis opacis areolata, dorso papillis tuberculosis magnis crebervimis rulde sermalo-papillosa; perichactialia longiora et basi longiore pellucida laxa; theca in pel. breviusculo flavido stricto erecta, ovali-oblonga aequalis $v$. plus minus incurva, exannulata, collo brevissimo praedita, parva sordide fuscescens, operculo oblique et breviter rostrato obtusiusculo; perist. dentes lanceolato-subulati integri minus fissi, dense trabeculati, rufopurpurei apice pallidi.

Br. Europ. 33-36. p. 11. t. 8. - Br. Germ. II. 2. p. 90. t. 33. W. procera Laurer in Br. Germ. I. c. 1. 82. t. 32. - Trichostom. paradoxum Brid. 1. p. 817.

Patrill. In summis alpibus Carinthiae, Tirolis, ubi in Mattreyer-Tauern ad rupes detexit Funk, et Salisburgiac. Rarior! - Augusto.

Flos masc. genmiformis terminalis. - Species foliis verrucoso-papillosis primo adspectu distinctissima. 


\section{Folia stricta.}

11. W. verticillata Brid. (Sp. Musc. I. p. 121.); dioica; laxe et late cespitosa plus minus elata, valde dichotome ramosa, glaucescens topho obtecta; folia caulina erecto-patentia laxe disposita, siccitate rigida, juniora paulisper curvata, lanceolatu subsubulata angusta, basi latiore longe pellucidu margine dentata elongute laxe reficulata, superne rotundato-quadrate areolata viridia, nervo crasso in acumen crassum exeunte; perichactialia basi laxius reticulata amplexicaulia; theca in ped. breviusculo purpureo erecta v. subobliqua, ovalis, angustissime annulate, evacuata truncata, fusca pachydermis, operculo oblique subulato; perist. dentes 16 simplices integri rel apice subbifidi, linea divisurali longitudinali carentes, pallide aurantiaci sublacies.

W. y!psacea sichleich. Cat. PI. Helv. 1807. p. 31. - Eucladium verticillatum Br. Eur. 33-36. p. 3. t. 1. - Coscinodon verticillutus Brid. 1. p. 374. - C. elongatus ej. 1. r. p. 376. - Barbula Atlantica Brid. I. p. 559. - Grimmia rerticillata W. et M. B. T. p. 129. - Trimatium tophaceum froüb. in Brid. Hb. - Bryum verticillatum Dicks. Pl, Cr. Exs. No. 19.

Putrie. In rupibus praesertim calcareis humidis praesertim tophum efficientibus, ut Trich. fophaceum tophun pariter formans, per regionem montanam et subalpinam totius Europae. - Junio et Julio.

PI. mascula gracilior, floribus terminalibus saepe aggregatis, foliis perig. externis e basi ovali concava lanceolatis, internis acuminatis evanidinervibus; antheridiis oblongis, paraph. longioribus filiformibus. - Ex habitu Trich. tophaceo similis, sed structura foliorum longe distans.

\section{B. Gymnostomate.}

\section{a. Robustiores.}

12. W. Kunzeann C. Mill.; dioica; pusilla cespitosa rigida sordide viridis parce fasciculato-ramosa; folia canlina sicca valde crispata rigida, madefacta stricta, e basi latiore oblonga e cellulis rectangularibus pellucidis teneris multis reticulata concava saepe subito fere lanceolata in- 
terdum reflexiuscula, minutissime quadrato-areolata, tenuissime papillosa opaca, margine involuta; perichaetialia basi laxiora; omnia nervo crasso flavido carinato in mucronem breviter excurrente; theca in ped. medio rubente erecta ovalis parva sordide fusca, operculo subulato obliquo tenuissimo.

Gymnost. marginatum Kze. mst. in Pöpp. PI. Cliil.

Patria. Chile: Pöppig.

A $\boldsymbol{W}$. viridula simillima theca gymnostoma differt.

13. w. rupestris C. Müll.; dioica; dense cespitosa, plus minus elata gracilis, dichotome ramosa, interrupte foliosa, laete viridis, inferne fuscescens, et tomentosoradiculosa; folia caulina erecto-patentia rigidiuscula, siccu crispula, lanceolato-linearia, obtusinscula, basi papillis cremulata, evanidinervia, e cellulis basi rectangularibus superne magis quadratis temissime papillosis igitur opucis minutis areolata; perichaetialia basi laxius pellucidus et magis hexagone reticulata, plus minus vaginantia; theca in ped. breviusculo tenuissimo ovalis brevicolla, subnitida brunnea, vix annulata, evacuata macrostoma, operculo oblique et longe rostrato.

Gymnost. rupestre Scliw. Suppl, I. I. p. 31. t. 11. - Br. Fur. 33-36. p. 7. t. 5 et 6. - Brid. 1. p. 77. - G. articulatum schkulu Ilent. Moos. P. 29. t. 11. c. et Br. Germ. I. p. 156. t. 10. - G. erythrostomum Brid. I. p. 85.

B. rumosissimu; dense compacta, folia breviora obtusiuscula, theca minor in ped. breviore. Br. Europ. 1. c.

$\gamma$. stelligera; laxe cespitosa, folia in innovationis apice valde comantia, stellate patentia subrecurra, lineari-lanceolata acutiuscula. Br. Eur. I. c. - Gymnost. stelligerum. $\mathrm{m}$. FI. Brit. III. p. 1164. - Brid. I. p. 89. - Br. Germ. I. p. 168. t. 11.

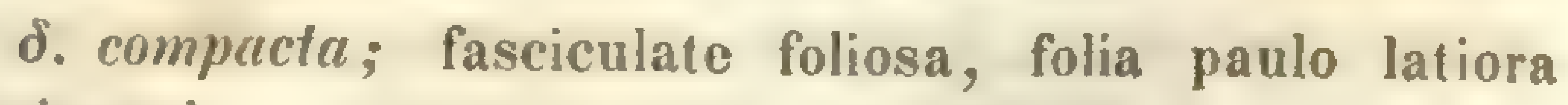
obtusiuscula. Br. Eur. 1. c.

Patria. In rupium fissuris humidis, e subalpinis ad alpes ascendens per totam Europam et in America septentrionali. - Vere et aestate.

c. Muller: Synops. musc. frond, 
Pl. mascula tenerior, foliis perig. internis oratis tenerioribus fuscis.

14. W. curvirostris C. Müll.; dioica; dense cespitosa clata fastigiate ramosa tomentoso-radiculosa, superne sordide viridis inferne ferruginea; folia caulina sicca et madefacta erecto-patentia vix crispula, lanceolata, acuta, rigidiuscula, ubique e cellulis diaphanis hand opacis quadratis basi rectangularibus lacvioribus areolata, inferne margine parum revoluta, basi late concava superne carinata; perichaetialia basi raginante laxius et pellucidius reticulata; theca in ped. breviusculo erecta, ex ovato globosa brevicolla, subnitida brunnea vix annulata, evacuata macrostoma, operculo longirostrato obliquo, in columella persistente.

Gymnost. curvirostrum Hdw. Musc. Fr. 11. p. 88. t. 34. - Br. Eur. 33-36. p. 8. t. 7 et 8. - Brid. 1. p. 84. - G. aeruginosum Sm. Fl. Brit. p. 1163.

B. pomiformis; folis tenuioribus angustioribus, theca oborato - subglobosa. Br. Eur. I. c. - Gymnost. pomiforme Nees et Hsch. Br. Grerm. I. p. 158. t. 10. - Brid. I. p. 79.

r. microcarpa; densius cespitosa, foliis paullo latioribus erecto-patentibus; theca obovato - globosa minor. Br. Eur. 1. c. - Gymnost. microcuryum Br. Germ. I. 1. 161. t.10. - Brid. I. p. 81.

f. pullidiseta; elongata gracillima valde ramosa fasciculato-foliosa; foliis patentibus tencrimis; theca in ped. abbreviato minuta obovata $\checkmark$. obconico-ovata, operculo brevius rostrato. Br. Fur. 1. c. p. 9. - Gymnost. pallidisetum Br. Germ. I. p. 166. t. 11. - Bril. I. p. 83. - G!nmn. brevisetum Br. Germ. I. p. 164. t: 10. - Brid. I. p. $8 \%$

Patria. In rupibus irroratis praeprimis calcareis per regionem subalpinam et alpinam, rarius montanam vel in planitie per totam Europam et in America septentrionali. Varietates in alpibus. - Julio, Augusto.

P1. mascula gracilior, innovationibus brevioribus, floribus $\boldsymbol{W}$. rupestris, a qua notis cursive impressis facile distinguitur. Species polymorpha. 
15. W. rigescens $C$. Müll.; divica; laxe cespitosa elata, ramis dichotomis saepe brevissimis valde divisa, gracilis flexuosa, sordide viridis, fragilis; folia caulina erecto-patentia parva, ex ovato subulate parum falcuta integerrima, concava, margine saepe revoluta, nervo subcontinuo ferrugineo, ubique e cellulis firmis quadratis parvis superne chlorophyllosis areolata, sublaevia; perichaetialia intima e basi latiore amplexante majus reticulata subito subulata; theca in ped. brevi flexuoso purpureo globoso-ovalis macrostoma.

Gymnostom. rigescens Br. et sch. in Musc. Alyssin. Schimp. No. 447.

Patria. Abyssinia, ad rupes alpis Silke, 12. Febr. 1840: W. Schimper.

\section{b. Tenellae.}

16. W. calearen C. Müll.; dioica; compacte cespitosa gracillima tenerrima humilis, innovando ramosa viridissima, inferne ferruginea; folia caulina erecta crispula, madefacta patula, lineari-lanceoluta, tenera integerrima evanidinervia carinata, ubique e cellulis minutis quadratis viridibus superne opacis tenuissime papillosis areolata; perichaetialia e busi latiore amplexante subhexagone pellucidius laxius reticulata subito subulata; theca in ped. medio flavido erecta ovalis brevicolla vix annulata parra, operculo oblique subulato.

Gymnost. calcaveum Nees et Hsch. Br. Germ. I. p. 153. t. 10. Br. Europ. 33-36. p. 6. t. 4. - Brid. I. p. 65.

B. tenella; brevissima 1-2 linearis parce ramosa, theca ex ovali elliptico-oblonga. Br. Eur. I. c.

$\gamma$. viridulu; caulis 2-3 linearis, ramis gracilescentibus, foliis patenti-recurvis ovato-lanceolatis, theca ovalis. Br. Eur. 1. c. t. 3. - Gymnost. riridulum Brid. I. p. 66.

ס. gracillima; ramis sterilibus fertilibus longioribus, theca oblonga. Br. Kur. I. c. - Gymnost. gracillimum Br. Germ. I. p. 149. t. 10.

Putria. In conglomerato calcareo pr. Monachium et Salisburgiam, praeterea in Littorale et Bosnia. Var. $\beta$. 
et $\gamma$. in muris calcareis pr. Monspelium et in rupibus tophaceis Sardiniae. Var. $\delta$. in schisto micaceo alpium Salisburgensium et Pyrenaeorum. - Junio, Julio.

Pl. mascula gracilior, flore minutissimo innovando laterali, foliis perig. internis ovato-acuminatis latiusculis parvis, antheridis breviter stipitatis, paraphysibus tenerrimis paucis mixtis. - A $\boldsymbol{W}$. tenui simili notis laudatis facile distinguitur.

17. W. tenuis C. Müll.; dioica; longe lateque cespitosa brevissima, e basi pluries divisa lutescens; folia inferiora minima linguaeformia, superiora lineari-lanceolata obtusa, margine parm crenulata; perichactialia ultra medium vaginantia, omnia minutissime areolata et papillosa, inferne laevia et pellucidius majus reticulata; theca in ped. stricto longiusculo flavido erecta oblonga, collo parvo praedita, pallide ferruginea, late annulata, operculo conico brevi subobliquo.

Gymnost. tenue Schrad. Coll. PI. Cr. No. 31. - Brid. I. p. 64. Br. Europ. 33 - 36. p. 5. t. 2. - G. pancifolium Eingl. Bot. t. 2806. Bryum paucifolium Dicks. Hasc. IV. PI. Cr. p. 7. t. 11. f. 3.

Patrie. Ad rupium arenacearum parietes et ad'muros per mediam Europam. - Julio, Augusto.

Pl. mascula femineac similis, fol. perig. externis ovato-lanceolatis obtusis, internis oratis enervibus mollibus; antheridiis minulis, paraph. mixtis vel nullis.

Sectio III. Mymenostomum R. Br. Trans, of the Linn. Sor. XII. 1I. p. อ̆73. - Hahitus omniı W. vividulae, sed thecae orificio columella apice dilatata clauso.

Columellam notam genericam non habemus, nam in generibus rariis diversissima, mox immersa mox exserta (e. gr. Pottia c. Desmalodonte), nunc cylindrica, nunc globosa (e. gr. Splachnucece) reperitur. Caeterum in Pottiu (Hyophila) involutifolia columella pariter apice dilatata observatur, dum in congeneribus aliis normalis invenitur.

\section{a. Foliu patula.}

18. W. mierostomn C. Müll.; monoica; late et plus minus dense cespitosa humillima tenella gracillima parce 
ramosa ditissime fructifera; folia sicca crispula, late lanceolata, nervo excurrente mucronata, margine imroluta, basi e cellulis parvis pellucidis teneris rectangularibus superne minute quadratis tenuissime papillosis igitur opacis viridibus areolata; perichaetialia basi tenuiora; theca in ped. brevi tenuissimo flavido mimutu, nunc erecta aequaliter oxata et elliptico-oralis, munc oblipma et yibba, sordide olivecea, microstoma, anmulata, operculo nunc anguste conico, nunc subulato.

Iymenost. microstomum R. Br. 1. c. - Br. Fur. 33-36. p. 4. t. 1. - Brid. II. p. 77. - Gymnost. microstomum Hdw. Musc. Fr. 1II. p. 71. t. 30. - G. phascoides Drumm. Musc. Amel. No. 12 forsan huc pertinet. Ic. in Schw. suppl. IV.t. 304. - Bryum microstomum Dicks. Fasc. IV. PI. Cr. p. 9.

B. oblifua; theca oblongo-cylindrica incurva, operculo anguste conico. Br. Eur. 1. c. - Hym. obliquum Br. Germ. I. p. 194. tab. 12. - Brid. II. p. 75.

$\gamma$. brevirostris; theca oblongo-cylindrica, regularis, operculo breviter conico. Br. Eur. 1. c. - Gymnost. sepincola Fk. in Brid. I. p. 74.

$\delta$. brachycarpa; theca brevius pedunculata abbreviate ovata el globosa, gibbosa. Br. Kur. 1. c. - Hymenost. brachycurpmen Br., Germ. 1, p. 196. tal). 12. - Brid. II. p. 76.

E. eluta; innorationibus elongatis, thecas superantibus, theca minore, subglobosa, operculo anguste conico. Br. Eur. 1. c.

Putria. In terra nuda umbrosa argillacea sylvarum et cultorum locorum per totam Europam vulgaris. - Vere.

Flos masc. in vicinia feminei, in ramulo brevissimo minutus, foliis perig. patulis, caulinis similibus, basi concavis margine haud vel vix involutis, vix opacis.

19. W. tortilis C. Müll.; monoica; pulvinate cespitulosa dichotome et fastigiate ramosa fasciculate foliosa, viridissima inferne ferruginea parce radiculosa, robusta; folia caulina conferta, sicca ralde incumbenti-tortilia, madefacta erecto-patula, inferiora minuta ovata, superiora late oblongo-lanceolata, nervo excurrente breviter mucronata, margine integerrimo incurva, carinala, subun- 
dulata, ubique e cellulis quadratis minutis firmis diaphanis apice folii opacis tenuissime papillosis areolata; perichactialia longiora, basi tenerius longius angustius pellucidius areolata; theca in ped. medio flavido turgide ovalis raro cylindracea aequalis v. gibba firma, orificio majori rubro post operculi lapsum medio apertum, fuscescens, simpliciter annulata, operculo longirostrato obliquo.

Hymenostomum tortile Br. Eur. 33-36. p. 6. tatl. 3 et 4. Gymnost. tortile schw. suppl. I. I. p. 29. t. 10. - G. condensatum Voit. Musc. Herhip. p. 14. - G. hymenostomoides Pöch in Musc. Bohemicis. - Weisiu involuta Brid. p. 336. e spec. auth. unico pessimo Hh. Brideliani huc pertincre videtur.

Patria. In rupium et murorum fissuris, terra calcarea impletis vel in terra calcareo-argillosa per regionem montanam usque ad alpinam totius fere prime meridionalis Europae, sed nusquam vulgare. - Vere.

Flos masc. $\boldsymbol{W}$. microstomae similis, a qua notis cursive impressis distat.

20. W. crispata C. Müll.; monoica; habitus praecedentis sed multo gracilior; folia longiora lineari-lanceolata spiraliter torla angustiora, nervo in mucronem producta, theca ovato-oblonga sacpe incurva, ore angusto.

Hymenostom. crispatum Br. Germ. I. p. 205. t. 12. - Br. Fur. 33 - 36. p. 6. t. 4. - H. Nülleri Bruch in Hegensh. Flora 1829. p. $38 \%$.

Patria. In hortis prope Tergestum: II ornschuch, in murorum fissuris terra impletis prope Cagliari Sardiniae: Fr. Mülier. Italia, Monte bello: Rabenhorst; Dalmatia pr. Spalato: S'endtner.

A $\boldsymbol{W}$. tortili simillima notis illustratis parum recedit.

21. W. micacea C. Müll.; dioica; dense et late cespitosa brevicaulis simplicissima $\vartheta$ e ex anice innoratione tenui, sordide viridis, rigida; folia caulina cirrhate incumbentia, madefacta stricta, densc conferta, e basi amplexante angusta oblonga tenuiter pellucide et rectangulari-areolata sensim subulato-lanceolatu, margine invoInta, apice parum incurva, superne minute quadrate areo- 
lata, superiora et perichactialia e basi latiore tenuiore laxiore superne subcoarctata subito subulato-lanceolata; nervus excurrens; theca in ped. elongato stricto flavidorubente tenui erecta parva ovalis, orifieio angusto, $p a-$ chydermis, fusca, orificio atro, maxime nitida, turgida, latiuscule sed simpliciter annulata, evacuata aperta, operculo subulato valde obliquo.

Hymenost. nitidulum in Br. Europ. 33-36. p. 3. memoratum? Hym. subglobosum Hsch. Fl. Bras. I. p. 6. - Gymnost, micuceum Schlechtd. Linnaea. X. 1835. p. 443.

Patria. Brasilia, terram arenosam micaceam habitans, in locis compluribus, ad Rio Janeiro a Beske et ad Rio Comprido (Gardner Coll. No. 9.) lectam vidimus. - Julio.

P1. mascula apice crassior, minor; flore crassilisculo terminali; foliis perig. externis e basi erecta patulis, internis e basi latiuscule ovata acuminata minora, nervo tenui excurrente $v$. in intimis ante apicem evanido; antheridiis mullis gracilibus curvatis, paraphysibus filiformibus flexuosis pachydermibus flavidis acutis multis mixtis. - Species theca vernicose splendente pachydermi primo adspectu discernibilis.

\section{b. Folia squarroso-reflexa.}

22. W. squarrosa C. Müll.; monoica; laxe cespitulosa, caule annosiore decumbente irregulariter ramoso; folia squarrosa latiora, margine erecto, hand inroluto; theca erecta ovata et elliptica aequalis, operculo anguste conico rostellato.

Hymenost. squarrosum Br. Germ. I. p. 193. t. 12. - Br. Eur. 33-36. p. 5. t. 2. 2- Brid. II. p. 74 .

Putria. In agris et pratis argillosis prope Bipontem detexit Bruch; in pratis urbis Francofurti ad Oderam siti: Itzigsohn; pr. Angers Galliae occidentalis: Guépin. E rarioribus, sed forsan praetervisa. - Sero anctumno et kyeme.

Caetera ut in $\boldsymbol{W}$. microstoma simillima; notis cursive impressis facile discernibilis. 
23. W. Breutelii C. Müll.; dioica; laxe cespitosa humilis subsimplex, basi interdum breviter ramosa, luteo-virens; folia caulina sicca tortilia, lineari-lanceolata acuta longiuscula, reflexo-patula, busi plus minus longu erecta, ibidem e cellulis angustis rectangularibus pellucidis, superne minutissime quadratis viridibus tenuissime papillosis parum opacis areolata, margine involuto, excurrentinervia; perichaetialia intima erecta haud reflexa, basi tenuiora pellucidiora parum convolutacea; theca in ped. longiusculo flavido tenui erecta, cylindrico-oblongu fuscidula, exannulata, operculo conico-subulato parum obliquo.

Hymenostomum cylindricum Br. et sch. Br. Eur. 33-36. p. 3 nomine memoratum? - Gymnost. Breutelii eor. in schedulis.

Patria. Ex insula Antillarum St. 'Thomas dicta retulit Breutel.

Weisiae non satis notae $r$. suspectae.

1. W. simplex Brid. (I. p. 803.); subacaulis cespitosa luteo-virens; folia oblongo-ovata obtusa concava evanidinervia, siccitate conniventia subcrispula; theca oblonga, operculo conico-subulato. $\leftarrow$.

Patria ignota. Hb. Candoll.

2. W. ccculta Wallr. (Linnaca XIV. p. 682.); caulis brevissimus fere subnullus simplicissimus oligophyllus; folia subulato-setacea enervia stricla, theca in ped. erecto ovata laevis, operculo tenui thecae diametrum aequante recto. $t$

Patria. In lapid. arenac. decompositis Hercyniae merid., societate Collemat. nigri, passim.

Habitu Brachyod. trichodis v. Campylostel. saxicolae, sed ex animadv. auctoris ab ambabus speciebus textura foliorum differre dicitur.

3. W. erythrogona Brid. (I. p. 337.); divicu; laxe cespitosa pusilla simplex tenera, luteo-virens; folia laxe imbricata lineari - lanceolata carinata margine parum revoluta pallide viridia acuta excurrentinervia, ubique e cel- 
lulis quadratis parvis sublaevibus basi sola laxioribus areolata, apice dentata, perichaetialia longiora.

Patria. America septentrionalis.

PI. mascula robustior ramosa; rami floribus crassiuscule gemmaceis coloratis terminati; folia perig. extema caulinis similia, basi latiora ovata, interiora late convolutacea breviter acuminata tenerius reticulata colorata, evanidinervia obtusiuscula integra, margine parum revoluta. Ad Weisiae genus si pertinet, species bene distincta erit.

4. Weisia zonata Brid. (I. p. 364.); compacte cespitosa; caulis gracillimus fragilissimus erectus elatiusculus, ramis paucis erectis cauli subuppressis divisus, nitidus intense viridis inferne plus minus zonate ferrugineus, folia appressa, madefacta et siccu paullo patentia, parra, lanceolato-acuminata firma amplexicaulia carinata, ubique minute quadrate flavide areolata, integerrima, nervo tenui subcontinuo.

Br. Germ. II. 2. p. 123. t. 35. - Dicranum sericeum Hsch. in schedulis. - Conostomum variegutum Brid. olin mst. - Conostonum boreale Hmp. in litt.

Patrict. In Pyrenaeis orientalibus 1803 aestate primus legit Bridel; dein ad rupes madidas montis Grossarl legit Hornschuch; e monte Bructero misit II a mpe.

Muscus memorabilis, habitu Angströmiis julaceis prime autem Conostomo boreali prino intuitu haud dissimilis, hucusque sterilis tantum repertus, observationibus bryologorum dignissimus.

Subtrib. II. ORTHOTRICHACEAE.

Cellulae folii basilares infimae solae molles, superiores plerumque incrassatae, rarins pellucidae normales.

Patria. Per omnes zonas totius orbis terrarum. 24.

Quoad reticulationem foliorum hujusce tribus plantas a Pottioideis praecedentibus separare nequivimus; nam pro omuibus congeneribus parenchymatica, maxime autem polymorpha plerumque incrassata reperitur. Habitum sci- 
licet proprium esse; notae tamen pottioideae multae 0 rthotrichaceurum sunt. Inter multas alias species affines Zygodon conoideus, Orthotrichum Sprucei, pumilum, rivulare, diaphanum, Grimmia pulvinata et Gïmbelia laxa folia perfecta Lupotliarum conservant; L'lozygodontes etsi robustiores Rhabloweisiis, Anoectangia Luneisiis maxime similes sunt; Orthotricha congeneres Calymperis, Brachystelea et Racomilria illos Leptodontii, Schlotheimiate surculis torquatis et calyptris campanulatis species Encclyptarum in memoriam referunt. Nffinitates adhuc multas illustrare possimus, sed his contenti sint bryologi et credant, auctorem haud leviter egisse. Ex omnibus autem his factis lex illa systematica profunde agens elucet: tribui omni esse reticulationis foliorum typum, hic perfectum, illic mututum, formam folii et habitum maxime variam effcientem.

\section{Hemicyclue I, ORTHOTRICHRAR.}

Folia distincte papillosa, papillis plerumque tuberculatis, saepe minutissimis, rarins obsoletis. Peristomia plerumqne carnosula et pallida, rarissime aurantiaco-colorata.

Patria. Orthotricha praesertim in terris hemisphaerae borealis, Zygodontes, Macromitria et Schlotheimiae illas hemisphaerae meridionalis praeferentes.

\section{Gen. XI. Zýgodon IIook. et T'ayl.}

Musc. Brit. p. 70. - Anoectangium al. - Amphidium Nees ab Es. - Heduigia Hook. - Codonoblepharon Schw. - Gymnostomum al. - Gagen Raddi. - Syrrhopodon al. - Aulacomnion nonn. - Gymnocephalus schw, partim. - Weisia al, - Grimmia al. - Bryum et Mnium antiq.

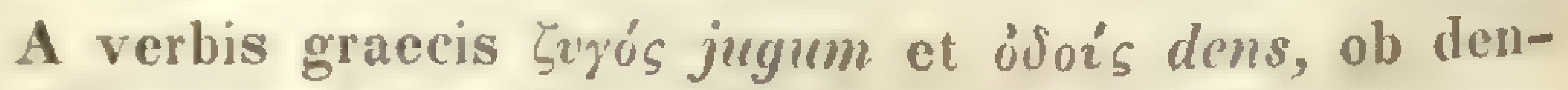
tes conjugatos nomen ductum.

Calyptra dimidiala. Peristomium nullum, simplex externum vel internum, s. duplex; externum $e$ dentibus orthotrichoideis 32 simplicibus geminatis 
v. bigeminalis conglutinatis planis pallidis rugulosis carnosulis, e cellularum serie unica formatis, siccilate patulis $v$. reflexis et thecae modo $0 r_{-}$ thotrichorum appressis compusilum; internum: cilia 8-16 linearia hyalina plus minus conniventia horizontalia $v$. dentibus externis similia. Theca pyriformis sulcata rarius glabra, examulata.

Zygodonteae Br. Europ.

sectio I. Amphidium Nees in Sturm FI. Germ. I1. 17. Folia lata sulspathulata e cellulis pottioideo - bexagonis areolata, planiuscula v. carinata laevia, erectn. Theca sulcata.

1. Z. conoideus Ilook. et Tayl. (Musc. Brit. p. 1 . t. 21!); monoicus; pulvinatus humilis breviter ramosus, inferne tomentosus viridissimus; folia caulina dense conferta, madefacta patula, e basi angustiore ampliuscule hexagone reticulata seusim late ovato-lanceolata s. subspathulato-acuminata, planiuscula nervo ante apicem evanido crassiusculo, integerrima, e cellulis ubirpe mugnis perfecte hexayonis chlorophyllosis firmis areolata; perichaetialia basi multo laxius reticulata; theca in ped. brevi flavido crassiusculo erecta, pyriformi-ovalis, fuscescens 8 -striata, ore coarctata, operculo conico subulato obliquo; perist. dentes cxterni 8 bigeminati latiusculi subrugulosi pallnde lutescentes sieci reflexi apice liberi, interni: cilia 8 cum dent. alternantia breviora anguste subulata hyalina subrecta.

Bryol. Eur. Fasc. 1V. p. 8. t. 2. - Brid. I. p. 590. - Z. conoideus $\beta$. succulentus Hnok. et Grev. in Edinb. Jnurn. of sc. 1824. Amphidium mulrinatum Nees in sturm Fl. Germ. II. Fase. 17. Gagea compucta Raddi. Nuova Raccolt. Dec. II. - Gymnocephalus convideus sichw. Suppl. I. 11. p. 87. - Weisia Forsteri Brid. I. p. 357. e sper. auth. Hh. Bridel.! - Grimmia Forsteri sm. Fl. Brit. III. p. 1196. - Bryum Forsteri IIchs. Fasc. III. PI. Cr. p. 4. t. 7. . 8 .

Patria. Ad arborum truncos Germaniae, Galliae merid. et Pyrenaeorum, Britanniae, Italiae et Sardiniac. In Norvegia indicat Ângström; e Brasilia lectum accepisse Br. et Sch. dicunt. Revera? - Vere. 
Flos masc. in ramulo tenero terminali gemmaceus, foliis perig. ovato-lanceolatis nervosis, antheridiis breviter stipitatis, paraphysibus filiformibus mixtis.

2. 2. Drummondi 'Tayl. (Lond. Journ. of bot. 1846. p. 46.); divicus; habitus praecedentis; folia spathulata acuminat a cancliculata, nervo subcontinuo, margine revoluta, basi e cellulis hexagonis mollibus ampliusculis pellucidis, superne valde incrassutis sacpe rotundatis vix chlorophyllosis areolata; theca in ped. brevi rubente tenui crecta, pyriformi-ovalis, pallida dein fuscescens, 8-sulcata, ore coarctata, operculo conico subulato obliquo basi aurantiaco superne flavido; perist. praccedentis.

Putria. Nova Iollandia, ad arbores reg. flum. Swan River legit J. Drummond, in regione' Port Adelaide ad Kowimanila leg. B e hr.

Species tenella, distincta, caulibus filis articulatis (Conferva Orthotrichi sic dictis) saepe terminatis.

Sectio II. Codonoblepharon schw. suppl. I1. p. 142. Folia parva angusta, e cellulis rotundatis superne arcolata, papillosa complicata v. carinata appresso-erecta. I'heca sulcatia.

3. Z. Menziesii W. Arn. (Disp. d. M. p. 15.); divicus; dense cespitosus tomentosus humilis subrobustus crassiusculus angulate teres undique fuscescens, ramulis fastigiatis brevibus; folia caulina erecto-appressa, madefacta parum patentia brevia, basi subdecurrente angustior sensim dilatata, medio latissima gibboso-conrexa, inde late lanceolata obtusiuscula $\imath$. subacuminata, integerrima, basi e cellulis elongatis laxiusculis plus mims hexagonis pellucidis $v$. fusco-striatis saepe interruptis laevibus superne rotundatis incrassatis tenuissime papillatis areolata; perichactialia perfecte erecta appressa oblongo-lanceolata obtusiuscula vel intima breviter acutata, basi multo longiore tenuiter elongate anguste et pellucide reticulata; omnia nervo sub apice evanido tenui fuscescente, inferne latius superne anguste et profunde carinata; theca in ped. brevi rubente flexuoso erecta, pyriformi-oxalis turgida, sordide fusca, profunde sulcata, ore courctata, operculo 
conico breviter obliquo; perist. duplex, dentes externi 8 bigeminati lato-lanceolati divisi longiusculi obscure articulati et mululoso-pallidi, sicci reflexi et thecae adpressi; interni: cilia 8 filiformia articulata connicentia albida.

Codonoblephavon Menziesii schw. Suppl. II. p. 142. t. 137. Brid. 1. p. 594.

Putria. Nova Seelandia: Archibald Menzies. Inter Leucod. hexastichum a Cl. Pöppig in Chile lectum reperimus. Ibidem: Philippi.

Flos masc. in pl. propria graciliore terminalis crassiuscule gemmaceus, foliis perig. lato-ovatis acuminatis concavis, internis omnino fere tenuiter et pellucide reticulatis fuscis obsoletinervibus; antherid. longis crassis, paraphysibus longioribus acutis flavidis. - Arevlatio folii $Z$. pentustichi, forma thecae $Z$. conoidei, species pulcherrima. Cilia perist. interni Schwägrichen 16 indicat, ipsi 8 tantum invenimus.

4. Z. Schwäigricheni C. Müll. (Linn. XVIII. p. 669.); dioicus; late et dense cespitosus erectus subgracilis mediocris fastigiate ramosus, brunnescens; folia caulina laxe cespitosa erecto-patentia crispula, madefacta strictiora, flexuosa, e basi amplexicauli e cellulis hexagonis pellucidis teneris reticulata longe pellucida oblongo-lanceolata angustata longiuscula, superne e cellulis quadrate hexagonis pachydermibus firmis brunneis subopacis tenuissime papillosis areolata, apice obsolete denticulata $v$. integra, nervo crasso ferrugineo continuo; perichaetialia basi magis vaginantia pellucidiora.

Syrrhopodon dutius schw. Suppl. IV. t. 312.

Putria. Nova Hollandia: G. S i eber.

5. Z. papillatus Mont. (Ann. d. sc. nat. 1815. p. 106.); dioicus; laxe cespitosus, inferne tomentoso-radiculosus, humilis tenuissimus filiformis erectus, siccitate apice incurvus, innovando ramulosus, flexuosus fragilis sordide viridis; folia caulina erecto-appressa crispula, madefacta erecto-patentia, parva, lanceolutu mucronatu, nervo longe 


\section{STEGOCARPI. ACROCARPI. ZYGODON.}

infra apicem evanido fusco subtenui, carinata, margine parum convexa, integerrima, papillis ubique sparsis tenuissimis scaberrima, e cellulis basi paucis laxis pellucidis superne rotundato - angulatis maxime incrassatis areolata, plus minus fuscescentia; perichaetialia similia basi cellulis laxis crebrioribus; theca in ped. brevi tenuissimo erecta minula obovalis 8 -striata haploperistomata, ciliis internis octonis, operculo oblique rostellato.

Patria. Chile australior, ad cort. arborum: C. Gay.

Z. obtusifolio maxime similis, sed notis cursive impressis species propria, pulcherrima. Perist. non vidimus et florem masculum nec in caule femineo nec alio invenimus.

6. 2. obtusifolius Hook. (Musc. Ex. t. 159.); monoicus; laxe cespitosus humilis tenuissinus filiformis erectus, siccitate apice incurvus, innovando ramulosus, flexuosus fragilis aureus; folia caulina erecto-appressa crispula, madefacta erecto-patentia, parva, oblongo-ligulata obtusute, papillis margine convexiusculo et ubique scaberrima, fusca, nervo aureo crasso longe infra apicem evanido, basi infima e cellulis rectangularibus paucis firmis superne maxime incrassatis minutis rotundate angulatis areolata; perichaetialia simillima intima breviora; theca in ped. brevi tenui erecta minuta perfecte pyriformis longicolla fusca, octies sulcata, operculo conico oblique et breviter rostellato; perist. duplex: dentes externi 8 bigeminati breves lato-lanceolati dense articulati pullide lutei siccitate reflexi et thecte adpressi, interni: cilia octo cum dentibus alternantia filiformia subconniventia.

Brid. I. p. 594. - schwägr. Suppl. II. p. 140, t. 136.

Patria. Nepal: Garduer.

Flos masc. in ramo proprio longiusculo terminalis minutissime gemmaceus, foliis perig. lato-ovatis concavis breviter acuminatis, basi laxe et In seriebus obliquis superne rotundato-reticulatis, antherid. paucis parvis, paraphys. paucis brevibus teneris mixtis. 
Sectio III. Euzygodon. Folia angusta, margine plus minus convexa, e cellulis rotundatis superne areolata papillosa complicata $\checkmark$ carinata, e basi erectà reflexa v. squarrosa. Theca sulcata.

\section{A. Folia integra. \\ a. Perist. nullum.}

7. Z. viridissimus Brid. (I. 592. excl. Syn. Grimm. Forsteri.); dioicus; pulvinatus fastigiate ramosus dense foliosus intense viridis; folia caulina erecto-appressa subtorta, madefacta parum recurva perfecte lanceolata integerrima, nervo cunido, carinato-concara, marginibus conexiusculis, busi e cellulis tenerrimis pellucidis quadrate hexagonis superne rotundatis sublaevibus amoene viridibus areolata; perichaetialia similia; theca in ped. breviusculo flavido erecta, obovata brevicolla olivacea dein fuscescens obscure 8-striata, operculo conico oblique rostrato aurantiaco; perist. nullum.

Br. Eur. IV. p. 7. t. 1. excl. Syn. I'eis. Forsteri. - Gymnost. viridissimum Hook. et Tayl. Musc. Brit. p. 10, tah, 6. excl. syn. Grimmia Forsteri. - Dicrun. viridissimum sm. Musc', Brit. III. p. 1224. - Bryum viridissimum Dichs. Fase. IV. P1. ('r. p. 9. t. 10. f. 18.

Patriu. In truncis arbor. sylvat., praeprimis quercuum et castanearum, per totam fere Europam mitiorem et calidiorem passim, rarius in muris et saxis. - Vere.

Flos masc. in pl. graciliore terminalis gemmifornis, foliis perig. externis ovato-lanceolatis, intimis ovatoacuminatis nerrosis $v$. enervibus, antheridiis et paraphys. filiformib. copiosis. - Folia maxime ad illa Enpottiurum accedunt.

\section{b. Perist. simplex.}

8. 2. intermedius Br. et Sch. (Br. Eul. IV. p. 9.); sedem tenet inter $Z$. viridissimum et Brebissoni, peristomio simplici interno 8 -ciliato. $\div$.

In coll. Schimp. Ahyss. species sub nom. eodem a Br. et Sch. edita est, rujus diagnosin Juc damus: diniıus; dense cespitostus intertextus diclotone ramosus gracilis luteo-virids; folia caulina madefacta recurva. lanceolata complicata, margine plicate convexa, integerrima subundulata, ubique e cellulis firmis pachydermibus basi 
parum majoribus quadratis superne minutis subopacis rotundis tenuissime papillosis areolata, evanidinervia; perichaetialia longiora angustiora apice falcata, hasi laxius pellucidius reticulata; theca in ped. Iongiusculo erecta cylindraceo-pyriformis 8-sulcata longicolla, operculo e conico ohlique subulato. - PI. mascula vix gracilior, foliis perig. e basi late ovata concava colorata tenuiter reticulata hreviter acuminatis olssoletinervibus; antheridiis longis stipitatis, paraphysibus tenuibus filiformibus mixtis. - An haece species cum praecedente Novae seelandiae conveniat, dubii sumus; quoad patriam vix credimus.

Patriu. Nova Seclandia: Hb. Hooker.

9. Z. anomalus Dz. et Molkb. (Ann. d. sc. nat. 1814. p. 316.); hermaphroditus; humilis pulvinato-cespitosus erectus, innovando parce et fastigiate ramulosus, flavide viridis; folia recurvo-patentia inferiora erecto-patentia, sicca contorta, oblongo-lanceolata complicate carinata undulata integerrima, margine convexiuscula haud revoluta, ubique e cellulis firmis minutis subrotundatis flavidis infima basi quadratis areolata, nervo in apiculum breve excurrente; perichaetialia exteriora lanceolata recurvoacuminata erecta, interiora breviora stricta ovato-lanceolata evanidinervia tenuius laxius pellucidius superne rotundate areolata; theca in ped. breviusculo luteo-rubro flexuoso crecta, subpyriformi-ovalis basi plicata, cxsiccata ore contructa et octies plicuta fusca, operculo conico-rostrato incurvo breviori; perist. simplex: dentes 16 brevissimi basi membrana interiore thecae conjuncti, linearilanceolati horisontules, sicci erecti vix emersi teneri hyalini.

Nozy et Molhh. Musc. Archip. Ind. IV. p. 92. t. 31.

Patria. Java: Korthals.

In foliis fila confervoidea repentia reperiuntur, unde nomen triviale ineptum. A $Z$. tetragonostomo notis laudatis differt.

10. 2. cylindricus Schimp. (in litt.); dioicus; laxe cespitosus conspicuus divisus, ad apicem usque tomento rufo obtectus; folia inferiora erecta, superiora e basi erecta patula et recurva, illa oblongo-lanceolata, haec linearilanceolata acuminata; perichactialia erecta lineari - lan- 
ceolata, haud raginantia; omnia carinata; thera in ped. elongato erecta, elongato-cylindrica, longicolla, calyptra ad mediam thecam fere producta, operculo e basi conica subulato; perist. simplex interum, cilis brevibus pallidis. $\div$.

Putria. Mexico, Pico de Orizaba: Liebmann.

E generis majoribus et habitu ad $Z$. tetragonostomum et Reinuardi accedens; peristomio et thecae membrana huicce proximus.

11. 2. Liebmanni Schimp. (in litteris.); dioicus; folia erecto-patentia oblongo - et lineari-lanceolata, comalia e medio palula, margine integra, perichaetialia erecta, haud raginantia, ab externo ad internum sensim minora; theca in ped. mediocri erecta, obovato-oblonga brevicollis, operculo mediocriter rostellato; perist. simplicis externi dentes bigeminati breves obtusi fugacissimi. $\uparrow$.

Patria. Mexico, Pico de Orizaba ad arbor. truncos: I. i e b m a n $n$.

A Z. Brebissoni proximo differt: folis densioribus minus patentibus, pedunculo breviore et crassiore, theca solidiore et peristomio simplici breviore.

12. $z$. stenocarpus Tayl. (Lond. Journ. of bot. 1847. p. 330.); laxe cespitosus erectus uncialis subdichotomus; folia caulina imbricata patenti-recurva, sicca subappressa, lineari-lanceolata acuta, canaliculata integerrima, margine subundulata, evanidinervia, dense et maculate areolata; theca in ped. tenui stramineo erecta cylindrica striata obconice apophysata, operculo longirostro declinato; perist. simplex internum $\mathbf{1 6}$-ciliatum, membrana annulari cinctum. t.

Patria. Andes Quitenses, monte Pichincha: IV. Jameson, Nov. 1846.

A $Z$. viridissimo statura altiore, theca cylindrica et peristomio differt.

\section{c. Perist. duplex.}

u. Humilew.

13. Z. Mrebissoni Br. et Sch. (Br. Eur. IV. p. 8. t. 2.); dioicus; $Z$. viridissimo simillimus, sed folia magis c. Müller: Bynops. musce frond. 


\section{S'TEGOCARPI. ACROCARPI. TYGODON.}

acutato - acuminata, nervo et pagina magis papillosa, theca pyriformi-oblonga longicolla, proeprimis autem pevistomio duplici; externum e dentibus octo bigeminatis late planis pallide luteis subrugulosis fugacissimis, siccitate erectis densius articulatis compositum; internum ciliis brevibus fugacissimis albidis.

Z. conoideus Inook. et Tayl, Musc. Brit. p. 71. t. 21. excl. Synt. Bryum conoideun Dicks. IV. P1. Cr. p. 9. t. 11. f. 2. - Mninm conoideum sm. H'. Brit. HII. p. 1345.

Patria. In arboribus pr. Inverary Scoliae: Dickson, pr. Manchester: Hobson; in Sormandia c. Z. viridissimo commixtum legit De Brébisson.

14. Z. Brownii Schw. (Suppl. IV. t. 31\%); monoicus; dense cespitosus humilis gracillinus radiculosus erectus fastigiate ramosus luteo-viridis; folia caulina parra erecto-recurea oblonga $r$ spathulato-sblonga acuta integerrima pellucida, nervo crasso ad ultimum apicem subevanescente lutescente, integerrima carinata, e cellulis "bique subrotundis areolata; perichactialia similia erecta; theca in perd. breviusculo tenuissimo flavido erecta, ocata, busi sensim attemutu, sicea costata, badia; perist. duplex, externum dentibus 8 bigeminatis, internum ciliis 8 lanceolato-linearibus, e tribus cellulis compositis albidis. $t$.

\section{Patria. Terra van Diemen: R. Brown.}

Z. papillato ex ic. simillinus, sed notis cursive inpressis longe distare videtur. Perist. externum imperfectum auctor vidit. Flores masc. terminales, post innovatum caulem laterales sessiles, foliis perig. duplo minoribus late oratis concavis tenuiter reticulatis breviter acuminatis fuscis, antheridiis ovatis turgidis, paraphysibus aequalibus filiformibus acutis limpidis.

15. z. ventricosus C. Müll. (Linn. XVIII. p. 668.); laxe cespitosus humilis laxe folious parce ramosus; folia erecto-patentia lanceolata curviuscula, basi ventricosoconcura, integra s. cellulis margine prominulis, nervo excurrente; perichaetialia nervo evanido; theca e collo brevi 
oblongo-elliptica, deoperculata ore plicato, 6-striata, breviter pedunculata, operculo conico brevi recto; perist. duplex: dentes externi lanceolati brevinsculi latinsculi rugulosi, interni ejusdem formae illos aequantes, linea longitudinali instructi, mallidi.

Patria. Clile in ramis arborum: Philippi. Ith. Reg. Berolin.

\section{B. Elati.}

16. Z. pentastichns C. Müll.; dioicus; robustus elatus, caule repente valde tomentoso, ramis remotis ascendentibus saepe elongatis flexuosis simplicibus, innorationibus ramulosis; folia caulina sicca dense appressa pentasticha, madefacta squarroso-recurva, e basi erecta lata oblonga e cellulis elongatis pachydermibus pellucidis flavidis $v$. fuscis igitur fusce striatis flexuosis reticulatâ recurva, ovato-acuminata complicata plicata semel torta, minute areolata, utraque pagina tenuiter papillosa, integerrima; perichaetialia erecta lato-acuminata, intima e cellulis ubique elongatis laxiusculis diaphanis basi plus minus fusce striatis reticulata; omnia evanidinervia; theca in ped. breviusculo purpureo tortili crasso elongate cylindrica erecta brevicolla 8 -sulcata fuscescens, operculo e conico subito subulato recto; perist. duplicis dentes ext. 16 lati carnosuli opaci rugulosi dense approximati robusti obtusiusculi linea longitudinali pallida divisi tessellati, interni: membrana ad basin externorum enata celIulosa, processibus irregularibus rugulosis, illis dense adglutinata; calyptra magna laevis straminea nitens.

Aulacomnion pentastichum Mont. Amm. d. sc. nat. 1845. p. 103. et in Gay Hist. de Chile Bot. Crypt. t. 5. f. 1.

Patria. Chile australis, ubi primus legit Pöppig, dein C. Gay.

Archegonia pauca, paraphysibus numerosis strictissimis intermixtis. - Zyygodon pulcherrimus, e robustissimis, Z. spuarroso soli proximus.

17. Z. squarrosus C. Müll.; laxe cespitosus subramosus, ramis erectis; folia caulina pentasticha laxa pa- 


\section{6}

STEGOCARPI. ACROCARPI. ZYGODON.

tenti-recurva latiuscule ovata integerrima acuta margine flexuosa; perichaetialia latiora erecta; theca in ped. longiusculo obovata subaequalis striata, operculo tenuiter longirostro; perist. duplex. $千$.

Aulacomnion flexifolium H. et WV. Lond. Journ. of bot. 1846. p. 448. t. 15. - Leptostomum squarrosum Tayl. 1. c. p. 43.

Patria. In Andibus Quitensibus, loca uliginosa habitans: W. Jameso n legit altitud. 14000' ad Cayambe.

Ex animadv. Wilson i habitu Paludellue, et Aulacomn. pentasticho Mont. proximus dicitur. Spec. Montagn. Zygodon verus est; speciem Tayloriancum igitur ex analogia et icone huc retulimus. A prima folis flexuosis angustioribus fide Wilson differt.

\section{Non satis noti.}

18. 7. angustatus Schimp. (in litt.); polygamus; dense cespitosus, tomento rufo ad apicem usque obductus; folia conferta, patentia lineari-acuminata, carinata, margine plana vel hic illic reflexa; theca in ped. breviore pallido suberecto elongato longicolla, operculo longe rostellato; perist. imperfectum. $\leftarrow$.

Putria. Mexico, ad monten Orizaba: Liebmann.

Z. viridissimo proximus, primo intuitu theca elongata distinctus. - Flores masc. secus hermaphroditos et his similes, antheridiis et paraphysibus copiosis.

19. z. Ehrenbergii C. Müll. (Linn. XVIII. p. 672.); dioicus; late et laxe pulvinatus subrobustus elatiusculus erectus, apice incurvo, valde fastigiatim ramulosus, luteoviridis inferne ferrugineus, inter folia usque ad apicen radiculosus; folia dense conferta erecta parum torta, madefacta superne subrecurvo-patula, e basi subdecurrente angusta minute quadrate et pellucide reticulata brevi ovato-lanceolata complicate concava undulata, apice torsione unica obliqua, integerrima, margine convexiuscula, e cellulis minutissimis rotundatis viridissimis subopacis tenuissime papillosis areolata; perichactialia similia; theca in ped. perbrevi octies sulcata. 
Patria. Mexico: C. Ehrenberg.

Caetera desunt. Archegonia numerosa, paraphysibus brevioribus paucis filiformibus acutis pellucidis mixta.

20. T. Schimperi Hmp. (C. Müll. in Linn. XVIII. p. 671.); divicus; laxe cespitosus erectus elatus fastigiate ramosus; folia caulina erecto-recurva, madefacta squarroso-reflexa, e basi late oblonga inferne longius laxius reticulata sensim lanceolato-acuminata subcuspidata, margine plerumque valde revoluta integerrima, nervo excurrente ferrugineo, e cellulis amoene flavidis maxime incrassatis minutis inaequaliter angulatis tenuissime subobsolete papillosis areolata; perichaetialia longe exserta, basi late amplexicauli multo tenuiora laxius longius tenerius et laeve reticulata apice reflexa; theca in ped. medio purpurascente pyriformi-ovalis.

Patria. Abyssinia: W. Schimper Coll. No. 428.

Archegonia pauca, paraphysibus numerosis strictis acutis flavidis mixta. Fructus imperfectus fuit.

\section{B. Folia dentata. \\ a. Perist. nullum.}

21. 2. tetragonostomus A. Br. (Br. Eur. IV. p. 9.); hermaphroditus; folia sermulata; theca quater striata, sicca evacuatu tetragonu, gymnostoma. t.

Patria. Java: Blume.

22. Z. trichomitrius Hook. et Wils. (Lond. Journ. of bot. 1846. p. 143. t. 4. B.); laxe cespitosus ultrauncialis parce dichotome ramosus, inferne radiculis purpureis tomentosus, ramis erectis; folia caulina Iaxiuscula, sicca suberispata, patula subrecurva flexuosa linearia apiculata carinata, margine subrecurra, apice minute denticulata luteo-viridia, inferiora fusca, punctiformi-areolata; perichaetialia erecta latiora; vaginula pilosa, theca in ped. brevi erecta, elliptico-oblonga gymuostoma, ore angustata, sicca plicata, fusco-badia, operculo e conico subulato subobliquo thecam dimidiam aequante; calyptru pilis lutescentibus kirta. t. 
Putria. Prom. b. spei, ad trunc. arbor. sylvar. Grootvaterbosch dictarum, in districtu Kwellendam: 'Ze yher. $\mathbf{E x}$ animadv, auct. $\boldsymbol{Z}$. viridissimo proximus dicitur.

\section{b. Perist. simplex.}

23. 2. Reinwardti A. Br. (Br. Europ. IV. p. 9.); hermaphroditus $v$. polygamus; laxe cespitosus inferne tomentosus elatiusculus parce ramosus ascendens; folia longe decurrentia, laxe imbricata erecto-patentia, madefucta magis patula erectu, lanceolata flexuoso-undulata, apice parce et remote dentata, convexiuscula complicatocarinata, rarius torta, margine haud revoluta, ubique $\theta$ cellulis rotundatis firmis tenuissime papillosis haud opacis areolata, nervo excurrente mucronulata; perichaetialia interiora parum latiora erecta lanceolato-acuminata evanidinervia multo tenuiora, basi rotundata multo laxius tenerius pellucidius et colorate reticulata integra; theca in ped. elongato flavido tenuissimo erecta subcylindraceoelliptica microstoma 8-sulcata fuscescens, operculo conico subulato obliquo; perist. simplex internum, e cilis sedecim formatum.

Syrrhopodon Reinuardti Hsch. Nov. Art. Plyss, Med. Acad. Leop. XIV. II. p. 700, t. 39. - Schwägr. Suppl. IV. t. 312.

Patria. Java: Reinwardt.

A sequente notis cursive impressis refugit. Flos paraphysibus mumerosis acutis pracditus.

24. Z. Moritzianus C. Müll. (Linn. XIX. p. 199.); dioicus; laxe cespitosus inferne tomentosus elatiusculus parce ramosus erectiusculus; folia laxe imbricata erectopatentia, madefacta plus mimus recureu, lanceolata flexuoso-undulata, apice parce et remote dentata, convexiuscule complicato-rarinata, semel torta, margine haud revoluta, ubique, cellulis basis infimae laxioribus pellucidinribus exceptis, minute rotundate subopace arcolata, minutissime papillosa, nervo in mueronulum brevissimum acutum producto flavido; perichaetialia erecta lanceolatoacuminata breviora tenuiora inferne pellucidius longins laxius reticulata, superne integra; theca in ped. elongato 
flarido tenuissimo erecta, cyllindrica longinscula subcurra 8-sulcata olivacea, dein fusca, operculo conico longe subulato incurvo; perist. simplex internum, e cilis octo tenerrimis filiformibus fugacissimis formatum.

Putria. Columbia, prov. Nerida, in montibus nivosis: Moritz.

Archegonia c. 10, paraphysibus numerosis filiformibus acutis flavidis mixta. Calyptra glabra. - Habitus $\boldsymbol{Z}$. Reinurulti, a quo foliis semper reflexis, inflorescentia dioica et perist. 8 - ciliato facile distinguitur.

25. Z. denticulatus 'I'ayl. (Lond. Journ. of bot. 1847. p. 329.); laxe cespitosus erectus dichotomus 1-2-uncialis viridis; folia caulina imbricata subquarroso-patentia oblongo-orata, apice denticulata, dense arcolata, margine flexuosa, nervo apiculata; theca crecta ovata basi obconice strumosa (i. e. collo praedita?), sicca striatocostata, operculo subulato; perist. simplex brevissimum: dentes 16 ralde irregulares subtriangulati acuminulati pallidi. $\div$.

Pulviu. Andes Quitenses; monte Pichincha: IVill. Jameson, Nov. 1846.

Lx animadr, auctoris hahitu $Z$. viridissimi.

\section{Non satis noti.}

26. Z. Sullivanti C. Müll.; laxe cespitosus erectus elatus ascendens flexuosus gracillimus, rumis incuequalibus remotis tenuissimis divisus; folia laxe imbricata erecto-patentia, flavida, e basi lata ovato-acuminata, complicate concava, parum reflexa, margine inferne vulde revoluta, superne inaegualiter serruta, nerso excurrente mucronulata, basi infima e cellulis anguste rectangularibus paucis fuscis laxioribus superne rotundatis valde incrassatis tenuissime papillosis areolata. sterilis.

syrrhopodon? excelsus sulliv, in Muse. Allegh. Exs. No. 180.

Patria. In summo cacumine montis Grandfather Carolinae septentrionalis, arboreus: Sullivant. 
27. 2. campylophyllus C. Müll.; dioicus; laxe cespitosus elongatus gracilis flexuosus, ramis dichotomis longis pluries divisus, intense viridis inferne tomento radiculoso ferrugineus; folia erecto-patentia crispula, madefacta valde arcuto-reflexu, suepe circulum fere delineantia, longiuscula, e basi decurrente lanceolata, nervo excurrente mucronulata, apice grosse et irreguluriter serratu, carinata, marginibus perfecte convexis igitur veluti revolutis, ubique e cellulis minutis rotundatis tenuissime papillosis haud opacis areolata, flavida; perichaetialia similia; theca in ped. breviusculo erecta, anguste longe myriformi-oblonga 8-sulcata.

Bartramia brachypus schimp. in Hh. Schleshtend.

\section{Patria. Mexico: C. Ehrenberg.}

Nectio IV. Ulozygodon. Folia angusta flexuosa patula, parum reflexa, superne rotundate areolata, crispula v. spiraliter torta, carinata. Theca sulcata.

28. 7. Tapponicus Br. et Sch. (Br. Eur. IV. p. 6.); monoicus; late et laxe cespitosus gracilis plus minus elatus, ramis dichotomis paucis erectis gracilibus; folia crispata, madefacta patula, oblongo-lanceolata angusta curvata, aculalu, evanidinervia integerrima, margine non revoluta, basi e cellulis parvis subquadratis pellucidis teneris superne mimtissimis rulde chlorophyllosis viridissimis maxime opacis areolata, tenuissime papillata; perichaetialia e busi angustata superne latiove elongate vaginante tenuiter plus mimus pellucide reticulata breviter acuminuta lacvissima, nervo longe infra apicem evanido; theca in ped. breviter exserto stricto pyriformi-ovalis 8-sulcata, siccitate urceolata, operculo e conico subito oblique breviter subulato.

Anoectany. Lappronicum Hiw. Np. Muse. p. 40. - Gymnostom. Lapponicum Hdw. Muse. Fr, III. p. 12. t. 5. - Hedlitia Lapponica Brid. Huse. Hec. II. 1. 33. - Gil/mnost, striatum Brid. 1. p. 90.schistidium striutum ej. Mant. Musc. p. 22. - Bryum Iapponicum Dicks. IV. Pl。Cr. p. 10.

Patria. In rupium fissuris per alpinas regiones totius Europae non raro, in America septentrionali: Drummond. - Aug., Septbr. 
Flos masc. parvus, foliis patulis lato-ovatis breviter acuminatis convolutis tenero-reticulatis intimis enervibus, antheridiis cum vel sine paraphysibus.

29. Z. Mougeotii Br. et Sch. (Br. Eur. IV. p. \%); divicus; habitus praecedentis; folia lanceolatu acute acuminata angustiona longiora, crassius nevosu, ubigne $e$ cellulis incrassutis vix vel menquam opacis plus minus fluridis et quadratis sublacvibus areolata, margine revoluta; perichaetialia longe et sensim ucuminatu amplexicaulia non convolute vaginantia ut caulinia areolata, intima margine non revoluta, subexcurrentinericia; theca in ped. longius exserto, operculo longius rostrato.

Patria. Ad rupes catarractae, Cascade du Mont Dore" Averniae, pulcherrime fructificans, dein lectus pr. Zell am See Pinzgoviae alp. Salisb., in 'Tiroli, Vogeso et Norvegia, unde nobiscum communicavit Hübener. Aestate.

Flos masc. in pl. propria terminalis gemmiformis, fol. perig. externis ovato-lanceolatis non recurvis, antheridiis paucis, paraphysibus nullis.

30. T. curvipes C. Mült.; dioicus; humilis, ramis fastigiatis brevibus dense approximatis; igitur caule crasso; folia caulina involuto-torta, e basi oblonga cellulis parvis pellucidis teneris quadratis reticulata angustissime lineuria acuminatu flexuosa, nervo crasso fusco excurrente acututa, apice obsolete denticulatu, medio margine parum revoluta, superne e cellulis minutis incrassate quadratis sublaevibus non opacis areolata; perichactialia interiora subvaginantia, basi longa laxe pellucide ef temiter reticulute longe acuminata; theca in pedunculo vix c.xserto versus apicem sensim crassiore arcuto globosa 8 -sulcata.

Anoectany. Lapponicum Kze. in Holl. Coll. Pl. ins. Madeirae.

Patria. Insula Madeira: II oll.

A Z. Mongeotii, cui structura folii proxima, notis cursive impressis certe distat, a $\boldsymbol{Z}$. Lupponico foliis caulinis multo angustioribus longe acuminatis excurrentinervibus non opacis obsolete denticulatis, perichaetialibus 
longissime acuminatis, pedunculo thecae forma et inflorescentia longe refugit.

31. 2. eyathicarpus Mont. (Ann. d. sc. nat. 1845. p. 106.); monoicus; humilis ramis fastigiatis gracilioribus laxe dispositis; folia caulina involuto-torta, e basi oblonga angustissime linearia, ubipue distincte sed remote dentata, evanidinervia, basi e cellulis pellucidis parvis quadratis teneris paucis subito minoribus vividibus subopacis tenuissime papillosis areolata, margine inferne parum revoluta; perichaetialia e basi late ouato-oblonga inferne elongate laxe pellucide tenerrime superne firmius reticulata margine denticulata subraginantia, caeterum superne caulinis simillima; theca in ped. breviter exserto stricto breviter pyriformis $\mathbf{1 6}$-striata, siccu evacuatu cyuthiformis, operculo plano-convexo oblique et obtuse apiculato.

Mont, in Gay. Hist, de Chile Bnt, Crypt. t. 3. f. 1. - Gymnost. linearifolium Tayl. Lond. Joun. of hot. 1s46. 1. 42. ex obs. Wilson i 1. r. p. 477. hu pertinct. - Syrrhopodon tortuosus Hsch. in Musc. Capens, Linu. XV. p. 117.

Putriel. Chile, ad S. Antonio in terra nuda: C. Gay. Augusto. Ex Andibus, monte Pichincha habuit Taylor. Prom. b. sp., monte Diaboli: Ecklon.

Flos masc. ad pedem feminei crassiuscule gemmaceus, foliis e basi late ovata concava tenerrime et pellucide reticulata margine denticulata subito anguste subulata integra, antheridiis majusculis. - $\boldsymbol{Z}$. Lapponico valde similis, magis autem e structura folii $\boldsymbol{Z}$. Mougeotii 2 . curripedi, a quibus notis cursive impressis facile distinguitur.

32. Z. torquatus Liebm. (in Wickström Jahresber. Deutsch v. Beilschm, für 1839-42. p. 430.); divicus; dense cespitosus, sed laxe cohacrens erectus clatus gracilis fasciculato-ramosus, amoene viridis inferne fuscescens s. brunnescens; folia caulina in spiram contorta erectu subuppressu, madefacta subpatentia, lanceolatoacuminata complicate carinata, ubique e cellulis minutis rotundatis incrassatis firmis subopacis tenuissime papillosis areolata, integerrima nerro in superioribus in pilum 
breve suepe producto; theca Z. Lupponici, sed obsolete striata, operculo breviori erectiori.

Dryptodon torquatus Brid. I. p. 782. - Grimmia torquata Hsch. Grer, scrot. Crypt. Fl, n. 40, t. 199. - Gr. tortu Br. Germ. II. I. p. 179. t. 24 .

Patria. In alpibus summis Carinthiae, ubi ad rupes praeruptas detexit Hornschuch, T'irolis et Helvetiae, in Scotia, Norvegia, in Rocky Mountains Americae septentrionalis et Islandia, ubi ad fontes rulcanicos calidos fertilem legit Steenstrup.

Fructum non vidimus. Grimmiae spirali habitu similis.

sectio V. Anoectangium Hdw. sip. Musc. I. p. 40. - $\mathrm{Br}$. Europ. Fasc. 29 - 30. Anoectanginceae. - Folia angusta plus minus lancenlata superne dense areolata. Thera lafvis. Infloresc. dioica. - E structura folii quam fructus situ laterali ad Zygodontes certe pertinens.

\section{A. Folia brevia tenellu.}

33. Z. compactus C. Müll.; compacte cespitosus elatus gracilis frugilis dichotome ramosus, amoene viridis inferne ferrugineus et radiculosus; folia remota superne confertiora spiraliter tortilia, madefacta patentia, lanceolata, nervo excedente mucronulata, carinata, ubique e celIulis quadratis firmis superne minutissimis subopacis areolara, tenuissime papillosa, margine igitur plus minus erosodenticulata; perichaetialia e basi late vaginante acuminata evandinervia longius tenerius laxius laeve reticulata, externa brevia lato-lanceolata acuminata; theca in ped. breviusculo supra cespitem exserto flavido tenui erecta minuta ovali-oblonga, operculata subpyriformis collo distincto, operculo longe subulato valde obliquo tenuissimo.

Anoectangium compactum seliw. siupl. I. 1. 1. 36. t. 11. Br. Europ. $29-30$. p. 5. t, 1. sub nom. An. aestiri. - Gymmost. compactum silfeich. (r. Helv. Cont. II. 11. 7. - Hrirl. I. p. \&i, G. aestirum Huw. Sp. Musc. 1. 32. t. 11? - G. Wistichon Wihlenh. Fl. Lapp. 1. 303. - G. Inteolum EngI. Hot. t. 2201, fide Hooker. 
Patria. In rupibus humidis umbrosis, praeprimis micaceo-schistosis per totius Europae regionem alpinam. Auctumno.

Pl. mascula femineae similis, floribus axillaribus numerosis solitaris $v$. aggregatis. Folia perig, cum v. sine nervo, caulinis tenuiora, e basi ovata concava acuminata; antheridia eparaphysata.

34. 2. pusillus C. Müll. (Limn. XIX. p. 200.); cespites pusilli basi compacti ramis ascendentibus brevibus laxissimi; caulis ex apice innovans ramosiusculus gracillimus; rami apice incurviusculi; folia sicca spiraliter torta, oblongo-lanceolata apicem versus parum dilatatu mucronata excurrentinervia, superne e cellulis minutissimis muxime opacis basi pallidioribus majus rotundatis areolata, utrapue pagina et ncrvo valde conspicuo-pupillata, margine igitur perfecte crenulata; perichaetialia externa late lanceolata acuminata, interiora convolutacea acuminata, tenerius laxius pellucide laeve areolata, evanidinervia; theca in ped. Iongiusculo tenui flavido erecta ovalis minor brevicolla fusca, operculo longe subulato obliquo.

Anoectany. Breutelimum Br. et sclo. Fase. 29-30. p. 6. memoratum? - Gymnostom. Guadeloupense spr. syst. Veget. IV. I. p. 145. - G. euchlorum Nicliw. II. 2. p. 83. t. 176. - G. Maschalocarpus Mont. in sched. ad De Notaris. - G. lumprocarpum Dont. Ann. d. sc. nat, IX. 1838, p. 49.

Patria. Insulae Antillarum, ubi in Guadeloupe primus legit Bertero, et in Mexico: Deppe et Schicde.

Planta tenella ramis apice curvatis gracillimis haud fragilibus amoene luteo - viridibus primo momento a $\boldsymbol{Z}$. compacto distat.

35. Z. tenerrimms C. Müll.; densissime compachs humilis lutescenti-viridis, inferne sensim ferrugincus zonatus, caulis tenerrime filiformis, innovando ramosus; folia caulina minutissimu purem tortu, inferiora oblonga obtusa brevia minus opace, nervo carinato ante apicent evanido, superiora et perichactialia longiora acula, nervo subexcurrente, illa modo caulinolum integerrima, hace basi latiora hand comolutacen, sed amplexicuulia laxins 
areolutu ad medium temissime crenulatu; theca in ped. supra cespitem longiuscule exserto tenuissimo flavido subinclinata v. recta minutissima ovalis brevicolla fuscescens, operculo conico subulato obliquo, calyptra minuta tenera.

Anoectany. tenerrimum C. Miill. Bot. Zeit. 1847. p. 801. Gymnost. Iaxifolinm Kze, in Pöpp. Pl. Chil. Coll. 111. 268(5̋3).

Putriu. Chile australis, in truncis arborum et rupibus ad Antuco: Pöppig.

A Z. pusillo affini caule filiformi tenuissimo jam primo intuitu differt.

\section{B. Folia longa robusta.}

36. z. Mornschuchianus C. Miill.; late et plus mimus dense cespitosus elatus robustus pluries dichotome ramosus luteo-viridis, mollis, inferne pallide ferrugineus, radiculosus; folia caulina laxe conferta subcrispula erecta, madefacta subpatula longa, e basi longiuscula erecta latoovata anguste pellucide subelongate hexagono-reticulata margine denticulatà parum reflexa lanceolata acutiuscula subsubulata canaliculata, e rellulis minutis rotundatoquadratis subopacis sublaevibus areolata, integerrima, excurrentinervia; perichaetialia e baśi multo latiore subvaginante laxius reticulata margine distinctius eroso-denticulata subito longe subulata; theca in ped. brevi flavido inferne purpurascente erecta, globoso-pyriformis pallide olivacea, operculo longe subulato obliquo basi aurantiaco, evacuata fusca.

Anoectangium Hornschuchianum Hoppe in Regensh. bot. Zeit. 1819. I. p. ㅈ.3. et $1 \times 20$. I. p. $1 \times 2$. - Br. Furop. 29-30. p. 6. t. 2.Gymmost. Hornsch. Fk. in Br. Germ. I. p. 176, t. 11. - Brid. I. p. xr. - Hedriyin Hornseh. Hook. Muse, Ex. t. 103.

Patria. In alpibus Carinthiae pr. Ifeiligenblut, ad cataractas Gössnitzfall et Leiterbachfall, ubi in locis perpetuo irroratis imperviis primus legit Hornschuch, anno 1816. E rarissimis! - Angusto, Septembri.

Flores masculi numerosi aggregati, raro solitarii. Caetera sectionis. - Pl. pulcherrima, cum alia specie nunquam confundenda. 
37. 2. Sendtnerianus C. Miill.; habitus praecedentis, sed caule fragili huniliore minus radiculoso, folia ejusdem innovationis sensim majora lineuri-lanceolatu robustiora et robustius basi magis quadrate et firme areolata, ubipue integervima, dense conferta subfasciculata mugis glaucescentia; perichaetialia angustiora; theca in ped. longiore supra cespitem exserto parra oralis brevicolla.

Anoectang. Sendtueriunum Br. et sich. Br. Fur. 29-30. p. 7. t. 3. - Gymnost. Hornschuchionum Br. Germ. I. p. 178, loco Rauris indicatum.

Patrice. In alpibus Salisburgiae, in der Rauris prope dem 'Tauernhaus", ubi leg. Funk et La urer; in alpibus Julicis, loco Pad Mangerskaskala, altitud. 6000': Sendtner legit 14. Junio 1843.

A praecedente certe distat.

$$
\text { Zygodontes? }
$$

Didymodon? papillatus Hook. et Wils. (I ‘ond. Journ. 1844. p. 544.); elongatus ramosus; folia patenti-recurva solidinervia papillosa, sicca erecta subincurva. $i$.

Leskea rubricaulis Tayl. mst.

Putria. Terra Van Diemen.

Muscus ex animadv. auct. excellens, habitu Leslieue perichaetiis autem terminalibus, innovationibus attamen lateralibus.

\section{Gen. XII. Drummondia Hook.}

Drumm. Musc. Americ. No. 62. - Macromitrium silhwägr. et C. Müll. - Leiolheca Brid. - Orthotrichum Hook. - Gymnostomum Hdw. - Hypnum Dill.

In memorian perpetuam Drummondi, bryologi indefessi et peregrinatoris Americae septentrionalis scrutantis genus conditum, egregium, prius a nobis errantibus deletum.

Calyptra dimidiala magna, thecam juvenilem superans, late concava, amoene straminea laevissima nitida, primum nt ill Schlotheimiis conica. Pe- 
ristomium simplex, dentibus sedecim brevissimis, veluli imperfectis truncatis, integris, linea longiIudinali tenuissima notatis, dense trabeculatis rufis leptodermibus laevibus.

Habitus Amphidli generis Zygodontis, pedunculo antem certe terminali et theca laevi.

a. Folia perichaet. canlinis similia.

1. Dr. elavellata Hook. (l. c.); dioica; pulvinuli pusilli densi longe et late extensi depressi, amoene virides, dein sordidi vel inferne nigricantes, surculis longe repentibus brevissime ramosis; folia caulina dense imbricata appressa, madore erecto-patentia, late ovato-lanceolata, brevia, obtuse acuta, margine erecto $\mathrm{v}$. parum involutaceo, cellulis ubique rotundis firmis viridibus, concava, nervo carinato evanido; perich. conformia, basi cellulis magis quadratis; theca in ped. brevi recto subglobosoovata laevissima turgida leptodermis fusca, operculo oblique rostrato, annulo nullo.

Macromitr. (Chuenomitrium) clavellutum (". Müll. Bot. Zeit.

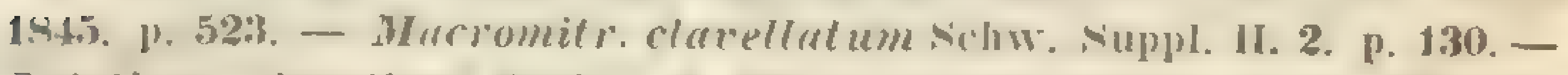
Leiothera clarellati Brid. I. p. $72 \%$. - Orthotrichum clavellatum Honk. et Grev. Brewst. Hadiuh. Journ. I. p. 11t. t. 4. - Gymnost. frovepens Ildw. Sp. Husc, p. 35. t. 3. f. 1-4. - Anodontium grompens Brid. Sp. Muss. I. p. 41. - Ifpnum clavellatum parrum, repeus. setis lorevihus. Dill. Must" p. 531. t. 8.3. r. 17 !

Patria. America septentrionalis, ad corticem arborum in Marylandia, Virginia et Carolinis.

b. Folia perichaet. caulinis dissimilia.

2. Dr. obtusifolia C. Müll.; monoica; longe repens, ramis densius approximatis brevibus viridissimis, inferne sordidis, brevissime fastigiatim ramulosis, apice curviusculis, tenuibus; folia subrecta, madore erecto-patentia, e basi latiuscule orata ad iusertionem laxiuscule reticulata biplicatà angustate lanceolata acuta, strictiuscula, nervo canaliculato - carinato, ante apicem evanido, margine basi distincte involuto apice erecto, rotundate areolata viridissima; perich. latissime orato-ligulata obtusa, intima 
688 STEGOCARPI. ACROCARPI. ORTHOTRICHUM.

basi laxissime reticulata; theca in ped. brevi ovata magna laevis leptodernis sordide fusca, calyptra glabra.

Macromitr. clarellatum Kze. in Pöpp. Pl. Chil. No. 16.

Pulviu. Andes Chilenses: Pöppig 1826.

Flos masc. ad basin feminei crassus, fol. perig. latissime ovatis obtusis $v$. breviter ligulatis obtusatis, inferne laxe reticulatis subseminervibus, antherid. magnis, paraphys. copiosissimis superne brevissime articulatis elongatis flexuosis. Operculum, calyptra matura et theca perfecta desunt. - Species praecedenti maxime similis. Calyptram quidem maturam nondum vidimus, species tamen procul dubio huc certe pertinet. Dentes praecedentis.

\section{Gen. XIII. Orthótrichum Hdw.}

Minsc. Frond. II. p. 96. - Brachytrichum et Orthotrichum Röhr. - Grimmia et Weisia al. - Polytrichum Dill. - Hypmum antiq.

Ab ỏ@Yós rectus et $\vartheta \varrho i ́ \xi$ cupillus, propter pilos calyptrae saepius hirtae rectos nomen conditum.

Cal!ptra companulata plicata. Peristomium mullum, simplex v. duplex; externum e dentilus 32 geminatis (16) vel bigeminatis (8), rarius sedecim integris haud fissis, granulosis caruosulis s. fragilibus, plerumque pallidis, rarius aurantiacis, erectis, dein reflexis, sub ore thecae oriundis compositum. Internum: cilia 8 vel 16, simplicia hyalina v. dentibns (rarius tamen) similia. Vaginula ochracea. Infloresc. monoica v. dioica. Theca exannulata, plus minus pyriformis sulcata rarius glabra, operculo cupulato-conico.

sertio I. Orthophyllaria. Folia erecto-appressa, sicra atque madefacta erecta stricta.

A. Folia margine plus minus ineoluto.

1. D. obtusifolium Schrad. (Crypt. Gew. p. 14.); dioicum; dense pulvinatum humile turgescens compactum lu- 
tescenti-viride breviter et parce dichotomum; folia caulina arcte uppressu, madefacta crecto-patentia brevia, e basi breviter erecta ubique regulariter parenchymatice reticulatâ parum recurva, oblongo-ligulata obtusatu evanidinervia, margine erecto subinvolutaceo, apice dein canescentia, superne grosse elliptico - areolata diaphana grosse papillosa; perich. majora latiora plicata; theca terminalis brevipedunculata immersa, e rollo longo ovalis late 8 -striata, operculo acute cupulato; perist. ext. dentes lanceolati 8 bigeminati rubelli apice saepe pertusi, int. cilia 8 breviora e cellul. serieb. 2 composita carinata rufescentia; calyptra ampla straminea, apice badia, plicata, basi sublacerata, ubique scabra.

Br. Eur. 2-3. p. 13. t. 1. - Bridl. 1. p. 248. - Neisia obtusifolia hoth. Tent. Fl. Germ. III. I. P. 218. - Wrth. gymnostomum Blytt in sched. pr. Christianiam lectum.

Putria. Ad trunc. arborum campestrium per magnam partem Europae, sed raro fertile. - Aprili-Junium.

Pl. masc. multo gracilior, floribus terminalibus, innovando lateralibus sessilibus gemmaceis; fol. perigon. caulinis similia minora convolutacea, intima multo tenerius reticulata fusca obsoletinervia; anth. longe stipitata majuscula, paraphys. filiformibus flaridis. Folia fila brevia articulata saepe efficientia.

2. 0. gymnostomum Bruch (Brid. I. p. 782.); dioicum; praecedenti simillimum, sed laxius pulvinatum, robustius, folia caulina margine toto cumbitu valde involuto, upice igitur cochleuriformi-concava, ubique fere e cellulis rhomboiduliter angulatis temissime pupillosis obscuris areolata, majora, lutius ligulatu; perich. acutiora; theca immersa oblonga gymnostoma substriata; calyptra nuda v. parce pilosa ubique scabriuscula basi sublacera.

Br. Europ. 2-3. p. 8. t. 1.

Patria. Ad Populum tremulam sylvae unicae pr. Bipontum: Brueh. - Martio et initio Aprilis.

Infloresc. praccedentis, quocum notis illustratis nunquam confundi potest, pulcherrima species, alibi forsan praetervisa. 
3. D. inflexum C. Müll.; doicum; O. obtusifolio simillimum; folia caulina oblongo-lanceolata angustate ligulatu acutiuscula, apice plus minus inflexo, margine erecto v. parum involuto, e cellulis yrossissimis angulatis temiter papillosis ubique areolata; perich. caulinis majora latiora basi firma; theca vix emersa cylindrico-oblonga striata, operc. acute cupulato, perist. et calyptra 0. obtusifolii.

O. Rogeri Br. et Sch. in rorreet. Musc. Drumm, Iond, Journ, of bot. 1843. p. 667. - O. obtusifolium Hook. 1)rumm. Musc. Amer. No. 157.

Patrie. E Canada usque ad Rocky-Mountains transiens: Drum mond.

4. D. plicatum P. B. (Prodr. p. 81.); monoicum; tenellum repens, ramis, erectis, sterilibus simplicibus, fertilibus parce et breviter dichotomis, teretibus grocilibus tenuibus acuminatis densifolis; folia caulina laxius imbricata oblonga obtusa, juniora submucronata, sicca complicata paulum tortilia mollia et obesa, superne e luteo viridia, inferne e viridi fuscescentia, nervo crasso ad apicem vix perdurante ferugineo, minute rotundate arcolata; perich. ovato-lanceolata, interna minora teneriora; theca in pedunculo vaginula longu exsertu cincto exserto brevi tenuissimo minuta subyluboso-pyriformis brovicolla, sulcis subsenis exarata, brunnea, ore rufescens, operc. breviter apiculato, calyptra conico-campanulata integra non plicata sursum pilosa thecam omnino obtegente; perist. dentes 8 bigeminati breves lati, sicci reflexi, pallidi, cilia 8 linearia albida simplicia articulata. $\dagger$.

schwägr. Suppl. H1. II. p. 18. t. 52. - Clota plicata Brid. I. p. 303.

Putrice. Insula Franciae, ad arbores: Aub. du PetitThours.

Ex animadr. Schwägricheni flores masculi rari ad apices ramulorum, fol. ex ovato brevius acuminatis vovato-lanceolatis, quandoque denticulatis, paraph. paucis ter articulatis. - Ex habitu $Z$. obtusifolio simile esse videtur. 
Species obscurae.

- Orth. submarginatum Brid. (I. p. 792.); clongafum fastigiate ramosum; folia oblonga obtusa, apice subundulata, insuper margine tenui ex unica cellularum serie composito, nervo continuo. $t$.

Putria. Insula 'Terre Neuve: I a Pyair.

In Hb. Brideliano non vidimus.

\section{B. Folia margine erecto.}

5. D. crassifolium Ilook. et Wils. (Lond. Journ. 1844. p. 546.); monoicum; laxe pulvinatum lumile parce et breviter ramosum sordide viride $v$. fuscescens; folia caulina erecto-appressa, madefacta electo-patentia ou $($ to-lanceoluta obtusiusculu, curmosu, margine erecto, ubique e cellulis subparenchymaticis, superne minutis obscu$r$ is inferne majoribus magis rectangularibus cressis areolata, laevia, nervo crasso fuscescente evanido; perich. majora; theca breviter exserta subgloboso-pyriformis brevicollu, orificio dilatato, obsolete striata, operculo breviter apiculato, perist. simplici: dentes 16 geminati longiuscule lanceolati comosi fluciduli, praesertim marginc eroso - rugulosi, calyptra parva conico - campanulata mudu fusca basi subintegra sulcato - plicata.

ß. acutum; foliis acutioribus, thera subimmersa.

Putriu. Insulae Fremitae, Ancklandi et Falklandi. Var. ß. in Terra Kerguelen: J. D. Hooker.

Species solitaria, ex habitu 0 . psychrophilo Mont. hand dissimilis, flore masc. axillari, fol. perig. late oratis breviter acuminatis, inferne teneris coloratis, superne carnosulis, anth. Iongis angustis, paraph. Iongis filif. mixtis.

6. A. angustifolium Hook. et Wils. (Lond. Journ. 1844. p. 547.); 0. erassifolio simile, nigricans, folia anguste lanceolata evanidinervia, vel subulata, nervo in subulum carnosulam obscuram acutiusculam subcontinuo, e rellulis ubique mollioribus hand incrussutis areolata; theca immersa subsessilis ellipticu, operc. rostellato, perist. simplici: dentes sedecim. 
Putriu. Insula Campbelli antarctica: J. D. II o oker. Fructum non vidimus.

\section{Folia margine revoluto.}

7. D. Hutchinsiae Ilook. et 'I'ayl. (Muse. Brit. p. 73. t. 21.); monoicum; dense pulvinatum sed laxe cohaerens teretiusculum densifolium breviter et parce ramosum sordide viride inferne fuscescens rigidum; folia caulina erecto-appressa, madefacta erecto-patentia stricta oblongo-lanceolata saepe plus minus incurva, subcomplicate carinata, margine convexa vel parum revoluta, ubique incrassate arcolata, perich. conformia; theca longe exserta ovali-oblonga 8 striata fuscidula, operculo acute conico, calyptra conico-campanulata pallide pilosa; perist. dentes 8 bigeminati, pallidi rugulosi, sicei retlexi, cilia 8 subduplicia hyalina subaequantia.

Br. Eur. 2-3. p. 20. t. 10. - Brill. I. p. 278 et 820 . - 0. Americanum P. B. Prodi, p. 80 et schwägr. suppl. II. p. 144. tals. 138. - o. strictum Britl. I. p. 289. - Llota nigricans Brid. I. p. 792, colore nigricante fusco-luteo.

Patria. Ad rupes, rarius ad radices arborum, in montosis per lotam fere Europam et Americam borealem. In comitatu Wicklow Iliberniae prima legit Miss Hutchins. - Julio.

Flores masc. axillares sub femintum positi crasse gemmacei, fol. perig. late ovato-acuminatis scminervibus ubique fere incrassate arcolatis, anth. longis angustis, paraph. longis aureis tenuibus.

8. O. nigritum Br. et Sch. (Br. Eur. 2-3. p. 11. t.4.); monoicum; O. Uutchinsiue simile, sed gracilescens, inferne nigricans superne laete viride, folia margine revoluta, nervo ad apicem usque producto, punctulate areolata, vaginula pilosa, theca longe exserta purve subpyriformis breviculla, pallide fusca, 8 striata, sicca ore constricta, operc. conico pallido, calyptra campanulata stramiuea pilosissima fusca $2 / 3$ obtegente; perist. dentes 16 geminati per paria approximati serius partim divisi punctulato-lutei, sicci patuli, cilia mulla. †. 
Putriu. Ad rupes in loco "Rofflen" dicto pr. Andecr 1н. Splügen Rhaetiae: A. Brall 1825; rarissimum. Aestale.

9. 0. Pylaisaei Brid. (I. 722 et 790.); monoicum; dense pulvinatum compactum erectum elatiusculum parce dichotomum rigidum densifolium sordide viride inferne ferrugineum; folia caulina late ovato-lanceolata obtusiuscule acutata canaliculata, margine ubique fere revoluta, e celInlis superne incrassate rotundatis majusculis firmis obscuris tenuissime papillosis basi magis quadratis diaphanis, parietibus plus minus interuptis, areolata; perich. basi teneriora; theca breviter exserta, subpyriformis parviule, everuata e collo breviusculo angusto urnigera, orificio amplo haud constriclo praedita, ochracea, anguste et obsolete 8 striatu, operculo cupulato longiuscule apicuJato; perist. dentes 8 bigeminati, dein secedentes, late lanceolati rubiginosi robusti, rugulosi, obscuri, cilia 8 fragilissima simplicia dentibus adglutinata lutea; calyptra ucute conico-companulatu brunneo-fusca subpilosu.

o. Brentelii Hmp. in litt. et Nendtuer in Regensb. Bot. Zeit. 1849. p. 273.

Putria. Grönlandia, unde primus habuit Breutel, dein Sendtner, cujus specimina a D. Barth collecta. In insula Terre Neuve primus omnium legit La Pylaie.

Flores masc. axillares plures crassi, fol. perig. late ovato-acuminatis, internis obsoletinervibus tenuiter reticulatis. - O. anomalo habitu simillimum, sed foliis nunquam recurvis primo momento discernibile; notis cursive impressis a praecedentibus primo intuitu distinguitur.

10. D. Barthii Sendtner (in Regensb. Bot. Zeit. 1849. p. 27.); 0. Pyluisuci simillimum, sed folia magis acuminata, densius et angulate hexagono-areolata, magis chlorophyllosa, distinctius papillosa; theca multo robustior major, perist. dentibus selecim discretis basi dense approximatis frugilissimnis temeissime membremereis luerissimis hyalinis irregulariler lancendalis, ciliis 8 linearilanceolatis, dentibus brevioribus, c duplici cellularum serie compositis. 
691 STLGOCARPI. ACROCARPI. ORTHOTRCHEM.

Putrie. Grönlandia, in saxis quarzosis v. graniticis, unde misit D. Barth.

sectio II. Euorthotrichum. Folia sicra imbricata, madcfacta subito reflexo-sguarosa. dein erecto-patula, recurva.

\section{A. Folia chlorophyllosi.}

a. Theca exserta.

11. O. anomalum Hdw. (Sp. Musc. p. 162.); monoicum; orbiculariter pulvinatum parce dichotomum humile crassiusculum sordide viride vel lutescens; folia caulina erecto-appressa, perfecte lanceolata, margine e basi usque ad apicem valde revoluta, obtusiuscula, evanidinervia, profunde carinata, e cellulis minutis rotundatis chlorophyllosis basi rectangularibus densis diaphanis areolata; perich. acutiora longiora, basi tenerrima; theca in ped. breviter exserto oblonga, sedecies striata aureofusca, operc. breviter apiculato, calyptra aurea parce pilosa omnino obtecta, peristomio simplici, dentibus 8 bigeminatis pallidis sublaevibus late lanceolatis breviusculis erectis.

Br. Kur. 2-3. P. 10. t. 3. - O. surrutile Brit. I. p. 275. Brachytrichum sarratile Höhl. Amn. d. Wrtter. (ies. III. P. 194. W'eisia anomala Hoth. F'. Germ. III. I. p. 215. - W. ilhyphylla B. minor E.hrl. Beitr. 1. p. 191. - Grimmin orata sichrank. Batersclie Fl. 11. p. 443. - Orthotr. aureum Mart. Fl. Frlang. Crypt. p. 11. t. 11, - O. humile schleich. Cent. IV. 1. 15.

Putriu. In tectis, muris et rupibus, rarius ad arbores per totam Europam vulgare et ditissime fructificans.

Flos mase. axillaris ad basin feminei; fol. perig. ovala breviter acuminata, ext. nervosa, interna obsoletinervia tenera colorata.

b. Theca immersa v. emergente.

a. Pilifers,

12. O. diaphanum Schrad. (Spic. Fl. Germ. p. 69.); monsicum; laxe et irregulariter pulvinatum humile parre dichotomum viridissimum incanum; folia canlina erectoconferta, oblongo-lanceolata louge acuminata apice subdenticulata semper fere cancscentia igitur veluti pilifera, 
ubique cellulis mollibus ampliusculis basi rectangularibus superne subrotundate hexagonis sublaevibus amoene chlorophyllosis areolata, margine ultra medium revoluta, plus minus complicate concava; perich. basi teneriora; theca immersa cylindrico-oblonga 8 plicata pallescens, operc. breviter conico; perist. dentes ext. 16 geminati robusti pallidi rugulosi, int. cilia 16 hyalina simplicia; calyptra $1 / 3$ brevior straminea apice scabra parce pilosa $\mathbf{v}$. nuda.

B1. Fur. 2-3. p. 26. t. 14. - Brid. 1. p. 293. - O. heterophollum P. B. Prodi. p. 80. - o. pilosum e.i. p. 81. - o. ulmicola Lagasca, Anu. d. C'iens. Nat. 11. 14. p. 186. - O. aristutum Turn. Muse. Hih. p. 100, t. 9. f. 2. - Weisia diaphana Hoth. Fl. Germ. III. I. p. 223.

Putric. Ad arbores campestres, rarius ad saxa, per totam Europam. - Martio, Amili.

Flos masc. in ramulo proprio subbasilari terminalis; folia perig. ext. ovato-acuminata breviter pilifera evanidinervia, int. late ovata convolutacea colorata obsoletinervia tenerrima; anth. turgida parvula, paraph. brevibus filiformibus.

13. 1. glaucum Spreng. (Syst. Veget. IV. II. p. 323.); monoicum; 0 . dictphano simillimum; sed folia caulina densius areolata haud granuloso-chlorophyllosa sed utriculo primordiali instructa, juniora haud diaphana, sed flavide pilifera, angustiora, distinctius tenuiter papillosa; theca subemersa, calyptra straminea pilosa omnino obtecta, perist. ext. dentes 16 lanceolati linea longiludinali obsoleta exarati breves pallidi rugulosi, ciliis $\mathbf{1 6}$ simplicibus alternantes.

Palria. Prom. b. spei, ubi ad montem tabularem legit Lcklon; ad trunc. Mimosarme pr. Fort Beaufort ad flum. Katrivier terae Cafirorum Julio 1829. Mundt.

Infloresc. 0. diuphuni, fol. perig. cxt. flavide piliferis.

B. Nipilifera.

+ Angusle lanceolata.

14. 0. Ieucomitrium Bruch (Br. Eur. 2-3. p. 26. 1. 15.); monoicum; subpulvinatum lumile parce ramosun; 
folia patula, siccitate laxe imbricata leviter contorta, lanceoluta acutiuscula carinata, margine revoluta; ureolatione 0. diaphani; perich. magis erecta basi plicata; theca emergens ovato-elliptica s. elongato-pyriformis, longicolla, pallide fuscescens luteola, striis 8 angustis subconcoloribus, sicca sub orificio vix angustata, operculo altius convexo, calyptra $2 / 3$ obtegente campanulata albide luteola apicem versus breviter pilosa leviter plicata; perist. dentes sedecim geminali per paria approximati sicci reflexi lineari-lanceolati ferruginei, cilia totidem filiformia hyalina longa conniventia. $f$.

Patria. Ad arbores campestres, praesertim populos, pr. Carlsruhe, Baden, Dahn in Vogeso, Argentoratum, Bipontum ubi Bruch detexit, Münster Alsatiae, Monachium, Salisburgum et in Bosnia. - Majo, Junio.

Flores masc. in ramulis brevibus terminales, interdum ad basin feminei laterales, fol. perig. orato-acuminatis, interioribus enervibus. - Habitus 0 . tenello et areolatio folii $\boldsymbol{O}$. diaphano similes dicuntur. Ab ulteriori, cujus folia saepe apice hyalino echlorophylloso carent, haud recedere videtur.

15. 0. pumilum Sw. (Musc. Suec. p. 42 et 92. t. 4.); monoicum; pulvini parvuli tenelli densi virides; caulis tencllus parce breviter dichotomus; folia caulina erecta. madefacta recurvo - patula, lanceolata obtusiuscula vel breviter acutata, margine e basi usque fere ad apicem revoluta, carinate concara, mollia, ubique e cellulis hexagonis valde chlorophyllosis sublaevibus basi longioribus et subquadratis areolata: perich. majora; theca immersa turgide oralis brevicolla igitur subylobosa, ore constricta, perfecte late et fusce 8 sulcata, calyptra late campanulata $2 / 3$ obtegente fusce striata nuda lutea, operculo brevi, perist. dentibus 8 bigeminatis late lanceolatis pullide anruntiacis rugulosis, cilis 8 hyalinis brevioribus subsimplicibus.

Br. Europ. 2-3. p. 14. t. 5. - Brid. 1. p. 283. - sillägr. Supp. I. 1.22. t. 50 - O. affine, Rumilum H. rt T. Muse, Brit. p. 74. 
Putria. Ad truncos arborum campestrium per totam fere Europam passim. - Martio, Aprili, Majo.

Flores masc. axillares $v$. in ramulis terminales minuti, fol. perig. ovatis tenerrimis evanidinervibus, anth. et paraph. paucis. - 0 . diaphano saepe associato haud dissimile, sed foliis haud piliferis et peristomio primo momento discernibile, ab 0 . fallaci notis cursive impressis distat.

16. D. fallax Bruch. (in Brid. I. p. 787.); monoicum; 0. pumilo simillimum, sed folia acutiora, magis erecta, theca longiculla cylindraceo-oblonga, siccitate emersa, anyuste 8 striata, pallida dein fuscescens, ubique concolor, perist. dentibus pullidis subrugulosis 8 bigeminatis, ciliis hyalinis brevioribus subsimplicibus, calyptra conicocampanulata pallidior, ubique conculor.

Br. Enrop. 2 - 3. p. 15. t. 5.

Putria. Ad trunc arbor. campestrium per totam fere Europam, hic illic rulgatissimum, verosimiliter saepe praetervisum. - Aprili, Mujo.

17. 0. stramineum IIsch. (in Brid. I. p. 789.); monoicum; pulvinuli phninsculi laxi; caulis subhumilis gracilis flavide virdis fastigiate breviter ramosus; folia caulina laxe conferta, madefacta erecto-patula recurva, e basi erecta decurrente longiusculà anguste lanceolatoacuminata, margine usque fere ad apicem valde revoluta, carinata, cellulae basilares angustae rectangulares longiusculae teneriores laeves, superiores minute rotundatae sublaeves; perich. basi teneriora; theca emersu longicolla myriformis tenella parula e lutescente fuscu profunde 8 sulcata, sporangio et collo subinflatis, evacuata longe rylindrico-ampullacea, operc. breviter apiculato, calyptra $2 / 3$ obtegente amoene plicata basi breviter laciniata straminea apice fusca, perist. dentibus 8 bigeminatis late lanceolatis luteolis subrugulosis, cilies 8 aerualibus $थ .8$ longis of 8 brevibus tenuibus byalinis.

Br. Fur. 2-3. p. 24. 1. 13. - 0. umbonatum Brid. 1. p. 788. 
Patria. Ad truncos arborum, per magram partem Germaniae, Helvetiae, Vogesi, Sueciae (Gothiae) et Norvegiae. - Junio, Julio.

Pulchella et distinctissima species, thecac forma, cespitibus laxis planis et foliis laxe imbricatis primo adspectu discernibilis.

18. ๑. alpestre Hsch. (in schedulis); monoicum; 0. stramineo simillimum, sed robustius, densius pulvinatum, folia breviora, basi haud decurrente latiore, minus recurva, amplius et tenerius arcolata, distinctius papillosa, minus chlorophyllosa, theca vix emerse oralis brevicolla sordide olivacea, calyptra omnino obtegente parce pilosa, perist. dentibus similibus, apice magis divisis pallidioribus striatulis, ciliis 8 aequalibus constuntibus simplicibus subulatis hyalinis.

o. stramineum Br. Europ. 2-3. p. 24.

Patria. Ad truncos arborum alpium Irelvetiae, ubi Il or ns li uch detexit. Albula Rhactiac: W. P. Sch.Julio, Augusto.

19. 0. fastigiatum Bruch (in Brid. I. p. 785.); monoicurm; 0. "ffini habitu simillimum, sed foliorum cellulae superiores valde chlorophyllosae laciores majores at magis rotundate hexagonae, basilares angustae elongutac hexugonae tenerrimae pellucidae, mediue rectangulares subdiaphanae, omnes molles; perist. dentes 8 bigeminati pallidi rugulosi, cilia 8 filiformia hyalina breviora simplicia.

Br. Europ. 2-3. p. 18. t. 8. - o. affine sichw. suppl. I. II. p. 19. t. 49 .

Patrill. Ad arbores campestres, pracripue populos, rarius ad saxa, nunguam in sylvaticis, per Europam forsan totam, O. "ffini saepe associatum. - Aprili et initio Maji.

Br. Europ. speciem ab 0 . alfini distinguit notis sequentibus partim valde relativis: pulvinulis densioribus. foliis brevioribus latioribus sensim acuminatis, areolationc laxiore, theca crassiore ovato-pyriformi late striata lon- 
gicolla, calyptra pallida v. straminca apice fuscidula, operculo majori, ciliis perist. interni brevioribus atque latioribus, tempore denique fructus maturitatis. Flores mase. o. uffinis.

it Late lanceolata.

20. D. rivalare 'Turn. (Nusc. Nib. p. 96. t. 8.); monoicum; laxe pulvinatum flaccidum prostratum pluries dichotomum intense viride; folia caulina laxe conferta, madefacta erecto-patentia vix recurva, latissime oruto-lanceolutu obtusa, apice interdum dentata, margine e basi usque ad apicem fere revoluta, ubigue e cellulis minute hexagonis ralde chlorophyllosis firmis areolata, evanidinervia, basi biplicata valde concava superne profunde canaliculata, sublaevia; perich. majora; theca subemersa majuscule pyriformis fusca 8 plicata, operc. convexo apiculato; calyptra nuda sordida ampla brevis, basi late laciniata, plicis apice flexuose serratis; perist. ext. d. late lanceolati 8 big. pallidi, cilia 16 rarins 8 hyalina.

Br. Europ. 2-3. p. 25. t. 14. - Brid. I. p. 292.

Pretria. In locis montosis aquosis, saxa rivulorum amans, hic illic per Germaniam, Galliam occidentalem, Pyrenaeos, Angliam et Hiberniam, rarius ad trunc. arborum humidos. - Majo ad Julium.

Flos mase. crassiusculus, fol. perig. latissime or atis aculis concavis molliter areolatis.

21. o. Sprucei Mont. (Lond. Journ. of bot. 13t5. p. 186.); O. rimlari simillinum, sed humilius parce ramosum; folia late ligulate lanceolata rotundata breviter upiculutu, ubique e cellulis amplis hexagonis mollibus, busi luxis majoribus, ommibus utriculo primordiali valde instructis areolata, sublaevia; theca immersa subglobosopyriformis crassa anguste 8 striata; perist. cilia 8 hyalina.

Patria. Anglia ad loca plura, truncos arborum humidos in societate Burb. Iutifoliue et loca littorea habitans. W. Arnolt 1821. pr. Glasgow detexil. - Jumurio.

Flos masc. O. rimeluris. Areolatio Zyyodontis conoidei. 
22. 0. cupulatum Hoffm. (Deutschl. Fl. II. p. 26.); monoicum; laxissime pulvinatum pluries dichotomum erectum intense viride; folia caulina erecto-appressa, madefacta erecto-patentia, perfecte late lanceolata, apice obtusiusculo v. acutiusculo saepe canescenti echlorophylloso, margine usque fere ad apicem revoluto, sublaevia, nervo crasso evanido, aequaliter concava, basi e cellulis rhomboideo-rectangularibus angustis, apicem versus sensim minutis subrotundate hexugonis, omnibus densis sed mollibus et chlorophyllosis areolata; perich. majora, basi teneriora; theca subimmersa subgloboso-oblonga, sedecies striata evacuata urceolata macrostoma rufo-badia, operc. minuto apiculato; perist. simplicis dentes 16 gemimati late lanceolati corneo-lutescentes, dein rufi laevissimi inanes; calyptra ampla brevis late laciniata, nuta v. pilis nodoso-scabris parce obtecta tenera pallida.

Br. Fur. 2-3. p. 8. t. 2. - Brid. I. p. 272. - o. urceolutum sichleich. Cat. Pl. Helv. p. 42. - O. confertum Bruch in Brid. I. 1). 7×3. - Brachytrichum cupulatum Hölı. Ann. d. Wett. Ges. III. 1. 195. - Weisia cupulata hoth. FI. Germ. III. I. 1. 217. - O. Rudolphianum Lehm. in Hegensh. hot. Weit. 1827. p. 6.56.: forma calyptra pilosa. - O. Flörlei et reftexum Hsch. - o. commulutum Bruch in Brid. 1. p. 784. - $\rightarrow$ O. nudum sim. Fl. Brit. III. p. 1268, thera exserta, calyptra nuda. - 0 . cupulatum $\gamma$ - riparium Hiib. Musc. Germ。 p. 381.

Patria. Ad rupes et muros humidos per Europam totam montanam et Americam septentrionalem. - Mijo, Junio, in alpibus Julio et Augusto.

Flores masc. laterales, in ramulis brevissimis crassiusculi, fol. perig. late ovatis ligulate obtusis brevibus tenuiter reticulatis coloratis, nervo evanido r. obsoleto; anth. longa late et longiuscule stipitata, paraph. anreis filiformibus.

\section{B. Folia echlorophyllosa.}

1. Tenella humilia dense pul vinata.

a. Calyptra glabra.

23. 0. Mogeri Brid. (Mant. Musc. p. 110.); monoicum; dense pulvinatum humile parce dichotomum viri- 
descens; folia caulina dense conferta appressa, e basi maxime rentricoso-concuva tenuiter reticulatâ ungustate liyuluta acutiuscula profunde canaliculata, margine inferne convexe revoluta, superne plana e cellulis amplis pottivideis rotundatis diaphanis pachydermibus sed mollibus areolata, laevia, apice parum inflexa; perich. longiora magis lanceolata, basi teneriora haud ventricosa; omnia nervo ante apicem evanido; theca immersa pyriformi-oblonga late 8-striata, operc. convexiusculo breviter acuminato; perist. ext. dentes 8 bigeminati pallidi, siccitate reflexi, int. cilia 8 filiformia luteola simplicia dentibus breviora; calyptra glabra.

Brid. I. p. 286. - Br. Eur. 2-3. p. 16. t. 6.

Putrill. In monte Jura Helvetiae in fagorum cortice: Roger.

Flores masc. in ramo proprio saepe elongato termimales 2 -3 aggregati; folia perig. late ovata concava involutacea breviter acuminata, basi fusca tenerrime retirulata, intima obsoletinervia. - $O$. pullenti proximum, sed foliis basi ventricosis laxius areolatis longe distat.

24. D. pallens Bruch (in Brid. I. p. 788.); monoicum; dense pulvinatum humile parce dichotomum viridescens; folia caulina dense conferta appressa, tenera, e basi upqualiter concura cellulis rectangularibus flaridis firmis veticuluta recurvo-patula lanceolata obtusiuscula, murgine ultra medium usque culde revoluta, profunde carinata, firme angulate rolunduto-areolatu tenuissime papillosa; perich. longiora basi laxius tenerius reticulata; theca immersa elliptice oblongu, exacuta sicca ampullaceo-courctuta interdum infundibuliformi-urceolata, 8 plirata pallide olivacea, operc. breviter acuminato; perist. ext. đ. 8 bigeminati pallidi, cilia 8 vel 16 simplicia hyalina; calyptra nuda parum scubriusculu.

Br. Eur, 2-3. p. 24. t. 13.

ß. immersum; calyptra subpilosa. o. immersum Brid. I. 1. 786. e sper. auth. a Ia Pylaie in insula Terue Neuve lectis, haud reredere videtur. 
Patria. Ad truncos et ramulos fruticum, praesertim Crataegi oxyucunthae, Pruni spinosue, Rhammi cutharticae et Ribis Grossuluviue hic illic per Germaniam. Bruch detexit. In Halicia, truncos Acerum habitans pr. pagum

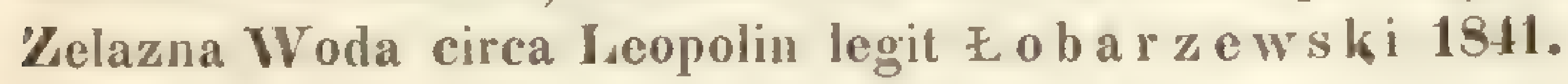

Flos masc. in ramulo brevi terminalis minutus, fol. perig. late ovatis convolutis breviter acuminatis basi fuscis teneris. - Notis illustratis ab O. Rogeri diversum.

25. D. Iraunii Br. et Sch. (Br. Europ. 2-3. p. 16. t. \%.); monoicum; 0. patenti simile, sed humilius confertius pulvinatum, theca pyriformis immersa, pachyderma luteo-fuscu, siccu et cercuatu urceolatu, inferne rentricosa striis 8 latis luteis inferne obsoletis, calyptra 1/2 obtegente mulu laevius plicata, peristomii cilia breviora obscuriora inferne duplicia.

Patria. Ad arbores, praesertim juniores, frutices (al Fagos jun. et Crataegum oxyac.) et saxa pr. Carlsruhe et Baden, ubi A. Bra un detexit; in ditione Salisburgensi, pr. Aschaffenburg et Bipontum. - Majo.

Folia perig. late ovato-acuminata, apice obtusiuscula obsoletinervia, superne rotundate areolata.

\section{b. Calyptra pilosa.}

26. D. strangnatum P. B. (Prodi. p. 81.); monoicum; dense pulvinulum tenellum pusillum mulchellum parce dichotonum sordide viride; folia caulina erecto-appressa, madefacta recurvo-patula, late ovato - lanceolata breviuscula vigidiuscula, complicate carinata, margine usque fere ad apicen revoluta, e cellulis rotundatis firmis tenuissime papillosis subobscuris basi infima rectangularibus arcolata, evanidinervia, acutiuscula; perich. conformia; theca immersa hemisphaevicu ampla tenella minutu una cum calyptra late campumulatu parce pilosu tenera ${ }^{2 / 3}$ obfegente amoene struminer anyustissime octies sulcutu, operc. breviter apiculato; perist. simplicis dentes brevissimi irregulariter lancesolati obsolete divisi igitur sellecim subintegri pallidi rugulosi. 
S'chw. Nuppl. I. II. p. 33. t. 54. - Brid. 1. p. 273. - 0. affine $"$. prumilum Hook. in Jrumm. Musc. Amer. No. 150. - O. slellatum Brid. I. p. 274.

Putria. America sept., in arboribus. Mühlenberg primus legit.

Flos mase. O. striuti. Species pulcherrima!

27. o. patens Bruch (in Brid. I. p. 787.); monoicum; O. strunguluto affine, foliis similibus, sed robustius altius magis fasciculate ramosum lutescens; theca subpyriformis subemersa, e collo angustissimo breriusculo oualis, evecuata ampla suburnigera tenella leptodermis amoene struminea anguste octies sulcuta, operculo brevi, calyptra late campanulata $\% / 3$ fere obtegente parce pilosa superne brunnescens tenella, perist. dentes 8 bigeminati pallide lutenli rugulosi angustiusculi, cilia 8 hyalina breviora.

Br. Eur. 2-3. p. 17. t. 7.

Patria. Ad frutices, arbores campestres et sylvestres, rarius ad saxa per totam fere kuropam; ad fagos juniores pr. Bipontum detexit Bruch.

Flores mase. pseudolaterales, fol. teneris coloratis Iaxe reticulatis obsoletinervibus ovato-acuminatis, antherit. longiusculis, paraph. filiformibus. - species pulcherrima.

28. D. Canadense Br. et Sch. (Lond. Journ. of bot. 1843. p. 667.); monoicum; O. putenti simillimum; sed folia molliora, theca longius emersa, dentibus sedecim integris linea longitudinuli obsoleta rix exuratis brevibus obtusis albidis striatulis dein luteolis, ciliis totidem brevissimis pracdita, calyptra straminea parce pilosa omnino fere obtecta.

0. affine Hook. in Drumm. Musc. Anter. No. 151.; forma major theca minus emersa sub No. 149.

Putria. Canada superior, ad Rocky Mountains et ad lacum superiorem, truncos arborum habitans: Drummond.

Theca 0. patentis, peristomium externum 0 . stranguluto affine, sed interno 16 -ciliato certe distincta species. 
29. 0. assimile C. Müll.; monoicum; habilus inter 0. strumineum et alpestre; pusillum parce dichotomum, folia 0 . alpestris, sed echlorophyllosa, theca ejusdem, ovalis brevicolla, sed minutu, breviter sed longius quam in O. strumineo exserta, calyptra pilosa et peristomium 0 . alpestris, sed dentes ubique rugulosi luteoli.

\section{Patria. Chile: Pöp pig.}

Flos masc. O. straminei.

30. 0. tenellum Bruch (in Brid. I. p. 786.); monoicum; humile; folia acuta firme areolata 0 . "lfimi similia, theca subemersu longe cylindracer ungustu, octies late striata, evacuata superue aequalis, calypira longe cylindraceo-campunuluta $\$ / 4$ obtegente stramineo-fuscidula, acuta, subpilosa.

Br. Europ. 2-3. p. 15, t. 6.

I'utria. Ad arbores campestres, praeprimis populos, hic illic per Germaniam, ubi pr. Bipontum detexit B r urh, Galliam, Italiam superiorem et Sardiniam, ubi ad Cactum Opuntiam legit Fr. M üller.

Flos masc. 0 . affinis.

31. D. psychrophilum Mont. (in D'Orbigny Toy. dans l'Im. ner. VII. Crypt. p. 89.); monoicum; raulis erectus densifolius pusillus innoutionibus iteratis fertilibus brevissimis densifolits parce ramosus, lutescenti-fuscescens, rigidus; fola caulina erecta, madefacta distantıa, recurviuscula, robustu, longiuscula, e basi ovatooblonga lanceolata acuminata, margine ultra medium usque revoluta, evanidinervia, complicate carinata subtortuoso-flexuosa, grosse angulate rotundate basi ubique incrassate rectangulari-areolata, grosse mpillosa; perich. majora basi tenerius reticulata; theca immersa oblonga longicollis, obscure sulcata, operculo convexo mucronato, perist. duplici: dentes 8 bigeminati pallidi rugulosi, cilia 8 uodosa, calyptra conica fusca rigidu pilosiuscula.

Pulviu. In jugis Andium prov. Potosi, ad rupes pr. glacies aeternas, 2500 hexap. alt., ubi legit D'Orbigny. 
Flores mase. axillares anguste et longiuscule gemmarei fol. perig. oblongo-lanceolata acuta, basi breviore tenera, enervia; anth. parvula. - Ab O. affini haud dissimili notis superioribus facile distinguitur. Statura Grimmicue muritimue formas minores haud male refert.

2. Robusta elata laxe pulvinata.

a. perist, intern. 8-ciliatum.

32. O. affine Schrad. (Spic. FI. Germ. p. 67.); mouoicum; pulvinatum plus minus elatum erectum v. decumbens fastigiate ramosum viride; folia plus minus conferta, madefacta recurvo-patula, oblongo-lanceolata, superiora apicem versus obtusiuscule acutata, profunde carinata subcomplicata, basi planiuscule concava, margine ubique valde revoluta, cellulae ungulate rotundatue incrassatue firmae papillis scabrue obscurue, basilares teneriores angustue longinsculae lueviores, purietibus subintermutis instructue; theca matura subimmersa, e collo brevi oblongo-elliptica olivacea, evacuata subpyriformis, plicis 8 luteis, operculo breviter apiculato, calyptra ochracea subpilosa, perist. dentes 8 bigeminati, sed paulisper separati, pallidi rugulosi, sicci reflexi, cilia 8 hyalina simplicia aequalia.

Br. Kurop. 2-3. p. 17. t. 7. - Brid. I. p. 281 et $785 .-0$. netoblepharis Brid. Muse. Rer. 1I. II. F. 24. - O. umbonatum Brid. I. P. 787! - Weisin affinis et octoblepharis Roth. N1. Germ. II. I. p. $217 \mathrm{ct} 218$. - Bryum affine (imel. Nyst. Nat. 11. p. 133j? Ir. seminacuume Vill. PI. Dauph. III. [. 86\%? - Splachnum semipacuum P. 13. Prodr. P. 89. - Polytrichum rapsulis sessilibus, foliis brevihus rectis carinatis. Dill. Musc. p. 432. t. 5. . . 10?

Patria. Per totam Europam rulgatissimum, in America boreali et Africa septentrionali (Br. Enrop.), arbores campestres et sylvestres, rarius saxa habitans. - Junio, Julio.

Flores masc. numerosi axillares, fol. perig. ovatis acuminatis obtusiusculis. - Ab 0 . fustigiuto, habitu simillimo, notis cursive impressis certe differ?.

33. D. speciosum Nees ab Es. (in Sturm Deutschl. Fl. Cr. Fasc. 16.); monoicum; laxe pulvinatum elufum 
fastigiute rumosum sublecumbens intense viride: folia canlina longinscula erecto - appressa, madefacta subrecurvopatula, late orato-lanceolata acuminata, pluries plicata, complicate carinata, usque fere ad apicem margine revoluta, evanidinervia, e cellulis grosse rotundatis obscuris tenuiter papillosis basi teneris angustis longiusculis, parietibus parum interruptis praeditis, diaphanis areolata; perich. majora basi teneriora; theca distincte emersa subcylindrico-oblongu obsolete striatu pallescens, operc. breviter apiculato, calyptra ungusle campunulutu pilosissima; perist. ext. d. 8 bigeminati late lanceolati ubique lugulosi pallidi, cilia 8 aequantia e cellularum pellucidarum seriebus duabus composita flaccida.

Br. Europ. 2-3. p. 19. t. 9. - Brid. I. p. 280. - O. elegans sichw. Richards, in Franklin's Append. p. 756. et Hook. in Hounm. Muse. Am. Wo, 155. - O. Bruchie Hüh. pedumculn subcurvato.

Putrie. Ad trunc. campestres atque sylraticos, rarius ad saxa totius fere Europae et Americac septentrionalis. - Junio, Julio.

Hlores masc. sub femineum complures axillares; cactera 0 . striati.

34. C. Ieptocarpon Br. et Sch. (Musc. Abrss. No. 429. b.); dense mulinutum evectum parer dichotomum lutescens; folia (). speciosi, sed mimule rofumlute arcolata; theca immorsu oblongo-ovalis angusta distincte orlies anguste striata pallescens, calyptra ninus pilosa; perist. dentes inferne rugulosi, superne laeviores magis diaphani, cilia subsimplicia hyalina Rexuosa firagilia.

Patria. Abyssinia: W. Schimper legit in monte Silke, ad truncos Ericue acrophyue Fres., in reg. sup. ericarum, 16. Febr. 1840.

Flores masc. (). speciosi, a quo notis laudatis facile distinguitur.

35. D. elongatum Tayl. (Lond. Journ. of hot. 1816. p. 45.); monoicum; late pulvinatum biunciale elongatum adscendens, apice caulis proliferum, apice incrassato; folia imbricata recurvato - patentia lanceolata acuminata, 
margine reflexa, substriata, theca breviter pedunculata elongate ovalis laevis, calyptra pilosa; perist. ext. d. 8 bigeminati siccitate reflexi, int. cilia octo duplicia, per paria dentibus geminatis opposita. †.

Putrie. Ad truncos arbolum prope Quito: Prof. Wr. Jameso in 1815.

Ab O. stricto affini habitu robustiore, ralyptra magis pilosa, pedunculis longioribus of rilis hand fimbriato-erosis differre legitur.

36. D. Tasmanicum Ilook. et Wils. (Lond. Journ. of bot. 1843. p. 27.); monvicum; laxe pulvinatum fuscobrunneum elatiusculum; folia caluna suberecta, madefacta patula subrecurva lanceolato-subulata, margine reflexa, flavide viridia; pedunculus thecam superans longiusculus; theca elliptico-oblonga, sicca striata cylindrica, operculo conico apiculato rubente dimidio breviori, calyptra pilosiuscula pallida nitida, vaginula pilosa, ciliis 8 latissimis rorinatis integris connirentibus. $\leftarrow$.

Putril. Ad ramos juniores Hymenumtherere angustifolice 'Tasmaniac, ad N. Hisk, Launcestor: H. Gunn, Sept. 1841.

E cilis latis 0 . elonguto 'Tayl. affune, sed folis et calyptra distans dicitur.

37. D. rupestre Schleich. (Crypt. Helr. Exs. Cent. III. n. 24.); monoicum; laxe et late pulvinatum elongatum pluries dichotomum subdecumbens viridescens; folia caulina erecto-appressa, madefacta recurvo-patula, late lanceolata, robusta, profunde complicate carinata, margine usque fere ad apicem revoluta, evanidinervia, e cellulis minute rotundatis tenuissime papillosis obscuris, inferne magis rectangularibus, densis, infima basi fuscis areolata; perich. latiora conformia; theca immersa crassiuscule pyriformis 8 striata, operc. brevi apiculato; calyptra ommino fere obtegente pilosa fusea; perist. dentes y bigeminati pallidi rugulosi late lanceolati patentes, cilia octo diaphana duplicia. 
Brid. 1. p. 279. - Br. Europ. 2-3. p. 19. 1.9. - 0. rupincola Fli, in Brid. 1. 1. 284., forma humilion, - o. Sehlmeyeri Hsith. in Brid. 1. p. 784., forma elongata.

Putric. In rupibus regionum montanarum et alpestrium per totam fere Europam. - Mujo, Junio, in ulpibus Julio et Angusto.

Flores mase. illis 0 . urnigeri similes, a quo notis cursive impressis facile differt.

38. O. Sturmii HIsch. et IIpp. (Regensb. Bot. Zcit. 1819. p. 89.); monoicum; O. rupestri simillimum, sed theca immersa obovata brevior obsolete striuta, calyptra pilosa brevior, peristomio simplici, dentibus sedecim gominatis angustis divisis plus minus secedentibus heteolis superne obsolete trabeculatis.

Br. Europ. 2-3. p. 9. t. 2. - Brid. I. p. $27 \%$.

Patria. In rupibus reg. montosarum et alpestrium totius fere Europae.

\section{b. Perist. intern. 16-cilintum.}

39. O. striatum IIdw. (Musc. Fr. II. p. 99. 1. 36.); monoicum; laxe lateque pulvinatum elatum valde ramosum viridescens; folia caulina falcato-patula, sicca erectoappressa, lanceolato-acuminata, carinata, margine usque fere ad apicem valde revoluta, recurva, basi anguste longiuscule dense reticulata brevi, superne e cellulis irregulariter rotundatis obscuris tenuiter papillosis firmis areolata, evanidinervia; perich. conformia submajora; theca immersa ovalis ampla estriatu laevissima pallide fusca, operc. longiuscule rostellato; calyptra thecan $1 / 2$ obtegens straminea nudiuscula $v$. parce pilosa; perist. ext. d. 16 geminati longe lanceolati arcte approximati carnosuli rugulosi pallidi sicci reflexi, cilia totidem breviora maxime irreguluriter eroso-articuluta rugulosu.

Brill. I. p. 290. - O. Ieiosarpum Br, Fur. 2-3. p. 28. t. 15. Grimmia striata Hdw. Fund. Husc. II. p. $\nless 9$. - Groblonya Schrank. Naicrsche FI. II. P. 4.43. - Weisin striate Roth. Fl. Germ. III. I. p. 120. - W. polytrichoidles Wigw. Prim. Fl, Hols. n. s21. - Wr ithyphylla major Filnth. Beitr. I. p. 191, - Bryum 
striatum L. Np. Pl. p. 1579. - Polytrichum, Bryi rupalis facie, rapsulis sessilibus majus. Dill. Muse. 1). 130. t. 5.5. f. \&.

J'utria. Ad arbores sylraticas et campestres, rarius ad rupes per totan Huropan et Americam septentrionalem. In prom. b. sp. quoque indicatur. - Aprili, Mujo.

Hos masc, in vicinia feminei gemmiformis, fol. perig. late oratis breviter acuminatis teneris coloratis encrvibus, antherid. et paraph. majusculis.

10. 0. pyenophyllum Schimp. (in litt.) ; habitus, inflorescentia et theca 0 . speciosi; folia patula, sicca incumbentia lanceolata anguste acuminata canaliculata, margine reflexa apice subtorta, nervo subexcurrente, theca emersa oblonga leptodernis obsolete striata, calyptra parce pilosa, perist. interno 16 ciliato. $t$.

Patria. Mexico, ad Chimantla et Pico de Orizaba: L i c b m a $\mathrm{n}$.

Inter 0. speciosum et Lyellii ambigumm, primo habilu et theca, sccundo foliis margine crenulatis et dorso papillosis, calyptra parce pilosa et perist. interui cilis solitis margine erosis affine.

11. 0. recurvans schimp. (iu litt.); pracechenti simillimum, sed differt: foliis mollioribus flexuoso-recurvis, peristomii interni cilis pallidis et solo uno latere erosis, altero integris. $t$.

Patria. Mexico, ad m. Orizaba all. $8-10000$ ped., una cum praccedente: Lieb a a nn.

42. a. Hyelli Ilook. et Tayl. (Musc. Brit. p. 76. t. 22.); divicum; laxe et late pulvinatum flexuoso-ascenlens clatum fastigiate ramosum lutescens flaccidum; folia caulina longa, erecta, inferne appressa, superne apicilus flexuoso-patulis, madefacta valde recurva, c basi erecta subcomplicate oblonga inferne clongate anguste fusco ubique incrassate reticulata margine revoluta et papillis geminatis divergentibus veluti ciliata recurve lanceolatoactuminata profumb canaliculata minute rotundate et incrassate areolata acula apice suberoso-crenulata, margine crecto, ciliato-papillosa; perich. majora basi tenc- 


\section{STEGOCARPI. ACROCARPL. ORTHOTICILA.}

riora laevia; theca brevipedunculata immersa subpyriformis laeviter 8 striata, pallida, calyptra acuminato-campanulata pilosa, perist. dentes 16 geminati angusti longi valde rugulosi pallidi, cilia sedecim aequalia carnosa fuscescentia lineari-lanceolata trabeculata ad marginem albide limbata.

Putria. Ad truncos arborum praesertim sylvestrium humidarum, rarius ad saxa, sed raro fertile, per totam fere Europam, hic illic vulgare. - Julio, Alugusto.

Pl. mascula gracilior, floribus in ramulis propriis terminalibus, fol. perig. ext. ovato-lanceolatis, int. acuminatis, enervibus; anth. et paraph. copiosis. - Ab omnibus congeneribus planta fertilis peristomii fabrica, pl. sterilis 0 . specioso et striato similis folis, cellulis anomalis tubulosis plus minus ramulosis luxuriantibus fuscis arliculatis, fila confervoidea (Con/erwam Orhotrichi Ilook. et 'Tayl. vulgo dictam) sistentibus, obtectis primo intuitu distinguitur.

43. D. urnigerum Myrin (in Corallar. Fl. [qs.p.71.); monoicum; laxe pulvinatum elatum pluries dichotomum intense viride; folia caulina erecto-appressa, madefacta recurvo-patula, late ovato-lanceolata acuta robusta majuscula complicate profunde carinata, margine usque fere ad apicem valde revoluta, evandinerva, e celluls mimute rotundutis tenuissime papillosis obscuris supra basin infimum longe decurrentem laxius reficulutam fiscum magis rectangularibus densis, firmis areolata; perich. majora; theca subemersa magna subgloboso-obovata 8 striata ampla, operc. brevi apiculato; calyptra obutuse campanulata $\% / 3$ obtegente pilosa; perist. dentes late lanceolati 16 longi geminati lutescentes laeves patentes, cilia sedecim filiformia subsimplicia.

Br. Europ. 2-3. p. 29. t. 17.

Patria. In rupibus sublumidis Sueciae pr. Ciottsunda: Myrin, pr. Holniam et Upsaliam: Jindgren; in valle fluminis Bode Hercyniat: II a mpe; in saxis vallis Ferrara dictae pr. Antleer: W. P. Sch.; in Prenacis: spruce. - Junio. 
Flores masc. sub femineum plures axillares crassi gemmacei fusci; fol. perig. Iatissime ovata breviter acuminata, interna encria, tenera, colorata, antherid. clavatis majusculis, paraph. filif: aequalibus flavidis. - $\boldsymbol{O}$. cupuluto haud dissimile, sed e foliorum areolatione primo adspectu sub microscopio distinguitur.

Sectio 11. Clota Brid. I. p. 298. - Folia sicca crispata, madefitrit primum subito reflexo-squarosa, dein erecto-patula, recurvá.

\section{a. Calyptra nuda.}

44. D. pulchellum Hook. et 'Tayl. (Musc. Brit. p. 75. 1. 21.); monuicum; pulvinos tenellos humiles parulos sistens, lutescens fastigiate ramosum; folia caulina perum crispula, madefacta recurvo-patula, anguste lanceolatoacuminata acuta falcata, complicate carinata, margine usque fere ad apicem anguste revoluta, c cellulis rotundis parum obscuris distincte papillosis inferne rectangularibus infima basi subdecurrente ubique laxioribus fuscis areolata, tenera, evandinervia; perich. conformia basi teneriora; theca exserta brevipedunculata pyriformis 8 striata pallescens mimute mulchella, operculo breviter apiculato basi aurantiaco, calyptra ${ }^{2}, 3$ obtegente pulchre reguluriter plicula mula; perist. dentes 16 geminati anguste lancoolati remote articulali rugulosi anruntiuci, cilia sedecim tenuissime filiformia fusce cerpuntia.

Brid. 1. p. 294 et 724. - Br. Kurop. 2-3. 1. 29. t. 18. - o. stenocurpon Brid. I. p. 281 . e spec. revera huc pertinet.

Putria. Ad pinos et fagos Angliae, Hiberniac et Normandiae, ad arbores et frutices campestres atque hortenses Germaniae septentrionalis, ubi 1840 prope Jever et Wittmund legimus, in iislem locis Belgii septentrionalis et Gothiae Suecicac. - Marlio usgue ad Junimm.

Hores mase. axillares plures minuti fusci, fol. perig. late ovatis acmminalis coloralis tenerrme reticulatis. Species pulcherrima, ab 0. crispulo hand dissimili notis illustratis facillime discernibilis. 


\section{b. Calyptra pilosa. \\ a. Peristom, simplex.}

45. O. Drummondi Hook. et Grev. (in Grev. Scolt. Crypt. Fl. t. 115.); monoicum; extense prostrato-pulvinatum repens fastigiate ramosum subhumile, tomentosun, viride $v$. lutescens, ramis crassis densifoliis brevibus; folia cauliua crecto-appressa subcrispula brevia, madefacta patentia arcte imbricata, e basi ovata subrentricoso-concava ad nervum utrinque e cellulis ellipticis angustis incrassatis, ad alam utramque parum parenchymaticis diaphanis areolatà lanceolata, profunde canaliculate concava, rotundate incrassate areolata sublaevia, margine inferne parum revoluta; perich. basi haud ventricosa, majora; theca brevipedunculata pyriformis 8 sulcata pallida, ore coarctata, operculo oblique rostrato straninco; calyptra $1 / 2$ obtegente conico - campanulata pilosa fusca, perist. dentibus clongate lanceolatis 16 geminatis pallidis rugulosis.

Br. Eur. 2-3. p. 12. t. 3. - O. subrepens Sommert. Fl. Lalpl!. p. 191. t. 1. f. 2. - Clota Drummondi IBrid. I. 1. 299. - U. birolor Brid. 1. p. 792. - Nacromitrium Drummondi Hmp. Hegensh bot. Zeit. 1837. p. 280.

Patriu. Id betulas retustas Scotiac, ubi Drumnoud primus legit, et Norvegiae, ad Sorbum ancupariam Hercyniae super. ad rupes, "Hohneklippen" dictas: II a m p e. - Septbr.

Hlos masc. minute gemmaceus terminalis, dein innovando lateralis, fol. perig. late ovatis breviter acuminalis inferne tenerioribus nervosis.

\section{B. Periston, duplex. \\ t. Internum 8-ciliatum.}

46. 0. crispum IIw. (Sp. Nusc. p. 162.); monvictm; late et laxiuscule pulvinatum valde crispun lutescens humile breviter dichotomo et fastigiate ramosun dense foliosum; folia caulina madefacta subrecurv-pafula, c basi ovata concava ad nervun utrinque e rellulis maxime incrassatis angustis oblique seriatis inferne fuscis superne 
Jutescentibus, ad utramque alam parenchymaticis diaphauis late creumductà lanceolata complicate carinata flexuosa, margine parum reflexa, distincte papillosa; perich. majora; theca in ped. flexuoso exserto myriformis longicolla, evacualc ore ampliata, pallescenti-straminea, 8 plia. cata, operc. longiuscule apiculato stramineo, perist. duplici; dentes sicci reflexi, pallidi 8 bigeminati anguste lanceolati rugulosi, cilia 8, rarius 16 , inferne duplicia hyalina; calyptra pilosa.

Br. Kur. 2-3. p. 23. t. 12. - Ulota crispa Brid. I. p. 299. Nechera ulophylla Wrob. et Mohr. Bot. Taschb. p. 236. - Wreisia crispa Roth. Fl. Germ. HII. I. p. 222. - Grimmie capillata Morm.h. F1. Marp. p. 731. - Gr. sylrutica Willd. Prudr. Fl. Bir. 11. 906. Bryum sylvaticum Gmel. Syst. Nat. II. P. 1331. - Br. crispum Hoffim. Deut. Fl. 11. p. 25. - Br. striatum S. Limn. Sp. PI. p. 15 Mo. - Br. capillaceum Hull. Brit. Fl. p. 219. - Polytrichum strintum Veck. Meth. Musc: 1. 121. var. $\gamma_{-}-$P. bryoides $v$. capillaceum Wris. Crypt. Gött. p. 177. - P. arborenm Oed. Fl, Wan, t. $6 \mathrm{k},-$ P. capillaceum, crispum, calyptris acutis pilosissimis. bill. Musc. p. 483. t. 5ั5. f. 11. - Inter synonyma haecce antiquorum 0 . courctutum et crispulum forsan inveniantur.

Putria. Ad arbores sylvestres praesertim umbrosas humidas per totam fere kuropam. - Aug., Septbr.

Flores masc. ad basin feminei minuti, fol. perig. anguste lanceolatis acutis, superne incrassate, inferne laxe rhomboidco-areolatis, anth. et paraph. paucis.

47. D. conretatum P. B. (Prodr. p. S0.); monoicum; ). crispo simillimum, sed minus crispulum, folia lacviora, cellulis basilaribus ad nervum positis longroribus laxioribus, theca altius exserta oevlis, evecula elongute angusle atlenuatu ure coarctatu, operculo longiori; perist. cilia simpliciora.

131. Eur. 2-3. p. 21. t. 11. - Brid. I. P. 228. - Ilotu Bru-

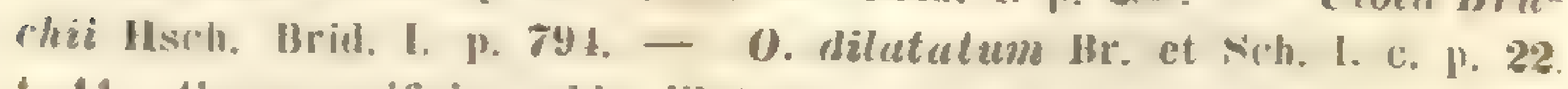
t. 11., thecae orificio valde dilatato.

Putriu. In isslem locis cum O. crispulo per totan fere Europan et in America boreali. - Juliu ad Septbr.

48. D. crispulum Hsch. (in Br. Hur. 2-3. 1) 23. 1. 12.); monuicum; 0. crispo simillimum, scul gricilius 


\section{STEGOCARPI. ACROCARPI. ORTHORICHCM.}

tenuius, thecae longicollae pyriformis minutue tenellar brevius pedunculatue orificio magis dilatato, collo subito et maxime coarctuto, perist. dentibus apice pertusis.

о. crispum ß. minus sichw. suppl. I. 11. p. 25. - O. cirrhutum Bernhardi in Brid. I. p. 301. suh O. crispo. - Llotu crispulu Brid. I. p. 793.

Putria. In iistem locis 0 . crispi, rarius ad saxa.Majo, Jumio.

Ab 0. crispo notis cursive impressis, maturitatis tempore et foliis basi e cellulis minus incrassatis arcolatis, alis minus parenchymatice limbatis, primo adspectu partibus omnibus minoribus et theca evacuala, superine minute urnigera, inferne subito valde coarctata certe distat.

49. 0. Ludwigii Schw. (Supul. I. II. p. 24. t. 51.); monoicum; prostrato-repens fasciculate ramosum, ramis brevibus curvatis subsciuroideis intense v. sericeo-viridibus; folia parum tortilia, madefacta patula, e basi plus minus rentricosa, alis parum parenchymatice circumductis instructô breviter lanceolata complicate carinata, margine parum vel vix revoluta, sublaevia; perich. majora, basi cellulis longioribus; theca Iongiuscule perlunculata oborutopyriformis, superne subylobosa, orificio maxime courctuto et octies plicato, inferne laevis pullescens nitidinscula leptodermis, evacuata longicolli-pyriformis fuscu, operculo longe apiculato recto, perist. dentes 8 bigeminati late lanceolati apice plus minus pertusi rugulosi palinii obscuri, cilia 8 fuyacissima temissimu, calyntra pilosissima fuscescens fugax.

Br. Europ. 2-3. p. 12. t. 4. - O. clausum Hsch. in sched. Ilota Luduigii Brid. I. p. 302 et $794 .-$ o. plicalum L.ulw, in sched., o. striatum olim in Cent. Pl. Crypt.

Putria. Ad arbores praesertim sylvestres montanas et prime fagos hic illic per totam fere kuropam. - Jugusto, Septbr.

Flos masc. (). J) mommondi. Notis illustratis cum alia specie nunquam confundendum. Ilabitus pulvinorum (). Drummondi. Cilia perist. int. ab aliis auctoribus negantur. 
50. 0. curvifolium Wahlenb. (Fl. Lapp. p. 365.); dioicum; laxe pulvinatum, dichotome lastigiate ramosum, inferne nigricuns superne glancum $v$. amoene lutescens $\imath$. fuscescens; folia caulina appressu tortiliu, madefacta erecto-patentia dense imbricata, e basi oblongo-ovata ubique fere incrussute areolata ad marginem purum parenchymatice limitata concavà lanceolata brevia, carinata, margine vix vel parum revoluta, muxime incrussate angulato-areolutu, papillis remotiusculis distinctis scuberrima; perich. conformia majora; theca brevipedunculata e collo longo obovata, orificio dilatato, 8 plicata, brunnescens, operculo longiuscule apiculato, perist. duplici; dentes 8 bigeminati apice fissibiles pallidi rugulosi, cilia 8 filiformia duplicia hyalina; calyptra $\frac{2 / 3}{7}$ obtegente pilosa.

Br. Europ. 2-3. p. 21. t. 10. - O. Laureri Hsch. Regensl). Bot. Zeit. 1\$27. p. 6556. - Llota curvifolia Brid. I. p. 302.

Patria. In saxorum lateribus umbrosis Norvegiae borealis et Lapponiae australis, ubi $W_{\text {a }}$ hlenberg detexit, in alpibus Carinthae, in alpe Kirknitz dicta: La urer et in alp. Salisburgiae: Bruch IIb. Prope Mittersill Pinzgroviac alt. $4500^{\prime}$ s a $u t$ er legisse dicitur. Rarissima species. - Aestate.

Pl. masc. gracilescens, flore terminali.

5̃1. 0. germanum Mont. (Ann. d. sc. nat. 184j. p. 121.); monuisum; 0 . cocerclalo sinule, sed humilius, mimus cortile, folia caulina e basi oxatu lanceoluta longe et angustissime ucuminutu acutu, rubentinervia, tencra, Iutescentia, distincte papillosa; theca ovalis brevirollu aurantiacia, crucuetu subcylindrucer, leviter 8 striata, perist. dentes 8 bigeminati, cilia 8 duplicia lutescentia; calyptra pilosa conica straminea.

O. Inteolum Ifook. et Wils. in sc.lied. musc, antilurtir, quo at diagnosin usi sumus.

Putriu. Chile, ad cort. arborum: C. (iay. Insula Eremitac ad Cap. Horn: J. D. Hooker.

52. D. EckIoni Usch. (Limu. XV. P. 129.); pusillopulvinatum crectum scminnciale breviter fastigiate ramo- 


\section{STEGOCARPI. ACROCARPI. OHTHOTRCIIY.}

sum dense foliosum; folia caulina crispata, madefacta erecto-patentia subflexuosa, e basi ventricosa lincarilanceolata canaliculata, margine plano, infernc rufescentia, superne viridi-lutea, cellulis ad marginem basis folii quadratis laxis hyalinis, ad nervum linearibus angustis leusis, superne minute rotundis; perich. longissima thecum superuntic lanceolato-linearia, basi ad medium vaginata; theca parve vix emersu ovata longicolla s. clavata 8 striata, sicca infra os parum coarctata, viridibrunnea, evacuata cylindrica angustissima torta lutescens, operc. brevissime apiculato, calyptra acuminate campanulata laciniata pilosissima pallida, perist. dentes 8 bigemi"lati latissimi albidi, cilia 8 breviora filiformia basi duplicia hyalina. $t$.

Putvia. Prom. b. spei, in rupis fissura ad cacumen m. tabularis editi quarti: Éck $\mathbf{k}$ \%

Ab 0 . crispo notis cursive impressis facillime distinguitur.

tt. Internum 16 - cilinum.

53. D. Magellanicum Mont. (Voy. au pòle Sud, Crypt. Ł. 20. f. 2.); monvicum; repens tenellum grucillimum presillum, ramis brevibus erectis ad apicem incrussulis, pullide viride; folia caulina subtorlilia, madefacta recurvopatula, e basi orata ventricoso-concur'̂ angustissime lunceolato-acuminata, secunda, valde falcuta, nervo longe infra apicem evanido viridi, parum complicate carinata, margine erecto, rarissime supra basin parum revoluto, sublaeria, flexuose subulata, grossiuscule rotundate, supra basin infimam fuscam parum laxiusculam cllipticoarcolata, ad alas basilares paulisper parenchymatice limitata; theca longe exserta unguste cluretu minutu longicolla, obsolete 8 striata, fuscidula, operculo amplo convexo apiculato, perist. duplici: dentes sicei reflexi, 16 per paria approsimati, cilia 16 plana irregularia, calyptra parec pilosa.

Putria. Ad cortic. arbor. et fruticum Freti Magellanici, loci Port-Fomine: Jac quinot. 
Notis cursive impressis jam primo adspectu ab omnibus congeneribus differt. Flores masc. plures sub femineum in ramis propriis brevibus positi, fol. perig. angustis, internis e basi longe oblonga concava tenerrima colorata nervosa breviter acuminatis rotundate areolatis viridibus.

\section{Species non satis notae.}

51. D. Jutlandieum Brid. (I. p. 296.); laxe et latissime pulvinutum prostratum repens, ramis erectis flucridis longinsculis parce dichotomis, amoene viridis, lutescens v. fuscescens; folia caulina laxe conferta valde fortilia, madefacta erecto-patentia, flaccida, longa, e busi longe oblonga concava lanceoluta longe acuminata flexuo$s a$, margine inferne magis superne angustissime vel haud revoluta, basi elongate anguste incrassate fuscate subserpentine areolata, ad alas valde plicutus serie cellulurum purenchymaticurum unicu suepe obsoletu limitutu, papillis remotis inferne tuberculosa superne sensim minute et valde incrassate rotundate areolata, tenera, lutescentia, nervo crasso parum carinato fuscescente cranido $\%$ excurrente et in cellulas tubulosus anomalas apice caulis stellation disposites dissoluto.

O. phyllanthum siteud. Noucnel. Fal. 1. - Br. Furop. 2-3. p. 30. t. 18. - Clota phyllantha Brid. Mant. Musc. p. 113. - $\boldsymbol{U}$. rispum Hook. et Wils, in sched. Husc. antarct. - O. fasciculnre Brid. I. p. 790.!

I'utrice. Ad arbores campestres rarius, ad sylvestres, praesertim fagos, sylvarum humidarum Germaniac sept. maritimae pr. Jever Duc. Oldenburgensis 1840 copiosissime legimus; in iisdem locis Belgii septentr., Jutlandiae Danicae, Gothiae (Scaniac) Suecicae et Norvegiae occidentalis ut in Gallia septentr. rupes maritimas habitans. Insula Eremitac ad Cap. Horn, unde J. D. Hooker specimina, cum Europaeis omnino congruentia, retulit. In insula Terre Neuve arctica legit La Pylaic!

Species distinctissima et pulcherrima, O. crispulo similis, spretis examinibus acuratissimis a nobis semper sterilis reperta. 


\section{STEGOCARPI. ACROCARPI. C'RYPTOCARPIS.}

55. Clota fulva Brid. (1. p. 301.); Orthotricho crispo simillima, sed saturate aureo-fulra, non flarescens; folia madore incurva nec erecta subreflexa, lineari-lanceolata incurva; theca in ped. duplo fere longiore non tam evidenter e basi sensim in thecam dilatato, sed fere lineari tortili ovata, evacuata inaequalis subcernua, operculo convexo-conico. t.

Orth, crispum var, Brid. \$p. Musc. I. p. 5.

Patria. Insula Bourbonis: Bory St. Vincent.

Calyptra ef peristomium desunt. In IIb. Brideliano non vidimus, species autem bona videtur.

Orthotricha delenda.

1. Drth. heteromallum Schw. Brid. I. p. 29\%, nomine solo notum.

2. Orth. fasciculatum Brid. I. p. 297. - Grimmich fasciculata ej. Want, Mluse. p. 37. - In Hh. Brideliano non vidimus: forsan Grimmia.

3. Orth. radieulosum Brid. I. p. 791. E. sper. Hl, Brideliani Barbula antedam sterilis ad sectionem Nenomyllum revoranda videtur.

\section{Gen. XIV. Cryptocarpus Dz. et M.}

Muse, Apchip. Ind. p. 37. t. 13. - Macromitrium Hook, et Wils. C. Niïll. olim.

Nomen ob thecam immersam conditum.

Calyptra mitraeformis brevissima operculum solum oblegens, haud plicata, pilosa. Peristomium nullum.

Plantac habitu Macromitriorum, calyptra glabra Schlotheimiarum, sed brevi Grimmiarum, a gregibus ambabus prioribus, ut Grimmine a Brarhystelis, distinguuntur et genus egregie conditum sistunt. Inter omnes Orthotrichuceus caulibus heteromorphis facillime cognoscuntur. Ob thecae et calyptrae formam Cryphacis hand male aemulantur.

1. Cr. apiculatus Dz. et M. (1. c.); hermaphroditus; caulis repens, ramis sterilibus brevibus gemuaeformibus 
densifoliis rrassis, fertilibus elongatis gracilibus, ob folia in series nonnullas distincte erectas cauli subtorto parum spirales disposita polystiche angulatis, summo apice breviter brachiate fasciculatim divisis, fusco-luteis; folia ram. steril. late oblongo-ligulata obtusa mucronata, alis convexiusculis grosse incrassate rotundate areolatis inferne mammillate papillosis; fol. ram. fertil. multo breviora late orata, apice parum retuso acuminato; perich. latissime ovata, apice emarginata valde eroso-crenulata, medio apicis brevissime mucronata, multo pallidiora tenuiora, cellulis maxime incrassatis in membranam veluti conflatis linearibus; theca inmersa minutissime ovato-oblonga microstoma laevissima pallide olivacea, operc. brevi conico, calyptra pilis longis erectis angulate flexuosis incrassatis multis pilosissima, basi incisula.

Mncromitr. brachiutum Hnok. et Wils. Ic. PI. Rar. Hooker. 1845. t. 746. B.

Putriu. Insulae Philippinae: Cum in g. Borneo, jurta Martafoeram una cum Macromitries arborum habilans: Korthals.

\section{Gen. XV. Mracromitrinm Brid.}

Hant. Huse, p. 132 et I3r, Univ. I. p. 306. - Orthotrichum Honk. et Grev. - Leiotheca Brid. - Hypnum antiq.

A Huxoós longus et uírouv, ob calyptrac insiguem longitudinem nomen compositum.

Calyptra campanulata plicata, basi plus minus profunde laciniala. Perist. nullum, simplex vel duplex; exterum: dentes 16 lancenati discreti v. geminati, wanuloso-albidi v. rufescentes; internum: membrana plus minus elata truncata vel in dentes externis similes fissa. Theca exannulata vel rarius simpliciter annulata.

Plantae magis hypnoideo-repentes, qua nota ab $\mathrm{Or}$ thofrichis proximis primo adspectu distinguuntur. 
Sictio I. Macrocoma IIsch. in HW. Kunzcano. - Caulis rigidus longe repens, ramis siccitate filiformibus teretibus dense foliosis remotis plus minus pimatis. Folia stricta, hasi acetabuliformi concava s. ventricosil, parva, dense applessa, evanidinervia, mador" patcutia, strictr, superne canaliculata, hexagrone-rotundato-areolata. Theea microstoma.

1. M. fliforme Schw. (Suppl. II. II. 1. p. 64. t. 171.); monoicum; valde decumbens gracillimum, ramis teretibus filiformibus breviter ramulosis viridulis ditissime fructiferis; folia latiuscule lanceolata plus minus acuta, parum papillosa; perich. acutiora; theca in ped. longiusculo cylindraceo-ovalis cinnamomea sublacris, parvula, operc. conico acuto brevi, dentibus (externis) brevibus sedecim linea media exaratis geminatis rugulosis, calyptra thecum aeruunte, filis longis incrassatis nodosis hirla, perfecte campanulata.

Leiotheca fliformis Brid. 1. p. 727 et 795. - Orthotrich. filiforme Hook, et Grev, in Brewst. Wdinb. Jouru. I. 1. 116. t.4. Lasia orthotrichoides Raddi in schedulis.

P'utric. In Brasilia, ubi haud rara videtur, Sellow primus legit; e Chile retulit $\mathbf{P} \ddot{\text { pppig. }}$

Flores masc. axillares plures minutissimi, fol. perig. pancis minutis ovato-acuminatis subintegris basi teneris fuscis.

2. M. tenue Brid. (I. p. 740.); monoicum; late pulvinatum, repens, ramis brevibus tenuibus fusco-viridibus, ditissime fructiferis; folia caulina $M$. pulchelli; perich. majora; theca in ped. elonguto perfecte cylindracea rectu, longe madefacta yibboso-ovalis suboblinua, leviter, sed distincte sulcata, pallide fusca, dein cinnamomea, orificio angustissimo, opere. e basi minute conica longinscule achtissime subulato stricto, mulore conico acuto, flavo, caIyptra thecam superanto, peristomio simplici interno, e membrana brevissima truncata rugulosa composito.

schwigr. Nuppl. Il. II. 2. p. 112. t. 191? - Orthotr. tenue Illooh. et Grev, in Brewst. Finlin. Jomm. I. p. 120. t. j. - Maschalucarpus declinatus Nipr. syst. Veeret. IV. I. p. 1.88.

Putria. Prom. b. spei, ubi primi legerunt Menzies et Burchell. 
Wlos masc. minute gemmaceus infra femineum posiIus, fol. perig. paucis, e basi late ovata tenero-reticulata fusca margine distincte crenulata, breviter acuminata.

3. N. Perrottetii C. Müll.; monoicum; M. tenui simillimum, sed folia longior acutiore, perich. caulinis multo majora, intima basi tenerius laxius et longius reticulata; theca in ped. elongato, siccu et madefacta minute 't anguste elliptica cylindracea, leviter striata, perist. simplici interno: membrana vix exserta truncata, calyptra pilosissima.

M. tenue Mont, in Musc. Neelgheriens.

Patria. Montes Neelgherienses: Perrot tet.

Flos mase. in ramulo ad basin feminei floris posito, ferminalis gemmaceus, foliis $M$. temis. Operculum et calyptra natura desunt. Theca illi $\boldsymbol{M}$. filiformis proxima.

4. M. microphyllum Brid. (I. p. 737.); M. tenui simillimum, sed statura vulde pusillu, folia sublacria, teneriora, theca longicolla pyriformis anyusta, distincte sulcata.

Orthotrich. microphyllum Hook, et Grev, in Hrewst, Edinl. Journ. I. p. 121. t. 6.

Patria. Prom. b. spei, ubi primus legit Burchell, rarius.

5. M. Dregei Isch. (Linn. XT. p. 131.); monoicum; M. temi maxime simile, sed folia minora, pellucidiora, Heca angustion minor sublaerissima rel evacuata ore et busi purum plicata, operculo acute subulato, calyptra ut in M. pulchello thecum $2 / 3$ obtegente, pilis longis geniculatis hirta.

Patria. Prom. b. spei: Albany 1. Decbr. 1831, Paarlberg 1500' soc. Burb. piliferce 30. Mart. 1528, Enon in sylva 500' 18. Mart. 1833: Drège.

Flos masc. $M$. tenuis.

6. M. lycopodioides Schw. (Suppl. II. II. 2. p. 141. 1. 193.); dioicum; M. temi sinillimum, sed ramis crassioribus, folia magis curvata, perichaetialia magis acumimata longiora, pedunculus brevis, maxima parte raginula

C. Muller: Synops, muse, frond. 
longe exserta vaginatus et paraphysibus longe exsertis simulac cinctus, theca anguste elliplica brevior minus distincte striata cinnamomea, operculo conico obliquo, caIyptra thecam superante et clavaeformi-cingente pilosissima, peristomio nullo.

Maschalocarpus Eckloni spr. Syst. Veget. IV. II. p. 321. Onthotrichum lgcopodioides Burch. (aat. gengr. PI. Africae australis extratropicae No. â14t- 4 . - Macrocome eleyans Hsch in sched.

Patria. Prom. b. spei, ubi Burchell primus legit, affinium congenerum rulgatissimus.

Infloresc. Schwägrichen monoicam et dioicam dixit, nos ipsi dioicam semper observavimus.

7. M. Abyssinicum C. Müll.; dioicum? M. lycopodioidi simillimum, sed rami longiores et fertiles fastigiate ramosi; folia caulina majora longiora acutiora, murgine basis papillis distinctis acutis scaberrima ef denticulatu, perich. mulloso-plicata margine inferne distincte denticulata; theca in ped. elongato longicolla clavaeformis obliqua submacrostoma.

M. Iycopodioides Br. et Nih. in W. schimp. Musc. Allyss.

Patria. Abyssinia: W. Schimper.

8. M. pulchellum Brid. (I. p. 313 et 737.); divicum? repens pluries divisum, ramulis brevissimis subrosulatis approximatis, tenellum, pallide viride; folia angustiuscule lanceolata, obtusiuscule acutata, parum papillosa, alis convexis, cellulis minutis subrotundis, basi tenerioribus plus minus pellucidis hexagonis; perich. latiora; theca in ped. longiusculo substricto angustissime oblonga minuta, sulcata, operc. conico acuto, calyptra thecum dimidiam obtegente mimuta, pilis squamueformibus brevibus latis erectis obtecta, basi pluries profunde laciniata, liteo-fusca, dentib. ext. 16 brevibus obtusis, perist. int. e membrana brevi truncata composito.

schlotheimia pulchellı IIsch. in Hor. Phys. Berol. p. 61, t.12. schw. suppl. III. I. 2. t. 249. - Orthotr. Hornschuchii Hook. et Gr. Brewster Edinb. Journ. I. p. 129. t. 6. 
Patria. Prom. b. spei, ubi in cortice Proteae conocurpae ad M. 'l'abularem m. Octobr. leg. Bergius.

A M. tenui et affinibus jam calyptra distat.

Sectio II. Drthophyllina. Plantae densius pulvinatae, caulis teres, foliis appressis strictis, cirrulariter areolatis ubique cantliculatis.

9. M. hymenostomum Mont. (AnI. d. sc. nat. 1845. 4. p. 120.); dioicum; repens, sed dense pulvinatum, ramis erectis teretiusculis subrobustis breviter ramulosis sordide viridibus, dein fuscis, fragilibus; folia dense appressa, madore parum patentia oblongo-lanceolata subacuminata acutiuscula, margine inferne anguste revoluta, profunde canaliculata, evanidinervia, incrassate angulate rotundate areolata, firma; perich. latiora obtusiora, acumine acuto; theca in ped. breviter exserto minute ovata 8-striata, operculo conico-acuminato dimidio breviori, perist. simplici interno, e membrana altiuscula integra iruncata composito, calyptra glabra fuseata parva obsolete plicata.

\section{Putria. Chile australis: C. Gay.}

Calyptram juniorem solam vidimus. Species Drummondice haud dissimilis. An Macromitrium?

Sectio Ill. Dumacromitrium. Caulis plus minus incrassattus, rigidus v, flaccidus, foliis siccitate flexuosis v, crispatis v. spiraliter contortis, canaliculatis.

A. Folia strictiuscula parum flexuosu.

$\varkappa$. Folia madore erecta.

10. M. dnbium Schimp. (in Hlb. Hampeano!); longissime repens, ramis remotis robustissimis densifoliis fastigiatim ramulosis fuscescentibus; folia caulina longissima flexuoso-erecta, madore caulem scopaeformem 2. mosum laxe imbricatum efficientia laxe patentia, late lanceolata longissime et temissime acuminata, veluti aristuta, excurrentineria, canaliculata, alis planiusculis, ad marginem erectum remote et obsolete denticulatis, cellulis ubique elongutis rectunguluribus angustis, purietibus sub- 
interruptis moculitis pallide rufis; perich. breviora; theca in ped. elonguto intense purpureo majuscule ovalis nitide fusca laevis, gymnostoma (?), operculo longe subulato recto, calyptra glabra longa angusta fusca parum angulata.

Putria. In truncis arborum montium insulae St. Kitts: Hb. Sch imper.

Syrrhoporl. longisetuceo habitu valde simile, sed, calyptra matura licet nondum visa, ad gemus hocee pertinere videtur. A $M$. Leprieurii, specie affini unica, notis cursive impressis longe differt.

11. M. Eeprieurii Mont. (Ann. d. sc. nat. Ser. I. XIV" p. 347. t. 20.); caulis repens, ramis magis approximatis rigidis; folia dense imbricatu uppressu, mimus fleruosa, multo breviova, haud longe ruspidata, sed anguste lanceolata acuta, superne longiuscule elliptice aveoluta, theca operculo cupulato-conico brevissimo tecta gymnostoma, calyptra breviore.

Patria. Guiana Gallica, ad truncos arborum circa Cayennam: Leprieur.

M. dubio maxime affine et, operculum si longe subulatum esset, varietatem putaremus.

\section{B. Folia madore reficxa.}

12. M. trunentum C. Müll. (Linn. XVII. p. 383.); dioicum? longe repens, ramis remoliusculis simplicibus fuscis robustiusculis densifoliis; folia erecto-appressa, multifaria, madore divergenti-divaricata, longiuscule angustata, ultra medium plicata, semitorta, plus minus regulariter truncata, nervo excedente breviter apiculata, canaliculata, mareine convexo, cellulis basis longae elongatis incrassatis angustis, superne longiuscule quadratis dein elliptico - incrassatis; perich. longissime acuminata, lamina inaequali attenuata, nervo longe excedente flexuoso, ubique elongate reticulata; theca in ped. elongato flexuoso cylindracen-oblonga sulcata, ore coarctata, operculo aciculari recto, perist. simplici, dentibus geminatis rarnosulis obtusatis pallidis rugulosis. 
Patria. Insula St. Vincent: Hb. Kunzean.

Notis illustratis species ab omnibus congeneribus distinctissima. Calyptra ignota.

\section{B. Folia in spiram contorta.}

a. Calyptra pilosa.

13. M. prorepens Schw. (Suppl. II. II. 1. P. 62. ^. 171.); divicum? longe repens, sed ramis brevibus crectis subsimplicibus rigidlis crassis sordide fuscis dense approximatis subcompactum; folia leviter in spiram contorta, madore dense erecto-conferta, oblongo-lanceolata, dilatate valde canaliculata, obtusiuscula, nervo valido in cuspidem brevissimam exeunte, inferne lutea teneriora, superne sordide viridia firma, cellulis minutissime rotundatis opacis, basi minute quadratis pallidioribus; perich. latiora; theca in ped. brevi ovalis parvula laevis badia, apice fusca, operc. rostrato recto (?), calyptra anguste conica pilosa budia, apice firsce, perist. dentibus externis brevibus pallidis geminatis. $t$.

Leiotheca mrorepens Brid. 1. 11.305, 727, 795, - Orthotrich. provepens Hook. Musc. Exot. t. 120.

Patria. In sinu Dusky-Bay Novae Seclandiae: Nenzies 1791.

Notis cursive impressis primo adspectu cognoseitur.

14. M. Nepalense Schw. (Suppl. II. II. 2. p. 134. t. 192.); dioicum; repens, ramis brevissimis dense approximatis densifoliis luteo-fuscis subsimplicibus; folia caulina spiraliter imbricata, madore crecto-patentia, apicibus crecto-curvetis, breviter lanceolatis, alis convexis, basi firmis minute quadrate areolatis luteis, superne opacis carnosulis breviter sed densissime papillosis viridissimis, nervo subexcurrente, canaliculata, perich. majora exsertu late lanceoluta longé recte cuspidutu pluries plicutu incrassate irregulariter anguste quadrate areolata lutea; theca in ped. breviter exserto cyliudraceo-oblonga latevis, orificio aurantiaco, operc. recte conico subulato. perist. simplici, dentibus geminatis breviusculis albidis, calyptrat longe anguste conica pilosissima thecam sinperunte. 
Arid. 1. p. 732. - Orthotr. Nepalense Hook. et Grev. Brewst. Hidinb. Journ. I. p. 117. t. 4.

Putria. Nepal, Dhoopabasah et Beahico: Wallich.
b. Calyptra nuda.
a. Pedunculus brevis.

1. M. urceolatum Schw. (Suppl. II. II. 2. p. 128. t. 189.); dioicum? longe repens, ramis dense approximatis erectis brevissime ramulosis crassis sordide viridibus pollicaribus strictis rigidis dense pulvinatum; folia arcte denseque imbricata subspiraliter contorta, madore erectiuscula, terminalia paullum patentia, rigida, e viridi flavescentia, aetate fere aurea, inferiora badia, frugiliu, unguste lanceolato-attenuata obtusinscula, acumine brevissimo acuto terminuta, nervo ante apicem abrupto viridi, dein ferrugineo, cellulis basilaribus rectangularibus, superioribus minute subquadratis opacis granulosis viridibus, margine saepe involuto praedita; perich. breviora; theca brevipedunculata breviter urceoluta majusculu laevis badia, operc. recte aciculari, calyptra profunde laciniata glabra, perist. simplici, dentibus pallidis crassis solidariis brevibus. \%

Brid. 1. p. 312, 730. - Orthotr. urceolatum Hool Musc. Fxot. t. 124.

Palvia. Insula St. Helena: M enzies.

16. M. Mauritianum Schw. (Suppl. II. II. 2. p. 127. t. 189.); dioicum? longe repens, ramis approximatis brevibus v. longioribus, dense foliosis subsimplicibus luteoviridibus inferne fuscescentibus clavato-incrassatis rigidis; folia in spiram densam sinistrorsum ductam disposita, madore erecto-patentia stricta rigida, lancenlatu, nervo crasso in cuspidem brevem producto, cellulis subrotundis minutis obscurioribus, basi subquadratis lunatis; perich. caulinis similia, neque longiora; theca in ped. perlberi urceolat are contracta, laevis, fusco-badia, opere. thecam aequante aciculari recto, calyptra theca paulisper hrevior glabra sulcata luteo-badia, perist. simplicis dentes externi breves lanceolati albidi. $\dagger$. 


\section{Patrie. Insula Mauritii: Sieber.}

A M. urceolcto ramis gracilioribus et notis caeteris descriptis facile discernibile.

17. M. microcarpum C. Müll.; dioicum; humile tenellum, longe repens, sed ramis erectis gracilibus brevibus simplicibus vo brevissime rumulosis sordide viridibus dense approximatis dense pulvinatum, rigidiusculum; folia apice praesertim in spiram dense contortam congesta, madore erecto-patentia subappressa densissime imbricata brevia, lanceolata acuta substricta, profunde basi latiuscule canaliculata, margine integro convexo, nervo subevanido, cellulis ubique incrassatis, minute rotundatis, subopacis, basi quadratis pallidioribus laevibus; perich. conformia, theca breviter pedunculata minute oralis laevis, ore valde plicata contracta, brunnea nitida, operc. oblique aciculari, perist. simplici interno, e membrana truncata brevi composito, calyptra glabra.

M. microstomum Schw. in Hb. Kunzeano.

Patria. Chile: Pöppig.

M. microstomo proximum videtur.

18. M. mierostomum Schw. (Suppl. II. II. 2. p. 130.); repens, ramis longis strictis apice ramosus, ramulis fastigiatis brevissimis; folia spiraliter contorta, lanceolata apiculata pallide e brunneo viridia, theca ovata laevis, ore contracto plicata, profunde brunnea, perist. simplicis externi dentes angusti erectiusculi geminati trabeculati albi, calyptra elongato-cylindracea angusta glabra laevis basi pluries laciniato - fissa. $\leftarrow$.

Leiotheca microstoma Brid. I. p. 729. - Orthotr. microstomum Hook. et Grr. in Brewst. Edinh. Journ. I. p. 114. t. 4.

Patria. Terra Van Diemen: Dr. Spence.

A M. microcarpo, cui ex icone et diagnosi auctoris pauperimis simillimum videtur, peristomii fabrica longe refugit.

19. M. apieulatum Brid. (I. p. 311.); dioicum; dense pulvinatum intertextum inferne radiculosum, ramis longiusculis valde fastigiation divisis robustiusculis viridibus; 
folia maxime inordinate horride spiraliter crispula, madore erecto-patentia, longiuscule lanceolato-acuminata, nervo stricte excedente breviter cuspidata, canaliculata, alis valde convexis minute rotundate basi infima ad nervum cellulis nonnullis laxis fuscis areolatis, e basi ultra medium folii limbo angusto pellucido proeditis; perich. conformia multo latiora; theca in ped. breviusculo majuscule urceolato-ovclis macrostomu, sub ore coarctata, lacvis, sicca evacuata basi plicata, brevicolla firma, operculo conico aciculari recto, calyptra thecam subaequante glabra sordide lutea, apice fusca, multilida, perist. simplici, c membrana truncata firma composito.

Nichw. Suppl. II. II. 1. p. 5ૅ. t. 170. - Leiotheca apiculale Brid. I. p. 734, 796. - Orthotrich, apiculatume Hook. Musc. Bant. t. 45. - Mucromitr. macrostomum sichw. suppl. 11. H. 2. t. 196!--

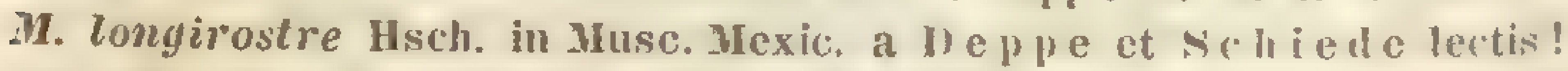

Putric. Mexico, Xalapa, regione temperata: II umboldt et Bonpland. Brasilia, Serra dos Orọòs: B eyrich, Gardner No. 58. Guatemala: Friedrichsthal No. 85.

Notis illustratis facile distinguendum. Inflorescenliam Schwägrichen in speciminibus Mexicanis monoicam, in ramulis propriis gracillimis terminalem, fol. perig: parvis ovatis acutis, observase dicit. In sper. nec Brasiliensibus nostris, a quibus diagnosin duximus, nec Mexicanis a Deppe et sehiede lectis, non ridimus.

20. N. brevipes C. Müll.; dioicum; dense pulvinatum tenellum humile rigidissimum luteo-fuscum longe repens, ramis brevibus simplicibus $v$. fastigiatim ramulosis, folia inordinate horride spiraliter contorta, madore erecto-patentia, oblongo-ligulata obtusiuscula, nervo excurrente breviter mucronata, cellulis hexagone-rotundatis ob papillas granulosas opacis, basi magis incrassatis, alis convexis hic illic plicatis, basis margine in limbun angustum incrassatis, viridibus; perich. conformia; theca in ped. nevbrevi curvulo, madore recto rigido flavido purpurasecnte minute elliptica microstoma lacvis pallide fuscia yymnostoma, operc. breviter aciculari recto, calyptra uuda. 
M. apiculatum C. Mïll. Bot. 'Jeit, 18t5. p. 525. - Orthotr. eleguns Hsch. (non Schw.) in Musc. Siel,. No. 21.

P'atria. Insulae Martinque: Hb. F'ée, Guadeloupe: Berter o, Trinidad: Si eber.

A M. Swainsoni notis cursive impressis facile distinguitur. A M. cupiculato, cujus forma tanquam humilis putari potest, statura humili, foliis magis ligulatis et thecae gymnostomae forma jam satis differt.

21. M. longirostre Schw. (Suppl. II. I. p. 38. 1.112.); dioicum? caulis longe repens densifolins crusse filiformis, ramis pimatis fastigiate divisis et iterum ramulosis tongiusculis multis erectis aureis incrussutis, sed apice acutis, rigidis fragilibus; folia in spiram lax amjinordinutam horridum contorta, madore erecto-conferta arcte imbricata, late lanceolata cuspidata stricte rigillissima excurrentinervia, basi dilatate canaliculata, alis convexiusculis, cellulis minutis punctiformi-quadrutis sublucribus, diaphanis pellucide flavidis; perich. conformia; theca in pedunculo brevi crasso flavido dein purpureo oblonga leviter 8 plicata subaurea dein brunnea, operculo aciculari recto, perist. simplici, dentibus erectis longiusculis calyptra glabra aurea multifida.

Brid. 1. p. 310. - Orthotrich. Congirostre Hook. Musc. Exot. t. 25. - Macromitr. acutifolinm brid. 1. 13. 735. sed Urlhotr. acu

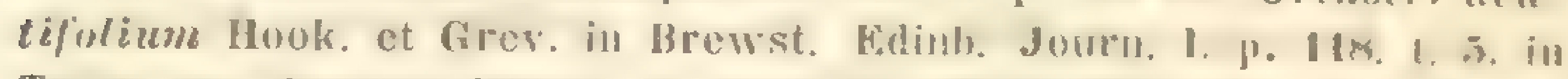
Torra van llemen lectum e specim. antareticis Howherianis forma theca mitgis ovali pracdita huc revocandum est.

Putriu. Dushy-Bay Novae Seelandiae: Menzics. Terra Van Diemen: Dr. Spence el Neill. Iusulae Aucklandi et Camphelli: J. D. Ilooker.

species pulcherrima, ramis aureis saepe nitilis incrassatis inordinate spiraliter foliosis primo intuitu distinguenda.

B. Pedunculus longissimus.

22. M. longipes Schw. (Suppl. II. 2. p. 117. 1.139.); divicum? M. longirostri simillimum, sed deflert foliis lanreolutis obtusinsculis brevioribns, pedunculis longissimis 
thecisque oblongo-cllipticis sordide fuscis sublacvibus ore plicatis. t. t. 24.

Brid. I. p. 317, 737. - Orthotrich. longipes Hook. Musc. Exot.

\section{1.}

Putria. Dusky-Bay Novae Seclandiae: Menzies

23. M. Blumei Nees (in Schw. Suppl. IV. t. 316.); dioicum; laxissime pulvinatum intertextum longe repens, ramis erectis longiusculis gracilibus teretibus subrigidis fastigiatim ramulosis fusco-luteis, inferne ferrugineis, siccis apice acutis; folia spiraliter contorta, madore erccto-patentia, latiuscule lanceolata, nervo cxcedente acute mucronata, profunde canaliculata, medio utrinque subgibbosa, alis convexiusculis, cellulis grosse rotundatis incrassatis subviridibus inferne magis rectangularibus luteis tuberculose papillosis; perich. perichaetium subtrigonum efficientia breviora latissime ovatu obtusa crenulata, mucronata; theca in ped. longissimo rigido subpyriformiurceolata brevicolla nitidissima laevissima, ore coarctuta, aurantiaca dein brunnea, sicca basi plicata, operc. longe aciculari recto, calyptra nitidissima latiuscule campanulata apice scabra ubique valde plicata, perist. simplici externo imperfecto, dentibus brevissimis truncatis pallidis basi connatis.

M. Miquelianum Mont. in litt. - Schloth, teres Uz. et M. Ann. des sc. nat. 1844. 2. p. 314.

Patria. Java: Blume primus legit. E provincia Buitenzorg lectum Hb. Miquel. copiosissime accepit.

Notis illustratis species pulcherrima.

C. Folia incumbenti-contorta.

1. Folia elongate a cuminata aristata.

24. M. pilliferum Schw. (Suppl. II. II. 1. p. 66. 1. 172.); dioicum; longe repens, ramis remotis incrassatis subclavatis rectis luteo-viridibus, dein fuscis subsimplicibus; folia caulina dense imbricata crispula, madore erecto-patentia, lanceolata et in aristam flexuosum temuissimam acicularem productu, fragilia, complicata, subqua- 
drate minute areolata, summa et perich. longiora; theca in ped. breviuscule exserta oblongo-ovuta, utrinque contracta, costis elevatis subsenis, badio-fusca, operc. rostrato recto, peristomio nullo, calyptra magna thecam aequante pilosissima. $t$.

Brid, 1. p. 797. - Orthotrich. lanceolatum W. Arn. Disp, d. M. 1825. p. 16; suh pag. 17 anctor eandem speciem nomine M. piliferi iterum enumeravit! - Clota pilifera Nees in Nov. Act. Acad. Caes. Leop. XVI. Suppl. II. 1843. p. 477.

Patria. In insulis Sandwicensibus leg. Ga udich a ud et Menzies. Oahu: Meyen.

A $M$. cuspidato notis illustratis longe recedit.

25. M. cuspidatum IImp. (Ic. Musc. t. 20.); dioicum; caulis longissime repens, ramis erectis remotis incrassatis dense foliosis sordide viridibus subsimplicibus; folia caulina late lanceolata, lamina apice acuminata $v$. increqualiter obtusinscula emarginata angusta, nevro excedente longe Rexnose aristata, margine basi parum revoluta, longitudinaliter plus minus plicata, profunde canaliculata, integra, cellulis longiusculis angustis pellucidis lunatis apice quadratis minoribus; perich. longius aristata; theca in ped. breviter exserto ovalis laevis, operc. conico longe aciculari recto, calyptra amoene plicata parum hirta, perist. simplici e dentibus brevibus involutis teneris sedecim solitariis composito.

M. elongutum D\%, et M. Ann. des sc. nat. 1844. 11. p. 311.

Putric. Java: B l une, J u ng h hn; Borneo et Sumatra: Korthals.

Notis datis a $\boldsymbol{M}$. pilifero affini facile refugit.

26. M. pentastichum C. Müll. (Linu. XXI. p. 186.); divicum; longissime repens, ramis remotiusculis elongatis Maccidis subsimplicibus viridibus eximie pentastiche foliosis grucilibus; folia caulina parum crispula, malore valde patula patenti-divergentia laxe imbricata, anguste lanceolat acuminata longinsculu, margine undulato-flexuso erecto v. convexiusculo, ubique fere tenuitér crenulato, grosse papillosa, profunde canaliculata, viridia rufinervia, 
ccllulis hexagono-rotundatis striatis; perich. longissime loriformia; omnia excurrentinervia; theca in ped. breviter exserto ovalis leptodermis laevis, calyptra maxime profunde laciniata angusta, pilis latis incrassatis flexusis valde hirta.

Putria. Surinam, in sylvis valde humidis opacis pr. Mariepaston ad flum. Saramacca dictum, ramos arborum tenues habitans, sed rarius: Kegel 1816. Majo.

Operculum et peristomium desunt. Notis illustratis jam facillime cognoscendum. I'heca annulata videtur.

27. M. cirrhosum Brid. (1. p. 316, 738, 798.); dioicum; longe repens, ramis elongatis simplicibus v. dichotomis, madore flaccide foliosis, pallide luteis; lolia caulina valde crispula, elongata, e busi latiore lanceoluta et in acumen angustum longum acutum aryule et tenuiter serrulatum productu, canaliculata, minus re/lexu, ala unica basilari depressa, superne vix rugulosa, cellulis basilaribus rectangularibus flexuosis incrassatis tuberculoso-papillosis, superioribus sensim minoribus quadratis; theca in ped. breviusculo globoso-avalis leevis brunnescens, operc. e basi conica recte subulato, perist. duplici: dentes ext. 16 geminati brevinsculi rufescentes, interni membrunu erecta irregulariter in dentes $\mathbf{1 6}$ breviores fissa lutea, calyptra laevis.

Schlotheimia cirrhosa schw. Suppl. 1H. 1. 1. 1. 201. - Orthotrich. cirrhosum IIook. et Grev. Brewst. Bilinh. Joul't. I. p. 130. t. 6. - Neckera cirrhosa sw. Fl. Ind. U(r. III. p. 1812. - Anaectanyium cirrhosum Hdw. Np. Insc. p. 12. t. 5. - Hypmum cirrhosum sw. Prodr. FI. Ind. p. 142.

Patria. Jamaica temperata, supra truncos arborum: Swartz; insula St. Vincent: Menzies et al.; Brasilia: Beyrich, Gardner No. 70.

A M. longifolio proximo notis cursive impressis litcile distinguitur. Peristomium imperfectum tantum bdimus.

28. M. Dehraceum C. Müll. (Bot. Zeit. 1815. p. ă 14 ); divicum? longe prorepens lage ramosum, ranis distanti- 
bus elongatis adscendentibus simplicibus v. fastigiatim divisis ochraceo-lutescentibus; folia caulina tortilia, madore recurvo-patentia, elongata, e basi late oblongà recurva lanceolata longe acuminata, flexuosa, margine medio folii parum convexo, apice crenulate denticulato, nervo rufo excurrente, cellulis basi dense angustis longinsculis acute elevate papillosis scabervimis superne incrassate rotundatis veluti mammillari-punctutis, profunde canaliculata; perich. longissime acuminata, nervo excurrente quasi cuspidata; theca in ped. elonguto scuberrimo erecta ovalis, siccu costuto-plicuta, operc. convexo subulato, calyptra basi laciniata dense pilosa.

Schlothemia ochracea $\mathrm{Dz}_{\text {, }}$ et M. Ann. d. sc. nat. 1811. 2. p. 31. - Macromitr. cirrhosum Dz, et Molkb. et A. Braun Mst.

Patria. Java: Zi ip pelius.

Notis cursive impressis a $M$. cirhoso affini primo momento distinguitur. Peristomium et calyptram non vidimus.

29. M. perichnetiale C. Müll. (Bot. Zcit. 1845. p. 544.); repens, ramis longiusculis parce divisis fuscescentibus robustis densifoliis; folia crispatula, madore patentia, dense imbricata, lunceoluta ucutu carinata, luteofuscescentia, nervo ferrugineo in cuspidem brevem in perichuptialibus longissimam setuceum exeunte, cellulis clongatis angustis densis, apice incrassate anguste ellipticis; theea in ped. longo ovalis laevis fusco-badia, perist. duplici frugilissimo; dentes externi lineari-lanceolati obtusi linea longitudinali valde exarati, interni sedecim ima hasi connati latiusculi lutescentes, calyptra pilosa $4-5$ fida. to

Nohlotheimia perichatialis Nchw. Nuppl. II. II. 1. p. 56. t. 169. - Leintheca perichatialis Brid. 1. p.731. - Orthotrich, perichactiale Hook. et (irev, in Brewst, Edinb. Journ. I. p. 127, t. 6.

Putria. Insula St. Vincent: Menzics et Guilding.

M. truncuto habitu ex icone simile videtur, sed obscurius.

30. M. gracile Schw. (Suppl. II. 2. p. 39. t. 112.); dioicum? ramis gracilibus elongatis flexuosis remotis sub- 


\section{STEGOCARPI. ACROCARPI. MACROMITRUN.}

simplicibus inaequalibus luteo-fuscis; folia crispata, madore laxe patentia erecta, lanceolato-acuminata, ungustu, nervo in subulam elongatam flexuosam madore quorpue semel tortum excurrente, canaliculata, cellulis minute quadratis punctatis, basi elongatis, parietibus transversalibus obsoletis; perich. duplo fere longiora; theca in ped. breviter exserto oblonga laevis, basi subplicata, fusca, operculo thecam aequante $v$. superante tenuissime aciculari, calyptra profunde multifida glabra fusca angusta; perist. simplicis ext. dentes breves obtusi pallidi. $\dagger$

Brill. I. p. 315. - Leiotheca gracilis Brid. I. p. 730. - Orthotrich. gracile Hook. Musc, Exot. t. 27.

Patriu. Dusky-Bay Novae Seelandiac: Menzics 1791.

2. Folia lanceolata jlus minus acuminata.

\section{a. Robusta.}

a. Folia erecto - patentia.

31. M. tomentosum Isch. (fl. Bras. I. p. 21.); dioicum; repens, dense pulvinatum tomentosum, ramis erectis subsimplicibus, inferne radiculoso-tomentosis, superne foliosis; folia densa erecta, apice paullo incurva, sicca tortilia, linearia mucronulata carinata basi ad medium (papillis?) denticulata, apicem versus integerrima, inferiora fusca, suprema luteo-viridia, nervo subevanido, cellulis circularibus minutis seriatis; theca in ped. vix semiunciali purpurascente erecta oblongo-cylindrica angusta, 4 sulcuta, sicca tortilis, purpurascens, operc. subulato recto duplo breviori luteo-albo, calyptra theca dimidia fere brevior glabra sulcata, lobis 8 ovatis brevibus, inferne ferruginea superne fusca; perist. simplicis membrana tenera integra reticulata albida subhyalina apice fatiscens. $T$.

Patria. Brasilia, in campis Montevidensibus: Sellow.

Auctor M. longirostri Schw. comparavit, sed mirum sane! speciem hancee Norae Iollandiae (Seclandiae!) indigenam ab eo (p. 21.) rectius denotatam in pag. 23. Brasiliae habitantem enumeravit! 
32. M. nitidum Hook. et Wils. (Lond. Journ. of bot. 1814. fasc. Mart.); dioicum; repens, ramis erectis fustigiatim ramulosis dense approximutis luteo-viridibus densifoliis conferte pulvinatum; folia crispula, madore erectopatentia, oblongo-acuminata acuta, upice parum curvata, canaliculata, alis parum convexis, cellulis basi sublunatis, superne minute rotundatis, luteis; perich. late lanceolata cuspidatu tenuiora; theca in ped. longiusculo flexuoso flavido purpurascente ovalis, ore angusto, laevis fuscidula, sicca plicata, operc. conico aciculari recto, aurantiaco, calyptra longe conica glabra, dentibus externis longe infra orificium oriundis granulosis albidis longiusculis obtusis subintegris discretis.

M. microstomum Hsch. (nec Hooker!) Fl. Bras. I. p. 21?

Patria. Brasilia: Gard ner No. 52.

M. Reinwardti haud dissimile, sed ramis multo gracilioribus, nec incrassatis turgidis, nec simplicibus jam primo adspectu distinguendum.

33. M. Reinwardti Schw. (Suppl. II. II. 1. p. 69. 1. 173.); monoicum; longe vepens prostrutum pinnate rumosum, ramis depressis brevibus incrassatis densifoliis upice attematis luteo-viridibus subsimplicibus; folia crispula, madore parum patentia erecto-curvata, e basi lanceolata anguste acuminata acuta erecto-uncinata, profunde canaliculata, margine integerrimo erecto v. vix convexo, cellulis basi sublunate elongatis angustis luteis, superne quadratis multo minoribus incrassatis; perich. late lanceolata acuminata, intima nervo excedente recte et tenuiter cuspidata; theca in ped. elongato flexuoso mujuscule ovata brevicolla laevis fusca, ore plicata, operc. longe et recte subulato tenui, perist. simplici, e dentibus lanceolatis albidis rugulosis discretis linea longitudinali exaratis composito, calyptra glabra.

Leiotheca Reinwardii Brid. I. p. 796.

Putria. Java: Reinwardt primus legit.

Flos mase. in vicinia feminei turgide gemmaceus, fol. perig. late ovatis obtusis crenulatis, acumine brevi acuto terminatis, antherid. majusculis, paraphys. flavidis cinctis. 


\section{STEGOCARPI. ACROCARPI. MICRONITIEM.}

34. N. hemitrichores Schw. (Suppl. II. II. 2. p. 136. t. 193.); dioicum; longe repens, sed dense pulvinatum, ramis brevibus densissime upproximutis robustis densissime foliosis luteo-fuscis subsimplicibus rigidissimis fragilibus subclavatis; folia caulina parum crispula, madore crecto-patentia densissime conferla apice substellatim disposita, oblongn-lunceoluta substricta rigida, canaliculata, alis margine reflexo-convexis, basi papillis elevtis remotis scabris et cellulis flavidis anguste rectangularibus incrassatis, superne rotundate areolata viridia opuca densissime breviter papillosa; perich. lanceolata, intima apice haud opaca; theca in ped. rigido longiusculo purpureo apice flavido elliptica, ore angustata, lacvis, sicca rugulosoplicata, operc. aciculari recto, perist. simplici, dentibus brevibus latiusculis obtusis inflexiusculis ruguloso-albidis, calyptra angusta angulate plicata, pilis simplicibus fuyucissimis pancissimis obtectu, plerumque glabra.

\section{Putric. Nova Ilollandia: G. Sieber.}

Notis cursive impressis facile cognoscitur.

35. M. Mooreroftii Schw. (Suppl. II. 1I. 1. p. 67. 1. 172.); dioicum; longe repens, ramis approximatis longiusculis parce breviter divisis luteo-viridibus; folia caulina crispula, madore flexuoso-patula, laxius imbricutu, apicibus crecto-curvatis, anguste lanceolata acuta acuminata, apice falcato acuto, nervo excurrente, profunde canaliculata, cellulis viridissimis, busi rectanguluribus rectis incrassatis, ad nevum infimum laxis, superne minutissime rofundutis granuloso-opacis, ad marginem erectum tenuiter cremulatis; perich. conformia; theca in ped. purpureo longiusculo oblongo-cylindracea purpureoancenticect, busi aureu, sulcata, operculo recte rostrato, calyptra latiuscule campanulata pilosa, perist. simplici externo, dentibus brevibus albido-rugulosis.

Brid. I. p. 305, 727, 79\%. - Orthotrich. Moorcroftii Hook. et Grev. in Brewst. Edinh. Journ. I. p. 116. t. 4.

Patriu. Nepal, Simiraguc: Dr. Mo or croft.

Notis illustratis, praesertin thecac angulatac colore primo adspectu distinctissima species. 
36. M. Neelgheriense C. Müll.; divicum; laxe pulvinatum longicuule subgrucile valde et elongate fastigiate divisum luteo-fuscescens; folia caulina crispula, madore erecto-patentia, e basi latiuscule oblongà anguste lanceolata longins acutissima curvata hand undulute, cellulis basi angustis longiusculis parum tuberculoso-papillosis, superne multo minoribus subrotundatis obscuris epapillosis; perich. longins et angustins acuminata, superne valde uncinata; theca in ped. Iongiusculo cylindraceo-oralis profunde sulcata, brevicolla, recte rostellata, calyptra glabra straminea, perist. duplici.

M. serpens Mont. in Musc. Neelgheriensil.

Putriu. Hontes Neelgherienses: Perrottet.

Perist. illud. M. sulcuti, e foliis simillimi, sed notis cursive impressis rerte distincti, videtur.

B. Folia reffexa.

37. M. longifolium Brid. (I. p. 309 et 735.); divicum; amoene aureum, inferne tomentosum, ramis longiusculis subsimplicibus; folia caulina valde crispata, madore maxime patula flaceida, elongata ubirne cungustutoInnceoluta ucuminuta acutiuscula, apice minute denticulata, basi longa erecta, superne distincte reftexa flexuosa, margine convexa, apicem versus plus mimes muglosa, cellulae basilares rectangulares incrassatae tuberculosopapillosae, superiores sensim rotundatae, papilla unica notatae igitur unipunctatae, perich. Iongius acuminata; omnia apice cremulato - denticulata subexcurrentinervia; theca in ped. longiusculo flexuoso urnigero-ovalis brevis, sub ore courctuta, profunde sulcuta, cimnamomea, annulata, operculo e basi conica subito aciculari concolori, perist. duplici: dentes ext. bigeminati late lanceolati dense articulati longinsculi, articulis margine rotundatis, interni: membrana alta in dentes multo tencriores breviores, subregulures mucinulos fissu, calyptra glabra.

schlotheimin longifolin sichw. suppl. III. 1. 1. t. 201. - Schl. oblongu Tayl. Lond. Journ, of lot. 18t6. p. 46, ex animadv. Wilson i 1. c. p. 449. huc pertinct. - Urthotrich. longifolium Ilook. Musc. Ex. t. 44.

C. M li ler: Synops. musc, frond. 
Putvia. Ad radices Befuriae glancue alt. 950 hexapod., reg. temperata, in devexis montis Avilae pr. Caracas Columbiae: Humbold t et Bonpland. Silla de Caracas: Moritz. In Andibus prope Quito legit W.Jameson.

A M. cirrhoso proximo notis illustratis longe distat.

38. N. sulcatum Brid. (I. p. 319, 738.); dioicum; M. longifolio simillimum, sed flavo-virens, folia breviora, lanceolata longiuscule acutissima, basi papillis tuberculosa, superne minutissime rotundate areoluta viridia epcopillosu, valde undulata, integra vel obsolete crenulata, basi cellulis nonnullis laxioribus tencris fuscis; theca annulata; peristomium duplex, internum: membrana alta in lacinias irregulares hic illic fissu, calyptra glabra.

Schlotheimia sulcata Hook. Musc. Exot. t. 156. - Orthotrich. sulcatum Honk. et Grer. Brewst. Kidinh. Journ. I. p. 129.

Patria. Nepal: Gardner.

39. M. Regnellii IImp. (in litteris!); divicum; laxe intertextum, ramis elongatis inaequaliter fastigiatim ramulosis gracilioribus mayis teretibus flexuosis luteo-viridibus inferne fuscescentibus; folia crispula, madore reflexa flexuosa, longiuscule ungustate oblongo-lanceolata, haud longe acuminala subulatu, apice tenuiter et argute serrata, alis convexis undulatis, canaliculata, cellulis basi rectangularibus brevibus, papillis tuberculosis scabris, superne minutissimis punctiformibus, nervo excurrente; perich. erecta late lanceolata acuminata plicata pellucidiora lutescentia subintegra; theca in ped. elongato flexuoso purpureo urceolato-ablonga brevicolla, ore angusto, intense fusca nitida, laevissine plicata, operc. conico aciculari recto, calyptra lacvi straminea; perist. duplex: externum e dentibus brevissimis veluti truncatis obtusatis valde trabeculatis latis pallidis in membranam veluti connatis, internum e membrana tenui truncata formata.

Patria. Brasilia, Minas Geraës, ad Caldas: Dr. Regnell.

Notis cursive impressis a $\boldsymbol{M}$. cirrhoso proximo longe distat. 


\section{b. Graciliora.}

c. Folia erecto-patentia.

t. Theca laevis.

40. M. fimbriatum Schw. (II. I. p. 37. t. 111.); repens ramosior, rami crassiores densius foliosi; folia madore erecto-patentia, duplo minora oblonga, mucronata, apice erecto-curvata; perich. oblongo-lanceolata; theca in ped. magis terminali magis elongata oblonga $v$. cylindrica laevis, operculo brevius aciculari, calyptra thecam aequante basi crenato-laciniata, peristomio nullo $? \div$

Orthotrich. fimbriutum P. B. Prodr. p. 80. - Macromitr. uncinatum Brid. I. p. 308, 735, 797. - Weisin uncinala ej. Mant. Musc. p. 42.

Patria. Insula 'Tristan d'Acunha et Franciae: A ub. du Petit-Thouars. An patria duplex recta?

Notis cursive impressis a $\boldsymbol{M}$. acimulari differt.

41. M. serpens Brid. (I. p. 736.); dinicum; longe repens prostratum, ramis tenellis erectis breviusculis gracilibus amoene pallide viridibus inferne ferrugineis subsimplicibus; folia crispula, madore erecto-patentia, apicibus parum erecto-curvatis, dense conferta, oblongo-attenuata obtusiuscula 2 . acutiuscula, alis basi convexoplicatis pellucidis breviter lunate areolatis, remote tenuissime papillosis, superne minutissime areolatis granulose opacis pallidis convexiusculis, profunde canaliculata; perich. intima magis lanceolata ubique pellucida; theca in ped. breviusculo aurantiaco minute elliptica laevis, sicca evacuata leviter plicata, pallide aurantiaca dein fusca nitens, operc. conico tenuissime subulato recto, calyptra thecam aequante amoene maxime multifida pallide straminea, filis maxime singulis simplicibus lic illic tecta; perist. simplicis ext. dentes anguste lanceolati valde rugulosi albidi.

Orthotrich. serpens Hook. et Grev, in Brewst. Hdinh. Jonrn. I. p. 119. t. 5 .

Putria. Prom. bonae spei, ubi in truncis ramisque arborum sylvaticarum pr. George's Plain regionis Anteni- 
qua - Land primus leg. Burchell; Olifantshoek distr. Uitenhagen: Ecklon.

Notis cursive impressis a $\boldsymbol{M}$. subtili affini facillime distinguendum.

42. M. amoenum IIsch. (in Musc. Sieber. Nov. Itoll.); dioicum; M. serpenti simillimum, sed folinrum cellulae basilares rectungulares $v$. rotundate quadratue flavidae multo robustiones distinctius pupillosue, superiores viridissimac; perich. late lanceolata plicata, omnia supra basin granulose reticulata.

Patrie. Nova Hollandia: Sie ber.

Operculum et calyptram non vidimus.

43. M. Japonieum Dz. et M. (Ann. d. sc. nat. 1844. 2. p. 311.); repens, ramis brevissimis erectis simplicibus; folia contorta, madore dense imbricata patula apice erectocurvata oblongo-lanceolata acuminata acuta, canaliculata, evanidinervia, alis convexis, e cellulis ubique minutissime quadratis lapribus busi hic illic larioribus pellucidis areolata; theca crecta ovato-oblonga, operculo convexo-conico subulato-rostrato, calyptra profunde incisa pilosa, perist. simplici, dentibus brevibus.

Patria. Japonia: a Siebold.

A M. subtili et angustifolio notis cursive impressis primo momento differt.

\section{tt. Theca sulcato.}

44. M. Riehardi Schw. (Suppl. II. II. 1. p. 70. tab. 173.); dioicum; longe repens tenellum, ramis brevissimis simplicibus $v$. longioribus breviter et fastigiatim ramulosis viridibus; folia crispa, madore erecto-jotentia, breviter Innceolata rectiuscula canaliculata, nervo in acumen brevissimum exeunte, superne minute rotundate areolata; perich. conformia; thera in ped. longiusculo minute ovata, ore angusto, plicis octo ad orificium profundioribus, in thecue mudidue ventre obliteratis, sicca angustior et profunde plicata, badia, dentibus externis brevibus obtusis pallidis. ' $f$ 
Brid. I. p. 798.

\section{Patria. Guiana: Richard.}

M. filicauli proximum, sed quoad sectionem jam distinctum.

45. M. brachyrrhynchum Schimp. (mst.); divicum; repens intertextum, ramis gracilibus temnibus elongatis parce divisis luteo-ferrugineis, summis apicilus viridibus; folia crispula, madore laxe imbricata erecto-putentia, oblango-lanceolata acuta, parum cureutu, margine convexiuscule flexuoso v. undulato subcrenulato, canaliculata, excurrentinervia, cellulis basi quadratis minutis subpellucidis, superne grossius rotundute hexugonis tenuissime papillosis; perich. magis acuminata, cellulis superne magis ellipticis; theca in ped. brevi suburceolutooblongu brevicolla, sulcutı fusca, dein brunnea, annulata, operculo conico recte aciculari breviusculo, calyptra thecam subaeguante angusta laevi; perist. externi dentes in membranam carnosulam upice crenato-rotundatam truncatum veluti comuti, interni membrana vix conspicua tenuissime membranacea truncata.

Schlotheimia brachyrrhyncha schw. Suppl. 11 11. 1. p. 53. tah. 168. - Brid. I. p. 800. - Schloth. riticulosa Radd. Critt. Bras. p. 28? sen Hacromitr, eiticulosum Brid. 1. p. 73*.

Putriu. Brasilia, ad saxa pr. Rio Janeiro: Beyrich.

Notis cursive impressis alb affinibus facile distinguitur. Calyptram nobis saepius visam, a Schwägrichen subpilosam dictam, glabram semper invenimus.

46. M. Didymodon Schw. (Suppl. II. II. 2. p. 138. 1. 190.); monoicum; prostratum, ramis ascendentibus gracilibus teneris luteo-viridibus breviter ramulosis; folia erispata, madore erecto-patentia, upicibus erecto-curcutis, oblongo-attenuata, apice purum incurruta, profunde canaliculata, ala una muxime comrexo-reflexa, alterce planinsculu, cellulis grosse rotundis et turgide popillosis diaphanis subopacis, nervo evanido; perich. erectu late Ianceolata cuspiclata; theca in ped. longiusculo purpureo crasso flexuoso minute cylindraceo-ocalis microstoma, 


\section{STEGOCARPI. ACROCARPI. MACRONITHUM.}

8 plicata pallide fusca leptodermis, calyptra anguste conica sordide straminea, basi parum laciniatu truncuta thecu breviore appresso-pilosu, operc. recte aciculari; perist. simplicis dentes solitarii latiuscule lanceolati obtusi ruguloso - albidi.

Patria. Brasilia, ubi ad vicum Novo-Friburgum primus legit Beyrich mens. Decbr. Serra dos Orgaòs: Gardner No. 5t. Insula St. Catharina: Pabst, Juu. et Julio $184 \%$.

F'los masc. ad basin rami fertilis minutus, fol. perig. parvis late ovatis subligulatis.

47. M. macrothele C. Müll. (Bot. Zeit. 1848. p. 766.); dioicum; late dense pulvinatum tenellum densifolium rubiginosum, apice solo luteo-viride, repens, ramis humilibus subsimplicibus; folia dense crispula, madore erectopatentia, angustissime lanceoluto-acuminatu, nerro excedente longiuscule mucronata apice erecto-curvata, canaliculata, alis planiusculis, cellutis grossiuscule hexagone rotundatis, ob papillas granulosas opacis, basi majoribus rectangularibus angustis incrassatis ob papillas solitarias verruciformes mammillate tuberculosis; perich. brevia, late lanceolata acuminata, cellulis grossiuscule ellipticis; theca in ped. brevi minute pyriformi-oblonga sublongicolla profunde sulcata brunnescens, operc. recte subulato, calyptra nuda; perist. duplex, externum: dentes arctissime approximati, in membranam veluti conflati aurantiaci, internum: membrana rugulosa albida altiuscula, in dentes irregulares fugacissimos fissa.

Putria. Columbia, Galipan prov. Caracas, alt. 5000': Funck et Schlim in Coll. Linden. No. 364, in lapidibus humidis. Varietatem fol. magis flexuosis ad trunc. arbor. prope Lagunitta prov. Meridae alt. 6000', Septbr. lect. sub No. 993 accepimus.

Notis cursive impressis species tenella facile cognoscenda.

\section{B. Folia reflexa.}

48. M. Iongienule C. Müll.; dioicum; longicanle parce divisum luteo-virens, ueyualiter gracile; folia cau- 
lina crispula, madore reflexa, e basi erecta oblongà valde reflexa anguste lanceolat acuminata, apice remote et obsolete denticulata, liaud rugulosa, cellulis basilaribus lunatis pellucidis elevato-papillosis, cacteris supra basin brevem positis quadratis obscuris veluli granulosis diaphanis, nervo evanido; perich. conformia; theca in ped. brevissime exserto globosu laevis badia, operculo recte rostrato, peristomio simplici: dentibus sedecim discretis late lanceolatis granuloso-albidis, calyptra late campanulata apice parum hirtu, pulchre plicata et laciniata.

M. cirrhosum Mont. in Hb. Miquel.

Patria. Java: Miquel Hb.

A $\boldsymbol{M}$. cirrhoso parum simili notis cursive impressis longe distat.

49. M. nngustifolium Dz. et M. (Ann. I. sc. nat. 1814. 2. p. 311.); dioicum; repens, ramis ascendentibus approximatis longiusculis gracilibus densifoliis simplicibus v. fastigiatim divisis, ramis brevioribus intermixtis, sordide flavidis; folia valde crispula, madore horisontalia, apicibus erecto-currutis, lineari-lanceolata, basi erecta, medio reflexa, apice curvata, acuta, margine integro erecto v. parum convexo, profunde canaliculata excurrentinervia, cellulis pallidis, basi breviter lunatis pellucidis, superne minute quadratis opacis sublacvibus; perich. conformia; theca in ped. breviusculo subyloboso-viculis, evacuata urceolula, obsulete plicutu, fusca, operc. conico recte aciculari, calyptra angusta pilosa, perist. simplici, dentibus brevibus irregulariter lanceolutis tenuiter membrunaceis laevibus veluti obsoletis.

Putria. Amboina, unde habemus, Sumatra, Borneo, Java.

Ex habitu $\boldsymbol{M}$. longicuuli affine et notis illustratis facile discernibile.

50. M. semipellucidum Dz. et M. (Ann. d. sc. nat. 1844. 2. p. 311.); divicum; longe prorepens flexuosum vage ramosum, ramis rectis brevibus tenellis densifoliis luteis simplicibus; folia caulina crispula, madore subhori- 


\section{$7 H 4$ STEGOCARPI. ACROCARPI. MACROMTRUM.}

zontalia apicibus patentibus, hand erecto-curvatis, anguste lanceolata obtusiuscula, nervo excerlente breviter mucronata, substrictu, margine integerrimo saepe undulato erecto vix convexo, profunde canaliculata, basi longu pelIncida e cellulis breviter lunatis reticulata, superne cellulis minutissimis rotundutis maxime opncis tenuissime granulosis; perich. conformia; theca in ped. breviusenlo ovato-oblongu basi plicata, operculo convexo subulato, calyptra pilis appressis parum hirta angusta.

Putria. Borneo: Korthals.

A M. ungustifolio notis cursive impressis facile distinguitur. Thecam et peristomium (nullum?) non vidimus.

51. N. subtile Sichw. (Suppl. II. II. 2. p. 140. 1. 192.); dioicum; longe repens tenellum, ramis vagis breviusculis gracilibus subsimplicibus luteo - viridibus; folia caulina crispula, madore laxissime conferta tener"l subhorizontatlia, erecto-flexuosa, anguste lenceulatu ucruminula ucuta mucronata, basi erecta brevi pellecida lunato-areolatit, medio reflex $a$, apice erecto-curvata, superme valde opaca granulosa viridia, margine plerumcue convexo; theca in ped. breviusculo minute ovalis sublatevis, operculo conico acuto recto, perist. mullo, calyptra anguste conica pilosiuscula.

M. incurvifolium Mont. Voy. au Pòle sud.

Putriu. Otaheite: Menzies primus legit.

A M. semipellucidu notis cursive impressis distat, a M. angustifoilo statura multo teneriore humiliore, therae forma, peristomio carente et foliis superue multo obsentrioribus laxissime imbricatis distinguitur.

52. M. acienlare Brid. (Mant. Musc. p. 132.); dioicum; longe repens, ramis erectis subsimplicibus longiusculis $\mathrm{v}$. brevibus pallide viridibus tenellis gracilibus subteretibus; folia in scries obliquas contorta crispula, madore reflexu, ungreste lunceolutu ucruminutu ucutu, basi crecta, superne reflexo-curretu, rarinata, alis convexis, cellulis hasilaribus pellucidis breviter lunatis, superioribus minu- 
tis punciformibus opacis granulosis; perich. perfectius lanceolate erectu; thera in ped. longiusculo subglobosa parel laceis, operculo subulato recto, calyptra maxime et profunde laciuiata glabra, dentibus externis brevibus geminatis lanceolatis albidis.

schw. suppl. I1. I. p. 35. t. 111. - Brid. 1. p. 307, 730. orthotrich. aciculare How. et Grev, in Brewst. Ediub. Journ. I. p. 114. - 0. pallidum P. B. Prodl. p. 81. - 0. brere ej. I. c. p. 80 . quod bridel sub nomine ..O. laere" P. B. false escripto ad schlotheim. torguatam retulit. - Ncholh. aciouluris Brid. Sp. Mus:. 11. p. 21. - Trichostom. arbustorum ej. I. c. 1. P. 211. Lasia acicularis spreng. in steud, Nom. Cryt. p. 231.

Patria. Insulae Bourbonis et Franciae: A ubert d u Petit Thouas.

53. M. filicanle C. Müll.; lioicum; longe et flexuose repens, ramis rectis curvatis gracilibus tenellis breviusculis luteo-viridibus subsimplicibus; folia in series obliquas contorta crispula, madore rellexa, brevia, lanceolato-acuminata, apicibus sacpe attenuatis curvatis, angusta, camaliculata, alis vix convexis, cellulis huteis, busi angustis clongatis densis, superne mimute quallulis; perich. late Ianceolatu nervo excedente longiuscule mucronatu; theca in ped. elonguto flexuoso tenui purpurascente flavido perfecte ovalis parvela brumescens nitidu lasis, ore plicuta, opreve. longe subulato oblipno, dentibus refernis brevibus oblusis carnosulis ruguloso-albidis.

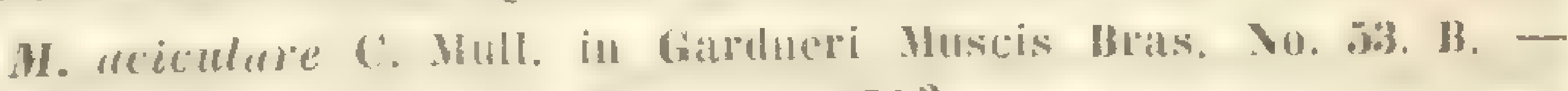
M. microstomum Hsch. H. Bras. 1. p. 21?

Putria. Brasilia: Gardner.

A $\boldsymbol{M}$. aciculari, habitu affini, notis cursive impressis longe refugit; a 1 . Richurdi folis perfecte reflexis jam distat.

54. M. orthostichum Nees (in Schw. Suppl. 1V. 1. 316.); divicum; repens, sed inferne intertextum radienlosum, ramis erectis pluries beviter ramulosis luteo-viridibus gracilibus rigidiusculis; folia crecto-imbricata crispula, mulore vulde syurerrosu, breviler lanceolatu reAlex, nervo excedente mucronata carinata, alis hic illic 
convexis, cellulis ubique hexagonis ampliusculis pellucidis mollibus pottivideis, integra; perich. maxime reflexa; theca in ped. brevi ubique scaberrimo crasso rubro subgloboso-ovalis magna laevis badia, operc. conico-aciculari brevi, perist. simplici interno, e membrana truncata brevi composito, calyptra thecam totam obtegente, pilis patentissimis fuscis valde hirta.

\section{Patria. Java: Junghuhn.}

Areolatio perfecte pottioidea et species excellentissima. - PI. mascula gracilior, fioribus pluribus terminalibus minutiuscule gemmaceis, fol. perig. parvis late ovatis acuminatis, basi tenuiter laxe reticulatis.

3. Folia oblongo-ligulata mucronata.

55. M. mueronifolium Schw. (Suppl. II. II. 1. p. 61. t. 170.); monoicum; longe repens tenellum, ramis brevibus gracilibus subsimplicibus plus minus approximatis, quare plus minus dense pulvinatum, viride, inferne ferrugineum; folia crispula, madore subreflexo-patentia, arcte imbricata, oblongo-ligulata obtusa, mucrone brevi reflexiusculo terminata, ruguloso-plicutu, tenera, canaliculata, excurrentinervia, alis convexis integris pallide viridibus ubique minute rotundate areolatis, basis margine limbo angustissimo incrassato praeditis; perich. conformia; theca breviter pedunculata urceolato-ovalis brevicolla laevis leptodermis sordide fusca, sicca evacuata basi plicata, gymnostoma, angustissime annulata, operculo conico subulato recto, calyptra thecam dimidiam obtegente glabra, profunde laciniata, laciniis distantibus.

Leiotheca mucronifolia Brid. I. p. 729 et 795. - Orthotr. mucronifolium Hook. et Grev. in Brewst. Edinb. Journ. 1. p. 116. t. 4.

Putrie. Insulae Antillarum Trinidad, St. Vincent, Guiana Batavorum, Brasilia plaua, vulgare: Sicber et Crüger, Menzies, Weigelt et Kegel, Beske.

Flos masc. in ramo proprio caulis fertilis repentis minutissime gemmaceus, foliis perig. ovato-acuminatis, antheridiis et paraphys. paucis. - Species foliis ligulatis ad Schlotheimias sect. Ligulariue accedens, distinctissima. 
56. M. Swaingoni Brid. (I. p. 318.); dioicum; late dense pulvinatum subcompactum humile densissime foliosum repens, ramis brevibus brevissime ramulosis luteoviridibus inferne ferrugineis; folia crispula, matore patentia arcte imbricata, late oblongo-ligulata obtusissima, mucrone recto brevissimo terminata, hic illic plicuta nec rugulosa, dilatate canaliculata, alis convexis integris obscure viridibus, robustius rotundate areolatis, basi vix conspicue papillata margine limbo angustissimo pallido praeditis; perich. magis acuminata; theca $\boldsymbol{M}$. mucronifolii, sed minor, calyptra longe multifida, lacinis densius approximatis; perist. simplicis dentes externi longiusculi albidi subintegri.

Leiotheca Swainsoni Brid. I. p. 730. - Orthotrich. Nucainsoni Hook. Musc, Exot. t. 127.

Patria. Brasilia, pr. Rio Janeiro: Swaiuson. Cuba: Döring, cujus specimina descripsimus.

Peristomium thecarum vetustarum spec. nostrorum non vidimus. - A. M. mucronifolio proximo notis illustratis facillime distinguitur.

57. M. stellulatum Brid. (I. p. 314, 741.); dioicum; M. Suainsoni simile, sed rami foliis subhorizontalibus upice stellatim foliosis; folia densissime imbricata, late oblongo - ligulata breviter acuminato - mucronata, superne mimutissime rotundate, basi ninute quadrate areolata distincte tuberculose papillata, limbo marginis carentia, alis valde convexis plicate gibbosis; perich. late lanceolata acuminata plicata pallicliora magis elliptice areolata subcrenulata; theca in ped. longiusculo oblongo-ovatu sulcuta pallide fusca, operculo conico acuto breviusculo, calyptra thecam $2 / 3$ obtegente laevi profunde multifida, laciniis distantibus; peristomium duplex, externum: dentes longiusculi late lanceolati dense trabeculati densissime approximati in membranam veluti connati, ruguloso-albidi, latere crenati, internum: dentes totidem, externos aequantes, tenues lanceolato-subulati albidi in membrana brevissima positi. 
Schlotheimia stellulata Hsch. in Hor. Phys. Berol, p. 61. t. 12.sidsügr. suppl. II. 1. 2. t. 249. - Orthotrich. stellulutum Hook. et Grev. in Brewst. Hdinf. Journ. 1. p. 119. - Macrumilr. Swainsoni Hook, et Wils, in Galuer. Muse. Bras. Mo. Mo! - N. ruhthocarpum Hsch. Fl. Bras. 1. p. 26. e spec. Hl,. Acad. Monacens, forma foliis minus horizontalibus.

Patria. Brasilia, ad flum. Orinoco: Hb. IVilldenow; dein leg. Pohl., in prov. Goyaz pr. Arrayas leg. Gardner mens. Martii. Coll. No. 60.

58. M. fuscescens Schw. (Suppl. II. II. 2. p. 129. t. 191.); late laxius pulvinatum breviusculum longe repens, ramis brevibus saepe iterum repentibus simplicibus v. fastigiatim divisis remotiusculis laxiuscule foliosis fuscescentibus; folia tortilia, madore patula erecta, Iuteofusca, lanceoluto-obtusa, nevvo crasso in cuspidem longinsculum moducto, ferrugineo, cellulis subrotundis, basi clongato - quadratis; perich. conformia; theca in ped. brevi rufo ovato-oblonga laevis, apice et basi plicata, badia, operc. conico acuto recto, brevi, concolori, calyptra anguste conica nuda multifida nitens, flavo-badia; perist. dentes breves albidi. $f$.

Patrice. Insulae Narianae: Gaudichaud.

Macromitria non satis nota.

59. M. punetatum Brid. (I. p. 739.); caulis decumbens? folia laxa lineari-oblonga acuta punctata pellucida plana patula, nervo evanido, sicca insigniter involuta; theca oblongo-pyriformis sulcata, calyptra junior apice subpilosa, inferne sulcata basi fimbriata, operculo conico brevi aciculari. t.

Orthotrich, punctatum Hook, et Grev, in Brewst. Hdinl. Journ. 1. po 119. to 5. co ic, pauperrimis.

Patria. Brasilia inter M. fliforme: Raddi.

Ex animadv. auctorum prim. species solitaria, cujus folia illis Cathurineue undulutue similia dicuntur. An M. Didymodon?

60. M. quinquefarium Hsch. (F'. Bras. 1. p. 26.); caulis declinatus ramosus apice stoloniformis, ramis secundis erectis subsimplicibus dense foliosis rulis; folia 
quinquefaria patentia, sicca appressa crispula, cordatoovata obtusiuscula concava, margine parum revoluta, viridi-ferruginea, nervo crasso solido ferrugineo evanido, cellulis rotundis seriatis pusillis; perich. interiora basi submembranacea, oblongo - lanceolata longe acuminata, nervo angustiore concolore supra medium evanescente, cellulis laxis, basi subquadratis, intima lanceolata mucronata; theca in ped. semiunciali apice in sporangium transiente erecta clavata 8 sulcata, amoene badia, ore angustata; perist. dlentes ext. lanceolati bigeminati, igitur octo lato-lanceolati ferruginei, interni octo filiformes articulati lutescentes, ex unica serie cellularum formati. t.

Patria. Brasilia, in montibus ad Lages, Sincora et ad Rio de Contas, in mediterraneis prov. Bahiensis: Martius.

61. M. undulatum Schw. (Suppl. II. II. 2. p. 137.); laxe pulvinatum biunciale repens, ramis erectis aliquoties divisis, numerosis tumidis pallide luteis, ramulis fastigiatis; folia longinscule oblongo-ligulata oblusa mucromulata, margine insignifer undulata, sicca tortilia, cellulis subrotundis, basilaribus subquadratis triplo majoribus, mo more Syrrhopodontium pellucidis laxis, theca oblongocylindracea laevis, operculo aciculari longo recto, calyptra thecam stperante multifida pilosa. $\leftarrow$.

Leiotheca undulata Brid. I. p. 733. - Orthotrich. undulatum Hook. et Grev. Brewst. Edinh. Journ. of hot. p. 11\%, t. 4. c. ic. pauperrimis.

Patria. Insula Ternate: IIb. Dickson.

62. M. involutifolium Schw. (Suppl. II. II. 2. p. 144.); repens, ramulis brevibus intumescentibus, folia oblongo-lanceolata obtusiuscula apice insigniter involuta, substriato-carinata, theca oblongo-ovata laevis, calyptra inferne laciniata. $f$.

Leiotheca inmolutifolin Brid. I. p. 733. - Orthotrich. involutifolimm Hook, et Grev. Brewst, Edinb. Journ. I. p. 117. t. 5. c. ic. pauperrimis. 
Putria. In freto King George's Sound: IIb. Dickson. Nova Seelandia et Paramatta Novae IValesiae australis: Hb. Hobson.

63. M. incurvifolium Schw. (Suppl. II. II. 2. p. 144.); repens, folia lanceolato-acuminata, carinata, apice incur'va, sicca crispata, theca ovata laevis, calyptra longe laciniata pilosa, operc. aciculari recto. $\leftarrow$.

Leiotheca incurvifolia Brid. I. p. 732. - Orthotrich. incurvifolium Hook. et Grev. Brewst. Edinb. Journ. I. p. 117. t. 4. c. ic. pauperrimis.

Patriu. Insula Ternate Archip. Indici, et in freto King George's Sound dicto: Dickson Hb.

61. M. subtortum Schw. (Suppl. II. II. 2. p. 145.); caulis repens, ramis erectis, fusco-brunneis biuncialibus, folia lanceolato-acuminata carinata oblique recurva, sicca subspiraliter torta, theca ovato-oblonga, ore sulcato. $\leftarrow$.

I.eiotheca subtorta Brid. I. p. 734. - Orthotrich. subtortum Hook. et Grev. Brewst. Edinb. Journ. I. p. 117. t. כ. c. ic. pauperrimis.

Patria. India orientalis.

Plantac speciosae, ex animadv, auclorum habitu $\boldsymbol{M}$. longifolii, sed incomplete notum.

65. M. recurvifolium Brid. (I. p. 740.); caulis repens, folia ovata longe acuminata carinata, recurvata, sicca spiraliter torta, perich. majora convoluta, theca ovato-oblonga laeviter sulcata. $\dagger$.

Orthotrich. recurrifolium Hook. et Grev. Brewst. Edinh. Journ. I. p. 120. t. 5. c. iconibus pauperrimis haud explicabilibus!

Patria. Java, unde Dickson jam habuit.

$$
\text { Species delenda. }
$$

Rrachypodium parasiticum Brid. (1. p. 149.); caulis erectus subsimplex, sterilis brevissimus, fertilis longior, folia dense conferta patula subreflexa, lanceolatolinearia carinata, sicca margine undulata, nervo crasso ferrugineo continuo; perich. conformia erecto-conniventia ; theca in ped. perbrevi saepius gemello apice incrassato vix tortili brunneo erecta cylindrica laevis, operc. e con- 
vexiusculo subulato thecam aequante, dentibus sedecim parvis erectiusculis trabeculatis albis, calyptra junior longe subulata pallida ore aequali, latere demum fissa. $f$.

Ëncalypta parasitica Sw. FI. Ind. Occ. III. p. 1739. - Schw. Suppl. I. I. p. 60. t. 17. - Anictangium parasiticum Brid. Sp. Musc. I. p. 270. - Bryum parasiticum Sw. Prodr. kl. Ind, Occ. p. 139.

Patria. Hispaniola, in ramis Hucmutoxyli et Mimosae Unguis cati: Swartz.

Habitum Macromitrii refert quidem, sed rectius sentiente Hookero Calymperes videtur.

\section{Gen. XVI. Schlotheimia Brid.}

Mant. Musc, p. 114. t. 1I. f. 10, et Br. univ. I. p. 320. - Orthotrichum et Macromitrium C. Mïll. errans.

In honorem investigatoris palaeontologici celeberrimi Gothani a Schlotheim ab auctore amico genus egregium conditum.

Calyptra campanulata glabra, i.e.haud plicata, basi laciniis involutis constricta. Perist. dentes $e x$ terni in spiram revoluti, sedecim, linea Inngitudinali exarati, plerumque valde rugulosi carnosi; interni totidem jolus minus perfecti, saepe rudimentarii, e membrana pallida oriundi. Theca exannulata. Operculam omnium cupulatum recte subulatum leptoderme tenero-reticulatum. Cactera Macromitrii.

Habitu, praesertim calyptra, Encalyptas in memoriam valde revocantes, e reliquis Macromitriis proximae species.

sectio 1. Aracilaria. Caulis filiformis subteres, foliis appressis, in spiram contortis oblongis, laevibus, nec plicatis, nec corrugatis.

S. squarrosa Brid. (I. p. 324.); dioica; laxe pulvinata elata flexuosa, innovationibus brevibus valde divisa, rigida, intense fusca; folia caulina dense appressa, subspiraliter conferta, madore in orthostichas obliquas plures distinctas disposita, squarrosa, breviter reflexiuscule et anguste oblonga, nervo excedente acute apicu- 
lata, profunde canaliculata, magine hic illic vix revoluto, cellulis amoene fuscis, ubique conflato-incrassalis rhomboidaliter quadratis minulis; perich. latiora magis concava; theca in ped. tenuissimo longo, innovationes superante $\mathrm{v}$. occulto, inter furcam innovationum posito minute obovata fusca, sicca plicata, brachydonta, calyptra parva, basi tumida, appendicibus 4 brevibus latis, intense fusca, nitida, laevissima.

Schloth. squarposa s'dew. Suppl. I. II. p. 39. t. 56? - Orthotrich. squrrorosum Hook. et Grev. Brewster Edinh. Jumrn. I. p. 128.

Petriu. Insula Bourbonis: Hb. Mo nt a gin.

Ab ommibus congeneribus teneritate partium omnium primo adspectu differt et Mucromitr. filiformi haud dissimilis.

Sertio II. Acuminella. Caulis robustus densifolius, foliis appressis in spiran ronturtis lanceolato - aruminatis, v. cuspidatis laevibus vel corrugatis.

\section{a. Theca immerst.}

2. S. teeta IIook. et Wills. (Isond. Journ. of bot. 1844. p. 157.); dioica; clatiuscula subrobusta, ramis brevibus dichotomis strictis, ubique ferruginea, inferne nuda; folia caulina dense imbricata leviter spiraliter torta, madore patentia, lanceolato-acuminata, latiuscula, complicate concara, margine hic illic parum revoluto, apice breviter dentato, cellulis basi angustis longis rectangularibus, superne sensim rotundatis, ubique incrassatis, excurrentinervia; perich. in cuspidem elongatam crassam flexuosam producta; theca immersa majuscule ovalis laeris, dentibus ext. et int. Iongiusculis, his angustis pallidis rugulosis subbifidis, calyptra magna firna intense fusca, apice scaberrima.

Schloth. immersa ('. Vüll. Bot. Zeit. 1814. P. 7 10. - Macromitr. immersum 6. Miill. Bot, Zeit. 18t.5. P. 5.12.

Patria. Brasilia, Siera dos Orgàos: (farduer No. 71.

E pulcherrimis et distinctissimis. 
b. Theca exserta.

3. s. quadrifida Brid. (Mant. Musc. p. 114.); humilis erecta parce dichotome robusta densifolia basi tomentosa, apice incrassata, viridis, inferne ferruginea; folia densissime conferta parum tortilia, madore erecto-patentia, oblongo-acuminata, nerro in cuspidem plus mimus reflexum longiusculam producta, margine convexo, cellulis minute circularibus basi parallelogrammis; perich. conformia immersa; theca in ped. pseudolaterali elongato flexuoso oblongo-cylindracea, laevis brunnea, operc. recte longe subulato, calyptra laevi brunneo-fusca, basi appendicibus 4 latis, dentibus ext. longis angustis, int. irregularibus in membrana breviuscula positis. $\dagger$.

Brid. I. p. 321. - schw. suppl. I. II. p. 41. t. 57. - Orthotr. qundrifulum Ilook. et Grev, in Brewst. Edinh. Journ. I. p. 128. O. angulosum P. B. Prodr. p. 90. fide schwägrichen.

Patria. Insulae Bourbonis et Franciae: A ubert du Petit-'thouars.

Notis illustratis a sequente longe differt. - In insula 'Tristan d'Acunha Africae occidentali-meridionalis, verosimiliter attamen false, enumeratur.

4. S. Camplelliana C. Müll.; dense pulvinata, inferne radiculosa, robusta densifolia, nitide ferruginea, subhumilis, ramis erectis parce et breviter dichotomis; folia caulina subspiraliter torta, madore crecto-patentia, basi verala, medio angustiora, suprerne latiora, apice lumina! inceynali rotundata emurginata pracilitu, rarius acuminata, nervo profunde canaliculato intense fusco in uristum crassam longam luevem producta, cellulis grossis rhomboidaliter quadrate incrassatis conflatis aureis, basi rectangularibus pellucidioribus, basi subcomplicate concava, interdum parum rugulosa; perich. breviora magis oblonga tencriora; theca in ped. longiusculo flexo cylindrica, sicca plicala.

S. quadrifula Hook, et Wils, in sched.

Patria. Insula Campbelli: J. D. II o oker.

E distinctissimis et pulcherrimis! cujus foliorum forma Syntrichias refert.

c. Muller: Synops, musc, frond. 


\section{S'TEGOCARPI. ACROCARPI. SCH.THEIM.}

sectio 11. Tigularia. Caulis rohustus densifolius, foliis appressis in spiram contortis, oblongo-ligulatis, corrugatis v. laevibus,

\section{a. Calyptra glabra, plus minus scabra.}

a. Folia distincte torquata.

t. Humiles.

כ. S. nitida Schw: (Suppl. II. II. 1. p. 5̈1. t. 167.); dioica; dense pulvinata inferne tomentosa, humilis, ramis erectis dichotomis viridibus, inferne fuscis, robustiusculis; folia caulina distincte spiraliter torta, oblonga, obtusiuscula, nervo rufo excedente reflexiuscule apiculata, perfecte incrussule rotundate, busi elliptice, haud rhomboidaliter ureolutu, superne valde rugulosa, magis carinate basi subentricose concava, perich. conformia, majora pauca, latiora, magis acuminala recte apiculata, plicata, theca in ped. brevi pureula cylindricu angustu, evacuata plicata, dentibus ext. et int. breviusculis, calyptra amoene aureo-luteu valde nitida, apice vix scubra.

Bril. I. p. 798.

Patria. Brasilia, in Serra dos Orgaos pr. Rio Janeiro primus leg. Beyrich. Insula Stae. Catharinae vicina: Pabst.

A S. rugifolia notis cursive impressis differt.

6. \$. fusco-viridis IIsch. (Fl. Bras. I. p. 32.); dioica; S. nitidae simillima, sed minus torquata et magis fusca; folia caulina breviter oblongo-ligulata, breviter et reflexiuscule apiculata, basi subventricose concava, superne haud vel vix plicata, alis convexis, cellulis rotundis minutis, dein pachydermibus diaphanis, basi tenerioribus subrectangularibus; perich. conformia, intima acuminata minora angustiora haud plicata; theca in ped. brevi erecta, juvenilis cylindrica, calyptra nitida fusco-lutea, superne vix scabra.

Putriu. Brasilia, Villa Rica in cort. arborum: Martius.

7. S. Kegeliana C. Müll.; divica; S. fusco-viridi simillima, innovationibus repentibus gracillimis, obscure 
viridis; folia caulina busi uno latere, rarius quoque altero, ventricoso-concura, cellulis amoene fuscis et diaphanis pachydermibus, folia innovationum repentium angustissime oblonga viridissima, cellulis minute rotundis obscuris; perich. latiora carinato-concara laevia vix undulata; theca in ped. brevi minuta cylindrico-oblonga, sicca subrugulosa, operc. cupulato brevi, dentibus ext. et int. aequaliter longis, breviusculis, calyptra intense fusca, superne scaberrima.

Macromitr. Kegelianum C. Müll. Linn. XXI. p. 187.

Patria. Surinam, pr. Paramáribo, locis magis apricis, ad trunc. arborum, ubi in scissuris bene viget: Kege 1, Julio 1844. Rara.

Notis cursive impressis a $S$. fusco-viridi refugit.

8. S. Brownei Schw. (Suppl. II. II. 1. p. 52. t. 167.); dioica; repens, ramis fastigiatis brevibus dichotomis, fusco-viridibus robustiusculis; vix tomentosa; folia caulina parum spiraliter torta, oblonga obtusiuscula, acute et recte apiculata, nervo evanido, superne profunde canaliculato, alis convexis parum rugulosis, basi concava, haud ventricosa, cellulis S. nitidae, sed minoribus, perich. conformia haud rugulosa, parum latiora; theca in ped. longo cylindraceo-oblonga, sicca plicata, operc. conico recte subulato, calyptra intense fuscu, apice vix scabra, dentibus ext. longis angustis, int. cerpualibus e membrana longa pallida oriundis.

Brid. I. p. 799. - Macromitr. Brounei C. Miill. Bot. Zeit. 1845. P. 54.

Patria. Nova Hollandia, ubi ad Port Jackson legit H. Brown.

Notis cursive impressis a $S$. nitida affini differt.

9. S. ferruginen Brid. (I. p. 743.); dioica; late depresse et densiuscule pulvinata, repens, ramis brevibus turgidis robustis vix ramulosis, foliis in spiram contortis apice acutis, luteo-fusca nitida mollis; folia caulina madore erecto-confertu, longiuscule anguste oblongo-ligulata, recte apiculata, superiora sensim magis acuminata, 48 * 
ubique profunde canaliculata $थ$. basi plus minus ventricosu, superne rugulosa, juniora laeviora, cellulis minute rotundatis, basin maesertim ad nevvum versus sensim vomboidulibus, infima basi magis rectangularibus teneris, alis saepe valde convexis; perich. basi latiora multo teneriora pallidiora, interiora longiuscule acuminata, haud rugulosa; theca in ped. longiusculo anguste cylindrica, sicca sulcata, operc. longe subulato, dentibus ext. brevilusculis, int. in membrana brevissima duplo brevioribus fugacibus, calyptra acutissima, pulchre struminea nitida laevissima, appendicibus longis teneris subsenis.

Macromitr. ferruginenm c. Müll. Bot. Zeit, 1845. p. 544. orthotrich. Ferruyineum Hook, et Grev, in Brewster Edinb. Juurls. 1. p. 118, to 5 .

Patria. Prom. b. spei, ubi hand rara truncos arborum in montibus sylvestribus habitat: Burchell, Ecklon; Drege.

A S. Brownei haud dissimili notis cursive impressis longe recedit.

10. S. ventrosa C. Müll.; divica; S. rugifoliae simillima, sed folia caulina distinctius etsi parum toryuata, basi uno rel altero proune latere ventroso-concava, e cellulis mimute rotundatis pallide rividibus basi ellipticis $r$. rectungulavibus areolata, valde rugulosa, perich. immersu late lanceolato-acuminata, parum majora, nec rugulosi nec plicata; theca angustius cylindrica brevicolla laevissima v.obsolete striata cinnamomea, dentibus brevioribus tenuioribus, calyptra apice scaberima appendicibus 4 latis intense fusca.

Patria. Prom. b. spei, Olifantshoek in Districtu Citenlagen: Ecklon. Hb. Kunz.

11. S. Sullivantii C. Müll.; divica; humillima demesse late pulvinata prostrato-repens fusco-viridis, innovationibus breviter pinnatis, densifolia, folia caulina dense imbricata forquata, madore erecto-conferta breviter oblongo-ligulata obtusa, breviter apiculata, value corrugata, basi uno lateve vel altero quorue latere ventricose 
concuva, alis convexis, cellulis minute rotundutis, ad busin teneriorem rhomboidalibus; perich. immersu, interna pauca late lanceolata nec majora nec rugulosa; theca in ped. perbrevi minute orulis laevissima, evacuata plicata, dentibus ext. brevibus, int. breviuribus, calyptra intense fusca, apice minus scabra.

Sch. rugifolia sulliv, Musc. Allegh. II. No. 146.

Patria. America sept. Cn., ubi in Ludovicia arborum corticem habitat.

A S. rugifolic notis cursive impressis longe refugit, a ceteris congeneribus jam exiguitate differt.

12. S. Chamissonis IIsch. (Fl. Bras. I. p. 31.); dense pulvinata robusta densifolia, dense ramosa atro-fusca, ramis brevibus simplicibus; folia caulina appressa torquata, madore erecto-imbricata, lineuri-lanceolutu obtusa canaliculata, nervo crasso ferrugineo brevissime mucronata, margine parum involuta, subinde longitudinaliter plicuta cellulis basi linearibus, superne rotundis obscuris; perich. interiora oblongo-lanceolata, intima minutu oruto-ucuminuta temeissima raginata, basi hyalina, upicem rershs pellucida, nereo crusso vividi eranido, theca in ped. bilineari erecta cylindrica angusta laevis, ore purpureo, calyptra fuscescente laevi (?). †.

Macromitr. Chumissonis C. Mäll, Bot. Zeit. 1845. p. $5 ! 3$.

Petrie. Insula Sta. Catharina Brasiliae: Chamisso.

A S. rmyifolia notis illustratis certe distare videtur.

\section{tt. Elatiores.}

13. S. Jamesoni Brid. (I. p. 7.12.); divira; laxe prostrato-pulvinata, ramis ascendentibus longiusculis breviter dichotomis luteo-ferrugineis subgracilibus, folia pulchre torquata, madore erecto-patentia lute lunceuluto-ligulatu $\because$ acuminutu, complicate canaliculata, apice reflexiuscule apiculato, alis flexmosis, hand monhlusis, convexiusculis, cellulis minute rutundatis, basi ellipticis; perich. longe acuminata exserta, laevia complicata el plicala; theca in ped. elonguto majuscule cylindraceo-oblonga bre- 


\section{8}

STEGOCARPI. ACROCARPI. SCHLOTHEMA.

vicolla laevis, evacuata subplicata cinnamomea, operc. majuscule cupulato acute subulato, dentibus ext. longis, valde rugulosis, int. in membrana longa pallidioribus rugulosis brevioribus, calyptra apice scabriuscula intense fusca.

schw. Suppl. III. I. 1. t. 202. - Macromitr. Jamesoni C. Müll. Bot. Zeit. 1845. p. 543. - Orthotr. Jamesoni Arnott in Trans. of the Werner. soc. V. p. 201, et Hook. et Grev. in Brewst. Edinl, Journ. I. p. 129, t. 6 .

Patria. Brasilia, unde pr. Hio Janeiro lectam primus habuit Jameson.

Notis designatis a S. Sprengelii simillima differt.

14. S. Sprengelii Hsch. (Fl. Bras. I. p. 34.); dioict; S. Jamesoni simillima, sed folia breviter oblongo-ligulata, apice breviter acuminato apiculato recto, superne valde rugulosa; perich. longe exserta, longissime suepe loriformi-acuminate plicata, haud rugulosa, cellulis magis lineari-ellipticis; theca in ped. brevi anguste cylindrica brevior.

Sch. torquata spr. Hl. - Macromitr. Nyengelii C. Müll. Bot. Zeit. 1845. 1. 543. - sch. nitida Wils. et C. Müll. in Gardner. Musc. Bras. No. 65.

Patria. Brasilia: Hb. Sprengelii, B lanchet No. 3799, Gardner.

15. S. torquata Brid. (1. p. 323. excl. Syn. P. B.); longe repens crassiuscula conferta, ramis vix pollicaribus, versus apices decrescentibus minoribus confertis erectis simpliciusculis subinde divisis teretibus subacutis strictis; folia undique conferta, oblonga acuta carinata, madore patentia, sicca spiraliter per totos ramos disposita adpressa, flavo-viridia, vetustiora fusco-ferruginea; perich. ramos terminantia plura, rameis duplo longiora altenuata erecta, conniventia carinata longitudinaliter striata pallidiora rigida; theca in ped. semipollicari erecto oblongocylindracea recta, laevis, operc. acuminato recto, calyptra straminea, apice fusca nitida glaberrima (?), appendicibus $5-7$ aequalibus, dentibus ext. et int. $S$. rugifoliae. $\dot{\tau}$. 
Schl. torta schw. Suppl. I. 11. p. 243. - Orthotr. tortum Hook. et Grev. Brewster Filinh. Journ. 1. 1. 127. - Neclera torta sw. Fl. Ind. Oce. III. p. 1800. - Hypmum torquatum IIdw. Sp. Muse. p. 246. $t .63$.

Patria. In truncis retustis muscosis montiun sylvestr. Jamaicae: Swartz.

A S. Jamesoni fol. perich. exsertis longioribus, a S. Sprengelii fol. caulinis haud (rel vix?) rugulosis longe tistare videtur.

16. S. Dttonis Schw. (Suppl. II. II. 1. p.51.1.168.): dioica; longe repens, ramis elongatis flexis parum divisis, senioribus subpinnatis, teretibus subgracilibus, fusca; folia caulina appressa, vix spiraliter torta, madore patentirecuria, ex ovatu basi paullo angustiora, deinde in apicem subrotundum terminata, nervo exeunte rufo apiculata, concava, margine parum involuto, cellulis luteis quadratis, basi paullo longioribus, incrassatis pracdita, haud rugulosa; perich. cxserta duplo longiora, e lanceolato-cuspidata, plica una alterave distincta, intima longissima; theca in ped. brevi cylindracea, basi siccitate plicata, operc. recte subulato, dentibus ext. longis, int. lanceolatis hiantibus rigidis inaequalibus. $\frac{\square}{-}$

Brid. I. p. 801. - Macromitr. Ottonis C. Müll. Bot. Zeit. 1845. p. 544.

Patria. Brasilia, Monte Video, unde habuil Ot to, Hort. Berol. olim inspector.

Notis cursive impressis a $\boldsymbol{S}$. Sprengelii refugit.

17. \$. Iongifolin IIsch. ( $\mathbf{H l}$. Bras. I. p. 34.); Hioica; laxe pulvinata mollis subflaccida gracilis pallide viridis inferne fuscescens, valde dichotoma, fastigiate ramosa; folia laxe imbricata torquata, madore reflexa, anguste longinscule oblonga ligulata reflexe apiculata $\imath$ acuminata acuta, currata, alis parum undulatis reflero-convexis, cellulis mimute rotumatis pallide viridibns obscuris, basi subhyalinis irregulariter rectangularibus, nervo pallide rufo profunde canaliculato excurrente; perich. magis acuminata, basi latiora, majora, magis clliptice areolata; thera in ped. tenui longiusculo angustissime cylindrica laevis- 
sima, evacuata interdum ovata, operc. cupulato breviter acuminato, calyptra angusta amoene aurea nitida superne vix scabra, dentibus ext. et int. longiusculis aequalibus.

Macromitr. linearifolinm C. Miill. Bot. Zeit. 1845. p. 543.

Putria. Brasilia, Monte Video: Sellow.

Notis cursive impressis a $S$. Otfonis simillima refugit.

18. S. Martiana IIsch. (FI. Bras. I. p. 32.); repens 1-2 uncialis subnuda ramosissima fusca torquatifolia, ramis erectis $\mathbf{v}$. assurgentibus superne fastigiatim divisis dense foliosis; folia caulina madore erecto-patentia, oblongo-ovata, basi concava, fusco-brunnea, nervo crasso ferrugineo mucronulata, cellulis basi laxioribus subquadratis, superne subrotundis seriatis minutissimis; perich. majora, ext. oblongo-lanceolata acuta, intima lonuriora lanceolato - acuminata, vaginata longitudinaliter plicata; theca in ped. pseudolaterali brevi erecta cylindrica laevis brunnea, dentibus ext. lanceolatis, int. in membrana, illis dimidio breviore, linearibus $v$. lanceolatis, calyptra straminea nitida superne pallide ferruginea 4 appendiculata laevi (?). t.

Macromitr. Martiannm C. Müll. Bot. Zeit. 1845. p. 543.

I'rtria. Brasilia, pr. Rio de Janciro, Mandiocea, in Serra dos Orgaos, Villa Rica, ad trunc. arbor. demortuos sylvarum: Martius, in Serra d'Estrella pr. Corrego secco, Februario: Beyrich.

Cui affinis?

\section{Folia magis erecto-appresa.}

19. S. rugifolia Brid. (I. p. 322. excl. Syn. Schwägr.!); dioica; prostrato-repens dense pulvinata elatiuscula robusta breviter ramulosa densifolia ferruginea; folia caulina dense appressa, vix spiraliter torta, madore erectopatentia, oblongo-liguluta, nervo profunde canaliculato in mucronulum reflexiusculum exeunte, alis planiusculis convexis, superne ruguloso-undulatis, cellulue rhombuidaliter incrassate yuadratue, basi rectungulares, purictibus transcersulibus flexusis; perich. multo majora ex- 
serta longins apiculata irregulariter complicutu apice valde rmgulosu; theca brevipedunculata cylindraceo - oblonga laevis, sicca evacuata plicata cinnamomea, operc. cupulato recte subulato, dentibus ext. longis obscuris, int. in membrana brevi angustissimis aequaliter longis, calyptra intense fusca, superne subspinoso-scaberrima.

Brid. I. p. 322. - Macromitr. rugifolium ('. Miill. Bot. Zeit. 1845. p. 543. - Orthotrich, rugifolium Hook, Nusc. Ex. t. 128. S. Merkelii Hsch. Fl. Bras. I. p. 29. t. 1.

Patria. Brasilia, ubi pr. Rio Janeiro primus legit Swainson.

20. S. Julacea IIsch. (FI. Bras. I. p. 30.); S. rugifolice simillima, sed differt foliis brevioribus latissime ovato-oblongis, superne angustioribus, perich. perfecte acuminatis, haud ligulatis, haud rugulosis, theca evacuata breviore ovali nitida ruguloso-plicata, calyptra minus scabra.

Macromitr. julaceum C. Müll. Bot. Zcit. 1845. p. 543.

Patria. Brasilia, Serra d'Estrella: Martius.

E spec. auth. IIb. Reg. Monacensis distinctissima.

21. S. sinuata Hsch. (Fl. Bras. I. p. 31.); S. mugifolice simillima, sed folia caulina superiora oblongn-lentceoluta apiculata, inferiora pariter ligulata, bessi dilutate rentricose concura ef inde utrimpre plicatione unica longitudinali undulatu et medio constricta, cellulis rotumdalis, basi ellipticis; perich. coulinis superioribus similia, hand majora immersa, acuminatu, haud rugulose, intima minuta lineari-aceminuta; theca brevissime pedunculata parvula cylindracea, calyptra ubique scuberrima, in $\quad$ ippendicibus fimbriuto-papillosa.

s. rugifolia scliw. suppl. II. 2. t. 139 ! - S. rugifolia Wils. et ('. Müll, in Musc. Bras. Gardner. No. 68. - Macrounit): sinuatum C. Müll. Bot. Zeit. 1845. p. 543.

P'utria. Brasilia, insula Sa. Catharina: C'hamisso, Praia Vermelha: Gardner.

22. S. affinis C. Nüll.; dioica; S. rugifolicte simillima, sed haud tomentosa, laxissime pulvinata, folia cau- 
lina oblongo-ligulata, nervo reflexe apiculata, valde rugulosa, basi ventricose concava, igitur medio saepe constricta v. simuata, superne rotundate haud rhomboidaliter et basi anguste elliptice areoluta; perich. conformia rugulosa majora plicata, theca anguste cylindricu brevicolla laevis v. obsolete striata cinnamomea, calyptra apice scabriuscula.

S. torquata C. Müll, in Musc. Bras, Gardnel. No. 66. - S. squarrosa? Hook. et Wils. ibidem.

Patria. Brasilia, Morro Velho: Gardner.

23. S. recurvifolia Hsch. (Fl. Bras. I. p. 35.); dioica; longe repens, ramis erectis ascendentibus longiusculis subsimplicibus, haud compacta, ferruginea, subgracilis, folia caulina erecto-appressa, madore patentia, longinscule oblonga, longiuscule acuminato-apiculata, valde rugulosa, margine inferne angustissime revoluto, cellulis rotundis minutis, basi irregulariter rectungularibus, perich. majora latiora apice rugulosa, inferne plicata, theca in ped. brevi cylindrica laevis, dentibus longiusculis.

Putriu. Brasilia, montibus Araracoara (unde lectasn vidimus) et Cupati, prov. Rio Negro, pr. urbem Villa Rica dictam, nec non pr. Lages et Sincora et Rio de Contas prov. Bahiensis: Martius.

A S. rugifolia notis illustratis differt.

24. S. Inxa Hsch. (FI. Bras. I. p. 33.); dioica; prostrata repens, ramis elatiusculis ascendentibus dichotomis, ubique ferruginea; folia caulina sublaxe conferta crispulu, vix spiraliter torta, madore patentia, reflexiuscula, oblongo-lanceolata, latiuscule acutata, vix corrugata $\imath^{\circ}$ latevia, nervo profunde canaliculato in apiculum producto, margine hic illic convexo, cellulis ubique valde incrassatis, minutissime rotundatis, basi rhomboideis; perich. latiora nec. exserta, nec rugulosu; theca in ped. breviusculo ereeta cylindraceo-oblonga laevis, operc. conico acuminato brevi, calyptra glabra, vix scubra, ferruginea angusta, lacinis inflexis, dentibus ext. angustis longis crassis obtusis, linea longitudinali exaratis, int. in membranam co- 
nicam lutescentem superne in lacinias irregulares fissam, basi integram conflatis.

Macromitr. Iaxum C. Müll, Bot. Zeit. 1⒋5. p. 543.

Patria. Brasilia, Villa Rica in Minis generalibus: Martius, Aprili.

A S. rugifolia foliis vix corrugatis $\mathrm{v}$. laevibus et notis caeteris primo momento differt.

\section{b. Calyptra pilosa.}

25. S. trichomitria Schw. (Suppl. II. II. 1. p. 55. t. 169.); dioica; prostrata tomentosa, ramis erectis dichotomis densifoliis mollibus ferrugineis, folia caulina subspiraliter crispa laxius conferta, madore erecto-patentia, breviter oblonga obtusiuscula, nervo in apiculum reflexiusculum exeunte, profunde canaliculato, basi subventroso-concava, alis margine convexis, superne maxime rugulosis, ubique rhomboidaliter incrassate quadrateareolata; perich. conformia, intima longins apiculata; theca in ped. brevissimo cylindricu, laevis, operc. recte subuIato, calyptra amoene aurea pilosissima mollis.

Brid. 1. p. \&01. - Macromitr. trichomitrium C. Müll. But. Zeit. 1845. p. 543.

Patria. Brasilia, Monte Video: Scllow.

A $S$. rugifolic notis cursive impressis facile distinguitur.

26. S. compacta C. Müll.; dioica; a S. rugifolie simillima differt: calyptra ad lacinias pilis crispis flexuosis longis, apice brevibus appressis strictis,' paucis instructa.

Schloth trichomitria C. Miill. Bot. Zeit. 1845. p. 107. - Schl. squarrosa? Hook, et Wils. Lond, Journ. of bot, 184t. fasc. Martii.

Patriu. Brasilia, Pajol: Garduer No. $6 \%$.

Schlotheimiae obscurae.

1. S. graeilis Hsch. (Fl. Bras. I. p. 35 ); repens gracilis nuda ramosa, ramis ascendentibus gracilibus sparse ramulosis foliosis; folia remota patenti-recurva, sicea torta, oblonga acuta, canaliculata integerrima fuscescen- 
tia, nervo valido ferrugineo excurrente, cellulis subquadratis minutis obscuris. $\%$

Macromitr. gracile C. Mïll. Bot. Zeit, 1845, p. 544 .

Putria. Brasilia: Martius.

2. \$. acuminata Reinw. et Hsch. (Nov. Act. Leop. XIV. II. Suppl. 1829. p. 711.); repens ramosa, ramis secundis erectis uncialibus fasciculato-ramulosis, densissime foliosis, inferne fuscis, apice purpurascentibus; folia flexuosa lanceolata acuminata integerrima canaliculata, inferiora fusca, superiora flava vel pallide rufescentia, nervo ferrugineo excurrente, cellulis basi linearibus undulatis, superne rotundatis seriatis minutis. $t$.

Macromitr. acuminatum C. Mäll. Bot. Zeit. 1815. p. 54.t.

Patria. Java: Reinwardt.

3. Clota plicata Brid. (I. p. 726 excl. Syn. Hooker.); longe repens, ramis brevibus crassiusculis densifoliis fuscatis, parum spiraliter foliosis, subsimplicibus; folia late oblongo-ligulata, apice mucronato reflexiusculo brevi, basi valde concava, superne canaliculata, cellulis basilaribus oblique ellipticis maxime incrassatis luteo-fuscis, superioribus incrassate rotundatis intense fuscis, laevibus; perich. magis exserta stricta late lanceolata subcuspidata, ubique elliptice areolata pallidiora.

Patria. Insula Terre Neuve Americae septentrionalis: La Pylaie.

Species ob patriam borealem memorabilis, nunquam cum Clota plicata insularum Mascarenium conjungenda, liabitu Schlotheimiae nitidae.

Hemicyclus II. GRIMMIEAE.

Folia multo lacviora, papillis plerumque olsoletis, rarius distinctis. Peristomia constanter colorata, purpurea, rufa v. aurantiaca.

P'alvia. Per totum orbem terrarum.

Gerr. XVII. Coscinodon Spreng.

Einleit. in das situd. der Kryptos. Gew. 19ll. p. 2nl. - Grim mia Hdw. 
Nomen a graecis vocibus xóoxıvov cribrum el ỏdur's dens ob dentes cribrosos ductum.

Calyptra orthotrichoideo-campanulata $8 / 4$ thecae obtegente magna, laevis haud plicata, basi pluries fissa. Perist. Grimmiae, sed dentibus in cilia multa plus minus cohaerentia fissis, igitur valde crihrosis. Caetera Grimmiae gencris.

1. C. cribrosus Spruce. (Anu. and. mag. of. nat. hist. 1819. p.188.); dioicus; dense pulvinatus, sed laxissime cohaerens parce dichotomus humilis obscure viridis canescens; folia caulina appressa, madefacta erecto-subpatentia, lanceolata, apice obtusiusculo pilo elongato sublaevi terminato, margine erecto, concava, ad apicem angustatum pluries et ad basin bi-plicata, cellulis superne rotundate incrassatis minutis opacis, basi quadratis diaphanis majoribus; perich. intima basi tenerrima apicem versus tantum plicata; theca subemersa ovalis macrostoma laevis leptodernis pallida, operc. cupulato-conico acuto purpureo, annulo simplici, calyptra ochracea leptodermi.

C. pulvinatus spr. 1. e. p. 372. t. 8. f. 75. - Br. Kurop. 2-3. Coscinodon; p. 3. t. 1. - Grimmia cribrosa Hdw. Muse. Frond. III. 1. 73. t. 31. - Brid. I. p. 174. - Bryum cribrosum Hoffm. Deut. Fi. II. p. 31.

Patria. Ad muros et rupes montium editiorum hic illic Germaniae, ubi pr. Gosslar primus legit Persoon; per totam Europam caetcram passim.

Pl. masc. gracilior ramosior, floribus in axillis furcarum ramorum positis, fol. perig. late ovatis breviter acuminatis, antherid. parvulis eparaphysatis. - Grimmine apoccerpue primo adspectu liabitu affinis.

\section{Gen. XVIII. Glyphomitrium Brid.}

Method. Musc. 1m22. p. 30, - Grimmin Hook, et Tayl. - Encalypta sim. - Griffithia R. Br. - Bryum Dichs.

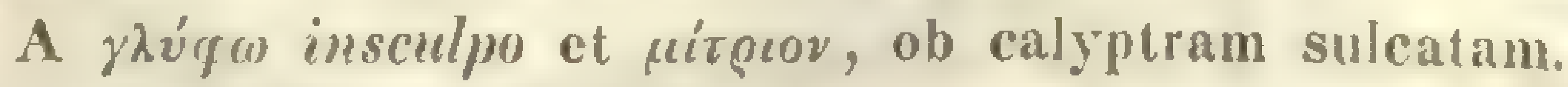

Calyptra campanulata magna thecam totam includens, profunde laciniata plicata. Peristomium 
e dentilus sedecim brevibus lanceolatis dense trabeculatis integris linea media exaratis per paria approximatis incurvis infra orificium oriundis aurantiacis Inevibus compositum. - Infloresc. monoica.

Orthotrichi sectioni Ulotae ex habitu affine.

1. G. Daviesii Brid. (l.c. p. 31.); dense pulvinatum humile crispulum parce dichotomum, intense viride, inferne ferrugineum; folia madore erecto-patentia, linearilanceolata curvata, profunde carinata, margine erecto $\mathrm{v}$. vix revoluto, cellulis maxime incrassate quadratis, basi laxioribus; theca in ped. breviusculo stricto minuta subglobosa lacvis, operc. conico acuto recto, annulo nullo, calyptra laevi pallida.

Br. Europ. 2-3. p. 3. t. 1. - Encalypta Daviesii Sm. F1. Brit. III. p. 1188. - Grimmia Daviesii Turn. Musc. Hil, p. 24. Griffithic Dariesii R. Br. Transact, of the Linנ, soc. XII. Il. P. 375. - Bryum Dariesii Dicks. II. PI. Crypt, p. 3. t. 7. f. 6.

Patria. In alpibus Cambro-Britannicis Davies detexit; in rupibus marinis in Anglesea, et in Iribernia ad basaltum pr. locum "Giant's Causeway" promontorii Fairhead, societate Grimmiae muritimae. - Aestute.

Flores masculi axillares minuti compressiusculi, fol. perig. intimis latiuscule convolutaceo-ovatis reflexo acuminatis, antherid. et paraph. paucis.

\section{Gen. XIX. Brachystéleum Rchb.}

Findl. Gen. 49. n. 507; et Hsch. Fl. Bras. Fasc. I. p. 19; et Limn. XV. p. 126-9. - Ptychomitrium Br. et Sch. - Notarisia Hmp. - Macromitrium Kze. - Brachypodium Brid. haud P. B. Glyphomitrium Brid. - Racomitrium Brill. - Trichostomum Noww. - Cecalyphum P. B. - Dicranum sm. - Orthotrichum Hook. et Grev. - Grimmia al. - Encalyptas schw. - Bryum antiq.

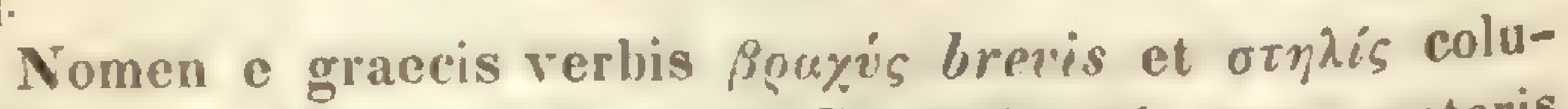
mella, ob pedunculum brevem $\boldsymbol{B} r$. crispati, pro cacteris congeneribus vage conditum.

Calyptra Glyphomitrii, thecam omnino vel partem maximam oltegens mitraeformis longe et pluries 
Iaciniata leviter plicata. Perist. Trichostomi, cujus dentes plus minus ad basin usque in crura duo fissi. - Infloresc. monoica.

\section{a. Folia dentata.}

1. B. polyphyllum Hsch. (Linn. XV. p. 127.); planta in pulvinos densiusculos hemisphaericos subdepressos congesta, ascendens elatiuscula subrobusta viridissima, inferne nigricans, crispata, densifolia, ditissime fructificans; folia malore valde patula, elonguta, late lanceolato-acnminata, apice remote grosse dentata, margine medio folii revoluto, cellulis basi angustissimis elongatis, ad alas infimas laxis amplis dein fuscescentibus, superne minuliuscule quadratis, nervo valde canaliculato, plicata; theca in ped. elongato rubro stricto cylindrico-elliptica pallida leptodermis erecta, operc. Ionge subulato recto rubro, annulo latissimo; dentes longissimi purpurei, cruribus temissimis rugulosis, calyptra upice scubriusculu.

Ptychomitrium polyphyllum Br. Eurnp. 2-3. p. 4. t. 1. - Racomitr. polyphyllum Brid. I. p. 22.5. - $n$. lingulatum Brid. I. p. 787. - R. falcifolium cj. Mant. Muse, p. 82. - Trichost. polyphyllum sidw sippl. 1. 1. p. 153. t. 39. - Tr. serratum sichleich. PI. Helv, Cent. H, No, 19. - Tr. cirrhatum Sill. Fl. Hrit. HI. p. 1239. - Cecalyphum tortile P. B. Prodr. 1. 52. - Dicran. polyphyllum sm. Fl. Brit. Ill. p. 1225. - D. agyregatum Brid. olim sp. Musc. I. p. 203. - Bryum nolyph. Dicks. 111. Crypt. p. 7. - Br. eirratum setis et capsulis breviuribus et pluribus. Dill. Husc. p. 378. t. 18. f. 41. - Mnium tortile Brid. olim sp. Musc. II. p. 64.

Patria. Ad rupes et muros reg. montanae per totam Europam passim, in insula Madera, ubi in Pico Ruiro ad saxa legit $\mathbf{H}$ oll, et in America sept. - Vere et aestate.

Flores masculi in vicinia feminei plures compressi minuti, fol. perig. late ovatis acuminatis valde concavis integerrimis, anth. et paraph. parvulis paucis.

2. I. lepidomitrium C. Müll.; habitus, foliorum forma et flores $\boldsymbol{B}$. polyphylli; diversum foliis e medio ad apicem densius et argutius dentatis, thecis in ped. brevioribus anguste cylindraceis, saepe $2-6$ aggregatais, ca- 
lyptra longiore, apice spinosa, inferne pilis brevibus et squamulosis instructa, dentibus paulo brevioribus.

Ptychomitr. leyid. Schimp. in litt.

Patriu. Mexico, M. Orizaba: Liebmann.

3. B. serratum C. Nüll.; B. polyphyllo simillimum, sed differt foliis latioribus obtusiusculis, apice argute serratis, haud plicatis, thecae pedunculo breviore et dentibus minoribus. $f$.

Ptychomitrium serratum sichimp. in litt. et Br. Furop. 2-3. p. 4.

Putria. Mexico, Pico de Orizaba cum B. lepidomitrio: Lieb mann.

\section{b. Folia integra.}

a. Elatiora,

4. B. erispatum IIsch. (Limn. XV. p. 126.); habitus, foliorum forma et flores $\boldsymbol{B}$. polyphylli, sed folia haud plicata integerrima, cellulis inlima basi ubique laxe pellucidis, superne multo minoribus opacis, margiue hic illic parum revoluto, theca brevius pedunculata, cylindraceo-obovata, dentibus brevibus angustioribus, cruribus cohacrentibus, calyptra laevi.

Ptychomitr. Migricuns Br. Europ. 2-3. p. 5. - Noturisia Capensis Hmp. Limm. XI. p. 379. - Macromitrium niyrescens Kze. Megnsh. Bot. Zeit. 1830. p. 373. - M. tenerum Kze. 1. c. - Ptychomitr. nigricans Br. Kur. 2-3. p. 5. - Brachyporlum crisputtum Brid. I. p. 147 et 817 . - Orthotrich. crispatum IIook. et Grev. in Brewster Edinl). Journ. of Sc. 1. 1824. p. 115. - Glyphomitr. rrispatum Brid. Mant. Musc. p. 30. - Encalypta crispata sichw. suppl. 1. I. p. 60. t. 17. - Grimmia crispata Hook. Bot. Hise. 1 30. p. 133. t. 36.

Putria. In prom. b. spei, ubi primus lg. 'Thu hberg, vulgatissimum in arboribus et saxosis, usque ad altitud. c. 6000' ascendens, insula Madera lg. Holl. - Junio ad Angustum.

5. E. Indienm C. Müll.; B. polyphyllo simillimum, folia autem e basi late vaginunte comolutuced lanceolatoacuminata, integerrima; theca elliptico-cylindracea longipedunculata, oper. longe subulato recto, dentibus longissimis. 
Trichost. Indicum Willd. in Römer und Usteri Magaz. fïr die Botanik. 1787. IV. p. 7. t. 1!

Putviu. India orientalis, unde inter alias plantas accepit Willdenow.

Habitus et thecae forma $\boldsymbol{B r}$. polyphylli, folia $\boldsymbol{B}$. crispati, sed basi late convolutacea.

6. B. Sellowianum C. Müll.; B. crispeto simillimum, sed theca lateraliter emergente brevissime pedunculata ovalis parvula, collo brevi angulate plicato instructa, dentibus brevibus vix ad basin fissis.

B. crispat um Hsch. in Fl. Bras. Fasc. 1. p. 20. verosimiliter huc pertinet.

Patriu. Brasilia, in campis Montevidensibus: Sellow.

\%. E. cuenllatifolium C. Müll.; humile parce ramosum dense pulvinatum, gracilius; folia caulina madore densissime conferta patentia vigida hand flaccida, breviora, oblusinscule acutata, apice plerumpue incurvo cucullato-concava, basi longius tenera, margine hic illic parum revoluto, theca brevissime pedunculata, breviter ovalis, operc. breviori; calyptra lacris thecum superans; dentes multo breviores, in crura duo, haud stricta valde conniventia aequalia prismatica cohaerentia angusta, sed inaerpuliter latiuscula secedentia planiuscula fissi.

B. crisputum $\beta$. brachycarpum Hsch. Liun. XV, 1. 126.

Patria. Prom. b. spei, Wilbergen in rupibus, altit. 7500', Januario 1833: Drège.

A B. crispato affnissimo notis cursive impressis certe distat.

\section{B. Pusilla.}

8. B. glyphomitrioides C. Nüll.; musillum subramosum dense foliosum intense viride; folia $\boldsymbol{B}$. cucullatifolii, sed margine ubipue erectu, breviora; theca in ped. parum longiore ovalis minuta, operc. longe subulato recto, dentibus pallide purpurascentibus, rugulosis, in crura duo temissime filiformia elonguta inaequalia disjuncta vo cohaerentia, vix ad basin usque fissis; calyptra laevis theca $2 / 3$ brevior.

C. Müller: Synopg. musc. frond. 
Pty/chomitr. pusillum Br. Europ. 2-3. p. 5. t. 1. - Notarisia Italica Hmp. Linn. 183\%. - Grimmia glyphomitrioides Bals. et De Not. Prodr: Bryol. Mediol, p, 153.

Putriu. Ad saxa calcarea in collibus pr. Corgeno in agro Nediolanensi: Balsamo; pr. pagum Camnago pr. Como: Cesati; in Pyrenacis: Spruce.

A B. cucullatifolio notis cursive impressis facile distinguitur.

9. E. incurvum C. Müll.; B. glyphomitrioidi simillimum, sed dentes multo angustiores, cruribus valde inaequalibus, altero brevissimo tenuissimo saepe fugaci vel obsoleto, altero latiusculo subulato.

Ptychomitr. pusillum sulliv. Musc. Allegh. No. 135. - Biatchỷstel. Hampeanum C. Müll. Linn. XVII, p. 597. - Notarisiı Virginica Hmp. XI. p. 379. - Grimmia Hookeri Drumm. Mluse. Amer. No. 61! - Gr. Mühlenbergii Brid. 1. p. 181. - Gr. incurva Mühlenl,. Cat. PI. Amer. sept. p. 78, - Weisia incurva Schw. Suppl. II. I. p. 51. t. 116.

Patria. America septentrionalis, passim: Mühlenberg detexit.

10. B. Drummondi C. Müll.; B. incrvvo simillimum, sed differt foliis lineari-lanceolatis acutis, haud apice incurvis, siccitate valde crispatis, crassiusculis haud nitentibus, theca magis elliptica minuta excmulatu, ore rubra, dentibus longe infra orificium orindis subimmersis conniventibus late subulatis, subinde perforatis, apice vix fissis, leniter trubeculatis, saturate fulvis, basin versus rubris, calyptra thecam $2 / 3$ obtegente. $\div$.

Grimmia Drummondi Hook. et Wils. in Lond. Journ. of bot. IV. 1842, p. 422. t, 25. B. et HI. p. 90, t. 3.

Putria. Isouisiana, in arborum truncis: Drum mond.

\section{Gen. XX. Giombelia Imp.}

Bot. Zeit. 1846. p. 124. - Grimmia al.

In honores domini Gümbel, Bryologiae Europaeae socii, nomen conditum.

Calyptra dimidiata. Caetera Grimmiae. 


\section{a. Pedunculus immersus.}

1. G. Iaxa C. Müll.; dioica; laxe pulvinata humilis, basi cohaerens, flaccida mollis, viridis, dein ferruginea et subtomentosa, folia caulina laxe conferta crecto-patentia, e basi erecta longiuscula late oblongo-dilatata laxiuscule hexagone tenuiter pellucide reticulatâ oblique lanceolata, pilo longo denticulato terminata, superne molliter et multo minutius areolata opace viridia, margine erecto; perich. basi multo laxius et longius reticulata; theca vix emersa erecta longiuscule ovalis macrostoma brunnea, obsolete striata, dentibus late lanceolatis, calyptra parvula basi in lacinias inflexas fissa.

Grimnia laxa C. Müll. Bot. Zeit. 1847. p. 801.

Patria. Mexico, in monte Orizaba: Deppe et Schiede. No. 1070. a.

Folia innovationum imberbia s. mucronata, apice incurva; caulina speciminum viridissimorum ad alas striis nonnullis, e seriebus simplicibus pluribus cellularum incrassatarum compositis, ornata. Operc. et caetera desunt. - Grimmice pulvinatue haud dissimilis, magis tamen ad $G r$. Hoffmami spectans.

\section{b. Pedunculus emergens curvulus.}

2. C. crinita Hmp. (1. c.); monoicu; plus minus pulvinata canescens tenella; folia caulina laxe imbricata erecto-appressa, oblongo-ovata, inferiora obtusa $\varepsilon$. mutica, superiora pilifera, concava, margine erecta, basi tenuiter longiuscule diaphane superne magis incrassate areolata; theca in ped. brevi curvulo subemersa subventricoso-ovata pachyderma obsolete striata, operculo breviter conico obtusiusculo; perist. dentes ob annulum latissinum longe persistentem erecti intense aurantiaci, superne plerumque pluries fissi granulosi, calyptra lata.

Grimmia crinita Brid. Mant. Musc. p. 32. Br. univ. I. p. 163. Br. Europ. 25-28. p. 10. t. 2. - Gr. capillata De Not, Mant, Musc. ad Fl. Pedem. p. 40. - Gymnost. decipiens Web. et Mohr. Bot. Taschb. p. 79. 


\section{STEGOCARPI. ACROCARPI. GünBELA.}

Patria. In muris calce lutatis hic inde per totam Furopam temperatam et calidiorem, ex $\hat{\Lambda} \| \mathrm{g} s \mathrm{t}$ röm et in Norvegia et Lapponia. - Vere.

Flores nasc. plures emersi crassiusculi, foliis perig. interioribus obtusis; antheridiis eparaphysatis. - Gr.plagiopodiae habitu haud dissimilis.

3. G. Sindiea Hmp. (1.c.); G. crinitue simillima, sed differt theca minus ventricosa, in pedunculo longiore constanter lateraliter emergente et dentibus duplo latioribus superne $3-4$ fidis, sed cohaerentibus. $\div$.

Grimmia Sinaica Br. Eur. 25-28. p. 11.

Putriu. Monte Sinai: W. Sch imper.

c. Pedunculus exsertus.

a. Folia crispula.

4. A. Abyssiniea Hmp. (1. c.); dioica; dense pulvinata, sed laxe cohaerens, elatiuscula, fastigiate ramosa, subdecumbens fusco-lutea crispula, folia caulina erectopatentia, sicca crispula, lanceolata, longe subulata, haud pilifera, concava, margine inferne convexo-reflexo, foliorum cellulae basi angustae elongatae densae, superne minutae quadratae incrassatae, parietibus interruptis $\mathbf{v}$. crenulatis; perich. Iongiora, basi laxius longius reticulatac cellulis haud interruptis; theca in ped. valde decurvato minute ovalis laevis pallescens, operc. oblique conico obtuso, annulo lato duplici, dentibus angustis integris vel apice parum fissibilibus asperis remote articulatis purpureis.

Grimmia Abyssinira Br, et sich. in Musc. Alyyss. schimp. No. 435.

Patria. Abyssinia, monte alpestri Silke, 18. Febr. 1840: W. Schimper.

Grimmice upiculutue haud dissimilis. Calyptram non vidimus.

\section{B. Folia conferta.}

5. G. alpestris IImp. (1. C.) ; divica; depresso-pulvinata compacta, virescens v. mgricans, cancscens, humilis; folia canlina crecto-patentia, e basi oblongo-ovatà lanceolato - acuminata pilifera, valde concava, obsolete 
plicata, margine erecto, cellulis diaphanis basi quadrate hexagonis superne depressis pachydermibus minoribus sublaevissimis; perich. majora latiora molliora tenuius reticulata magis chlorophyllosa; theca in ped. breviter exserto erecta, plus mimes elliptica brunnescens laevissima, operc. obtuse conico, annulo angusto triplici; perist. dentes angusti aurantiaci irregulariter bifidi, calyptra angusta.

Grimmia alpestris schleich. PI. Helv, exs. - Bro Germ. II. I. p. 139. t. 21. - Br. Europ. 25-28. p. 27. t. 15.

Patria. Ad rupes siccas alpium editiorum totius fere Europae. - Aestate.

Pl. mascula ramosior, fol. perig. int. muticis, antherid. eparaphysatis. - A G. orbiculuri aliquantulum simili, inflorescentia et notis illustratis longe distat; ab aliis cum Grimmice obtusa habitu affini commutata est.

6. Go caespiticin C. Müll.; dioica; G. alpestri simillima, sed folia plicis basi duabus flaris interdum obsoletis, superne phuribus, utrinue juxta nerrum crassum profunde cunaliculatum viridem igitur sulcalu, basi cellulis quadratis hexagonis pellucidis, superne opacis minutis tenuissime papillosis, mutica, superiora brevissime pilifera; theca longe exserta oblonga cylindrucea, operculo acututo, annulo angusto, perist. dentibus lanceolatis integris rugulosis, calyptra minuta.

G. sulcata Hup. 1. c. - Grimmin Jacquini Garev, Bryol. Allstr. exc. 1840. P. 25. et ('atalogin di alcune (rittugatme 1×37. p. 7 et 25. teste sauter. - Gr. sulcata saut. Regensh. het. Zeit. 1841. I. p. 39. - Br. Kurop. $25-28$. 1. 27. t. 16. - Dryptodon caespiticius Brid. 1. p. 200!

Patria. In rupibus praeprimis schistosis subhumidis summarum alpium Salisburgiae: Sa uter, 'Tirolis: W. P. Sch., Pyrenaeorum: Endress, Spruce. In monte sancti Bernhardi Ilelvetiae cespitibus irregularibus incanis ad rupes habitantem primus legit ante multos annos Schleicher.

Plicac foliorum illis fol. Coscinodontis simillimae reperiuntur. 


\section{STEGOCARPI. ACROCARPI. GÜMBELA.}

7. G. montana Hmp. (1. c.); dioica; dense pulvinata, depressa, canescens gracilis humilis; folia caulina erectopatentia, oblongo-lanceolata longe sublaevipila curvata, valde concava, margine erecto, s. subincurvo, cellulis besi diaphanis quadrate hexagonis superne minutis rotundate incrassatis opacis sublaevibus; perich. longiora, basi angustius longius et tenuius reticulata; theca in ped. breviter exserto erecta, ovatu parva lutescens, dein fusca, laevissima, operc. oblique rostruto, annulo simplici; perist. dentes superne irregulariter lacerati; calyptra major.

Grimmia montana Br. Europ. 25-28. 1. 26. t. 14.

Patria. In rupibus schistosis, basalticis et porphyraceis Galliae occidentalis, vallis Badensis Murgthal: A. Braun, Hassiae superioris, pr. Biedenkopf: B r uch, "m. Donnersberg Vogesi: Gü $\mathrm{mbel}$, Norvegiae pr. Christianiam: Blytt, et in alpe Dorrefjeld: W. P. Sch.

Pl. masc. minor, floribus pluribus, foliis perig. internis late ovatis breviter acummatis s. brevipilis, anth. eparaphysatis. - A $G$. alpestri simili notis cursive impressis distinguitur.

8. A. ovalis C. Mïll.; divica; latissime laxe pulvinata, elatiuscula robustu substricta, viridissima, pilis grisea; folia caulina laxe praesertim inferiora subsquarvosoconferta, madefacta prime reflexa, dein curvato-erecta patula, e basi ovatâ reflexo-lanceolata longe sublaevipila, margine erecto, cellulis infimae basis angustis densis flavidis utrinque et supra magis quadratis diaphanis, superne minutis rotundate incrassatis opacis; perich. Iongiora basi longius laxius pellucidius reticulata; theca in ped. breviter exserto stricto erecta turgide ovalis $\imath$. elliptica magna fuscescens, operc. oblique rostrato, annulo latissimo, calyptra lata thecam dimidiam obtegente; perist. dentes longi lati densissime trabeculati, inferne purpurei, superne pluries ciliati asperuli pallidi.

G. elliptica Hmp. I. с.- Grimmia commutata Hüls. Musc. Germ. p. 185. - Br. Lurop. 25-28. 1. 25. t. 19. - Gr. elliplica Fk. Monstaschh. p. 16. t. 11. - Dryptodon or"utus Brid. 1. p. 202.Cumplopus ovatus ej. Mant. p. 76. - Dicrunum ovale Hdw. Minsc. 
Fr. 111. 1. 81. t. 34. - D. durum Lagasc, Ann. de Cienc. Mat. IV. p. 177. - Trichost. oratum Weh. et Moli. Bot. Tashl. 1\%, 110. Bryum orale Hoffm. D. HI. II. p. 35. - Br. brevicaule Vill. PI. Dauph. 111. p. 871.

Patria. Per reg. montanam totius Europae, rupes labitans, vulgatissima. - Vere, in Scandinaria anctumno.

Pl. mascula similis subfasciculata, fol. perig. int. late oratis breviter acuminatis. Species notis datis ab omnibus congeneribus primo intuitu distinguenda.

9. F. orbicularis IImp. (1. c.); monoica; dense hemisphacrico-pulvinata humilis grisea s. canescens virescens gracilis; folia caulina erecto-patentia, profunde carinato-lanceolata, pilo longo sublacvi, apice curvula, celJulis ubique minute quadratis, basi diaphanis, superne chlorophyllosis, margine erecto; perich. angustiora Jongiora, basi elongate anguste laxe reticulata; theca in ped. apice arcuato flavido inclinata v. nutans orbicularis, aurantiaca dein brunnescens, laeviter striatula, operculo mammillato purpureo, anuulo simplici, calyptra parva, perist. dentibus basi latis trabeculatis superne pluries ciliato-fissis aurantiacis asperulis, calyptra parvula.

Grimmia orbicularis Br. Furop. 25-28. p. 13. t. 5. - Gr. mammillaris Pöch in Musc. Bohenicis. - Drylodon obtusus Brid. I. P. 198. partim.

Patria. In muris et rupibus calcareis hinc inde per totam Europam temperatam et meridionalem. - Vere.

Grimmiae pulvinatae, cujus infloresc. habet et quacum persaepe commixtam leginus, simillima, sed theca minor in isdem locis prius matura, notis cursive implessis praesertim calyptra primo adspectu discernibilis.

10. A. calyptrata C. Müll.; divica; dense pulvinata cancscens breviter rumosa erecta, folis superioribus erectis substricta, folia caulina laxe conferta erecta subappressa, oblongo-lanceolata, inferiora pilo carentia, superiora longe et subleviter pilifera, subcomplicate carinata, cellulis basi diaphanis longiusculis angustis ad marginem majoribus magis quadrate hexagonis, superne minutis in- 
crassatis subrotundatis, margine erecto vix convexo; perich. longiora latiora basi laxius tenerius pellucidius reticulata; theca in ped. parum exserto erecta, cylindraceooblonga, laevis fusca, calyptra majuscula thecam totum muturam obtegente, operculo conico rostrato; perist. dentes subintegri purpurei, annulo angusto.

Grmmia calyptrata Hook. in Drumm. Musc, Amer. No. 60.

Patria. Ad rupes in Rocky - Mountains: Drummond.

A Grimmia lencophere simillima notis cursive impressis primo adspectu differt.

\section{Gen. XXI. Grimmia Ehrh.}

Beitrăge I. P. 176. - Schistidium Br. et sch. - Dryptodon Brid. - Rhacomitrium Brid. - Trichostomum al. - Dicranum al. - Bryum, Fontinalis et Hypmum antiq.

In memoriam Joh. Fr. Car. Grimm, Archiatri Gothani, Botanici peritissimi et auctoris F'lorae Isenacensis ab Ehrharto impositum, a posterioribus Hedwigio praesertim nomen emendatum.

Calyptra mitraeformis laciniala, operculum vix superans laevis, $v$. brevior. Perist. simplex: dentes 16 lanceolati linea melia exarati trabeculati, sacpe vero fissiles, quare valde polymorphi, plus minus ad medium usque $2-4$ fidi vel in crura duo ad basin usque fissi.

sectio I. Platystoma. Plantae plus minus orhiculariter puIvinatae, saepe gracilescentes, dichotomae; foliorum cellulae plerumque incrassatae rotundatae v. quadratae, parietibus laevibus, rarius crenulatis. Theca inmersa, rarissime exserta, laevis, aperta macrostoma urniformis $v$. cyathiformis. Perist. dentes pluries fissi, sed crurihus hic illic colaterentibus, igitur cribrosi, vel apice solo fissi, rarius integri, vel nulli.

\section{A. Theca immersa.}

a. Folia imbricata.

a. Laxe pulvinatae.

1. Gr. apocarpa Hdw. (Musc. Fr. I. p. 104. t. 39.); monoicu; laxe pulvinata, fusco-lutea, rigida, plus ninus 
elata et dichotome ramosa, ramis theca terminali apice incrassatis; folia caulina mudefacta prime reflexa, dein erecto-patentia, sicca appressa, e basi onata rectiuscula recurvato-lanceolata, superiora apiculo hyalino terminata, margine basi revoluta ubique mimute rotumdate 2. phus mimus quadrute areolata, superne opaca, firma sordida; perich. emersa multo latiora, longiora stricta, vaginantia, longe acuminuta brevipila, apice denticulata, basi anguste tenerrime pellucide laxe superne minute reticulata; theca immersa urniformi-ovalis, exannulata, macrostoma, glabra coriacea pachydermis, operc. cupulato oblique rostellato, dentibus longe lanceolatis intense purpureis parce cribrosis v. integris curnosulis.

Brid. I. p. 169. - Gr. polyodon Ehrh, Beitr. 1. 169. - Gr. fusca Br. Germ. II. I. p. 120. t. 19. - Gr. rolusta ihid. 123. tal. 20. - Gr. apocaulos 1)ec. Fl. Franç. I. p. 45̄x. - Gr. striyosa Brid. I. p. 171. - Gr. fusciculata Brid. Mant. p. 33. - Gr. Torreyuna ej. 1. p. 172? quod in Hb. autoris non invenimus. - Dicranum? phascoideum P. B. Prodr. 1. 54. et Brid. I. P. 467 ? Bryum apocarpum L. Sp. PI. P. 1579. - Fontinalis apocurpa Limn. Jun. Meth. Muse', p. 366. - sphagnum subhirsutum obscure virens, capsulis ruhellis. Dill. Musc. p. 243. t. 32. f. 4.

$\beta$. rivuluris; elongata valde dichotome ramosa gracilis magis flaccida intense viridis, folis ovato-lanceolatis obtusiusculis. Gr. rirularis Brid. I. p. 166. - Gr. alpicoll sw. Musp. suer. p. 27 et 81. t. 1. f. 1. - Gr. Helvetica schk. Dent. Moos. p. 48. t. 21.

$\gamma$.gracilis; longior gracilescens decumbens, foliis undique patentibus $v$. homomallis, perichactiis secundis. Gr. gracilis schl. in schw. suppl. 1. 1. 1. 98. t. 23. - Gr. schleicheri spreng. Eiuleit. in d. stud. d. Krypt. (icw. p. 277. t. 7. f. 59. Gr. trichodon Brill. I. p. 171. - Gr. strictu Turn. Muse. Hib. p. 20. t. 2. f. 1.

d. conferta; dense pulvinata, saturate viridis, folia breviora obtusiora, perich. minus vaginantia brevius pilifera, theca brevior, dentibus aurantiacis. Gr. confertu Fk. Moostaschly. p. 18. t. 12. Gr. glacialis Br. Germ. II. I. 1. 11\%. t. 19. - Gr. urceolaris ihid. p. 121. - Gr. latifolia Brid. 1. p. 162. - Schistidium confertum Br. Europ. 25-28. p. 7. t. 1. 
Patriu. Per totam partem Europae, Asiae et Americae septentrionalis, vulgatissima, rupes, muros, tecta, rarius arborum truncos habitans, et in alpes ascendens. In montib. Chilensibus leg. Pöp pi g, ad Cap. Horn: J. D. Hooker. Var. $\beta$. ad rivulorum ripas; $\gamma$. in locis apricis; $\delta$. in montosis et alpestribus Europae et Abyssiniae.

Flos masc. terminalis v. pseudo-lateralis.

2. Gr. depilis C. Müll.; monoica; laxe pulvinata elatiuscula gracilis, inferne muda, superne foliosa, fistigiate ramosa, luteo-fusca, rigida, ramis apice theca vix incrassatis; folia caulina arcte appressa, madefacta reflexa, dein patentia, parva, lanceolata depilia obtusiuscula, basi ad latus sinistrum solum margine revoluto, ubique minute incrassate rotundate areolata, firma; perich. caulinis longiora latiora emersa stricta vaginantia oblongo-lanceolutu, acumine brevissimo hyalino denticulato tenuissimo fugaci terminata, inferne tenerius laxius pellucidius reticulata; theca omnino clutes subsessilis ovalis macrostoma, glabra coriacea, operculo conico obtuso recto calyptra tenera angusto tecto, annulo simplici imperfecto, dentibus teneris aurantiacis.

Grimmia maritima v. australis Hmp. in H1). Kunzean.

Patriu. Prom. b. spei, Philippstown ad Kat-Rivier: Pap pe.

Flos masc. minutus, fol. perig. teneris late ovatis inferne tenuius laxius apice minutius frmius arcolatis, antherid. longis curvatis eparaphysatis. - A Gr. apocarpa $\delta$. conferta notis cursive impressis facile distinguitur.

3. Gr. fuliginosa Schimp. (in litt.); dioice; pulvinata, semiuncialis, dichotome ramosa; folia inferne parvula appressa acuminato-ovata, media et superiora conferta patula, apice incurva, sicca flexuosa, lineali-lanceolata pilifera; perich. vaginantia; theca immersa minuta ovalis, pedunculo paullo longiore, recto $v$.curvulo, operc. conico acuto, calyptra conica basi lacera; perist. Gr. ubtusae. t. 
Patria. Mexico, in summo Pico de Orizaba, alt. 1400(1): Liebman ${ }^{4}$.

Habitus Gr. apocarpae var. confertue; theca minor quam in congeneribus affinibus.

4. Gr. amblyophylla C. Müll.; monoica; pusilla parce et breviter ramosa, inferne tomentosa, ramis inferne nudis, apice dense foliosis, fusco-viridis, compacte pulvinata; folia caulina conferta, madefacta primum haud reflexa, sed erecto-patentia, anguste lanceolata subacuminata, curviuscula, carinata, superiora latiora magis acuminata, brevissime hyuline apiculata, margine hic illic convexiusculo, cellulis rectangularibus superne quadrat is latere cremulatis incrassatis firmis luteis; perich. e basi oblonga sensim dilatuta ligulato-obtusuta, margine erecto, cymbiformi - carinata, caulinis multo latiora, robustius areolata; theca subsessilis immersa urceolata brevis exannulata, operc. cupulato recte rostellato, dentibus subintegerrimis aurantiacis linea media exaratis punctulatis latis.

Gr. apocarpa var. Hook, et Wils. in sched. musc. antarct. partim.

Putria. Insula Eremitae et Kerguelen ad Cap. Horn: J. D. Hooker.

Flos masc. minutus angustus, fol. perig. oblongis obtusiusculis. - A Gr. apocurpa reticulatione crenulata, haud leviter quadrata sub microscopio primo momento distinguitur.

\section{B. Compacte pulvinatae.}

5. Gr. plagiopodia IIdw. (Sp. Musc. p. 78. t. 15.); monoica; latissime compacte pulinata, sed laxe cohaerens, griseo-viridis humilis; folia caulina arcte imbricuta, inferiora ovata obtusa, superiora orato-acuminata breriter laevipila, cochleariformi-concura, margine erecto, temiter membranacea, cellulis basi pellucidis hexagonis, superne roturidatis magis chlorophyllosis, dein inanibus; perich. majora, basi longius et laxius reticulata; theca in ped. curvelo brevissimo immersa, operculo cupulato mam- 
millato ovalis, macrostoma, lutea, dentibus pulchre aurantiacis, dense trabeculatis, superne valde ciliato-fissis glabris, annulo duplici.

Br. Europ. 25 - 28. p. 9. t. 1. - Brid. 1. p. 162. - Gr. obtusa Brid. schrad. Bot. Journ. IV. p. 276, - Gr. playiopus sichw. Suppl. I. I. p. 95. - Coscinodon plagiopus sipreng.

Patria. In arena variegala pr. Jenam: Flörke 1798, pr. Naumburgum ad Salam sit. ad ruinas arcis Schönburg: Beneken 1846, ad Steinholz pr. Quedlinburg: Hampe, in Pyrenacis: Spruce. - Vere.

Flos masc. terminalis infra femineum, fol. perig. ligulato - ovalibus cochleariformi-concavis evanidinervibus diaphanis, antl. eparaphysatis. - Coscinodonti cribroso simillima.

6. Gr. anodon Br. et Sch. (Br. Europ. 25-25, p. 8. t. 1.); monoica; Gr. plagiopodice simillima, sed theca e basi valde ventricosa subglobosa minor, peristomio nullo, annulo simplici.

Patria. In muris et rupibus calcareis, pr. Ileidelherg ad arcem: A. Braun, pr. Gefrees m. piniferi: Funk, loco Brühl pr. Vindobonam ad latera viae cavac: Putterlick, Pad Mangerskaskala alp. Julic.: Sendtner, pr. Mende Galliae merid.: Prost, in alpib. Tirolis et Styriac: W. P. Sch., Carinthiae pr. Heiligenblut: $\mathbf{F u n k}$, in Pyrenaeis: Spruce.

7. Gr. Moffmanni C. Müll.; monoica; minute dense pulvinata rigida, inferne fusco-nigricans, apicibus Juteoviridibus griseis; folia caulina anguste lanceolata currula, ubique minute incrassate elliptico-areolata firma, flavidu, superiora et perichaetialia majora latiora longins pilifera, basi pellucidius laxius tenerius superne minute subruudrate arcolata, firma, haud chlorophyllosa, omnia margine distincte revoluta; theca subsessilis erecta sulgglobosa symmetrice, operculo cupulato mammillato, destibus rudimentariis, annulo angusto duplici.

Schistialium pulninatum Brid. I. 1. 114. - Br. Eurnp. 25-29. 1. 6. t. 1. - Gymnost. pulvinatum Hoffon. Dent. FI. 179\%. in Add. Anoectangium prulvinatum Höhl, Ann. Wett. Ges. H. p. 207. 
Patvia. In rupibus reg. montanae, ubi pr. Reinhausen circa Göttingam detexit Hof fmann, usque in nivalem hine inde per totam Europam, in Canada superiore et in rupibus montium Simensium (Abyssiniae) inde a 9000 ped. supra mare usque ad 13000 pedes: W. Schim per, 6. Jun. 1838. - Vere, in alpibus aestate.

F'los masc. sub femineo pseudolateralis, fol. perig. int. ovalibus concavis; anth. paucis, paraphysibus brevibus v. nullis. - Notis cursive impressis a Gr. plagiopodic et anodonte facile distinguitur.

\section{b. Folia tortuosa.}

8. Gr. maritima 'Turn. (Musc. Hib. p. 23. t. 3.); monoicu; dense pulvinata fusco-lutea humilis; folia caulina erecto-patentia stricta, sicca pruesertion superiora fulcuto-curcuta, rigida, caetera subtortuosa ovato-lancolata, in acumen brevissimum hyalinum denticulatum saepe producta, canaliculato-concava, margine convexo, celiulis plus minus dolioliformibus superne minoribus firmis incrassatis inanibus; perich. multo longiora ef latiora, emersa, sicca distincte fulcala, basi oblonga laxe pellucide elongute reticulata, medio latiora, superne subpilifero-acuminatu, margine erecto vix involuto; theca exannulata obovata urniformis truncata lacvis, operculo cupulato oblique rostellato calyptra vix tecto, dentibus magnis lato-lanceolatis purpureis remote articulatis plus minus cribrosis.

IBrid. I. p. 164. - Schistidium maritimem Br. Europ. $25-28$. p. 10. t. 5. - Grinmia rigida Brid. I. p. 768.

Putrile. In scopulis maritimis Gothiae, Norvegiae, Lapponiae australis, Scotiae, Angliae, Hiberniae, Galliae occidentalis et teste II übener orae Slesovico-Holsaticae. In insula 'l'erre Neuve Americae sept. legit La Py laic. - Initio aestatis.

Flos masc. ad pedem feminei crassinsculus terminalis, foliis perig. late ovatis breviter acuminatis, anth. eparaphysatis. - A Gr. apocarpa habitu simillima notis illustratis facile distinguitur. 
9. Cr. tortuose Hook. et Wils. (Lond. Journ. of " bot. 1844. p. 540.); divica; laxe pulvinata, sed inferne maxime cohuerens tomentosa, valde fustigiate rumosa, humilis mollis flaccida robusta obscure viridis, ramis multis brevibus gracilibus dense approximatis; folia caulina subtortuose, madefacta flaccide patula longiusculu, anguste lanceolato-acuminata, pilo breviusculo sublaevi acuto terminata, carinata e cellulis minutissimis rotundatis opacis viridibus basi angustis elongatis pellucidis areolata, margine erecto; perich. conformia basi laxiore magis concava; theca breviter urceolata laevis perfecte immersa, subsessilis, operc. convexo umbonato, calyptra parva basi multoties laciniata, dentibus carnosis purpureis opacis.

Patriu. Insulae Falklandi: J. D. Hooker.

Notis designatis species maxime propria, Gr. maritimue similis. 'l'heca exannulata videtur.

\section{c. Folia falcato-secunda.}

10. Gr. falenta Hook. et Wils. (Lond. Journ. of bot. 1844. p. 540.); dioica; laxissime intertexta, procera gracillima flexuosa, valde ramosa, ramis elongatis apice falcatis pendula sordide viridis; folia falcato-secunda laxissime imbricata, late lanceolata breviter subulata obtusiuscula, carnosula crassinervia, ubique minute quadrate incrassate et densissime areolata subopaca, margine erecto vel parum involutaceo; theca urceolata magna brevis fusca exannulata macrostoma immersa subsessilis lacvis majuscule reticulata, operc. rostellato obliquo, calyptra parva latere fissa cucullato-mitraeformi tecto, columella persistente emergente elevato, dentibus latissime lanceolatis late et ditissime trabeculatis purpureis laevissimis linea longitudinali laevi exaratis integerrimis.

\section{Patria. Insula Kerguelen: J. D. H o oker.}

Pl. mascula floribus terminalibus crassiusculis, fol. perig. latissime oratis breviter acuminatis, basi tenerius et pellucidius areolatis; antherid. elongatis curvulis com- 
pacte approximatis eparaphysatis numerosis. - Ab omnibus congencribus notis illustratis distans.

\section{B. Theca exserta.}

11. Gr. Iaxifolia Ilook. fil. (Lond. Journ. of bot. 1810. p. 5; tabula in Hook. Ic. Pl. Rar. 194. B.); elongata cespitosa flaccida, subramosa; folia erecto-patula laxe imbricata, oblongo-lanceolata acuta, carinata, mollia lurido-virescentia flaccida, sicca crispa; theca in ped. recto pseudolaterali longe exserto elliptica oblonga brevis macrostoma, late angulari-reticulata, rufo-brunnea dentibus brevibus rufis, superne flavis. $\leftarrow$.

Patria. Himalayae montes: Royle.

Ex animadv, auctoris nulli speciei cognitae similis. Gr. opoctrpue var. rivulari ex icone habitus affinis videtur.

sectio 1I. Eugrimmia. Plantac plus minus orbiculariter pulvinatue, humiles, dichotomae: foliorum rellulae uhique quadratae, hasi plerumque quadrate hexagonae, parietibus lacvibus, inrassatae v. molles. Theca microstoma, pedunculo exserto recto 2 . cyyneo. Perist. dentes regularter $\mathbf{2}-\mathbf{3}$ fidi, rarius integri.

\section{A. Pedunculus cygneus.}

a. Areolatio mollis chlorophyllosa.

12. Gr. pulvinata IIook. et Tayl. (Musc. Brit. p. 38. t. 13.); monoica; dense haemisphacrico - pulvinata canescens virescens humilis; folia caulina erecto-patentia, late lanceolatu, carinata, pilo longo sublaevi, margine erecto $v$ parum revoluto veluti tumidiusculo, cellulis ubique quadratis, basi majoribus diaphanis, superne opacis chlorophyllosis mollibus; perich. magis cymbiformia basi laxius reticulata; theca in ped. arcuato flavido declinata ovalis lutea dein fuscescens octies plicata, operc. rostrato recto, purpureo, annulo lato, dentibus intense purpureis late lanceolatis plerumque trifissilibus integris parum pertusis subrugulosis.

Br. Europ. 25-28. p. 12. t. 4. - Dryptodon pulvinatus Brid. 1. p. 196. - Campylopus pulvin. ej. Mant. Muse. p. 75. - Dicran. pulvinatum sichw. suppl. I. I. t. 189. - Trichost. pulvinatum Web. et Mohr. Bot. Taschl. p. 109. - Fissidens pulvin. Hdw. Np. Musc. 


\section{S'TEGOCARPI. ACROCARPI. GRIMMA.}

p. 158. t. 40. - Leersia pulvinata ej. Fund. Musc. I. t. 10. f. 65.Afzelia pulvinata Elorl. Crypt. 163. - Bryum' pulvinatum Limn. Ap. P1. p. 1586. - Bryum orhiculare, pulvinatum, hirsutie canescens, capsulis immersis. Dill. Musc. p. 395. t. 50. f. 65.

ß. obtusa; humilior, theca in ped. breviore breviovalis, operc. conico obtuso v. papillato, dentibus brevioribus. Br. Eur. I. c. - Fissidens pulvinatus $\beta$. Africamus Hdw. sp. Musc. p. 159. t. 40, - Dryptodon obtusus Brid. I. p. 198 ex parte. - Gr. cygnicolla Tayl. Lond. Journ. of bot. 1846. 1. 44 fide Wils on huc pertinet.

Patric. In substratis maxime variis, rarius arboribus, per totum fere orbem terrarum sed haud arcticum, vulgatissima. Var. $\beta$. in locis apricis regionum praesertim meridionalium. - Martio et Aprili.

\section{Gr. arenaria Hmp. (Linn. X. p. 404.); mo-} noica; pulvinuli tenelli depressi humiles canescentes; caulis pusillus parce dichotomus gracilis; folia caulina crectopatentia, longiuscule et anguste lunceulutu, longissime sublacvipila, plus minus flexuosa, mollia, margine erecto, cellulis basi angustis elongatis pellucidis, superne sensim minutis quadratis amoene chlorophyllosis opacis; perich. intima breviora basi laxius reticulata; theca in ped. brevi curvulo lateraliter emergente minute ovalis leptodermis amoene pallide lutea glabra, operc. conico brevi obtusiusculo aurantiaco, anmlo simplici ungustissimo, dentibus angustis teneris dense articulatis superne cribrosis aurantiacis glabris, siccitate recurvis.

Gr. curvula Br. Europ. 25-28. p. 11. t. 3. 1845. - Gr. incuv va schleich. in litt. - Gr. Zahlbruckneri Garov. Bryol. Austr. p. 26 ex sauter.

Patria. In rupibus schistosis IIelvetiae: Schleicher primus legit, in schisto transitionis Galliae occidentalis pr. Angers: Guépin, Pyrenaeorum: Spruce, in rupibus arenaceis loci Regenstein pr. Blankenburg Hercyniae: II a mpe. - Martio.

Flos masc. lateralis minutus, fol. perig. minute ovatis, anth. eparaphysatis. - A Gr. obtusa simillima notis cursive impressis primo adspectu distat. 


\section{b. Areolatio firma.}

a. Infloresc, dioica.

14. Gr. Triehophylla Grev. (Scot. Crypt. Fl. t. 100.); late et laxe pulvinata humilis hoteo-viridis parce dichotoma ascendens gracilis rigidiuscula; folia caulina erectoconferta, madefacta subito erecto-patentia, anguste curvato-lanceolata, pilo acuto sublaevi terminata, profunde carinata, margine medio folii parum revoluta, cellulis ubique firmis quadrate rotundatis incrassatis, luteis, basi rectangularibus, superne minutis; perich. latiora vaginantia, inferne tenuiter et laxe pellucide reticulata; theca in ped. pluries decurvato longe exserto flavido reclinata, ovalis, flavida, dein fuscescens, sicca valde angulate plicata, operc. rostrato subulato, purpureo, vectinsculo, annulo lato triplici, dentibus purpureis angustis apice $2-\mathbf{3}$ fidis laevibus dense trabeculatis.

Br. Europ. 25-28. p. 16. t. 9. - Gr. Schultzii Hüh. Musc. Germ. p. 196. - Dryptodon schultzii Brid. I. p. 199. - Dr.trichophyllus ej. 1. c. p. 771.

ß. meridionalis; elatior gracilior, foliis minutius et inferne magis incrassate areolatis, theca minutula subgloboso-ovalis, dentibus brevioribus.

Putria. In saxis regionis montanae et subalpinac totius Europac et in Asia minore. Var. $\beta$. Ilispania, in collibus apricis pr. Granada et Escurial in Sierra de Guadarrama: W. P. Sch. - Aprili, Majo.

Pl. masc. gracilior subsimplex, flore terminali, fol. perig. late ovatis brevi-acuminatis obtusiusculis, ubique fere laxe et tenuiter reticulatis, anth. eparaphysatis breviusculis. - Gr.pulinatae parum affinis et pulvinis luteo-viridibus parum canescentibus et theca in pedunculo supra perichaetium exserto atque cygneo reclinata angulate costata parva facile cognoscitur.

15. Ar. consobrina Kze. (in Pöpp. Pl. Chil.); Gr. trichophyllae simillima, sed folia superiora atque perich. basi multo tenuius longius et pellucidius reticulata, omnia

c. Müller: Synops. musc, frond, 
Iongiora, molliora sub microscopio amoene luteo-viridia, perich. intima angustissima tenerrima, annulo angusto, dentibus angustissimis aurantiacis remote articulatis, usque ad basin in crura inaequalia apice tenuissima fissis.

Patric. Chile australis: Pöppig.

16. Gr. Misne De Not. (Spicil. p. 15 et Syllab. p. 251.); Gr. trichophyllue simillima, sed differt foliis late lanceolatis, magis recurvis, margine c basi usque ad medium convexo-revolutis, theca subglobose pomiformi, basi impressa, orificio coarctato - angustato, laevi, operculo constanter oblique subulato.

Patria. In collibus pr. Taurinum ad rupes: Lisa, in insula Caprariae: De Notaris, Lisa.

Species, notis constantibus repertis, distinctissima.

17. Gr. Snxdoa De Not.; Gr. trichophyllae var. meridionuli simillima pusilla, sed folia magis reflexa, e basi valde dilatata lanceolata, apice falcuto-curvata, margine longe ultra medium folii valde revoluto, cellulis minutissimis, apice veluti punctiformibus, inferne minute quadratis, infima basi utrinque margine nonnullis pellucidis majus quadratis, cacteris plus minus chlorophyllosis; perich. basi amplexante, hand raginunte, brevi minus laxe areolata; theca in ped. maxime ad basin plantae spectante reclinato turgide globosa, lacrissime octies plicula, nitida leptodermis flavido-anrantiacu, dentibus subintegris, basi lata densissime approximatis.

Putria. Sardinia, ad rupes montium: De Notaris Martio 1835 legit.

18. Gr. ancistrodes Dur. et Mont. (in Fl. Alger. mox ed.); laxe pulvinata erecta altiuscula gracilis griseoviridis dichotome divisa; folia crecto-conferta, madore subito maxime fulcuto-reflexa, anguste lanceolato-acuminata, pilo denticulato plus minus longo terminata, alis parum revolutis, cellulis mimutissimis rotundis viridibus, basi quadratis pellucidis; perich. latiora, basi longiuscula laxe reticulata, cellulis superne magis quadratis; theca 
in ped. brevi maxime decurvato minule orulis sublcuevis, anuulo latiusculo, dentibus ad medium bifidis latiusculis.

Patria. Algeria: Durieu.

Foliis subito maxime et constanter recurvis alb affinibus praecedentibus primo adspectu distinguenda.

\section{B. Infloresc, monoica.}

19. Ar. Eekloni Spreng. (Syst. Veget. IV. II. p. 321.); habitus ( $r$. trichophyllac; folia caulina densissima, perfecte anguste lanceolata longiuscula strictiuscula, margine alis sensim convexis hand revolutis, longe sublaevipila, cellulis minutiuscule punctiformibus rotundatis basi quadratis diaphanis plus minus laxis, superiora latiora magis curvata; perich. intima subvaginantia, basi tenuius areolata; theca in ped. pluries curvato flavido ovalis maxime costato-plicata lutea, operc. conico brevi obtuso purpureo, annulo lato triplici, dentibus late lanceolatis carnosulis purpureis, dense leviter articulatis, rugulosis, apice irregulariter bifidis $\mathbf{v}$. integris subcribrosis.

Putria. Prom. b. spei, ad saxa montis leonis: Ecklon et pr. Zwellendam.

Fol. perig. generis longius acuminata basi laxe reticulata, externa basi ventricoso-concava. - A Gr. trichophylla notis cursive impressis facile distinguitur. $G r$. pygmaeae foliis subaffinis.

20. Gr. pygmaea C. Müll, ; laxiuscule pulvinata humillima subsimplex $v$ semel dichotoma luteo-viridis paulisper canescens, basi mude, apice foliis densissimis incrussata; folia caulina erecta paullo patentia, brevia, stricta, latiuscule elliptica, in pilum longum sublaevem latiusculum producta, parum carinata, marginibus haud revolutis, sed alis sensim convexis, cellulis incrassate quadratis, busi multo laxioribus pellucidis hexayonis; perich. intima apice magis acuminata; theca in ped. brevissimo semel decurvato ovalis, laceiler plicata, pallide fusca, operc. conico acuto brevi purpureo, annulo lato, dentibus brevibus late lanceolatis, inferne purpureis dense articu- 
latis, superne in cilia $2-3$ pallida rugulosa apice cohaerentia $v$. secedentia fissis.

Gr. trichophylla var. anstralis Hmp. in Plant. Preiss, exsicc. Gr. Africumu ej. in Pl. Preiss. ed. Lehmann. II. p. 116.

Putrice. Nova Ilollandia, ad rupes graniticas: Pre iss.

Flos masc. in ramo brevi terminalis crassus, fol. perig. late ovatis breviter acuminatis, ubique fere laxe reticulatis. - A Gr. trichophylla atque pulvinatu $\beta$. obtusa (Gr. Africuma) toto coclo notis cursive impressis distans et pulcherrina species, cui habitus Grotrichophyllae et folia similia $G r$. leucophuene.

21. Cr. imberbis Kze. (Hb.); dense pulvinata musilla subfastigiate ramosa fusco-viridis gracilis; folia caulina madefacta erecto-patentia, breviu, curvula, e busi anguste lanceolatu curinate conaliculate acuminatu, margine medio folii revoluto, e cellulis basi rectangulari-hexagonis fiavidis margine utrinque hyalinis, apicem versus sensim depresso - quadratis subopacis incrassatis firmis areolata, superiora apice plerumque curvato, acumine hyulino brevissimo ccuto terminata; perich. basi latiora et tenuius reticulata; theca in ped. parum arcuato minute oralis distincte et angustissime plicata, latiuscule annulata, operc. conico recto obtusiusculo, dentibus angustissime et breviter lanceolatis dense articulatis apice solo parum bifidis rufis glabris.

Putrie. Chile australis, ad rupes: Pöppig.

Fol. perig. late ovata apice breviter coarctato-acuminata, intima obtusiuscula, basi laxius reticulata, anth. turgide ellipticis breviusculis. - Statura humili et fol. depilibus brevibus facile cognoscitur. Gr. trichophyllae et affinibus similis.

\section{c. Areolatio conflato-incrassata. \\ a. Polia crispato-tortuosa,}

22. Gr. incurva Schwägr. (Suppl. I. I. p. 90. t. 97.); dioica; irregulariter laxe et depresso-pulvinata, dichotome ramosa, humilis, subfasciculatim foliosa, mollis, obscure viridis, dein migricaus, sicca subcrispata; folia la- 
xissime inaequaliter imbricata tortuoso-curvata, madore patentia, angustissime lanceolato-acuminata Iongiuscule subulata, apice diaphana, basi erecta, superne curvata, margine haud vel vix revoluta; perich. basi longa vaginante tenera; theca in ped. lateraliter vix emeryente matdore curvulo minute ovalis leptodermis pallide fusca laevis, operc. conico obtusiusculo vel acutato, anmulo triplici, dentibus plus minus longis irregulariter apice bifidis rufis subrugulosis.

Brid. I. p. 185. - Br. Germ. II. I. p. 168. t. 23. - Gr. uncinata Kaulf, in sturm. Dent. Fl. ('rypt. Fasi. 15. - Br. Hurnp. 25-28. p. 19. t. 12. - Dryptodon contortus Brid. I. B. 199. Camplop. contortus ej. Mant. p. 74. - Dicran. contortum Wahlenb. 11. Carpath. p. 346, t. 4?

Putria. Ad saxa quarzosa, praeprimis ad corum latera obtecta, nee non in cryptis petrosis soli imperviis, per regionem subalpinam Sudetorum, m. Piniferi, ubi in m. Schneeberg sterilem legit Funk, Styriae, in ,Seethaler-Alp": Ka ulfuss, m. Splügen et Vogesi: W. P. Sch. Hara et rarissime fertilis! - Vere.

Pl. masc. ramosior, floribus terminalib., fol. perig. int. convolutaceis breviter acuminatis. - Ex habitu Blindicue cirrhatue et notis supra deseriptis e distinctissimis alque pulcherrimis.

\section{B. Folia spiraliter torta.}

23. Gr. spiralis Hook. et Tayl. (in Drumm. Musc. Scot. V. 2. No. 29.); dioict; dense pulvinata, sed laxissime cohaerens, gracilis elatiuscula dichotome ramosa $v$. fastigiata, ramis funiformi-tortis, junioribus interdum acutate triquetris, coerulescenti-viridis canescens, inferne ferruginea; fol. caulina dense subspiraliter conferta, madefacta erecto-patentia, oblongo-lanceolata, infima depilia, superiora pilo imaequaliter longo acuto sublacvi terminata, margine medio folii parum revoluto, cellulis ubique conflato-incrassatis, basi longiuscule ellipticis, margine utrinque vix ullis pellucidis quadratis, smperne rotundatis minutis; perich. Iongiora latiora longe pilifera, intima basi laxius et tenerius reticulata, magis amplexan- 
tia; theca in ped. brevi arcuato minute ovalis, flavida, dein fuscescens, obsolete striata, operc. obtuse rostellato aurantiaco, annulo triplici, dentibus angustis rufo-purpureis apice bifidis integriusculis rugulosis.

Bryol. Europ. 25-28. p. 14. t. 7. - Hook. et Tayl. Musc. Brit. ed. 11. p. 69. t. Suppl. 2. - Dryptodon spivalis Brid. 1. p. 77t. Grimmia cernua Bı. Germ. 1I. 1. p. 174. t. 24. - Gr. incurva Br. Hurop. I. c. p. 15. t. 8. nohis haud visa forma theca rostrate operculata, dentibus subintegris et foliis vix spiraliter tortis huc pertinere videtur.

Patria. In rupibus siccissimis, praeprimis micaceis summarum alpium totius Europae, sed parce fructificans. - Aestate.

P1. masc. humilior, floribus terminalibus, fol. perig. int. late ovatis obtusiuscule acutis inferne laxe reticulatis, anth. parvulis eparaphysatis. - Folia spiraliter conferta Macromitria in memoriam referunt.

\section{$\gamma$. Rolia stricta,}

24. Gr. fnsco-luten Hook. (Musc. Exot. t. 63.); monoica; compacte et tenelle pulvinata subhumilis fuscolutea rigida erecta fastigiate ramosa; folia caulina mulefacta et sicca stricta, crecto-patentia, curvata anguste lanceolato-acuminata, pilo longo sublaevi terminata, infima depilia rigida, lutea, margine inferne revoluto interdum erecto; cellulae valde incrassatue subconflatae angustae longiuscule quadratue margine valde cremulatue, basi longiores et utrinque margine nounullae tenerae liyalinae; perich. basi laxius et longius reticulata; theca in ped. decurvato brevi ovalis parvula laevis, pallide lutea, leptodermis, operc. conico obtusiusculo recto, annulo lato composito, dentibus anguste subulatis remote articulatis rugulosis rufo-fuscis, vix pertusis.

Brid. I. p. 188.

Putrie. In frigidis 'Toluccac et Islahuacac regni Mexicani, alt. 1300 hexap.: II u mboldt et Bonpland; in monte Orizaba: Deppe et Schiede No. 1080. b; forma minor. 
Flos mase. Iateralis, fol. perig. late ovatis acuminatis, int. ubique fere laxe et tenuiter reticulatis, anth. eparaph. longis curvulis. - Gr. apiculutue simillima.

25. Gr. apieulata IIsch. (Br. Germ. II. I. p. 171. t. 24.); monoica; Groluteo-fiescue simillima et affinissima, folia brevius et laevius pilosa; perich. raginuntia tenniora, cellulis basi amplioribus laxioribus et usque medium folii elliptico-incrassatis; theca magis globoso-oralis, magis exserta, dentibus bifule fissis maxime rugulosis carnosulis.

Br. Europ. 25-28. p. 13. t. 6. - Brid. I. p. 186.

Patria. In rupibus micaceis liumidis alpium summarum: Messerlingwand alpium Windisch-Maltreyer T'auern et Leiter pr. Heiligenblut Carinthiae: II ornschuch 1816, in Zirknitz-Alpe pr. Döllach: Laurer, in Nassfelder - Tauern pr. Gastein: Funk, in summo Dovrefjeld Norvegiae loco deserto Nystüchöe: Blytt. Rarius occurrit! - Aestate.

Specimina a Cl. Blytt missa retustiora imperfecta statura graciliore elatiore, foliis madefactis magis reflexis minus rigidis brevissime vel haud pilosis, brevioribus recedunt. An propria species?

\section{B. Pedunculus rectus.}

a. Theca immersa.

26. Gr. pilifera P. B. (Prodr. p. 58. 1805.); divica; densius pulvinata, pallide viridis, inferne nigrescens, rigida, strictu, humilis, parce dichotoma, ramis apice attennatis; folia caulina madefacta pro primo momento reflexa, subito erecto-patentia, e basi late ovata, margine utrimque valde reflexo instructà subito lanceolata et pilo longo denticulato terminata, ubique robustius areolata; perich. multo longiora latiora longins piliferce vaginantia pallida, e cellulis basi laxioribus tenuioribus, a medio reluti confluentibus incressutis, purietibus phus mimes intermptis, superne clliplicis areolata; theca immersa cylindrico-ocalis, orificio angustiori, glabra pallida, operc. 
cupulato recte rostellato, dentibus superne ciliato-fissis angustioribus aurantiacis tenuins membranaceis dense articulatis.

Brid. I. p. 173. - Gr. Pensylvanica sichw. suppl. I. I. p. 91. t. 25. (1811.) - W'eisia pilifera Röhl. Ann. Wett. Ges. III. p. 113.

Patria. America septentrionalis: P. B. detexit.

Cum Gr. apocarpa nunquam confundi potest.

27. Gr. Schimperi Br. et Sch. (in Musc. Abyss. No. 584.); dioica; Gr. piliferae simillima, sed fastigiate valde ramosa, folia caulina infevior imberbia, superiora brevius pilifera, omnia basi oblonga, supra basin margine paulisper revoluta, angustiora, angulate incrassate oblongo-areolata, superne opaca; perich. superne opuca; theca breviter pedunculata immersa compresse ovalis parvula basi umbilicate impressu, orificio ungustissimo courctato, operculo longe rostellato calyptra basi 5 lobata omnino tecto.

\section{Patria. Abyssinia: W. Schimper.}

Fructum immatur. tantum vidimus, annulus autem et peristomium angustissimum adesse videntur.

\section{b. Theca exserta.}

ח. Atratae.

28. Gr. elongata Kaulf. (in Sturm Deutschl. Fl. Crypt. Heft 5.); divica; dense pulvinata prostrato-depressa, elongata gracilis, inferne muda, atrato-viridis, rigida; folia caulina patentia, e basi anguste oblongî curvate lanceoluta obtusa, summa et perich. apice plerumque diaphana, margine evecto, cellulis basi rectangularibus, superne sensim minutis depresso-quadratis firmis, luteis, ad basin utrinque margine lyyalinis; perich. basi magis vaginantia laxius reticulata; omnia distincte tenuissime papillosa; theca in ped. brevi recto mimute ovalis glabra fuscescens, operc. breviter et obfuse conico, annulo triplici, dentibus lanceolatis remote articulatis integerrimis v. hic illic pertusis, rufo-fuscis, siccis reflexis; calyptra cucullato-mitraeformis.

Br. Europ. 25-28. p. 28. t. 22. - Brid. I. p. 179. 
B. patula; fol. longioribus, squarroso-patulis, summis subpiliferis, theca obliqua. Br. Eur. I. c $^{\circ}$

Patria. In rupium fissuris humidis, auf der Seethaler-Alp" Styriae: Kaulfuss 1812; Velber-Tawern alt. 6500': Sauter; ad perlem "des untern Aargletscher": W. P. Scl.; in monte Splügen Rhatiac Garovaglio legisse dicitur; Dovrefjeld Norvegiae in rupibus cataractae Sprönbăhker: Blyt t. Var. $\beta$. locis siccis Messerlingwand Tirolis: Hornschuch. E rarissimis! - Augusto.

Pl. masc. ramosior, florib. termin. minutis, fol. perig. muticis, anth. brevibus eparaphysatis.

29. Gr. unicolor Grev. (Scot. Crypt. Fl. t. 123.); dioice; late pulvinata, prostrata, laxe cohacrens, atroviridis subpurpurascens, elata fastigiate ramosa rigida, rumis filiformibus microphyllis; folia caulina erecto-patentia, sicca dense conferta, e basi oblonga curvate lanceolata obtusa, nunquam apice diaphana, margine erecto, e cellulis basi rectangularibus, superne sensim minutis depresso-quadratis firmis incrassatis areolata, apice opaca carnosula, lacviora; rumulina late obovata breviter et obtuse acuminuta; perich. latiora magis vaginantia, basi laxius reticulata; theca in ped. exserto erecta v. subobliqua, turgide ouralis, leptodermis stramineo-luteu laevis, operc. rostruto obliquo $v$. subrecto anrantiaco, annulo lato triplici, dentibus purpureis apice bifidis dense trabeculatis glabris; calyptra cucullato-mitraeformis.

Br. Furop. 25-28. p. 29. t. 23. - Brill. 1. p. 182.

Patria. In rupibus lumidis v. saepius irrigatis alpium Scotiae: Ogelvies primus legit; in Norvegiae subalpinis: 131ytt; in Rhatia inter Andeer et Splügen loco hoffla: W. P. Sch. - Aestate.

pl. masc. gracilior, floribus terminal., fol. perig. ovatis, anth. majusculis eparaphysatis. - A Gr. plomgula et atreta proximis notis cursive impressis facile distillguitur. 


\section{Viridi-canescentes. \\ *. Infloresc, dioica.}

30. Gr. Iencophaea Grev. ('I'ransact. of the Werner. Soc. IV. t. 6.); dense pulvinata, sed laxissime cohuerens, conescens, sordide viridis, subsimplex, parce et breviter dichotoma, ramis apice subclavetis erecta subhumilis, dense foliosa; folia caulina madefacta erecto-patentia, sicca appressa, ovato-oblonga, pilo elongato margine et dorso denticulato terminata, cymbiformi-concu'a, margine erecto, cellulis mollibus viridibus, ubique quadrate rotundatis, apice opacis minutis; perich. majora, basi tenuius et laxius areolata; omnia teminervia; theca in ped. breviter exserto evectu plus minus ovalis, rufo-fusca, glabra, operc. rostrato recto, annulo duplici revolubili, latiusculo, dentibus dense articulatis $\mathbf{2}-\mathbf{3}$ fido-cribrosis rugulosis rufo-purpureis, calyptra operculo longiore.

Br. Europ. 25-28. p. 23. t. 20. - Dryptodon leucophueus Brid. I. p. 783. - Grimmia campestris Burchell in Hook. Vuse. Exot. t. 129. - Gr. laevigata Brid. I. p. 184! - Gr. Oertzeniana schultz in syllog. Hatishon. 1828. p. 134. teste siblügrichen.

B. subrotunda; theca rotundato-ovata. Wilson in Lond. Journ. of hot. 1846. p. 449. - Gr. leiocarpa Tayl. I. c. p. 44 ex animadv. Wilsoni.

Patria. Per Europam totam, Americam septentrionalem, terras mediterraneas usque ad Africam meridionalem et in Abyssinia, in montosis, rupes habitans. Var. ß. ad Swan River Novae Hollandiae: J. D r u m mond. Vere.

Pl. mascula femineae similis et cum ea commixia, fol. perig. int. late ovatis brevipilibus, anth. curvulis, paraphysibus brevibus mixtis.

31. Gr. Tergestina 'lommas. (Br. Europ. 25-28. p. 24. t. 21.); Gr. lencophueue simillima, pulchre argenteo-canescens; folia caulina infima obtusa v. mutica, e cellulis viridissimis basi angustis longiusculis areolata; perich. multo latiora et longiora, e basi late vaginante angusta elongale et chlorophyllose reticulata, merginc utringue plus minus late tenerrime membranaceo pellu- 
cido praedita, longiuscula subito plus minus courctatoucuminutu, apice opace areolata; theca immersa majuscule elliptico-conica pallida, annulo lutissimo composito, dentibus anguste lanceolatis carnosulis intense purpureis, medio plus minus pertusis, remote articulatis, calyptra stricta.

Gr. crinita var. Garovagl. Musche Comasche. Dec. 7.

Putria. Prope Tergestum, in muro sylvam quercuum loci Melara cingente, ad limitem aquaticum inter Longera et Rozzol: 'Tommasini, in sylva querc. sub locum Melara in rupibus arenaceis : ab He ufler.

Pl. mascula femineae similis. - A Gr. leucophuer notis illustratis species distinctissima et pulcherrima.

32. Gr. reflexidens C. Müll.; Gr. leucophaene simillima, sed pusilla, ramis apice longe crinitis attenuatis; folia caulina arcte appressa, madefacta minus patentia, $e$ basi orata subito angustuto-lanceolata, inferiora currula brevipilia, superiora superne margine plicuta, igitur veluti reroluta, longe sublaevipilia, cellulis basi quadratis diaphanis, superne sensim rotundatis opacis; perich. longiora latiora, basi laxissime quadrate hexagone reticulata, onnia crassinervia et margine erecto, curinuto-concura; theca vix emersa minute oralis mucrostoma, glabra rufofusca, operc. conico obliquo brevi, dentibus lanceolatis subintegris v. apice parum bifidis, dense articulatis, rugulosis rufis, angustis, siccitate usque ad thecae parietem reflexis.

Patria. Chile australis inter Gr. consobrinam: Pöppig. Hb. Kunzean.

\section{tt. Inflorese, monoica.}

33. Gr. Iomgirostris Hook. (Musc. Exot. 1. 62.); dense pulvinata, sed laxe cohaerens, fastigiate et breviter ramosa, densifolia, subhumilis, inferne fermginen, superne luteo-viridis; folia caulina appressa, madefacta patentia, e basi oboceta 2 . oblongre lenceoluta, pilo longiusculo denticulato terminata, profunde carinala, margine medio saepe convexiusculo, caeterum erecto, cellu- 
lis basi incrassate ellipticis, utrinque margine nonnullis pellucidis quadratis, superne sensim incrassate quadratis minutis, parum opacis; perich. conformia, exserta; theca in ped. breviter exserto erecta cylindraceo-ovalis glabra coriacea, operc. rostrato recto mediocri, annulo angusto, dentibus anguste subulatis subintegris, calyptra interdum latere fissa.

Brid. I. p. 182.

Patria. In locis scopulosis apricis, in declivitate montis Chimborazo, altitud. 14,280' super porphyrite: Humbold t et. Bonpland.

Flos masc. lateralis minutus, fol. perig. oblongis $v$. ovatis evanidinervibus, anth. parvulis eparaphysatis. Gr. lencophaeae haud dissimilis, sed notis cursive impressis jam facile differt.

34. Cr. obtusa Scliwägr. (Suppl. I. I. p. 88. t. 25.); Gr. arenariae simillima, sed folia breviora latiora, cellulae superne minus chlorophyllosae magis angulatae firmiores, perichactialium basi breviores minus laxae; theca in ped. Ureviter exserto recto erecte, annulo triplici lato.

Br. Kurop. 2a-28. p. 20. t. 13. - Brid. I. p. 174. - Gr. sudetica schwägr. Nuppl. 1. I. p. 87. - Gr. Donniana sim. El. Brit. III. p. 1198, theca magis immersa.

Patria. In rupibus arenaceis et graniticis montium editiorum usque ad alpes ascendens per totam Europam. - Martio usque ad Junium.

35. Gr. ovata Wreb. et Mohr (in It. Succ. p. 132. t. 2. f. 4.); laxe pulvinata canescens viridis v. nigricans elatiuscula pluries dichotoma, robusta; folia caulina erecto-patentia, e basi oblongo-ovata anguste lanceolata, pilo brevi parum denticulato terminata, margine erecto $\mathrm{v}$. supra basin parum revoluto, cellulis basi densis angustis longiusculis utrinque margine solo pellucidis, sensim ellipticis, apice minute rotundatis oparis; perich. subvaginantia longiora latiora, sed angusta, basi teneriora; omnil firmu; theca in ped. breviter exserto $\mathrm{v}$. emerso stricto erecta ovata v. elliptica laevis fusco-brumnea, operc. bre- 
viusculo oblique rostellato, annulo duplici, dentibus plerumque bifido-cribrosis rufo-purpureis, dein recurvis.

Br. Furop, 25-28. p. 21. t. 17 et 18. - Brid. 1. p. 176. Dicran. oratum Fk. Fasc. Crypt. IV. n. 86, - Grimmia sciuroides Br. Germ. II. I. p. 155. t. 22. - Gr. patens ihid. p. 148. t.21. Brid. 1. p. 179. - Gr. nigricans Lam, et Dec. Syn. Fl. Gall. No. 1215? Brid. I. p. 178.

$\beta$. affinis; robustior, theca in ped. breviore plerumque haud exserto. Gr. affinis Br. Germ. II. I. 1, 142. t. 21. Brid. 1. p. 178. - Gr. canescens sibleich. Cat. Pl. Helv, 1807. 1. 29.

$\gamma$. oblipuc ; theca subobliqua. Gr. obliqua Br. Germ. 1. p. 153. t. 22. - Brid. I. p. 180.

d. cylindrica; theca longior oblongo-cylindrica. Gr. cylindrica Br. (term. 1.c. p. 161. t. 23.

Patria. E montosis usque ad alpes summas per totam Europam. Var. $\beta$. loca saepius irrigata, $\gamma$. siccissima ventosa, $\delta$. umbrosa praeprimis convallium alpestrium praeferentes. - Aestute.

A Gr. obtusa primo adspectu habitu robustiore, theca brumescente oblique rostellata et notis ceteris illustratis distinguitur.

sectio III. Dryptodon Brid. Mant. Musc. p. 71 et Br. univ. I. p. 191. - Plantac procerae late ireflulariter, haud orbiculariter, laxissime pulvinatae, rewlaritel dichotome ramosae, ramis fastimiatis. Foliorum cellulae incrassatae, parictihus plus minus crenulutis ". sinuatis. Perist. dentes Euyrimmiue, vel ad basin usque in crura duo filiformia fissi. Caetera Eugrimmiue.

a. Pedunculus arcuatus.

36. Gr. patens Br. Europ. (25-28. p. 18. t. $\mathrm{X}$ bis); dioica; laxe et late pulvinata decumbens longiscens, ramis curvatis pluries dichotoma, inferne nudiuscula nigrescens v. luteo-fusca, superne foliis densis siccitate appressis teretiuscula gracilis, luteo-viridis v. fuscescens; folia caulina madore subito reflexa, dein patentia, currute lanceolato-acuminata obtusiuscula, angusta elonguta, margine e basi ultra medium reroluto, profunde canaliculata, cellulis minutissime subrotundatis, basi paullo majoribus, angulatis, dein maxime incrassatis, nerro dorso 
pluries lamelloso; perich. breviora; theca in ped. decurvato breviusculo flavido demissa majuscule ouclis, laevis flavida, dein fuscescens, operc. conico subulato recto rubro, annulo latissimo, dentibus longiusculis purpureis dense trabeculatis, in crura duo inaequalia interdum cribrosa fissis, subrugulosis, calyptra laevi.

Gr. arcuata De Not. Mant. No. 77. et Nyllah. p. 252. - Racomitr. putens Hüb. Musc. Germ. p. 198. - Dryptudon patens Brid. I. p. 192. - Trichost. patens schw. suppl. I. I. p. 151. t. 37. Dicran. patens sim. N1. Brit, III. p. 1213. - D. arcuutun siclbleich. - Fissidens patens Wahtenl. F1. Lapp. 1. 334. - Bryum patens I icks. Hase. 11. Pl. Crypt. p. 6. t. 4. f. 8. - Orthotrichum curvatum Brid. I. p. 791 !!

Patria. Ad rupes humidas regionis subalpinae per totan Europam et in America sept. - Primo vere.

Pl. masc. gracilior simplicior, floribus terminalibus, fol. perig. convolutace - ovatis breviter acuminatis teneris. - Gr. ellipticae et affinissimis ex habitu similis, sed primo momento notis cursive impressis disceruibilis.

37. Gr. elatior Br. Furop. (25 - 28. p. 17. t. 10.); divicu; late pulvinutu clata laxe cohuevens canescens, inferne nigricans, superne intense viridis, ramis dichotomis longis et brevibus, basi nuda, superne densifolia, robusta; folia caulina erecto-appressa, madefacta prime valde reflexa, dein erecto-patentia, lato-lanceolata clongata, parum recurva, pilo longiusculo sublaevi terminata, profunde canaliculato-concuve, margine inferne revoluto, cellulis basi longiuscule ellipticis sinuatis, apicem versus sensim minutis perfecte rotundatis, apice opacis, incrassatis; perich. crecta basi teneriora, laxius hexagone reticulata, majora; theca in ped. arcuato mujuscule ovcelis decies plicatu pallide fusea, operc. longe rostellato recto, annulo triplici, dentibus late subulatis, dense et robuste articulatis, atrantiacis, apice bifidis et perforatis.

Racomitr. incurvum Hïl). Musc. Germ. p. 201. - Trichostom. incurvum Hsch. in Regensb. Bot. Zeit. 1819. p. 89. - Dryptodou incurvus Brid. I. p. 194. 
Putria. Ad rupes graniticas et schistosas per regionem subalpinam et alpinam alpium Germaniae, Helvetiae, Pyrenaeorum et Scandinaviac. - Vere.

P]. mascula ramosior, floribus terminalibus, fol. perig. late ovatis breviter acuminatis, anth. elongatis curvulis, paraph. brevissimis paucis mixtis. - A Gr. funceli simillima notis cursive impressis differt.

38. Gr. funalis Br. Europ. (25-28. p. 17. t. 11.); monoice; Gr. clationi simillima, sed statura humilior, folia breviora pilo valde denticulato terminata, cellulae incrassato-quadratac, perietibus cremulis instructae, minutae, basi longiores et utrinque margine nonnullae quadratae magis pellucidae tenerae, perichatialium basi laxius quadratae pellucidac, medio ellipticae; theca oborrtu r. elliptica octoties plicatu, dentibus profunde irregulariter bifidis.

Rncomitr. funale Hülb. MUse'. Germ. p. 200. - Dryptodon funalis Brid. I. p. 193 et $771 .-$ Cumpylopus funalis ej. Mant. Muss. p. 75. - Trichost. funale sichw. suppl. I. 1. p. 150. t. 37.

Pulvia. In rupibus et saxis regionis montanac, rarius subalpinae totius Europae. - Primo rere.

Flos masc. terminalis ad pedem feminei, fol. perig. late ovatis breviter acuminatis depilibus basi laxe irregulariter hexagone reticulatis; anth. elongatis curvatis breviter stipitatis.

\section{b. Pedunculus rectus.}

e. Folia obtusa.

39. Gr. elliptien C. Müll.; dioica; depresso-pulvinala luteo-fusca, dein nigricans, rigida dichotome ramosa, clatiuscula erecta fragilis, inferne denudata; folia appressa, madefacta paulisper erecto-patentia, substricta, breviter oblongo-lanceoluta obtusa, carinato - concava, margine erecto $v$. parum convexiusculo, e cellulis ubique incrussutis valde conflutis pachydermibus luteis margine vulule punctuluto-crenulutis, basi angustissimis, longis, superue minutis areolata; perich. conformic; theca in ped. exserto subglobosa parula pachydermis, lacvis pallide 
fuscescens, operc. subulato recto calyptra apice scabra omnino et ultra tecto, annulo lato duplici, dentibus anguste lanceolatis dense trabeculatis rufo-purpureis laevibus apice bifidis.

Racomitrium ellipticum Br. Europ. 25-28. p. 5. t. 24; in tabula Dryptodon. - Dryptodon ellipticus Brid. I. p. 204. - Camgylopus ellipt. ej. Mant. Musc. p. 76. - Dicran. ellipticum schw. suppl. I. I. p. 184. t. 47. - Trichoston, elliplicum Hook, et Tayl. Musc. Brit. p. 62. t. 19.

Patric. Ad rupes irrigatas $v$. humidas Iliberniae: Brown detexit, alpium Scotiae et litoris Norvegiae occidentalis pr. Bergen: Blytt. - Aestate.

$G r$. aciculuri et Gr. protensae haud dissimilis.

40. Trr. aquatica C. Müll.; dioica; laxe pulvinata elongata rigida, ramis teretiusculis, sordide viridis, ascendens, folia caulina dense imbricata, madefacta crectopatentia, interdum paulisper secunda, late ovato-lanceolata, obtusiuscula, canaliculata, margine convexo revoluto, igitur biplicata, reticulatione $G r$. ellipticue; perich. inferne laxius et tenuius reticulata; theca in ped. longe exserto tortili pseudolaterali erecta, elliptico-cylindracea, Iaevis pallida, operc. subulato recto rubro, annulo lato, dentibus ad basin usque fissis ciliformibus subulatis laevibus rufis.

Racomitrium protensum A. Braun in Br. Europ. 25-28. p. 6. t. 2. - R. ayuaticum Brid. 1. p. 222. - R. cataractarum A. Br. in Bricl. I. p. 786. - Trichost. ayunticum Brid. Musc. Rer. II. I. p. 102. - Tr. aciculare $\beta$. aquaticum Weh. et M. Bot. Taschb. p. 192. - Dicran. aquaticum Brid. Sp. Musc. I. p. 190. - D. aciculare fluituns Turn. Musc. Hib. p. 67. - D. subulatum Böhl. Moosg. Dent. p. 347. - Bryum rivulare Hoffm. Deut. F1. 11. p. 37. - Br. nigrescens Vill. Fl. Damph. IIl. p. 8xa. - Bryum Jypnoides aquatirum, calyptris nigris acutis. Dill. Musc. p. 367. t. 46. f. 26. - Hypnum aciculare ß. aquaticum Web. Spic. Fl. Gütt. p. 84 .

Patria. Ad rupes irriguas totius Europae in regione montana et subalpina. - Majo et Junio.

Pl. mascula femineae similis, floribus terminalibus, fol. perig. ovatis breviter acuminatis, anth. curvulis turgidis, paraphysibus paucis tenuissimis. 


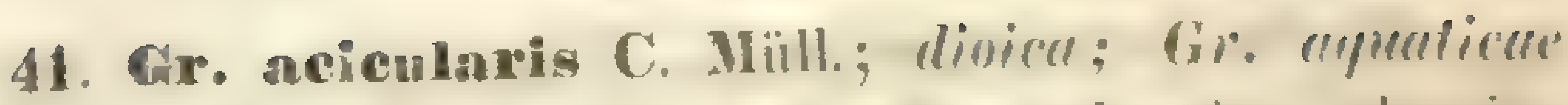
similis, sed laxins cohacens et multo rohustior, densissime foliosa; folia caulina appressa, madefatefa crectopatcntia subsecunda, late veceto-oblonga lignlalo-ubluse

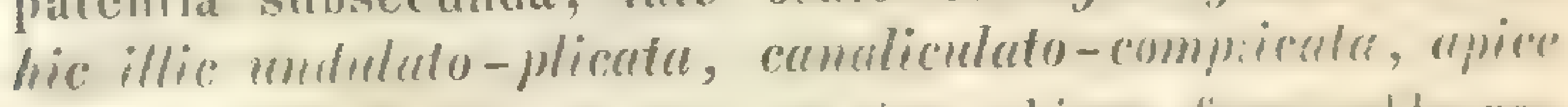
peree el obsulete dentala, margine ubique fere valde revoluta, cellulis utrinque ad alas infimas nommullis lasioribus fuscidulis, basi cactera angustissimis crenulalis, apicem versus sensim grossiuscule rotundatis; perich. intima inferne tenuiora laxius reticulata; theca breviler pedunculata, majuscule ovali-elliptica microstoma, late annu-

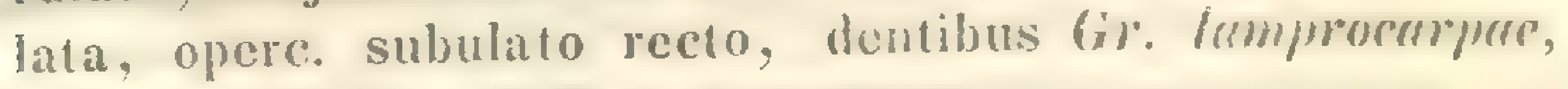
sed basi dense articulatis.

Racomitvinm aciculare Bril. 1. P. 219. - Br. Kurop. 2. -22. 1. 3. 1. 1. - Trichostom. acientare seliw. Suppl. I. I. p. 1.8. Dicran. aciculare Hdw. Muse. Fr. III. p. zis. t. 33. - Mnimm aci-

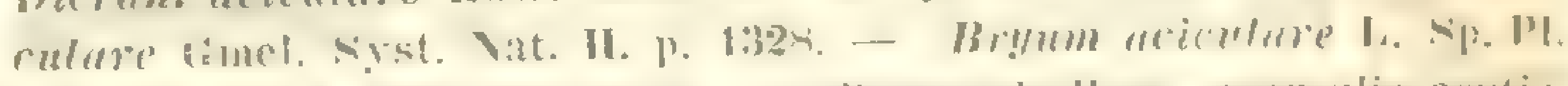

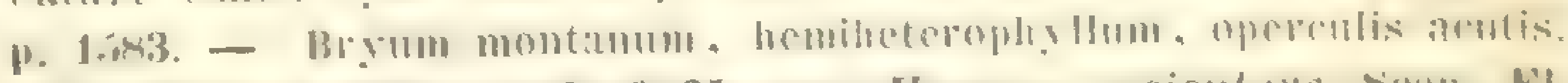

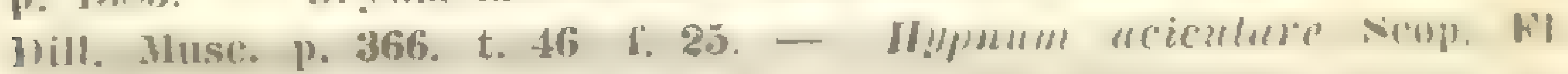
Caru. ed. 11. No. 1225.

Putrill. In locis humidis, praesertim saxis rivulorum per regionem montanam et subalpinam totius Furopae ef Americae septentrionalis. - V're.

Pl. mascula Gr. aquaticne.

\section{B. Folia ecuta,}

42. Cr. nigrita C. Mïll.; dioica; Gr. anputicue similis, sed gracilior; folia madore ralde patentia, late lanconlata arumimutu aculu, cellulis maxime incrassatis con- flulis valde crenulatis fuscis; theca in ped. brevinsculo flaro tenni terminali v. pseudolaterali elliptico-rylindrarea mimute angustissimn pallida, opere. subulato recto, anmulo angusto, demibus anguste subulatis, oul bosin usyue in crure suberpualiu, basi cohuerenliu of urlienlatu, temia muxime rugulosa fissis rufis; calyptra upice sccibre.

Rucomitrium frotensum var. Hook, ot Wils, in suches.

Potria. Insula Eremilac ad Cap. IIorn: J. D. II ooker.

C. Muller: Synops, muse. frond. 
43. Gr. Inmprocarpa C. Müll.; dioica; Gr. aquaticae simillima, sed robustior; folia caulina latissime lanceolata acuta, concava, nervo canaliculato, margine e basi ultra medium valde revoluto, cellulis infimu basi utrinque ad alas laxissimis fuscis; perich. intima latere alarum laxissime reticulata; thecae saepe geminatae brevipedunculatue mujuscule clliptica turgidu, siccata angulata leptodermis nitida microstoma, operc. subulato recto, annulo latissimo, dentibus in crura duo robustu uequalia rugulosa profunde, haud usrue ad basin, fissis, densissime approximatis, basi obscure articulatis, carnosis aurantiacis.

Racomitrium catarractarum var. 3. Hook, et Wils, in sched.

Patriu. Insulae Falklandi: J. D. Hooker.

Inter Gr. aquaticam et acicularem medium tenens.

44. Gr. didyma Mont. (Ann. des se. nat. IV. 1845. p. 122.); Gr. aquaticue similis, folia undique patentia vix subsecunda, ovato-lanceolata acutatu $\varkappa$. acumine hyalino brevissimo mucronata; theca cylindracea anguste annulata, operc. recte rostrato theca dimidia breviori, dentibus latiuscule lanceolatis lacunosis quartam diametri thecae partem aequantibus, madore inflexo-conniventibus.

Patria. Chile australior: C. Gay.

Pedunculi interdum geminati, unde nomen triviale.

45. Gr. convoluta C. Müll.; procumbens dichotome ramosa, ramis fastigiatis, siccitate incurvatis brevissime ramulosis, sordide viridibus; folia ovato-lanceolata acutiuscula, margine reflexa, integerrima evanidinervia, madore subrecurva, sicca imbricata, firma; minute dense areolata; perich. convolutu rotumduto-obtusissima; theca in ped. pseudolaterali erecto posita, calyptra striata glabra basi laciniata.

Racomitr. convolutum Mont. in Ann, d. sc, nat. 1845. p. 122.

Patria. In truncis arborum reipublicac Chilensis: C. Gay.

Ex habitu Gr.putenti v. didymae proxima, ab ultcriore notis cursive impressis facile distinguitur. 
46. Gr. rupestris C. Müll.; divicu; laxe cohacrens procera parce dichotoma squarrosula sordidu nigricuntiviridis, inferne nuda, apice robusta; folia sicce et madefactu synurrosulo-patentia substricta, breviter oblongolanceolata acuta, latiora, margine, concavitate el reticulatione Gr. elliplicue; perich. intima magis vaginantia, basi margine utrinque tenuius laxius et laevius reticulata obtusiuscula; theca in ped. brevi pseudolaterali erecta cylindreceo-vblongu, fusca lacvis nitida pachydermis, opere. conico-aciculari.

Dryptodon ruyestris Hook. et Wils. Lond. Journ. of bot. 1814. 1. 514.

Patrict. Insula Eremitae ad Cap. Horn: J. D. H o o ker.

Dentes, calyptram, operculum et pl. masculam non vidimus. - Notis cursive impressis a $G r$. elliptice facillime differt.

47. Gr. atrata Mielichh. (in Regensh. Bol. Zeit. 1819. p. 85.); dioica; late dense pulvinata, inferne subtomentosa, procera, ubique dense foliosa, ramis elongatis, inferne nigricans, superne obscure viridis v. lutea, rigida; folia caulina appressa, madefacta erecto-patentia, brerifer lanceolutu, robustu, latiuscule acuta substrictu, margine convexiusculo, profunde canaliculata, cellulis pachydermibus quadratis, minutis, paridibus punctulato-crenlatis procditis, basi paulisper rectangularibus, utrinque margine nonnullis pellucidis lacvibus; perich. intima cymbiformi-concava, semiamplexicaulia, basi leviter laxius et pellucidius reticulata; theca in ped. brevi crusso crecta v. subobliqua, oblongo - arata, collo brerissimo, luteofusca laevis, operc. obtuse et breviter rostellato aurantiaco, annulo lato e cellularum seriebus pluribus $3-4$ composito, dentibus dense trabeculatis glabris ferrugineis, apice pertusis $v$. bifidis, siccis reflexis; calyptra cucullato-mitraeformis.

Br. Hurop. 25-28. P. 30. t. 23. - Bric. 1. p. 181.

Putrie. Ad rupes humidas $v$. irroratas summatrum alpitum, a sylvarum reg. suprema ad nives aeternas, circa fodinas schwarzwand dictas vallis Salisburgensis Gross- 
arl, ubi Mielichlo fer 181 jetexit; ad latus septentrionale jugi Malnitzer-' 'auern Gastuniae: W'unk; Dove Norvegiae et Salten Lapponiae ex Angström; in summis Pyrenaeis leg. Spruce ct Wr. P'. Sch. - fuctumno.

Pl. masc. similis, floribus Gr. unicoloris, a qua el Gr. elongate notis dictis species pulcherrima facillime distinguitur.

48. Gr. crispuln C. Müll.; habitus Gr. ellipticue; folia sicca appressa, parum crispula, rigicla, madelacta crecto-patentia, ex ovuto lunceolate, in acumen longum apice hyulinum productu, parum carinata, plicuta, murgine distincte revoluto, reticulatione Gr. ellipticue, sed magis incrassata robustiore; theca in ped. perbrevi elliptica, operculo rostrato.

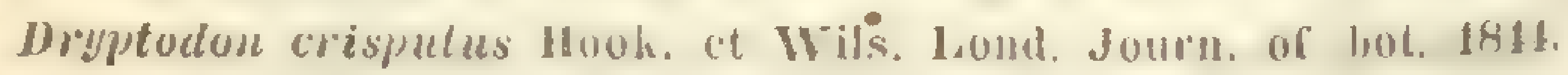
P. 544 .

Patrie. Insula Campbelli antaretica: J. D. Hooker. Pl. sterilem solan vidimus.

\section{$\gamma$. Folia pilitera.}

19. Gr. microcarpa C. Müll.; divica; late pulvinala intertexta decumbens, gracilis dichotome micropliyla, ramis regularibus, luteo-viridibus, inferne nigricans; folia caulina erecto-conferta, madore rellexal, dein erecto-patentia, lanceolato-acuminata, pilo breni rigido denlato ferminate, margine ulta medium revoluto, carinata, firmiuscula, reticulatione crenulata; theca in ped. cebreciato furum curcuto minute oralis lacris flavida, orificio minuto, operc. breviori rubro, annulo latiusculo, dentibus brevibus plerumune incerpuliter tripartitis, cruribus plus minus cohacrentibus subrugulosis, inferne nodosiusculis, calyptra laevi.

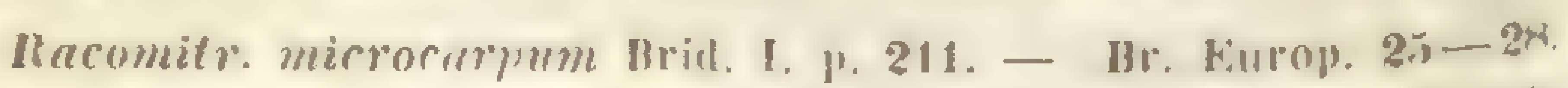

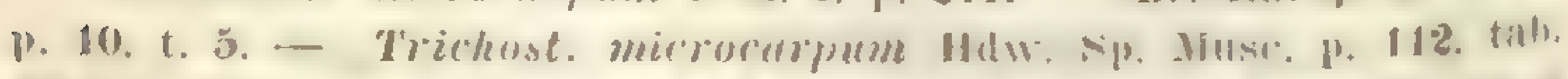

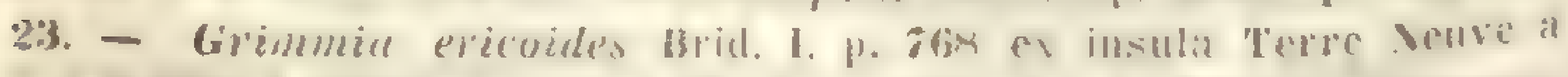

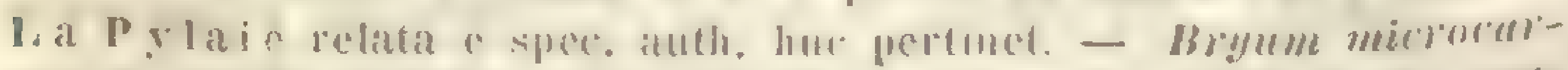

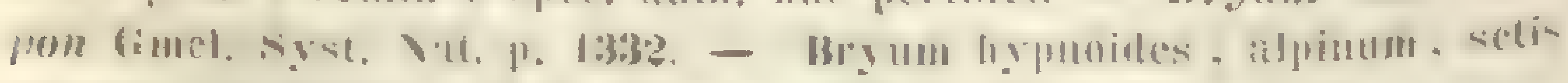

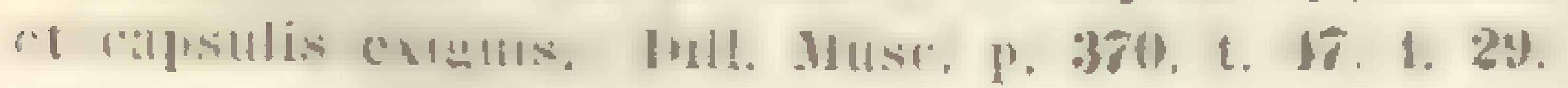


Racomit). Suleticum Bryol. Hulop. 25-24. p. 7. t. 1. $-\boldsymbol{R}$. ohtusum Brid, I. p. 213. - Grimmia mocera Bals. et De Dot. Palsill. Iuse. No. 17. et syllah. Musc. p. 252. - Dry/lodon sudetiCu.s Brid. 1. 1). 195. - Trichost. Nuleticum Fli. C'rypt. Fasc. 27.

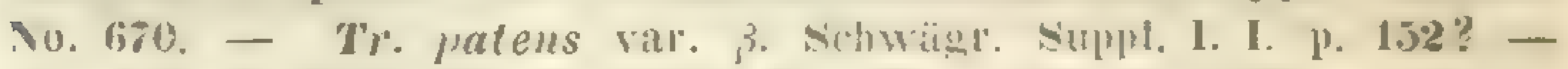

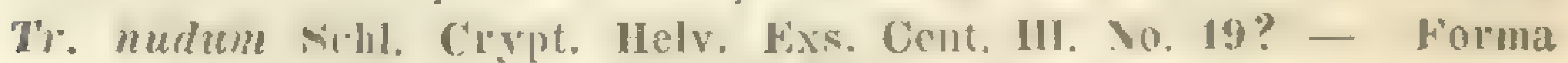
procerat, minus pamosa, strictior, ex ommilsus partibus autem essentialibus huc certe pertinens.

Putria. Per totam Europam, in subalpinis et alpinis ct in America septentrionali. - Ex anctumno in eer primum vigens.

Flores masculi congenerum.

50. Gr. cylindrica C. Müll.; Gr. microcaryae simillima, sed differt statura majore robustiore, theca longiore anguste cylindrica. $\leftarrow$.

Rucomitr. cylivdricum schimp. in litt.

Patria. Mexico, Pico de Urizaba: Li ebmanu.

51. Ga. sulcipilar C. Müll.; divica; laxissime cohaerens subhumilis purcissime breviter dechotoma gracilis rigilla fusco-lutec, ascendens; folia caulina dense imbricata subsecunda brevia, madore subito reflexa, dein erectofatcutia, lute luncestuta, breviler, tenuiter denticulate pilifura, alis planiusculis, margine hic illic parum revolutis, nervo profunde canaliculato, cellulis ubique incrassatis valde crenulatis quadratis, superne minutis, luteo-diaphanis; superiona et perich. pilo longo cellulis angustis elungutis distincte visibilibus reluti striato, terminata, hace basi laxius reticulata magis plicata; theca in ped. brevi ovalis recta laevis, annulo latiusculo, dentibus angustis brevibus dense trabeculutis ultra medium inueyurliter bifitis, rulis subrugnlosis.

I'utriu. India orientalis, litus Coromandel: ex $11 \mathrm{~b}$. Tilesii habuit Kinne.

p. mase. sinplicissima, flore terminali ob caulem apice innovatem laterali, fol. perig. interioribus late ovafis convolutis teneris colorats, anth. magnis, paraph. brenissimis temuissimis. - Formis pymacis gractlimis Gr. protensue similis. 
Sectio 1V. Thacomitrium Brid. Mant. Musc. p. 78 et Br. univ. 1. 1. 207 sub nomine colrigendo Racomitrii. - Plantac irregulariter ramosae, rumulis lateralibus plaries divisae, innovationibus haud fastigiatis. Pedunculus rectus. Cactera Dryptodontis.

\section{a. Folia pilifera.}

51. Gr. lanuginosa C. Müll.; dioica; laxissime pulvinata procera, ramis alternis sterilibus vel fertilibus brevibus maxime ramosa lanoso-canescens; folia caulina conferta, madore subito reflexa et subito laxe erectopatentia, elongata, late lanceolato-acuminata, cum nervo canaliculato in aristam elongatam fuccidum hyalinam producta, margine basi revoluto, apice valde sinuate erosu cunescente, concava; ubique valde granulate crenulatoareolata; perich. intima vaginantia, superne subito acuminato-pilifera, margine ubique integro; thecae creberrimac in pedunculis brevibus scabris saepe geminatis erectae ovales parvulae flavide fuscescentes, late annulatae, operculis recte subulatis, dentibus ciliaeformibus ad basin usque fissis tenuissimis rugulosis rufis, calyptra apice scabra.

Racomitrium lanuginosum Brid. I. p. 215. - R. Canadense Brid. 1. p. 217? quod in Hb. Brideliano non invenimus et in Rich. Fl. Anrer. Bor. II. p. 296 nomine Trichost. Canadense descriptum est. - R. Borbonicum Brid. I. p. 218 et $\boldsymbol{R}$. lanuginosum $\beta$. squalidum p. 217 e spec. sterilibus liuc pertinere videntur. - Br. Kurop. 25-28. p. 11. t. 6. - Trichost. lanuginosum Hdw, Musc. Fr. III. p. 3. t. 2. - Tr. hymoides Willd. Prodr. Fl. Berol. No. 916. Tr. ramigerum Timm. Prodr. Fl. Megap. No. 774. - Tr. serratum Elhrh. Crypt. Exs. No. 94. - Bryum lanuginosum Hoffm. Deut. FI. II. P. 42. - Br. hypnoides L. Sp. Pl. p. 1581. - Bryum hypnoides, polycephalum, lanuginosum, montanum. Dill. Musc. p. 372. t. 47. f. 32. - Hypmum canescens Wel). Sp. Fl. Gütt. p. 81.

Patria. In montanis, lapidosis sylvisque praesertim arenosis per orbem totum fere terrarum usque in floram arcticam et antarcticam, regionem frigidam sylvaticam pracferens, ubi ditissime fructificat. - destute.

Pl. masc. similis, floribus multis in ramis brevibus lateralibus, saepe aggregatis; fol. perig. concoloribus ovatis acutis, anth. turgidis, paraph. brevibus paucis. 
53. Gr. canescens C. Müll.; dioica; latissime et laxissime pulvinata canescens, luteo-viridis, inferne sordida, humilior et minus ramosa; folia caulina breviore squarroso-reflexa, sicca subappressa, late ovate $\mathrm{v}$. lan-

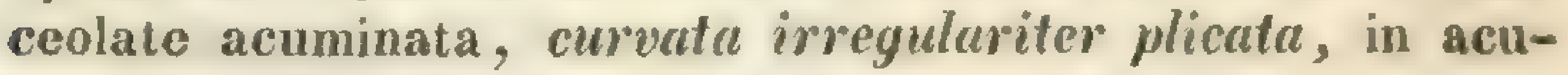
men flaccidum hyalinum minute erosum breviusculum producta, reticulatione multo densiore minore infima basi utrinque ad alas decurrentes laxa, ubique papillis scabervima; perich. intima subraginantia basi laxe reticulata; theca in ped. elongato luevi erecta, elliptico-cylindracea angustior, substriata, sicca angulosu, operculo thecum subsupercunte aciculari, annulo latiusculo, dentibus similibus, sed longissimis.

Racomitrium canescens Brid. I. p. 208. - Br. Kurop. 25-28. p. 12. t. 7 et 8. - R. Canadense Brid. I. p. 217? - Trichost. canescens Hdw. Musc. Fr. III. p. 5. t. 3. - Bryum canescens Hoffm. Deut. Fi. II. p. 41. - Br. hypnoides \$chrelt. Nipic. FI. Lips. p. 77. - Bryun hypnoides, hirsutie canescens, vulgare Dill. Muse. p. 368. t. 47. f. 27. - Hypun canescens, yilosum Weis, Cr. Gött. p. 213.

B. ericoides; caulis ramulis creberrimis brevibus obtusis alternis divisus. Racomitr. ericoides Brid. 1. p. 210. Trichost. ericoides schw. Suppl. I. I. p. 147. t. 38. - Tr. elongetumb Eirlil. Crypt. Exs. No. 233. - Bryum ericoidles Dicks. IV. Crypt. p. 14. - Br. elongatum Hoffm. Neut. kI. Il. p. 41. - Br. hypnoides, ericae facie, capsulis harbatis, alpinum. Dill. Musc. p. 371. t. 47. f. 31.

Putria. In ericetis planitiei quam montium, terram atque rupes habitans, per totam Europam et Americam septentrionalem rulgatissima. - Auctumno et vere.

Pl. mase. Gr. lannginosue, a qua notis cursive impressis facile distinguitur.

54. Gr. heterosticha C. Müll.; divica; laxe pulvinata subprostrata, luteo-viridis canescens, gracilis inaequaliter ramosa; folia caulina conferta, madore subito reflexa, dein erecto-patentia vo subsecunda, e basi late ovatd lanceolato-acuminata in pilum elongatum hyalinum denticulatum flaccidum producta, v'alde curvata, plicata, profunde canaliculata et complicata, margine e basi ad 
"picem usque veroluto, reticulatione tencra basi angusta elongata superne subrotumlata crenulata: porich. intima convolutaceo-vaginanta inferne multo tencrins laxius el longius reticulata; theca in ped. longiusculo oblongo-rylindrice, leptodermis laevis fuscescens, opere. breviter subulato subobliquo, annulo latiusculo, diculibus breviusculis, cruribus tenuissimis lacvibus inacqualihus plerumque perfecte ad basin usque fissis solitaris, calyplra apice scabra.

Racomitr. heterostichum Brid. I. p. 214. - Br. Europ. 2528. p. 9. t. 2 et 3. - Dryptodon carnosus livid. I. p. 206! - Trichost. heterostichum IIdw. Husc. Fr. H. 1. 70. 1. 25. - Bryum heterostichum Hoffm, Deut. Fl. II. 1). 40. - Br. secumdum (itucl. syst. Nat. II. 1. 1333. - Bry Hm homoides, hirsutie rituescens rulgare. Dill. Musc. p. 368. t. 47. f, 27, A. F, G.

B. rlopecura; elongata fasciculato-ramosa, foliis brevipilis, thecis minoribus. Br. Furop. I. 1. - Ruromitr. Alom pecurum Brid. I. p. 215. - T'richost. Alopecumu sidik. Dent. Moos. p. 77. t. 35. - Tr. affine sichl, Cat. PI. IIelv, 1k17. p. 31. Cont. IV. No, 18.

$\gamma \cdot$ gracilescens; subramulosum, foliis obtusis $v$ : apiculo diaphano brevissimo instructis, thecis mintis brevius pedunculatis. Bryol. Hinop. 1. 2 .

Patria. Per totam Furopam, in montanis et subalpinis pracsertim lapidosis saxosis. Tar. $\beta$. in locis hmmidis montium editiorum una cum var. $\gamma_{0}$ - I'ere.

55. Ar. crispipila C. Müll.; clecta fasciculalim ramosa, ramis brevibus, erectis, pallide olvacea; folia imbricata erectiuscula, ovato-lanceolata, margine reflexa, in acumen subservulutum pilifurme crisyum proluctu; perich. convoluta stricta obtuse upiculutu; theca in peel. laterali innoentionibus vir longione lineari-rylimbira crecta subaequalis, dentibus filiformilus angustis ad basin usque fissis. $t$.

Trichostom. crispipilum Tayl in Iond. Journ. of lint. 1816 p. 47.

Patria. In summis Andibus Quitensibus: W. Jameson 184 .

Gr. fusciculuri ex animadr. auctoris proxima. 


\section{b. Folia depilia.}

56. Gr. fascienlaris C. Müll.; dioica; subprostrata luteo-viridis, inferne ferruginea, ramis brevibus subfasciculata; folia caulina sicca subappressu, madefacta subito reflexa, dein erecto-patentia, parum curvula, late lanceolato-acuminata obtusiuscula, tenero-membranacea, plicata, margine revoluta, irregulariter canaliculata, reticulatione firme elongata angusta conflata crenulata ad basin infimam decurrentem laxiuscula; perich. intima plicatovaginantia, inferne tenerius areolata; theca in ped. breviusculo oblongo-ovalis, laevis flavida, operculo recte rostrato aurantiaco, annulo lato, dentibus longis ciliaeformibus ad basin usque fissis subrugulosis, calyptra ubique fere scaberrima.

Racomitr. fasciculare Brid. I. p. 218. - Br. Europ. 25-28. p. 8. t. 4. - Trichost. fasciculare Hdw. Sp. Musc. p. 110. Schw. Suppl. I. I. p. 155. t. 38. - Tr. saxatile Tayl. Trans, of the Edinb, Bot. Soc. II. I. 1845. p. 1; forma dentibus brevioribus. Bryum fasciculare Hoffm. Deut. Fl. II. p. 41. - Br. lutescens Dicks. IV. Crypt. p. 14. - Br. hypnoides et lirsutie virescens, fasciculare, alpinum. Dill. Musc, p. 370. t, 47, f. 28.

Patria. In subalpinis et alpinis totius Europae et Americae septentrionalis, rupes humidas habitans. - Vere.

Pl. mascula congenerum, a quibus notis supra cursive impressis facile distinguitur.

57. Gr. symphyodonta C. Müll.; Gr. fasciculari similis, sed erecta elongata, ramis dichotomis longis, ramulis brevibus subfasciculata gracilis; folia caulina hyaline apiculata; perich. acutiuscula; theca in pedunculo flavido tenuissimo cylindrica microstoma, dentibus brevibus, usque ad basin fere fissis, sed cruribus valde rugulosis robustioribus arctissime cohaerentibus.

Racomitr. fasciculare var. 2 et 3. Hook. et Wils, in schedulis.

Patria. Insula Eremitae ad Cap. Horn: J. D. Ho o ker.

Grimmiae obscurae.

1. Gr. conferruminata Wallr. (Linnaea 1840. p. 683.); caulibus erectis simplicibus polyphyllis densissime

c. M ill er: Synops, musc, frond. 
congestis veluti in massam conformem conferruminatis, foliis e basi vaginante linearibus carinato-costatis acutiusculis integerrimis siccando adpresso-patulis. $\leftarrow$.

Patria. Hercynia australis in fissuris rupium calcarearum apricarum, ubi densissime habitat: Wall roth.

$$
\text { Species delendae. }
$$

1. Gr. Gebhardi Spreng. in Steud. Nom. Crypt. p. 189. olim, in Syst. Veget. omissa in ejus herbario quoque deest.

2. Gr. nutans Bruch. in Regensb. Bot. Zeit. 1829. p. 391, pr. Smyrna a Fr. Müller lecta, in Bryol. Europ. ipsa silentio deletur.

3. Gr. nlbida Spreng. Syst. Veget: IV. II. p. 321. e Bryo argenteo et Trichostomo convoluto composita est. p. 189.

4. Gr. nana Schleich. in Steud. Nomencl. Crypt.

5. Gr. ramosa Schleich. I. c.

6. Gr. ventricosa ej. 1. c. Omnes hae species tres nobis nunquam visae, ab omnibus recentioribus auctoribus ignoratae.

7. Dryptodon brevifolins Brid. I. p. 775, s. Dicran. brevifolium Schl., forsan ad Gr. pulvinatam pertineat.

8. Dr. crispus Brid. I. p. 206, s. Dicran. crispum Thunb. ad Leptotrichum Capense revocandum sit.

9. Dr. eurvifoling Brid. I. p. 201, s. Campylopus curvifolius ej. Mant. Musc.p. 78, a Seligero in comitatu Glatziensi lectus, sentiente B ride lio ad Gümbeliam ovalem adscribendus sit.

10. Dr. diehotomus Brid. I. p. 201, s. Campylop. dichotomus ej. Mant. Musc. p. 87, s. Dicran. dichotomum P. B. Prodr. p. 53.

11. Dr. cribrosus Brid. Br. univ. I. p. 198, s. Campylopus cribrosis ej. Mant. p. 76; e Grimmia trichophyllu et lencophuea compositus est! 


\section{Trib. XX. DIPHYSCIACEAE.}

Gregarie cespitosae humiles. Folia dimorpha: caulina linguaeformia, e cellulis perfecte pottioideis dense hexagonis parenchymaticis chlorophyllosis areolata; perichaetialia maxime emersa, caulina superantia, e cellulis chlorophyllo dein destitutis igitur laxioribus reticalata. Theca maxima obliqua gibbosa buxbaumioidea. Infloresc. monoica. Archegonia et antheridia normalia, paraphysibus filiformilus.

Habitus perfecte buxbaumioideus, sed e foliorum structura dimorpha a Buxbaumiaceis distinctus. Quod ad affinitatem hancee magnam generum Diphyscii et Buxbaumiae pertinet, ex observationibus recentioribus persuasum habemus: Buxbaumiis quoque folia caulina diphysciacea, sed ad hue nee observata nec conjectata adscribenda, ambo genera igitur tribum unicam formatura, sed quoad methodum nostram separanda esse usque adeo donec folia caulina Buxbaumiarum observata sint.

Putria. Plantae per Europam totam Americam septentrionalem et Asiam passim.

\section{Gen. I. Diphyscium Mohr.}

Obs. Bot. p. 34. Wel, et Mohr. Bot. Taschb. 1807. p. 377. t. 11. f. 1. - Buxbaumia al. - Hymenopogum P. B. - Webera Ehrh. - Bryum al. - Phascum al.

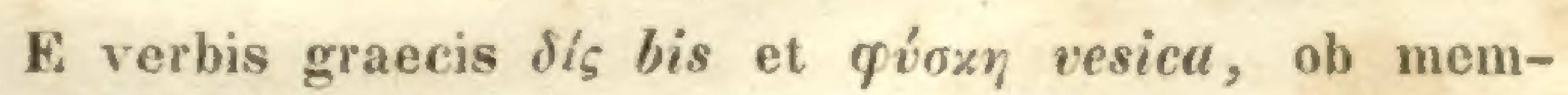
branam duplicem thecae, epidermidem inflatam et sporangidium, nomen ductum.

Calyptra operculum obtegens conica. Peristomium simplex internum Buxbaumiae, basi annulo multiplici solubili magno cinctum.

Si genera Diphyscii et Buxbaumice tribum naturalem unicam efforment, Diphyscii species ad Buxbaumius, sectionem naturalem caule abbreviato et foliis perichae- 


\section{STEGOCARPI. ACROCARPI. DIPHYSCIUM.}

tialibus maximis illustratam efformantes, revocandae sunt. Peristomium externum non reperimus.

1. D. Poliosum Mohr. (1. c.); abbreviatum, folia caulina linguaeformia, plus minus concava, obtusa v. acuminata, apice saepe cucullato-concava, e stratis cellularum compluribus composita, evanidinervia, dense areolata; perich. maxima late lanceolata, nervo longe excedente crasso pilifera, apice laciniato-ciliata, calyptra glabra.

Br. Europ. I. Buxbaumiaceae, c. tab. - Brid. I. p. 326. Buxbaumia foliosa Linn. Syst. Veg. ed. XIV. p. 925. - B. sessilis Schmidel Diss, de Buxbaumia p. 26, c. ic. - Webera Diphyscium Elhrh. Hann. Mag. 1779. p. 257. Ejusd, Beitr. I. p, 177. Hymenopogum heterophyllum P. B. Prodr. p. 60. - Bryum Hallerianum Neck. Meth, Musc, p. 233. - Br. phascoides Jacq. Collect. 11. p. 220. - Phascum Hallerianum Poll. PI. Pal. III. n. 984. Ph. Halleri 0. F. Müll. Act. Holm. 1764. p. 29. c. ic. - Ph. maximum Lightf. Fl. Scot. II. p. 693. - Ph. montanum Huds, Fl. Ang1. II. p. 466. - Sphagnum acaulon, maximum, foliis in centro ciliaribus. Haller in Dill. Musc. p. 253. t. 32, f, 13. et in Itin. Alp. 1739. p. 83. c. ic.

D. foliosum $\beta$. Dominghense Brid. II. p. 740. nullo modo a specie Europaea recedit et patria Hispaniola forte falsa indicata est.

Patria. In locis umbrosis sylvarum praeprimis montosarum totius Europae et Americae septentrionalis.

2. D. Iongifolium Griff. (in Schwägr. Suppl. IV. t. 325.); a praecedente foliis caulinis excurrentinervibus, perichaetialibus nunquam ciliatis sed integerrimis differt.

Patria. In Assam superiore Indiae orientalis detexit W. Griffith. 